\title{
ENDOCRINOLOGIE ET COMMUNICATIONS CELLULAIRES
}

Simon IDELMAN et Jean VERDETTI

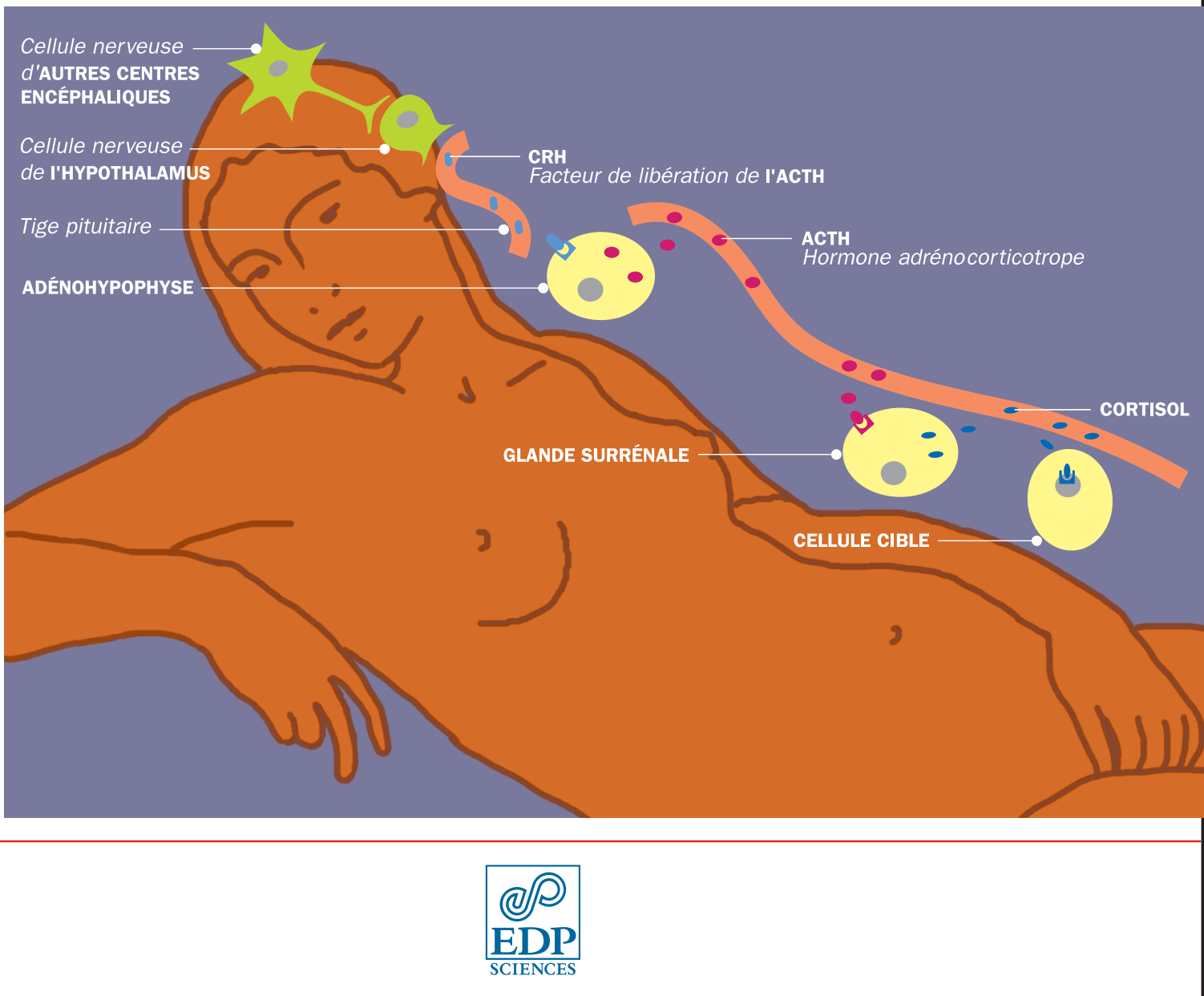





\section{ENDOCRINOLOGIE}

ET

\section{COMMUNICATIONS CELLULAIRES}




\section{Grenoble Sciences}

Grenoble Sciences poursuit un triple objectif :

- réaliser des ouvrages correspondant à un projet clairement défini, sans contrainte de mode ou de programme,

- garantir les qualités scientifique et pédagogique des ouvrages retenus,

- proposer des ouvrages à un prix accessible au public le plus large possible.

Chaque projet est sélectionné au niveau de Grenoble Sciences avec le concours de referees anonymes. Ensuite, les auteurs travaillent pendant une année (en moyenne) avec les membres d'un comité de lecture interactif dont les noms apparaissent au début de l'ouvrage.

\section{Directeur scientifique de Grenoble Sciences}

Jean BORNAREL, Professeur à l'Université Joseph Fourier - Grenoble 1

\section{Comité de lecture pour " Endocrinologie et communications cellulaires"}

- J. ANDRÉ, Professeur à l'Université Claude Bernard de Lyon

- E.E. BAUlieU, Professeur au Collège de France, INSERM U 488

- E. CHAmbaz, Professeur à l'Université Joseph Fourier de Grenoble

- J.E. DUMONT, Professeur à l'Université Libre de Bruxelles

Grenoble Sciences reçoit le soutien :

du Ministère de l'Éducation nationale, de la Recherche et de la Technologie de la Région Rhône-Alpes

du Conseil général de l'Isère

de la Ville de Grenoble

Réalisation et mise en pages, Centre technique Grenoble Sciences

ISBN 2-86883-484-1

Copyright : EDP Sciences 


\title{
ENDOCRINOLOGIE
}

\author{
ET \\ COMMUNICATIONS \\ CELLULAIRES
}

Simon Idelman et Jean Verdetti

EDP Sciences

2000 


\section{Grenoble Sciences}

Deux collections existent chez EDP Sciences :

- la "Collection Grenoble Sciences", maintenant bien connue pour son originalité de projets et sa qualité,

- "Grenoble Sciences - Rencontres Scientifiques", collection plus récente, qui présente des thèmes de recherche d'actualité, traités par des scientifiques de premier plan issus de disciplines différentes.

Des ouvrages portant le logo de Grenoble Sciences sont également édités chez d'autres éditeurs français et étrangers

\section{Collection Grenoble Sciences}

Chimie. Le minimum vital à savoir - J. Le Coarer

Minimum Competence in Scientific English - J. Upjohn, S. Blattes \& V. Jans

Introduction à la Mécanique statistique - E. Belorizky \& W. Gorecki

Exercices corrigés d'Analyse (tomes 1 et 2) - D. Alibert

Bactéries et environnement. Adaptations physiologiques - J. Pelmont

La plongée sous-marine à l'air. L'adaptation de l'organisme et ses limites - Ph. Foster

Listening Comprehension for Scientific English - J. Upjohn

Electrochimie des solides - C. Déportes et al.

La Turbulence - M. Lesieur

Mécanique statistique. Exercices et problèmes corrigés - E. Belorizky \& W. Gorecki

La symétrie en mathématiques, physique et chimie - J. Sivardière

La cavitation. Mécanismes physiques et aspects industriels - J.P. Franc et al.

L'Asie, source de sciences et de techniques - M. Soutif

Enzymes. Catalyseurs du monde vivant - J. Pelmont

L'ergomotricité. Le corps, le travail et la santé - M. Gendrier

Introduction aux variétés différentielles - J. Lafontaine

Analyse numérique et équations différentielles - J.P. Demailly

Speaking Skills in Scientific English - J. Upjohn, M.H. Fries \& D. Amadis

Thermodynamique chimique - M. Oturan \& M. Robert

Mathématiques pour les sciences de la vie, de la nature et de la santé - F. \& J.P. Bertrandias

Magnétisme : I - Fondements - II - Matériaux et applications

sous la direction d'E. du Trémolet de Lacheisserie

Probabilités et incertitudes dans l'analyse des données expérimrntales - K. Protassov

Approximation hilbertienne. Splines, ondelettes, fractales - M. Attéia \& J. Gaches

Du Soleil à la Terre. Aéronomie et météorologie de l'espace - J. Lilensten \& p.L. Blelly

\section{Grenoble Sciences - Rencontres Scientifiques}

Radiopharmaceutiques. Chimie des radiotraceurs et applications biologiques sous la direction de M. Comet \& M. Vidal

Turbulence et déterminisme - sous la direction de M. Lesieur

Méthodes et techniques de la chimie organique - sous la direction de D. Astruc 


\section{AVANT - PROPOS}

Le changement du titre de cette deuxième édition de l'ouvrage "Endocrinologie, fondements physiologiques", qui devient "Endocrinologie et communications cellulaires", traduit l'ampleur des modifications ou des compléments apportés à la première édition.

La contribution des collaborateurs, qui ont bien voulu apporter le fruit de leur compétence à cet ouvrage, a permis non seulement une réactualisation des données de l'Endocrinologie, mais aussi une extension du public concerné.

Les collaborateurs en médecine clinique (Docteurs Robert ELKAÏM, Philippe LÉGER et Danielle PALLO) et hospitalo-universitaires (Professeurs Ivan BACHELOT et Robert HALIMI) ont contribué à une "médicalisation" de cet ouvrage et en font un outil utilisable non seulement pour les étudiants en médecine, mais aussi pour les médecins désireux d'actualiser leurs connaissances en endocrinologie. La participation de spécialistes de la communication cellulaire, comme Claude COCHET et Jean VERDETTI, devrait faire de cet ouvrage une référence pour les étudiants de troisième cycle orientés vers la recherche dans ce domaine.

Compte tenu de son importance croissante dans la vie quotidienne, le stress a été particulièrement développé (chap. $6, \S 5$ ), ainsi que ses conséquences sur le système immunitaire (chap. 16, § 4).

La partie "Endocrinologie de la reproduction" a été enrichie d'un chapitre (chap. 15) qui apporte des données actuelles particulièrement utiles aux enseignants du secondaire, dans le cadre du planning familial et de la procréation médicalement assistée.

L'évolution du profil démographique vers un accroissement du nombre de personnes âgées a justifié l'approfondissement du rôle de l'épiphyse en rapport avec le vieillissement (chap. 10, § 2.3) et des additions dans d'autres chapitres sur les aspects endocriniens du vieillissement (chap. $4, \S 4.2 .6$ et $4.3 .3 ; 6, \S 6$ ).

Dans cette deuxième édition, nous avons voulu également souligner le développement de disciplines intégrées qui donnent lieu à des recherches fécondes, telles la psycho-neuro-endocrinologie (chap. $4, \S 10$ ), l'endocrino-immunologie (chap. 16) et la psycho-neuro-immunologie (chap.16, § 4) dont l'ensemble constitue le cadre d'une psycho-neuro-immuno-endocrinologie.

Enfin, cette actualisation n'a été possible que grâce au Professeur Jean VERDETTI qui a accepté d'être co-auteur de cette deuxième édition, en nous faisant bénéficier de ses connaissances, fondées sur une recherche de pointe, et de ses qualités de pédagogue. 
Nos remerciements vont à J. BORNAREL et à son équipe, pour leur patience et leur confiance malgré la charge représentée par cette deuxième édition, ainsi qu'aux membres du comité de lecture, J. ANDRÉ, E.E. BAUliEU, E. ChAmbAZ et J.E. DUMONT qui ont accepté de lire cet ouvrage et de nous exprimer leur avis, tout particulièrement E.E. BAULIEU et E. CHAMBAZ dont les remarques et critiques ont été très constructives. 


\section{AUTEURS ET COLLABORATEURS}

Ivan BACHELOT Professeur au CHU de Grenoble - Service d'endocrinologie Révision du chapitre 5 (la glande thyroïde).

Claude COCHET Directeur de recherches à l'INSERM

Rédaction du chapitre $1, \S 8$ et du chapitre $3, \S 1$ (mécanismes de réception et de transmission des signaux mitogéniques).

Robert ELKAÏM Médecin - Spécialité endocrinologie et métabolismes

Rédaction du chapitre $7, \S 8$ (les diabètes sucrés).

Serges HALIMI Professeur au CHU de Grenoble - Service d'endocrinologie Révision du chapitre 7 (le pancréas endocrine).

Simon IDELMAN Médecin - Professeur honoraire à l'Université Joseph Fourier Compléments aux chapitres $4, \S 10$ (psycho-neuro-endocrinologie) ; $6, \S 5$ et 6 (le stress) ; 10, $§ 2.3$ (l'épiphyse et le vieillissement) et chapitre $16, \S 4$ (hormones et immunité). Rédaction du chapitre 15 (la commande de la reproduction). Révision générale et coordination de la nouvelle édition.

Philippe LÉGER Médecin-Spécialité gynécologie et obstétrique

Nouvelle rédaction de la troisième partie (endocrinologie de la reproduction).

Danielle Pallo Médecin-Spécialité endocrinologie et métabolismes

Rédaction du chapitre 4, § 9 (les pathologies du complexe hypothalamo-hypophysaire).

Jean VerdeTti Professeur à l'Université Joseph Fourier

Rédaction des chapitres 2 et 3 (les messagers chimiques) à l'exception du chapitre $3, \S 1$.

Révision générale de la nouvelle édition. 



\section{INTRODUCTION}

\section{GÉNÉRALITÉS}

\subsection{ENDOCRINOLOGIE ET PHYSIOLOGIE DES RÉGULATIONS}

La complexité croissante des organismes pluricellulaires a conduit à la mise en place de systèmes de régulations responsables d'un contrôle coordonné des "grandes fonctions" végétatives et sexuelles, dans le cadre de leurs interactions réciproques et de leur adaptation à l'environnement. Au cours de l'Evolution, trois systèmes de régulations se sont ainsi successivement développés :

- à partir des Cœlentérés, le système nerveux central (SNC), spécialisé dans l'interface environnement/organisme (organes sensoriels), et dans une régulation rapide sur des cibles individuelles;

- à partir des vers, le système neuro-endocrinien, puis endocrine périphérique, spécialisé dans un contrôle plus lent et soutenu, exercé sur des cibles diversifiées ;

- à partir des invertébrés supérieurs, le système immunitaire, spécialisé dans la destruction des protéines étrangères à l'individu (protéines du non-soi).

Au niveau élémentaire, un système de régulation se définit comme une collection de "composants" interconnectés et interagissants, avec notamment : des composants détecteurs (transducteurs de signaux physiques ou chimiques internes ou externes), des composants d'intégration de signaux d'origines diverses, y compris génétiques, et des composants de transmission, assurant la continuité de la transmission intercellulaire de l'information codée (influx nerveux, pulsatilité hormonale) à l'intérieur des systèmes de régulation.

Les signaux de communication intercellulaire sont de nature physique (potentiel d'action, potentiel récepteur) ou chimique. Les principaux signaux chimiques sont des stéroïdes, des acides aminés ou leurs dérivés, et des peptides. Quelle que soit leur nature chimique, ils se distinguent au niveau fondamental, avant tout par le compartiment du milieu intérieur à travers lequel ils assurent la communication intercellulaire. On distingue ainsi :

- les signaux diffusant dans le liquide interstitiel : facteurs locaux paracrines et autocrines (facteurs de croissance et de développement, facteurs de la réaction inflammatoire et de l'immunité cellulaire), et neurotransmetteurs diffusant dans l'espace synaptique ; 
- et les signaux sécrétés dans le sang et utilisant la convection sanguine pour atteindre leurs cibles cellulaires : hormones et anticorps.

Le concept d'hormones n'est donc pas fondé sur une définition chimique ou d'origine cellulaire, mais uniquement sur une définition physiologique concernant le sous-compartiment liquidien dans lequel ces signaux sont véhiculés. C'est ainsi, par exemple, qu'un signal de régulation chimique qui est sécrété par un neurone dans une synapse interneuronale est un neurotransmetteur ou un neuromodulateur, alors que s'il est sécrété dans le sang (système hypothalamo-hypophysaire) il est une neurohormone.

\subsection{LE SYSTÈME NERVEUX}

Le système nerveux de la vie de relation (système nerveux central et système nerveux périphérique) permet les relations avec le milieu extérieur. Les récepteurs périphériques reçoivent les stimulus provenant du milieu extérieur et les transforment en messages codés qui parviennent aux centres. Le stimulus peut donner lieu à une réponse réflexe (centre essentiellement médullaire et cérébro-tronculaire) ou à une réponse volontaire (centre cortical : cortex cérébral). Le signal sensoriel pour le centre comme le signal moteur pour l'effecteur (muscle strié) sont transmis de façon caténaire, par une chaîne de neurones connectés par des synapses. Le temps de latence est bref, de l'ordre de la seconde ou de la fraction de seconde. Ce système nerveux permet l'adaptation de l'individu au milieu extérieur.

Le système nerveux de la vie végétative est caractérisé par des voies motrices qui constituent deux ensembles (orthosympathique et parasympathique) fonctionnant de façon couplée et parfois antagoniste ; il constitue un système coordonnateur et régulateur du milieu intérieur. Il contrôle en effet les grandes fonctions de l'organisme : digestion, respiration, circulation, sexualité et intervient dans la régulation de la température interne, de la pression artérielle, du rythme cardiaque...

\subsection{LE SYSTÈME HORMONAL (glandes endocrines et cellules endocrines ou neuro-endocrines)}

Le système hormonal intervient dans le métabolisme des glucides, lipides et protides, dans la croissance, la sexualité, la régulation de la température interne, de la glycémie, de la calcémie, de l'équilibre hydrominéral...

Les cellules endocrines déversent dans le sang des hormones qui vont agir à distance, sur des cellules cibles, à des concentrations voisines de la nanomolarité. Leur temps d'action varie de moins de 5 min pour les hormones hypothalamiques à quelques heures pour les hormones stéroïdes. Une cellule endocrine peut fonctionner comme un volorécepteur sensible à la variation de la volémie, comme un chimiorécepteur sensible à la concentration ionique $\left(\mathrm{Na}^{+}, \mathrm{K}^{+}, \mathrm{Ca}^{2+} \ldots\right)$ ou à une substance hormonale 
(celle qu'elle sécrète, c'est alors une rétroaction (feed-back) courte, ou à une autre hormone dont elle constitue alors la cellule cible).

L'activité des hormones est liée à la qualité de leur liaison avec une protéine vectrice, à leur affinité pour des molécules protéines "récepteurs" présentes dans la membrane (hormones hydrosolubles) ou dans le noyau (hormones liposolubles) des cellules cibles, à leur vitesse de dégradation (par exemple le foie) et d'excrétion (par exemple le rein).

En fait, le fonctionnement de ces deux systèmes est étroitement intriqué. En particulier, ils contractent des relations étroites (corrélations neuro-humorales) au niveau de l'hypothalamus, qui constitue une véritable "plaque tournante" entre le système nerveux et le système hormonal, entre le milieu extérieur et le milieu intérieur. Ces cellules de l'hypothalamus se sont différenciées dans un sens à la fois nerveux et sécréteur (cellules neurosécrétrices) qui leur permet de répondre à des stimulus nerveux (d'origine psychique, sensorielle...), ioniques (variation de la natrémie), chimiques (variation de la glycémie), hormonaux ou physiques (pression osmotique). Une agression exogène ou endogène constituant un état de stress mettra en jeu cette plaque tournante ainsi qu'un autre organe neurosécréteur, la médullo-surrénale.

Le système nerveux central et le système hormonal contribuent ainsi à maintenir la constance du milieu intérieur (homéostasie). Une telle régulation est assurée par un mécanisme de rétro-contrôle : feed-back dit négatif, car il tend à annuler toute variation des constantes physiologiques.

\subsection{LE SYSTÈME IMMUNITAIRE}

Impliqué essentiellement dans la défense de l'organisme contre des agressions externes ou des modifications internes (transformation virale ou cancéreuse), il intervient de fait dans l'homéostasie. Les cellules immunitaires sécrètent des substances qui agissent comme certaines hormones hypothalamiques ou hypophysaires et sont sensibles (par des récepteurs spécifiques) à de nombreuses hormones (GH, ACTH, prolactine, insuline, adrénaline, enképhalines et endorphines...) dont la sécrétion est particulièrement accrue lors du stress. D'autre part, la stimulation antigénique retentit sur l'activité électrique du cerveau ${ }^{1}$ qui exerce une influence stimulatrice ou inhibitrice sur le système immunitaire. Des mécanismes de rétrocontrôle tendent enfin à moduler et à réguler toutes les réactions du système immunitaire.

1 On observe une multiplication par 3 de la fréquence des décharges dans les neurones de l'hypothalamus ventro-médian ou de l'aire pré-optique après une immunisation par des globules rouges de mouton. 
On peut concevoir avec Blalock que ces trois systèmes aussi étroitement intriqués constituent un ensemble essentiel à la régulation interne et à l'ajustement au milieu extérieur ${ }^{2}$.

\subsection{HISTORIQUE}

On peut distinguer plusieurs étapes dans l'évolution de l'endocrinologie.

- Pendant la deuxième moitié du XIX clinique, où l'on définit la nature et l'action physiologique des principales glandes endocrines : surrénale, hypophyse, thyroïde... C'est la période de la physiologie endocrinienne classique (ablation, greffe, opothérapie à l'aide d'extraits glandulaires...). En 1905, Bayliss et Starling créent le terme d'hormone pour désigner une substance, la sécrétine, qui est sécrétée par la muqueuse duodénale, au passage du bol alimentaire, pour "exciter" à distance la sécrétion des enzymes du suc pancréatique.

- La première moitié du XXe siècle est dominée par la biochimie endocrinienne. L'adrénaline est la première hormone isolée (1901) et synthétisée (1904). L'ocytocine est la première hormone peptidique synthétisée (1952). L'insuline (isolée en 1922) est la première hormone protéique dont la séquence peptidique est identifiée (Sanger, entre 1944 et 1953, prix Nobel en 1958). Cette période permet de mettre en évidence la plupart des hormones, de les isoler et d'en préciser la structure.

- La deuxième moitié du $\mathrm{XX}^{\mathrm{e}}$ siècle est caractérisée par des recherches sur le mode d'action des hormones (travaux de Sutherland entre 1950 et 1965, prix Nobel en 1971), sur l'adrénaline et le glucagon, puis d'autres hormones polypeptidiques, qui mettent en évidence le rôle de l'AMP cyclique. Le mode d'action des stéroïdes, étudié par Jensen, O’Malley, Baulieu, n'est pas encore totalement élucidé. La mise au point du dosage radioimmunologique des hormones (Berson et Yalow) permet à Guillemin et Schally (prix Nobel en 1977 avec Yalow) de purifier et d'identifier (à partir de 1969) un certain nombre d'hormones hypothalamiques. C'est alors un renouvellement de l'endocrinologie dite moléculaire, avec :

- l'étude approfondie de la liaison des hormones avec leur protéine vectrice et surtout de leur action au niveau des récepteurs membranaires ou intracellulaires. Les hormones peuvent être classées selon deux grands groupes :

- les hormones peptidiques ou protéiques, qui circulent à l'état libre dans le sang, ont une demi-vie assez courte (en général moins de $60 \mathrm{~min}$ ), un

2 Il faut remarquer toutefois que si l'hypophysectomie entraîne une dépression immunitaire que seules la GH ou la prolactine peuvent restaurer, les déficiences immunitaires graves n'entraînent pas de troubles endocriniens notables. 
temps de latence (délai de réponse) assez bref (quelques secondes pour l'effet hyperglycémiant du glucagon), ne pénètrent pas dans les cellules et agissent au niveau d'un récepteur membranaire spécifique ; leur structure a varié au cours de l'évolution (GH, insuline...) ;

- les hormones stéroïdes (gonades, corticosurrénales) ou thyroïdiennes, qui circulent dans le sang couplées à une protéine de transport (TBG, CBG, SBG, albumine), pénètrent dans la cellule où elles vont s'associer à une protéine spécifique du noyau. Elles vont agir au niveau de l'ADN. Elles ont un temps de latence assez long (quelques heures). Leur structure a peu ou pas varié au cours de l'évolution.

- le développement de la neuro-endocrinologie. C'est la découverte de la neurosécrétion hormonale par des neurones hypothalamiques (Scharrer, 1928 ; Bargmann, 1949) qui a ouvert le champ de la neuro-endocrinologie ; celui-ci a subi récemment un extraordinaire développement après la caractérisation de toute la gamme des neurohormones hypothalamiques (Guillemin, 1969 ; Schally, 1971) et de leur contrôle fonctionnel par des réseaux neuronaux complexes d'origine hypothalamique, cérébro-tronculaire et limbique. On notera également que c'est à partir d'études immunocytochimiques sur les neurones endocrines de l'hypothalamus qu'on a découvert ultérieurement l'utilisation des mêmes signaux neurochimiques comme neurohormones (neuro-endocrinologie) ou comme neurotransmetteurs ou neuromodulateurs (neurophysiologie) (TRH, CRH, LH-RH, SRIF, ADH, Ot...), voire comme hormones périphériques (endocrinologie) (CCK, VIP, noradrénaline, adrénaline...). C'est aussi la découverte des endorphines et des enképhalines ouvrant des perspectives non encore maîtrisées sur l'analgésie : mise en évidence dans le cerveau de peptides présents dans certaines cellules du tube digestif (CCK), ou inversement dans le tractus digestif d'hormones peptidiques présentes dans le cerveau (somatostatine). L'activité des neurones hypothalamiques neurosécréteurs est modulée par des neurones aminergiques ( $\beta$-endorphine...).

\section{LES RYTHMES BIOLOGIQUES}

Faute de vivre dans un "bain de nourriture" (c'est le cas des Protistes, du fœtus), la faculté d'adaptation est conditionnée par la possibilité de stocker de l'énergie et de l'utiliser en cas de besoin. L'énergie est fournie par l'alimentation au cours de l'activité vigile. Activité diurne et repos nocturne constituent pour les animaux diurnes un premier exemple d'activité rythmique endogène, conditionnée par un rythme exogène. 
En fait, toutes ces fonctions homéostasiques (Cannon, 1926), du niveau cellulaire au niveau de l'organisme intégré dans son milieu, présentent des fluctuations rythmiques qui ne sont qu'un aspect particulier de l'adaptation physiologique. Composants fondamentaux des régulations physiologiques, les hormones montrent elles aussi, tout naturellement, toute une gamme de rythmes sécrétoires.

D'une manière générale, les rythmes biologiques, dont l'étude concerne le domaine de la chronobiologie (Reinberg), se répartissent en deux familles, selon qu'ils dépendent ou non des horloges cosmiques de l'environnement naturel : rotation de la terre sur elle-même ( $24 \mathrm{~h}$ ) et autour du soleil ( 365,25 jours).

\subsection{LES RYTHMES BIOLOGIQUES INDÉPENDANTS DE L'ENVIRONNEMENT}

Ils se caractérisent par une grande variété de périodes, en général brèves (périodes ultradiennes) et dépendent de générateurs endogènes de rythmes "pacemakers". Les cycles cellulaires, les rythmes cardiaque et respiratoire en sont des exemples bien connus. En endocrinologie, la sécrétion pulsatile de la plupart des neurohormones et hormones appartient à la même famille : rythmes pulsatiles proches d'1 $\mathrm{h}$ (circhoraux) décrits pour LH-RH, CRH, SRIF, ADH et Ot chez le rat et chez la plupart des Mammifères, y compris l'homme, pour ACTH, LH, FSH, Prl, GH, testostérone et corticostérone ou cortisol. Cette pulsatilité apparait aujourd'hui comme un élément fondamental de l'activité des hormones, en particulier parce qu'elle est le garant d'une "sensibilisation" optimale des récepteurs hormonaux.

Les mécanismes "pacemakers" des rythmes pulsatiles hormonaux sont encore peu connus mais on sait, au moins pour les rythmes neurohormonaux, que les "horloges" pulsatiles comportent en particulier des réseaux neuronaux aminergiques et gabaergiques localisés dans le tronc cérébral, et qui innervent les neurones endocrines de l'hypothalamus (voir Assenmacher, 1986).

\subsection{LES RYTHMES BIOLOGIQUES INFÉODÉS À L'ENVIRONNEMENT}

Ils comportent deux grandes familles, d'ailleurs interconnectées : les rythmes circadiens (environ $24 \mathrm{~h}$ ) et les rythmes circannuels (environ un an).

\subsubsection{Les rythmes circadiens ${ }^{3}$}

Les rythmes circadiens (fig. 0.1) sont universels en biologie et pour la grande majorité des neurohormones et hormones, cette rythmicité a été clairement mise en évidence chez tous les Mammifères. Le plus anciennement connu est celui de l'ACTH et de la corticostérone (rat) ou du cortisol (homme).

3 Le lecteur qui souhaite traduire les concentrations exprimées en unités masse/volume en concentrations molaires trouvera une table de conversion à la fin de cet ouvrage. 
ACTH plasmatique $(\mathrm{pg} / \mathrm{ml})$

Cortisol plasmatique $(\mu \mathrm{g} / 100 \mathrm{ml})$

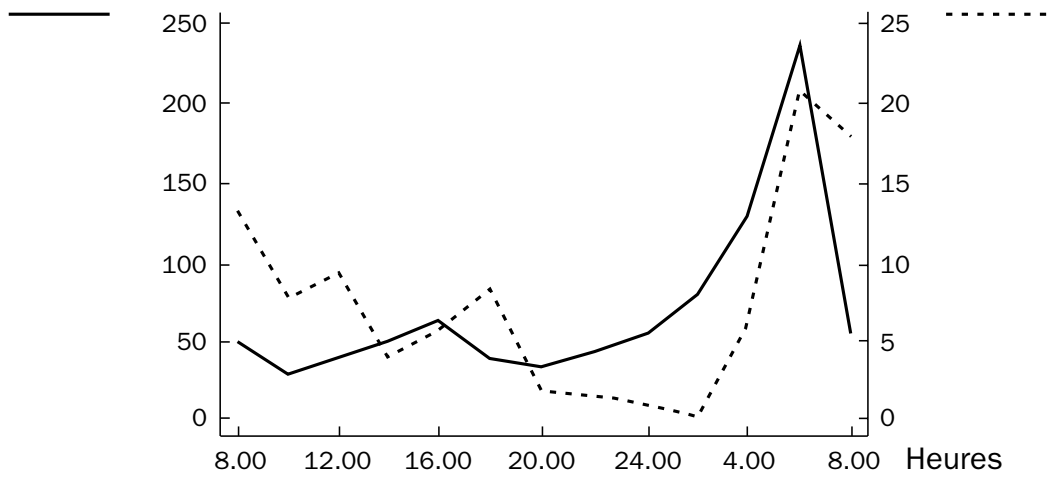

a - Rythme circadien de I'ACTH et du cortisol chez un homme normal

(d'après Matsukura et coll., 1971)

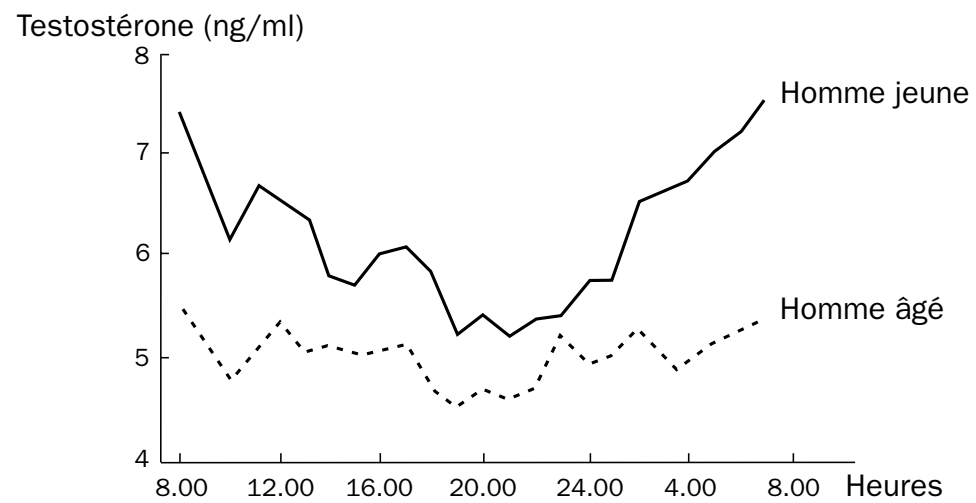

b - Rythme circadien de la testostérone chez un homme jeune et un homme âgé (d'après Bremner et coll., 1983)

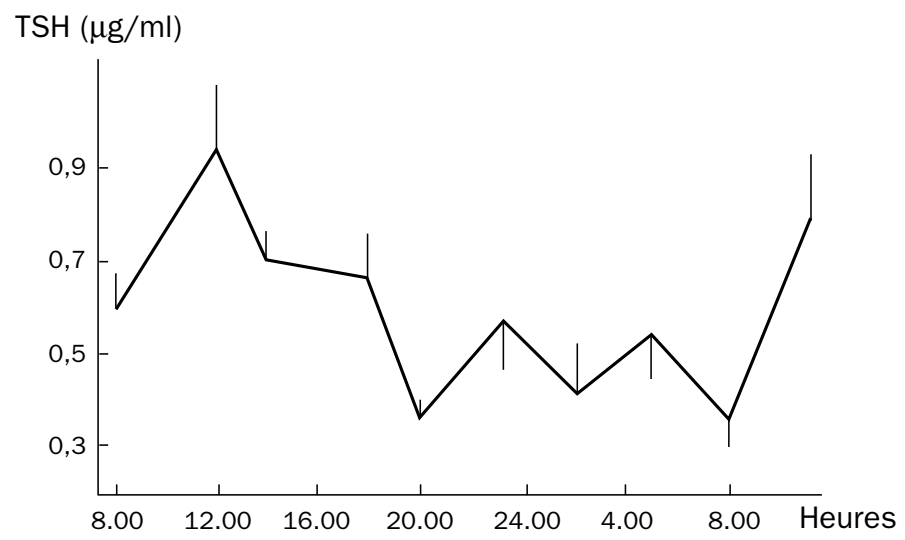

c - Rythme circadien de la TSH chez le rat (d'après Jordan et coll., 1979)

La courbe représente la moyenne, les traits l'erreur type de la moyenne (pour 8 animaux).

Figure 0.1 - Rythmes hormonaux circadiens

La période est de $24 h \pm 4 h$, le moment d'amplitude maximum correspond à l'acrophase. 
Sa valeur adaptative est évidente du fait que, quelles que soient les habitudes, diurnes ou nocturnes, de l'espèce, c'est toujours pendant la deuxième moitié de la phase de repos quotidien (après 1-2 $\mathrm{h}$ du matin chez l'homme) que survient l'activation du système CRH-ACTH-cortisol, qui assure par anticipation à l'organisme une glycémie normale avant le passage à l'activité quotidienne, sans l'apport aléatoire du premier repas.

Les caractéristiques essentielles des mécanismes des rythmes circadiens sont les suivantes :

- Les rythmes circadiens sont générés par des pacemakers circadiens endogènes (horloges biologiques circadiennes), qui assurent la rythmicité circadienne, même dans un environnement non fluctuant. Lorsqu'ils sont seuls en jeu, leur période est proche mais différente de $24 \mathrm{~h}$ (par exemple chez des hommes aveugles, étudiés "hors du temps" : $24,7 \mathrm{~h}$; chez des rats aveugles, dans les mêmes conditions : $24,3 \mathrm{~h}$ ).

Tout porte à penser que cette période endogène appartient au patrimoine génétique de l'espèce, car des études récentes de génétique moléculaire chez des drosophiles "mutants de période" ont montré l'existence, la constitution chimique et la possibilité de délétion et de transfection réparatrice d'un "gène de période", caractéristique de l'espèce.

- Les pacemakers circadiens n'entrent en fonction que dans les jours ou semaines qui suivent la naissance. Ce n'est que progressivement que les rythmes pulsatiles pré-existants sont entraînés sur un mode secondaire, circadien, qui peut subir ultérieurement d'importantes modifications. Ainsi, les rythmes circadiens de LH et de RH, très marqués chez la fillette, s'estompent après la puberté sous l'effet inhibiteur des stéroïdes ovariens (Krieger, 1979).

- Dans les conditions naturelles les pacemakers circadiens sont "entraînés" quotidiennement, c'est-à-dire mis à l'heure $(24,0$ h) des synchroniseurs externes :

- Facteurs physiques

- essentiellement la lumière (le rythme circadien n'existe pas chez certains cavernicoles) ; on peut expérimentalement faire "retarder" ou "avancer" l'horloge, mais entre certaines limites seulement ;

- la température extérieure ;

- les autres facteurs (humidité, ionisation) sont encore peu connus.

- Facteurs de comportement

- la nourriture, mais elle ne prime pas sur l'éclairement ;

- le sommeil : il ne semble pas un synchroniseur important, sauf pour la température centrale et la consommation d'oxygène ;

- l'activité musculaire.

- Contraintes socio-professionnelles

- c'est le cas du travail de nuit, du travail "posté" (par exemple $3 \times 8 \mathrm{~h}) \ldots$ 
Le rythme biologique peut être assimilé à une variation sinusoïdale qui permet de définir différentes caractéristiques constituant les paramètres de ce rythme :

- la phase, référence à une origine temporelle définie arbitrairement, par exemple minuit, heure locale, dans un rythme circadien, 22 décembre à minuit (solstice d'hiver) dans un rythme circannuel ;

- l'amplitude (A) avec son intervalle de confiance ;

- le niveau moyen de rythme, ou mésor (M) (par exemple $37^{\circ} \mathrm{C}$ pour la température interne chez l'homme) avec son intervalle de confiance ;

- l'acrophase, moment de l'amplitude maximale, avec son intervalle de confiance ;

- et enfin, la période.

Leur représentation graphique peut se faire soit selon des coordonnées classiques, avec le temps en abscisse et, par exemple, la concentration hormonale en ordonnée (voir fig. 0.1), la durée de la période obscure est alors indiquée le long de l'abscisse, soit selon des coordonnées polaires (s'il s'agit d'un cycle circadien), où sont représentées les durées respectives de la lumière (light, L) et de l'obscurité (darkness, D) et les acrophases avec leur intervalle de confiance (fig. 0.2 et 0.3 ).

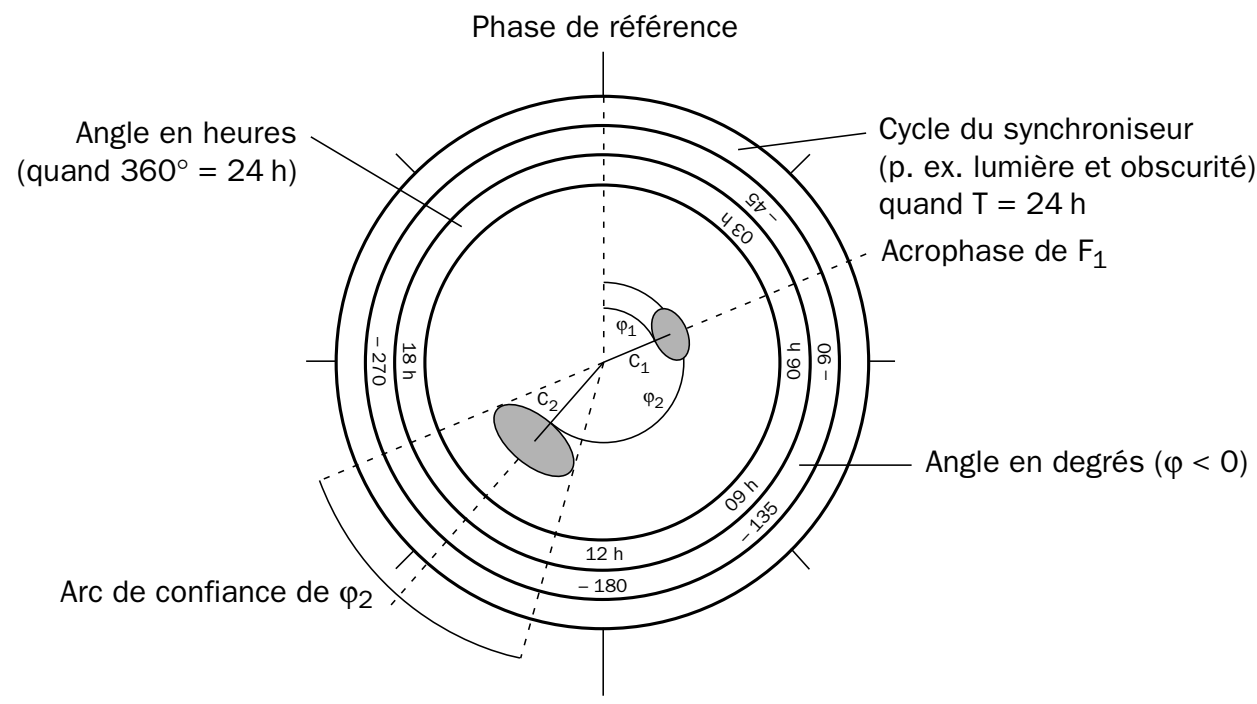

$\left.\begin{array}{l}C_{1} \text { et } C_{2} \text { amplitudes } \\ \varphi_{1} \text { et } \varphi_{2} \text { angles de phases }\end{array}\right\}$ des fonctions $F_{1}$ et $F_{2}$

ellipse d'erreur pour une sécurité de 95\%

Figure 0.2 - Rythmes biologiques de deux fonctions exprimées en coordonnées polaires (d'après Halberg et Reinberg, 1967) 


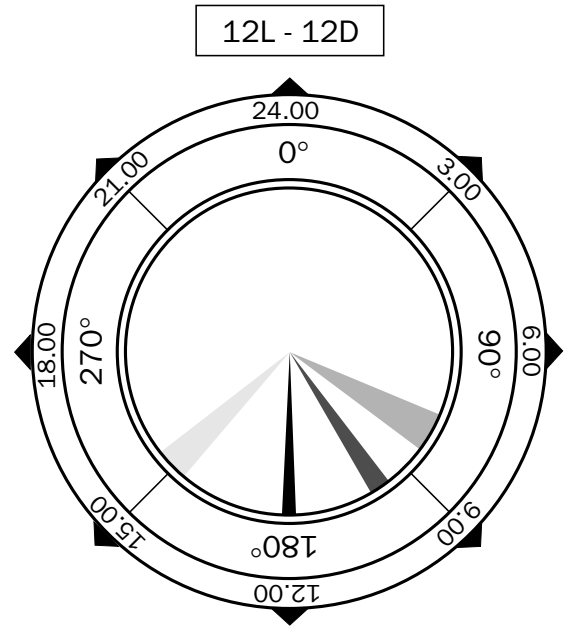

Activité générale Température interne

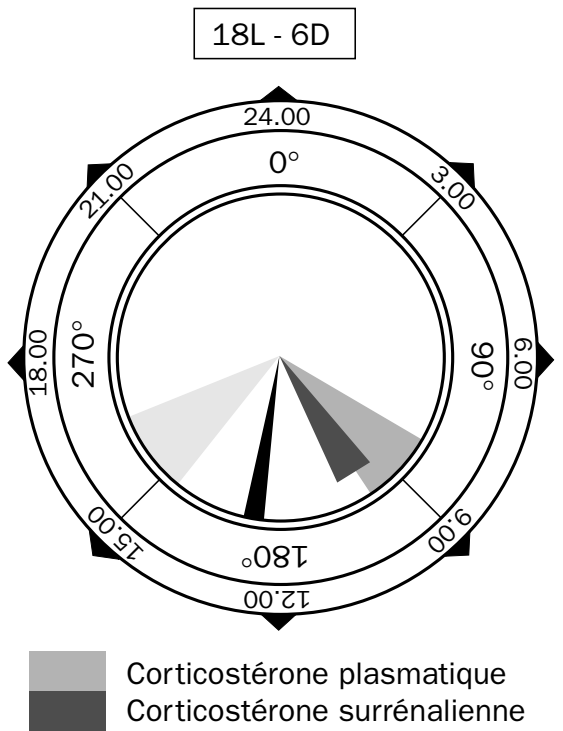

Corticostérone surrénalienne

Figure 0.3 - Rythmes circadiens des taux plasmatique et surrénalien de la cortisone chez la caille (d'après Assenmacher et Boissin, 1969)

Mais les données enregistrées ne révèlent pas d'emblée une variation cyclique, d'autant que les variations observées peuvent comporter plusieurs périodes élémentaires (par exemple $24 \mathrm{~h}$ et un an). L'analyse, qui décompose la variabilité observée comme un prisme décompose les différentes longueurs d'onde de lumière, constitue l'analyse spectrale (Halberg) (fig. 0.4).

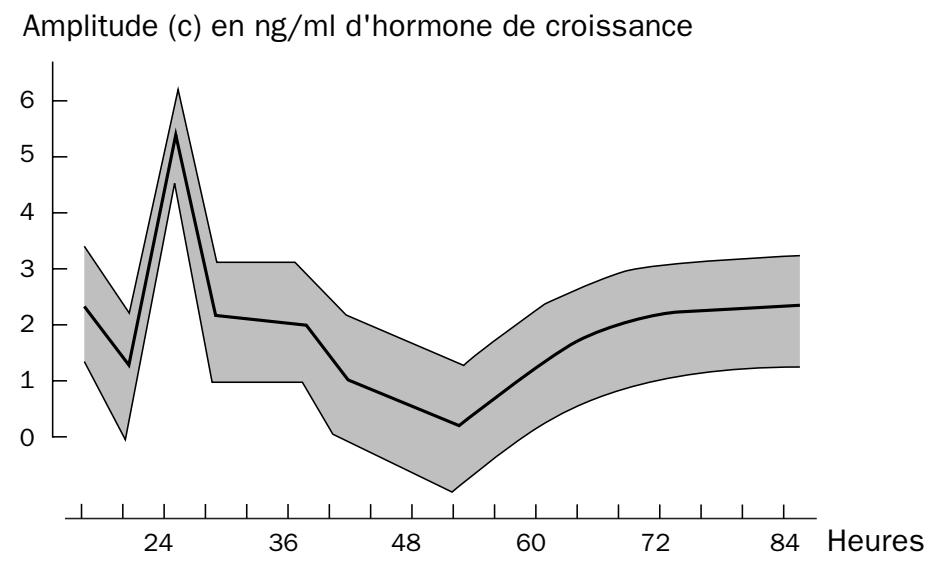

Echelle des valeurs des périodes utilisées pour l'analyse

Figure 0.4 - Analyse spectrale des rythmes des taux d'hormone de croissance chez un sujet en bonne santé (d'après d'Agata et Vigneri, 1971)

Un pic significatif est observé pour une période de $24 \mathrm{~h}$, pour lequel l'erreur type (exprimée par les hachures) est minimum. 
- Toute perturbation intervenant dans la synchronisation externe des pacemakers circadiens (travailleurs de nuit, travailleurs "postés" de type $3 \times 8 \mathrm{~h}$, voyageurs aériens transméridiens [fuseaux horaires]) provoque une désynchronisation temporaire des rythmes circadiens et en perturbent la phase et l'amplitude. La resynchronisation des rythmes sur leur nouvel environnement dépend de l'ampleur de la désynchronisation, mais aussi du sens de la désynchronisation (avance ou retard de phase). C'est ainsi que, pour un décalage horaire de $6 \mathrm{~h}$ (6 fuseaux horaires), le réajustement nécessite un délai de 11 à 15 jours pour un vol Ouest-Est (par exemple USA-France) et 3 à 4 jours seulement pour un vol Est-Ouest.

- Pour toutes les sécrétions endocriniennes et comportementales, l'un des pacemakers circadiens les plus importants est localisé dans la complexe circuiterie neuronale d'un petit noyau hypothalamique, le noyau suprachiasmatique (NSC). Mais d'autres réseaux neuronaux d'origine hypothalamique, cérébro-tronculaire et limbique, et de nature notamment adrénergique, sérotoninergique et gabaergique, contribuent de façon déterminante à cette machinerie complexe.

\subsubsection{Les rythmes circannuels}

Les rythmes circannuels, qui sont très prononcés chez les animaux vivant en milieu naturel (cycles sexuels, métaboliques, hibernatoires...), se retrouvent de façon plus discrète chez l'homme. Selon les théories modernes, ils dérivent d'un mécanisme circadien de photosensibilité qui entraîne, dans des centres cérébraux actuellement inconnus, la survenue quotidienne d'une courte phase de photosensibilité, c'est-à-dire de réponse, stimulante ou inhibitrice, de mécanismes neuro-endocriniens et neurovégétatifs photodépendants. Selon la position de cette phase photosensible par rapport à la longueur des jours, variable avec les saisons, et qui peuvent ou non coïncider, selon leur longueur, avec la phase photosensible, l'organisme peut "lire" la durée du jour. Selon les espèces, ce seront les jours "longs" ou "courts" qui déclencheront l'activation circannuelle de telle fonction hormonale (par exemple fonction gonadotrope, prolactinique...) (Boissin et Canguilhem, 1988). La glande pinéale (épiphyse), dont il sera question plus loin (chap. 10), joue un rôle important dans ce processus.

La connaissance de ces rythmes est importante. Les ignorer conduit à une appréciation erronée de la physiologie endocrinienne, à une thérapeutique inadaptée ou excessive. C'est le domaine de la chronopharmacologie, de la chronothérapeutique (fig. 0.5).

Leur prise en considération (travaux de Knobil) a permis, au contraire, le traitement de certaines stérilités chez la femme, à l'aide de LH-RH injectée par une pompe pulsatile qui mime la sécrétion physiologique $(1 \mathrm{mg} / \mathrm{min}$ pendant $6 \mathrm{~min}$, toutes les $60 \mathrm{~min})$. 


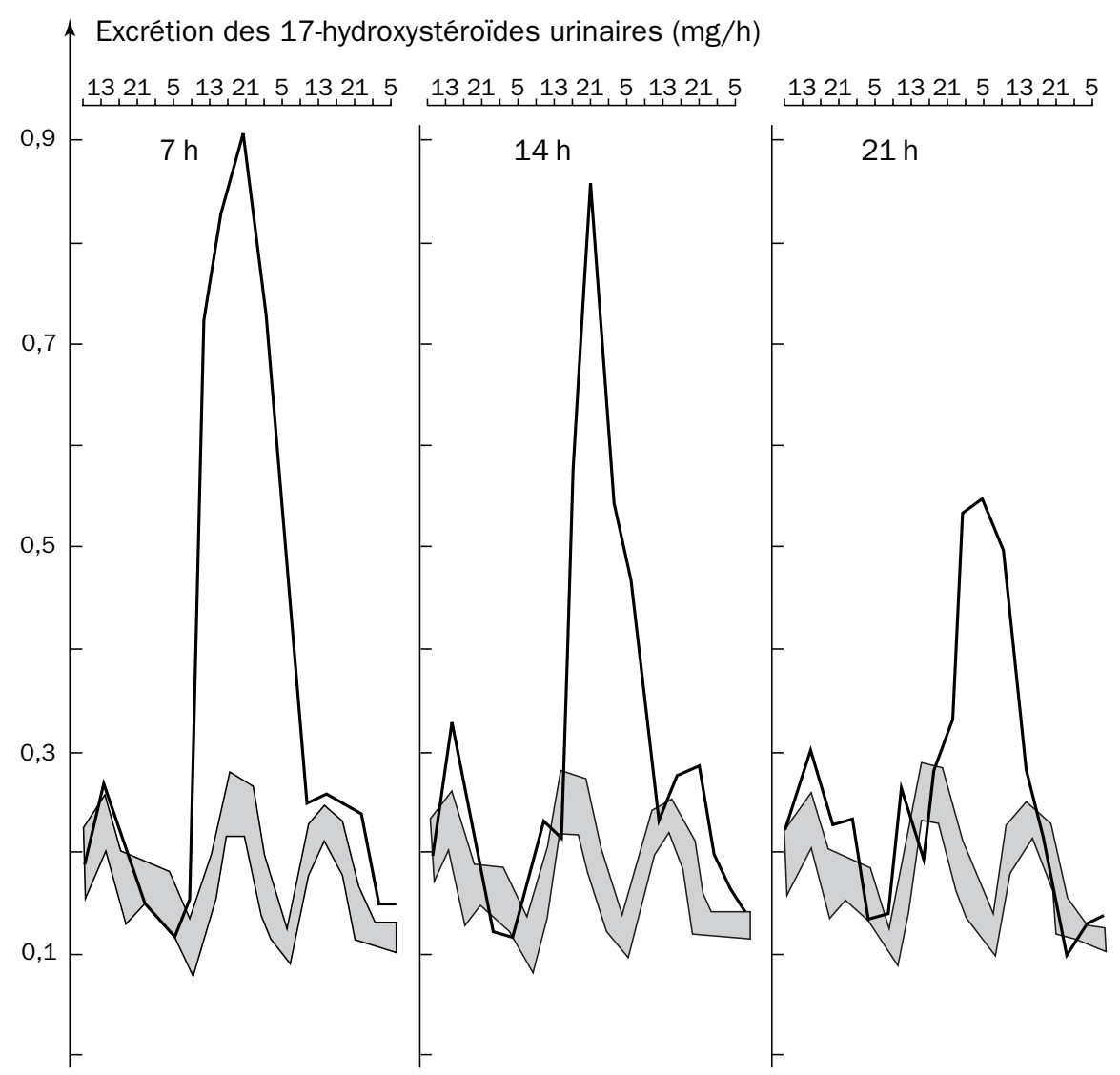

Figure 0.5 - Chronopharmacologie (d'après Reinberg, 1980)

Cette série de courbes illustre la notion de chronergie (chrono-efficacité globale) : il s'agit de la variation circadienne de la réponse de la glande corticosurrénale à l'hormone hypophysaire ACTH, chez l'homme. 100 mg d'une ACTH synthétique (ACTH 1-17) ont été injectées respectivement à 7,14 et $21 \mathrm{~h}$. Les courbes en filet maigre représentent le rythme circadien physiologique de l'excrétion urinaire des 17-OH-CS (épreuves de contrôle). La réponse la plus forte, en quantité et en durée, apparaît après l'injection d'ACTH 1-17 à $7 \mathrm{~h}$, cependant que la réponse la plus faible correspond à l'injection faite à $21 \mathrm{~h}$.

L'étude chronologique du taux des lymphocytes (Lévy et coll., 1985) a permis de constater que le rapport LT4 (lymphocyte helper)/ LT8 (lymphocyte suppresseur) peut passer de 1 à 4 selon le moment de l'examen chez un individu normal (variation de $400 \%$ ), alors qu'une variation de $25 \%$ était considérée comme significative dans le dépistage du SIDA ! Des corrélations existent certainement entre ces variations et celles de nombreuses hormones dont on a identifié des récepteurs spécifiques sur les lymphocytes B ou T. 


\subsection{VARIABILITÉ PHYSIOLOGIQUE DES HORMONES}

En dehors même de la variabilité méthodologique, qui nécessite la répétition des dosages sur plusieurs animaux à un moment donné de la journée, on peut donc s'attendre en expérimentation courante en endocrinologie à trois ordres de variabilité :

- un rythme ultradien, dit pulsatile, qui affecte, parmi les hormones les mieux connues, celles de l'axe hypothalamo-gonadique, aussi bien dans le sexe mâle que dans le sexe femelle : LH-RH, LH et FSH, et $17 \beta$-œstradiol surtout autour du pic pré-ovulatoire chez la femelle, les hormones testiculaires (surtout la testostérone), mais aussi les hormones corticosurrénaliennes (cortisol, DHEA), la GH, la prolactine... L'importance de cette variabilité pulsatile est considérable, car elle conditionne la sensibilité du récepteur hormonal ;

- un rythme circadien, à programmation temporelle interne, mais synchronisé par l'alternance jour/veille et activité/repos ;

- un rythme circannuel, ou saisonnier, observable sur les espèces hibernantes ou à activité sexuelle saisonnière.

\section{RÉFÉRENCES BIBLIOGRAPHIQUES}

\section{OUVRAGES GÉNÉRAUX}

BAULIEU E.E. \& KELLY P.A., Hormones, Hermann, Paris, 1990.

BROOK C.G.D. \& MARSHALL N.J., Endocrinologie, De Boeck Université, Bruxelles, 1998.

Endocrinology, de Groot L.J. ed., vol. 1 (1994) et vol. 2 (1995), Hardcover.

DUPOUY J.P., Hormones et grandes fonctions, t. I et II, Ellipses, Paris, 1993.

GIROD C., Leçons sur les glandes endocrines, Simep, Paris, 1980.

HALL R., EVERED D. \& GREENE R., Atlas en couleurs d'endocrinologie, Maloine, Paris, 1981.

HAZARD J. \& PERLEMUTER L., Endocrinologie, Masson, Paris, 1990.

LEHNINGER A.L., NELSON D.L. \& COX M.M., Principes de biochimie, Flammarion, Paris, 1994.

TURNER C.D., Endocrinologie générale, Masson, Paris, 1969.

STRYER L., Biochimie, Flammarion, Paris, 1995.

VOET D. \& VOET J.G., Biochemistry, J. Wiley \& Sons, 1990.

WILLIAMS R.H., Traité d'Endocrinologie, Flammarion, Paris, 1972.

WILSON J.D. \& FOSTER D.W., Textbook of Endocrinology, Saunders Co, 1992. 


\section{RYTHMES BIOLOGIQUES}

AGATA R. (d') \& VIGNERI R., Circadian variations of human growth hormone serum levels, longitudinal study, Ann. Endocrinol., 32, 283-344, 1971.

ASSENMACHER I., Cerveau et rythmes hormonaux, Contraception-fertilitésexualité, 14, 379-385, 1986.

ASSENMACHER I. \& BOISSIN J., Rythmes circannuels et circadiens du fonctionnement corticosurrénalien et thyroïdien en relation avec le réflexe photosexuel, in "Neuro-endocrinologie", n927, Colloques Nat., CNRS, 1969.

ASSENMACHER I. \& coll., CNS structures controlling circadian neuroendocrine and activity rhythms in mammals, Comparative Physiology of Environmental Adaptations, Pévet ed., vol. 3, 56-70, 1987.

ATEHESON J.A. \& TYLER F.H., Circadian rhythm : man and animals, in "Handbook of Physiology", Endocrinology, VI, sect. 7, 127-134, 1975.

BAILLAUD L., Les rythmes biologiques, Experientia, 27, 489-501, 1971.

BOISSIN J. \& CANGUILHEM B., Les rythmes circannuels chez les Mammifères, Arch. Intern. Physiol., 96, A289-A345, 1988.

BREMMER W.J., VITIELLO M.V. \& PRINZ P.N., Loss of circadian rhythmicity in blood testosterone levels with aging in normal men, J. Clin. Endocrinol. Metab., 56, 1278-1281, 1983.

CANON C. \& coll., Variations circadienne et saisonnière du rapport indicateur/suppresseur (OKT4 + : OKT8 +) dans le sang veineux de l'homme adulte sain, CR Acad. Sci., 302, 519-524, 1986.

Endocrine rhythms, Krieger D.T. ed., Comprehensive endocrinology series, Raven Press, New York, 1979.

EPSTEIN I. \& coll., Les réactions chimiques oscillantes, Pour la Science, 67, 69-79, 1983.

GUIGNARD M.M. \& coll., Circadian rhythms in plasma levels of cortisol, dehydroepiandrosterone, $\Delta 4$-androstenedione, testosterone and dehydro-testosterone of healthy young men, Acta Endocrinol., 94, 536-545, 1980.

HALBERG F. \& REINBERG A., Rythmes circadiens et rythmes de basse fréquence en physiologie humaine, J. Physiol., 59, 117-200, 1967.

HIROSHIGE T. \& SAKAKURA M., Circadian rhythm of corticotropin-releasing activity in the hypothalamus of normal and adrenalectomized rats, Neuroendocrinology, 7, 25-36, 1971.

JORDAN D. \& coll., Participation of serotonin in thyrotropin release. II. Evidence for the action of serotonin on the phasic release of thyrotropin, Endocrinology, 105, 975-979, 1979.

KRIEGER D.T., Rhythms of ACTH and corticosteroid secretion in health and disease and their experimental modification, J. Steroid Biochem., 785-791, 1975.

LEVY F.A. \& coll., Circadian and/or cirhemidian rhythms in nine lymphocyterelated variables from peripheral blood of healthy subjects, J. Immunol., 134, 217-222, 1985. 
MATSUKURA S. \& coll., A new phenomenon of usefulness in the radioimmunoassay of plasma adrenocorticotropin hormone, J. Lab. Clin. Med., 77, 490-500, 1971.

ORTH D.N., ISLAND D.P. \& LIDDLE G.W., Experimental alteration of the circadian rhythm in plasma cortisol (17-OHCS) concentration in man, J. Clin. Endocrinol. Metab., 27, 549-555, 1967.

REINBERG A., Des rythmes biologiques à la chronobiologie, Gauthier-Villars, Paris, 1974.

REINBERG A., Rythmes circadiens et circannuels des résultats d'épreuves fonctionnelles en endocrinologie, Ann. Endocrinol. (Paris), 43, 309-335, 1982.

REINBERG A., La chronopharmacologie, la Recherche, 132, 478-489, 1982.

REINBERG A. \& coll., Circadian and circannual rhythms in plasma hormones and other variables of five healthy young human males, Acta Endocrinol., 88, 417-427, 1978.

REINBERG A. \& coll., Clinical chronopharmacology of ACTH 1-17. I. Effects on plasma cortisol and urinary 17-hydroxycorticosteroids, Chronobiologia, 7, 513-523, 1980.

REINBERG A. \& coll., Circadian and seasonal changes in ACTH-induced effects in healthy young men, Eur. J. Clin. Pharmacol., 25, 657-665, 1983.

REINBERG A. \& coll., Circadian changes in effectiveness of corticosteroids in eight patients urth allergic asthma, J. Allergy Clin. Immun., 71, 425-433, 1983.

REINBERG A. \& coll., Chronobiologie et nutrition, Enc. Méd. Chir., 10390 A 10 , $1-10,1984$.

SCAPAGNINI V. \& coll., Effect of $\alpha$-methyl- $\rho$-tyrosine on the circadian variation of plasma corticosterone in rats, Eur. J. Pharmacol., 11, 266-268, 1970.

SCAPAGNINI V. \& coll., Relation of brain 5-hydroxytryptamine content to the diurnal variation in plasma corticosterone in the rat, Neuroendocrinology, 90-96, 1971.

SHEPHERD G.M., Neurobiology, Oxford Univ. Press, 467-486, 1983.

SOLLBERGER A., Biological rhythm research, Elsevier, 1965.

THALABARD J.C. \& coll., Rythmes et reproduction, Pour la Science, 77, 92-102, 1984.

TUREK F.W. \& coll., Role of circadian system in reproductive phenomena, Rec. Progr. Horm. Res., 40, 143-177, 1984. 



\section{Première PARTIE}

\section{MÉTHODES \\ ET COMMUNICATIONS CELLULAIRES}

Chapitre 1 Méthodes utilisées en endocrinologie

Chapitre 2 Les messagers chimiques

Mécanismes de traduction de leur information

Chapitre 3 Des messagers chimiques particuliers :

kinines, NO, PAF, endothéline, ecdysone 



\section{MÉTHODES UTILISÉES EN ENDOCRINOLOGIE}

\section{LOCALISATION DES HORMONES "IN SITU"}

Elle est réalisée par des méthodes immuno-histochimiques, à l'aide d'anticorps qui ont été couplés à un marqueur : fluorochrome ou enzyme. La méthode la plus simple (méthode directe) consiste à utiliser un anticorps anti-hormone couplé, soit à de la fluorescéine (FITC) ou à de la rhodamine, soit à une enzyme telle que la peroxydase, la $\beta$-galactosidase ou la phosphatase alcaline. Une technique plus récente et plus précise (méthode indirecte) consiste à mettre la coupe de tissu, préalablement incubée avec un anticorps anti-hormone, en présence d'un anticorps antigammaglobuline couplé à un fluorochrome ou à une enzyme (généralement la peroxydase). La coupe est ensuite examinée soit au microscope à UV, soit après détection histochimique de l'activité enzymatique (fig. 1.1).

Cette technique suppose qu'on dispose d'un anticorps anti-hormone spécifique de l'hormone (il faut donc l'avoir obtenu avec l'hormone à l'état purifié), ce qui n'exclut pas la possibilité de spécificités croisées, au moins avec les anticorps conventionnels. La disponibilité, qui va croissant, d'anticorps monoclonaux augmente considérablement cette spécificité.

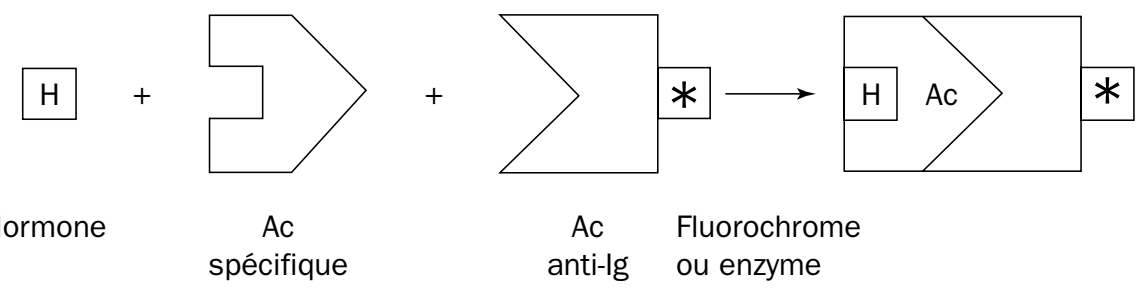

Figure 1.1 - Immunomarquage par un fluorochrome ou une enzyme 


\section{SÉCRÉTION DE L'HORMONE - TAUX DE PRODUCTION}

En général, l'hormone n'est pas ou peu stockée (sauf pour l'ocytocine et l'ADH). La réserve hormonale est inférieure aux besoins journaliers normaux. On peut distinguer trois catégories chimiques d'hormones :

- des dérivés des acides aminés : catécholamines, hormones thyroïdiennes ;

- des polypeptides et protéines ; leur biosynthèse peut se faire dans le réticulum endoplasmique granuleux sous forme d'une séquence plus longue, constituant une pro-hormone (cas de l'insuline, du glucagon, de certaines hormones antéhypophysaires...);

- des stéroïdes, dont la biosynthèse se fait à partir du cholestérol et qui peuvent constituer soit la forme directement active dans la cellule (cas général), soit une pré-hormone, dont le métabolisme est la forme directement active (cas de la testostérone qui est transformée en dihydrotestostérone, du sulfate de DHEA qui est converti en œstrogène dans le placenta, de la vitamine D3 qui est transformée en une hormone stéroïde, la 1,25-(OH) 2 -D3).

Le taux d'une hormone dans le sang ne reflète pas nécessairement l'importance de sa sécrétion, puisqu'il est la résultante à la fois de la sécrétion de l'hormone, de son catabolisme (surtout dans le foie, le rein et parfois toutes les cellules de l'organisme) et de son excrétion (rénale, biliaire, intestinale) ${ }^{1}$. A cela peut s'ajouter le cas où une synthèse (conversion) métabolique de l'hormone s'ajoute à sa sécrétion classique (par exemple la synthèse de l'androstérone par le foie, à partir de la testostérone, s'ajoutant à sa sécrétion surrénalienne ou gonadique).

Le taux de sécrétion d'une hormone est la quantité sécrétée par la glande dans l'unité de temps.

- Si l'on mesure simultanément la concentration dans l'artère afférente (Ca) et dans la veine efférente $(\mathrm{Ce})$, ainsi que le débit plasmatique (D), le taux de sécrétion est $\mathrm{S}=\mathrm{D} \times(\mathrm{Ce}-\mathrm{Ca})$.

Ces mesures ne sont pas toujours faciles et ne rendent compte que de l'aspect instantané d'une sécrétion.

- Une mesure plus fiable consiste à injecter une dose traceuse de l'hormone radioactive. Elle va se diluer dans l'hormone sécrétée, en suivre le métabolisme et sera excrétée dans l'urine en même temps que les métabolites de l'hormone et dans les mêmes proportions.

1 Toutefois, dans des cas favorables, l'excrétion des métabolites urinaires constitue un reflet (plus ou moins fidèle) de la sécrétion hormonale : c'est le cas des 17-cétostéroïdes pour les hormones androgènes (surrénaliennes chez la femme, mais surrénaliennes et testiculaires chez l'homme), des 17-hydroxystéroïdes pour le cortisol. 
Si la dilution a été parfaite, si le métabolite urinaire est un métabolite exclusif de l'hormone, sachant que :

$\mathrm{R}=$ radioactivité injectée,

$\mathrm{U}=$ taux d'excrétion urinaire du métabolite (quantité excrétée en 24 h),

$\mathrm{A}=$ radioactivité du métabolite urinaire ;

$$
\frac{\mathrm{R}}{\mathrm{S}}=\frac{\mathrm{A}}{\mathrm{U}} \text {, d'où } \mathrm{S}=\frac{\mathrm{R} \times \mathrm{U}}{\mathrm{A}} \text {. }
$$

- A côté de la sécrétion proprement dite peut s'ajouter une synthèse périphérique, en général à partir d'un précurseur très élaboré. La quantité d'hormone produite pendant l'unité de temps (c'est le taux de production TP) est alors la somme du taux de sécrétion et de la conversion périphérique.

La technique consiste à réaliser une perfusion à débit constant avec l'hormone radioactive. Le taux d'hormone dans le sang s'élève brusquement puis atteint un plateau. A l'état d'équilibre entre l'hormone infusée et l'hormone endogène sécrétée (équilibre isotopique), le taux de catabolisme de l'hormone est égal au taux de production. Des prélèvements de sang répétés permettront d'établir le taux de clairance métabolique (TCM) de l'hormone exprimé en $\mathrm{ml} / \mathrm{min}$ ou en $1 / 24 \mathrm{~h}$, qui est égal au rapport du taux de catabolisme (donc du taux de perfusion $\mathrm{P}$ ) sur la concentration radioactive de l'hormone $\mathrm{C}: \frac{\mathrm{TCM}}{\mathrm{ml} / \mathrm{min}}=\frac{\mathrm{P} \mathrm{dpm} / \mathrm{min}}{\mathrm{Cdpm} / \mathrm{ml}}$.

Le taux de production est alors une fonction directe du TCM qu'il compense et de la concentration $\mathrm{C}$ qu'il assure : $\mathrm{TP}(\mathrm{ng} / \mathrm{min})=\mathrm{TCM}(\mathrm{ml} / \mathrm{min}) \times \mathrm{C}(\mathrm{ng} / \mathrm{ml})$, qu'on exprimera ensuite en TP (mg/24 h).

Cette méthode n'est valable que sous réserve de plusieurs conditions :

- l'hormone administrée doit être radiochimiquement pure ;

- elle doit avoir une haute activité spécifique pour que la quantité perfusée ne modifie pas le pool d'hormone endogène et ne perturbe pas le métabolisme concerné ;

- l'hormone radioactive doit être métabolisée de la même façon que l'hormone endogène ;

- l'isotope doit être stable et non-échangeable ;

- le taux d'hormone endogène doit rester constant au cours de la perfusion ;

- la dilution de l'hormone radioactive dans le sang doit être homogène.

\section{Protéines DE TRANSPORT}

\subsection{PRINCIPE GÉNÉRAL}

La liaison de l'hormone $\mathrm{H}$ avec sa protéine de transport ou avec le récepteur protéique membranaire de la cellule cible répond au même principe général que l'on retrouve en biochimie dans la liaison de l'enzyme avec son substrat. La liaison aux protéines est non-covalente (liaisons essentiellement ioniques ou hydrophobes). 
Elle est réversible à l'équilibre suivant l'équation : $(\mathrm{H})+(\mathrm{BP}) \frac{\mathrm{k}_{\mathrm{a}}}{\mathrm{k}_{\mathrm{d}}}(\mathrm{H}-\mathrm{BP})$ où,

- $\mathrm{k}_{\mathrm{a}}$ et $\mathrm{k}_{\mathrm{d}}$ sont les constantes de vitesse d'association et de dissociation ;

- (H) est la concentration (en M, c'est-à-dire en molécules par litre) d'H libre ;

- (BP) représente la concentration de sites libres de la protéine de liaison (BP ou binding protein);

- $(\mathrm{H}-\mathrm{BP})$ est la concentration des complexes (hormone-sites de la protéine);

- $\mathrm{N}$ est le nombre des sites de liaison (concentration de $\mathrm{H}$ à partir de laquelle la macromolécule est saturée) ; il correspond à (H-BP) maximum ;

- $\mathrm{K}_{\mathrm{A}}$ est la constante d'association intrinsèque $\left(\mathrm{en} \mathrm{mol}^{-1}\right)$ à l'équilibre.

La loi d'action de masse permet d'écrire :

$$
\begin{aligned}
& \mathrm{K}_{\mathrm{A}}=\frac{(\mathrm{H}-\mathrm{BP})}{(\mathrm{H})(\mathrm{BP})}=\frac{\text { (hormone liée) }}{\text { (hormone libre) (sites non occupés) }}=\frac{\mathrm{k}_{\mathrm{a}}}{\mathrm{k}_{\mathrm{d}}} ; \\
& \mathrm{K}_{\mathrm{D}}=\frac{1}{\mathrm{~K}_{\mathrm{A}}} \text {, est la constante de dissociation de l'équilibre. }
\end{aligned}
$$

$\mathrm{Si}\left(\mathrm{H}_{\mathrm{T}}\right)$ est la totalité de l'hormone :

$$
\begin{aligned}
\left(\mathrm{H}_{\mathrm{T}}\right) & =(\mathrm{U})+(\mathrm{B}) & \mathrm{U}(\text { ou } \mathrm{F})=\text { unbound, hormone libre, } \\
& =(\mathrm{H})+(\mathrm{H}-\mathrm{BP}) & \mathrm{B}=\text { bound, hormone liée }
\end{aligned}
$$

et $\left(\mathrm{R}_{\mathrm{T}}\right)$ représente la totalité des sites de liaison du récepteur, $\left(\mathrm{R}_{\mathrm{T}}\right)=\mathrm{N}=(\mathrm{BP})+(\mathrm{H}-\mathrm{BP})$.

La représentation la plus simple de la liaison de l'hormone avec sa protéine est la représentation de Michaelis (fig. 1.2).

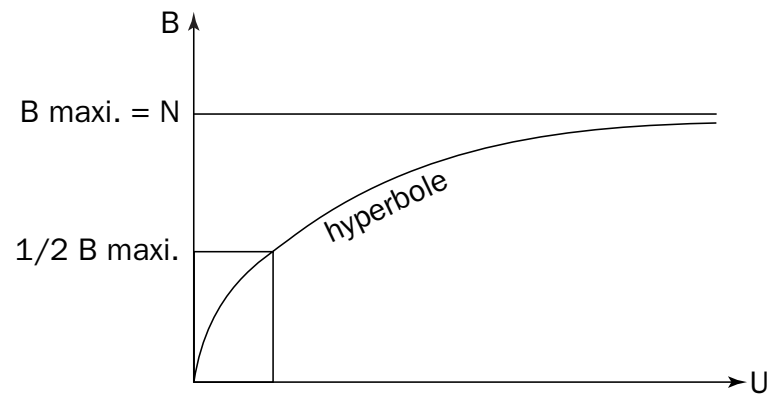

Figure 1.2 - Représentation de type Michaelis

$B$ : bound, hormone liée; $N$ : nombre de sites ; $U$ : unbound, hormone libre.

\subsection{LES PROTÉINES DE TRANSPORT}

Elles sont utilisées par les hormones thyroïdiennes ou les hormones stéroïdes. La liaison peut se faire :

- avec une protéine spécifique, de grande affinité $\left(\mathrm{K}_{\mathrm{D}} \leq 10 \mu \mathrm{M}\right)$ et de spécificité relativement étroite. 
Ces protéines (BP ou binding proteins) sont en général des glycoprotéines, de PM 25000 à 100000 :

- CBG (corticosteroid binding globulin) ou transcortine pour le cortisol, la progestérone et la 17 -hydroxyprogestérone; son $\mathrm{K}_{\mathrm{D}}$ est égal à $1,5 \mu \mathrm{M}$ à $2^{\circ} \mathrm{C}$ et $30 \mathrm{nM}$ à $30^{\circ} \mathrm{C}$ pour le cortisol; la $\mathrm{CBG}$ lie les stéroïdes en $\mathrm{C} 21$ avec une structure $\Delta 4-3$ céto (cortisol, corticostérone, progestérone, 17-hydroxyprogestérone). C'est une $\alpha$-glycoprotéine de PM 25000 . L'augmentation de la transcortine sous l'effet des œstrogènes favorise la liaison de la progestérone qui circule essentiellement liée à la transcortine pendant la grossesse.

- SBG (sex hormone binding globulin) pour l'œstradiol, la testostérone, la dihydrotestostérone ; c'est une $\beta$-glycoprotéine, de PM 50000 à 100000 , sécrétée par le foie ; elle lie ces hormones avec une forte affinité (respectivement $0,5 \mathrm{nM}, 1 \mathrm{nM}$ et $4 \mathrm{nM}$ pour l'œstradiol, la testostérone et la dihydrotestostérone). Plus l'affinité de l'hormone pour la SBG est grande, plus la clairance métabolique est faible; au cours de la grossesse, l'augmentation de la capacité de liaison de la SBG entraîne l'augmentation de la testostérone totale plasmatique.

- TBG (thyroxin binding globulin) pour T3 et T4, surtout T4 ;

- ou à une protéine non-spécifique, généralement l'albumine pour laquelle les hormones présentent moins d'affinité, mais une très grande capacité de liaison. Sa C est égale à $40 \mathrm{~g} / 1,1000$ à 100000 fois plus que la concentration des protéines spécifiques. L'albumine lie tous les stéroïdes avec des $\mathrm{K}_{\mathrm{D}}$ allant de $1 \mu \mathrm{M}$ (œstrogènes) à $1 \mathrm{mM}$ (cortisol); la liaison hormone/protéine de transport se comporte comme un réservoir capable de "tamponner" les changements de concentration de l'hormone, ou plus souvent d'accentuer, d'amplifier les variations hormonales. Si la sécrétion d'hormone augmente, il y a rapidement saturation de la protéine de transport et la concentration de l'hormone libre augmente relativement plus vite qu'elle ne l'aurait fait en l'absence de cette protéine.

Certaines protéines sont propres à certaines espèces ou à certaines situations physiologiques. C'est le cas de la PBP (progesterone binding protein), présente chez le cobaye gestant. Dans tous les cas, seule la fraction libre de l'hormone est active au niveau des cellules cibles.

L'efficacité de l'hormone dépendra donc non seulement de sa concentration plasmatique, mais aussi de la concentration de la protéine de transport qui peut varier suivant la situation physiologique (grossesse, malnutrition, médicaments...). Une faible partie de la concentration totale de l'hormone circule sous forme non-liée à la protéine de transport : 1 à $3 \%$ pour les stéroïdes, 0,1 à $0,2 \%$ pour T3 total, les quantités de T3 et T4 libres sont voisines. La forme libre étant la seule efficace, c'est sous cette forme que l'hormone se fixe sur le récepteur, mais elle est constamment régénérée à partir de la forme liée au fur et à mesure de sa consommation. La présence de la protéine de transport n'est toutefois pas une condition obligatoire, puisque dans 
certaines anomalies génétiques où elle est absente, le fonctionnement endocrinien n'est pas notamment altéré.

Les variations de concentration circadiennes ou saisonnières de ces protéines sont importantes, car elles peuvent affecter la fraction d'hormone liée ou libre et modifier ainsi des états physiologiques ou pharmacologiques.

La concentration des protéines plasmatiques est modifiée (de 7 à 13\%) chez la personne âgée, en fonction de l'heure de prélèvement du sang, et de la saison. Elle est plus basse en janvier et nettement plus basse en mars et en juin que chez le jeune, et cela aussi bien chez l'homme âgé que chez la femme âgée. En octobre, le taux des protéines plasmatiques s'élève presque au niveau de celui de l'homme jeune, soit un différentiel de $8 \mathrm{~g} / 1$ par rapport au minimum en juin (la différence entre le maximum et le minimum n'est que de $2,5 \mathrm{~g} / 1$ chez l'homme jeune). La variation circadienne de la volémie ne peut expliquer ces modifications, car la périodicité circadienne des protéines plasmatiques diffère de celle de l'hématocrite, de l'hémoglobine et du nombre des hématies, paramètres qui sont souvent utilisés comme des indicateurs du taux de la volémie.

\section{Dosage RADIOIMMUNologigue}

Développée depuis 1960, grâce aux travaux de Yalow et Berson qui ont dosé l'insuline à l'aide d'anticorps anti-insuline, cette méthode a supplanté par sa rapidité et sa sensibilité les dosages biologiques ou chimiques. La sensibilité est de l'ordre du $\mathrm{ng} / \mathrm{ml}$ de plasma. Appliquée d'abord aux hormones polypeptidiques, elle a pu être étendue aux stéroïdes et aux hormones thyroïdiennes que l'on utilise comme haptènes pour obtenir l'anticorps spécifique. Le principe, qui est celui d'une analyse par saturation, repose sur la loi d'action de masse, la liaison se faisant cette fois entre l'hormone et l'anticorps spécifique. La méthode avec la courbe d'étalonnage sera décrite au chapitre $4, \S 4.7$ (fig. 4.17), la quantité inconnue d'hormone à doser dans l'extrait prélevé est déterminée par sa capacité à déplacer l'hormone radioactive de son complexe, par référence à la courbe étalon.

Comme pour les protéines de transport, certaines conditions sont nécessaires pour établir la validité du dosage :

- L'anticorps doit être spécifique pour l'hormone à doser. Mais des immunités croisées sont possibles, soit que des hormones différentes présentent des séquences identiques et donc des motifs antigéniques communs, soit que la prohormone est présente dans le sang en même temps que l'hormone définitive (cas de l'insuline). Le taux d'hormone immunoréactive ne sera pas forcément le taux de l'hormone biologiquement active.

- Le marquage de l'hormone ne doit pas modifier sa capacité de liaison avec l'anticorps spécifique. 


\section{DOSAGE IMMUNO-ENZYMATIQUE}

Les techniques immuno-enzymatiques se sont développées, surtout depuis les travaux d'Avrameas (1966) qui introduisit des enzymes comme marqueurs dans les tests immunologiques. Par rapport à l'immunofluorescence, ces méthodes nécessitent un équipement moins onéreux et les mêmes réactifs peuvent être utilisés pour la microscopie optique et la microscopie électronique. Par rapport à la radioimmunologie, les réactifs utilisés sont moins coûteux et moins polluants et les produits marqués se conservent pendant plusieurs années.

La technique la plus utilisée est un dosage en phase hétérogène, la méthode ELISA (enzyme linked immunosorbent assay) développée en 1971 par Engvall et Perlmann. Elle utilise, comme son nom l'indique, un immuno-absorbant (insoluble dans l'eau) sur lequel on fixe l'antigène (Ag) ou l'anticorps (Ac). Elle nécessite, comme le dosage radioimmunologique, une étape préalable à la mesure : la séparation de l'antigène lié à l'Ac du milieu réactionnel. On peut employer deux méthodes :

- soit une méthode compétitive, où l'anticorps, dont les sites actifs sont limités, forme des liaisons avec le mélange d'Ag marqué à l'enzyme et d'Ag à doser, l'intensité de la coloration (lue en DO) est proportionnelle à celle d'Ag à doser,

- soit une méthode sandwich, où l'antigène se lie d'un côté à l'anticorps absorbé, et de l'autre à l'anticorps marqué à l'enzyme, l'intensité de la coloration est proportionnelle au taux d'Ag présent.

\section{Application au dosage de la progestérone (méthode compétitive)}

L'anticorps utilisé est de l'anticorps de lapin. La progestérone est marquée à la $\beta$-galactosidase.

Les complexes marqués et non-marqués sont insolubilisés sur une phase magnétique solide (anticorps anti-Ig de lapin fixé sur particules magnétiques).

La séparation des formes libres et liées se fait par piégeage des particules magnétiques (aimantation). Après élimination du surnageant, l'activité enzymatique du complexe lié à la phase solide magnétique est révélée par addition du substrat (ONPG ou orthonitrophénylgalactopyranoside). Son hydrolyse fait apparaître une coloration jaune dont l'intensité est mesurée au spectrophotomètre.

Le dosage comprend quatre étapes (fig. 1.3) :

1. extraction de la progestérone et formation d'un complexe insoluble par réaction immunologique spécifique, (A);

2. séparation de l'hormone libre et liée au complexe insoluble, $(\mathbf{B})$;

3. révélation de l'activité enzymatique liée au complexe, $(\mathbf{C})$;

4. lecture de la densité optique, (D).

Cette technique, facilement automatisable et précise, se prête bien aux dosages en série. 


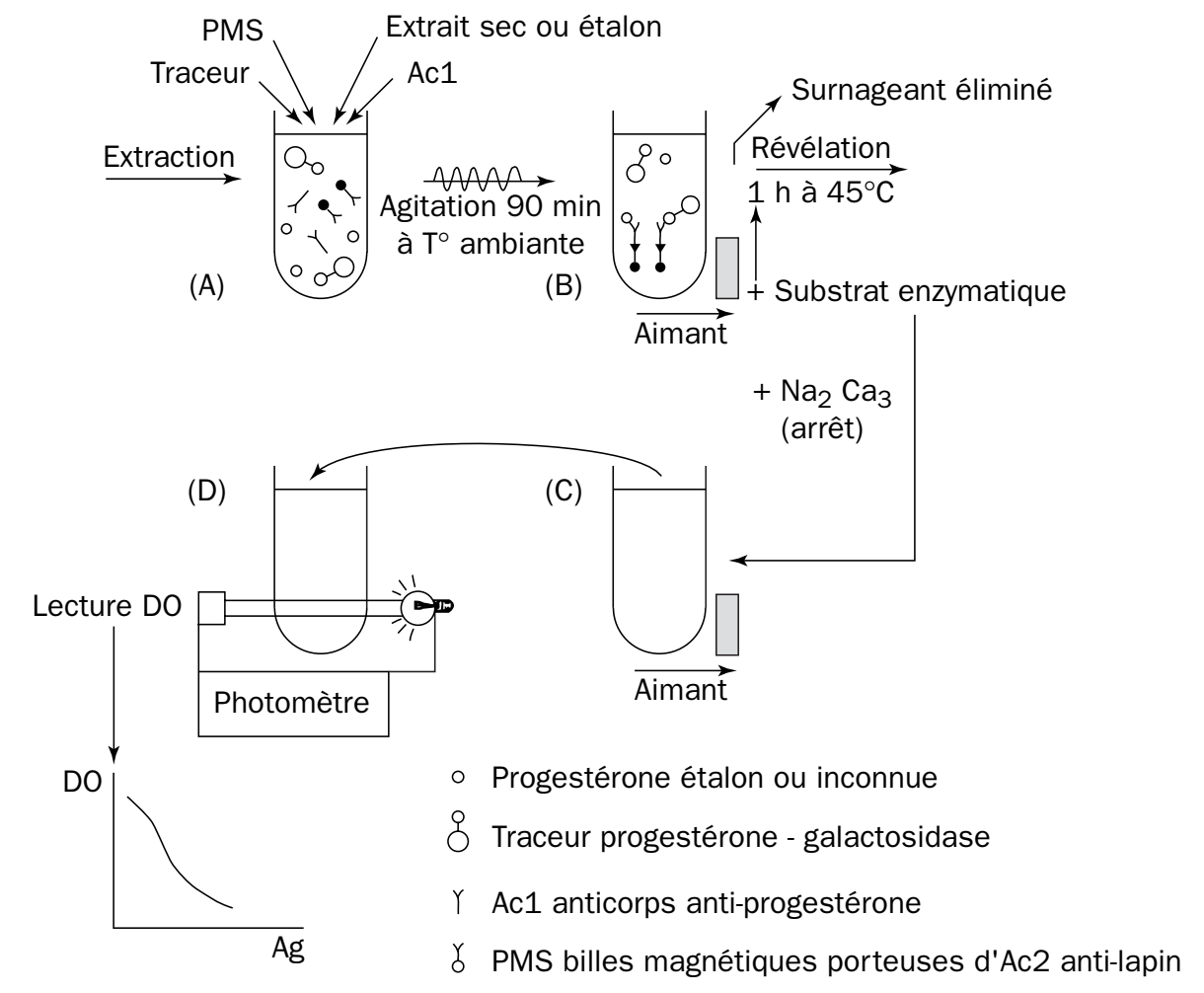

Extrait sec ou étalon

Figure 1.3 - Méthode de dosage de la progestérone

\section{LE RÉCEPTEUR HORMONAL - GÉNÉRALITÉS}

\subsection{STRUCTURE DU RÉCEPTEUR}

Les récepteurs sont des protéines le plus souvent membranaires, parfois nucléaires. Ils sont capables de reconnaître un message spécifique et transmettent ensuite un signal soit à un système enzymatique intracytoplasmique, soit au génome de la cellule. Les récepteurs sont des transducteurs et des traducteurs d'information.

Leur localisation peut être déterminée par autoradiographie in vitro à partir du complexe protéine-messager, marqué au tritium ou à l'iode radioactif $\left({ }^{131} \mathrm{I}\right)$. Il en est de même de leur étude. Cependant, cette étude n'est pas toujours facile à réaliser, car la purification après isolement du récepteur peut aboutir soit à provoquer une dégradation (par protéolyse enzymatique ou physique) du récepteur, et on lui attribuera un PM inférieur à son PM réel, soit le plus souvent à isoler un ensemble plus important que le récepteur spécifique, et à lui attribuer un PM supérieur à son PM réel. 
On peut distinguer deux classes de récepteurs membranaires par le mode d'ancrage dans la membrane :

- La chaîne des AA du récepteur traverse une seule fois la membrane, c'est le cas des récepteurs à l'insuline à IGF1 et IGF2. Il présente trois parties :

- une partie à l'extérieur qui est le site de reconnaissance ;

- un segment intermédiaire à AA très hydrophobes ;

- une partie intracytoplasmique, de taille variable, éventuellement associée à des systèmes enzymatiques.

- La chaîne des AA traverse plusieurs fois la membrane : sept segments de la chaîne traversent la membrane. C'est le cas de nombreux récepteurs et, par exemple, des récepteurs aux catécholamines.

\subsection{PROPRIÉTÉS DU RÉCEPTEUR}

Un récepteur n'est pas seulement une macromolécule de liaison spécifique, telle que :

$$
\mathrm{H}+\mathrm{R} \leftrightharpoons \mathrm{HR} \text {. }
$$

Il faut que cette liaison induise de façon directe l'activité spécifique de l'hormone, autrement dit le récepteur est une structure impliquant à la fois :

- la reconnaissance du message, du signal,

- le déclenchement de la réponse (avec amplification du signal), c'est l'activation du récepteur.

Lorsqu'une molécule de structure analogue à l'hormone est reconnue par le récepteur et déclenche la réponse spécifique, elle est un agoniste de l'hormone. Si elle est seulement reconnue, mais ne provoque pas l'activation du récepteur, elle constitue un antagoniste de l'hormone (phénomène d'inhibition compétitive).

S'il y a nécessairement une spécificité stérique entre l'hormone (ou son agoniste ou son antagoniste) et son récepteur, il peut exister plusieurs récepteurs pour un même message hormonal (par exemple quatre types de récepteurs pour la noradrénaline).

La spécificité du récepteur pour l'hormone est parallèle à son action biologique, l'interaction qui résulte de la liaison est à l'origine de la réponse cellulaire à l'hormone.

La transduction du signal communiqué au récepteur par une hormone polypeptidique peut s'effectuer selon trois modèles de récepteurs membranaires :

- certains récepteurs transduisent eux-mêmes le signal extracellulaire. C'est le cas des récepteurs canaux ioniques (récepteur cholinergique nicotonique, $\mathrm{GABA}_{\mathrm{A}} \ldots$ ).

- un autre modèle de transduction directe est constitué par les récepteurs enzymes (insuline, IGF1, IGF2, EGF, certains facteurs de croissance). Le récepteur comporte lui-même sur sa partie interne une activité kinase liée à une unité autophosphorylante. 
- dans le troisième modèle, le plus fréquent, les récepteurs sont associés, par l'intermédiaire d'une protéine de couplage $\mathrm{G}$, à des systèmes effecteurs distincts (adénylate cyclase, phospholipase C, GMP cyclase), produisant une série de seconds messagers : AMPc, IP3, diacylglycérol, $\mathrm{Ca}^{2+}$, GMPc. Ces seconds messagers vont provoquer la phosphorylation de diverses protéine kinases de la cellule.

Pour d'autres hormones (T3, stéroïdes), le récepteur est nucléaire.

Ce qui caractérise en plus le récepteur (par rapport à une macromolécule de transport quelconque) c'est :

- une affinité plus élevée, soit un $\mathrm{K}_{\mathrm{D}}$ faible de $1 \mathrm{nM}\left(10^{-9} \mathrm{M}\right)$ à $10 \mathrm{pM}\left(10^{-11} \mathrm{M}\right)$, valeur qui est beaucoup plus de mille fois inférieure au $K_{M}$ des enzymes. Ceci permet une occupation suffisante des sites récepteurs, alors même que les concentrations d'hormone circulante sont très basses ;

- la capacité à transmettre une information.

En se reportant aux formules exposées dans le paragraphe 3.1, on peut représenter $\mathrm{N}$ et $K_{D}$ par solution graphique. De fait, on a intérêt à exprimer les courbes de saturation par deux méthodes différentes qui présentent chacune un intérêt propre (fig. 1.4).

Au niveau des cellules cibles, la concentration d'hormone active est de l'ordre de la nanomolarité et même moins : de $10 \mu \mathrm{M}$ à $10 \mathrm{pM}$.

\subsection{RÉGULATION DU NOMBRE DES RÉCEPTEURS}

Le nombre limite de récepteurs spécifiques permet de restreindre la réponse cellulaire en cas de concentration hormonale élevée.

En fait, les phénomènes ne sont pas toujours aussi simples. On suppose pour simplifier que les sites, pour un même type, n'interagissent pas. Le nombre des sites des récepteurs peut varier en fonction de l'état physiologique (et surtout hormonal) de la cellule, témoignant d'un mécanisme régulateur portant sur la biosynthèse ou sur la dégradation du récepteur ou sur les propriétés structurales du récepteur.

C'est ainsi qu'une stimulation prolongée du récepteur nicotinique entraîne une plus grande affinité pour l'agoniste, mais le canal devient imperméable aux ions sodium. L'hormone peut elle-même agir sur le nombre de ses récepteurs. C'est le cas de l'insuline, l'insulinémie élevée dans l'obésité s'accompagne d'une diminution du nombre des récepteurs Au contraire, l'œstradiol augmente la teneur en récepteurs de ses cellules cibles. Par ailleurs, l'effet "facilitant" de l'œstradiol sur la sécrétion des hormones progestagènes ou de la FSH sur la sécrétion de la LH s'explique par le fait que les œstrogènes augmentent la synthèse du récepteur utérin de la progestérone et que la FSH augmente le nombre des récepteurs de la LH au niveau de la granulosa. 


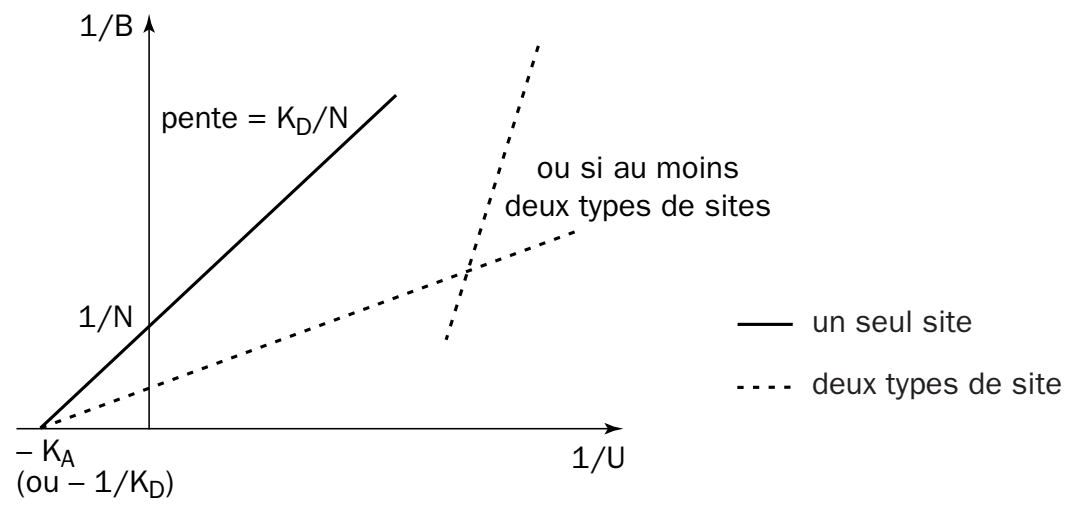

\section{a - Représentation de Lineweaver-Burk}

Les points de forte concentration sont tous proches du B maximum, mais il y a une imprécision sur $K_{D} s^{\prime} i l y$ a deux types de sites.

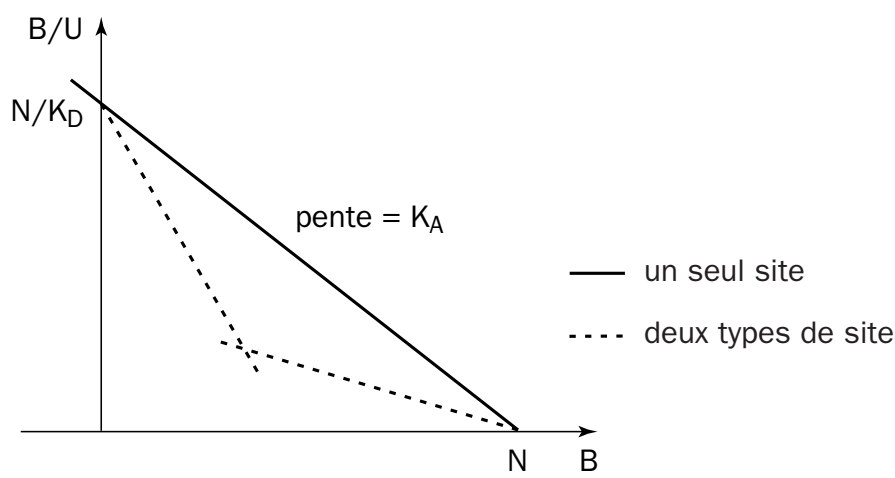

b - Représentation de Scatchard

Il y a une imprécision sur $B$ maximum, mais une meilleure précision sur $K_{D}$ s'il y a deux types de sites.

\section{Figure 1.4 - Courbes de saturation}

$B$ : bound, hormone liée ; $N$ : nombre de sites ; $U$ : unbound, hormone libre.

Le nombre de récepteurs sur la membrane cellulaire n'est pas fixe et peut augmenter (up-regulation) ou diminuer (down-regulation). Le nombre de récepteurs peut varier en fonction :

1. du programme génétique (développement, puberté, ménopause, âge...),

2. de l'action du messager chimique sur ses récepteurs (régulation homospécifique),

3. de l'action d'autres messagers chimiques agissant sur leurs récepteurs (régulation hétérospécifique),

4. de la présence d'agents qui ne sont pas des messagers chimiques (virus...).

Le nombre de récepteurs peut être régulé au niveau du génome mais aussi au niveau de la membrane. A ce niveau, le messager peut agir en provoquant l'internalisation du récepteur. Celle-ci a souvent lieu lorsque le récepteur est lié à son ligand. Elle peut être 
provoquée par des phosphorylations homo- ou hétérospécifiques. Lorsque le couple récepteur-messager est internalisé, il peut :

1. être dissocié par les lysosomes (le messager chimique et/ou le récepteur peuvent alors être dégradés),

2. être dissocié, et seul le messager chimique est dégradé, le récepteur étant, lui, recyclé,

3. se lier (un ou les deux éléments du couple) à des récepteurs intracellulaires ou intranucléaires.

\subsection{INTERNALISATION DES COMPLEXES RÉCEPTEURS-HORMONES POLYPEPTIDIQUES}

Des hormones polypeptidiques telles que l'insuline, l'hormone de croissance, la LHRH, la TRH, la prolactine, subissent, après avoir formé un complexe avec leur récepteur membranaire, un processus d'internalisation par endocytose. La vésicule endocytotique, recouverte de clathrine (réceptosome), s'enfonce dans la cellule en perdant son enveloppe de clathrine. Elle peut gagner l'appareil de Golgi où elle fusionne avec une vésicule golgienne. L'appareil de Golgi apparaît ainsi très riche en récepteurs. L'hormone polypeptidique peut être ensuite transférée dans un lysosome où elle est dégradée. Une autre alternative, qui paraît s'appliquer à l'EGF (epidermal growth factor), à la LH-RH, à la TRH, serait, après l'étape golgienne, un transfert vers le noyau sur lequel l'hormone pourrait avoir une action directe.

Pendant ce temps, les molécules de récepteurs, après s'être séparées des molécules hormonales, peuvent être recyclées en reprenant leur place au niveau de la membrane plasmique. Le recyclage n'exclut pas la possibilité de néo-formation de récepteurs par synthèse protéique.

Le processus d'internalisation du récepteur explique pour partie le phénomène de la "down-regulation", c'est-à-dire la diminution du nombre des sites récepteurs lorsque le nombre de molécules apportées par la circulation augmente.

\section{BIOSYNTHÈSE DES HORMONES}

\subsection{HORMONES POLYPEPTIDIQUES}

La biosynthèse des hormones a d'abord été le fait des chimistes qui ont réussi à faire la synthèse d'hormones polypeptidiques. Mais seuls les peptides de moins de $20 \mathrm{AA}$ peuvent être obtenus par synthèse chimique de façon rentable.

La plupart des hormones peptidiques telles l'insuline, l'hormone de croissance, ont une taille plus grande, et la production s'est d'abord tournée vers l'extraction à partir d'organes, avec des limitations diverses : 
- si l'insuline porcine ou bovine est active chez l'homme (avec un risque nonnégligeable de réactions immunes), seule l'hormone de croissance humaine est active dans notre espèce ;

- l'extraction est faite en général à partir de glandes de gros animal, mais dans le cas de l'hormone de croissance, on doit partir d'hypophyses humaines qui sont prélevées sur des cadavres, d'où des quantités disponibles restreintes ;

- la nécessité de mélanger un grand nombre de glandes accroît le risque de contamination ; c'est le cas pour le prion, protéine responsable de la maladie de Creutzfeldt-Jacob qui a contaminé des lots d'hormone de croissance, entrainant la suspension de la mise en circulation de nouveaux lots aux USA et en Angleterre respectivement en avril et mai 1985, tandis que la France n'a cessé la production d'hormone extractive qu'en 1988, pour la remplacer par une hormone synthétique obtenue par manipulation génétique.

Car l'intérêt s'est très vite imposé d'obtenir des hormones par biotechnologie (ingénierie génétique) dont l'avantage considérable est de permettre une production massive et, théoriquement, en toute innocuité. Le principe consiste à isoler le gène de l'hormone et à le faire se reproduire, soit dans un colibacille, soit dans des levures, soit dans certaines cellules animales en culture.

La première hormone produite a été la somatostatine, qui présentait l'avantage d'être un petit polypeptide (14 AA). La séquence de nucléotides peut se déduire de l'enchaînement des acides aminés dans le polypeptide et le gène a pu être reconstruit par synthèse dès 1977. Au gène de structure ont été ajoutées dix paires de bases nécessaires à l'insertion du fragment d'ADN double brin dans un plasmide qui a été ensuite introduit dans des bactéries Escherichia coli (fig. 1.5). Pour éviter une dégradation trop rapide de la somatostatine par des enzymes bactériennes, une molécule de méthionine est ajoutée en tête de la molécule de somatostatine.

L'hormone ainsi produite (1980) est identique à l'hormone humaine naturelle, chaque cellule produisant environ 10000 molécules d'hormones.

La même technique a été appliquée à l'insuline ${ }^{2}$ (deux chaînes polypeptidiques de 21 et $30 \mathrm{AA}$ respectivement), pour laquelle furent synthétisées en $1978^{3}$ les deux gènes correspondant aux deux chaînes. Les deux polypeptides sont ensuite assemblés pour former l'insuline. Celle-ci était mise sur le marché en 1982. Chaque bactérie synthétise environ 100000 molécules. L'apparition d'IgG, que l'on observe dans $19 \%$ des cas avec l'insuline de bœuf, dans $17 \%$ avec celle de porc, ne s'observe plus que dans $6 \%$ des cas avec l'insuline humaine.

2 Laboratoire Eli Lilly.

3 Un "synthétiseur" permet actuellement d'assembler des nucléotides (étape chimique), et les fragments d'oligonucléotides (quinze à vingt) peuvent être unis par une ligase (étape enzymatique). Cela a permis de faire la synthèse du gène de l'interféron (514 nucléotides). 


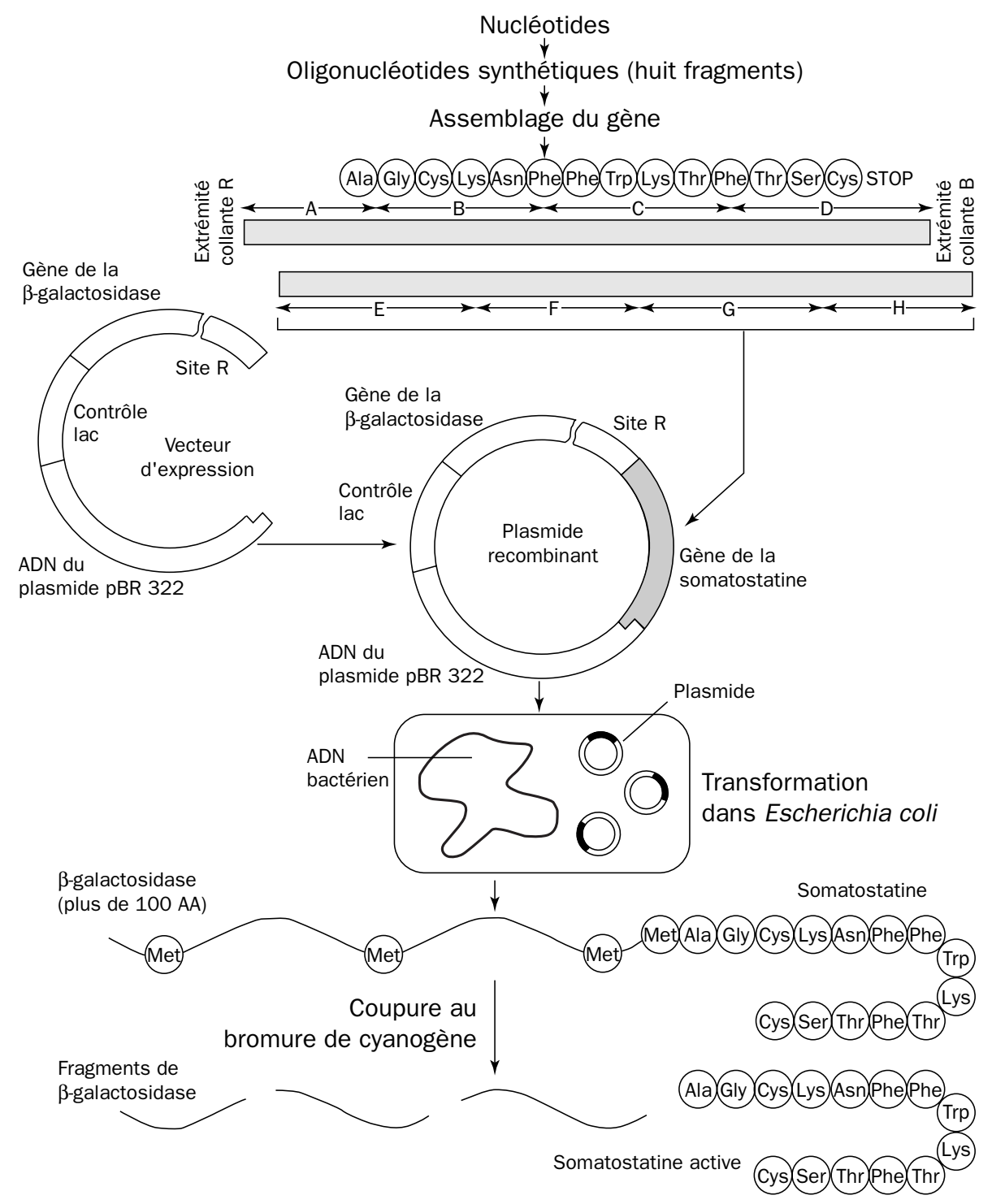

Figure 1.5 - Biosynthèse de la somatostatine (d'après Aharonowitz et Cohen, 1981)

Dans le cas de l'hormone de croissance humaine (HGH), le gène ne peut être synthétisé et il faut l'isoler à partir de cellules humaines. La méthode consiste à partir de l'ARN messager, extrait de tissus hypophysaires humains, à fabriquer à l'aide d'une enzyme, la transcriptase réverse, une copie d'ADN complémentaire (ADNc). La molécule d'ADN double brin, répliquée de nombreuses fois, est alors introduite dans la bactérie Escherichia coli. Les colibacilles en culture produisent jusqu'à 10\% de leurs protéines totales sous forme d'une hormone, qui n'est toutefois pas en tout point identique à l'HGH. Comme pour la somatostatine, elle porte à son extrémité une méthionine, d'où son nom de Met-GH. Son action physiologique est satisfaisante 
et elle n'a pas de toxicité particulière. Toutefois, les sujets traités pendant plusieurs mois développent des anticorps anti-GH.

Une approche différente consiste à utiliser les cellules animales en culture, par exemple des cellules rénales de singe, dites Vero. Le gène ainsi transféré (de cellules hypophysaires dans des cellules rénales) sécrèterait une hormone identique à l'hormone de croissance humaine ${ }^{4}$. Ce procédé de culture industrielle en fermenteur de cellules animales présente des avantages et des inconvénients par rapport à la culture bactérienne.

Dans le cas de la culture de cellules animales, l'hormone est sécrétée dans le milieu de culture au lieu de rester à l'intérieur de la bactérie, et sa purification est facilitée d'autant. Les risques résident dans les acides nucléiques de l'hôte (risque tumorigène) ou dans les éventuelles contaminations bactériennes ou endotoxines, susceptibles de réactions pyrogènes ou immunogènes.

Compte tenu de tous ces facteurs, du temps de passage du stade pré-industriel à l'échelle industrielle, des contrôles et expérimentations nécessaires chez l'animal d'abord et chez l'homme ensuite, conformément aux règlementations diverses, il faut compter entre 5 et 10 ans pour qu'une technique considérée comme efficace en laboratoire aboutisse au produit pharmaceutique sur le marché public.

\subsection{ETUDE DYNAMIQUE DE LA BIOSYNTHÈSE DES HORMONES POLYPEPTIDIQUES}

La dynamique de la biosynthèse des hormones polypeptidiques peut être suivie à l'aide des méthodes suivantes :

\subsubsection{L'autoradiographie en microscopie électronique}

La culture cellulaire (ou l'animal entier) est brièvement exposé à un "pulse" d'un précurseur spécifique (par exemple les leucines pour les protéines, l'uridine pour l'ARN) habituellement tritié, qui émet un rayonnement $\beta$. Après une incubation ou une période du durée variable, le tissu est fixé et traité pour l'observation à l'aide de microscopie électronique. Chaque préparation (coupes fines déposées sur un treillis posé sur une lame) est ensuite recouverte dans l'obscurité d'une mince couche d'émulsion photographique dite nucléaire. Après un temps de latence de plusieurs jours, l'émulsion est développée. Les protéines qui ont incorporé le précurseur, l'ARN messager, pourront être localisées par la position des grains d'argent dans la cellule. Leur déplacement dans la cellule pourra être apprécié par la variation de la position des grains suivant la durée qui sépare l'exposition au "pulse" de la fixation du tissu. On peut suivre ainsi, par exemple, les étapes intracellulaires de la biosynthèse de la parathormone dans la cellule parathyroïdienne.

4 Laboratoires Sanofi. 


\subsubsection{L'immunocytochimie en microscopie électronique}

Là encore, la technique immunocytochimique est appliquée sur des coupes ultra-fines qui seront ensuite observées au microscope électronique. L'immunomarquage permettra de préciser le lieu de synthèse ou d'accumulation de l'hormone ou de la molécule protéique étudiées. La réaction utilise un anticorps (Ac) spécifique, elle est révélée par un marqueur opaque aux électrons. La méthode de marquage peut être directe (le marqueur est fixé directement sur l'Ac) ou indirecte (l'Ac n'est pas marqué, mais il est détecté par un deuxième Ac lié au marqueur). Le marqueur peut être une enzyme (peroxydase de raifort) qui sera révélée par la 3-3'diaminobenzidine (DAB), ou une substance faite de particules denses aux électrons (or colloïdal, ferritine).

\subsubsection{L'hybridation in situ}

C'est la méthode la plus performante pour quantifier la dynamique de la synthèse d'une hormone protéique, ou d'une enzyme clé de l'hormonogenèse.

Pour étudier la transcription d'un gène au cours du cycle cellulaire ou au cours d'un processus physiologique, la méthode conventionnelle est la méthode de biologie moléculaire de Northern blot. Cette méthode consiste à isoler les ARN du prélèvement biologique, qui sont ensuite séparés sur un gel d'électrophorèse. La bande contenant l'ARN que l'on veut étudier est le plus souvent repérée par hybridation sur gel avec une sonde complémentaire. Une étude semi-quantitative de l'intensité du marquage dans les différentes bandes peut être réalisée.

L'utilisation de méthodes d'hybridation in situ (c'est-à-dire sur des préparations cytologiques ou histologiques) est justifiée :

- dans le cas où il existe une transcription différente de ce gène dans les structures histologiques ou même au sein de la population cellulaire ;

- dans le cas où une coloration cytologique doit être effectuée simultanément (par exemple une "coloration" de la protéine codée par le gène étudié).

Il faut disposer d'une sonde d'acides nucléiques (ADN ou ARN) monobrin, dont la séquence en base est complémentaire de celle de l'ARN à étudier. Cette sonde doit être marquée, soit avec un radioisotope, soit avec un haptène (molécule pouvant être reconnue par un anticorps).

Les principales étapes de cette technique sont :

- la fixation qui consiste à immobiliser, dans leur localisation cellulaire, les ARN que l'on veut détecter ;

- la dénaturation partielle pour éliminer les repliements secondaires de l'ARN sur lui-même ;

- le dépôt de la sonde sur la préparation et une incubation dans des conditions très strictes de $\mathrm{pH}$, force ionique et température permettant l'hybridation moléculaire. L'hybridation moléculaire est la formation d'un acide nucléique bicaténaire entre 
la sonde et la séquence d'ARN à étudier. Cette association résulte de la formation de liaisons hydrogène entre les bases complémentaires portées par la sonde et l'ARN à étudier ;

- le lavage pour éliminer l'excès de sonde ;

- la révélation des sondes hybridées se fait dans le cas des sondes radioactives par dépôt d'une émulsion photographique. Cette émulsion est ensuite développée ;

- dans le cas des sondes portant des haptènes, la révélation se fait par des anticorps fluorescents ou permettant d'obtenir une réaction colorée.

Une quantification du marquage dans chaque cellule ou dans les structures histologiques peut être effectuée par analyse d'image. C'est dire qu'une mesure de la coloration résultant des sondes hybridées est effectuée (mesure de la densité optique de la coloration) dans la préparation cytologique.

\subsection{HORMONES STÉROÏDES}

Leur fabrication fait appel à des méthodes de bioconversion dans lesquelles des micro-organismes prennent en charge des étapes isolées de la biosynthèse globale, dont les chaînons intermédiaires seront réalisés par une synthèse non-biologique (fig. 1.6).

Dans le cas de la cortisone, la synthèse chimique seule nécessitait 27 étapes à partir des stérols végétaux, aboutissant à un coût de revient très élevé. La prise en charge de l'hydroxylation de la progestérone sur le carbone 11 par un champignon a permis de réduire la synthèse de 75 à 11 étapes, divisant le coût de revient par 30. Depuis, les micro-organismes sont utilisés dès la dégradation de la chaîne latérale (Mycobactéries), ainsi que pour des déshydrogénations (sur C1, C2) qui donnent des dérivés de synthèse importants en thérapeutique.

\section{LES SOURIS TRANSGÉNIQUES : UN OUTIL POUR UNE APPROCHE MOLÉCULAIRE DE L'ENDOCRINOLOGIE}

L'introduction et/ou l'invalidation d'un gène dans le patrimoine héréditaire d'un individu définit la transgenèse. Cette approche peut être réalisée chez les Mammifères par recombinaison homologue (RH). La RH est un événement au cours duquel les séquences d'un fragment d'ADN modifié viennent remplacer les séquences endogènes avec lesquelles elles présentent une homologie. La RH appliquée aux cellules souches embryonnaires murines (ES) permet de créer des souris transgéniques portant une mutation déterminée. Cette technique pemet, entre autres, l'inactivation d'un gène et, par là-même, de cerner au plus près sa fonction (Lemarchandel et Montagutelli, 1990). 


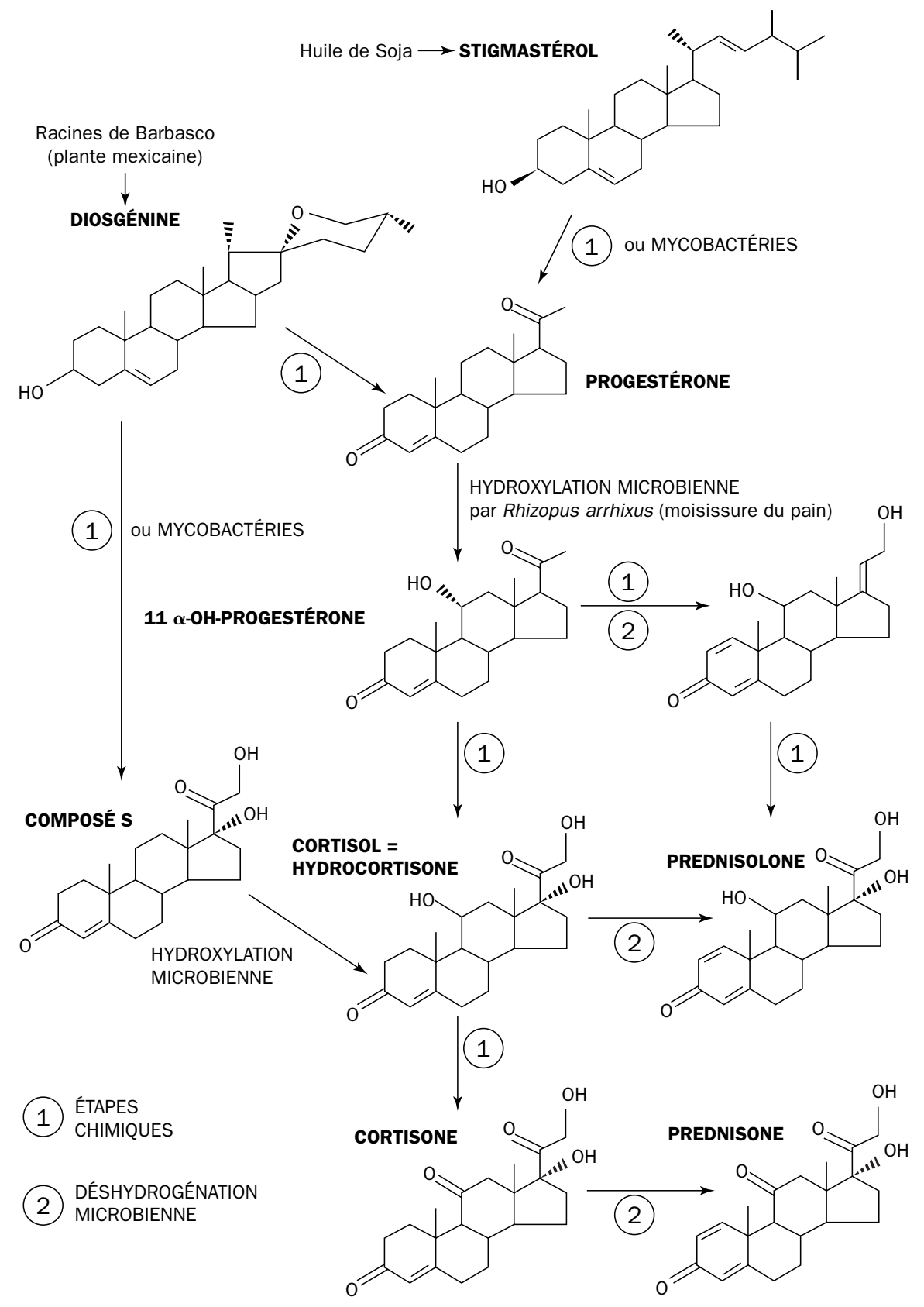

Figure 1.6 - Biosynthèse des stéroïdes (d'après Aharonowitz et Cohen, 1981)

Les cellules ES peuvent être maintenues ex vivo tout en conservant leur capacité à coloniser l'embryon après l'injection dans un blastocyte receveur. L'obtention de souris chimères permet la transmission germinale de la modification génétique introduite dans les cellules ES. Grâce à l'utilisation de nouveaux vecteurs de recombinaison homologue, fondés sur le système de recombinaison Cre-lox du 
bactériophage $\mathrm{P} 1$, il est maintenant possible de contrôler de manière spatio-temporelle l'apparition de la mutation désirée chez la souris (Viville, 1995). Un avantage fondamental du système Cre-lox est de permettre l'étude de fonctions de gènes à l'état adulte lorsque la mutation a un effet délétère sur le processus du développement embryonnaire.

La possibilité de modifier un gène donné dans un sens prédéterminé ouvre de très larges horizons, notamment dans le domaine de l'endocrinologie. En effet, au-delà de la possibilité de cerner la fonction régulatrice d'un gène au cours du développement d'un organe endocrinien, les méthodes de transgenèse permettent la création de modèles animaux de maladies humaines génétiquement déterminées. Nous nous contenterons ici de décrire un exemple particulièrement démonstratif.

Les mécanismes qui gouvernent la progression du cycle cellulaire reposent sur l'activation séquentielle de protéine kinases de la famille cdk (voir chap. $3, \S 1$ ). L'engagement des cellules en phase G1 dépend de l'association de cyclines de type D avec les protéine kinases cdk4 et cdk6. Les formes activées de ces protéine kinases phosphorylent la protéine du rétinoblastome $(\mathrm{Rb})$ qui régule négativement la transition G1/S.

Des souris transgéniques dans lesquelles le gène cdk4 a été inactivé ont été décrites, et les conséquences phénotypiques de l'élimination de l'expression de cdk4 ont été ainsi analysées in vivo (Rane et coll., 1999).

L'observation majeure de cette étude est de montrer que les souris adultes $c d k 4^{-/}$ présentent les caractéristiques d'un phénotype diabétique. Comparée aux souris normales, la concentration en insuline dans le sérum des souris $c d k 4^{-/}$est réduite de $90 \%$, tandis que la glycémie est fortement élevée. L'analyse histologique du pancréas de ces animaux révèle une sévère diminution de la taille des cellules $\beta$ se traduisant par une réduction dramatique de la surface du tissu pancréatique endocrine. Cependant, ces animaux répondent normalement à une administration d'insuline, ce qui montre que le phénotype diabétique observé résulte d'un défaut de production de l'hormone. De plus, l'insulinodéficience de ces souris transgéniques est probablement à l'origine de leur taille réduite et de leur stérilité.

Cette étude montre que la présence de cdk4 est impérativement requise pour la prolifération et le développement postnatal des cellules $\beta$ pancréatiques, et que la perte de l'expression de cdk4 chez la souris mime un phénotype qui ressemble en tout point aux diabètes insulinodépendants observés chez l'homme.

En conclusion, il s'agit là d'un exemple parmi d'autres d'une approche génétique de la différenciation d'un organe endocrine. Il illustre clairement la possibilité de produire chez la souris des modèles d'une maladie génétique humaine. 



\section{CHAPITRE 2}

\section{LES MESSAGERS CHIMIQUES}

\section{MÉCANISMES DE TRADUCTION DE LEUR INFORMATION}

Pour maintenir la composition de leur milieu intérieur constante et différente de celle du milieu externe, les êtres vivants ont besoin, d'une part, d'énergie et, d'autre part, d'obtenir des informations sur la composition de ce milieu externe, leur propre composition, ainsi que sur le fonctionnement de leurs organes. Trois types de mécanismes participent à ces transferts d'informations : les communications nerveuse, chimique et immune.

Dans cet ouvrage, et plus particulièrement dans ce chapitre, nous ne parlerons que de la communication chimique entre cellules animales. Notons que ce choix n'exclut pas totalement les autres types de communication, il existe des interconnexions entre eux. De plus, les mêmes messagers et mécanismes peuvent être impliqués dans plusieurs de ces trois types de communication.

\section{LA COMMUNICATION INTERCELLULAIRE}

\subsection{NOTIONS D'ÉMETTEUR-MESSAGE-RÉCEPTEUR}

La communication entre cellules met en jeu une cellule émettrice productrice du message (essentiellement chimique) et une cellule réceptrice (ou cellule cible) capable de traduire le message.

Les cellules émettrices d'un même message peuvent être rassemblées pour constituer une glande ou, au contraire, être réparties dans l'ensemble de l'organisme (cas de l'endothélium vasculaire), ou être isolées (cas des terminaisons nerveuses). De même, les cellules réceptrices peuvent être regroupées dans un organe spécifique ou disséminées dans l'ensemble de l'organisme.

Le message émis par les cellules productrices peut être de nature chimique variée (de la très petite molécule comme NO jusqu'à la protéine) et peut avoir une durée de vie brève (quelques secondes) ou longue (quelques jours). Il peut agir à proximité de son lieu de production ou à distance (dans ce cas, il est convoyé par le sang). 
Les cellules cibles sont équipées de récepteurs membranaires ou intracellulaires capables de traduire le message et de provoquer son amplification. Souvent, les modifications induites par le message au niveau de la cellule cible rétroagissent directement ou non sur la cellule émettrice pour en moduler l'émission.

\subsection{LES DIFFÉRENTS MODES DE COMMUNICATION ENTRE LES CELLULES}

La figure 2.1 schématise les différents types de communication entre la cellule productrice et la cellule cible. Lorsque le message émis agit au voisinage de la cellule cible, ou lorsque la cellule productrice est elle-même la cellule cible, il s'agit de communications paracrine ou autocrine. Le terme de communication endocrine est utilisé pour traduire le fait que les cellules productrices (cellules endocrines) généralement rassemblées dans une glande (glande endocrine) déversent leur message dans le sang. Dans ce cas, le message est une hormone au sens classique du terme. Le messager chimique ainsi véhiculé par le sang peut transiter (lié ou non à des protéines - binding proteins - qui le protègent des dégradations) jusqu' au niveau des cellules cibles.

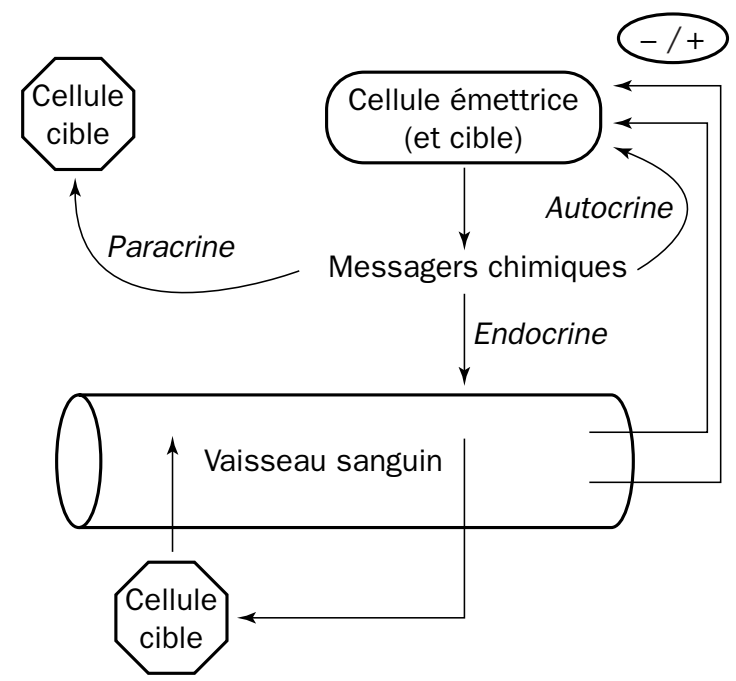

Figure 2.1 - Modes de communication entre cellules

Dans le cas de communication autocrine, la cellule émettrice est aussi la cellule cible. Lorsque le messager chimique agit sur les cellules voisines, il s'agit de communication paracrine (neurocrine pour les cellules nerveuses). Dans le cas de communication endocrine (neuro-endocrine pour les cellules nerveuses), le message est convoyé par le sang avant d'atteindre la cellule cible.

Un autre type de communication met en jeu les contrats cellules/matrice extracellulaire et cellules / cellules.

Les contacts cellules / matrices extracellulaires sont assurés par les intégrines et le CD44. Les intégrines sont des glycoprotéines transmembranaires ; elles interagissent 
avec des molécules impliquées dans la polarisation intracellulaire (enzymes à fonction tyrosine kinase, Src...) qui, dans de nombreux cas, conduisent à l'activation des MAP kinases (mitogen activated protein kinase). Le CD44 est un protéoglycane transmembranaire relié au cytosquelette actinique qui, par son rôle de présentation des facteurs de croissance, est impliqué dans la prolifération cellulaire.

Les cadhérines assurent le contact cellules/cellules. Ce sont des glycoprotéines portant des domaines de liaison au calcium. Leur domaine terminal ( $\alpha$ - et $\beta$-caténine) peut, dans certaines situations, se transloquer dans le noyau et interagir avec des récepteurs aux facteurs de croissance.

Cet aspect de la communication intercellulaire, comme les mécanismes impliqués dans l'immunité, ne seront pas abordés dans cet ouvrage.

\subsection{LES DIFFÉRENTS TYPES DE MESSAGERS CHIMIQUES IMPLIQUÉS DANS LA COMMUNICATION INTERCELLULAIRE}

La découverte constante de nouveaux messagers, ainsi que la mise en évidence de nouvelles propriétés des messagers existants font que la classification classique (fondée sur les fonctions et/ou le mode d'action des messagers) est régulièrement remise en cause.

Les neuromédiateurs, les phéromones (moyens de communication - différés ou non - entre individus), ainsi que les cytokinines ne font pas l'objet de cet ouvrage. Les neurohormones, en tant que telles, ne seront pas spécifiquement abordées dans ce chapitre (elles ne diffèrent pas particulièrement des hormones). Nous distinguerons donc ici cinq types de messagers chimiques.

\subsubsection{Les hormones}

Une hormone est une substance chimique produite par une cellule sécrétrice qui la libère dans la circulation. L'hormone ainsi convoyée va agir, en quelques secondes, sur différents types de cellules cibles. Cette action se traduit par des modifications de la physiologie de la cellule réceptrice, et résulte de la liaison du messager hormonal avec des récepteurs spécifiques membranaires ou intracellulaires de la cellule cible.

\subsubsection{Les pro-hormones}

Les pro-hormones sont de grosses molécules, généralement peptidiques, précurseurs des hormones. Ces pro-hormones peuvent être découpées (éventuellement pour la même pro-hormone, d'une façon variable) pour donner une ou plusieurs hormones. Il existe ainsi des pré-pro-hormones dont le découpage comporte une ou plusieurs étapes supplémentaires. Le découpage des pro-hormones peut se faire au niveau du site de production - cas de la pro-opiomélanocortine (POMC) -, mais aussi au niveau du sang et/ou de l'organe cible (cas de l'angiotensinogène). Remarquons avec cet exemple, qu'au sens strict, l'angiotensine produite par dégradation de l'angiotensinogène par la rénine sanguine (ou endothéliale) ne peut être considérée comme une 
hormone. Un certain nombre de vitamines (A, B, D, K), qui ne sont pas synthétisées directement par l'organisme (apport alimentaire, action des UV, synthèse par les bactéries intestinales), peuvent être cependant considérées comme des pro-hormones, voire des hormones.

\subsubsection{Les facteurs de croissance (voir chap. $3, \S 1$ )}

Les facteurs de croissance sont des messagers chimiques produits par une grande variété de types cellulaires (neurones, glandes salivaires, cellules vasculaires, plaquettes...) qui stimulent la prolifération et/ou la différenciation. Leur mode d'action n'est pas différent de ceux décrits plus haut (ils exercent cependant essentiellement une action autocrine ou paracrine). Un certain nombre d'hormones (insuline, endothéline, angiotensine, prolactine...) exercent, en outre, des actions de type facteur de croissance (pour certaines, leur récepteur est couplé à une protéine possédant une fonction tyrosine kinase), ou sont des agents co-mitogènes.

\subsubsection{Les parahormones}

Un certain nombre de substances impliquées dans des modes de communication auto-, para- ou endocrine sont des messagers chimiques que l'on ne peut pas (toujours) classer comme des hormones vraies. C'est le cas de l'histamine, l'acide arachidonique et ses dérivés (leucotriènes, thromboxane, prostaglandines), le monoxyde d'azote (voir chap. 3, § 3), le PAF (platelet activating factor) (voir chap. 3, § 4), les endothélines (voir chap. $3, \S 5$ ).

Un autre mode de classification des messagers chimiques consisterait à prendre en compte leur capacité à traverser ou non la membrane cellulaire et à considérer que les messages hydrosolubles sont actifs sur les récepteurs membranaires et que les messagers liposolubles possèdent des récepteurs intracellulaires. Cette classification ne peut (commes les autres) être appliquée strictement, car certains messagers peuvent diffuser dans l'eau et dans les lipides et, de plus, certains possèdent des récepteurs membranaires et intracellulaires. Aussi, dans ce chapitre, nous envisagerons successivement, et avec les restrictions formulées plus haut, la traduction des messagers chimiques via la mise en jeu des récepteurs membranaires puis la traduction des messages via la mise en jeu de récepteurs intracellulaires.

\section{TRADUCTION MEMBRANAIRE DES MESSAGES CHIMIQUES}

Les messagers qui ne peuvent traverser la membrane cellulaire agissent sur les cellules cibles par leur liaison avec des récepteurs spécifiques membranaires. Cette liaison messager/récepteur induit, via la mise en jeu ou non d'une protéine G, soit la synthèse d'un messager intracellulaire appelé second messager, soit (et) des 
modifications de la composition ionique intracellulaire (en particulier calcique) amplificatrices du message. L'ensemble de ces modifications va provoquer des changements radicaux de la physiologie cellulaire.

\subsection{LES RÉCEPTEURS MEMBRANAIRES}

Les récepteurs membranaires sont des glycoprotéines complexes fichées dans la membrane plasmique. Leurs fonctions principales sont de reconnaitre le message chimique, de le traduire et de l'amplifier. Il existe quatre types de récepteurs membranaires : les récepteurs canaux ioniques, les récepteurs enzymes, les récepteurs couplés à des protéines $\mathrm{G}$ et les récepteurs de la superfamille des cytokines.

\subsubsection{Les récepteurs canaux ioniques}

Un certain nombre de récepteurs essentiellement activables par des neuromédiateurs (acétylcholine, glutamate, gamma-amino-butyric acid [GABA]) sont des canaux ioniques. L'activation de ces récepteurs provoque des variations locales de potentiel qui peuvent conduire à des modifications à court (ou à long terme) du fonctionnement cellulaire (potentiels post-synaptiques excitateur [PPSE] ou inhibiteur [PPSI]), et peuvent participer aux mécanismes de potentialisation à long terme (LTP) (fig. 2.2).
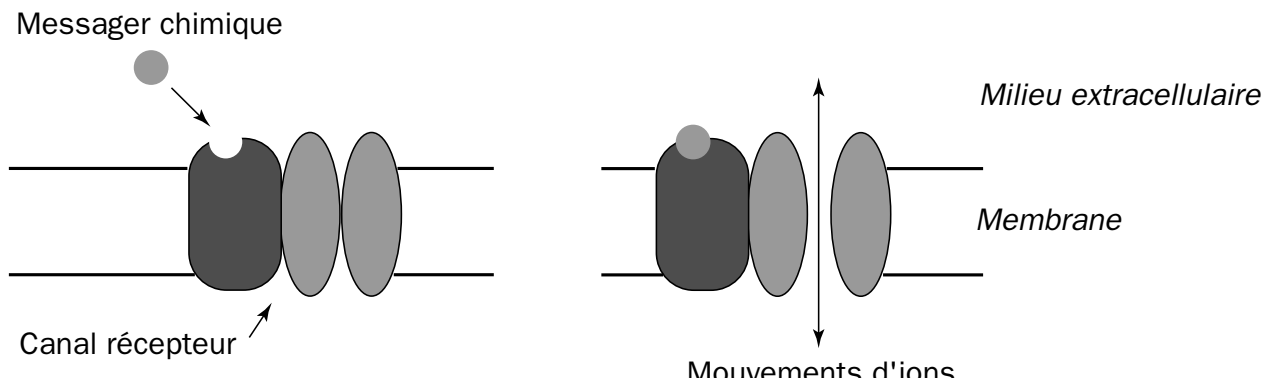

Figure 2.2 - Représentation schématique d'un récepteur canal ionique

La fixation d'un messager chimique sur un canal récepteur induit un changement de conformation de la protéine qui entraîne l'ouverture du canal. Suivant le type d'ions mis en jeu, ce changement de perméabilité provoque des modifications de la composition ionique intracellulaire, qui génèrent une hyperpolarisation ou une dépolarisation de la membrane et, finalement, des modifications du comportement des canaux ioniques sensibles au voltage. Lorsque ces modifications affectent les canaux calciques, les répercussions sur le métabolisme cellulaire peuvent être majeures.

\subsubsection{Les récepteurs enzymes}

Ces récepteurs enzymes sont soit des protéine tyrosine kinases (cas des récepteurs aux facteurs de croissance), soit des enzymes capables d'induire directement la synthèse d'un second messager cyclique (cas des récepteurs au facteur natriurétique atrial ou ANF). 
La fixation du ligand (facteurs de croissance, insuline) sur les récepteurs tyrosine kinases provoque (lorsqu'ils ne sont pas déjà des dimères) une dimérisation et une transphosphorylation des récepteurs (voir chap. $3, \S 1$ ).

Les récepteurs tyrosine kinases ainsi activés phosphorylent différentes enzymes sur des résidus tyrosine (les autres kinases phosphorylent généralement sur des résidus sérine ou théonine). Ces phosphorylations peuvent conduire à la synthèse de seconds messagers (inositol [1,4,5] triphosphate [IP3], diacylglycérol [DAG]), ainsi qu'à l'activation en cascade d'une grande variété d'enzymes impliquées dans les processus de différenciation et/ou prolifération cellulaires (fig. 2.3).

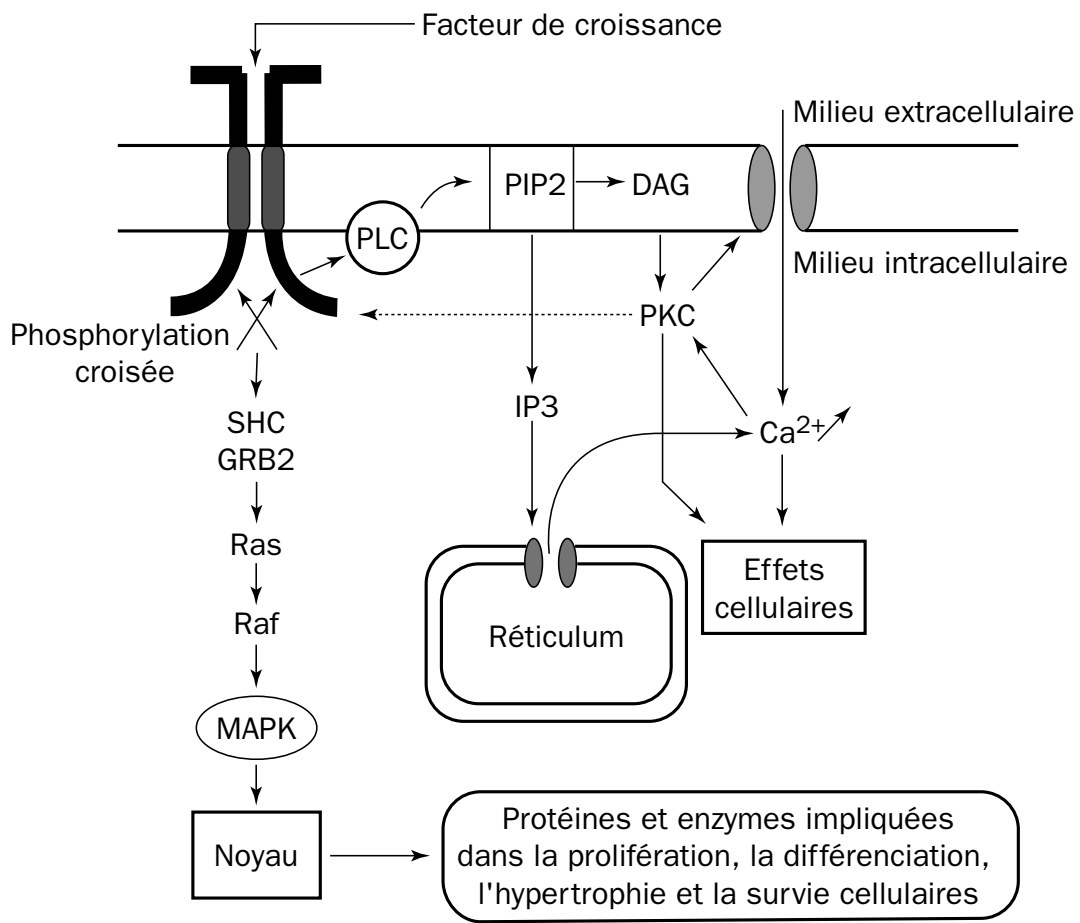

Figure 2.3 - Enzymes et protéines impliquées dans la prolifération, la différenciation, l'hypertrophie, la survie cellulaires

DAG : diacylglycérol ; GRB2 : growth factor receptor-bound protein 2; IP3 : inositol $(1,4,5)$ triphosphate; MAPK : mitogen activated protein kinase ; PIP2 : phosphatidylinositol $(4,5)$ biphosphate; PKC : protéine kinase de type C; PLC : phospholipase C; Ras, Raf : proto-oncogènes ; SHC : domaine de reconnaissance 3 ; Sos : son of sevenless.

Le récepteur pour l'ANF est une guanylate cyclase membranaire. Son activation entraîne la transformation du GTP (guanosine triphosphate) en GMPc (guanosine monophosphate cyclique) capable d'agir directement sur différentes perméabilités ioniques ou d'activer des protéine kinases G (PKG). Les rôles des PKG sont peu connus. Toutefois, leur implication a été démontrée dans la régulation de différentes perméabilités ioniques membranaires, ainsi que dans l'homéostasie calcique via la stimulation des Ca-ATPases du réticulum et probablement du sarcolemme. 


\subsubsection{Les récepteurs couplés aux protéines $G(R-C P G)$}

De nombreux récepteurs sont couplés à une classe de protéine liée au GDP (guanosine diphosphate) ou protéine $\mathrm{G}$. Les protéines $\mathrm{G}$ sont des hétérotrimères membranaires composés de sous-unités appelées : $G \alpha-G \beta-G \gamma$. Il a été identifié environ vingt types de sous-unités $\alpha, 4$ de $\beta$ et 7 de $\gamma$. En l'absence de ligand, la sous-unité $\alpha$ est liée à du GDP. L'activation du récepteur génère des modifications au niveau de la protéine G : le remplacement du GDP porté par la sous-unité $\alpha$ par du GTP (il ne s'agit pas d'une phosphorylation) et la dissociation de la protéine G (fig. 2.4).

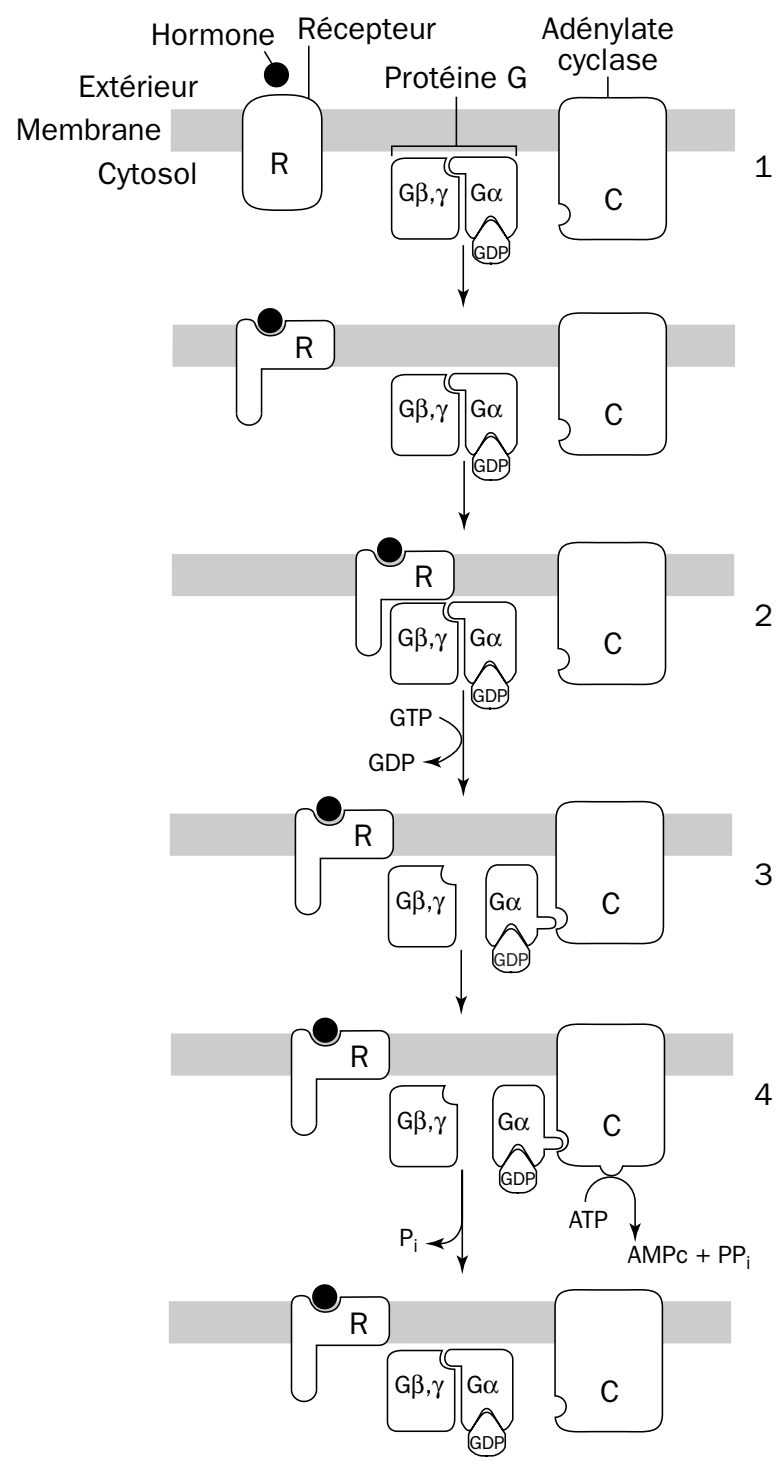

Figure 2.4 - Transduction du message hormonal par I'intermédiaire de la protéine Gs. Le processus conduit à la synthèse d'AMPc. 
Selon le type de récepteur, la sous-unité $\alpha$ activée ( $\alpha$-GTP) peut alors agir sur différentes enzymes (adénylate cyclase, guanylate cyclase, phospholipase A ou C) pour stimuler ou inhiber (protéines Gs ou Gi dans le cas de l'adénylate cyclase) la synthèse de seconds messagers, ou agir directement sur divers types de canaux ioniques tels que certains canaux potassiques ou calciques. Ce dernier type d'action a aussi été mis en évidence pour les sous-unités $\beta$ et $\gamma$ qui semblent agir de concert. La sous-unité $\alpha$ est douée d'activité GTPasique, ce qui limite dans le temps son action.

L'utilisation d'analogues non-hydrolysables du GTP $\left(\mathrm{ALF}_{3}-\mathrm{GTP} \gamma \mathrm{S} \ldots\right)$ permet de maintenir en activité les protéines G. De plus, un certain nombre de protéines $\mathrm{G}$ sont sensibles à la toxine du choléra (Vibrio cholerae) qui inhibe l'activité GTPasique de la sous-unité $\alpha$ et/ ou à la toxine de la coqueluche (Bordetella pertussis) qui découple la liaison récepteur/protéine G. Comme le montre le tableau 2.1 (non-exhaustif), un grand nombre de messagers chimiques activent des récepteurs membranaires couplés à des protéines G. Il semble que la majorité de ces récepteurs possèdent sept domaines transmembranaires (voir fig. 2.5).

Tableau 2.1 - Exemples de messagers chimiques dont certains récepteurs sont couplés à des protéines $\mathbf{G}$

\begin{tabular}{|lll|}
\hline Neuromédiateurs & Acétylcholine & $\mathrm{Gs}, \mathrm{Gi}, \mathrm{G}_{\mathrm{k}}$ \\
& Adrénaline $(\mathrm{R} \beta)$ & $\mathrm{Gs}$ \\
& Dopamine $(\mathrm{RD} 1, \mathrm{RD} 2)$ & $\mathrm{Gs}, \mathrm{Gi}$ \\
& Neuropeptide $\mathrm{Y}$ & $\mathrm{G}_{\mathrm{k}}$ \\
& Noradrénaline $(\mathrm{R} \alpha 1-\mathrm{R} \alpha 2)$ & $\mathrm{G}$ \\
& Opiacés $(\mu, \delta, \mathrm{K})$ & $\mathrm{Gi}$ \\
& Sérotonine & $\mathrm{Gs}$ \\
\hline Hormones & ACTH & $\mathrm{Gs}$ \\
& Bradykinine & $\mathrm{Gi}$ \\
& Calcitonine/CGRP & $\mathrm{Gs}$ \\
& GHRH & \\
& Glucagon & $\mathrm{Gs}$ \\
& LH & $\mathrm{Gs}$ \\
& Ocytocine & \\
& Somatostatine & $\mathrm{Gi}$ \\
& TRH & \\
& TSH & $\mathrm{Gs}$ \\
& Vasopressine (V2) & $\mathrm{Gs}$ \\
\hline Autres messagers & Cytokines & $\mathrm{G}$ ? \\
& Prostaglandines & $\mathrm{Gs}, \mathrm{Gi}, \mathrm{G}_{\mathrm{PLX}}$, autres ? \\
& Thromboxane & $\mathrm{Gs}$ \\
\hline
\end{tabular}

$G i$ : protéine $G$ inhibitrice ; $G_{k}$ : protéine $G$ provoquant l'ouverture de canaux $K^{+}$; $G_{P L A}$ : protéine $G$ activatrice d'une phospholipase $A ; G_{P L X}$ : protéine $G$ stimulatrice d'une phospholipase quelconque ; Gs : protéine G stimulatrice. 


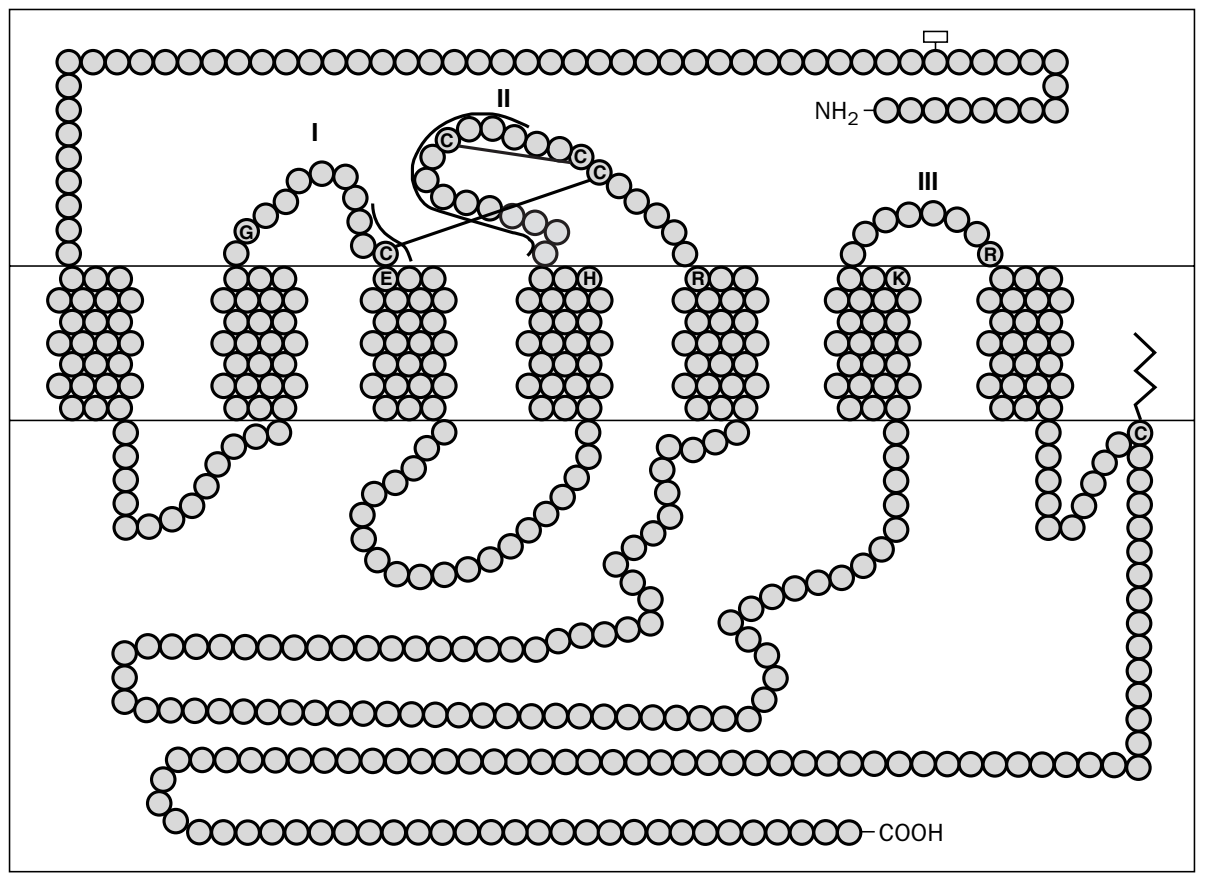

Figure 2.5 - Schéma d'un récepteur heptamembranaire

Chaque cercle correspond à un acide aminé. Les sept régions transmembranaires sont une structure en hélice $\alpha$. Les boucles extracellulaires sont numérotées de I à III. Les ponts disulfures extracellulaires sont schématisés.

Toutefois, jusqu'alors, il n'a pas été possible de déterminer une structure spatiale commune à tous les ligands susceptibles d'activer ce type de récepteurs. Quelles que soient les structures impliquées, la liaison ligand / récepteur provoque l'activation de plusieurs protéines $\mathrm{G}$, ce qui déclenche la synthèse d'une grand nombre de molécules de seconds messagers et, finalement, conduit à une très forte amplification du message (fig. 2.6).

\subsubsection{Les récepteurs de la superfamille des cytokines}

Ce sont les récepteurs de l'érythropoïétine, de la GH, de la prolactine, de l'HCG, de la leptine... Ces récepteurs ne possèdent pas de fonction tyrosine kinase. Cependant, leur activation met en jeu des mécanismes similaires à celui des récepteurs tyrosine kinases : dimérisation du récepteur, activation de protéines à fonction tyrosine kinase. Ceci donne lieu à une transphosphorylation de ces protéines et à la phosphorylation du récepteur. La suite de la cascade similaire à celle résultant de l'activation des récepteurs à fonction tyrosine kinase conduit à la prolifération et/ou la différenciation tissulaire (fig. 2.7). 


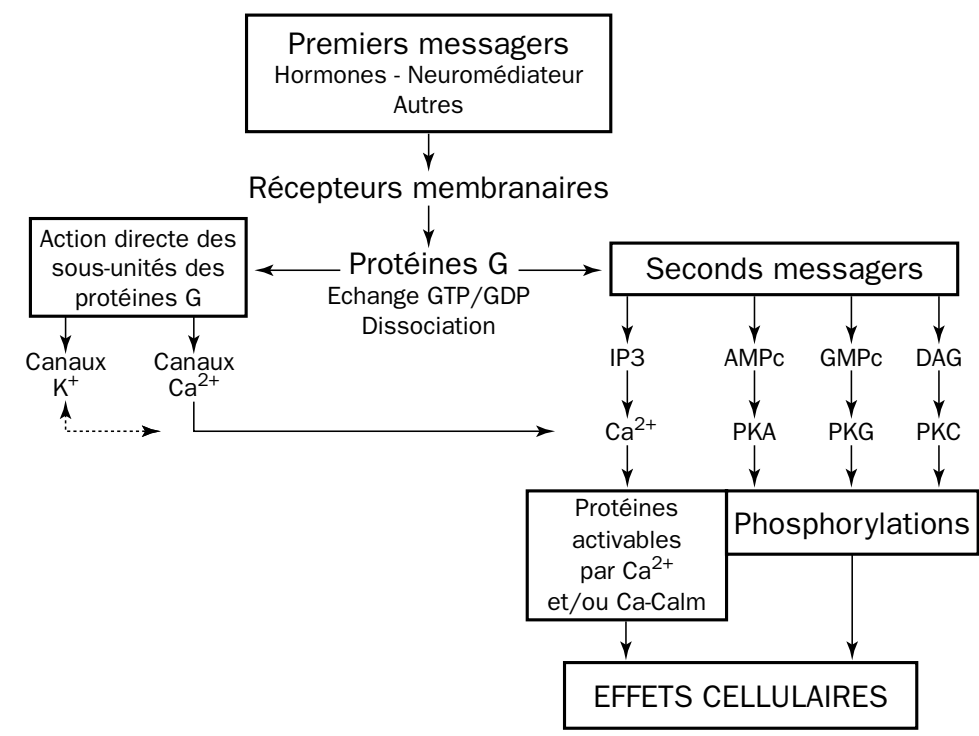

Figure 2.6 - Représentation schématique de la cascade de processus impliqués dans l'activation de récepteurs liés à des protéines $\mathbf{G}$

Ca-Calm : calcium-calmoduline; PKA : protéine kinase $A$; PKC : protéine kinase $C$; PKG : protéine kinase $G$.

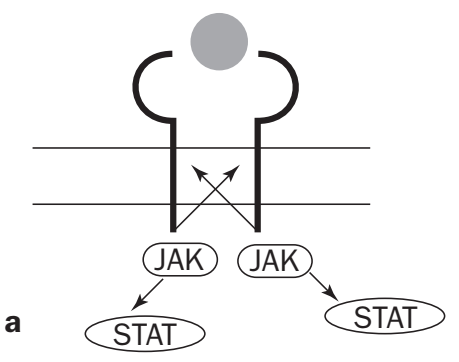

C

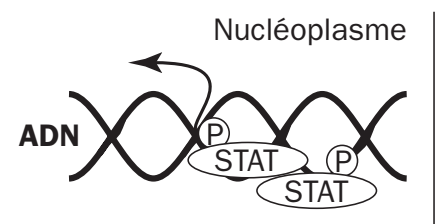

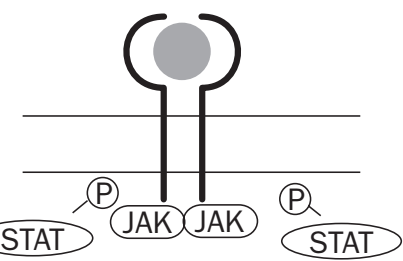

b

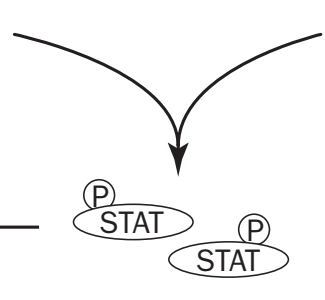

Figure 2.7 - Mécanisme de la transduction du signal par les récepteurs des cytokines (d'après Vaisse, 1997)

JAK : Janus activated kinase ; STAT : signal transducers and activators of transcription.

a - La liaison du ligand au récepteur entraîne la dimérisation de celui-ci.

b - Elle entraîne en outre l'activation de protéines JAK associées au récepteur. Ces protéines se transphosphorylent et phosphorylent le récepteur qui devient un site de liaison pour des protéines cytoplasmiques, les protéines STAT.

c - La liaison des protéines STAT au récepteur entraîne leur activation par phosphorylation. Les protéines STAT activées forment des homo- ou hétérodimères, sont transloquées dans le noyau où elles lient des séquences spécifiques d'ADN et activent une série de gènes cibles. 


\subsection{LES SECONDS MESSAGERS}

L'activation des récepteurs tyrosine kinases, des récepteurs couplés à des protéines $\mathrm{G}$, ainsi que celle d'autres types de récepteurs, de même que la mise en jeu de facteurs physico-chimiques (comme l'étirement membranaire) induisent la production de seconds ou troisièmes messagers. Les principaux seconds messagers connus sont : l'AMPc (adénosine monophosphate cyclique), le GMPc (guanosine monophosphate cyclique), le DAG ( $s n-1,2$ diacylglycérol), les dérivés de l'acide arachidonique (prostaglandines et thromboxane), le monoxyde d'azote (NO), l'ADPRc (adénosineribose diphosphate cyclique).

En 1984, il apparaissait que les hormones polypeptidiques qui n'agissaient pas selon un mécanisme AMPc-dépendant mettaient en jeu un mécanisme calci-dépendant (à l'exception de la prolactine, de l'insuline et de la GH). C'était le cas :

- en augmentant le $\mathrm{Ca}^{2+}$ intracellulaire libre,

- de la noradrénaline (sur les récepteurs $\alpha 1$ ),

- de l'ADH dans le foie,

- du stimulus glucose sur la sécrétion de parathormone ;

- en diminuant le $\mathrm{Ca}^{2+}$ intracellulaire libre.

Depuis, nos connaissances ont beaucoup évolué.

\subsubsection{L'AMP cyclique}

L'adénosine monophosphate cyclique (voir fig. 2.8) a été le premier second messager découvert (1967). Il agit dans un très grand nombre de types cellulaires pour participer à la régulation d'une très grande variété de processus physiologiques. Un grand nombre de messagers chimiques stimule la synthèse d'AMPc via l'activation d'une protéine Gs, d'autres (moins nombreux) l'inhibent par la mise en jeu d'une protéine Gi (voir tab. 2.1 et fig. 2.9). Il a été montré que l'action inhibitrice de Gi ne peut s'exercer que sur l'adénylate cyclase préalablement activée par Gs. L'AMPc formé stimule différentes protéines et, en particulier, la protéine kinase A (PKA). La protéine kinase A phosphoryle un grand nombre de protéines, ce qui a pour conséquences majeures :

1. d'induire l'activation de la phosphorylase b (enzyme impliquée dans le métabolisme énergétique),

2. de stimuler la calcium ATPase du réticulum (stimulation du repompage du calcium),

3. d'induire l'ouverture de canaux ioniques membranaires sensibles au voltage $\left(\mathrm{K}^{+}\right.$, $\left.\mathrm{Ca}^{2+}\right)$,

4. de moduler la synthèse protéique via son action sur la MAPK (mitogen activated protein kinase).

Lorsque le ligand se sépare de son récepteur, soit après phosphorylation directe par la PKA ou par une phosphorylation via une cascade dont le point de départ est la PKA, 
ou après phosphorylation par d'autres kinases telle que le $\mathrm{PKC}$ (protéine kinase C), la protéine G n'est plus activée, l'AMPc formé disparaît sous l'action d'une phosphodiestérase des nucléotides cycliques (phosphodiestérase stimulée par le GMPc). Il est à noter que cette dernière présente plus d'affinité pour l'AMPc que pour le GMPc. L'action stimulatrice des phosphorylations réalisées par la PKA disparaît sous l'action de phosphatases (pour certaines, préalablement activées par une phosphorylation dépendante de la PKA elle-même).

\subsubsection{Le GMP cyclique}

Le guanosine monophosphate cyclique ${ }^{1}$ (GMPc) est formé lors de :

1. l'activation d'une guanylate cyclase membranaire (récepteur à l'ANF) ou cytoplasmique (NO) (voir chap. 16, § 3),

2. processus mettant en jeu une protéine $\mathrm{G}$ (rhodopsine) activée par la lumière,

3. la stimulation de récepteurs couplés à une protéine $\mathrm{G}$ (acétylcholine...).

Le GMPc peut avoir une action directe pour inhiber ou activer différents types de perméabilités ioniques ou une action indirecte par la stimulation de protéine kinases G. En outre, comme il a été dit plus haut, il stimule une phosphodiestérase active sur les nucléotides cycliques. Les rôles joués par les protéine kinases G sont mal connus. Toutefois, il a été mis en évidence l'implication de phosphorylations dépendantes des PKG dans la modulation de certaines perméabilités ioniques, ainsi que dans l'activation des calcium-ATPases du réticulum (et/ou de la membrane plasmique), ce qui finalement conduit à diminuer la teneur en calcium libre cytoplasmique. De ce point de vue, et c'est souvent le cas, l'AMPc et le GMPc ont des effets opposés, sauf semble-t-il au niveau des cellules musculaires lisses vasculaires. Comme l'AMPc, le GMPc est désactivé par une phosphodiestérase qu'il stimule.

\subsubsection{L'ADPR cyclique}

L'adénosine-ribose diphosphate cyclique (ADPRc) (fig. 2.8) a été découvert en 1987. Depuis, sa présence a été détectée, des Invertébrés à l'Homme, dans un grand nombre de types cellulaires. La formation d'ADPRc à partir de $\mathrm{NAD}^{+}$est, en large majorité, réalisée par une enzyme de la membrane du réticulum. Cette enzyme est bifonctionnelle : elle assure à la fois la synthèse et l'hydrolyse de l'ADPRc. L'ADPRc agit sur les canaux calciques du réticulum sensibles à la ryanodine (alcaloïde végétal) et au calcium (impliqué, à ce titre, dans ce qu'il est convenu d'appeler le " $\mathrm{Ca}^{2+}$ induced $\mathrm{Ca}^{2+}$ release" [CICR] : le calcium induit la libération de calcium). A ce niveau, il a été clairement démontré que l'ADPRc agit sur le réticulum indépendamment des effets de l'IP3.

1 L'emploi du masculin est incorrect. Toutefois, nous sacrifierons à cet usage qui tire son origine de l'anglais et de l'acception (sous-entendue) de second messager. Il en est de même des accords réalisés avec l'AMPc, l'IP3, l'ADPRc. 


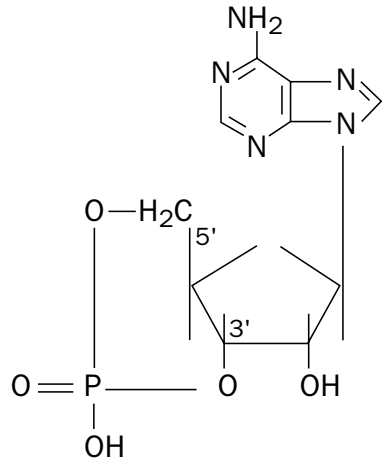

Adénosine 3',5' monophosphate cyclique ou AMP cyclique (AMPc)<smiles>[R]C(=O)OCC([2H])(CO)OC([R2])=O</smiles>

sn-1,2 diacylglycérol (DAG)<smiles>[R11]CC=CC(O)C([2H])(CO)NC([R1])=O</smiles>

Céramide (N-acylsphingosine)

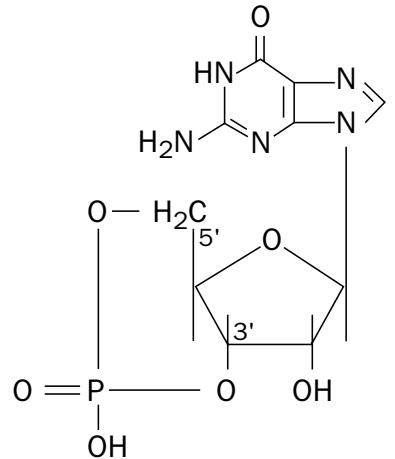

Guanosine 3',5' monophosphate cyclique ou GMP cyclique (GMPc)

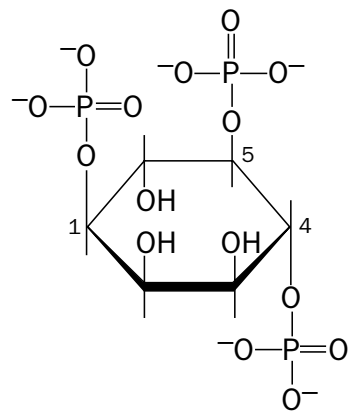

Inositol $(1,4,5)$ triphosphate (IP3)

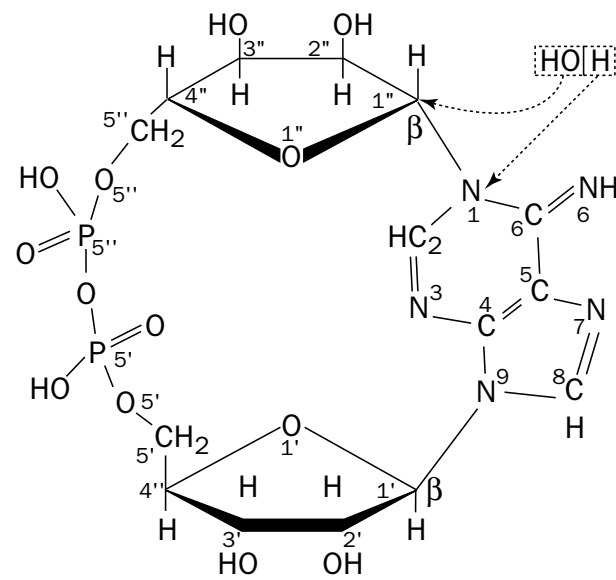

Adénosine-ribose diphosphate cyclique (ADPRc)

Figure 2.8 - Structure de quelques seconds messagers

S'il a été démontré l'implication de l'ADPRc dans l'augmentation du calcium libre intracellulaire d'œufs fécondés, ainsi que dans l'activation in vitro de certains canaux ioniques du réticulum, on ne connaît pas de messager chimique susceptible d'induire la production de l'ADPRc. Aussi, le rôle physiologique de l'ADPRc dans d'autres situations reste donc à démontrer. 


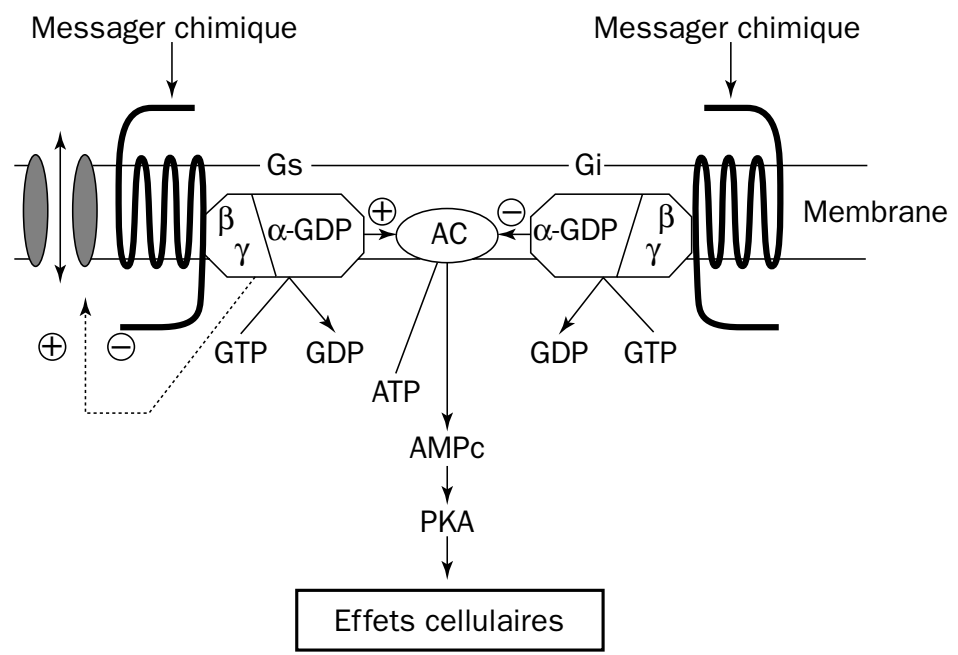

Figure 2.9 - Représentation schématique des rôles des protéines Gs et Gi dans la synthèse de l'AMPc

L'activation de récepteurs à sept domaines transmembranaires de types différents peut stimuler deux formes de protéines G (Gs : stimulatrice ; Gi : inhibitrice) qui peuvent agir sur l'adénylate cyclase (AC). L'activation de l'adénylate cyclase conduit à la production d'AMPc qui va stimuler différentes protéine kinases et, en particulier, la protéine kinase $A$ (PKA). La PKA activée phosphoryle une grande variété de protéines (enzymes, canaux ioniques, protéines impliquées dans la contraction...), ce qui génère d'importantes modifications de la physiologie cellulaire.

\subsubsection{Les inositols phosphates et le diacylglycérol}

De nombreux messagers stimulent leurs cibles via l'activation du métabolisme des phosphatidylinositols (Ptd Ins), ce qui conduit à la synthèse d'inositol $(1,4,5)$ triphosphate (IP3) et de $s n-1,2$ diacylglycérol (DAG). Un troisième messager est formé lors de ce métabolisme, l'inositol $(1,3,4,5)$ tétraphosphate (IP4). L'IP4 joue, dans certains types cellulaires, le rôle de second messager actif sur le métabolisme du calcium (fig. 2.10). L'IP3 et le DAG sont synthétisés lors de l'activation des récepteurs tyrosine kinases activables par les facteurs de croissance (voir fig. 2.3), ainsi que dans le cas de récepteurs membranaires couplés à une protéine $\mathrm{G}$ qui stimule une phospholipase membranaire (fig. 2.11). De même, il a été montré que l'étirement de la membrane de certains types cellulaires induit la synthèse d'IP3. En outre, une synthèse d'IP3 existe au niveau de la membrane nucléaire. Le DAG provoque l'activation de la protéine kinase $\mathrm{C}$ (sensible au calcium). La fixation du calcium sur ses récepteurs canaux ioniques du réticulum conduit à la libération de calcium. Enfin, il a été montré que, dans certains types cellulaires, l'existence des canaux cationiques membranaires activables par l'IP3 laisse passer le calcium. L'IP4 est lui aussi capable, dans certains types cellulaires, d'activer des canaux du réticulum et, peut-être, de la membrane plasmique. 


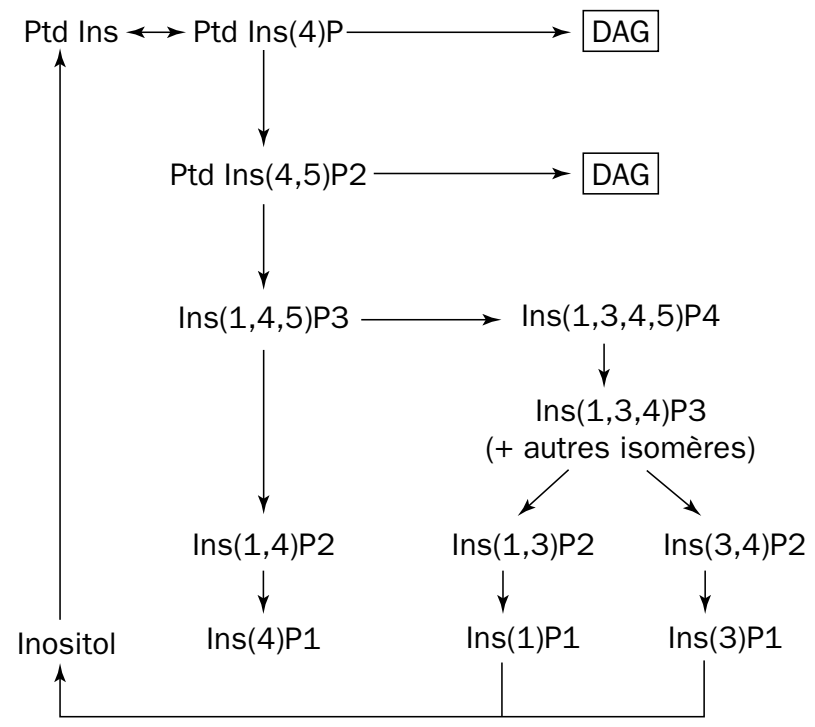

Figure 2.10 - Représentation schématique du cycle des inositols phosphates DAG : sn-1,2 diacylglycérol ; InsP : inositol phosphate(s) ; IP3 : Ins(1,4,5)P3 ; IP4 : Ins(1,3,4,5)P4 ; PIP2 : Ptd Ins(4,5)P2 ; Ptd Ins : phosphatidylinositol.

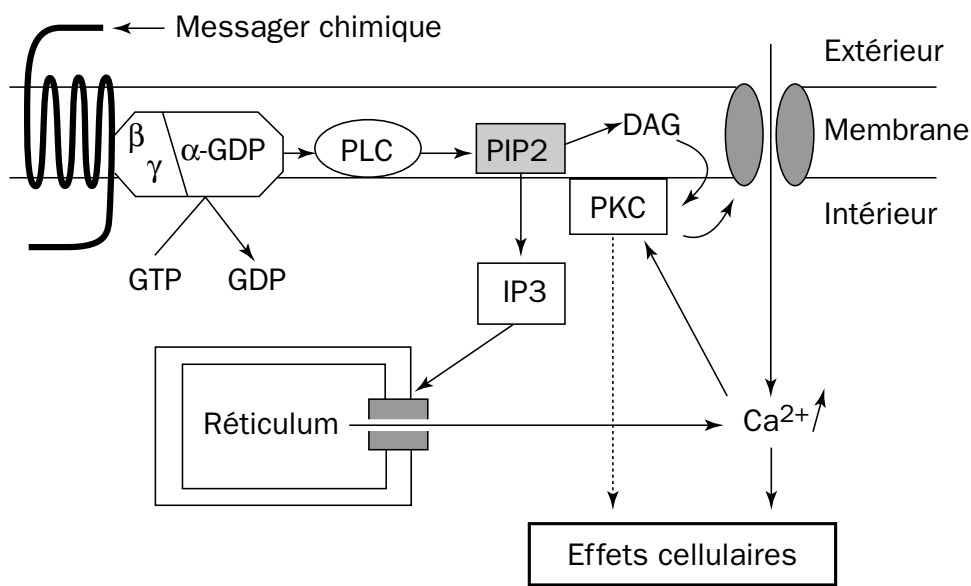

Figure 2.11 - Représentation schématique de la synthèse d'IP3 et de DAG

DAG : sn-1,2 diacylglycérol ; IP3 : Ins(1,4,5)P3 ; PIP2 : Ptd Ins(4,5)P2 ; PKC : protéine kinase $C$; $P L C$ : phospholipase $C$.

\subsubsection{Les céramides}

La sphingomyéline et la sphingomyélinase sont deux protéines colocalisées du côté externe de la membrane cellulaire. L'activation de la sphingomyélinase (enzyme inductible) par différents agents ou messagers chimiques conduit à la production de céramide. Les céramides sont des seconds messagers impliqués, suivant le type 
cellulaire, dans des mécanismes variés tels que la différenciation, la prolifération, la senescence cellulaires ou l'apoptose ${ }^{2}$ (fig. 2.12).

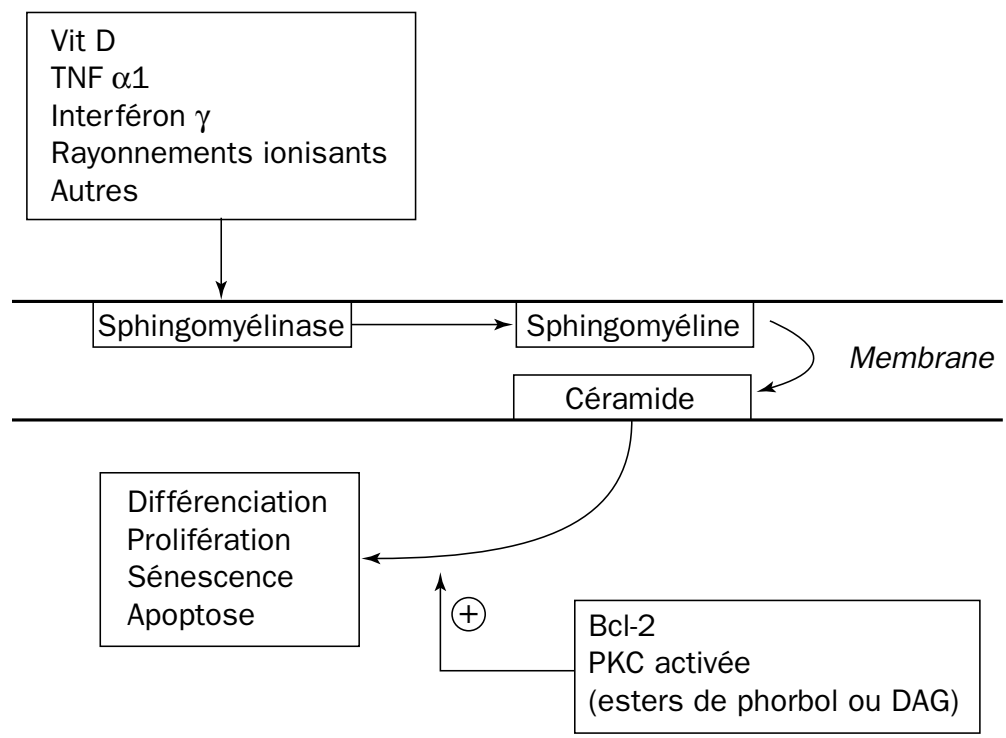

Figure 2.12 - Représentation schématique des mécanismes impliqués à la suite de l'activation de la sphingomyélinase

\subsubsection{Le calcium}

La teneur en calcium libre cytoplasmique $\left[\mathrm{Ca}^{2+}\right]_{i}$ est un paramètre fortement régulé. La concentration cytoplasmique, de l'ordre de $5 \cdot 10^{-6} \mathrm{M}$, est très faible, si on la compare aux teneurs du calcium extracellulaire ou au calcium contenu dans les sites de stockage (de l'ordre de $10^{-3} \mathrm{M}$ ). Les variations de la $\left[\mathrm{Ca}^{2+}\right]_{\mathrm{i}}$ constituent un message (second ou troisième) pour un grand nombre d'actions enzymatiques. Le calcium peut agir directement ou via la calmoduline, une protéine qui lie le calcium.

A concentration élevée, le $\mathrm{Ca}^{2+}$ se lie réversiblement à des protéines spécifiques ou calciprotéines. En même temps que Ebashi, à Tokyo en 1970, découvrait que le $\mathrm{Ca}^{2+}$ déclenche la contraction musculaire en se liant à une calciprotéine : la troponine $\mathrm{C}$, d'autres auteurs japonais découvrent que l'adénylate cyclase est activée par une calciprotéine, la calmoduline. En fait, la calmoduline apparaît comme le modulateur de la majorité des effets cellulaires du calcium, la troponine $\mathrm{C}$ n'étant qu'une forme spécialisée de la calmoduline.

2 L'apoptose est un processus initié par l'activation d'un programme de mort cellulaire. Ce type de mort cellulaire est caractérisé par une fragmentation de l'ADN, sans libération du contenu de la cellule dans le milieu extracellulaire. Lors de l'apoptose on n'observe pas, comme dans la nécrose, de réactions inflammatoires. L'apoptose joue un rôle fondamental dans des processus aussi différents que le développement embryonnaire, les mécanismes de l'immunité, l'action des hormones sur certains tissus, le renouvellement cellulaire. 
La calmoduline est ubiquitaire, elle est présente depuis les végétaux jusqu'aux animaux supérieurs. C'est une protéine de PM 17000 (148 AA). Elle possède quatre sites de liaisons $\mathrm{du} \mathrm{Ca}^{2+}$. Elle intervient :

- comme sous-unité de la phosphorylase b kinase dans la contraction du muscle strié,

- dans l'assemblage et la dissociation des microtubules,

- en favorisant la phosphorylation de la myosine (via l'activation d'une protéine kinase) dans l'interaction actine / myosine au cours de la contraction des cellules musculaires lisses et d'autres cellules non-musculaires,

- sur l'adénylate cyclase, qu'elle active,

- en activant la pompe à $\mathrm{Ca}^{2+}$ membranaire liée à des $\mathrm{ATPases} \mathrm{Mg}^{2+}$ dépendantes.

Elle permet la régulation du flux du $\mathrm{Ca}^{2+}$ entre, d'une part, le cytoplasme et l'extérieur de la cellule et, d'autre part, le cytoplasme et les réservoirs intracellulaires qui "séquestrent" le $\mathrm{Ca}^{2+}$ (réticulum endoplasmique). Au repos, le cytoplasme contient peu de $\mathrm{Ca}^{2+}$, alors qu'il y en a :

- jusqu'à 200000 fois plus dans le milieu extracellulaire,

- et jusqu'à $10^{6}$ fois plus dans les réservoirs intracellulaires.

L'énergie nécessaire au pompage membranaire permanent qui maintient ces concentrations est fournie par l'hydrolyse de l'ATP, sous l'effet d'une ATPase $\mathrm{Mg}^{2+}$ dépendante. L'élévation puis la diminution du taux intracellulaire de calcium constituent un mécanisme "marche-arrêt" pour l'action de la calmoduline.

Un mécanisme hormonal peut être uniquement calci-dépendant (par exemple la réponse des récepteurs $\alpha 1$ aux catécholamines, ou la réponse de la cellule $\beta$ des îlots de Langerhans du pancréas au stimulus glucose) ou impliquer, à la fois, un mécanisme AMPc dépendant et un mécanisme calci-dépendant, les deux convergeant vers une même stimulation enzymatique (cas de la TRH).

Le muscle, au cours de l'effort physique, illustre un exemple de convergence d'un mécanisme hormonal AMPc dépendant (effet de l'adrénaline libérée) et d'un mécanisme nerveux $\mathrm{Ca}^{2+}$ dépendant (contraction musculaire), qui tous deux aboutissent à la glycogénolyse (fig. 2.13). L'adrénaline active la glycogénolyse via l'AMPc à des concentrations de $\mathrm{Ca}^{2+}$ faibles $\left(10^{-7} \mathrm{~mol} / \mathrm{l}\right)$ qui sont celles du muscle au repos. Lorsque celui-ci se contracte, l'augmentation de $\mathrm{Ca}^{2+}$ qui en résulte $\left(10^{-5} \mathrm{~mol} / \mathrm{l}\right)$ stimule la phosphorylase b kinase du muscle, indépendamment de l'augmentation de concentration de l'AMPc.

\subsubsection{L'acide arachidonique et ses dérivés}

Un certain nombre d'acides gras polyinsaturés peuvent être métabolisés pour donner des composés appelés prostanoïdes ou éicosanoïdes. Ces composés comprennent les prostaglandines, les thromboxanes, prostacyclines, leucotriènes, lipoxines et une grande variété de tri-, di- ou monohydroxy acides gras (fig. 2.14). Le plus important de ces types de composé est l'acide arachidonique. 


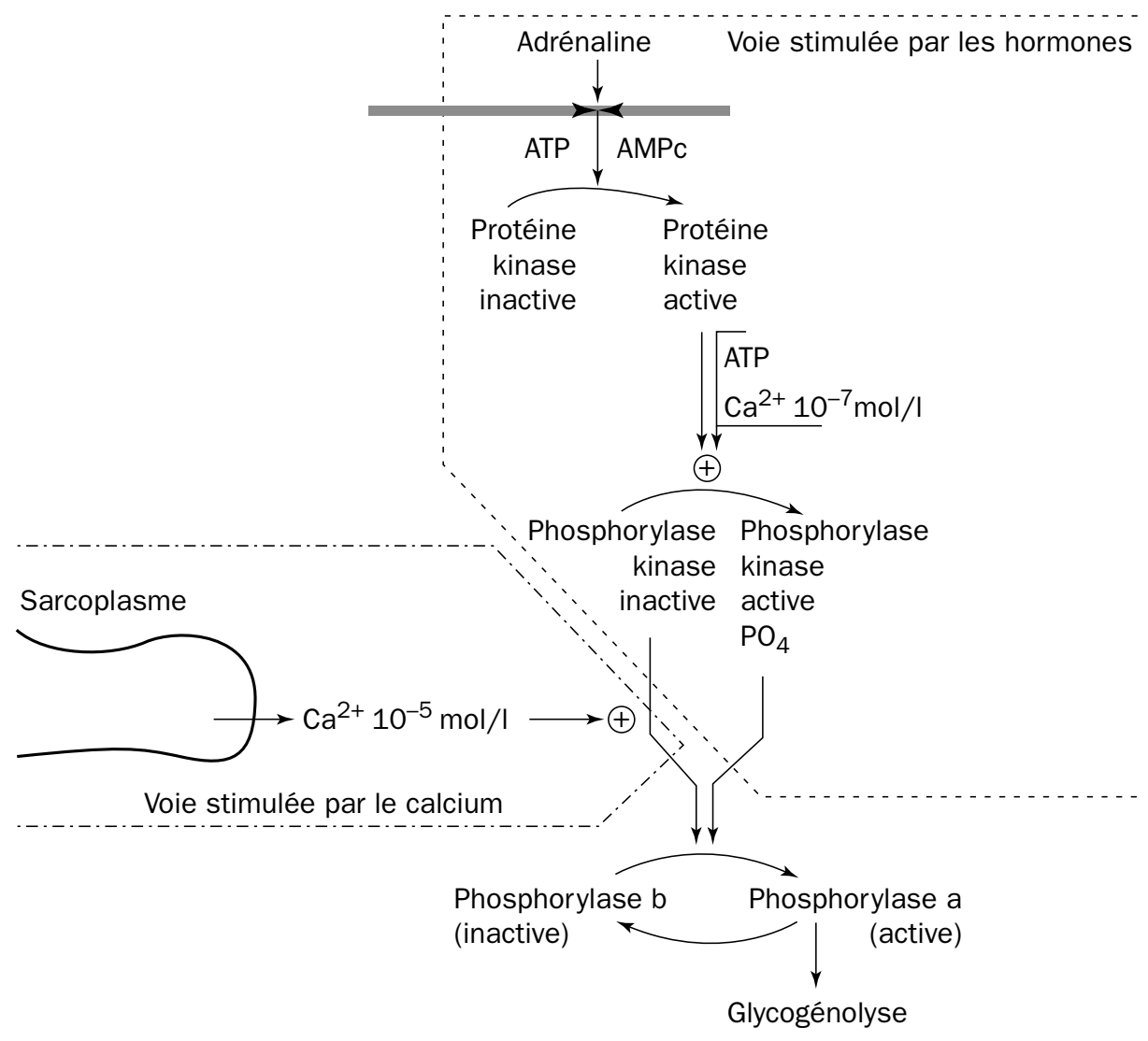

Figure 2.13 - La glycogénolyse dans le muscle

L'acide arachidonique et certains de ses dérivés (formés au niveau de la membrane cellulaire) peuvent agir d'une façon paracrine ou autocrine, directement au niveau intracellulaire et/ou via l'activation de récepteurs spécifiques conduisant à la synthèse de seconds messagers "classiques". Ces composés dérivés de l'acide arachidonique, dont certains ont une durée de vie extrêmement courte, peuvent agir localement avec force et modifier radicalement le fonctionnement cellulaire.

\section{TRADUCTION DES MESSAGERS CAPABLES DE DIFFUSER AU TRAVERS DES MEMBRANES}

Un certain nombre de messagers sont à même de diffuser au travers des membranes et d'agir au niveau intracellulaire. C'est le cas de certains dérivés de l'acide arachidonique (voir plus haut), des hormones stéroïdiennes et thyroïdiennes, c'est aussi le cas du monoxyde d'azote (NO). En outre, parmi eux, certains peuvent exercer une action directe et/ou peuvent agir après activation de récepteurs membranaires ou cytoplasmiques. 


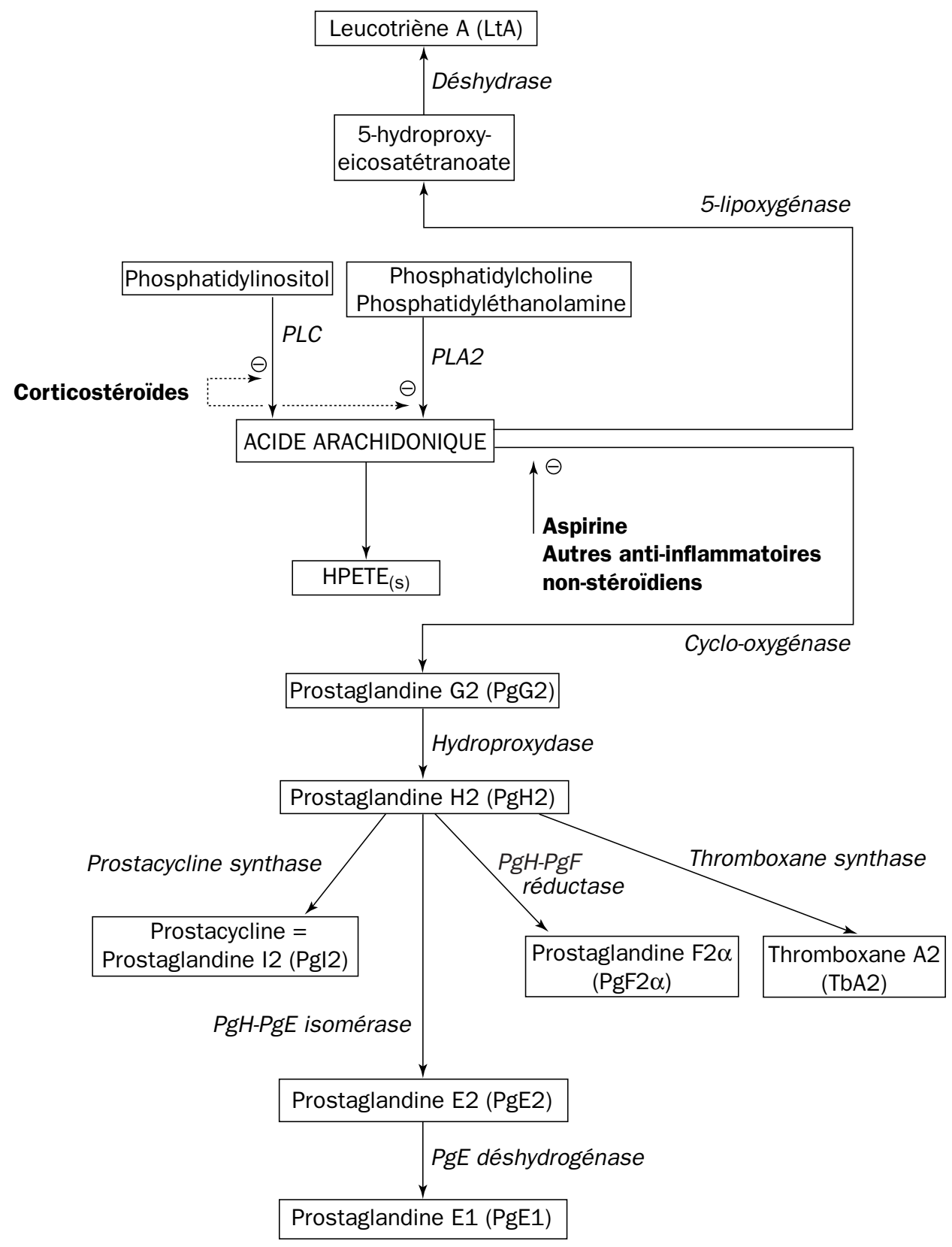

Figure 2.14 - Représentation schématique et simplifiée du métabolisme de l'acide arachidonique $(20 ; 4 \omega 6)$

$\operatorname{HPETE}_{(s)}$ : hydroperoxy-licosotétraénoïque ; PgE1 : prostaglandine E1 ; PgE2 : prostaglandine E2; PgF2 $\alpha$ : prostaglandine F2 $\alpha$; PgG2 : prostaglandine G2; PgH2 : prostaglandine H2; Pgl2: prostaglandine 12 (prostacycline); PLA2 : phospholipase A2; PLC: phospholipase $C$; LtA : leucotriène $A$; TbA2 : thromboxane A2. 


\section{LES RÉCEPTEURS HORMONAUX NUCLÉAIRES}

Les récepteurs nucléaires des hormones stéroïdes font partie d'une famille de protéines au sein de laquelle on trouve les récepteurs de la 1,25- $(\mathrm{OH})_{2}-\mathrm{D} 3$, les récepteurs des hormones thyroïdiennes et les récepteurs des rétinoïdes (les rétinoïdes sont des composés apparentés à l'acide rétinoïque, forme carboxylique de la vitamine A1).

La comparaison des séquences en acides aminés de ces récepteurs fait apparaître plusieurs séquences très conservées, ainsi que des régions qui diffèrent profondément d'un récepteur à l'autre. Il s'agit de protéines nucléaires qui sont dotées de la capacité de lier spécifiquement certaines séquences de l'ADN et qui, par suite de l'interaction avec leurs ligands respectifs, agissent comme facteurs transcriptionnels.

Tous les récepteurs contiennent une séquence centrale de 66 à 68 AA très semblable d'un récepteur à l'autre ; c'est le domaine de liaison à l'ADN (région C), qui a une structure retrouvée dans d'autres protéines connues pour se lier à l'ADN. Ces domaines de liaison à l'ADN ont en commun une structure en "doigts de zinc", séquence contenant huit résidus de Cys pouvant lier deux $\mathrm{Zn}^{2+}$ qui stabilisent le domaine de liaison à l'ADN. Une autre région (région E) constitue le site de liaison du récepteur avec l'hormone (Evans, 1988 ; Beato, 1989).

Ces récepteurs nucléaires constituent des hétérodimères avec la molécule $\mathrm{R}-\mathrm{XR}$, récepteur de l'acide rétinoïque 9 cis (voir plus loin), qui joue ainsi pour les hormones stéroïdes, thyroïdiennes et la 1,25-(OH) 2 -D3, un rôle de partenaire commun dans l'activation de ces hormones (fig. 2.15).

\subsection{RÉCEPTEUR DES ESTROGÈNES}

Il serait constitué par une seule chaîne polypeptidique, dont le gène a été cloné puis séquencé. Il possède 595 AA de PM 65 kDa, avec deux sites fonctionnels, l'un, de liaison avec l'hormone, localisé dans la moitié $\mathrm{N}$-terminale du récepteur et l'autre, de liaison avec l'ADN, localisé dans la moitié C-terminale du récepteur. Le $\mathrm{K}_{\mathrm{D}}$ est de 2,5 pM.

\subsection{RÉCEPTEUR DE LA PROGESTÉRONE}

Il comporte, selon O’Malley (1984), deux sous-unités, une sous-unité A (PM 79000) ou sous-unité effective qui lie l'ADN avec une haute affinité et une sous-unité B (PM 105000$)$ qui joue un rôle dans la spécificité de localisation du récepteur. Le $\mathrm{K}_{\mathrm{D}}$ est de 1 à $10 \mu \mathrm{M}$, selon les espèces. Cette forte affinité pour la chromatine ne se manifeste qu'après liaison avec l'hormone, en l'absence d'hormone le récepteur est faiblement lié au noyau. 


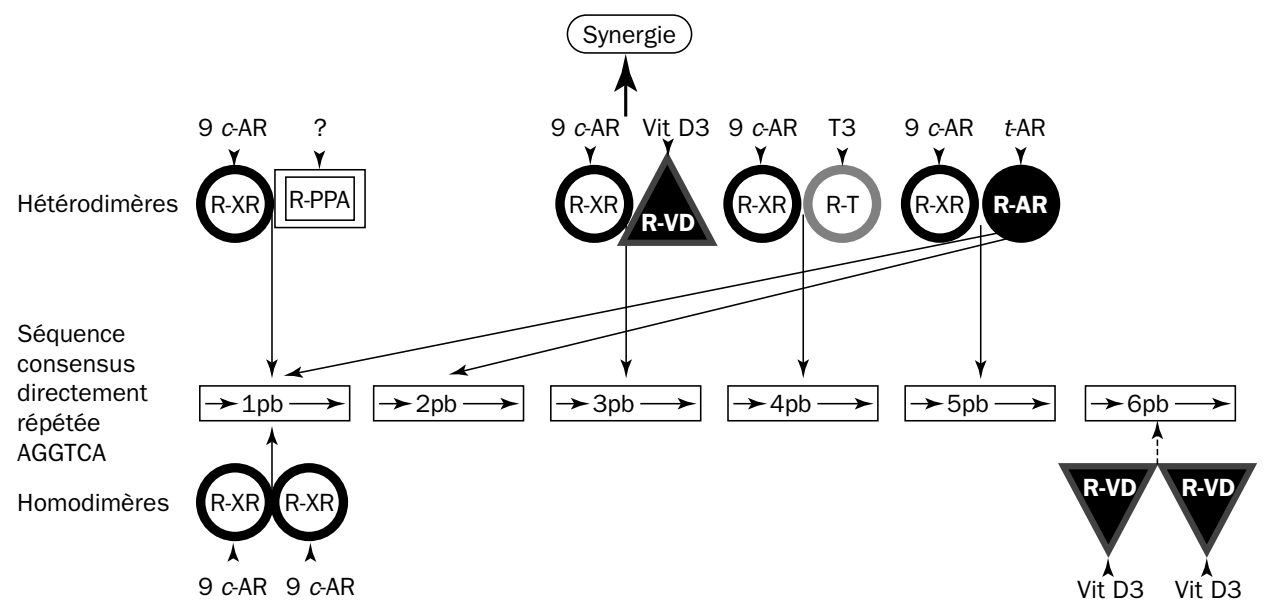

Figure 2.15 - Spécificité de liaison des récepteurs nucléaires à leurs cibles (d'après Lavau et coll., 1994)

$R-A R$ : récepteur de l'acide rétinoïque tout-trans (t-AR); $R$-PPA : récepteurs activés par les proliférateurs de peroxysome et les acides gras; $R-T$ : récepteur de l'hormone thyroïdienne ; $R-V D$ : récepteur de la vitamine $D 3 ; R-X R$ : récepteur de l'acide rétinoïque 9 cis (9c-AR).

Les récepteurs nucléaires, sous la forme d'un hétérodimère avec la molécule $R$-XR, lient un motif d'ADN, présent dans la région promoteur des gènes cibles, composé d'une séquence consensus (AGGTCA) directement répétée et espacée par un nombre variable de nucléotides (de une à six paires de bases). La protéine $R$-XR joue ainsi le rôle majeur de partenaire "universel" au sein de voies d'activation hormonale multiples.

\subsection{RÉCEPTEURS DES ANDROGÈNES}

Selon les cellules cibles le meilleur ligand endogène est la testostérone $\left(\mathrm{K}_{\mathrm{D}}=0,5 \mathrm{nM}\right)$ ou la dihydrotestostérone $\left(\mathrm{K}_{\mathrm{D}}=0,3 \mathrm{nM}\right)$.

La forme "native" du récepteur est un hétéropolymère d'environ $300 \mathrm{kDa}$, la forme "activée" est un monomère de $117 \mathrm{kDa}$. En fait, l'existence de deux sous-unités pour le récepteur est discutée. Pour Baulieu (1990), la protéine de $90 \mathrm{kDa}$ est une "heat shock protein" (voir chap. $3, \S 5.10$ ), hsp 90, qui serait liée de façon réversible au récepteur et marquerait la région liant l'ADN (région C). Le processus de transformation décrit par O'Malley serait en fait une dissociation du récepteur d'avec la protéine hsp 90, ce qui explique le passage de la forme 8S, non-active, à la forme 4S, active. Après liaison avec certaines molécules pharmacologiques, cette dissociation ne se ferait pas, ce qui expliquerait la propriété anti-hormone de ces molécules.

\subsection{RÉCEPTEURS DE L'ACIDE RÉTINOÏQUE}

Deux sous-groupes de récepteurs nucléaires de l'acide rétinoïque ont été identifiés (fig. 2.16) : le premier, composé des récepteurs de type R-AR qui présentent une affinité élevée pour l'acide trans-rétinoïque ; le second, des récepteurs de type R-XR qui affichent une affinité plus élevée pour l'acide rétinoïque 9 cis. Ces derniers 
constituent également des facteurs auxiliaires, ayant la propriété d'interagir avec d'autres récepteurs nucléaires tels que ceux de la vitamine $\mathrm{D}$, de l'hormone thyroïdienne et les récepteurs R-AR (Leid et coll., 1992).

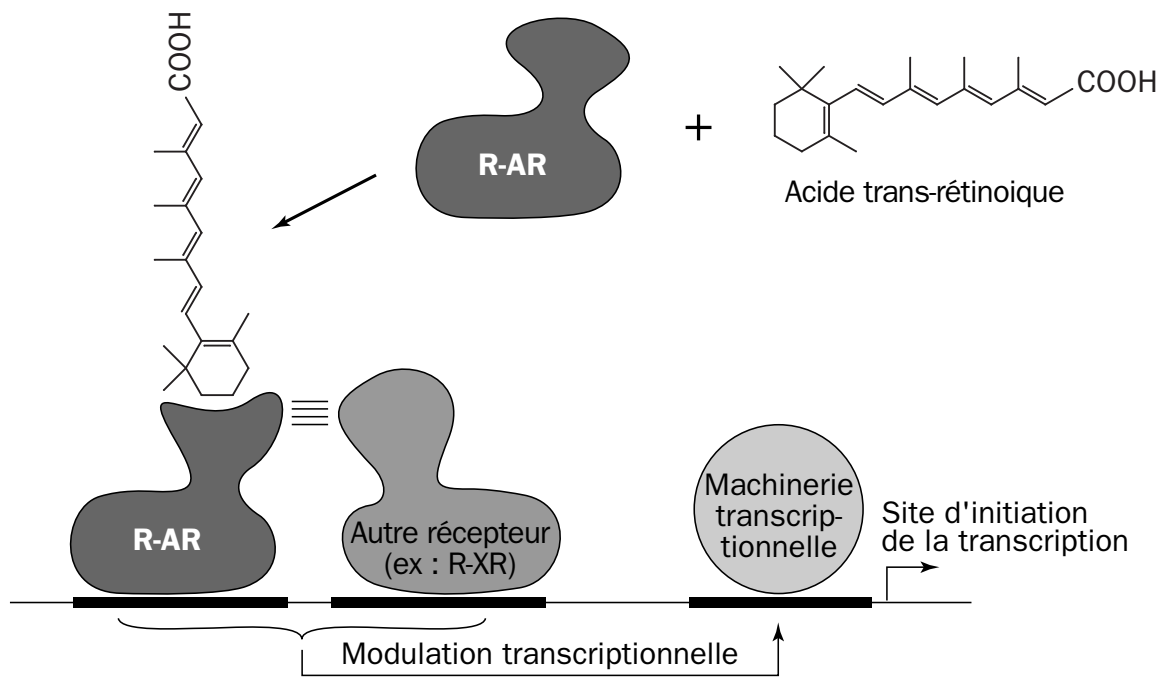

Figure 2.16 - Représentation schématisée du mode d'action

des récepteurs de l'acide rétinoïque (d'après Houle et Bradley, 1993)

Après avoir pénétré le noyau cellulaire, l'acide rétinoïque interagit avec la partie $\mathrm{N}$-terminale d'un récepteur de type $R$-AR. Le récepteur se dimérise avec un autre récepteur nucléaire, notamment un récepteur de type R-XR. Le complexe a la capacité de lier des séquences spécifiques de l'ADN (représentées par les segments gras), présentes en amont de certains gènes répondant à l'acide rétinoïque, ce qui se traduit par une modulation de l'activité transcriptionnelle des gènes cibles.

\subsection{CAS PARTICULIERS}

La testostérone, comme la vitamine D3, se comportent comme des pré-hormones qu'une action enzymatique, la $5 \alpha$-réductase cytoplasmique pour la testostérone, une double hydroxylation pour la vitamine $\mathrm{D} 3$, transforme en hormone active.

\section{INTERACTIONS ENTRE LES DIFFÉRENTS SYSTÈMES ACTIVÉS PAR LES MESSAGERS CHIMIQUES}

Quel que soit le processus de traduction, il existe toujours, au niveau de la cellule cible, une amplification du message. Néanmoins, compte tenu de la grande variété des messagers chimiques, de la grande diversité des récepteurs portés par la même cellule et de l'existence de plusieurs types de récepteurs pour le même messager (fig. 2.17), divers types d'interaction peuvent s'établir entre les multiples systèmes mis en jeu par les messagers chimiques. 


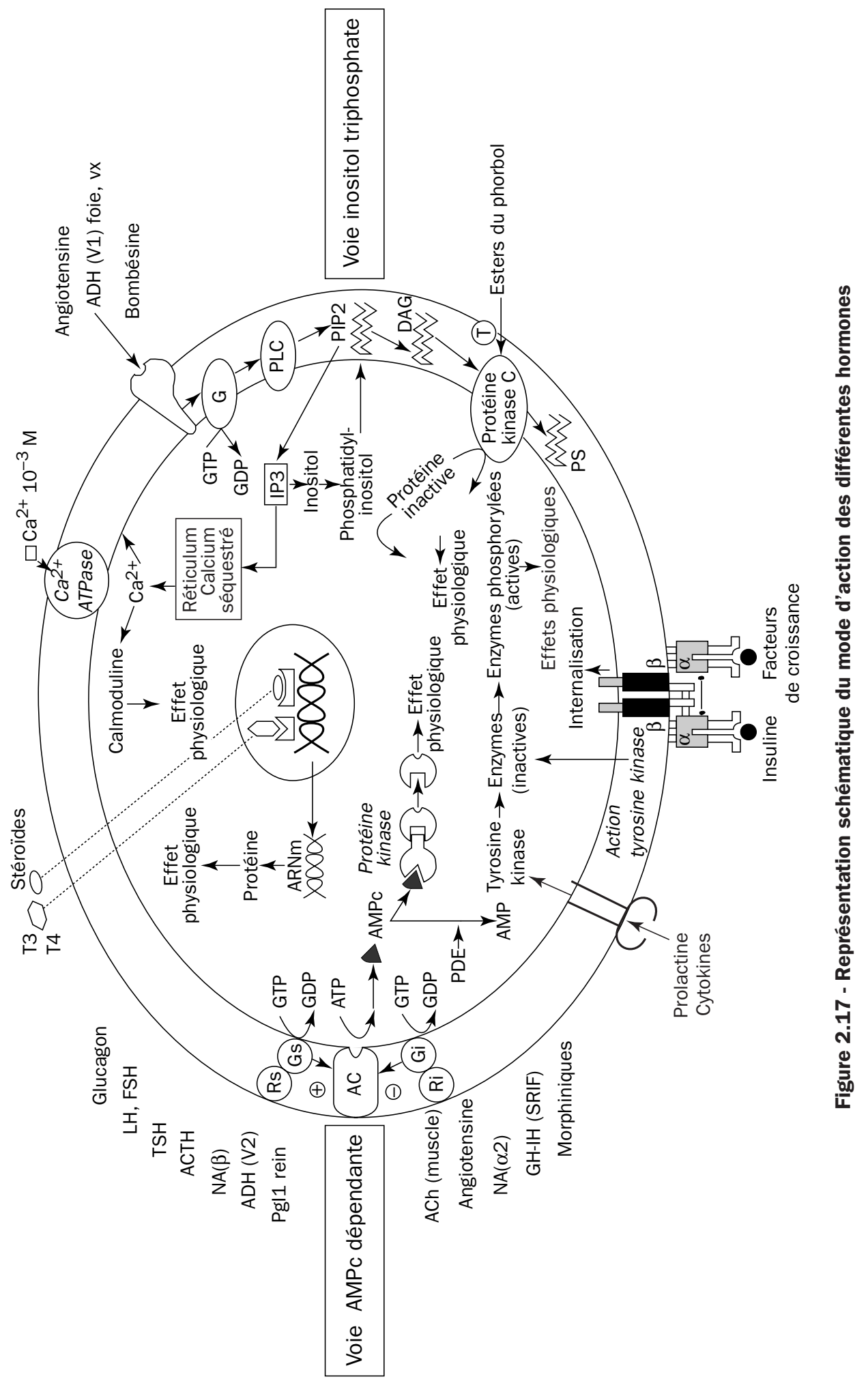


Ainsi, plusieurs messagers différents peuvent agir sur leur récepteur spécifique pour générer des modifications physiologiques régulées par le même second messager : convergence ou sommation de l'information. Au contraire, dans certains cas, un messager peut limiter la synthèse, stimulée par ailleurs, d'un second messager (cas des récepteurs couplés à une protéine $\mathrm{Gi}$ ) : occlusion de l'information. D'une manière similaire, le même messager, agissant sur des récepteurs différents, peut conduire à la synthèse de seconds messagers aux effets opposés. En revanche, l'activation de récepteurs différents (ou la mise en jeu par l'activation du même récepteur de mécanismes complémentaires) peut induire l'augmentation simultanée de la teneur en $\left[\mathrm{Ca}^{2+}\right]_{\mathrm{i}}$ et celle d'un second messager dont la synthèse et/ou les effets sont régulés par le calcium : synergie d'action ou modulation de l'information. Enfin, la mise en jeu de plusieurs types de récepteurs par le même messager chimique peut conduire à une divergence de l'information.

Il est clair que les modifications physiologiques de cet effecteur final commun que représente la cellule cible varieront en fonction du type, du nombre et de l'affinité des récepteurs, et bien entendu de la libération simultanée ou non de messagers chimiques différents.

\section{Pathologies de la communichtion INTERCELLULAIRE ET THÉRAPIE}

Différentes pathologies acquises ou héréditaires peuvent résulter de perturbations prenant place à toutes les étapes des processus de la communication intercellulaire : synthèse et libération du messager - diffusion ou distribution du message - réception et traduction - cascades de processus biochimiques prenant place après la synthèse de seconds messagers. Suivant le niveau des altérations, différents types d'intervention peuvent être envisagés : manipulations de la synthèse et/ou de la libération de messager, apport de messager exogène ou de substances agonistes, blocage de la réception du message (utilisation de substances antagonistes), manipulations génétiques. 
CHAPITRE 3

\section{MESSAGERS CHIMIQUES PARTICULIERS : SIGNAUX MITOGÉNIQUES, KININES, NO, PAF, ENDOTHÉLINE, ECDYSONE}

\section{MÉCANISMES DE RÉCEPTION ET DE TRANSMISSION DES SIGNAUX MITOGÉNIQUES}

Le développement harmonieux d'un organisme pluricellulaire nécessite une coordination rigoureuse, dans l'espace et dans le temps, de deux processus caractéristiques de la vie, la prolifération et la différenciation cellulaires. Chez un organisme adulte, certaines cellules différenciées ne se divisent plus, comme les neurones ou les cellules musculaires striées ; d'autres, au contraire, continuent à se diviser et / ou à se différencier pendant toute la vie, comme les cellules souches des spermatozoïdes et des cellules du sang; d'autres enfin ne se divisent que pour réparer une lésion ou compenser la mort d'autres cellules.

C'est au début du XX' $\mathrm{XX}^{\mathrm{e}}$ siècle que l'établissement de communications intercellulaires fut impliqué dans la balance entre prolifération et différenciation cellulaires. Dès lors, l'enjeu fut de trouver des conditions adéquates pour la culture in vitro de tissus ou de cellules, puis de définir la nature des substances nécessaires à la croissance. Ces recherches ont conduit à l'identification, à côté des vitamines et autres nutriments, du premier facteur soluble défini comme un facteur de croissance cellulaire, le facteur de croissance épidermique (epidermal growth factor ou EGF) (Cohen, 1962). Cette découverte capitale a été à l'origine de la caractérisation de très nombreux facteurs de croissance. Ces facteurs représentent des molécules "signal", clés du réseau de communication entre les cellules d'un organisme.

Les facteurs de croissance sont des polypeptides ayant des caractéristiques particulières qui les distinguent des hormones: d'une part les facteurs de croissance sont synthétisés par des types cellulaires nombreux et variés, alors que les hormones sont synthétisées par des glandes spécialisées, d'autre part ils agissent localement sur leur lieu de synthèse, alors que les hormones sont excrétées et véhiculées par le sang jusqu'au tissu cible. 
De cette "endocrinologie locale" exercée par les facteurs de croissance, sont nés les concepts de paracrinie et d'autocrinie (voir chap. 2 , § 1). Contrairement à l'endocrinie qui suggère que la cellule sécrétant l'hormone soit distincte et à distance de la cellule cible, la paracrinie implique que la cellule sécrétant le facteur de croissance et les cellules cibles soient dans un environnement immédiat, et l'autocrinie implique que la cellule sécrétrice soit sa propre cible.

\subsection{RECONNAISSANCE ET TRANSMISSION DES SIGNAUX MITOGÉNIQUES}

Afin d'adapter son comportement à son environnement immédiat, la cellule doit être capable de reconnaître un stimulus externe spécifique et de transmettre l'information qu'il porte à l'intérieur de la cellule. Pour cela, les facteurs de croissance se lient à des récepteurs protéiques spécifiques situés au niveau de la membrane plasmique (Van der Geer et coll., 1994).

\subsubsection{Fixation du facteur de croissance et activation du récepteur}

Les récepteurs des facteurs de croissance sont des protéines constituées d'un domaine extracellulaire porteur d'un site de liaison spécifique pour le ligand, d'un domaine transmembranaire et d'un domaine cytoplasmique possédant une activité protéine tyrosine kinase intrinsèque chargée du relais avec la machinerie intracellulaire.

Enfin, une région carboxy-terminale de longueur variable et possédant plusieurs résidus tyrosine prolonge le domaine catalytique. Les récepteurs existent normalement sous la forme de monomères diffusibles dans le plan de la membrane plasmique (fig. 3.1).

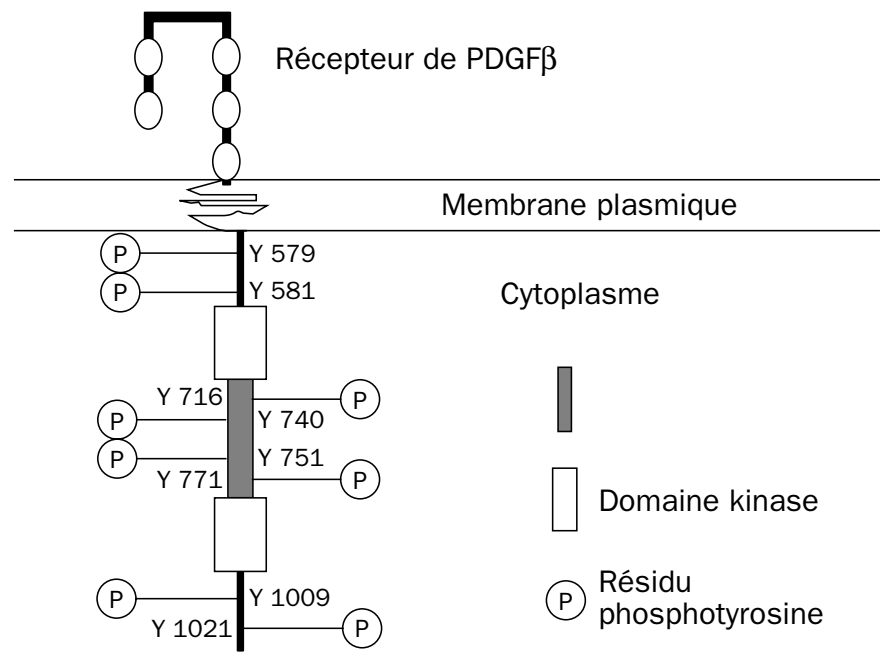

Figure 3.1 - Schéma représentant les résidus phosphotyrosine impliqués dans la liaison du récepteur humain de PDGF $\beta$ aux protéines de signalisation PDGF : platelet derived growth factor. 
La fixation du facteur de croissance à son récepteur provoque la dimérisation des domaines extracellulaires qui s'accompagne d'un changement de conformation du récepteur. Cette dimérisation induit une juxtaposition des domaines cytoplasmiques qui permet une transphosphorylation de plusieurs résidus tyrosine présents dans ce domaine. Bien que resté mystérieux pendant de nombreuses années, le rôle de cette transphosphorylation est double : elle permet non seulement l'activation maximale du récepteur dimérique, mais elle représente aussi un mécanisme essentiel pour le recrutement des substrats qui seront des cibles de l'activité tyrosine kinase du récepteur.

Les récepteurs pour les différents facteurs de croissance montrent des homologies de structure qui permettent de les regrouper en familles. La topologie moléculaire de quelques sous-familles de récepteurs est illustrée dans la figure 3.2.

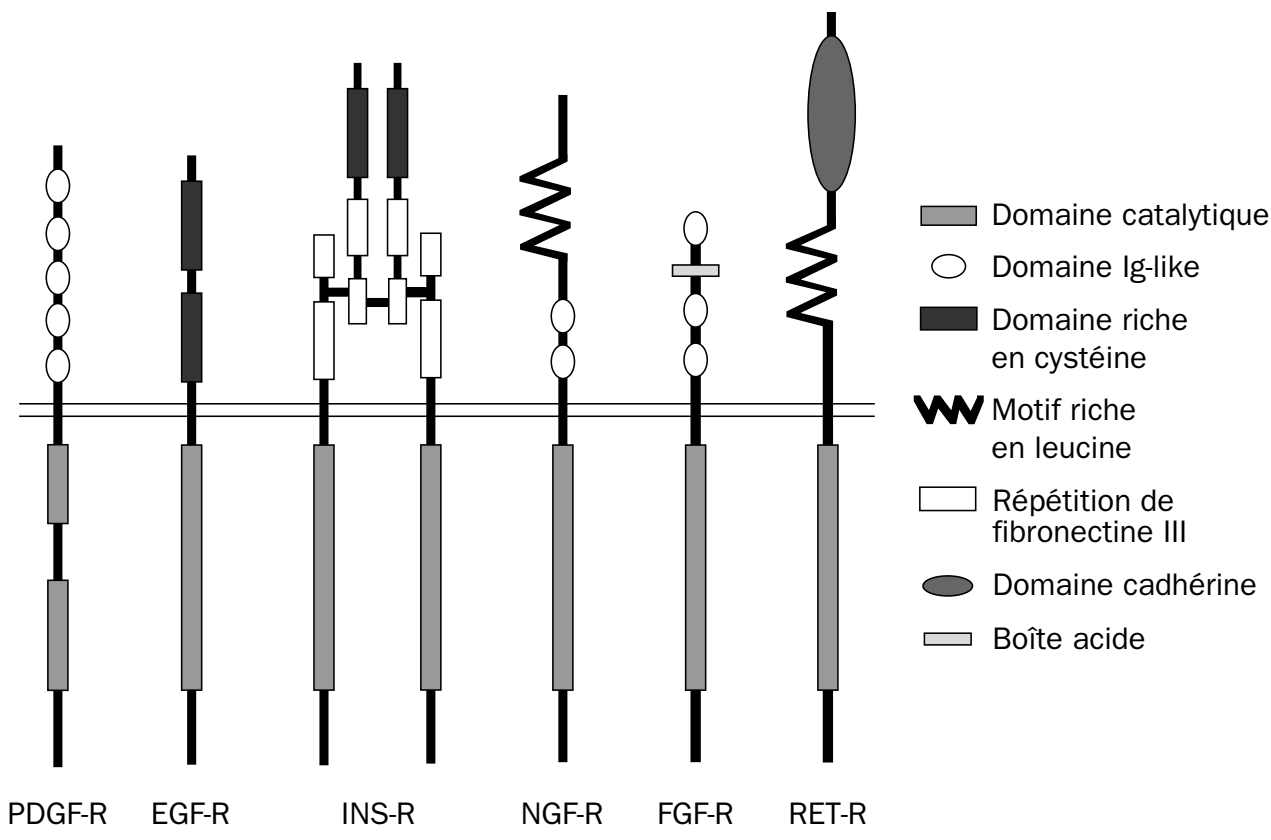

Figure 3.2 - Structure schématique

de quelques récepteurs protéine tyrosine kinases

EGF : epidermal growth factor ; FGF : fibroblast growth factors ; Ins : insuline ; NGF : necrosing growth factor ; PDGF : platelet derived growth factor ; $R$ : récepteur.

\subsubsection{Fonctions des récepteurs de facteurs de croissance}

Dès leur découverte, il est apparu clairement que les récepteurs pour les facteurs de croissance sont des récepteurs enzymes et qu'une de leurs fonctions majeures est de phosphoryler des protéines intracellulaires sur des résidus tyrosine. Une découverte plus récente a montré que, bien que les protéines cibles des récepteurs tyrosine kinases aient des activités biochimiques et des fonctions biologiques différentes, elles ont en commun des domaines qui fonctionnent de façon autonome (Pawson, 1995). 
Comme nous allons le voir, une des fonctions de ces modules est de permettre l'assemblage de complexes moléculaires dans le proche voisinage du récepteur activé.

\subsubsection{Rôle des domaines $\mathrm{SH} 2, \mathrm{SH}, \mathrm{PtB}$ et $\mathrm{PH}$ dans les réseaux de signalisation cellulaire}

La figure 3.3.a illustre quelques protéines porteuses de modules de signalisation. Les protéines qui possèdent des domaines $\mathrm{SH} 2$ (SRC-homology 2 domain) ou PtB (phosphotyrosin binding domain) se fixent avec une forte affinité $\left(K_{D}=1 \mathrm{nM}\right)$ sur les sites d'autophosphorylation des récepteurs activés. Les domaines $\mathrm{SH} 2$ représentent des modules protéiques d'une centaine d'acides aminés qui reconnaissent avec affinité et spécificité les phosphotyrosines et les 3 à $5 \mathrm{AA}$ adjacents. La liaison de protéines cibles via leur domaine $\mathrm{SH} 2$ ou PtB aux récepteurs activés peut avoir trois types d'effets :

1. cette liaison peut faciliter la phosphorylation de la protéine cible complexée au récepteur. Phosphorylation qui peut soit activer, soit inhiber la protéine cible ;

2. la liaison de la protéine au récepteur peut se traduire par une activation allostérique ;

3. enfin, cette liaison peut représenter un mécanisme de localisation de la protéine à proximité de son substrat, notamment au niveau de la surface interne de la membrane plasmique.

Un autre type de domaine permettant des interactions protéine-protéine est le domaine SH3 (SRC-homology 3 domain). Ce type de domaine est retrouvé dans de nombreuses protéines de signalisation mais également dans des composants du cytosquelette (fig. 3.3.a).

Les domaines PH (plectrin homology) sont des domaines globulaires de 120 AA dont les ligands sont moins bien définis. Toutefois, ils semblent capables de se lier à certains lipides du type phosphoinositides tels que l'inositol $(1,4,5)$ triphosphate (IP3) et le phosphatidylinositol $(4,5)$ biphosphate (PIP2).

Ainsi, lors de l'activation d'un récepteur par un facteur de croissance, les sites d'autophosphorylation permettent un assemblage moléculaire, au niveau de la membrane cellulaire, d'un réseau de protéines qui préexistent dans le cytoplasme sous des formes inactives. Différentes combinaisons des domaines SH2, SH3 et PH sont fréquemment retrouvées dans les mêmes protéines, domaines qui peuvent ainsi collaborer entre eux pour former des complexes de signalisation en aval des récepteurs actifs (fig. 3.3.b).

\subsubsection{Cas des récepteurs à plusieurs sous-unités}

Sur les lymphocytes, les récepteurs pour les antigènes utilisent des mécanismes d'activation et de signalisation identiques à ceux que nous venons de décrire. Toutefois, le site de liaison du ligand, l'activité tyrosine kinase et les protéines à SH2 résident sur des entités protéiques différentes. 


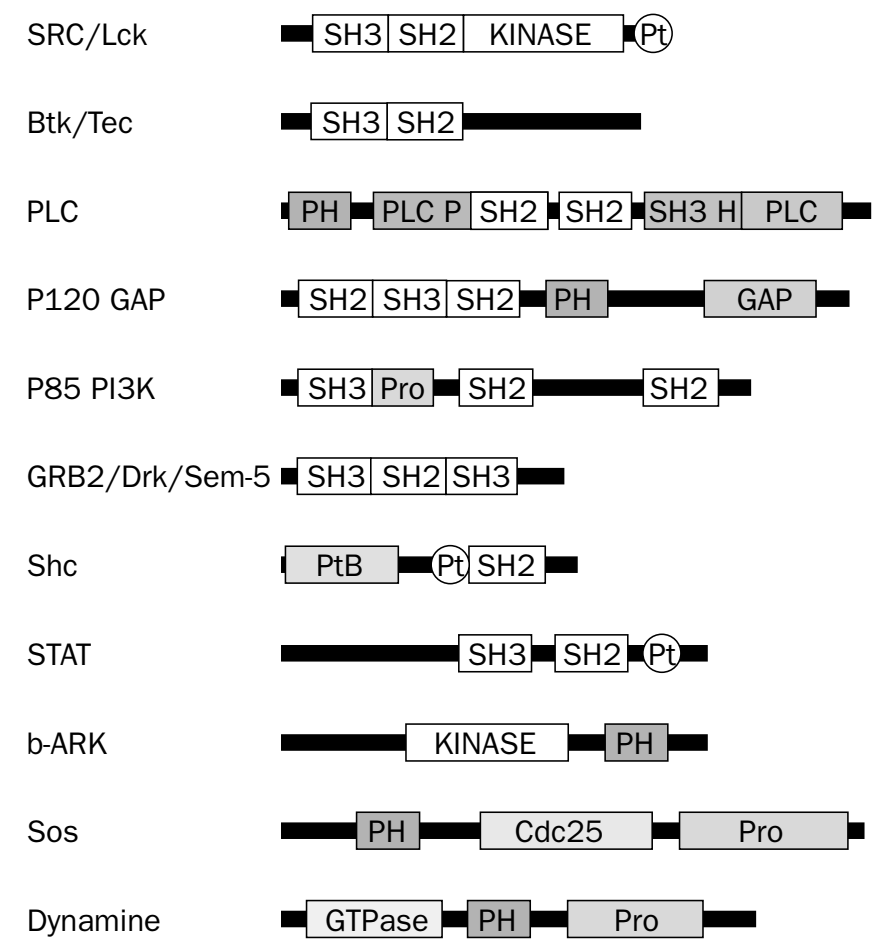

Figure 3.3.a - Quelques protéines contenant des domaines SH2, PtB, SH3 et PH Cdc25 : domaine d'échange du nucléotide guanine de Ras ; Pt : phosphotyrosine ; Pro : domaine riche en proline.

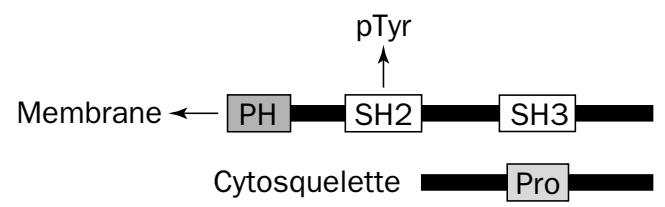

Figure 3.3.b - Les domaines SH2, SH3 et PH peuvent former un réseau de protéines.

De même, les récepteurs pour les cytokines et les interférons sont dépourvus d'activité enzymatique. Après fixation du ligand, ces récepteurs s'associent avec une tyrosine kinase cytoplasmique appelée Janus activated kinase (JAK), qui va phosphoryler le récepteur sur des résidus tyrosine et ainsi créer des sites d'interaction pour des protéines à domaine $\mathrm{SH} 2$.

\subsection{PROPAGATION DES SIGNAUX DE LA MEMBRANE PLASMIQUE AU NOYAU CELLULAIRE : UN RÉSEAU À MULTIPLES RELAIS}

L'un des plus fascinants développements récents de la biologie cellulaire a été la dissection étape par étape de plusieurs réseaux de signalisation qui permettent la transmission de signaux extracellulaires de la membrane au noyau cellulaire. 
Parmi les cinq réseaux de signalisation distincts identifiés à ce jour, ceux qui s'activent en réponse à des facteurs de croissance présentent un intérêt particulier car leur dérèglement conduit souvent à la transformation cellulaire.

Un réseau de signalisation mitogénique peut schématiquement se décomposer en une phase membranaire et une phase cytoplasmique. La première de ces phases se déroule à proximité du récepteur activé et conduit à la fixation d'une protéine adaptatrice GRB2 sur une des tyrosines phosphorylées du récepteur. Cette fixation entraîne en réalité la translocation sous la membrane plasmique du complexe GRB2-Sos à proximité de la protéine de liaison du GTP (Ras) qui, elle, est ancrée dans la membrane. Sos est une protéine d'échange de nucléotide dont la caractéristique essentielle est de convertir la forme inactive de Ras (Ras-GDP) en une forme active (Ras-GTP). L'activation de Ras est l'étape déterminante pour déclencher la phase cytoplasmique de la propagation du signal qui est constituée par l'activation séquentielle de plusieurs protéine kinases appelées collectivement la cascade de signalisation des MAP kinases (mitogen activated protein kinase ou MAPK).

Par souci de clarté, la description de cette voie sera ici simplifiée (le lecteur pourra se référer à l'excellente revue de R. Seger et E. Krebs, 1995). La propriété essentielle de cette voie de signalisation est qu'elle met en jeu plusieurs protéines qui vont dialoguer principalement par des interactions moléculaires faisant intervenir des domaines $\mathrm{SH} 2$, $\mathrm{SH} 3, \mathrm{PtB}$ et $\mathrm{PH}$, ainsi que des réactions de phosphorylation. Le premier étage de la cascade de protéine kinases est occupé par Raf, une sérine thréonine protéine kinase qui s'associe via son domaine régulateur avec Ras activé. Cette association permet de délocaliser Raf du cytoplasme vers la membrane où la kinase est activée par un mécanisme impliquant une phosphorylation. Parmi les candidats pour cette phosphorylation, citons la protéine kinase $\mathrm{C}$ et la protéine tyrosine kinase c-SRC. Raf, une fois activée, est une kinase qui phosphoryle et active sélectivement la protéine kinase MEK. MEK appartient à une famille de protéine kinases particulières, MAP kinaseskinases, capables de phosphoryler aussi bien des résidus thréonine que tyrosine (kinases à double spécificité). MEK activée va, à son tour, phosphoryler sur des résidus thréonine et tyrosine et ainsi activer ERK1 et ERK2 qui représentent deux isoformes des MAP kinases. A la différence de Raf et de MEK, les MAP kinases possèdent un large éventail de substrats protéiques qui sont localisés soit dans le cytoplasme, soit dans le noyau (fig. 3.4). Plusieurs des cibles des MAP kinases sont des facteurs de transcription nucléaires tels que Elk-1, c-Fos, c-Myc, p53 et l'ARN polymérase II, suggérant que ces kinases sont des régulateurs importants d'activités transcriptionnelles. Cette vision est renforcée par l'observation que les formes activées des MAP kinases subissent une translocation du cytoplasme vers le noyau. Il est donc clair que la cascade de signalisation des MAP kinases est nécessaire et suffisante pour propager et amplifier un signal extracellulaire dans le cytoplasme, et finalement le convertir en événements transcriptionnels au niveau du noyau. In fine, cette stimulation va permettre d'activer de nombreux gènes précoces qui jouent un rôle clé dans la prolifération cellulaire. 


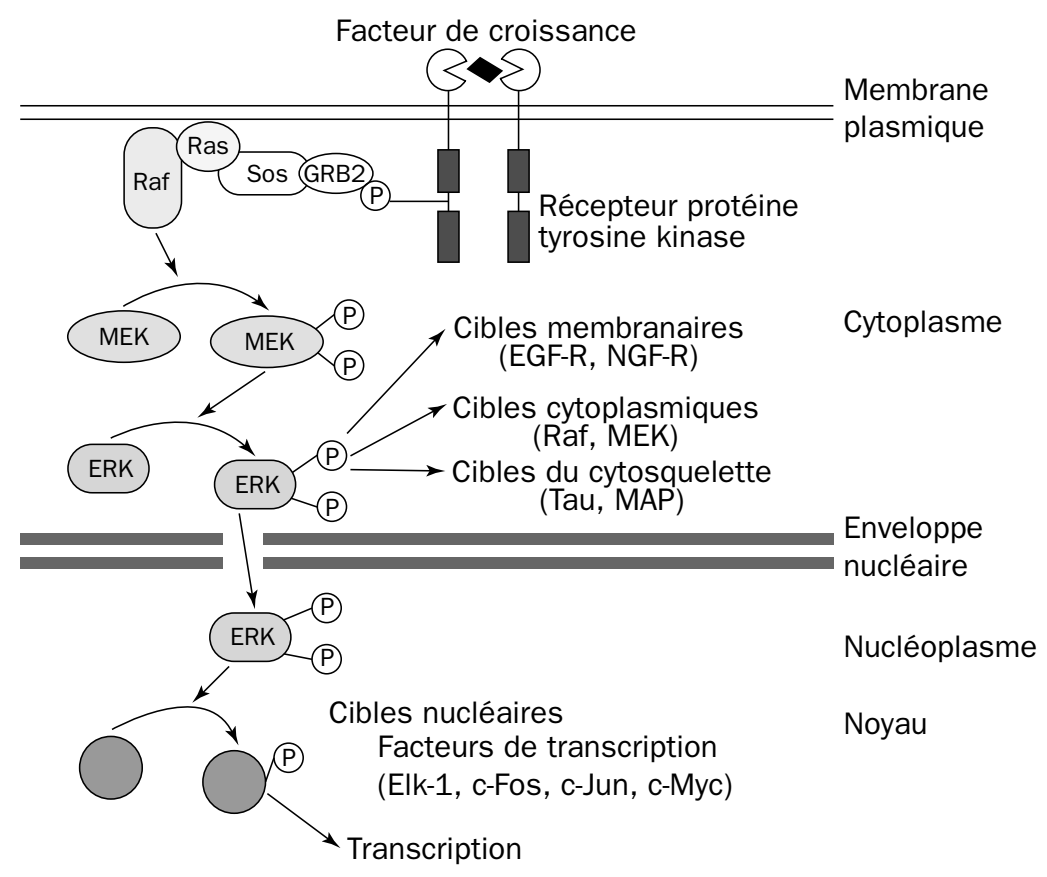

Figure 3.4 - La cascade de signalisation des MAP kinases

\subsubsection{Signalisation mitogénique et oncogenèse}

Un intérêt considérable s'est développé autour de ce type de voie de signalisation lorsqu'on a réalisé que, parmi la cinquantaine d'oncogènes connus actuellement, la plupart sont des acteurs de la cascade d'événements déclenchée par les facteurs de croissance lors de la division cellulaire normale. A titre d'exemple, des oncogènes peuvent représenter des protéines homologues de facteurs de croissance, des récepteurs pour des facteurs de croissance, des effecteurs des voies de signalisation ou des facteurs de transcription activés lors de la prolifération cellulaire.

\subsubsection{La voie des MAP kinases: une voie de signalisation mitogénique universelle?}

Il a été observé depuis longtemps que de nombreux agonistes tels que la thrombine, l'acide lysophosphatidique, dont les récepteurs à sept domaines transmembranaires sont couplés à des protéines $\mathrm{G}$ trimériques, sont des mitogènes puissants. La question d'un couplage des voies de signalisation utilisées par ce type de mitogènes avec la voie des MAP kinases devait être posée.

De fait, il a été clairement montré que l'activation cellulaire par la thrombine ou l'acide lysophosphatidique permet la dissociation de la protéine $\mathrm{G}$ trimérique et que les sous-unités $\beta$ et $\gamma$ du complexe peuvent stimuler Ras et par conséquent la voie des MAP kinases. Toutefois, les récepteurs couplés aux protéines $\mathrm{G}$ trimériques peuvent également stimuler la voie MAP kinase en l'absence d'activation détectable de Raf. 
Ceci suggère une voie de signalisation mettant en jeu une MEK kinase différente de Raf (fig. 3.5).

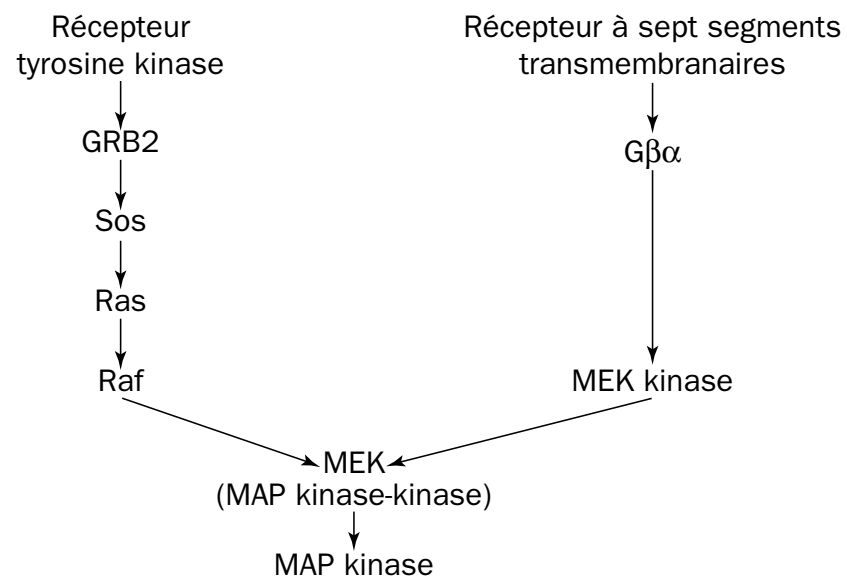

Figure 3.5 - Schéma représentant les deux voies conduisant à l'activation de MEK

Les interférons, ainsi que des cytokines telles que les interleukines, activent de nombreux gènes en réponse à la liaison de facteurs de transcription appelés protéines STAT. Ces protéines s'assemblent dans le cytoplasme sous la forme d'un complexe actif qui migre dans le noyau, où il se fixe à des séquences d'ADN spécifiques localisées dans les régions promotrices de plusieurs gènes.

Il a été observé que l'activation du complexe STAT nécessite une phosphorylation sur un résidu tyrosine. Cette phosphorylation est assurée par une protéine tyrosine kinase cytoplasmique appelée JAK qui se lie aux récepteurs membranaires des interférons ou des cytokines. Il s'agit là d'une voie de signalisation étonnamment simple. Cependant, il est à présent établi que les interférons et les cytokines stimulent également la voie des MAP kinases. Inversement, les facteurs de croissance sont capables d'activer le complexe STAT et de provoquer sa translocation nucléaire (fig. 3.6). Il existe donc une coordination entre les voies d'activation de STAT et des MAP kinases, ce qui se traduira par un accroissement de la transcription des gènes en réponse à différents signaux.

\subsubsection{Spécificité et plasticité des réseaux de signalisation cellulaire}

Les axes de signalisation décrits précédemment font partie de systèmes dynamiques dont les composants dialoguent principalement par des interactions moléculaires et des réactions de phosphorylation.

\section{Vers une circuiterie semi-solide}

Les interactions protéine-protéine mises en jeu font appel soit à des modules reconnaissant spécifiquement des résidus tyrosine phosphorylés dans un contexte particulier (cas des domaines $\mathrm{SH} 2$ et $\mathrm{PtB}$ ), soit à des séquences riches en protéine (domaine $\mathrm{SH} 3$ ) ou à des lipides (domaine $\mathrm{PH}$ ou plectrin homology). 


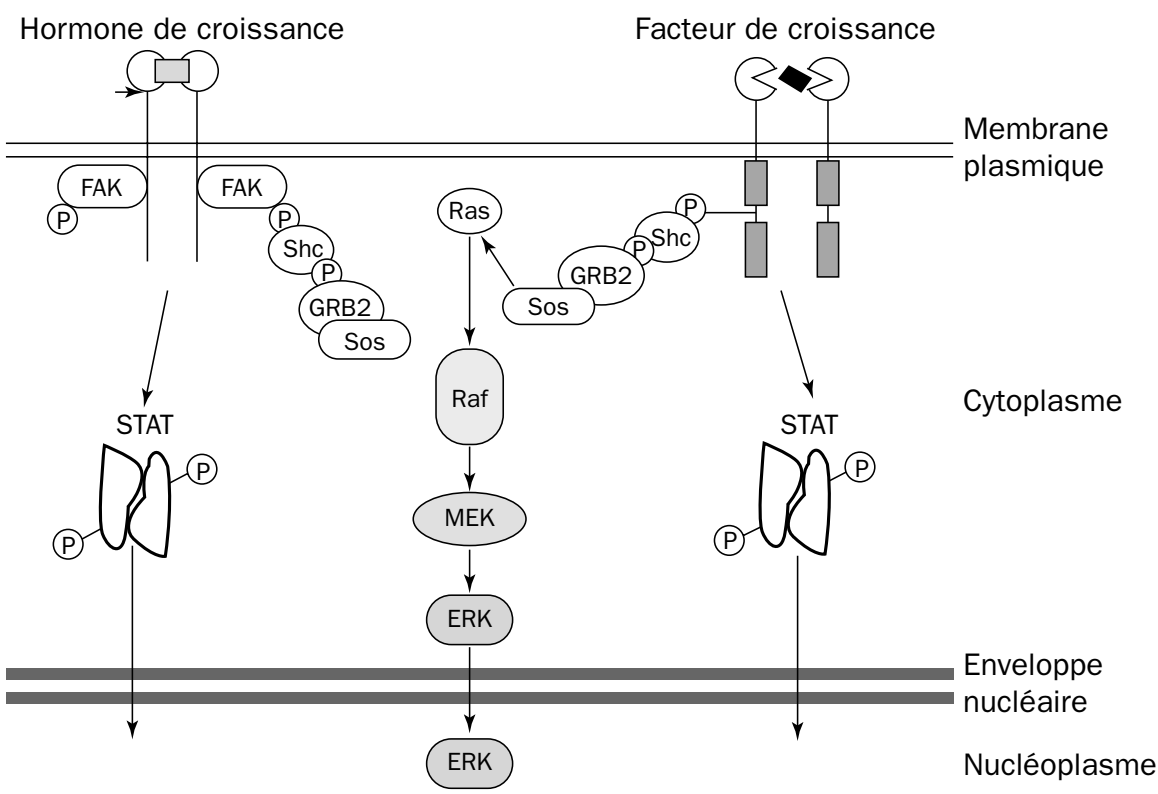

Figure 3.6 - Activation des STAT via JAK2 et de ERK / MAPK par les hormones et / ou les facteurs de croissance

Ces assemblages moléculaires, tel un "lego", permettent d'établir une circuiterie où la notion de proximité entre les protéines semble représenter un principe aussi important que la diffusion passive de messagers secondaires.

\section{Spécificité cellulaire}

Un des problèmes pour ce type de signalisation est de comprendre comment des centaines de récepteurs membranaires différents peuvent engendrer des réponses cellulaires spécifiques, alors qu'il existe un nombre relativement restreint de voies de signalisation de la membrane au noyau. Une solution à ce problème réside dans le fait que les différents réseaux de signalisation sont utilisés de façon combinatoire, chaque récepteur utilisant une combinaison spécifique "d'intégrateurs". Une autre possibilité implique que la réponse cellulaire à un récepteur donné soit dictée par la disponibilité, au niveau de la membrane dans le proche environnement du récepteur, des composants des différentes voies de signalisation. Dans cette hypothèse, il est nécessaire d'envisager l'existence entre la membrane et le noyau de microdomaines dans lesquels le trafic des protéines est restreint.

Comme il a déjà été mentionné, les composants trouvés aux mêmes "étages" des différentes voies de signalisation présentent à la fois des homologies structurelles mais aussi fonctionnelles très importantes. Malgré cela, on observe que chaque voie est spécifique d'un stimulus donné (ainsi l'activation de la voie spécifique du stress cellulaire ne fera jamais proliférer la cellule). 


\section{Combinaisons multiples pour réponses spécifiques}

Au-delà de cette signalisation linéaire de la membrane au noyau, il est clair que la plupart des circuits sont dotés d'une extraordinaire plasticité. Cette propriété leur permet de coopérer de façon spatio-temporelle (voie MAP kinase, voie JAK), et ainsi d'activer de multiples facteurs de transcription dont la présence simultanée est nécessaire à l'activité de nombreux promoteurs.

\section{Intensité des signaux : notion de seuil}

Des observations troublantes ont montré qu'en fonction du type cellulaire, les mêmes facteurs de croissance pouvaient induire soit une prolifération, soit une différenciation. Ainsi, le FGF (fibroblast growth factor) qui est un mitogène puissant pour de nombreux types cellulaires induit une différenciation d'une lignée cellulaire (cellules PC12). Un autre facteur de croissance EGF (epidermal growth factor) stimule la prolifération de ces mêmes cellules. Globalement, les deux facteurs de croissance empruntent les mêmes voies de signalisation. Cependant, une analyse détaillée a permis de montrer que la différence observée en réponse au FGF est corrélée à une activation persistante de Ras-GTP et des MAP kinases qui se délocalisent dans le noyau pendant plusieurs heures. Au contraire, la prolifération des cellules PC12 en réponse à l'EGF est corrélée à une activation transitoire de Ras-GTP et de la MAP kinase qui demeure localisée dans le cytoplasme.

Ainsi, la modulation de l'intensité et/ou de la durée d'activation provoquée par les deux facteurs de croissance semble représenter une composante importante de la réponse cellulaire finale.

Ce concept rejoint les effets de seuil bien connus en biologie du développement, où des variations graduelles de la concentration d'un ligand ou de celle d'un facteur nucléaire provoquent des différences fondamentales de l'expression génique.

\section{Vers une multitude de réseaux de signalisation}

Les techniques de biologie moléculaire ont récemment révélé l'existence de nouvelles protéines homologues des protéine kinases de la cascade des MAP kinases. Ces résultats ont permis l'élucidation de plusieurs voies parallèles de transduction de signaux qui, en activant de façon séquentielle des protéine kinases, fonctionnent de manière analogue à la voie classique mitogénique.

Ce type de modules de signalisation a été mis en place très tôt dans les processus d'évolution puisqu'ils existent dans la levure. Il est à noter que la voie des MAP kinases est activée par la plupart des facteurs de croissance et joue un rôle dans la prolifération cellulaire et l'activation des autres voies. Elle est observée en réponse à des facteurs qui "agressent" la cellule, tels les rayons ultraviolets, les chocs thermiques, les changements d'osmolarité ou l'exposition à des inhibiteurs de synthèse protéique. 


\subsection{RÉGULATION DU CYCLE CELLULAIRE}

La division des cellules au sein d'un organisme repose sur le déroulement correct des phases successives du cycle cellulaire (fig. 3.7). Sous l'effet des facteurs de croissance, une cellule sort de son état quiescient (phase G0) pour accomplir la phase G1 qui prépare la cellule à dupliquer son $\mathrm{ADN}$. La division de l'ADN se fait lors de la phase S suivie d'une courte phase G2 qui prépare la mitose proprement dite (phase M).

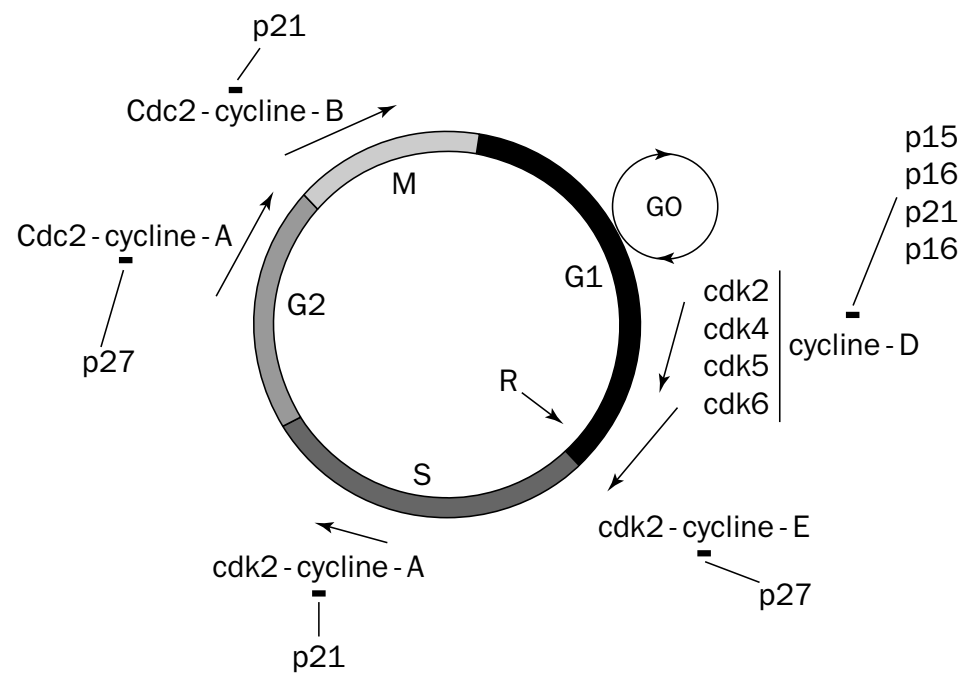

Figure 3.7 - Les acteurs principaux du cycle cellulaire

La division cellulaire correcte, qui repose donc sur le déroulement chronologique strict de ces différentes phases, est assurée par une famille de protéine kinases appelées kinases dépendantes des cyclines (cyclin dependent kinases ou cdk). Pour être actives, les cdk doivent s'associer à une sous-unité régulatrice nommée cycline, dont l'expression cyclique conditionne la chronologie de l'activation des cdk (Wolowiec et French, 1996). Les cyclines sont divisées en deux groupes : les cyclines mitotiques, regroupant les cyclines A et B, et les cyclines de la phase G1H. Les cyclines de la phase $\mathrm{G} 1$, cyclines $\mathrm{D}$ et $\mathrm{E}$, sont présentes dans les cellules dès la phase G1 et activent les cdk engagées dans les étapes précoces du cycle cellulaire.

\subsubsection{Régulation des cdk-cyclines par phosphorylation-déphosphorylation}

L'activité des cdk dépend non seulement de leur association avec les cyclines, mais également de modifications post-traductionnelles par réactions de phosphorylationdéphosphorylation. Deux sites de phosphorylation des cdk ont des effets inhibiteurs et doivent être impérativement déphosphorylés lors de l'activation de la kinase. Un site de phosphorylation des cdk est activateur, la phosphorylation de ce site est essentielle pour une activité maximale du complexe cdk-cycline. 
Les cdk activées participent à la régulation du cycle cellulaire par la phosphorylation de la protéine Rb qui contrôle l'activité de plusieurs facteurs de transcription.

\subsubsection{Protéines inhibitrices des cdk-cyclines}

L'horloge du cycle cellulaire fait également appel à une série de petites protéines (protéines 16, 21 et 27) capables de se lier aux complexes cdk-cyclines et d'inhiber leur activité kinase (voir fig. 3.7). Ces protéines inhibitrices participent à la régulation du cycle cellulaire en retardant l'activation des divers complexes cdk-cyclines spécifiques des phases $\mathrm{G} 1$ et $\mathrm{S}$ jusqu'au temps adéquat, assurant ainsi leur mise en œuvre ordonnée. La perte ou le disfonctionnement de ces inhibiteurs pourrait entraîner une prolifération cellulaire incontrôlée telle qu'on l'observe dans les cellules cancéreuses.

\section{LES KININES}

C'est au début du siècle qu'il est fait référence, pour la première fois, à une substance (l'urohypotensine) extraite de l'urine humaine, substance qui, injectée chez le chien, produit une forte hypotension. Toutefois, ce n'est qu'à la suite des travaux du groupe de Werle (Frey et coll., 1932-1950) que ce facteur hypotensif que l'on pensait alors produit par le pancréas (killikreas en grec) est appelé kallicréine.

L'action des kallicréines, protéases à sérine (plasmatique ou cellulaire) sur leur substrat - les kininogènes (de haut et de bas poids moléculaire) -, conduit à la production de peptides bioactifs : les kinines. Le plus connu de ces peptides est un nonapeptide vaso-actif, la bradykinine (fig. 3.8). Les kinines sont rapidement métabolisées par des peptidases - les kininases - présentes dans la circulation et les tissus. Une de ces kininases (KII-ACE) n'est autre que l'enzyme de conversion de l'angiotensine (ACE) (voir chap. 6, § 2.4.3).

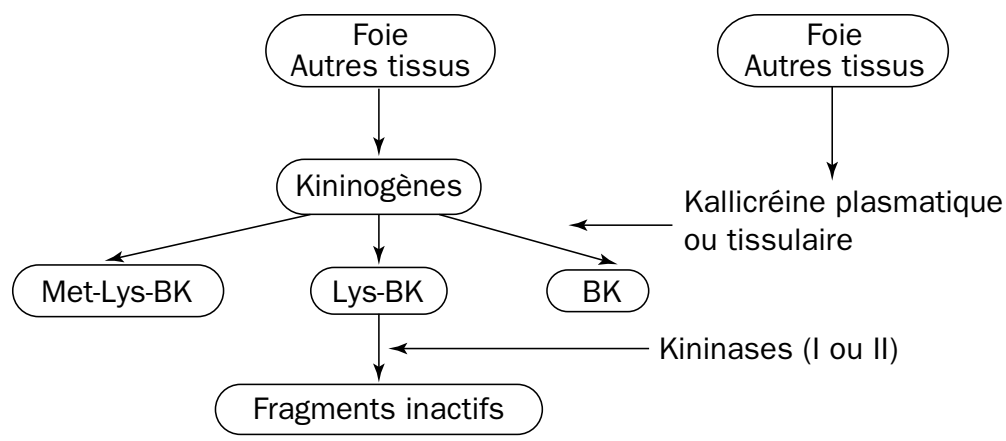

Figure 3.8 - Représentation schématique du métabolisme des kininogènes

BK : bradykinine ; Lys-BK : lysyl-bradykinine (kallidine); Met-Lys-BK : méthyl-lysyl-bradykinine. 


\subsection{LES KALLICRÉINES}

Les kallicréines appartiennent à la famille des protéases à sérine. Ces protéases présentent des structures voisines et ont tendance à cliver leurs substrats au niveau des résidus arginine. Les kallicréines plasmatique ou cellulaire induisent la production de kinines à partir des kininogènes.

\subsubsection{La kallicréine plasmatique}

\section{Structure chimique et métabolisme}

La kallicréine plasmatique $(60 \mathrm{kDa})$ est produite au niveau des hépatocytes sous la forme d'un hétérodimère inactif : la pro-kallicréine. La pro-kallicréine circulante est complexée au kininogène de haut poids moléculaire. Elle est clivée en kallicréine plasmatique active par le facteur XII activé. Le facteur XII, qui par ailleurs est impliqué dans la régulation des processus conduisant à la coagulation, est rétroactivé positivement par la kallicréine elle-même (fig. 3.9).

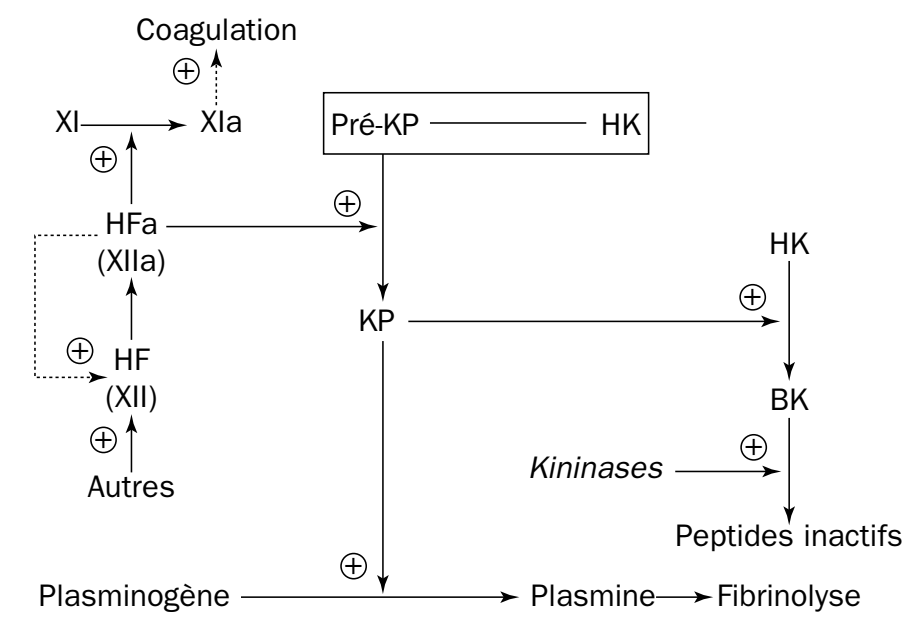

Figure 3.9 - Représentation schématique de l'activation de la pré-kallicréine (d'après Bhoola et coll., 1992)

BK : bradykinine ; HF : Hageman factor ou facteur XII ; HK : kininogène de haut poids moléculaire ; Pré-KP : pré-kallicréine plasmatique ; KP : kallicréine plasmatique.

\section{Propriétés - Rôles physiologiques}

La kallicréine plasmatique entraîne, à partir du kininogène de haut poids moléculaire, la production d'un nonapeptide, la bradykinine.

\subsubsection{Les kallicréines tissulaires}

\section{Structure chimique et métabolisme}

Les kallicréines tissulaires (24-45 kDa) ont été mises en évidence au niveau du pancréas, des glandes salivaires, du rein, du cerveau. Elles sont codées par plusieurs 
gènes portés, chez l'homme, par le chromosome 19. Dans la majorité des espèces, les kallicréines tissulaires induisent la production d'un décapeptide : la lysyl-bradykinine ou kallidine. En revanche, chez les rongeurs, l'action de la kallicréine conduit à la production de bradykinine (BK).

Ces kallicréines sont des glycoprotéines produites à partir de l'action de la trypsine et de la chémotrypsine sur un précurseur, la pro-kallicréine. Les kallicréines sont stockées dans des granules intracellulaires dont la localisation varie en fonction des types cellulaires et du rôle joué par l'enzyme. Il faut noter que les neutrophiles qui possèdent une kallicréine tissulaire présentent, en outre, sur leur membrane externe, des sites de fixation pour les kininogènes de haut et de bas poids moléculaires, ainsi que pour la kallicréine plasmatique.

\section{Propriétés - Rôles physiologiques}

La localisation tissulaire des kallicréines conduit à penser qu'elles exercent, à côté de leur propriété de kininogénase, des actions spécifiques. Ainsi, il a été montré que les kallicréines sont impliquées dans le "processing" (apprêtage) de facteurs de croissance, de certaines hormones (pro-insuline, pro-rénine), du peptide intestinal vasoactif (VIP), ainsi que dans le clivage de grosses molécules (angiotensinogène, procollagène). Les kallicréines tissulaires participent, par la synthèse de kinines actives, à la régulation des débits sanguins locaux. De plus, il est maintenant admis que les kallicréines tissulaires peuvent se retrouver dans la circulation où elles joueraient un rôle similaire à celui de la kallicréine plasmatique. La source principale de ces kallicréines tissulaires circulantes semble être le rein. Toutefois, leur libération en fin de cycle cellulaire, lors de la lyse des neutrophiles, pourrait être une source nonnégligeable d'enzyme. Enfin, il a été montré que les cellules musculaires lisses vasculaires possèdent les éléments de l'ensemble de ce système (kallicréine, kininogènes, kinines, kininases), ce qui laisse supposer, via une action autocrine, un rôle possible dans la régulation du tonus vasculaire.

\subsection{LES KININOĠ̀NES}

\subsubsection{Structure chimique et métabolisme}

Si la source majeure des kininogènes est le foie, la présence de kininogènes et celle des ARNm correspondants ont été montrées au niveau du rein, des cellules endothéliales humaines et des plaquettes. Les kininogènes sont synthétisées par les hépatocytes sous la forme de glycoprotéines. Outre un kininogène spécifique (le T-kininogène), présent uniquement chez le rat, il existe deux types de kininogènes : l'un de haut poids moléculaire (110000), l'autre de bas poids moléculaire (68 000). De plus, ces kininogènes diffèrent par leur structure spatiale (le kininogène de haut poids moléculaire est constitué de six domaines ; le kininogène de bas poids moléculaire est, lui, constitué de quatre domaines), ainsi que par leur sensibilité aux kallicréines (voir plus haut) ; enfin, le T-kininogène est clivé non par une kallicréine, 
mais par la trypsine. Comme l'indique la figure 3.10, les deux kininogènes sont constitués de trois chaînes, une chaîne de haut poids moléculaire et une de bas poids moléculaire séparées par la bradykinine.

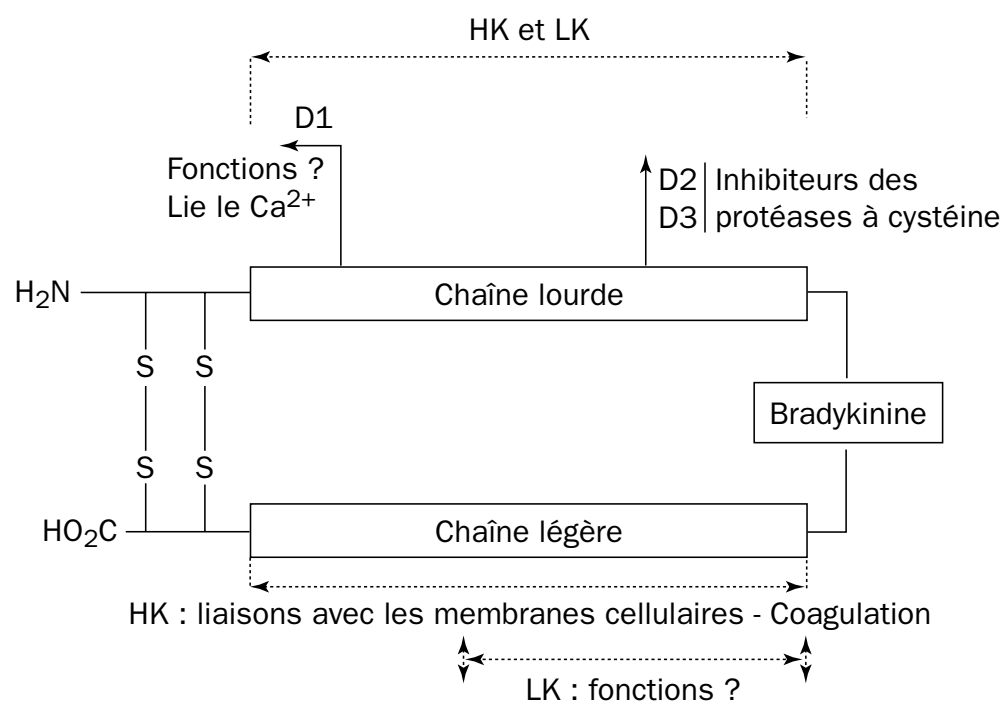

Figure 3.10 - Représentation schématique des molécules de kininogènes (d'après Carbini et coll., 1993)

La chaîne lourde constituée de trois domaines (D1, D2, D3) est identique pour les kininogènes de haut poids moléculaire (HK) et de bas poids moléculaire (LK). En revanche, la différence entre ces deux kininogènes porte sur la structure de la chaîne légère, constituée de deux domaines dans le cas du HK et d'un seul dans celui du LK. Plusieurs ponts disulfures lient les chaînes entre elles.

\subsubsection{Rôles physiologiques}

Les kininogènes, en tant que précurseurs des kinines, jouent un rôle fondamental dans la régulation du tonus vasculaire. Cependant, ils exercent d'autres rôles physiologiques importants. Ainsi, en association avec les facteurs XII et XI et la prékallicréine plasmatique, la molécule de kininogène de haut poids moléculaire est un co-facteur de la coagulation (voir fig. 3.9).

Différents types de récepteurs spécifiques pour les molécules entières ou clivées des différents kininogènes ont été mis en évidence sur différents types cellulaires (cellules endothéliales, plaquettes...). L'existence de plusieurs types de récepteurs, ainsi que le rôle des différents domaines des deux molécules de kininogènes dans l'internalisation (en particulier au niveau des cellules endothéliales) des molécules entières ou fragmentées de kininogènes (et des kinines) sont discutés.

Comme le montre la figure 3.10, la structure de la chaîne lourde des deux types de kininogène est identique. Cette chaîne est constituée de trois domaines. Les domaines D2 et D3 sont des inhibiteurs des protéases à cystéine. Bien qu'il ait été montré que le 
domaine D1 peut lier le calcium, son rôle est inconnu. Les kininogènes diffèrent par leur chaîne légère : le rôle de la chaîne légère de kininogène de faible poids moléculaire (LK) est inconnu. En revanche, la chaîne légère du kininogène de haut poids moléculaire (HK) est impliquée dans la fixation membranaire du HK, ainsi que dans le rôle joué par le HK dans les processus conduisant à la coagulation.

\subsection{LES KININASES}

Les kinines sont rapidement inactivées (quelques dizaines de secondes) par des kinases appelées kininases. Deux familles de kininases (KI et KII) clivent la bradykinine. Les kininases KI (KI-CPN et KI-CPM) clivent la bradykinine au niveau de l'arginine terminale pour donner un résidu actif sur les récepteurs BK1. Les kininases KII (KII-ACE et KII-NEP) sont des peptidases qui clivent la bradykinine au niveau du $8^{e}$ AA de la terminaison carboxylique. A côté de ces deux types de kininases, on connait deux kininases tissulaires (A et B), une aminopeptidase clivant la méthyl-lysyl-bradykinine au niveau du résidu méthionine, une autre clivant la lysbradykinine au niveau du résidu lysine et une troisième clivant le résidu arginine initial de la bradykinine (tab. 3.1).

\subsection{LES KININES}

\subsubsection{Structure chimique et métabolisme}

Les kinines sont des peptides actifs produits par l'action des kinigénases sur les kininogènes. Il est généralement admis que la kallidine est produite par l'action de la kallicréine tissulaire sur le kininogène de faible poids moléculaire, alors que la bradykinine est produite par l'action de la kallicréine plasmatique sur le kininogène de haut poids moléculaire. Différentes aminopeptidases peuvent convertir la kallidine ou Lys-BK en BK. Un analogue endogène de la bradykinine, la Met-Lys-BK, est formé par l'action de la pepsine et de l'uropepsine sur les kininogènes. L'existence d'autres kinines présentes chez les Mammifères a été rapportée (T-kinine, Met-Tkinine). De plus, il a été montré que les kinines des Mammifères possèdent beaucoup d'homologies avec les kinines présentes dans les venins d'insectes et de reptiles, la peau des amphibiens, ainsi qu'avec les kinines des oiseaux.

Le taux de bradykinine circulante est estimé entre 3,8 et $50 \mu \mathrm{g} / \mathrm{ml}$ (dispersion des mesures liée aux techniques de dosage). L'action très efficace des kininases fait que les actions biologiques de la bradykinine circulante et de la kallidine sont de courte durée (demi-vie de 15 à $30 \mathrm{~s}$ ).

Les deux kinines des Mammifères (kallidine et bradykinine) sont impliquées dans les mécanismes de l'inflammation, la régulation de la pression artérielle et des débits sanguins locaux, le métabolisme du glucose et des électrolytes, ainsi que dans la différenciation et la prolifération cellulaires. 


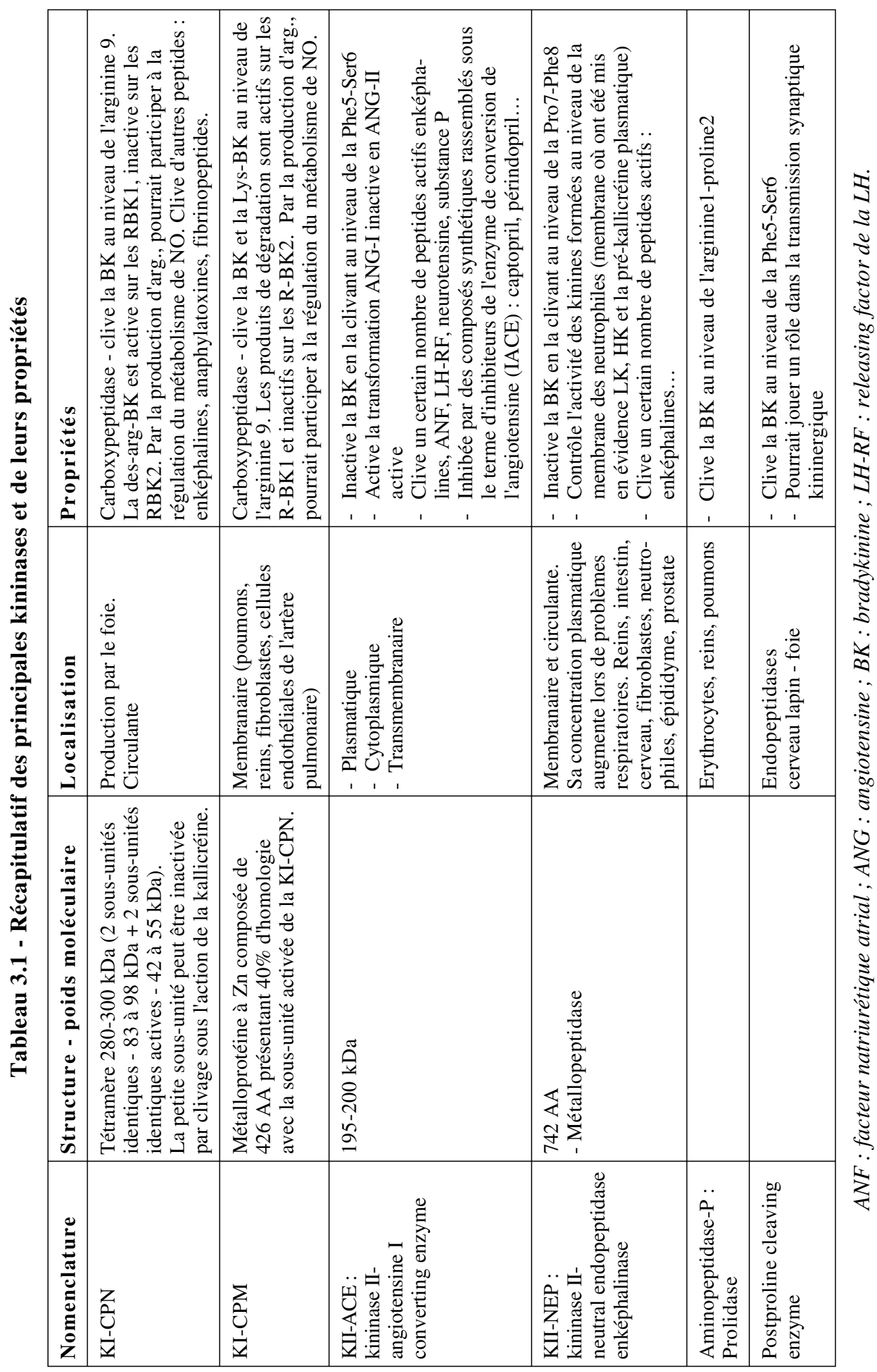


Ces actions résultent soit d'un effet direct mettant en jeu des récepteurs membranaires spécifiques, soit de la libération d'autres messagers (platelet activating factor [PAF], métabolites de l'acide arachidonique, neuromédiateurs...).

\subsubsection{Les récepteurs des kinines}

A la suite de nombreux travaux utilisant différents types de préparation (aorte, veine mésentérique, jugulaire, duodénum), ainsi que le clivage de la molécule de BK et/ou la substitution de divers acides aminés, il a été distingué pour les kinines deux types de récepteurs à sept domaines transmembranaires : les récepteurs BK1 (R-BK1) et BK2 (R-BK2).

Les récepteurs BK1 semblent, dans les conditions non-pathologiques, être peu présents, voire absents. Cependant, leur densité augmente (en particulier sur les fibroblastes et les cellules musculaires lisses) dans les situations d'agression telles que celles conduisant à la réponse inflammatoire.

C'est par l'activation des récepteurs BK2 que les effets intracellulaires de la bradykinine et de la kallidine s'expriment. Il a été suggéré l'existence, en particulier au niveau de l'épithélium pulmonaire, de récepteurs BK3, de même que celle de soustypes de récepteurs K2 (R-K2-A ; R-K2-B) au niveau du cerveau, des fibroblastes et de l'épithélium intestinal.

Les récepteurs BK1 et BK2 sont couplés via des protéines G (dont la nature n'a pas été, dans tous les cas, clairement explicitée) à des phospholipases $\mathrm{A} 2$ et $\mathrm{C}$ (fig. 3.11). La grande variété de seconds messagers qui peuvent être ainsi synthétisés, ainsi que l'action autocrine de certains d'entre eux (en particulier des dérivés de l'acide arachidonique), alliées à l'augmentation de calcium libre intracellulaire, peuvent conduire à des effets variables selon le type cellulaire et la densité relative des couplages avec l'une ou l'autre des phospholipases (fig. 3.11 et tab. 3.2).

Dans certains types cellulaires (comme les cellules endothéliales vasculaires) possédant une NO synthase constitutive (activable par le calcium), la stimulation de récepteurs couplés à une PLC et la production d'arginine via le métabolisme des kinines (voir plus haut) peuvent conduire à la stimulation de la synthèse de NO (fig. 3.11).

C'est principalement par son action sur le métabolisme calcique des cellules endothéliales (voir plus loin), que s'exerce l'effet vaso-dilatateur de la BK. Celle-ci pourrait stimuler la libération du facteur hyperpolarisant dérivé de l'endothélium (EDHF). Ce facteur, de nature inconnue (probablement du potassium), provoque la fermeture des canaux calciques sensibles au voltage, induisant ainsi la relaxation des cellules musculaires lisses. 
Tableau 3.2 - Récepteurs membranaires des kinines, cellules impliquées, rôles et voies de traduction (d'après Caroline Lagneux, 1999, com. pers.)

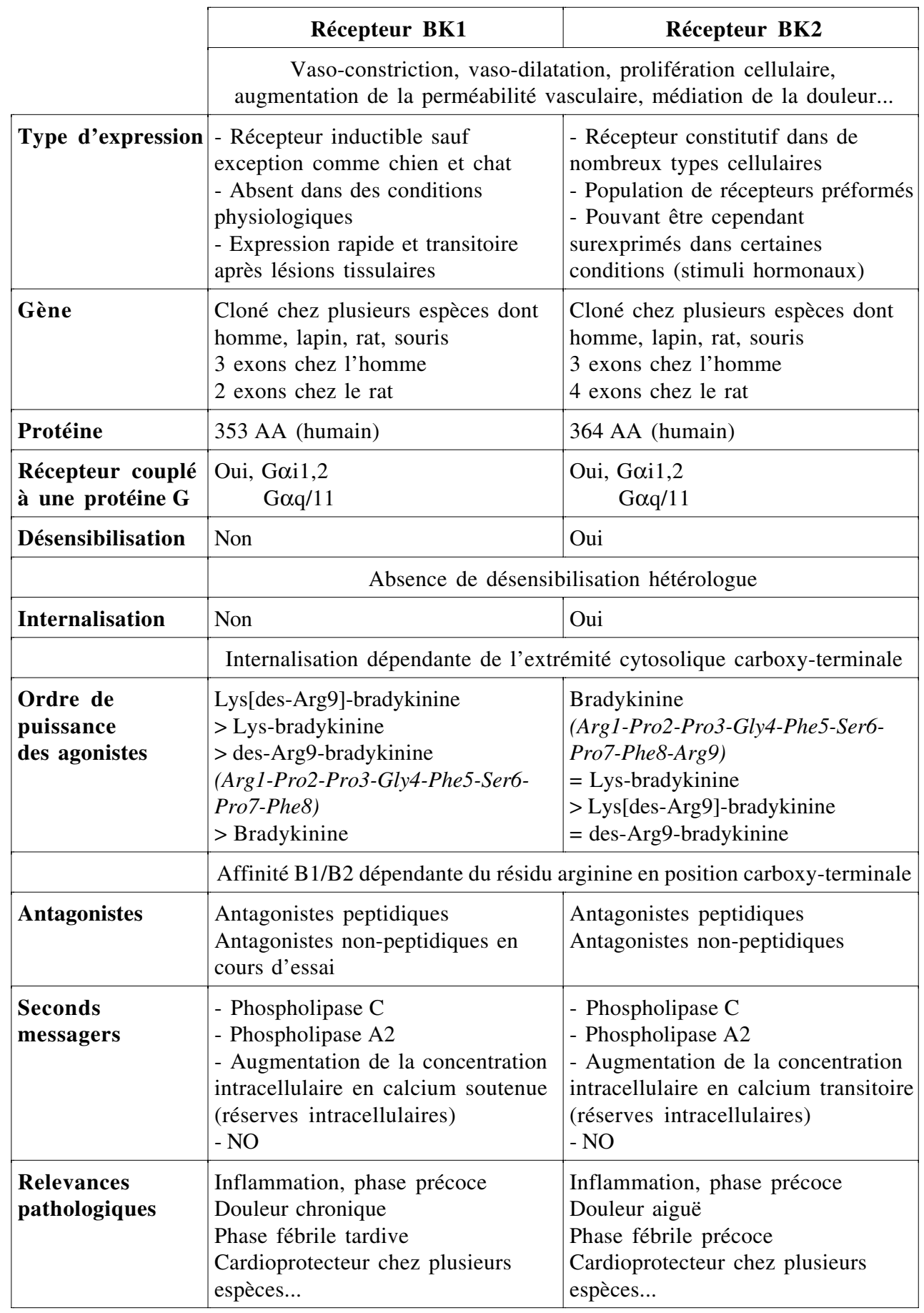




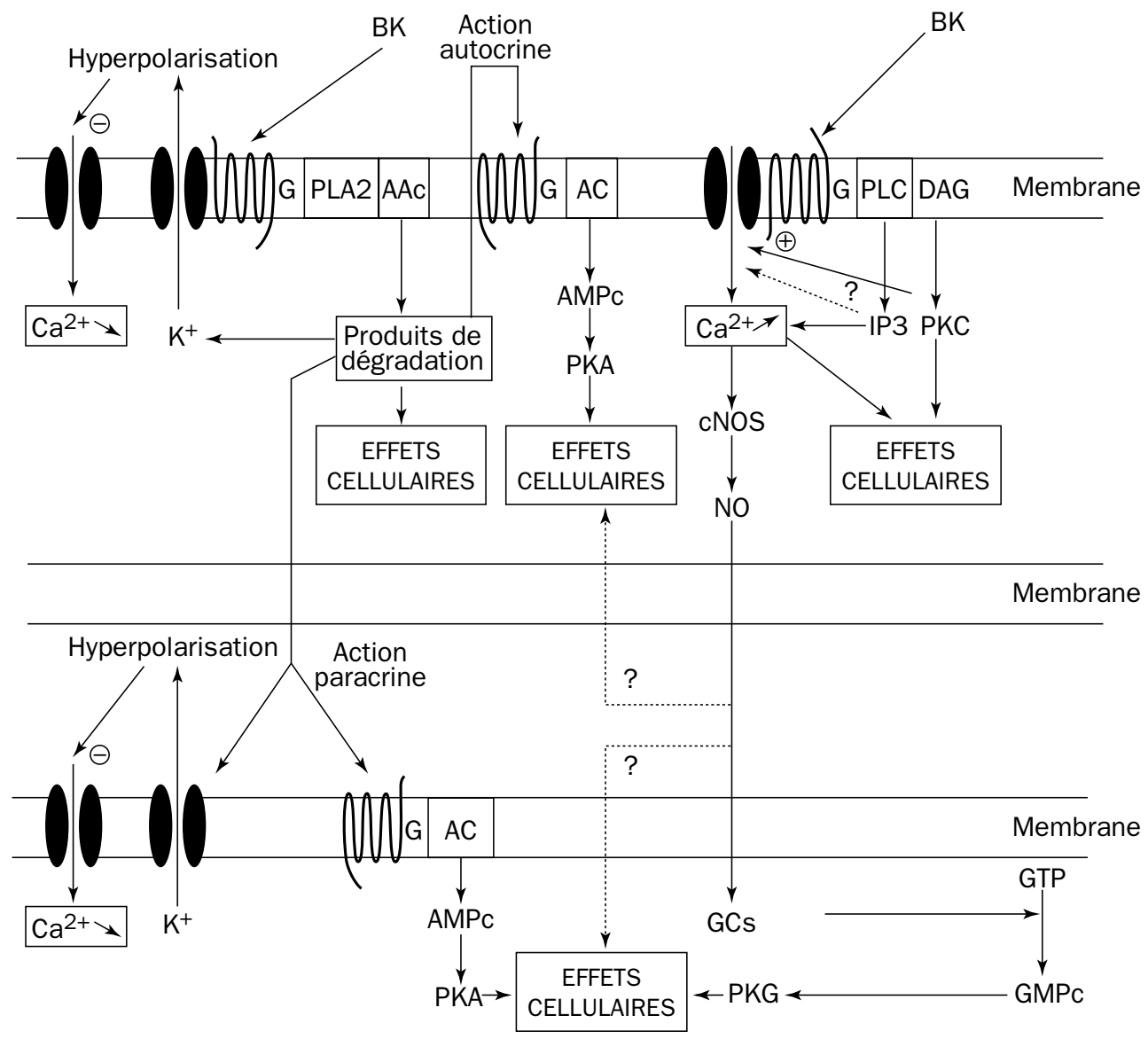

Figure 3.11 - Représentation schématique des effets de l'activation des récepteurs BK2 $A A c$ : acide arachidonique; $A C$ : adénylate cyclase ; $A M P c$ : adénosine monophosphate cyclique; DAG : diacylglycérol; GCs : guanylate cyclase soluble; GMPc: guanosine monophosphate cyclique ; IP3 : inositol $(1,4,5)$ triphosphate ; PKA : protéine kinase $A$; PKC : protéine kinase $C$; PLA2 : phospholipase A2; PLC: phospholipase $C$; VOC: voltage operated channel.

Le type de couplage (type de protéines G) du récepteur BK2 avec ses effecteurs cellulaires (PLC-PLA) varie suivant le type cellulaire. II en résulte une proportion différente de la nature et/ou de la quantité des seconds messagers synthétisés et, par là, des effets cellulaires différents. En outre, suivant la voie de dégradation mise en jeu, les dérivés de l'acide arachidonique peuvent être, eux aussi, de nature et de quantité variables, et vont conduire à des effets cellulaires divers (voir chap. 2, § 2.2.7). De plus, ces dérivés peuvent agir de façon autocrine et/ou paracrine. Dans le cas d'une action autocrine, suivant le dérivé synthétisé, le récepteur mis en jeu peut moduler l'activité cellulaire via la stimulation (ou l'inhibition) de la synthèse de seconds messagers tels que I'AMPC. Dans le cas de cellule possédant une NO synthase constitutive, cNOS (voir $\S$ 3.2.1), l'augmentation de la teneur en calcium libre intracellulaire peut conduire à la stimulation de la synthèse de NO. Cette production de NO peut conduire à son tour (action paracrine) à la synthèse de GMPc via l'activation d'une GCs (guanylate cyclase soluble), GMPc qui, dans le cas des cellules musculaires vasculaires, provoquera une relaxation (voir chap. $2, \S 2.2 .2$ ). 


\subsubsection{Rôles physiologiques}

\section{Actions sur le système cardio-vasculaire}

La bradykinine est connue essentiellement par son action sur le système cardio-vasculaire. Elle agit au niveau des vaisseaux et du myocarde.

\section{Action sur les vaisseaux}

La bradykinine exerce un effet vaso-dilatateur puissant qui, in vivo, provoque une forte hypotension. Cet effet résulte de la libération par l'endothélium du NO, du facteur hyperpolarisant (EDHF), de diverses prostaglandines et du PAF. Cet effet vaso-dilatateur s'observe in vivo et in vitro sur les coronaires, d'où l'intérêt des inhibiteurs de l'enzyme de conversion de l'angiotensine (IACE) qui limitent la dégradation de la bradykinine. D'une façon analogue à ce qui est rapporté pour d'autres messagers dont l'action vaso-dilatatrice dépend de l'endothélium, la bradykinine exerce, en l'absence d'endothélium, un effet constricteur direct sur les cellules musculaires lisses. Cet effet résulte principalement de la libération, sous l'action de l'IP3, du calcium du réticulum. En outre, l'activation de la PKC, l'éventuelle synthèse d'AMPc résultant de la production de prostaglandines et l'activation de la PKA qui en résulte, conduisent à des modifications profondes de la physiologie des cellulaires musculaires vasculaires. Ces modifications, comme le montre la figure 3.12 peuvent entraîner un remodelage vasculaire pathologique. Il faut noter que les cellules endothéliales, ainsi que les cellules musculaires lisses vasculaires, possèdent une partie et/ou la totalité de l'équipement enzymatique nécessaire au métabolisme des kinines et des kininogènes. La part prise par cet équipement enzymatique dans le métabolisme de la BK (de même que dans celui de l'angiotensine) est mal connue. De ce fait, il semble admis que les effets hypotenseurs des inhibiteurs de l'enzyme de conversion de l'angiotensine (ACE), qui inhibent la transformation de BK active en BK inactive, passent, en majorité, par l'inhibition de l'ACE portée par l'endothélium, et non par celle de l'ACE plasmatique.

\section{Action sur le cour}

Les cellules myocardiques possèdent l'équipement enzymatique nécessaire à la production de kinines. Toutefois, nous ne disposons pas de données précises quant à la part respective de ces cellules, des endothéliums vasculaire et cardiaque et des cellules neutrophiles (en particulier lors d'ischémie ou d'infarctus du myocarde) dans la production locale de bradykinine. L'action directe de la bradykinine sur les myocytes cardiaques en culture ou isolés conduit à une forte augmentation de la teneur en calcium libre intracellulaire. Sur le cœur isolé et perfusé, les kinines stimulent le rythme et la force des contractions, ainsi que le débit cardiaque. Les inhibiteurs de l'ACE ou l'infusion de bradykinine exercent un effet protecteur contre les altérations cardiaques induites par l'ischémie. En particulier, le statut énergétique est préservé et, lors de la reperfusion post-ischémique, le débit cardiaque est augmenté alors que la fréquence d'apparition des arythmies est diminuée. 


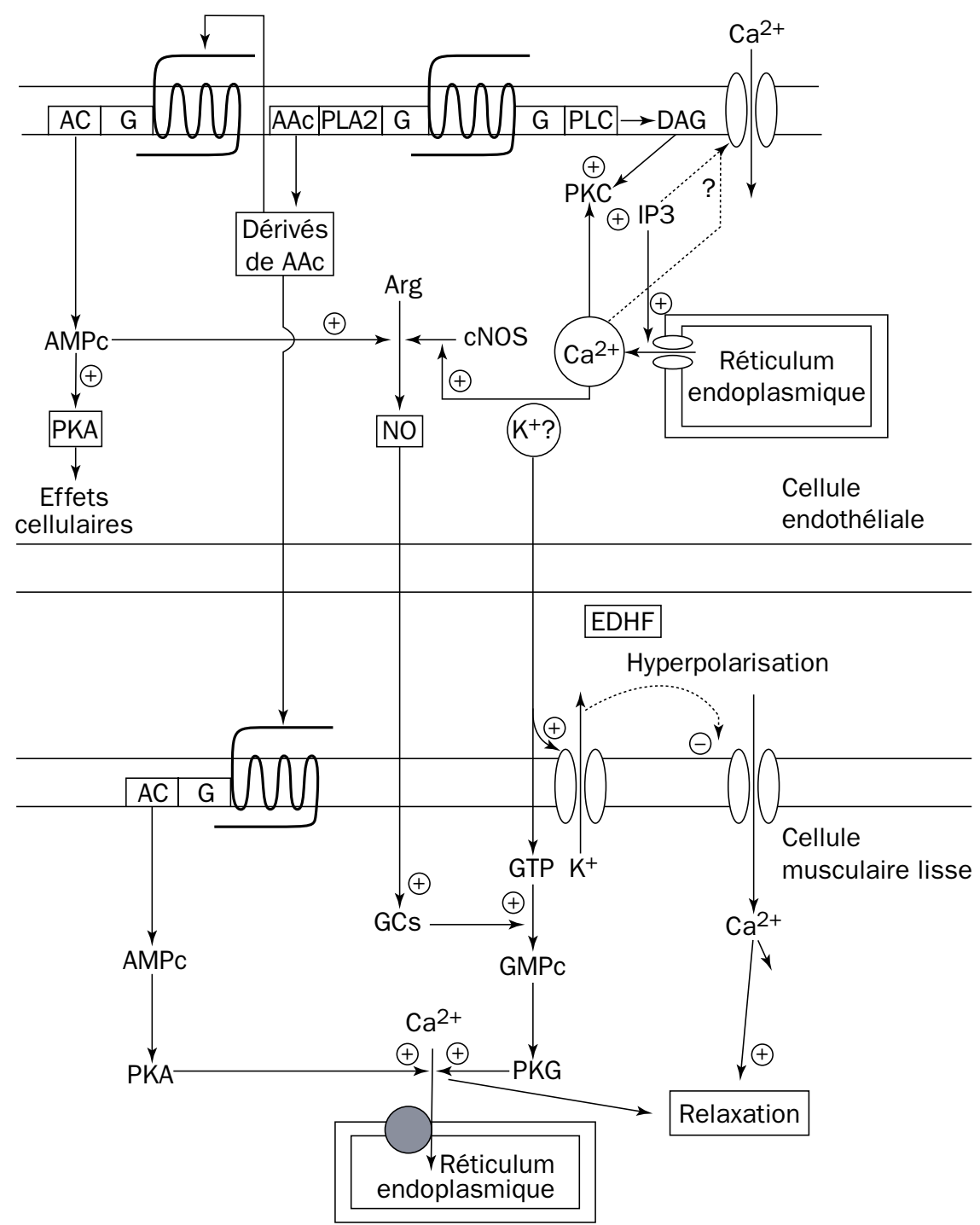

Figure 3.12.a - Représentation schématique des effets de la bradykinine sur les cellules endothéliales vasculaires

$A A c$ : acide arachidonique ; $A C$ : adénylate cyclase ; $A M P C$ : adénosine monophosphate cyclique ; Ang II : angiotensine II ; BK : bradykinine ; DAG : diacylglycérol ; Et1 : endothéline 1 ; G : protéine G ; GMPc : guanosine monophosphate cyclique ; GTP : guanosine triphosphate ; IP3 : inositol $(1,4,5)$ triphosphate ; MAPK : mitogen activated protein (MAP) kinase; MEK : MAP kinase-kinase ; PLA : phospholipase A ; PLC : phospholipase $C$

En présence d'endothélium, la bradykinine induit une vaso-dilatation médiée par NO, des dérivés de l'acide arachidonique, et peut-être le facteur hyperpolarisant (potassium ?). Lorsque la stimulation est intense, la contraction des cellules endothéliales des capillaires, provoquée par une augmentation massive de la teneur en calcium libre intracellulaire, alliée à la libération des dérivés de l'acide arachidonique, peut conduire à un état de choc (hypotension - extravasion). 


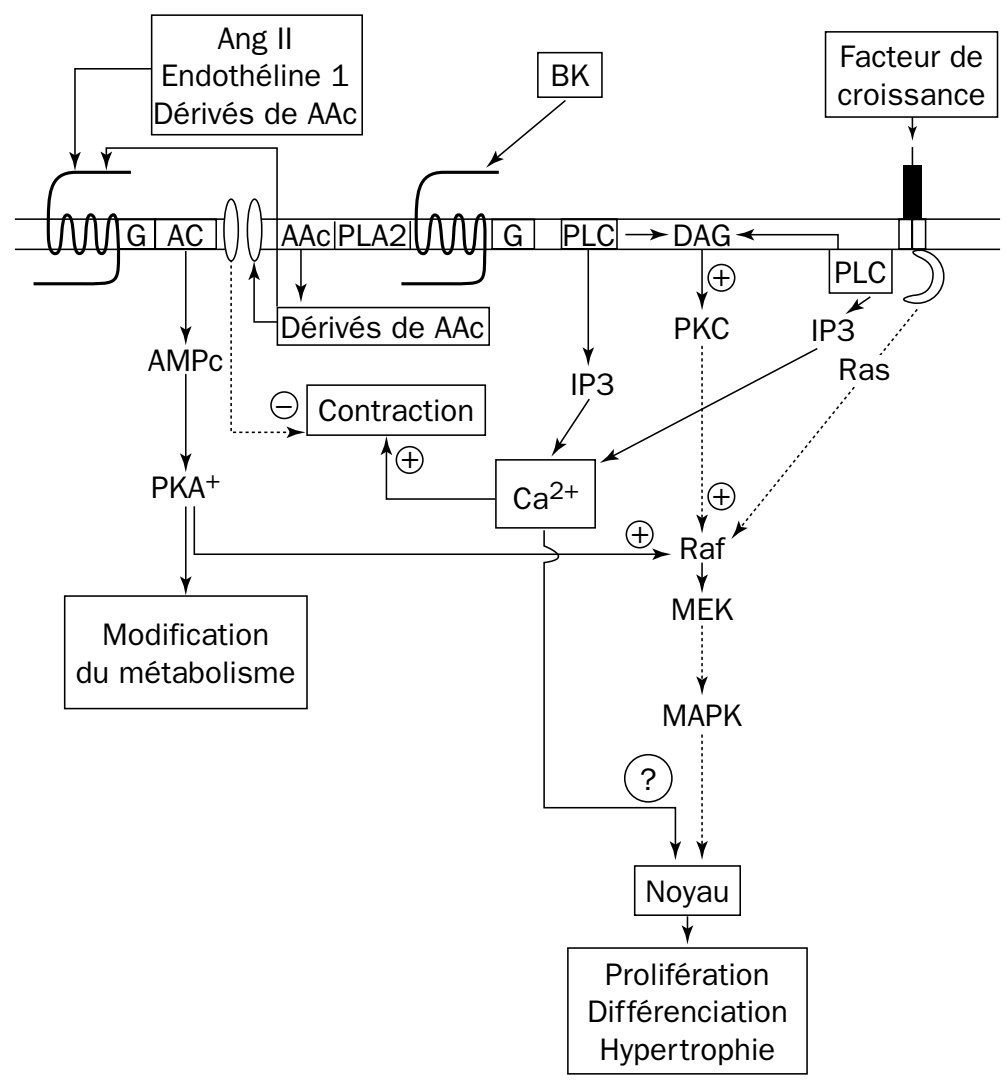

Figure 3.12.b - Représentation schématique des effets de la bradykinine sur les cellules musculaires lisses vasculaires

En l'absence d'endothélium, la bradykinine, comme d'autres messagers tels que la thrombine, l'angiotensine, l'endothéline, provoque la contraction des cellules musculaires lisses et exerce une action co-mitogène conduisant à leur prolifération et à leur différenciation. Le remodelage vasculaire qui en résulte peut conduire à des pathologies (hypertension - thrombose).

Ces observations sont à mettre en parallèle avec le fait que, lors de ligatures expérimentales de l'artère coronaire, ou chez des patients présentant un infarctus du myocarde, le taux plasmatique de kinines augmente alors que celui du kininogène diminue.

Enfin, chez un grand nombre d'espèces, l'application épicardiale de bradykinine entraine une activation des terminaisons végétatives. Elle peut provoquer une tachycardie et l'augmentation de la pression sanguine conduisant, dans certains cas, par voie réflexe, à une bradycardie génératrice d'une importante diminution de la pression sanguine.

\section{Action au niveau rénal}

La présence de kallicréine tissulaire, de kininogène et de kinines (bradykinine, lysylbradykinine, méthyl-lysyl-bradykinine) a été mise en évidence dans l'urine humaine. 
L'étude chez l'animal a permis de montrer que plus de $90 \%$ de la kallicréine est produite par certaines cellules du cortex rénal. La kallicréine rénale peut agir sur le kininogène produit par les cellules du tubule et/ou le kininogène circulant au niveau des capillaires, et ainsi conduire à la production de kinines qui seront retrouvées dans les urines et dans la circulation, et vont agir localement. Les kinines ainsi produites vont agir, d'une part, sur le système circulatoire rénal (vaso-dilatation médullaire et glomérulaire) et, d'autre part, sur le métabolisme hydrominéral en diminuant la réabsorption d'eau et de $\mathrm{Na}^{+}$. Par ailleurs, la kallicréine rénale peut agir sur la prorénine pour produire la rénine (fig. 3.13).

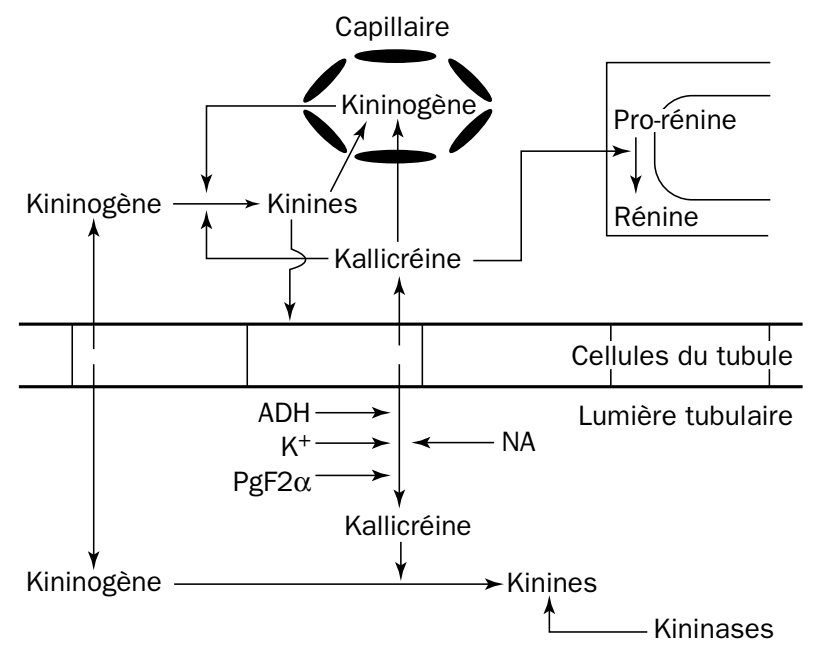

Figure 3.13 - Le système rénal kallicréine-kinine

L'action des kinines produites au niveau rénal conduit, via l'activation de récepteurs BK1 et BK2, à une vaso-dilatation locale, ainsi qu'à une augmentation de la natriurèse et de la diurèse.

\section{Autres effets biologiques des kinines}

Outre leurs actions au niveau des reins et du système cardio-vasculaire, les kinines exercent de nombreux autres effets biologiques.

\section{Action des kinines sur le système nerveux}

La présence de récepteurs à la BK2 a été mise en évidence au niveau des différentes régions du cerveau, en particulier au niveau des centres régulateurs de l'activité cardio-vasculaire. Cette action passerait par la régulation de la libération d'amines (noradrénaline, sérotonine). De plus, la BK est directement impliquée, au niveau central, dans la conduction d'informations nociceptives (fibres A et C). Par ailleurs, l'injection intraventriculaire de bradykinine entraîne une vaso-dilatation des vaisseaux cérébraux, ce qui induit une augmentation de la pression artérielle et une réduction de la production d'hormone antidiurétique. Le rôle éventuel de la bradykinine dans le développement des œdèmes cérébraux et la maladie d'Alzheimer reste à démontrer. 


\section{Action des kinines sur les leucocytes}

Les leucocytes humains possèdent deux kallicréines, l'une capable d'agir sur un kininogène spécifique, le leucokininogène, et une seconde, proche de la kallicréine plasmatique, active sur les kininogènes plasmatiques. La production de kinines, ainsi que l'induction par ces substances de la libération d'interleukine 1 par les monocytes, conduit à penser que les kinines sont impliquées lors de la réponse inflammatoire dans l'adhérence, la diapédèse et la migration des monocytes.

Action des kinines sur les muscles lisses (autres que vasculaires) et les épithéliums

Les kinines provoquent la contraction de l'utérus, du colon, de l'iléon et des bronches. Au niveau des épithéliums, les kinines stimulent la sécrétion de $\mathrm{Cl}^{-}$et de mucus. Ces mécanismes mettent en jeu les deux types de récepteurs des kinines.

Par ailleurs, les kinines stimulent la production de bicarbonate par la vésicule biliaire et modulent le contenu en eau et sodium de la sueur.

\section{Les kinines et la reproduction}

L'activation des récepteurs de type BK2 stimule la mobilité des spermatozoïdes, induit la contraction de l'utérus et est impliquée dans la rupture du follicule ovarien. En outre, il a été mis en évidence, au niveau de l'hypophyse antérieure et intermédiaire, une enzyme analogue à la kallicréine tissulaire. Cette enzyme, ainsi que les kinines (de même que l'angiotensine II), pourraient intervenir dans la modulation de la sécrétion de prolactine.

\subsection{CONCLUSION ET PERSPECTIVES}

Un certain nombre de pathologies (allergie, asthme, arthrite, œdème) semblent être corrélées avec une hyperproduction de kinines et/ou l'expression d'un nombre anormalement élevé de récepteurs. En particulier des récepteurs BK1 dont l'expression est stimulée par les cytokines. En revanche, il n'a pas été démontré de relation nette entre certains types d'hypertension et une hypoproduction de bradykinine ou du nombre (et/ou de l'efficacité) des récepteurs. Néanmoins, l'action bénéfique exercée par les inhibiteurs de l'enzyme de conversion de l'angiotensine (qui sont aussi des inhibiteurs des kinases) sur certains types d'hypertension, sur l'athérosclérose, ainsi que sur les altérations liées à la reperfusion post-ischémique, suggère un rôle possible de la bradykinine.

L'ensemble des données actuelles ne permet pas de déterminer avec précision le rôle respectif des récepteurs BK1, BK2 (et éventuellement des autres types ou sous-types de récepteurs) dans ces situations. De l'ensemble des données cliniques et expérimentales, découlent des interrogations quant au rôle bénéfique et/ou délétère des kinines. Il se peut que la réponse ne soit pas univoque et que, comme dans le cas de $\mathrm{NO}$, la bradykinine soit un médiateur à deux visages. 


\section{LE MONOXYDE D’AZOTE : NO}

Le monoxyde d'azote est - probablement avec $\mathrm{CO}$ - la plus petite biomolécule présentant des propriétés de messager chimique. Il est synthétisé par une grande variété de types cellulaires des Invertébrés aux Mammifères. Depuis la mise en évidence, par Furchgott et Zawadski, en 1980, que la vaso-dilatation induite par l'acétylcholine nécessite la mise en jeu d'un facteur relaxant libéré par l'endothélium (l'endothelium derived relaxing factor ou EDRF) et l'identification de ce facteur à NO (Moncada et coll., 1987), il a été montré que le monoxyde d'azote est impliqué dans un grand nombre de processus physiologiques ou physiopathologiques. Processus aussi complexes que les mécanismes de vaso-dilatation, de neurotransmission, de transcription génétique ou de réaction inflammatoire et immunitaire.

\subsection{PROPRIÉTÉS PHYSICO-CHIMIQUES}

A température et pression ambiantes, le monoxyde d'azote est un gaz coloré, sa solution dans l'eau est de l'ordre de celle de l'oxygène $\left(2-3 \mathrm{mM}, 20^{\circ} \mathrm{C}, 1 \mathrm{~atm}\right)$. C'est une molécule non-polaire qui peut facilement franchir les membranes biologiques car il est aussi soluble dans les lipides. Du fait de sa forte réactivité, sa durée de vie dans les milieux biologiques est courte (quelques secondes) et sa capacité de diffusion estimée à quelques fractions de millimètre.

NO comporte un nombre impair d'électrons, ce qui lui confère la nature d'un radical libre $\left[\mathrm{NO}^{\circ}\right]$ présentant des propriétés paramagnétiques. La structure électronique de NO (fig. 3.14) lui permet d'être considéré soit comme une base, soit comme un acide de Lewis. De plus, suivant l'environnement rédox, il sera oxydant ou réducteur.

$$
\ddot{*} \cdot \ddot{\cdot} \cdot \ddot{0} \rightarrow \ddot{N}:: \ddot{0}:
$$

Figure 3.14 - NO : structure de Lewis

$\mathrm{NO}$ peut réagir avec $\mathrm{O}_{2}$ pour former le dioxyde d'azote $\mathrm{NO}_{2}$. Si, dans l'air, le produit terminal est bien le gaz $\mathrm{NO}_{2}$, en solution aqueuse, $\mathrm{NO}_{2}$ se décompose en nitrite $\mathrm{NO}_{2}{ }^{-}$et nitrate $\mathrm{NO}_{3}{ }^{-}$(fig. 3.15). En présence du radical $\left[\mathrm{O}_{2}{ }^{-}\right]$, $\mathrm{NO}$ réagit pour former un intermédiaire instable, l'anion peroxynitrite $\mathrm{ONOO}^{-}$. L'anion peroxynitrite est un générateur de radical $\left[\mathrm{OH}^{*}\right]$ et un puissant oxydant qui pourrait être, en partie, le vecteur de la toxicité de NO.

Dans des conditions de température et de $\mathrm{pH}$ physiologiques, $\mathrm{NO}$ est capable de réagir avec les groupements thiols pour donner des thionitrites ou S-nitroso-thiols (S-NO). Les S-nitroso-thiols peuvent être formés, en particulier, au niveau de protéines portant des groupes thiols (fig. 3.15) (sérum albumine, cathepsine B, glutathion, hémoglobine...). Ces S-nitroso protéines sont particulièrement stables et, pour certaines, sont considérées comme des donneurs de NO. En particulier, il a été 
démontré récemment que la S-nitro-hémoglobine formée au niveau des poumons peut libérer $\mathrm{NO}$ au niveau des vaisseaux et pourrait ainsi participer à la régulation de la pression artérielle.

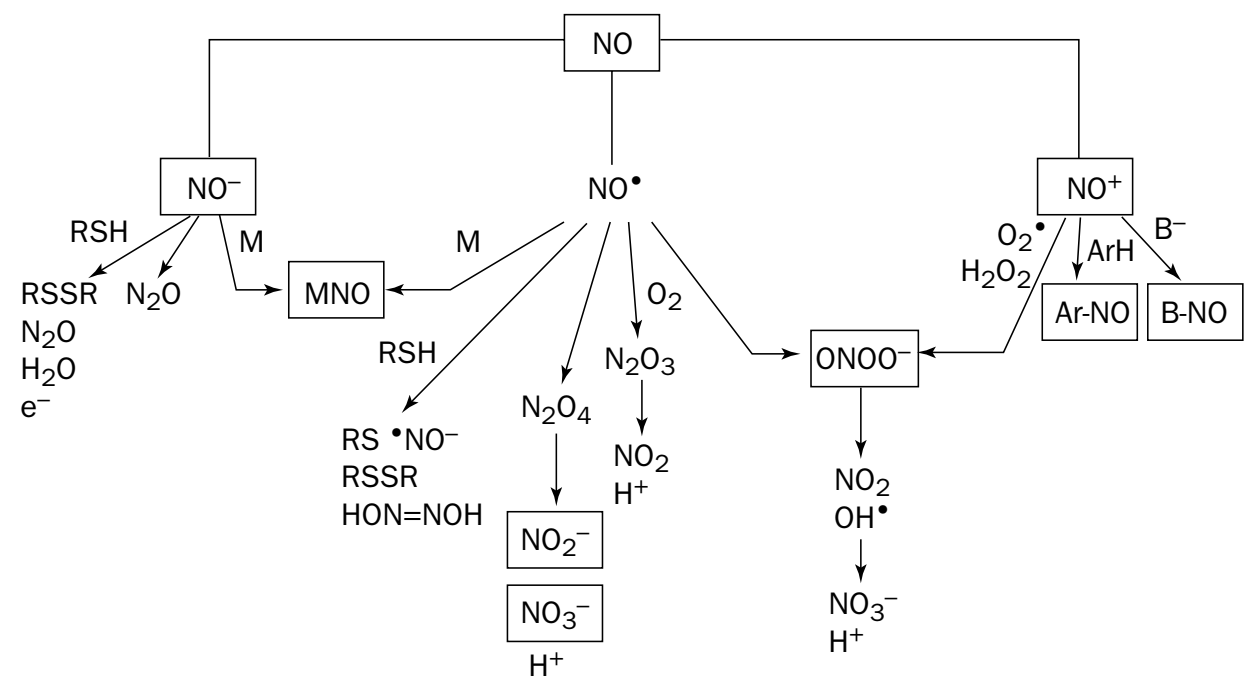

Figure 3.15 - Représentation des réactions possibles de NO sous forme d'anion, de radical et de cation

NO anion peut réagir avec des thiols pour donner des composés qui, finalement, conduisent à la production de disulfites. Ceux-ci vont produire de l'oxyde nitreux et de l'eau. NO, sous la forme anionique ou radicalaire, peut réagir avec des métaux (M) pour donner des métallo-nitro-complexes (M-NO). La dimérisation spontanée de $\mathrm{NO}^{-}$induit la formation de $\mathrm{NO}_{2}{ }^{-}$, et la réaction de l'acide correspondant sur un groupe thiol déclenche la formation de disulfite et d'acide hyponitreux. Les mêmes produits sont formés lors de la réaction de NO radicalaire sur les thiols. En outre, $\mathrm{NO}^{\bullet}$ peut se lier à l'oxygène pour donner des nitrites et des nitrates, et avec l'oxygène radicalaire pour produire l'anion peroxynitrite générateur de $\mathrm{OH}^{-}$. Le cation $\mathrm{NO}^{+}$peut être oxydé par $\mathrm{H}_{2} \mathrm{O}_{2}$ pour produire, lui aussi, l'anion peroxynitrite. De plus, $\mathrm{NO}^{+}$peut donner des réactions de nitrosation avec des composés aromatiques $(\mathrm{ArH})$ ou des bases $\left(\mathrm{B}^{-}\right)$comme les amines.

Un des aspects les plus importants de la chimie de NO est sa capacité à réagir avec des métaux et, en particulier, les métalloprotéines (voir fig. 3.15). Ainsi, NO réagit avec les hémoprotéines (hémoglobine, guanylate cyclase, NO synthases, prostaglandine $\mathrm{H}$ synthase), les protéines impliquées dans le métabolisme du fer (ferritine, ferroxydases, transferrine, le récepteur à la transferrine, l'iron responsive factor), les oxydoréductases du métabolisme de $\mathrm{O}_{2}$ et $\mathrm{O}_{2}{ }^{\cdot-}$ (la céruloplasmine, les superoxydes dismutases à $\mathrm{Cu}-\mathrm{Zn}$, à fer, à Mn).

La formation de liaisons de coordination entre $\mathrm{NO}$ et le centre métallique de ces protéines conduit à des modifications importantes de leurs propriétés. Ainsi, dans certains cas, ces modifications provoquent le passage de l'état inactif à l'état actif (guanylate cyclase soluble), dans d'autres elles conduisent à des altérations qui pourraient être à l'origine d'une partie des propriétés cytotoxiques du NO. 


\subsection{BIOSYNTHÈSE ET DONNEURS DE NO}

\subsubsection{Biosynthèse de NO}

$\mathrm{Si}$, chez les microbes, NO peut être produit par la réduction des nitrites ou l'oxydation de l'ammoniaque, la synthèse de NO chez les Mammifères résulte, quant à elle, de processus différents : la L-arginine est oxydée par des NO synthases (NOS), constitutives (cNOS) ou inductibles (iNOS), en NO et L-citrulline (fig. 3.16 et 3.17).

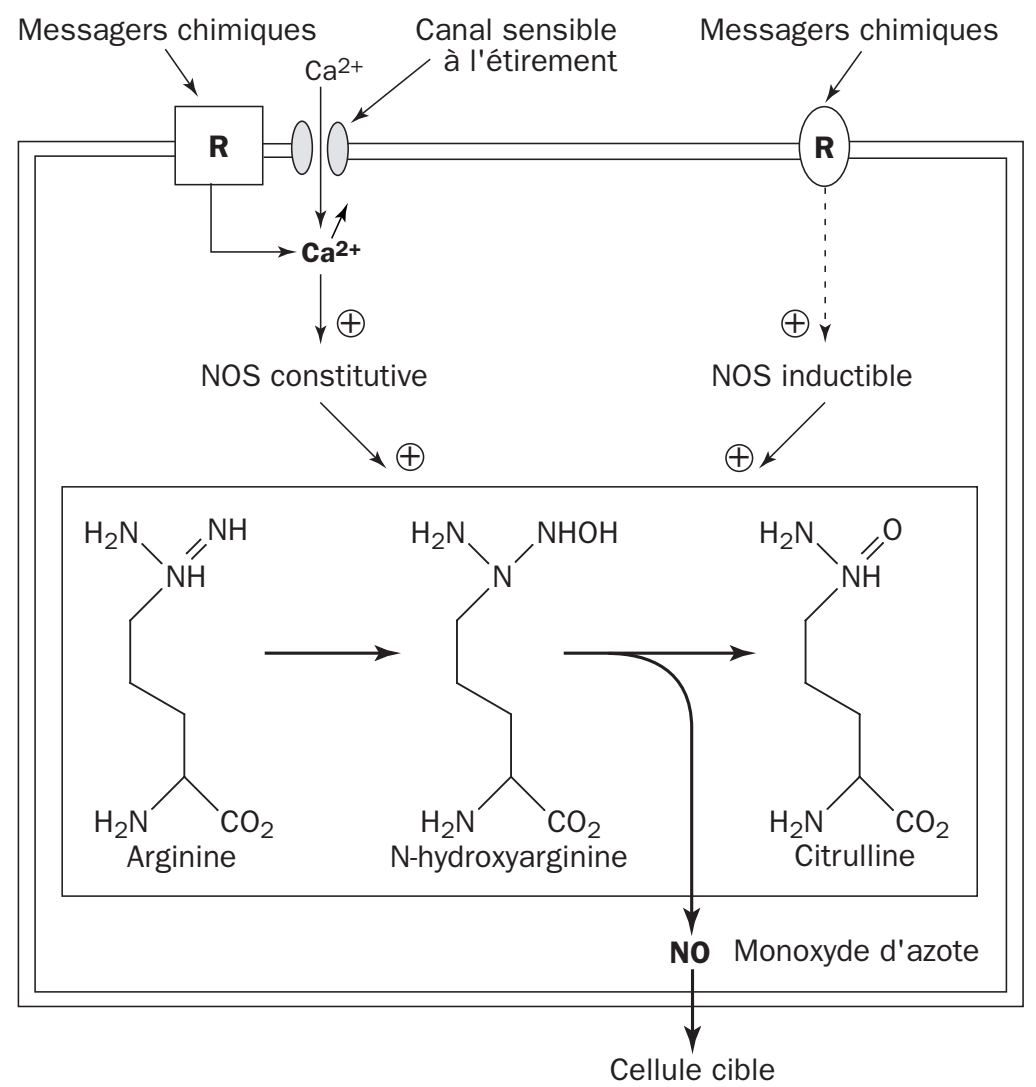

Figure 3.16 - Représentation schématique des mécanismes impliqués dans la synthèse de NO

Ca-Calm : calcium-calmoduline; NOS : NO synthase inductible ou constitutive.

Ces deux types de NOS sont des enzymes dimériques composées de deux sous-unités identiques de poids moléculaire compris entre 130 et $150 \mathrm{kDa}$. Ces deux formes ont des activités spécifiques proches, comprises entre 0,8 et $1,3.10^{-6} \mathrm{~mol} / \mathrm{min} / \mathrm{mg}$ de protéine $\left(37^{\circ} \mathrm{C}\right)$, et elles présentent beaucoup d'homologies avec la cytochrome $\mathrm{P}-450$ réductase. Trois isoformes de ces enzymes ont été identifiées (fig. 3.18). 


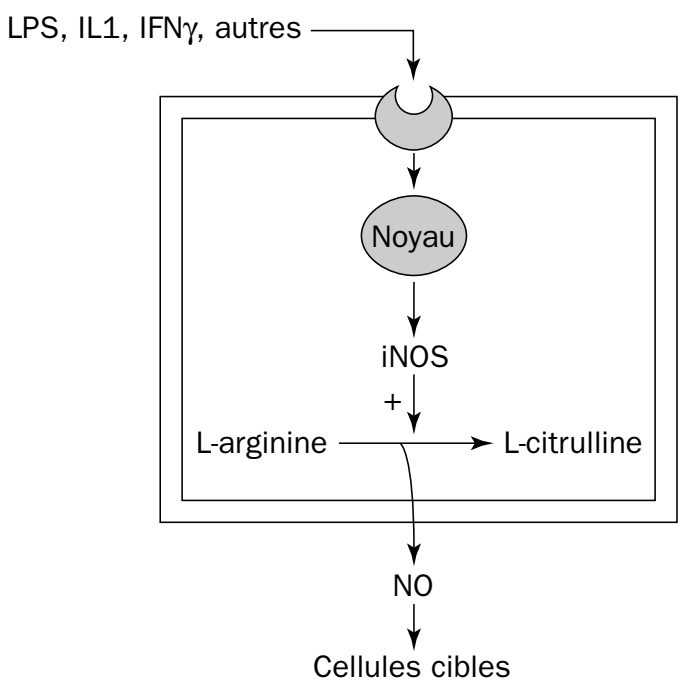

Figure 3.17 - Production de NO via l'activation de la synthèse d'une NO synthase inductible

IFN $\gamma$ : interféron $\gamma$; IL1: interleukine 1; LPS : lipopolysaccharide ; NADPH : adénine dinucléotide phosphate.

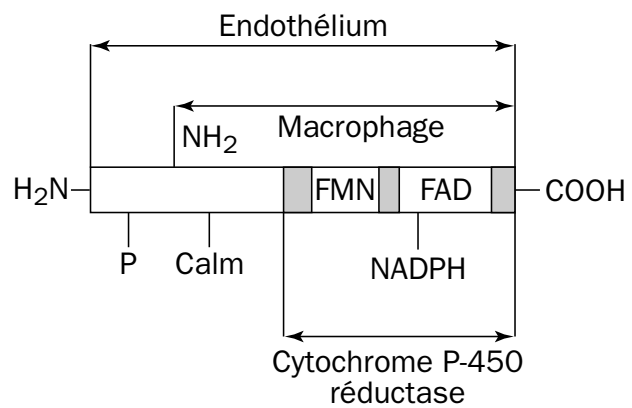

Figure 3.18 - Représentation schématique de la structure des NO synthases de l'endothélium et du macrophage, ainsi que celle de la cytochrome P-450 réductase Ces enzymes présentent des sites communs de fixation pour l'adénine dinucléotide phosphate (NADPH), la flavine adénine dinucléotide (FAD), la flavine mononucléotide $(F M N)$, ainsi que des sites probables de fixation pour la calmoduline (Calm), et de phosphorylation $(P)$.

Les NO synthases constitutives de l'endothélium (eNOS) et du système nerveux (nNOS ou bNOS) sont respectivement appelées NOSIII (ou NOS3) et NOSI (ou NOS1), et la NOS inductible qui est présente dans de nombreux types cellulaires (hépatocytes, macrophages, chondrocytes...) est appelée NOSII (ou NOS2). Ces isoformes diffèrent pour leur sensibilité au calcium et à la calmoduline, leur cinétique et leurs mécanismes de régulation qui peuvent nécessiter comme co-facteurs du NADPH de la tétrahydrobioptéridine, du FAD et/ ou de la FMN (tab. 3.3). Ainsi, les deux NOS constitutives ont leur activité régulée par le calcium. En revanche, la NOS inductible est considérée comme largement indépendante du calcium. 


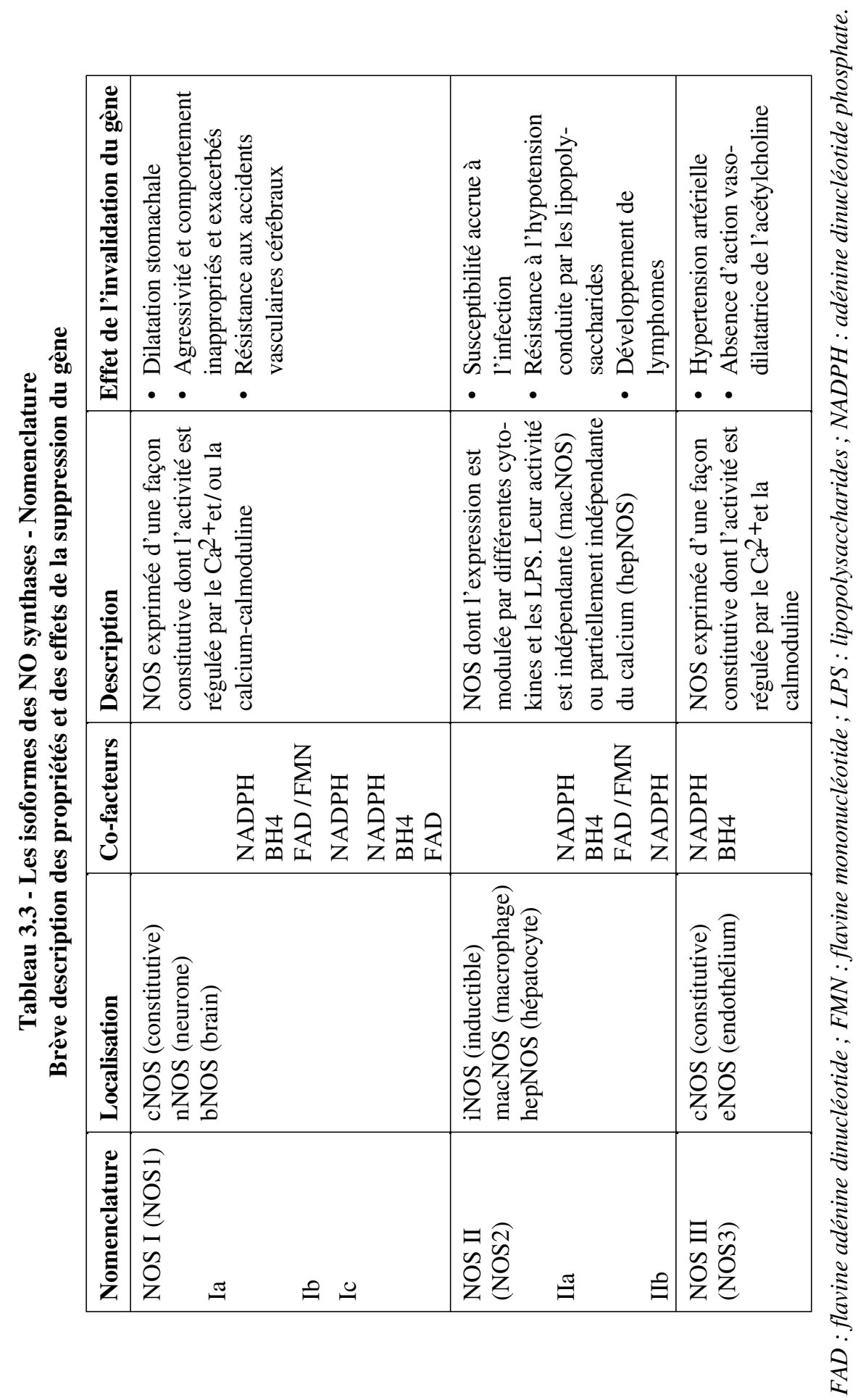


Dans les cellules possédant une NOS constitutive, lors de l'activation de récepteurs membranaires (ou lors de la mise en jeu de canaux ioniques sensibles à l'étirement) conduisant à une augmentation de la teneur en calcium libre cellulaire, les cNOS produisent, pendant une période courte (quelques secondes, quelques minutes) une petite quantité de NO (de l'ordre de la picomole). En revanche les iNOS produisent, lorsqu'elles sont stimulées, une quantité beaucoup plus grande $(\mathrm{nmol} / \mathrm{min} / \mathrm{mg}$ ) de NO et ce, pendant un temps beaucoup plus long (plusieurs heures).

Parmi les cytokines susceptibles d'induire l'activation de la iNOS, il a été montré que l'interféron $\gamma$ agit en synergie avec les lipopolysaccharides (LPS) pour stimuler la transcription des ARNm de l'iNOS, mais aussi pour le stabiliser. En revanche, le transforming growth factor $\beta$ (TGF $\beta$ ) possède une action opposée. De plus, il a aussi été démontré que NO exerce une rétroaction négative sur sa synthèse via une action probable sur le gène qui régit cette synthèse. Le tableau 3.4 donne les niveaux connus de la régulation de la synthèse des iNOS ; la complexité de ces régulations (un grand nombre est probablement inconnu) suggère le double rôle que peut jouer NO : agent de défense, mais aussi agent cytotoxique pour la cellule productrice.

Tableau 3.4 - Régulation de l'activité de la iNOS

\begin{tabular}{|c|c|}
\hline Niveau de la régulation & Agents \\
\hline Augmentation de la synthèse de l'ARNm & $\begin{array}{l}\text { Agents actifs sur la synthèse de AMPc } \\
\mathrm{UV}, \mathrm{O}_{3}\end{array}$ \\
\hline $\begin{array}{l}\text { Transcription } \\
\text { Stimulation } \\
\text { Suppression } \\
\text { Facteur de transcription }\end{array}$ & $\begin{array}{l}\text { IFN } \gamma ; \text { LPS } \\
\text { LPS ; TGF } \beta \text {-glucocorticoïdes } \\
\text { NF-KB }\end{array}$ \\
\hline $\begin{array}{l}\text { Stabilité de l'ARNm } \\
\text { Augmentée } \\
\text { Diminuée }\end{array}$ & $\begin{array}{l}\text { IFN } \gamma \\
\text { TGF } \beta\end{array}$ \\
\hline $\begin{array}{l}\text { Translation de l'ARNm } \\
\text { Supprimée }\end{array}$ & TGF $\beta$-dexaméthasone \\
\hline $\begin{array}{l}\text { Régulation post-translationnelle ou autre } \\
\text { Suppression de la stabilité } \\
\text { Rétrocontrôle négatif } \\
\text { Limitation de la quantité de substrat } \\
\text { Limitation de la quantité de co-facteur } \\
\text { Phosphorylation }\end{array}$ & $\begin{array}{l}\text { TGF } \beta \\
\text { NO } \\
\text { L-arginine } \\
\text { BH4-Calm activée ou non par } \mathrm{Ca}^{2+} \\
\text { Statut énergétique cellulaire }\left(\mathrm{O}_{2} ?\right)\end{array}$ \\
\hline
\end{tabular}

AMPc : adénosine monophosphate cyclique ; BH4 : tétrahydrobioptéridine ; Calm : calmoduline ; IFN $\gamma$ : interféron $\gamma$; LPS : lipopolysaccharides ; TGF $\beta$ : transforming growth factor $\beta$; UV : rayonnement ultraviolet. 
L'augmentation de la teneur en calcium cytoplasmique résultant de l'activation de récepteurs membranaires - ou de l'ouverture de canaux ioniques sensibles à l'étirement - provoque une activation de la NO synthase qui, en deux étapes successives, conduit à la production de $\mathrm{NO}$ et de citrulline (voir fig. 3.16). Un certain nombre d'analogues de la L-arginine tels que la $\mathrm{N}^{\mathrm{G}}$-monométhyl-L-arginine (L-NMMA), analogue non-métabolisable de la L-arginine, sont des inhibiteurs de la synthèse de NO, alors que l'adénine dinucléotide phosphate (NADPH), la flavine adénine dinucléotide (FAD), la flavine mononucléotide (FMN) et la tétrahydrobioptéridine (BH4) sont des activateurs.

Différents messagers chimiques tels que les lipopolysaccharides (LPS), l'interféron $\gamma$ (IFN $\gamma$ ) et l'interleukine 1 (IL1) peuvent conduire à la synthèse d'une NO synthase. La présence d'une NO synthase inductible a été mise en évidence dans un grand nombre de types cellulaires : les macrophages, les cellules neutrophiles, les cellules endothéliales et les cellules musculaires vasculaires.

\subsubsection{Les donneurs de NO, le métabolisme de NO, cible potentielle d'actions thérapeutiques}

L'implication de NO dans un grand nombre de situations physiologiques et pathologiques conduit à penser qu'il existe un intérêt à intervenir sur son métabolisme (fig. 3.19).

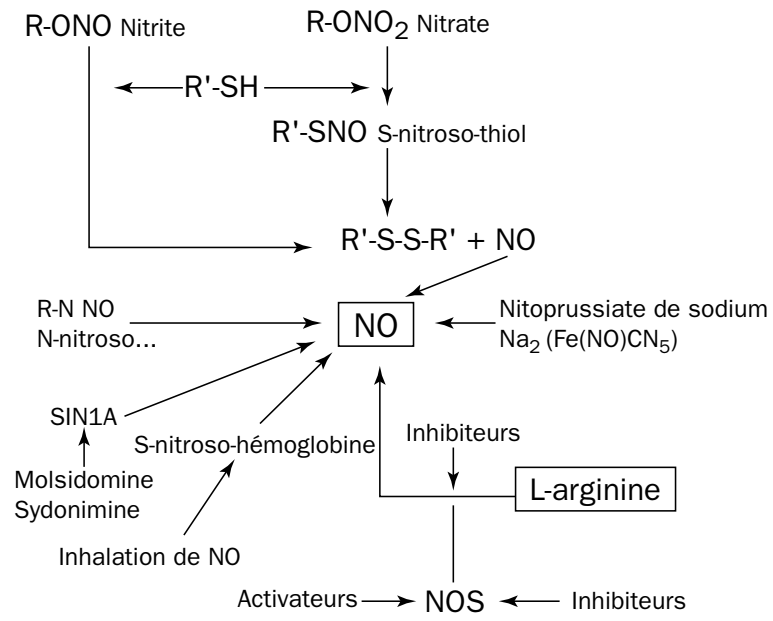

Figure 3.19 - Représentation schématique des interventions possibles sur le métabolisme de NO

La L-arginine est le seul précurseur physiologique connu de NO. Il existe un grand nombre d'analogues synthétiques non-métabolisables de la L-arginine qui sont des inhibiteurs de cette synthèse ; c'est, parmi d'autres, le cas de la L-NAME $\left(\mathrm{NG}^{\mathrm{G}}\right.$-nitroL-arginine méthyl ester), de la L-NMA ( $\mathrm{N}^{\mathrm{G}}$-méthyl-L-arginine) ou de la L-NAA

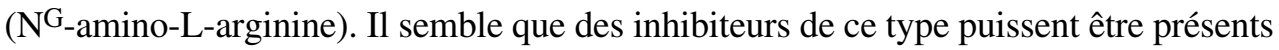


d'une manière endogène (en particulier au niveau du tissu rénal). Il existe des inhibiteurs tels que les isothiourées, différentes substances portant le groupe amidine des NOS et des activateurs $\left(\mathrm{Ca}^{2+}\right.$, tous les inducteurs de la synthèse des iNOS). Différentes substances utilisées ou non en thérapeutique sont des donneurs potentiels de NO (nitrates, nitrites, S-nitroso-thiols, nitroprussiate de sodium, SIN1A). Toutefois, il faut avoir à l'esprit que, lors de l'utilisation de ces substances, la production de NO peut être accompagnée de la production d'une grande variété de substances biologiquement actives dont certaines sont toxiques. Il est aussi possible que l'inhalation de NO exerce non seulement un effet bénéfique par son action au niveau des bronches, mais pourrait agir, via la formation de S-nitrosohémoglobine, comme une technique potentielle de vaso-dilatation active à long terme (voir fig. 3.19).

Ainsi, lors du choc septique ou en présence de certaines altérations du fonctionnement du système nerveux central, il pourrait être intéressant de limiter la production de NO soit en inhibant l'activité des NO synthases, soit en utilisant des analogues nonmétabolisables de la L-arginine. Au contraire, lors de situations d'ischémie, d'hypertension chronique ou d'impuissance masculine, la stimulation des NO synthases ou l'utilisation de donneurs de NO peuvent avoir un effet bénéfique. Enfin, l'inhalation de NO, qui produit une vaso-dilatation transitoire des artérioles pulmonaires, pourrait aussi agir sur la dilatation bronchique et sur la pression artérielle (via la formation de S-nitroso-hémoglobine) et serait un moyen de lutte contre différents types d'affections respiratoires.

\subsection{NO ET LA PHYSIOLOGIE CARDIO-VASCULAIRE}

\subsubsection{NO et les vaisseaux}

Les veines et les artères sont essentiellement constituées de deux types cellulaires : les cellules endothéliales et les cellules musculaires lisses. Les cellules endothéliales constituent une monocouche - l'endothélium - $\left(2 \mathrm{~kg}, 1000 \mathrm{~m}^{2}\right)$ qui forme une interface entre le sang et les cellules musculaires lisses. Ces dernières assurent la tonicité vasculaire. L'endothélium, qui peut être considéré comme une glande endocrine diffuse (voir chap. 9) joue un rôle important dans la régulation, à court et à long terme, du tonus vasculaire, ainsi que dans la modulation de processus physiologiques tels que l'inflammation, l'agrégation plaquettaire, la fibrinolyse, l'angiogenèse, le métabolisme de certains messagers circulants (angiotensine, bradykinine, catécholamines). L'endothélium synthétise et libère une grande variété de substances actives paracrines et/ou autocrines. Parmi celles-ci, des dérivés de l'acide arachidonique, des facteurs de croissance, le facteur VIII de Willebrandt, des molécules anti-adhésives et anti-agrégatives, l'endothéline et au moins deux facteurs de nature inconnue. L'un de ces facteurs (facteur hyperpolarisant) induit une hyperpolarisation des cellules musculaires lisses et, par là, une vaso-dilatation, l'autre provoque une vaso-constriction. 
Comme nous l'avons vu plus haut, l'endothélium synthétise également le NO. C'est l'utilisation de différentes techniques de mesure (résonance paramagnétique électronique, électrode sensible à NO) de donneurs de NO, d'inhibiteurs de la production de NO et d'animaux déficitaires en NOS constitutive endothéliale qui a permis d'admettre que l'EDRF est bien NO. L'endothélium vasculaire contient une eNOS constitutive qui joue un rôle physiologique primordial, mais aussi une NOS inductible dont les rôles sont mal connus ou soupçonnés (la situation est symétrique pour les cellules musculaires lisses vasculaires, dont la iNOS semble jouer un rôle prépondérant dans le fonctionnement de base et dont le rôle de la NOS constitutive est mal défini).

Au niveau de l'endothélium vasculaire, le monoxyde d'azote est libéré soit sous forme de $\mathrm{NO}^{\circ}$, soit pris en charge par une molécule contenant un groupe $\mathrm{SH}$. L'acétylcholine, la 5-hydroxytryptamine, la thrombine, l'acide arachidonique et d'autres messagers chimiques, ainsi que tous les facteurs chimiques ou physiques (forces de cisaillement, pression sanguine) qui induisent une augmentation du calcium libre cytoplasmique, sont des facteurs qui stimulent cette production via l'activation de la NOS constitutive (fig. 3.20).

Le monoxyde d'azote libéré active une guanylate cyclase soluble présente au niveau des cellules musculaires lisses vasculaires, des plaquettes et de l'endothélium luimême. Il a été émis l'hypothèse que c'est la liaison de NO avec le fer hémique de la guanylate cyclase et la libération simultanée d'une histidine fixée axialement qui provoquent l'activation enzymatique. L'importante production de guanosine monophosphate cyclique (GMPc) qui résulte de cette activation provoque, au niveau de la cellule musculaire lisse vasculaire, une activation d'une ou plusieurs protéine kinases G dépendantes du GMPc (PKG). S'il est clair que cette activation des protéine kinases $\mathrm{G}$ entraîne une diminution de la teneur intracellulaire en calcium libre responsable de la vaso-relaxation, les mécanismes mis en jeu sont encore mal connus. Il est cependant probable que ce sont la phosphorylation d'une protéine régulatrice de la calcium-ATPase du réticulum (et peut-être de celle du sarcolemme), ainsi que celle des canaux calciques activables par l'inositol $(1,4,5)$ triphosphate (IP3) qui sont responsables de cette vaso-relaxation (fig. 3.20).

Il faut aussi garder à l'esprit que les protéine kinases $\mathrm{G}$ exercent d'autres actions (fig. 3.21) qui pourraient elles aussi contribuer à la vaso-relaxation. En particulier, les PKG phosphorylent des canaux potassiques, ce qui augmente leur sensibilité au calcium, l'hyperpolarisation résultante réduit l'entrée de calcium par les canaux calciques sensibles au voltage. Il a été, en outre, montré que NO pouvait directement stimuler ce type de canal potassique, mais aussi les canaux potassiques sensibles à l'ATP, contribuant ainsi à l'hyperpolarisation induite par l'activation des PKG. La vaso-dilatation ainsi provoquée rétroagit négativement sur les facteurs physicochimiques (diminution de la $\mathrm{pO}_{2}$, forces de cisaillement, pression sanguine) qui ont pu engendrer la production de NO. Cette action vaso-dilatatrice et son implication 
dans la régulation physiologique de la pression artérielle sont confirmées par l'observation d'une hypertension (35\% d'augmentation) et la perte de l'action vasodilatatrice de l'acétylcholine induites chez la souris par délétion du gène de la eNOS.

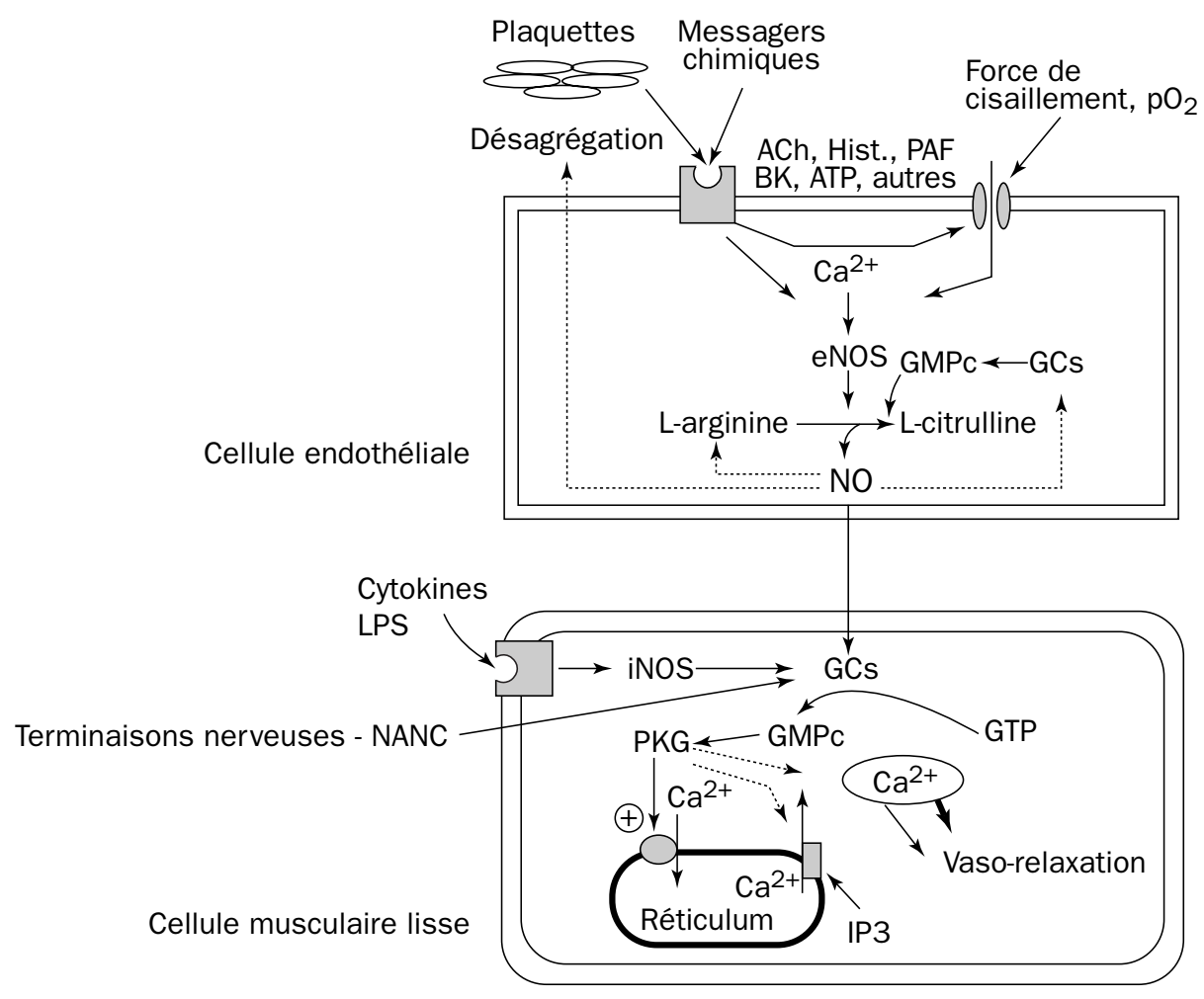

Figure 3.20 - Action vaso-dilatatrice de NO

La NO synthase constitutive de l'endothélium (eNOS) est activée par tous les mécanismes qui conduisent à une augmentation de la teneur cytoplasmique en calcium. A ce niveau, le NO rétroagit négativement sur sa production, soit directement, soit via l'activation d'une guanylate cyclase soluble (GCs). Le NO produit diffuse jusqu'aux plaquettes où il réduit l'agrégation, et jusqu'au niveau des cellules musculaires lisses où il stimule fortement la production de GMPC. Cette production provoque l'activation d'une ou plusieurs protéine kinases G sensibles au GMPc (PKG). L'activation des PKG provoque, au niveau du réticulum sarcoplasmique, une phosphorylation inhibitrice des canaux calciques activables par l'inositol $(1,4,5)$ triphosphate (IP3) et une phosphorylation activatrice de la calciumATPase, et, au niveau de la membrane plasmique, une phosphorylation des canaux potassiques sensibles au calcium. II a aussi été montré que NO peut directement stimuler ce type de canal, de même que les canaux $\mathrm{K}^{+}$sensibles à l'ATP. L'hyperpolarisation qui en résulte diminue l'entrée de calcium par les canaux calciques membranaires sensibles au voltage. L'ensemble de ces mécanismes conduit, au niveau de la cellule musculaire lisse, à une diminution de la teneur cytoplasmique en calcium et, par là, à une vaso-dilatation.

Au niveau des cellules musculaires lisses, le NO peut provenir non seulement de l'activité des cellules endothéliales, mais aussi des différents types d'innervation vasculaire, où NO peut être libéré par des neurones "nitrinergiques" ou co-libérés (voir § 3.4.1). En outre, les cellules musculaires lisses possèdent une NOS inductible (iNOS), activable par différentes cytokines et le lipopolysaccharide (LPS). 
Augmentation de la conductance des canaux $\mathrm{K}^{+}$sensibles au calcium, ce qui entraîne une hyperpolarisation et la réduction de l'entrée de calcium par les canaux membranaires sensibles au voltage.

Diminution de la sensibilité au calcium des protéines contractiles.

(ou PKG)

Augmentation de l'activité des calcium-ATPases de la

membrane plasmique et du réticulum sarcoplasmique.

Diminution de l'activité des canaux calciques

(phosphorylation de protéines cytosquelettiques

régulatrices des canaux).

Figure 3.21 - Représentation schématique des propriétés des protéine kinases GMPcK (ou PKG), activables par le GMPc (d'après Lincolm et Cornwell, 1993)

A côté du rôle que joue NO dans la régulation du tonus vasculaire, il a été montré (utilisation d'inhibiteurs de synthèse) que NO est impliqué dans l'état de choc septique ou hémorragique. Le platelet activating factor (PAF) participe, lui aussi, à l'état de choc. Il pourrait agir directement mais aussi via l'induction de la synthèse de NO. L'état de choc est caractérisé, entre autres symptômes, par une vaso-dilatation périphérique importante responsable d'une hypotension dramatique, une augmentation majeure de la perméabilité vasculaire et une insensibilité aux vaso-constricteurs, l'ensemble de ces altérations pouvant conduire à la mort. C'est, semble-t-il, l'activation de la iNOS des cellules musculaires lisses (mais aussi de la iNOS des cellules endothéliales), ainsi que l'altération de la eNOS, qui participent à l'état de choc. Cette défaillance circulatoire majeure est, de plus, accompagnée d'une diminution de la contractilité cardiaque (voir paragraphe suivant), mécanisme contribuant à amplifier l'hypotension qui devient alors irréversible.

Par ailleurs, il a été mis en évidence que NO est un facteur anti-angiogénique. L'angiogenèse est un processus qui met en jeu plusieurs étapes (migration, prolifération, différenciation des cellules endothéliales et musculaires lisses) ; il est impliqué dans des mécanismes fondamentaux tels que le développement des hypertrophies cardiaque et musculaire, ainsi que dans celui des tumeurs solides. Cette action anti-angiogénique du NO est à rapprocher de ses effets antiprolifératif et cytotoxique (voir $\$ 3.5$ ).

NO produit par l'endothélium apparaît donc, dans les conditions physiologiques, comme un facteur majeur de la régulation de la pression sanguine. Ce mécanisme de régulation est altéré dans certaines pathologies comme l'athérosclérose et certains types d'inflammation. Au niveau vasculaire, NO participe en outre (avec la prostacycline) à l'inhibition de l'agrégation plaquettaire, ainsi qu'à l'inhibition de l'adhésivité des leucocytes à la paroi vasculaire. L'action conjuguée du PAF, de différentes cytokines et l'expression, au niveau des cellules endothéliales, de facteurs 
chémotactiques et d'adhésion conduisent à l'activation des leucocytes. Les leucocytes activés libèrent des enzymes protéolytiques, $\mathrm{O}^{\bullet-}$, ainsi que divers radicaux libres. La genèse de ces espèces radicalaires participe à la défense de l'organisme contre "le non-soi" mais pourrait être aussi, en partie, responsable des altérations tissulaires observées au niveau de différents organes lors d'épisodes d'isché$\mathrm{mie} /$ reperfusion.

\section{Conclusions et perspectives}

Ainsi, compte tenu des rôles fondamentaux joués au niveau vasculaire par NO, la possibilité d'agir sur sa synthèse ou son lieu de production (d'une façon aiguë ou chronique) est un objectif d'une importance majeure. L'utilisation de donneurs de NO (considérés comme libérant $\mathrm{NO}$ au niveau des cellules musculaires lisses, mais aussi endothéliales) est réalisée depuis plus d'un siècle. Néanmoins, une intervention plus fine est souhaitable. Aussi des interventions permettant d'agir spécifiquement sur un type de NO synthase, alliées à l'inhalation de NO (voir § 3.6) et/ ou à des techniques de thérapie génique (les cellules endothéliales sont un matériel de choix pour ce type d'intervention), sont-elles en cours d'élaboration.

\subsubsection{NO et le muscle cardiaque}

La structure fractale du réseau vasculaire coronaire et la présence de l'endocarde font que NO produit par ces endothéliums peut facilement agir au niveau de la cellule myocardique (fig. 3.22). En outre, cette cellule, qui possède une NOS inductible et une NOS constitutive, est capable de synthétiser de grandes quantités de NO, et de le dégrader avec une vitesse cent fois plus grande que celle mesurée dans les vaisseaux.

Le NO diffusant à partir des cellules de l'endocarde, des cellules des vaisseaux coronaires et celui synthétisé au niveau de la cellule myocardique elle-même réduisent l'activité contractile du muscle cardiaque. Cette action inotrope négative de NO a pour cause, d'une part, une moindre production d'énergie et, d'autre part, une inhibition du courant calcique de type L. Le monoxyde d'azote inhibe directement la production d'énergie par son action sur différentes enzymes mitochondriales, en particulier, en entrant en compétition avec l'oxygène au niveau de la cytochrome oxydase. En revanche, NO inhibe le courant calcique de type L via la production de GMPc par un mécanisme analogue à celui décrit au niveau de la cellule musculaire lisse vasculaire.

L'endotoxémie, ou l'exposition aux cytokines inflammatoires, induit au niveau de tous les types cellulaires une production importante de NO via l'activation de NOS inductibles indépendantes du calcium. Cette forte production de NO conduit à une importante réduction de l'activité contractile du myocarde qui peut, dans certains cas, conduire à la défaillance cardiaque. Ainsi, il est probable qu'une surproduction de NO pourrait être impliquée dans différentes situations pathophysiologiques comme les myocardites d'origine variée et le rejet de greffes. 


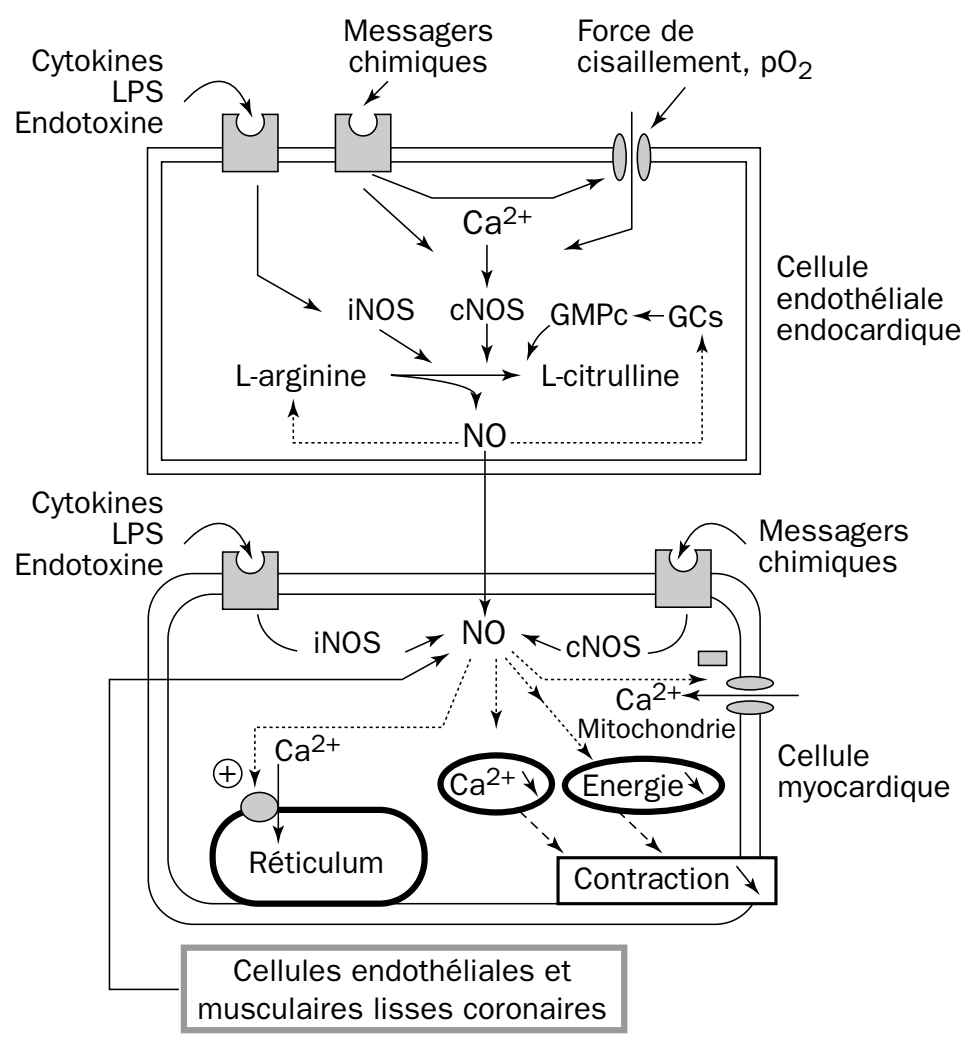

Figure 3.22 - NO et le cœur

Le NO diffusant ou produit par la cellule myocardique elle-même génère une diminution de la production d'énergie, la synthèse de GMPc et une réduction de l'activité contractile du myocarde. Cette diminution de l'activité contractile du myocarde rétroagit négativement sur les facteurs physico-chimiques qui ont pu conduire à la synthèse de NO (la diminution de $\mathrm{pO}_{2}$ agit probablement par réduction de la production d'ATP, ce qui provoque une augmentation du $\mathrm{Ca}^{2+}$ cytoplasmique, ainsi que par une action directe sur la eNOS). Lorsque la réduction de l'activité contractile du myocarde est trop importante, elle peut conduire à la défaillance cardiaque.

\section{Conclusion et perspectives}

NO joue donc un rôle fondamental au niveau de la physiologie cardio-vasculaire. Toutefois, un grand nombre de questions restent à élucider. En particulier, les mécanismes intimes du fonctionnement des différents types de NOS, de même que la connaissance de leurs localisations et de leurs régulations devront être approfondis. Une autre question reste posée, celle d'une synergie possible entre NO et les autres facteurs actifs sur le tonus vasculaire ou myocardique (prostaglandines, acide arachidonique, hormones, autres facteurs libérés par l'endothélium). Ainsi, la compréhension de l'implication de NO dans la physiologie et la pathophysiologie cardiaques ne fait que débuter et la réponse à ces questions devrait nous permettre de mieux utiliser la production de NO à des fins thérapeutiques. 


\subsection{NO ET LE SYSTÈME NERVEUX}

Depuis la mise en évidence du rôle de NO comme agent dérivé de l'endothélium capable d'induire une vaso-dilatation, un grand nombre de données ont permis de démontrer que NO était impliqué, à différents niveaux, dans le fonctionnement du système nerveux.

Ces découvertes ont bouleversé la notion de communication synaptique. En effet, jusqu'alors, la communication au niveau des synapses chimiques était conçue comme résultant de la libération par les cellules nerveuses pré-synaptiques d'une substance nommée neuromédiateur qui, se fixant sur des récepteurs métabotropiques (dont l'activation conduit à la synthèse de seconds messagers) ou canal ionique situés sur la membrane post-synaptique, induirait des modifications du métabolisme et/ou des perméabilités ioniques membranaires. Ainsi, dans le cas des cellules excitables, la fixation du neuromédiateur est responsable de variations locales de potentiel : les potentiels post-synaptiques inhibiteur (PPSI) ou excitateur (PPSE). Le PPSE, lorsqu'il atteint un niveau de dépolarisation suffisant, génère l'ouverture des canaux sodiques sensibles au voltage et donne naissance à un potentiel d'action propagé.

\subsubsection{NO et le système nerveux central}

C'est en 1988 que J. Garthwaite a montré que la stimulation de neurones en culture par un acide aminé excitateur, le glutamate, induisait la libération d'une substance labile capable de provoquer la relaxation de cellules musculaires lisses. Puis, il a été mis en évidence que cette stimulation générait une forte synthèse de GMPc. Enfin, la présence au niveau des neurones d'une NOS constitutive (nNOS ou bNOS) a été démontrée (depuis elle a été purifiée, son $\mathrm{ADN}$ a été cloné et séquencé). L'ensemble de ces données suggérait que NO pouvait jouer un rôle au niveau du système nerveux.

Les études électrophysiologiques réalisées sur des neurones en culture ou des coupes de cerveau, alliées à l'utilisation de donneurs et/ou d'inhibiteurs de la synthèse de NO, ainsi qu'à celle du 8-Br-cGMP (analogue de GMPc capable de traverser la membrane cellulaire), ont permis de montrer que NO pouvait stimuler ou inhiber l'activité de certains neurones. NO peut agir soit directement, soit via le GMPc - ou encore par l'intermédiaire des PKG activées - sur l'activité de certains canaux ioniques, en particulier les canaux potassiques sensibles au calcium ou ceux sensibles à l'ATP. Par ailleurs, il a été mis en évidence que NO peut moduler la libération d'hormones par le complexe hypothalamo-hypophysaire. Toutefois, le rôle physiologique exact joué par NO dans ces processus (comme dans beaucoup d'autres) reste largement inconnu.

Les premiers travaux portant sur le système nerveux et NO, s'ils ont été largement contestés, voire remis en question, ont eu le mérite d'ouvrir la voie à toute une série de recherches portant sur le rôle de NO dans la plasticité du système nerveux central. 
La plasticité du système nerveux résulte de la capacité de connexions synaptiques à devenir sélectives d'une façon durable - potentialisation à long terme (LTP) - ou, au contraire, à être bloquées (ou devenir labiles ?), en réponse à un stimulus externe - dépression à long terme (LTD) - . Ce phénomène qui est présent dans de nombreuses structures nerveuses (hippocampe, cortex, cervelet) a suscité beaucoup d'intérêt car il pourrait être impliqué dans les phénomènes d'apprentissage et de mémorisation. Le phénomène le plus étudié de plasticité du système nerveux central est la potentialisation à long terme qui a été bien observée aux niveaux des synapses glutaminergiques excitatrices de l'hippocampe CA1. Il peut être mesuré comme une augmentation différée ( $1 \mathrm{~h}$ à $3 \mathrm{~h}$ ) de l'amplitude et de la vitesse d'établissement du PPSE après un train de stimulations. L'utilisation des inhibiteurs des NOS et des donneurs de NO a confirmé la participation (partielle ?) de NO dans le phénomène de LTP. Le mécanisme hypothétique proposé est schématisé dans la figure 3.23.

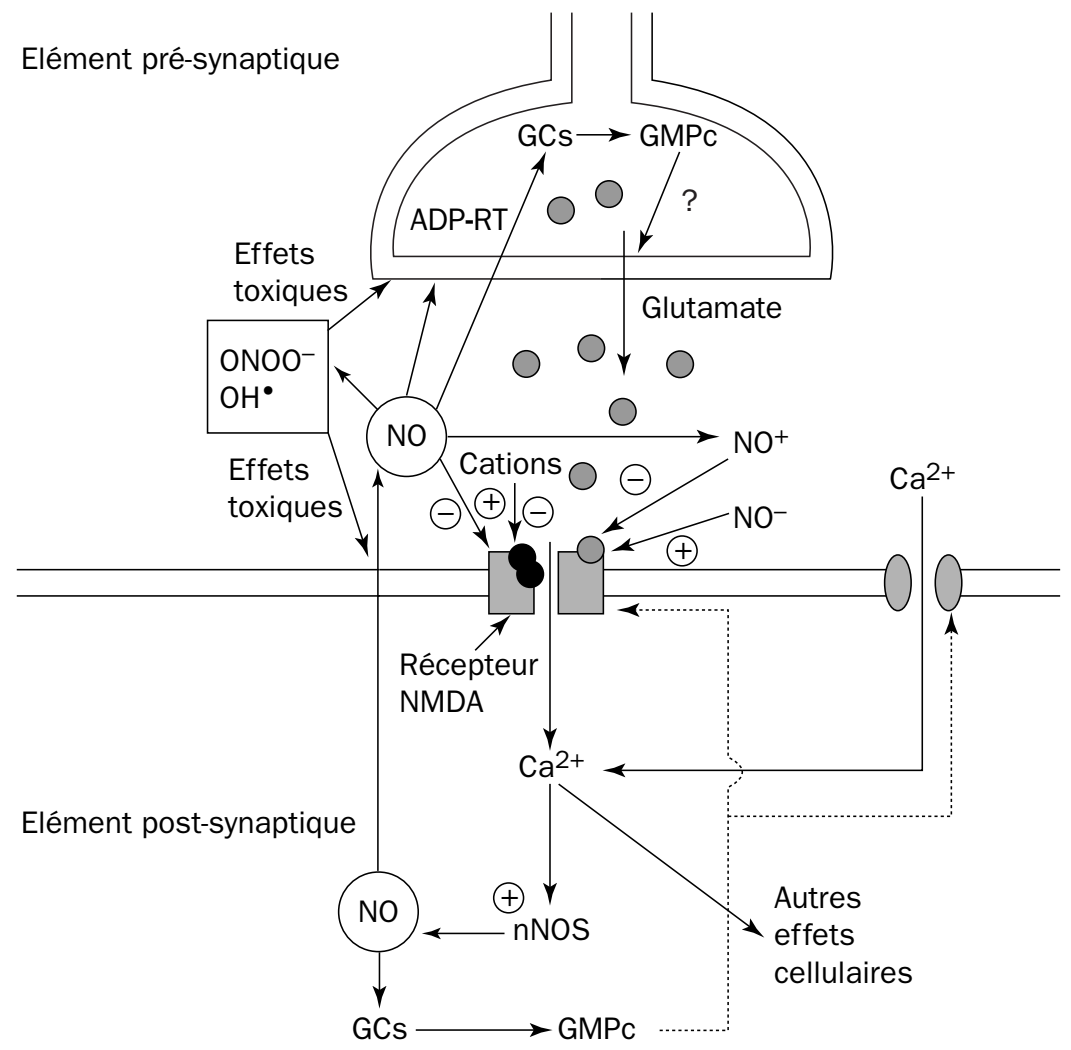

Figure 3.23 - Représentation schématique du rôle hypothétique de NO au niveau de la transmission synaptique glutaminergique

ADP-RT : ADP-ribosyltransférase ; GCs : guanylate cyclase soluble ; NMDA : N-méthyl-Daspartate ; nNOS : NOS neuronale.

Une libération importante de glutamate est nécessaire pour la stimulation des récepteurs NMDA (N-méthyl-D-aspartate). L'entrée de calcium consécutive à cette 
stimulation stimule à son tour la NOS neuronale. Le NO libéré pourrait alors rétroagir pour modifier, à long terme, la capacité de production et/ou de libération de neuromédiateur. Ce mécanisme impliquerait pour partie la synthèse de GMPc et/ou une action de NO sur une ADP-ribosyltransférase mais une action directe de NO n'est pas à exclure. D'autre part le NO produit au niveau de l'élément post-synaptique intervient pour moduler le fonctionnement des récepteurs NMDA et des récepteurs AMPA ( $\alpha$-amino-3-hydroxy-5-methyl-4-isoazolepronic acid) de cet élément postsynaptique. Cette modulation pourrait s'exercer par un effet allostérique des formes ioniques $\left(\mathrm{NO}^{-}, \mathrm{NO}^{+}\right)$de $\mathrm{NO}$ et/ou par une action, variable en fonction du voltage, sur l'inhibition exercée, à ce niveau, par les cations bivalents.

Les mêmes mécanismes (variations dans l'intensité et/ou mise en jeu préférentielle d'un mécanisme particulier) peuvent être évoqués pour expliquer la dépression synaptique à long terme (LTD) observée au niveau du cervelet. Dans ce cas, cette plasticité synaptique pourrait sous-tendre les apprentissages moteurs cérébelleux. Cependant, il est à noter que d'autres mécanismes ont été proposés en particulier la mise en jeu des récepteurs métabotropiques (Glu 1 et Glu 5) au glutamate semble participer à ces processus de LTP et LTD sans implication de NO.

Par ailleurs, l'administration à des rats d'inhibiteurs des NOS induit une perte des capacités de mémorisation spatiale, ainsi qu'une altération du comportement. Des études récentes ont montré que des souris mâles transgéniques déficitaires en nNOS présentent des comportements agressif et sexuel inappropriés et exacerbés. Le NO joue aussi, lors du développement embryonnaire, un rôle déterminant dans la mise en place des connexions synaptiques et exerce des effets protecteurs ou délétères lors de l'ischémie et la reperfusion de l'encéphale. Les neurones contenant une quantité importante de NOS sont les plus résistants aux altérations provoquées par des fortes doses de glutamate ou par l'ischémie, et ne dégénèrent pas lors de pathologie du système nerveux telles que la maladie de Huntington ou d'Alzheimer. Toutefois, l'interprétation de ces résultats reste délicate car on trouve, dans ces neurones, parallèlement à la présence de NOS, une quantité importante d'enzymes qui peuvent réduire la teneur et la production de radicaux libres, donc exercer un effet protecteur.

Les neurones ne sont pas les seules cellules du système nerveux central à posséder des NOS. En effet, des NOS inductibles ont été détectées dans les astrocytes et les cellules de la microglie. Le rôle physiologique de ces iNOS indépendantes du calcium est peu connu. Il semble que les astrocytes qui présentent beaucoup de similitudes avec les macrophages pourraient jouer un rôle dans le mécanisme de défense du système nerveux.

\subsubsection{Neurotoxicité de NO}

A côté des effets bénéfiques de faibles quantités de NO, une surproduction de $\mathrm{NO}$ a des effets délétères. Ces effets toxiques ont été aussi bien observés sur des modèles expérimentaux in vitro qu' in vivo. Ainsi, in vivo, les inhibiteurs des NOS et des 
antagonistes des récepteurs NMDA protègent-ils contre les destructions neuronales générées par des épisodes d'ischémie/reperfusion. D'autre part, in vivo, une forte induction, par différents types de virus, des iNOS neuronales provoque une importante destruction des neurones. NO pourrait être impliqué dans différentes pathologies neurodénégératives. Cette opinion est essentiellement fondée sur l'observation in vitro d'une forte induction des NOS par les protéines $\beta$-amyloïdes 25-35 caractéristiques de la maladie d'Alzheimer.

\section{Conclusions et perspectives}

Ainsi, au niveau de l'encéphale, les deux faces de NO bénéfique/toxique apparaissent-elles clairement. Lorsque NO est produit en faible quantité, il exerce un effet positif sur le transfert synaptique de l'information et probablement sur l'apprentissage, voire sur la protection neuronale. En revanche, lorsqu'il est produit en forte quantité, il devient un "cytotueur" agissant sans discrimination. Une meilleure connaissance du rôle de NO et de ses sites de production devrait nous aider à comprendre le fonctionnement physiologique et cognitif du cerveau, mais devrait aussi faire émerger de nouveaux types de psychotropes utilisables comme agents thérapeutiques et/ou neuroprotecteurs.

\subsubsection{NO et le système nerveux périphérique}

L'existence d'une neurotransmission non-adrénergique et non-cholinergique (NANC) a été, pendant de nombreuses années, un sujet de controverse. Cependant, de même que les multiples rôles physiologiques de NO sont bien établis, l'existence, au niveau du système nerveux périphérique, d'une transmission de type NANC mettant en jeu NO est maintenant largement admise. La démonstration de ce type de transmission synaptique, où NO est le médiateur de l'information ${ }^{1}$, est essentiellement fondée sur la détermination immuno-histochimique de la présence de nNOS dans certains neurones périphériques et sur l'utilisation de donneurs de NO et d'inhibiteurs de NO synthases, ainsi que sur la constatation que les souris transgéniques déficitaires en nNOS présentent une dilatation stomachale importante. Ce type de transmission NAC mettant en jeu NO a été observée au niveau des tractus gastro-intestinal et urogénital, ainsi qu' au niveau de certains vaisseaux. Toutefois, on ne peut pas exclure l'existence d'autres médiateurs que NO dans la transmission synaptique de type NANC (CO ?), neuromédiateurs qui pourraient agir en synergie avec les neurones libérant NO, de même qu'avec les neuromédiateurs classiques (fig. 3.24). Au niveau des différents types de muscles lisses innervés par des neurones à NO (ou neurones nitrinergiques), les mécanismes générés par NO conduisant à une relaxation ne sont pas différents de ceux décrits au niveau de la cellule musculaire vasculaire pour le NO produit par les cellules endothéliales (voir fig. 3.20).

1 Le rôle de NO comme neuromédiateur remet en cause la notion classique de neuromédiateur activant un récepteur membranaire post-synaptique. 


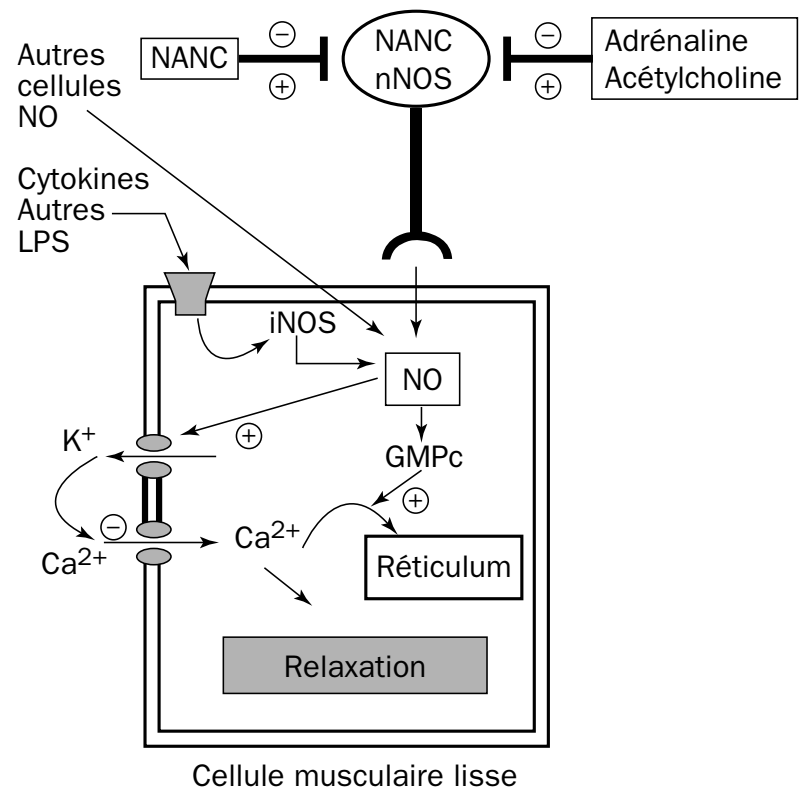

Figure 3.24 - Représentation schématique d'une neurotransmission NANC mettant en jeu NO (transmission nitrinergique)

Les neurones NANC (non-adrénergiques et non-cholinergiques), qui contiennent une nNOS (neurones nitrinergiques), libèrent NO qui diffuse et agit sur une guanylate cyclase soluble pour induire la production de GMPc qui active une ou plusieurs PKG. L'ensemble des actions directes ou non de NO et du GMPc conduit à une réduction de la teneur en calcium libre cytoplasmique, responsable de la relaxation de la cellule musculaire lisse (pour plus de détails, voir la figure 3.20). Il est possible que des neurones de type NANC ne produisant pas NO, de même que des neurones à neuromédiateurs "classiques" (par exemple les neurones à acétylcholine), puissent moduler l'activité des neurones NANC produisant NO. Par ailleurs, NO peut être produit par d'autres cellules possédant des NOS, ainsi que par la cellule musculaire lisse elle-même, qui possède une NOS inductible.

D'un point de vue physiologique, on considère que ces types de neurones à NO sont impliqués dans la régulation du tonus musculaire lisse, en particulier des sphincters. Ces neurones participent aussi au fonctionnement physiologique de l'estomac (régulation de l'irrigation sanguine et production d' $\mathrm{HCl}$ ), ainsi qu'à celui du corps caverneux pénien. L'absence d'une production suffisante de NO pourrait être à l'origine des spasmes pyloriques observés chez l'enfant et de certains types d'impuissance. Dans ce dernier cas, on peut utiliser des donneurs locaux de NO (pommade) ou des inhibiteurs spécifiques (Viagra ${ }^{\circledR}$ ) de l'enzyme de dégradation du GMPc en GMP.

\subsection{NO - AUTRES EFFETS CYTOTOXIQUES}

Nous avons évoqué dans un paragraphe précédent l'action neurotoxique de NO lorsque celui-ci est produit en grande quantité. Ce n'est pas toujours le cas, dans certaines situations une forte production de NO peut être bénéfique. L'utilisation de donneurs de NO, d'inhibiteurs des NOS et d'animaux modifiés génétiquement ne 
possédant pas de NOS inductible a permis de montrer, essentiellement au niveau des macrophages, le rôle bénéfique d'une forte production de NO.

\subsubsection{NO et les macrophages}

Les macrophages contiennent une NOS inductible. La transcription du gène de cette iNOS est contrôlée par une grande variété de messagers chimiques appelés cytokines, ainsi que par le lipopolysaccharide qui est un des constituants de la paroi des bactéries gram-négatives. Les inducteurs les plus importants sont l'interféron $\gamma$, le tumor necrosing factor (TNF), les interleukines 1 et 2 . Le TNF (et peut-être d'autres cytokines) semble agir en synergie avec l'interféron $\gamma$. Le transforming growth factor $\beta$ (TGF $\beta$ ), les interleukines 4 et 10 sont des inhibiteurs de la production de NO par les macrophages. Il faut cependant noter que les mécanismes intimes des régulations exercées par ces cytokines sont mal connus, de même que les effets d'une rétroaction de NO sur les facteurs contrôlant sa production et sur les macrophages eux-mêmes (voir fig. 3.25). Le NO produit par les macrophages activés diffuse dans les tissus voisins où il peut agir directement sur les métallo-enzymes ou via la production de peroxynitrite et de radicaux $\left[\mathrm{OH}^{*}\right]$ (voir $\S 3.1$ ). Parmi les enzymes dont le fonctionnement est modifié et qui pourraient être impliquées dans les effets cytotoxiques de NO, figurent des enzymes du métabolisme énergétique de l'ADN. Ainsi, NO produit par les macrophages agirait sur l'aconitase mitochondriale, une enzyme clé du cycle de Krebs, enzyme qui pourrait être connue, au niveau cytoplasmique, sous un autre nom "l'iron regulatory factor" (un modulateur post-transcriptionnel de gènes impliqués dans le métabolisme du fer), ainsi que sur d'autres enzymes mitochondriales, la glycéraldéhyde-3-phosphate déshydrogénase (enzyme de la glycolyse) et la ribonucléotide réductase (enzyme qui convertit les ribonucléotides en désoxyribonucléotides utilisés dans la synthèse de l'ADN). De plus, NO déplète la teneur intracellulaire en glutathion, augmentant ainsi la susceptibilité au stress oxydatif. Il est probable que, suivant le type cellulaire, l'intensité du métabolisme énergétique et son type (glycolytique/lipolytique), l'action de NO sera plus ou moins intense et pourra conduire à une gamme d'effets allant de l'inactivation à la destruction cellulaire, en passant par des effets mutagènes. Finalement, de l'ensemble des données obtenues in vitro et in vivo, on peut considérer que $\mathrm{NO}$ peut avoir une action antiproliférative et qu'il peut être un nouveau médiateur de la réponse immunitaire non-spécifique (fig. 3.25). Cette opinion est fondée sur un certain nombre d'expériences réalisées in vivo et in vitro, qui ont permis de mettre en évidence les capacités antihelminthe, antibactérienne (Listeria, Fularemia, Salmonella, Mycobacterium), antivirale (Herpes, Vaccinia, Ectromelia), antifongique (Candida albicans, Cryptococcus), antiparasitaire (Leishmania, Plasmodium, Toxoplasma, Trypanasoma, Shistosoma). Néanmoins, là encore, les deux facettes de NO se manifestent. En effet, à côté de ses effets bénéfiques, il est probable qu'une production incontrôlée de NO pourrait être à l'origine de phénomènes d'auto-immunité (les macrophages activés sont cytotoxiques pour les cellules $\beta$ du pancréas) et d'immunosuppression par destruction des lymphocytes $\mathrm{T}$. 


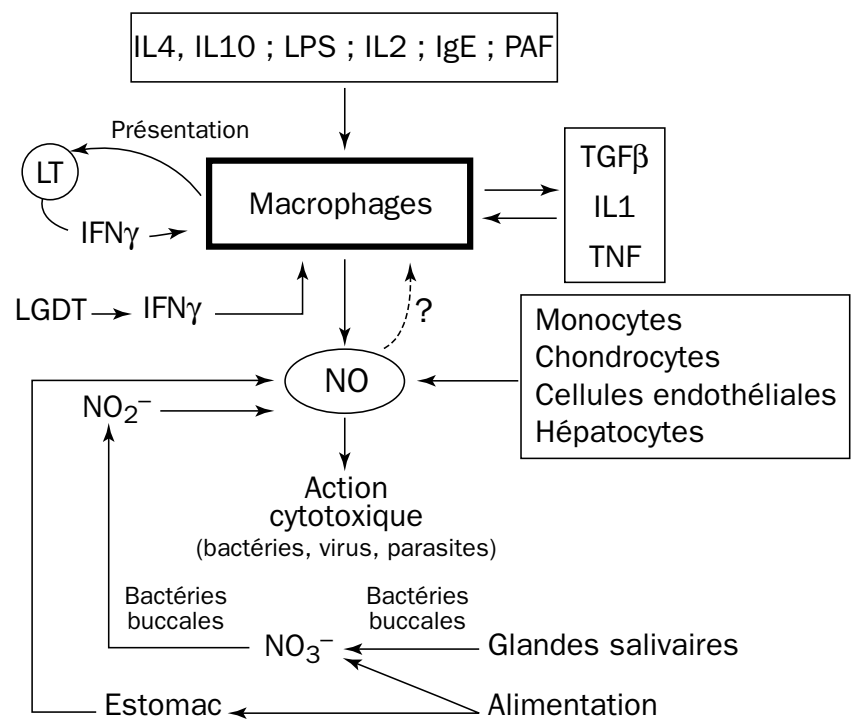

Figure 3.25 - Représentation schématique des différents types cellulaires impliqués dans une production cytotoxique de NO

IgE : immunoglobuline $E$; IFN $\gamma$ : interféron $\gamma ; \operatorname{IL1}, 2,4,10$ : interleukines 1, 2, 4, 10 ; $L T$ : lymphocyte $T$; PAF : platelet activating factor ; TGF $\beta$ : transforming growth factor $\beta$; TNF : tumor necrosing factor.

\subsubsection{Autres types cellulaires et cytotoxicité de NO}

Comme le montre la figure 3.25, d'autres types cellulaires peuvent produire du NO impliqué dans les mécanismes de défense de l'organisme. C'est le cas des monocytes activés par les immunoglobulines $\mathrm{E}$, des cellules endothéliales qui, in vitro, ont révélé un pouvoir antitumoral et des hépatocytes qui, in vitro, ont montré leur capacité de produire NO après activation par des cytokines.

En outre, il a été récemment montré que les nitrates contenus dans la salive (les glandes salivaires sont impliquées dans le métabolisme des nitrates ; leur teneur en nitrates est cent fois plus grande que celle du plasma) sont dégradés en nitrite par des bactéries de la surface de la langue. Ces nitrites, lorsqu'ils sont acidifiés par d'autres bactéries buccales, ou après ingestion dans l'estomac (il en serait de même des nitrites et nitrates ingérés), pourraient générer du NO. Ce NO serait alors susceptible d'exercer une action antiproliférative pour les bactéries et champignons ingérés comme certaines bactéries buccales ou Helicobacter pylori (facteur associé dans près de $90 \%$ des cas à l'ulcère gastrique). Ainsi, ce mode de production de NO serait un nouveau type de symbiose entre les bactéries et les Mammifères, symbiose dévolue à transformer les nitrates salivaires en nitrites et finalement en NO jouant un rôle protecteur.

Enfin, il a été rapporté une production excessive de NO dans les cas de colite ulcéreuse, de psoriasis, d'arthrite, de rejet du greffon, de certains types d'inflammation, de lupus érythémateux et de choc (voir § 3.3). Dans ces pathologies, les sources potentielles de NO peuvent être multiples, les cellules endothéliales, les 
cellules musculaires lisses vasculaires, les macrophages, les hépatocytes, les chondrocytes étant les principaux types cellulaires impliqués.

\section{Conclusions et perspectives}

La production de NO au niveau des macrophages, ainsi que son implication dans la réponse immunitaire non-spécifique, sont clairement démontrées et ouvrent la voie à de nouvelles recherches. Les inhibiteurs des NOS synthases deviendront probablement des agents importants dans le traitement des hypotensions induites par le choc septique, ou chez les cancéreux traités à l'aide de différents types de cytokines (interleukines 1 et 2 ; TNF). Il faut cependant noter qu'actuellement, des réserves sont formulées quant à leur utilisation (à cause des effets secondaires cardiaques et rénaux de ces inhibiteurs). Si les premiers travaux concernant un rôle de NO dans la régulation de l'expression génique et la mise en évidence des capacités mutagéniques de NO sont confirmés, c'est une nouvelle page qui s'ouvre dans notre connaissance de NO.

\subsection{NO ET LE SYSTÈME RESPIRATOIRE}

L'utilisation d'inhibiteurs de la synthèse de NO, la mise en évidence de NOS synthase au niveau de l'épithélium pulmonaire, les mesures de NO dans l'air expiré (en particulier la détection d'une production pulmonaire de NO et d'une surproduction dans certaines pathologies comme l'asthme) conduisent à penser que NO pourrait être un médiateur physiologique responsable d'une dilatation des bronches et des vaisseaux pulmonaires.

Chez l'homme et l'animal, l'inhalation de faibles doses de $\mathrm{NO}(<80 \mathrm{ppm})$ augmente les capacités respiratoires, la teneur en oxygène du sang et réverse la vaso-constriction observée lors d'hypoxie ou d'hypertension pulmonaire. Ces effets ne sont pas accompagnés d'hypotension systémique (NO est rapidement inactivé par l'hémoglobine). Dans toutes ces situations, NO semble agir par induction d'une dilatation des artérioles pulmonaires au niveau de segments pulmonaires dilatés donc mieux ventilés.

\section{Conclusions et perspectives}

Bien que l'inhalation de NO ait été présentée comme le traitement magique de certaines pathologies pulmonaires telles que l'hypertension pulmonaire (et par certains probablement comme une forme sans danger de dopage), elle doit être considérée, actuellement, comme une forme expérimentale de thérapie. Thérapie qui ne devrait être utilisée qu'avec précautions et dans le cadre de protocoles d'utilisation établis entre plusieurs équipes. En effet, l'inhalation de NO n'est certainement pas inoffensive. Les dangers potentiels peuvent résulter de l'interaction de $\mathrm{NO}$ avec $\mathrm{O}_{2}$ et $\mathrm{O}_{2}{ }^{-}$(voir $§ 3.1$ ) et de la probable potentialité mutagénique des dérivés oxygénés de l'azote (suspectés d'être générateurs des cancers pulmonaires provoqués par la fumée de cigarettes). 


\subsection{NO ET LE MUSCLE SQUELETTIQUE}

La mise en évidence, au niveau du muscle squelettique, d'une NO synthase de type neural ne date que de 1994. Cette forme de NOS, sensible au calcium, qui est plus abondante au niveau des fibres rapides (type II) est localisée au niveau du sarcolemme. Le rôle physiologique de NO produit à ce niveau est largement méconnu. Il est possible que le GMPc synthétisé sous l'action de NO, en particulier durant la contraction par activation de la NOS due à l'augmentation de calcium, puisse exercer une action inhibitrice sur la contraction. En revanche, les dérivés provenant de réactions de S-nitrosylation pourraient induire une libération de calcium par le réticulum et ainsi favoriser la contraction. Des travaux récents montrant une liaison de la NOS du sarcolemme avec le complexe protéique associé à la distrophine, de même que la diminution, chez les souris $m d x$ ou chez des patients atteints de myopathie de Duchesne, de la teneur sarcolemmique en NOS, suggèrent qu'une réduction de la production de NO serait, en partie, impliquée dans ce type de pathologie.

\section{Conclusions et perspectives}

L'implication de NO dans la physiologie musculaire n'avait, jusqu'alors, été montrée qu' au niveau de la synapse neuromusculaire. Une nouvelle ère de recherches s'ouvre avec ces premiers résultats. Ces recherches devraient permettre d'établir rapidement des corrélations entre certaines formes de myopathies congénitales présentant des lésions des tissus nerveux et musculaire.

\subsection{NO ET DIABÈTE}

Une cNOS ainsi qu'une iNOS ont été mises en évidence au niveau des cellules $\beta$ du pancréas. Une série de travaux convergents réalisés in vitro et in vivo - en particulier l'observation et la stimulation de la libération d'insuline par la L-arginine et son inhibition par des analogues non-métabolisables de celle-ci - conduisent à penser que $\mathrm{NO}$, dans les conditions physiologiques, pourrait participer à la régulation de la libération d'insuline. NO pourrait agir, entre autres modalités, via son action sur le métabolisme calcique. Il a été montré qu'une surproduction de NO par les cellules $\beta$ ou par les macrophages pourrait contribuer à l'induction du diabète de type I.

\section{Conclusions et perspectives}

Parallèlement à une meilleure compréhension du rôle de NO dans l'activité des cellules $\beta$ du pancréas, l'objectif actuel est de trouver un inhibiteur spécifique des NOS de ces cellules. Cet inhibiteur pourrait être un agent susceptible de limiter, sinon d'inhiber, la progression du nombre de malades atteints de diabète de type I. 


\subsection{NO - FUTURES DIRECTIONS}

NO, dont le rôle physiologique dans les processus de vaso-dilatation n'était que suspecté dans les années 80, est devenu, en 1992, la "Molécule de l'année" et voit sans cesse révélée son implication dans de nouveaux processus physiologiques.

Nos connaissances exactes des rôles et modes d'action de ce gaz restent néanmoins partielles. Ainsi, il est impossible de manipuler finement l'activité d'une NOS spécifique dans un type cellulaire donné. Gageons que l'intérêt thérapeutique (et financier) stimulant la recherche, ceci sera réalisé dans quelques années.

\section{LE FACTEUR ACTIVATEUR DES PLAQUETTES (PAF)}

Le facteur activateur des plaquettes (platelet activating factor ou PAF) est un phosphoglycéride. Il doit son nom au groupe de Benveniste qui, en 1972, avait étudié un médiateur produit par les basophiles, capable de stimuler le relargage d'amines vasoactives par les plaquettes. Ce n'est qu'en 1980 que la structure chimique du PAF a été clairement élucidée. Depuis, de nombreux travaux ont permis de montrer que cette molécule, impliquée dans de nombreux processus physiologiques et pathophysiologiques, est produite par une grande variété de types cellulaires où elle joue le rôle de médiateur inter- et/ou intracellulaire.

\subsection{STRUCTURE CHIMIQUE}

Le PAF est un phospholipide (1-O-alkyl-2-acétyl-sn-glycéro-3-phosphorylcholine) (fig. 3.26). Pour être actif, le PAF doit posséder un résidu O-alkyl éther de 14 à 18 atomes en position $s n-1$, un radical acyle court en position $s n-2$, la position $s n-3$ devant être occupée par un groupement polaire O-phosphorylcholine.

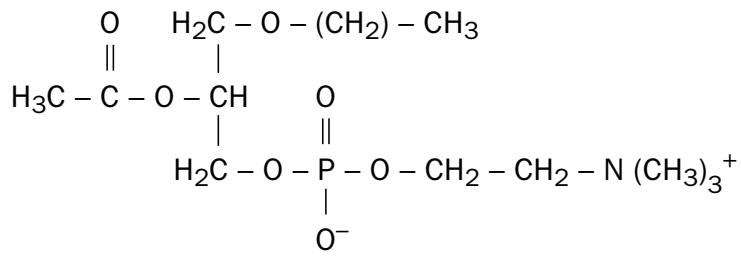

\section{Figure 3.26 - Structure chimique du PAF (platelet activating factor)}

Le PAF est un glycérophospholipide de formule 1-0-alkyl-2-acétyl-sn-glycéro-3-phosphorylcholine, où $n$ peut être égal à 15 ou 17.

Les analogues du PAF, obtenus (ou présents in vivo) par des variations de la longueur et de la saturation de la chaîne $s n-1$, peuvent être extrêmement actifs. Un grand nombre d'antagonistes spécifiques du PAF présentent des analogies structurales importantes avec le PAF. 


\subsection{MÉTABOLISME}

Deux voies métaboliques conduisent à la synthèse du PAF (fig. 3.27). L'une, la synthèse vicariante, utilise une molécule préexistante proche structuralement du PAF, molécule qui est remodelée, l'autre, la synthèse de novo, met en jeu le simple transfert d'une phosphorylcholine.

La biosynthèse de PAF a été mise en évidence au niveau des cellules endothéliales après stimulation par la bradykinine, la thrombine, l'angiotensine II (ensemble de messagers qui provoquent une augmentation du calcium libre intracellulaire). De même, le A 23187 (un calcium ionophore) induit la synthèse de PAF par les polynucléaires neutrophiles, éosinophiles, basophiles, les monocytes, les lymphocytes, les macrophages, les plaquettes, les cellules de Küpffer, les cellules rénales.

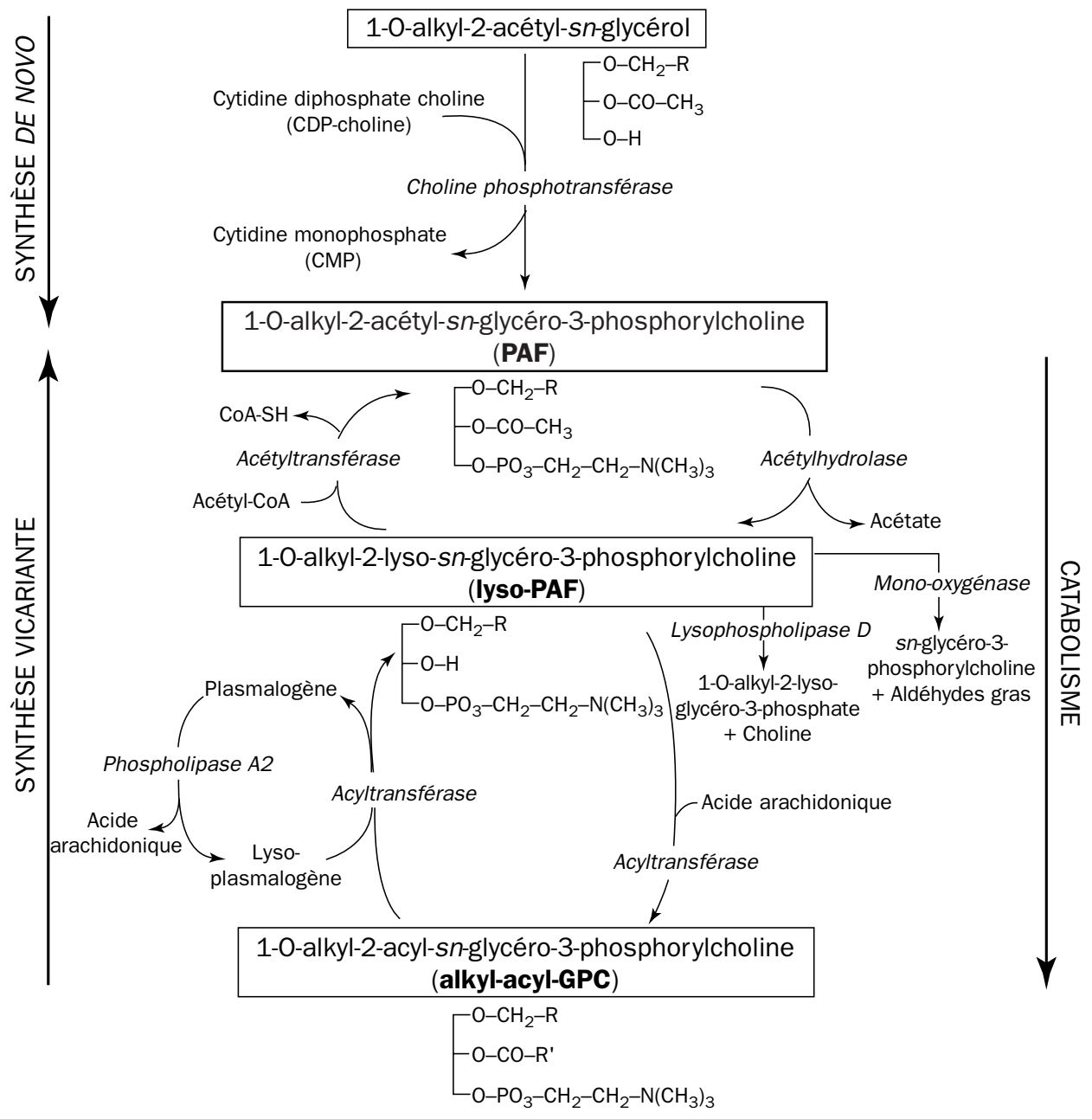

Figure 3.27 - Métabolisme du PAF

Biosynthèses et catabolisme du PAF (1-0-alkyl-2-acétyl-sn-glycéro-3-phosphorylcholine). 


\subsubsection{La synthèse vicariante}

Bien que cette synthèse ait été la première décrite, elle ne semble intervenir que dans des processus physiopathologiques (réponses allergique ou inflammatoire).

Elle implique un phospholipide, le 1-O-alkyl-2-acyl-sn-glycéro-3-phosphorylcholine qui, sous l'action d'une phospholipase A2 (activable par le calcium), conduit à la formation de 1-O-alkyl-2-lyso-sn-glycéro-3-phosphorylcholine ou lyso-PAF et d'acide arachidonique ${ }^{2}$. Ensuite, l'action d'une acyltransférase stimulée par le calcium, ainsi que par les kinases A et C, permet le transfert d'un acyl sur le lysoPAF pour donner le PAF.

\subsubsection{Synthèse de novo}

Dans cette synthèse, le transfert, sous l'action d'une choline phosphotransférase insensible au calcium, d'une phosphorylcholine à un 1-O-alkyl-2-acétyl-sn-glycérol, conduit directement à la synthèse de PAF. Il est probable que cette voie de synthèse permette une production basale de PAF qui pourrait jouer un rôle physiologique.

\subsubsection{Catabolisme}

Deux boucles successives de dégradation permettent de remonter les étapes de la synthèse vicariante. Dans la première, le PAF est catabolisé en lyso-PAF par une acétylhydrolase. Le lyso-PAF (composé toxique) peut suivre deux voies de dégradation. L'une - correspondant à la seconde boucle de la synthèse vicariante - conduit, sous l'action d'une acyltransférase inhibée par le calcium, à la réincorporation de l'acide arachidonique pour donner le 1-O-alkyl-2-acyl-sn-glycérol-3-phosphorylcholine. L'autre met en jeu une mono-oxygénase qui transforme le lyso-PAF en $s n$-glycéro-3phosphorylcholine. La première boucle d'activation/inactivation (PAF/lyso-PAF) est une plaque tournante de la biodisponibilité de ce médiateur. Cependant, il semble bien que, dans certaines conditions et dans certains types cellulaires, seule une faible partie du PAF synthétisé soit sécrétée. Ceci suggère que le PAF pourrait être à la fois un médiateur des communications inter- et intracellulaires.

\subsection{LES RÉCEPTEURS DU PAF ET LEUR ACTIVATION}

\subsubsection{Les récepteurs}

L'utilisation du [H3]-PAF a permis de montrer l'existence de récepteurs hautement spécifiques du PAF sur les membranes d'un grand nombre de types cellulaires, aussi bien chez les rongeurs que chez l'homme. Ces récepteurs, dont la densité est faible (quelques centaines par cellule) ont été observés dans les cellules nerveuses, endothéliales, musculaires lisses, les cellules de la lignée hématoḯtiques, ainsi qu'au niveau

2 L'acide arachidonique, ainsi que ses produits de dégradation sont eux-mêmes des messagers fortement actifs (voir chap. $2, \S 2.2 .7$ ). 
des tissus hépatique, rénal et pulmonaire. Ils possèdent sept domaines transmembranaires et sont couplés à des protéines G. Les récepteurs pour le PAF montrent une grande hétérogénéité d'un type cellulaire à l'autre, tant dans l'affinité vis-à-vis du PAF $\left(K_{D}\right.$ de $10^{-11}$ à $\left.10^{-5} \mathrm{M}\right)$ que dans la coexistence sur le même type cellulaire de plusieurs types de récepteurs d'affinités différentes. Il semble aussi exister des différences dans l'intensité de l'action des antagonistes du PAF et des différences dans les effets de l'activation de ces récepteurs par le PAF. Le PAF régule directement l'expression de ses récepteurs (down-regulation). Les protéine kinases $\mathrm{A}$ et $\mathrm{C}$ (lorsque cette dernière est fortement stimulée) inhibent les récepteurs pour le PAF. En revanche, la protéine kinase $C$ faiblement activée les stimule. Par ailleurs, les ions modulent la liaison PAF/R-PAF, ainsi, $\mathrm{Na}^{+}$et $\mathrm{Zn}^{2+}$ l'inhibent alors que $\mathrm{Mg}^{2+}$, $\mathrm{Ca}^{2+}, \mathrm{Mn}^{2+}$ la favorisent.

De plus, l'existence de récepteurs du PAF sur les membranes intracellulaires a été montrée dans quelques types cellulaires, corroborant ainsi l'hypothèse d'un rôle de messager intracellulaire pour le PAF.

\subsubsection{Activation des récepteurs du PAF}

L'activation des récepteurs du PAF conduit, via la mise en jeu de protéines $\mathrm{G}$, à une stimulation directe des canaux calciques, à la production de DAG et d'IP3, ainsi qu'à celle d'acide arachidonique (fig. 3.28). La production de ce dernier messager et de ses dérivés peut conduire à des actions paracrines et autocrines (voir chap. $2, \S 2.2 .7$ ).

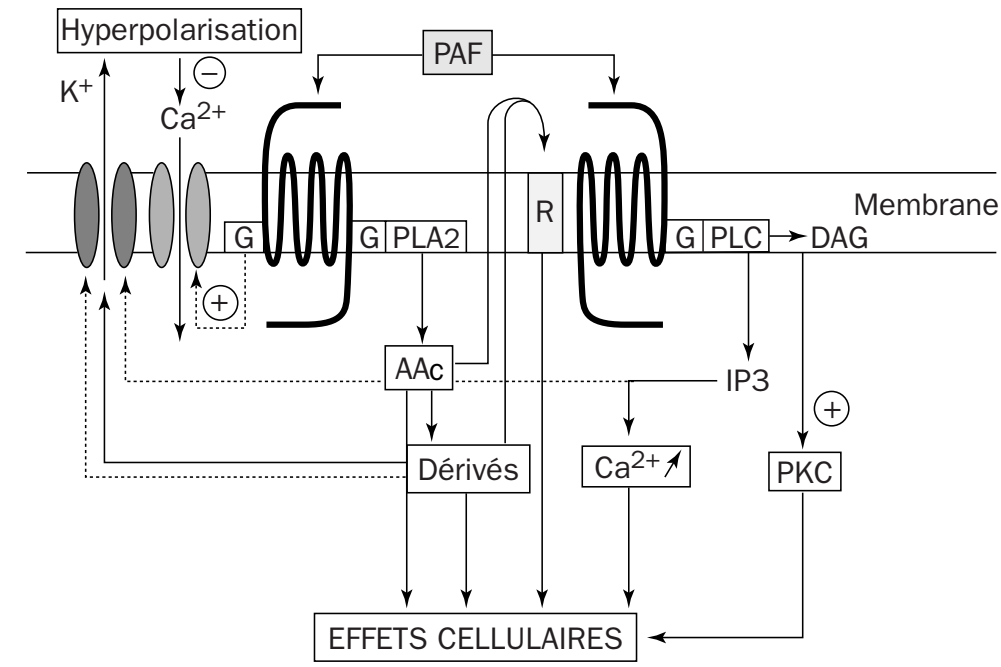

Effets immédiats : modifications des activités enzymatiques et caractéristiques des canaux ioniques Effets tardifs : modulation de l'expression génétique

Figure 3.28 - Effets de l'activation des récepteurs du PAF

$A A c$ : acide arachidonique ; DAG : diacylglycérol ; $G$ : protéine $G$; IP3 : inositol $(1,4,5)$ triphosphate ; PAF : platelet activating factor ; PKC : protéine kinase C ; PLA2 : phospholipase $A 2$; $P L C$ : phospholipase $C$; $R$ : récepteurs de l'AAC ou récepteurs de ses dérivés. 


\subsection{RôLES PHYSIOLOGIQUES}

Le PAF produit lors de situations physiologiques ou physiopathologiques est actif pour des concentrations comprises entre $10^{-12} \mathrm{M}$ et $10^{-9} \mathrm{M}$. La grande variété de ses récepteurs, ainsi que celle des seconds messagers qui découlent de leur stimulation, conduit à de multiples effets cellulaires, dont certains sont pathologiques. Le tableau 3.5 (non-exhaustif) récapitule les principaux effets biologiques du PAF.

\subsection{CONCLUSIONS ET PERSPECTIVES}

Le PAF agit via la mise en jeu de récepteurs spécifiques variés dont l'activation conduit à la synthèse de multiples seconds (troisième, quatrième) messagers. Cette grande diversité explique la diversité en qualité et en intensité des réponses biologiques initiées par le PAF. L'utilisation des techniques de la biologie moléculaire et de l'immunologie devrait permettre de mieux comprendre l'origine de l'hétérogénéité des récepteurs et, par là, devrait conduire à la synthèse d'antagonistes et/ou d'agonistes spécifiques d'un type d'action donnée. Enfin, le rôle du PAF dans les mécanismes d'adhésion (et de migration) cellulaire reste à explorer.

\section{L'ENDOTHÉLINE}

L'endothéline est essentiellement produite par l'endothélium vasculaire (fig. 3.29).

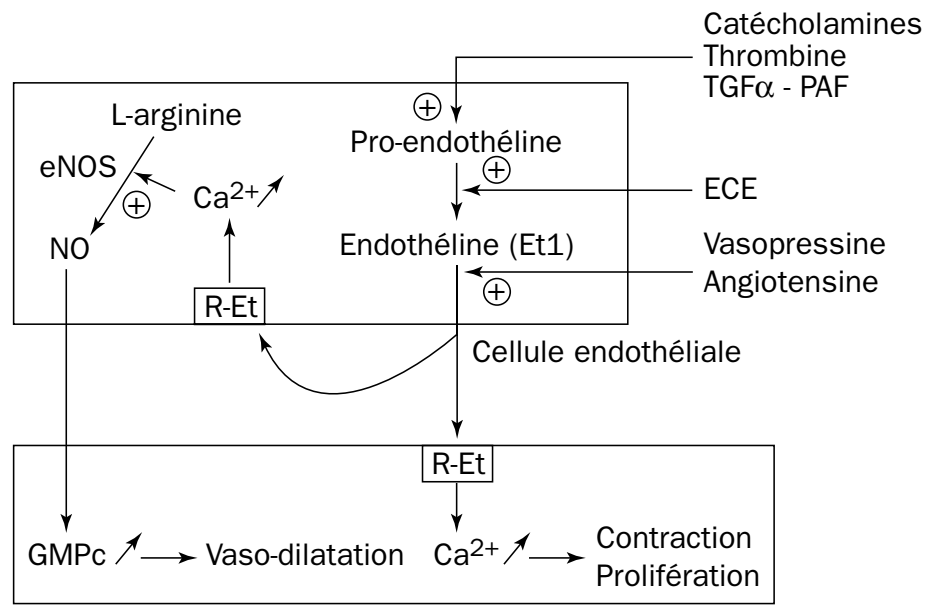

Cellule musculaire lisse

Figure 3.29 - Représentation schématique de la synthèse et de la libération d'endothéline (Et1) par l'endothélium vasculaire

ECEt: enzyme de conversion de l'endothéline; eNOS: NO synthase constitutive de l'endothélium ; PAF : platelet activating factor ; $R$-Et : récepteur à l'endothéline ; TGF $\alpha$ : transforming growth factor $\alpha$. 
Tableau 3.5 - Principaux effets biologiques du PAF

\section{Plaquettes}

- Adhésion - agrégation - formation de thrombus

- Relargage par les plaquettes d'amines vaso-actives

\section{Système cardio-vasculaire}

- Vaso-dilatation

- Hypotension - modification des résistances vasculaires périphériques

- Extravasion plasmatique

- Choc : hypotension gravissime, modification des perméabilités

- Athérogenèse

- Réduction du débit coronaire et de la force de contraction du myocarde

- Arythmie

\section{Système immunitaire}

- Chimiotactisme des polynucléaires éosinophiles et neutrophiles

- Stimulation des polynucléaires neutrophiles, éosinophiles, basophiles et des macrophages

- Production de radicaux libres

- Inflammation

- Rejet de greffes

- Manifestations allergiques - eczéma

- Anaphylaxie

- Chocs endotoxiniques

\section{Système rénal}

- Hémodynamique rénale

- Filtration glomérulaire - transport des électrolytes

- Altérations rénales

- Modulation de la production de rénine

\section{Système respiratoire}

- Broncho-constriction

- Asthme

\section{Système gastro-intestinal}

- Hypertension portale

- Stimulation de la sécrétion pancréatique

- Pancréatites

- Formation d'ulcères gastro-intestinaux

- Glycogénolyse hépatique

\section{Système reproducteur}

- Ovulation - fertilisation - nidation - grossesse - parturition

\section{Système nerveux}

- Neuromodulateur

- Potentialisation à long terme (LTP) ?

- Edème cérébral 
La masse de celui-ci $(2 \mathrm{~kg})$ et sa surface $\left(1000 \mathrm{~m}^{2}\right)$, ainsi que la grande variété de substances qu'il produit, en font une véritable glande diffuse. L'endothéline est un petit peptide de 21 AA. Il existe trois isoformes de l'endothéline appelées Et1, Et2, Et3. Seule Et1 est produite par l'endothélium et Et3 semble être impliquée dans les mécanismes de neurotransmission centrale. Ces trois isoformes codées par trois gènes différents sont produites sous forme de pré-pro-endothéline, clivée en proendothéline, puis finalement sous l'action d'une enzyme de conversion (ECEt) en endothéline. L'enzyme de conversion de l'endothéline (ECEt) a été localisée au niveau de différents organes (rein, poumons, microcirculation, système nerveux...).

Il existe deux types de récepteurs à l'endothéline (R-EtA et R-EtB). L'activation de ces récepteurs conduit à la synthèse d'inositol $(1,4,5)$ triphosphate et de diacylglycérol, et donc à la libération de calcium par le réticulum ainsi qu'à l'activation de la protéine kinase C. Les récepteurs à l'endothéline sont présents sur un grand nombre de types cellulaires (cellules endothéliales et musculaires lisses vasculaires ; cardiomyocytes, neurones).

\section{EFFETS CARDIO-VASCULAIRES DE L'ENDOTHÉLINE}

La production majeure d'endothéline est réalisée par l'endothélium, ce qui explique ses effets au niveau du système cardio-vasculaire. L'effet majeur immédiat de l'endothéline est une vaso-constriction et donc une augmentation de la pression artérielle. Cette vaso-constriction résulte de la libération de calcium au niveau des cellules musculaires lisses (fig. 3.30). Cependant, l'activation de ses récepteurs portés par les cellules endothéliales induit une vaso-dilatation temporaire. Cette vaso-dilatation est due à la stimulation de la NO synthase constitutive endothéliale, enzyme activée par le calcium. L'action de l'endothéline sur le muscle cardiaque, ainsi que sur le système nerveux central, contribue aussi à une augmentation de la pression artérielle.

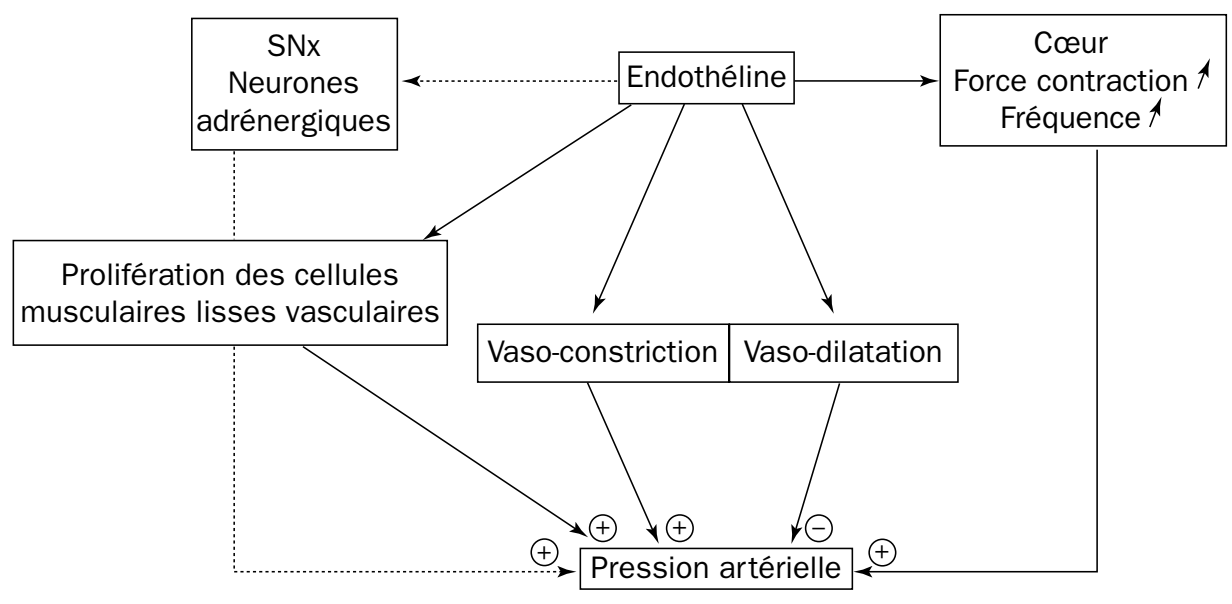

Figure 3.30 - Représentation schématique des effets de l'endothéline sur la pression artérielle 
L'utilisation d'inhibiteur des récepteurs à l'endothéline ainsi que la production d'animaux transgéniques ont permis de montrer qu'il existe une production basale d'endothéline. Cette observation, alliée à d'autres données expérimentales, laisse penser qu'un dérèglement de la production d'endothéline et/ou de la synthèse de ses récepteurs pourrait être responsable de certains types d'hypertension artérielle. Aussi, les travaux actuels s'orientent-ils vers la production d'inhibiteurs des récepteurs à l'endothéline et l'élaboration d'un vaccin anti-endothéline.

\section{L'ECDYSONE}

\subsection{ISOLEMENT DE L'ECDYSONE}

L'hormone de mue ou ecdysone (fig. 3.31) a été isolée pour la première fois par Butenandt et Karlson, en 1954. En traitant $500 \mathrm{~kg}$ de chrysalides de ver à soie (Bombyx mori), ils ont obtenu $25 \mathrm{mg}$ d'hormone cristallisée. Par la suite, ils obtinrent $100 \mathrm{mg}$ d'ecdysone à partir de $3000 \mathrm{~kg}$ de chrysalides.

Si l'on injecte du cholestérol tritié à un asticot de Calliphora, on retrouve de l'ecdysone radioactive dans son sang ou son hémolymphe (les insectes étant incapables de synthétiser un stérol, l'ecdysone a son origine dans le cholestérol alimentaire).

Immédiatement après sa synthèse, l' $\alpha$-ecdysone est déversée dans l'hémolymphe. Elle est convertie dans le corps gras en $\beta$-ecdysone qui est beaucoup plus active et qui circule dans l'hémolymphe liée à une protéine, comme les hormones stéroïdes chez les Vertébrés.
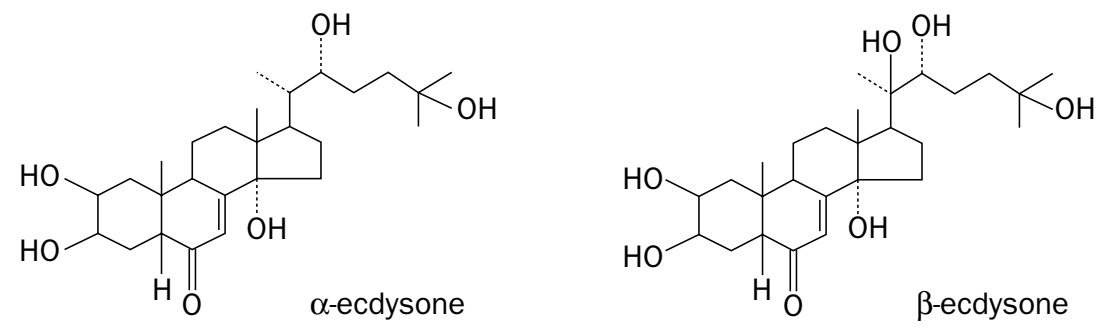

Figure 3.31 - Structure de l'ecdysone

\subsection{LE PUPARIUM DES DIPTÈRES}

La nymphe des Diptères est une pupe, entourée par un puparium constitué par la dernière cuticule larvaire brunie et durcie.

La formation de ce puparium est un phénomène de sclérotisation (brunissement et durcissement), il est sous la dépendance de l'ecdysone. Or, la cuticule des Insectes renferme essentiellement des protéines riches en tyrosine, et associées à de la chitine (qui est un polymère de $\mathrm{N}$-acétylglucosamine). 
Fraenkel ligature une larve de mouche Calliphora erythrocephala en arrière de l'anneau de Weissmann. La région antérieure seule forme un puparium, si on pose la ligature avant la "période critique" ( $16 \mathrm{~h}$ avant la formation du puparium). L'unité Calliphora a été définie comme la quantité d'ecdysone nécessaire pour déclencher la formation du puparium dans le tronçon postérieur d'une larve ainsi ligaturée. Elle correspond à $0,0075 \mu \mathrm{g}$ d'hormone cristallisée, soit 7,5 ng d'ecdysone.

\subsection{CHROMOSOMES GÉANTS ET PUFFS (fig. 3.32)}

Les Diptères possèdent quatre paires de chromosomes homologues $(2 \mathrm{n}=4)$ :

I : ce sont les chromosomes sexuels XY ou XX (si XY, Y est très court par rapport à $\mathrm{X}$ ),

II : $107 \mu \mathrm{m}$ de long,

III : $106 \mu \mathrm{m}$ de long,

IV : le plus petit a $0,1 \mu \mathrm{m}$ de long.

Ces chromosomes sont réunis par un chromocentre chez Drosophila (fig. 3.32.a) et seulement soudés deux à deux chez Chironomus.

Des dilatations riches en ARN, appelée puffs ou anneaux de Balbiani, apparaissent au niveau des bandes (correspondant à un ou plusieurs locus de gènes), à des moments et à des endroits variés. Quelques locus forment des puffs seulement à certains stades de la métamorphose; les gènes correspondants prennent part à des activités métaboliques en rapport avec ces stades (fig. 3.32.b).

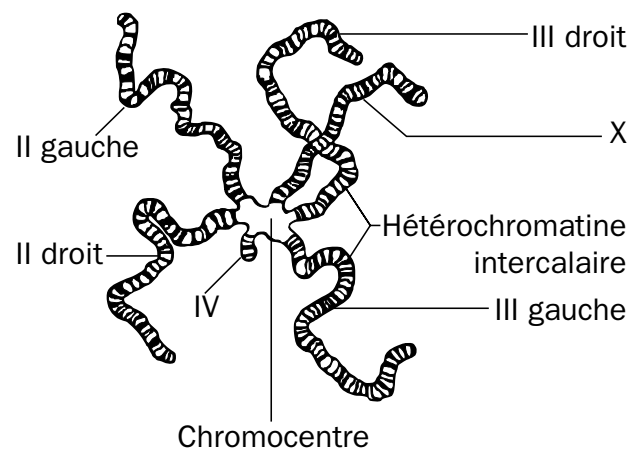

a - Chromosome de

Drosophila melanogaster

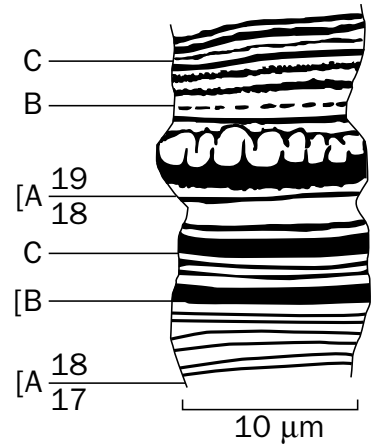

b - Loci 18 et 19 du chromosome I de Chironomus tentans

Figure 3.32 - Chromosomes géants de Diptères (d'après Beermann, 1952)

\subsection{MISE EN ÉVIDENCE DU RÔLE DE L'ECDYSONE}

- En 1960, Clever et Karlson injectent de l'ecdysone au dernier stade larvaire de Chironomus. Ceci déclenche la métamorphose. Or :

- 15 à 30 min après l'injection, apparaît un puff au niveau du chromosome I au locus $18 \mathrm{C}$; 
- 30 min à $1 \mathrm{~h}$ après, un autre puff au niveau du chromosome IV, au locus $2 \mathrm{~B}$. Par la suite apparaissent d'autres puffs, mais ils ne sont pas caractéristiques car ils s'observent aussi à l'intermue. Puis, plus tard, se forment des puffs caractéristiques de la période prénymphale qui prélude à la métamorphose, en même temps qu'augmente le métabolisme protidique.

Il existe au moins deux gènes dont la mise en activité est spécifique de la métamorphose, et qui ont été activés par l'hormone spécifique.

Le seuil de réaction de ces gènes a pu être établi à l'aide de quantités très faibles d'ecdysone :

- pour le locus $18 \mathrm{C}$ de I : avec $10^{-7} \mathrm{mg}$ d'extrait larvaire ;

- pour le locus $2 \mathrm{~B}$ de IV : avec $10^{-6} \mathrm{mg}$ d'extrait larvaire.

L'adjonction à l'eau de l'aquarium d'actinomycine D (qui bloque l'ARN polymérase et agit donc sur la transcription) fait disparaître ces puffs.

Chez des prénymphes qui entrent en diapause avant d'avoir accompli leur mue nymphale (sans doute par insuffisance d'ecdysone dans l'hémolymphe de 1'Insecte), ces puffs n'apparaissent pas.

- En 1952, Karlson et Sekeris prouvent, à l'aide de substances marquées, que l'ecdysone intervient en deux points de cette chaîne en provoquant la synthèse de deux enzymes : la DOPA-décarboxylase et une phénoloxydase.

On peut évidemment se demander si l'action de l'ecdysone sur les chromosomes est une action directe ou indirecte. Or :

- l'apparition des puffs est le premier des effets observables de l'ecdysone : les changements de téguments n'apparaissent que 20 à $30 \mathrm{~h}$ après l'injection ;

- des doses d'ecdysone infimes font apparaître les puffs mais ne déclenchent pas la nymphose.

Karlson est alors conduit à penser, tenant compte des données sur la structure de l'ADN et du schéma de Monod et Jacob, que l'ecdysone agit sur le chromosome en déspiralant l'hélice à un locus donné (dérépression du gène). Ceci se traduit par la synthèse de l'ARN messager qui se concrétise, sur ces chromosomes géants, par l'apparition d'un puff. Ce puff correspond à ce qu'on appelle maintenant un complexe de transcription (déroulement en boucles du nucléofilament d'ADN + histones, sites de synthèse des fibrilles d'ARN en cours d'élongation).

Depuis les travaux de Karlson, les mécanismes d'action des hormones stéroïdes sont mieux connus et rentrent dans le cadre des messagers à récepteurs nucléaires (voir chap. $2, \S 4)$.

Le gène du récepteur de l'ecdysone (R-Ec) a été cloné. Le complexe lié à l'ADN comporte deux protéines, l'une R-Ec est le produit du gène, l'autre est une protéine "ultraspiracle", USP (messager unique d'un gène usp), homologue des récepteurs R$\mathrm{XR}$, constituant un hétérodimère (voir chap. 2, § 4). Chacune des protéines de l'hétérodimère comporte un site de liaison avec l'ecdysone et un site de liaison avec l'ADN. Les ecdystéroïdes régulent ainsi, de façon séquentielle, plusieurs classes de 
gènes (fig. 3.33) (Leid et coll., 1992 ; Deutsch, 1993 ; Thomas et coll., 1993 ; Yao et coll., 1993). L'action des ecdystéroïdes sur différents ARNm a été étudiée par Hiruma et coll. (1997).

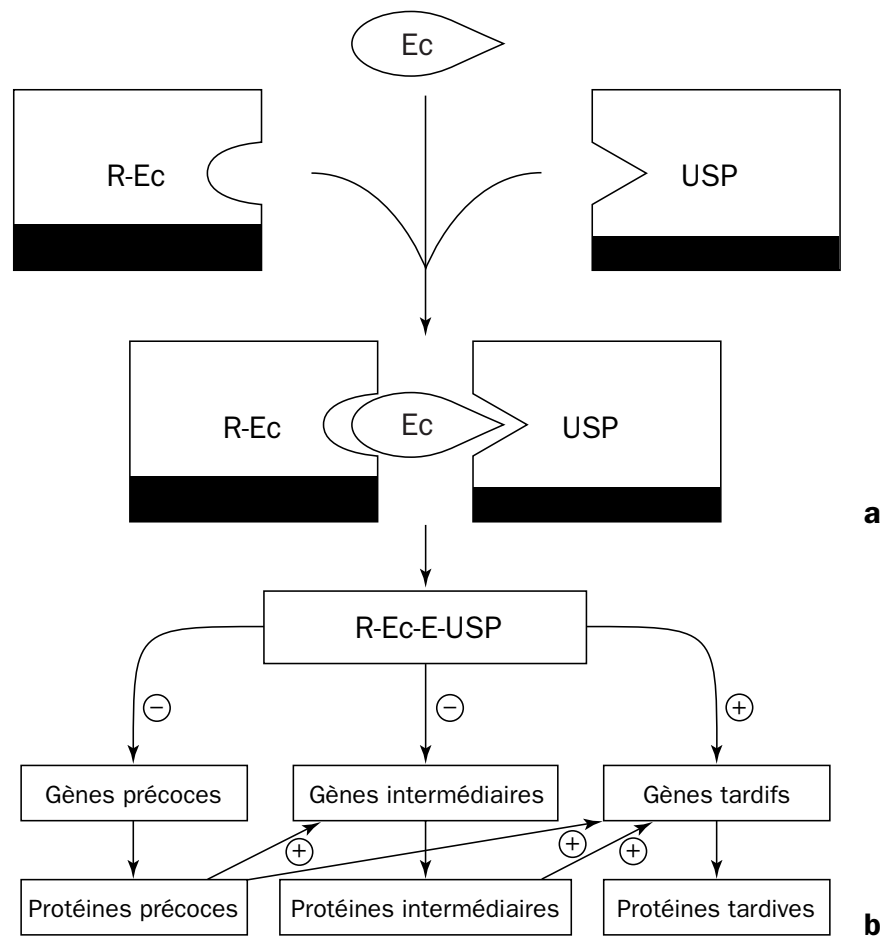

Figure 3.33 - Représentation schématique de l'action des ecdystéroïdes sur leurs cellules cibles

Ec : ecdysone ; R-Ec : récepteur de l'ecdysone ; R-Ec-E-USP : hétérodimère constitué par le récepteur de l'ecdysone et la protéine ultraspiracle, liés à l'ecdysone; USP: protéine ultraspiracle.

a - La formation d'un hétérodimère (R-Ec-E-USP) entre le récepteur à l'ecdysone (R-EC) et le produit du gène ultraspiracle (USP) conduit à un complexe actif dont une partie (noire) correspond au domaine de fixation à l'ADN.

$\boldsymbol{b}$ - La régulation de la transcription des gènes se déroule selon un modèle dérivé de celui proposé par Ashburner en 1974, certains gènes seraient activés et d'autres réprimés. Les produits de l'activation des gènes précoces déréprimeraient des gènes intermédiaires dont les produits agiraient pour déréprimer les gènes tardifs. 


\section{RÉFÉRENCES BIBLIOGRAPHIQUES DE LA PREMIÈRE PARTIE}

\section{MÉTHODES UTILISÉES EN ENDOCRINOLOGIE}

AHARONOWITZ Y. \& COHEN G., Les micro-organismes et l'industrie pharmaceutique, Pour la Science, $\mathrm{n}^{\circ}$ spécial novembre, 93-105, 1981a.

AHARONOWITZ Y. \& COHEN G., The microbiological production of pharmaceuticals, Sci. Am., 245, 140-152, 1981 b.

AVRAMEAS S., Immunoenzyme techniques: enzymes as markers for the localization of antigens and antibodies, Int. Rev. Cytol., Bourne \& Danielli eds, 27, 349-407, Academic Press, New York \& London, 1970.

ENGVALL E. \& PERLMANN P., Enzyme-linked immunosortent assay (ELISA), Quantitative assay of immunoglobulin G, Immunochemistry, 8, 871-874, 1971.

LEMARCHANDEL V. \& MONTAGUTELLI X., La recombinaison homologue, Médecine/Sciences, 6, 18-29, 1990.

RANE S.G., DUBUS P., METTUS R.V., GALBREATH E.J., BODEN G., REDDY E.P. \& BARBACID M., Loss of Cdk4 expression causes insulindeficient diabetes and Cdk4 activation results in $\beta$-islet cell hyperplasia, Nature genetics, 22, 44-52, 1999.

TOUITOU Y., FEVRE M., LAGOGUEY M., CARAYON A., BOGDAN A., REIBERG A., BECK H., CESSELIN F. \& TOUITOU C., Age and mental health-related circadian rhythm of plasma levels of melatonin, prolactin, luteinizing hormone and follicle-stimulating hormone in man, J. Endocrinol., 91, 467-475, 1981.

VIVILLE S., Recombinaison homologue : nouveaux vecteurs, nouvelles perspectives, Médecine/Sciences, 11, 735-746, 1995.

YALOW R.S. \& BERSON S.A., Immunoassay of endogenous plasma insulin in man, J. Clin. Invest., 39, 1157-1175, 1960. 


\section{LES MESSAGERS CHIMIQUES}

\section{MÉCANISMES DE TRADUCTION DE LEUR INFORMATION}

ASHBURNER M., CHIHARA C., MELTZER P. \& RICHARDS G., Temporal control of puffing activity in polytene chromosomes, Cold Spring Harb. Sym. Quant. Biol., 38, 655-662, 1974.

BAULIEU E.E. \& KELLY P.A., Hormones, Hermann, Paris, 1990.

BEATO M., Gene regulation by steroid hormones, Cell, 56, 335-344, 1989.

CHAN L. \& O’MALLEY B.W., Steroid hormone action : recent advances, Ann. Intern. Med., 89, 694-701, 1978.

CSABA G. (ed.), Development of hormone receptors, Birkhaüser Verlag, 1987.

EVANS R.M., The steroid and thyroid hormone receptor superfamily, Science, 240, 889-895, 1988.

FEUILLOLEY M. \& coll., Quels sont les rôles du cytosquelette dans les processus de sécrétion des hormones stéroïdes ?, Médecine/Sciences, 5, 674-677, 1989.

GORSKI J., The nature and development of steroid hormone receptors, in "Development of hormone receptors", Csaba G. ed., 67-77, 1987.

GROYER A. \& coll., Antiglucocorticosteroid effects suggest why steroid hormone is required for receptors to bind DNA in vivo but not in vitro, Nature, 328, 624626, 1987.

HANOUNE J. \& SALTIEL H., Mécanisme d'action des hormones, Enc. Méd. Chir., 1510-4.10.06, 1984.

HOULE B. \& BRADLEY W.E.C., Cancer du poumon, rétinoïdes et RAR $\beta$, Médecine/Sciences, 9, 528-533, 1993.

LAVAU C., JANSEN J., WEIS K., LAMOND A. \& DEJEAN A., Leucémie aiguë promyélocytaire et acide rétinoïde : le paradoxe, Médecine/Sciences, 10, 817-824, 1994.

LEID M., KASTNER P. \& CHAMBON P., Multiplicity generated diversity in the retinoic acid signalling pathways, Trends Biochem. Sci., 17, 427-433, 1992.

O'MALLEY A., Steroid hormone action in eucaryotic cells, J. Clin. Invest., 74, 307312, 1984.

VAISSE C., Leptine : après le récepteur, la voie de transduction, Médecine/Sciences, 13, 99-101, 1997. 


\section{DES MESSAGERS CHIMIQUES PARTICULIERS}

\section{Facteurs de croissance}

COHEN S., Isolation of a mouse submaxillary gland protein accelerating incisor eruption and eyelid opening in the new-born animal, J. Biol. Chem., 237, 15551559, 1962.

DER GEER P. (Van) \& HUNTER T., Receptor protein-tyrosine kinases and their signal transduction pathways, Ann. Rev. Cell. Biol., 10, 251-337, 1994.

PAWSON T., Protein modules and signaling network, Nature, 373, 573-580, 1995.

SEGER R. \& KREBS G. (de), The MAPK signaling cascade, Faseb J., 728, 726-735, 1995.

WOLOWIEC D. \& FRENCH M., Kinases dépendantes des cyclines : rôles biologiques et implications dans la pathologie humaine, Médecine/Sciences, 12, 165-173, 1996.

\section{Kinines}

BASCONDS J.L. \& GIROLAMI J.P., La bradykinine. Médecine/Sciences, 5, 582-592, 1996.

BHOOLA K.D., FIGUEROO C.D. \& WORTHY K., Bioregulations of kinins : kallikreins, kininogens, and kinases, Pharmacol. Rev., 44, 1-80, 1992.

CARBINI L., GUILLERMO SICLI A. \& CARRETERO O.A., The molecular biology of the kallikrein-kinin system : III. The human kallikrein gene family and kallikrein substrate, J. Hypertension, 11, 893-898, 1993.

LINZ W., WIEMER G. \& SCHÖLKENS B.A., Role of kinins in the pathophysiology of myocardial ischemia. In vitro and in vivo studies, Diabetes, 45, 551-558, 1996.

\section{NO}

ÄNGGOR E., Nitric oxide : mediator, murderer, and medicine, Lancet, 343 : 8907, 1199-1206, 1994.

BREDT D.S. \& SNYDER S.H., Nitric oxide : a physiological messenger molecule, Annu. Rev. Biochem., 63, 175-195, 1994.

FURCHGOTT R.F. \& ZAWADZKI J.V., The obligatory role of endothelial cells in the relaxation of arterial smooth muscle by acetylcholine, Nature, 288, 373-376, 1980.

GARTHWAITE J. \& coll., Nitric oxide signaling in the control nervous system, Annu. Rev. Physiol., 57, 683-736, 1988. 
GRIFFITH O.W. \& STUEHR D.J., Nitric oxide synthases : properties and catabolytic mechanism, Annu. Rev. Physiol., 57, 707-736, 1995.

GROSS S.S. \& WOLIN M.S., Nitric oxide : pathophysiological mechanisms, Annu. Rev. Physiol., 57, 737-769, 1995.

KERWIN J.F., HELLER J.R. \& M., The arginine-nitric oxide pathway : a target for new drugs, Med. Res. Rev., 14, 23-74, 1994.

KOSTKA P., Free radicals (Nitric oxide), Anal. Chem., 57, 411R-416R, 1995.

LINCOLN T.M. \& CORNWELL T.L., Intracellular cyclic GMP receptor proteins, 7, 328-338, Faseb J., 1993.

MEHTA J.L., Endothelium, coronary vasodilatation and organic nitrates, Am. Heart J., 129, 382-391, 1995.

MONCADA S., HIGGS E.A. \& PALMER R.M., Characterization and biological significance of endothelium-derived relaxing factor, Biochem. Soc. Trans., 16, 484-486, 1988.

RAND M.J. \& LI C.G., Nitric oxyde as a transmitter in peripheral nerves : nature of transmitter and mechanism of transmission, Annu. Rev. Physiol., 57, 659-682, 1995.

UMANS J.G. \& LEVI R., Nitric oxide in the regulation of blood flow and arterial pressure, Annu. Rev. Physiol., 57, 771-790, 1995.

ZHANG J. \& SNYDER S.H., Nitric oxide in the nervous system, Annu. Rev. Pharmacol. Toxicol., 35, 213-233, 1995.

\section{PAF}

BRAQUET P., Ginkgolides chemistry, biology, pharmacology and clinical perspectives, J.R. Prous Science ed., 1988.

CHAO W. \& OLSON M.S., Platelet-activating factor : receptors and signal transduction, Biochem. J., 292, 617-629, 1993.

DISERBO M., Action du Platelet-Activating Factor (PAF) sur les cellules de la lignée N1E-115 : effets sur la concentration du calcium libre cytosolique et sur les flux ioniques transmembranaires, Thèse de l'Université de Grenoble I, 1995.

VENABLE M.E., ZIMMERMAN G.A., Mc INTYRE T.M. \& PRESCOTT S.M., Platelet-activating factor : a phospholipid autocoid with diverse actions, J. Lipid Res., 34, 691-702, 1993.

\section{Endothélines}

DOUGLAS S.A. \& OHLSTEIN E.H., Signal transduction mechanisms mediating the vascular actions of endothelin, J. Vasc. Res., 34, 152-164, 1997. 
KRÄMER B.K., ITTNER K.P., BEYER M.E., HOFFMEISTER H.M. \& RIEGGER G.A., Circulatory and myocardial effects of endothelin, J. Mol. Med., 75, 886-980, 1997.

NEWBY D.E. \& WEBB D.J., Advances in clinical pharmacology and therapeutics : endothelin, Brit. J. Hosp. Med., 56, 360-364, 1996.

ORLÉANS-JUSTE P. (d'), GRATTON J.P., LEDUC R., BKAILY G. \& CLAING A., L'endothéline : pharmacologie cardiovasculaire et considérations physiopathologiques, Médecine/Sciences, 12, 563-564, 1996.

ORTEGA MATEO A. \& ARTIÑANO A.A., Highlights on endothelins : a review, Pharmacol. Res., 36, 339-351, 1997.

ROSENDORFF C., Endothelin, vascular hypertrophy, and hypertension, Cardiovasc. Drug Ther., 10, 795-802, 1997.

SCHIFFRIN E., L'endothéline est-elle impliquée dans l'hypertension?, Médecine/Sciences, 12, 599-608, 1996.

TURNER A.J. \& MURPHY L.J., Molecular pharmacology of endothelin converting enzymes, Biochem. Pharmacol., 51, 91-102, 1996.

WARREN J.B. (ed.), The endothelium, J. Wiley \& Sons, 1990.

WEBB D.J., Endothelin : from molecule to man, Brit. J. Clin. Pharmaco., 44, 9-20, 1997.

\section{Ecdysone}

DEUTSCH J., Ultraspiracle et récepteur de l'ecdysone ou les relations dans la famille des récepteurs hormonaux nucléaires de la drosophile au mammifères, Médecine/Sciences, 9, 701-705, 1993.

HIRUMA K., BÔCKING D., LAFONT R. \& RIDDIFORD L.M., Action of different ecdysteroids on the regulation of mRNAs for the ecdysone receptor, MHR3, dopa decarboxylase, and a larval cuticle protein in the larval epidermis of the tobacco hornworm, Manduca sexta, Gen. Comp. Endocr., 107, 84-97, 1997.

LEID M., KASTNER P. \& CHAMBON P., Multiplicity generated diversity in the retinoic acid signalling pathways, Trends Biochem. Sci., 17, 427-433, 1992.

THOMAS H.E., STUNNENBERG H.G. \& STEWART A.F., Heterodimerization of the Drosophila ecdysone receptor with retinid $\mathrm{X}$ receptor and ultraspiracle, Nature, 362, 471-475, 1993.

YAO T.P., FORMAN B.M., JIANG Z., CHERBAS L., CHEN J.D., Mc KNEOWN M., CHERBAS E. \& EVANS R.M., Functional ecdysone receptor is the product of EcR and ultraspiracle genes, Nature, 366, 476-479, 1993. 



\section{DEUXIÈME PARTIE}

\section{ENDOCRINOLOGIE GÉNÉRALE}

Chapitre 4 Le complexe hypothalamo-hypophysaire

Chapitre 5 La glande thyroüde

Chapitre 6 Les glandes surrénales

Chapitre 7 Le pancréas endocrine

Chapitre 8 Les parathyroüdes et l'équilibre phosphocalcique

Chapitre 9 Les structures endocrines diffuses

Chapitre 10 L'épiphyse 



\section{CHAPITRE 4}

\section{LE COMPLEXE}

\section{HYPOTHALAMO-HYPOPHYSAIRE}

L'hypophyse a été longtemps considérée comme le "chef d'orchestre" des glandes endocrines. En fait, son fonctionnement est "contrôlé” par l'hypothalamus.

Logée dans la selle turcique (qui fait partie de l'os sphénoïde), l'hypophyse est une glande grossièrement sphérique, appendue à la face ventrale de l'hypothalamus. Elle pèse environ $0,6 \mathrm{~g}$ chez l'homme.

\section{EMBRYOLOGIE DE L'HYPOPHYSE}

Son origine est mixte (fig. 4.1) :

- nerveuse, par le diverticule infundibulaire issu du plancher du $3^{\mathrm{e}}$ ventricule (origine hypothamique);

- ectodermique, par un diverticule qui s'isole en une poche chez les Mammifères : la poche de Rathke (origine stomodéale).

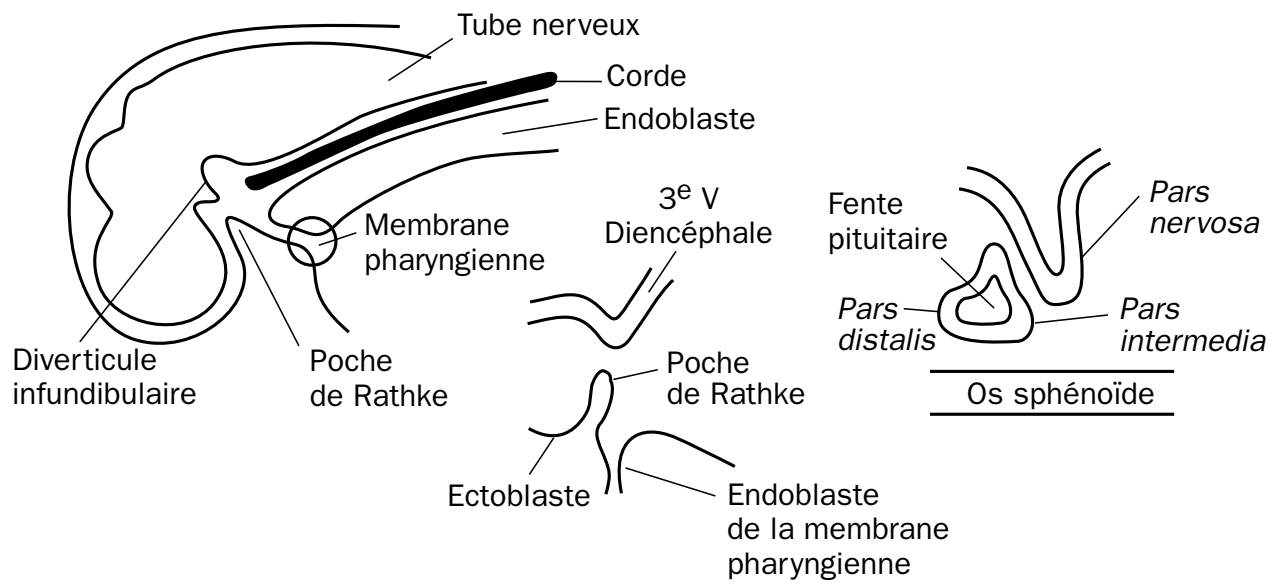

Figure 4.1 - Développement de l'hypophyse chez le Mammifère 
La neurohypophyse est formée de l'éminence médiane ou infundibulum (portion rétro-chiasmatique du plancher du $3^{\mathrm{e}}$ ventricule), de la tige infundibulaire (pituitaire) et de la pars nervosa $(\mathrm{PN})$.

L'adénohypophyse est formée de la pars distalis (PD), de la pars intermedia (PI) et de la pars tuberalis (PT).

\section{HISTOLOGIE DU COMPLEXE HYPOTHALAMO-HYPOPHYSAIRE ${ }^{1}$}

\subsection{HISTOLOGIE DE L'ADÉNOHYPOPHYSE}

L'adénohypophyse est constituée de trois parties (voir fig. 4.2) :

- la pars distalis constituée de cellules sécrétrices endocrines.

- la pars intermedia qui n'existe pas chez les Oiseaux et est peu développée chez l'homme adulte. On y distingue des travées cellulaires à type sécrétoire et des fibres nerveuses d'origine hypothalamique.

- la pars tuberalis (lobe infundibulo-tubéral) qui est formée de cordons cellulaires peu différenciés. Elle est peu développée chez les Mammifères.

\subsection{Histologie DE LA PARS NERVOSA (PN)}

Elle est caractérisée par une richesse en fibres nerveuses dont les corps cellulaires (péricaryons) se trouvent dans l'hypothalamus, ainsi que par la présence de cellules névrogliques (pituicytes).

\subsection{HISTOLOGIE DE L'HYPOTHALAMUS}

Le système circulatoire sera décrit p. 46.

On distingue chez l'homme (fig. 4.2) :

- un hypothalamus antérieur, comprenant les noyaux supra-optiques (NSO) et rétro-chiasmatiques, les noyaux suprachiasmatiques, les noyaux pré-optiques et les noyaux paraventriculaires (NPV);

- un hypothalamus médian, avec le noyau dorso-médian en haut et le noyau ventro-médian et le noyau infundibulaire (ou arqué) en bas ;

- un hypothalamus postérieur avec l'aire dorsale en haut, les noyaux supra- et prémamillaires en bas.

1 En plus de ces relations avec l'hypophyse, l'hypothalamus est intégré dans un ensemble "système limbique-hypothalamus-zone réticulée du tronc cérébral" par des voies nerveuses dont la principale est le faisceau médian du télencéphale. 


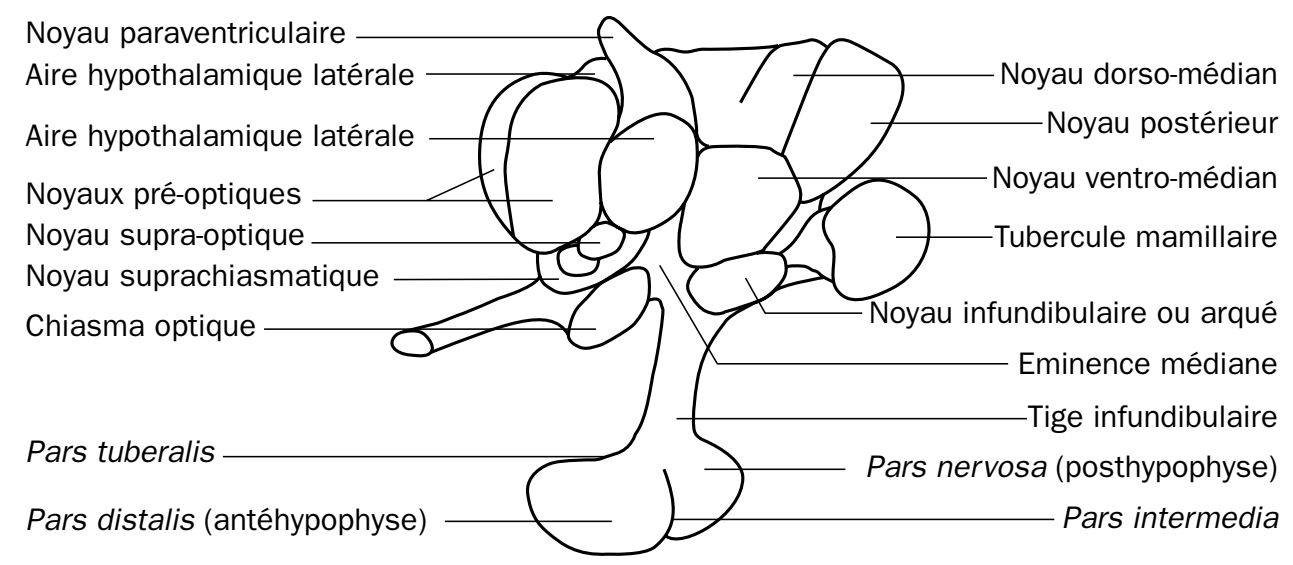

Figure 4.2 - Structure générale du complexe hypothalamo-hypophysaire chez l'homme

Dans ces différents territoires, il est distingué :

- des neurones à peptides hypophysiotropes, dont les corps cellulaires se trouvent non seulement dans l'hypothalamus, au niveau du noyau ventro-médian, du noyau arqué et du NPV, mais aussi dans des régions extrahypothalamiques. Un certain nombre de ces neurones vont constituer le tractus tubéroinfundibulaire. Il a été mis en évidence, par immuno-histochimie, des neurones à GnRH, mais aussi à peptides de type ACTH, MSH, LPH, endorphine et enképhaline. La plus grande partie de ces fibres se termine au contact du réseau capillaire primaire du système porte hypophysaire (fig. 4.3.a).

- des neurones à peptides post- (ou neuro-) hypophysaires, provenant pour la plupart des NSO et NPV. Ils constituent l'essentiel du tractus supra-opticohypophysaire, dont la majorité des fibres se terminent dans la PN et dans la zone externe de l'éminence médiane (fig. 4.3.b).

- des neurones mono-aminergiques : noradrénaline (NA), dopamine (Da), sérotonine (5-HT).

- les neurones dopaminergiques font partie du système tubéro-infundibulaire. Dans le noyau arqué, se trouvent côte à côte des neurones à somatostatine et des noyaux à dopamine ;

- les neurones noradrénergiques constituent un faisceau réticulaire ventroascendant dont les corps cellulaires sont localisés dans le bulbe et dans la protubérance, et se terminent dans la région pré-optique ;

- les neurones sérotoninergiques localisés dans le mésencéphale se terminent dans l'hypothalamus antérieur et dans l'éminence médiane.

On a pu observer dans le faisceau tubéro-infundibulaire des dendrites de neurones infundibulaires, permettant de véritables réflexes hypothalamo-hypophyso-hypothalamiques. 


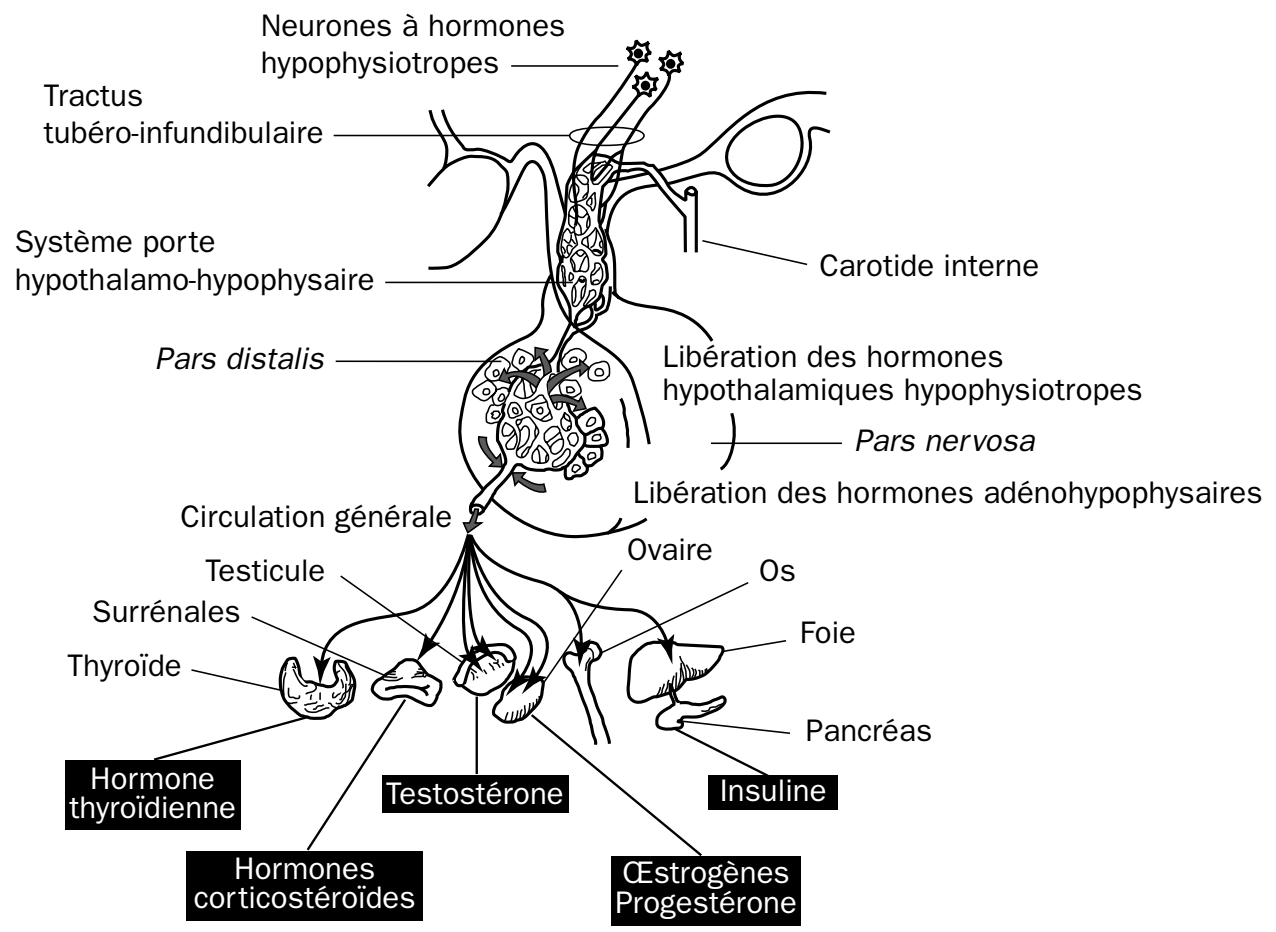

\section{a - Hypophyse antérieure}

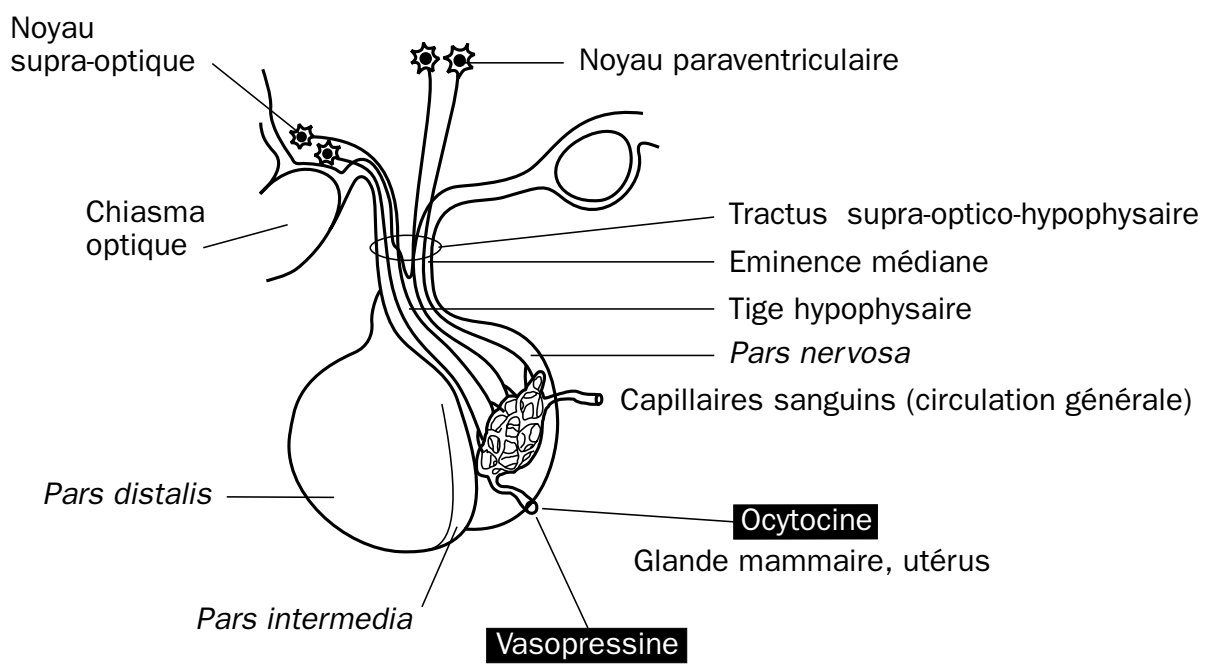

Régulation de l'équilibre hydrique

\section{b - Hypophyse postérieure}

Figure 4.3 - Le complexe hypothalamo-hypophysaire et ses relations neurovasculaires 
Enfin des cellules différenciées de l'épithélium épendymaire du $3^{\mathrm{e}}$ ventricule, les tanicytes, bombent dans la cavité ventriculaire et s'étendent ("stretch cells") jusqu'au voisinage des vaisseaux du système porte. Certains auteurs ont émis l'hypothèse que les cellules pouvaient transporter les peptides hypothalamiques ou des mono-amines, et les déverser soit dans la circulation porte, soit dans le liquide céphalo-rachidien.

\section{DONNÉES ANATOMO-CLINIQUES ET EXPÉRIMENTALES}

\subsection{DONNÉES ANATOMO-CLINIQUES}

Ce sont des syndromes pathologiques d'hyper- et d'hypofonctionnement de l'hypophyse (ou de l'hypothalamus).

\section{L'hyperfonctionnement peut donner :}

- de l'acromégalie ${ }^{2}$ ou gigantisme (adénome des cellules $\alpha$ );

- un syndrome de Cushing (provoqué par une tumeur hypophysaire ou surrénalienne).

\section{L'hypofonctionnement peut donner :}

- un syndrome adiposo-génital de l'enfant (résultant d'une lésion hypothalamique ou d'une tumeur hypophysaire) ;

- le syndrome de Sheehan survenant (par ischémie hypophysaire) à la suite d'une hémorragie lors d'un accouchement (voir $§ 9.1 .2 .2$ ). Le défaut de lactation et l'involution mammaire sont les premiers signes d'un tableau de cachexie grave.

\subsection{DONNÉES EXPÉRIMENTALES : L'HYPOPHYSECTOMIE}

L'hypophysectomie n'est pas mortelle. Elle a été pratiquée chez tous les animaux de laboratoire. Chez l'homme, en cas de tumeur, on peut pratiquer soit une ablation partielle (chirurgicale), soit une destruction totale (application de produits radioactifs).

Les troubles provoqués correspondent à la déficience en hormones sécrétées par les différentes glandes endocrines que stimule le complexe hypothalamo-hypophysaire. L'effet de l'hypophysectomie diffère suivant qu'elle est pratiquée chez le jeune ou chez l'adulte.

- L'absence de gonadostimulines entraîne une atrophie des gonades, de l'aménorrhée chez la femme, l'involution des caractères sexuels secondaires et la perte de la libido. Chez le jeune, il n'y a pas d'apparition de la puberté.

- L'absence de thyréostimuline provoque un abaissement du métabolisme basal, de la bradycardie, de l'hypothermie. Il n'y a pas de métamorphose chez le Batracien.

2 L'acromégalie est plus souvent due à un déficit en sécrétion de somatostatine (GH-IH) hypothalamique, qu'à une hypersécrétion de GH hypophysaire. 
- L'absence de corticostimuline provoque hypoglycémie, hypotension, ainsi qu'une diminution de la résistance aux agressions.

- L'absence d'hormone de croissance entraîne une déficience de l'anabolisme protidique, la tendance à l'hypoglycémie. Elle provoque l'arrêt de la croissance chez le jeune. La croissance de la larve de Batracien n'est que légèrement ralentie.

- Il y a dépigmentation chez le Batracien par suppression de la MSH.

- L'absence d'hormones de la pars nervosa provoque une polyurie transitoire et de l'hypotension.

\section{LES HORMONES DE LA PARS DISTALIS ET DE LA PARS INTERMEDIA (tab. 4.1)}

Ce sont neuf hormones ${ }^{3}$ que l'on peut regrouper, en fonction de leurs similitudes de structure ou d'origine, en trois groupes :

- hormone de croissance (GH) et prolactine ( $\mathrm{Prl})$;

- hormones thyréotrope (TSH) et gonadotropes (FSH et LH) ;

- hormones corticotropes, toutes dérivées d'un même précurseur (POMC).

\subsection{L'HORMONE DE CROISSANCE (STH = somatotropic hormone ou $\mathrm{GH}=$ growth hormone)}

\subsubsection{Caractéristiques générales}

Cette hormone est sécrétée par les cellules $\alpha$. C'est une protéine de PM environ 20000 et plus. Sa structure varie selon les espèces animales, le PM est d'autant plus bas que l'animal est plus élevé dans l'échelle de l'évolution. Son activité ne s'exerce que sur l'espèce dont elle est extraite ou sur des espèces animales moins évoluées (elle est active dans le sens descendant de l'échelle évolutive). La séquence des acides aminés chez l'homme (191 AA) est connue, la chaîne polypeptidique possède deux ponts S-S entre C 53 - C 165 et C 182 - C 89 (fig. 4.4). En fait, elle est élaborée sous la forme d'une pro-hormone qui comprend 26 AA supplémentaires.

L'activité biologique de cette hormone nécessite la présence des 134 premiers AA. La séquence des acides aminés de l'hormone de croissance humaine (HGH) est très proche de celle de l'hormone lactogène placentaire ( $85 \%$ de résidus identiques) et voisine de celle de la prolactine humaine (32\% de résidus identiques). Sa demi-vie dans le plasma est, chez l'homme, de 20 à 30 min et son taux plasmatique moyen de 2 à $4 \mathrm{ng} / \mathrm{ml}$ chez l'adulte jeune (correspondant à une sécrétion de 1 à $2 \mathrm{mg}$ par jour) et de 5 à $8 \mathrm{ng} / \mathrm{ml}$ chez l'enfant et l'adolescent.

3 L'hypophyse sécrète aussi du FGF (fibroblast growth factor) et probablement d'autres facteurs de croissance. 


\begin{tabular}{|c|c|c|c|c|c|c|c|c|c|}
\hline 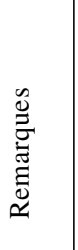 & & & 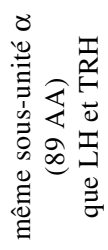 & 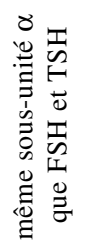 & 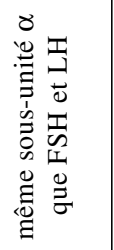 & & & 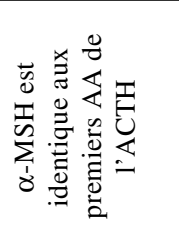 & \\
\hline 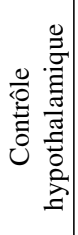 & 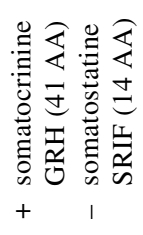 & 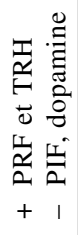 & 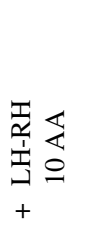 & $\begin{array}{l}\text { 焉 } \\
\text { 岕 } \\
+ \\
+\end{array}$ & 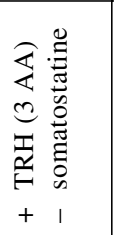 & 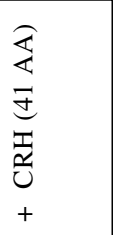 & & & \\
\hline 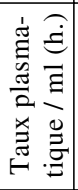 & 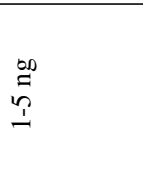 & 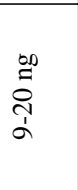 & $\begin{array}{l}\stackrel{\infty}{\stackrel{1}{i}} \\
\stackrel{i}{\sim}\end{array}$ & $\begin{array}{l}\stackrel{\infty}{\Xi} \\
\stackrel{n}{I} \\
I\end{array}$ & $\begin{array}{l}\frac{0}{3} \\
\frac{1}{1} \\
0 \\
0\end{array}$ & 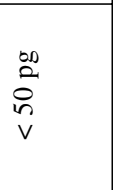 & 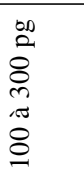 & $\begin{array}{l}\text { के } \\
\text { مे }\end{array}$ & \\
\hline 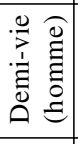 & $\begin{array}{l}\text { 苂 } \\
0 \\
\text { ते } \\
\text { ते }\end{array}$ & $\begin{array}{l}\text { 声 } \\
\text { 只 }\end{array}$ & $\begin{array}{l}\text { 罗 } \\
\stackrel{\rho}{\varrho}\end{array}$ & 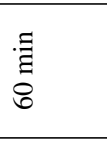 & 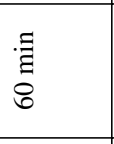 & 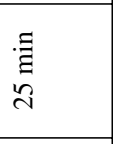 & & & \\
\hline 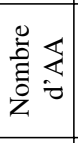 & 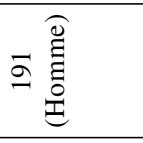 & 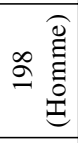 & 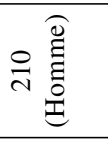 & 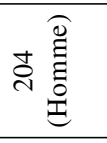 & 穴 & ले & б & $\underset{\square}{11}$ & $\vec{m}$ \\
\hline$\sum_{\Omega}^{i}$ & 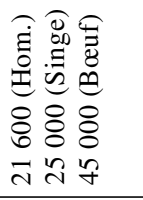 & 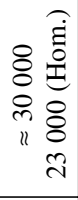 & 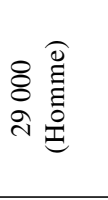 & 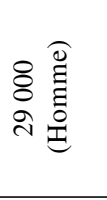 & 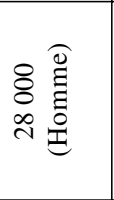 & $\begin{array}{l}8 \\
i n \\
+ \\
11\end{array}$ & $\begin{array}{l}8 \\
8 \\
0 \\
11\end{array}$ & & \\
\hline 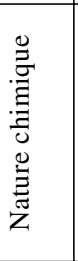 & 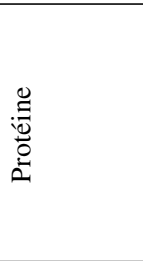 & $\begin{array}{l}0 \\
\text { : } \\
0 \\
0 \\
0\end{array}$ & 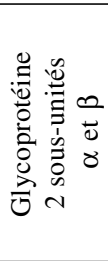 & 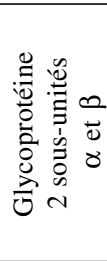 & 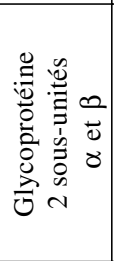 & 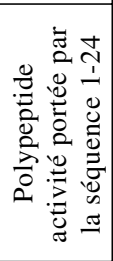 & 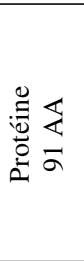 & 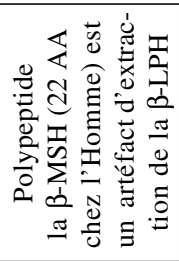 & 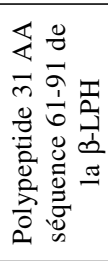 \\
\hline 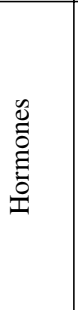 & 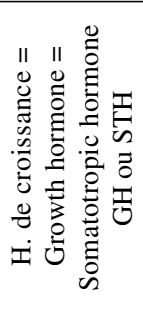 & 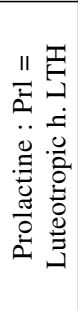 & 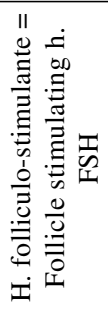 & 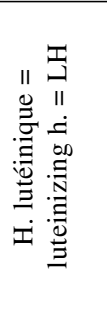 & 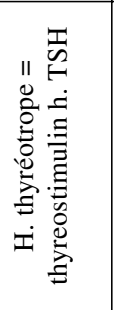 & 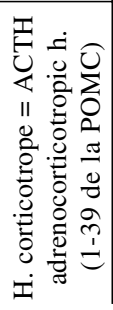 & 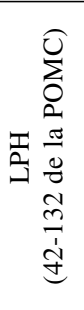 & 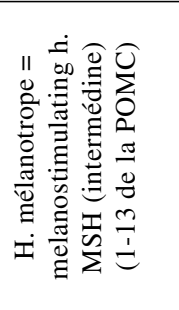 & 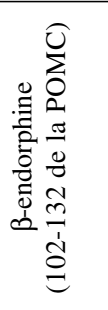 \\
\hline 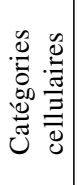 & 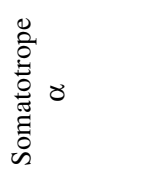 & 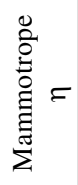 & 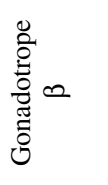 & 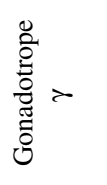 & 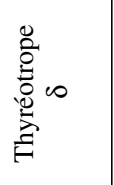 & \multicolumn{4}{|c|}{ 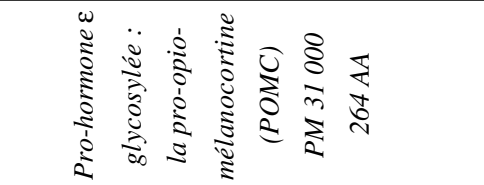 } \\
\hline & - & $\mathrm{N}$ & $m$ & $\forall$ & $n$ & \multicolumn{4}{|c|}{6} \\
\hline
\end{tabular}




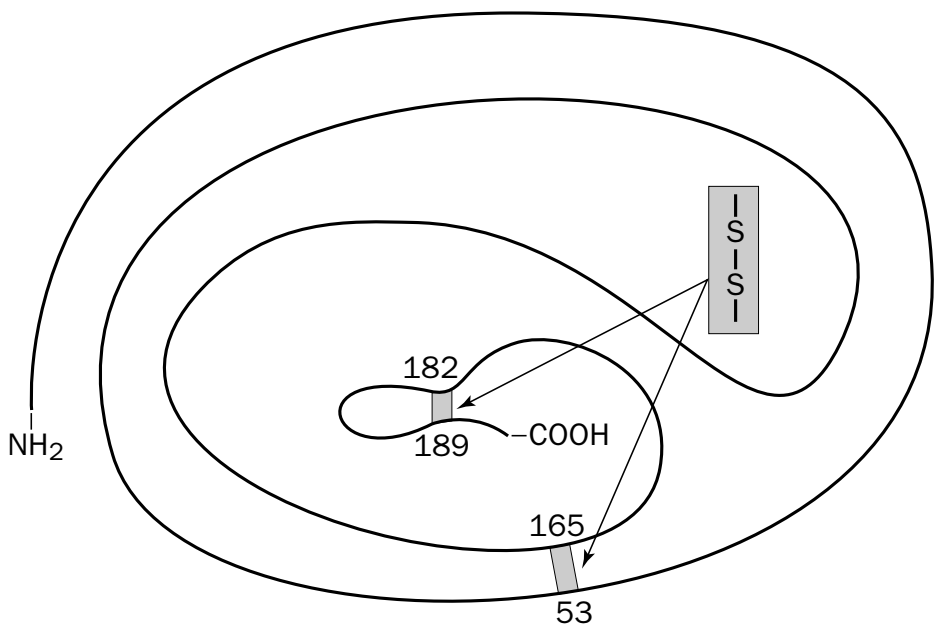

Figure 4.4 - Structure de I'hormone de croissance humaine (d'après Li et coll., 1969)

Le taux s'élève 3 à $4 \mathrm{~h}$ après le repas, ainsi qu' $1 \mathrm{~h}$ après le début du sommeil. La GH est sécrétée de façon pulsatile, avec une période d'environ $3 \mathrm{~h}$ chez le rat (fig. 4.5), mais il n'y a pas de rythme ultradien chez l'homme.

Si la régulation de la pulsatilité est centrale (hypothalamique) sous l'influence de la sécrétion antiparallèle de la GH-RH et de la somatostatine, la GH intervient également dans le contrôle de sa propre pulsatilité (Epelbaum et coll., 1977).

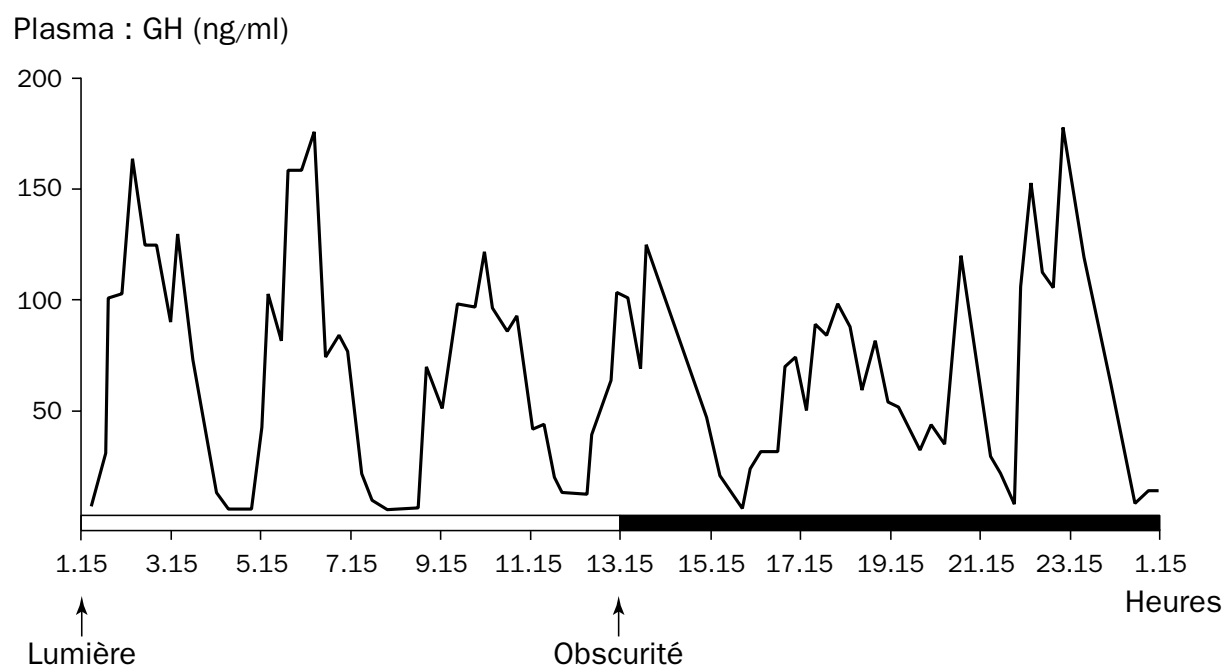

Figure 4.5 - Sécrétion pulsatile de la GH chez le rat (d'après Tannenbaum et Martin, 1976)

On a pu isoler l'ARNm codant la biosynthèse de l'hormone de croissance humaine (HGH) et en faire la copie en ADN par la transcriptase réverse. Le gène (présent sur le chromosone 17) a pu être introduit et exprimé dans des colibacilles en culture et dans des cellules animales (issues de rein de singe). 


\subsubsection{Action}

- L'hormone de croissance est une hormone pléiotrope qui agit à la fois comme facteur de croissance (os et muscles) et comme facteur de différenciation et régulateur métabolique (foie, tissu adipeux et muscles). Elle est donc un agent anabolisant physiologique indispensable à la croissance staturale et au maintien de la masse protéique chez l'adulte. Son action sur la croissance s'exerce de manière dépendante de la dose, ce qui n'est pas le cas d'autres hormones (insuline, hormones thyroïdiennes) qui participent aussi à la régulation de la croissance corporelle. La déficience en GH entraîne le nanisme et son excès l'acromégalie.

- Elle stimule davantage la chondrogenèse que l'ostéogenèse, déterminant une multiplication des cellules du cartilage sérié (hypertrophie des cartilages de conjugaison).

- C'est une hormone "métabolique" :

- Elle stimule l'anabolisme protidique (à partir des acides aminés dont elle favorise le transport à l'intérieur de la cellule).

- C'est une hormone hyperglycémiante, diabétogène (elle active la sécrétion du glucagon).

- Elle stimule la mobilisation des lipides qui sont catabolisés pour pourvoir aux besoins énergétiques de l'organisme, entraînant une augmentation des AGL (acides gras libres, non-estérifiés) dans le plasma. La glycogenèse peut s'effectuer à partir des lipides mobilisés (néoglucogenèse), ce qui accroît le pouvoir diabétogène de la GH. L'action de la GH sur la lipolyse est une action directe au niveau des tissus adipeux. Elle est donc de type anti-insulinique.

\subsubsection{Contrôle}

La sécrétion de GH est contrôlée par l'hypothalamus.

- Elle est activée par la GRH ou somatocrinine (voir § 6.1.1), facteur de décharge constitué par 37, 40 ou 44 AA.

- Elle est inhibée par la somatostatine (14 AA). Le déficit de la GH, lorsqu'il survient avant la maturité sexuelle, entraîne un nanisme. Son excès provoque :

- avant la maturité sexuelle, un gigantisme ;

- après la maturité sexuelle, de l'acromégalie (croissance en épaisseur des os au niveau des extrémités et de la face).

\subsubsection{Récepteur et mode d'action de la GH}

Le récepteur de l'hormone de croissance fait partie de la superfamille des cytokines (Carter-Su et coll., 1996 ; voir chap. 2, § 2.1.4).

La GH n'agit pas toujours directement sur les cellules cibles. Elle permet en effet la synthèse et l'action d'un ensemble de facteurs d'origine hépatique, les somatomédines. Il s'agit d'un ensemble de substances qui sont des composés proches de l'insuline, dits "insulin-like growth factors" (IGF). Elles sont véhiculées dans le sang 
par une protéine de transport. Les principales sont IGF1 (somatomédine A) et IGF2 (somatomédine $\mathrm{C}$ ). On distingue donc des effets directs (sur le cartilage sérié des os longs) et indirects (via les somatomédines) de la GH.

L'action de l'hormone de croissance au niveau de son récepteur passe par trois étapes (Le Cam et Lagraverand, 1993) :

- la liaison de l'hormone avec son récepteur. Une molécule d'hormone se lie à deux molécules de GH-BH (GH binding protein), qui est produite chez l'homme par coupure protéolytique de la partie extracellulaire du récepteur. Cela suggère que la dimérisation du récepteur est importante pour son internalisation et la transmission du message hormonal ;

- la transmission du signal (transduction) passe par au moins deux voies (fig. 4.6) : - celle initiée par la phosphorylation de la protéine JAK2 qui possède une fonction tyrosine kinase. Elle conduit à la phosphorylation de la protéine ribosomale S6, ce qui induit une augmentation de la synthèse protéique.

- celle des médiateurs dérivés de la dégradation des lipides membranaires (phosphoinositides et protéine kinase C) ;

- l'activation d'une phospholipase conduit à la stimulation de la protéine kinase C qui, dans l'hépatocyte, stimule l'activation de différents gènes, en particulier ceux codant pour IGF1. Cette action de la protéine kinase $\mathrm{C}$, qui nécessite la présence d'une protéine inconnue (?), est modulée par la protéine kinase A (voir chap. 2, $\S 2.1 .4)$.

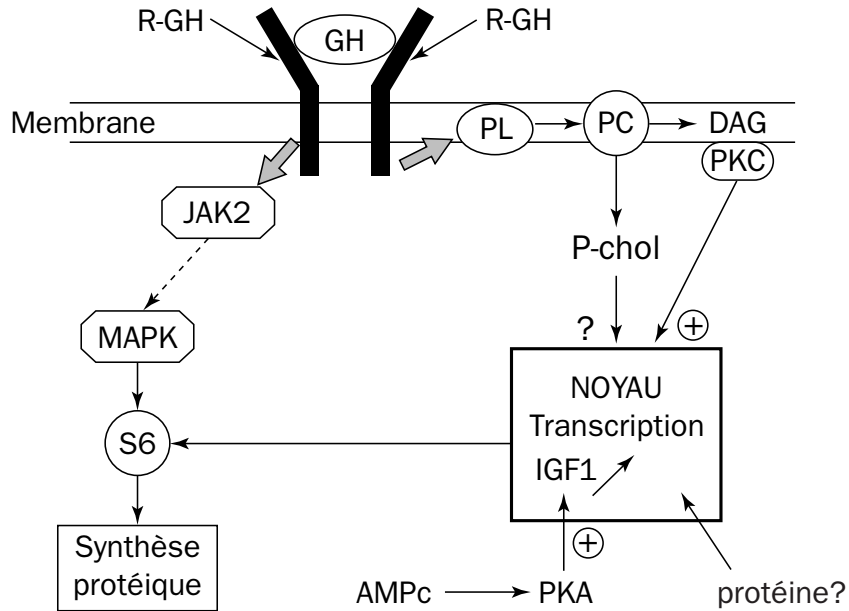

Figure 4.6 - Représentation schématique des voies de transduction stimulées par l'hormone de croissance

MAPK : mitogen activated protein kinase; PC : phosphatidylcholine ; P-chol : phosphocholine ; PKA : protéine kinase $A$; $P K C$ : protéine kinase $C$; $P L$ : phospholipase.

La régulation de l'expression des gènes par l'hormone de croissance se traduit par le codage pour des facteurs de transcription, des facteurs de croissance IGF (insulin-like growth factors 1 et 2), des récepteurs hormonaux, des enzymes, des protéines plasmatiques... 


\subsection{LA PROLACTINE (Prl ou LTH = luteotropic hormone)}

\subsubsection{Caractéristiques générales}

Elle est sécrétée par les cellules $\eta$ (éta). C'est une protéine de PM environ 23000 dont les acides aminés constitutifs ont été déterminés et leur séquence établie chez le mouton, le bœuf, le porc et chez l'homme (199 AA). Pour ces différentes espèces, les séquences sont identiques à près de $70 \%$. La structure primaire et l'activité de la prolactine se superposent de façon importante à celle de la GH (et de l'hormone placentaire lactotrope, HPL), suggérant une évolution à partir d'un précurseur commun (fig. 4.7).
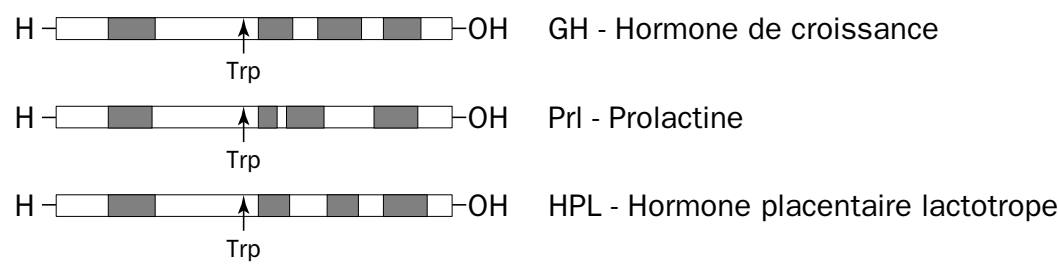

Figure 4.7 - Représentation diagrammatique comparée des molécules d'hormone de croissance humaine, de prolactine ovine et d'hormone placentaire lactogène humaine Les régions grisées représentent les séquences homologues.

A côté de la prolactine "normale" circulent dans le sang des formes polymériques ("big prolactin" et "big big prolactin") d'activité biologique nettement plus faible.

La prolactine est élaborée sous la forme d'une pro-hormone comportant 29 AA supplémentaires du côté $\mathrm{N}$-terminal. L'ARNm codant pour sa synthèse a été isolé. Le gène de la prolactine est situé sur le chromosome 6.

Dans l'espèce humaine, sa demi-vie est de l'ordre de $30 \mathrm{~min}$. Son taux plasmatique est de l'ordre de $20 \mathrm{ng} / \mathrm{ml}$ chez la femme et inférieur à $15 \mathrm{ng} / \mathrm{ml}$ chez l'homme. Elle présente un cycle circadien avec des fluctuations ultradiennes de période d'environ 20 min (fig. 4.8). Chez la femme, le taux ne s'élève pas significativement au cours de la grossesse : $100 \mathrm{ng} / \mathrm{ml}$ à partir de la $8^{\mathrm{e}}$ semaine.

\subsubsection{Action}

- Elle est sécrétée dans la deuxième moitié du cycle œstrien chez les rongeurs ${ }^{4}$, en permanence lors de la gestation. Elle stimule la sécrétion de progestérone par le corps jaune, avant que celle-ci ne soit relayée par la sécrétion placentaire (hormone lutéotrope).

4 De nombreuses et multiples fonctions ont été attribuées à la prolactine chez les vertébrés. Elles peuvent être classées en sept catégories : actions associées à l'équilibre de l'eau et des électrolytes; effets sur la croissance et le développement; action sur les fonctions de reproduction; effets métaboliques ; effets sur le comportement ; immunorégulation et action sur l'épiderme et la peau. 


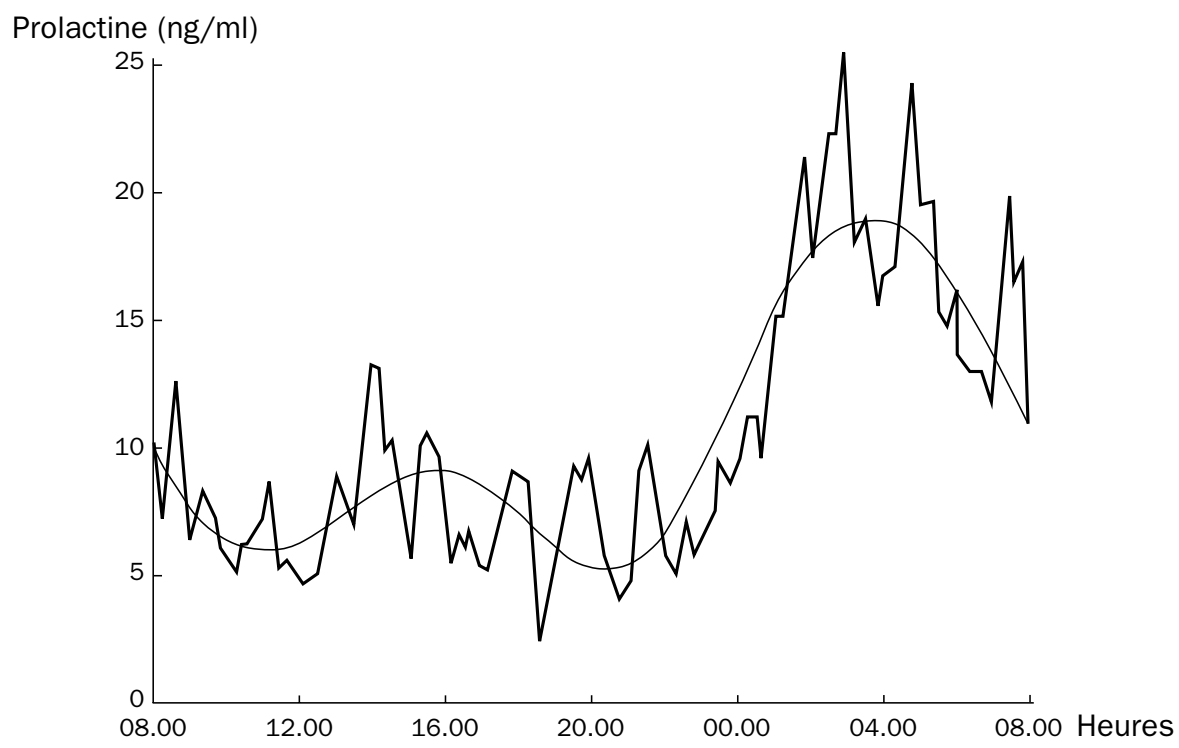

Figure 4.8 - Variations nycthémérales de la prolactine sérique (d'après Buvat et Buvat-Herbaut, 1982)

- Chez les Mammifères, elle prépare les glandes mammaires à la sécrétion du lait.

- Enfin, après l'accouchement ou la mise-bas, lorsque l'utérus s'est vidé, elle assure la sécrétion du lait (mais non son excrétion, qui est sous la dépendance d'un réflexe tacto-hypothalamo-hypophysaire qui provoque la sécrétion d'ocytocine).

- Son rôle s'étend toutefois, chez les Mammifères, à d'autres aspects que la lactation (voir chap. 14, § 6.6).

\subsubsection{Contrôle}

La sécrétion de prolactine est :

- stimulée par la TRH, les œstrogènes, le stress, l'exercice, les opiö̈des endogènes, l'excitation du mamelon, l' $\alpha$-méthyl DOPA, de nombreux tranquillisants (réserpine, phénothiazines). Les œstrogènes ont une action stimulatrice importante, à la fois au niveau de l'hypophyse et de l'hypothalamus (action antidopaminergique).

- inhibée par la l-DOPA, des dérivés de l'ergot de seigle (bromocriptine), l'acide $\gamma$-amino-butyrique (GABA).

\subsubsection{Aspect évolutif}

La structure de la prolactine a varié au cours de l'évolution (voir chap. 17, § 3.1). Cette variation s'accompagne d'une différenciation des fonctions :

- chez les Mammifères, elle stimule la sécrétion lactée ;

- chez tous les Oiseaux, la prolactine préside à la croissance, à la couvaison au moment de la nidation, à la production du "lait" chez le Pigeon et même à l'éveil de l'instinct maternel ; 
- chez les Poissons, ses effets vont de la régulation des échanges ioniques au niveau des branchies (Poissons euryhyalins), au contrôle de la formation du nid (Poissons cyclidés). Elle présente déjà des propriétés gonadotropes (sur les gonades et les glandes annexes). Elle règle la sécrétion de mucus cutané...

\subsubsection{Récepteurs et mode d'action de la prolactine}

Le mode d'action de la prolactine est semblable à celui de la GH (voir chap. 2, $\S 2.1 .4)$. Le récepteur de la prolactine $\left(\mathrm{K}_{\mathrm{D}}=0,3 \mathrm{nM}\right)$ reconnaît aussi la $\mathrm{GH}$ (fig. 4.9).

Les récepteurs membranaires à la prolactine peuvent subir une "up-regulation" (augmentation du nombre de récepteurs disponibles) en réponse aux œstrogènes, à l'insuline ou une "down-regulation" en réponse à la progestérone ou à une élévation aiguë du taux de la prolactinémie. Dans ce cas, en effet, le complexe récepteurprolactine est internalisé de façon accélérée, conduisant à une diminution du nombre des récepteurs disponibles.

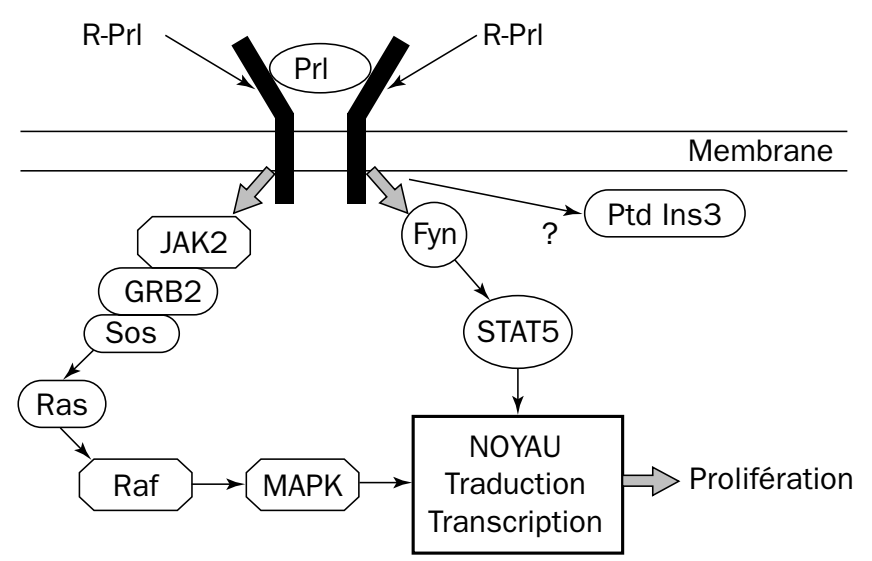

Figure 4.9 - Représentation schématique des voies de transduction stimulées par la prolactine

GRB2 : growth factor receptor bound protein 2 ; JAK2 : Janus activated kinase 2 ; MAPK : mitogen activated protein kinase ; Prl : prolactine ; Ptd Ins 3 : phosphatidylinositol 3 ; Ras et Raf: proto-oncogènes ; R-Prl : récepteur à la prolactine ; Sos : son of sevenless ; STAT5 : signal transducers and activators of transcription 5.

La liaison de la prolactine à son récepteur conduit à plusieurs cascades de phosphorylation qui débutent par la phosphorylation de protéines à fonction tyrosine kinase (JAK2 et Fyn). Finalement, la phosphorylation de la MAPK conduit au niveau du noyau à la stimulation de la transcription, ce qui permet la prolifération cellulaire.

L'obtention de souris sans récepteur à la prolactine $\left(R-\mathrm{Prl}^{-/}\right)$permet de réaliser que le récepteur de la prolactine constitue une molécule régulatrice clé de la reproduction (Binart, 1997 ; voir chap. 14, § 6.6). 


\subsubsection{L'hormone de croissance et la prolactine au cours du vieillissement}

$\mathrm{Au}$ fur et à mesure du vieillissement, les pulses nocturnes de ces hormones décroissent à la fois en fréquence et en amplitude, tandis que les concentrations basales ou diurnes ne sont pas modifiées (Murri et coll., 1980). La production hépatique de somatomédines, qui constituent des médiateurs de certains des effets de la GH, décroît également avec l'âge (principalement la somatomédine C). Cette décroissance est probablement liée à la réduction nocturne des concentrations plasmatiques de la $\mathrm{GH}$, qui n'est pas la conséquence de changements dans le rythme du sommeil chez la personne âgée car, en particulier, les stades 3 et 4 de celui-ci ne sont pas significativement modifiés.

Le rythme circadien de la prolactine présente également un pic (acrophase) nocturne en phase avec le sommeil (Sassin et coll., 1972). Le sommeil paraît le synchroniseur essentiel du rythme de la sécrétion de prolactine ; toutefois dans des protocoles faisant varier le cycle du sommeil, Desir et coll. (1982) constatent que la prolactine possède un rythme circadien intrinsèque. Les données concernant le rythme sécrétoire de Prl chez la personne âgée varient selon les auteurs, sans qu'on ait pu expliquer ces résultats par une variabilité biologique, ou des facteurs démographiques et/ou ethniques. Il existe enfin un rythme sécrétoire circannuel chez la femme jeune ou âgée, mais il n'apparaît pas chez l'homme jeune ou âgé (Touitou et coll., 1983b).

\subsection{LES HORMONES GONADOTROPES OU GONADOTROPHINES HYPOPHYSAIRES}

Ces glycoprotéines (FSH et LH) sont formées de deux sous-unités appelées $\alpha$ et $\beta$ (fig. 4.10), liées de manière non-covalente et portant, chacune, une ou plusieurs chaînes polysaccharidiques.

HCG

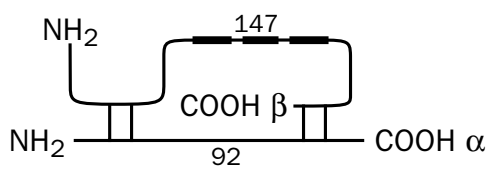

FSH

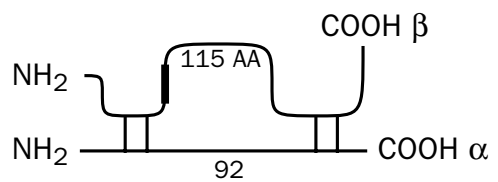

LH

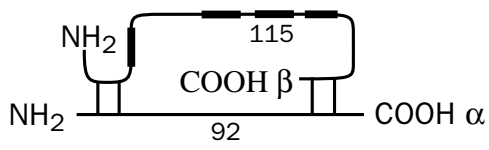

TSH

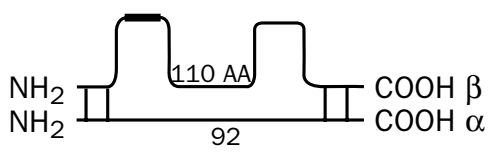

Figure 4.10 - Représentation schématique de la structure de HCG, FSH, LH et TSH chez l'homme (d'après Baulieu, 1978 et Wilson et Forster, 1992)

Les zones hachurées représentent globalement les ponts disulfures entre les chaînes. Les zones épaissies des chaînes $\beta$ indiquent de façon arbitraire les homologies partielles de leur structure primaire. 
Elles ont des propriétés structurales communes avec la TSH et la gonadotrophine chorionique (HCG), et correspondent à l'évolution d'une même molécule primitive. La sous-unité $\alpha$ a 92 AA chez l'homme et 96 AA dans d'autres espèces, la spécificité d'action de chaque hormone repose sur les différences structurales de la chaîne $\beta$.

Les deux chaînes sont codées par des gènes différents :

$\alpha$, sur le chromosome 6 humain ;

$\beta$, sur le chromosome 19 humain pour la $\mathrm{LH}$;

sur le chromosome 11 humain pour la FSH (11p13);

sur le chromosome 1 pour la TSH (1p22).

L'activité biologique globale des hormones gonadotropes (gonadotrophines) est dépendante de leur efficacité lors de trois étapes successives :

1. leur maintien plus ou moins long dans la circulation ;

2. leur affinité pour leur récepteur spécifique ;

3. et leur aptitude à stimuler les réponses de leurs cellules cibles après liaison au récepteur (Combarnous, 1999).

\subsubsection{La FSH (follicle stimulating hormone)}

\section{Caractéristiques générales}

Elle est sécrétée par les cellules $\beta$. C'est une glycoprotéine de faible PM (20 k Da chez le porc, 28 à $29 \mathrm{k} \mathrm{Da}$ chez l'homme). Sa demi-vie est d'environ $170 \mathrm{~min}$. Le taux de base est de l'ordre de 2 à $5 \mathrm{mUI} / \mathrm{ml}$ de plasma. Au moment du pic ovulatoire, le taux s'élève de 5 à $10 \mathrm{mUI} / \mathrm{ml}$ (voir fig. 10.6).

\section{Action}

Elle provoque

- chez la femelle

- la croissance et la maturation des follicules ovariens ;

- la sécrétion d'œstradiol par la thèque interne de ces follicules ;

- indirectement, par la sécrétion d'œstradiol, une action de type "folliculinique" sur le tractus génital (utérus et vagin essentiellement);

- chez le mâle

- le développement des tubes séminifères et l'activation de la spermatogenèse.

\subsubsection{La LH (luteinizing hormone) ou ICSH (interstitial cells stimulating hormone)}

\section{Caractéristiques générales}

Elle est sécrétée par les cellules $\gamma$. C'est une glycoprotéine de PM environ 30000 . Sa demi-vie est d'environ $60 \mathrm{~min}$. Le taux de base est de l'ordre de 2 à $5 \mathrm{mUI} / \mathrm{ml} \mathrm{de}$ plasma. Au moment du pic ovulatoire, il s'élève de 16 à $25 \mathrm{mUI} / \mathrm{ml}$ (voir fig. 10.6). 


\section{Action}

- Chez la femelle

- en synergie avec la FSH, elle provoque l'ovulation et la transformation du follicule ovarien en corps jaune (cellules lutéiniques) ;

- la sécrétion de progestérone (et d'une petite quantité d'œstradiol) par les cellules folliculaires. C'est elle qui déclencherait l'ovulation. L'effet est amplifié après l'ovulation, les cellules folliculaires devenues des cellules lutéiniques ont un aspect hypersécréteur. Par la sécrétion combinée de progestérone et d'œstradiol, elle favorise la nidation de l'ovule dans l'utérus (dentelle utérine) ;

- Chez le mâle

- elle stimule la production de testostérone par les cellules interstitielles du testicule (cellules de Leydig).

\subsubsection{Récepteurs et mode d'action des hormones gonadotropes}

Le récepteur de la LH (Misrahi et coll., 1995)

Il fait partie d'une famille de récepteurs heptatransmembranaires (7-TM) couplés à des protéines $\mathrm{G}^{5}$ (voir chap. 2 , § 2.1.3). La protéine mature comprend chez le Porc 669 AA et trois domaines principaux. Elle comporte un domaine de 266 AA avec sept hélices transmembranaires hydrophobes séparées par des boucles extra- ou intracellulaires. La partie C-terminale hydrophile comprend 66 AA, la partie N-terminale, extracellulaire, 333 AA. Ce volumineux domaine extracellulaire est le domaine de liaison à l'hormone. Le poids moléculaire du récepteur, dans sa forme complète, est de $85 \mathrm{kDa}$. Le mécanisme de couplage est AMPc dépendant (stimulation).

Le clonage du récepteur de la $\mathrm{LH}$ porcine a été réalisé ; il l'a été également chez le rat. Le récepteur humain a été cloné par hybridation croisée avec le récepteur de rat (Minegish et coll., 1990).

Le gène du récepteur de la LH est localisé au niveau du chromosome 2 (2p21). Des mutations de ce gène provoquent une maladie autosomiale dominante, dans laquelle le jeune garçon développe une puberté précoce, par activation du récepteur à la $\mathrm{LH}$ (Lefkkovitz, 1993).

Des mutations semblables ont été observées pour les récepteurs à la TSH, la MSH et la rhodopsine (fig. 4.11). Ces mutations sont observées pour les récepteurs à la MSH (1 et 2), la TSH (3 et 4), la LH (5) et la rhodopsine (6). La région mutée in vitro dans les récepteurs surrénaliens activés recouvre la région correspondant aux points 3 et 4 .

Les anticorps monoclonaux ont permis d'étudier la distribution du récepteur de la $\mathrm{LH}$ au niveau de l'ovaire de truie. L'immunoréactivité n'apparaît sur les cellules thécales

5 Ces récepteurs 7-TM font partie du groupe des récepteurs couplés aux protéines G (R-CPG). 
qu'au stade de follicule secondaire. Les cellules de la granulosa sont également marquées dans les follicules pré-antraux et pré-ovulatoires.

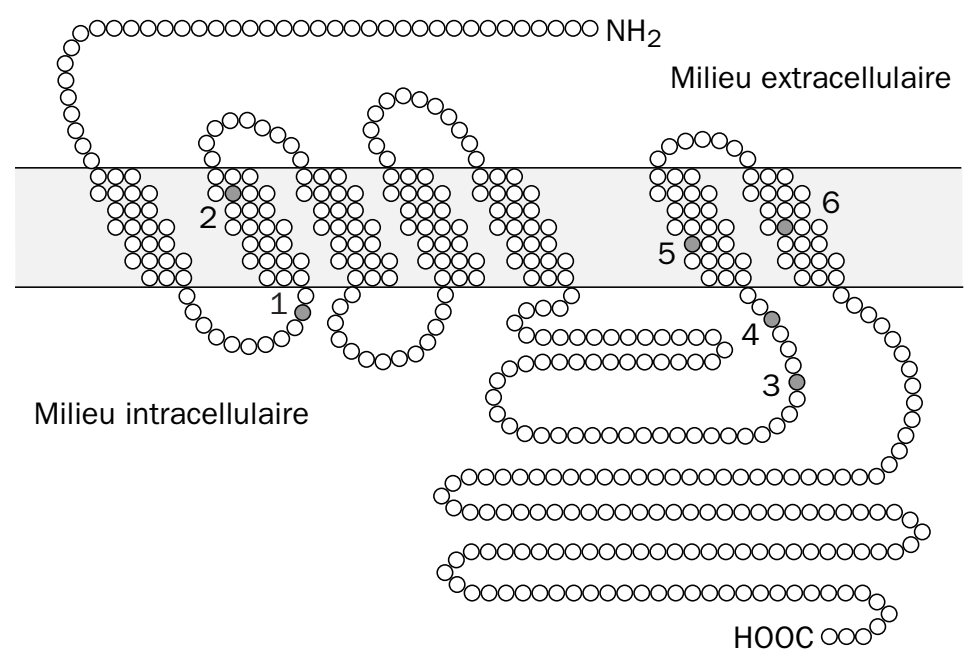

Figure 4.11 - Représentation du modèle du récepteur à sept domaines transmembranaires (7-TM), couplé à une protéine G, montrant la localisation des mutations spontanées qui provoquent une activation du récepteur (d'après Lefkowitz, 1993)

\section{Le récepteur de la FSH}

Il a été cloné chez le rat (Sprengel et coll., 1990) puis chez l'homme (Minegish et coll., 1995). C'est une protéine heptatransmembranaire de PM 669 à 674 kDa, qui existe sous une forme dimérique. L'activation du récepteur induit la synthèse d'AMPc.

Le gène du récepteur de la FSH est, comme celui de la $\mathrm{LH}$, localisé au niveau du chromosome $2(2 \mathrm{p} 21)$. Ces deux gènes sont de grande taille $(>70 \mathrm{kpb})$ et comprennent respectivement 10 et 11 exons.

La comparaison de ces deux récepteurs ainsi que de celui de la TSH, qui appartient à la même famille de récepteurs heptatransmembranaires couplés à des protéines $\mathrm{G}$, montre (Misrahi et coll., 1995) que le domaine le plus homologue est le domaine transmembranaire (voir fig. 4.12).

\section{L'axe hypophyso-gonadique au cours du vieillissement}

Les effets de l'âge sur la sécrétion de testostérone ont été très controversés. En fait, cela dépend du moment de la journée où sont réalisés les prélèvements. On observe une diminution de cette sécrétion si les prélèvements sont effectués dans la matinée, mais pas s'ils le sont dans l'après-midi. La raison en est que le rythme circadien de la sécrétion de testostérone de l'adulte (voir Introduction) n'est pas retrouvé chez la personne âgée (Bremmer et coll., 1983). Des résultats semblables ont été observés chez le rat âgé (Simpkins et coll., 1981 ; Miller et Reagle, 1982). 
Les concentrations d'œstradiol et de progestérone dans le plasma diminuent chez la femme après la ménopause. La diminution de la sécrétion des hormones sexuelles au cours du vieillissement entraîne une élévation des taux de FSH et de LH. Il est difficile de mettre en évidence un rythme circadien de ces hormones chez la personne agée (fig. 4.12) mais elles conservent leur caractère pulsatile.

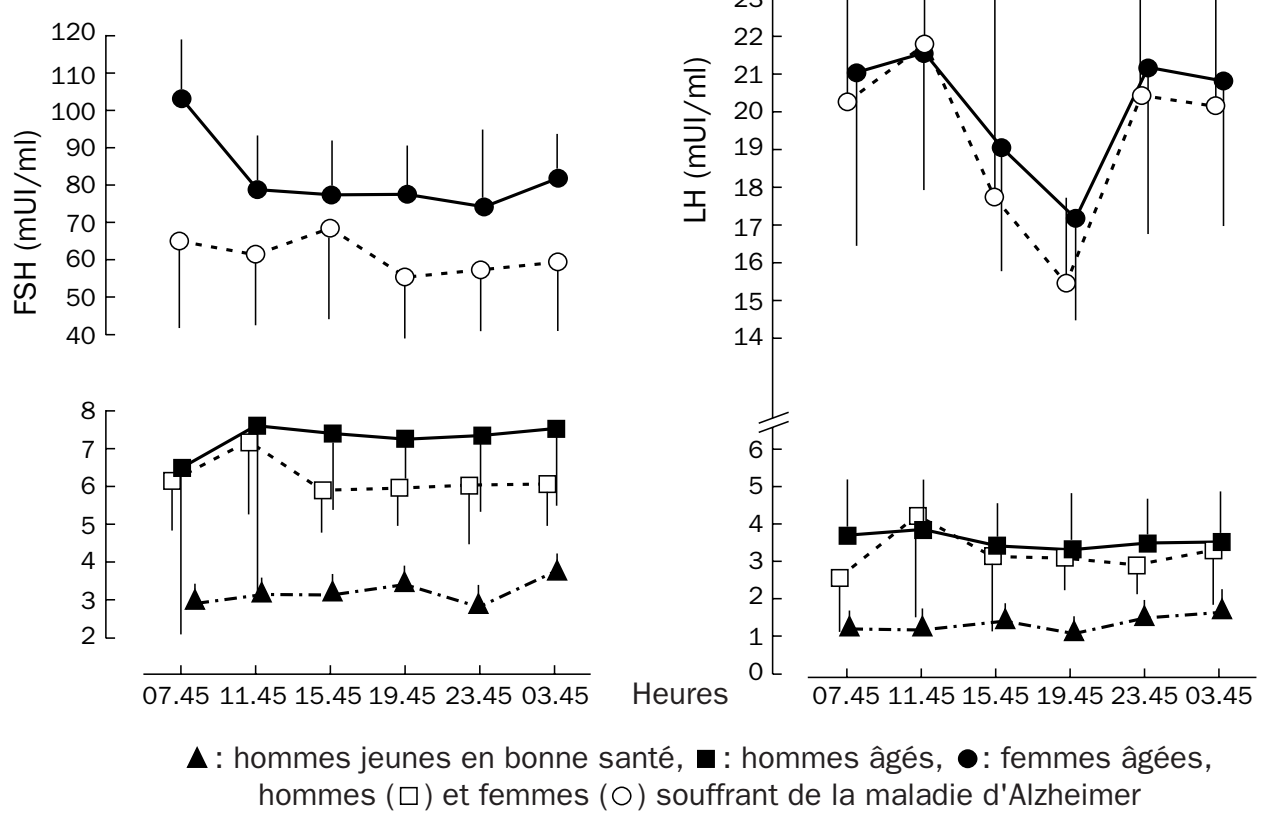

Figure 4.12 - Rythmes circadiens des concentrations plasmatiques de FSH et de LH (d'après Touitou et coll., 1981)

On observe également un rythme circannuel de la LH chez l'homme âgé (mais pas chez la femme âgée), avec un maximum en avril-mai (fig. 4.13). Ainsi, l'absence d'hormones sexuelles ou leur taux très bas n'affecte pas, chez la personne âgée, la périodicité de ces hormones hypophysaires.

\subsection{L'HORMONE THYRÉOTROPE (TSH OU THYRÉOSTIMULINE)}

\subsubsection{Caractéristiques générales}

Elle est sécrétée par les cellules $\delta$. C'est une glycoprotéine de 201 AA chez l'homme (voir fig. 4.10). Son PM est de 28000 . Sa demi-vie est d'environ 60 min et son taux plasmatique moyen de $3 \mathrm{ng} / \mathrm{ml}$ chez l'homme ( 0,1 à $4 \mathrm{mUI} / \mathrm{l})$. 


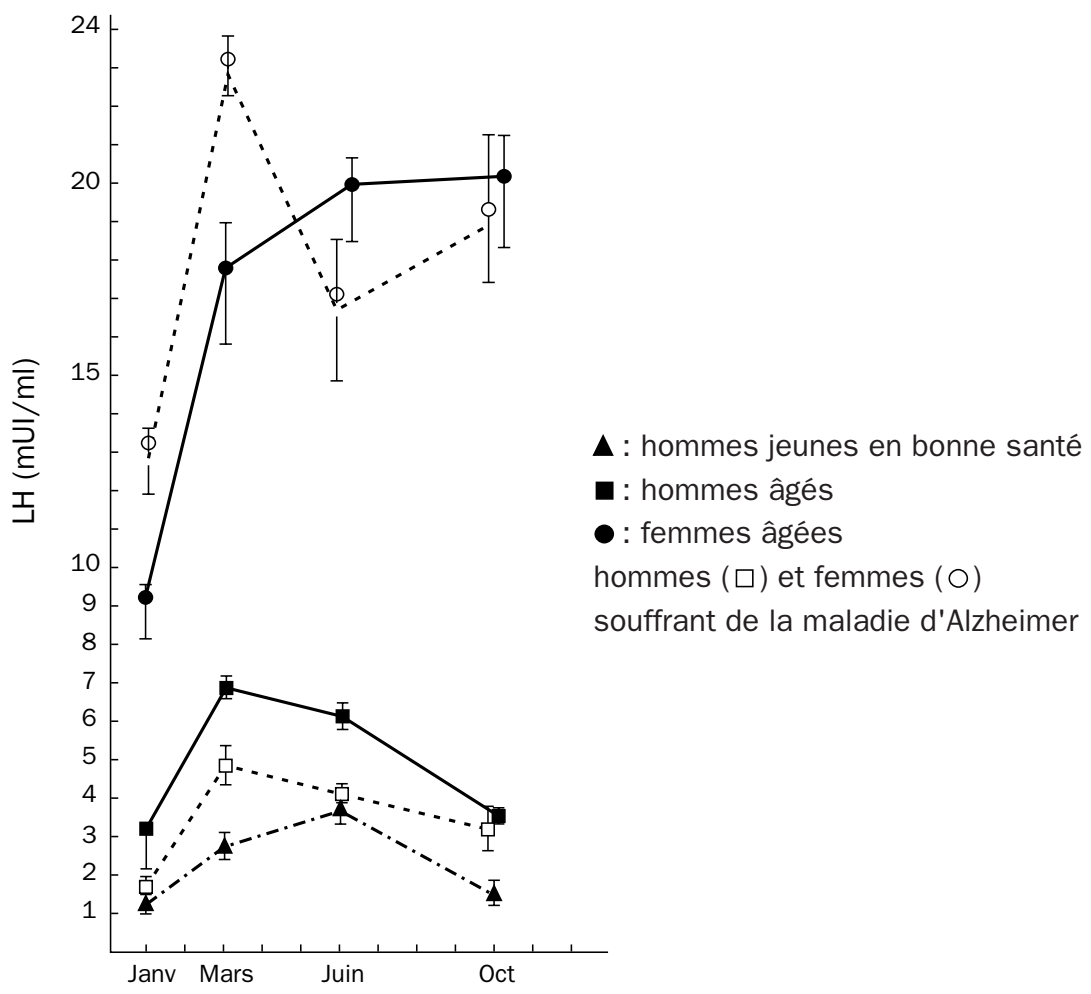

Figure 4.13 - Variations saisonnières de la concentration plasmatique de LH (d'après Touitou et coll., 1981)

\subsubsection{Action}

Elle provoque indirectement (par stimulation des hormones thyroïdiennes) l'élévation du métabolisme basal (accélération du rythme cardiaque, des échanges respiratoires, augmentation du métabolisme glucidique et azoté). La TSH peut stimuler directement la lipolyse au niveau du tissu adipeux.

\subsubsection{Contrôle}

La sécrétion de TSH est augmentée sous l'action d'une hormone hypothalamique, la TRH (voir § 6.1.4). Elle est inhibée par la somatostatine (GH-IH).

Le froid stimule la sécrétion de TSH, en grande partie par la stimulation de la TRH. Les hormones thyroïdiennes (T3 et T4) exercent normalement un feed-back (rétrocontrôle), à la fois au niveau hypothalamique et au niveau hypophysaire. Les œstrogènes ont une action synergique sur la thyroïde, ils annulent l'effet inhibiteur des hormones thyrö̈diennes.

L'action de la TSH est rapide. L'adénylate cyclase thyrö̈dienne est activée $3 \mathrm{~min}$ après l'injection, et les hormones thyroïdiennes sont libérées $10 \mathrm{~min}$ après l'injection. 


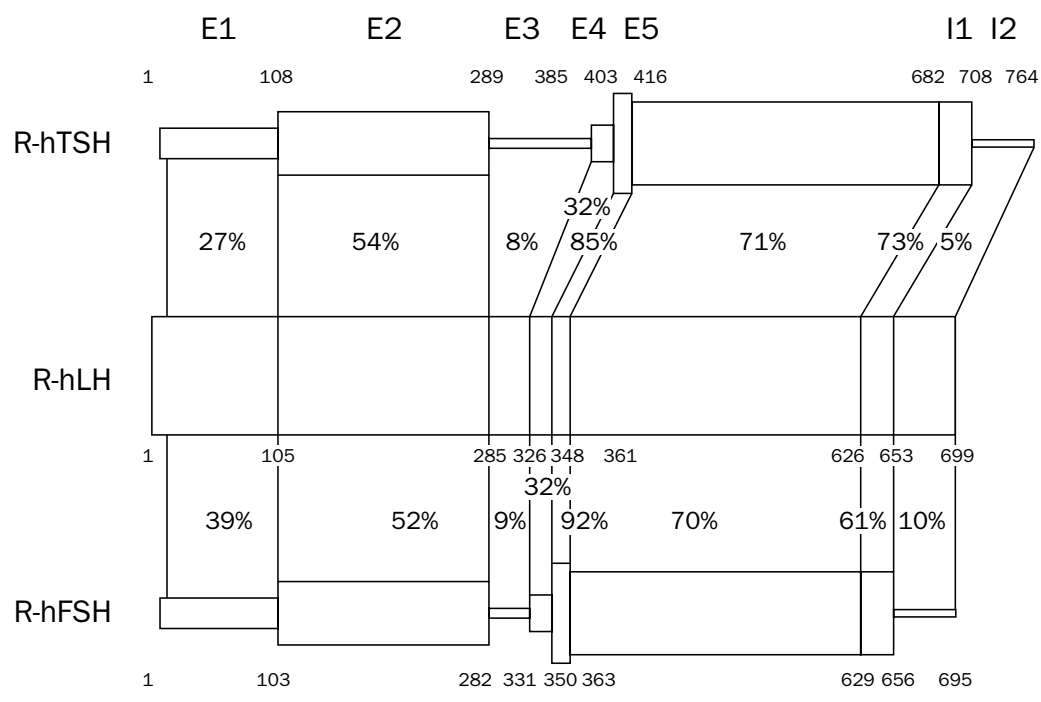

Figure 4.14 - Comparaison de la structure des récepteurs humains de la TSH, de la LH et de la FSH (d'après Misrahi et coll., 1995)

Les récepteurs sont divisés en régions selon leur degré d'homologie (indiqué par la surface représentant les récepteurs de la FSH et de la TSH).

\subsubsection{Récepteur et mode d'action de la TSH}

Le récepteur de la TSH a été étudié par l'équipe de Milgrom (Misrahi et coll., 1995). Il fait partie de la même famille que les récepteurs à la FSH et la LH.

Il est constitué au niveau de la thyroïde humaine de deux sous-unités unies par un ou plusieurs ponts disulfures :

- une sous-unité a, extracellulaire et glycosylée d'environ $53 \mathrm{kDa}$;

- une sous-unité b, transmembranaire et intracellulaire d'environ 33-42 kDa. Le précurseur monomérique pourrait être une forme de $120 \mathrm{kDa}$.

Le gène humain du récepteur de la TSH a été localisé sur le bras long du chromosome 14 (bande q31). L'activation du récepteur induit la synthèse d'AMPc. Il est intéressant de noter que des mutations du gène du récepteur peuvent produire un adénome avec hyperthyroïdisme (Parma et coll., 1993) en maintenant un état activé au niveau du récepteur.

\subsection{LES HORMONES DÉRIVÉES DE LA PRO-OPIOMÉLANOCORTINE}

Avec le perfectionnement de nos méthodes d'analyse qui "cassent" moins les molécules extraites, il est apparu que les cellules corticomélanotropes sécrètent une pro-hormone : la pro-opiomélanocortine ou POMC (fig. 4.15) ${ }^{6}$ dont le précurseur (pré-POMC) possède $265 \mathrm{AA}$ chez les bovins et $267 \mathrm{AA}$ chez l'homme.

6 Se reporter aux travaux de Mains et coll. (1977), Nakanishi et coll. (1979). 


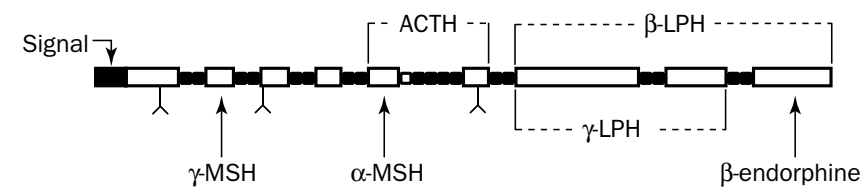

Met Pro Arg Leu Cys Ser Ser Arg Ser Gly Ala Leu Leu Leu Ala Leu Leu Leu Gin Ala $-120$

Ser Glu Thr Thr Leu Asp Gin Cys Gin Ser Ser Glu Leu Cys Trp Gly Arg Val Glu Met Asn $-100$

Leu Leu Ala Cys lle Arg Ala Cys Lys Pro Asp Leu Ser Ala Glu Thr Pro Val Phe Pro GAMMA-MSH $-80$

Arg Phe His Gly Met Val Tyr Lys Arg Pro Asn Glu Thr Leu Pro Gin Glu Asp Gly Asn $\operatorname{Trp}$ $-60$

Asp Arg Phe Gly Arg Arg Asn Gly Ser Ser Ser Ser Gly Val Gly Gly Ala Ala Gin Lys $-40$

Arg

Gly Thr Glu Ala Asp Asp Gly Arg Pro Gly Pro Gly Glu Gly Val Ala Val Glu Glu Glu $\begin{array}{ll}\text { Pro } & \text { CORTICOTROPHINE } \\ \text { ALPHA-MSH } & -20\end{array}$

Arg Glu Asp Lys Arg Ser Tyr Ser Met Glu His Phe Arg Trp Gly Lys Pro Val Gly Lys $-11$

Lys

Pro Phe Ala Gin Ala Ser Glu Asp Glu Ala Gly Asn Pro Tyr Val Lys Val Pro Arg Arg

$\begin{array}{lll}\text { Leu CLIP } & \text { BETA-LIPOTROPHINE } & 20\end{array}$

Glu Phe Lys Arg Glu Leu Ala Gly Ala Pro Pro Glu Pro Ala Arg Asp Pro Glu Ala Glu 40

Ala Ala Glu Ala Glu Ala Glu Ala Val Leu Gly Tyr Glu Leu Glu Ala Arg Ala Ala Ala Glu BETA-MSH

Lys Lys Asp Ser Gly Pro Tyr Lys Met Glu His Phe Arg Trp Gly Ser Pro Pro Lys Asp 80

Lys Phe Leu Thr Val Leu Pro Thr Gin Ser Lys Glu Ser Thr Met Phe Gly Gly Tyr Arg Asn BETA-ENDORPHINE

Ala lle lle Lys Asn Ala His Lys Lys Gly Gin

Figure 4.15 - Séquence de la pro-opiomélanocortine (d'après Bloom, 1987)

La pro-opiomélanocortine est une protéine qui peut donner par coupure enzymatique les séquences suivantes :

- La corticotrophine (ACTH 1-39) à partir de laquelle seront scindées dans le lobe intermédiaire :

- l' $\alpha$-MSH (1-13)

- le CLIP (ACTH 19-39) ${ }^{7}$

7 CLIP = "corticotrophin like intermediate peptide", isolé dans le lobe intermédiaire du rat. C'est un peptide qui reproduit la séquence 18-39 de l'ACTH; il stimulerait la sécrétion d'insuline chez la souris et aurait une action sur le cortex surrénalien fœtal. 
- La $\beta$-LPH (42-132) qui peut être scindée dans le lobe intermédiaire pour donner :

- la $\gamma$-LPH (42-99)

- la $\beta$-MSH

- la $\beta$-endorphine $(102-132)^{8}$

- une enképhaline : met-enképhaline (102-106).

La pro-opiomélanocortine donnera donc essentiellement de l'ACTH dans la pars distalis et l' $\alpha-\mathrm{MSH}$ et la $\beta$-endorphine dans le lobe intermédiaire.

\subsubsection{L'ACTH (adrenocorticotropin hormone) ou hormone corticotrope ou corticotrophine}

\section{Caractéristiques générales}

C'est un polypeptide de 39 AA (PM 4500) dont une partie de la séquence (25 à 39) varie selon les espèces animales (fig. 4.16). Les 24 premiers AA constituent la fraction active de l'ACTH (Synacthène chez Ciba). Les treize premiers résidus correspondent à la séquence de l' $\alpha$-MSH. Les seize premiers résidus de l'ACTH suffisent pour déterminer son activité stéroïdogène, et le pentapeptide de 6 à 10 son activité mélano-stimulante.
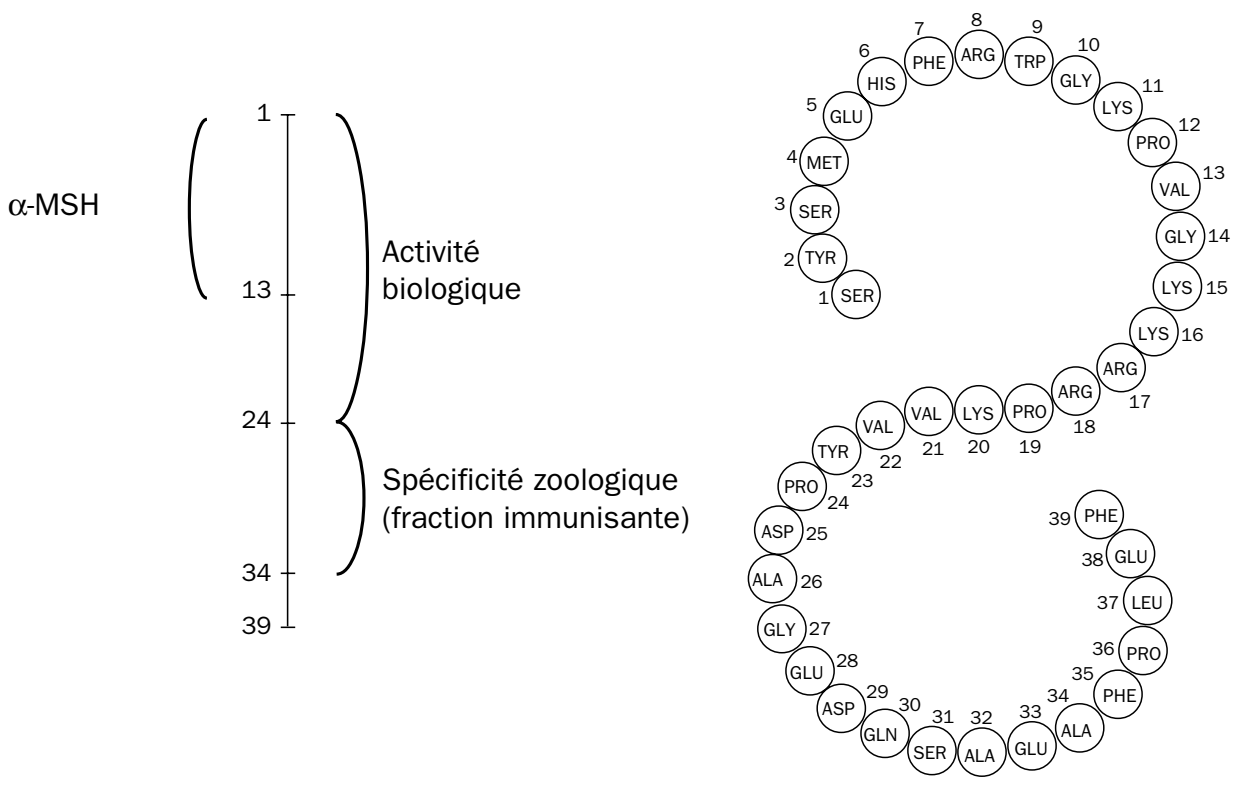

Figure 4.16 - L'ACTH

La concentration plasmatique de l'ACTH chez l'adulte normal est en moyenne de 20 à $50 \mathrm{pg} / \mathrm{ml}(4,4$ à $11 \mathrm{pmol} / \mathrm{l})$ et sa demi-vie est d'environ $15 \mathrm{~min}$. L'ACTH présente un rythme nycthéméral de sécrétion avec un pic à $120 \mathrm{pg} / \mathrm{ml} 2 \mathrm{~h}$ avant le lever. Dans l'insuffisance surrénalienne, il peut s'élever à 400 pg / ml (88 pmol/1).

8 Voir Guillemin et coll. (1973). 
Après administration de métopirone, inhibiteur de la $11 \beta$-hydroxylation, il s'élève à $600 \mathrm{pg} / \mathrm{ml}(132 \mathrm{pmol} / \mathrm{l})$.

L'ACTH présente également une sécrétion pulsatile qui se greffe sur le rythme circadien, avec des élévations épisodiques toutes les $2 \mathrm{~h}$ environ. La réactivité du cortisol à l'ACTH varie également selon que l'on est au début ou en fin de nuit, et suivant la nature de la stimulation.

\section{Action}

L'ACTH stimule essentiellement les cellules corticosurrénales qui sécrètent les hormones glucocorticoïdes (corticostérone, cortisol...), et celles qui sécrètent les hormones androgènes. Il n'a pas d'action importante sur les cellules de la zone glomérulaire (sécrétant l'aldostérone). L'hypophysectomie entraîne une diminution de 90\% de la sécrétion des hormones glucocorticoïdes.

L'hypersécrétion d'ACTH provoque un syndrome de Cushing (voir chap. 6, § 2.1), par hypersécrétion des hormones glucocorticoïdes.

L'ACTH a une faible activité mélanotrope mais il peut être, seul ou associé à la $\beta$-LPH, la cause majeure d'une hyperpigmentation quand les taux de la POMC plasmatique sont élevés.

\section{Contrôle}

La sécrétion d'ACTH est sous le contrôle d'une CRH hypothalamique, dont la séquence a été identifiée chez l'homme (elle est analogue à celle du rat) : 41 AA. Le stress entraîne une élévation considérable de la sécrétion d'ACTH.

L'exploration de l'axe hypothalamo-hypophyso-corticosurrénal fait appel aux épreuves suivantes :

- administration d'ACTH 1-24 de synthèse (Synacthène®) ;

- épreuve de freinage à la dexaméthasone (dérivé de synthèse des glucocorticoïdes, inhibiteur des récepteurs hypothalamiques et hypophysaires) ;

- épreuve à la métopirone, qui bloque la $11 \beta$-hydroxylation donc la biosynthèse des stérö̈des 9 .

\section{Mode d'action}

Les effets de l'ACTH sur la stéroïdogenèse peuvent être distingués en effets aigus, qui surviennent en quelques minutes, et en effets subaigus ou chroniques, qui se manifestent au bout de quelques heures ou quelques jours (Simpson et Waterman, 1988 ; Colby et coll., 1973).

9 Par exemple, chez le lapereau âgé de 5 à 7 semaines, alors que le taux normal d'ACTH est de $280 \pm 30 \mathrm{pg} / \mathrm{ml}$ de plasma, sous l'effet de la dexaméthasone il passe à $0 \mathrm{pg} / \mathrm{ml}$, et sous l'effet de la métopirone à $\mathrm{t}=0: 260 \mathrm{pg} / \mathrm{ml}(57 \mathrm{pmol} / 1)$, à $\mathrm{t}=120 \mathrm{~min}: 1400 \mathrm{pg} / \mathrm{ml}$ $(308 \mathrm{pmol} / \mathrm{l})$ et à $\mathrm{t}=240 \mathrm{~min}: 280 \mathrm{pg} / \mathrm{ml}(60 \mathrm{pmol} / 1)$ (Monnier et Desbals, 1985). 
Les effets aigus de l'ACTH résultent de la conversion du cholestérol en $\Delta 5$ prégnénolone (voir fig. 6.3), qui est la première étape et l'étape limitante de la biosynthèse du cortisol (voir chap. 6, § 2.2.1) (Hall, 1985 ; Schimmer, 1980). Au contraire, les effets chroniques de l'ACTH impliquent l'augmentation de la synthèse de la plupart des enzymes de la stéroïdogenèse, en particulier la $11 \beta$-hydroxylase.

\subsubsection{La LPH (lipotropic hormone)}

La LPH existe sous deux formes :

- une $\beta$-LPH de PM 9500 (91 AA), qui a été isolée chez le mouton, le porc et l'homme. La séquence comprend la totalité de la $\beta$-MSH (segment 41-58) et la séquence de la $\beta$-endorphine ; elle est sécrétée en quantités équimoléculaires avec l'ACTH ; elle possède une faible activité lipolytique mais son rôle serait plutôt d'être le précurseur des $\beta$-endorphines.

- une $\gamma$-LPH, analogue chez le mouton à la $\beta$-LPH, en ce qui concerne les 48 premiers AA.

La concentration plasmatique de la $\beta$-LPH est de $10-40 \mathrm{pg} / \mathrm{ml}$.

\subsubsection{La MSH (melanocyte stimulating hormone) ou hormone mélanotrope}

\section{Caractéristiques générales}

Elle est classiquement sécrétée dans le lobe intermédiaire. C'est un polypeptide de faible PM. On distingue deux MSH :

- une $\alpha-\mathrm{MSH}$, à faible activité corticotrope : 13 AA. Elle a été entièrement synthétisée. Ces 13 AA correspondent aux 13 premiers AA de l'ACTH.

- une $\beta$-MSH (18 AA) qui n'existerait pas chez l'homme.

La concentration plasmatique de la MSH est d'environ $20 \mathrm{pg} / \mathrm{ml}$.

\section{Action}

Elle provoque l'hyperpigmentation chez le porc. Mais l' $\alpha-\mathrm{MSH}$ n'existe pas comme une hormone distincte dans l'espèce humaine et la mélanodermie de la maladie d'Addison semble due essentiellement à l'hypersécrétion d'ACTH.

Elle favorise, chez le Mammifère, l'état trophique (nutritif) de la neurohypophyse. Elle intervient dans le métabolisme de l'eau chez les animaux désertiques qui ont un lobe intermédiaire très développé (Rongeurs désertiques, chameau).

\section{Mode d'action}

Elle agit sur la répartition des mélanosomes (grains de mélanine) autour du noyau : les grains de mélanine se dispersent de façon homogène dans le cytoplasme au lieu de rester concentrés au voisinage du noyau.

Elle stimule la mélanogenèse (synthèse des mélanosomes, qui met en jeu plusieurs enzymes dont une tyrosinase). 


\subsection{LA $\beta$-ENDORPHINE}

Elle est retrouvée à la fois dans les cellules corticomélanotropes de l'adénohypophyse et dans les cellules nerveuses situées à la base de l'hypothalamus (noyau arqué).

Elle est libérée en même temps que l'ACTH dans le stress. Son rôle à cet égard n'est pas encore bien élucidé. La $\beta$-endorphine stimule la sécrétion de prolactine, qui favoriserait le métabolisme des neurotransmetteurs cérébraux. Elle inhibe au contraire la sécrétion pulsatile de $\mathrm{LH}$.

Son rôle analgésique (vingt fois supérieur à celui de la morphine) ne s'exercerait qu'en d'autres lieux de sécrétion (substance grise péri-acqueducale, système limbique).

\subsection{DOSAGE DES HORMONES DE LA PARS DISTALIS}

- Historiquement, le dosage était biologique.

- Hormone de croissance :

- modifications histologiques de l'os tibial du rat hypophysectomisé ;

- augmentation du poids du rat hypophysectomisé.

- TSH : fixation de l'131I.

- ACTH : c'est le test de Thorn.

Après perfusion pendant $8 \mathrm{~h}$ de $75 \mathrm{UI}$ d'ACTH ou injection I.M. de $120 \mathrm{UI}$ d'ACTH-retard, on mesurait :

- dans le sang, l'éosinopénie (chute du taux des éosinophiles) de 50\% chez le rat normal, de $80 \%$ chez l'homme : de 100 à $300 \mathrm{~mm}^{3}$, elle passe de 20 à $60 \mathrm{~mm}^{3}$ dans le sang ;

- dans les urines, l'augmentation du taux des 17-cétostéroïdes et des 17hydroxystéroïdes.

- Hormones gonadotropes (voir tests de grossesse chap. 14, § 4.2.4) :

- ovulation de la lapine séparée du mâle ;

- augmentation du poids des testicules du canard impubère maintenu à l'obscurité ;

- réaction du jabot de pigeon pour la prolactine.

- Il est actuellement remplacé par le dosage radioimmunologique dont le principe a été appliqué en 1956 par Yalow et Berson au dosage de l'insuline (fig. 4.17).

Le principe est celui d'une compétition entre l'hormone froide introduite (dans le tube à essais) et l'hormone radioactive liée (B = bound) à l'anticorps spécifique. Après avoir effectué une courbe étalon, pour une radioactivité initiale déterminée, on recommence l'expérience avec l'hormone à doser. La radioactivité résiduelle du complexe (hormone liée-anticorps) donne sur la courbe la concentration correspondante de la quantité d'hormone introduite. 
Pratiquement, il faut séparer l'hormone radioactive liée $(\mathrm{B}=$ bound) à son anticorps de l'hormone radioactive devenue libre $(\mathrm{F}=$ free $)$. On le réalise par électrophorèse, immunoprécipitation du complexe par un anticorps antigammaglobuline ou immuno-adsorption de l'hormone libre.

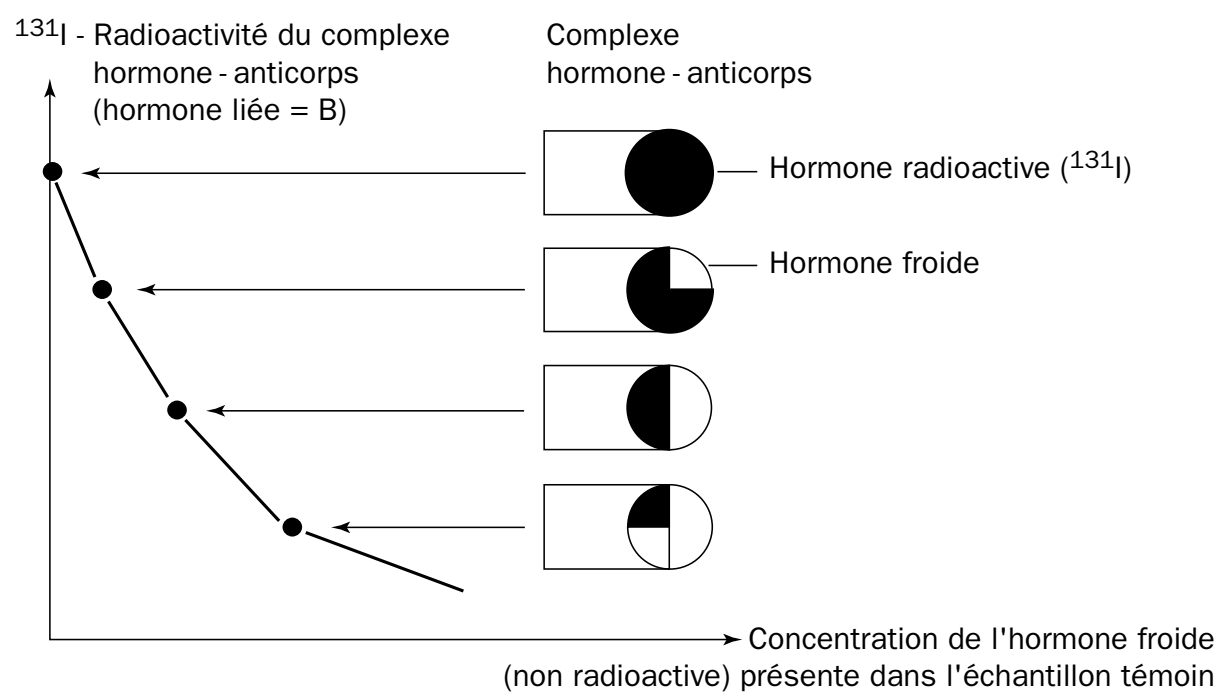

Figure 4.17 - Principe du dosage radioimmunologique par la méthode de Yalow et Berson

\section{NOTION DE COMPLEXE HYPOTHALAMO-HYPOPHYSAIRE}

- L'hypophyse et les glandes endocrines qu'elle stimule ne fonctionnent pas comme un système autonome : l'hypophyse est soumise aux influences du système nerveux central (SNC).

- On sait maintenant que le stress (agression) psychique entraîne la sécrétion d'hormones : adrénaline, ACTH, cortisol, GH, $\beta$-endorphine.

- On connaissait l'influence des émotions sur l'activité des gonades (aménorrhées psychiques, lésions testiculaires des condamnés à mort).

- Mais c'est surtout la mise en évidence de l'action gonadostimulante de la lumière par Benoit, puis Benoit et Assenmacher, qui a apporté le premier exemple précis de corrélations neurohumorales. Benoit démontre d'abord (1935-1938) chez le canard la relation lumière (éclairement de 15 h sur 24 h) rétine - hypophyse - gonades; 15 h d'éclairement entraînent en 20 jours une multiplication par 80 du poids des testicules. Puis Benoit et Assenmacher (1952-1958) mettent en évidence le relais hypothalamique (fig. 4.18). Ils étudient le retentissement sur le développement testiculaire de différents types de lésions du complexe hypothalamo-hypophysaire. La section de la tige 
infundibulaire n'empêche pas le développement des testicules sous l'effet de l'éclairement. Ce développement est en revanche inhibé par les autres types de sections.

CO : chiasma optique

$E M$ : section de l'éminence médiane

$H t$ : lésion de l'hypothalamus antérieur

NPV : noyau paraventriculaire

NSO : noyau supra-optique

$P D$ : pars distalis

$P N$ : pars nervosa

$T$ : section de la tige infundibulaire

$\operatorname{Tr}$ : section des veines portes

du tractus porto-tubéral

$3^{e} V$ : troisième ventricule

VP : vaisseaux portes.

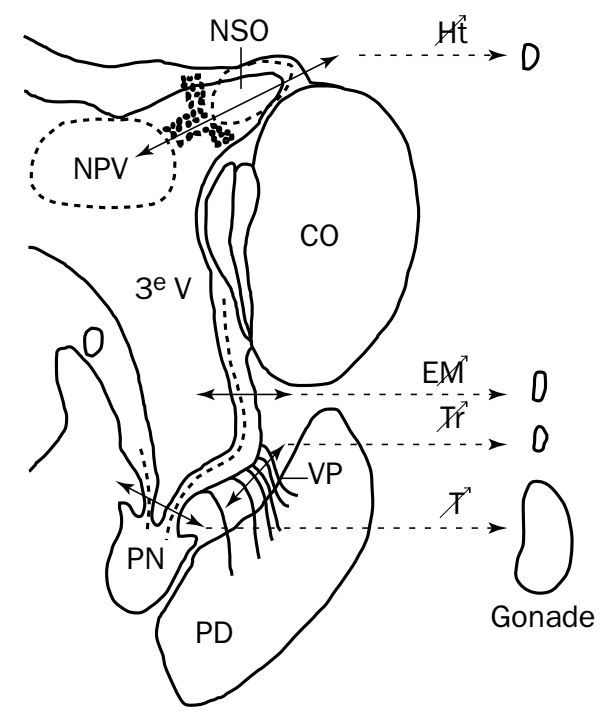

Figure 4.18 - Le complexe hypothalamo-hypophysaire chez le canard

(d'après Assenmacher, 1958)

- La démonstration de la neurosécrétion hypothalamique par Scharrer (1928) et Harris (1948), et la découverte du système porte de Popa et Fielding (1931), et surtout du sens descendant hypothalamo-hypophysaire de sa circulation (Wislocki et King, 1936), et des connexions neurovasculaires de l'éminence médiane (Green et Harris, 1948), permettent de comprendre les relations neurovasculaires entre l'hypothalamus et l'hypophyse.

Les fibres des neurones dont les corps sont situés dans le noyau ventro-médian ou dans le noyau arqué descendent le long de l'éminence médiane et de la tige infundibulaire. Un certain nombre de fibres se terminent à des niveaux différents de cette tige, où elles libèrent leur neurosecrétat (voir fig. 4.3.a). Celui-ci est repris à tous les niveaux par un lacis capillaire (réseau capillaire primaire) issu de l'artère hypophysaire supérieure (branche de la carotide interne), passe dans des vaisseaux portes, et est enfin déversé dans un réseau capillaire secondaire qui irrigue la pars distalis.

A côté de ce dispositif vasculaire dont le courant suit le sens hypothalamushypophyse s'ajouterait un réseau rétrograde qui permet aux hormones hypophysaires d'exercer un effet de rétroaction courte (Porter et coll., 1973-1978).

D'autres fibres issues du tractus supra-optico-hypophysaire ne se terminent que dans la pars nervosa (relations nerveuses directes, voir fig. 4.3.b). 
La section des fibres nerveuses des tractus nerveux hypothalamo-hypophysaires entraîne :

- l'accumulation, à l'extrémité des axones sectionnés, d'un neurosécrétat identifiable par des colorations histochimiques ou l'injection d'acides aminés radioactifs ;

- une atrophie progressive des cellules de la pars distalis, à l'exception des cellules à prolactine dont l'activité sécrétrice paraît stimulée ;

- une involution des gonades, de la thyroïde et de la corticosurrénale. Mais les fonctions de ces glandes ne disparaissent pas complètement, leur involution est beaucoup moins accentuée qu'après une hypophysectomie. Si l'activité des cellules de la pars distalis est bien sous le contrôle de l'hypothalamus, elles possèdent une certaine marge d'autonomie.

NB - La chlorpromazine (Largactil®), comme la réserpine, est un frein, un déconnecteur partiel de la liaison hypothalamo-hypophysaire. La chlorpromazine agit par inhibition non-spécifique de l'activité des récepteurs aux catécholamines (dopamine et noradrénaline), la réserpine en inhibant la vésiculisation du neuromédiateur, ce qui l'expose à la dégradation par une mono-amino-oxydase. D'où la stimulation de la sécrétion lactée par la réserpine, ou l'effet favorable du Largactil sur les troubles d'hypersécrétion FSH ou LH de la ménopause.

\section{LES HORMONES HYPOTHALAMIQUES HYPOPHYSIOTROPES}

\subsection{NATURE ET RÔLE}

Une architecture vasculaire aussi particulière permet à Green et Harris (1947-1955) de suggérer la possibilité d'une influence régulatrice de l'hypothalamus sur l'adénohypophyse : une telle influence pourrait s'exercer par voie humorale, les produits de sécrétion des neurones hypothalamiques étant transportés vers l'adénohypophyse par le système porte hypophysaire.

Cette neurosécrétion, qui atteint les différentes cellules de la pars distalis et de la pars intermedia, constitue pour chacune des catégories cellulaires un facteur provoquant leur excrétion dans la circulation sanguine, d'où le nom de releasing factor (RF) ou releasing hormone $(\mathrm{RH})$, ou encore libérine. C'est un facteur de libération (facteur de décharge). Dans quelques cas, ce facteur sera au contraire inhibiteur, inhibiting factor (IF) ou inhibiting hormone (IH).

Les produits de sécrétion des neurones de l'hypothalamus contrôlent donc toutes les sécrétions hormonales adénohypophysaires. Il y a au moins autant de types de neurones que de catégories cellulaires hypophysaires. Tous ces RF ou IF sont des polypeptides. Lorsque la structure chimique du facteur est identifiée, on peut parler d'une hormone : RH ou IH, suivant le cas. Ces facteurs, synthétisés par des 
neurones, qui déclenchent des sécrétions hormonales, peuvent être considérés comme des messagers chimiques neuro-endocriniens.

Leur localisation a pu être précisée. Trois types d'expériences peuvent être pratiqués :

- section de l'hypothalamus ;

- lésions électriques ;

- et surtout immunofluorescence et immuno-histochimie à l'aide d'anticorps spécifiques.

\subsubsection{Cas des cellules somatotropes (cellules productrices de l'hormone de croissance, GH ou hormone somatotrope)}

Deux principes hypothalamiques :

- Une GH-RH ou GRH ou SRF (somatotropin releasing factor) qui est un polypeptide : somatocrinine ou somatolibérine, dont la séquence a été établie (trois formes : 37, 40 ou $44 \mathrm{AA}$ chez l'homme). Elle est synthétisée sous la forme d'une pré-pro-hormone de 107 à $108 \mathrm{AA}$ (Guillemin et coll., 1984) (fig. 4.19). Le gène de la GRH est situé chez l'homme sur le chromosome 20. La séquence de la GRH extraite d'une tumeur pancréatique chez l'homme est précédée d'un peptide signal. L'activité biologique réside dans les 29 premiers AA à partir de la terminaison aminée ${ }^{10}$. Les neurones à GH-RH sont localisés dans la partie médiobasale, et dans le noyau arqué ou tubéroinfundibulaire de l'hypothalamus.

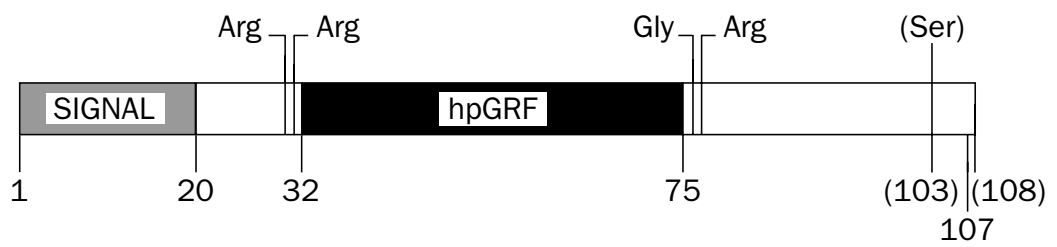

Figure 4.19 - Représentation schématique de la pré-pro-GRH

- Une forme inhibitrice SRIF (somatotropin release inhibiting factor) appelée somatostatine par Guillemin et ses collaborateurs (1973), tétradécapeptide à séquence connue et reproduite par synthèse (fig. 4.20).

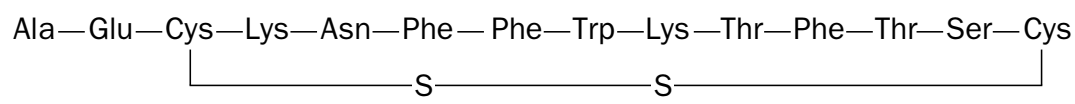

Figure 4.20 - SRIF ou somatostatine

L'acromégalie serait due soit à une hyperactivité hypophysaire primitive, soit à un défaut de sécrétion de somatostatine, donc maladie hypothalamique et nonhypophysaire. La somatostatine a également un effet inhibiteur sur la libération de

10 Le peptide a été utilisé pour remplacer l'hormone de croissance (Ross et coll., 1987). 
TSH par la TRH. Son mode d'action à l'échelle moléculaire implique une inhibition de la synthèse de l'AMPc. La somatostatine est synthétisée sous la forme d'une pré-pro-somatostatine de 119 AA (Goodman et Habener, 1980). On a identifié deux autres formes (25 AA et 28 AA) plus actives que SRIF 14 sur l'inhibition de la sécrétion d'insuline, mais SRIF 14 agit plus spécifiquement sur l'inhibition de la sécrétion du glucagon. Elle a été localisée dans toute la région externe de l'éminence médiane.

L'utilisation d'anticorps antisomatostatine a permis de la découvrir dans diverses cellules du tractus digestif (intestin, cellules D du pancréas) et aussi dans de nombreuses régions du système nerveux, du cortex cérébral aux ganglions sympathiques ! La stomatostatine pancréatique est inhibitrice à la fois de la production du glucagon, de l'insuline et de l'hormone de croissance.

Le mode d'action de la somatocrinine passe par la synthèse de l'AMPc. Celui de la somatostatine est plus complexe. L'hormone liée à son récepteur subit une internalisation. Son mécanisme implique un couplage inhibiteur de la synthèse d'AMPc, avec probablement une inhibition de l'entrée des ions calcium par les canaux voltage-dépendants.

La GH-RH et la somatostatine contrôlent de manière interactive différents aspects de la pulsatilité de GH : la GH-RH est essentielle pour l'induction de l'épisode sécrétoire, alors que la somatostatine est importante pour contrôler les valeurs basses (nadir) entre les pics. La somatostatine semble également impliquée dans la génération du pic.

\subsubsection{Cas des cellules à prolactine}

Le contrôle exercé par l'hypothalamus sur la production de prolactine est essentiellement réalisé par des facteurs inhibiteurs ou PIF (prolactin inhibiting factors). L'un d'eux est un polypeptide de $56 \mathrm{AA}$ (GAP $=\mathrm{GnRH}$ associated peptide), sécrété sous forme d'un précurseur commun au PIF et à la LH-RH ${ }^{11}$. Par ailleurs, des neurones dopaminergiques interviennent dans le contrôle inhibiteur de la sécrétion de prolactine. Un agoniste dopaminergique, la bromocriptine, inhibe la sécrétion de prolactine (traitement des tumeurs hypophysaires à prolactine).

La culture organotypique d'une hypophyse isolée fait apparaître une atrophie importante des différentes catégories de cellules, à l'exception des cellules à prolactine qui sont très actives. De même, l'hypophysectomie d'une rate suivie de la greffe de cette hypophyse entraîne une hypertrophie des glandes mammaires.

La sécrétion de prolactine est stimulée par la TRH, qui se comporte donc comme un prolactine-RF.

11 Tandis que la dopamine inhibe l'accumulation de l'AMPc dans les cellules hypophysaires à prolactine, le GAP inhibe l'accumulation des inositolphosphates. Son action inhibitrice sur la sécrétion de Prl s'exerce donc par un mécanisme qui diffère de l'inhibition dopaminergique. 


\subsubsection{Cas des cellules gonadotropes (à FSH et LH)}

Une hormone unique (!) FSH-LH-RH ou plus simplement LH-RH (LH releasing hormone ou lulibérine) ou GnRH (gonado-releasing hormone ou gonadolibérine) (fig. 4.21).

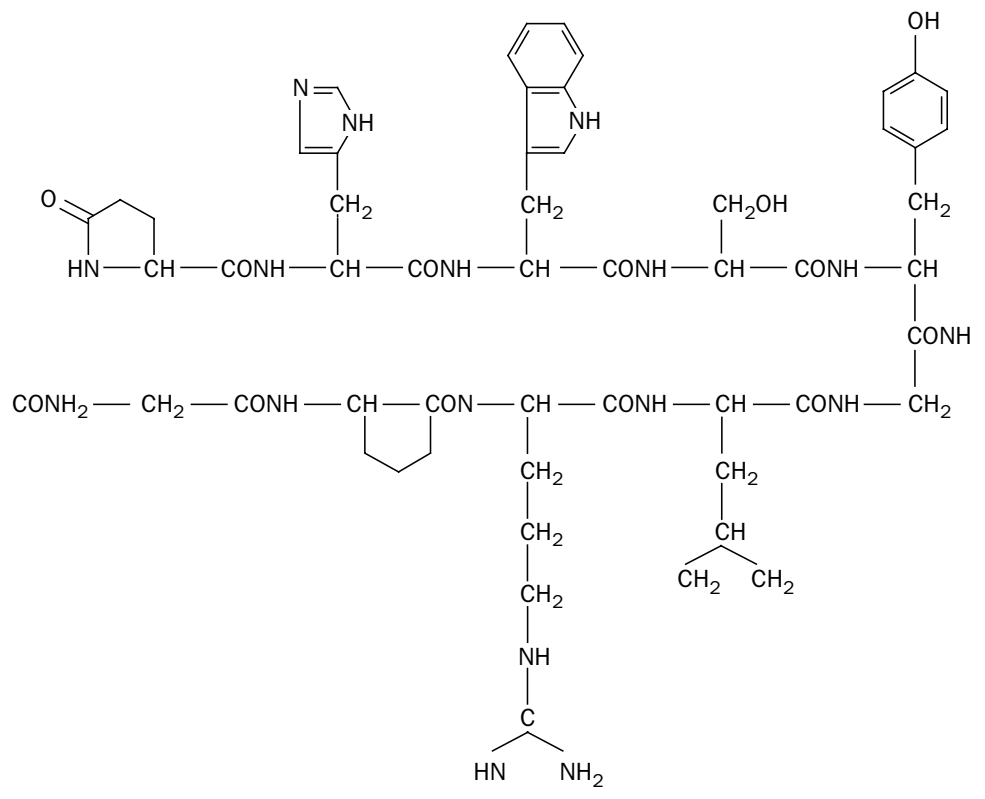

Figure 4.21 - LH-RH ou GnRH ou gonadolibérine

Sa structure a été découverte par Schally (1971), après utilisation de 250000 hypothalamus de porc. C'est un décapeptide dont la synthèse a été réalisée et qui agit à la fois comme facteur de décharge et comme facteur stimulant la synthèse de FSH et LH. Le gène humain de la GnRH a été cloné et séquencé (1984), il code pour un précurseur (pro-hormone) de $92 \mathrm{AA}$.

La GnRH est localisée principalement dans la partie latérale de la zone externe de l'éminence médiane et dans le noyau arqué (noyau ventriculaire).

L'injection de GnRH dans la région pré-optique induit, chez un rat mâle ou femelle, dans un délai de quelques dizaines de minutes, la position de copulation. Ce messager peptidique semble donc coordonner plusieurs activités (y compris comportementales) liées à la reproduction.

Son action sur les cellules hypophysaires $\alpha$ et $\beta$ est médiée par l'AMPc. La structure du récepteur, avec un $\mathrm{K}_{\mathrm{D}}$ de $0,25 \mathrm{nM}$, est encore indéterminée.

La GnRH, de même que la TRH, ayant la même structure chez les divers Mammifères, n'a donc pas de spécificité d'espèce. Si l'effet de cette hormone unique se traduit parfois par une stimulation des cellules $\gamma$, plus souvent par celle des cellules $\beta$, ou simultanément des deux types cellulaires, c'est en fonction d'interactions avec la présence d'hormones sexuelles, progestérone et œstrogènes. 
L'obtention d'analogues agonistes ou antagonistes au niveau de récepteurs hypophysaires ou d'anticorps anti-GnRH constitue une nouvelle voie d'approche de la contraception. La GnRH est susceptible d'avoir une action directe sur les gonades (testicules, ovaire) où l'on a retrouvé des récepteurs à la $\mathrm{GnRH}$, mais en faible quantité. L'épreuve à la GnRH est un des moyens d'exploration de l'axe hypothalamohypophyso-gonadique.

\subsubsection{Cas des cellules thyréotropes (à TSH)}

Une thyrotropin releasing hormone (TRH ou thyrolibérine) (fig. 4.22). Cette TRH intervient à la fois dans la décharge de la TSH et dans sa synthèse. Elle se comporte donc à la fois comme une hormone de décharge et comme une stimuline. En 1968, Guillemin avait réussi à purifier $1 \mathrm{mg}$ de facteur actif à partir de 750000 hypothalamus de mouton (soit 500 tonnes de cerveau).

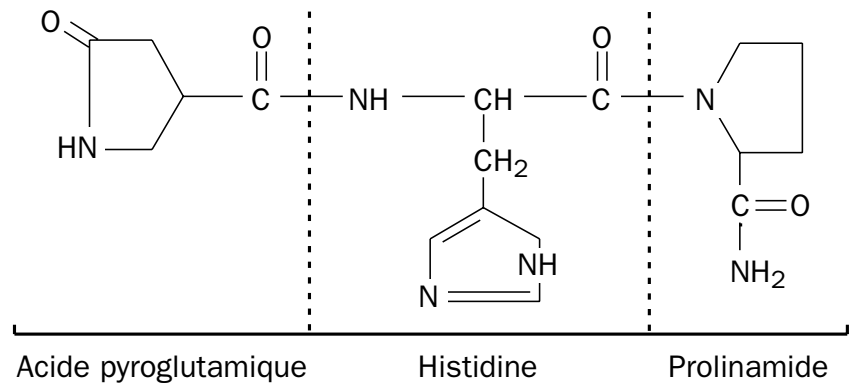

Figure 4.22 - Structure de la TRH

Sa structure a été élucidée par Schally (chez le porc) et Guillemin (chez le mouton) (1969) et sa synthèse réalisée. C'est un tripeptide pyroglutamil-histidine-proline $\mathrm{NH}_{2}$ (Gln-Hist-Pro- $\mathrm{NH}_{2}$ ). Sa demi-vie est d'environ 2 min chez l'homme.

Le froid (stimulus physique, action sensori-nerveuse) stimule la sécrétion de TRH. La TRH stimule également la sécrétion de prolactine.

L'épreuve à la TRH est un des moyens d'exploration de l'axe hypothalamo-hypophyso-thyroïdien. Le mécanisme de couplage de la TRH, au niveau de ses cellules cibles hypophysaires, est médié par la synthèse IP3. Fixée à son récepteur, la TRH est internalisée jusqu' au noyau, où des sites de liaison nucléaires ont été décrits dans des cellules tumorales.

\subsubsection{Cas des cellules corticotropes (à ACTH)}

Une corticotropin releasing hormone (CRH ou corticolibérine). C'est le premier exemple connu du contrôle d'une activité hypophysaire par l'hypothalamus. Il a été démontré par Guillemin ${ }^{12}$ et coll., en 1955, sur une culture d'association d'extraits

12 Guillemin (San Diego, USA) et Schally (Nouvelle-Orléans, USA) sont prix Nobel 1977. C'est Guillemin qui a élucidé le premier la structure de la TRH. 
d'hypophyse et d'hypothalamus. Sa séquence a été élucidée ${ }^{13}$, elle est la même chez l'homme et chez le rat: $41 \mathrm{AA}^{14}$. Sa concentration plasmatique serait de 2 à $28 \mathrm{pg} / \mathrm{ml}$ et sa demi-vie, relativement longue, d'environ $60 \mathrm{~min}$. Il faut noter que la lysine-vasopressine a une action proche de celle de $\mathrm{CRH}$, son emploi permet de tester le degré de réactivité de l'hypophyse dans les syndromes surrénalotropes. Toutefois, les récepteurs hypophysaires à la $\mathrm{CRH}$ et à la vasopressine seraient différents. Mode d'action : 2 min après injection de CRH marquée à l'iode radioactif, on la retrouve dans les cellules corticotropes hypophysaires ; son action est médiée par la synthèse d'AMPc.

\subsubsection{Cas des cellules mélanotropes (à MSH)}

Il apparaît que les facteurs hypothalamiques de décharge ou d'inhibition qui les contrôlent corrrespondent à des produits de dégradation de l'ocytocine.

- Le facteur inhibiteur (MSH-IH ou MIF) est un tripeptide : Pro-Leu-Gly- $\mathrm{NH}_{2}$.

- Le facteur de décharge (MSH-RH) est un pentapeptide.

En fait, il semble que la dégradation enzymatique de n'importe laquelle des neurohormones hypophysaires par une préparation de microsomes hypothalamiques donne des produits ayant une activité MSH-IH (MSH inhibiting hormone).

Les hormones hypothalamiques hypophysiotropes ont des demi-vies de l'ordre de 2 à 5 min chez l'homme. Compte tenu de leurs caractéristiques particulières au sein des hormones (structure : petits polypeptides, diffusion quasi régionale, demi-vie très courte), Guillemin a suggéré de leur donner un nom spécial : cybernines. Il semble qu' actuellement ce terme soit plutôt retenu pour les hormones peptidiques ovariennes.

\subsection{CONTRÔLE MONO-AMINERGIQUE OU PEPTIDERGIQUE DES NEURONES HYPOTHALAMIQUES HYPOPHYSIOTROPES}

Les neurones hypothalamiques hypophysiotropes sont soumis à l'influence de neurones hypothalamiques (à corps cellulaires situés dans l'hypothalamus) ou extrahypothalamiques (à terminaisons hypothalamiques) qui déversent au niveau de synapses axo-somatiques, axo-axoniques ou même dendro-dendritiques leurs neuromédiateurs (fig. 4.23). Ceux-ci sont soit des neurotransmetteurs classiques (mono-amines) : dopamine $(\mathrm{Da})$, noradrénaline $(\mathrm{NA})$, adrénaline $(\mathrm{A})$, sérotonine (Ser ou 5-HT = 5-hydroxytryptamine), acétylcholine (ACh), acide $\gamma$-amino-butyrique (GABA), soit des peptides divers, dont le nombre connu s'accroît chaque année (neurotransmetteur vrai, neuromodulateur... ?) et dont le rôle reste parfois imprécis : endorphines (surout $\beta=31 \mathrm{AA}$ ), enképhalines à $5 \mathrm{AA}$ (leucine-enképhaline ou méthionine-enképhaline),

13 En 1981 seulement, à partir de "rebuts" hypothalamiques d'isolement de la GnRH et de la somatostatine, provenant des 500000 hypothalamus de mouton utilisés par Guillemin et ses collaborateurs (Vale et coll., 1983).

14 On a trouvé de la CRH dans la surrénale, ce facteur exerce-t-il une action directe sur cette glande? 
angiotensine II (8 AA), VIP (vasoactive intestinal peptide, $28 \mathrm{AA}$ ), substance $\mathrm{P}$ (11 AA), CCK-PZ (cholecystokinine-pancréozymine, 33 AA), neurotensine (13 AA)...

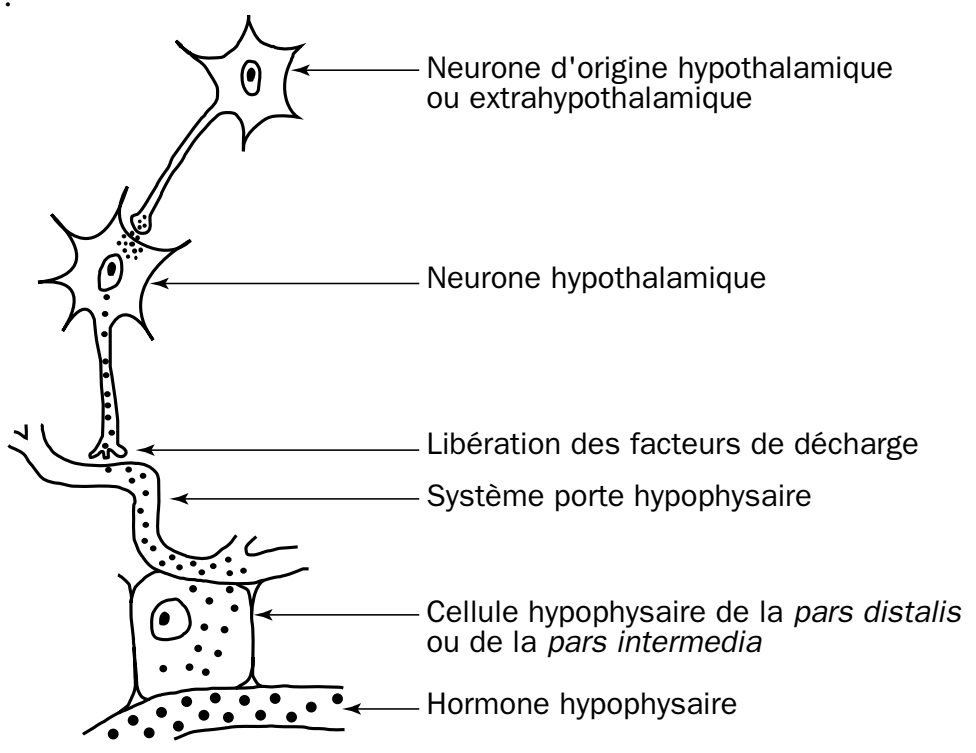

Figure 4.23 - Contrôle des neurones hypothalamiques hypophysiotropes

Un même neurone peut aussi libérer au niveau de sa terminaison une mono-amine plus un peptide (par exemple sérotonine + substance $\mathrm{P}$ ) dont le rôle respectif est mal élucidé. Les neurones hypothalamiques hypophysaires sont eux-mêmes des neurones peptidergiques (à $\mathrm{RH}$ ou $\mathrm{IH}$ ) qui déversent donc dans le système porte leur sécrétion hormonale sous l'influence :

- d'autres neurones sécréteurs mono-aminergiques ou peptidergiques

- des facteurs hormonaux hypophysaires ou extrahypophysaires

- de facteurs chimiques $\left(\mathrm{Na}^{+}\right.$, glucose...).

\subsubsection{Axe somatocrinine/somatostatine et $\mathbf{G H}$}

L'effet des mono-amines varie selon l'espèce. Chez l'homme, les trois monoamines : Da (dopamine), NA (noradrénaline) et Ser (sérotonine) élèvent le taux plasmatique de $\mathrm{GH}$, le neurone dopaminergique, par une action problablement directe sur la cellule antéhypophysaire à $\mathrm{GH}$, les neurones $\alpha$-noradrénergiques et sérotoninergiques, par une action sur le neurone hypothalamique (simulation du neurone à GRH ou inhibition du neurone à SRIF ? ).

Parmi les peptides, la $\beta$-endorphine stimule la sécrétion de GH, par effet sur la GRH ; la bombésine (14 AA) ${ }^{15}$ interférerait avec les sites d'action de la somatostatine pour

15 La bombésine est un peptide découvert dans la peau d'amphibien, puis retrouvé dans le cerveau de Mammifères, dont des analogues (gastrin-releasing peptides, GRP), présents dans le tube digestif de Mammifères, jouent un rôle dans l'apparition de tumeurs digestives. 
moduler ses effets sur la GH. La neurotensine et la substance P agiraient par l'intermédiaire de voies histaminergique ou cholinergique.

\subsubsection{Axe PIF et prolactine}

Le neurone tubéro-infundibulaire sécréteur de dopamine est inhibiteur de la sécrétion de prolactine. La sérotonine, qui stimule la sécrétion de Prl, serait responsable du pic sécrétoire nocturne de Prl. Enfin, divers peptides cérébraux stimulent la sécrétion de Prl : TRH, $\beta$-endorphine, leucine-enképhaline. De nombreux agents psychotropes (phénothiazine, antidépresseurs de la série de IMAO ${ }^{16}$ ) sont également stimulants, d'où la fréquence des hyperprolactinémies iatrogènes ${ }^{17}$. Les œstrogènes empêchent l'effet inhibiteur de la dopamine.

\subsubsection{Axe gonadolibérine}

Le contrôle positif est essentiellement noradrénergique. Les terminaisons noradrénergiques de la région pré-optique, dont les corps cellulaires sont situés dans la protubérance et le bulbe, entrent en contact avec les neurones libérateurs de GnRH. La perfusion avec l' $\alpha$-méthyl DOPA (analogue compétitif d'un précurseur de la NA) dans l'éminence médiane bloque l'ovulation.

Les opiacés endogènes (essentiellement la $\beta$-endorphine) exercent en revanche un contrôle inhibiteur sur la sécrétion pulsatile de la LH. La naloxone, antagoniste des opiacés, stimule cette sécrétion.

\subsubsection{Axe thyréolibérine et TSH}

Des neurones $\alpha$-adrénergiques stimulent les neurones à TRH tandis que les neurones dopaminergiques exercent un effet inhibiteur, ici encore par une action probablement directe sur la cellule hypophysaire à TSH. Le froid est un stimulus fondamental qui stimule la TRH, les récepteurs au froid situés dans l'aire pré-optique pourraient être les neurones adrénergiques, ou seraient reliés à ces neurones.

\subsubsection{Axe CRH, ACTH et hormones glucocorticoüdes (voir Assenmacher et coll., 1987)}

Le neurone sécréteur de CRH semble régulé par de nombreux neuromédiateurs :

- la noradrénaline via des récepteurs $\alpha$ à action activatrice ;

- la sérotonine dont le taux intracérébral suit chez le rat un rythme circadien parallèle à celui de la corticostérone plasmatique (acrophase à $20 \mathrm{~h}$ et minimum à $4 \mathrm{~h}$ ). L'injection de P-chlorophénylalanine (PCPA), un inhibiteur de la biosynthèse de la sérotonine, bloque la variation circadienne de la corticostérone (fig. 4.24);

16 IMAO : inhibiteurs de la mono-amino-oxydase, qui est l'une des deux enzymes dégradant les catécholamines et l'enzyme dégradant la sérotonine.

17 Iatrogène : provoqué par des médicaments. 
Corticostérone plasmatique

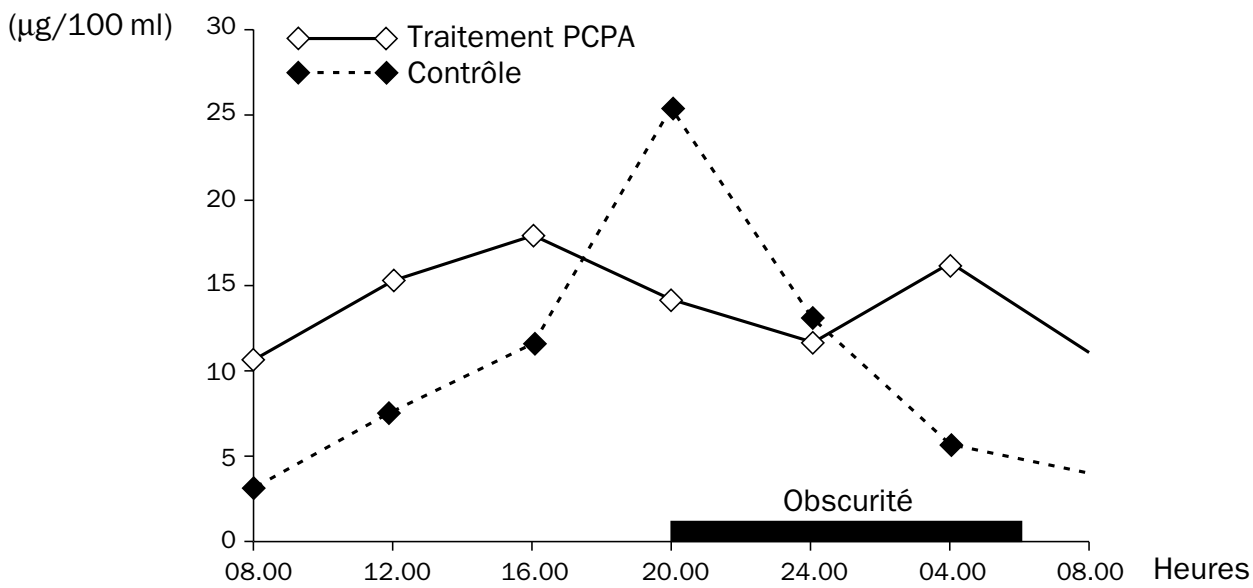

Figure 4.24 - Effet du traitement par le P-chlorophénylalanine (PCPA), inhibiteur de la biosynthèse de la sérotonine, sur le rythme circadien de la sécrétion de corticostérone chez le rat (d'après Scapagnini, 1971)

- GABA, dont un agoniste, le baclofène, accroît l'activité de neurones du noyau ventro-médian de l'hypothalamus et un antagoniste, la picrotoxine, la réduit (fig. 4.25). Les neurones gabaergiques agiraient à un niveau pré-synaptique sur des neurones régulateurs du neurone à $\mathrm{CRH}$, leur stimulation réduit la sécrétion d'ACTH et donc de corticoïdes.

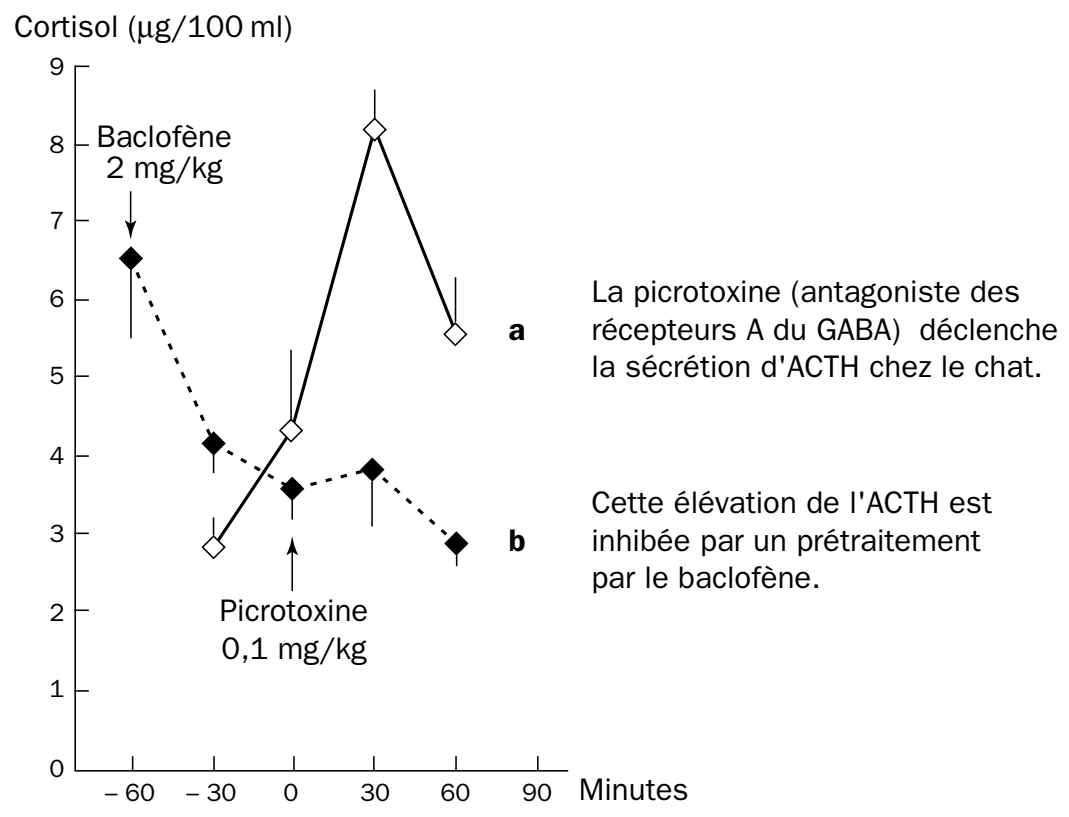

Figure 4.25 - Effet des agonistes ou antagonistes GABA sur la sécrétion d'ACTH (d'après Matheson, 1980) 
- d'autres substances pourraient fonctionner comme neuromédiateurs ou neuromodulateurs de la sécrétion de CRH : l'acétylcholine (action stimulatrice), l'histamine, l'angiotensine II, les opiacés, le neuropeptide Y.

\subsection{LA NOTION DE FEED-BACK (RÉTRO-CONTRÔLE)}

L'homéostasie est assurée, tant dans le domaine du système nerveux central que dans celui des glandes endocrines, par une régulation dont le mécanisme est "réfléchi". C'est un rétro-contrôle (feed-back en anglais).

L'effet réalisé (par exemple la pression artérielle augmente ou diminue, la teneur en $\mathrm{CO}_{2}$ sanguin augmente ou diminue...), ou la quantité d'hormone produite (augmente ou diminue), contrôle en retour l'organe à l'origine de la variation de la fonction ou de la sécrétion observées. Dans la plupart des cas, le feed-back est négatif : la réaction tend à annuler la variation et à rétablir l'équilibre initial. Mais le rétro-contrôle est parfois dit positif : stimulation de la décharge de LH (ou de GnRH) sous l'effet de taux élevés d'œstrogènes.

\subsubsection{Hormone de croissance}

Il existe un rétro-contrôle court : la GH en circulation inhibe sa propre sécrétion.

\subsubsection{Axe hypothalamo-hypophyso-thyroüdien}

Le rétro-contrôle est négatif. Les hormones thyroïdiennes agissent au moins à deux niveaux : sur les neurones hypothalamiques et sur les cellules thyréotropes hypophysaires. Il existe là aussi un rétro-contrôle court de la TSH sur la sécrétion de TRH (fig. 4.26).

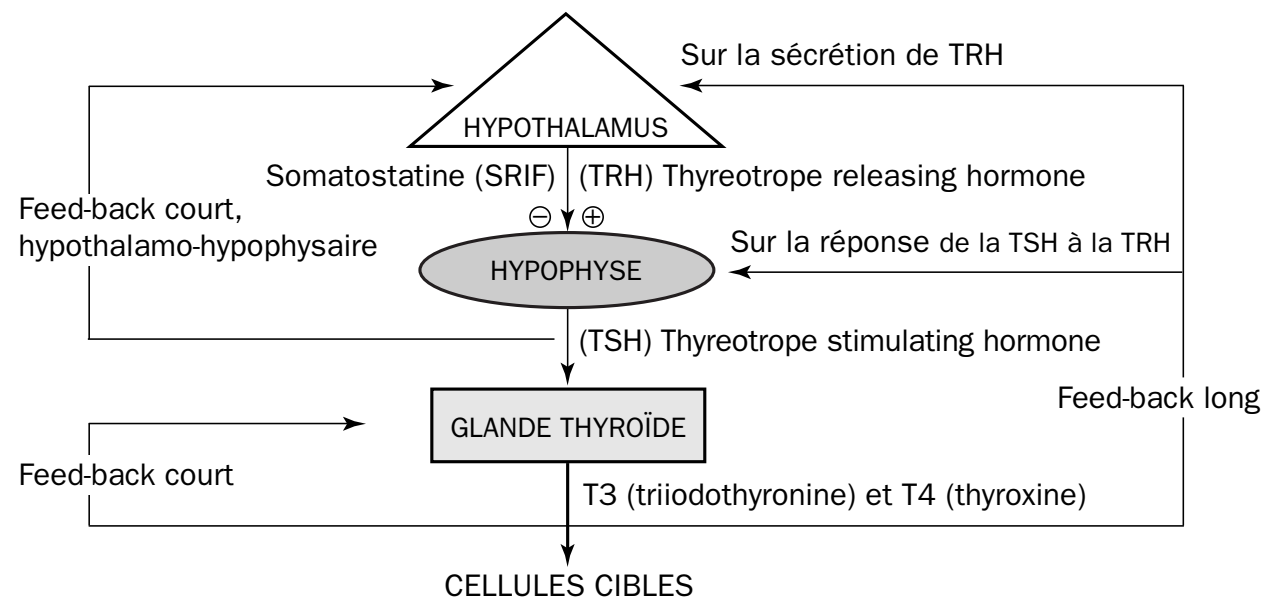

Figure 4.26 - Exemple d'un feed-back (négatif) endocrinien. Relations hypothalamo-hypophyso-thyroïdiennes 
L'hypophyse est soumise à un contrôle positif (stimulation) par la TRH et à un contrôle inhibiteur par la somatostatine. Le taux d'hormones thyrö̈diennes retentit sur la sécrétion hypothalamique de TRH comme sur l'action de la TRH sur les cellules hypophysaires à TSH (feed-back long). Elles pourraient aussi inhiber leur propre sécrétion (feed-back court).

\subsubsection{Axe hypothalamo-hypophyso-surrénal}

Les hormones glucocorticoïdes exercent essentiellement un rétro-contrôle négatif sur l'hypophyse et sur l'hypothalamus. Avec un rétro-contrôle court de l'ACTH circulant sur sa propre sécrétion.

Le stress, au contraire, exerce un effet stimulant sur la sécrétion de CRH qui provoque la décharge d'ACTH, et sous l'effet de celle-ci la sécrétion des hormones glucocorticoïdes du cortex surrénal.

\subsubsection{Axe hypothalamo-hypophyso-gonadique}

Les phénomènes sont assez complexes, compte tenu de l'existence d'un seul facteur hypothalamique et d'une activité gonadique qui est cyclique chez la femelle et à peu près constante chez le mâle (en période d'activité sexuelle).

Chez le mâle, le rétro-contrôle négatif est assuré par la testostérone ; il s'exerce à la fois sur les neurones hypothalamiques (sécrétion de $\mathrm{GnRH}$ ) et sur les cellules hypophysaires (réponse de la LH à la GnRH). Le contrôle de la sécrétion de FSH est exercé par une substance inhibitrice d'origine testiculaire ou ovarienne : l'inhibine.

Chez la femelle, œstrogènes et progestérone exercent un rétro-contrôle négatif. Les œstrogènes peuvent agir soit sur l'hypothalamus, soit sur l'hypophyse, et la FSH en implant hypothalamique agit à la fois sur la sécrétion de GnRH et celle de FSH hypophysaire (rétro-contrôle court). Mais les œstrogènes ont également une influence stimulante sur l'hypothalamus au niveau de l'aire pré-optique, provoquant la décharge cyclique de LH (rétro-contrôle positif).

\section{LE “SEXE” DE L'HYPOTHALAMUS}

Des expériences réalisées chez le rat (Pfeiffer, 1936 ; Harris, 1955-1970 ; Gorski, 1963-1978) ont mis en évidence une "période critique" de maturation de l'hypothalamus, pendant laquelle la présence (chez le mâle) ou l'absence (chez la femelle) d'androgène plasmatique déterminera le caractère continu (chez le mâle) ou cyclique (chez la femelle) de la sécrétion de GnRH et influencera l'activité sexuelle de l'adulte.

- Si l'on injecte des androgènes à un rat nouveau-né femelle, la femelle devenue mature n'aura pas d'ovulations.

- La castration ou l'administration d'anti-androgènes chez le rat nouveau-né mâle entraîne chez l'adulte une sécrétion cyclique de FSH et de LH. 
La testostérone bloque donc au niveau de l'hypothalamus la possibilité d'une activité cyclique et réalise ainsi son orientation "mâle" : sécrétion à peu près constante de GnRH (1 à 6 ng/ml). L'absence de sécrétions androgènes détermine le développement de l'hypothalamus selon un type "neutre" pourvu d'une activité cyclique qui caractérise la femelle. Cette période critique se situe dans les 48 h qui suivent la naissance chez le rat (pic de testostéronémie $2 \mathrm{~h}$ après la naissance [Roffi, 1977]) (fig. 4.27), vers le 3e mois après la naissance chez l'homme (Forest et coll., 1974) (fig. 4.28).

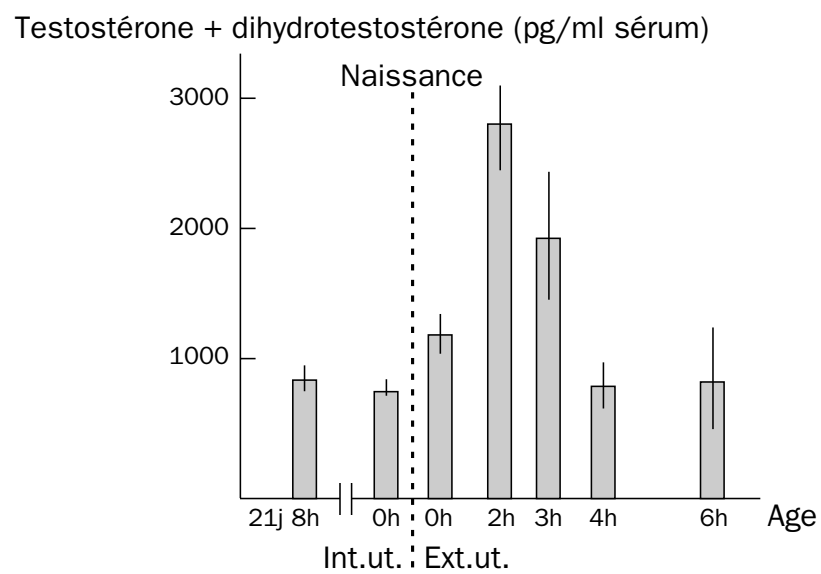

Figure 4.27 - Evolution du taux de la testostérone (+ dihydrotestostérone) sérique au cours de la période périnatale chez le rat (d'après Corbier et coll., 1977)

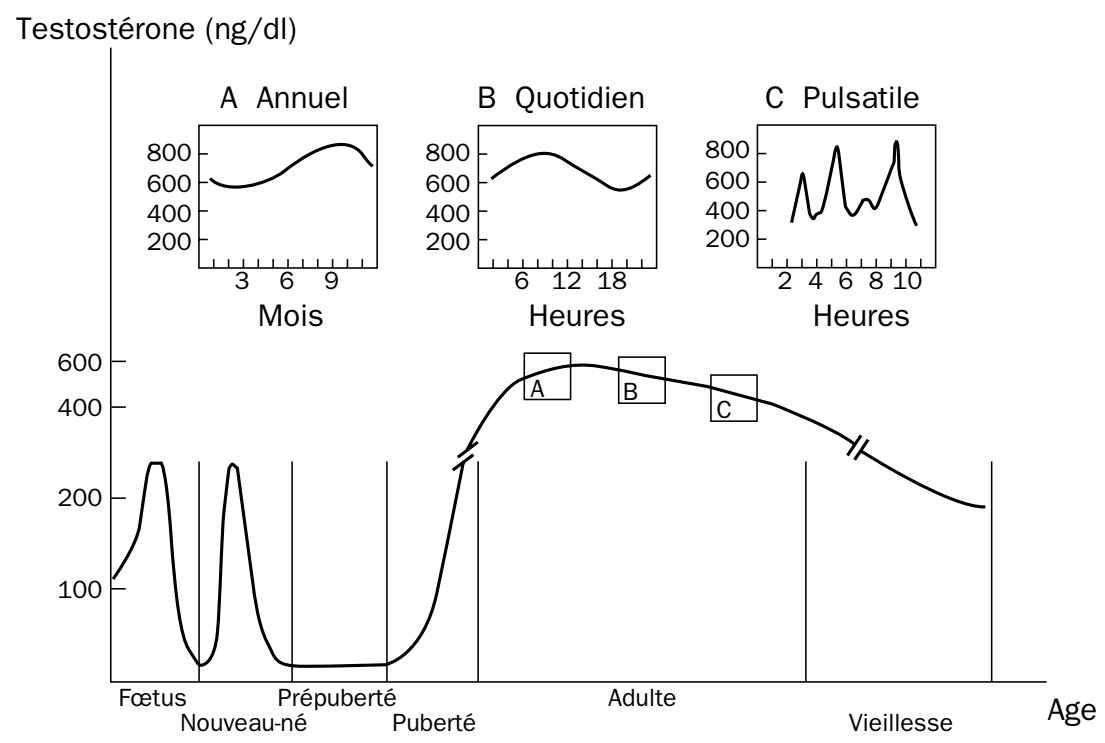

Figure 4.28 - Concentration de la testostérone plasmatique chez l'homme à différentes périodes de sa vie. Pulsatilité et rythmes circannuel et mensuel de cette sécrétion (d'après Ewing et Zirkin, 1983) 
Les structures nerveuses responsables de cette réceptivité spécifique et d'une réponse sécrétoire différente suivant le sexe seraient localisées dans l'aire pré-optique et l'hypothalamus ventro-médian (noyau arqué en particulier). Dans l'aire pré-optique du rat, la zone mâle (androgène-dépendante) est périphérique, entourant la zone femelle qui est centrale (Gorski et coll., 1978).

Des expériences réalisées, chez le macaque mâle ou femelle castré et prétraité à l'œstradiol avant l'injection d'une forte dose d'œstradiol, démontrent pourtant que cette orientation précoce du "sexe" de l'hypothalamus (Hodges, 1980) n'est pas irréversible (fig. 4.29).
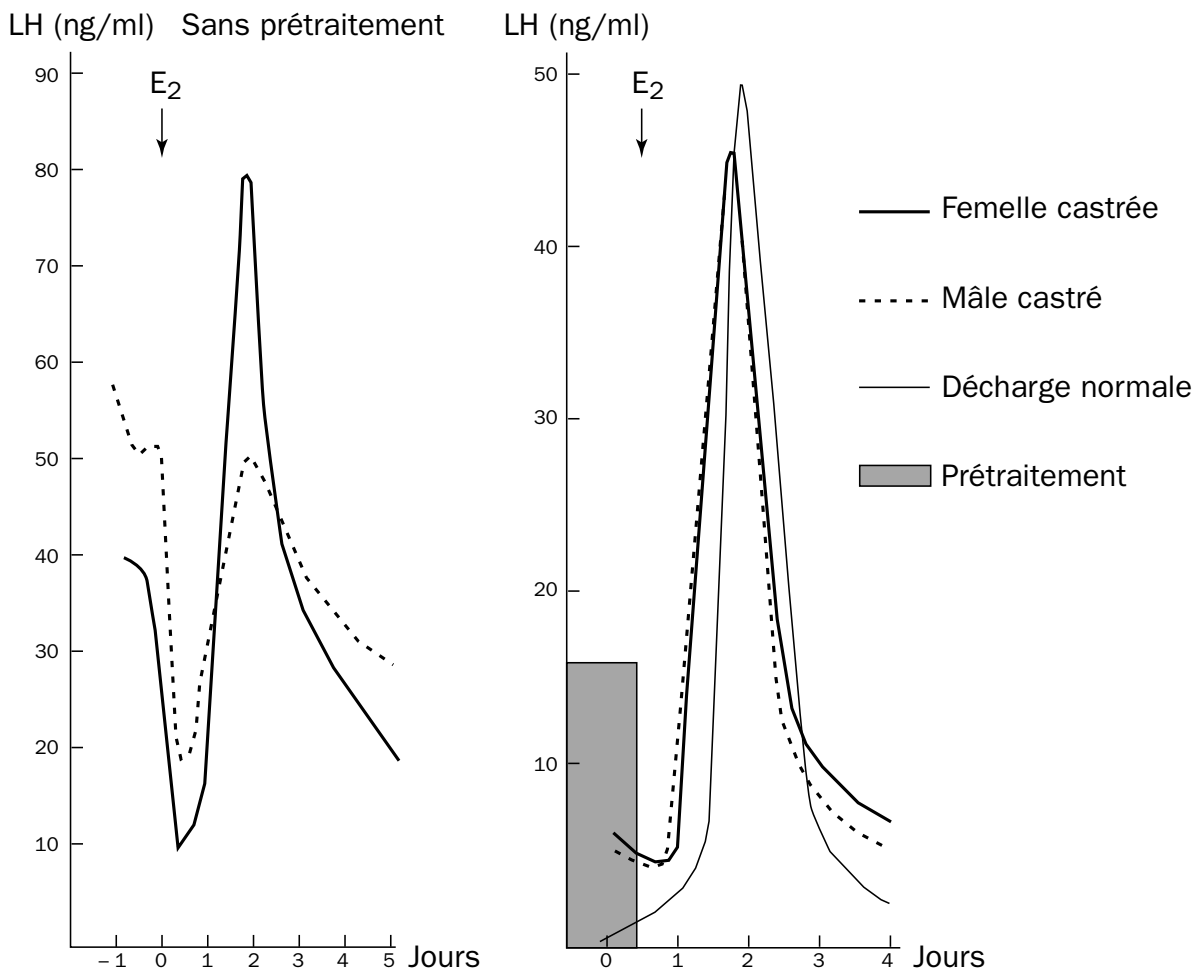

Figure 4.29 - Réversibilité de l'orientation du "sexe" de l'hypothalamus chez le macaque rhésus (d'après Hodges, 1980)

Après une simple injection d'œstradiol (E2), le mâle castré de macaque présente une élévation non-significative de LH plasmatique. En revanche, sous l'effet d'un prétraitement qui mime la situation physiologique de la femelle (imprégnation par l'œstradiol), l'injection d'œstradiol provoquera une élévation de la LH semblable chez le mâle castré et la femelle castrée, et d'une intensité identique à la décharge cyclique de la femelle normale. 


\section{LES HORMONES NEUROHYPOPHYSAIRES}

La sécrétion hormonale dépend de la genèse et de la propagation de potentiels d'action dans les neurones sécréteurs, la libération des hormones dans les terminaisons neurosécrétrices étant liée à l'entrée de calcium (Douglas, 1981). Cette sécrétion s'effectue par exocytose à partir des granules de neurosécrétion. Ces granules contiennent l'une ou l'autre hormone en concentration équimoléculaire avec des protéines spécifiques : protéines de Van Dyke ou neurophysines, de PM relativement faible (environ $10000)$ qui constituent des protéines vectrices, libérées en même temps que les hormones dans la circulation veineuse. La migration des granules de sécrétion le long des axones longs jusqu'à leur terminaison dans la pars nervosa requiert environ $12 \mathrm{~h}$ chez l'homme.

\subsection{LES NEUROPHYSINES}

Constituée de 93 AA, on en distingue deux classes principales :

- les MSEL-neurophysines, protéines vectrices pour 1'ADH (antidiuretic hormone).

- les VLDV-neurophysines, protéines vectrices pour l'ocytocine, qui diffèrent dans la séquence 1 à 9 , la séquence 10 à 75 étant pratiquement invariante.

Les neurophysines constituent en fait un fragment d'un précurseur commun avec l'hormone :

- un précurseur pour la MSEL-neurophysine (neurophysine II) et l'hormone antidiurétique $(\mathrm{ADH})$; c'est une pré-pro-hormone de poids moléculaire $20 \mathrm{kDa}$ environ (fig. 4.30.a).

- un précurseur pour la VLDV-neurophysine (neurophysine I) et l'ocytocine.

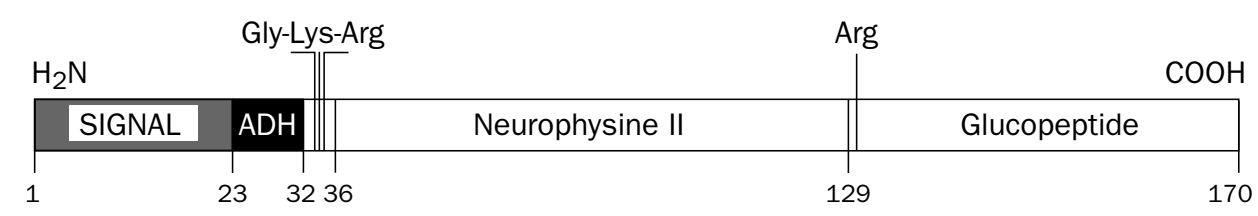

a - Structure du précurseur de l'ADH

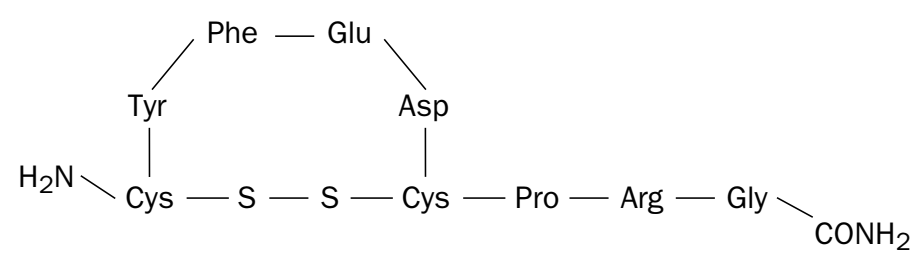

b - Structure de I'ADH chez les Primates

Figure 4.30 - L'hormone antidiurétique 


\subsection{L'HORMONE ANTIDIURÉTIQUE OU VASOPRESSINE (HAD OU ADH : antidiuretic hormone)}

\subsubsection{Structure et localisation}

C'est un nonapeptide de formule parfaitement connue. Le $8^{\mathrm{e}}$ AA est l'arginine chez la plupart des Mammifères (arginine-vasopressine), sauf chez le porc, l'hippopotame et le pécari (lysine-vasopressine). Le $3^{\mathrm{e}} \mathrm{AA}$ est la phénylalanine chez les Mammifères (voir fig. 4.30.b), l'isoleucine chez les non-mammaliens dont l'ADH est appelée arginine-vasotocine (tab. 4.2).

Tableau 4.2 - Structure chimique des hormones neurohypophysaires

\begin{tabular}{|c|c|c|c|}
\hline \multirow[t]{3}{*}{$\begin{array}{l}\text { Hormones du } \\
\text { genre de la } \\
\text { vasopressine }\end{array}$} & $\begin{array}{c}\text { Lysine- } \\
\text { vasopressine }\end{array}$ & H-Cys-Tyr-Phe-Glu( $\left.\mathrm{NH}_{2}\right)$-Asp $\left(\mathrm{NH}_{2}\right)$-Cys-Pro-Lys-Gly- $\mathrm{NH}_{2}$ & $\begin{array}{l}\text { Porc } \\
\text { Hippopotame } \\
\text { Pécari }\end{array}$ \\
\hline & $\begin{array}{c}\text { Arginine- } \\
\text { vasopressine }\end{array}$ & H-Cys-Tyr-Phe-Glu( $\left.\mathrm{NH}_{2}\right)$-Asp( $\left.\mathrm{NH}_{2}\right)$-Cys-Pro-Arg-Gly- $\mathrm{NH}_{2}$ & $\begin{array}{l}\text { La plupart des } \\
\text { Mammifères }\end{array}$ \\
\hline & Vasotocine & H-Cys-Tyr-Ile-Glu( $\left.\mathrm{NH}_{2}\right)$-Asp $\left(\mathrm{NH}_{2}\right)$-Cys-Pro-Arg-Gly- $\mathrm{NH}_{2}$ & $\begin{array}{l}\text { Vertébrés non- } \\
\text { mammifères }\end{array}$ \\
\hline \multirow[t]{3}{*}{$\begin{array}{l}\text { Hormones du } \\
\text { genre de } \\
\text { l'ocytocine }\end{array}$} & Ocytocine & H-Cys-Tyr-Ile-Glu( $\left.\mathrm{NH}_{2}\right)$-Asp $\left(\mathrm{NH}_{2}\right)$-Cys-Pro-Leu-Gly- $\mathrm{NH}_{2}$ & $\begin{array}{l}\text { De nombreux } \\
\text { Vertébrés, } \\
\text { surtout les } \\
\text { Mammifères } \\
\text { et les Oiseaux }\end{array}$ \\
\hline & Mésotocine & H-Cys-Tyr-Ile-Glu( $\left.\mathrm{NH}_{2}\right)$-Asp $\left(\mathrm{NH}_{2}\right)$-Cys-Pro-Lys-Gly- $\mathrm{NH}_{2}$ & $\begin{array}{l}\text { Batraciens, } \\
\text { Dipneustes }\end{array}$ \\
\hline & $\begin{array}{l}\text { Ichtyocine } \\
=\text { isotocine }\end{array}$ & H-Cys-Tyr-Ile-Ser-Asp $\left(\mathrm{NH}_{2}\right)$-Cys-Pro-Ile-Gly- $\mathrm{NH}_{2}$ & $\begin{array}{l}\text { Certains } \\
\text { Téléostéens }\end{array}$ \\
\hline
\end{tabular}

Elle est essentiellement sécrétée par les neurones des noyaux supra-optiques du tractus $\mathrm{SOH}$, mais aussi dans les noyaux paraventriculaires. Elle est stockée dans la pars nervosa.

\subsubsection{Données cliniques}

Son absence (par lésion hypothalamique) provoque le diabète insipide : polyurie (5 à $101 /$ jour) avec des urines de densité 1001-1005 et polydipsie (exagération anormale de la sensation de soif, conduisant à une augmentation de la prise de boisson). En revanche, l'hypophysectomie seule ne donne qu'un diabète insipide transitoire. L'étude génétique d'un diabète insipide héréditaire chez un rat mutant Brattleboro montre que la maladie est due à une simple délétion par absence de guanine sur la séquence de l'ADN du précurseur, au niveau de la transcription en neurophysine. L'altération de la neurophysine et l'absence probable de codon stop font que ces animaux ne libèrent pas d'ADH dans le sang (Schmale et Richter, 1984). 
Son injection détermine une rétention de l'eau, elle sera plus facilement objectivée après une diurèse aqueuse par surcharge hydrique. Elle élève la pression artérielle, mais de façon rapide et transitoire d'où le nom de vasopressine.

Son hypersécrétion (syndrome de sécrétion inappropriée d'hormone antidiurétique : SIADH) entraîne une hyperhydratation de l'organisme avec hyponatrémie.

\subsubsection{Mode d'action}

La réabsorption dite "facultative" de l'eau (15\% de l'ultrafiltrat plasmatique), au niveau du tube distal du rein (tube contourné distal et tube collecteur, fig. 4.31), est sous la dépendance de l'ADH. Chez les Mammifères, elle n'agirait pas sur le transfert des électrolytes. En revanche, elle agit sur les transfert d'eau et de sels chez les Vertébrés inférieurs ${ }^{18}$. La demi-vie de l'hormone varie entre 2 et 10 min.

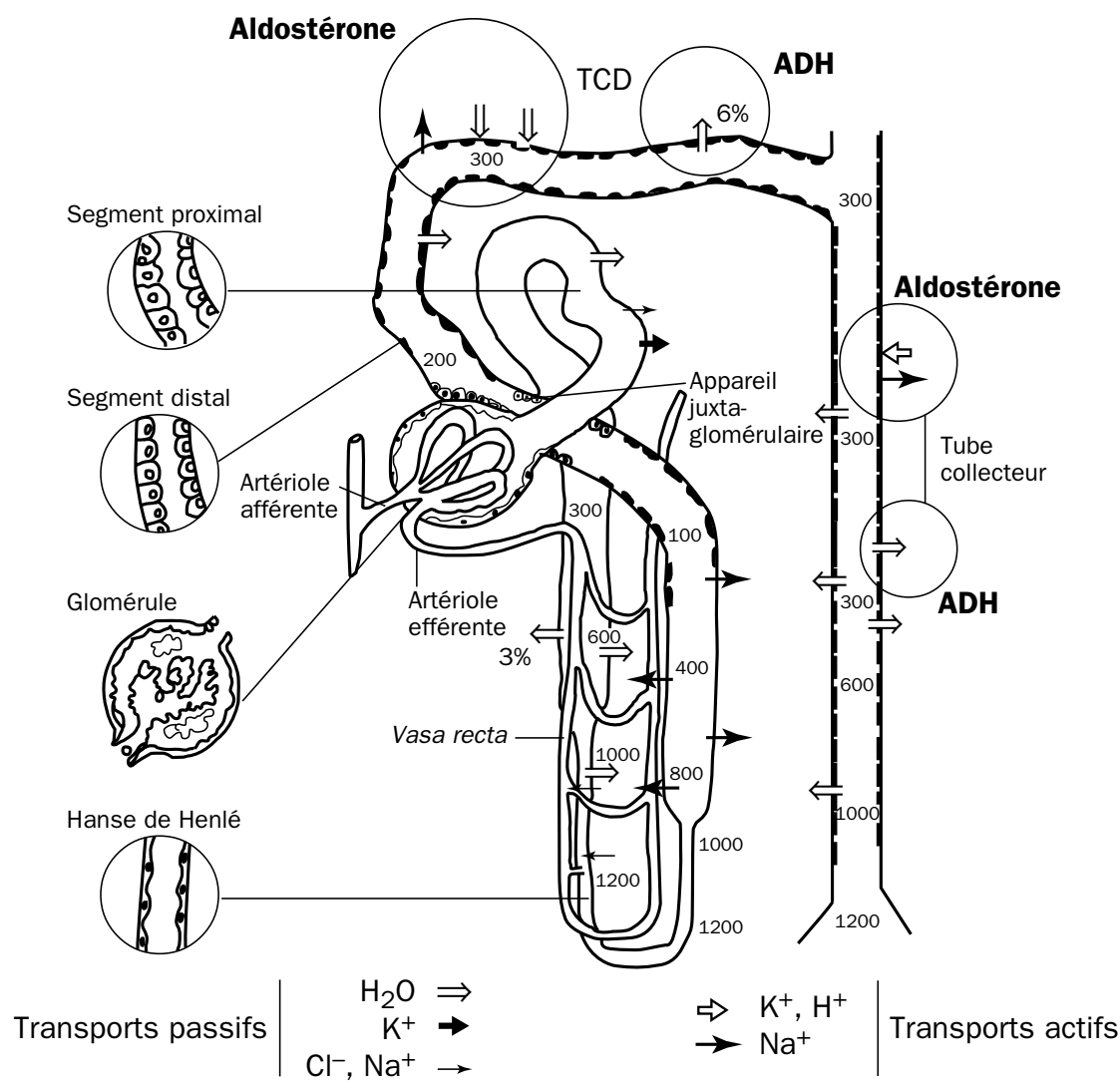

Figure 4.31 - Mouvements de l'eau et des sels dans le néphron

Les chiffres indiquent l'osmolarité en mosmoles (osmolarité du plasma $=300 \mathrm{mOsm}$ ). En l'absence d'ADH, l'osmolarité de l'urine est de l'ordre de $100 \mathrm{mOsm}$ à 400 mOsm.

18 L'ADH de Vertébrés non-mammaliens (vasotocine) exerce un effet vasopresseur et ocytocique chez les Vertébrés mammaliens. 
Dans le rein, l'hormone se lie à des récepteurs de sous-classe V2 situés dans la membrane basale des cellules distales. Cette liaison active une adénylate cyclase. L'élévation de l'AMPc active une protéine kinase qui entraîne une augmentation de la perméabilité à l'eau, via la mise en jeu d'aquaporines (fig. 4.32).

Mais elle se lie aussi à des récepteurs de sous-classe V1 à mécanisme IP3 dépendant (V1a sur la glycogénolyse hépatique, V1b sur les cellules hypophysaires sécrétrices d'ACTH).

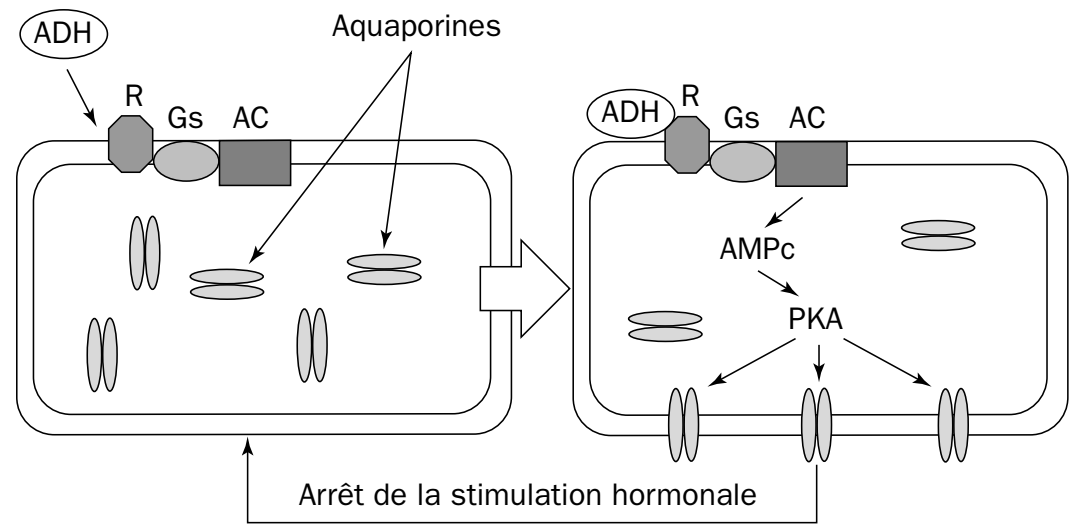

Figure 4.32 - Représentation schématique et hypothétique de l'action de I'ADH sur la perméabilité à l'eau du canal collecteur (d'après Benoit et coll., 1996) L'activation du récepteur à l'ADH (R) entraîne la synthèse d'AMPc via la mise en jeu d'une protéine $G$ stimulatrice (Gs) et l'activation de l'adénylate cyclase. La stimulation de la protéine kinase $A(P K A)$, qui découle de cette synthèse d'AMPc, provoque la translation du cytoplasme vers la membrane de la face apicale de protéines perméables à l'eau, les aquaporines. L'augmentation de la perméabilité à l'eau permettrait alors sa réabsorption.

\subsubsection{Régulation}

La sécrétion de l'ADH est mise en jeu par deux types de récepteurs :

- des osmo-récepteurs hypothalamiques, très sensibles, d'action très rapide : l'accroissement de la pression artérielle (injection de solution hypertonique, hémoconcentration) stimule la sécrétion d'ADH (fig. 4.33.a) avec un effet immédiat sur la diurèse (oligurie). La diminution de la pression osmotique entraîne une inhibition de la sécrétion d'ADH, mais avec un effet retardé sur la diurèse (fig. 4.33.b).

Ce ne sont pas les neurones sécréteurs eux-mêmes qui répondent à une élévation de la tonicité du plasma sanguin par une séquence excitation-inhibition, mais plutôt les neurones voisins à réponse monophasique (accélération de la décharge après l'injection carotidienne de solution hypertonique). Entre ces deux types de neurones, la synapse serait cholinergique.

La régulation est très sensible (une augmentation de l'osmolarité de $2 \%$ ontraîne la libération d' $\mathrm{ADH}$ ), ce qui permet de maintenir l'osmolarité du plasma à $300 \mathrm{mOsm} / 1$. 


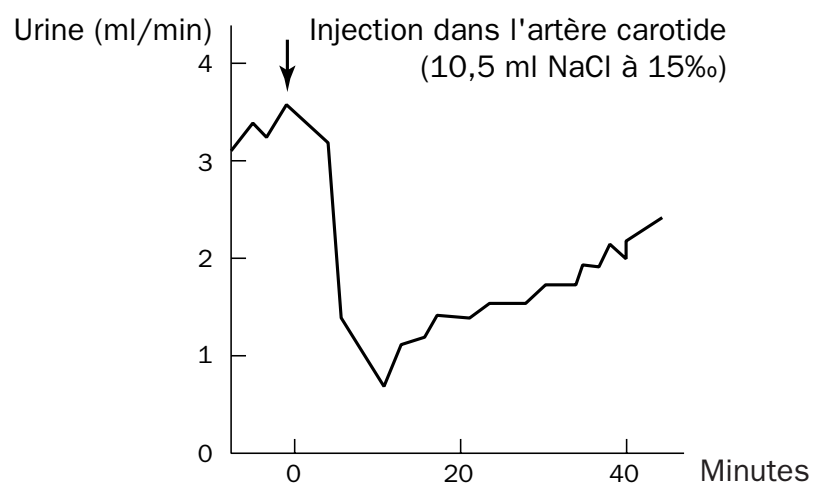

\section{a - Effet sur la diurèse de l'injection intracarotidienne (flèche) d'une solution de chlorure de sodium hypertonique}

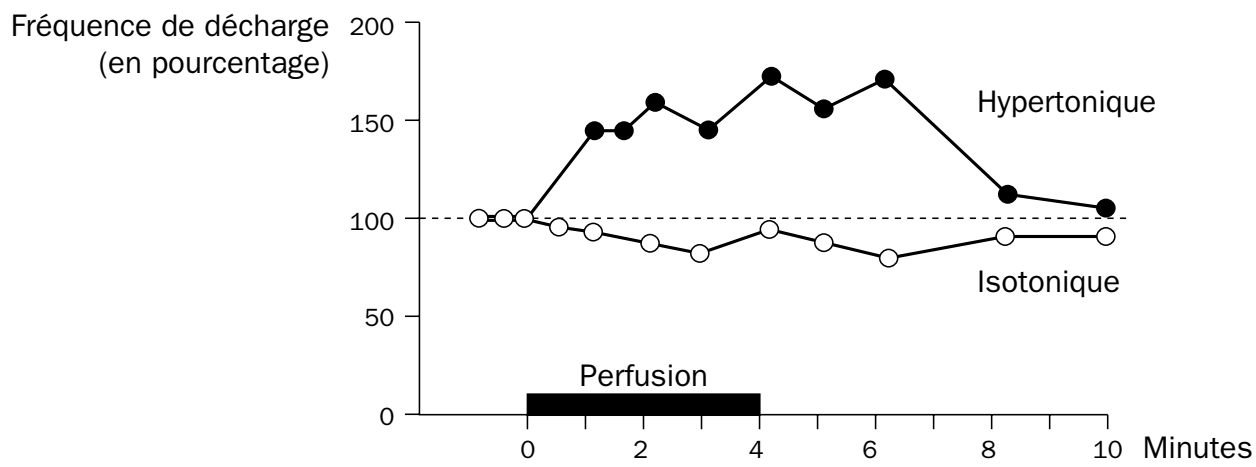

b - Effet sur l'activité électrique d'un neurone hypothalamique de la perfusion d'une solution de chlorure de sodium hypertonique et d'une solution isotonique

Figure 4.33 - Rôle du facteur natrémique dans la sécrétion de l'ADH

(d'après Berthezène et coll., 1979)

- des baro-récepteurs dont il existe deux types :

- des baro-récepteurs à basse pression, sensibles aux variations de la volémie, et situés dans l'oreillette gauche :

- la diminution de la volémie entraîne une stimulation de la sécrétion d'ADH ;

- l'augmentation de la volémie provoque une inhibition de la sécrétion d'ADH.

- des baro-récepteurs à haute pression, sensibles aux variations de la pression artérielle, et situés au niveau de la crosse de l'aorte et de la bifurcation carotidienne. Il est cependant à noter que, d'une façon générale, la volémie est étroitement liée à la pression artérielle.

Dans les conditions pathologiques habituelles (par exemple la déshydratation qui entraîne une baisse de la volémie et une hypernatrémie), volémie et pression osmotique agissent de façon couplée sur la sécrétion de l'ADH. Toutefois, si expérimentalement on fait varier ces facteurs suivant un couplage inverse (par exemple une perfusion intraveineuse avec un grand volume de sérum hypertonique), la régulation se fait avec priorité pour la volémie. 
L'ADH assure donc l'homéostasie de l'organisme pour deux constantes fondamentales : l'osmolarité du milieu intérieur et la volémie, avec priorité pour la volémie.

D'autres facteurs agissent sur la sécrétion d'ADH (mais ce ne sont pas des facteurs de régulation) : facteurs émotifs qui augmentent l'ADH, thermiques (le froid entraîne une diminution de l'ADH, la chaleur une augmentation) et pharmacodynamique (adrénaline et alcool provoquent une diminution de l'ADH, acétylcholine et nicotine une augmentation).

L'acétylcholine en injection a un effet antidiurétique qui est aboli après hypophysectomie. Elle excite les neurones supra-optiques et accélère la décharge des neurones paraventriculaires.

\subsubsection{Méthodes d'exploration fonctionnelle de la neurohypophyse}

- Epreuve de Carter et Robbins : sous perfusion de sérum glucosé isotonique qui provoque une diurèse à $5 \mathrm{ml} / \mathrm{min}$, on injecte :

1. du sérum salé hypertonique,

2. de l'ADH. Cette épreuve permet de distinguer un diabète insipide hypothalamique d'un diabète insipide néphrogénique (fig. 4.34).

- Epreuve à la nicotine qui stimule la sécrétion d'ADH. Elle permet de distinguer un diabète insipide d'une potomanie (prise excessive de boisson d'origine psychologique).

- Epreuve de restriction hydrique. Elle permet de distinguer un diabète insipide d'une potomanie (à réaliser avec précaution, car la déshydratation qui en résulterait dans un diabète insipide vrai pourrait être dangereuse pour le malade).

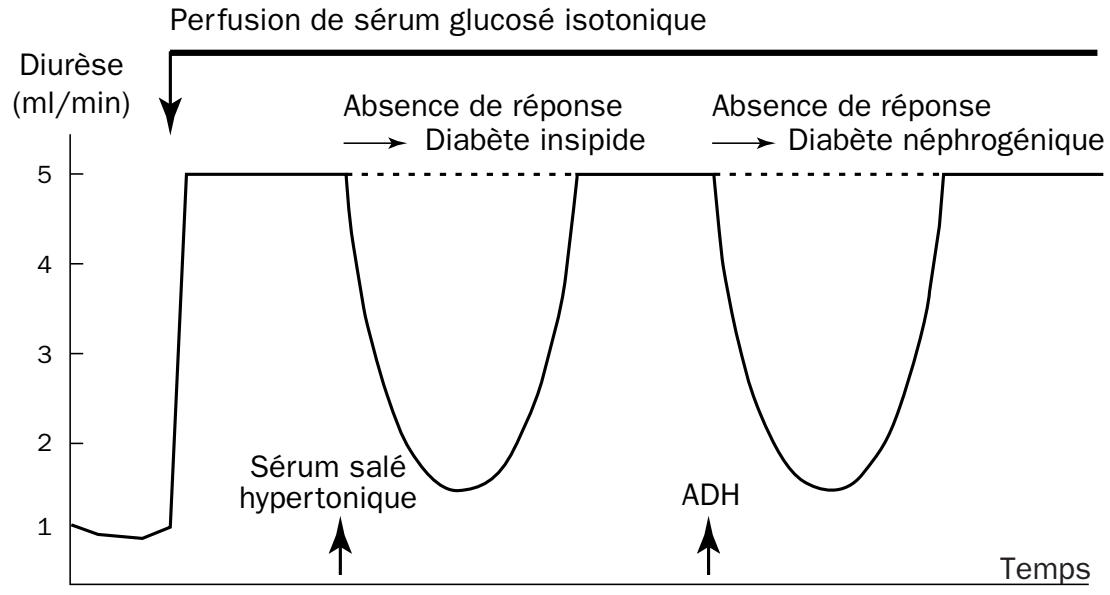

Figure 4.34 - Réponse de la diurèse à une injection de sérum salé hypertonique puis à l'ADH chez un sujet normal 


\subsection{L'OCYTOCINE (OT)}

\subsubsection{Structure et localisation}

C'est un nonapeptide qui, chez les Mammifères, ne diffère de l'ADH que par l'échange de $2 \mathrm{AA}$ (le $3^{\mathrm{e}}$ : isoleucine, le $8^{\mathrm{e}}$ : leucine). L'ADH des Batraciens (arginine-vasotocine) est de structure intermédiaire entre l'ADH de Mammifère et l'ocytocine de Mammifère (le $3 \mathrm{e}$ : isoleucine, le $8^{\mathrm{e}}$ : arginine).

L'ocytocine est sécrétée essentiellement par les neurones des noyaux paraventriculaires, mais on la retrouve également dans les noyaux supra-optiques.

\subsubsection{Actions physiologiques}

L'ocytocine se trouve chez la femme dans le plasma à la concentration de quelques $\mathrm{UI} / \mathrm{ml}$. Sa demi-vie est de 3 min environ.

L'ocytocine a une double action :

- sur la motilité utérine (fibres musculaires lisses), une action qui nécessite une imprégnation préalable par les œstrogènes. Son rôle physiologique éventuel dans l'induction du "travail", en fin de gestation et sur la gestation et la parturition en général, sont remis en question (Nishimori et coll., 1996). D'ailleurs, le travail peut avoir lieu chez l'animal hypophysectomisé. En revanche, l'induction du travail pourrait être due à l'ocytocine du foetus qui peut traverser la barrière placentaire et existe à des taux élevés dans le sang fœtal.

- sur l'éjection du lait. La sécrétion du lait est, nous l'avons vu, sous le contrôle de la prolactine sécrétée par la pars distalis. Son extrusion est due à la conjonction de deux actions :

- la succion mécanique, qui déclenche par un mécanisme réflexe (tactohypothalamo-hypophysaire) la sécrétion par les neurones hypothalamiques de l'ocytocine. Cette sécrétion résulte d'une élévation des décharges dans les neurones hypothalamiques (fig. 4.35.a).

- la contraction des cellules myo-épithéliales de la glande mammaire, sous l'influence de l'ocytocine sécrétée (fig. 4.35.b).

Mais sécrétion du lait et éjection ne peuvent avoir lieu que sur une glande mammaire qui a subi préalablement une imprégnation hormonale par les œstrogènes et la progestérone (à un taux qui n'est réalisé qu'au cours de la gestation).

\subsection{OPIACÉS ET HORMONES NEUROHYPOPHYSAIRES}

Trois familles d'opiacés sont présentes au niveau de l'axe hypothalamo-hypophysaire. On trouve des enképhalines et de la dynorphine dans les neurones magnocellulaires (noyaux supra-optique et paraventriculaire), mais le principal peptide opiacé est la $\beta$-endorphine, dont les neurones sécréteurs ont leurs corps cellulaires dans le noyau arqué et envoient leurs axones dans de nombreuses régions du cerveau, y compris dans les noyaux magno-cellulaires. 

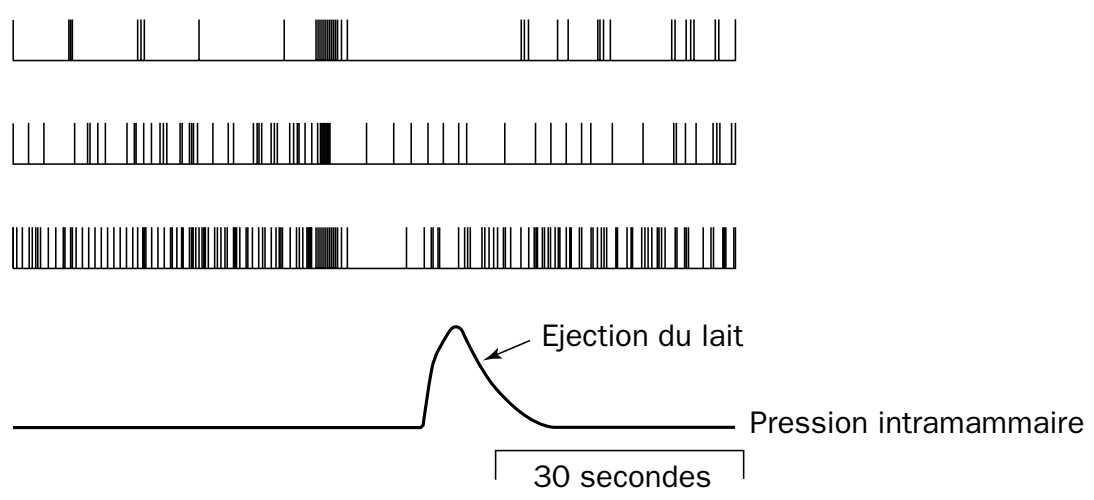

a - Activité électrique des neurones sécréteurs d'ocytocine au cours de la lactation (d'après Poulain et Wakerley, 1982)

Enregistrement de l'activité électrique de trois neurones ocytocinergiques chez des rats femelles anesthésiés, au cours de l'éjection du lait provoquée par la succion. Chaque déflexion correspond à un seul potentiel d'action (spike). Les trois neurones ont été enregistrés séparément, mais leurs réponses ont été alignées comparativement à l'élévation de la pression intramammaire. L'un des neurones était situé dans le noyau paraventriculaire ; les deux autres, dans le noyau supra-optique.

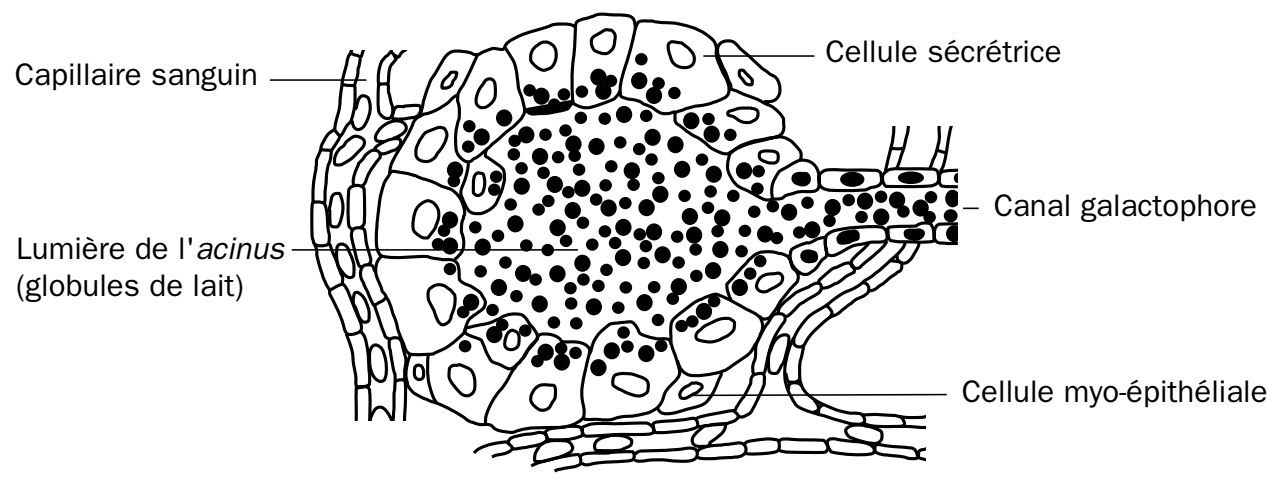

\section{b - Structure d'un acinus de la glande mammaire}

Figure 4.35 - Extrusion du lait

Chez l'homme, les opiacés inhibent la réponse de l'ADH à des stimulus osmotiques, mais la naloxone (antagoniste des opiacés) a peu d'effet sur la sécrétion basale de vasopressine. En revanche, elle élève considérablement chez le rat la libération d'ocytocine, par exemple à la suite d'une stimulation électrique (fig. 4.36).

\subsection{RÉCEPTEURS DES HORMONES NEUROHYPOPHYSAIRES}

L'étude des récepteurs des hormones neurohypophysaires a été développée à l'aide d'analogues artificiels de l'ADH et de l'ocytocine. Ces substances ont permis d'obtenir une pharmacologie précise des récepteurs hormonaux d'après les propriétés agonistes ou antagonistes des peptides par rapport à l'hormone naturelle. 


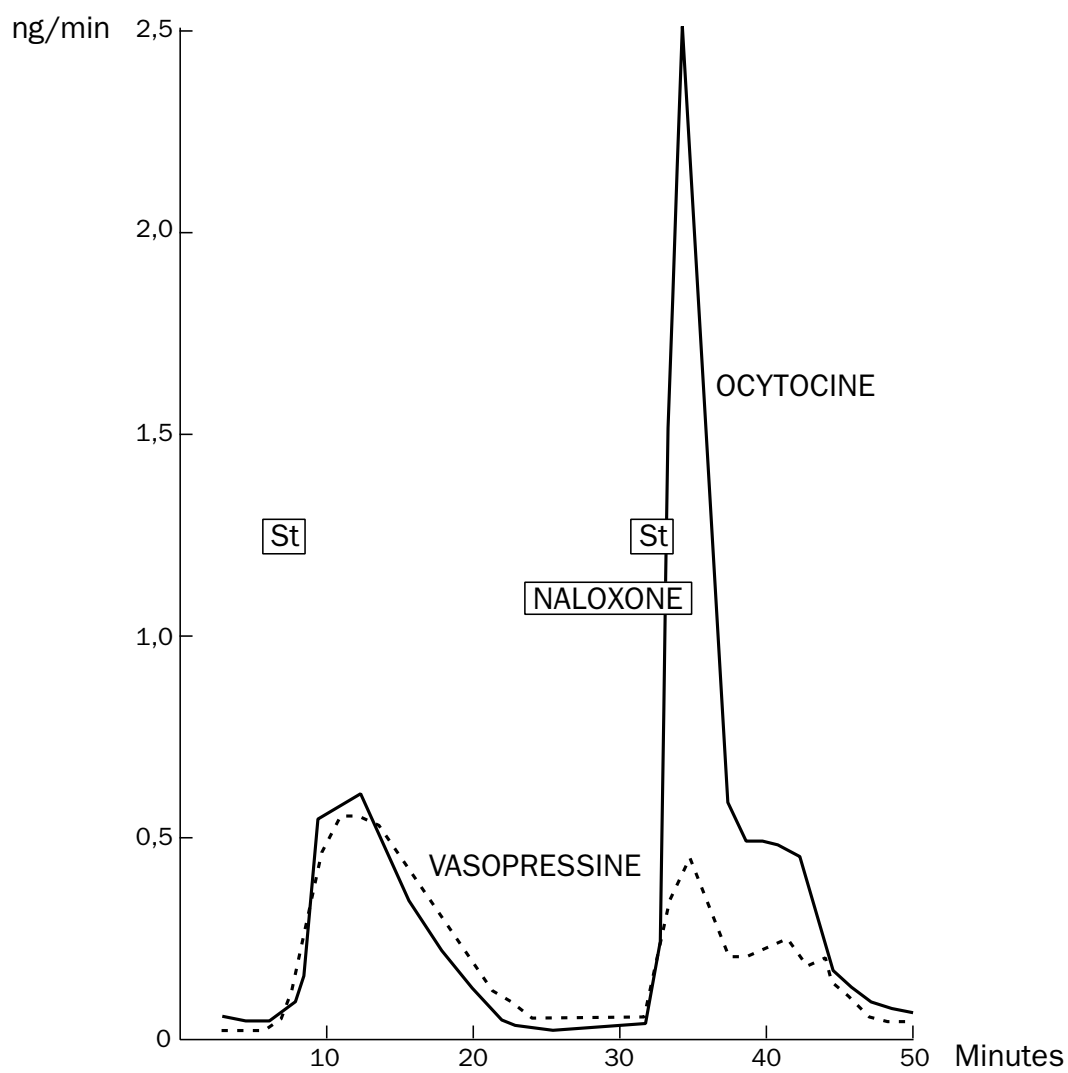

Figure 4.36 - Effet des opiacés sur les sécrétions neurohypophysaires (d'après Bicknell et Leng, 1982)

La naloxone, inhibiteur des récepteurs aux opiacés, accroît la sécrétion d'ocytocine provoquée par une stimulation électrique (St) de la pars nervosa $(13 \mathrm{~Hz})$. Elle n'a pas d'action sur la réponse de la vasopressine.

Le tableau 4.3 montre des exemples, avec les propriétés correspondantes. Grâce à de tels dérivés, on a pu identifier, dans le cas de la vasopressine, deux catégories principales de récepteurs.

Tableau 4.3 - Potentialités biologiques de quelques analogues artificiels de la vasopressine et de l'ocytocine

\begin{tabular}{|l|l|}
\hline DDAVP [1 désamino-8 D Arg] - VP & $\begin{array}{l}\text { antidiurétique pur (quatre fois plus que l'AVP) } \\
\text { pas d'activité vasopressine }\end{array}$ \\
\hline PORVP [Phe2 - Ile3 - Orn8] - VP & antivasopresseur uniquement \\
\hline Tyr (Me) $)^{2}$ - Ot & inhibiteur de l'ocytocine et de la vasopressine \\
\hline [N-Bromoacétyl] - Ot & bloque la stimulation de l'adénylcyclase \\
\hline [des-glycinamide] - VP & plus actif que la vasopressine pour la mémorisation \\
\hline
\end{tabular}


- Les récepteurs V1 sont associés au métabolisme des polyphosphoinositides. Ils paraissent cependant eux-mêmes hérérogènes et sont subdivisés en sous-classes (a, b) diversement localisées. Ces récepteurs sont mis en évidence au niveau du foie (contrôle de la glycogénolyse), de l'hypophyse (stimulation de la sécrétion d'ACTH exprimant un effet "CRF-like" de la vasopressine), du cerveau (contrôle des processus de mémorisation). Bien entendu, ils sont répandus dans la paroi du système vasculaire, où ils rendent compte de l'effet vasopresseur de l'hormone, y compris au niveau des glomérules rénaux où ils permettraient un contrôle du débit sanguin rénal.

- Les récepteurs V2, couplés positivement à l'adénylcyclase, sont responsables des effets que nous avons décrits au niveau du néphron (action antidiurétique).

Certaines observations tendent à montrer que d'autres catégories de récepteurs existent. Ainsi, l'analogue [des-glycinamide] - VP n'exerce pas d'activité rénale ou vasopressive, mais est plus puissant que la vasopressine pour la mémorisation du réflexe d'évitement. Son récepteur serait donc différent des récepteurs V1 et V2.

\section{LES PATHOLOGIES DU COMPLEXE HYPOTHALAMO-HYPOPHYSAIRE}

Les principales pathologies touchant l'hypothalamo-hypophyse, comme dans l'ensemble de l'endocrinologie, sont de type hyper- ou hypofonctionnel. Elles sont responsables de manifestations cliniques multiples, complexes du fait de l'association fréquente de l'hypersécrétion d'une hormone avec ses conséquences, à une insuffisance d'un ou plusieurs autres secteurs sécrétoires par l'effet compressif de la lésion sécrétante sur l'hypophyse saine.

\subsection{LES PATHOLOGIES DE L'ANTÉHYPOPHYSE}

\subsubsection{Etiologie des maladies antéhypophysaires}

Les causes des maladies antéhypophysaires sont très nombreuses.

\section{Tumorales bénignes}

Elles n'essaiment pas à distance (absence de métastases) mais peuvent entraîner des conséquences "malignes" au plan fonctionnel (cécité partielle progressive), notamment en raison de leur situation anatomique, proche d'un carrefour stratégique pour la vision, "le chiasma optique", qui peut être soumis à une compression progressive, destructrice pour les voies optiques.

Ces tumeurs bénignes sont appelées adénomes et se regroupent en deux principales entités sécrétantes ou non-sécrétantes. 


\section{Les adénomes sécrétants}

Ils produisent en excès et de manière autonome (ne répondant plus aux habituels stimuli) une hormone (Prl, HGH, ACTH, LH, FSH). Quelquefois, plusieurs sécrétions pathologiques s'associent. Ces adénomes représentent $80 \%$ de l'ensemble des tumeurs bénignes.

\section{Les adénomes non-sécrétants}

Ils représentaient, il y a 25 ou 30 ans, la majorité des adénomes de l'hypophyse et se trouvent actuellement en situation minoritaire ( $20 \%$ environ) grâce aux progrès réalisés dans le dosage des hormones circulantes d'une part, dans la caractérisation immuno-histochimique des lésions traitées chirurgicalement d'autre part. Ces progrès permettent ainsi l'établissement d'un diagnostic par dosage dans le sang périphérique de l'hormone sécrétée en excès. Il est confirmé, éventuellement complété, par la mise en évidence dans l'adénome lui-même par colorations spécifiques et immunofluorescence des grains sécrétoires propres à l'hormone, voire un contingent plus ou moins important de cellules adénomateuses d'une autre lignée ; on parle alors d'adénomes mixtes (l'exemple le plus fréquent étant l'adénome à $\mathrm{Prl} / \mathrm{GH}$ ).

\section{Autres tumeurs et lésions inflammatoires}

Elles peuvent être de type embryoplasique ou néoplasique (cancéreuses). La plus fréquente est le crâniopharyngiome. Il siège dans la région hypothalamo-hypophysaire et interfère partiellement ou totalement avec les connexions physiologiques entre hypothalamus et hypophyse. C'est par ce mécanisme purement anatomique que s'explique l'atteinte de la synthèse et de la libération de certaines hormones. La première touchée est habituellement l'hormone de croissance, responsable chez l'enfant d'un retard de croissance souvent complété par un déficit des hormones gonadotropes (LH-FSH) avec comme conséquence un retard d'apparition de la puberté.

Chez l'adulte, ce type de tumeur peut se révéler par le syndrome tumoral lui-même (céphalées, troubles du champ visuel), ou par des déficits hormonaux donnant un tableau d'insuffisance antéhypophysaire partiel ou total. De nombreuses autres tumeurs du système nerveux ou des enveloppes cérébrales peuvent être en cause (gliomes, chordomes, méningiomes, métastases).

Il est également possible d'observer à l'origine des manifestations endocrinologiques hypophysaires des lésions inflammatoires (hypophysite), infectieuses (tuberculose) ou infiltratives (sarcoïdose).

C'est dire la complexité de l'ensemble de ces pathologies.

\subsubsection{Description de deux pathologies types}

Pour illustrer ces pathologies qui ne seront pas détaillées de manière exhaustive, cet ouvrage étant avant tout orienté vers la physiologie endocrinienne, nous proposons deux exemples. Un exemple d'adénome sécrétant, l'adénome somatotrope, et un exemple de pathologie hyposécrétante, le syndrome de Sheehan. 


\section{L'adénome somatotrope}

Il réalise le tableau d'une maladie décrite en 1885 par Pierre Marie comme "une hypertrophie singulière et non-congénitale des extrémités supérieures, inférieures et céphaliques" dénommée acromégalie. Son incidence est de 3,3 pour 1 million, sa prévalence de 6,9 pour 100000 habitants.

Les manifestations cliniques, morphologiques s'expliquent par l'action de la GH sécrétée en excès, mettant en jeu son effecteur périphérique, la somatomédine $\mathbf{C}$ (IGF1), sur l'os, les cartilages, le tissu conjonctif, au niveau des extrémités mais également au niveau de l'ensemble du revêtement cutané et des viscères.

\section{Les signes cliniques}

- Signes de l'excès de GH

- un prognatisme, avec hypertrophie de toutes les saillies du visage, notamment des sinus frontaux et des arcades sourcilières, avec écartement de la denture, réalise un faciès facilement reconnaissable pour l'observateur averti,

- les mains et les pieds sont élargis, la peau épaissie, avec nécessité de changer de taille de gants et de chaussures, d'élargir les bagues,

- la colonne vertébrale n'est pas épargnée, avec déformation progressive du tronc et évolution à un stade avancé vers la gibosité,

- l'hypertrophie des viscères (cœur, foie, rate, colon) est constante : associée à une hypertension artérielle.

- Signes d'atteinte des autres secteurs

En cas d'adénome volumineux, compressif pour l'hypophyse saine, peuvent s'observer :

- une aménorrhée chez la femme, une impuissance chez l'homme, témoins d'un déficit de LR/FSH et de leurs glandes cibles ;

- une hypotension avec asthénie, une dépigmentation cutanée signant l'atteinte du secteur corticotrope (ACTH) ;

- exceptionnellement, une insuffisance thyroïdienne (déficit thyréotrope).

- Signes cliniques de tumeur hypophysaire

Céphalées, amputation du champ visuel sont assez rares dans l'acromégalie dont le diagnostic est habituellement précoce.

\section{Les signes radiologiques}

- Le cliché simple du crâne montre des modifications de la voûte du crâne, des sinus et du maxillaire inférieur avec déformation de la selle turcique où siège l'adénome hypophysaire.

- Le scanner, largement utilisé dans les années 1975-1990, a été supplanté à partir de cette date par l'IRM.

- L'IRM (imagerie en résonance magnétique nucléaire) permet une analyse tridimensionnelle de l'adénome, précisant son extension inférieure éventuelle vers le 
sinus sphénoïdal, supérieure vers le chiasma et latérale avec refoulement de l'hypophyse saine et déviation de la tige.

\section{Les signes biologiques}

- Elévation à l'état basal de GH (norme $<5 \mathrm{ng} / \mathrm{ml}$ ), les valeurs étant habituellement comprises entre 20 et $100 \mathrm{ng} / \mathrm{ml}$ dans l'acromégalie.

La particularité essentielle associée est l'autonomie de cette sécrétion, non-freinable (charge glucosée) et non-stimulable (hypoglycémie, arginine). De plus, cette sécrétion pathologique répond parfois à des stimulations paradoxales telles que la TRH.

- La somatomédine C (IGF1) élevée est un élément précieux complémentaire pour le diagnostic biologique, bien corrélé aux signes cliniques. Ce dosage est particulièrement intéressant dans le suivi au long cours de la maladie.

- Le retentissement sur les autres fonctions :

- métaboliques :

- le métabolisme phosphocalcique peut être anormal avec hypercalciurie, hyperphosphorémie, calcémie normale ;

- le métabolisme glucidique avec hyperglycémie à jeun ou courbe d'hyperglycémie provoquée orale anormale associée à un hyperinsulinisme.

- Les autres fonctions antéhypophysaires sont également explorées à l'état basal et sous stimulation pour évaluer d'éventuels déficits associés à l'hypersécrétion somatotrope.

Le diagnostic clinique et biologique posé, l'évaluation du retentissement réalisé, le traitement est discuté. Il sera décidé en fonction de certains critères. La plupart du temps, le choix se portera sur la chirurgie par voie transphénoïdale avec un succès de 80 à $90 \%$ selon la taille de l'adénome.

Si le résultat est insuffisant, il sera complété par la radiothérapie externe et les traitements médicamenteux : utilisation d'analogues retard de synthèse de la somatostatine et accessoirement d'un agoniste dopaminergique, la bromocriptine.

Un traitement complémentaire pourra être indispensable pour compenser d'autres déficits antéhypophysaires mis en évidence.

\section{Un exemple de pathologie hyposécrétante :}

\section{l'insuffisance antéhypophysaire complète ou syndrome de Sheehan}

Décrit en 1987, le syndrome de Sheehan atteint la femme puisqu'il s'agit d'une nécrose de l'hypophyse survenant dans les suites immédiates d'un accouchement habituellement hémorragique. Il constitue l'atteinte schématique d'une insuffisance hypophysaire.

\section{Les signes cliniques}

- Asthénie d'effort et de fin de journée, complétée progressivement par une asthénie psychique. 
- Troubles sexuels : l'absence de montée de lait du post-partum, l'absence de retour de couches sont retrouvées dans les antécédents. Existence d'une aménorrhée totale sans bouffées de chaleur (= déficit LH, FSH, œstradiol). Chez l'homme, l'insuffisance antéhypophysaire se traduit par une impuissance avec baisse de la libido.

- Pâleur particulière par anémie et dépigmentation (déficit en ACTH).

- Atrophie cutanée et phanérienne avec peau fine, ridée, cheveux fins et soyeux (déficit en $\mathrm{GH}$ ).

- Régression des caractères sexuels par déficit combiné des hormones sexuelles et corticosurrénaliennes :

- disparition de la pilosité des aisselles et du pubis, atrophie vulvaire et mammaire, décoloration des mamelons ;

- chez l'homme, disparition de la barbe, régression du volume testiculaire.

\section{- Hypotension artérielle}

\section{Les signes biologiques}

- Généraux :

- anémie,

- tendance à l'hypoglycémie, à l'hyponatrémie et à l'hypercholestérolémie (témoins du déficit en TSH, en ACTH et en GH).

- Déficits hormonaux, centraux et périphériques :

- secteur corticotrope : baisse de l'ACTH, du cortisol : l'aldostérone, peu dépendante de la stimulation de l'antéhypophyse, est conservée. ACTH et cortisol ne sont pas réactivables par les stimulations habituelles ;

- secteur thyréotrope : TSH basse non-stimulable par la TRH avec effondrement des hormones thyrö̈diennes périphériques $\mathrm{T} 3$ et $\mathrm{T} 4$;

- secteur gonadotrope: de manière identique, LH-FSH sont basses, non-réactivables et s'associent à une diminution de l'œstradiol chez la femme, de la testostérone chez l'homme ;

- secteur somatotrope: GH inférieure aux valeurs physiologiques et ne répondant pas aux stimulations par l'hypoglycémie et l'arginine.

Les tests dont disposent les cliniciens permettent - l'insuffisance antéhypophysaire étant prouvée - de s'assurer que l'atteinte anatomique est réellement hypophysaire et non pas hypothalamique.

Les stimulations par TRH, GnRH ou CRF montrent une aréactivité de TSH, LH-FSH, ACTH.

Les principales causes de l'insuffisance antéhypophysaire, outre la nécrose hémorragique du post-partum, sont les causes tumorales (adénomes hypophysaires sécrétants ou non, crâniopharyngiomes), les traumatismes de la base du crâne, etc. dont l'exploration radiologique se fait par radio simple, scanner ou IRM. 
Le traitement est représenté par la substitution des différents déficits utilisant non pas les hormones antéhypophysaires (actives en intramusculaire seulement et entraînant la formation d'anticorps inactivant leur action), mais les hormones des différentes glandes périphériques (thyroïdiennes, surrénaliennes, gonadiques et plus récemment somatotropes). Ce traitement substitutif est éventuellement complété, dans les insuffisances hypophysaires ayant d'autres causes que le syndrome de Sheehan, par un traitement de la cause lorqu'il y a tumeur (chirurgie, radiothérapie).

\subsection{LES PATHOLOGIES DE LA POSTHYPOPHYSE}

Comme pour l'antéhypophyse, les maladies touchant la posthypophyse sont, par ordre de fréquence, de type déficitaire, dues à une insuffisance de sécrétion de l'hormone antidiurétique (ADH) entraînant une perte d'eau et, de ce fait, appelée diabète insipide, ou de type hypersécrétion, plus rare, constituant le tableau du syndrome de Schwartz-Bartter.

\subsubsection{Le diabète insipide}

C'est une maladie due à l'impossibilité de réabsorption de l'eau libre au niveau distal du rein par déficit total ou partiel en ADH. Il se traduit essentiellement par une polyurie, polydipsie incoercible de l'ordre de 6 à 10 l/jour sans autres symptômes.

Biologiquement, la densité urinaire est basse,

- l'osmolarité inférieure à $100 \mathrm{mOsml} / 1$,

- la restriction hydrique met en évidence l'impossibilité du rein à concentrer les urines (la clairance de l'eau libre est constamment positive),

- l'ADH plasmatique reste basse.

Les causes de ce que l'on doit appeler "un syndrome" sont très nombreuses :

- séquelles de traumatisme de l'appareil hypothalamo-hypophysaire (neurochirurgie, traumatisme crânien...),

- tumeurs (crâniopharyngiomes, méningiomes...),

- maladies générales (sarcoïdose, tuberculose, leucémies, métastases...),

- diabètes insipides primitifs souvent familiaux.

Le traitement principal est l'administration en injection, en pulvérisation nasale d'analogues synthétiques de l'hormone. Très récemment est apparue une forme orale simplifiant la thérapeutique.

\subsubsection{Le syndrome d'hypersécrétion de Schwartz-Bartter}

Une hypersécrétion inadaptée d'ADH entraîne l'impossibilité de dilution par le rein des urines avec, de ce fait, une véritable "intoxication par l'eau".

Le tableau clinique est fait d'asthénie, de nausées, de vomissements, de troubles psychiques pouvant aller jusqu'au coma. 
La biologie montre une hyponatrémie profonde avec baisse de l'osmolarité et une clairance à l'eau libre négative.

La restriction hydrique, à $500 \mathrm{ml} / 24$ h, améliore l'état du patient.

Le dosage de l'ADH est habituellement très élevé.

Les causes, là encore, sont extrêmement nombreuses et variées. Par ordre de fréquence :

- certains types de cancers bronchiques qui sécrètent une molécule proche de l'ADH,

- certaines lésions tumorales, infectieuses, vasculaires ou traumatiques du système nerveux central,

- enfin, des causes médicamenteuses (iatrogènes) peuvent être responsables de ce syndrome (anesthésiques, barbituriques, opiacés, ou simplement surdosages en $\mathrm{ADH}$ d'un traitement de diabète insipide).

Le traitement repose essentiellement sur la restriction hydrique, accessoirement les corticoïdes et, bien sûr, sur le traitement de la cause lorsqu'elle est curable.

\section{PSYCHO-NEURO-ENDOCRINOLOGIE}

Cette nouvelle discipline est une approche intégrée de l'intrication entre les mécanismes psychologiques et neurobiologiques (Kalin, 1993) ${ }^{19}$. Dans l'état actuel des recherches que l'on peut attribuer à cette discipline, nous voyons se développer trois secteurs :

- hormones et comportement,

- stress,

- hormones et vieillissement.

Le premier sera abordé dans ce chapitre. On peut prendre comme exemples les rapports entre hormones et mémoire, entre hormones neurohypophysaires et comportement sexuel (la relation entre hormones sexuelles et comportement est connue depuis des temps immémoriaux et sera indiquée dans les différents chapitres de la deuxième partie), ainsi qu'entre neuromédiateurs et troubles psychiques.

Le stress sera traité dans le chapitre sur les glandes surrénales (chap. 6, § 5).

19 Il existe d'ailleurs une revue américaine, intitulée "Psychoneuroendocrinology". Ainsi que l'exprime le co-éditeur en chef Ned Kalin, "nous avons maintenant les techniques nécessaires pour répondre à d'importantes questions fondamentales concernant les mécanismes psychologiques, endocrines, neurochimiques et immunitaires qui interagissent pour maintenir la santé et qui, lorsqu'ils sont perturbés, contribuent à la physiopathologie d'un grand nombre de maladies". J'ajouterai que l'ensemble de ces mécanismes sont regroupés dans le cadre d'une discipline plus globale, qui les étudie dans une intégration "holistique", la (psycho)neuro-immuno-endocrinologie. 
Le thème du vieillissement connaît des développements importants depuis les travaux de l'école de Reiter (1995, voir chap. 10) sur la mélatonine. Les rapports entre le vieillissement et la mélatonine seront traités dans le chapitre 10, § 2.3. Les rapports entre le vieillissement et les autres glandes endocrines ont été développés dans les chapitres $4, \S 4.2 .6 ; 4, \S 4.3 .3 ; 6, \S 6$.

\subsection{HORMONES NEUROHYPOPHYSAIRES ET MÉMOIRE}

Les hormones neurohypophysaires sont retrouvées en d'autres régions de l'encéphale où elles pourraient fonctionner comme neuromodulateurs.

Selon certains auteurs, l'ocytocine aurait une action antagoniste de celle de l'ADH sur les processus membranaires :

- l'ADH favoriserait la mémorisation,

- l'ocytocine serait un neuropeptide "amnésiant".

Si séduisante soit cette hypothèse, elle n'est que l'interprétation de diverses expériences. L'une d'elles consiste à apprendre à des rats à ne pas entrer dans un compartiment sombre, ils sont "punis" par un choc électrique s'ils tentent d'y entrer. Cet apprentissage a des effets prolongés si l'on injecte à ces rats de l'ADH par voie souscutanée à de très faibles doses. Une autre expérience consiste à entraîner des rats à sauter sur un bâton pour éviter une décharge électrique par le plancher, annoncée par un signal lumineux. Puis des signaux lumineux sont émis sans décharge électrique. Alors que le groupe de rats témoins cesse de sauter $4 \mathrm{~h}$ après la fin de l'apprentissage, un deuxième groupe recevant $1 \mathrm{ng}$ de vasopressine continue à sauter jusqu'à 8 ou $10 \mathrm{~h}$ après la fin de l'apprentissage. On peut toutefois se demander si ces résultats ne sont pas simplement le résultat de l'élévation de la tension artérielle sous l'effet de l'ADH, qui maintiendrait les rats "en alerte" pendant plus longtemps.

\subsection{HORMONES SEXUELLES ET MÉMOIRE}

Un analogue de la GnRH, le D-Trp6-LHRH, a été administré en continu pendant au moins 28 jours à des rats femelles de 22 mois en état constant d'œstrus. Ces animaux ont été soumis à un appareillage destiné à tester leur mémoire (test d'Alexinsky et Chapouthier, 1978). Le résultat a été une annulation de l'effet délétère de l'âge sur la performance mnésique et sur l'inhibition ovarienne. Les auteurs (Alliot et coll., 1993) en concluent que l'axe hypothalamo-ovarien pourrait être impliqué dans le déficit mnésique de la femelle âgée.

Une autre étude, réalisée cette fois sur 19 femmes ménopausées après castration chirurgicale, porte sur les effets d'une thérapie de remplacement par des injections d'un œstrogène (valérate d'œstradiol) versus un placebo (Philips et Sherwin, 1992). Certaines fonctions de la mémoire étaient conservées par la thérapie de remplacement alors que les sujets traités par le placebo présentaient un déficit progressif de ces fonctions. 


\subsection{GLUCOCORTICOÏDES ET COGNITION (Lupien et Forget, 1995)}

Dans le syndrome de Cushing, la sécrétion excessive de glucocorticoïdes est associée à des troubles de l'humeur (irritation, dépression ou euphorie) et à des troubles cognitifs. On pouvait penser qu'ils étaient secondaires à l'hypersécrétion de glucocorticoïdes, d'autant que l'utilisation thérapeutique des glucocorticoïdes peut donner des effets secondaires sévères sur l'affect et la cognition. En revanche, des concentrations plasmatiques excessives de cortisol ont pu être observées dans la dépression endogène ou dans la démence de type Alzheimer. La formation hippocampique, située dans le plancher du ventricule latéral, est la structure cérébrale la plus riche en récepteurs de glucocorticoïdes (récepteurs de type II à faible affinité : Kf $=2$ à $5 \mathrm{nM}$ ) et son rôle dans la cognition est désormais bien établi. On a logiquement fait le lien entre l'action des glucocorticoïdes au niveau de l'hippocampe et les troubles cognitifs résultant de l'hypersécrétion des glucocorticoïdes.

\subsection{HORMONES NEUROHYPOPHYSAIRES ET COMPORTEMENT SEXUEL}

Chez une variété de campagnols du Middle West américain, la fidélité conjugale apparaît comme la conséquence de la sécrétion de l'hormone neurohypophysaire, l'ADH. Cet animal fait preuve dès le premier accouplement d'un attachement à toute épreuve vis-à-vis de sa compagne, partageant, sa vie durant, nid conjugal, corvées familiales et tendresse avec l'élue de son cœur. Or l'accouplement déclenche la sécrétion d'ADH et induit en 24 h, chez le mâle, un comportement d'exclusivité envers sa partenaire ; le campagnol éloigne les rivaux potentiels et reste parfaitement indifférent aux autres femelles. Le blocage sélectif de l'activité de l'ADH met fin à ce comportement d'exclusivité, le mâle "trompe" allègrement sa femelle et multiplie les "aventures extraconjugales". A l'inverse, l'administration, avant tout accouplement, d'ADH, conduit le mâle à reproduire vis-à-vis d'une seule femelle ce comportement jalousement protecteur (G. Monod, 1993). Toutefois, l'administration d'ADH chez une autre variété de campagnols, qui manifestent spontanément un comportement polygamique, ne modifient en rien leur comportement.

\subsection{NEUROMÉDIATEURS ET TROUBLES PSYCHIATRIQUES}

Une étude comparative a été effectuée sur sept patients souffrant de "désordre affectif saisonnier" (conformément à la définition du Diagnostic and Statistical Manual for Psychiatric Disorders, DSM III-R) et huit patients normaux (fig. 4.37, Coiro et coll., 1993). Les auteurs ont recherché l'effet d'un agent sérotoninergique, le $d$,l-fenfluramine, et d'un placebo sur les taux de prolactine et de cortisol sanguins, aussi bien en hiver (quand les patients sont dépressifs) qu'en été (lorsqu'ils sont euthymiques).

Pour la prolactine, la réponse hormonale reste constante après placebo, aussi bien l'hiver que l'été, pour les patients comme pour les contrôles ; après le $d$,l-fenflu- 
ramine, le taux de la prolactine s'élève, à un même niveau l'hiver comme l'été, mais plus bas chez les malades que chez les contrôles (fig. 4.37.a). Il en est de même pour le cortisol, à la différence près que le taux de la cortisolémie diminue progressivement après administration du placebo (fig. 4.37.b).
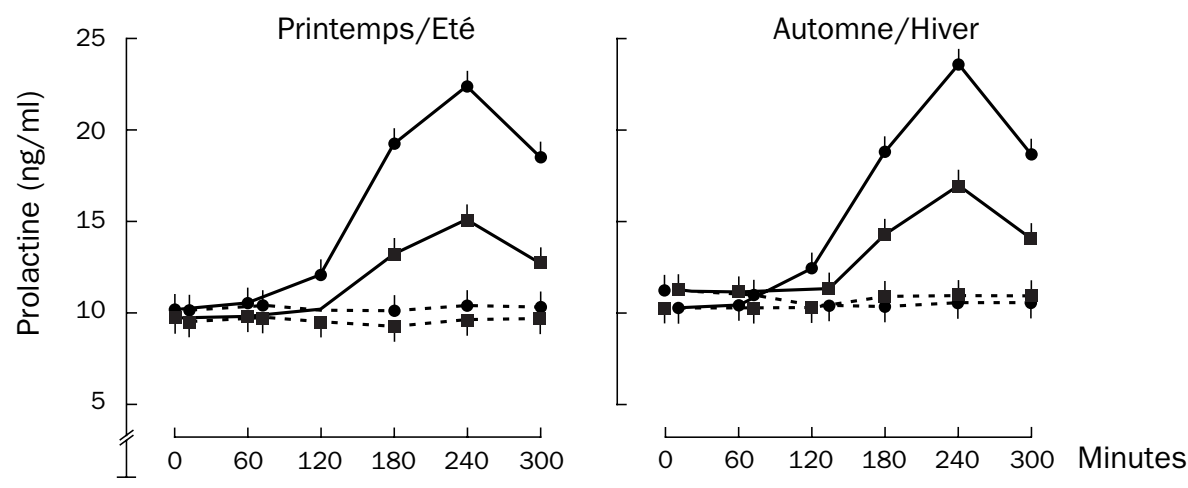

d,I-fenfluramine : contrôles, $\mathrm{n}=8 \bullet \longrightarrow$

SAD (patients atteints de désordre affectif saisonnier), $n=7 \square$

Placebo : contrôles, $n=8 \bullet \cdots \bullet$

$\mathrm{SAD}, \mathrm{n}=7 \mathbf{- \cdots}$

a - Réponse de la Prl sérique
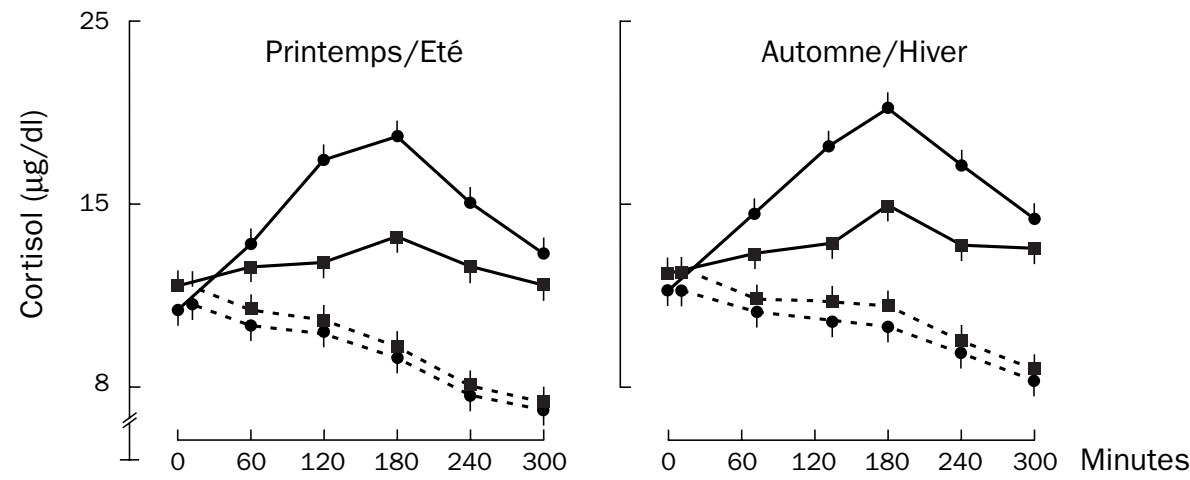

d,I-fenfluramine : contrôles, $\mathrm{n}=8 \bullet \longrightarrow$

SAD (patients atteints de désordre affectif saisonnier), $\mathrm{n}=7 \longrightarrow$

Placebo : contrôles, $n=8$

$\mathrm{SAD}, \mathrm{n}=7$

\section{b - Réponse du cortisol sérique}

Figure 4.37 - Réponse au d,I-fenfluramine ou au placebo

(d'après Coiro et coll., 1993)

Le d,l-fenfluramine (60 mg) ou le placebo ont été administrés per os au temps 0 . Chaque point représente la moyenne des observations $\pm S E$.

On peut en conclure que les patients souffrant de désordre affectif saisonnier présentent une diminution de l'activité sérotoninergique indépendante de la saison. 



\section{CHAPITRE 5}

\section{LA GLANDE THYROÏDE}

\section{CARACTÉRISTIQUES GÉNÉRALES}

Elle constitue une glande impaire bilobée, plaquée à la face antérieure de la région laryngo-trachéale. Elle pèse 25 à $30 \mathrm{~g}$ chez l'homme.

La glande thyroïde possède un métabolisme spécifique et une régulation comparables à celle des autres glandes endocrines hypophyso-dépendantes, mais elle en diffère par sa dépendance à l'égard de l'apport exogène d'iode, oligo-élément rare, dont le taux varie d'un jour à l'autre dans l'alimentation. D'où des mécanismes de stockage et de synthèse. Les rapports entre la thyroïde et l'iode ont été établis très tôt. C'est le cas dans le goître endémique des "crétins des Alpes" dont l'eau de boisson est trop pauvre en iode.

\section{Rappel embryologique}

La glande thyroïde constitue une ébauche de nature endoblastique, née du champ mésobranchial de HIS, près de l'ébauche linguale. Elle est médiane et ne provient donc pas d'une poche endobranchiale (fig. 5.1).

\section{Histologie}

L'organisation du parenchyme glandulaire est vésiculaire (fig. 5.2). Les vésicules (ou follicules) sont composées d'un groupement sphérique de cellules appelées principales. Ce sont ces cellules qui sécrètent T4 et accessoirement T3 (voir plus loin). La cavité du follicule contient une substance dite colloïde, composée essentiellement d'une glycoprotéine, la thyroglobuline ou Tg (PM 660000 ). Cette substance est élaborée en deux temps : la protéine est synthétisée dans l'ergastoplasme, le glucide est associé à la protéine dans l'appareil de Golgi. La thyroglobuline est rejetée dans la cavité du follicule après avoir été préalablement iodée (environ $1 \%$ d'iode), essentiellement au niveau des microvillosités de la membrane apicale. Puis la thyroglobuline iodée est reprise par pinocytose à l'apex de la cellule, protéolysée par les lysosomes pour donner T4 et T3 qui seront excrétés dans les capillaires. C'est une synthèse à double courant, une activité cellulaire à double polarité (voir fig. 5.3). 


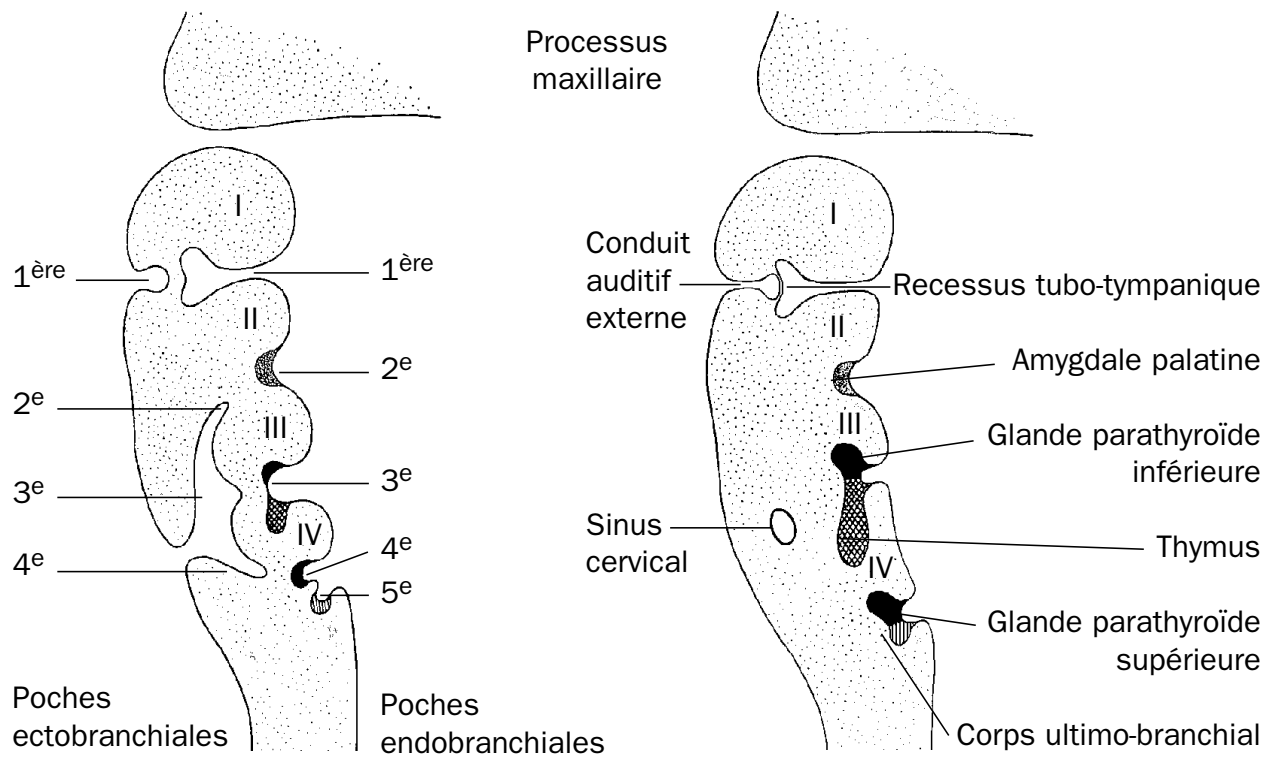

a - Représentation schématique du développement des poches branchiales ecto- et endoblastiques

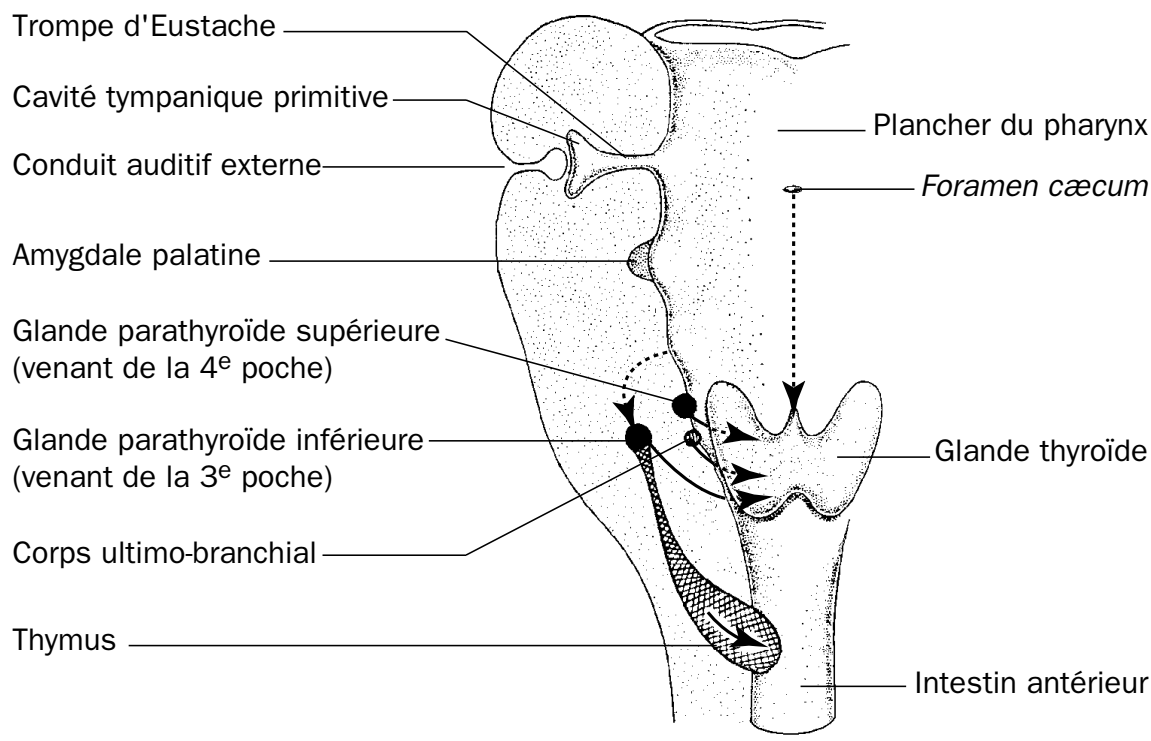

b - Représentation schématique de la migration du thymus, des glandes parathyroïdes et du corps ultimo-branchial (vue antérieure)

Figure 5.1 - Embryogenèse des glandes endocrines d'origine branchiale (thyroïde, parathyroïdes, thymus, corps ultimo-branchial) (d'après Embryologie médicale, J. Langman, Masson, 1968) 


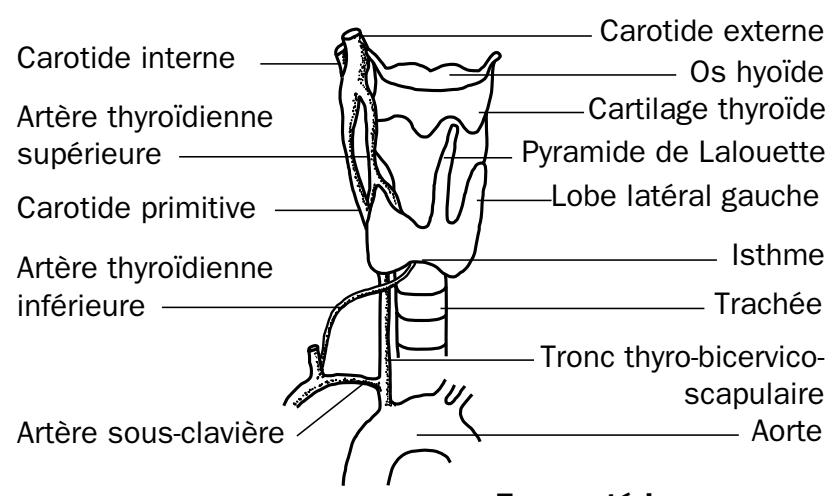

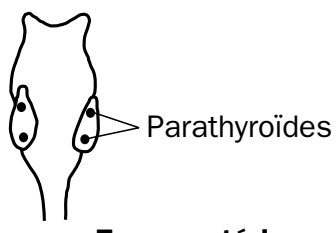

Face postérieure

\section{Face antérieure}

a - Le corps thyroïde

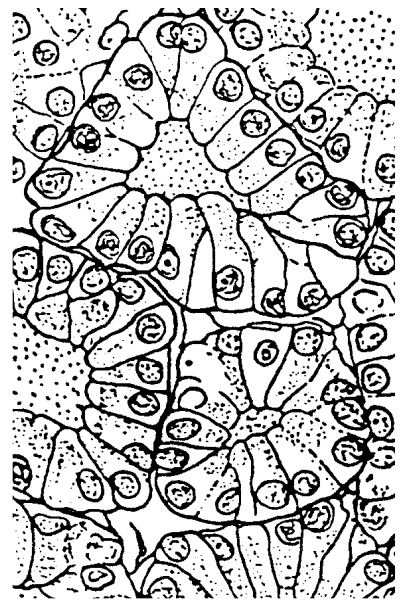

Thyroïde de rat normal ayant reçu pendant 10 jours des injections de thyréostimuline

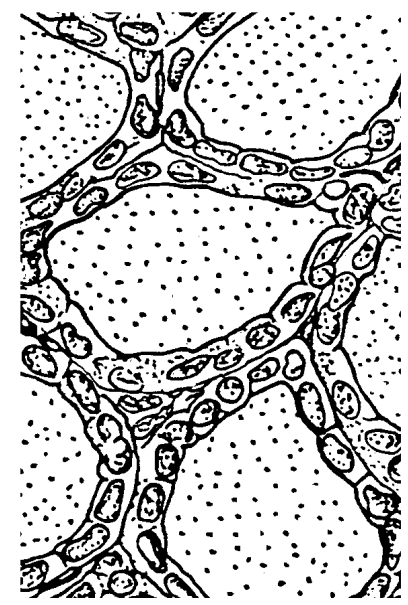

Thyroïde de rat normal après hypophysectomie totale

\section{b - Régulation de l'activité fonctionnelle de la glande thyroïde de rat par l'hormone thyréotrope de l'antéhypophyse}

\section{Figure 5.2 - La glande thyroïde}

Plaquées contre les cellules principales, des cellules en position parafolliculaire dites cellules $\mathbf{C}$ sont à l'origine de la calcitonine, qui est impliquée dans la régulation du métabolisme phosphocalcique (chap. 8). Elles proviennent embryologiquement du corps ultimo-branchial, c'est-à-dire de la partie ventrale de la $5^{\mathrm{e}}$ poche endobranchiale.

\section{Vascularisation et innervation}

Il faut noter l'importance des artères thyroïdiennes (issues de la sous-clavière et de la carotide externe) à disposition teminale. Elles assurent l'un des débits sanguins les plus élevés de l'organisme : $51 / \mathrm{h}$, soit deux fois plus que le rein, à poids égal de tissu. 
L'innervation est double :

- terminaisons myélinisées, centripètes (sensitives);

- terminaisons amyéliniques, centrifuges (effectrices) :

- parasympathiques, venues du X;

- orthosympathiques, nées de la chaîne cervicale.

Ces terminaisons ne commandent pas la sécrétion glandulaire, ce sont des terminaisons vaso-motrices.

\section{DONNÉES ANATOMO-CLINIQUES ET EXPÉRIMENTALES}

\subsection{OBSERVATIONS ANATOMO-CLINIQUES}

\subsubsection{Un hyperfonctionnement : la maladie de Basedow (anciennement appelée goître exophtalmique)}

C'est un syndrome caractérisé :

- sur le plan clinique, par :

- une hypertrophie du corps thyroïde (goître) ;

- une exophtalmie (protrusion des globes oculaires) ;

- des signes de thyrotoxicose :

- tachycardie (accélération du rythme cardiaque);

- tremblement menu des extrémités ;

- amaigrissement important ;

- sur le plan biologique, par :

- une élévation importante du taux de la triiodothyroninémie totale (T3) ;

- une élévation nette de la thyroxinémie (T4);

- une TSH indosable;

- la rapidité et l'importance de la fixation de l'iode radioactif (40 à $90 \%$ après $6 \mathrm{~h}$ au lieu de $35 \%$ );

- une hypocholestérolémie.

\subsubsection{Un hypofonctionnement : le myxœdème primitif}

La thyroïde exerçant un contrôle à la fois sur le métabolisme et sur la morphogenèse, l'hypofonctionnement thyroïdien engendrera avant tout :

- chez l'enfant, un trouble de développement ;

- chez l'adulte, un syndrome d'hypométabolisme.

- Chez l'adulte, on observera :

- une infiltration particulière des téguments (par une substance mucoprotéique);

- un ralentissement de l'activité physique et intellectuelle,

- des signes biologiques :

- une cholestérolémie élevée ;

- une augmentation de la TSH plasmatique ; 
- une hypohormonémie thyroïdienne (T3 et T4 sont effondrées) ;

- une fixation d'iode radioactif : $<20 \%$.

Tous ces symptômes régressent rapidement et remarquablement sous l'influence des hormones thyroïdiennes.

- Chez l'enfant :

Aux symptômes précédents sont associés des troubles graves du développement corporel et intellectuel aboutissant à un nanisme disproportionné (prédominant sur les membres) et à une arriération mentale. Il y a un retard pubertaire.

Le pronostic diffère suivant la rapidité et la date du diagnostic de la carence hormonale. Un dépistage précoce (au $5^{\mathrm{e}}$ jour de la vie) et par conséquent un traitement sont réalisables. La méthode consiste à apprécier le taux de TSH et de T4 sur papier filtre imprégné de sang capillaire prélevé par piqûre du talon.

\subsection{EXPÉRIMENTATION}

\subsubsection{La thyroïdectomie}

Elle peut être :

- chirurgicale : ablation de la glande,

- chimique : par des antithyroïdiens de synthèse,

- ou physique : par une dose cytotoxique $\mathrm{d}{ }^{\prime} * \mathrm{I}$ (iode radioactif).

- La thyroïdectomie chirurgicale : elle n'est aisée que lorsque les parathyrö̈des ne sont pas trop proches du corps thyroïde (chez les Herbivores). Elle reproduit le tableau de myxoedème, sans le goître. Elle varie en fonction de l'âge auquel l'opération est pratiquée. Chez l'enfant, on observe des troubles de la croissance et une altération plus ou moins irréversible du développement cérébral (crétinisme thyroïdien).

- La thyroïdectomie chimique : par la thiourée ou le thiouracile. Les cellules thyroïdiennes ne peuvent fabriquer d'hormones spécifiques, d'où un double effet :

- réalisation d'un syndrome myxœdémateux, comme après ablation chirurgicale ;

- développement d'un goître, par hypersécrétion de TSH (effet feed-back).

- La thyroïdectomie physique : l'administration d'une dose destructive d'iode radioactif ( ${ }^{131}$ I par exemple) lèsera spécifiquement les cellules thyrö̈diennes.

\subsubsection{L'administration d'hormones thyrö̈diennes}

- Chez les Vertébrés, l'administration d'hormones thyroïdiennes réalise un syndrome d'hyperthyroïdie, sans exophtalmie et sans goître.

- Chez les Batraciens, le résultat est particulièrement démonstratif, elle provoque la métamorphose des têtards (Gudernatsch, 1912). La thyroïdectomie ou l'administration d'antithyroïdiens aboutissent à des têtards géants. 
Les Perennibranches (axolotl, necturus, protée) sont des espèces néoténiques (des têtards qui ont acquis la possibilité de se reproduire). L'hormone thyroïdienne de Mammifère va provoquer la métamorphose de l'axolotl et sa transformation en amblystome, espèce connue dans les lacs d'Amérique latine. Mais elle n'a pas d'effet sur le protée ou le necturus dont les tissus ne possèdent pas la capacité de réagir aux hormones thyrö̈diennes (l'effecteur n'est pas “compétent”).

\section{BIOCHIMIE ET BIOSYNTHÈSE DES HORMONES THYROÏDIENNES (T3 ET T4)}

A la suite des travaux de deux écoles :

- Roche en France,

- Pitts-Rivers en Angleterre,

on sait que la synthèse s'effectue en quatre temps, dans la cellule principale (fig. 5.3).

\subsection{CAPTATION ET CONCENTRATION DES IODURES PAR LES CELLULES THYROÏDIENNES (TRAPPING)}

C'est un mécanisme membranaire de transport actif. La thyroïde est une "pompe à iode" ou "piège à iode". En effet, $25 \mathrm{~g}$ de thyroïde, soit $1 / 3000^{\mathrm{e}}$ du poids du corps fixent $1 / 3$ de l'iode total de l'organisme, soit 1 à $5 \mathrm{nmol} / \mathrm{g}$ de tissu frais, c'est-à-dire 9 à $12 \mathrm{mg}$ sur les $25 \mathrm{mg}$ de l'organisme. La thyroïde fixe ainsi environ $100 \mu \mathrm{g}$ d'iode par jour. Cette étape de concentration (d'un facteur 20 à 40 par rapport à la concentration plasmatique) est favorisée essentiellement par la TSH, mais aussi par la thiourée.

Le pourcentage d' $\mathrm{I}^{-}$(iodure) fixé par la thyroïde après ingestion d'iode radioactif est en moyenne, en cas d'alimentation iodée normale, de :

- $20 \%$ après $2 \mathrm{~h}$ (l'absorption digestive est totale en $3 \mathrm{~h}$ );

- $35 \%$ après $6 \mathrm{~h}$;

- 40 à $45 \%$ après $24 \mathrm{~h}$.

Ces étapes peuvent être bloquées par le chlorate de potassium $\left(\mathrm{ClO}_{3} \mathrm{~K}\right)$, les perchlorates $\left(\mathrm{ClO}^{4-}\right)$ et thiocyanates $\left(\mathrm{SCN}^{-}\right)$qui sont des inhibiteurs compétitifs. Le transport de l'iodure nécessite de l'énergie.

\subsection{OXYDATION DE L'IODE}

Elle s'effectue en quelques minutes.

$2 \mathrm{I}^{-} \rightarrow 2 \mathrm{e}^{-}+\mathrm{I}_{2}$ (iode moléculaire) sous l'action d'une peroxydase membranaire.

Cette oxydation est bloquée par la thiourée et le thiouracile ou le cyanure (qui est un inhibiteur enzymatique). 


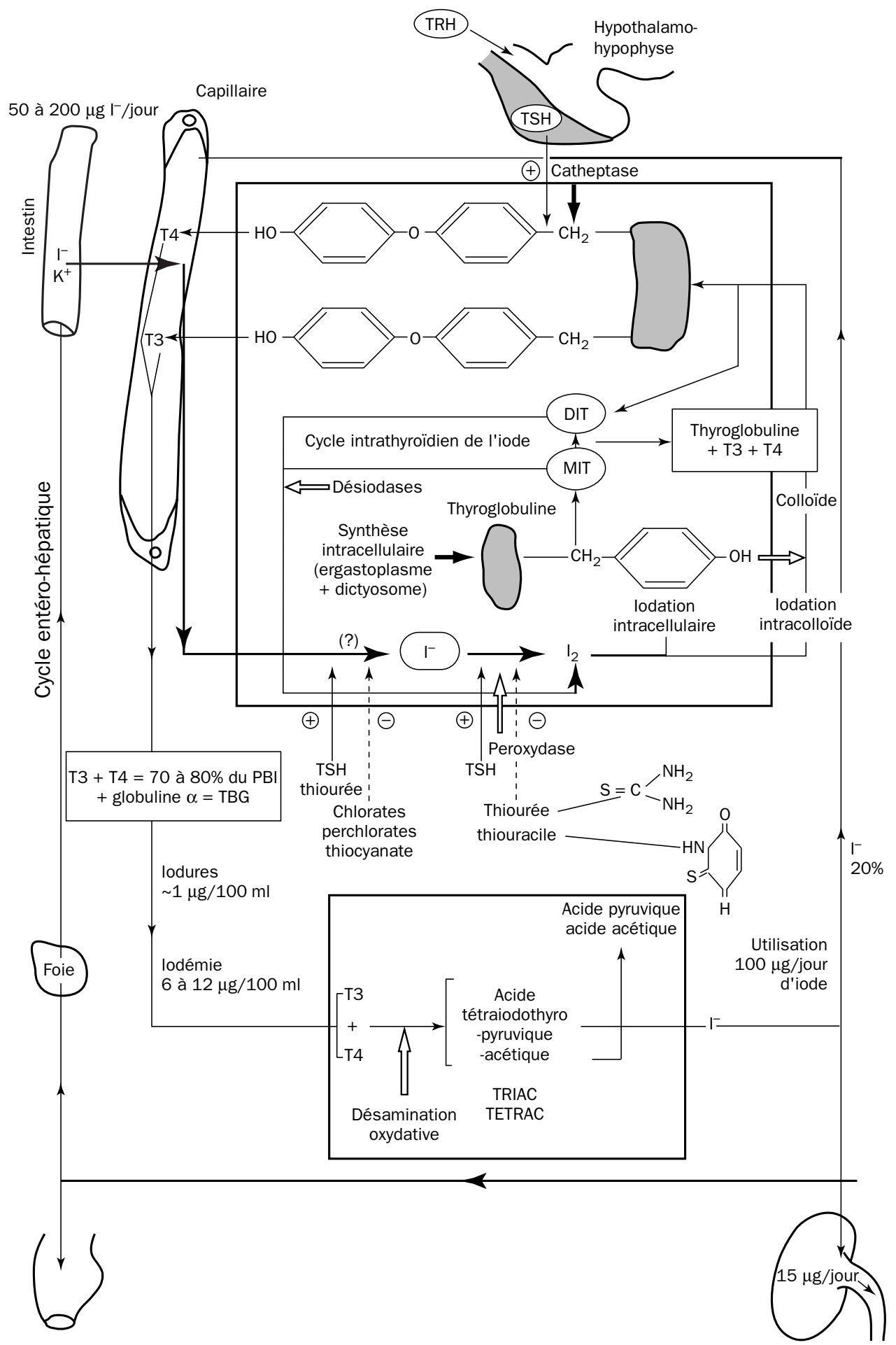

Figure 5.3 - Biosynthèse et cycle des hormones thyroïdiennes 


\subsection{INCORPORATION DE L'IODE MOLÉCULAIRE DANS LA THYROGLOBULINE}

Chez le rat, $50 \%$ d'un iodure radioactif (*I) sont incorporés dans les 2 min qui suivent une injection intraveineuse. D'abord sous forme de *MIT, puis de *DIT et seulement plus tardivement sous forme de *iodothyronines (l'iode utilisé est un traceur radioactif : $\left.{ }^{131} \mathrm{I}\right)$.

La thyroglobuline qui a été sécrétée par la cellule est halogénée par l'iode moléculaire en partie à l'apex de la cellule. La fixation de l'iode a lieu sur les groupements tyrosiniques de la thyroglobuline.

Soit $\mathrm{RH}_{2}$ la l-tyrosine :

$$
\mathrm{RH}_{2}+\mathrm{I}_{2} \rightarrow \mathrm{IH}+\mathrm{RHI}
$$

(monoiodotyrosine, MIT)

catalysée par une iodure-peroxydase

$$
\begin{gathered}
\mathrm{RHI}+\mathrm{I}_{2} \rightarrow \mathrm{IH}+\mathrm{RI}_{2} \\
\text { catalysée par la même enzyme }
\end{gathered}
$$

Toujours au sein de la tyroglobuline, il se forme finalement (fig. 5.4) :

- de la thyroxine ou tétraiodothyronine (T4) par condensation de deux résidus de DIT ;

- T3 ou 3,5,3'triiodothyronine par condensation intramoléculaire entre un résidu de DIT et un résidu de MIT.
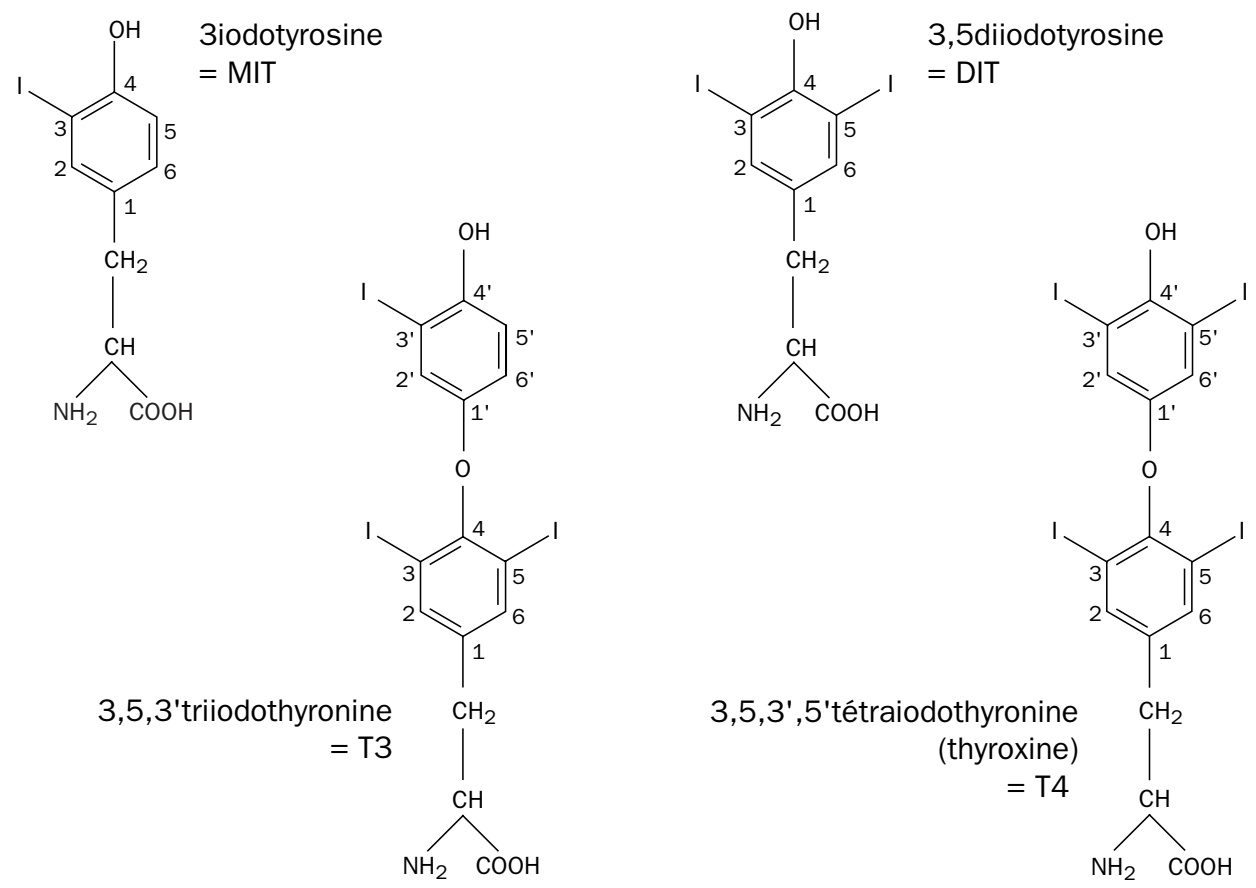

Figure 5.4 - Structure de la thyroxine (T4), de la triiodothyronine (T3) et des iodotyrosines (MIT, DIT) 
Si l'iodation des résidus tyrosyls est un processus rapide (quelques minutes), les réactions de condensation des MIT et DIT entre eux demandent plusieurs heures.

La thyroglobuline iodée est réabsorbée par pinocytose (endocytose), par les cellules thyrö̈diennes donnant des vacuoles de résorption qui fusionnent avec des lysosomes.

L'incorporation d'iode par les thyrocytes est assurée par un symport sodium-iode (NIS). Cette incorporation, qui se réalise contre un gradient électrochimique, nécessite de l'énergie (Kohrle, 1999). La TSH stimule l'activité du NIS. Des variations, d'origine génétique ou non, de l'expression du NIS ont été observées dans différents types de pathologie thyroïdienne (hypothyroïdisme congénital, thyroïdite d'Hashimoto, maladie de Basedow).

\subsection{PROTÉOLYSE DE LA THYROGLOBULINE}

Elle est stimulée par la TSH, inhibée par l'iode à fortes doses. Elle s'effectue sous l'effet d'endo- et d'exopeptidases, présentes dans les lysosomes qui vont libérer dans la cellule :

- les MIT et DIT, renfermant les 2/3 de l'iode de la thyroglobuline, qui ne vont pratiquement pas passer dans le plasma et seront reprises dans le métabolisme cellulaire. Une déshalogénase thyroïdienne va désioder les iodotyrosines et libérer

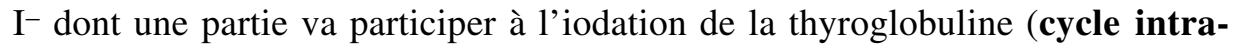
thyroïdien de l'iode) au même titre que l'iode prélevé dans le sang. Une autre partie pourra être déversée dans le sang.

- T4 et T3 qui seront secrétées dans la circulation sanguine. T4 représente 90\% des hormones thyroïdiennes. Elle a été isolée par Kendall en 1915 et synthétisée en 1926, c'est la deuxième hormone (après l'adrénaline) qui a été obtenue à l'état pur. Mais elle constitue en fait une pro-hormone de T3 qui est l'hormone active.

\section{RôLE PHYSIOLOGIQUE DES HORMONES THYROÏDIENNES}

Ce sont des hormones à vocation "générale". Elles contrôlent des fonctions essentielles chez l'adulte homéotherme :

- synthèse des protéines,

- et métabolisme énergétique.

\subsection{PRINCIPAUX EFFETS DES HORMONES THYROÏDIENNES CHEZ LES MAMMIFÈRES}

\subsubsection{Effets généraux}

- Après un temps de latence (environ $12 \mathrm{~h}$ ), on observe une augmentation du métabolisme basal (MB) chez l'homme. 
- Sur les hydrates de carbone, accélération de leur absorption intestinale, en même temps qu'une augmentation du catabolisme glucidique (augmentation de la glycogénolyse par stimulation des phosphorylases et inhibition de la glycogénosynthèse) ; la glycémie reste normale.

- Elles provoquent un accroissement de la lipolyse avec abaissement de la cholestérolémie.

- L'action sur les protides est complexe. Ce sont des hormones de synthèse protéique, mais le bilan azoté est généralement négatif. Il y a augmentation du "turn-over" des protéines plasmatiques. Les hormones thyroïdiennes favorisent aussi la biosynthèse de la GH.

- Elles favorisent la croissance par action sur les chondrocytes. Mais elles ne provoquent pas seules le gigantisme.

- Elles interviennent dans la thermorégulation.

- Elles accélèrent le rythme cardiaque et provoquent l'hypertrophie du cœur.

- Elles favorisent la trophicité du système nerveux et végétatif et potentialisent les effets $\beta$ du sympathique (augmentation de la synthèse des récepteurs).

- Au niveau des muscles, elles provoquent un raccourcissement de la phase de décontraction.

- Il y a augmentation de la diurèse et de l'élimination urinaire et fécale du calcium.

\subsubsection{Effets cellulaires}

- Les tissus périphériques, et en particulier le foie, sont capables de désioder la T4 (3,5,3',5'tétraiodo-L-thyronine) pour produire soit la T3 (3,5,3'triiodo-Lthyronine), soit la rT3 (T3 inverse ou "reverse", 3,3',5'triiodo-L-thyronine). La production périphérique de $\mathrm{T} 3$ est bien plus importante que la sécrétion thyroïdienne. Par ailleurs, l'activité biologique de la T3 est de cinq à huit fois plus forte que celle de la T4, en raison d'une diffusibilité beaucoup plus grande dans les tissus (T3 est moins fixée que T4 par les protéines de transport plasmatique) et d'une affinité des sites récepteurs nucléaires (protéines non-histones) plus élevée. La T3 inverse est métaboliquement inactive.

- Ces hormones se transforment par transamination en dérivés pyruviques puis acétiques (TRIAC et TETRAC) dans la cellule. Mais l'activité biologique de TRIAC ou TETRAC est faible ou nulle.

- Les hormones thyroïdiennes semblent avoir pour principale fonction de catalyser ou d'amorcer les principales réactions oxydatives de la cellule : elles stimulent la concentration des oxydases cellulaires par :

- une action relativement lente sur la transcription ;

- une action relativement rapide sur la traduction.

Chez l'hypothyroïdien, les tissus consomment moins d' $\mathrm{O}_{2}$.

Chez l'hyperthyroïdien, la consommation d' $\mathrm{O}_{2}$ est exagérée. 
- Les hormones thyroïdiennes accroissent la calorigenèse.

- L'effet terminal de ces hormones semble bien être mitochondrial (Weber, 1963). Il n'est pas exact que ces hormones agissent comme découplants de la phosphorylation oxydative, elles accroissent en fait à la fois la production et la dégradation de l'ATP.

- La T3 induit l'hypertrophie et la multiplication des fibres musculaires striées. Cette action s'exerce avant la naissance (après celle-ci, pour la plupart des espèces, ce nombre est peu modifié). Parallèlement, la T3 est impliquée au cours du développement dans le passage de la forme embryonnaire de la myosine à la forme adulte.

\subsection{MODE D'ACTION DES HORMONES THYROÏDIENNES}

L'impact cellulaire des hormones thyroïdiennes résulte en fait de la pénétration des hormones dans les cellules cibles où elles se fixent réversiblement sur une protéine nucléaire (c-erb A). Ce récepteur a une affinité quatre fois plus grande pour T3 que pour T4 (le $\mathrm{K}_{\mathrm{D}}$ pour $\mathrm{T} 3$ est compris entre 0,1 et $1 \mathrm{nM}$ ). Cette interaction hormone thyroïdienne-récepteur nucléaire constitue l'étape initiale du mécanisme d'action de T3, qui sera suivie de la synthèse des ARNm (4 à $20 \mathrm{~h}$ de latence), de leur transfert dans le cytoplasme et enfin de la synthèse des protéines contractiles et des enzymes respiratoires de la mitochondrie ( 24 à $30 \mathrm{~h}$ de latence chez le rat) (tab. 5.1 et 5.2). Toutefois, un mode d'action mitochondrial de la T3 ne peut être exclu (Wrutniak et Cabello, 1996). Les mécanismes de cette action sont décrits dans le chapitre 2 , $§ 4$ et dans la figure 5.5. L'action myogénique de la T3 est présentée dans la figure 5.6.

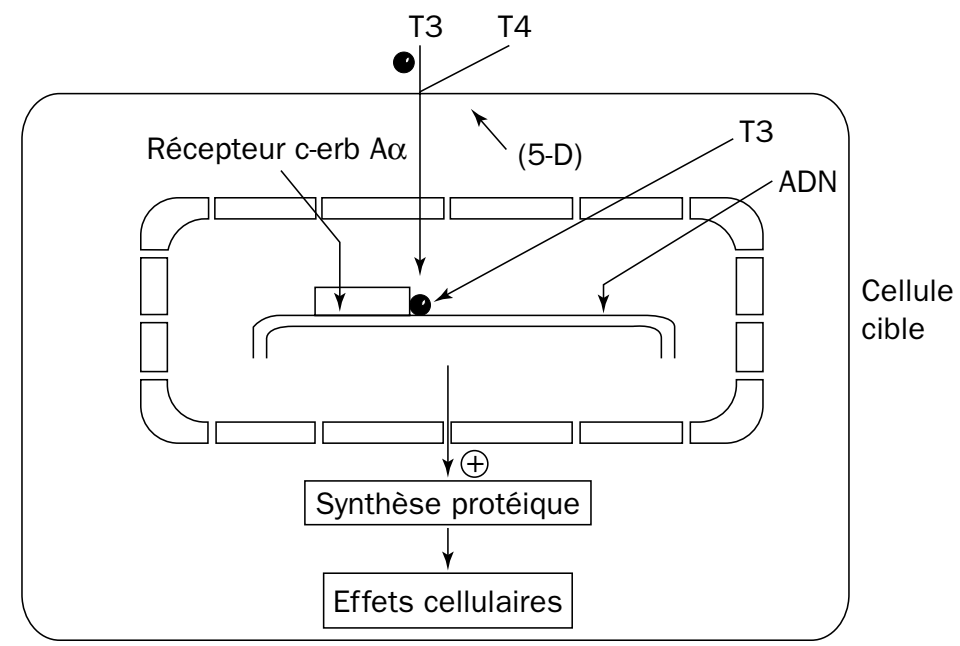

Figure 5.5 - Représentation schématique du mode d'action des hormones thyroïdiennes Les T3 et T4 circulantes peuvent pénétrer dans leur cellule cible. A ce niveau, la T4 est convertie en T3 sous l'action de la 5'-déiodinase (5-D). La T3 se fixe sur une protéine nonhistone de la chromatine. Le changement de conformation qui en résulte serait à l'origine de l'induction de la transcription conduisant à la synthèse des protéines. 
Tableau 5.1 - Classification des effets de la T3 au niveau mitochondrial et mécanismes d'actions proposés (d'après Wrutniak et Cabello, 1996)

\section{Actions immédiates}

Temps de latence : quelques minutes

- Activation de la respiration mitochondriale

- Activation de la synthèse d'ATP

- Activation de la translocase

Mécanismes proposés

- Augmentation du pool de calcium mitochondrial

- ADP-ribosylation d'une protéine de la membrane interne

- Modification allostérique d'une enzyme de la membrane interne

\section{Actions rapides}

Temps de latence : quelques heures

- Modification de la composition lipidique de la membrane interne induisant :

- une augmentation de la fuite des protons

- une stimulation de l'activité de plusieurs enzymes et transporteurs mitochondriaux

- Activation rapide de l'expression du génome mitochondrial

\section{Actions à long terme}

Temps de latence : supérieur à $24 \mathrm{~h}$

- Biogenèse mitochondriale

Mécanismes proposés

- Expression coordonnée des gènes nucléaires codant pour des protéines mitochondriales et des gènes mitochondriaux

- Implication des récepteurs nucléaires et mitochondriaux de la T3

Tableau 5.2 - Principales actions biochimiques des hormones thyrö̈diennes dans le foie du rat thyroïdectomisé (d'après Tata, 1974)

\begin{tabular}{|l|c|c|}
\hline $\begin{array}{l}\text { Stimulation ou augmentation } \\
\text { de la quantité }\end{array}$ & $\begin{array}{c}\text { Période de latence } \\
\text { (h) }\end{array}$ & $\begin{array}{c}\text { Temps de l'effet maximum } \\
(\mathrm{h})\end{array}$ \\
\hline $\begin{array}{l}\text { Synthèse d'ARN nucléaire } \\
\text { à marquage rapide }\end{array}$ & $4-6$ & 22 \\
\hline ARN polymérase A (ARNt) & $10-12$ & 40 \\
\hline ARN polymérase B (ARNm) & $18-20$ & 50 \\
\hline $\begin{array}{l}\text { Incorporation des acides aminés } \\
\text { dans les protéines }\end{array}$ & $18-24$ & $40-45$ \\
\hline $\begin{array}{l}\text { Synthèse des phospholipides } \\
\text { dans les microsomes }\end{array}$ & $12-16$ & 40 \\
\hline $\begin{array}{l}\text { Enzymes respiratoires } \\
\text { mitochondriales }\end{array}$ & $20-30$ & $50-60$ \\
\hline
\end{tabular}

Des rats thyroïdectomisés ont reçu 15 à $25 \mu \mathrm{g}$ de T3. 


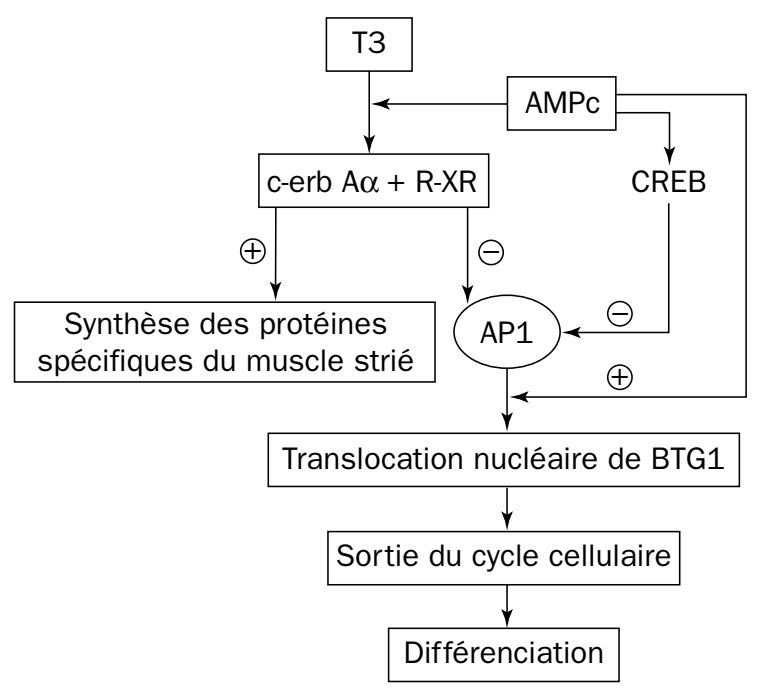

Figure 5.6 - Représentation schématique de l'action myogénique de la T3 (d'après Marchal et coll., 1996)

AP1 : proteic system activator; CREB : CAMP response element binding protein ; BTG1 : $B$-cell translocation gene 1.

Cette action s'exercerait via l'activation d'un des récepteurs nucléaires de la T3 (c-erb $A \alpha)$ et nécessite la présence de récepteurs fonctionnels à l'acide 9 cis-rétinoïque (R-XR). L'activation du complexe conduit à la synthèse de protéine et à la répression de l'activité inhibitrice de AP1. Par ailleurs, l'AMPC, soit directement, soit via l'activation de CREB, agit en synergie avec la T3.

\section{CYCLE DE L'IODE DANS L'ORGANISME}

L'iode se trouve dans l'organisme sous trois formes (voir fig. 5.3) :

- le "compartiment" iodure, dans la salive, le suc gastrique, le plasma et d'autres liquides extracellulaires ;

- le "compartiment" de l'iode thyroïdien : thyroglobuline et acides aminés iodés ;

- le "compartiment" de l'iode organique extrathyroïdien : c'est l'iode hormonal (combiné à une protéine des liquides extracellulaires ou cellulaires).

La thyroïde règle (sous l'influence de la TSH) :

- la quantité d'iode fixée par son parenchyme ;

- la quantité d'iode déversée dans la circulation.

Elle commande ainsi les échanges entre ces trois compartiments (turn-over).

\subsection{L'APPORT IODÉ}

L'iode est apporté par les aliments et les boissons (environ 50 à $200 \mu \mathrm{g} /$ jour). Il est absorbé par l'intestin sous forme d'iodures. Mais T3 et T4 passent telles quelles la barrière intestinale. L'iode peut également être d'origine endogène, par désiodation tissulaire des hormones thyroïdiennes. 
La thyroïde fixe rapidement les iodures après leur absorption digestive. Environ $100 \mu \mathrm{g} \mathrm{d}^{\prime} \mathrm{I}^{-}$sont fixés chaque jour par une glande à l'état d'équilibre. Sur les $25 \mathrm{mg}$ d'I du corps humain, on en retrouve 30 à 50\% dans la glande thyrö̈de (concentration près de 1300 fois supérieure à celle des autres tissus), soit de 9 à $12 \mathrm{mg}$.

\subsection{L'IODE PLASMATIQUE}

Dans le sang, l'iodémie est de l'ordre de 6 à $12 \mu \mathrm{g} / 100 \mathrm{ml}$ dont :

- de l'iode inorganique sous la forme d'iodure, environ $1 \mu \mathrm{g} / \mathrm{ml}$;

- de l'iode organique lié aux protéines (PBI ou protein bound iodine), 5 à $7 \mu \mathrm{g} / 100 \mathrm{ml}$ dont $5 \%$ correspond à la fraction non-hormonale (MIT et DIT) et $95 \%$ à T4, lié à une $\alpha$-globuline, la TBG (thyroxin binding globulin), protéine de transport de PM $50000^{1}$ (fig. 5.7).

L'iode total sérique est de l'ordre de 275 à $630 \mathrm{nmol} / 1$.

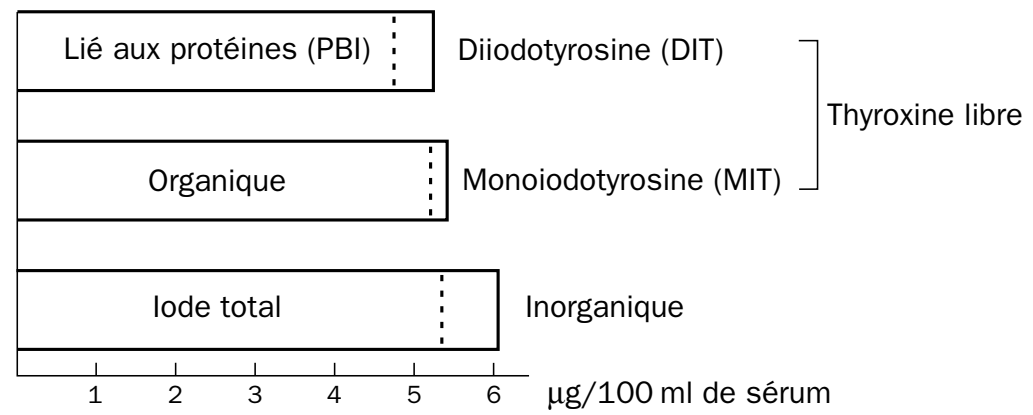

Figure 5.7 - Distribution de l'iodémie plasmatique (d'après Tepperman, 1969)

$75 \%$ de T4 est liée à la TBG. T4 présente une affinité plus faible pour TBPA (thyroxin binding prealbumin) de PM 70000 , et plus faible encore pour la sérumalbumine. T3 peut se fixer à ces mêmes vecteurs, mais avec une affinité 2 beaucoup plus faible. Les hormones libres constituent environ $0,4 \%$ de la T3, et $0,02 \%$ de la T4. Autrement dit, la quantité de T3 libre est peu différente de celle de T4 libre. Seules les hormones libres peuvent agir sur les cellules (fig. 5.8). T3 a, par rapport à T4 :

- une action plus rapide ;

- une demi-vie plus brève ;

- un espace de diffusion plus grand (401 au lieu de 101);

- une activité biologique cinq fois supérieure à celle de T4 .

1 Son taux augmente sous œstrogènes endogènes (grossesse) ou exogènes (pilule) par augmentation de la synthèse hépatique de la TBG.

2 - TBG a une affinité dix fois plus faible pour T3. Sa concentration dans le plasma est de $12 \mathrm{mg} / 1$.

- TBPA fixe $15 \%$ de T4. Sa concentration dans le plasma est de $300 \mathrm{mg} / 1$.

- L'albumine fixe de façon non spécifique $10 \%$ de T4. 


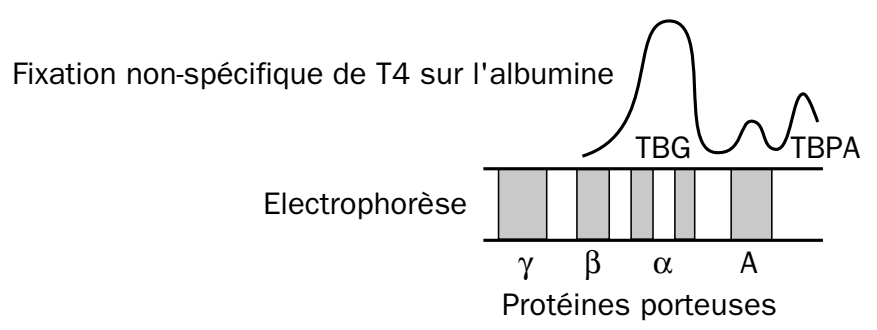

Figure 5.8 - Liaison des hormones thyroïdiennes avec leurs protéines de transport TBG : thyroxin binding globulin ; TBPA : thyroxin binding prealbumin

\subsection{L'IODE HORMONAL PÉRIPHÉRIQUE}

- Les protéines plasmatiques porteuses de l'iode hormonal libèrent T3 et T4 au niveau de la cellule où ces hormones pourront se fixer aux protéines nucléaires. Les hormones subissent sur le chaînon alanyl, d'abord, une désamination oxydative donnant de l'acide tétra- ou triiodothyropyruvique et de l'acide tétra- et triiodothyroacétique (TETRAC et TRIAC), puis elles sont déshalogénées par les désiodases présentes dans la plupart des tissus. L'iode libéré retourne sous la forme d'iodure dans le plasma.

- T3 et T4 subissent aussi éventuellement une glucurono- (pour T4) ou une sulfo(pour T3), conjugaison sur la fonction phénolique. Dans le foie, les hormones thyroïdiennes pourront être déversées dans la bile constituant un cycle entérohépatique, non-négligeable chez l'homme. La demi-vie de T4 est longue (6 jours), celle de T3 est courte ( $24 \mathrm{~h})$.

- Un mécanisme enzymatique de monodésiodation transforme T4 à l'intérieur des cellules réceptrices, soit en T3, soit en T3 “inversée" (3,3',5'triiodothyronine) d'action biologique nulle. T3 provient donc pour 20 à $30 \%$ de la thyroïde et pour 70 à $80 \%$ de la transformation périphérique de T4 en T3, ce qui permet de considérer T4 comme une pro-hormone de T3.

\subsection{EXCRÉTION DE L'IODE}

Chez l'adulte seront excrétés $150 \mu \mathrm{g} \mathrm{d} \mathrm{d}^{-}$par jour, dont l'essentiel par le rein et le reste par les matières fécales, la peau, le poumon et la sécrétion lactée. L'excrétion de l'iode dépend essentiellement de l'apport alimentaire. On peut admettre que l'iode suit un cycle fermé. Le volume de ce cycle fermé dépend plus de l'apport alimentaire que de la glande thyroïde, qui n'agit ni sur les entrées, ni sur les sorties. A l'intérieur de ce cycle, la TSH règle à un taux plus ou moins élevé, selon l'état de la thyroïde, la proportion d'iode à fixer et à transformer en hormones. 


\section{EPREUVES FONCTIONNELLES DE L'ACTIVITÉ THYROÏDIENNE}

\subsection{FIXATION DE L'IODE RADIOACTIF (fig. 5.9)}

L'131I de période courte ( 8 jours) a été utilisé en premier (émission de $\beta$ et $\gamma$ ). Il est remplacé, surtout chez le jeune enfant, par 1'123I (de période très courte : $2 \mathrm{~h} 30$ avec émission de $\gamma$ ). On utilise également le technetium ( ${ }^{99} \mathrm{TC}$ ) dont l'anion pertechnétate est comme l'iodure concentré par la thyroïde, mais il n'est pas incorporé sous une forme organique et quitte la glande par simple diffusion.

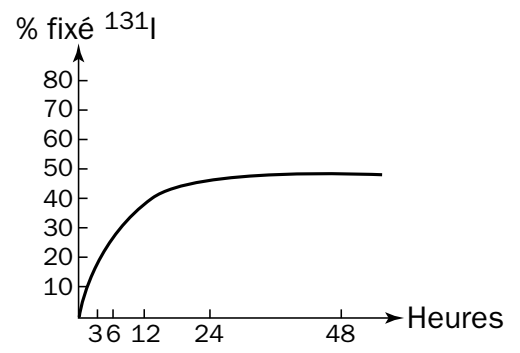

Courbe euthyroïdienne

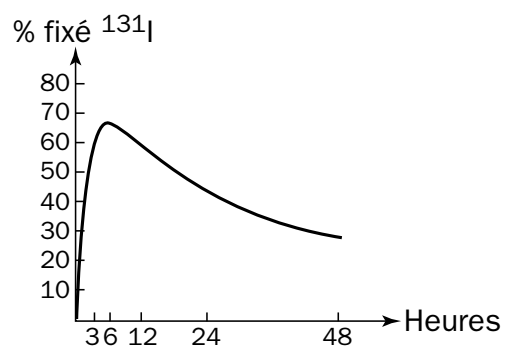

Courbe d'hyperthyroïdie

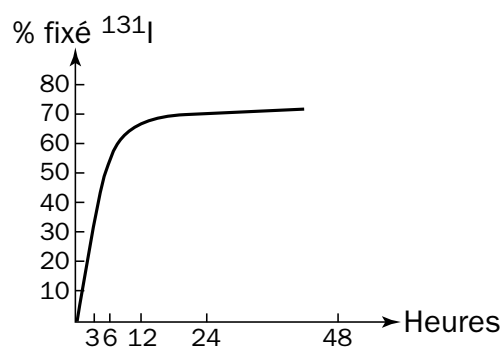

Courbe de goître simple "avide d'iode"

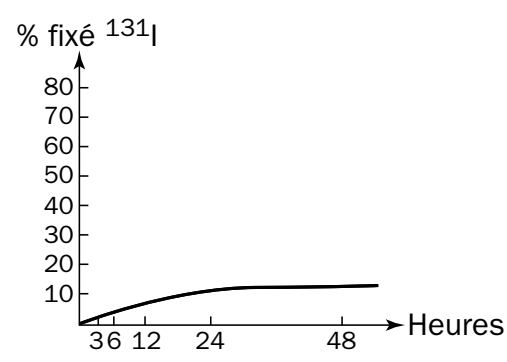

Courbe d'hypothyroïdie

Figure 5.9 - Courbes de fixation de l'iode radioactif (d'après Baulieu et coll., 1972) On donne au sujet "per os", ou par injection, $10 \mu \mathrm{Ci}$ d'INa. Le compteur est placé au contact du cou. La mesure du rayonnement est appréciée au bout de $2 h, 6 h, 24 h, 48 h$. La première partie de la courbe correspond à la captation de l'iode, la deuxième partie à son élimination (hormonogenèse).

Toutefois, cette méthode a perdu beaucoup de son intérêt depuis que l'on dispose de dosages hormonaux fiables.

- Courbe normale (euthyrö̈die) :

$2 \mathrm{~h}: 5$ à $25 \% ; 6 \mathrm{~h}: 10$ à $40 \% ; 24 \mathrm{~h}: 20$ à $60 \% ; 48 \mathrm{~h}: 20$ à $60 \%$

- Courbe basse :

Elle s'observe dans le myxœdème, mais aussi dans la saturation de la thyroïde par l'iode, après usage d'antithyroïdiens ou dans l'insuffisance hypophysaire. L'épreuve de stimulation à la TSH (test de Querido) consiste en une injection 
intramusculaire quotidienne de $100 \mu \mathrm{g}$ de TSH pendant 6 jours. Elle modifie la courbe et la rapproche de la normale si la lésion porte sur l'axe hypothalamohypophysaire, et non sur la thyroïde. Cette épreuve permet donc de distinguer les hypothyroïdies primaires (origine basse) des hypothyroïdies secondaires à l'hypofonctionnement hypothalamo-hypophysaire (origine haute). Il est plus simple maintenant de doser la TSH plasmatique. Le test de Querido reste utile dans les adénomes toxiques (tumeurs bénignes hypersécrétantes = "nodules chauds" qui échappent à la régulation normale par feed-back) car il permet, sur une scintigraphie, de "rallumer" le parenchyme thyroïdien "éteint" par l'adénome (voir fig. 5.9).

- Courbes hautes :

- avec angle de fuite : hyperthyroïdie vraie ;

- en plateau : goître avide d'iode (par trouble de l'hormonogenèse par exemple).

L'hyperthyroïdie ou thyrotoxicose (l'excès d'hormones circulantes qui la caractérise entraîne le blocage de la sécrétion hypophysaire de TSH) serait confirmée par l'épreuve de freinage avec T3. C'est le test de Werner : administration quotidienne de $100 \mu \mathrm{g}$ de T3 pendant 7 jours. Dans une thyrotoxicose, telle la maladie de Basedow ou l'adénome toxique, il n'y a pas de freinage, donc pas de chute de la courbe de fixation.

\subsection{SCINTIGRAPHIE THYROÏDIENNE (fig. 5.10)}

On utilise l'131I ou le ${ }^{99} \mathrm{TC}$. Le scintigramme précise avec exactitude les contours de la glande. Son aspect permet de visualiser d'éventuels goîtres plongeants, des thyroïdies ectopiques, l'hyperplasie ou l'hypoplasie du tissu thyroïdien, les nodules hyperfonctionnels (nodules chauds banals ou adénomes toxiques) et hypofonctionnels (nodules froids), et la réactivité du tissu thyroïdien aux tests de Werner ou de Querido.

L'étude du corps thyroïde peut être précisée par d'autres techniques "d'imagerie" thyroïdienne :

- La scintigraphie par fluorescence. Elle consiste à irradier la glande par un faisceau de rayons $\mathrm{X}$ ou $\gamma$, l'intensité du rayonnement $\mathrm{X}$ de fluorescence émis étant proportionnel au contenu en iode de la glande. Elle permet d'accéder à l'iode total, quelle que soit sa vitesse de renouvellement, alors que les examens isotopiques n'apprécient que l'iode échangeable.

- L'échotomographie thyroïdienne. Elle précise la structure du parenchyme glandulaire. On utilise une sonde émettrice-réceptrice qui produit des ultrasons de 5 à $7 \mathrm{MHz}$ de fréquence. Cette technique permet d'identifier les kystes, les nodules solides, les atteintes diffuses, mais elle ne permet pas de différencier un nodule bénin d'un nodule cancéreux. 


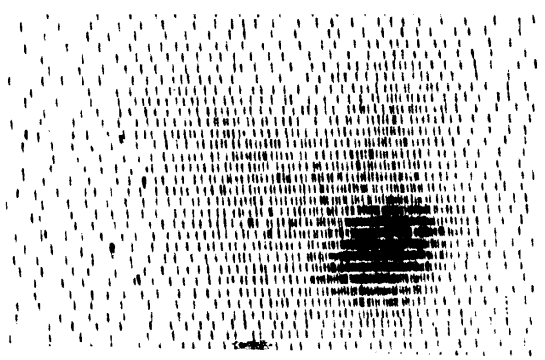

Thyroïde normale

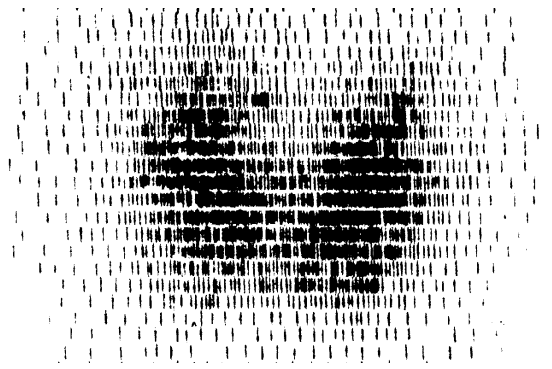

Nodule chaud avec hypofixation du tissu normal : adénome toxique

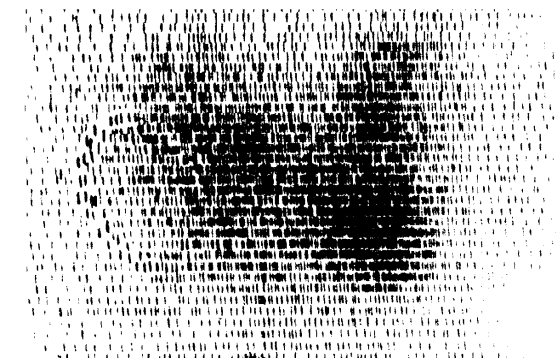

Après stimulation par la TSH : réapparition de la fixation dans l'ensemble de la glande

Figure 5.10 - Scintigraphie thyroïdienne

\subsection{ETUDE DES COMPOSÉS IODÉS CIRCULANTS ET DES PROTÉINES PORTEUSES}

\subsubsection{Mesures indirectes : épreuves de saturation}

La TBG (thyroxin binding globulin) n'est pas normalement complètement saturée par T3 et T4. On peut "in vitro" apprécier la fixation de T3 par le plasma ou le sang total du sujet étudié.

Habituellement, on apprécie, après saturation de la TBG du plasma par T3 radioactif de quantité connue, la fixation de l'excès de T3 sur les globules rouges (test de Hamolsky).

- Sujet normal (euthyroïdie) 0,9 à 1,1

- Hyperthyroïdie $>1,1$

- Hypothyroïdie $<0,9$

\subsubsection{Mesures directes}

Elles sont très importantes pour le clinicien.

- TBG $12 \mathrm{mg} / \mathrm{l}$

- T3 0,6 à $2 \mathrm{ng} / \mathrm{ml}$ (environ de 1,10 à $2,20 \mathrm{nmol} / \mathrm{l}$ )

- T4 40 à $120 \mathrm{ng} / \mathrm{ml}$ (environ de 70 à $150 \mathrm{nmol} / \mathrm{l}$ ) 


\subsection{ETUDE DE L'UTILISATION HORMONALE PÉRIPHÉRIQUE}

La thyroxine marquée par 1'131I est injectée par voie veineuse. La décroissance exponentielle de l'activité permet de définir la période biologique (environ 7 jours), le taux de renouvellement quotidien (environ 10\%) et de mesurer l'espace de dilution de la thyroxine (l'espace extracellulaire). Le degré d'imprégnation périphérique des cellules cibles par les hormones thyroïdiennes est mesuré par :

- la formule sanguine (par exemple leucopénie dans la thyrotoxicose);

- la cholestérolémie ;

- la modification du temps de demi-relaxation du réflexe achiléen. Le réflexogramme (fig. 5.11) qui n'est plus utilisé depuis que l'on dispose des paramètres beaucoup plus spécifiques que sont les dosages hormonaux dans le sang.

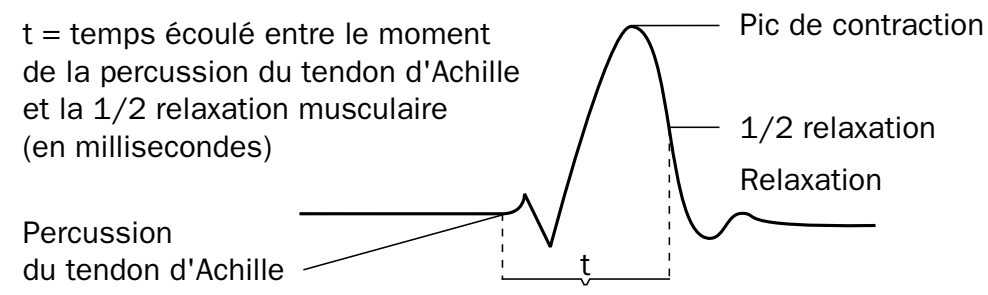

Figure 5.11 - Tracé du réflexogramme

\subsection{MESURE DE L'ACTIVITÉ THYRÉOTROPE HYPOTHALAMO-HYPOPHYSAIRE}

\subsubsection{L'épreuve à la TRH}

Cette épreuve (injection de TRH suivie d'un dosage de la TSH plasmatique) permet d'apprécier l'intégrité fonctionnelle des cellules thyréotropes hypophysaires. L'injection intraveineuse de TRH $(200 \mu \mathrm{g})$ provoque une augmentation de TSH qui est maximum au bout de 30 à 40 min et retourne au niveau de base en $3 \mathrm{~h}$ (fig. 5.12). Cette épreuve permet entre autres de différencier les lésions hypothalamiques des lésions hypophysaires, particulièrement dans les nanismes.

Ce test présente moins d'intérêt depuis que l'on dispose du dosage ultra-sensible de la TSH qui permet de mesurer des concentrations infranormales de cette hormone.

\subsubsection{Le dosage de la TSH}

Ce dosage par méthode radioimmunologique (normalement 0,47 à 4,6 mUI/ml) permet de distinguer les hypothyroïdies primitives (TSH supérieure $7 \mathrm{mUI} / \mathrm{l}$ ) des hypothyroïdies secondaires d'origine hypophysaire (TSH inférieure 0,15 mUI/l).

NB - L'épreuve au thiocyanate ( $1 \mathrm{~g}$ de thiocyanate de Na par jour) permet de diagnostiquer les insuffisances thyrö̈diennes par blocage de l'hormonogenèse. D'une part, il bloque les entrées d'iodure et d'autre part, il chasse l'iodure de la thyroïde. 


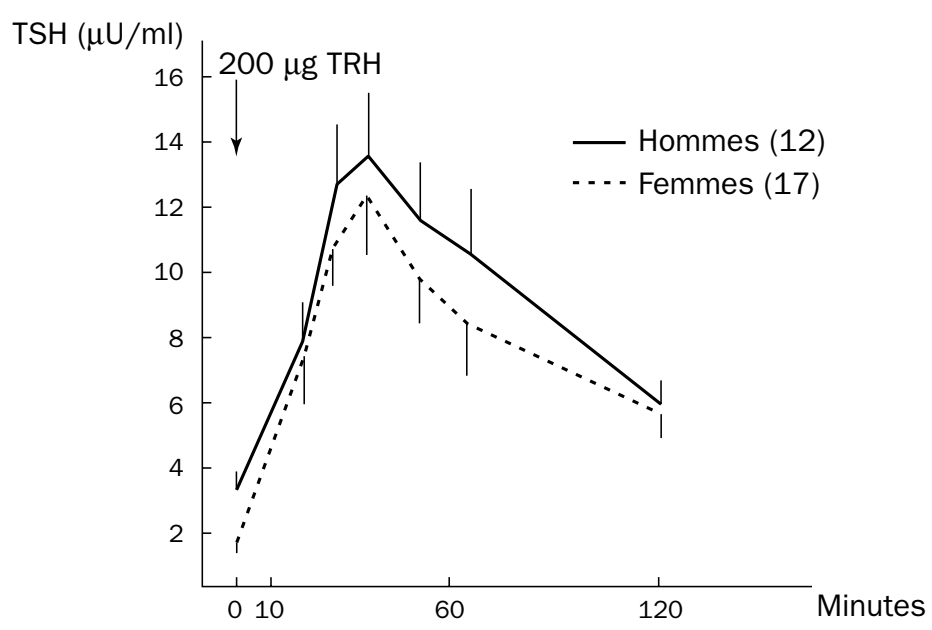

Figure 5.12 - Réponse à la TRH chez des sujets normaux

(d'après Mornex et Berthezène, 1974)

\section{THYROÏDE ET MÉTABOLISME CALCIQUE}

Voir le chapitre 8 sur les parathyroïdes.

La calcitonine (hormone des cellules parafolliculaires) s'oppose à la parathormone au niveau de la régulation du métabolisme calcique : elle abaisse la calcémie par inhibition de la résorption osseuse. Cependant, elle provoque, comme la parathormone, une hypophosphorémie.

C'est la thyroxine qui constitue dans l'organisme le facteur antagoniste de la parathormone et de la calcitonine à l'égard de la régulation du phosphore plasmatique, en augmentant la phosphorémie.

\section{CoRRÉLATIONS DE L'ACTIVITÉ THYROÏDIENNE}

La glande thyroïde est le centre de multiples corrélations glandulaires et humorales.

\subsection{AVEC L'HYPOTHALAMO-HYPOPHYSE}

- La TSH stimule toutes les étapes de l'hormonogenèse : fixation des iodures, formation de l'iode moléculaire organique, hydrolyse de la thyroglobuline et enfin libération des hormones thyrö̈diennes.

Comme pour d'autres hormones, la stimulation des cellules thyrö̈diennes par la TSH s'effectue au niveau de deux types de récepteurs, correspondant à deux effets distincts de la TSH : 
- récepteur couplé à l'adénylate cyclase, via une protéine Gs pour les effets hormonaux de la TSH, aboutissant à la libération de T3 et T4 (fig. 5.13) ;

- récepteur dont l'activation induit une augmentation de la teneur cytoplasmique en $\mathrm{Ca}^{2+}$ pour des effets trophiques sur la croissance de la cellule thyroïdienne.

- Des aliments tels que les choux, les tourteaux, les rutabagas contiennent des substances dont l'action est voisine de celle du thiouracile. Ce sont des aliments "goîtrigènes", l'hypothalamo-hypophyse réagit à la diminution des hormones thyroïdiennes dans le plasma par une hypersécrétion de TSH.

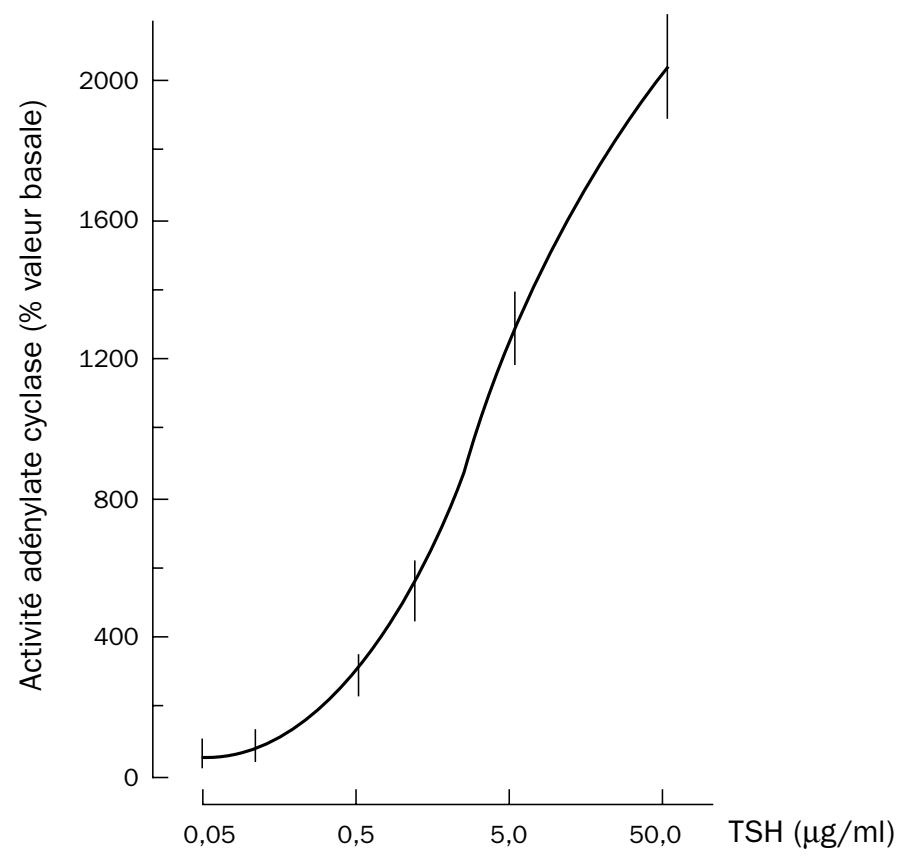

Figure 5.13 - Activation de l'adénylate cyclase thyroïdienne humaine par la TSH

(d'après Orgiazzi, 1976)

\subsection{AVEC LE CORTEX SURRÉNAL}

Leurs activités sont généralement parallèles. Les hormones thyroïdiennes augmentent le catabolisme du cortisol.

\subsection{AVEC LES GLANDES GÉNITALES}

L'action des hormones thyrö̈diennes s'exerce plus particulièrement sur les ovaires.

Leur activité est synchrone chez la femelle. En effet :

- l'activité thyroïdienne augmente au moment de l'ovulation chez la femme, la rate, la souris, la brebis ;

- le taux de la TBG augmente pendant la gestation. Les mesures des fractions libres montrent qu'elles pallient cette activité. 


\subsection{AUTRES INTERACTIONS DES HORMONES THYROÏDIENNES}

- Elles augmentent le catabolisme de l'insuline ;

- Elles potentialisent l'action des catécholamines.

\subsection{CONTRÔLE DE L'ACTIVITÉ THYROÏDIENNE}

Indépendamment des informations hormonales intéroceptives, de nombreuses variations de l'activité thyroïdienne sont liées à la croissance, à la puberté, à diverses étapes de la vie génitale, et surtout à l'adaptation au froid.

Le froid est le principal stimulus indépendant du rétro-contrôle de la thyroïde. Il stimule quasi immédiatement la TSH, par relais hypothalamique (cellules à TRH), par le biais de récepteurs de la sensibilité cutanée et viscérale, et cela quel que soit le taux plasmatique des hormones thyroïdiennes et le feed-back T4/TSH.

\section{LA MALADIE DE GRAVES-BASEDOW : UNE MALADIE AUTO-IMMUNE}

L'hyperthyroïdie basedowienne n'est pas freinable par l'hormone thyroïdienne. C'est une hyperthyroïdie ou thyrotoxicose. Elle a été longtemps imputée à une hypertonie diencéphalo-hypophyso-thyroïdienne, qui échapperait donc à un contrôle, à une régulation normale par effet feed-back.

L'existence fréquente d'un stress (émotif ou autre) à l'origine de cette maladie allait dans le sens de cette conception. Cependant, des faits cliniques et biologiques, en particulier :

- l'absence de taux élevé de TSH (constaté grâce au dosage radioimmunologique), ce taux est même plutôt diminué,

- l'aspect régressif des cellules thyréotropes hypophysaires,

- et l'activité thyréotrope anormale du sérum (Adams et Purves)

ont conduit à une autre interprétation de l'étiologie de la maladie de Basedow.

Le sérum des Basedowiens possède un effet thyréotrope tardif et prolongé (Adams et Purves, 1956) qui n'est pas imputable à la TSH (dont la demi-vie est égale à $15 \mathrm{~min}$ ). Il est dû à un facteur protéique de nature immunologique (IgG).

Sa demi-vie est de 7 h 30, son origine n'est pas hypophysaire. On l'a appelé LATS (long acting thyroid stimulator). Il s'agit d'un anticorps anticellules thyroïdiennes. La maladie de Basedow rentre alors dans le cadre des maladies dites auto-immunes, où l'organisme sécrète des auto-anticorps. Dans le cas présent, ceux-ci ont un rôle essentiellement stimulant. Le LATS agit sur la thyroïde de la même façon que la TSH, en stimulant le même récepteur adénylate cyclase spécifique (le LATS comme la TSH va provoquer la lipolyse de la cellule adipeuse). 
Comme pour d'autres maladies auto-immunes, une anomalie dans le fonctionnement ou le contrôle des lymphocytes $\mathrm{T}$ expliquerait le déclenchement de la maladie. Le traitement par des antithyroïdiens : PTU (propylthiouracile) ou méthymazole (méthylmercapto-imidazole) entraîne une diminution de la production hormonale. 



\section{CHAPITRE 6}

\section{LES GLANDES SURRÉNALES}

\section{CARACTÉRISTIQUES GÉNÉRALES}

Chez les Mammifères, elles constituent deux glandes situées au-dessus des reins et pèsent chacune de 4 à $6 \mathrm{~g}$ chez l'homme.

\subsection{HISTORIQUE}

Elles ont été découvertes en 1543 par Eustachi et appelées capsules surrénales. En 1855, Addison décrit le syndrome d'insuffisance surrénalienne (par tuberculose de la glande) auquel on a donné son nom.

L'interprétation d'Addison est confirmée par les expériences de Brown-Séquard en 1856 : la surrénalectomie s'avère mortelle chez l'animal. Les travaux portent alors plutôt sur la sécrétion du principe hypertenseur, isolé en 1901 : l'adrénaline. Puis les écoles de Kendall et Reichstein, autour des années 1930, font connaître les stéroïdes du cortex surrénalien.

\subsection{GÉNÉRALITÉS}

Suprarénales chez les Mammifères et les Oiseaux, ces glandes révèlent morphologiquement leur dualité chez les Vertébrés inférieurs où l'on distingue un organe interrénal pair (ou médian et impair), correspondant au cortex surrénal des Mammifères, et des corps suprarénaux, généralement échelonnés le long des chaînes ganglionnaires sympathiques et correspondant à la médullo-surrénale des Mammifères (fig. 6.1).

La glande surrénale est en effet composée de deux parties bien distinctes du triple point de vue embryologique, histologique et physiologique. Leur parenté paraît artificielle, mais les relations anatomiques (vascularisation) déterminent des relations physiologiques privilégiées (action des glucocorticoïdes sur la méthylation de la noradrénaline). 


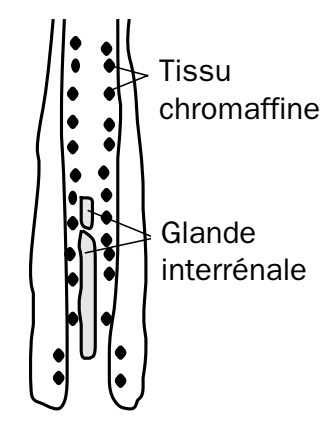

Elasmobranche

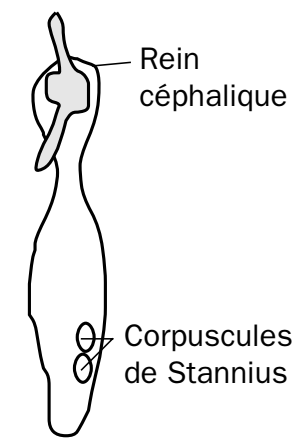

Téléostéen

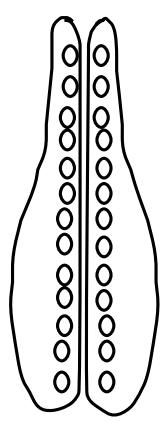

Urodèle

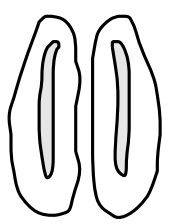

Anoure

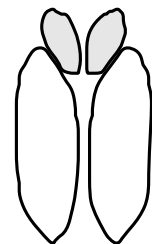

Lézard

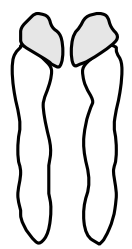

Oiseau

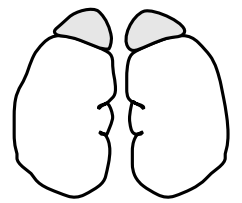

Mammifère

Figure 6.1 - Phylogenèse de la glande surrénale

\subsection{RAPPEL EMBRYOLOGIQUE (fig. 6.2)}
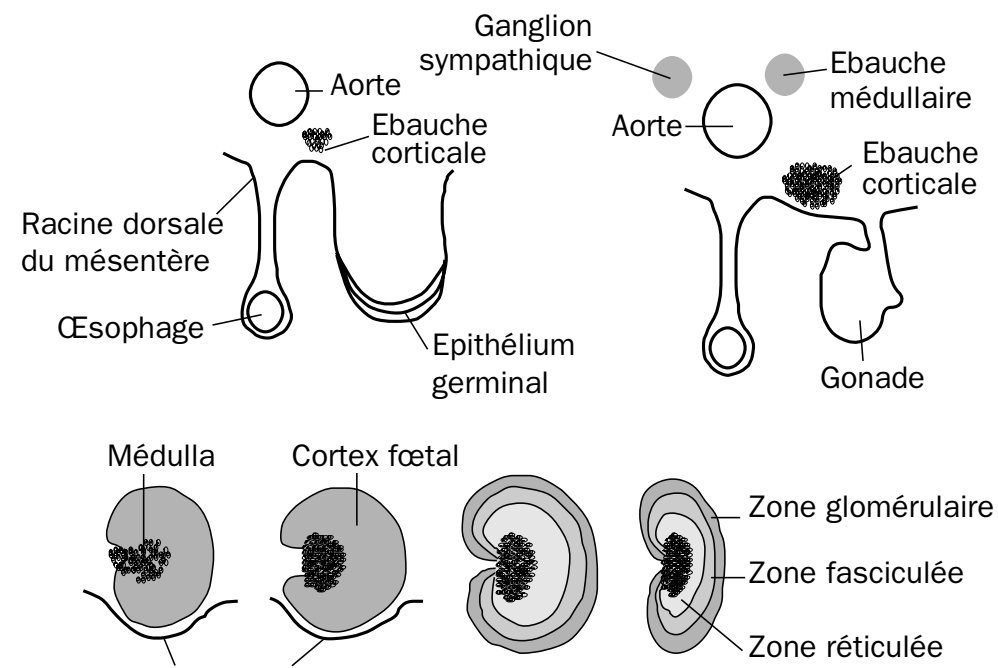

Epithélium cœlomique

Figure 6.2 - Embryogenèse de la glande surrénale chez le Mammifère

\subsubsection{Les cellules corticales (ou interrénales)}

D'origine mésodermique, elles proviennent de l'épithélium cœlomique, au voisinage du corps de Wolff, entre l'épithélium germinatif et la racine dorsale du mésentère. 
Ces cellules se différencient chez l'homme au 25e jour de la gestation (embryon de $6 \mathrm{~mm}$ ), puis elles constituent une ébauche située entre l'aorte et la gonade.

\subsubsection{Les cellules médullaires (ou chromaffines)}

Elles sont d'origine nerveuse, neurectodermique. Elles constituent une évolution particulière, par l'acquisition de propriétés sécrétrices, de neurones post-ganglionnaires. L'ébauche médullaire, formée à partir des ganglions de la chaîne sympathique, pénètre dans l'ébauche corticale. Elle constituera une glande centrale chez les Mammifères, chez les Oiseaux les deux types cellulaires restent intriqués.

\subsection{RAPPEL HISTOLOGIQUE}

Chez les Mammifères, on observe, de la superficie jusqu'au centre de la glande, les couches suivantes :

- une capsule conjonctive, faite de fibroblastes et de fibres de collagène.

- le cortex, comprenant trois zones :

- zone glomérulaire (ou glomérulée), origine de l'hormone minéralocorticoïde : l'aldostérone.

- zone fasciculée, composée de travées de cellules très riches en lipides. Après inclusion dans la paraffine, les gouttelettes lipidiques sont dissoutes, donnant aux cellules un aspect spongieux (spongiocytes).

- zone réticulée : les cellules sont organisées en travées autour des capillaires plexiformes.

Les zones fasciculée et réticulée sécrètent les hormones glucocorticoïdes (cortisol, corticostérone...). Les hormones androgènes seraient élaborées par la seule zone réticulée ou par les deux zones fasciculée et réticulée.

- La médulla, constituée de cordons richement vascularisés, au sein desquels on observe deux types de cellules : cellules à noradrénaline et cellules à adrénaline.

\subsection{VASCULARISATION ET INNERVATION}

Les artérioles, issues en général de l'aorte et de l'artère rénale, constituent un réseau péricapsulaire d'où vont partir :

- des vaisseaux courts, qui se capillarisent dans le cortex ;

- des vaisseaux perforants, qui irriguent la médullo-surrénale.

Les capillaires veineux confluent en une veine centrale pourvue de dispositifs musculaires qui permettraient les "décharges" brutales des hormones médullo-surrénaliennes. La veine surrénale se jette dans la veine cave inférieure à droite, dans la veine rénale à gauche. L'innervation de la glande surrénale est constituée exclusivement par des fibres préganglionnaires destinées à la médulla. Mais le contrôle de la sécrétion du cortex n'est pas indépendant de toute stimulation nerveuse (terminaisons cholinergiques). 


\section{LE CORTEX SURRÉNAL}

\subsection{DONNÉES ANATOMO-CLINIQUES ET EXPÉRIMENTALES}

\subsubsection{Observations anatomo-cliniques}

- Syndrome d'insuffisance surrénalienne globale : la maladie d'Addison

C'est un syndrome caractérisé par :

- la mélanodermie, pigmentation diffuse brune ou café au lait ;

- l'asthénie, maître-symptôme de l'insuffisance surrénalienne. C'est essentiellement une fatigabilité rapide, plutôt qu'une fatigue, l'asthénie est à la fois physique et psychique ;

- des troubles digestifs, génitaux...

Du point de vue métabolique :

- métabolisme minéral :

- une hyponatrémie à $135 \mathrm{mEq} / 1$ et au-dessous, accompagnée d'hypernatrurie (normalement $140 \pm 2 \mathrm{mEq} / 1$, soit 35 à $45 \mathrm{mmoles}$ de $\mathrm{Na}^{+}$par litre d'eau plasmatique);

- une hyperkaliémie à $6 \mathrm{mEq} / 1$ et au-dessus (au lieu de 4,6 $\pm 0,4 \mathrm{mEq} / \mathrm{l}$ );

- métabolisme glucidique et lipidique : de l'hypoglycémie et de l'hypocholestérolémie ;

- une diminution des 17-hydroxystéroïdes urinaires (jusqu'à $<1$ à $2 \mathrm{mg}$ au lieu de 3 à $8 \mathrm{mg}$ );

- un test de Thorn (épreuve de stimulation du cortex surrénal) négatif. Mais plutôt que de l'ACTH, il vaut mieux utiliser la 1-24 corticotrophine retard = Synacthène® ;

- un cortisol plasmatique abaissé $(<80 \mathrm{ng} / \mathrm{ml})$, qui n'augmente pas après Synacthène ${ }^{\circledR}$, et une élévation de l'ACTH plasmatique ;

- une aldostérone basse et une activité rénine élevée.

Le malade non-traité meurt en 6 à 24 mois dans un tableau de collapsus circulatoire et de défaillance rénale. Le traitement constitue l'un des succès de l'hormonothérapie substitutive, qui comporte généralement un minéralocorticoïde (la $9 \alpha$-fluorohydrocortisone, cinq fois plus active que l'acétate de désoxycorticostérone DOC) et un glucocorticoïde, sous forme d'hydrocortisone. La pigmentation n'est cependant pas réversible.

L'hyperfonctionnement de la glande est rarement global, il se traduit en général par des syndromes correspondant à l'hypersécrétion d'un seul type cellulaire.

- Hyperaldostéronisme primaire ou syndrome de Conn (1954)

Lié à un adénome de la zone glomérulaire ou à une hyperplasie surrénale bilatérale, il provoque une perturbation du métabolisme de l'eau et des sels. 
Cliniquement, on observe :

- une hypertension artérielle permanente ;

- des parésies musculaires liées à la baisse de la concentration du potassium cellulaire ;

- une hyperexcitabilité musculaire, avec au maximum des crises de tétanie (par alcalose ?).

La surcharge en aldostérone entraîne :

- une hypokaliémie ;

- une rétention sodique modérée : hypernatrémie ou natrémie normale ;

- de l'alcalose, par fuite urinaire d'ions $\mathrm{H}^{+}$;

- une fuite potassique : il y a hypokaliurie ; du point de vue urinaire, la diurèse potassique va l'emporter sur la rétention sodique d'où une polyurie d'urines alcalines.

L'aldostéronurie est multipliée par 20 ou par 30, l'activité rénine est abaissée en régime normosodé.

- Surcharge en glucocorticoïdes donnant un syndrome de Cushing

C'est la maladie de Cushing si l'hypercorticisme est secondaire à un dérèglement hypothalamique avec ou sans adénome hypophysaire. Mais il peut être consécutif à un hypercorticisme primaire (tumeur primitive de la surrénale).

Les signes cliniques comportent :

- une obésité de la face et du tronc ;

- un faciès élargi et coloré ;

- une hypertension artérielle, constante mais modérée ;

- une amyotrophie avec asthénie (par catabolisme azoté).

Les signes biologiques comportent :

- une sécrétion d'hydrocortisone (cortisol) multipliée par 2 à 10 (plus de $250 \mathrm{mg}$ / jour), avec perte du rythme circadien ;

- une hyperglycémie discrète à jeun ou, dans $80 \%$ des cas, une hauteur anormale de la flèche d'hyperglycémie provoquée (diabète dans $1 / 4$ des cas);

- de l'éosinopénie et de la lymphopénie (parfois même absence d'éosinophiles);

- une augmentation des 17-OH, le taux des 17-cétostéroïdes est normal ou légèrement élevé.

\section{- Hyperplasie surrénale congénitale}

C'est une des plus fréquentes endocrinopathies chez l'enfant (1 sur 5000 naissances). Un déficit enzymatique réalisera une hyperplasie surrénale congénitale avec virilisation chez l'enfant. On distingue plusieurs types suivant le niveau du blocage enzymatique :

- déficit en 21-hydroxylase (90\% des hyperplasies congénitales de l'enfant) ;

- déficit en $11 \beta$-hydroxylase, plus rare (5\%) et dont l'hyperandrogénie est moins sévère ; 
- déficit en $3 \beta$-OH-déshydrogénase ;

- ou des formes encore plus rares, tel le bloc de la 20-22 desmolase.

Les conséquences cliniques (par hypersécrétion d'ACTH) seront :

- hypertrophie du clitoris chez la fille ; fréquence des formes frustes à révélation tardive par un hirsutisme ;

- pseudo-puberté précoce chez le garçon, avec avance staturale pendant les premières années de la vie.

\subsubsection{Expérimentation}

La surrénalectomie totale entraîne la mort dans toutes les espèces. Elle survient 2 à 10 jours après l'intervention chez le cobaye, le chien et le chat. Elle est presque toujours causée par les perturbations du métabolisme hydrominéral. Elle sera retardée par l'addition de sel à l'eau de boisson et évitée par des injections répétées de DOC (désoxycorticostérone) ou d'aldostérone.

La suppression de la sécrétion d'aldostérone provoque une rétention potassique et une fuite du CINa (non-réabsorption du $\mathrm{Na}^{+}$dans le tubule rénal). L'hypernatrurie entraîne une hyponatrémie qui provoque une baisse de la pression osmotique des liquides extracellulaires, d'où un flux d'eau des liquides extracellulaires vers les cellules avec comme conséquences : la baisse de la volémie, une hémoconcentration secondaire et une augmentation de la viscosité sanguine. La baisse de la volémie provoque une défaillance circulatoire par :

- réduction de la pression artérielle ;

- réduction du débit cardiaque global.

Ces réductions entraînent au niveau du rein :

- une réduction de la pression de filtration glomérulaire ;

- une réduction du débit plasmatique rénal d'où une oligurie ou même une anurie.

Le débit urinaire n'est plus suffisant pour assurer l'élimination des produits du catabolisme protidique. Il y a élévation de l'urémie et décès par défaillance cardiaque et rénale.

Il est également possible de noter avant le décès des troubles dus à l'absence de glucocorticoïdes :

- une opsiurie (retard à l'élimination de l'eau lors d'une surcharge hydrique) ;

- de l'hypoglycémie, objectivée en cas de jeûne, d'exercice musculaire, de froid ;

- une sensibilité accrue à l'insuline.

Les troubles de l'absorption intestinale du glucose doivent être rapportés au déséquilibre hydrominéral par baisse de la concentration du Na intracellulaire. Quant à l'asthénie, elle est liée en partie, mais pas uniquement, à l'appauvrissement en réserves glucidiques. La pigmentation, qui apparaît lors de l'insuffisance surrénalienne installée progressivement chez l'addisonien, n'apparait pas après surrénalectomie. 


\subsection{BIOCHIMIE DES HORMONES CORTICOSURRÉNALIENNES}

\subsubsection{Biosynthèse ${ }^{1}$ (fig. 6.3)}

Elle s'effectue à partir du cholestérol (Hechter et coll., 1953), en partie exogène (apportée par absorption intestinale ou synthèse hépatique) et en partie endogène (synthétisée sur place à partir des acétates). Cette synthèse locale du cholestérol est effectuée par le réticulum endoplasmique.

Ensuite, le cholestérol se transforme en prégnénolone qui donne de la progestérone. La progestérone subit alors deux hydroxylations successives ( $21 \alpha$ - et $11 \beta$-) et devient de la corticostérone, ou trois hydroxylations successives $(17 \alpha-, 21 \alpha$ et $11 \beta$-) pour donner de l'hydrocortisone ou cortisol. Des modifications plus complexes la transforment en hormones androgènes, en C19, la $\Delta 4$-androstène3,17 dione, la $11 \beta$-hydroxy- $\Delta 4$-androstène- 3,17 dione et une troisième hormone androgène, la déhydro-épiandrostérone (en abrégé DHEA ou DHA), non-hydroxylée en $11 \beta$, une hormone qui présenterait une action antivieillissement (Baulieu, 1996, voir § 6.3).

Enfin, la 18-hydroxylation de la corticostérone suivie d'une oxydation de la fonction alcool en aldéhyde induit la synthèse de l'aldostérone.

Cette biosynthèse des hormones du cortex surrénal fait intervenir des enzymes tantôt mitochondriales (un système desmolasique complexe qui transforme le cholestérol en prégnénolone, et la $11 \beta$-hydroxylase), tantôt du réticulum endoplasmique (la $3 \beta$-déshydrogénase associée à une isomérase, qui transforme la prégnénolone en progestérone, les 21- ou 17-hydroxylases), ce qui implique un va-et-vient du précurseur entre ces deux organites cellulaires.

Chez le rat, le cortex surrénal synthétise un seul glucocorticoïde : la corticostérone, mais deux hormones minéralocorticoïdes : l'aldostérone et la 11-DOC (Vinson et Rankin, 1965).

Les hormones essentielles du cortex surrénal (cortisol, corticostérone, aldostérone et $11 \beta$-hydroxy- $\Delta 4$-androstène-3,17 dione) portent l'estampille de la $11 \beta$-hydroxylation, étape spécifique de cette glande. Cette $11 \beta$-hydroxylation est assurée par un système "caténaire" complexe (flavoprotéine; $\mathrm{NADPH}_{2}$; protéine ferrique non-hème ; cytochrome $\mathrm{P}-450$ ) situé dans la membrane interne des mitochondries.

La métopirone bloque électivement la $11 \beta$-hydroxylase, mais aussi la $18 \beta$-hydroxylase. Comme dans le cas du thiouracile pour la glande thyroïde, son emploi provoque l'hypersécrétion d'ACTH et l'hyperplasie (non-fonctionnelle) du cortex surrénal.

1 Une fraction non négligeable des éléments de cette chaîne de biosynthèse existe sous une forme sulfatée (Baulieu, 1965), principalement la DHEA, dont le sulfate DHEA-S pourra être converti en œstrogènes par le placenta. 


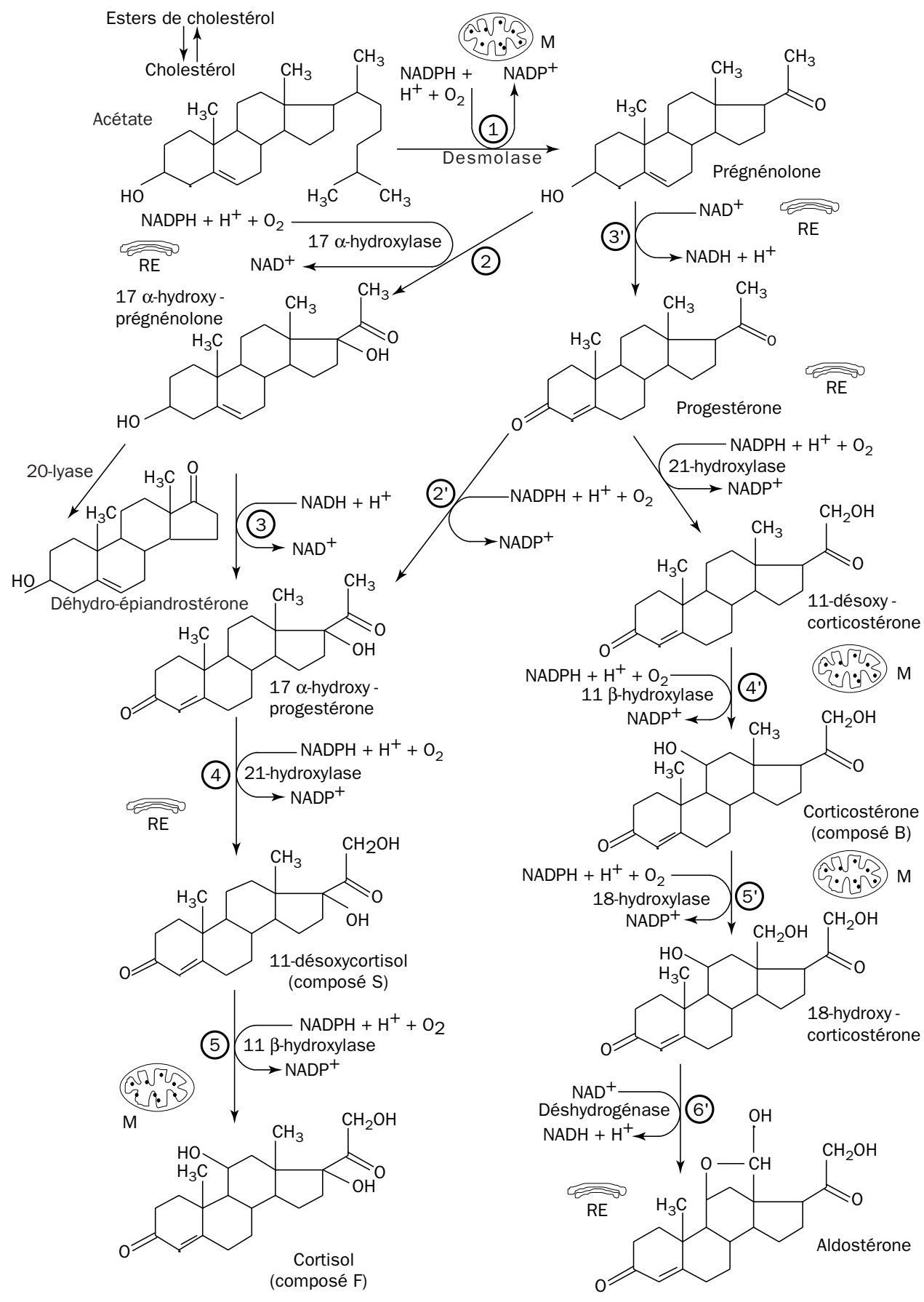

Figure 6.3 - Etapes intracellulaires de la biosynthèse des hormones du cortex surrénal 
Quelques chiffres chez l'homme (tab. 6.1 et 6.2):

Tableau 6.1 - Hormones sécrétées par le cortex surrénal chez l'homme

\begin{tabular}{|c|c|c|c|c|}
\hline Hormone & Taux dans le sang & Sécrétion / jour & $\begin{array}{c}\text { Sécrétion / jour } \\
\text { après ACTH }\end{array}$ & Demi-vie \\
\hline Aldostérone & $\begin{array}{c}222 \pm 111 \mathrm{pmol} / 1 \\
(80 \pm 40 \mathrm{ng} / 1)\end{array}$ & $\begin{array}{c}0,5 \text { à } 1 \mu \mathrm{mol} \\
(100 \text { à } 200 \mu \mathrm{g})\end{array}$ & $\times 2$ ou 3 & $20-50 \mathrm{~min}$ \\
\hline Cortisol & $\begin{array}{c}420 \pm 83 \mathrm{nmol} / 1 \\
(150 \pm 30 \mu \mathrm{g}) \text { à } 8 \mathrm{~h}\end{array}$ & $\begin{array}{c}41 \pm 15 \mu \mathrm{mol} \\
(15 \pm 5 \mathrm{mg})\end{array}$ & $\times 10$ & $95-130 \mathrm{~min}$ \\
\hline Corticostérone & & $\begin{array}{c}2 \text { à } 3 \mathrm{mg} \text { (dont } \\
310 \mu \mathrm{g} \text { en sulfate) }\end{array}$ & $\times 10$ & $45 \mathrm{~min}$ \\
\hline $\begin{array}{l}\text { Androgènes } \\
\text { - sulfate DHA } \\
\text { - DHA } \\
\text { - } \Delta 4 \text {-androstène-dione } \\
\text { - } 11 \beta \text {-hydroxy- } \\
\text { androstène-dione }\end{array}$ & $\begin{array}{l}\left\{\begin{array}{l}3,1 \text { à } 9 \mu \mathrm{mol} / 1 \\
2,8 \text { à } 9,7 \mu \mathrm{mol} / 1\end{array}\right. \\
10,2 \text { à } 23,6 \mathrm{nmol} / 1\end{array}$ & $\begin{array}{l}15 \mathrm{mg} \\
5 \mathrm{mg} \\
\left\{\begin{array}{l}2 \mathrm{mg} \\
4 \mathrm{mg}\end{array}\right. \\
5 \text { à } 10 \mathrm{mg}\end{array}$ & $\times 2$ & $6-8 \mathrm{~h}$ \\
\hline
\end{tabular}

Cette sécrétion est rythmique chez le rat, ainsi que le montre le tableau suivant.

Tableau 6.2 - Aspects cycliques des sécrétions de corticostérone (rat) et de cortisol (homme)

\begin{tabular}{|l|c|c|c|}
\cline { 3 - 4 } \multicolumn{2}{c|}{} & Glande $\mu \mathrm{g} / \mathrm{g}$ & Plasma $\mu \mathrm{g} / 1$ \\
\hline \multirow{2}{*}{ Corticostérone chez le rat } & $9 \mathrm{~h}$ & $5,13 \pm 1,11$ & $41,3 \pm 5$ \\
& $21 \mathrm{~h}$ & $25,4 \pm 4,60$ & $236 \pm 48$ \\
\hline \multirow{2}{*}{ Cortisol chez l'homme } & $8 \mathrm{~h}-9 \mathrm{~h}$ & & $80-250$ \\
& $18 \mathrm{~h}-24 \mathrm{~h}$ & & $<10$ \\
\hline
\end{tabular}

\subsubsection{Transport du cholestérol (fig. 6.4)}

Le transfert du cholestérol au niveau de la membrane externe de la mitochondrie est assuré par une protéine (canal-transporteur ?) appelée PTBR (peripheral type benzodiazepine receptor). PTBR est présent dans un complexe comprenant VDAC (voltage dependant anion carrier) et l'adenine nucleotide carrier protein (ANCP). Le ligand endogène de PTBR qui stimule la production de stéroïdes a été purifié. C'est une protéine appelée diazepam binding inhibitor (DBI). La stimulation de la synthèse d'AMPc modifie la distribution du complexe PTBR et augmente le nombre de sites de contact PTBR/StAR (steroidogenic acute regulatory protein), ce qui pourrait conduire à augmenter le transport de cholestérol et la synthèse de stéroïdes. 


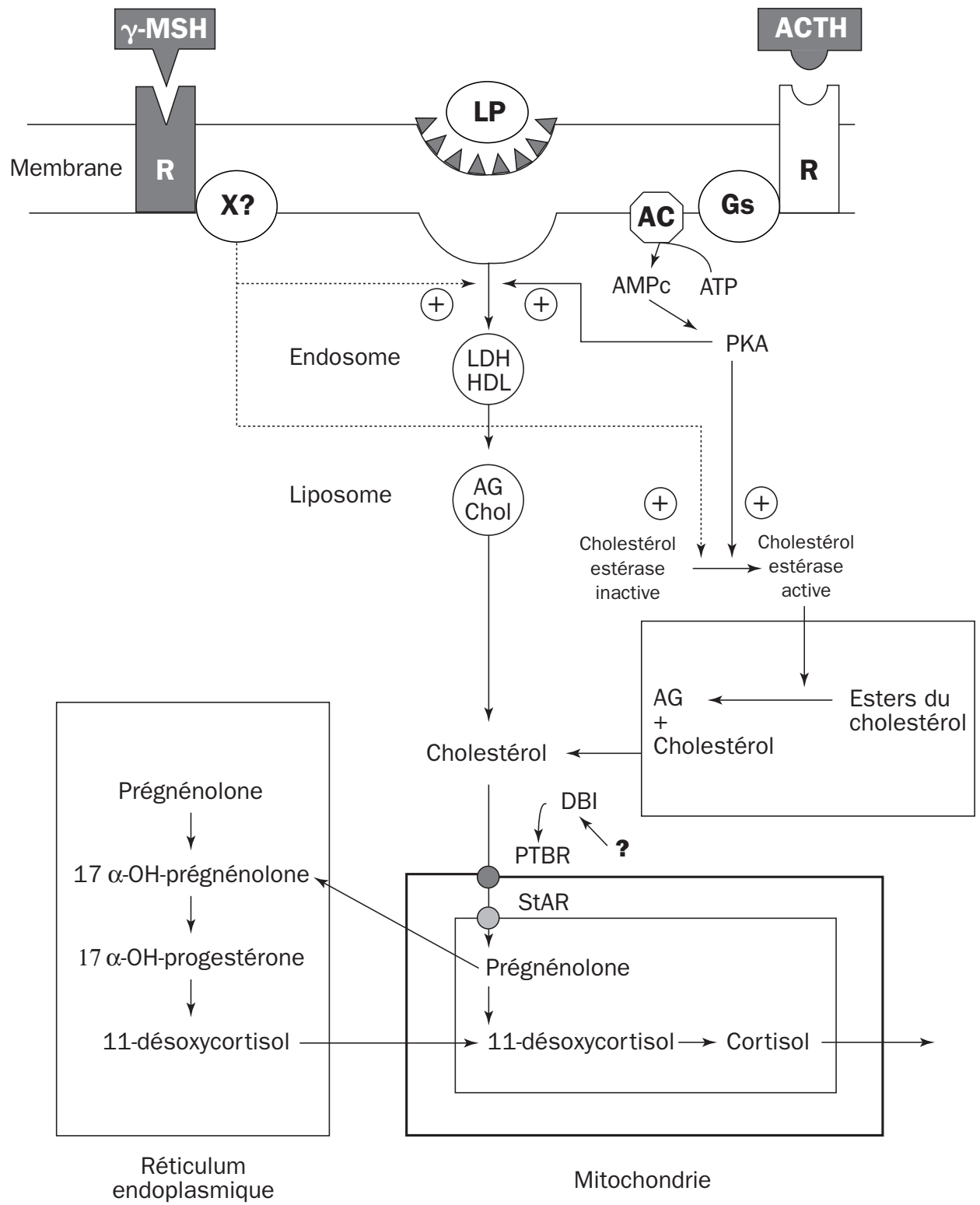

Figure 6.4 - Transport du cholestérol

AG : acides gras; HDL : high density lipoprotein ; $L D L$ : low density lipoprotein ; $L P$ : lipoprotéines ; DBI : diazepam binding inhibitor; PTR : peripheral type benzodiazepine receptor ; PKA : protéine kinase $A$; StAR : steroidogenic acute regulatory protein.

Les deux hormones stimulent, via la mise en jeu d'un récepteur $(\mathrm{R})$ couplé à une protéine Gs $(\mathrm{ACTH})$ et à un intermédiaire inconnu ( $\gamma$-3-MSH), l'incorporation de lipoprotéines (LP) dans la cellule de la zone fasciculo-réticulée de la surrénale. L'action de la cholesterol ester hydrolase conduit à la production de lipoprotéines de haute (HDL) et basse densité (LDL), puis d'acide gras (AG) et de cholestérol. 
Le transfert de cholestérol de la membrane externe à la membrane interne de la mitochondrie est une voie limitante de la synthèse des stéroïdes. De nombreux travaux ont conduit à mettre en évidence qu'une protéine appelée StAR, synthétisée dans le cytoplasme, est responsable de ce transfert. Elle est localisée sur la face interne et dans la matrice des mitochondries. La mise en évidence de protéines homologues à StAR laisse penser qu'il existe une famille de protéines impliquée dans la synthèse des stéroïdes (Waterman, 1998 ; Miller et Strauss, 1999 ; Stocco, 1999 ; Zilz et coll., 1999).

\subsubsection{Transport et action des hormones corticoüdes}

La majeure partie des hormones corticoïdes sont transportées dans le plasma sanguin sous une forme liée à des protéines, soit par une liaison non-spécifique avec l'albumine, soit par une liaison spécifique avec une $\alpha$-glycoprotéine, la CBG (corticosteroid binding globulin) ou transcortine, de poids moléculaire $25000^{2}$. Une fraction assez faible reste sous forme libre, sauf pour l'aldostérone (fig. 6.5). En effet, l'aldostérone est faiblement liée à une albumine ou à la transcortine, mais la majeure partie reste sous forme libre.

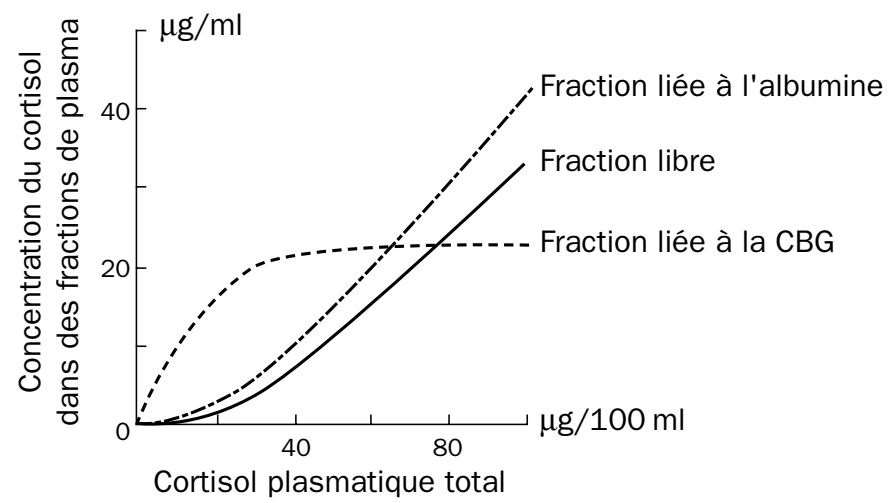

Figure 6.5 - Distribution du cortisol plasmatique entre les fractions libres,
liée à la transcortine (CBG) et liée à l'albumine selon ses concentrations
dans le plasma chez l'homme (d'après Ballard, 1979)

Après dissociation d'avec leur protéine de transport plasmatique, les stéroïdes traversent la membrane des cellules. Les cellules cibles sont caractérisées par l'existence de protéines réceptrices nucléaires définies par leur forte affinité $\left(K_{\mathrm{D}}=1 \mathrm{nM}\right)$ et leur étroite spécificité. Ces récepteurs ont été isolés, purifiés et clonés dans divers tissus cibles. Après fixation de l'hormone sur le récepteur, celui-ci se fixe à la chromatine. Le mécanisme qui conduit le complexe protéine-hormone à stimuler la biosynthèse d'une protéine, produisant l'effet caractéristique de l'hormone, n'est

2 Sa concentration dans le sang est d'environ $30 \mathrm{mg} / \mathrm{l}$. Elle augmente au cours de la grossesse ou lors de la prise d'œstrogènes (pilule). 
pas encore complètement élucidé. La fixation de l'hormone provoque la synthèse d'enzymes spécifiques en induisant, au niveau des chromosomes, l'élaboration de ARN messager. Dans le cas de l'aldostérone, il y a synthèse d'une "sodium-perméase" (Crabbe, 1987) qui, dans le cas de la vessie, perméabilise au Na la paroi muqueuse des cellules, d'où une augmentation du $\mathrm{Na}$ intracellulaire et une stimulation secondaire de la "pompe à sodium" de la paroi séreuse.

\subsubsection{Catabolisme}

La majeure partie du cortisol plasmatique (90\%) est liée à la CBG. C'est une liaison réversible qui règle l'action physiologique de l'hormone. C'est la forme libre (susceptible de pénétrer dans la cellule) qui est la forme active (fig. 6.6).

La dégradation des hormones est très rapide. La demi-vie du cortisol injecté en I.V. est de 95 à 130 min chez l'homme. La moitié de l'aldostérone administrée disparaît du plasma en 20 à 50 min chez l'homme, en 28 min chez le chien. De 1 à $5 \%$ des hormones surrénaliennes passent directement dans les urines (forme libre) ${ }^{3}$. Le reste est catabolisé par le foie où les hormones stéroïdes donnent des dérivés glucurono- et sulfo-conjugués solubles. Un trouble hépatique de la conjugaison ou de la dégradation pourrait entraîner un syndrome périphérique d'hyperfonctionnement.

Les catabolites sont excrétés par les urines.

- Le cortisol libre (taux normal $=20-100 \mu \mathrm{g} /$ jour) est un bon reflet du cortisol libre plasmatique.

- Les 17-hydroxystéroïdes (en C21) représentent la forme principale d'excrétion des glucocorticoïdes (en fait, du cortisol). L'hydrogénation dans le foie donne essentiellement des tétrahydrostéroïdes (cortol, cortolone), ou même des hexahydrostéroïdes qui sont éliminés sous forme glucurono-conjuguée. Taux normal : 20-100 $\mu \mathrm{g} /$ jour.

- les 17-cétostéroïdes (en C19) : l'androstérone et l'étiocholanolone sulfo- et glucurono-conjugués sont les principales formes d'élimination des hormones androgènes. Mais aussi d'une partie (1 à 5\%) des métabolites du cortisol (coupure de la chaîne 20-22). Ils constituent un critère grossier de l'activité corticosurrénalienne. Chez la femme, ils correspondent aux seuls androgènes surrénaliens : 5 à $15 \mathrm{mg}$ et chez l'homme, aux androgènes surrénaliens et testiculaires : 10 à $25 \mathrm{mg}$, soit $2 / 3$ pour la surrénale et $1 / 3$ pour le testicule. Le sulfate de DHA (DHA-S), qui est exclusivement d'origine surrénalienne, représente $15 \%$ des 17 -cétostéroïdes totaux. Taux normal : $1-3 \mu \mathrm{g} / \mathrm{ml}(0,5 \mathrm{à} 2 \mu \mathrm{g}$ chez la femme, 1 à $3 \mu \mathrm{g}$ chez l'homme). Il est éliminé en partie sous forme libre (sulfate de DHA), en partie après transformation en androstène-dione ${ }^{4}$ (fig. 6.7).

3 L'aldostérone urinaire est présente à la concentration de $18,9 \pm 8 \mathrm{nmol} / 1 / 24 \mathrm{~h}$, soit $6,8 \pm 2,9 \mu \mathrm{g} / 1 / 24 \mathrm{~h}$.

4 Une voie particulière du catabolisme du DHEA-S conduit à l'œstriol (E3). Elle expliquerait les quantités importantes d'E3 éliminées par la femme enceinte en fin de grossesse. 

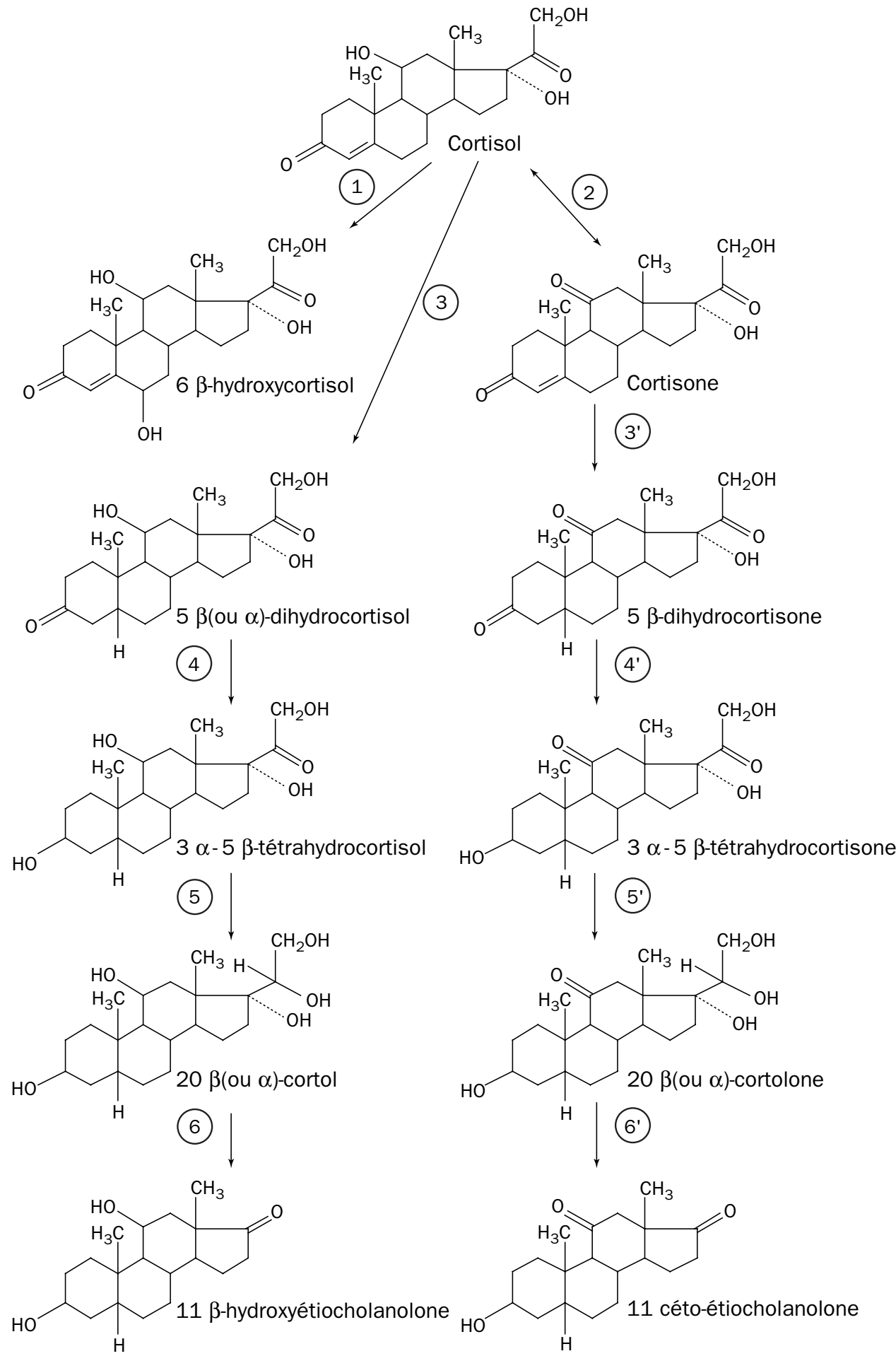

Figure 6.6 - Catabolisme du cortisol (d'après Louisot, 1983) 


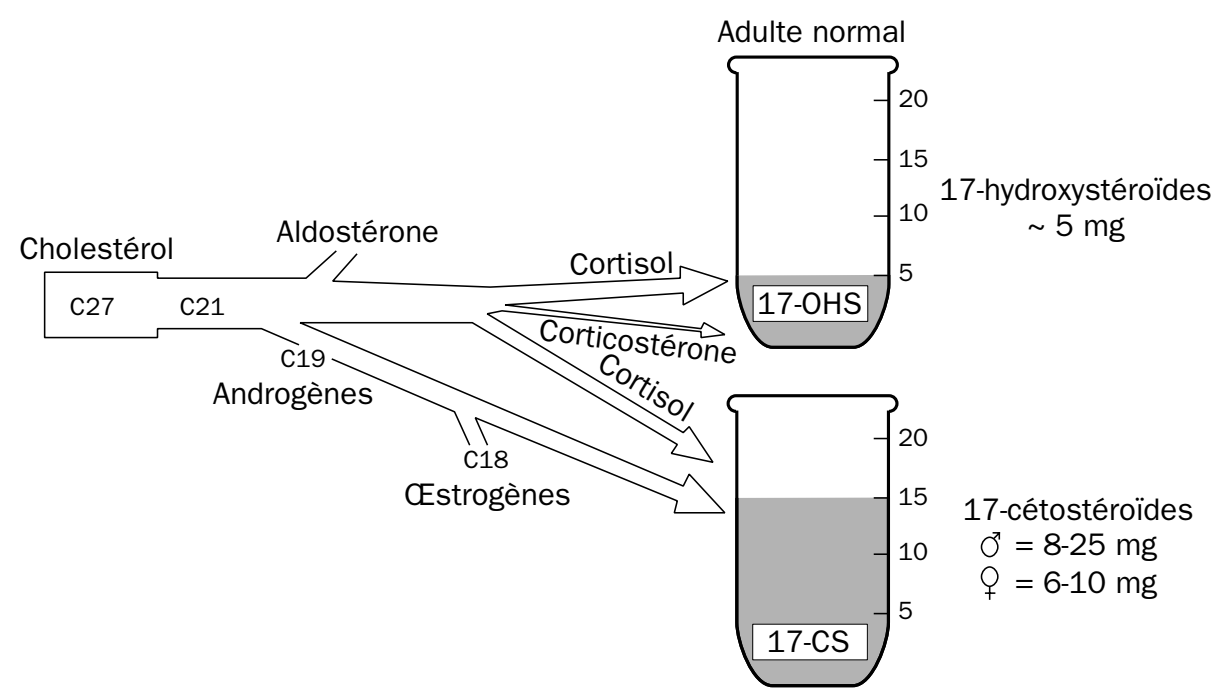

Figure 6.7 - Catabolisme des hormones du cortex surrénal

\subsection{RÔLE PHYSIOLOGIQUE DES HORMONES CORTICOSURRÉNALIENNES}

\subsubsection{L'aldostérone}

Cette hormone minéralocorticoïde contrôle les échanges entre le $\mathrm{Na}^{+}$du tube rénal distal et le $\mathrm{K}^{+}$qui a été filtré, puis réabsorbé dans le tube contourné proximal. Elle contrôle aussi les échanges $\mathrm{Na}^{+} / \mathrm{H}^{+}$. Elle provoque : rétention sodique et mobilisation du potassium, d'où hypernatrémie et hypokaliémie.

Elle entraîne une alcalose extracellulaire par transfert d'ions $\mathrm{H}^{+}$du milieu intérieur vers la cellule. L'excrétion rénale des ions $\mathrm{H}^{+}$est accrue, mais les urines restent alcalines par augmentation de l'ammoniogenèse 5 .

L'action de l'hormone (injectée par voie rénale) nécessite un temps de latence d'environ 20 à 60 min.

Elle agit aussi au niveau de la muqueuse intestinale, des glandes sudoripares (modifiant le taux des électrolytes de la sueur) et des glandes salivaires.

5 L'action de l'aldostérone sur la diurèse aqueuse est complexe, et finalement peu importante. La DOC favorise davantage l'œdème (rétention d'eau interstitielle) que l'aldostérone. En effet :

- par action directe sur le néphron, l'aldostérone est légèrement diurétique (diurèse par fuite potassique) ;

- en élevant la natrémie, l'aldostérone stimule indirectement la sécrétion d'ADH ;

- mais en favorisant une hypervolémie secondaire, l'aldostérone inhibe la sécrétion d'ADH. 


\subsubsection{Les glucocorticoüdes}

Leurs récepteurs sont présents dans presque toutes les cellules. Ils agissent sur :

- le métabolisme glucidique :

- les glucocorticoïdes favorisent la néoglucogenèse à partir des acides aminés issus du catabolisme protidique. Leur action serait indirecte, par un effet "permissif" sur la stimulation de la néoglucogenèse par le glucagon.

- Ils diminuent l'utilisation périphérique du glucose.

Ces deux actions s'opposent à l'action de l'insuline. Un diabète vrai est amélioré par la surrénalectomie. La tendance à l'hypoglycémie qui suit une surrénalectomie est accentuée par le jeûne, le froid, l'exercice.

D'autre part, un traitement prolongé par la cortisone peut provoquer chez le chien un diabète expérimental. Les glucocorticoïdes favorisent enfin le dépôt de glycogène dans le foie.

Les hormones glucocorticoïdes permettent à l'organisme soumis à une agression (stress) de maintenir le niveau de sa glycémie. Ce mécanisme est lent, comparé à l'effet de l'adrénaline, hormone "d'alarme" dont l'action est immédiate.

- le métabolisme protéique :

Les glucocorticoïdes ont un rôle catabolique, ils stimulent la protéolyse et la libération des acides aminés. Ils inhibent aussi le transfert membranaire des acides aminés.

- les dérivés mésodermiques (tissu conjonctif, cellules sanguines) :

- les glucocorticoïdes provoquent éosinopénie (normalement 100 à 300 éosinophiles $/ \mathrm{mm}^{3}$ de sang) et lymphopénie. Ils sont donc immunodépresseurs d'où leur emploi pour favoriser le maintien d'une greffe. Mais ils favorisent l'infection.

- ils ont une action inhibitrice sur l'activité du tissu collagène, ce sont des collagéno-dépresseurs, d'où leur action anti-inflammatoire dans certains rhumatismes.

- de façon plus générale, les glucocorticoïdes exercent une action inhibitrice sur la quasi-totalité des médiateurs de l'inflammation : inhibition de la libération, de la synthèse ou de l'action de l'histamine, ainsi que des dérivés de la voie de l'acide arachidonique ; réduction de la protection contre les dérivés toxiques de l'oxygène et en particulier l'anion superoxyde. Enfin, ils interfèreraient avec l'expression de récepteurs ou d'antigènes membranaires, ainsi qu'avec la synthèse d'interleukine.

- le pouvoir d'élimination de l'eau ingérée :

L'épreuve de l'eau consiste à faire ingérer 11 d'eau de $8 \mathrm{~h}$ à $8 \mathrm{~h} 30$; normalement, $965 \mathrm{ml}$ sont éliminés à $12 \mathrm{~h}$. Le retard à l'élimination de l'eau constitue l'opsiurie. L'opsiurie est constante dans les déficits en cortisol mais n'est pas spécifique. L'opsiurie est corrigée par le cortisol et non par les minéralocorticoïdes. 


\subsubsection{Les hormones sexocorticoüdes}

L'importance physiologique des hormones androgènes produites par la surrénale est modérée, compte tenu de leur taux de sécrétion. Elles ont un effet virilisant et stimulent l'anabolisme protidique. Leur action se manifeste surtout dans certaines tumeurs surrénaliennes, provoquant un syndrome dont la gravité dépend du sexe et de l'âge d'apparition. Le cortex surrénal sécrète aussi de faibles quantités d'œstrogènes (Vinson et Jones, 1964).

\subsection{RÉGULATION DE LA SÉCRÉTION CORTICOSURRÉNALIENNE}

\subsubsection{Contrôle de la sécrétion des glucocorticoüdes et des sexocorticoüdes}

- L'hypophysectomie entraîne une atrophie du cortex surrénal, à l'exception de la zone glomérulaire, qui échappe donc à la régulation hypophysaire.

- Au contraire, les injections d'ACTH provoquent une hyperplasie des zones fasciculée et réticulée. C'est l'ACTH qui contrôle la sécrétion des glucocorticoïdes et des sexocorticoïdes.

- Rôle de l'ACTH

Il y a 20 à 75 pg/ml (4,4 à 16,5 pmol/l) d'ACTH dans le sang humain, le taux varie selon un rythme circadien (rythme nycthéméral) parallèle à celui du cortisol. La demi-vie de l'ACTH est de 20 à $30 \mathrm{~min}$ chez l'homme, de $1 \mathrm{~min}$ chez le rat.

- après hypophysectomie, le taux des glucocorticoïdes et des androgènes s'effondre à un niveau très bas, mais non-nul (environ $10 \%$ du taux initial). L'injection d'ACTH provoque la reprise de la sécrétion, elle atteint un maximum 5 à 10 min après l'injection. Ce taux retombe au niveau de départ en 20 à 35 min. Le taux des glucocorticoïdes et des androgènes est sous contrôle direct et permanent de l'ACTH. La relation entre l'ACTH injecté et les stéroïdes sécrétés est proportionnelle, jusqu'à ce que la sécrétion corticale atteigne un plafond.

- l'ACTH a un autre rôle, un rôle trophique, sur la glande surrénale dont il stimule les mitoses.

\section{- Mode d'action de l'ACTH}

L'ACTH, comme toutes les hormones polypeptidiques, interagit avec une protéine réceptrice membranaire ${ }^{6}$, qui entraîne une stimulation de l'adénylate cyclase. L'élévation de l'AMPc active la protéine kinase A, ce qui provoque la phosphorylation d'un grand nombre de protéines dont la phosphorylase qui

6 Il n'y a qu'une seule classe de récepteurs à haute affinité $\left(K_{D}=1,6 \mathrm{nmol} / \mathrm{l}\right)$. Environ 3600 sites sont présents sur chaque cellule corticosurrénale. 
permet la formation de NADPH nécessaire à la stérö̈dogenèse. C'est au niveau de l'étape "desmolase" (coupure de la chaîne latérale du cholestérol) que s'effectue la régulation spécifique de l'ACTH. Cette étape est bloquée par un inhibiteur de synthèse, l'Elipten ${ }^{\circledR}$.

\section{- Feed-back hypothalamo-hypophyso-corticosurrénalien}

Le niveau du cortisol circulant exerce un effet inhibiteur sur la sécrétion d'ACTH. Ce rétro-contrôle n'existe pas pour les hormones androgènes, dont un taux élevé n'inhibera pas la sécrétion d'ACTH. Après surrénalectomie bilatérale, on observe dans les 2 jours qui suivent une élévation de l'ACTH et du CRF.

\subsubsection{Exploration de la fonction glucocorticoüde}

Elle est réalisée par les dosages hormonaux statiques et des épreuves dynamiques.

- Les dosages hormonaux statiques comportent le dosage de la cortisolémie et les dosages urinaires (cortisol libre et 17-OH corticostéroïdes). Pour la cortisolémie, il est capital de noter l'heure du prélèvement.

- Les épreuves dynamiques comportent :

- la stimulation de la surrénale par le Synacthène ${ }^{\circledR}$ (tétracosactide) : injection intramusculaire de $0,25 \mathrm{mg}$ de Synacthène ${ }^{\circledR}$ et dosage de la cortisolémie avant et $1 \mathrm{~h}$ après l'injection. Le cortisol doit dépasser $210 \mathrm{ng} / \mathrm{ml}$. Le test est négatif dans une insuffisance surrénale primaire.

- la stimulation de l'ACTH endogène par la métopirone $(1 \mathrm{~g}$ per os toutes les $6 \mathrm{~h}$ pendant $24 \mathrm{~h}$ ). L'ACTH s'élève normalement à 100-200 pg/ml. Le test est négatif dans toute insuffisance de l'axe hypophyso-surrénalien, il entraîne une réponse très intense dans la maladie de Cushing.

- le test de freinage par la dexaméthasone (DXM) à raison de $1 \mathrm{mg}$ per os (deux comprimés à $0,5 \mathrm{mg}$ ). Ce glucocorticoïde de synthèse freine la sécrétion d'ACTH et entraine une chute d'au moins 50\% de la cortisolémie. On l'utilise lorsque l'on soupçonne un syndrome de Cushing : absence de freinage.

\subsubsection{Contrôle de la sécrétion d'aldostérone}

La régulation de la sécrétion d'aldostérone par la zone glomérulaire du cortex surrénalien est contrôlée classiquement par voie systémique générale, par l'intermédiaire de l'angiotensine II. Mais des travaux récents (Gallo-Payet, 1993) permettent de penser que le contrôle se ferait davantage par voie autocrine et paracrine (fig. 6.8).

Ce diagramme résume l'ensemble des facteurs susceptibles de moduler les sécrétions d'aldostérone et de cortisol. Ceux-ci peuvent exercer leurs effets à travers les rayons médullaires, l'innervation médullo-corticale, ou encore de façon autocrine ou paracrine. 


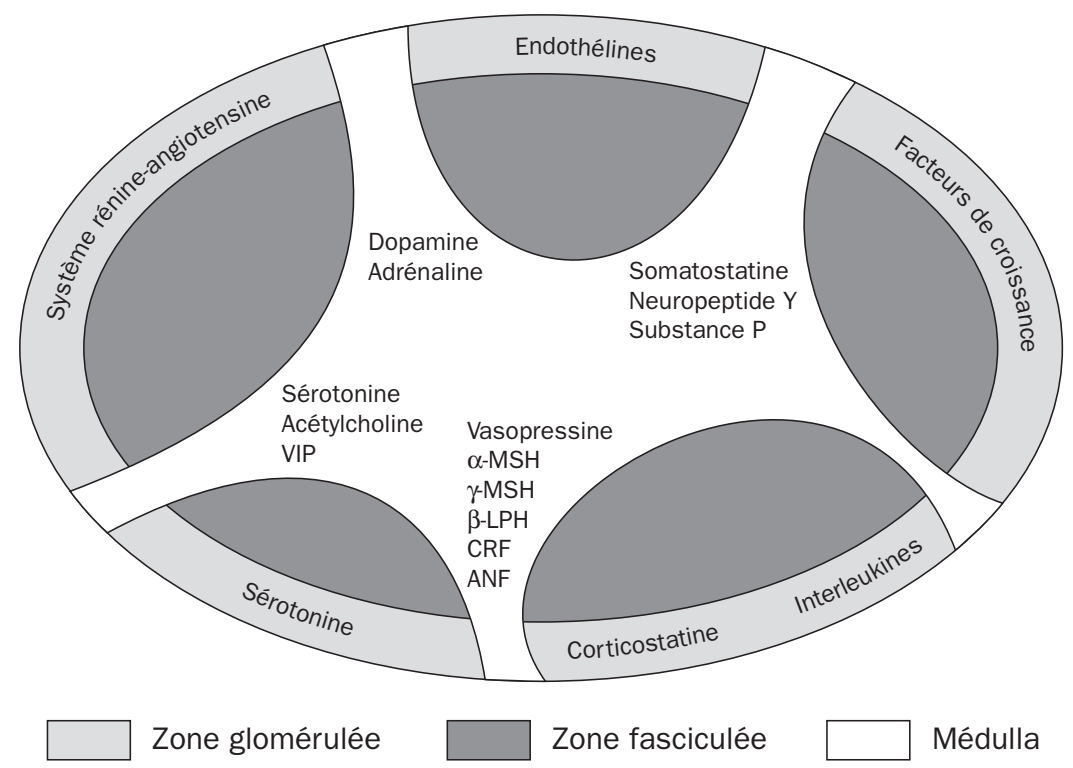

Figure 6.8 - Régulation intrinsèque de la sécrétion d'aldostérone (d'après Gallo-Payet, 1993)

\section{Régulation systémique}

\section{- Le système rénine-angiotensine ou SRA}

Il paraît être le facteur prédominant. Les cellules juxtaglomérulaires (fig. 6.9), présentes dans l'artériole afférente du glomérule rénal et dans la portion qui lui est contiguë du tubule distal (macula densa), sécrètent la rénine ${ }^{7}$.

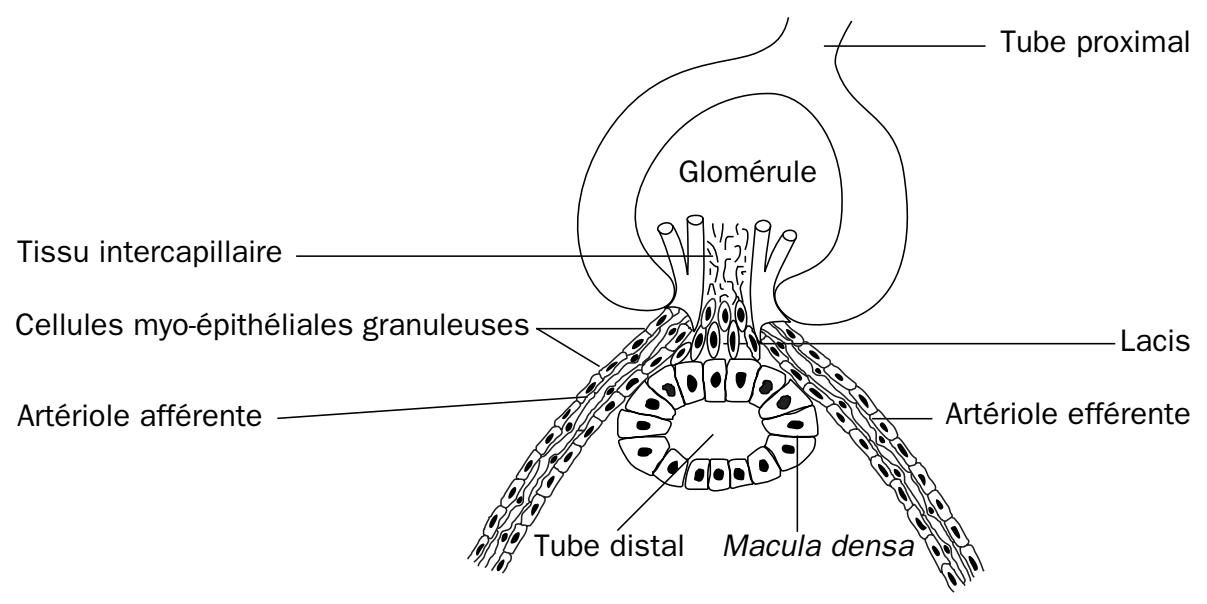

Figure 6.9 - Schéma de l'appareil juxtaglomérulaire

7 L'activité rénine plasmatique (ARP) est une mesure d'une grande importance pour apprécier le caractère primaire (ARP basse) ou secondaire (ARP élevée) d'un hyperaldostéronisme. 
Celle-ci est une enzyme de PM 40000, qui transforme in situ une globuline $\alpha$-plasmatique de 57000 daltons, l'angiotensinogène, synthétisée par le foie, en un décapeptide, l'angiotensine I. Une enzyme de conversion, présente dans le rein, le poumon et le plasma, détache alors deux aminoacides de l'angiotensine I et produit l'angiotensine $\mathrm{II}^{8}$, physiologiquement active, mais à vie brève (t $1 / 2=90 \mathrm{~s}$ ), qui est un puissant vaso-constricteur, et un stimulant de la sécrétion des cellules glomérulaires du cortex surrénal. Cette dernière action est modulée par la somatostatine (fig. 6.10 et 6.11).

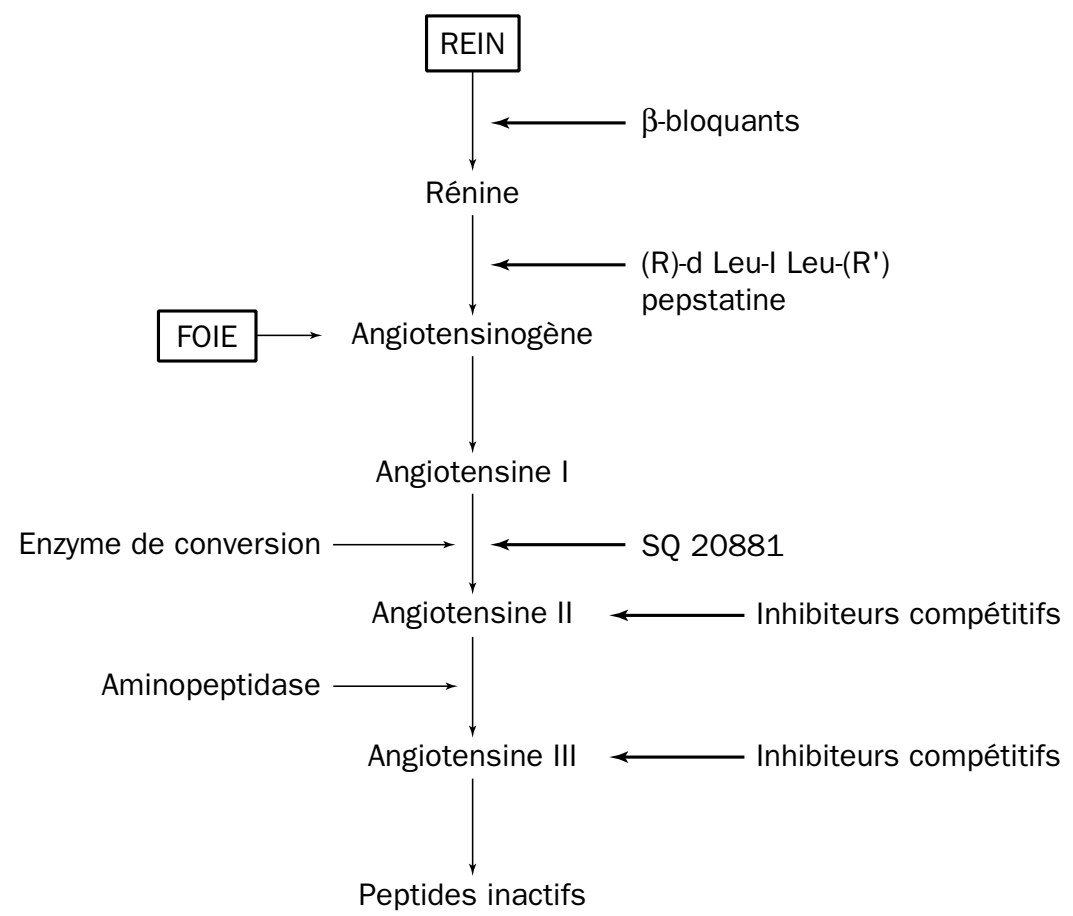

Figure 6.10 - Les inhibiteurs du système rénine-angiotensine

L'angiotensine II entraîne donc une sécrétion d'aldostérone (mais stimule aussi les enzymes de la stéroïdogenèse). Outre cet effet, l'angiotensine II provoque la constriction des vaisseaux sanguins qui irriguent la peau et les reins, l'augmentation de la pression artérielle, la dilatation des vaisseaux sanguins des muscles et du cerveau. Elle stimule également la sécrétion d'ADH. En injection sous-cutanée (quelques ng) ou intraventriculaire (quelques pg), elle induit un comportement dipsique : l'animal a soif et se met à boire de l'eau. Cette substance joue finalement un rôle important dans l'homéostasie du volume hydrique, en corrélation

8 Sous l'effet d'une aminopeptidase A, présente dans le plasma, le rein, les surrénales, l'angiotensine I et l'angiotensine II peuvent être clivées en angiotensine III. L'octopeptide dérivé de l'angiotensine II est un vaso-constricteur beaucoup moins puissant que l'angiotensine II, mais il paraît aussi efficace sur la sécrétion d'aldostérone. 
avec l'ADH (rôle synergique) et avec l'ANF ou facteur natriurétique atrial - voir le chapitre $9, \S 4$ (actions antagonistes). Son taux plasmatique est d'environ $20 \mathrm{ng} / 1$.

Le SRA (système rénine-angiotensine) apparait donc comme un système circulant avec trois composants : la rénine sécrétée par le rein, l'angiotensinogène par le foie et l'enzyme de conversion par le poumon. Mais on a découvert dans plusieurs organes, le cerveau, la surrénale, l'utérus, la paroi artérielle et même le cœur, des systèmes rénine-angiotensine II à action locale.

Les facteurs qui conditionnent la sécrétion de rénine sont la pression artérielle, la natrémie et le système nerveux adrénergique :

- La diminution de la pression artérielle dans l'artériole afférente glomérulaire augmente la sécrétion de rénine et donc la sécrétion d'aldostérone : les cellules juxtaglomérulaires présentes dans l'artériole afférente et au contact du tubule distal constitueraient des baro-récepteurs.

- La diminution de la natrémie augmente la sécrétion de rénine : ce sont les cellules de la macula densa (voir fig. 6.9), sensibles à la variation du taux du $\mathrm{Na}$ intratubulaire, qui constitueraient des osmo-récepteurs. L'inhibition par un $\beta$-bloquant (propanolol) permet de supposer l'existence de $\beta$-récepteurs adrénergiques.

\section{- Le potassium $\left(\mathrm{K}^{+}\right)$}

Bien que l'ion $\mathrm{K}^{+}$ne soit pas un stimulus physiologique, les cellules de la zone glomérulaire sont très sensibles in vitro à ses variations, pour des concentrations allant de 3 à $10 \mathrm{mM}$. La sécrétion d'aldostérone varie dans le même sens que la kaliémie. Le potassium agirait directement sur la phase initiale de la biosynthèse de l'aldostérone, ainsi que sur la $11 \beta$-hydroxylase. Si l'apport alimentaire varie de 60 à $0 \mathrm{mEq} \mathrm{Na/jour,} \mathrm{on} \mathrm{observe} \mathrm{une} \mathrm{élévation} \mathrm{importante} \mathrm{de} \mathrm{l'aldostéronurie.}$ Pour un apport alimentaire $>60 \mathrm{mEq} \mathrm{Na} /$ jour, l'aldostéronurie est basse et stable (5 à $8 \mu \mathrm{g} /$ jour). Le taux de $\mathrm{Na}^{+}$sanguin n'agirait que par voie indirecte.

Le $\mathrm{K}^{+}$augmenté (ou le $\mathrm{Na}^{+}$diminué) provoque une augmentation de la sécrétion d'aldostérone. Le $\mathrm{K}^{+}$diminué (ou le $\mathrm{Na}^{+}$augmenté) provoque une diminution de la sécrétion d'aldostérone. Comme l'aldostérone entrâne une rétention sodique et une fuite potassique, on voit que les taux du $\mathrm{Na}^{+}$et du $\mathrm{K}^{+}$sanguins ont un effet de rétro-contrôle sur la sécrétion d'aldostérone.

Le mécanisme est mal connu :

- l'élévation du $\mathrm{K}^{+}$, en dépolarisant la membrane, permet aux canaux ioniques dépendants du voltage de s'ouvrir, entraînant une augmentation de la concentration intracellulaire du calcium,

- mais le $\mathrm{Na}^{+}$agit surtout par action indirecte, les changements de concentration du sodium entraînent, dans les espaces extracellulaires, des variations du facteur volémique. 


\section{- La volémie}

La baisse de la volémie par hémorragie, hémoconcentration... entraîne une augmentation de la sécrétion d'aldostérone. Ce mécanisme est relativement indépendant de la concentration en $\mathrm{K}$ et si, éventuellement, ces deux facteurs varient en sens inverse, la régulation des électrolytes sera sacrifiée à celle des volumes. Par exemple, une surcharge hydrique (+ $\mathrm{ADH}$, pour stabiliser cette surcharge) provoque, malgré la baisse de la natrémie, une diminution de la sécrétion d'aldostérone. Les récepteurs de la volémie sont localisés dans l'oreillette droite, la veine cave inférieure et la jonction thyrocarotidienne. L'influx est transmis au système nerveux central par les $\mathrm{X}$ (pneumogastriques).

\section{- L’ACTH}

Chez le rat, l'ACTH est in vitro le plus puissant sécrétagogue connu. Mais, chez l'homme, l'hypophysectomie réduit seulement de 10 à $20 \%$ la sécrétion d'aldostérone.

\section{- Le facteur natriurétique atrial (atrial natriuretic factor ou ANF)}

Il diminue la sécrétion d'aldostérone induite par l'ACTH ou l'angiotensine II. Cet effet serait assuré à la fois par une phosphodiestérase sensible au GMPc et par une action directe sur les canaux calciques.

Régulation paracrine (Gallo-Payet, 1993)

Les catécholamines de la médullo-surrénale stimulent la sécrétion d'aldostérone en empruntant la voie de l'AMPc. Dans les situations de stress, certains peptides ou neurotransmetteurs agissent sur la sécrétion d'aldostérone (aussi bien que sur celle du cortisol), soit en la stimulant (acétylcholine, VIP, enképhalines...) via une augmentation d'AMPc, soit en l'inhibant (neuropeptide $\mathrm{Y}$, somatostatine) via une protéine de type Gi (fig. 6.11).

Parmi les principaux facteurs susceptibles d'agir sur la sécrétion d'aldostérone : le facteur de croissance plaquettaire (PDGF), la sérotonine, les endothélines de types II et III, le facteur de nécrose tumorale (TNF).

Cette régulation est favorisée par la présence de rayons médullaires qui mettent en contact étroit cellules chromaffines et cellules corticales de la superficie à la profondeur du cortex, permettant ainsi une modulation des niveaux de sécrétion des stéroïdes des zones corticales.

\section{Régulation autocrine}

La zone glomérulaire contient tous les composants du système rénine-angiotensine. La production locale d'angiotensine II serait même suffisante pour contrôler la sécrétion d'aldostérone.

Les facteurs de croissance FGF et TGF $\beta$, identifiés dans les cellules corticales et dans la médulla, peuvent agir à la fois de façon paracrine et autocrine. 


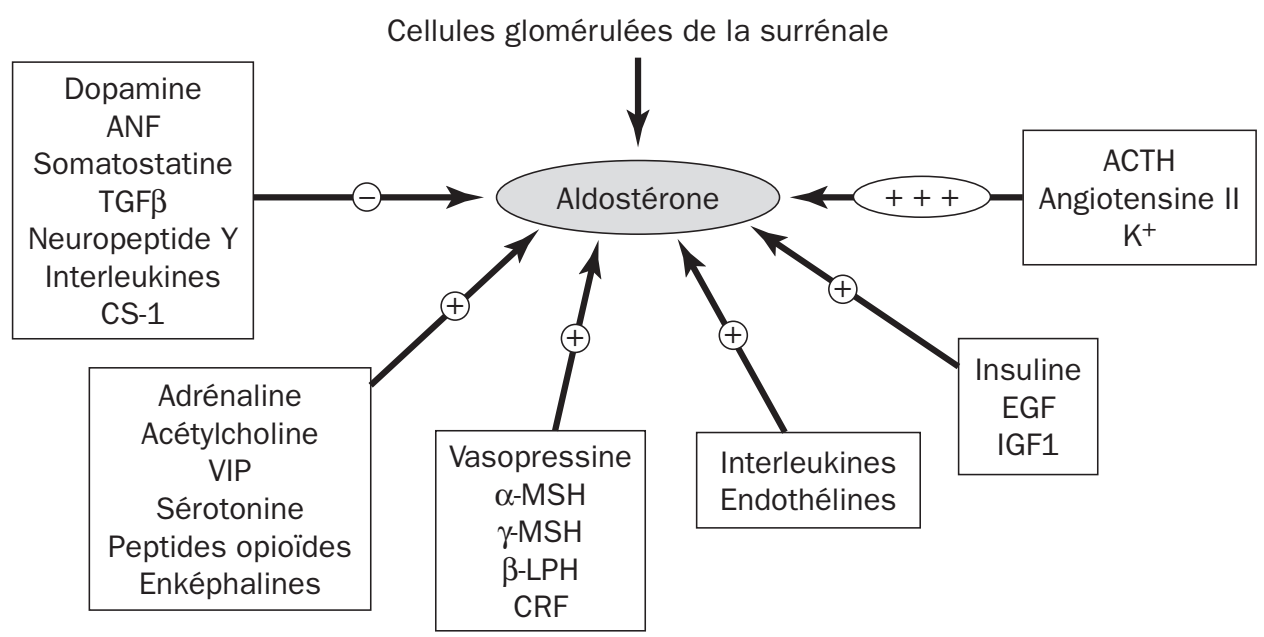

Figure 6.11 - Les principaux facteurs agissant sur la sécrétion d'aldostérone (d'après Gallo-Payet, 1993)

ACTH : hormone corticotrope ; ANF : facteur natriurétique atrial ; CRF : facteur de libération de l'hormone corticotrope ; CS : corticostatine ; EGF : facteur de croissance épidermique ; IGF : facteur de croissance insulinique ; $K^{+}$: ion potassium ; $L P H$ : hormone lipotrophique ; MSH : hormone mélanotrope ; TGF : facteur de croissance transformant ; VIP : peptide intestinal vaso-actif.

\subsection{CORRÉLATIONS DE L'ACTIVITÉ CORTICOSURRÉNALIENNE}

\subsubsection{Cortex surrénal et thyroüde}

L'administration de thyroxine chez le rat provoque une hyperactivité corticosurrénalienne (augmentation des hydroxylations) et un effet stimulateur direct sur la capacité de liaison transcortine-corticostérone.

\subsubsection{Cortex surrénal et hormones sexuelles}

La testostérone diminue directement la capacité de liaison transcortine-corticostérone. L'œstradiol et la progestérone ont un effet stimulateur, mais médié par l'axe hypophyso-thyroïdien (Labrie et coll., 1966).

\subsubsection{ADH et aldostérone}

L'impact de l'aldostérone sur le néphron (en un segment qui précède celui où a lieu l'action de l'ADH) favorise l'élévation de natrémie et, par conséquent, stimule la libération et l'action de l'ADH : l'aldostérone "fait le lit" de l'ADH.

Du point de vue de la régulation de l'équilibre hydrique, ces deux hormones sont stimulées ou inhibées conjointement lors d'une variation de la volémie. Leur sécrétion à toutes deux sera par exemple stimulée lors d'une hémorragie.

En revanche, leur réponse diffère lors d'une variation de la natrémie. La déshydratation, qui entraîne une élévation de la natrémie, stimule la sécrétion d'ADH et inhibe 
celle de l'aldostérone (mais l'hypovolémie qui lui est associée dans cette situation stimulera la sécrétion d'aldostérone et d'ADH, donc deux effets antagonistes pour l'aldostérone qui variera peu, et au contraire deux effets synergiques pour l'ADH qui sera l'hormone essentielle de régulation lors de cette variation physiologique).

L'ADH exerce également une action directe sur la sécrétion d'aldostérone. Cette action se manifeste après liaison avec des récepteurs de type V1a, suivant un mécanisme mettant en jeu l'IP3. L'action exercée peut être même endogène, car on a démontré la présence d'ADH dans des cellules chromaffines situées dans le cortex (Perraudin et coll., 1993).

\section{LA MÉDULLO-SURRÉNALE}

\subsection{CARACTÈRES GÉNÉRAUX}

La médullo-surrénale du Mammifère, les cellules phéochromes de l'Oiseau, les organes chromaffines des Vertébrés inférieurs correspondent à une même origine et une même différenciation neurosécrétrice de cellules qui sont l'équivalent des cellules post-ganglionnaires du système orthosympathique.

La glande médullo-surrénale contient deux types de cellules qui sécrètent l'un l'adrénaline, l'autre la noradrénaline. La proportion de ces deux hormones sécrétées varie selon l'espèce ( $20 \%$ de noradrénaline chez l'homme), et au sein de la même espèce en fonction de l'âge (la proportion d'adrénaline augmente avec l'âge) et de la nature du stimulus sécrétoire.

\subsection{DONNÉES ANATOMO-CLINIQUES ET EXPÉRIMENTALES}

\subsubsection{L'hyperfonctionnement}

Il est à l'origine d'une hypertension artérielle (HTA) paroxystique.

Il est caractérisé par :

- des crises paroxystiques d'HTA avec, au début, aucun trouble tensionnel entre les crises,

- et l'évolution lente vers l'insuffisance rénale et cardiaque.

Ce syndrome est provoqué par une tumeur de la médullo-surrénale (phéochromocytome). L'ablation de cette tumeur amène la guérison.

\subsubsection{La médullo-surrénalectomie}

Même complétée d'une sympathectomie, elle entraîne peu de troubles :

- la croissance et la gestation sont normales ; 
- il n'y a pas de retentissement circulatoire : ni bradycardie, ni hypotension. Mais les possibilités d'adaptation à une variation brutale, exogène (froid, hémorragie) ou endogène (diminution de la glycémie, diminution de la pression artérielle) sont limitées.

\subsubsection{Les injections d'hormones ou d'analogues hormonaux}

Elle ont précisé l'action des deux hormones de la médullo-surrénale.

- La substance était testée sur des organes isolés et perfusés.

On observe surtout :

- le relâchement de l'intestin de lapin ou du cœcum rectal isolé du coq (sensible de 100 à $200 \mathrm{ng}$ ) ;

- l'accélération du rythme du cœur isolé de grenouille ou de crapaud ;

- la dilatation de la pupille (mydriase) de l'œil énucléé de grenouille ou de crapaud ;

- la contraction de la membrane nyctitante du chat;

- la vaso-constriction de l'oreille énervée du lapin, qui est sensible à 10 pg $\left(10^{-11} \mathrm{~g}\right)$.

- Du sang prélevé par cathétérisme d'une veine surrénale ou un analogue hormonal peuvent aussi être injectés à un animal "réactif". Les deux pneumogastriques sont coupés afin de supprimer une éventuelle réponse vagale. On obtient (fig. 6.12) :

- de l'hypertension par vaso-constriction ;

- une accélération cardiaque ;

- la dilatation des bronches et un ralentissement du rythme respiratoire ;

- une inhibition intestinale ;

- de la dilatation pupillaire (mydriase)

- et aussi, une hyperglycémie par glycogénolyse hépatique.

Le sang efférent de la veine médullo-surrénale est hypertenseur et possède les mêmes propriétés qu'une solution de 0,1 à $1 \mu \mathrm{g}$ d'adrénaline $/ \mathrm{kg} / \mathrm{min}$ en injection intraveineuse continue.

\subsection{BIOSYNTHÈSE ET DÉGRADATION DES CATÉCHOLAMINES}

\subsubsection{La biosynthèse}

Elle s'effectue à partir de l'un des acides aminés essentiels, la phénylalanine (voir fig. 6.13.a). La phénylalanine est hydroxylée en tyronine (précurseur des hormones thyroïdiennes), qui est oxydée dans le foie (réaction non-réversible) sous l'effet d'une tyrosine-hydroxylase en dihydroxyphénylalanine ou DOPA. La DOPA est décarboxylée en noradrénaline (NA) qui sera le terme ultime de la biosynthèse dans certaines cellules de la médullo-surrénale. Dans d'autres cellules, une enzyme supplémentaire, la N-méthyl-transférase, transforme la noradrénaline en adrénaline (A). 


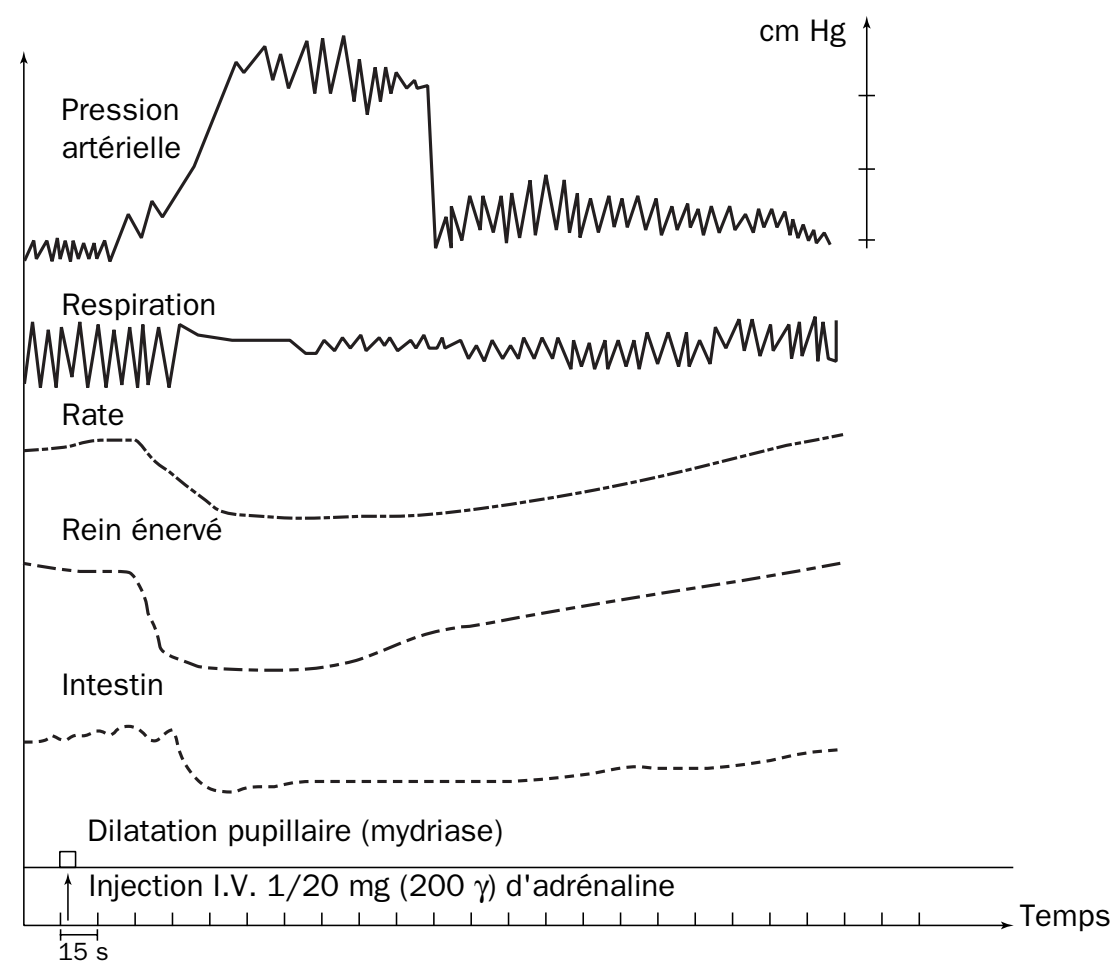

Figure 6.12 - Effets de l'adrénaline chez le chien

Adrénaline et noradrénaline sont des catécholamines ${ }^{9}$. Les catécholamines fonctionnent comme inhibiteurs allostériques de leur synthèse à l'étape tyrosine-hydroxylase. Au total, environ 6 à $10 \mathrm{mg}$ de catécholamines sont sécrétées, dans les conditions basales, par l'organisme humain chaque jour.

La valeur normale dans le plasma (sujette à de fortes fluctuations) est :

- pour l'A : d'environ $0,5 \mu \mathrm{g} / 1$;

- pour la NA : d'environ 3 à $5 \mu \mathrm{g} / 1$. Le dosage n'en est que très rarement pratiqué.

Le taux d'élimination urinaire serait chez l'homme :

- de $11,5 \mathrm{mg} / 24 \mathrm{~h}$ pour l'adrénaline ;

- de $29 \mathrm{mg} / 24 \mathrm{~h}$ pour la noradrénaline. Dosage en fait variable selon les méthodes.

Après surrénalectomie totale bilatérale, le taux de la noradrénaline urinaire est peu modifié. Celui de l'adrénaline est très abaissé : l'origine essentielle de l'adrénaline est bien la médullo-surrénale. La noradrénaline médullo-surrénalienne ne représente qu'environ $10 \%$ de la sécrétion de cette hormone dans l'organisme ${ }^{10}$.

9 On regroupe sous le terme de catécholamines des substances dérivées du noyau catéchol (1,2-déhydroxybenzène).

10 Les nerfs adrénergiques (neurones post-ganglionnaires du système orthosympathique) libèrent essentiellement de la noradrénaline. 


\subsubsection{La dégradation}

Elle est très rapide. La demi-vie de l'adrénaline exogène administrée par voie I.V. est de 10 à $20 \mathrm{~s}$.

Ce qu'on retrouve dans les urines, sous forme libre ou sulfo- ou glucuronoconjuguée ne correspond qu'à :

- $2,3 \%$ de l'adrénaline, et

- $3,8 \%$ de la noradrénaline.

Le reste est catabolisé en au moins deux étapes (fig. 6.13.b) :

- essentiellement une 3-oxométhylation sous l'effet d'une catéchol-O-méthyltransférase ${ }^{11}$ (COMT) qui transforme :

- l'A en métanéphrine (3-oxy-méthyl-adrénaline) ou métadrénaline ;

- la NA en normétanéphrine ou normétadrénaline ; leur taux urinaire est de 10$50 \mu \mathrm{g} /$ jour, variable selon les méthodes.

- et une désamination oxydative, sous l'effet d'une mono-amine-oxydase $\left(\mathrm{MAO}^{12}\right)$. C'est une étape lente. Les deux étapes aboutissent à l'excrétion, par les urines, d'acide 3-méthoxy-4-hydroxymandélique ou acide vanilmandélique (VMA). Son dosage (2-6 mg/jour) est un critère peu fiable.

La méthylation survient avant ou après la désamination oxydative. Les inhibiteurs de la mono-amine-oxydase (IMAO) ne pourront donc pas empêcher la dégradation des catécholamines, qui seront de toute façon inactivées par O-méthylation. En revanche, ils empêchent le catabolisme de la sérotonine cérébrale.

Les catécholamines circulant dans le sang (A, NA) ou libérées au niveau des synapses du système nerveux central (NA) sont susceptibles d'être recaptées par les cellules, pour y être soit stockées (captation de type I), soit dégradées (captation de type II).

La captation de type I concerne les neurones adrénergiques du SNC et du système nerveux végétatif. Elle a pour rôle d'interrompre la stimulation adrénergique, faute d'une activité enzymatique extracellulaire analogue à l'acétylcholinestérase pour l'acétylcholine. Ses inhibiteurs (cocaïne...) potentialisent les stimulations nerveuses.

La captation de type II concerne le transport des catécholamines dans les tissus périphériques extraneuronaux (muscles lisses, cœur...). Elle conduit à une dégradation intracellulaire rapide et est inhibée par la métadrénaline, normétadrénaline, certains stéroïdes ... Elle permet l'interruption de l'action de la NA dans les tissus périphériques.

11 La COMT (PM 24 000), présente dans le cytosol de rein, de foie, transforme principalement les catécholamines circulantes en métadrénaline. La normétadrénaline ne provient que de la NA neuronale libérée par le neurone sans avoir été recaptée.

12 La MAO (PM 290 000) contrôle le stockage de la NA dans les terminaisons nerveuses. Elle est inhibée par un dérivé de l'hydrazine, l'isoproniazide. 
<smiles>NC(COCCOCCO)C(=O)O</smiles><smiles>Cc1ccc(O)c(O)c1</smiles><smiles>NCCc1ccc(O)c(O)c1</smiles>
Dopamine - $\beta$-hydroxylase (DBH)<smiles>NCC(O)c1ccc(O)c(O)c1</smiles><smiles>CNCC(O)c1ccc(O)c(O)c1</smiles>
NORADRÉNALINE<smiles>NCC(O)c1ccc(O)c(O)c1</smiles><smiles>C=C(C)C(O)CN</smiles>

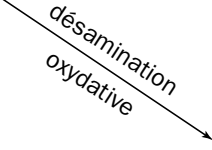

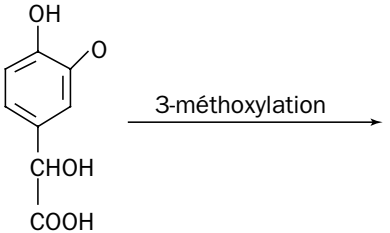

ACIDE 3,4-HYDROXYMANDÉLIQUE<smiles>CNCCC(O)c1ccc(O)c(O)c1</smiles>

ADRÉNALINE

NORADRÉNALINE

ADRÉNALINE
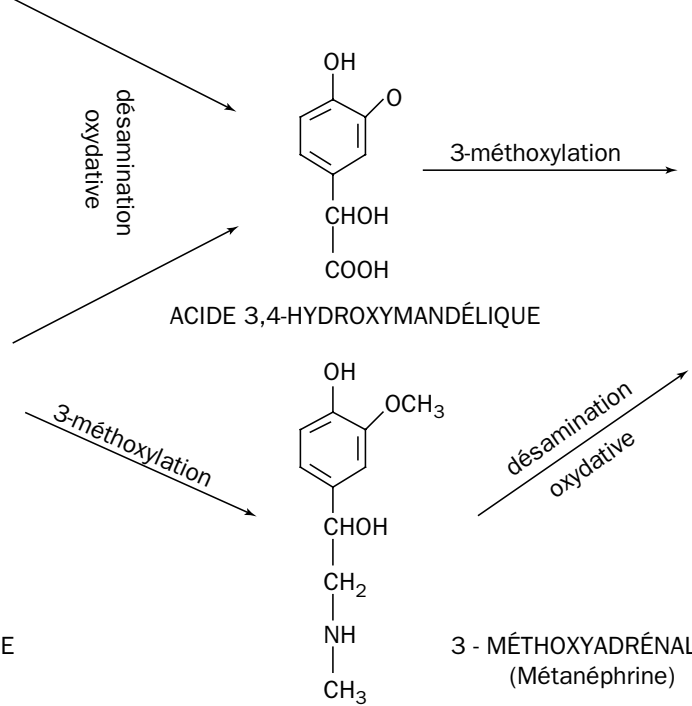

3 - MÉTHOXYADRÉNALINE
TYROSINE

DIHYDROXYPHÉNYLALANINE (DOPA)

DOPAMINE

a - Biosynthèse

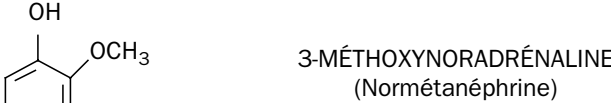

(Normétanéphrine)

b - Dégradation (Métanéphrine)

ACIDE 3-MÉTHOXY 4-HYDROXYMANDÉLIQUE (acide vanilmandélique VMA)<smiles>COc1cc(C(O)C(=O)O)ccc1O</smiles>

Figure 6.13 - Métabolisme des catécholamines 


\subsection{ACTION DES CATÉCHOLAMINES}

\subsubsection{Récepteurs adrénergiques $\alpha$ et $\beta$ (Ahlquist, 1948)}

Leur action repose sur l'efficacité relative de différents sympathomimétiques et inhibiteurs. La plupart des réponses physiologiques peuvent être divisées en deux catégories :

- Effets de type $\alpha$ : L'adrénaline est le composé le plus efficace et l'isoprénaline (substance de synthèse) le moins efficace. Agonistes : la noradrénaline et la phényléphrine. Antagoniste ( $\alpha$-bloquant) : la phentolamine. Ces effets sont :

- la constriction des vaisseaux sanguins et l'élévation de la PA;

- la contraction de l'utérus et de la vessie ;

- l'augmentation de la libération de l'acétylcholine des muscles squelettiques.

On distingue deux sous-types principaux de récepteurs $\alpha$ :

- $\alpha 1$, uniquement post-synaptique, pour les fibres musculaires lisses ;

- $\alpha 2$, à la fois post- et pré-synaptique (inhibiteur), pour le système nerveux central.

L'activation des récepteurs $\alpha 1$ induit la synthèse de DAG et d'IP3, tandis que l'activation des récepteurs $\alpha 2$ provoque une action inhibitrice de l'AMPc.

- Effets de type $\beta$ : L'isoprotérénol (agoniste de synthèse) est le plus efficace et la noradrénaline la moins efficace. Agoniste : l'adrénaline. Antagoniste ( $\beta$-bloquant) : le propanolol. Les effets de l'activation des récepteurs $\beta$ sont :

- au niveau du cœur :

- une augmentation de la force de contraction cardiaque (effet inotrope +);

- une augmentation de la fréquence cardiaque. C'est une tachycardie (effet chronotrope +) d'où augmentation du débit cardiaque ; on note également :

- un effet bathmotrope + (augmentation de l'excitabilité cardiaque);

- un effet dromotrope + (augmentation de la conductibilité cardiaque).

- au niveau des vaisseaux : une vaso-dilatation (VD);

- sur le système respiratoire : une broncho-dilatation (BD) ;

- sur les muscles lisses : une relaxation de l'utérus et de la vessie, la dilatation des sphincters intestinaux ;

- sur les muscles squelettiques : une augmentation de la glycogénolyse ;

- sur le tissu adipeux : une augmentation de la lipolyse.

On distingue trois sous-types de récepteurs $\beta$ :

- $\beta 1$, impliqué dans la stimulation cardiaque et la lipolyse ;

- $\quad \beta 2$, responsable de la broncho-dilatation, de la relaxation des muscles lisses et de la glycogénolyse ;

- $\quad \beta 3$, présent sur les adipocytes, le colon et la vésicule biliaire chez l'homme, et impliqué dans le métabolisme lipidique.

La structure des récepteurs adrénergiques est du type à sept domaines transmembranaires (voir fig. 6.14). La figure 6.15 décrit de façon détaillée la liaison de la noradrénaline à un récepteur $\beta 3$. 


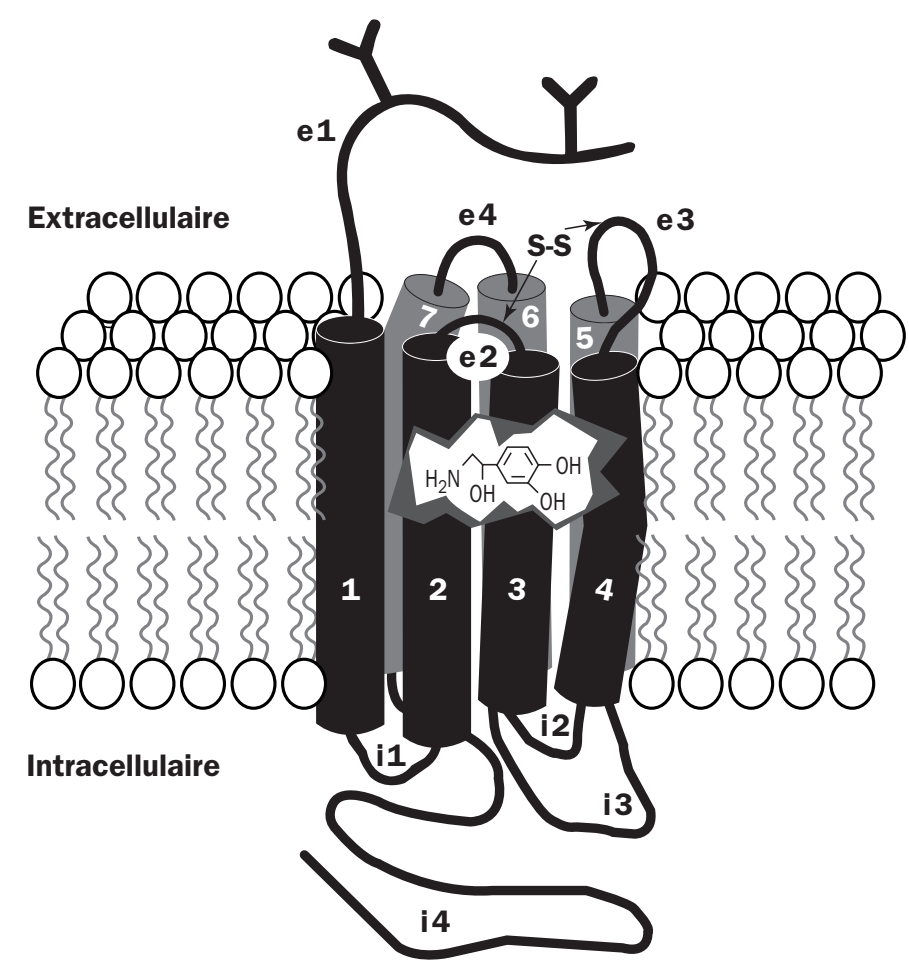

Figure 6.14 - Topologie membranaire des récepteurs $\beta$-adrénergiques

(d'après Emorine et Strosberg, 1993)

La noradrénaline est représentée dans le site de liaison du récepteur. Celui-ci forme une poche membranaire délimitée par les sept domaines hydrophobes en hélice $\alpha$ (cylindres marqués de 1 à 7), traversant la bicouche lipidique. Les régions intra- (i1 à i4) et extracellulaires (e1 à e4) sont indiquées, ainsi que le pont disulfure (-S-S-) essentiel à l'activité des récepteurs et qui relie e2 à e3. Les sucres greffés dans la partie N-terminale (e1) sur les sites de $\mathrm{N}$-glycosylation sont indiqués par le signe $Y$.

Le mécanisme d'action, établi par Sutherland (Sutherland et Rall, 1960), est un mécanisme de transduction mettant en jeu l'AMPc, second messager, responsable de tous les effets $\beta$ des catécholamines par activation de la protéine kinase A (PKA). Il y a activation des phosphorylases musculaire et hépatique, de la lipase du tissu adipeux et inactivation de la glycogène-synthétase.

\subsubsection{Action de l'adrénaline}

Elle se manifeste à la fois par des effets sympathomimétiques et des effets métaboliques qui lui sont spécifiques :

- sur le cœur, ces effets sont dus à une fixation sur des récepteurs $\beta$ d'où tachycardie, augmentation de la puissance des systoles et augmentation du débit cardiaque. La tachycardie s'observe sur le cœur isolé, ou chez l'animal vagotomisé. Il y a bradycardie réflexe chez l'animal normal ; 


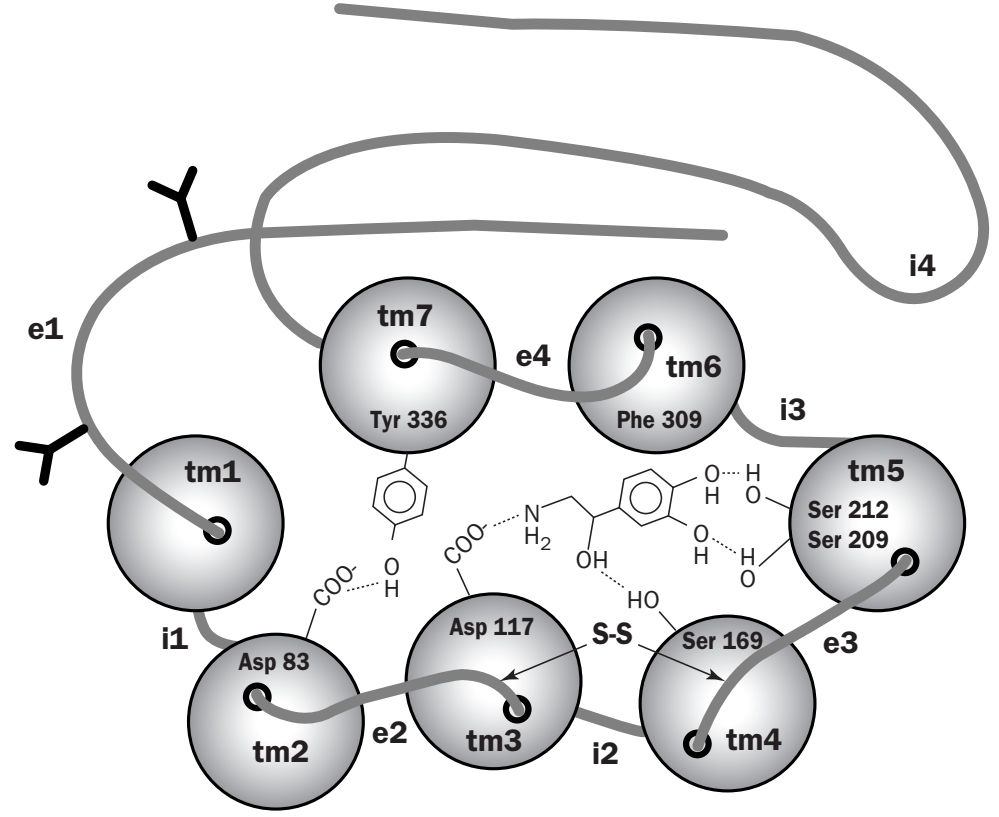

Figure 6.15 - Schéma de la liaison de la noradrénaline

au récepteur $\boldsymbol{\beta} 3$-adrénergique humain (d'après Emorine et Strosberg, 1993)

L'hormone interagit avec des résidus des domaines transmembranaires tm3 (liaison électrostatique entre le groupe -COO- de l'Asp 117 et le groupe aminé des catécholamines), tm4 (pont d'hydrogène entre les groupes - $\mathrm{OH}$ de la Ser 169 et de la chaîne éthanolamine du ligand), tm5 (ponts d'hydrogène entre les -OH des Ser 209 et Ser 212 et ceux du noyau catéchol), tm6 (Phe 309 dont le noyau aromatique interagit avec le noyau catéchol). Notons que le groupe $-\mathrm{OH}$ de la Tyr 336 de tm7 peut former un pont d'hydrogène avec celui de l'Asp 83 de tm2, jouant certainement un rôle crucial dans la transmission du signal de liaison à la protéine Gs.

- sur les vaisseaux : l'action diffère selon les territoires. Elle s'explique par une répartition quantitative différente des récepteurs $\alpha$ et $\beta$ du muscle lisse vasculaire. Il y a redistribution vasculaire des aires cutanées (pâleur) et splanchniques vers les muscles et le cœur. Il n'y a donc pas de vaso-constriction généralisée. Ces effets constituent une excellente adaptation à l'effort ;

- sur la musculature lisse :

- broncho-dilatation,

- inhibition du tonus et du péristaltisme intestinaux, avec spasme des sphincters,

- mydriase et contraction de la membrane nyctitante du chat ;

- spléno-contraction;

- augmentation de la diurèse ;

- et enfin, action directe sur le SNC, en particulier stimulation de l'hypothalamus avec sécrétion d'ACTH hypophysaire, réalisant un état de stress. L'injection d'adrénaline provoque un sentiment immédiat d'anxiété ; 
- sur le métabolisme (à des doses inférieures à celles nécessaires pour observer les effets précédents), l'adrénaline provoque de l'hyperglycémie par glycogénolyse hépatique. Le glycogène est dégradé dans le foie par une phosphorylase, puis une glucose-6-phosphatase qui aboutit à du glucose d'où élévation de la glycémie. Il n'y a pas de glucose-6-phosphatase dans le muscle où le glycogène donne du glucose-6-phosphate puis du fructose $6 \mathrm{P}$, et enfin de l'acide lactique qui peut être utilisé par le foie pour redonner du glycogène.

\subsubsection{Action de la noradrénaline}

- Elle se manisfeste essentiellement sur l'appareil cardio-vasculaire (elle agit préférentiellement sur les récepteurs $\alpha$ ). Elle est peu efficace sur le fonctionnement cardiaque. En revanche, elle provoque une vaso-constriction généralisée (à l'exception des coronaires), d'où de l'hypertension.

- Elle ne provoque pas de sentiment d'anxiété.

- Les autres effets sont moins accusés, en particulier les effets métaboliques.

En résumé, ces deux hormones provoquent de l'hypertension. Mais seule l'adrénaline a une action métabolique sensible. La noradrénaline, médiateur des nerfs adrénergiques, intervient essentiellement dans la régulation de la pression artérielle. L'adrénaline est l'hormone de l'adaptation à l'effort, au froid et au stress en général ${ }^{13}$.

\subsection{RÉGULATION DE L'ACTIVITÉ DE LA MÉDULLO-SURRÉNALE}

La médullo-surrénale est la seule glande endocrine dont la commande essentielle soit nerveuse.

\subsubsection{Les centres nerveux adrénalino-sécréteurs et leurs voies efférentes}

Les principaux centres sont bulbaires, localisés dans le plancher du $4^{\mathrm{e}}$ ventricule.

- leur excitation entraîne une décharge des catécholamines ;

- leur cocaïnisation provoque une réduction de la sécrétion médullo-surrénalienne.

Mais il existe aussi un contrôle au niveau hypothalamique et médullaire (entre D1 et D3). Les voies efférentes suivent le trajet des racines antérieures, de D4 à L1, elles constituent les nerfs grands splanchniques et accessoirement petits splanchniques. Elles n'ont pas de synapse, il s'agit de neurones préganglionnaires cholinergiques. Leur action est intensifiée par l'ésérine (anticholinestérasique).

13 Suite à une agression par exemple psychologique, il faudra distinguer deux types de réactions possibles (voir "Le singe nu" de D. Morris, 1970) :

- la peur, où prédomine la réaction vagale (parasympathique) avec hypotension, relâchement des sphincters..., peu propice à la défense ;

- la colère, où prédomine la réaction orthosympathique, avec augmentation du débit cardiaque, de la tension artérielle, de la glycémie, favorable à l'attaque ou à la fuite. 
La régulation exercée par la médullo-surrénale revêt trois caractères ; elle peut être : nerveuse, humorale ou intercentrale.

\subsubsection{La régulation nerveuse réflexe}

Un exemple de cette régulation nerveuse est la régulation de la pression artérielle (PA). La réponse de la médullo-surrénale aux variations de la PA n'est pas une réponse directe. Ces variations agissent au niveau de baro-récepteurs aortiques et sinu-carotidiens. La réponse humorale, tardive, suit la réponse nerveuse.

\subsubsection{La régulation humorale}

Elle se manifeste à propos de deux facteurs :

- l'adrénalinémie. L'adrénaline en excès (en injection I.V. par exemple) freine sa propre sécrétion par deux mécanismes :

- indirect : l'hypertension provoquée par la vaso-constriction agit sur les récepteurs baro-sensibles (inhibiteurs) aortiques et sinu-carotidiens ;

- direct, par action chimique sur les récepteurs chémo-sensibles.

- la glycémie. Une diminution de la glycémie est perçue par les neurones hypothalamiques, qui sont très sensibles à ce stimulus. L'insuline (qui est la seule hormone hypoglycémiante) provoque une décharge médullo-surrénalienne de catécholamines. Elle est utilisée comme test de réactivité de l'axe hypothalamique.

\section{RÉGULATION DE LA NATRÉMIE}

Pour maintenir constant le taux du sodium plasmatique, l'organisme fait appel à des mécanismes régulateurs extrêmement précis. Ainsi, lorsque le taux de sodium de l'organisme est insuffisant, le rein, sous l'effet de l'angiotensine II et de l'aldostérone, retient le sel, et l'empêche de passer dans les urines. L'aldostérone constitue un mécanisme protecteur, protégeant le capital sodé. Au contraire, lorsque le taux du sodium plasmatique augmente, le rein, soumis à l'action de l'ADH, empêche l'eau de s'échapper dans les urines, ce qui permet le maintien d'une concentration saline convenable dans le milieu intérieur. Mais, lors d'une expansion sodée aiguë ou chronique, tout le cœur sécrète l'ANF (voir chap. 9, § 4) qui détermine une natriurèse massive et immédiate.

\section{LE STRESS}

Le syndrome général d'adaptation, au sens de H. Selye (1936), est l'ensemble des réactions de l'organisme à des stimulus très divers, non-spécifiques, mais dont le caractère nociceptif (au sens large) conduit à une perturbation de l'homéostasie. 
Le stress est l'ensemble complexe de ces stimulus et des réactions en principe non-spécifiques auxquels ils donnent naissance.

\subsection{LES AGENTS STRESSANTS}

Cortex cérébral et système limbique sont stimulés lors des émotions. Ils sont reliés par des faisceaux nerveux à l'hypothalamus qui constitue l'interface entre le système nerveux, les systèmes endocrinien et immunitaire. L'hypothalamus possède aussi des récepteurs multiples, à la température (chaud, froid), à la glycémie, à l'insulinémie, à la natrémie... et déclenche, lorsqu'il "perçoit" un agent stressant, la chaîne de réactions qui va constituer le syndrome général d'adaptation.

Les agents susceptibles de créer un état de stress sont multiples. Ils peuvent être de nature thermique (chaleur ou froid), infectieuse (toxines bactériennes), toxique (venins), anaphylactique (allergie à une piqûre de guêpe), traumatique ("crush syndrome" ou syndrome d'écrasement, par exemple lors d'un éboulement), chirurgicale (anesthésie insuffisante ou excessive) ; l'agression peut être due aussi à une spoliation sanguine (hémorragie) ou à une brûlure. Elle peut enfin être psychique (deuil, émotion intense).

Certains types de stress permettent à l'organisme de mieux affronter l'agression, ce sont des stress positifs (eustress). D'autres le mettent dans une situation physiologique défavorable, ce sont des stress négatifs (distress).

En expérimentation animale, on peut utiliser : le stress de contrainte (l'animal est bloqué à l'intérieur d'un cylindre : "shuttle box"), l'isolement, la concentration, la nage forcée, les flashs lumineux, les chocs électriques sur la patte, le bruit intense... (voir sur ce sujet la monographie de Borysenko et Borysenko, 1982).

Contrairement à ce qu'avait exprimé Selye (1975) et à ce que laissent penser les échelles événementielles, un même agent stressant peut agir différemment suivant les individus, ou même suivant le moment chez le même individu. On voit apparaître la nécessité de la prise en compte de ce que Bonfils (1993), avec d'autres auteurs, appelle la "personnalité" de l'individu, dont l'importance est considérable dans le développement des maladies psychosomatiques.

La stimulation de l'hypothalamus par un agent stressant déclenche le syndrome général d'adaptation qui évolue suivant deux et éventuellement trois stades.

Le premier stade est à caractère plutôt nerveux, il traduit l'excitation du système nerveux sympathique (libération de noradrénaline, NA) et de la médullo-surrénale (NA + adrénaline, A). C'est la réaction d'alarme. Le second stade est à caractère plutôt hormonal, il correspond à la libération de facteurs de décharge hypothalamiques et d'hormones hypophysaires. C'est la phase de résistance, dont les effets sont plus ou moins durables. 


\subsection{LA RÉACTION D'ALARME (PHASE AIGÜ̈)}

Les réactions qui la caractérisent sont immédiates et de courte durée (réponse de type phasique).

- Il y a augmentation de la fréquence cardiaque (due aux catécholamines NA + A) et de l'intensité des contractions du muscle cardiaque (due à l'A), d'où une augmentation du débit cardiaque qui apporte rapidement et en plus grande quantité les substances nutritives (glucose...) dont l'organisme (et en particulier les muscles) a besoin pour répondre à l'agression.

- Grâce à l'A, la distribution de ce sang est favorisée au niveau des muscles et de l'encéphale (vaso-dilatation, effet $\beta$ ) au détriment de la peau et des viscères (vasoconstriction, effet $\alpha$ ), sauf pour le cœur et les poumons.

- Le rythme respiratoire s'accélère (A) et les bronches se dilatent (effet $\beta$ de l'A), favorisant l'apport d'oxygène au cœur et l'élimination du $\mathrm{CO}_{2}$.

- La contraction de la rate (A) apporte à l'organisme une quantité supplémentaire de globules rouges, qui accroît l'apport d'oxygène au cœur et permet une restauration plus rapide après une hémorragie.

- La glycogénolyse hépatique et musculaire, la lipolyse sont stimulées (effet $\beta$ de l'A), de même que l'utilisation du glucose par les tissus.

- Le système rénine-angiotensine est très rapidement stimulé, il contribue à accentuer la vaso-constriction, provoque une épargne sodée et une kaliurie.

- Enfin, sous l'effet de la sécrétion d'adrénaline, l'individu ressent une anxiété qui stimule l'attention. Au total, la réaction d'alarme, dans la plupart des cas, est une réponse physiologique favorable à l'adaptation de l'organisme au facteur stressant. Elle réduit les activités qui ne sont pas essentielles (digestive, urinaire, reproductive), mais stimule des processus qui concourent à faciliter l'éveil, la condition nerveuse, l'adaptation hémodynamique immédiate et la mobilisation de stocks énergétiques d'utilisation rapide pour le cœur, les muscles, l'encéphale.

Dans les conditions d'une vie naturelle, ces mécanismes permettront à un animal sauvage de répondre à un adversaire par le combat ou la fuite. Cette réaction d'alarme n'est pas toujours aussi opportune pour l'homme dans la vie courante. Si elle constitue une réponse favorable à une agression infectieuse, elle paraît moins adaptée lorsqu'elle survient à la suite d'une émotion, l'énergie ainsi brusquement libérée l'est généralement en pure perte, et si le stress est répété, elle peut instaurer un état d'élévation du tonus adrénergique vasculaire (fig 6.16) générateur d'hypertension et d'athérosclérose.

D'autre part, le syndrome ainsi réalisé peut être remplacé, chez l'homme, suivant les circonstances et lors d'une agression psychique, par un syndrome d'exagération du tonus parasympathique avec une bradycardie qui peut conduire à une syncope (perte de conscience). 


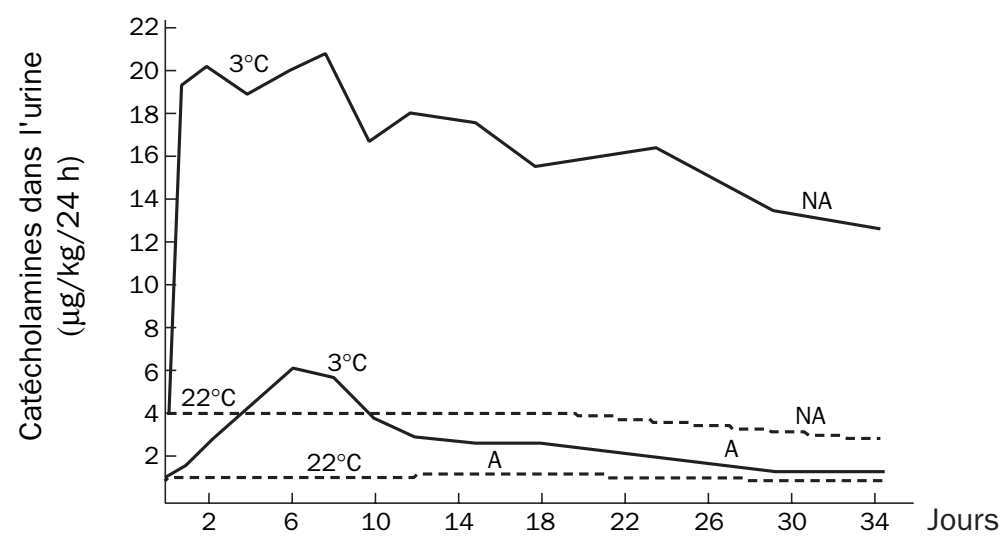

Figure 6.16 - Réponse au froid (d'après Leduc, 1961)

Excrétion urinaire d'adrénaline $(A)$ et de noradrénaline (NA) chez des rats de 170-180 g, maintenus à $3^{\circ} \mathrm{C}$ (ligne continue) et à $22^{\circ} \mathrm{C}$ (ligne pointillée).

Dans d'autres circonstances et par un mécanisme qui fait probablement intervenir une libération d'histamine, on assiste à une augmentation brutale de la perméabilité capillaire, avec vaso-dilatation périphérique, séquestration de la masse sanguine à l'extrémité des capillaires et hémoconcentration.

Un stress intense peut dépasser les limites d'adaptation de l'organisme et entraîner la mort de l'individu. Si l'individu a pu franchir l'étape critique de l'alarme, il entre dans la deuxième phase qui est la phase de résistance. Cette réponse est de type tonique.

\subsection{LA PHASE DE RÉSISTANCE (PHASE SUBAIGÜ̈ OU CHRONIQUE)}

Elle met en jeu, sous l'effet de la stimulation de l'hypothalamus, la libération de nombreux peptides hypotalamiques $\mathrm{CRH}, \mathrm{GRH}, \mathrm{TRH}, \mathrm{ADH}$, ce qui entraîne aussi la sécrétion d'ACTH, de GH, de TSH, de prolactine et de nombreux opiacés.

En fait, le schéma de Selye, impliquant le seul complexe hypothalamo-hypophysosurrénalien, était d'une simplicité cadrant mal avec la complexité des phénomènes biologiques. Devant la variété de stratégies nécessaires pour répondre à l'extrême diversité de l'environnement, il eut été étonnant que l'organisme n'ait adopté qu'une seule modalité réactionnelle pour répondre au problème de la survie de l'individu et, à travers lui, de l'espèce.

Bien avant l'identification de la $\mathrm{CRH}$, on distinguait déjà deux types de stress :

- le stress dit "systémique", qui se produit même si l'hypothalamus est complètement déconnecté du restant du cerveau. En fait, il met en jeu le système orthosympathique et regroupe certains des éléments de la réaction d'alarme ;

- le stress "neurotrope", comme celui qui suit une immobilisation forcée (contrainte) ou un choc électrique douloureux et dans lequel on observe la réaction d'alarme et la réponse hypothalamo-hypophysaire, caractéristique de la phase de résistance. 
Quels sont les peptides hypothalamiques et les hormones hypophysaires libérés sous l'effet de la stimulation nerveuse de l'hypothalamus?

\subsubsection{La décharge d'ACTH et de glucocorticoüdes}

La décharge d'ACTH, caractéristique du stress ${ }^{14}$ (fig. 6.17.a) qui est dépendant de la libération de la corticolibérine (CRH) hypothalamique, stimule la libération d'hormones glucocorticoïdes (fig. 6.17.b) dont l'effet va maintenir, en les relayant, certains des effets métaboliques des hormones médullo-surrénaliennes.
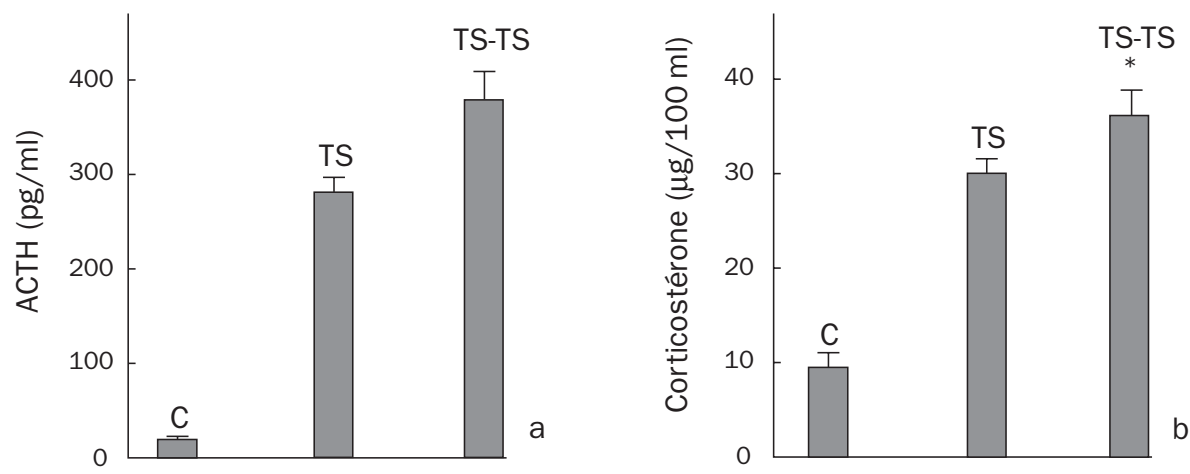

Figure 6.17 - Réponse sécrétoire de l'ACTH et de la corticostérone lors d'un stress aigu chez le rat (choc électrique sur la patte), simple (TS) ou répété (TS-TS), par rapport à un contrôle (C) (d'après Orr et coll., 1990)

Les hormones glucocorticoïdes stimulent la néoglucogenèse, en accélérant le catabolisme des protéines et la conversion des acides aminés en glucose. Ainsi, l'organisme bénéficie-t-il d'un apport constant en molécules de glucose, après que les réserves immédiates en glycogène, dégradées sous l'effet de l'adrénaline, aient été utilisées et voit ses réserves énergétiques reconstituées sous l'effet des glucocorticoïdes.

L'élévation du taux du cortisol est proportionnelle à la gravité du stress. Ceci est exact lorsque l'intensité de l'agent stressant est modérée. Cela ne l'est plus lorsque l'agent générateur de stress est très intense, car la sécrétion de glucocorticoïdes atteint alors un palier (Kant et coll., 1983). Huhman et coll. (1991) ont démontré, en utilisant comme agent stressant le choc électrique sur la patte chez le Hamster, que l'AMP cyclique constitue un bon index de l'intensité du stress, car la réponse de l'AMPc plasmatique est proportionnelle à l'intensité du stimulus (fig. 6.18).

L'effet inhibiteur des glucocorticoïdes sur le tissu conjonctif réduit les phénomènes inflammatoires qui ont pu accompagner le stress. Mais il réduira aussi les possibilités de cicatrisation (les blessures guérissent plus lentement lorsque l'état de stress se prolonge), ainsi que l'intensité d'une éventuelle réponse immunitaire après une infection.

14 Le blocage de la CRH par un anticorps limite, sans la supprimer, la réponse de l'organisme à l'agression. 
Figure 6.18 - Production d'AMPC en réponse à un stress (choc électrique sur la patte) d'intensité croissante chez le Hamster (d'après Huhman et coll., 1991) Chaque point représente la moyenne \pm SEM.

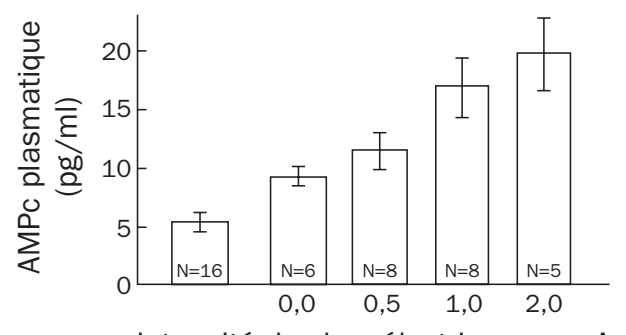

Intensité du choc électrique en $\mathrm{mA}$

Toutefois, l'effet direct (stimulant) de l'ACTH sur les cellules immunitaires compense l'effet inhibiteur des glucocorticoïdes, de sorte que les défenses immunitaires sont parfois augmentées dans certains états de stress. Dans d'autres cas, surtout à la suite de petits stress répétés, ou lorsque la phase de résistance se prolonge, les défenses immunitaires sont diminuées.

Les glucocorticoïdes libérés à l'occasion d'un stress agissent aussi sur l'hippocampe, qui contient des récepteurs à ces hormones. Dans le stress chronique, il y a diminution transitoire du nombre de ces récepteurs. Cet effet de rétroaction négative (downregulation) a comme résultat de limiter l'amplitude de la réponse à l'agent stressant.

Un autre résultat de l'action des glucocorticoïdes sur l'hippocampe est de stimuler les capacités de mémorisation et de signaler ainsi au cerveau que les circonstances de l'événement méritent d'être engrammées. Cette action, qui est démontrée par l'expérimentation animale (Leshner, 1981), constitue un mécanisme important pour la survie de l'individu. En effet, elle permet à l'organisme de faire le tri entre ce qui est important et ce qui ne l'est pas pour le maintien de son intégrité physique et mentale.

Les glucocorticoïdes jouent également un rôle régulateur en diminuant la synthèse ou la libération de nombreux médiateurs cellulaires : médiateurs de l'inflammation (prostaglandines), de l'immunité (lymphokines)...

La biosynthèse des corticoïdes nécessite la présence de vitamine $\mathrm{C}$ qui fonctionne comme un catalyseur, d'où l'intérêt de son administration dans un stress qui se prolonge (grippe, deuil...).

\subsubsection{Les minéralocorticoüdes}

Bien que l'ACTH agisse peu sur la sécrétion des hormones minéralocorticoïdes, celle-ci sera également augmentée par un mécanisme indirect. La réduction de la circulation sanguine dans les veines, lors de la réaction d'alarme, stimule la sécrétion d'aldostérone, d'où une conservation des ions sodium et une élimination accrue d'ions hydrogène. La rétention du sodium favorise également la rétention de l'eau, effet synergique de celui de l'ADH, ce qui maintient une pression artérielle élevée et compense la fuite liquidienne lors d'une hémorragie ${ }^{15}$.

15 Ce mécanisme, associé à l'effet des à-coups de sécrétion répétés de l'adrénaline, explique la genèse de certaines hypertensions. 


\subsubsection{L'hormone de croissance}

Libérée sous l'effet de la GRH (fig. 6.19 et 6.20), elle apparait comme une autre hormone caractéristique du stress. Elle contribue, avec les hormones glucocorticoïdes, à un apport accru en molécules de glucose, par stimulation de la néoglucogenèse, à partir de la dégradation des protéines et des lipides.

Elle favorise aussi la reconstitution du stock de glycogène hépatique.

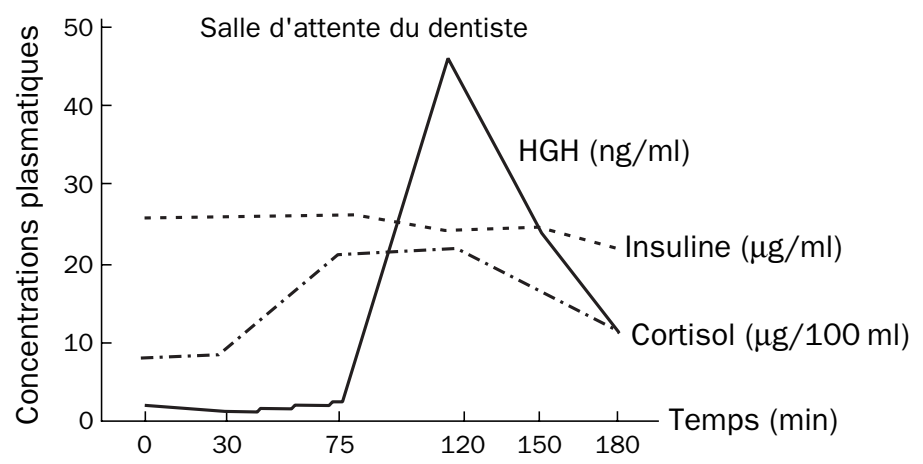

Figure 6.19 - Réponse à un stress émotif (d'après Bayliss et coll., 1968)

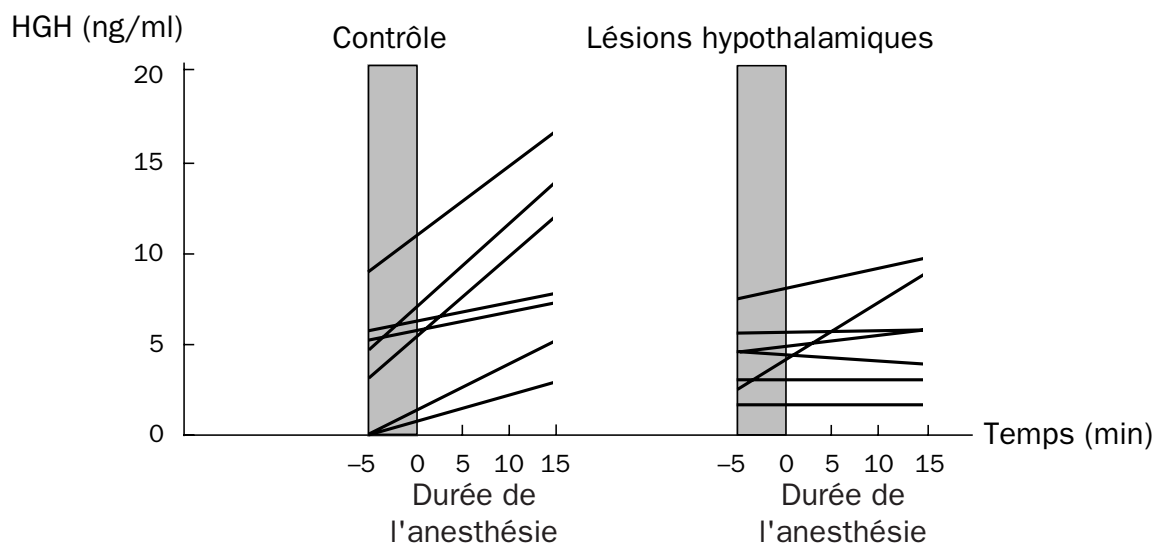

Figure 6.20 - Effet du stress anesthésique chez le rat

(d'après Schlach et Reichlin, 1968)

Chacune des lignes correspond à la variation observée chez un sujet d'expérience.

\subsubsection{La prolactine}

Cette hormone qui prépare l'allaitement chez la femme enceinte, puis entretient la lactation, est constamment libérée dans le stress, avec une cinétique égale à celle de l'ACTH (voir fig. 6.21). Son rôle dans le stress n'est pas clair.

La succion du mamelon par le nouveau-né déclenche une réponse nerveuse au niveau de l'hypothalamus (sécrétion d'ocytocine, de prolactine...), elle se comporte comme un "eustress" (voir chap. $4, \S 8.3 .2$ ). 
Figure 6.21 - Réponse sécrétoire de la prolactine lors d'un stress aigu chez le rat (choc électrique sur la patte), simple (TS) ou répété (TS-TS), par rapport à un contrôle (C)

(d'après Orr et coll., 1990)

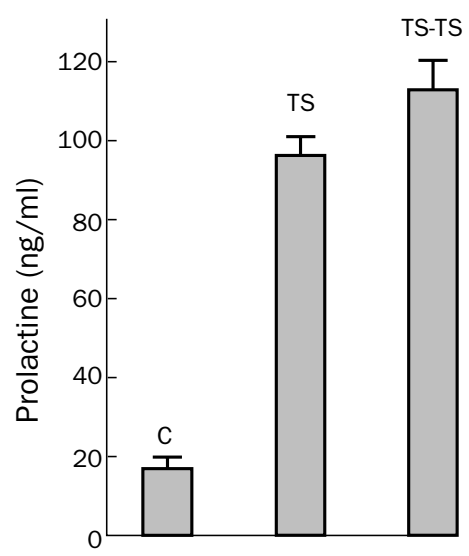

\subsubsection{La TSH}

Sous l'effet d'une libération éventuelle de la TRH, la décharge de TSH stimule la sécrétion de T3 et T4 qui augmentent l'absorption intestinale des glucides et indirectement leur utilisation. Le métabolisme basal, la glycolyse et la lipolyse augmentent. Des données récentes permettent de considérer qu'il existe un équilibre entre les deux facteurs hypothalamiques: CRH et TRH, qui conditionne la nature de la réponse viscérale au stress, particulièrement au niveau de l'estomac.

\subsubsection{Les endorphines}

La stimulation de l'hypothalamus entraîne aussi une libération massive, dans le sang périphérique, de $\beta$-endorphines (fig. 6.22) et d'autres peptides dérivés de la pro-opiomélanocortine (jusqu'à $10 \mathrm{mg} / \mathrm{ml}$ de $\beta$-endorphine chez le rat).

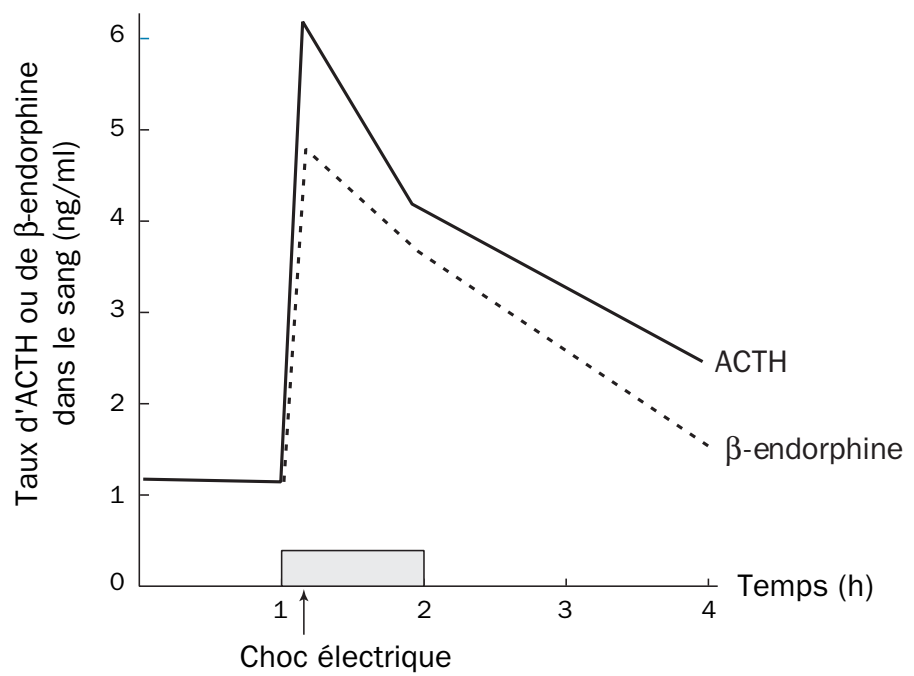

Figure 6.22 - Réponse hormonale à un choc électrique (d'après Rossier et coll., 1977) 
Le rôle de ces $\beta$-endorphines dans le stress n'est pas bien connu. On peut penser qu'elles permettent d'atténuer la douleur présente à la suite de certains traumatismes stressants (écrasement...). Mais l'injection de $\beta$-endorphine par voie intraveineuse n'a pas d'effet antalgique.

Après un stress de contention, la $\beta$-endorphine mesurable par dosage radioimmunologique au niveau de la substance grise péri-acqueducale chez le rat est diminuée, aussi bien chez les mâles que chez les femelles (Farabollini et coll., 1993), alors qu'elle ne varie pas dans l'hypothalamus ventral ni dans l'hypophyse. On observe en même temps une réduction de la production d'interféron $\gamma$ au niveau des splénocytes, principalement chez les femelles. Cette action sur le système immunitaire pourrait être sous la dépendance de la $\beta$-endorphine.

La libération de ces endorphines hypophysaires s'accompagne d'une libération d'enképhalines et autres peptides opiacés à partir des cellules chromaffines de la médullo-surrénale.

\subsubsection{L'insulinorésistance}

A la lyse protéique, conditionnée par les sécrétions des hormones néoglycogénétiques, s'ajoute une insulinorésistance marquée, par atteinte des récepteurs et effet antagoniste du glucagon.

La durée de ce stade de résistance est fonction de l'intensité du stress et des capacités d'adaptation de l'organisme, en particulier de l'état fonctionnel du cortex surrénal dont les réserves en acide ascorbique et en cholestérol diminuent. Nous parvenons généralement à faire face à une agression et à ses conséquences et l'organisme revient à un état physiologique normal. Si les possibilités de l'organisme sont dépassées, un stade d'épuisement est atteint.

\subsection{LE STADE D'ÉPUISEMENT}

Lorsque les capacités sécrétoires en glucocorticoïdes sont épuisées, le taux du glucose s'abaisse, les cellules ne peuvent plus être nourries convenablement. Du fait des échanges au niveau du rein qui privilégient la rétention du sodium au détriment des ions potassium et hydrogène, les cellules perdent des quantités de plus en plus grandes de potassium. Cet état retentit sur le cœur, les vaisseaux, le rein... et la mort peut survenir dans un état de collapsus général.

En fait, le concept de réaction "non-spécifique" et stéréotypée en réponse à des stimulus "stressants" multiples est certainement simplificateur et partiellement inexact. De fait, toutes les réactions de stress ne produisent pas les mêmes effets :

- un grand nombre de stimulus libèrent plutôt de l'ACTH ;

- d'autres stimulus libèrent en outre de l'ADH (oligurie émotionnelle);

- une hémorragie entraîne la libération d'ADH et d'aldostérone ; 
- l'anesthésie à l'éther provoque la sécrétion de prolactine plutôt que d'ACTH ou de $\beta$-endorphines ; mais l'ACTH est tout de même augmenté. Par exemple, chez le lapereau âgé de 5 à 7 semaines (Monnier et Desbals, 1985) :

- le taux normal est de $280 \pm 30 \mathrm{pg} / \mathrm{ml}$ de plasma ;

- après stress à l'éther : $670 \pm 60 \mathrm{pg} / \mathrm{ml}$;

- après surrénalectomie : $1225 \pm 85 \mathrm{pg} / \mathrm{ml}$.

\subsection{LE STRESS CHRONIQUE}

Des expériences de stress "chronique" mettent en évidence des modifications hormonales différentes de celles, classiques, que nous avons décrites dans les paragraphes précédents. Cela est d'autant plus intéressant que le stress chronique est beaucoup plus fréquent que le stress aigu.

Après une immobilisation chronique ( $2 \mathrm{~h}$ par jour pendant 13 jours) chez le rat mâle Sprague-Dawley, suivant la technique de Kvetnansky et Mikulaj (1970), Armario et coll. (1993) ont étudié les modifications de la sécrétion de la GH et de la TSH. Ce type de stress réduit le niveau de base de la GH et de la TSH sériques, et il sensibilise ces deux hormones, surtout la GH, aux effets d'un stress aigu. D'autre part, le stress chronique diminue la réponse de la GH et de la TSH aux hormones hypothalamiques, GRH et TRH respectivement. La même équipe (Marti et coll., 1993) analyse plus précisément les variations circadiennes des deux hormones hypophysaires, $\mathrm{GH}$ et TSH (voir fig. 6.23), ainsi que celles de l'ACTH et de la corticostérone (voir fig. 6.24), chez le rat immobilisé. La sécrétion de l'ACTH n'est pas modifiée (!), tandis que les taux de la corticostérone sérique sont augmentés. L'immobilisation prolongée diminue les taux de GH et de TSH chez les animaux expérimentés, mais l'altération du rythme circadien dépend du protocole adopté pour l'immobilisation.

\subsection{LA GESTION DU FAIRE FACE (OU COPING)}

Le terme de "coping" est un terme de Lazarus et Launier (1978), désignant les stratégies d'ajustement élaborées par les individus pour rendre tolérable la tension induite par une situation aversive.

Face à un danger, l'individu a, de façon schématique, trois stratégies de réponse possibles :

- l'action dans la fuite : se libérer de la situation ; c'est une solution, mais pas toujours possible ${ }^{16}$;

- l'action dans l'attaque : chercher à neutraliser l'agent stressant ; c'est une réponse rarement utilisée dans la vie de l'être humain civilisé ; 


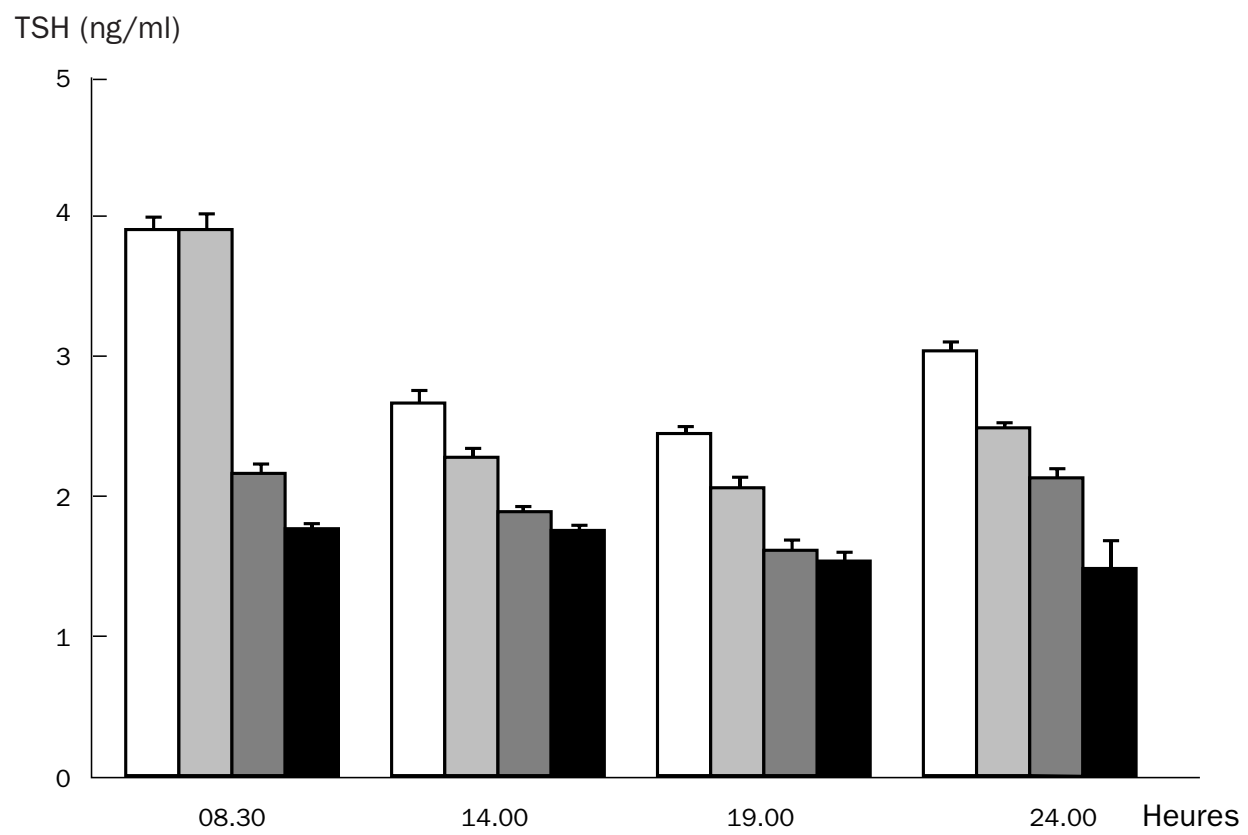

$\mathrm{GH}(\mathrm{ng} / \mathrm{ml})$

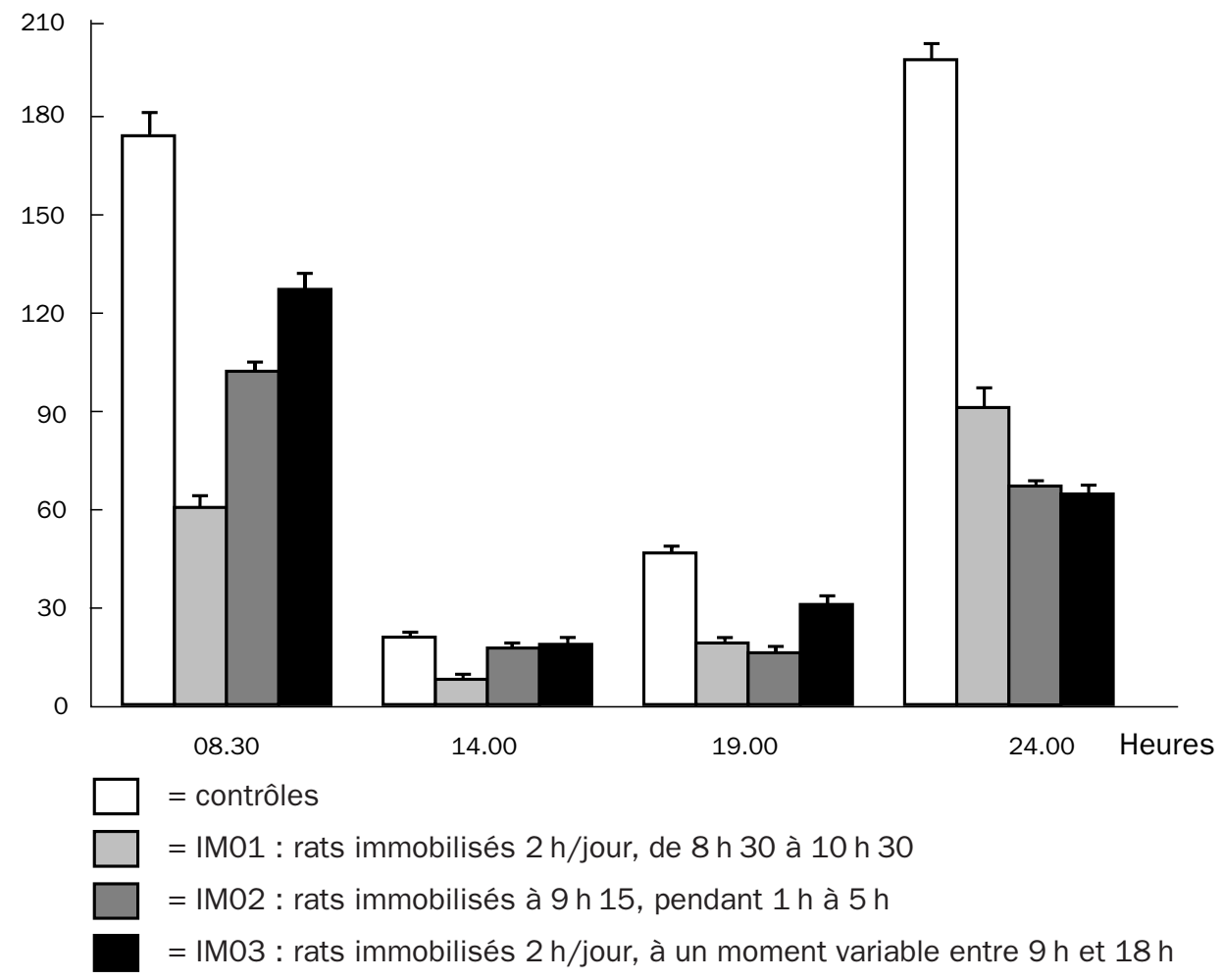

Figure 6.23 - Effet du stress chronique (par immobilisation) sur le rythme circadien de la TSH et de la GH (d'après Marti et coll., 1993) 

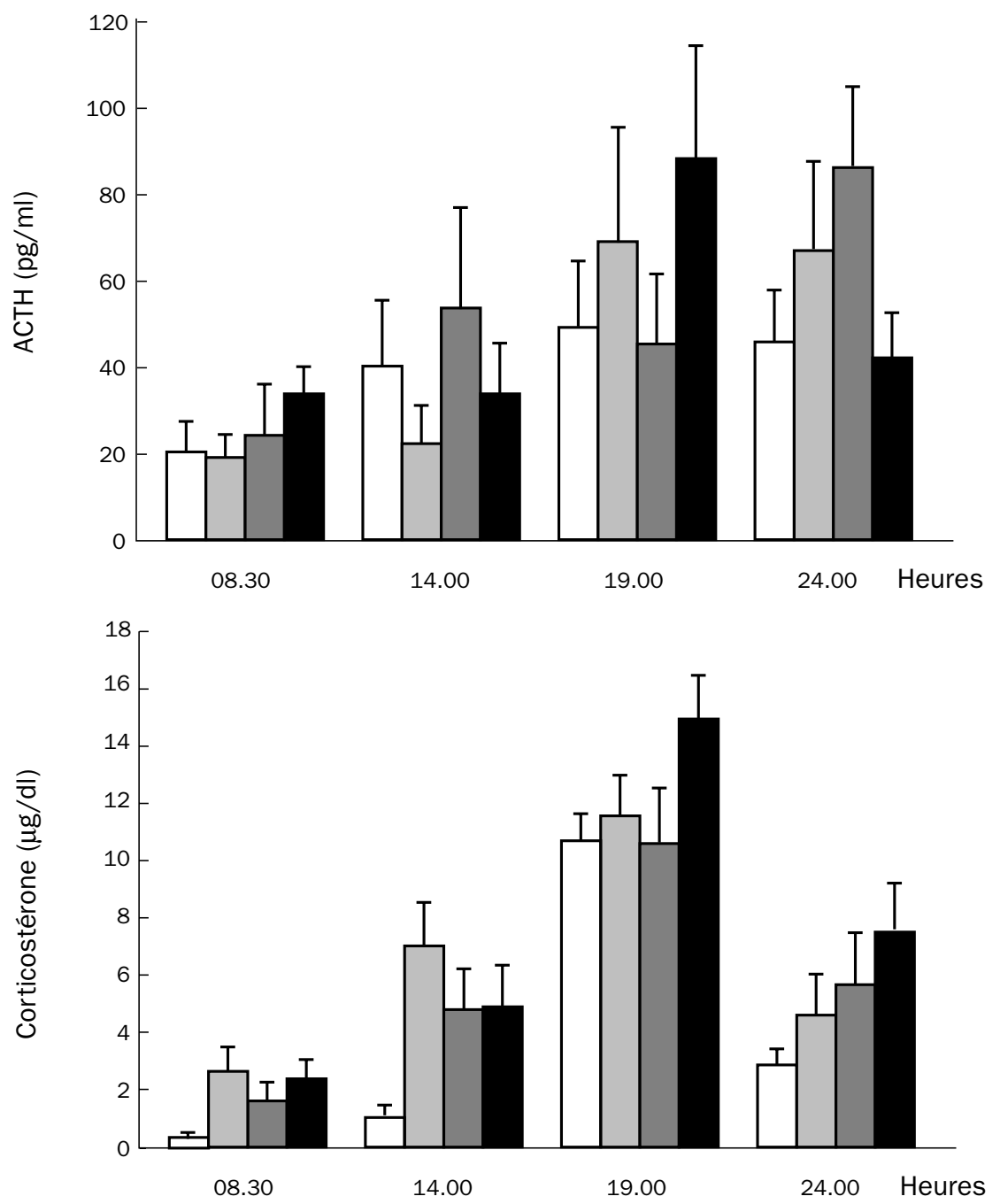

$\square=$ contrôles

$\square=$ IM01 : rats immobilisés $2 \mathrm{~h} /$ jour, de $8 \mathrm{~h} 30$ à $10 \mathrm{~h} 30$

$\square=$ IMO2 : rats immobilisés à $9 \mathrm{~h} 15$, pendant $1 \mathrm{~h}$ à $5 \mathrm{~h}$

W IM03 : rats immobilisés $2 \mathrm{~h} /$ jour, à un moment variable entre $9 \mathrm{~h}$ et $18 \mathrm{~h}$

Figure 6.24 - Effet du stress chronique (par immobilisation) sur le rythme circadien de l'ACTH et de la corticostérone (d'après Marti et coll., 1993)

- la non-possibilité d'action : dans ce cas, l'individu reste en contact avec l'agent stressant et ne s'en libère pas; Henri Laborit a développé l'étude de cette inhibition de l'action (1986).

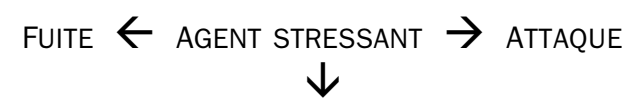

INHIBITION DE L'ACTION 
Pour apprécier l'efficacité de la stratégie mise en œuvre face à l'agression, et plutôt que d'essayer de mesurer l'anxiété, la tension, la frustration ou la colère, les psychologues ont cherché à définir le principe commun à ces différents états émotionnels qui poussent l'individu à réagir et l'ont appelé "activation". L'activation est plus faible lorsque la stratégie d'ajustement à la situation est mieux adaptée, et il est alors possible de quantifier l'efficacité de la stratégie d'ajustement par la réduction du niveau de l'activation.

Il y a une relation entre motivation et activation et l'on rejoint la notion d'activation des neurophysiologistes, qui est corrélée à la notion d'éveil et plus précisément au tonus de la substance réticulée, et de ses faisceaux activateur ascendant (SRAA) et activateur descendant (SRAD). Un lien bidirectionnel s'établit entre stress et activation, les hormones du stress sont à la fois dépendantes du niveau d'activation et responsables de celle-ci ${ }^{17}$. Ainsi, l'intensité de l'activation pourra être mesurée par les divers indicateurs nerveux ou hormonaux du stress. Il devient alors possible de quantifier l'efficacité de la gestion du stress.

Les acides gras dans le sang et les stéroïdes sont des indicateurs de l'émotion et des capacités de défense.

Les acides gras constituent des indicateurs très sensibles de l'émotion. Libérés sous l'effet de l'adrénaline dans la phase d'alarme, ils sont d'apparition plus précoce que l'élévation du taux de stéroïdes (fig. 6.25).

Variation du taux d'acides gras par rapport au taux de base (en \%)

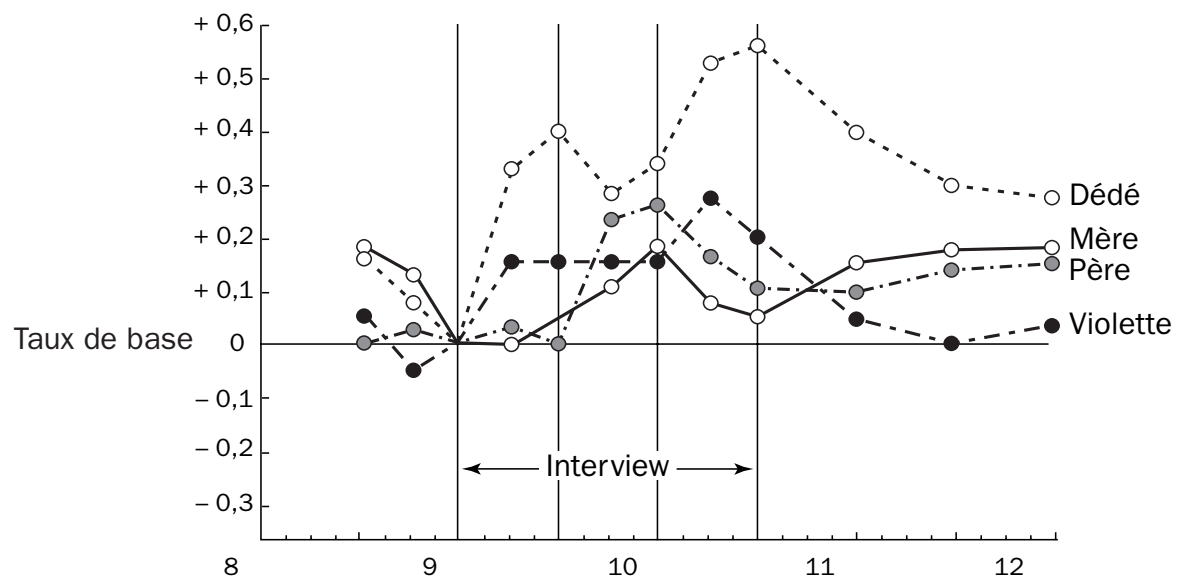

Figure 6.25 - Variations relatives des acides gras liées à un stress

(conflit entre les parents) chez les parents et les enfants (d'après Minuchin, 1979)

17 On retrouve cet aspect bidirectionnel de la relation à propos de l'émotion. En 1962, Schachter et Singer ont montré que l'émotion serait le résultat d'une interaction entre deux composantes : un éveil non-spécifique dû à l'excitation du système nerveux sympathique, et une cognition qui résulte de ce que l'on attribue la cause de cet éveil à tel ou tel élément de la situation provocatrice. 
L'élévation de la concentration du cortisol traduira également, mais de façon plus tardive, un état relativement indifférencié de l'activation ou de la participation émotionnelle. Le taux des corticostéroïdes surrénaliens dans le sang et dans l'urine constituera une indication sensible et objective pour la corrélation physiologique d'un état émotionnel. Des réactions émotionnelles intenses iront de pair avec des augmentations anormalement élevées de la concentration du cortisol.

Stress psychologique et anxiété influencent également le taux du cholestérol (fig. 6.26).

\section{INTERVIEWS}

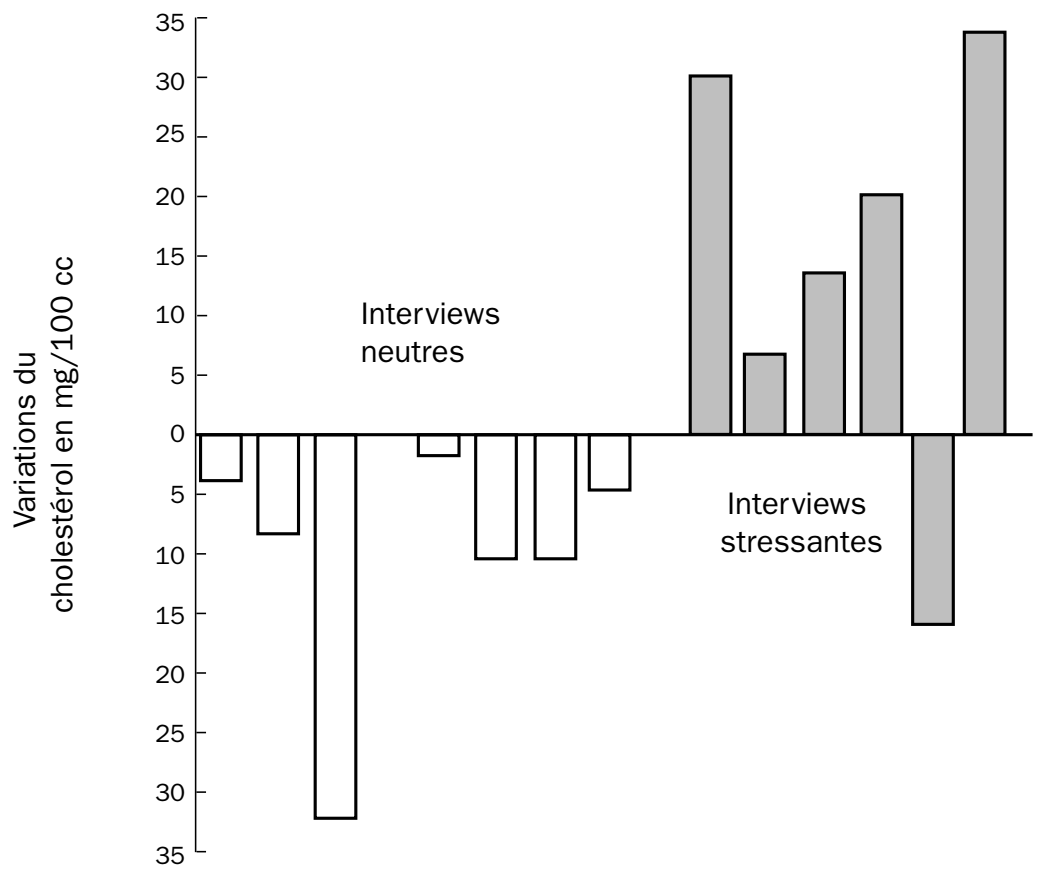

Figure 6.26 - Comparaison des modifications de courte durée du cholestérol sanguin pendant des interviews neutres ou stressantes (d'après Wolff et Goodell, 1968)

Chaque barre correspond à un individu. Les variations de la teneur en cholestérol sont appréciées à la fin de l'interview d'une heure.

La concentration des corticostéroïdes ne représente pas seulement une mesure de l'excitation émotionnelle, elle rend compte aussi des mécanismes de défense psychiques propres à un individu.

Friedman et coll. (1963), dans une étude à long terme réalisée sur des parents d'enfants leucémiques, ont montré qu'on pouvait répartir ces parents en groupes de sécrétion stéroïdique "élevée", "moyenne" ou "basse", ces derniers ayant une forte tendance au déni et au refoulement. Les parents ayant ces valeurs stérö̈diques basses réagissaient par une diminution encore plus grande de ces valeurs lors d'événements menaçants ou bouleversants, tandis que les parents présentant des concentrations 
élevées réagissaient par une élévation supplémentaire. On a pu démontrer (Rose et coll., 1968) qu'on pouvait alors prédire la sécrétion de 17-OH corticostérone d'une personne se trouvant dans une situation donnée.

\subsection{L'INHIBITION DE L'ACTION}

Comme l'exprime H. Laborit (1976), chaque individu cherche à se gratifier, ou plus exactement, par une action sur l'environnement, cherche à satisfaire son équilibre homéostasique, son bien-être, son plaisir. Cette action aboutit en réalité à conserver la structure complexe de l'organisme. Conservation de la structure et recherche du plaisir sont, pour Laborit, indissociables.

\subsubsection{Le système de la récompense}

Les expériences d'autostimulation chez le rat (Olds et Milner, 1954) ont permis de mettre en évidence un "système de la récompense" qui fait intervenir des circuits correspondant au faisceau médian du télencéphale ("median forebrain bundle" ou MFB), faisceau qui prend naissance dans "l'aire mésencéphalique limbique" de Nauta et fournit des branches terminales à l'hypothalamus latéral, à l'aire pré-optique, l'amygdale, le septum et le néo-cortex (cortex préfrontal). L'influx nerveux peut parcourir cette formation par voie ascendante (Stein, 1968) ou descendante, et permet ainsi la coïncidence entre l'intention et le résultat de l'action. Le rat dont le système est ainsi excité, peut appuyer jusqu'à cent fois par minute, ignorant la nourriture, l'eau et le sommeil et, s'il a le choix entre deux pédales, l'une procurant le "plaisir", l'autre la nourriture, il se laisse mourir de faim. Un animal plus évolué, comme un singe, se comporte exactement de la même façon.

Les voies du MFB mettent en jeu deux neuromédiateurs catécholaminergiques : dopamine et noradrénaline.

L'anticipation ou la recherche de la récompense, résultant de stimulus ayant été éprouvés antérieurement comme gratifiants, provoque la facilitation (renforcement positif) du comportement antérieurement récompensé. Il s'agit là d'un apprentissage.

\subsubsection{Le système de la punition}

Inversement, l'anticipation ou la crainte d'une punition, déjà éprouvée comme telle, provoque la suppression du comportement antérieurement puni.

Ce comportement d'inhibition, qui s'oppose au comportement d'action, a pour substratum anatomique une formation antagoniste du MFB, le "periventricular system" ou PVS (Stein, 1968), qui constitue un véritable système de la punition (ou de la non-récompense). Le circuit réalise une connexion entre cortex orbito-frontal, hippocampe, hypothalamus ventro-médian et la région dorso-médiane du mésencéphale. Il entraîne un comportement d'évitement. 
On doit à Anokhin (1975) les premières expériences, chez le rat, sur l'inhibition résultant du non-renforcement par la récompense alimentaire : l'émotion en rapport avec l'attente alimentaire n'est pas renforcée, l'excitation conditionnée n'entraine pas la gratification attendue (renforcement négatif). En fait, la punition peut déclencher soit la fuite ou la lutte, soit l'inhibition. L'inhibition de l'action survient seulement lorsque la punition ne peut être évitée par la fuite ou la lutte. Et pour savoir que cet évitement est impossible, il faut un apprentissage : l'apprentissage de l'inefficacité de l'action.

C'est un processus "d'inhibition en tension", et chez l'homme l'angoisse ou la dépression ne serait que l'impossibilité ou l'inutilité d'agir. Laborit, avec son équipe (Kuntz et coll., 1974), en apporte la démonstration avec des rats soumis à des stimulations électriques plantaires au rythme de 10 cycles de $21 \mathrm{~s}$ par jour pendant 7 jours consécutifs. Ces animaux qui n'ont ni la possibilité de fuir ni celle de lutter font une hypertension artérielle stable. Le système inhibiteur de l'activité motrice (SIA) mis en jeu nécessite un apprentissage donc une mémorisation donc l'intervention des aires limbiques. Laborit montre ensuite que deux systèmes doivent intervenir dans l'inhibition, les systèmes cholinergique et sérotoninergique, en mettant en jeu l'hypothalamus ventro-médian, l'hippocampe dorsal, l'amygdale latérale, le noyau caudé et certaines aires corticales, en particulier le cortex préfrontal.

Cette inhibition de l'action peut être à l'origine de la dépression ou de certaines maladies psychosomatiques.

\subsection{STRESS ET DOULEUR}

Deux catégories d'arguments lient stress et douleur :

- la libération des morphines endogènes (au niveau de la glande médullo-surrénale et de l'hypophyse) en même temps que celle des hormones du stress ;

- l'apparition d'une analgésie lors de l'exposition aux agents stressants.

De nombreuses expériences étayent cette découverte. Des rats soumis à des chocs électriques douloureux ou à une immobilisation forcée (stress de contrainte) présentent une analgésie presque comparable à celle provoquée par la morphine.

\subsubsection{Quel rôle peut jouer cette analgésie dans le stress?}

Pour Guillemin, les endorphines aident à ignorer la douleur d'une blessure ou d'un traumatisme. Dantzer (1989) résume ce phénomène en écrivant : "La peur diminue la douleur". Un animal attaqué et blessé par un agresseur ne peut trouver son salut que dans la fuite et il a besoin pour cela de pouvoir concentrer toute son attention et toutes ses ressources sur les moyens de faire face à la situation. La douleur (ou la conscience de la douleur) le priverait d'une partie de ses moyens. La peur ne peut coexister avec la douleur. Une fois le danger écarté, l'animal va pouvoir consacrer son activité au soin de ses blessures. De nombreuses expériences confirment cet antagonisme fonctionnel entre la peur et la douleur. 


\subsubsection{Mais quelle est l'origine de cette analgésie ?}

Est-elle bien due à la libération de morphines endogènes ?

Parmi les différents critères de démonstration, le plus simple est l'utilisation préalable de produits qui bloquent les récepteurs morphiniques : naloxone ou naltrexone. Elle a permis de différencier l'analgésie dite "opiö̈de" (c'est-à-dire provoquée par les morphines endogènes) de l'analgésie dite "non-opioïde". Toutefois, certaines formes d'analgésie opioïde ne disparaissent pas après ablation de l'hypophyse ou de la glande médullo-surrénale.

Terman et coll. (1984) ont démontré que l'administration d'un choc électrique continu pendant 3 min provoque une analgésie non-opioïde, alors que des chocs électriques intermittents (quelques secondes toutes les minutes pendant $20 \mathrm{~min}$ ) déterminent une analgésie opioïde ${ }^{18}$ (fig. 6.27).

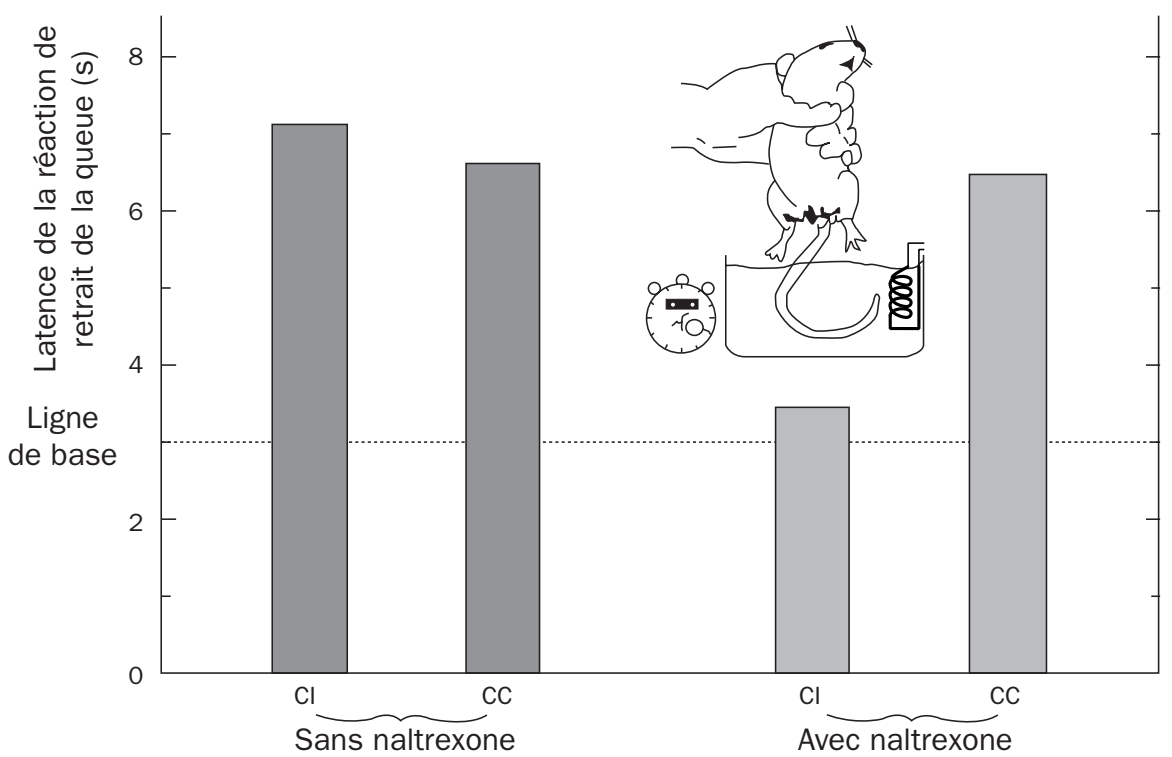

Figure 6.27 - Analgésie induite par le stress (d'après Terman et coll., 1984) Des rats sont soumis à des chocs électriques intermittents $(\mathrm{Cl})$ ou à un choc continu (CC). La latence de la réaction de retrait de la queue à la chaleur est mesurée avant le test (ligne de base) et à la fin du test. Le prétraitement par un antagoniste des récepteurs opiacés, la naltrexone, bloque l'analgésie induite par les chocs intermittents, mais pas celle due au choc continu.

Des expériences faites chez la souris mise en face d'un individu très agressif ont démontré que la forme d'analgésie produite dépend de la possibilité d'initiative de la souris par rapport au danger. Au moment des premières attaques, lorsque l'issue du combat n'est pas encore évidente, la souris présente une analgésie non-opiö̈de.

18 On peut distinguer aussi analgésie hormonale et analgésie nerveuse (ou non-hormonale), distinction qui ne recoupe pas forcément la précédente. 
Lorsque le danger ne peut plus être maîtrisé, l'analgésie est de type opiö̈de. Le sujet s'est alors replié sur lui-même, en posture de soumission. Au contraire, la souris attaquante développe une hyperalgie.

L'analgésie non-opioïde apparaît aussi lorsqu'en face d'un danger, l'animal conserve de nombreuses options de réponse possibles. On retrouve la théorie de Fanselow (1985) pour qui une peur modérée est accompagnée d'une analgésie non-opioïde, alors qu'une peur panique développe une analgésie opioïde (fig. 6.28).

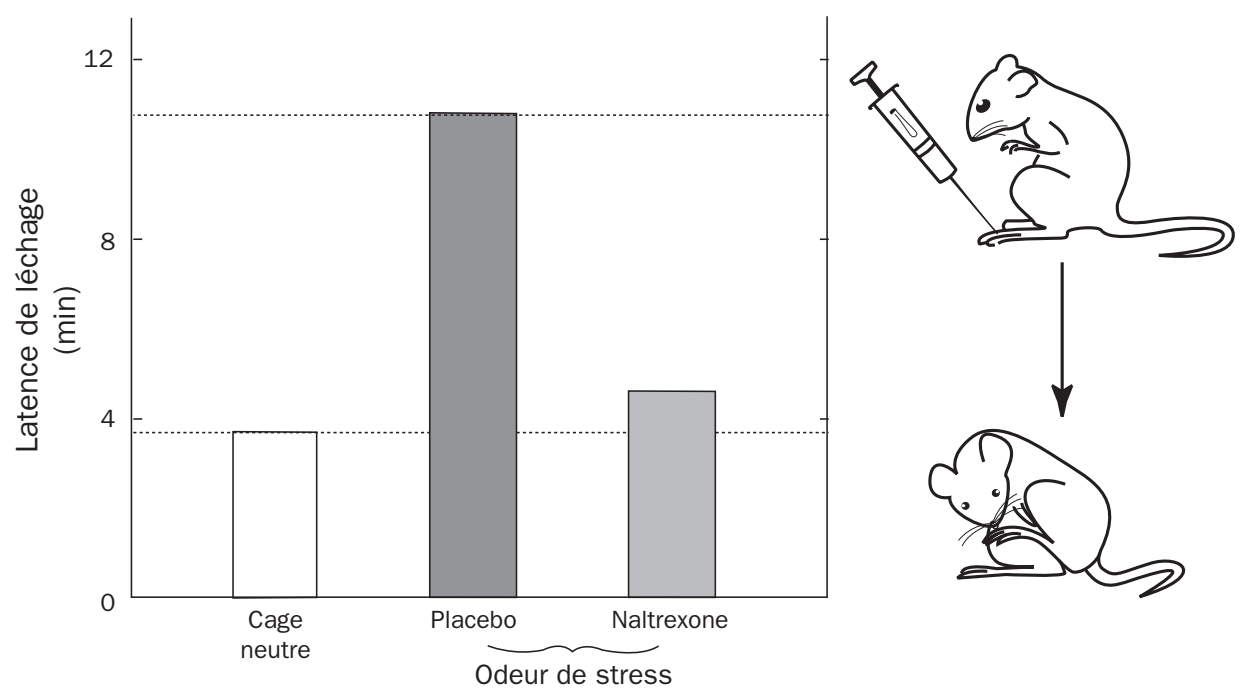

Figure 6.28 - Analgésie induite par la peur (d'après Fanselow, 1985)

La peur inhibe les comportements motivés par la douleur. Des rats ayant reçu une injection de formol dilué dans la patte sont placés dans une cage neutre ou dans une cage imprégnée de l'odeur d'un congénère exposé à des chocs électriques. Ce dernier dégage une odeur de stress qui est stressante pour ses congénères. Dans ce dernier cas, on observe une augmentation importante de la latence de léchage de la patte. Ce phénomène est dû à la libération d'opioïdes endogènes puisqu'il est bloqué par l'injection préalable de naltrexone.

\subsection{PSYCHO-NEUROCARDIOLOGIE : LE CEUR ET LE STRESS}

Le cœur est à la fois sous le contrôle du système nerveux central, via l'innervation du nerf vague, et sous le contrôle du système sympathique, à partir des noyaux paraventriculaires de l'hypothalamus (Natelson, 1985).

Les décès d'origine cardiaque sont fréquemment dus à une fibrillation ventriculaire. Elle peut être déclenchée par un épisode d'ischémie aiguë (infarctus du myocarde), ou survenir lors de poussées hypertensives ou d'augmentation du tonus sympathique (Meredith et coll., 1991). Plusieurs études ont montré l'existence d'un lien spécifique entre un stress émotionnel (générateur de décharges de catécholamines : adrénaline et 
noradrénaline) ${ }^{19}$ et la survenue d'une tachycardie (Dimsdale et Moss, 1980) ou d'une fibrillation ventriculaire (Fricchione et Vlay, 1986 ; Reich et coll., 1981 ; Follick et coll., 1988). L'ischémie cardiaque elle-même peut être provoquée par des stress psychologiques (le fait de parler en public ou les tensions de la vie quotidienne) (Deanfield et coll., 1984). On peut donc mourir d'émotion. Inversement, on a pu obtenir une diminution des arythmies ventriculaires par la psychothérapie, la relaxation ou après placebo.

\subsection{LES PROTÉINES DU STRESS}

Au départ considérées comme des protéines de "choc thermique" (hsp ou heat shock protéins), car elles avaient été décelées dans des cellules de drosophiles oubliées sur un radiateur, il s'agit en fait de protéines fondamentales pour la vie cellulaire qui ont été conservées au cours de l'évolution. Il en existe plusieurs familles, de poids moléculaires divers : hsp 110, hsp 90, hsp 70, hsp 60, hsp 20... Elles ont comme fonction essentielle de mettre en place, de maintenir ou de protéger la structure dans l'espace des autres protéines de la cellule, structure qui conditionne leur fonction ${ }^{20}$.

Les protéines du stress s'associent à d'autres protéines ayant perdu (par dénaturation), ou n'ayant pas encore acquis (par biosynthèse) leur conformation tridimensionnelle. La finalité de cette association est de prévenir l'agrégation des protéines altérées, éliminer les protéines anormales reconnues comme étrangères, participer au transfert des protéines du cytoplasme vers la membrane plasmique ou les organites cellulaires. Elles constituent en quelque sorte des "chaperons moléculaires" (fig. 6.29). Les protéines hsp 70 se fixent sur les protéines totalement dénaturées, tandis que celles de la famille hsp 60 se fixent sur les protéines partiellement repliées ("molten" globules).

Lorsque la cellule subit un stress, par exemple un choc thermique, la cellule se "fige", la fabrication des protéines est ralentie à l'exception des protéines hsp dont la synthèse est accélérée. Les autres protéines sont dénaturées par le choc qui fait apparaitre en surface leur zone hydrophobe, d'où la tendance à former des agrégats qui peuvent conduire à la mort de la cellule. Les protéines hsp 70 interviennent d'abord en masquant cette zone hydrophobe et permettent ensuite à la protéine de reprendre sa structure d'origine.

Le récepteur des glucocorticoïdes est complexé aux protéines hsp 90 et hsp 70 dans le noyau, les protéines cytoplasmiques se lient à l'hsc (heat shock cognate protein de

19 Ces catécholamines peuvent favoriser l'ischémie cardiaque et donc le risque d'arythmie par leur effet vaso-constricteur et leur action sur l'adhésivité plaquettaire (qui augmente le risque thrombogène : formation d'un caillot à l'intérieur du vaisseau).

20 L'importance du repliement correct de la protéine apparaît dans la maladie de CreutzfeldtJacob (voir chap. $3, \S 7.1$ ), dans laquelle certaines protéines particulières, les prions, présentent une conformation déformée par rapport à ceux qui interviennent dans les cerveaux sains. 
$70 \mathrm{kDa}$ ) au cours de leur synthèse, et à l'hsp 70 en cas de dénaturation. Pour Baulieu, la protéine hsp 90 serait liée de façon réversible avec le récepteur des androgènes et marquerait la région liant l'ADN (Baulieu, 1990).

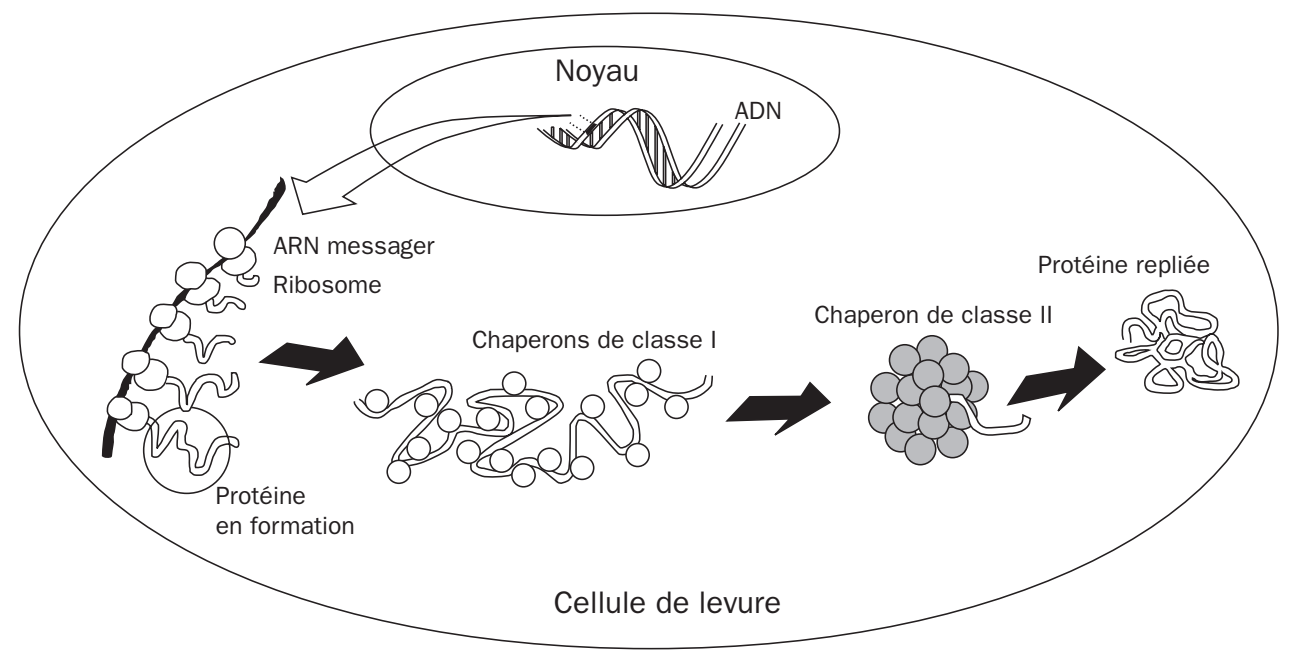

Figure 6.29 - Les protéines du stress : des molécules chaperons

(d'après Vincent, 1997)

Au moins deux types de molécules chaperons interviennent dans le repliement des protéines. Les chaperons de classe I, de petite taille, se fixent tout d'abord sur les régions hydrophobes de la chaîne protéique. Une fois partiellement repliée, celle-ci se place sous la protection d'un chaperon de classe II, grosse structure comportant une cavité en son centre.

Dans le cas de stress hypoglycémique, les protéines synthétisées ont une "maturation" incomplète. Des protéines de stress nommées "grp" (glucose regulated proteins) retiennent alors ces protéines dans le réticulum pour permettre leur maturation ultérieure. Les grp ont été classées dans la famille des hsp.

Les protéines hsp jouent également un rôle important dans la défense immunitaire (Baulieu, 1995). Elles représentent des antigènes majeurs lors des infections bactériennes ou parasitaires. Elles amplifient l'activation lymphocytaire et donc la réponse immunitaire, participent à la surveillance immune, à l'élimination des cellules $\mathrm{T}$ cytotoxiques, mais aussi à l'auto-immunité par mimétisme moléculaire entre les protéines hsp des agents pathogènes et celles de l'hôte. Associées à des peptides tumoraux, elles pourraient stimuler l'immunité antitumorale (Jacquier-Sarlin et Polla, 1994 ; Menoret et Le Pendu, 1994).

D'autres protéines de stress, les shsp (small heat shock proteins) - telle la hsp 27 peuvent apparaître comme de nouveaux inhibiteurs intracellulaires de la mort cellulaire (par nécrose ou apoptose), et jouer ainsi un rôle dans l'intégrité de l'organisme (Arrigo et coll., 1997). 


\subsection{STRESS ET MALADIE}

L'être humain est soumis, dans son existence quotidienne, à de multiples microagressions qui constituent autant de microtraumatismes pour son psychisme et son cortex surrénal, et élèvent vraisemblablement ses besoins en vitamine C. L'homme est génétiquement un hypo-ascorbémique et les micro-agressions accroîtraient cette infirmité d'où, selon Pauling, une fragilité devant les agressions bactériennes et virales, et une prédisposition au cancer. A cet égard, de nombreuses recherches réalisées chez l'animal (Shklar et Schwartz, 1993 ; Lupulescu, 1996...) ont permis de montrer qu'un grand nombre de micronutriments organiques ou inorganiques (caroténoïdes, tocophérol, quercétine, rutine, sélénium, zinc...) sont capables de prévenir l'apparition de certains cancers ou même d'exercer des effets anticancéreux. L'étude des mécanismes de ces effets a permis de montrer que ces substances agissent par leur propriété anti-oxydante, la stimulation du système immunitaire, l'expression de hsp (heat shock proteins), ainsi que par la répression de certains gènes tel que P53.

Comme tout agent susceptible de moduler le fonctionnement du système nerveux ou du système des glandes endocrines, un agent stressant modifie notre système immunitaire, et peut donc favoriser (ou parfois inhiber) le développement d'une maladie ${ }^{21}$.

De nombreux travaux, depuis une quinzaine d'années, s'attachent à démontrer et à préciser ces relations, en particulier entre stress et cancer (voir chap. 16, § 4.2). Mais si la genèse du cancer peut parfois mieux s'expliquer dans le cadre de la psychoneuro-immunologie, il faut se méfier de ce que Nicole Alby appelle le "tout psychologique", il faut éviter de construire un nouveau dogme. Il y a, en effet, des gens heureux qui ne guérissent pas d'un cancer, et des personnes profondément déprimées qui en guérissent.

\section{L'AXE HYPOTHALAMO-HYPOPHYSO-SURRÉNALIEN AU COURS DU VIEILLISSEMENT}

Durant le vieillissement normal, et a fortiori durant le vieillissement pathologique, la dégénérescence de neurones s'accompagne d'une prolifération gliale, tandis que les neurotransmetteurs présentent des modifications quantitatives et/ou qualitatives. Des modifications de la fonction endocrinienne pourront en résulter et être utilisées comme marqueurs de la dégradation du système nerveux central.

D'un autre côté, les maladies endocriniennes sont susceptibles d'entraîner des symptômes psychopathologiques, et Brambilla (1992) établit le parallèle entre les

21 Selye (1936) avait, le premier, signalé les modifications du tissu lymphoïde (thymus, rate, ganglions lymphatiques...) au cours du stress. 
aspects psycho-endocriniens du vieillissement normal et les aspects psychopathologiques de certaines maladies neuro-endocrines, qui auraient un substratum métabolique commun. C'est l'hypersomnie et la diminution de la libido dans l'acromégalie, l'anxiété, l'agitation et l'irritabilité dans l'hyperthyroïdisme, la dépression et les déficits cognitifs dans l'hypothyroïdisme, la dépression encore dans le syndrome de Cushing comme dans la maladie d'Addison et la diminution, pour les deux sexes, de la libido dans les syndromes hyperprolactinémiques.

Nous avons vu que les trois principales catégories d'hormones produites par le cortex surrénal humain sont le cortisol, l'aldostérone et la déhydro-épiandrostérone (DHEA) et son sulfate DHEA-S.

\subsection{LE CORTISOL}

Pour Touitou et coll. (1982), les productions d'ACTH et du cortisol surrénalien ne seraient pas modifiées au cours du vieillissement et les variations circadiennes de cortisol restent semblables chez le jeune et chez la personne âgée. Toutefois, la réponse du cortisol à l'ACTH serait augmentée chez la personne âgée.

Ferrari et coll. (1995), dans une étude portant sur seize femmes âgées de 66 à 90 ans et quatre sujets contrôles âgés de 20 à 30 ans, obtiennent des résultats différents. La courbe circadienne du taux de l'ACTH plasmatique est parallèle à celle du sujet jeune, mais à un niveau plus élevé, aussi bien la nuit que le jour (fig. 6.30.a). De même, le taux du cortisol plasmatique est en général plus élevé chez la personne âgée que chez le jeune (fig. 6.30.b). A l'acrophase, qui survient au même moment dans les deux cas pour le cortisol, les valeurs sont à peu près similaires, tandis que les valeurs minimum (nadir) sont significativement plus élevées chez la personne âgée. Autrement dit, les sécrétions de mélatonine et de cortisol ont une évolution inverse au cours du vieillissement, le taux de la mélatonine s'abaisse tandis que celui du cortisol s'élève.

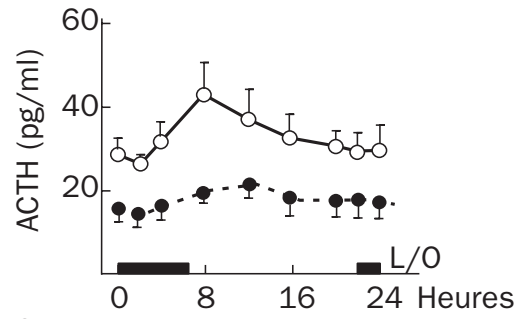

a

$$
\text { - - Sujet âgé - - Sujet jeune }
$$

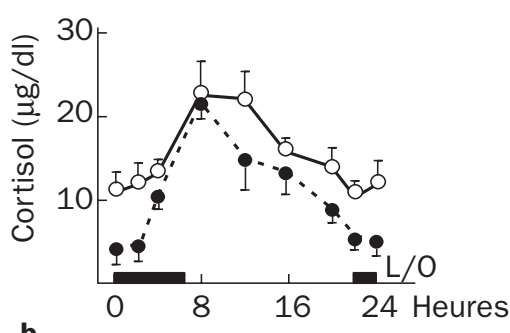

b

$L=$ lumière et $O=$ obscurité

Figure 6.30 - Courbes circadiennes de la sécrétion de I'ACTH (a) et du cortisol (b) plasmatiques (d'après Ferrari et coll., 1995)

Selon Touitou et coll. (1982 et 1983a), si la variation circadienne du cortisol persiste chez la personne âgée, le rythme saisonnier a disparu. Toutefois, l'augmentation de la fraction active libre du cortisol plasmatique, que l'on peut observer chez la personne 
âgée, pourrait être la conséquence de la diminution de concentration des protéines de liaison, et / ou d'une diminution de la capacité de liaison de ces protéines au cours du vieillissement.

Chez l'animal, des travaux expérimentaux démontrent que, si le vieillissement n'affecte en rien la capacité de déclencher la sécrétion de glucocorticoïdes en réponse à un stress, il altère la capacité de l'interrompre le moment venu (Sapolsky et coll., 1983). L'existence de ce dérèglement a été confirmée à plusieurs reprises chez le rat âgé.

De nombreux résultats suggèrent que l'hypersécrétion de glucocorticoïdes durant le vieillissement serait due à des modifications dégénératives au niveau de l'hippocampe, où l'on a pu mesurer une perte des neurones et une diminution d'environ $50 \%$ du nombre de récepteurs de glucocorticoïdes. Le dommage hippocampique aurait pour effet de désensibiliser l'axe hypothalamo-hypophyso-surrénalien à la rétroaction négative exercée par les glucocorticoïdes, d'où l'élévation de ceux-ci. Inversement, les glucocorticoïdes peuvent progressivement endommager l'hippocampe au cours du temps. D’où un cercle de dégénérescence, décrit par Sapolsky et coll., sous le nom de "cascade glucocorticoïde".

Chez l'homme, l'exposition prolongée à des concentrations élevées de glucocorticoïdes semble accélérer le processus de vieillissement cérébral et pourrait être à la base des troubles cognitifs observés à l'âge avancé.

\subsection{L'ALDOSTÉRONE}

Le vieillissement s'accompagne d'une diminution de la sécrétion d'aldostérone plasmatique, qui peut être attribuée à la diminution de l'activité de la rénine (Cugini et coll., 1982 ; Haus et coll., 1989).

\subsection{LES HORMONES ANDROGÈNES}

Les taux plasmatiques de DHEA et de DHEA-S s'abaissent progressivement dans les deux sexes au cours du vieillissement, tandis que la réponse de ces stéroïdes à l'ACTH est progressivement diminuée (Parker et coll., 1981). C'est ce que les chercheurs anglo-saxons appellent "adrénopause".

Le taux plasmatique de DHEA-S, qui apparaît à l'âge de 7 ans, atteint un maximum entre 20 et 30 ans puis décroît d'environ 2\% par an entre 80 et 90 ans (Migeon et coll., 1957 ; Orentreich et coll., 1984).

L'intérêt du DHEA-S est que sa concentration est relativement constante au cours de la journée (contrairement à celle du cortisol) et il paraît un des meilleurs indicateurs mesurables du vieillissement. Son action préventive ou curative à cet égard a été expérimentée chez l'animal et même chez l'homme. Le DHEA ingéré se transforme en grande partie en DHEA-S. Aussi, des doses relativement faibles de DHEA (50 mg jour) ont été données pendant 6 mois en double aveugle, comparativement à un placebo, par Morales et coll. (1994). 
Le résultat est net :

- une augmentation du bien-être (well-being) de l'ordre de $80 \%$ chez les femmes et $67 \%$ chez les hommes au bout de 3 mois, alors que l'effet du placebo restait inférieur à $10 \%$; mais il n'y a pas de changement de la libido (!) ;

- une élévation dans le sang du taux de l'IGF1 (dont on sait qu'il décroît avec l'âge), avec abaissement corrélatif de sa protéine porteuse.

Beaulieu, qui rapporte ces résultats (1995), suggère que l'amélioration du bien-être peut être rapportée à l'augmentation de l'IGF1, ou à un effet cérébral direct de la DHEA (dont la forme libre pénètre facilement dans le cerveau), ou à un autre mécanisme. 



\section{CHAPITRE 7}

\section{LE PANCRÉAS ENDOCRINE}

\section{CARACTÉRISTIQUES GÉNÉRALES}

\subsection{RAPPEL EMBRYOLOGIQUE}

C'est un dérivé endodermique du tube digestif, au niveau de l'ébauche hépatique.

Le pancréas exocrine provient des deux bourgeons ventraux et d'une partie du bourgeon dorsal.

Le pancréas endocrine provient du seul bourgeon dorsal.

Le pancréas mesure de 15 à $20 \mathrm{~cm}$ de long et pèse environ $100 \mathrm{~g}$ chez l'homme.

\subsection{Histologie}

A l'inverse du foie, le pancréas comporte deux parties anatomiquement et physiologiquement différentes :

- une partie exocrine, constituée par les acini ; les canaux de Wirsung et Santorini déversent dans l'intestin le suc pancréatique dont les enzymes dégradent lipides, glucides, protides ;

- une partie endocrine qui présente l'aspect d'une glande séreuse, avec de nombreux îlots (décrits par Langerhans), notamment dans la région de la queue de la glande et près des vaisseaux (au nombre de 1 à 2 millions). Ils ont un diamètre variant de 0,1 à $0,2 \mathrm{~mm}$; leur poids total ne constitue qu'environ $1 \%$ du poids total de la glande.

Elles déversent dans le sang des hormones qui contrôlent le métabolisme glucidique. Laguesse, dès 1893, associe la fonction endocrine du pancréas aux îlots de Langerhans.

On distingue aisément par immunofluorescence au moins trois types cellulaires : les cellules A2 qui sécrètent un facteur hyperglycémiant, le glucagon; les cellules B qui sécrètent la seule hormone hypoglycémiante, l'insuline ; un troisième type cellulaire (cellules $\mathrm{A} 1$ ou D) sécrète la somatostatine, isolée initialement à partir de l'hypothalamus. Le pancréas sécrète encore un polypeptide de $36 \mathrm{AA}$ (cellules PP ou F) qui exerce des effets biologiques sur le tractus digestif. 
Chaque îlot contient environ 3000 cellules productrices d'hormones, avec la distribution suivante (tab. 7.1). Les cellules A2, A1 et PP sont plutôt en périphérie de l'îlot, alors que les cellules B occupent plutôt une position centrale.

Tableau 7.1 - Répartition des différents types cellulaires dans les îlots pancréatiques

\begin{tabular}{|l|c|c|c|c|}
\hline Cellules & B (ou $\beta$ ) & A2 (ou $\alpha 2)$ & A1 (ou D) & PP (ou F) \\
\hline $\begin{array}{l}\text { dans un îlot dorsal } \\
\text { (queue et corps) }\end{array}$ & $66 \%$ & $28 \%$ & $4 \%$ & $2 \%$ \\
\hline $\begin{array}{l}\text { dans un îlot ventral } \\
\text { (tête du pancréas) }\end{array}$ & $74 \%$ & $20 \%$ & $4,5 \%$ & $1,5 \%$ \\
\hline
\end{tabular}

Les structures exocrine et endocrine fonctionnent indépendamment l'une de l'autre ; si on pratique une ligature des canaux de Wirsung et Santorini, la partie externe s'atrophie, tandis que les îlots de Langerhans restent intacts et continuent de sécréter leurs hormones.

\subsection{VASCULARISATION ET INNERVATION}

Les artères proviennent du tronc cœliaque et de l'artère mésentérique supérieure. L'irrigation propre aux îlots de Langerhans est moins intense que celle que reçoit, par exemple, la glande thyroïde.

L'innervation provient des plexus cœlique et mésentérique supérieur. Cette innervation des îlots de Langerhans est vagosympathique.

\section{ETUDE EXPÉRIMENTALE}

La pancréatectomie peut être chirurgicale ou chimique.

\subsection{PANCRÉATECTOMIE CHIRURGICALE}

\subsubsection{Ablation totale}

La première ablation a été effectuée par Von Mering et Minkovski (1889) :

- elle est incompatible avec la vie, chez le chien, le chat, l'homme ;

- elle n'est pas mortelle chez le mouton, le lapin, le singe.

Quand elle est réalisée, on observe :

- une action directe sur le métabolisme des glucides, qui se manifeste par une élévation du taux de la glycémie (hyperglycémie) : le taux du glucose passe de 0,8 à $5-7 \mathrm{~g} / 1$. 
Cette élévation de la glycémie provoque un syndrome associé de :

- glycosurie, c'est-à-dire de sucre dans les urines (de $10 \mathrm{~g}$ à $100 \mathrm{~g} /$ jour) ;

- polyurie par diurèse osmotique ;

- polydipsie (soif intense);

- polyphagie (due à l'insuffisance de production de calories).

L'ensemble de ces phénomènes caractérise le diabète sucré.

- Il s'accompagne :

- d'une diminution du glycogène hépatique ;

- pour compenser la glycogénolyse hépatique, il y a néoglucogenèse à partir des protéines dont le catabolisme est accéléré (amaigrissement). Pour compenser la diminution de l'utilisation du glucose dans les cellules, l'organisme réagit par un catabolisme accru des lipides, d'où élévation de la lipémie et en particulier des acides gras libres (AGL). Le foie est débordé par cette inondation d'AGL dont il ne peut oxyder la plus grande partie que jusqu'au stade acétylcoenzyme $A$, d'où la formation d'acide acéto-acétique et d'acide $\beta$ hydroxybutyrique qui passent dans le sang, ce qui entraîne :

- une cétonémie et une cétonurie. L'intensité de l'acidose sanguine prouve la gravité du diabète ; il y a dénutrition et baisse du métabolisme de base. La mort survient, en général, 10 jours après l'ablation.

\subsubsection{Ablation partielle (ablation des 3/5 de la glande)}

L'animal ne manifeste aucun trouble de la régulation des glucides, il ne présente pas de diabète. La partie restante de la glande suffit à assurer une sécrétion suffisante d'hormones, il n'y a pas d'hyperglycémie (il y a, en effet, néo-formation de cellules endocrines à partir de cellules de réserve).

En 1892, Hedon recherche une amélioration de la technique opératoire pour distinguer, avec précision, les conséquences dues au choc opératoire et celles dues à l'ablation de la glande : c'est la technique de la marcotte pancréatique. On laisse sous la peau une portion de la glande ("marcotte") pendant quelques jours, pour diminuer les effets du choc opératoire; puis on pratique l'ablation de la marcotte sous anesthésie cutanée : il y a apparition d'un diabète grave. Il est donc bien dû à la pancréatectomie effectuée et non au choc opératoire. En pratiquant cette ablation, les parties exocrine et endocrine sont éliminées en même temps. Il faut déterminer la nature du rôle de chacune d'elles.

\subsubsection{Ligature des canaux de Wirsung et Santorini}

A la suite d'une ligature des canaux de Wirsung et Santorini, il n'y a plus d'enzymes pancréatiques dans le duodénum, d'où apparition de troubles digestifs. Mais il n'y a pas de variation de la glycémie.

Les îlots de Langerhans, qui constituent la partie endocrine du pancréas, contiennent le principe hypoglycémiant capable de diminuer le taux du glucose dans le sang. 


\subsubsection{Greffe d'un fragment de pancréas}

En revanche, la greffe au cou, chez un animal pancréatectomisé, d'un fragment de pancréas en relation avec des vaisseaux et, par là, avec le reste de l'organisme, provoque la disparition du diabète ; c'est là une preuve supplémentaire en faveur de l'origine hormonale du diabète sucré.

\subsection{PANCRÉATECTOMIE CHIMIQUE}

Une vérification expérimentale est effectuée par Dunn et coll. (1943), ils pratiquent une pancréatectomie chimique à l'aide de l'alloxane. L'alloxane est un produit qui, par injection $(200 \mathrm{mg} / \mathrm{kg})$, provoque effectivement l'apparition du diabète sucré. Or l'observation de coupes histologiques du pancréas révèle une altération des cellules $\beta$ des îlots de Langerhans. Ce sont donc les cellules $\beta$ de ces îlots qui sécrètent un principe hypoglycémiant, appelé insuline.

NB - Certains sulfamides sont hypoglycémiants (étude de Loubatières en 1955). Ils stimulent la sécrétion des cellules $\beta$ des îlots de Langerhans et permettent ainsi le traitement de certains diabètes de type II (voir page 325), lorsque les cellules $\beta$ ne sont pas trop altérées.

\section{L'INSULINE}

Elle est isolée en 1922 par Banting, Best, Collip et Mac Leod.

De 1944 à 1953, Sanger (prix Nobel, 1958) étudie la molécule d'insuline, la purifie et, pour la première fois, détermine la séquence complète d'une protéine. Sanger découvre la présence de groupements S-S ; par réduction, les ponts S-S se rompent, se transforment en groupements $\mathrm{SH}$ et libèrent deux chaînes polypeptidiques différentes.

L'insuline est une hormone protéique constituée de 51 aminoacides, répartis en deux chaines (fig. 7.1.a) :

- chaîne A : 21 AA

- chaîne B : 30 AA.

La partie spécifique (caractéristique d'une espèce) porte sur quelques acides aminés seulement (les radicaux 8-9-10 et 12-14 de la chaîne B, et en particulier B30).

Malgré sa spécificité, l'insuline reste active chez tous les animaux, la séquence active est déterminée par une portion qui est donc restée constante dans sa configuration spatiale au cours de l'évolution (B23 à B25, plus A1, A5, A19 et A21).

L'unité constitutive a un poids moléculaire de 5734 chez l'homme. 


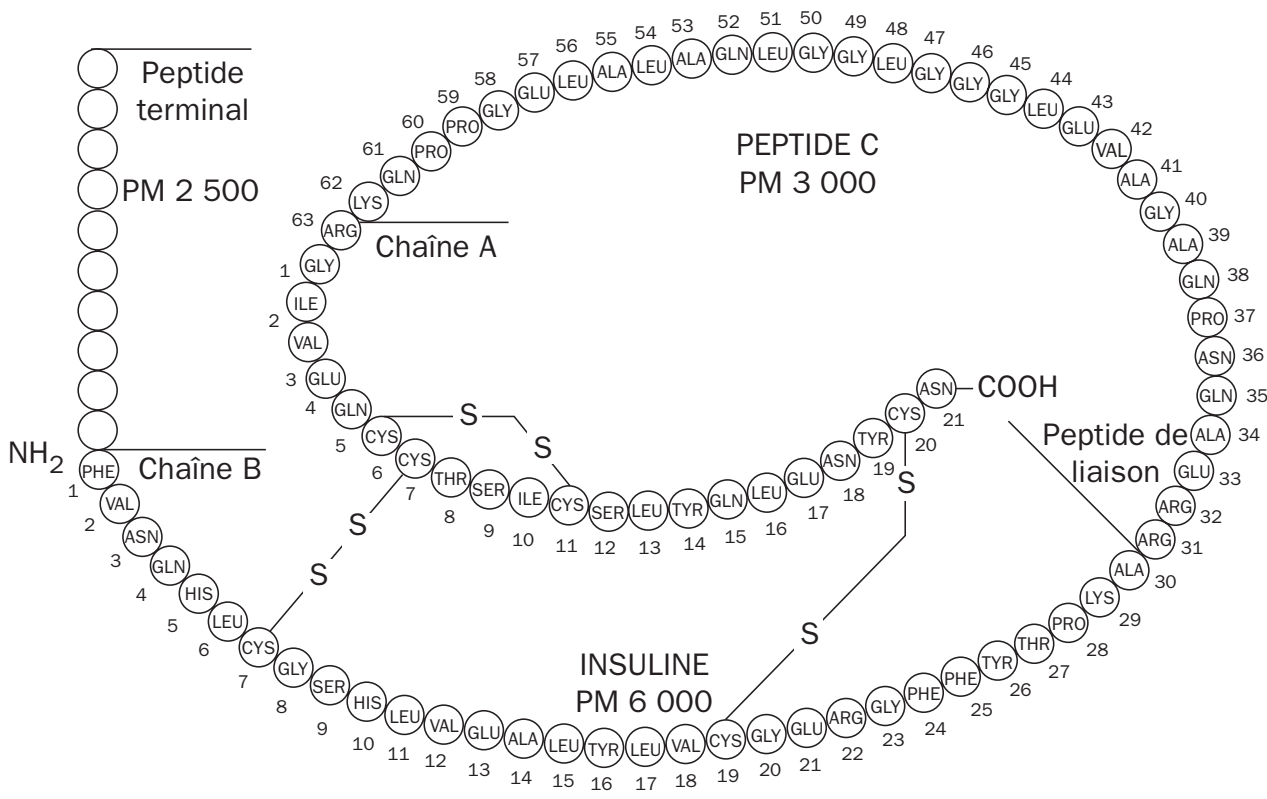

a - Structure de la pré-pro-insuline

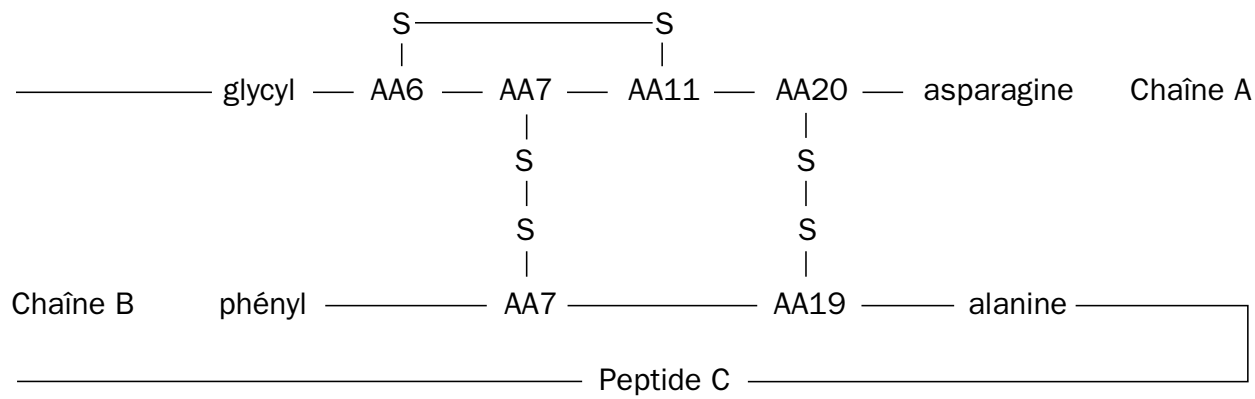

\section{b - Structure simplifiée de l'insuline}

Figure 7.1 - L'insuline

En fait, l'insuline est fabriquée dans le pancréas endocrine sous la forme d'une prépro-insuline, de PM environ 12000 (fig. 7.1.a), codée par un gène dont la séquence est connue depuis 1980. La séquence "pré" 1 est probablement coupée à l'intérieur de la citerne du réticulum endoplasmique pour libérer la pro-insuline de $86 \mathrm{AA}$ chez l'homme (84 AA chez le porc). Celle-ci est alors transportée par des vésicules vers l'appareil de Golgi ou des enzymes vont la scinder en un peptide $\mathrm{C}^{2}$, constitué par

1 Cette séquence constitue une "séquence signal" qui permet à la protéine élaborée par les polyribosomes de pénétrer dans les cavités du réticulum endoplasmique.

2 Le rôle de la séquence pro- (peptide C) est encore mal établi. Elle permet sans doute la mise en place de la structure tertiaire de l'insuline, et peut être une protection de l'insuline contre les enzymes protéolytiques de la cellule. 
33 AA (PM 3000 ), et en insuline. La transformation de la pro-insuline en insuline s'achève ${ }^{3}$ dans les vésicules sécrétoires, qui vont libérer par exocytose l'insuline et le peptide $\mathrm{C}$ en quantités équimolaires. Chez le diabétique insulinotraité, le peptide $\mathrm{C}$ constitue le seul marqueur fiable de l'insulinosécrétion résiduelle puisque uniquement d'origine endogène (pas de peptide $\mathrm{C}$ dans les insulines injectées), et du fait de l'absence d'interférence dans le dosage radioimmunologique de l'insuline avec les anticorps anti-insuline générés par le traitement insulinique chronique. Chaque vésicule libère près de 8000 molécules d'insuline. L'exocytose est un phénomène complexe qui fait intervenir les ions $\mathrm{Ca}^{2+}$ (voir fig. 7.2 et 7.3).

L'insuline, la pro-insuline et le peptide $\mathrm{C}$ sont présents dans le plasma sous une forme libre, non-liée à une protéine $(94 \%$ d'insuline + peptide $\mathrm{C}$ et près de $6 \%$ de pro-insuline + des fragments intermédiaires qui peuvent être immunoréactifs à des anticorps anti-insuline).

L'unité internationale d'insuline est la quantité de substance nécessaire pour abaisser la glycémie d'un lapin de $2 \mathrm{~kg}$ (à jeun depuis $24 \mathrm{~h}$ ) du niveau normal à $0,45 \mathrm{~g} / 1$, dans un délai de $5 \mathrm{~h}$. Un $\mathrm{mg}$ d'insuline correspond à une activité de 24,5 UI (ou $10 \mu \mathrm{UI}=0,4 \mathrm{ng}$ ).

Le foie est un site important d'action et de dégradation de l'insuline. A l'état basal, l'insulinémie périphérique est de 0,4-0,6 $\mathrm{ng} / \mathrm{ml}$ (soit 0,1 nmol/1). Le peptide $C$ est présent dans le sang à une concentration de 1 à $2 \mathrm{ng} / \mathrm{ml}$. L'insulinémie portale est de $1,2-1,6 \mathrm{ng} / \mathrm{ml}$.

La demi-vie de l'insuline est brève, environ $5 \mathrm{~min}$. La dégradation se fait essentiellement dans le foie et les reins, probablement sous l'effet de protéases membranaires, au moment de l'impact hormonal sur les cellules cibles.

\section{ACTIONS PHYSIOLOGIQUES ET MODE D'ACTION DE L'INSULINE}

\subsection{EFFETS DE L'INSULINE}

L'insuline stimule le processus anabolique et la mise en réserve de l'énergie. Elle agit essentiellement sur trois organes cibles et sur le métabolisme glucidique et lipidique des divers tissus périphériques. Son action métabolique générale s'exerce de deux façons :

- en favorisant l'entrée de certains substrats dans les cellules ;

- en agissant sur le métabolisme cellulaire de ces substrats.

3 Les insulines commerciales, isolées à partir de pancréas de porc ou de bœuf, contiennent toutefois environ $2 \%$ de pro-insuline. Pour éviter la formation d'anticorps contre ces insulines "étrangères", les laboratoires Lilly fabriquent depuis 1982 une insuline humaine obtenue par génie génétique (Umuline). 


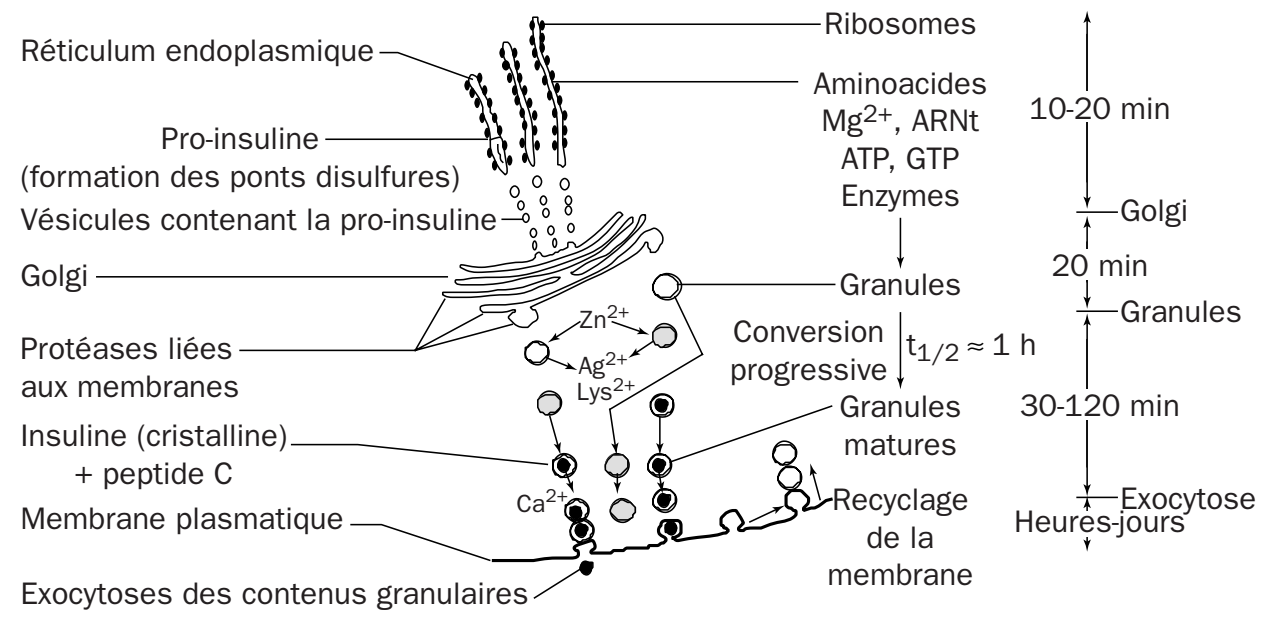

\section{a - Représentation de la biosynthèse de l'insuline au niveau des organites de la cellule $\beta$ du pancréas}

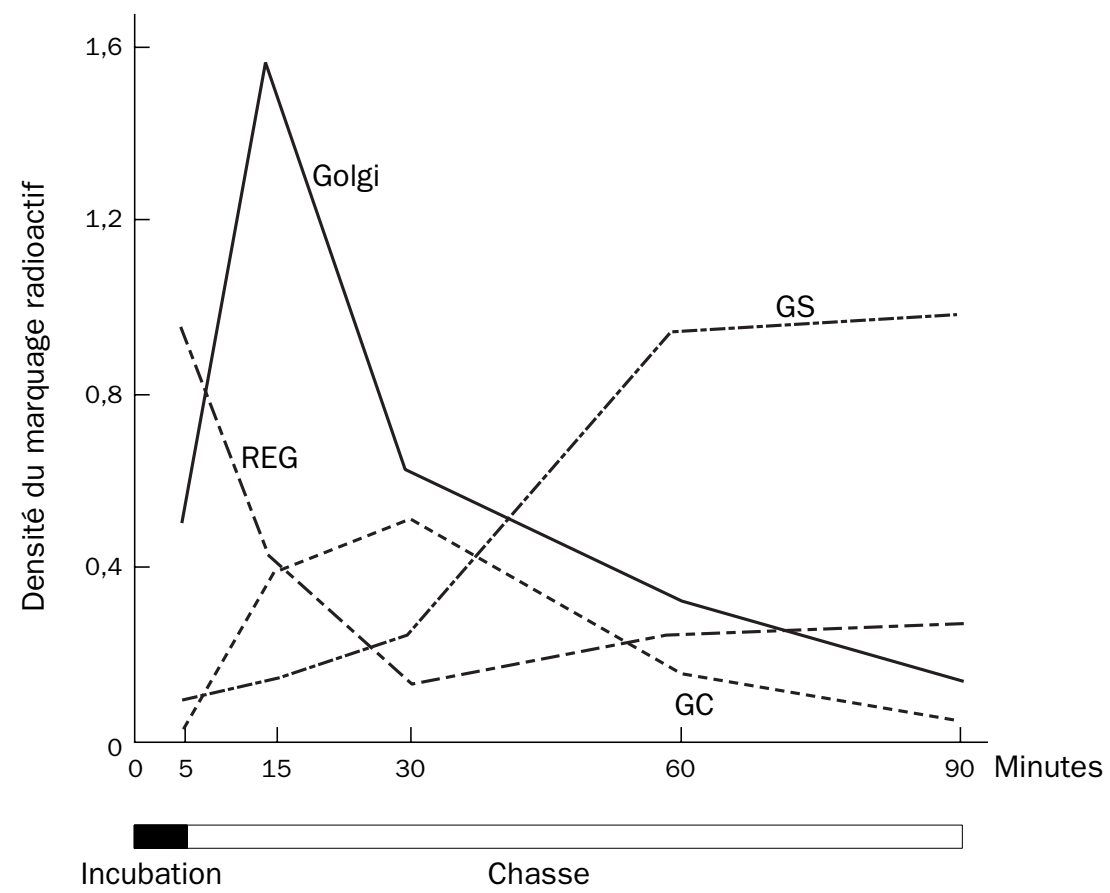

b - Représentation graphique du même phénomène

Figure 7.2 - Biosynthèse de I'insuline (d'après Orci, 1984)

GC: granule de condensation (ou recouvert) ; GS : granule de sécrétion (ou non-recouvert) ; $R E G$ : réticulum endoplasmique granulaire.

L'incorporation de la ${ }^{3} \mathrm{H}$-Leucine par des cellules $\beta$ en culture permet de déterminer simultanément la nature de la molécule hormonale marquée et la localisation du marquage à un instant donné après l'injection de l'acide aminé marqué. 


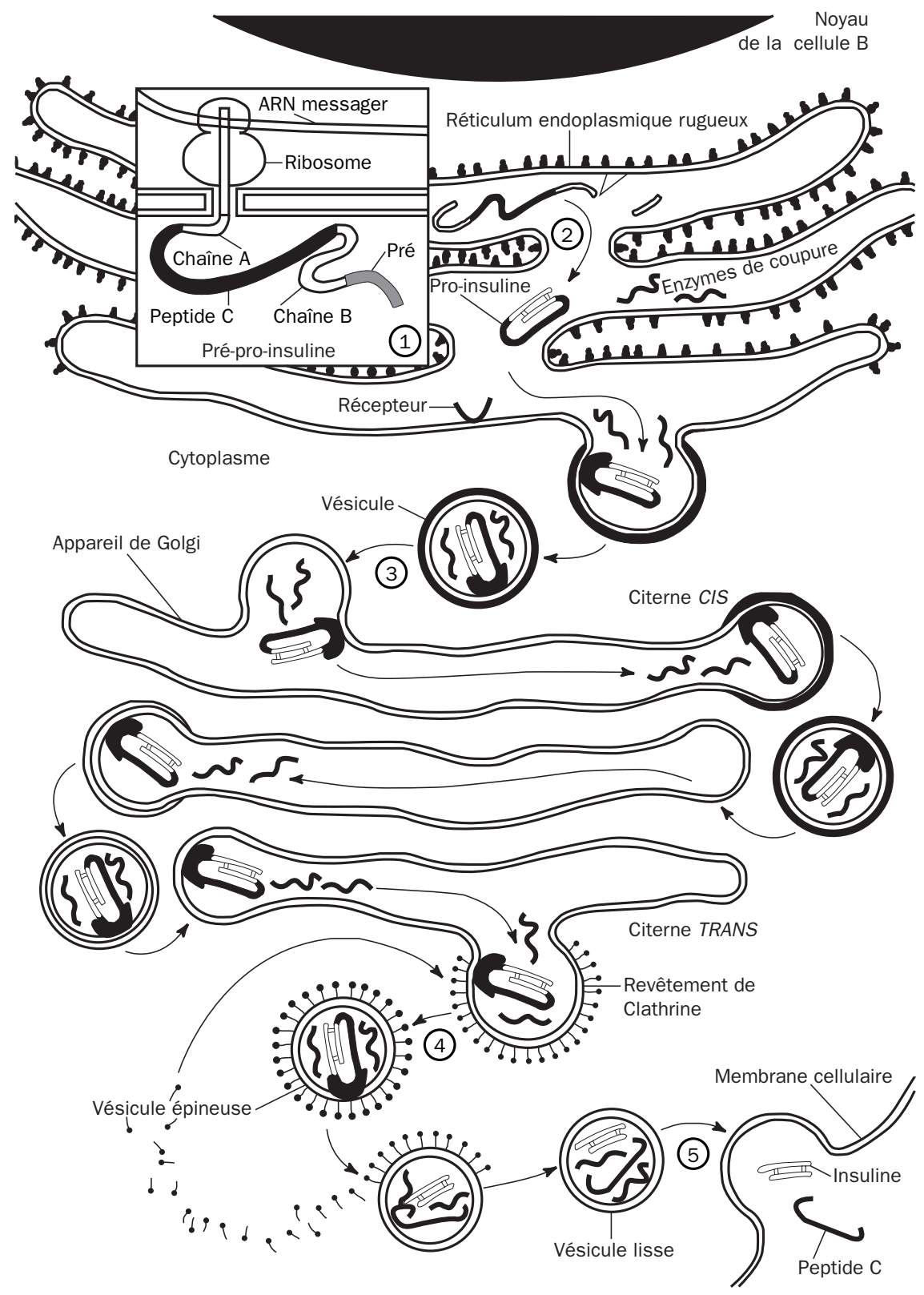

Figure 7.3 - Etapes cellulaires de la biosynthèse de l'insuline

(d'après Orci et coll., 1988)

Cette figure illustre les différentes étapes de la biosynthèse de l'hormone, depuis l'élaboration du précurseur (pré-pro-insuline) par les polyribosomes (1), la libération de la proinsuline dans les cavités du réticulum endoplasmique (2), le transfert de la pro-insuline dans les vésicules de l'appareil de Golgi (3) et la scission dans les vésicules sécrétoires de la pro-insuline en peptide $C$ et insuline (4) qui sont libérées par exocytose (5). 


\subsubsection{Effets sur le foie}

Le foie est le siège principal de la néoglucogenèse (fabrication de glucose à partir de précurseurs issus du catabolisme protidique et lipidique). C'est le siège exclusif de la cétogenèse. Le glucose y pénètre par simple diffusion ${ }^{4}$.

L'insuline stimule la synthèse de glucokinase, qui est une hexokinase spécifique du foie, favorisant la formation de glucose-6-phosphate et sa transformation en glycogène (ce qui accroît son effet hypoglycémiant) ou son utilisation (glycolyse). Elle stimule aussi la lipogenèse hépatique et inhibe l'effet cétogène du glucagon. Elle possède également sur les protides une action à la fois anabolique et anticatabolique.

\subsubsection{Effets sur le tissu adipeux}

C'est le principal réservoir d'énergie de l'organisme et la source des AGL (acides gras libres). Il représente $15 \mathrm{~kg}$ de tissu chez l'homme. L'insuline stimule la lipogenèse (stockage de triglycérides), c'est aussi la seule hormone antilipolytique de l'organisme. Elle diminue la glycogénolyse et la protéolyse. Elle s'oppose à l'effet cétogénique du glucagon et favorise l'utilisation périphérique des corps cétoniques.

\subsubsection{Effets sur le muscle strié (squelettique et cardiaque)}

L'insuline stimule la synthèse du glycogène (par stimulation de l'hexokinase), mais elle stimule surtout la glycolyse. Elle inhibe la protéolyse et la lipolyse musculaires et favorise le transport actif de certains acides aminés à travers la membrane cellulaire.

Dans le tissu adipeux, comme dans le muscle strié, il n'y a pas de G-6-phosphatase. La glycogénolyse aboutit non au glucose, mais au lactate.

\subsubsection{Effets périphériques (adipocytes et muscles)}

L'insuline stimule le transport du glucose par l'intermédiaire des transporteurs du glucose. Parmi les différentes formes de transporteurs aujourd'hui identifiés (glut 1 à glut 6), seul le glut 4, présent principalement dans les tissus adipeux et musculaires, voit son activité et sa synthèse accrues par l'effet de l'insuline. Les glut 1 ubiquitaires sont, pour l'essentiel, régulés par la concentration du glucose (Km bas) assurant un apport énergétique en glucose aux tissus dont la fourniture en glucose est vitale (système nerveux, placenta en particulier).

Les glut 2, présents dans le foie et les cellules $\beta$ pancréatiques, sont eux-mêmes régulés par la glycémie et non par l'insuline, mais à des niveaux de glycémie $(\mathrm{Km}$ plus élevé) en rapport avec leurs fonctions dans l'homéostasie du glucose. Le glucose est transformé ensuite en G-6-P dont les trois voies métaboliques (glycolyse, voie des

4 Au taux habituel de la glycémie et en l'absence d'insuline, la membrane cellulaire constitue une barrière imperméable (à l'exception de la cellule hépatique, des cellules sanguines, de la cellule nerveuse et de la cellule $\beta$ des îlots de Langerhans). Elle cesse d'être imperméable lors d'une hyperglycémie. 
pentoses-phosphates et glycogénogenèse) sont stimulées par l'insuline. La lipogenèse est accrue, la cholestérolémie augmente. Sur les protéines, l'insuline exerce un double effet anabolique et anticatabolique.

\subsection{MODE D'ACTION DE L'INSULINE (voir chap. 2, §2.1.2 et 3, § 1)}

Le récepteur à l'insuline est une glycoprotéine à fonction tyrosine kinase (voir fig. 7.4.a). Le nombre total de molécules d'insuline qui peut être lié par une cellule varie entre 1000 et 200000 . Le mécanisme moléculaire d'action de l'insuline est un mécanisme qui implique une autophosphorylation du récepteur lui-même. L'insuline a, en effet, un mode de transduction membranaire similaire à celui de certains facteurs de croissance. La figure 7.4.b montre les principales voies de transduction du signal insuline. Ainsi, dans le cas de la phospho-énol-pyruvate-carboxykinase, il a été montré que l'insuline régule directement la transcription du gène spécifique (Granner et coll., 1988).

\section{LE GLUCAGON}

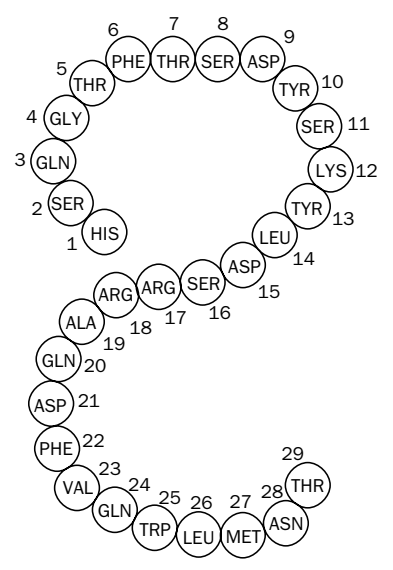

Figure 7.5

Structure du glucagon
C'est une hormone sécrétée par les cellules $\alpha 2$ des îlots de Langerhans. C'est un polypeptide de PM voisin de 3485 chez l'homme, composé de 29 AA (fig. 7.5). Il est élaboré sous la forme d'un précurseur, un pré-proglucagon, puis un pro-glucagon à $37 \mathrm{AA}$, dont le PM varie de 12000 chez le poisson à 18000 chez le rat.

Le pro-glucagon est transformé en glucagon par élimination d'un octopeptide à l'extrémité C-terminale.

La structure du glucagon ne semble pas avoir beaucoup varié au cours de l'évolution.

Comme l'insuline, le glucagon circule sous forme libre, non-lié à une protéine. Sa concentration est d'environ $0,1 \mathrm{ng} / \mathrm{ml}(0,05 \mathrm{nM} / 1)$. La dégradation est essentiellement hépatique.

\subsection{EFFETS DU GLUCAGON}

Le glucagon agit sur la glycogénolyse hépatique, comme l'adrénaline, mais seulement au niveau du foie ; il accroît donc la production hépatique du glucose. Il stimule la néoglucogenèse (les glucocorticoïdes exercent un effet "permissif" sur cet effet). Il inhibe la glycolyse en inhibant l'isoenzyme L de la pyruvatekinase et la phosphofructokinase. 


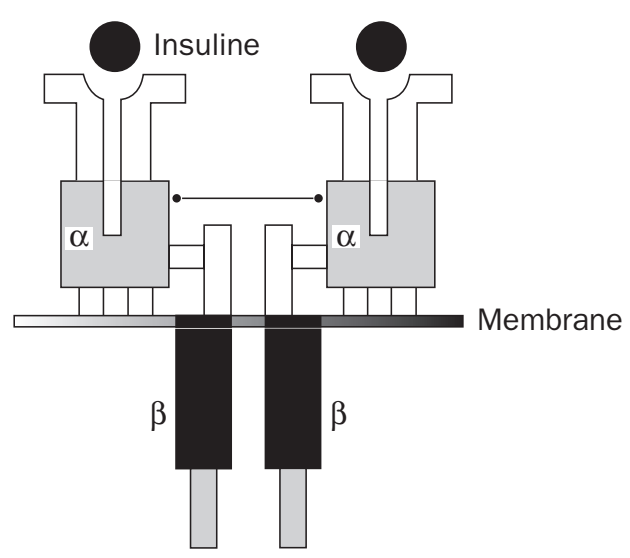

a - Représentation schématique du récepteur à l'insuline (d'après Clauser, 1988)

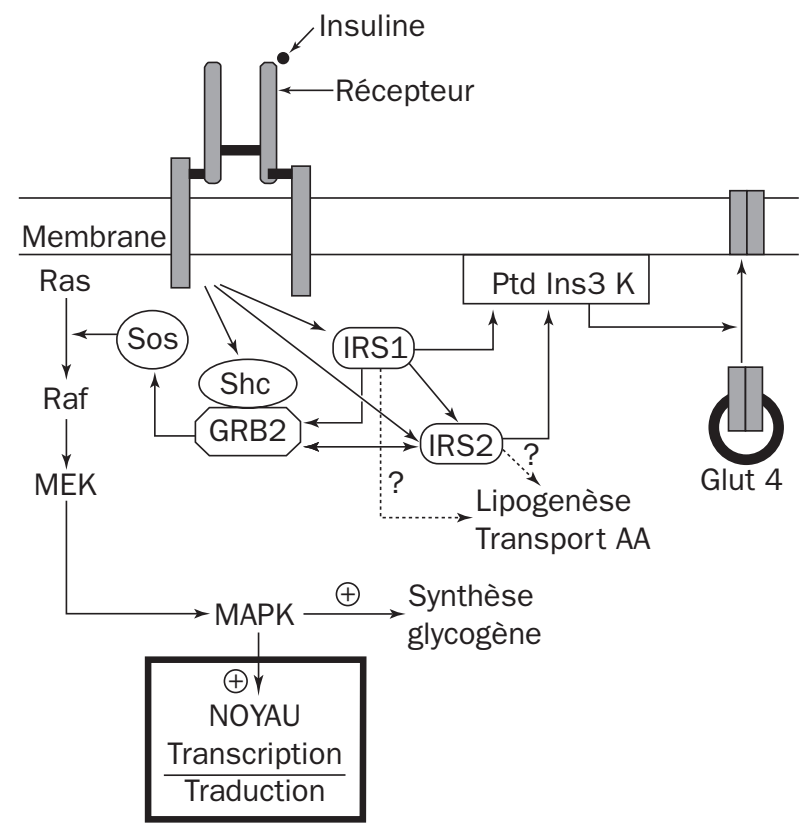

b - Représentation schématique des voies de transduction stimulées par l'insuline (d'après Roques et Pinget, 1996)

AA : acides aminés; Glut 4 : transporteur du glucose; GRB2 : growth factor receptor bound protein 2 ; IRS: insulin receptor substrat; MAPK: mitogen activated protein kinase; Sos : son of sevenless.

La liaison de l'insuline à son récepteur conduit à plusieurs cascades de phosphorylation qui débutent par la phosphorylation de SHC et des IRS1 et 2. Enfin, la phosphorylation de la MAPK conduit d'une part, via l'activation de la glycogène synthase, à la stimulation de la synthèse du glycogène et, d'autre part, à une action au niveau du noyau. La phosphorylation de la phosphatidylinositol-3-kinase provoque la translation des transporteurs du glucose du cytoplasme vers la membrane.

Figure 7.4 - Le récepteur à l'insuline et la transduction du signal insuline 
Le glucagon inhibe la lipogenèse hépatique mais stimule la cétogenèse. Il a, sur les protéines, un effet catabolique. Le glucagon exerce enfin un effet insulinosécréteur, qui est accru par l'hyperglycémie, réduit par l'hypoglycémie et inhibé par les catécholamines.

Certains diabètes de type I pourraient résulter d'altérations de la production (et/ou de la transduction) de glucagon.

\subsection{MODE D'ACTION DU GLUCAGON}

Le récepteur du glucagon (présent surtout dans la cellule hépatique) est une protéine de PM $62000\left(K_{D}=0,3 \mathrm{nM}\right)$. Il ne se lie ni à la sécrétine ni au VIP, malgré les homologies de structure et de fonction de ces trois peptides. Ce récepteur est couplé à une protéine $\mathrm{G}$ stimulatrice qui provoque, via l'activation de l'adénylate cyclase, la synthèse d'AMPc (fig. 7.6).

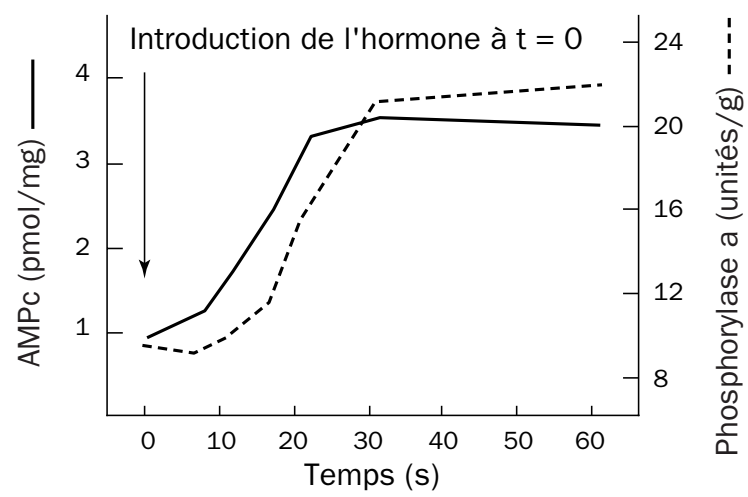

a - Action du glucagon (10-8 $\mathbf{M})$ sur des hépatocytes isolés de rat (d'après Exton, 1987)

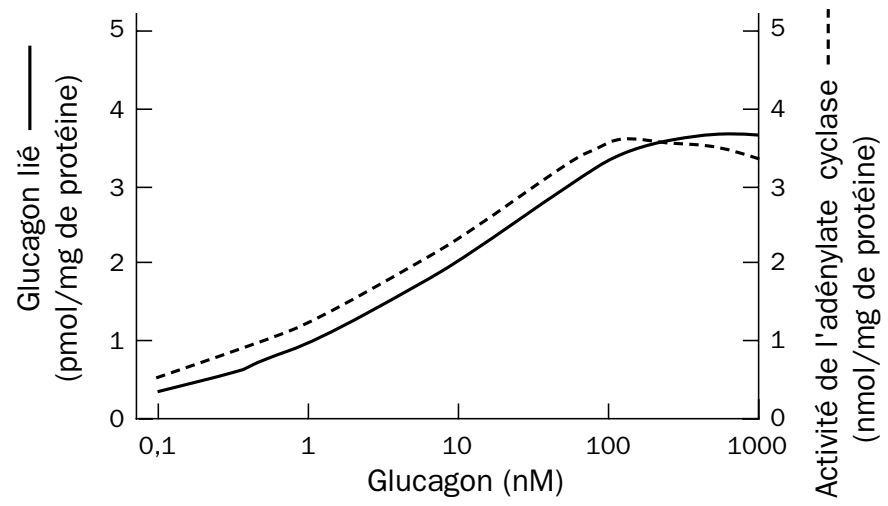

b - Corrélation entre la liaison du glucagon et l'activité de l'adénylate cyclase activée par cette hormone sur des membranes d'hépatocytes de rat (d'après Soman et Felig, 1977)

La liaison spécifique du glucagon et l'activité de l'enzyme sont indiquées en fonction de la concentration du glucagon dans le milieu. 


\section{RÉGULATION DE LA SÉCRÉTION DES HORMONES PANCRÉATIQUES}

\subsection{FACTEURS DÉCLENCHANT L'INSULINOSÉCRÉTION}

\subsubsection{La glycémie}

La sécrétion d'insuline est essentiellement déterminée par un facteur humoral, la glycémie (le taux moyen du glucose sanguin est de $0,80 \mathrm{~g}$ à $1 \mathrm{~g} / \mathrm{l}$ ). La preuve en est apportée par une greffe, au cou, d'un fragment de pancréas qui permet à un chien dépancréaté de réguler sa glycémie ; on étudie le sang veineux effluent :

- l'arrivée d'un sang riche en glucose provoque une libération d'insuline ;

- l'arrivée d'un sang hypoglycémique provoque, au contraire, l'arrêt de la sécrétion.

De même, chez l'homme après un repas glucidique, l'insuline est déversée dans la circulation. Quand la glycémie redevient normale, le taux d'insuline diminue (fig. 7.7).

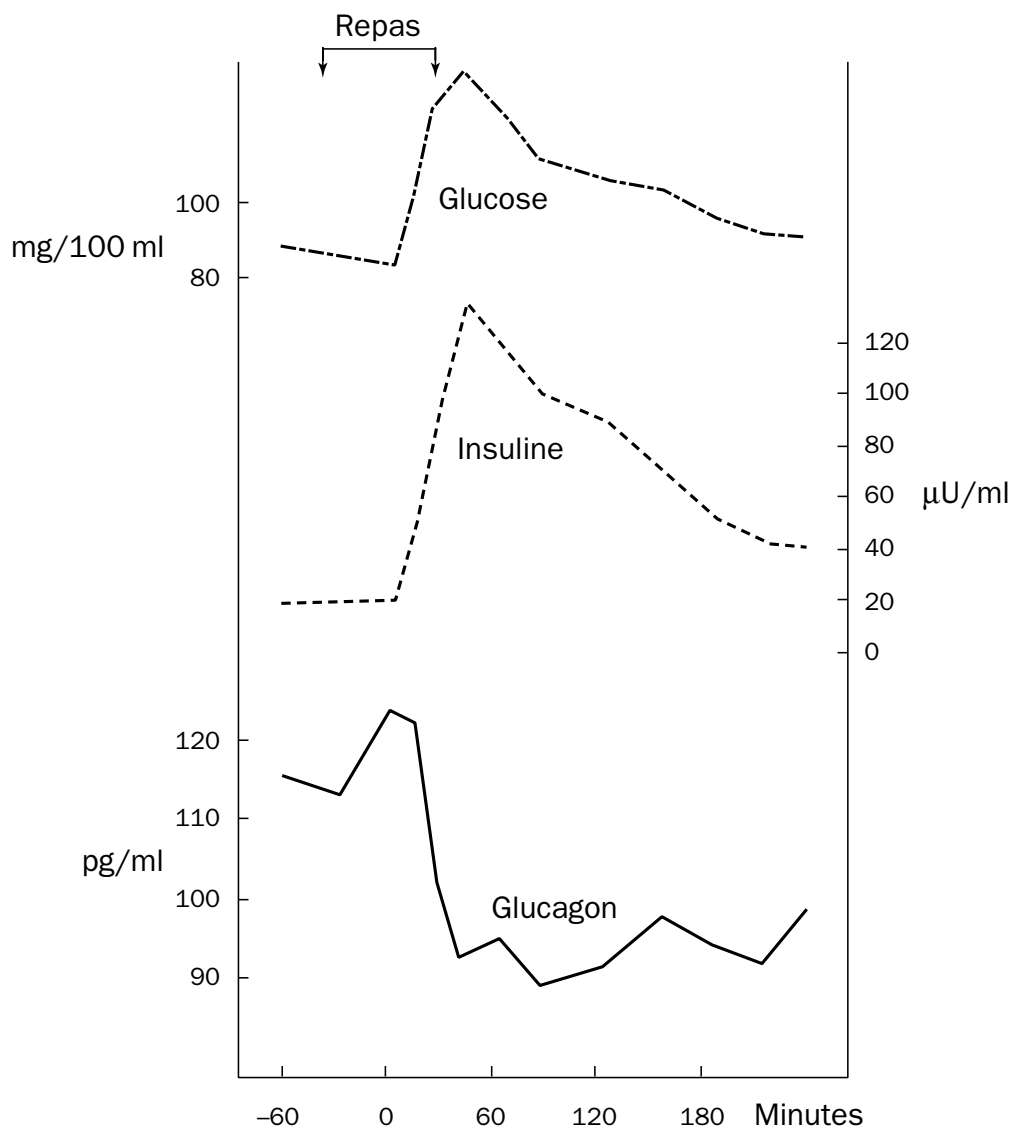

Figure 7.7 - Réponse des hormones pancréatiques après un repas riche en glucides (d'après Unger et Lefebvre, 1972) 
L'insuline est déversée dans la circulation "à la demande" (suivant le taux du glucose sanguin). Il y a autorégulation. Mais elle est élaborée dans la glande d'une manière continue (comme le lait dans la glande mammaire). La figure 7.8 schématise les mécanismes de la stimulation de la sécrétion d'insuline par le glucose.

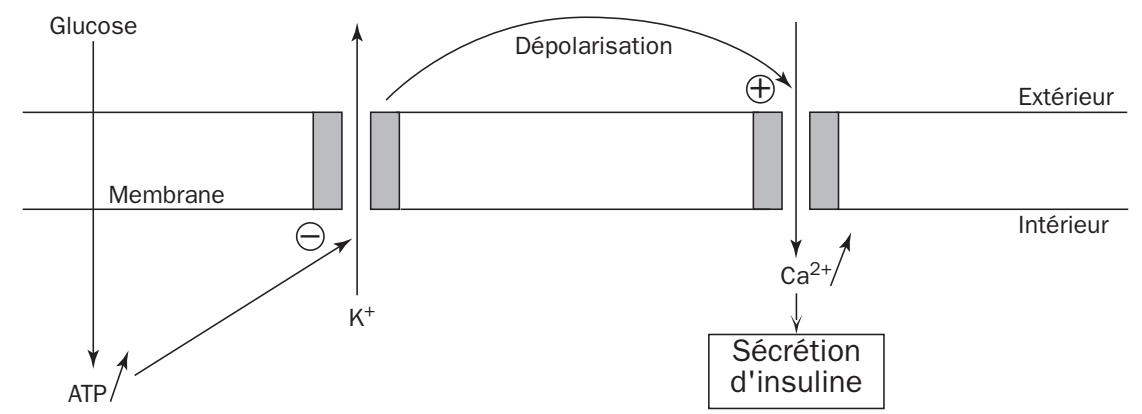

Figure 7.8 - Représentation schématique des mécanismes impliqués dans la libération d'insuline (d'après Henquin et Gilon, 1995)

L'augmentation de la glycémie entraîne une production d'ATP qui provoque la fermeture des canaux potassiques sensibles à la teneur cytoplasmique en ATP. La dépolarisation membranaire qui en résulte induit l'ouverture des canaux calciques sensibles au voltage. Cette entrée de calcium est alors responsable de la sécrétion d'insuline.

\subsubsection{Les acides aminés, acides gras et corps cétoniques}

La plupart des acides aminés, en particulier l'arginine, et à un moindre degré les acides gras et les corps cétoniques stimulent également la sécrétion d'insuline (fig. 7.9).

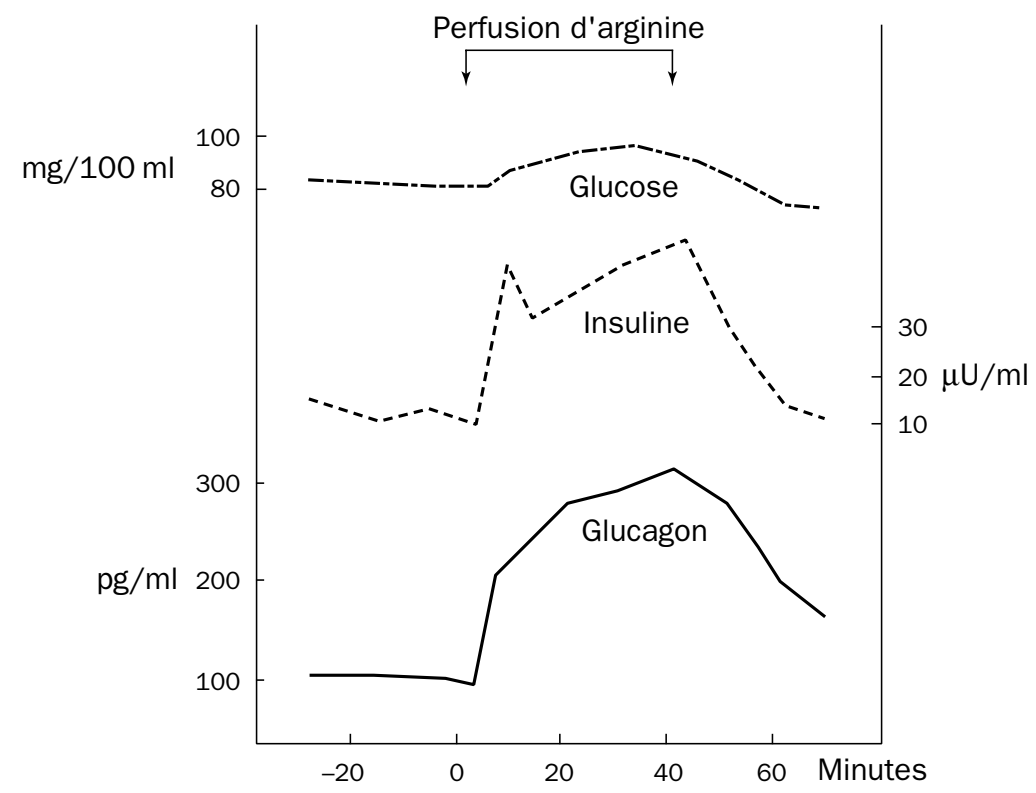

Figure 7.9 - Effet de l'arginine sur la sécrétion des hormones pancréatiques (d'après Unger et Lefebvre, 1972) 


\subsubsection{Les hormones gastro-intestinales}

Les différentes hormones gastro-intestinales (gastrine, sécrétine, CCK, entéroglucagon et le glucagon) stimulent la sécrétion d'insuline. Elle stimulent également l'effet insulinosécréteur des stimulus primaires, tels que le glucose et les acides aminés (médiation hormonale "entéro-insulaire"). La sécrétion d'insuline sera donc plus fortement stimulée par un apport oral de glucose ou d'acides aminés que par une injection intraveineuse d'une même quantité de ces nutriments.

\subsubsection{La somatostatine}

La somatostatine inhibe la sécrétion d'insuline.

\subsubsection{Le mécanisme nerveux}

Comme pour la médullo-surrénale, la sécrétion insulinique peut être déclenchée par un mécanisme nerveux. L'importance de ce contrôle est secondaire : après énervation du pancréas, hyper- et hypoglycémie sont corrigées, mais plus lentement. La sécrétion pancréatique est déclenchée par l'intermédiaire des pneumogastriques après excitation nerveuse centrale. Le centre gluco-sensible serait situé dans le tronc cérébral.

La région ventro-médiane de l'hypothalamus exerce un effet inhibiteur sur la sécrétion d'insuline, tandis que la région ventrale accroît le tonus vagal et stimule ainsi la sécrétion d'insuline. La sécrétion de base de l'insuline est enfin modulée par le tonus adrénergique (stimulation au niveau des $\beta$-récepteurs) : les agents $\beta$-bloquants diminuent cette sécrétion.

\subsection{RÉGULATION DE LA SÉCRÉTION DU GLUCAGON}

Les principaux facteurs qui interviennent dans cette régulation sont :

\subsubsection{Le glucose}

Contrairement à la régulation de l'insuline, l'hyperglycémie $(>1,5 \mathrm{~g} / \mathrm{l})$ déprime et l'hypoglycémie $(\leq 0,5 \mathrm{~g} / \mathrm{l})$ augmente la sécrétion de glucagon. La réponse est aussi rapide que la réponse symétrique de l'insuline (voir fig. 7.7).

\subsubsection{Les acides gras et les corps cétoniques}

Leur élévation diminue la sécrétion de glucagon (qui est cétogène).

\subsubsection{Les acides aminés ou protéines}

Ils stimulent la sécrétion du glucagon (voir fig. 7.9). C'est la seule situation physiologique dans laquelle les sécrétions de glucagon et d'insuline sont modifiées dans le même sens. 


\subsubsection{Les hormones gastro-intestinales}

Le CCK stimule la sécrétion de glucagon et accroît la sécrétion de glucagon stimulée par un apport oral d'acides aminés (médiation hormonale entéro-insulaire). La sécrétine accrôit l'inhibition de la sécrétion provoquée par le glucose lorsque celui-ci est administré par voie orale.

\subsubsection{Les mécanismes nerveux}

- Les agonistes $\beta$-adrénergiques provoquent la sécrétion de glucagon (et les $\beta$-bloquants l'inhibent), de même que :

- la stimulation de l'hypothalamus ventro-médian ;

- l'activation du sympathique.

- Au contraire, les cholinergiques diminuent la sécrétion de glucagon.

NB - Insuline et glucagon sont également présents dans le cerveau. S'ils fonctionnent là comme neurotransmetteurs, l'insuline serait le plus gros neurotransmetteur connu.

\subsection{CORRÉLATIONS AVEC LES AUTRES GLANDES ENDOCRINES}

Toutes les hormones qui agissent sur le métabolisme des glucides, à l'exception de l'insuline, sont des facteurs hyperglycémiants (fig. 7.10).

\subsubsection{L'hypophyse}

- L'hormone somatotrope antéhypophysaire $(\mathrm{GH})$ provoque :

- une hyperglycémie suivie de glycosurie ;

- une diminution de la sensibilité de l'animal à l'insuline.

Cet effet diabètogène est l'action essentielle de la GH chez l'adulte.

Mode d'action : La GH favorise la néoglucogenèse à partir des lipides et des protéines, elle s'oppose à ce niveau à l'action de l'insuline ; elle agit également sur la glucokinase, en antagonisme avec l'insuline.

Une injection de doses importantes et répétées de GH provoque un diabète (diabète de Jung).

L'hypophysectomie chez l'animal dépancréaté entraîne une "amélioration" du diabète (chien de Houssay). Si le niveau de la glycémie est devenu normal, sa régulation reste néanmoins précaire.

- Simultanément, l'hypophyse exerce une action indirecte sur la glycémie par l'intermédiaire de deux stimulines : ACTH et TSH.

\subsubsection{La corticosurrénale}

La sécrétion des hormones dites glucocorticoïdes (corticostérone, cortisol) active la néoglucogenèse à partir des protides et accessoirement des lipides. L'injection prolongée de ces hormones peut provoquer un diabète (diabète "cortisonique"). Au contraire, la surrénalectomie améliore le diabète pancréatique expérimental. 


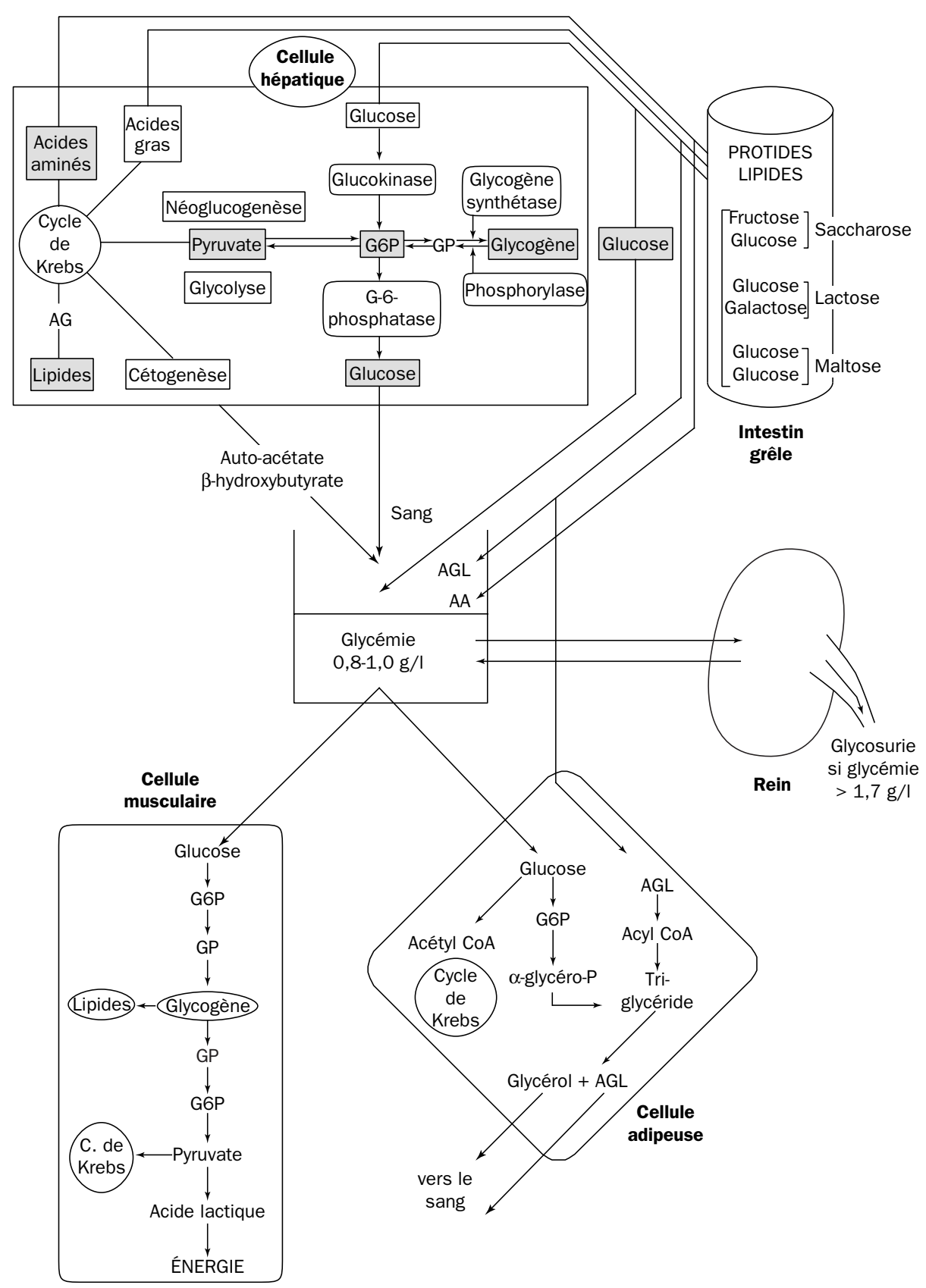

Figure 7.10 - Régulation endocrine de la glycémie

\subsubsection{La thyroïde}

Elle n'a qu'un effet hyperglycémique peu important. 


\subsubsection{La médullo-surrénale}

L'adrénaline a une activité hyperglycémiante. Elle provoque la glycogénolyse dans le foie et les muscles par activation de la phosphorylase b. Cette action entraîne la libération du glucose au niveau du foie, mais pas dans les muscles.

L'adrénaline assure dans des limites larges la régulation de la glycémie ; son action est rapide, efficace, mais transitoire. Elle peut être relayée par l'action des hormones corticosurrénales, dont l'action est lente, mais durable.

\section{MÉTHODES D'INVESTIGATION DE LA FONCTION PANCRÉATIQUE}

\subsection{MÉTHODE DYNAMIQUE : L'HYPERGLYCÉMIE PROVOQUÉE}

L'épreuve de l'hyperglycémie provoquée (fig. 7.11) permet la mise en évidence d'un diabète latent ou cliniquement asymptomatique. Elle doit être pratiquée après :

- une activité physique normale ;

- un régime glucidique suffisant $(250 \mathrm{~g} / 24 \mathrm{~h})$ pendant les 3 jours précédents.

Pratiquée per os (voie orale) ${ }^{5}$, ou en injection intraveineuse, l'épreuve est complétée par le dosage radioimmunologique de l'insuline.

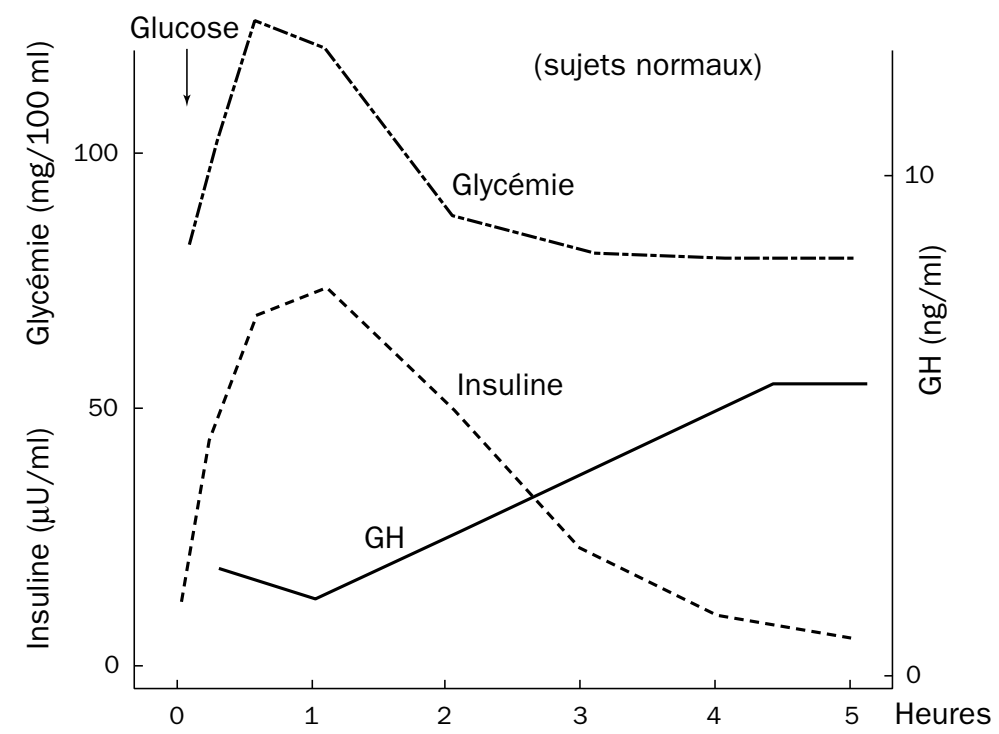

Figure 7.11 - Hyperglycémie provoquée par voie orale (d'après Rosselin, 1968)

5 Par absorption de $50 \mathrm{~g}$ de glucose pur et anhydre ou, si l'on veut être plus rigoureux, en fonction du poids corporel $(1,75 \mathrm{~g}$ de glucose $/ \mathrm{kg})$ ou de la surface corporelle $\left(45 \mathrm{~g} / \mathrm{m}^{2}\right)$, cas de la figure 7.11 . 
Sur $5 \mathrm{~h}$, elle permet d'apprécier :

- la tolérance au glucose (première partie de la courbe de glycémie) ;

- l'élévation insulinémique (le pic est souvent retardé et étalé dans le temps dans le diabète léger) ;

- le retour à la normale de la glycémie et de l'insulinémie.

Il peut être intéressant de suivre la variation précoce de l'insulinémie, qui présente normalement deux phases sécrétoires sous l'effet de la stimulation glucidique (fig. 7.12). La disparition du pic précoce est caractéristique du diabète de type II ; elle peut précéder parfois de 10 ans l'apparition de ce diabète dont elle constitue un test prédictif.

Figure 7.12 - Etude précoce de I'insulinosécrétion

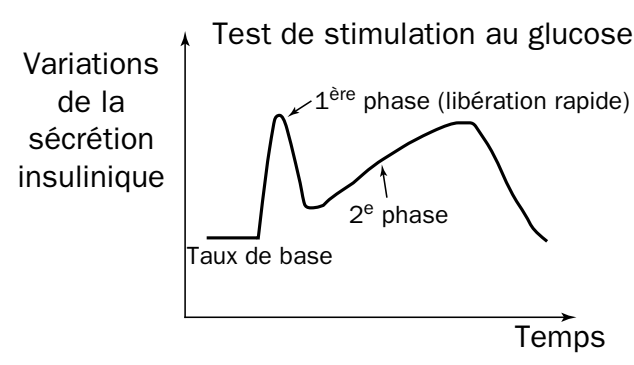

\subsection{MÉTHODES STATIQUES}

Elles sont habituellement réalisées après un jeûne de $12 \mathrm{à} 15 \mathrm{~h}$.

- le dosage de la glycémie : 0,75 à $1,10 \mathrm{~g} / 1$ (4 à $6 \mathrm{mmol} / \mathrm{l})$.

- le dosage de l'insulinémie : 0,4 à $0,6 \mathrm{ng} / \mathrm{ml}$.

- le dosage du glucagon plasmatique : 0,05 à $0,15 \mathrm{ng} / \mathrm{ml}$.

\subsection{LES DIFFÉRENTS TESTS DE STIMULATION DE L'INSULINE}

- le test au tolbutamide (sulfamide hypoglycémiant).

- le test au glucagon.

- le test à la leucine ou le test à l'arginine (acides aminés qui stimulent la sécrétion d'insuline).

\subsection{LES TESTS ÉVALUANT LA SENSIBILITÉ À L'INSULINE}

- Le clamp euglycémique hyperinsulinique : il consiste en la perfusion continue intraveineuse d'insuline à débit fixe chez un sujet (ou un animal) à jeun, et à la perfusion simultanée de glucose afin d'assurer le maintien d'un niveau stable et normal de glycémie $(0,8$ à $1 \mathrm{~g} / 1)$, en évitant ainsi l'hypoglycémie induite par l'infusion d'insuline. Après quelque temps nécessaire à l'atteinte d'un état d'équilibre, la quantité de glucose requise pour le maintien de la glycémie définit le degré de sensibilité à l'insuline de l'animal ou de l'individu entier (foie et tissu musculaire principalement) pour un palier donné d'insuline. La perfusion d'un traceur 
isotopique, stable ou radioactif du glucose, permet de plus de distinguer les effets différentiels de l'insuline sur le foie (réduction de la production endogène de glucose) des effets périphériques (stimulation du captage et/ou de l'utilisation du glucose par le muscle surtout). Plus la quantité de glucose perfusée est élevée et plus la sensibilité à l'insuline est grande. Ce test est à la base des principales données ayant permis d'affirmer et de chiffrer l'insulinorésistance de nombreux états physiologiques (vieillissement, grossesse) ou pathologiques (obésité, diabètes de type II, stress, effets des hormones diabétogènes, catécholamines, hormone de croissance, glucorticoïdes...).

- Le SSPG (steady state plasma glucose) s'apparente au précédent. Il consiste en la perfusion de somatostatine afin d'inhiber l'insulinosécrétion, d'une quantité donnée d'insuline et d'une quantité constante de glucose, et enfin à observer la dérive de la glycémie vers le haut puis s'y stabiliser. Plus le plateau de glycémie atteint est élevé, plus les sujets sont considérés comme résistants à l'action de l'insuline. Toutefois, ce test plus global ne permet pas de distinguer les effets de l'insuline sur le foie de ceux exercés sur le muscle.

\section{LES DIABÈTES SUCRÉS}

\subsection{DÉFINITION (tab. 7.2)}

Les diabètes sucrés constituent un groupe hétérogène d'affections dont le dénombrement est en cours. Toutefois, ils ont en commun, d'une part, leur définition, un état d'hyperglycémie chronique et, d'autre part, leur propension à développer des complications.

\section{Tableau 7.2 - Définition du diabète}

- deux glycémies à jeun $>1,40 \mathrm{~g} / 1$

- glycémie à jeun $<1,40 \mathrm{~g} / 1$ et glycémie $2^{\mathrm{e}}$ heure au cours d'une hyperglycémie provoquée $>2 \mathrm{~g} / 1$

- glycémie à jeun $<1,40 \mathrm{~g} / 1$ et glycémie $2^{e}$ heure au cours d'une hyperglycémie provoquée entre 1,40 et $2 \mathrm{~g} / 1$

Selon les critères de l'OMS, le diabète sucré est défini par la détermination indépendante de deux glycémies à jeun supérieures à $1,40 \mathrm{~g} / 1(7,7 \mathrm{mmol} / \mathrm{l})$. La mesure est réalisée sur sang veineux à l'aide de la glucose oxydase.

Lorsque la glycémie à jeun est inférieure à $1,40 \mathrm{~g}$ et supérieure à $1,15 \mathrm{~g}$ ou qu'un doute persiste, compte tenu par exemple d'antécédents diabétiques, on a recours à 
l'hyperglycémie provoquée per os (HGPO), qui consiste à administrer en 5 min $75 \mathrm{~g}$ de glucose dilué dans 200 ou $300 \mathrm{ml}$ d'eau chez l'adulte (ou $1,75 \mathrm{~g} / \mathrm{kg}$ chez l'enfant); on parle alors de diabète lorsque la glycémie à la $2^{\mathrm{e}}$ heure est supérieure ou égale à $2 \mathrm{~g} / 1$ (soit $11 \mathrm{nmol} / 1$ ), et d'intolérance aux hydrates de carbone lorsque la glycémie à jeun est inférieure à $1,40 \mathrm{~g}$ et la glycémie à la $2^{\mathrm{e}}$ heure entre $1,40 \mathrm{~g}$ et $2 \mathrm{~g} / 1$. Cette notion d'intolérance aux hydrates de carbone n'est pas simplement spéculative car 7\% de ces sujets développent, chaque année, un diabète authentique et, contrairement à des idées reçues, pour ces sujets, le risque de mortalité coronarienne est doublé.

De nouvelles normes actuellement discutées ont été proposées par l'ADA (American Diabetes Association); le diabète serait alors défini par une glycémie $\geq 1,26 \mathrm{~g}$ $(7,0 \mathrm{mmol} / \mathrm{l})$.

\subsection{CLASSIFICATION (tab. 7.3)}

On oppose les diabètes primitifs ou essentiels (classiques diabètes insulinodépendants : DID, et non-insulinodépendants : DNID), de loin les plus fréquents et d'étiologie mal connue, aux diabètes secondaires de cause bien établie.

Tableau 7.3 - Les diabètes sucrés

\begin{tabular}{|c|c|c|}
\hline Primitifs & \multicolumn{2}{|c|}{$\begin{array}{l}\text { DID (type I) - } 15 \text { à } 20 \% \\
\text { DNID (type II) - } 80 \%\end{array}$} \\
\hline \multirow{5}{*}{$\begin{array}{l}\text { Secondaires } \\
\text { (rares) }\end{array}$} & Pancréatiques & $\begin{array}{l}\text { - pancréatite chronique } \\
\text { - hémochromatose } \\
\text { - cancer }\end{array}$ \\
\hline & Endocriniens & $\begin{array}{l}\text { - Cushing } \\
\text { - acromégalie } \\
\text { - phéochromocytome } \\
\text { - glucagonome } \\
\text { - somatostatinome }\end{array}$ \\
\hline & Iatrogènes & $\begin{array}{l}\text { - corticoïdes } \\
\text { - diurétiques } \\
\text { - œstroprogestatifs }\end{array}$ \\
\hline & Génétiques & $\begin{array}{l}\text { - Turner } \\
\text { - Klinefelter } \\
\text { - trisomie } 21\end{array}$ \\
\hline & Insulinopathies & (exceptionnelles) \\
\hline
\end{tabular}

Hormis les diabètes d'origine pancréatique, et notamment la pancréatite chronique calcifiante qui se rencontre avec une relative fréquence, les diabètes secondaires 
s'avèrent être des raretés ; leur intérêt réside dans leur physiopathologie ; c'est le cas des diabètes survenant au cours d'endocrinopathies; généralement dans ces affections l'hyperglycémie est modérée, révélant souvent un terrain diabétique et réversible avec la guérison de la maladie causale; c'est ainsi, par exemple, qu'au cours des hypercorticismes type syndrome de Cushing, l'hyperglycémie à jeun, due à l'hypersécrétion de cortisone, ne se rencontre que chez $20 \%$ des patients; en revanche, l'administration de corticoïdes, même en infiltration intra-articulaire, entraînera un déséquilibre glycémique parfois sévère chez le diabétique.

De même, le diabète de l'hémochromatose s'explique aisément par la surcharge en fer des îlots de Langerhans qui entraîne une atrophie de ces derniers.

Le diabète gestationnel qui peut entraîner des risques foetaux apparaît au cours du $2^{\mathrm{e}}$ trimestre de la grossesse et disparait après l'accouchement ; les critères retenus, lors d'une hyperglycémie per os avec $100 \mathrm{~g}$ de glucose sont : une glycémie à jeun inférieure à $5,8 \mathrm{mmol} / 1(1,05 \mathrm{~g} / 1)$, une glycémie à $1 \mathrm{~h}$ inférieure à $10,6 \mathrm{mmol} / 1$ $(1,90 \mathrm{~g} / \mathrm{l})$ et une glycémie à $2 \mathrm{~h}$ inférieure à $9,2 \mathrm{mmol} / 1(1,65 \mathrm{~g} / \mathrm{l})$.

Des diabètes sont associés à des maladies génétiques; citons les plus fréquentes : le mongolisme ou trisomie 21, le syndrome de Klinefelter (caryotype XXY), le syndrome de Turner (caryotype XO), le syndrome de Wolfram (diabète sucré, diabète insipide, cécité, surdité).

Les insulinopathies, s'accompagnant d'une affection dermatologique, l'Acanthosis nigricans, d'une extrême rareté, illustrent de façon exemplaire les anomalies du récepteur à l'insuline, soit par la présence d'auto-anticorps antirécepteurs, soit par la diminution, d'origine génétique, du nombre de récepteurs.

Dans cette classification, il ne faut pas perdre de vue que les diabètes sucrés sont dominés en fréquence et en importance par les diabètes insulinodépendants (type I) et surtout non-insulinodépendants (type II). Les autres étiologies s'avèrent être rares ou exceptionnelles et ne conservent souvent leur intérêt que sur le plan physiopathologique.

\subsection{EPIDÉMIOLOGIE}

Les diabètes sucrés représentent des affections fréquentes estimées à 100 millions dans le monde et qui devraient atteindre 200 millions en 2020.

La prévalence (pourcentage de la population atteinte par la maladie) varie d'un pays à l'autre ; elle est de 2 à $5 \%$ dans les pays européens et le Canada, 5 à $10 \%$ aux EtatsUnis et de 1 à $2 \%$ en Afrique. En France, on l'estime de 3 à 4\%, soit 1,5 à 2 millions de personnes : $6 \%$ des lits d'hôpitaux sont occupés par des diabétiques. Le diabète a le triste privilège d'être la première cause de cécité de l'adulte, la première cause d'amputation des membres inférieurs et la première cause de décès par insuffisance rénale chez les sujets jeunes.

La maladie est en constante progression, comme l'atteste l'incidence (nombre de nouveaux cas par an). En Finlande, on compte 42 nouveaux cas de diabète insulino- 
dépendant pour 100 000, 16 aux Etats-Unis. En France, l'incidence du diabète insulinodépendant est de 7,2 cas pour 100000 chez les enfants de moins de 19 ans (Technical reports, 1985).

La fréquence du diabète varie également en fonction de l'âge : rare chez l'enfant $(1 \% o)$, il augmente régulièrement pour atteindre $7 \%$ chez les personnes âgées. Le sexe ne semble pas jouer de rôle déterminant.

\subsection{LES DIABÈTES PRIMITIFS OU ESSENTIELS}

Ils constituent la très grande majorité des diabètes. Leur étiologie étant méconnue, on les divise en fonction du traitement, en diabète insulinodépendant et non-insulinodépendant.

\subsubsection{Le diabète insulinodépendant (DID) ou diabète de type I (diabète maigre)}

\section{Généralités}

Il représente en France 15 à $20 \%$ des diabètes et survient essentiellement chez le sujet jeune avant 20 ans. Il peut aussi atteindre des adultes jeunes, voire des sujets d'âge mûr (environ $50 \%$ des diabètes de type I). Son début est souvent brutal mais chez l'adulte volontiers plus progressif et trompeur, d'où son nom de type I lent de l'adulte. Il semble exister un gradient Nord-Sud, les pays scandinaves et notamment la Finlande ayant l'incidence la plus élevée, alors que la France se situe parmi les pays à incidence faible.

Il est la conséquence de la destruction des îlots $\beta$ de Langerhans aboutissant à une carence profonde en insuline. C'est dans cette forme que l'on observe les symptômes classiques tels que la polyurie et la polydypsie ; un coma acido-cétosique peut survenir lorsque le traitement par insuline n'a pas été assez rapidement institué.

\section{Physiopathologie}

Le diabète insulinodépendant fait partie des maladies auto-immunes comme la maladie de Basedow, la thyroïdite de Hashimoto, la sclérose en plaques ou l'insuffisance surrénale.

La destruction du potentiel insulinosécréteur est secondaire à une réaction autoimmune provoquée par un ou plusieurs facteurs d'environnement (virus, toxiques, stress) sur un terrain génétique prédisposé. La production de monoxyde d'azote (NO) par les macrophages semble impliquée dans ce processus.

Rôle de l'hérédité (Maugendre et coll., 1993)

Il est bien établi, mais il ne confère qu'une susceptibilité à la maladie. Cette prédisposition au diabète insulinodépendant est attestée par un risque de 5\% chez les enfants dont l'un des parents est atteint; de même, le risque par la fratrie est de 3 à $8 \%$ alors que, dans la population générale, il ne représente que $0,2 \%$. 
Le terrain génétique est lié principalement à des gènes codant pour les antigènes de classe II du complexe majeur d'histocompatibilité (CMH) ou système HLA (human leucocyte antigen). Ils siègent sur le bras court du chromosome 6 et codent pour les antigènes HLA DR, DQ, DP, qui jouent un rôle essentiel dans les phénomènes de tolérance ainsi que dans la reconnaissance de l'antigène par les cellules du système immunitaire.

Dans les années 1970, on s'est intéressé aux allèles HLA B8, B15, B18 (antigènes de classe I) ; dès les années 1980, cette piste a été abandonnée au profit des antigènes de classe II : le risque relatif pour les porteurs de DR3 ou DR4 se situe entre 5 et 7 . En cas d'hétérozygotie DR3 - DR4, le risque s'élève à 40 ; à l'inverse, DR2 serait protecteur.

L'avènement de la biologie moléculaire a permis d'impliquer la région DQ plutôt que DR. Du fait de la proximité de ces deux gènes, certains allèles sont en déséquilibre de liaison ; DR3 est ainsi associé à DQ2 (DQB1 0200) et DR4 à DQ3 (deux spécificités ont été identifiées pour ce dernier, DQ7 et DQ8). Les haplotypes DR3, DQ2 et DR4, DQ8 prédisposent au diabète de ce type, alors que DR4, DQ7 protégeraient.

Tous les allèles de protection chez les caucasiens possèdent un acide aspartique en position 57 sur la chaîne $\beta$ (les allèles de classe II sont formés de deux chaînes $\alpha$ et $\beta$ ), alors que les allèles de susceptibilité montrent la présence de valine, alanine ou serine dans cette même position. Toutefois, on connaît de nombreuses exceptions et certains diabétiques caucasiens sont Asp+/Asp+.

Le risque de survenue d'un diabète insulinodépendant chez un patient augmente en fonction du degré de concordance des allèles du probant (c'est le parent malade) diabétique (tab. 7.4) :

\section{Tableau 7.4 - Risque de survenue d'un diabète insulinodépendant en fonction du degré de concordance des allèles du probant}

\begin{tabular}{|l|c|c|c|}
\hline Lien avec le probant & $\begin{array}{c}\text { Risque } \\
\text { global }\end{array}$ & $\begin{array}{c}\text { Risque en fonction du } \\
\text { nombre d'haplotype HLA } \\
\text { identique au probant }\end{array}$ & $\begin{array}{c}\text { Risque en } \\
\text { présence } \\
\text { DR3/DR4 }\end{array}$ \\
\hline Parents & $3 \%$ & & \\
\hline Fratries & $3-8 \%$ & $2 \longrightarrow 8-16 \%$ & $10-13 \%$ \\
& & $\begin{array}{l}2 \longrightarrow 3-9 \% \\
1 \longrightarrow<\%\end{array}$ & \\
\hline Jumeaux monozygotes & $30-50 \%$ & & $70 \%$ \\
\hline Enfants & $5 \%$ & & \\
\hline
\end{tabular}

En dehors du système HLA, d'autres gènes de susceptibilité ont été invoqués, par exemple celui situé dans la région du gène de l'insuline et de l'IGF2, sur le chromosome 11 des sujets DR4. 
Néanmoins, il faut remarquer que le risque de 30 à $50 \%$ de développer un diabète chez le jumeau monozygote prouve que des facteurs autres que génétiques interviennent dans le déclenchement du diabète.

Rôle de l'auto-immunité (Maugendre et coll., 1993 ; Grimaldi et coll., 1993)

- Les facteurs immunitaires ont été très tôt appréhendés en raison de l'association à d'autres maladies auto-immunes: vitiligo, anémie de Biermer, maladie de Basedow, thyroïdite d'Hashimoto. De même, la constatation d'insulite au niveau des îlots de Langerhans, avec présence de lymphocytes activés, a renforcé cette idée. Par ailleurs, un ensemble d'obervations conforte le lien entre diabète et facteurs immunitaires. Ainsi, des lymphocytes provenant de diabétiques inhibent in vitro l'insulinosécrétion des cellules $\beta$. De même, il est possible de transférer la maladie à des animaux sains par l'injection de lymphocytes $\mathrm{T}$ issus de souris ou de rats diabétiques (type souris NOD ou rats $\mathrm{BB}$, modèles animaux de diabète auto-immun). Enfin, l'utilisation chez l'homme d'un immunosuppresseur, la cyclosporine, induit des rémissions, mais transitoires et de courte durée.

- La présence d'auto-anticorps a confirmé l'importance de l'immunité. Des anticorps anti-îlots (islet cell antibody ou ICA) ont été retrouvés chez 60 à 90\% des sujets les plus jeunes et chez moins de $50 \%$ si la révélation est plus tardive, après 50 ans. Ils représentent un excellent marqueur de l'atteinte auto-immunitaire mais ne sont pas directement responsables de l'agression (d'ailleurs, ils disparaissent progressivement en quelques années). Un taux élevé d'ICA, supérieur à 80 unités JDF (juvenil diabete foundation), chez un sujet apparenté aurait une valeur prédictive dans $100 \%$ des cas.

D'autres anticorps ont été retrouvés :

- Des anticorps anti-insuline, avant toute injection d'insuline, ont pu être mis en évidence dans un cas sur deux.

- Plus intéressants sont les anticorps dirigés contre une protéine de poids moléculaire 64000 . Cet auto-antigène a été identifié à la décarboxylase de l'acide glutamique (GAD), enzyme localisée dans les cellules $\beta$ et le cerveau. Elle est impliquée dans la synthèse de l'acide $\gamma$-amino-butyrique (GABA); cet autoanticorps est retrouvé très précocement et semble avoir une valeur prédictive élevée.

- Un autre auto-antigène, de poids moléculaire 38000 , présent à la surface des granules de sécrétion d'insuline, a été également incriminé.

- L'immunité cellulaire, dont le rôle est prééminent dans le phénomène de l'insulite et de la maladie, ne peut être évaluée directement. L'augmentation des lymphocytes activés ou du rapport CD4/CD8 manque de spécificité.

\section{Les facteurs d'environnement}

Ils consistent surtout en facteurs infectieux. Certains virus sont particulièrement visés : virus coxsackie B4, oreillons, rubéole, grippe, cytomégalovirus, Epstein Barr. 
On a pu constater une corrélation entre la fréquence des diabètes et les épidémies d'oreillons. De même, une augmentation d'anticorps spécifiques (IgM) pour le virus des oreillons et le virus coxsackie a été parfois retrouvée. Néanmoins, ces virus n'ont pas un rôle pathogène direct, mais présenteraient des réactions antigéniques croisées avec l'acide glutamique décarboxylase ou la protéine $38 \mathrm{KD}$ (Thivolet, 1994). Par ailleurs, il a été montré que, dans ces situations, la production de NO par les macrophages activés exercerait une action cytotoxique sur les cellules $\beta$. Enfin, il a été montré récemment (Conrad et coll., 1987), chez les diabétiques de type I, l'existence d'un rétrovirus responsable de la production d'un superantigène (SADs) impliqué dans les mécanismes d'auto-immunité.

Parmi les facteurs alimentaires, les protéines du lait de vache seraient diabétogènes, ainsi que le soja et le blé (Scott, 1996) ; au contraire, l'allaitement maternel protégerait. On connaît le rôle toxique de la streptozotocine, utilisée en expérimentation animale, et de la lomidine, prescrite dans le traitement des pneumopathies à Pneumocystis carinii. Quant aux agents stressants physiques (accidents, interventions chirurgicales, maladies graves) ou psychiques (deuil, choc affectif), ils interviendraient uniquement en tant que facteurs de déclenchement ou révélateurs.

\section{Les différents stades évolutifs de la maladie (fig. 7.13)}

- Le début correspond à une prédisposition génétique.

- Au deuxième stade, apparaît l'insulite, mais sans déficit en insuline (prédiabète).

- Au troisième stade (diabète préclinique) est notée la présence d'anticorps anti-îlots (ICA) ; le pic précoce d'insuline, au cours des $11^{\text {ères }}$ minutes d'une hyperglycémie provoquée par voie intraveineuse, disparaît, témoignant d'une altération de l'insulinosécrétion.

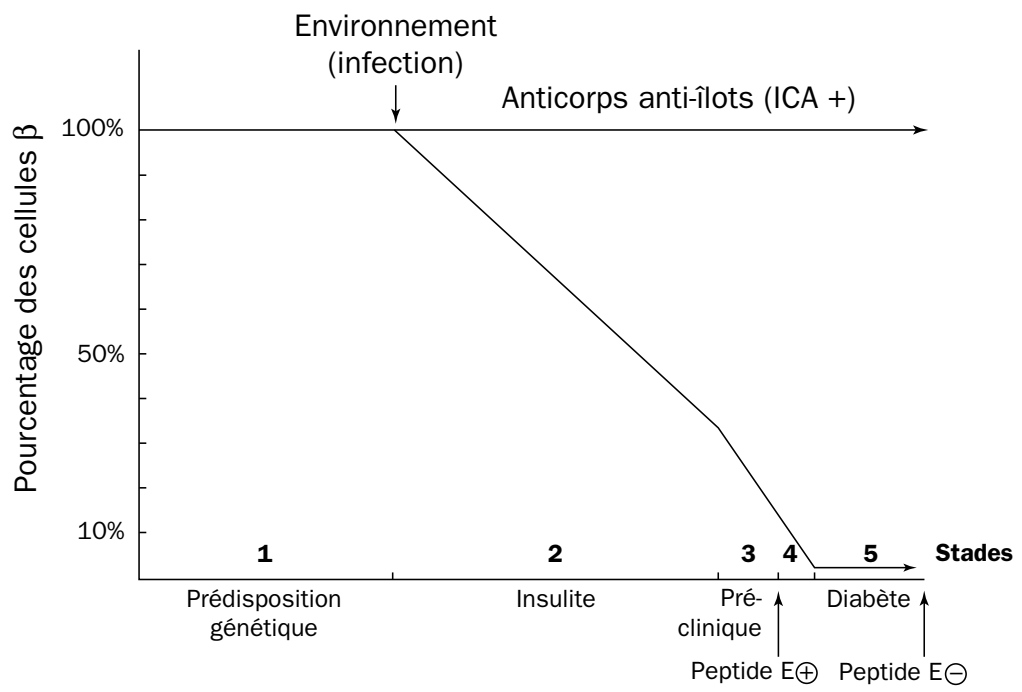

Figure 7.13 - Les différents stades du diabète 
- Succède le diabète patent où, bien que profondément diminuée, l'insulinosécrétion persiste ; le taux positif de peptide C (peptide de connexion entre les chaînes $\alpha$ et $\beta$ de l'insuline secrété de façon équimoléculaire avec l'insuline) prouve la persistance de cette sécrétion.

- Au dernier et cinquième stade, le peptide $C$ est effondré, témoignant de la carence totale en production d'insuline; les auto-anticorps ne sont plus détectables.

\subsubsection{Le diabète non-insulinodépendant (DNID) ou diabète de type II (classique diabète gras)}

\section{Généralités}

Le plus fréquent, il représente $80 \%$ des diabètes en France. Rare chez le sujet jeune, c'est une maladie de l'âge mûr, après 40 ans, dont la prévalence augmente avec l'âge (10\% chez les sujets de plus de 70 ans). La prévalence est variable d'un pays à l'autre ; $2 \%$ en France, 6,6\% aux USA, 1\% au Japon, elle s'élève jusqu'à 35\% chez les Indiens Pima d'Arizona, 34\% chez les Micronésiens Nauru d'Océanie (Papoz et Eschwege, 1990). Le mode de vie avec régime hypercalorique, hyperglucidique et la diminution de l'activité physique accroît la fréquence du diabète (ce sont, pour partie, les raisons de la prévalence du diabète chez les Micronésiens). Quatre sujets DNID sur cinq ont, ou ont eu, un excès pondéral. Contrairement au DID, le DNID s'accompagne rarement de symptômes évidents car, au début, les glycémies restent modérément élevées. Ceci explique qu'il évolue longtemps à bas bruit et que, parfois, le diagnostic n'est envisagé qu' au moment des complications.

\section{Physiopathologie}

Elle est loin d'être élucidée. Sur un fort terrain génétique, des facteurs d'environnement, dont l'obésité, conduisent à une double anomalie constante :

- l'une siège au niveau pancréatique et est responsable d'un déficit de l'insulinosécrétion;

- l'autre se situe au niveau périphérique (muscles, tissus adipeux, foie) et est responsable de l'insulinorésistance.

\section{La génétique}

L'importance du facteur génétique est attestée par l'étude des jumeaux monozygotes (Barnett et coll., 1981) : si l'un des jumeaux est atteint de diabète non-insulinodépendant, l'autre le deviendra dans près de $100 \%$ des cas. Lorsque l'un des parents est diabétique, le risque pour le descendant est de 25 à $30 \%$. Il atteint $50 \%$ lorsque les deux parents sont diabétiques. On ignore toujours les gènes et le mode de transmission. Il est vraisemblable qu'il s'agit d'un défaut polygénique.

Plusieurs gènes, dits "gènes candidats", ont été étudiés :

- Le gène de l'insuline ou de son récepteur a été exceptionnellement mis en cause.

- Les gènes des transporteurs de glucose (glut 2 pour les cellules $\beta$ et glut 4 pour les cellules musculaires) et le gène de l'amyline ne semblent pas intervenir. 
- L'association d'un DNID à un polymorphisme du gène de la glycogène synthétase a été rapportée ; mais cela reste rare tout comme les mutations de l'ADN mitochondrial.

- En revanche, il existe des formes de type monogénique, pour lesquelles on a isolé une mutation d'un seul gène et où le diabète est transmis de manière mendélienne.

- 5\%, voire 10\%, des diabètes de type II (DNID) apparaissent dès l'adolescence et surtout à partir de l'âge de 20 ou 30 ans, et constituent la forme la plus héréditaire des DNID. Ils sont appelés, selon leur terminologie anglo-saxonne : diabètes MODY (maturity onset diabetes in the young). Ces diabètes MODY sont ainsi caractérisés par leur apparition précoce, l'absence de tendance à la cétose (pas d'insulinodépendance d'emblée et parfois durant des décennies), la forte hérédité de DNID (type II) dans la famille sur trois générations. C'est dans cette forme de diabète, que les études génétiques ont été les plus fructueuses. Ainsi, dans cette forme de diabète plusieurs mutations d'enzymes clés du métabolisme glucidique ont été démontrées. Ces diabètes MODY sont au minimum au nombre de trois : MODY 1, MODY 2, MODY 3, ces derniers semblant évoluer plus rapidement vers l'insulinodépendance et vers des complications dégénératives.

Dans le diabète de type MODY 2 rencontré dans 2 à 5\% de DNID, des mutations du gène de la glucokinase, localisé sur le chromosome 7p (Froguel et coll., 1992), ont été mises en évidence. Tout récemment, en 1996, Yamagata et coll. ont identifié, chez les diabétiques de type MODY 3 , une mutation du gène d'HNF I $\alpha$ (facteurs hépatiques nucléaires). De fait, l'HNF $\alpha$ interviendrait peut-être dans tous les diabètes; des souris déficitaires en HNF I $\alpha$ développeraient des complications rénales.

Par ailleurs, des diabètes héréditaires de transmission matrilinéaire associant des troubles neurosensoriels (surdité familiale) sont identifiés depuis peu. Ils semblent liés à des anomalies de fonctionnement des mitochondries (i,e, de la chaîne respiratoire) et sont liés à des mutations de l'ADN mitochondrial dont on sait aujourd'hui qu'il est uniquement transmis par la mère. En général, ils apparaissent chez des adultes d'âge moyen et évoluent rapidement vers l'insulinodépendance.

- Il n'y a apparemment aucune relation entre le diabète non-insulinodépendant et le système HLA.

\section{L'obésité}

L'importance de ce paramètre est démontrée par la prévalence du diabète dans des populations telles que les Indiens Pima ou les Micronésiens de l'île Nauru qui ont adopté un mode de vie à l'occidentale. Outre la sédentarité et la diminution de l'activité physique, l'obésité joue un rôle majeur par le biais de l'insulinorésistance. C'est surtout la répartition androïde des graisses, définie par le rapport périmètre du tour de taille/ périmètre du tour de hanche, supérieur à 0,8 chez la femme et supérieur à 1 chez l'homme, qui augmente le risque de diabète non-insulinodépendant, multiplié ainsi par 3 à 6 . 
L'obésité et le DNID sont étroitement liés chez l'Homme (Bjorntorp, 1991). Tous les deux ont une forte composante génétique et sont associés à une insulinorésistance (Mantzoros et Flier, 1995). L'insulinorésistance et le diabète sont une des caractéristiques des souris obèses $o b / o b$ (voir chap. 12, § 8.4) et les deux s'améliorent en réponse à l'administration de leptine (Pelleymounter et coll., 1996 ; Girard, 1997); les souris $o b / o b$ ont en effet un déficit de sécrétion de cette hormone ; il est à remarquer que, chez l'homme obèse, l'anomalie ne se situe pas généralement au niveau de la sécrétion en leptine mais au niveau des récepteurs.

Ces résultats et d'autres suggèrent un rôle possible de la leptine dans la pathogenèse de la résistance à l'insuline et dans l'apparition du DNID chez l'Homme. La leptine peut effectivement diminuer la production d'insuline (Emilsson et coll., 1997) aussi bien que l'action de l'insuline sur le foie, le muscle ou l'adipocyte.

\section{L'insulinorésistance}

Elle est soupçonnée sur la coexistence d'une insulinémie normale ou élevée et d'une hyperglycémie. Elle est démontrée par la technique du clamp euglycémique hyperinsulinique (fig. 7.14) : après avoir supprimé la production hépatique de glucose et établi une glycémie constante, on perfuse des quantités croissantes d'insuline exogène. La quantité de glucose qu'il est nécessaire de perfuser pour maintenir l'euglycémie correspond à la quantité consommée par les tissus périphériques. Cette technique peut être rendue plus sensible par l'utilisation de glucose marqué au tritium et permet alors l'étude de la production hépatique de glucose. Chez le diabétique non-insulinodépendant, la quantité de glucose métabolisé est diminuée de 35 à $40 \%$ (de Fronzo, 1988).

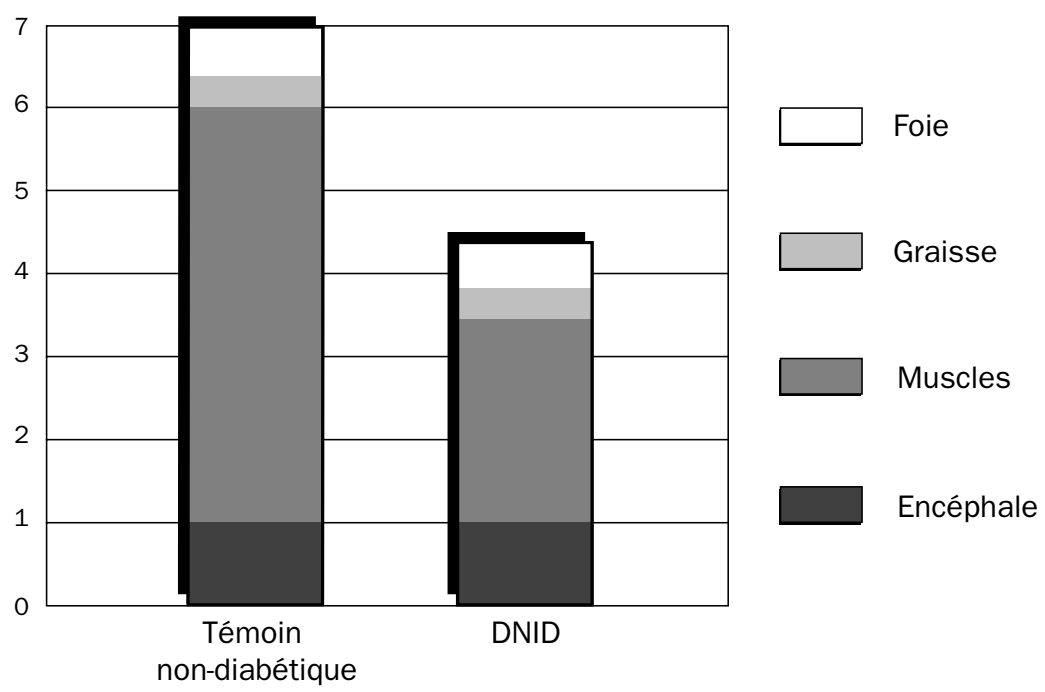

Figure 7.14 - Captage du glucose au cours d'un clamp euglycémique hyperinsulinémique (approximativement $100 \mathrm{mU} / \mathrm{ml}$ ) 
L'insulinorésistance s'observe au niveau hépatique et surtout au niveau du muscle squelettique et, à moindre degré, des tissus adipeux (ce qui pourrait être une cause de l'obésité associée à ce type de diabète).

Au niveau hépatique, on constate une élévation du débit glucosé à jeun malgré une hyperinsulinémie ce qui, chez l'individu normal, aurait un effet freinateur. L'accroissement de la néoglycogenèse à partir des lactates, alanine et glycérol, explique l'augmentation du débit glucosé hépatique. Mais c'est au niveau musculaire que se situe l'essentiel du phénomène. La diminution de la clairance métabolique du glucose résulte en majeure partie de la réduction du captage musculaire. Ainsi, le stockage de glycogène musculaire, sous la dépendance de la glycogène synthétase, est diminué. Ce processus est plus affecté, dans le DNID, que l'oxydation du glucose ; celle-ci serait également altérée en relation avec la diminution d'activité de la pyruvate déshydrogénase (PDH) insulinodépendante. Il est possible que l'oxydation des acides gras libres augmentés dans l'obésité et le DNID conduisent à une accumulation d'acyl CoA inhibiteur de la PDH, et par là-même de la glycolyse. De plus, ces acides gras entraîneraient une diminution de la captation de glucose par inhibition de l'hexokinase via la glucose-6-phosphatase.

\section{- Mécanisme cellulaire de l'insulinorésistance}

L'insulinorésistance peut se situer soit au niveau même du récepteur, soit en aval évoquant un déficit post-récepteur.

L'analyse des courbes doses réponses au cours des clamps euglycémiques hyperinsulinémiques a permis de mettre en évidence des anomalies, à la fois du récepteur et du post-récepteur (fig. 7.15).

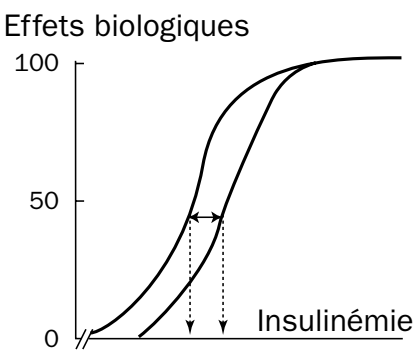

Anomalie du récepteur
Effets biologiques

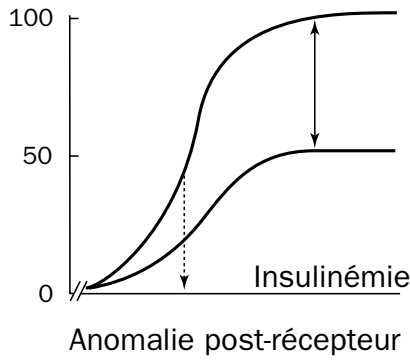

Effets biologiques

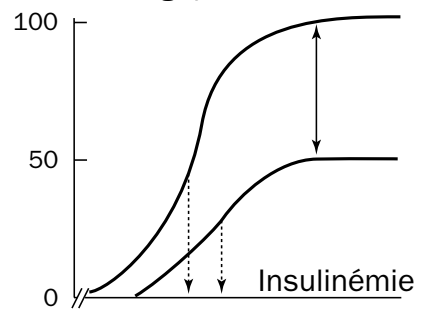

Anomalie combinée

Figure 7.15 - Courbes doses - réponses au cours des clamps euglycémiques hyperinsulinémiques

- Chez le sujet ayant un diabète modéré, inférieur à $1,40 \mathrm{~g} / 1$, la diminution du nombre de récepteurs par "down-regulation" induite par l'hyperinsulinémie prédomine.

- Dans les diabètes sévères, le défaut du post-récepteur est l'anomalie prépondérante. 


\section{- Différents mécanismes ont été proposés}

- l'activité de la tyrosine kinase exprimée par la sous-unité $\beta$ du récepteur à l'insuline, aboutissant à des phénomènes d'autophosphorylation, est diminuée d'environ $50 \%$ au niveau des cellules périphériques et hépatiques.

- la diminution de l'activité et du nombre des transporteurs de glucose, et notamment du glut 4 musculaire, pourrait être le défaut primitif de l'insulinorésistance.

\section{La carence en insuline}

On a décrit au cours du diabète non-insulinodépendant la disparition des pics rapides (périodicité de 10 à 14 min chez l'individu normal) et la réduction de la périodicité des oscillations lentes (périodicité de $90 \mathrm{~min}$ ) de l'insulinosécrétion.

Au cours de l'administration intraveineuse de glucose, le pic précoce d'insulinosécrétion est aboli.

L'insulinémie à jeun est le plus souvent normale ou élevée en valeur absolue, mais rapportée à la glycémie correspondante, elle témoigne en fait d'une insulinopénie. La courbe en cloche de Starling (fig. 7.16), qui représente l'insulinémie basale en fonction de la glycémie à jeun, montre qu'à partir de $1,20 \mathrm{~g} / 1$ les valeurs des insulinémies s'abaissent très nettement (de Fronzo, 1988). Enfin, la mise au point de techniques plus élaborées (radioimmunodosage) a permis de doser de façon spécifique l'insuline. On s'est aperçu ainsi que les dosages radioimmunologiques anciens surestimaient les taux d'insuline en raison d'une antigénicité croisée avec la proinsuline. De fait, il existe une insulinopénie absolue.

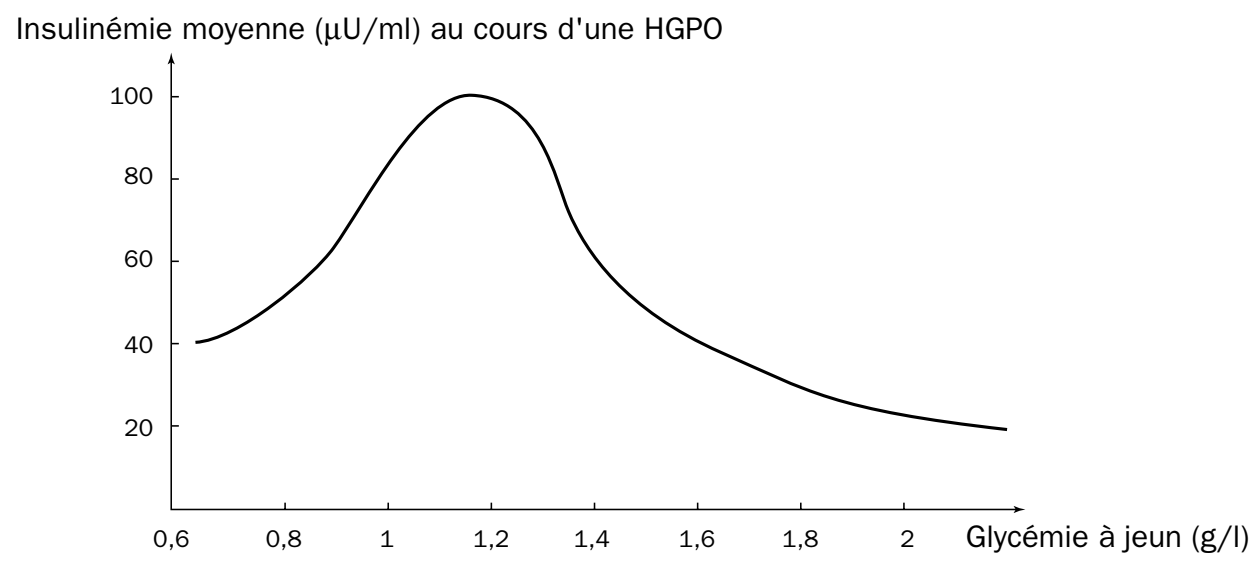

Figure 7.16 - Courbe de Starling montrant, au cours d'une HGPO (hyperglycémie provoquée), l'évolution de l'insulinémie en fonction de la glycémie à jeun

Les causes des anomalies de l'insulinosécrétion sont d'ordre anatomique et fonctionnel. Le DNID s'accompagne d'une réduction d'environ 50\% des cellules $\beta$, mais un dysfonctionnement des cellules $\beta$ résiduelles semble nécessaire pour l'apparition d'un diabète patent. La découverte de dépôts amyloïdes dans les îlots de Langerhans 
accrédite cette thèse ; les dépôts amyloïdes sont dus à la précipitation d'un peptide, l'amyline, normalement co-sécrété avec l'insuline. Elle aurait un effet délétère sur les cellules $\beta$ et sur la diffusion locale de glucose et d'insuline. Son action antagoniste de l'insuline au niveau périphérique est controversée.

Quelle que soit l'atteinte primitive, les deux anomalies, insulinodéficience et insulinorésistance, sont intimement liées et peuvent retentir l'une sur l'autre, créant ainsi des cercles vicieux. C'est ainsi que l'hyperinsulinémie réduit le nombre de récepteurs à l'insuline, aggravant l'insulinorésistance; celle-ci entraîne une sécrétion accrue d'insuline, ce qui à terme réduit l'insulinosécrétion (fig. 7.17).

Enfin, il faut tenir compte également de la glucotoxicité, notion selon laquelle l'hyperglycémie elle-même altère l'insulinosécrétion et la sensibilité à l'insuline. Chez des patients DNID, la normalisation de la glycémie améliore la sécrétion insulinique : de même, un traitement par insuline de sujets DNID entraîne une amélioration du déficit post-récepteur dès lors que l'euglycémie est obtenue.

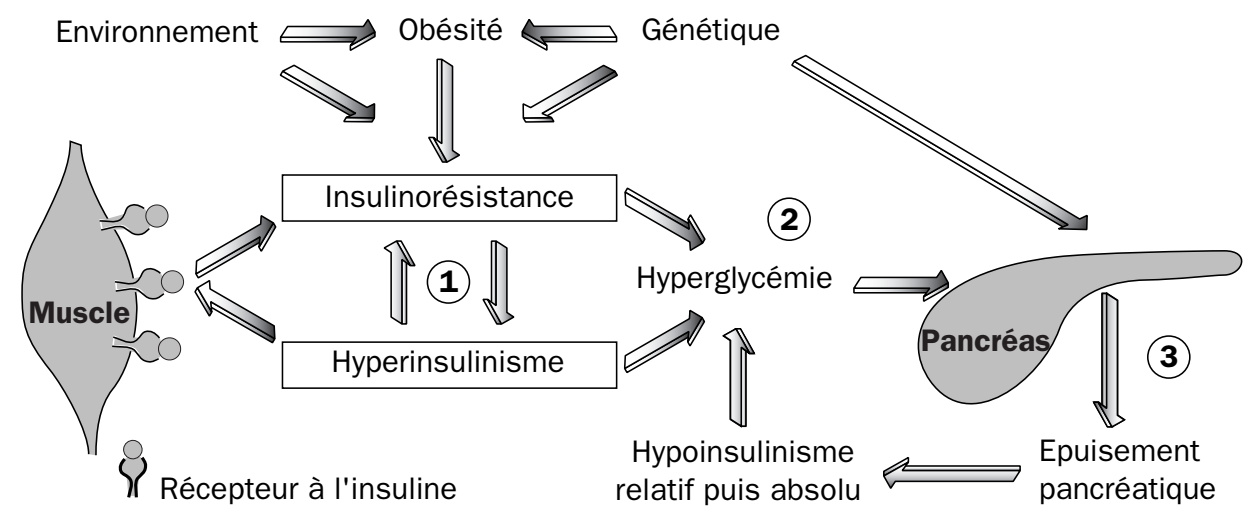

Figure 7.17 - Physiopathologie du DNID

\section{Anomalies au niveau des récepteurs}

Des anomalies au niveau des récepteurs : récepteur à l'insuline, récepteur du glucagon, récepteur $\beta$-adrénergique, récepteur de la leptine et PPA (peroxisome proliferator activated) récepteur $\gamma$, peuvent être impliquées dans la pathogenèse et les complications du DNID. Leur compréhension permettra non seulement de clarifier la pathogenèse de ce type de diabète, mais aussi de déterminer la thérapeutique la mieux appropriée (Xiong et Gray, 1999).

\subsubsection{Le diabète insulinonécessitant}

La division purement didactique entre DID et DNID ne correspond pas totalement à la réalité.

- En effet, dans environ 30\% des cas, le DNID évolue lentement vers l'épuisement insulinosécrétoire, nécessitant la mise sous insulinothérapie. C'est ce que l'on appelait autrefois le diabète intermédiaire, dénommé aujourd'hui diabète insulino- 
nécessitant ou insulinorequérant ; dans un certain nombre de cas, ces diabètes sont des DID d'évolution lente, survenant chez des patients non-obèses avec présence d'auto-anticorps, et notamment des anticorps anti-GAD.

- Mais, généralement, ces diabétiques ne présentent pas de profil particulier sinon un long passé d'hyperglycémie, probablement responsable de surmenage pancréatique.

\subsection{LES COMPLICATIONS}

- Elles affectent tous les types de diabète.

- Elles sont responsables de la gravité de la maladie. Invalidantes par leurs complications oculaires (cécité), artérielles (amputations), elles entrainent un risque vital dont témoigne la réduction de l'espérance de vie (diminution de 5 à 10 ans chez les patients âgés de 50 ans).

- Elles sont liées à l'hyperglycémie chronique comme l'a prouvé l'étude du DCCT (Diabete Control and Complication Trial) (Pirart, 1977) sur les complications micro- et macrovasculaires : un strict contrôle glycémique, quelle qu'en soit la méthode, notamment par insulinothérapie intensive, fait diminuer le risque de rétinopathie de 50 à $16 \%$ (fig. 7.18).

Fréquence d'apparition des rétinopathies en fonction des modalités de traitement (\%)

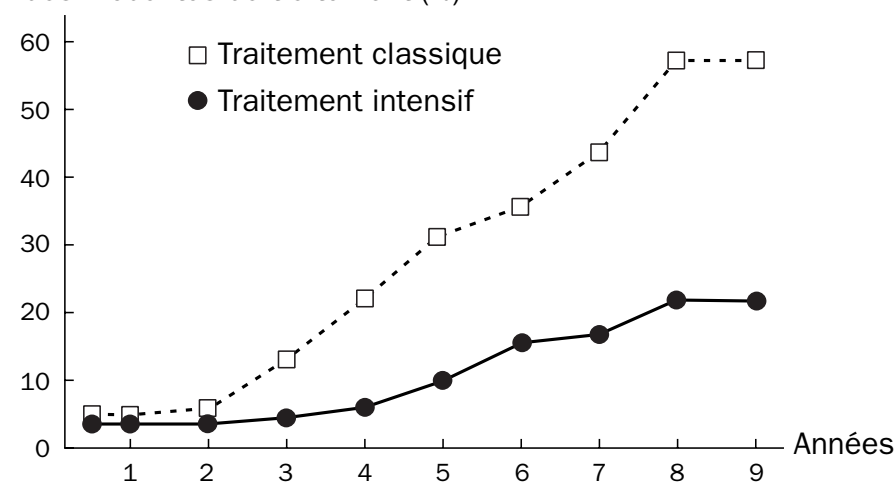

Figure 7.18 - Prévention primaire des rétinopathies

\subsubsection{Complications aiguës métaboliques}

Avec l'amélioration de la prise en charge des diabétiques, elles sont devenues plus rares.

\section{L'acidocétose}

Elle complique surtout le diabète insulinodépendant, parfois de façon inaugurale. La carence en insuline entraîne une augmentation de la lipolyse. Les acides gras ainsi libérés sont oxydés en acétyl CoA au niveau du foie, et réutilisés dans la synthèse 
exagérée de corps cétoniques, acide acéto-acétique et acide $\beta$-hydroxybutyrique : ces corps cétoniques, acides forts, aboutissent à une acidose métabolique. Grâce aux techniques de réanimation, le pronostic vital s'est considérablement amélioré.

Les hypoglycémies (glycémie $<0,40 \mathrm{~g} / \mathrm{l}$ )

Elles se rencontrent le plus souvent au cours des traitements insuliniques, soit par surdosage, soit au cours d'une activité physique importante imprévue ou lors d'erreurs diététiques imprévues, par exemple un repas pauvre en hydrate de carbone. Les hypoglycémies, au cours des traitements des diabètes non-insulinodépendants par sulfamides, sont plus rares mais parfois plus sévères, car survenant chez des personnes âgées.

Dans l'ensemble, le pronostic reste bon si la correction de l'hypoglycémie par absorption de sucre ou par injections intraveineuse de glucose ou intramusculaire de glucagon est réalisée rapidement.

\section{L'acidose lactique}

C'est une accumulation d'acide lactique par catabolisme anaérobie du glucose. Aussi grave que rare, elle complique les DNID traités par biguanide en cas d'insuffisance rénale ou d'insuffisance hépatique.

\section{Le coma hyperosmolaire}

Egalement très rare et grave, il survient chez le sujet âgé, porteur d'un diabète non-insulinodépendant. L'hyperosmolarité supérieure à $350 \mathrm{mmol} / 1$ est due à l'hyperglycémie importante de l'ordre de 8 à $10 \mathrm{~g} / 1$. Cette hyperglycémie induit une polyurie responsable d'une déshydratation majeure ; mais il n'existe pas de cétose, probablement en raison d'une insulinémie périphérique suffisante, tout au moins au début.

\subsubsection{Les complications infectieuses}

Fréquentes, elles témoignent d'un déséquilibre du diabète et aggravent à leur tour celui-ci. L'antibiothérapie a grandement amélioré le pronostic de ces complications.

Les infections génitales, balanites chez l'homme, vulvo-vaginites chez la femme, révèlent parfois le diabète. Elles sont dues à des mycoses et notamment au Candida albicans. C'est également ce champignon que l'on rencontre dans l'infection des plis (intertrigo) et des pieds.

Les infections urinaires à Escherichia coli, très fréquentes et asymptomatiques chez la femme, justifient la pratique systématique d'une cytobactériologie des urines.

Le staphylocoque "se plaît dans le glucose" et occasionne furoncles, phlegmons, abcès, folliculites.

Le "pied diabétique" (voir aussi p. 317) est une complication à la fois neurologique et vasculaire qui se surinfecte aisément ; cette affection peut aboutir à des délabrements importants et atteindre l'os. Généralement, une flore polymicrobienne, 
staphylocoque, streptocoque, protéus et le redoutable pyocyanique, s'installe ; l'ischémie favorise le développement des germes anaérobies, et notamment le Perfringens dont le traitement s'avère délicat en raison de sa résistance aux antibiotiques.

Les infections broncho-pulmonaires, plus fréquentes et plus sévères, réagissent bien au traitement antibiotique : de même, la tuberculose doit être dépistée systématiquement chez le diabétique. La vaccination par le BCG reste le meilleur moyen de lutter contre cette maladie qui, actuellement est en nette régression. Faut-il rappeler que les vaccinations, tétanos, poliomyélite, grippe... sont tout particulièrement recommandées chez le diabétique?

\subsubsection{Les complications chroniques}

Elles rendent compte de la morbidité et de la mortalité. Elles atteignent les deux formes de diabète. On les divise classiquement en micro-angiopathies, caractéristiques et quasi spécifiques de la maladie, au niveau rétinien, rénal et nerveux et en macro-angiopathie, responsable des complications cardio-vasculaires.

\section{La micro-angiopathie}

Elle intéresse les artérioles et les capillaires de tout l'organisme.

\section{Physiopathologie}

La coupe d'un capillaire normal (fig. 7.19) distingue de la lumière vers l'extérieur :

- l'endothélium qui sécrète différents messagers chimiques et facteurs : l'endothéline (chap. 3, § 5), le NO (chap. 3, § 3), des dérivés de l'acide arachidonique (chap. 2 , $\S 2.2 .7)$, le facteur VIII de Willebrandt, l'enzyme de conversion et le PAI1 (plasminogène activateur inhibiteur),

- la membrane basale,

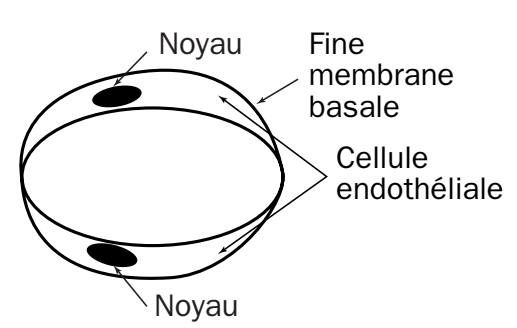

Figure 7.19 - Coupe schématique d'un capillaire

- des péricytes, cellules de soutien capillaire.

Les anomalies concernent les parois vasculaires et l'endothélium, d'une part, et le contenu, d'autre part.

- La lésion élémentaire est l'épaississement de la membrane basale en rapport avec une accumulation excessive de collagène type IV, de protéoglycannes, de fibronectines et de laminine. La prolifération des cellules endothéliales contraste avec la disparition progressive des péricytes, ce qui expliquerait la formation des microanévrismes.

- Les anomalies du contenu concernent les perturbations hémorhéologiques et de la coagulation :

- altérations de la production de NO (endothelium derived relaxing factor ou EDRF), 
- augmentation de la viscosité plasmatique en rapport avec la diminution de la déformabilité des globules rouges et l'augmentation de leur agrégabilité.

- troubles trombogènes de l'hémostase :

- augmentation du facteur VIII,

- hyperagrégabilité des plaquettes par libération accrue du PDGF (platelet derived growth factor),

- déséquilibre en facteurs agrégants (thromboxane A2 plaquettaire) et antiagrégant (la prostacycline). Se surajoute une déficience du système fibrinolytique par élévation du PAI1.

Les troubles hémodynamiques vont ainsi créer une hyperpression intracapillaire, expliquant l'hyperperméabilité capillaire et les lésions des cellules endothéliales qui peuvent être arrachées et être ainsi source de thrombus et d'oblitération capillaire.

- Il en résulte une hypoxie tissulaire, responsable d'une vaso-dilatation et d'une atteinte de la perméabilité capillaire. De même, cette hypoxie engendrerait une prolifération cellulaire des cellules endothéliales et mésangiales par production du facteur de croissance IGF1 (insuline growth factor) ou suppression d'inhibiteur (TGF), mécanismes qui pourraient être en partie responsables de l'hypertension observée au cours du diabète.

L'hyperglycémie est à l'origine de ces anomalies. L'étude du DCCT a démontré de façon indiscutable la relation étroite entre l'hyperglycémie et ces complications chroniques, même si vraisemblablement d'autres facteurs individuels, notamment génétiques, peuvent expliquer des diabètes fortement déséquilibrés sans complications. Plusieurs hypothèses, à vrai dire complémentaires, ont été avancées.

\section{- La voie des polyols ou voie du sorbitol}

Le glucose en excès est transformé en sorbitol sous l'effet de l'aldolase-réductase en présence de NADH, puis en fructose par la sorbitol-déshydrogénase ; l'accumulation du sorbitol entraverait la captation du myoinositol et retentirait sur le métabolisme des phosphoinositides, et par là sur la $\mathrm{Na}^{+} / \mathrm{K}^{+}$ATPase. La diminution d'activité de celle-ci serait responsable de rétention d'ions sodium et d'un défaut de captation d'acides aminés sodium-dépendants (fig. 7.20).

Ces anomalies métaboliques expliqueraient la neuropathie et la cataracte.

\section{- La glycation protéique}

Le glucose peut se lier, de façon non-enzymatique, à des protéines (hémoglobine, albumine) donnant naissance à une base de Schiff instable. Celle-ci subit un réaménagement dit "d'Amadori" pour former une cétosamine stable (fig. 7.21). Cette glycation modifie la propriété de ces protéines ; ainsi, l'affinité pour l'oxygène de l'hémoglobine glyquée est-elle augmentée ; l'albumine glyquée, quant à elle, augmente les capacités d'endocytose de l'endothélium. La glycation aboutit aussi à la formation de produits terminaux irréversibles appelés AGE (advanced glycation end products), remarquables par leur brunissement et leur fluorescence ; ces produits peuvent expliquer l'épaississement de la membrane basale. 


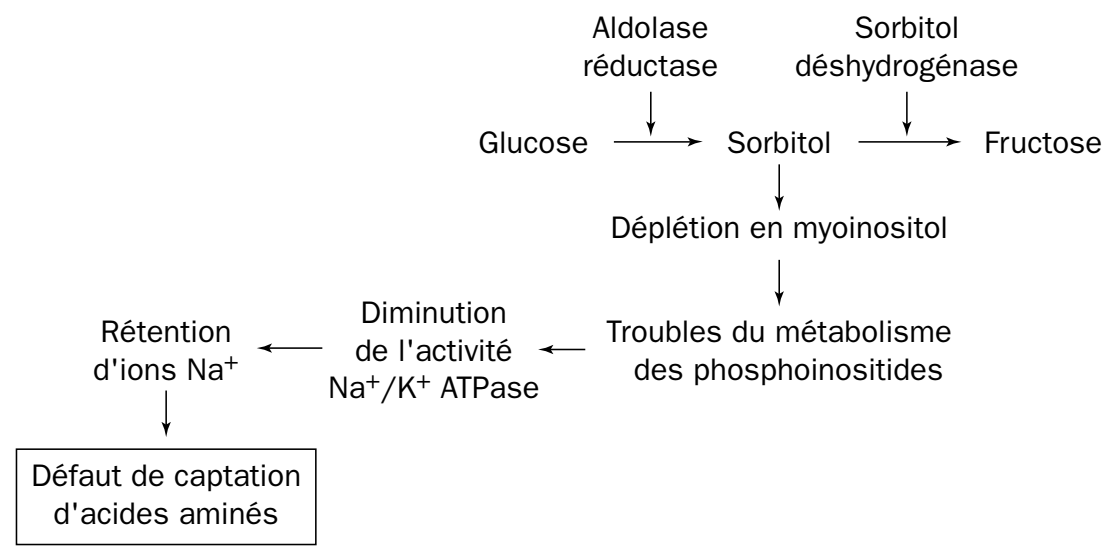

Figure 7.20 - La voie des polyols (d'après Greene dans Grimaldi et coll., 1993)

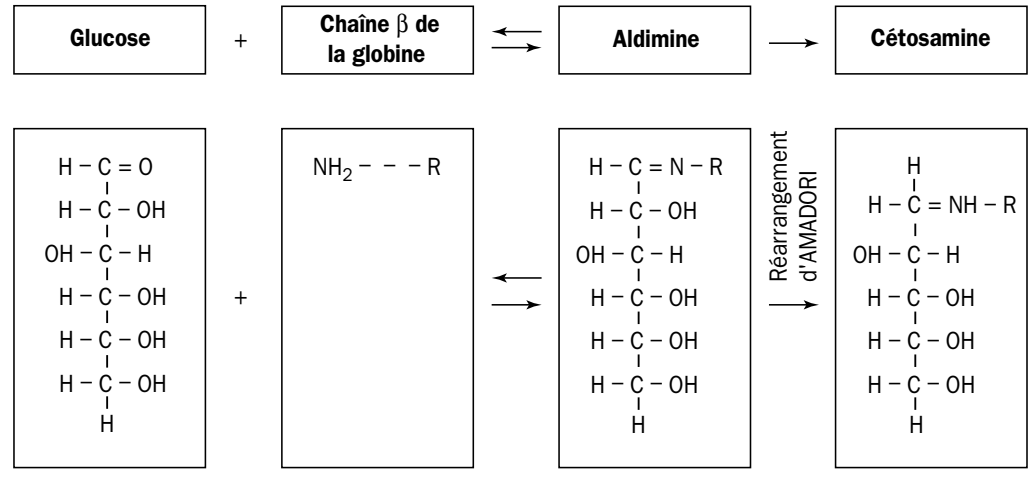

Figure 7.21 - Biosynthèse de l'hémoglobine $A_{i} c$

\section{- D'autres hypothèses ont été mises en avant :}

- l'implication de l'hormone de croissance a été suspectée dans l'évolution de la rétinopathie d'autant que l'administration de somatostatine semblait avoir des effets bénéfiques ;

- la formation de radicaux libres en excès et la diminution des anti-oxydants, notamment du glutathion réduit, aggraveraient les altérations plaquettaires.

- l'hyperglycémie pourrait aussi agir en augmentant l'expression génétique de nombreuses protéines, par exemple l'aldolase-réductase.

\section{Les complications du diabète}

La rétinopathie, la néphropathie et la neuropathie constituent la triade caractéristique des complications du diabète.

\section{- La rétinopathie}

Aux USA, le diabète est responsable de $8 \%$ de cécités et en représente l'une des premières causes. La durée du diabète est l'élément déterminant dans l'éclosion de la rétinopathie : elle est de 25 à $50 \%$ entre 5 et 10 ans d'évolution (fig. 7.22). 
La fréquence est moindre dans le diabète non-insulinodépendant. Pour une durée d'évolution de 35 ans, on note une prévalence de $60 \%$ dans les diabète non-insulinodépendants, $80 \%$ dans les diabètes insulinotraités et $100 \%$ dans les diabètes insulinodépendants (Klein et coll., 1984). Cependant, il a noté que $15 \%$ des DNID sont déjà porteurs de rétinopathies lors du diagnostic de leur maladie.

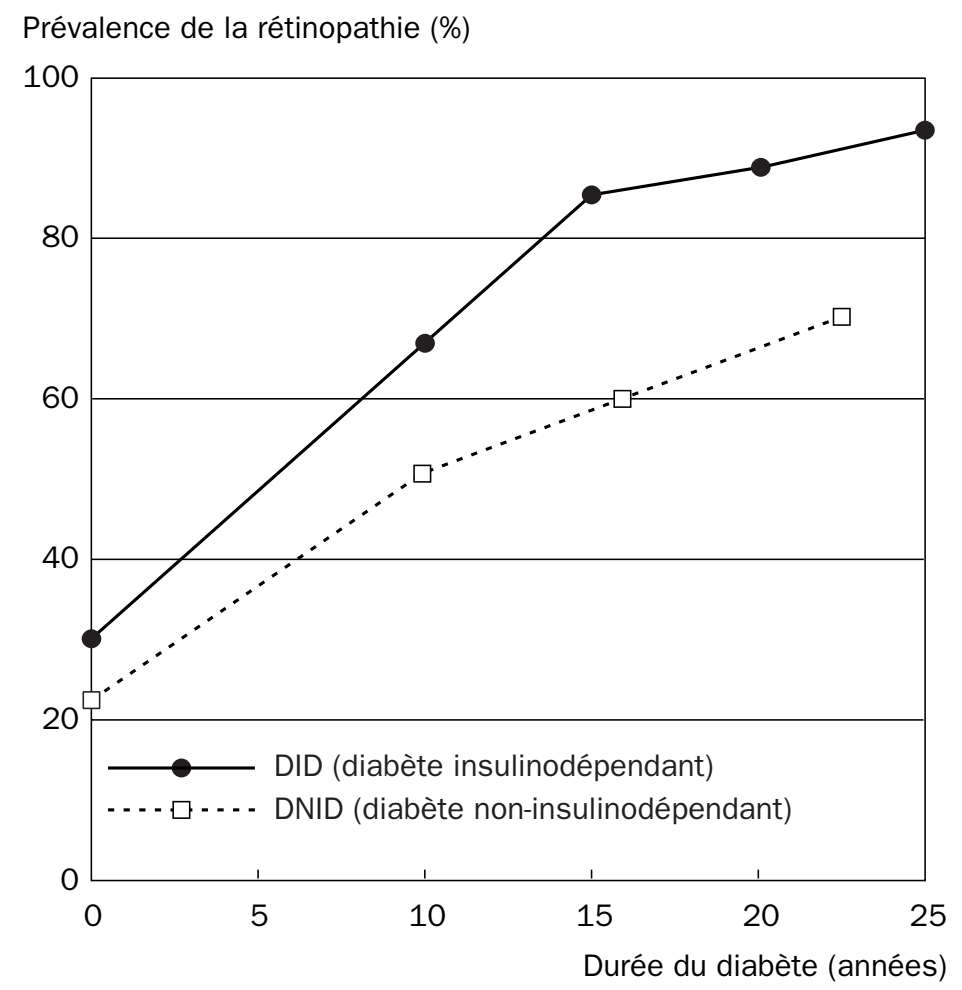

Figure 7.22 - Prévalence de la rétinopathie en fonction de la durée d'évolution du diabète

Grâce au fond d'œil, pratiqué systématiquement chaque année, et à l'angiographie fluorescéinique (prise de photographie après injection intraveineuse de fluorescéine qui imprègne les vaisseaux rétiniens), les lésions seront dépistées tôt. On détermine ainsi :

- les lésions débutantes d'une rétinopathie simple avec micro-anévrismes,

- la rétinopathie œdémateuse avec ou sans exsudats,

- la rétinopathie ischémique où des territoires plus ou moins importants ne sont plus irrigués,

- la rétinopathie proliférante avec son risque grave d'hémorragie du vitré.

Longtemps privée de traitement efficace, la rétinopathie a vu son pronostic amélioré grâce à la photocoagulation par le laser à l'argon ; celle-ci s'adresse aux formes œdémateuses, ischémiques et proliférantes et stoppe l'évolution. 


\section{- La néphropathie}

Les diabètes constituent aujourd'hui la première cause d'insuffisance rénale terminale en dialyse (14 à $40 \%$ des nouveaux dialysés).

Contrairement aux deux autres complications micro-angiopathiques, la néphropathie engage le pronostic vital. Le pourcentage de diabétiques parmi les dialysés, en France, est de 7 à $8 \%$ dont les $2 / 3$ sont des DNID. L'insuffisance rénale représente $6,2 \%$ des causes de décès en cas de diabète non-insulinodépendant ; $30 \%$ des DID et 3\% des DNID meurent en insuffisance rénale (Mogensen, 1984).

Parmi les facteurs de risques, on retiendra le mauvais équilibre du diabète, sa durée, l'hérédité d'hypertension artérielle et de néphropathie (race noire), le tabac.

La glomérulopathie diabétique évolue en cinq stades :

- La néphropathie fonctionnelle

Elle se caractérise par une hypertrophie rénale et une augmentation de la filtration glomérulaire, lésions réversibles avec un meilleur équilibre glycémique. La micro-albuminurie (définie par un taux inférieur à $30 \mathrm{mg} / 24 \mathrm{~h}$ ) est absente ou transitoire. Elle se rencontre essentiellement au cours du DID.

- La néphropathie préclinique

Elle correspond à des modifications histologiques : épaississement de la membrane basale, hyperplasie du mésangium; la micro-albuminurie augmente à l'effort mais est normale au repos.

Dans un cas sur deux la glomérulopathie reste à ce stade-là, tout au moins dans le DID.

- La néphropathie débutante ou incipiens

En principe, elle est définie par un taux de micro-albuminurie supérieur à 10$15 \mu \mathrm{g} / \mathrm{mm}$, soit 15 à $20 \mathrm{mg} / 24 \mathrm{~h}$ et inférieur à $300 \mathrm{mg} / 24 \mathrm{~h}$ (les bandelettes réactives type albustix ne les détectent pas).

Ces lésions peuvent être stabilisées par une insulinothérapie maximale ; un traitement par inhibiteur de l'enzyme de conversion, alors qu'il n'existe pas d'hypertension artérielle, a été proposé avec efficacité ; toutefois, peu de diabétologues l'utilisent à ce stade-là.

- La néphropathie patente

L'albuminurie est supérieure à $300 \mathrm{mg} / 24 \mathrm{~h}$, détectable par l'albustix; parfois elle peut atteindre plus de $5 \mathrm{~g} / 24 \mathrm{~h}$ rentrant dans le cadre d'un syndrome néphrotique avec hypoalbuminémie ; la filtration glomérulaire diminue ; l'hypertension artérielle ou la rétinopathie y sont souvent associées; les lésions histologiques sont caractéristiques avec formation de nodules mésangiaux : c'est la glomérulosclérose nodulaire de Kimmelstiel-Wilson.

- L'insuffisance rénale terminale

Elle coïncide avec la défaillance de la filtration glomérulaire; lorsque la clairance à la créatinine est inférieure à $10 \mathrm{ml} / \mathrm{min}$, seules sont proposées 
l'hémodialyse avec création d'une fistule artérioveineuse aux membres supérieurs ou la dialyse péritonéale ambulatoire et continue réalisée à domicile. Les transplantations rénales, rein-pancréas, restent une éventualité rare bien qu'en progression. Malheureusement, les autres complications diabétiques continuent à évoluer.

La néphropathie peut être aggravée par des infections urinaires à répétition (cystites), fréquentes chez la femme diabétique. Ces infections non seulement déséquilibrent le diabète, mais se compliquent parfois de pyélonéphrites ou de nécroses papillaires.

On retiendra la valeur prédictive de la micro-albuminurie pour le dépistage de la néphropathie, mais aussi sa valeur pronostique chez le DNID en révélant le risque accru de décès par complication coronarienne et vasculaire.

\section{- Les neuropathies}

Elles sont parfois révélatrices du DNID. Leur fréquence clinique augmente avec la durée du diabète : $50 \%$ après 25 ans, $75 \%$ après 40 ans de diabète.

La pathogénie fait intervenir une atteinte directe des cellules nerveuses par l'accumulation de sorbitol (action de l'aldolase-réductase).

Cliniquement, on divise les neuropathies en :

- Polynévrites des membres inférieurs

De loin les plus fréquentes, avec un taux de $80 \%$ des neuropathies. Elles se manifestent par des paresthésies de type fourmillement, décharges électriques, sensations de brûlure, mais parfois les douleurs des membres inférieurs sont insupportables. L'atteinte est donc généralement sensitive, mais il existe des formes purement motrices avec parésie ou paralysie des membres inférieurs. Les réflexes ostéotendineux achilléens et parfois rotuliens sont abolis; des troubles de la sensibilité profonde et superficielle sont constants.

- Mononeuropathies

- Elles intéressent le plus souvent les membres inférieurs; leur caractère isolé incite souvent à rechercher d'autres causes que le diabète. La cruralgie, avec sa douleur à la face interne de la cuisse, est très évocatrice.

- L'atteinte des nerfs crâniens oculomoteurs avec paralysie du III (nerf moteur oculaire commun) ou du VI (nerf moteur oculaire externe) peut être isolée ou multiple.

- L'amyotrophie proximale des quadriceps est d'ordre moteur, entravant la marche. Elle s'associe parfois à une polynévrite des membres inférieurs.

Le pronostic de ces mononeuropathies s'avère être excellent et la régression en est la règle.

- La neuropathie végétative

Elle résulte de l'atteinte du système sympathique ou parasympathique. Elle s'observe après une longue évolution du diabète, et s'associe toujours à une 
polynévrite et aux autres complications, notamment la rétinopathie. Son traitement est toujours difficile.

- L'hypotension orthostastique avec chute de la tension artérielle en position debout, de 3 à $5 \mathrm{~cm}$ de mercure lorsqu'elle est sévère, est invalidante par son syndrome vertigineux. Le traitement par la dihydro-ergotamine, mais surtout la $9 \alpha$-hydrocortisone et le midodrine (Gutron ${ }^{\circledR}$ ), l'améliore indiscutablement.

- Les troubles de la sudation et la tachycardie sont d'observation courante.

- Les manifestations digestives consistent en diarrhées profuses et gastroparésies (nausées, vomissements et pesanteur post-prandiaux).

\section{- Les manifestations urogénitales}

Elles sont une complication liée en partie à la neuropathie végétative.

- L'impuissance est fréquente chez l'homme; il ne faut pas ignorer la participation psychique à ce symptôme.

- L'éjaculation rétrograde (dans la vessie) est source d'infertilité.

- L'atteinte vésicale avec diminution de la sensation du besoin d'uriner est démasquée par la débimétrie urinaire.

\section{- Le pied diabétique}

Il est à la fois la conséquence de l'atteinte neurologique et artérielle avec prédominance de l'une ou de l'autre. Se greffent des surinfections mycosiques et bactériennes.

- Le pied artéritique : l'ischémie explique que le pied soit sec, froid ; les pouls ne sont pas perçus.

- Le pied neurologique entraîne un pied chaud, dû à un hyperdébit sanguin par ouverture des shunts artérioveineux en rapport avec une atteinte des nerfs sympathiques. Des microtraumatismes entraînent des tassements et des déformations accentuant les zones d'appui, notamment au niveau de la tête des métatarsiens; ces frottements anormaux finissent par créer une lésion caractéristique : le mal perforant plantaire. Cette complication est la plus fréquente de la polynévrite diabétique, véritable trou dans le pied, elle est souvent négligée car indolore ; par surinfection, elle conduit à l'abcès et à l'ostéite, nécessitant souvent des mises à plat chirurgicales importantes et des amputations.

- La cataracte : il ne s'agit pas à proprement parler d'une micro-angiopathie ; la cataracte (opacification du cristallin) revêt au moins deux types :

- soit la cataracte de type sénile identique à celle du sujet âgé mais plus précoce et cinq fois plus fréquente chez le diabétique,

- soit la cataracte du diabétique mature jeune qui est dix fois plus fréquente que chez le non-diabétique.

Au début, simple brouillard visuel, elle aboutit à une quasi-cécité. Heureusement, le traitement chirurgical, extraction capsulaire du cristallin avec mise en place d'un 
implant, permet la restitution ad integrum de la vision à condition que le trouble visuel ne soit pas dû à la rétinopathie.

\section{La macro-angiopathie}

On regroupe sous ce vocable les lésions des artères de gros et moyen calibres, tout particulièrement des artères des membres inférieurs, des coronaires et des artères cervicales et cérébrales.

On a coutume d'associer la macro-angiopathie à des lésions d'athérosclérose commune ; bien que l'athérogenèse soit multifactorielle, le diabète sucré représente un facteur de risque artériel indépendant. Toutefois la macro-angiopathie s'individualise par:

- $\quad$ sa précocité : la coronopathie, maladie du sujet âgé, survient parfois avant 40 ans dans le diabète insulinodépendant.

- sa fréquence : dans l'enquête de Framingham (tab. 7.5) le risque cardiovasculaire est multiplié par 2 chez l'homme et 3 chez la femme.

- sa gravité évolutive, due à la sévérité des lésions et à sa diffusion ; l'amputation du pied est trois fois plus fréquente que chez l'artéritique non-diabétique.

- son égalité de chances entre les deux sexes : alors qu'une prédisposition masculine notable est observée en cas de non-diabète.

Tableau 7.5 - Risque relatif d'atteinte cardio-vasculaire (CV) chez les diabétiques (d'après Kannel et coll., 1976)

\begin{tabular}{|l|cc|rc|rcc|}
\hline \multirow{2}{*}{ Type d'atteinte } & \multicolumn{6}{|c|}{ Risque relatif \% } \\
\cline { 2 - 9 } & \multicolumn{2}{|c|}{ Non-ajusté } & \multicolumn{2}{|c|}{ Ajusté à l'âge } & \multicolumn{2}{c|}{ Ajusté aux } \\
facteurs de risque \\
& $\mathrm{H}$ & $\mathrm{F}$ & $\mathrm{H}$ & $\mathrm{F}$ & $\mathrm{H}$ & $\mathrm{F}$ \\
\hline Toute atteinte CV & 2,5 & 3,7 & 2,2 & 2,8 & 2,1 & 2,0 \\
\hline Mortalité CV & 2,6 & 7,2 & 2,1 & 4,9 & 1,7 & 3,3 \\
\hline Insuffisance cardiaque & 2,8 & 7,7 & 2,2 & 5,4 & 1,8 & 3,8 \\
\hline Infarctus cérébral & 3,3 & 5,6 & 2,7 & 3,8 & 2,2 & 2,2 \\
\hline Atteinte coronarienne & 1,9 & 3,6 & 1,7 & 2,7 & 1,7 & 2,1 \\
\hline Claudication intermittente & 4,7 & 8,9 & 4,0 & 6,4 & 4,2 & 5,0 \\
\hline
\end{tabular}

Physiopathologie (Leutenegger et Bertin, 1995)

\section{- L'athérome}

Anatomiquement, l'athérome diabétique ne diffère pas de l'athérome habituel. On y rencontre quatre types de lésions :

- la strie lipidique ;

- la plaque fibreuse, épaississement gris de l'intima ; 
- la plaque d'athérome constituée de cellules musculaires lisses, de collagène, de dépôt de cholestérol ;

- la plaque est le siège d'ulcération, d'hémorragies, de calcifications et de thromboses responsables d'ischémie.

Il faut signaler, dans le diabète, une lésion caractéristique de la média mais non-spécifique, la médioacalcose.

- Au début, les LDL (low density lipoproteins) plasmatiques infiltrent l'intima et, détruisant les cellules endothéliales, les LDL oxydées par les radicaux libres ne sont plus reconnues par leurs récepteurs mais par les macrophages "éboueurs" ou "scavengers"; ces macrophages se chargent de lipides et se transforment en cellules spumeuses expliquant la strie lipidique.

- Les cellules musculaires lisses sous l'influence des LDL oxydées migrent de la média vers l'intima; elles se multiplient et sécrètent du tissu conjonctif donnant l'aspect de plaques fibreuses.

- Des lésions endothéliales activent l'agrégation plaquettaire. Les plaquettes libèrent alors divers facteurs, notamment le PDGF (platelet derived growth factor) qui accroît la prolifération des cellules musculaires lisses.

- Le dernière étape est l'ulcération avec formation d'un thrombus qui, par son volume, oblitérera progressivement la lumière vasculaire.

Le diabète interviendrait à tous les stades de l'athérogenèse par au moins trois mécanismes: l'hyperglycémie, les troubles lipidiques, l'hyperinsulinisme et l'insulinorésistance.

\section{- L'hyperglycémie}

Son rôle dans la macro-angiopathie est souligné par l'étude du DCCT (The Diabete Control and Complications, 1995) publié récemment ; le nombre d'accidents cardio-vasculaires majeurs est diminué de $42 \%$ lorsque le contrôle glycémique est intensifié.

On retrouve certaines caractéristiques de la micro-angiopathie :

- Troubles de l'hémostase et hémodynamiques par :

- des anomalies des facteurs plaquettaires : production de thromboxanes A2 pro-agrégants, de PDGF responsable de la prolifération des cellules musculaires lisses.

- des anomalies de la cellule endothéliale : augmentation du facteur VIII de Willebrandt, diminution de la synthèse de prostacycline anti-agrégante, augmentation de l'endothéline, puissant vaso-constricteur et stimulant de la prolifération des cellules musculaires lisses, anomalies de la libération de NO (la relaxation vasculaire est ainsi altérée).

- des anomalies rhéologiques : une augmentation de la viscosité et du fibrinogène ; une augmentation de la PAI1 (inhibiteur de l'activité du plasminogène) diminuerait la fibrinolyse. 
- Glycation des protéines

La glycation du collagène provoque un épaississement pariétal; celle des lipoprotéines jouerait un rôle dans l'athérogenèse ; la glycation de l'apo-B des LDL (low density lipoproteins) ralentit leur catabolisme et réduit la captation par leurs récepteurs ; les LDL glyquées sont mieux captées par les macrophages avec formation de cellules spumeuses dont on connaît le rôle dans l'athérogenèse.

- Production accrue de radicaux libres

Ils accélèrent la formation des produits glyco-oxydés à partir des protéines glyquées, de même l'importance dans le développement de la plaque d'athérome des modifications oxydatives des LDL n'est plus à souligner.

\section{- Les troubles lipidiques}

Ils sont fréquents chez le diabétique, notamment dans le diabète de type II. Au cours du DNID, l'anomalie la plus commune est l'hypertriglycéridémie liée à une augmentation des VLDL (very low density lipoproteins). Ces VLDL, enrichies en triglycérides, seront catabolisées en remnants, particulièrement athérogènes ; les LDL sont augmentées, mais elles subissent des modifications de type oxydatif ; les HDL (high density lipoproteins) protectrices sont abaissées.

Dans le DID équilibré, seuls des perturbations qualitatives et non-quantitatives sont décrites avec des VLDL enrichies en triglycérides, des LDL petites et denses, une glycation de l'apo-B et A1 importante. Tout ceci confère un profil athérogène (tab. 7.6).

La LPa (lipoprotéine a) de faible densité, proche des LDL, serait peut-être un facteur de risque d'athérosclérose dans le diabète, ce qui ne semble pas se confirmer totalement par des études récentes (Durlach et coll., 1996).

Tableau 7.6 - Le syndrome métabolique de l'insulinorésistance (d'après Reaven, 1988)

\begin{tabular}{|l|l|}
\hline D'après Reaven : syndrome X & D'après Zimmet : syndrome X+ \\
\hline Insulinorésistance tissulaire & Insulinorésistance tissulaire \\
Intolérance au glucose & Intolérance au glucose \\
Hyperinsulinémie & Hyperinsulinémie \\
VLDL - triglycérides élevés & VLDL - triglycérides élevés \\
HDL - cholestérol bas & HDL - cholestérol bas \\
Hypertension & Hypertension \\
& Obésité “androïde” \\
\hline
\end{tabular}

\section{- L'hyperinsulinisme et l'insulinorésistance}

L'insuline aurait un effet direct sur la paroi artérielle par son action mitogène sur les cellules musculaires lisses et sur la prolifération plaquettaire. Elle pourrait 
intervenir également par le biais des troubles lipidiques et de l'hypertension artérielle. Dans le diabète de type II, l'insulinorésistance serait déterminante : Reaven (1988) a montré que plus l'insulinorésistance est importante chez des sujets non-diabétiques, plus la tension est élevée ainsi que la tendance à l'hypertriglycéridémie et à l'hyperglycémie. Cet auteur a rapporté cet ensemble de manifestations dans le "syndrome X" et avance l'idée qu'il pourrait expliquer le diabète et l'athérosclérose (voir tab. 7.6).

L'ensemble des facteurs responsables de la macro-angiopathie est résumé dans le tableau suivant (tab. 7.7) :

Tableau 7.7 - Les facteurs responsables de la macro-angiopathie

- L'athérome $\longrightarrow$ anatomique
biologique $:$ les quatre types de lésions
- Le diabète intervient par :
- l'hyperglycémie $\longrightarrow \begin{aligned} & \text { troubles de l'hémostase } \\ & \text { glycation des protéines } \\ & \text { radicaux libres }\end{aligned}$
- des troubles lipidiques
- l'hyperinsulinisme et l'insulinorésistance
cellules endothéliales
anomalies rhéologiques

\section{Artérite des membres inférieurs}

Après 20 ans d'évolution, elle atteint 40 à $50 \%$ des diabétiques; $50 \%$ des amputés pour artérite sont diabétiques. Les lésions se caractérisent par leur distalité, au niveau des jambes (artères tibio-péronières et tibiales antérieures); toutefois les autres artères, iliaques, fémorales sont plus souvent atteintes qu'il n'est classique de le dire. Le maître-symptôme de l'artérite est représenté par la claudication intermittente; le patient est contraint d'arrêter sa marche en raison de douleur au mollet : celle-ci cesse avec le repos mais reprend aussitôt avec la marche. La lésion est d'autant plus importante que la distance parcourue - périmètre de marche - est courte. La diminution ou l'abolition des pouls périphériques tibiaux et pédieux est très évocatrice. L'examen ultrasonographique couplé à l'échographie confirme le diagnostic et le siège de la lésion. Cet examen externe, non-invasif, fondé sur l'effet Doppler, évite la pratique de l'artériographie (après ponction d'une artère fémorale ou aortique, on injecte un produit iodé qui visualise les artères des membres inférieurs). L'artériogaphie n'est actuellement indiquée qu'à titre pré-opératoire.

En l'absence de tout traitement, l'artérite évolue progressivement vers la gangrène du pied par ischémie. L'unique solution sera alors l'amputation.

Actuellement les traitements, médical et chirurgical, ont modifié partiellement l'évolution de cette artérite. Le traitement médical par vaso-dilatateur et anti-agrégant plaquettaire s'envisage au début de l'artérite stade 1 (abolition des pouls fémoraux sans 
symptomatologie) et stade 2 (claudication intermittente). Au stade 3 (douleur de décubitus) et stade 4 (gangrène) le traitement chirurgical s'impose.

La dilatation endoluminale consiste à gonfler un ballonnet au niveau de la lésion afin de dilater l'artère. Les pontages par greffons veineux ou prothétiques court-circuitent l'artère sténosée. La sympatectomie chimique ou par résection des ganglions sympathiques a des indications limitées par les contre-indications et impossibilités chirurgicales.

\section{L'atteinte des vaisseaux à destinée cervico-encéphalique}

Elle est responsable d'accidents vasculaires cérébraux (AVC), généralement par ramollissement cérébral ou par hémorragie cérébrale due à l'hypertension artérielle. Dans le diabète, la fréquence des AVC est multipliée par 2,5 chez l'homme et 3,5 chez la femme. La gravité est attestée par la mortalité qui est doublée et par les récidives 1,5 à 2 fois plus élevées. La sténose des carotides détectée par Doppler se voit chez un diabétique sur deux et doit inciter à l'auscultation systématique des carotides. Cliniquement, on assiste à l'installation brutale d'une hémiplégie avec ou sans aphasie. Si la régression est possible, le pronostic reste mauvais en raison de l'existence de lésions, notamment au niveau des membres inférieurs et des coronaires.

\section{L'atteinte coronarienne (angor, infarctus)}

- Le diabète multiplie par 2 l'insuffisance coronarienne chez l'homme et par 3 chez la femme. Dans le DNID, l'étude d'Uusitopa et coll. (1985) montre une prévalence de 3,5 chez l'homme.

- La fréquence des infarctus est plus élevée dans le DNID, 17\% chez l'homme, $18 \%$ chez la femme.

- A la Joslin Clinic (USA), à l'âge de 55 ans, $60 \%$ des diabétiques sont décédés dont $35 \%$ par maladies coronariennes.

- Le risque de rédicive d'infarctus est doublé, le risque de mortalité à 5 ans après infarctus est de $50 \%$.

Selon plusieurs études (Uusitopa et coll., 1985), la sévérité des lésions coronarriennes serait due, en grande partie, aux particules riches en triglycérides (LDL et VLDL).

Il faut savoir que la symptomatologie est souvent atypique et même silencieuse. Il n'est pas rare que les douleurs précordiales soient absentes. On rappelle la valeur prédictive de la micro-albuminurie dans les coronopathies latentes.

Des méthodes non-invasives, telles que l'enregistrement électrocardiographique par Holter, au cours d'une épreuve d'effort sur bicyclette ergométrique, ou la scintigraphie myocardique au thallium, dépistent précocement l'insuffisance coronarienne. La coronarographie, méthode de choix mais non dénuée de tout danger, visualise les artères, les coronaires et permet parfois un geste de thérapeutique par la dilatation de l'artère coronaire lésée. Le pontage coronarien est souvent le seul et dernier recours lorsque plusieurs coronaires sont thrombosées. 


\section{La cardiomyopathie}

Dans le diabète, l'insuffisance cardiaque est 5 fois plus importante chez la femme et 2,4 fois chez l'homme. Le diabète en serait responsable par un mécanisme spécifique autre que l'hypertension artérielle ou l'insuffisance coronarienne. L'une des hypothèses ferait appel à la micro-angiopathie ; une deuxième hypothèse serait une infiltration interstitielle en glycoprotéines.

\section{Hypertension artérielle (HTA)}

Elle est définie, selon les critères de l'OMS, par une pression artérielle supérieure à 9,5-16 cm de Hg. Deux fois plus fréquente que chez les non-diabétiques, elle atteint $1 / 3$ des diabétiques et $50 \%$ des diabètes non-insulinodépendants.

- Dans le DID, l'hypertension artérielle est secondaire à la glomérulopathie et augmente en fonction de l'albuminurie (Parving, 1993, tab. 7.8).

Tableau 7.8 - Prévalence de l'HTA en fonction de la présence d'une protéinurie (d'après Parving, 1993)

\begin{tabular}{|l|c|c|c|c|}
\cline { 2 - 5 } \multicolumn{1}{c|}{} & \multicolumn{2}{c|}{ DID } & \multicolumn{2}{c|}{ DNID } \\
\cline { 2 - 5 } \multicolumn{1}{c|}{} & TA $>140 / 90$ & TA $>160 / 95$ & TA > 140/90 & TA > 160/95 \\
\hline Normo-albuminurie \% & 42 & 15 & 71 & 51 \\
\hline Micro-albuminurie \% & 52 & 26 & 90 & 73 \\
\hline Macro-albuminurie \% & 79 & 61 & 93 & 82 \\
\hline
\end{tabular}

L'association de l'hypertension artérielle et de la micro-angiopathie glomérulaire multiplie par 50 le risque de mortalité par rapport à des diabétiques de type I ne présentant pas de micro-angiopathie.

Le mécanisme de cette hypertension impliquerait une hypervolémie, une rétention d'eau et de sodium, une activité normale mais inappropriée du système rénineangiotensine.

- Dans le DNID, l'atteinte rénale est la conséquence de l'hypertension artérielle. Comme nous l'avons vu plus haut, la participation de l'hypertension artérielle dans le syndrome $\mathrm{X}$ aux côtés du DNID, de l'obésité androïde, de l'hypertriglycéridémie, de l'hyperglycémie et de la baisse de l'HDL cholestérol, a fait évoquer le rôle de l'insulinorésistance et/ou de l'hyperinsulinémisme. La constatation d'une insulinorésistance chez l'hypertendu non-diabétique, non-obèse, plaide en faveur de cette thèse.

L'incidence des maladies cardio-vasculaires, notamment l'insuffisance coronarienne et les AVC, de même que les rétinopathies, sont franchement influencées par l'hypertension artérielle.

On comprend dans ces conditions qu'il est impératif de traiter l'hypertension artérielle afin de ramener la pression artérielle à des chiffres bien inférieurs à ceux souhaités 
pour les non-diabétiques. Une tension à $14-8,5$ semble un objectif raisonnable, l'idéal étant de 12 à 13-8. Pour ce faire, les praticiens disposent d'une panoplie de médications au premier rang desquelles il faut citer les IEC (inhibiteur de l'enzyme de conversion) et les inhibiteurs calciques.

\subsection{NOTIONS DE THÉRAPEUTIQUE}

- Le traitement, notamment du DID, a bénéficié ces dernières années de la possibilité d'autosurveillance glycémique par le malade lui-même ; une gouttelette de sang capillaire imprègne une bandelette source d'une réaction enzymatique. A partir de cette bandelette, introduite dans un lecteur de glycémie, le taux de glucose capillaire, à peine différent de la glycémie veineuse, est déterminé automatiquement. Ainsi cette autosurveillance permet entre autres de moduler les doses d'insuline et de dépister les hyper- ou hypoglycémies.

- Un traitement du diabète ne peut se concevoir sans évaluation de l'équilibre diabétique. Autrefois, on ne disposait que des glycémies pratiquées en laboratoire au cours d'un cycle (par exemple à $8 \mathrm{~h}, 14 \mathrm{~h}, 18 \mathrm{~h}$ ); actuellement on dispose de marqueurs fondés sur la glycation de l'hémoglobine, hémoglobine glycosylée de l'albumine, fructosamine et plus récemment des AGE (advanced glycation end products). L'hémoglobine $\mathrm{Hb} \mathrm{a}_{1} \mathrm{C}$ glyquée ou glycosylée est le dosage le plus couramment utilisé ; il intègre la glycémie moyenne des 2 à 3 mois qui précèdent le dosage. Plus le taux des $\mathrm{Hb}_{1} \mathrm{C}$ est élevé, plus le diabète est déséquilibré (taux normal d' $\mathrm{Hb} \mathrm{a}_{1} \mathrm{C}: 4$ à 6\%).

Le dosage de la fructosamine, moins souvent utilisé, a la même signification que l'hémoglobine glyquée ; il correspond à la glycémie moyenne sur 1 mois.

- L'hémoglobine AGE ne se dose pour l'instant qu'en recherche (Wolffenbuttel et coll., 1996).

Nous n'envisageons ici que le traitement médicamenteux, étant bien entendu que les règles hygiénodiététiques et l'exercice physique représentent également des éléments essentiels dans la recherche de l'euglycémie.

\subsubsection{Le diabète insulinodépendant}

En raison de l'insulinopénie, le traitement repose sur l'insulinothérapie. Jusque dans les années 1980, les insulines provenaient de pancréas d'animaux, bovins ou porcins. Depuis cette date, grâce au génie génétique, les insulines synthétisées ont la même composition chimique qu' une insuline humaine.

Les insulines sont définies selon leur durée d'action :

- insuline rapide ou ordinaire : durée d'action d'environ 3 à $6 \mathrm{~h}$;

- insuline semi-lente : durée d'action d'environ $12 \mathrm{~h}$;

- induline lente : durée d'action d'environ $24 \mathrm{~h}$. 
Actuellement, on utilise deux à trois injections par jour ; le plus souvent on associe une insuline rapide à une insuline semi-lente, de type NPH (neutral protamine hagedorn), matin et soir.

Détruite par les sucs digestifs, l'insuline ne peut être administrée que par voie injectable (à l'aide de seringues à usage unique) ; toutefois des tentatives de traitement par voie nasale ont donné des résultats encourageants mais pas suffisamment démonstratifs et fiables. Ces expérimentations sont réservées pour l'instant à la recherche ; tout récemment, il a été proposé des inhalations d'insuline, voie qui semble prometteuse, notamment pour réduire le nombre d'injections avant le repas.

D'autres modalités d'injection ont été introduites ces dix dernières années :

- les stylos avec cartouches d'insuline et, plus récemment, les stylos à usage unique ont apporté un confort appréciable aux patients.

- les pompes à insuline, externes ou implantables, délivrent de l'insuline rapide en continu : on les réserve notamment aux diabétiques déséquilibrés avec complications et aux cours des interventions chirurgicales.

Si l'immunothérapie par cyclosporine marque le pas, la greffe des îlots de pancréas semble prometteuse : la greffe totale de pancréas, associée ou non à la greffe rénale, demeure exceptionnelle.

\subsubsection{Le diabète non-insulinodépendant}

Rappelons que la diététique par régime hypocalorique hypoglucidique occupe une place prépondérante dans la thérapeutique des diabètes obèses.

Le traitement repose sur trois groupes de médications :

- les sulfamides,

- les biguanides,

- les inhibiteurs de l' $\alpha$-glucosidase.

Des médications luttant contre l'insulinorésistance sont en expérimentation; de même, une nouvelle classe thérapeutique de type insulinosécréteur : la répaglinide (et la nétaglinide) est déjà utilisée dans certains pays d'Europe et verra le jour très prochainement en France sous le nom de Novonorm®.

\section{Les sulfamides}

Proches des sulfamides utilisés en infectiologie, ils agissent par stimulation de l'insulinosécrétion de la cellule $\beta$. Une sécrétion résiduelle d'insuline est donc indispensable ; leurs effets extrapancréatiques sur l'insulinorésistance sont controversés et peu probables. Les sulfamides agiraient en se liant à un récepteur de la membrane de la cellule $\beta$, inhibant le canal $\mathrm{K}^{+}$ATP-dépendant et, par là, inhiberaient la sortie de potassium. Il s'ensuivrait une dépolarisation de la membrane et une activation des canaux calciques ; l'accumulation cytosolique de calcium ionisé déclencherait la libération de l'insuline par contraction de l'appareil tubulo-fibrillaire (fig. 7.23). 
Seuls doivent être utilisés des sulfamides de deuxième génération, à demi-vie courte, d'efficacité importante et à concentration de produit relativement faible, de l'ordre de $5 \mathrm{mg}$. L'apparition de nouvelles formes galéniques, à effet osmotique, permet une prise unique du médicament qui se libère progressivement tout au long du nycthémère.

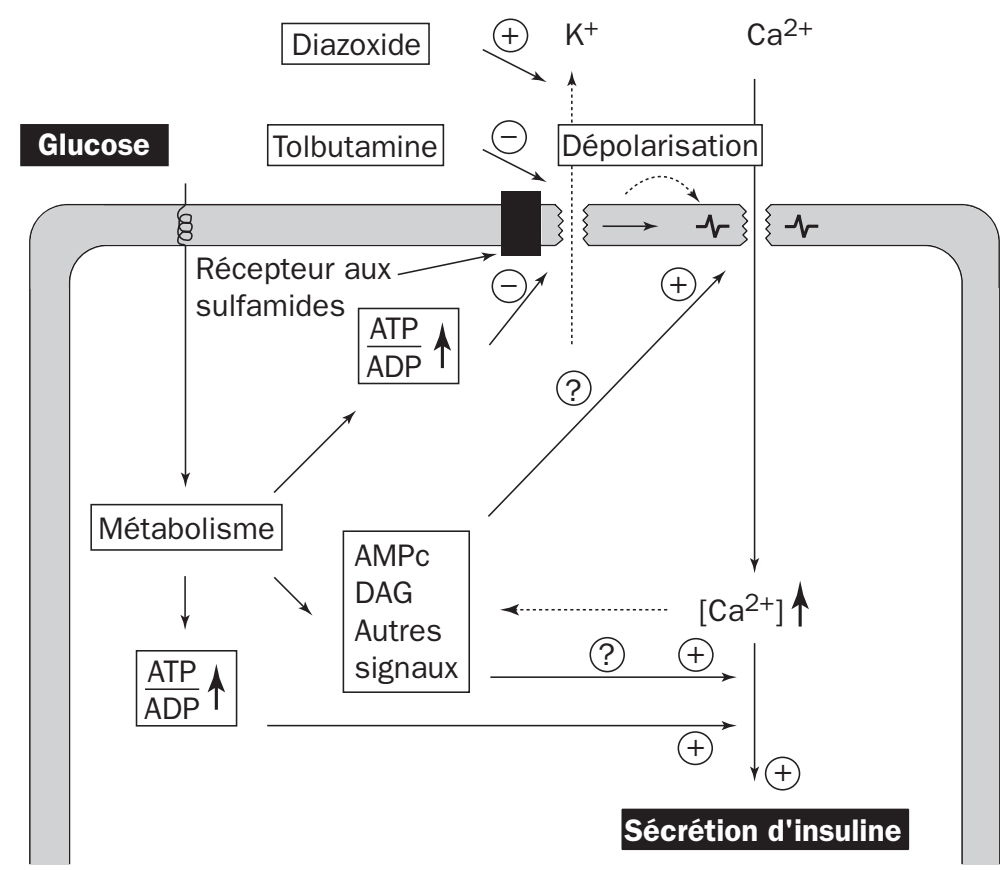

Figure 7.23 - Mécanisme d'action des sulfamides hypoglycémiants au niveau de la cellule $\boldsymbol{\beta}$ (d'après Henquin et Gilon, 1995)

\section{Les biguanides}

En France, il n'existe qu'une seule biguanide, la metformine. Les biguanides agissent au niveau périphérique ; elles sont actives sur l'animal pancréatectomisé et ne modifient pas la sécrétion d'insuline, elles diminuent la production hépatique de glucose à jeun en inhibant la néoglycogenèse, et améliorent l'utilisation périphérique du glucose (niveau musculaire) par activation de l'hexokinase et de la phosphofructokinase (fig. 7.24).

Elles auraient une action anti-athérogène et une action sur la fibrinolyse. Ainsi, leur action sur l'insulinorésistance en fait un traitement de choix chez l'obèse diabétique d'autant qu'elle a un effet anorexique.

Très efficaces, elles sont à proscrire en cas d'insuffisance rénale ou d'insuffisance hépatique en raison de la production accrue d'acide lactique.

\section{Les inhibiteurs des $\alpha$-glucosidases}

Connus de longue date, ils ont été récemment introduits en diabétologie. Leur point d'impact se situe au niveau de l'intestin grêle où ils entrent en compétition avec les 
$\alpha$-glucosidases nécessaires à l'absorption des hydrates de carbone ; par conséquent, ils agissent uniquement sur la glycémie post-prandiale. En France, le seul produit disponible est l'acarbose (Glucor®). Leur efficacité et leur tolérance (flatulences) les limitent à des diabètes modérés ou en association à d'autres antidiabétiques oraux.

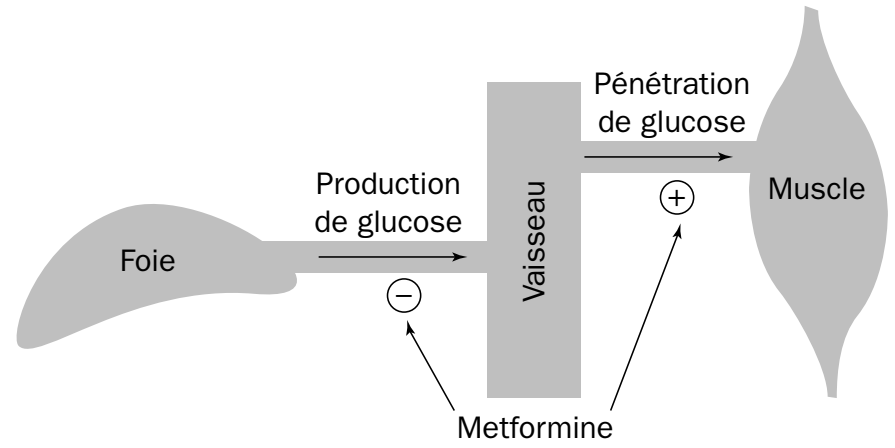

Figure 7.24 - Mécanisme d'action des biguanides

\section{La troglitazone}

La troglitazone agit directement sur l'insulinorésistance. Elle fait partie d'une nouvelle classe thérapeutique et vient tout juste d'être testée aux USA dans une étude du DPP (Diabetes Prevention Program, 1996) sur des sujets intolérants au glucose ; les résultats ne sont pas encore publiés ; toutefois la toxicité thérapeutique de ce produit risque d'entraîner son élimination des marchés français et européens. Des dérivés (reniglitazone et pioglitazone) n' auraient pas les mêmes effets délétères sur le foie ; ils pourraient être commercialisés prochainement.

Dans les DNID, généralement, deux ou trois médications sont prescrites conjointement ; l'insulinothérapie n'est pas indiquée, mais a sa place en cas de diabète insulinorequérant, seul ou en association aux biguanides et aux sulfamides.

\subsection{CONCLUSION}

Le diabète est un enjeu de santé publique en raison de :

- sa fréquence : 1500000 diabétiques en France et 100 millions dans le Monde,

- sa gravité due à ses complications responsables d'invalidité et de mortalité. Les relations entre ces complications et l'euglycémie doivent conduire à un équilibre diabétique satisfaisant en ne perdant pas de vue que d'autres facteurs, notamment génétiques et métaboliques, interviennent de façon concomitante.

Il faut de même se souvenir que, finalement, le traitement actuel est purement symptomatique avec pour objectif l'euglycémie ; l'idéal viserait un traitement étiologique ; mais les causes intimes pour l'instant nous échappent même si dans le DID la génétique et l'immunologie occupent une place importante, et si dans le DNID l'insulinorésistance et l'altération de l'insulinosécrétion apparaissent comme les mécanismes les plus plausibles. 



\section{CHAPITRE 8}

\section{LES PARATHYROÏDES ET L'ÉQUILIBRE PHOSPHOCALCIQUE}

\section{CARACTÉRISTIQUES GÉNÉRALES}

Les Vertébrés possèdent généralement quatre glandes parathyroïdes :

- deux externes ou inférieures ;

- deux internes ou supérieures.

- Chez l'homme : elles mesurent 6 à $7 \mathrm{~mm}$ de longueur. Poids : $140 \mathrm{mg}$ en tout.

- Chez les carnivores : deux de ces glandes sont incluses dans la thyroïde, les deux autres lui sont fortement accolées (une thyroïdectomie sans précautions spéciales est toujours une thyroparathyroïdectomie).

- Chez les herbivores : ces glandes sont toujours distinctes de la thyroïde, deux au moins en sont très éloignées.

- Chez le rat, la souris : il n'y a qu'une paire de glandes.

- Chez les poissons : elles sont absentes.

\subsection{RAPPEL EMBRYOLOGIQUE (voir fig. 5.1)}

Les glandes parathyroïdes dérivent de la paroi dorsale des $3^{\mathrm{e}}$ et $4^{\mathrm{e}}$ paires de poches endobranchiales. La $3^{e}$ paire est externe ou inférieure (du fait de l'entraînement par le mouvement de descente du thymus). La 4 e paire est interne ou supérieure.

Chez l'homme, les premières cellules apparaissent nettement dès le stade $9 \mathrm{~mm}$. Les parathyroïdes fœtales sont fonctionnelles à 12-13 semaines.

\subsection{RAPPEL HISTOLOGIQUE}

On peut distinguer trois catégories de cellules :

- les cellules principales sont les plus nombreuses, leur taille va de 5 à $12 \mu \mathrm{m}$ de diamètre. L'immunofluorescence permet de caractériser, dans ces cellules, la présence de parathormone (PTH).

- elles peuvent se transformer en cellules claires, par transformation vacuolaire. 
- des cellules oxyphiles, riches en mitochondries, paraissent très actives. Leur rôle est encore inconnu. Ces cellules manquent chez les rongeurs de laboratoire.

\subsection{VASCULARISATION ET INNERVATION}

- La vascularisation provient d'artères terminales, branches des artères thyroïdiennes (d'où un syndrome parathyréoprive d'origine ischémique par nécrose des glandes parathyroïdes lors de certaines thyroïdectomies totales).

- L'innervation est assurée par :

- des rameaux du nerf récurrent issu du pneumogastrique ;

- des rameaux du sympathique cervical.

C'est une innervation purement vaso-motrice.

\section{DONNÉES ANATOMO-CLINIQUES}

\subsection{HYPOPARATHYROÏDIE : \\ L'INSUFFISANCE PARATHYROÏDIENNE VRAIE}

L'insuffisance parathyroïdienne vraie doit être distinguée de la pseudo-hypoparathyroïdie ${ }^{1}$.

Elle provoque un syndrome spécifique où domine l'hyperexcitabilité neuromusculaire : la tétanie. Elle est réalisée par la parathyroïdectomie et sera le plus souvent mortelle chez les carnivores, alors que les herbivores opérés ne présenteront que des troubles mineurs (existence de parathyroïdes accessoires ?).

\subsubsection{Signes cliniques}

- Le syndrome parathyréoprive chez le chien, après parathyroïdectomie totale, débute après une période latente de $48 \mathrm{~h}$ et se traduit par :

- un fond de troubles permanents (modification du comportement, troubles de la digestion, excitabilité neuromusculaire),

- sur lequel se greffent des accès intermittents constituant les crises de tétanie. Celles-ci évoluent en deux phases : clonique (convulsions des membres), puis tonique avec rigidité des membres et du tronc. Ces accès sont de plus en plus fréquents et l'animal meurt vers le $9 \mathrm{e}$ jour.

- Le syndrome parathyréoprive chez l'homme se manifeste sous une forme semblable à celle du chien, mais les crises sont essentiellement toniques, avec

1 La pseudo-hypoparathyrö̈die résulte d'une non-réceptivité (résistance) périphérique à la PTH (parathormone). Elle réalise le tableau clinique de l'hypoparathyroïdie associée à des anomalies morphologiques. 
parfois quelques secousses convulsives dans la grande crise de tétanie (assez rare) qui peut simuler une crise d'épilepsie. Dans tous les cas, il faudra rechercher le syndrome biologique.

\subsubsection{Syndrome biologique}

Il est caractéristique et se traduit par :

- une hypocalcémie (par exemple $70 \mathrm{mg} / \mathrm{l}$ au lieu de $100 \pm 5 \mathrm{mg} / \mathrm{l}$ );

- une hyperphosphorémie (par exemple 60 à $100 \mathrm{mg} / 1$ au lieu de $36 \pm 2 \mathrm{mg} / 1$ ) ;

- une hypocalciurie et une hypophosphaturie (la calciurie normale est comprise entre 0,15 et $0,20 \mathrm{~g} / 1$; la phosphaturie normale entre 350 et $1000 \mathrm{mg} / 24 \mathrm{~h}$ ).

Une injection de citrate de sodium précipite le calcium sous forme de citrate de calcium et provoque :

- l'apparition de la crise tétanique chez l'hypothyroïdien,

- un état pseudo-tétanique chez la personne normale.

L'hypocalcémie paraît donc être le facteur responsable des accidents tétaniques.

On pourra également les observer après toute hypocalcémie, qu'elle soit liée

- à une avitaminose $\mathrm{D}$ (rachitisme du jeune ou ostéomalacie de l'adulte),

- ou à une affection digestive grave (sprue) qui réalise une hypovitaminose $\mathrm{D}$ secondaire.

Le traitement de la crise tétanique consiste en injections de calcium intraveineux associées à de fortes doses de vitamine $\mathrm{D}$ per os, le traitement vitamino-calcique sera poursuivi comme traitement de fond de l'hypoparathyroïdie.

\subsubsection{Pathogénie de la tétanie}

La crise de tétanie est donc provoquée par une hypocalcémie,

- qu'elle soit due à une insuffisance parathyroïdienne avec hyperphosphorémie,

- ou que cette carence calcique relève de cause diverses : avitaminose $\mathrm{D}$, troubles digestifs, mais le syndrome tétanique peut s'observer aussi dans l'alcalose (par surcharge en bicarbonate, lors de vomissements répétés entraînant une perte d'ions $\mathrm{H}^{+}$, ou dans l'hyperventilation pulmonaire qui provoque une perte d'ions $\mathrm{CO}^{--}$).

Le facteur important n'est pas le taux sanguin du calcium global, mais l'abaissement du taux du calcium ionisé $\mathrm{Ca}^{2+}$.

Normalement, le rapport : $\frac{\mathrm{Ca}^{++} \text {Protéine }}{\text { Ca Protéine }}=\mathrm{K}=\frac{4,5}{4} \approx 1$.

En fait, l'excitabilité neuromusculaire ne dépend pas seulement du taux du calcium ionisé, mais du rapport : $\frac{\text { cations monovalents et anion } \mathrm{OH}^{-}}{\text {cations divalents et cations } \mathrm{H}^{+}}=\frac{\mathrm{Na}^{+} \mathrm{K}^{+} \mathrm{OH}^{-}}{\mathrm{Ca}^{++} \mathrm{Mg}^{++} \mathrm{H}^{+}}$, d'où l'importance du taux du $\mathrm{Mg}^{2+}$ plasmatique, qu'il faut rechercher en même temps que celui du $\mathrm{Ca}^{2+}$. Pratiquement, le praticien avisé, devant une tétanie ou même une spasmophilie, demandera un ionogrammme complet. 


\subsection{HYPERPARATHYROÏDIE}

Elle s'observe chez l'homme dans l'ostéite fibrokystique ou maladie osseuse de Recklinghausen, liée à un adénome de la parathyroïde.

Elle comporte des manifestations osseuses et rénales. Les symptômes osseux sont des douleurs, fractures ou déformations liées à une décalcification généralisée. Les symptômes rénaux : essentiellement une lithiase avec calculs de phosphate ou oxalate de chaux. Aux signes cliniques est associé un syndrome biologique inverse de celui de l'hypoparathyrö̈die :

- une hypercalcémie : 150 à $200 \mathrm{mg} / 1$ avec hypercalciurie ;

- une hyperphosphaturie avec hypophosphorémie.

\subsection{SPASMOPHILIE}

La spasmophilie est un syndrome clinique mal défini associant des crises tétaniques et des manifestations neurovégétatives. Chez un sujet qui paraît normal, des phénomènes intercurrents tels qu'une émotion violente, une intoxication, pourront déclencher des crises toniques des membres et/ou de la face. La spasmophilie peut être objectivée par le signe de Chvostek (contraction réflexe à la percussion de la joue) ou le signe de Trousseau (aspect de la "main d'accoucheur" provoquée par la mise en place d'un garrot).

Il n'y a pas de troubles biologiques évidents : la calcémie est normale, la magnésémie presque toujours normale. On recherchera cependant :

- une fuite calcique urinaire fréquente ;

- des troubles digestifs prolongés, capables d'entraîner hypokaliémie et hypomagnésémie.

\section{MÉCANISME DE L'OSSIFICATION}

\subsection{L'OS}

L'os définitif de l'adulte contient environ :

- $35 \%$ d' $\mathrm{H}_{2} \mathrm{O}$;

- $35 \%$ de sels minéraux dont $75 \%$ de phosphate tricalcique $\left(\mathrm{PO}_{4}\right)_{2} \mathrm{Ca}_{3}, 10 \%$ de carbonate de calcium, du citrate de calcium $(1 \%) \ldots$

- $20 \%$ de protéines : collagène, glycoprotéines...

- $10 \%$ de lipides.

L'os est un tissu conjonctif rendu rigide par dépôt de cristaux de sels minéraux dans une matrice organique. La matrice organique (osséine) comporte une substance fondamentale glycoprotéique dans laquelle on peut reconnaître des fibres de collagène organisées en travées plus ou moins régulières. Elle correspond à environ $1 / 3 \mathrm{du}$ poids de l'os. 
La fraction minérale (65\% de l'os) est constituée par des cristaux d'hydroxyapatite. Le complexe $\mathrm{Ca}_{10}(\mathrm{OH})_{2}\left(\mathrm{PO}_{4}\right)_{6}$ forme le noyau du cristal qui est entouré par une double couche :

- une couche d'absorption dans laquelle le carbonate est remplacé partiellement par des ions $\mathrm{OH}$, citrate, chlorure, fluorure, tandis que $6 \%$ du calcium est remplacé par des ions $\mathrm{H}^{+}, \mathrm{Na}^{+} \ldots$ A pH élevé, du phosphate dicalcique $\mathrm{PO}_{4} \mathrm{HCa}_{2}$ peu soluble se forme aux dépens du phosphate monocalcique $\left(\mathrm{PO}_{4} \mathrm{H}_{2}\right)_{2} \mathrm{Ca}$ très soluble et complètement ionisé. C'est ainsi que l'alcalose entraîne une diminution de la calcémie et peut provoquer ou favoriser la tétanie.

- une couche d'hydratation où l'eau liée représente $5,4 \%$ du volume du cristal.

Ces cristaux ont $5000 \times 2500 \times 1000 \mathrm{~nm}$. Ils sont disposés parallèlement aux fibres de collagène avec lesquelles ils contractent des liaisons étroites.

\subsection{L'OSSIFICATION}

Son mécanisme est encore mal élucidé, il comporte deux étapes :

\subsubsection{L'apparition de la matrice organique}

Les cellules conjonctives différenciées (futurs ostéoblastes) sécrètent la substance fondamentale et déterminent à leur contact l'apparition de fibres de collagène. Cette étape est sensible à un certain nombre d'actions hormonales ( $\mathrm{GH}$, insuline, hormones thyroïdiennes).

\subsubsection{La calcification}

Elle comporte deux temps :

\section{- une précipitation du phosphate tricalcique}

Ce sel se forme aux dépens de la fraction ionisée $\mathrm{Ca}^{2+}$ et $\mathrm{PO}_{4} \mathrm{H}^{--}$du plasma.

La concentration de ces ions y est proche de la saturation. Elle constitue un état d'équilibre tel que $\left[\mathrm{Ca}^{+}\right] \times\left[\mathrm{PO}_{4} \mathrm{H}^{--}\right]=$cste (environ 30 si les concentrations sont exprimées en $\mathrm{mg} / 100 \mathrm{ml}$ ). Il suffit alors pour précipiter du phosphate tricalcique insoluble d'enrichir localement le milieu en calcium ou en phosphate.

La calcémie étant en principe constante, le seul mécanisme possible résulte d'un enrichissement local en phosphate. On retrouve en effet une phospho-monoestérase dans l'os, capable d'hydrolyser les esters phosphoriques sanguins, d'en libérer le phosphate et de précipiter ainsi le phosphate tricalcique ("phosphate theory" de Robison).

En fait, le plasma contient trop peu d'esters phosphoriques utilisables et ceux-ci proviennent plutôt de la glycogénolyse des cellules du cartilage sérié. On peut d'ailleurs bloquer la calcification par des inhibiteurs de la glycogénolyse : fluorures, cyanures, iodacétates. L'ATP produit par la glycogénolyse donne de l'AMP $+\mathrm{P} \approx \mathrm{Pi}$ (phosphate inorganique). Une pyrophosphatase libère alors le phosphate, ce qui permet la précipitation de phosphate tricalcique. 


\section{- la fixation du phosphate tricalcique sur la matrice protidique}

Il y a induction de phosphate tricalcique au contact de la trame des fibres de collagène. Un système protéasique libère des groupements polaires - $\mathrm{COOH}$, - $\mathrm{CONH}_{2}$, capables de fixer des radicaux phosphoryl et calcium.

Le dépôt du phosphate tricalcique dans l'os et sa fixation dépendent spécifiquement de l'hormone parathyroïdienne : la parathormone. Les hormones sexuelles agissent sur les deux étapes, mais favorisent surtout la fixation du calcium lors de l'ossification des cartilages de conjugaison.

\section{LA PARATHORMONE (PTH)}

\subsection{NATURE CHIMIQUE}

Présente chez tous les Vertébrés, sauf les Poissons, c'est un polypeptide qui a été isolé par Collip en 1925. Son PM (8500) correspond à 84 AA (Potts, 1968).

La parathormone est élaborée chez l'homme sous la forme d'une pré-pro-hormone de 115 AA (fig. 8.1) qui libère dans la cavité du réticulum endoplasmique ${ }^{2}$, sous l'effet d'une signal-peptidase, une pro-hormone de 105 AA et de PM 12 000. Celle-ci passe dans l'appareil de Golgi (fig. 8.2.a) où elle sera clivée pour libérer dans la circulation, par exocytose des grains de sécrétion, l'hormone définitive.

Chez l'homme, le gène de la parathormone est situé sur le bras court du chromosome 11 (fig. 8.2.b).

Sa demi-vie est brève, de 10 à 20 min.

Sa concentration plasmatique est de 10 à $56 \mathrm{pg} / \mathrm{ml}$. Elle se distribue dans un volume équivalent à $30 \%$ du poids corporel et qui correspond au tubule proximal, à l'os, aux plaques épiphysaires et au cartilage.

\subsection{DÉTERMINISME DE LA SÉCRÉTION}

La sécrétion de parathormone est déterminée par le taux du calcium ionisé plasmatique.

La perfusion de parathyrö̈de de chèvre avec du sang (Care et coll., 1966) contenant $14 \mathrm{mg} / 100 \mathrm{ml}$ entraîne en une $1 / 2 \mathrm{~h}$ une diminution de $80 \%$ de la sécrétion hormonale.

2 Grâce à la liaison avec le récepteur membranaire d'une particule de reconnaissance (SRP) qui s'est préalablement fixée à la séquence signal (Conn et coll., 1983). 


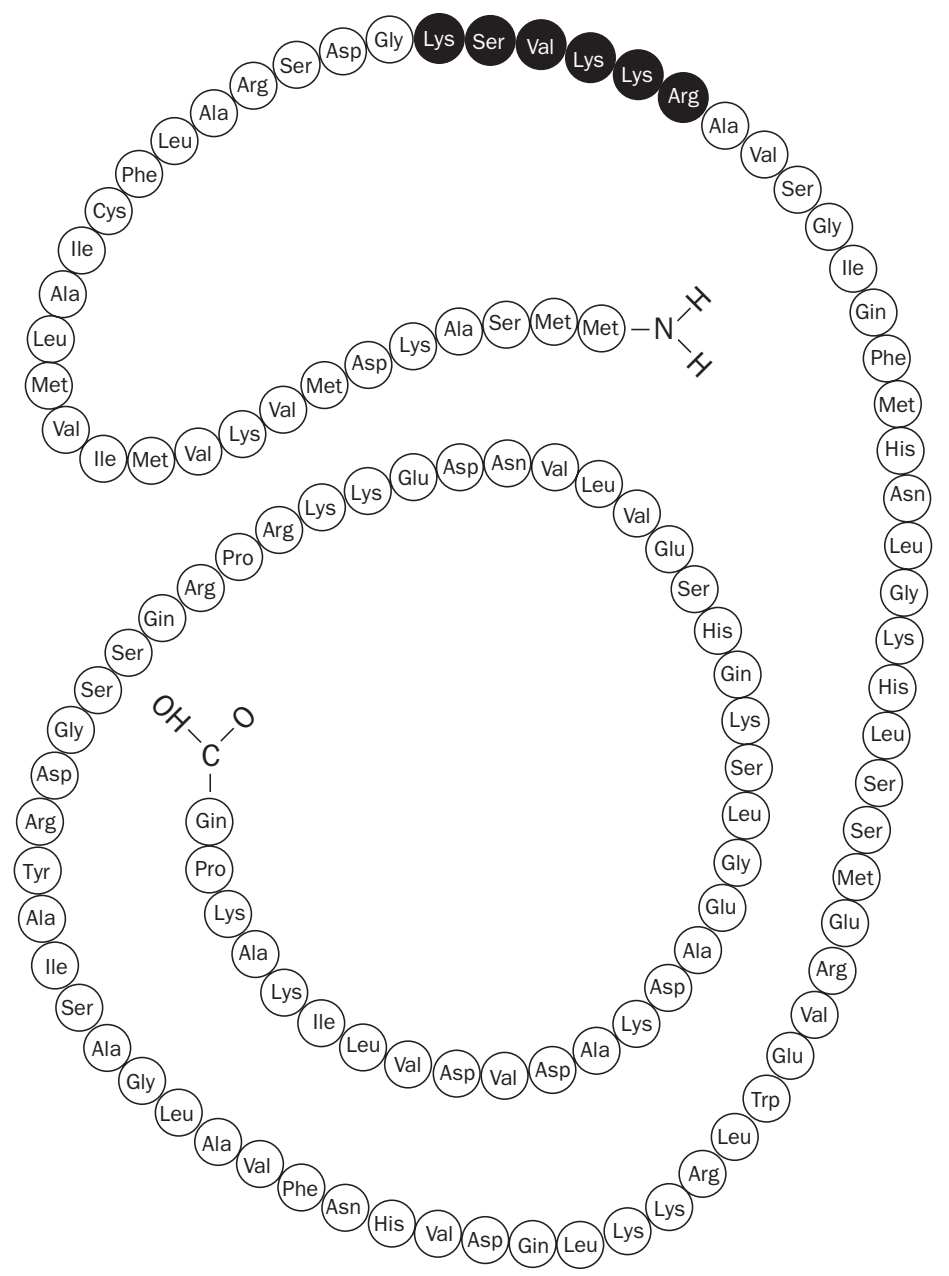

Figure 8.1 - Séquence des acides aminés de la pré-pro-parathormone bovine (d'après Kronenberg et coll., 1986)

La séquence "pro", en noir, sépare la séquence de l'hormone définitive de la séquence "pré" qui est une séquence signal. La fonction physiologique de ce peptide sur les tissus squelettiques et rénaux est dévolue aux 34 premiers $A A$ à partir de l'extrémité $N$-terminale de la molécule.

En revanche, la perfusion par du sang artificiellement décalcifié par de l'EDTA (acide éthylène diamino-tétracétique) entraîne en 2 ou 3 h une élévation de la calcémie de 15 à $45 \mathrm{mg}$ au-dessus du niveau de départ, en même temps qu'une hyperactivité parathyroïdienne (fig. 8.3).

Le magnésium a un effet inhibiteur sur la sécrétion de parathormone.

Les cellules des parathyroïdes, comme celles de la thyroïde ou du tubule rénal qui synthétisent la 1,25 dihydroxyvitamine D3, possèdent la capacité "d'apprécier" le niveau de la calcémie. Cette capacité de "sensor" est assurée par un récepteur au calcium extracellulaire (R-Ca). 


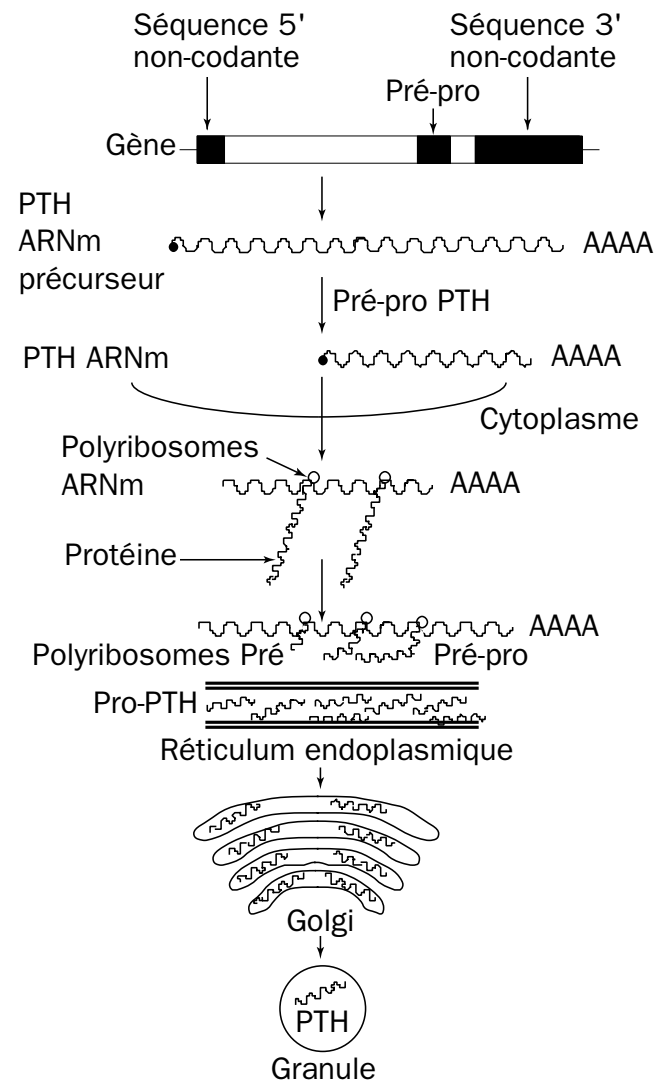

a - Synthèse et sécrétion de la parathormone dans la cellule parathyroïdienne

(d'après Kronenberg et coll., 1986)

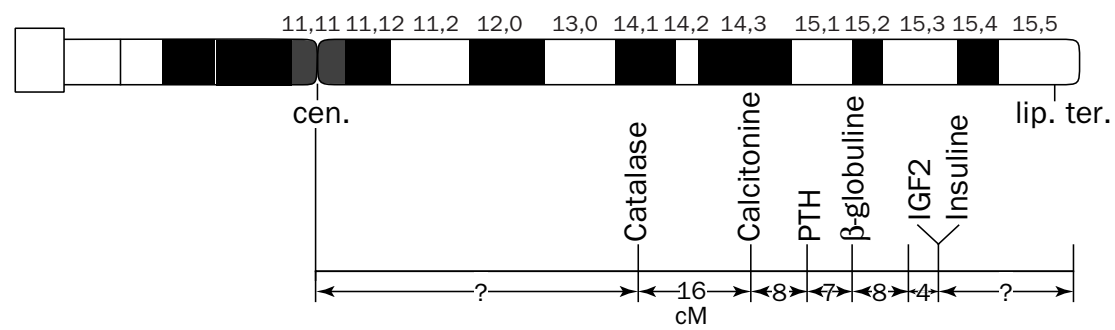

b - Carte génétique du bras court du chromosome 11 chez l'homme

Figure 8.2 - La parathormone

Ce récepteur exerce une action inhibitrice sur la production de PTH par les parathyroïdes. Cette action s'exercerait via l'activation de phospholipases (A2i, C, D) et/ou la modulation de la synthèse d'AMPc. Elle se traduirait par des variations de la teneur en calcium cytoplasmique et par celle de l'expression du gène de la PTH. Des anomalies de l'expression de $\mathrm{Ca} \mathrm{R}$ ou des mécanismes de transduction associés à son activation pourraient être à l'origine d'hyper- ou d'hypoparathyroïdismes (Akizawa et Fukagawa, 1999 ; Brown et Pollack, 1998 ; Pearce et Thakker, 1997). 


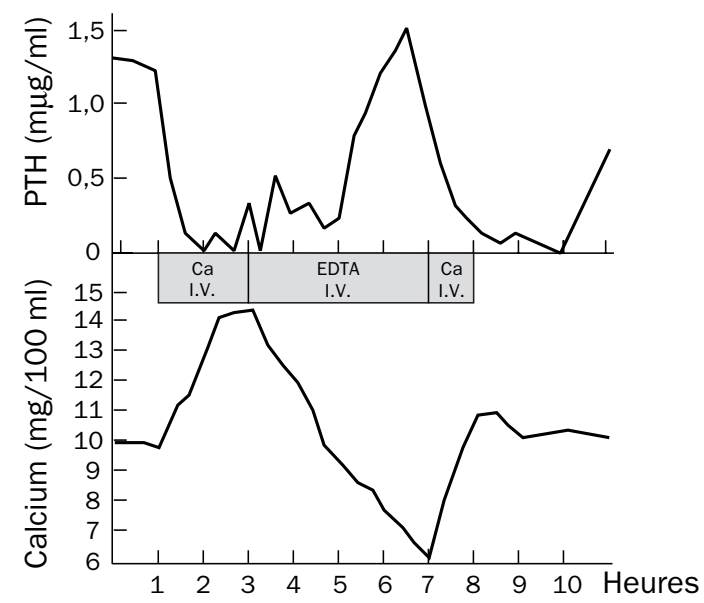

Figure 8.3 - Effets du calcium et de l'EDTA intraveineux sur le taux de parathormone et de calcium dans le plasma (d'après Care et coll., 1966)

\subsection{MODE D'ACTION}

La parathormone agit essentiellement sur deux effecteurs : l'os et le rein.

\subsubsection{Au niveau de l'os}

La parathormone mobilise le calcium osseux.

- Elle favorise l'ostéolyse en stimulant la formation et l'activité des ostéoclastes et en dépolymérisant les muccopolysaccharides de la substance fondamentale, les rendant incapables de fixer le calcium circulant.

- Elle inhibe l'ostéogenèse en favorisant la dédifférenciation des ostéoblastes. La PTH libère ainsi à partir du tissu osseux : du calcium, des phosphates, de l'hydroxyproline, du citrate et du magnésium.

\subsubsection{Au niveau du rein}

La parathormone favorise l'élimination des phosphates par le rein. L'hyperphosphaturie serait due à une inhibition de la réabsorption tubulaire des phosphates. Elle entraîne une hypophosphatémie. L'hypophosphatémie déclenche une déminéralisation osseuse pour ramener à la normale le produit $|\mathrm{P}| \times|\mathrm{Ca}|$ sanguin. La PTH provoquerait également une inhibition de la réabsorption du Na. L'action osseuse serait soit une action directe de l'hormone, l'action rénale étant alors secondaire, soit une action secondaire à l'hyperphosphaturie.

En fait, la parathormone agit directement sur ces deux effecteurs.

- l'action osseuse est démontrée par :

- l'action de la parathyroïde sur un implant osseux en culture ;

- l'action hypercalcémiante d'une parathyroïde qui est irriguée par du sang hypocalcique chez un animal néphrectomisé ;

- l'action rénale est démontrée par perfusion directe de l'artère rénale par la PTH. 


\subsubsection{Activation de la 1 $\alpha$-hydroxylase rénale}

La $1 \alpha$-hydroxylase permet la transformation ultime de la vitamine D3 en principe actif. Celui-ci, la 1,25-(OH) $)_{2}$-D3 ou calcitriol présente en retour une action permissive sur l'activité de la PTH, au niveau des cellules mésenchymateuses osseuses, favorisant l'élévation de la concentration calcique du cytosol qui favorise à son tour la transformation de la cellule en ostéoclaste.

\subsubsection{Accessoirement : au niveau de l'intestin}

La parathormone exerce une action indirecte sur l'intestin en potentialisant les effets de la 1,25-(OH) $)_{2}$-D3 (voir p. 233).

En résumé, la parathormone :

- augmente la calcémie,

- au détriment du bilan calcique osseux.

En fait, la PTH peut, tout au début de son action, faire baisser la calcémie (fig. 8.4). Elle agirait ainsi par augmentation de la perméabilité des membranes cellulaires au $\mathrm{Ca}^{2+}$.

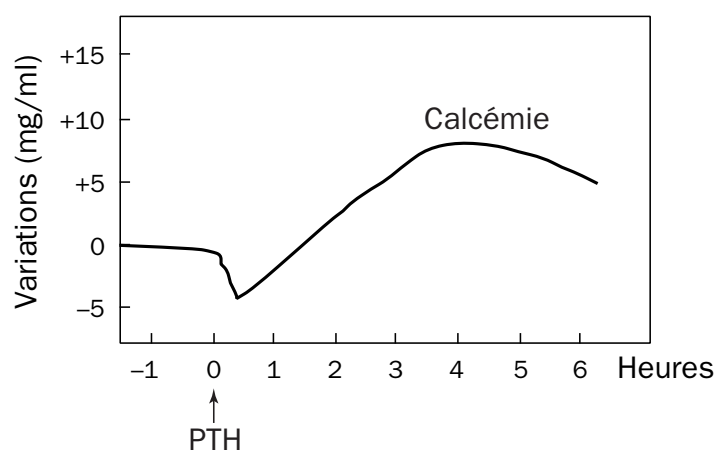

Figure 8.4 - Courbe de la calcémie après une injection de parathormone

\subsection{LE RÉCEPTEUR DE L'HORMONE PARATHYROÏDIENNE}

Il appartient à une famille de récepteurs à sept domaines transmembranaires couplés aux protéines G (R-CPG), tels ceux de la GH-RH, PTH, calcitonine, glucagon, VIP... Son gène est le second de cette famille à avoir été cloné, après celui de la GH-RH (Lee et coll., 1996).

Il peut interagir avec deux ligands, PTH et l'hormone dite PTH related peptide (PTHrP), qui est un agent responsable de l'hypercalcémie associée aux tumeurs malignes. La PTH interagit avec les récepteurs des cellules rénales et osseuses pour contrôler la concentration de calcium dans le milieu extracellulaire. 


\section{CALCITONINE ET VITAMINE D}

Deux autres substances exercent une action spécifique sur le métabolisme phosphocalcique : une autre hormone polypeptidique, la calcitonine (hormone produite par les cellules $\mathrm{C}$ de la glande thyroïde); une vitamine qui se comporte comme une prohormone stéroïde, la vitamine D3.

\subsection{CALCITONINE}

La calcitonine $(\mathrm{Ct})$ est une hormone hypocalcémiante.

\subsubsection{Nature biochimique (fig. 8.5)}

Elle a été mise en évidence par Copp et coll. en 1962.

On a pu démontrer ensuite (1964-1966) qu'elle est sécrétée par la thyroïde et élaborée par les cellules "parafolliculaires" (cellules claires ou cellules C). Ces cellules contiennent en fait deux hormones : la calcitonine et la katacacine, plus divers neuromédiateurs dont la sérotonine et la dopamine ${ }^{3}$.

Ces cellules à calcitonine migrent au niveau de la dernière poche branchiale chez les Poissons (les corpuscules de Stannius sont issus de ces cellules et constituent les glandes parathyroïdes des Poissons téléostéens) et les Oiseaux (corps ultimo-branchial), mais s'intriquent aux cellules principales de la thyroïde chez les autres Vertébrés.

Les calcitonines de saumon, de porc, de bovidés et d'homme comportent toutes $32 \mathrm{AA}$, mais avec des différences d'espèce à espèce qui ne nuisent pas à l'activité biologique. Chez l'homme, c'est un polypeptide de 3400 daltons.

La demi-vie de la calcitonine circulante est de l'ordre de $16 \mathrm{~min}$ chez le porc et l'homme. Sa concentration plasmatique est de l'ordre du pg $/ \mathrm{ml}(<10 \mathrm{pg} / \mathrm{ml})$.

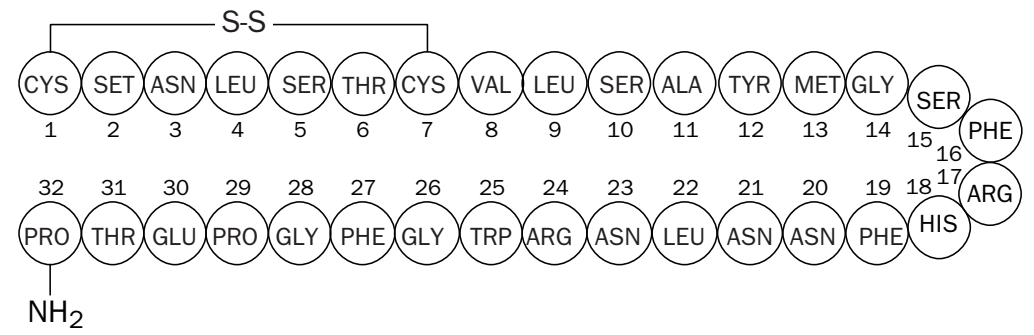

Figure 8.5 - Structure de la calcitonine du porc

3 Le gène de la calcitonine, situé non loin du gène de la parathormone, est susceptible de produire, suivant la cellule, soit de la calcitonine, soit une autre hormone appelée CGRP (calcitonin gene related peptide) dont l'action se manifeste surtout sur l'appareil cardiovasculaire, soit les deux (Rosenfeld et coll., 1981-1985). 


\subsubsection{Déterminisme de la sécrétion}

On observe une sécrétion de calcitonine dans le sang veineux efférent thyrö̈dien en réponse à une hypercalcémie provoquée. Là encore, c'est le $\mathrm{Ca}^{2+}$ ionisé plasmatique qui constitue le stimulus spécifique.

Une sécrétion de calcitonine apparait également dans trois types de tumeurs thyroïdiennes : une tumeur bénigne, l'adénome à cellules $\mathrm{C}$, et deux tumeurs malignes : le cancer trabéculaire, et surtout le carcinome médullaire du stroma amyloïde.

\subsubsection{Mode d'action}

La calcitonine joue un rôle d'épargne calcique et favorise la formation d'os nouveau.

La calcitonine a un point d'impact spécifique : l'os. Son mode d'action est l'inhibition du catabolisme osseux alors que l'ostéogenèse n'est pas modifiée. Ces deux phénomènes conjugués expliquent l'hypocalcémie et l'hypophosphatémie provoquées par l'hormone. Mais la calcitonine a également un impact rénal. Elle inhibe la $1 \alpha$ hydroxylase rénale et augmente l'excrétion urinaire $\mathrm{du} \mathrm{Ca}$, des phosphates, du sodium et du potassium. Elle favorise l'entrée du calcium au niveau du tube digestif.

\subsection{LES VITAMINES D}

Elles sont utilisées en thérapeutique pour :

- la prophylaxie et le traitement du rachitisme ;

- le traitement de la tétanie, de l'hypoparathyroïdie.

\subsubsection{Nature chimique}

Ce sont des substances liposolubles dérivées des stérols. Elles possèdent en commun de dériver d'une provitamine à noyau cyclopentanophénanthrénique, qui se transforme en vitamine D sous l'effet des UV par ouverture du cycle B et formation d'une troisième double liaison (voir fig. 8.6).

Les vitamines les plus courantes sont :

- la vitamine D3 (cholécalciférol), de provenance animale. C'est la vitamine naturelle constituant la seule source endogène par photosynthèse cutanée ;

- la vitamine D2 (ergocalciférol) qui provient de l'irradiation de l'ergostérol des levures et champignons ;

- le tachystérol.

En fait, la vitamine D3 n'est active qu'après une double hydroxylation : sur le C25 au niveau du foie, puis sur le $\mathrm{C} 1$ au niveau du rein. Le $1 \alpha$-dihydroxycholécalciférol ou 1,25-(OH) $)_{2}$-D3 (calcitriol) est l'hormone stéroïde active dont le métabolisme s'apparente à celui des autres hormones stéroïdes surrénaliennes ou gonadiques. La vitamine D3 n'est donc qu'une pré-hormone ultraviolet-dépendante.

La concentration plasmatique de la 1,25-(OH) 2 -D3 est de l'ordre de 43 à 148 pmol/1. 


\subsubsection{Origine et besoins}

La source de vitamine $\mathrm{D}$ est double :

- endogène par photosynthèse cutanée (D3). La transformation à partir de la provitamine D est due à des radiations UV de 2300 à $3130 \mathrm{~nm}$. La provitamine située dans le derme provient d'une déshydrogénation du cholestérol dans le foie et l'intestin (fig. 8.6).
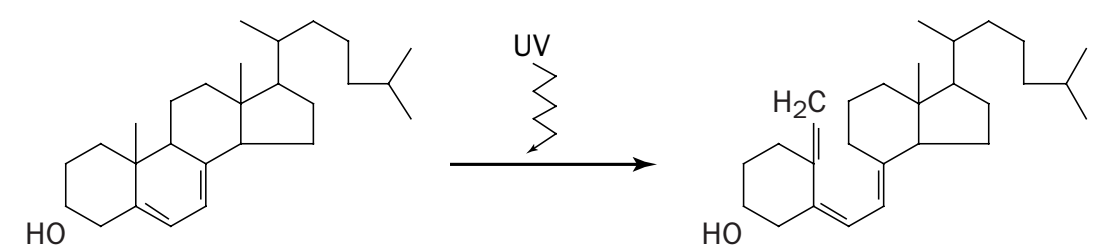

Figure 8.6 - Transformation du 7-déhydrocholestérol (peau) en vitamine D3

- exogène par apport alimentaire. 1 unité internationale $=0,025 \mathrm{mg}$ de calciférol ; $1 \mathrm{mg}$ vitamine D3 = 40000 UI. On trouve la vitamine D3 dans les huiles de foie de poisson (8000 à $30000 \mathrm{UI} / 100 \mathrm{~g}$ chez la morue, 20000 à $400000 \mathrm{UI} / 100 \mathrm{~g}$ chez le flétan), dans le jaune d'œuf (200 UI/ 100 g)...

En revanche, les aliments usuels et notamment le lait, les huiles et graisses végétales contiennent très peu de vitamine $\mathrm{D}$, d'où le risque de rachitisme (chez le jeune) ou d'ostéomalacie (chez l'adulte), chez des sujets convenablement nourris mais privés de soleil ${ }^{4}$. Les besoins sont difficiles à chiffrer, environ 12,5 à $25 \mu \mathrm{g} /$ jour chez l'adulte si l'exposition au soleil est faible. Ils sont plus importants au cours de la croissance, la gestation et la lactation.

\subsubsection{Mode d'action}

La vitamine $\mathrm{D}$ assure les transports cellulaires du calcium, surtout au niveau de deux organes cibles : l'intestin et le tissu osseux. La vitamine D va régler le niveau de la calcémie et celui de la phosphatémie.

- Son action physiologique primaire est d'accroître l'absorption intestinale du calcium.

Elle exige un certain temps de latence (4 à $12 \mathrm{~h}$ ), l'action est maximale vers la $60^{\mathrm{e}}$ heure. Ce temps de latence s'explique par l'activation préalable, en deux étapes, de la vitamine $\mathrm{D}$ par la biosynthèse d'une protéine de transport de l'hormone stéroïde active, et par l'augmentation d'activité d'une ATPase $\mathrm{Ca}^{2+}$ dépendante.

4 Parmi les maladies héréditaires portant sur les récepteurs hormonaux, on a identifié un rachitisme vitamino-résistant, maladie autosomique récessive, caractérisée par la résistance des tissus cibles à l'action de la 1,25-(OH) 2 -D3 (Hughes et coll., 1988). 
- le cholécalciférol élaboré dans la peau est transporté dans le plasma par une protéine spécifique : la D3-binding protein (D3-BP). Il est hydroxylé dans le foie pour donner la 25-OH-D3 sous l'effet d'une 25-hydroxylase microsomiale.

- la 25-OH-D3 est transportée sur une globuline (25-OH-D3-BP) et transformée dans le rein en 1,25-(OH) 2 -D3 sous l'effet d'une $1 \alpha$-hydroxylase.

En définitive, la régulation de la calcémie et de la phosphorémie aura comme plaque tournante la modulation de l'activité de cette $1 \alpha$-hydroxylase, hormone définitive issue du métabolisme de la vitamine D3. Le lieu d'action de la $1,25-(\mathrm{OH})_{2}-\mathrm{D} 35$ rénale se situe dans le grêle, où le pH est encore à 7 . Cette action est potentialisée par la parathormone et inhibée par le cortisol. Indirectement, elle favorise l'absorption intestinale du phosphore et peut-être d' autres ions $\left(\mathrm{Mg}^{2+} \ldots\right)$.

- Le deuxième effecteur est osseux : il y a mobilisation $\mathrm{du} \mathrm{Ca}^{2+}$ de l'os profond et vieilli. L'action de la vitamine est complexe, en particulier dépendante de la dose :

- elle peut avoir une action ostéolytique ;

- elle a le plus souvent une action minéralisante qui peut prédominer sur l'hypercalcémie consécutive à l'augmentation d'absorption intestinale, et provoquer une crise de tétanie par création d'une hypocalcémie lors du traitement d'un rachitisme par injection de fortes doses de vitamines D !

- Au niveau du rein la 1,25-(OH) 2 -D3 favorise la réabsorption du calcium et du potassium.

Le récepteur de 1,25-(OH) $)_{2}$-D3 fait partie de la famille des récepteurs nucléaires (voir chap. 2, § 4).

\section{EQUILIBRE PHOSPHOCALCIQUE ET RÉGULATION}

\subsection{LE CALCIUM}

Le calcium se répartit à : $99 \%$ dans les os et les dents et à $1 \%$ dans les parties molles.

\subsubsection{Rôle de l'ion $\mathrm{Ca}^{2+}$}

L'ion $\mathrm{Ca}^{2+}$ participe aux phénomènes physiologiques suivants :

- la régulation de l'activité de la membrane cellulaire qui conditionne l'activité neuro-musculaire (constitution et variation du potentiel de membrane);

- l'activité rythmique du cœur ;

- la formation des os et des dents ;

- la production du lait ;

- l'activation d'un grand nombre de systèmes enzymatiques.

5 Dosage : $90 \pm 30 \mathrm{nmol} / 1 \mathrm{chez}$ l'adulte,

$120 \pm 37 \mathrm{nmol} / 1$ chez l'enfant jusqu'à 12 ans. 


\subsubsection{L'apport en Ca ${ }^{2+}$ (voir fig. 8.7)}

L'apport calcique est d'origine alimentaire (500 à $800 \mathrm{mg} /$ jour). Seul le lait est riche en calcium $(1,25 \mathrm{~g} / 1)$. Mais une nourriture normale apporte suffisamment de calcium à l'organisme.

Le calcium est absorbé au niveau de la partie haute de l'intestin grêle. Un trouble de l'absorption des graisses inhibera doublement cette assimilation :

- en permettant la formation de "savons" ${ }^{6}$ calciques insolubles ;

- en déterminant une avitaminose D (la vitamine D est une vitamine liposoluble).

Cette absorption, pour être normale, devra être couplée à une certaine quantité de phosphore, telle que $0,5<\frac{\mathrm{Ca}}{\mathrm{P}}<2$. Dans le lait, $\frac{\mathrm{Ca}}{\mathrm{P}}=1,3$.

Certains produits inhibent cette absorption (acide phytique ou oxalates), d'autres la favorisent (citrates). La vitamine D et la parathormone interviennent également et dans le même sens en favorisant cette absorption.

\subsubsection{Le calcium dans le sang}

On retrouve environ $0,5 \mathrm{~g}$ de calcium dans le sang, et $0,5 \mathrm{~g}$ dans le reste des liquides extracellulaires. Mais le tissu qui stocke le calcium sous une forme qui peut être plus ou moins rapidement remise en circulation est l'os (environ $1200 \mathrm{~g}$ de calcium).

Il y a $100 \pm 10 \mathrm{mg}$ de calcium dans le sérum. Il s'y trouve sous deux formes :

- du calcium lié aux protéines, surtout à l'albumine. C'est la forme de transport du calcium (environ $40 \mathrm{mg} / \mathrm{l}$ ) ;

- du calcium ultra-filtrable $(66 \%)$ dont les $4 / 5^{\mathrm{e}}$ sont ionisés et représentent la fraction biologiquement active. Le reste est du calcium salifié (surtout le citrate qui représente une forme inactive de pénétration du calcium).

\subsubsection{Excrétion du calcium}

Le calcium est excrété :

- en partie dans les urines (environ $1 / 10^{\mathrm{e}}$ ), soit $100 \mathrm{mg} / \mathrm{jour}$ (à condition que la calcémie soit supérieure à $75 \mathrm{mg} / \mathrm{l})$;

- et surtout par les fèces $\left(9 / 10^{\mathrm{e}}\right)$. Le calcium fécal correspond pour $1 / 3$ au calcium alimentaire non-absorbé, et pour les $2 / 3$ aux sécrétions digestives (calcium de l'organisme).

Chez l'adulte normal, apport et excrétion s'équilibrent (bilan calcique nul) et toute modification de l'absorption calcique entraînera une variation parallèle de la calciurie.

NB - Le bilan est $>0$ pendant la croissance, la gestation.

Il est $<0$ dans la lactation, l'hyperparathyroïdie.

Le besoin normal est d'environ $9 \mathrm{mg} / \mathrm{kg} /$ jour.

6 Un savon est un ester d'alcool et de sel d'acide gras (acide palmitique...). 


\subsection{LE PHOSPHORE}

Il y a 450 à $700 \mathrm{mg}$ de phosphore dans l'organisme dont $66 \%$ dans les os et les dents, et $33 \%$ dans les parties molles dont $1 \%$ dans les liquides extracellulaires.

Le phosphore est un des constituants essentiels de la cellule. Il participe à la minéralisation de l'os. Il intervient sous forme de phosphate dans le métabolisme des hydrates de carbone. Il joue un rôle de tampon, en particulier dans les urines.

On trouve dans le sang $40 \mathrm{mg} / 1$ de phosphate inorganique ionisé, qui joue un rôle actif dans le métabolisme phosphocalcique (le phosphore inorganique du sang est presque totalement à l'état ionisé). L'excrétion se fait :

- par les urines (60\%) pour le phosphore de l'organisme ;

- par les fèces, pour le seul phosphore alimentaire non-absorbé.

\subsection{RÉGULATION DE L'ÉQUILIBRE PHOSPHOCALCIQUE (HOMÉOSTASIE PHOSPHOCALCIQUE) (voir fig. 8.7)}

Cette régulation se manifeste à deux niveaux :

\subsubsection{Le bilan phosphocalcique}

Elle va permettre d'assurer un équilibre convenable entre les entrées et les sorties de calcium et de phosphore, de façon à assurer et à maintenir la minéralisation du squelette.

- L'absorption du $\mathrm{Ca}^{2+}$ et du $\mathrm{PO}_{4} \mathrm{H}^{---}$sera réglée par :

- la vitamine D qui l'augmente,

- et qui est plus efficace que la parathormone qui l'augmente également.

Ces deux facteurs sont donc synergiques.

- L'excrétion du $\mathrm{Ca}^{2+}$ et du $\mathrm{PO}_{4} \mathrm{H}^{---}$est sous la dépendance des trois facteurs :

- la vitamine $\mathrm{D}$ augmente la réabsorption du $\mathrm{Ca}^{2+}$ et du $\mathrm{PO}_{4} \mathrm{H}^{-\cdots}$ dans le tube proximal, entraînant une diminution de la calciurie et de la phosphaturie ;

- la PTH a une action inverse au niveau du tube proximal mais augmente la réabsorption calcique au niveau du tube distal ;

- la Ct inhibe la réabsorption du $\mathrm{Ca}^{2+}$ et du $\mathrm{PO}_{4} \mathrm{H}^{--}$. Elle entraîne une augmentation de la calciurie et de la phosphaturie.

\subsubsection{Le taux plasmatique de calcium et de phosphate}

La régulation va assurer, dans le milieu intérieur, un niveau de calcium ionisé et de phosphatémie aussi constants que possible. Une telle homéostasie fait intervenir non seulement parathormone, calcitonine, vitamine $\mathrm{D}$ et cortisol, mais aussi la thyroxine (T4). Elle est essentiellement réalisée par des échanges entre la substance minérale mobilisable de l'os, et le calcium et le phosphore sanguins. 


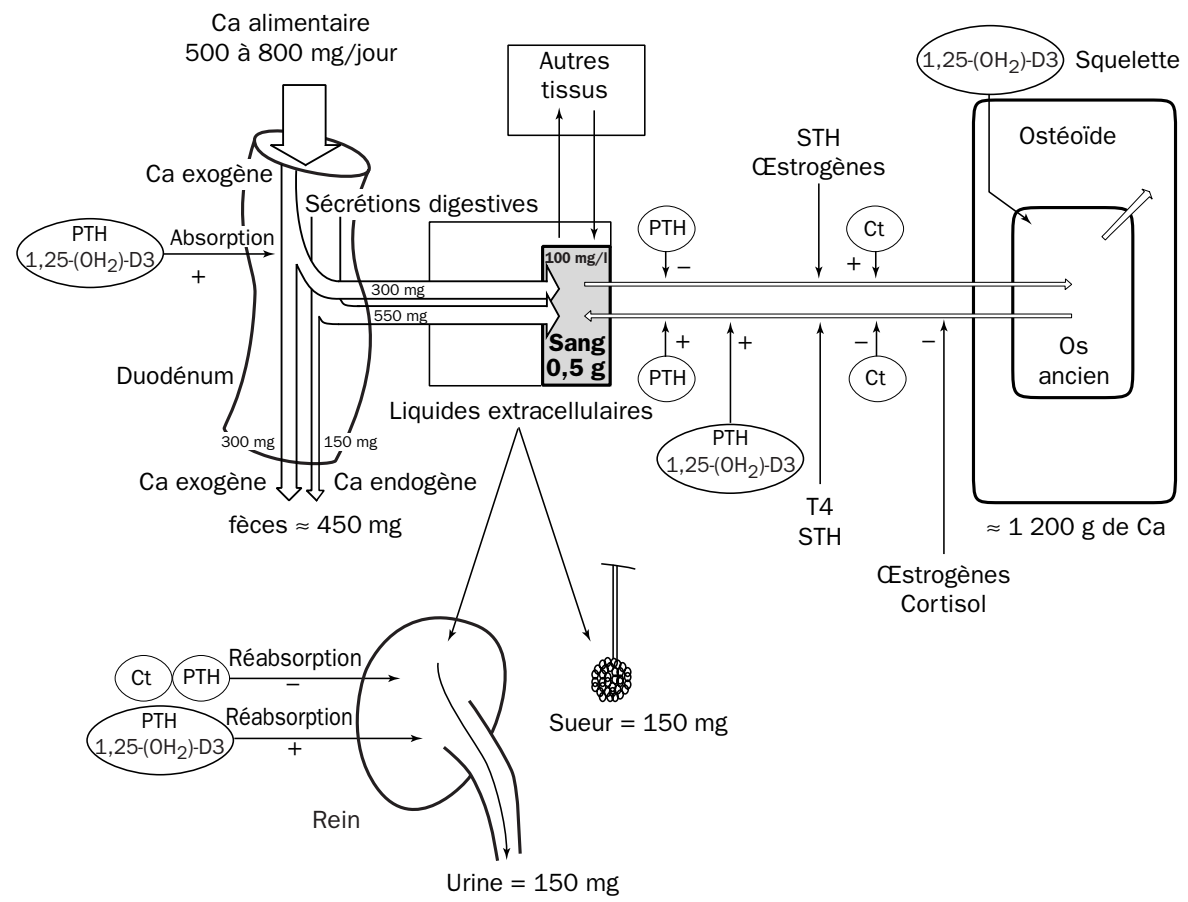

Figure 8.7 - Régulation de l'équilibre phosphocalcique

- La calcémie est susceptible d'être augmentée par la parathormone dont le taux de sécrétion, chez l'individu normal, est adapté au maintien d'un taux moyen de $100 \mathrm{mg} / 1$. Cette majoration est réalisée à la fois par une stimulation de l'ostéolyse et par une inhibition de l'ostéogenèse. Au contraire, la calcitonine tend à abaisser la calcémie en inhibant l'ostéolyse.

Une régulation du taux de la calcémie est néanmoins possible chez l'animal parathyroïdectomisé (ou traité par des chélateurs du calcium : EDTA ou citrates), elle se fait seulement à un niveau plus bas que chez l'animal normal. Elle est alors probablement assurée par l'adaptation du taux de la calcitonine.

Les deux hormones thyroïdiennes - calcitonine et thyroxine - sont nécessaires pour que la calcitonine produise un effet hypocalcémiant maximal. Au niveau de la calcémie, la thyroïde et les parathyroïdes sont antagonistes.

- La phosphatémie n'est modifiée que par voie indirecte. Elle peut être abaissée à la fois par la parathormone (suite à une action rénale qui provoque une élévation de la phosphaturie) et par la calcitonine (suite à une action osseuse qui entraine une inhibition de la libération du calcium et du phosphore osseux dans la circulation sanguine). Les deux hormones, antagonistes quant à la régulation de la calcémie, sont donc au contraire synergiques quant à celle de la phosphatémie.

Le facteur antagoniste nécessaire, capable d'élever la phosphatémie, est la thyroxine. Elle inhibe l'effet hypophosphatémiant de la calcitonine et de la parathormone. Il ne s'agit pas d'une action rénale directe, car la thyroxine est 
hyperphosphaturique. L'hormone somatotrope est également capable d'élever la phosphatémie, mais son action est lente et doit faire intervenir des facteurs intermédiaires.

L'intrication anatomique des glandes thyroïdes et parathyroïdes dans la plupart des espèces animales, et leur origine embryologique commune préfigurent l'existence d'interactions physiologiques étroites.

\section{NB - Autres actions hormonales}

- Les œstrogènes, qui diminuent la réactivité de l'os à la PTH ;

- Le glucagon, qui diminue la calcémie ;

- T3 et T4, qui stimulent les ostéoclastes ;

- Les glucocorticoïdes, qui ont une action antivitamine D ;

- La GH, qui accroît l'absorption intestinale du $\mathrm{Ca}^{2+}$. 


\section{CHAPITRE 9}

\section{LES STRUCTURES ENDOCRINES DIFFUSES}

D'autres glandes et cellules endocrines interviennent dans la régulation des fonctions de l'organisme. Leur absence dans les traités classiques d'endocrinologie provient, soit de leur structure aux limites mal définies (tissu endocrinien de l'endoderme gastro-intestinal), soit de leur absence chez les Vertébrés supérieurs (corps ultimobranchial, corpuscules de Stannius et système neurosécrétoire caudal), soit parce que leur rôle était encore mal connu il y a quelques années.

On n'envisage ici que les cellules endocrines présentes chez les Vertébrés supérieurs.

\section{LE THYMUS}

Organe dérivé de la 3 e poche endobranchiale, le thymus se développe pendant toute la croissance pour atteindre 35 à $38 \mathrm{~g}$ chez l'homme jeune. Il régresse ensuite, mais ne s'atrophie jamais complètement.

Après une période où est soupçonné un rôle endocrinien du thymus, Miller (1961) démontre que le thymus est à l'origine de l'immunité à médiation cellulaire. Les lymphocytes précurseurs $\mathrm{T}$ acquièrent leur maturité immunologique (leur compétence) à leur passage (ou après leur passage) thymique, sous l'effet de facteurs humoraux.

- L' $\alpha$-thymosine (Goldstein et coll., 1966) est un polypeptide de 3100 daltons à 28 AA. Mais c'est plutôt la pro-thymosine, de PM 12000 (113 AA), qui serait la véritable hormone. On retrouve ce facteur dans d'autres cellules : la rate, les poumons, le rein, le foie. Il n'est donc pas spécifique du thymus.

- La thymuline : le facteur thymique sérique (FTS) ou thymuline (Bach, 1972), de PM 860 (9 AA), est un facteur dont l'activité n'apparaît qu'après l'élimination d'un facteur sérique inhibiteur. Sa formule : Glu-Glu-Ala-Lys-Ser-Glu-Gly-SerAsp. Les précurseurs éventuels sont des protéines de 48 à $54 \mathrm{kDa}$.

- La thymopoïetine II (Goldstein, 1975) est un facteur spécifique du thymus ; il est constitué de 49 AA. Les travaux de Comsa (1973, 1979, 1982), puis de Deschaux (1980), démontrent qu'en plus de son rôle immunitaire, le thymus 
exerce aussi, au moins juqu'à la maturité sexuelle (chez le rat), un rôle endocrinien : sur la sécrétion hypophysaire de GH, $\mathrm{LH}$, et $\mathrm{ACTH}$, et sur la sécrétion de glucocorticoïdes par les cellules corticosurrénaliennes.

La thymectomie chez le jeune rat de 30 jours provoque :

- un abaissement des taux plasmatiques d'ACTH et de corticostérone ;

- une élévation du taux plasmatique de la GH ;

- une élévation du taux de LH et de testostérone.

\section{LES HORMONES GASTRO-INTESTINALES}

Les hormones gastro-intestinales sont des polypeptides sécrétés par des cellules endocrines particulières du tube digestif 1 .

Des quinze types différents de cellules endocrines digestives découverts chez les Mammifères (grâce aux anticorps fluorescents), cinq ont pu être retrouvés chez l'anguille : le glucagon, l'insuline, la somatostatine, la met-enképhaline et la sérotonine.

\subsection{LES PRINCIPALES HORMONES DE LA PAROI DU TUBE DIGESTIF}

Elles interviennent :

- dans la régulation des activités sécrétoires des glandes exocrines du tube digestif : gastrine pour l'estomac, pour la vésicule biliaire, sécrétine et CCK pour le pancréas. C'est une véritable autorégulation.

- dans le métabolisme des sucres (indirectement, par la sécrétine et la CCK). Gastrine, sécrétine et CCK sont des polypeptides linéaires dont le regroupement carboxyl terminal est amidé $\left(\mathrm{CONH}_{2}\right)$. La gastrine est chimiquement plus apparentée à la CCK, tandis que la sécrétine l'est au glucagon. Toutefois, des séquences communes à ces quatre hormones, ainsi qu'au VIP, permettent de les considérer comme une famille évolutive dérivant d'un gène ancestral commun.

\subsubsection{La gastrine}

C'est un heptadécapeptide (17 AA) qui pourrait être sécrété à partir d'un précurseur de 34 AA. Son activité biologique réside essentiellement dans sa portion C-terminale.

Les cellules sécrétrices (cellules G) sont localisées dans l'anse gastrique et le duodénum proximal. La gastrine stimule essentiellement la sécrétion des ions $\mathrm{H}^{+}$par les cellules pariétales gastriques. Cette action est facilitée par l'acétylcholine (donc par

1 L'origine à partir de la crête neurale n'a, en fait, été établie que pour les cellules à calcitonine, les chémorécepteurs (cellules de type I) du glomus carotidien et, bien entendu, les cellules médullo-surrénaliennes (Le Douarin et Teillet, 1973). 
excitation vagale), de même que par l'histamine exogène du fundus gastrique. Cependant, ni l'acétylcholine, ni l'histamine n'interviendraient comme médiateurs de l'effet de la gastrine sur les cellules pariétales.

La gastrine stimule la motricité gastro-intestinale et relâche le sphincter pylorique et le sphincter d'Oddi. Elle exerce des effets trophiques sur la muqueuse gastro-intestinale et le pancréas.

Les principaux stimulus de la sécrétion de gastrine sont :

- d'origine alimentaire : polypeptides et aminoacides ;

- d'origine nerveuse (parasympathique), au niveau :

- céphalique (l'hypoglycémie insulinique provoque une stimulation vagale);

- gastrique (réflexes locaux par distension fundique ou/et antrale).

Sa demi-vie est d'environ 3 min. Elle est dégradée dans les reins et l'intestin grêle.

\subsubsection{La sécrétine}

Mise en évidence par Bayliss et Starling en 1902, c'est un polypeptide linéaire de 27 AA. Les cellules à sécrétine (cellules S) sont surtout duodénales, on les retrouve dans toutes les classes de Vertébrés.

La sécrétine stimule la sécrétion de l'eau et des bicarbonates (et diminue celle des ions $\mathrm{Cl}^{-}$) au niveau des cellules épithéliales des canaux intrapancréatiques. Cette sécrétion ne dépend pas du système nerveux parasympathique. La sécrétine exerce de nombreux autres effets sur:

- la cholérèse et la sécrétion de pepsine, qui sont stimulées ;

- le tonus du sphincter œsophagien inférieur et la motilité gastrique, qui sont inhibées.

Le stimulant majeur de la libération de sécrétine est l'acidification du contenu duodénal.

Sa demi-vie est de $17 \mathrm{~min}$ chez l'homme. Sa dégradation est essentiellement hépatique.

\subsubsection{La cholécystokinine (CCK)}

C'est un polypeptide linéaire de 33 AA. L'activité biologique est surtout liée à la partie C-terminale. Les cellules sécrétrices sont localisées essentiellement dans le duodénum ${ }^{2}$.

En fait, les cellules digestives sécrètent différentes CCK dont le nombre d'acides aminés est variable : 58, 33, 12, 8 ou 4. Leur synthèse s'effectue à partir d'un précurseur commun, une pré-pro-CCK de 114 AA.

2 CCK et VIP (vasoactive intestinal peptide)sont également présents dans le cerveau où ils fonctionnent probablement comme neurotransmetteurs (CCK, VIP et somatostatine sont les peptides principaux du cortex cérébral). 
Les effets majeurs de la CCK sont stimulants :

- sur la contraction de la vésicule biliaire ;

- sur la sécrétion enzymatique des cellules acineuses pancréatiques (amylase).

Expérimentalement, elle stimule également :

- la sécrétion gastrique d'ions $\mathrm{H}^{+}$et de pepsine ;

- la motilité de l'intestin grêle et du colon ;

- la sécrétion de trois hormones polypeptidiques : insuline, glucagon et calcitonine ; mais ces effets peuvent ne pas être physiologiques. En revanche, elle inhibe dans les conditions physiologiques la motilité du sphincter œsophagien inférieur et de l'estomac, et ralentit l'évacuation gastrique ${ }^{3}$.

Ses effets seraient médiés par l'AMPc (qu'elle diminue) ou/et par le GMPc (qu'elle augmente). Les principaux stimulants de la sécrétion de CCK sont :

- les graisses émulsionnées et les acides gras à chaîne longue ;

- certains aminoacides et oligopeptides ;

- les sels biliaires et la distension jéjunale.

Cette sécrétion varierait en raison inverse de la concentration de trypsine et de chymotrypsine dans le contenu duodénal : elle est facilitée par la stimulation du parasympathique. Sa demi-vie est d'environ $6 \mathrm{~min}$ chez l'homme. Son catabolisme est encore mal connu.

\subsection{LES AUTRES HORMONES DU TUBE DIGESTIF 4}

Certaines hormones du tube digestif sont des polypeptides qui ont été isolés et caractérisés, mais dont on ignore si elles sont libérées en réponse à des stimulus physiologiques :

- le GIP (gastric inhibitory peptide), polypeptide inhibiteur gastrique de 43 AA, sécrété par les cellules $\mathrm{K}$ du duodénum, inhibe la sécrétion induite par la gastrine ;

- le VIP (vasoactive intestinal peptide), polypeptide intestinal de 28 AA, provoque vaso-dilatation et hypotension artérielle, stimule la sécrétion d'eau et d'électrolytes par l'intestin grêle, stimule la glycogénolyse hépatique et la lipolyse ;

- la gastrone, glycoprotéine gastrique et duodénale, inhibe la sécrétion gastrique acide ;

3 Par ses effets sur le tube digestif, la CCK agit localement pour limiter l'ingestion de nourriture. Mais elle aurait également une action sur le système nerveux central, au niveau duquel elle constitue une molécule "coupe-faim".

4 Le tractus gastro-intestinal contient également de nombreuses substances de nature non-hormonale (histamine, sérotonine, neurotensine, substance P...), qui sont en réalité des neurotransmetteurs appartenant au système nerveux intramural des parois gastro-intestinales. 
- l'entéroglucagon, d'origine intestinale, apparenté au glucagon, stimule la glycogénolyse, l'insulinosécrétion et la lipolyse ;

- et des polypeptides apparentés au polypeptide pancréatique (PP) :

- le neuropeptide Y (NPY), 38 AA, qui inhibe la sécrétion hydro-électrique intestinale ;

- le peptide YY (PYY), 38 AA, qui inhibe les sécrétions exocrines gastrique, pancréatique et intestinale, et stimule l'absorption hydro-électrique intestinale ;

- la chymodénine, polypeptide duodénal, qui stimule la sécrétion du chymotrypsinogène pancréatique.

\section{L'ÉRYTHROPOÏÉTINE (EPO)}

Le plasma sanguin des Mammifères anémiques contient un facteur capable d'élever l'érythropoïèse lorsqu'on l'administre à un animal normal. Cette substance, que l'on pensait être élaborée au niveau des reins, a été appelée érythropoiétine (Erslev, 1966 ; Reissmann et Samorapoompichit, 1969).

En fait, l'érythropoiétine ne peut être considérée comme une hormone exclusivement rénale. Il existe aussi, pendant la vie fœtale, une production extrarénale d'érythropoïétine, le foie en est le siège initial et l'érythropoïetine continue d'y être sécrétée par des hépatocytes distribués autour des veines centrolobulaires du foie. Dans le rein, elle est sécrétée au niveau de l'appareil juxtaglomérulaire par une sous-population de cellules péritubulaires situées dans le cortex rénal et la médullaire externe.

Le facteur déclenchant la production d'érythropoïétine est l'abaissement de la pression partielle d'oxygène du sang $\left(\mathrm{pO}_{2}\right)$.

Le récepteur de l'érythropoïétine appartient à la superfamille des récepteurs des cytokines (voir chap. $2, \S 2.1 .4$ ). C'est une protéine de $66 \mathrm{kDa}$, les récepteurs sont présents en petit nombre à la surface des cellules cibles (de 1000 habituellement à 10000 au maximum). La stimulation des récepteurs membranaires par l'hormone induit une cascade de phosphorylation empruntant les voies de la PI-3-kinase et des Ras / MAP kinases.

Un certain nombre de facteurs endocriniens (thyroxine, androgènes, insuline, prolactine, système rénine-angiotensine) interviendraient dans la régulation de la sécrétion d'érythropoïétine.

Depuis son isolement à partir de plasma de moutons anémiques, cette hormone a été progressivement purifiée mais, depuis 1985, sa production par génie génétique permet d'obtenir une érythropoḯtine en quantité suffisante pour l'utiliser comme médicament (24 à $48 \mathrm{UI} / \mathrm{kg}$ en intraveineuse, trois fois par semaine chez les dialysés). Son PM est d'environ 34000. 
L'érythropoïétine est essentiellement utilisée (en association avec le fer) dans le traitement des différents types d'anémie ; elle pourrait être aussi utilisée dans le cas d'autotransfusion. Enfin, l'érythropoïétine est aussi utilisée comme agent dopant que l'on met en évidence par son effet sur le taux de l'hématocrite. Dopage qui présente des risques importants, en particulier celui de thrombose.

\section{LE CEUR, ORGANE ENDOCRINE}

Des cellules présentes dans les oreillettes 5 sécrètent une hormone hypotensive. C'est un polypeptide de 28 AA (fig. 9.1), à peu près identique chez le rat et chez l'homme. C'est le facteur natriurétique atrial (ANF) ou atriopeptide.

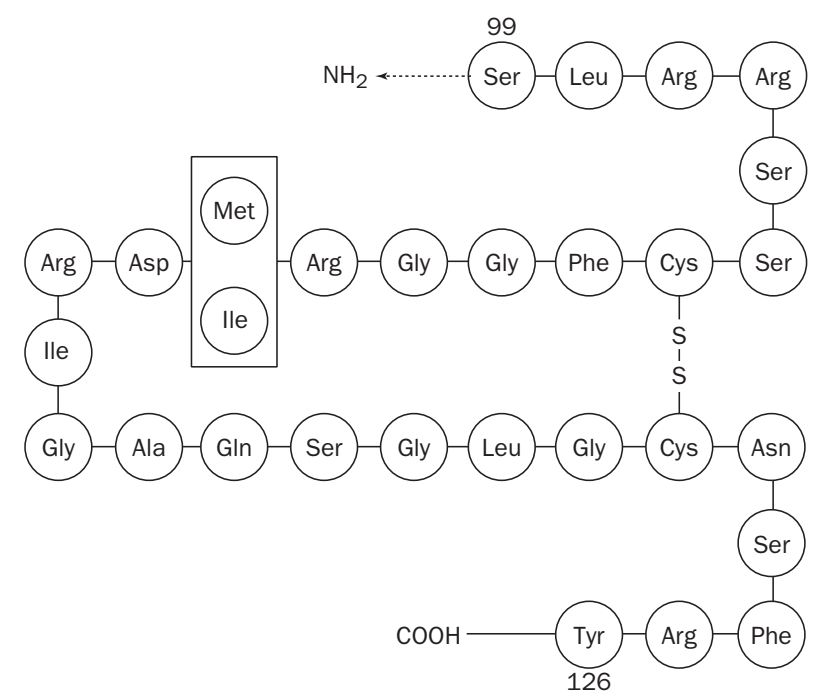

Figure 9.1 - Structure du facteur natriurétique atrial

Il est formé à partir d'un précurseur de 152 AA. Il a été isolé en 1981 par De Bold et coll., cloné en 1984, synthétisé et administré chez l'homme depuis 1985.

Son activité biologique nécessite un pont disulfure et les derniers acides aminés. Il est libéré sous l'effet d'une distension mécanique de l'oreillette gauche, donc dans l'inflation volémique. Il reconnaît des récepteurs spécifiques sur les reins, les surrénales, les vaisseaux (où il induit la production de NO par les cellules endothéliales) et l'hypothalamus. Il agit à leur niveau par un mécanisme GMPc dépendant.

Son action s'intègre dans la régulation (l'homéostasie) liquidienne de l'organisme en favorisant :

5 Et probablement aussi dans les ventricules. 
- la diurèse, par action sur l'hémodynamique glomérulaire (vaso-dilatation de l'artériole afférente) ;

- la natriurèse, par action sur le tube distal ;

- la vaso-dilatation par la production de NO et par blocage de l'angiotensine II et des catécholamines; il permet donc d'empêcher l'excès de volume liquidien circulant.

Sa demi-vie est courte, de 2 min 30. Sa valeur normale, appréciée par dosage radioimmunologique est, chez l'homme, de 65 à $68 \mathrm{pmol} / \mathrm{ml}$ de plasma.

Il agit dans le même sens que l'ADH en favorisant l'excrétion rénale du sodium mais, contrairement à l'hormone hypothalamique, il n'a aucune action inhibitrice sur les pompes ioniques cellulaires et maintient un relâchement normal de la musculature lisse des parois artérielles.

Une pression artérielle normale résulterait donc d'un équilibre harmonieux entre les sécrétions de ces deux hormones (ADH et ANF), c'est-à-dire de leur effet synergique sur l'excrétion sodée et de leur effet antagoniste sur la musculature des vaisseaux.

En revanche, les effets biologiques de l'ANF sont diamétralement opposés à ceux de l'angiotensine II :

- d'une part par son impact rénal ;

- d'autre part au niveau du cerveau principalement, où l'on retrouve l'ANF, surtout dans la paroi antérieure du $3^{\mathrm{e}}$ ventricule. La destruction de cette zone provoque une hypodipsie et une hypernatrémie chroniques, l'injection d'ANF dans le $3^{\mathrm{e}}$ ventricule bloque la libération spontanée d'ADH et la réponse comportementale (boisson) et hormonale (libération d'ADH) à une stimulation osmotique ou à une injection d'angiotensine II ;

- enfin, au niveau des vaisseaux, pour lesquels l'angiotensine II est un puissant vaso-constricteur.

L'ANF fonctionne donc en synergie avec l'ADH et en antagonisme avec l'angiotensine II (et l'aldostérone) pour assurer au niveau du rein, comme au niveau des vaisseaux, une réponse adéquate aux variations de la masse liquidienne.

\section{L'ENDOTHÉLIUM VASCULAIRE}

L'endothélium vasculaire peut être considéré comme une glande endocrine diffuse ( $2 \mathrm{~kg}$ et $1000 \mathrm{~m}^{2}$ chez l'homme) qui participe à la régulation du tonus vasculaire, et est impliquée dans les processus d'agrégation plaquettaires et d'immunité. L'endothélium produit des facteurs vaso-dilatateurs (NO, PAF, facteurs hyperpolarisants, certains dérivés de l'acide arachidonique) et des facteurs vaso-constricteurs (l'angiotensine II, l'endothéline qui a été étudiée au chapitre 3 , § 5, et aussi certains dérivés de l'acide arachidonique). 



\section{CHAPITRE 10}

\section{L'ÉPIPHYSE}

Située sous le corps calleux, reposant sur les tubercules quadrijumeaux antérieurs, l'épiphyse, ou glande pinéale, est un appendice nerveux de la partie postérieure du toit du diencéphale ou épithalamus (fig. 10.1). Cette situation, au centre même du cerveau, a depuis longtemps conduit à des spéculations diverses sur le rôle de cet organe. On sait que Descartes y voyait le siège de l'âme. C'est à la fin du XIX' siècle que l'association clinique de tumeurs épiphysaires infantiles avec une macrogénitosomie (puberté précoce) a projeté la pinéale dans le domaine de l'Endocrinologie. On lui attribua tout naturellement un rôle inhibiteur sur la sexualité, et on admit pendant longtemps que cette action "antigonadotrope" était l'un des facteurs importants du blocage prépubertaire de la fonction gonadotrope. On sait aujourd'hui qu'il n'en est rien, et que l'explication de ces observations anatomo-cliniques de puberté précoce réside dans la sécrétion ectopique de peptides à activité gonadotrope par ces tumeurs. Un tel phénomène de production hormonale ectopique est rencontré dans de nombreuses autres tumeurs.

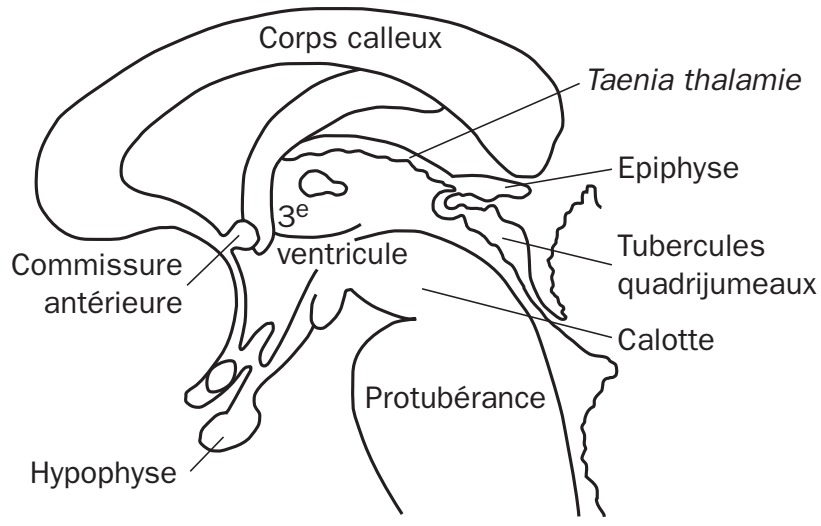

Figure 10.1 - L'épiphyse

Section sagittale du tronc cérébral humain, montrant les relations de l'épiphyse.

C'est à partir de la découverte de son hormone majeure, la mélatonine (Mt), que la physiologie de la pinéale a pris un tout autre essor. Il s'y ajoute que la structure de l'épiphyse, ou plutôt des "pinéalocytes", a connu une importante évolution au cours 
de la phylogenèse. En effet, chez les Vertébrés sous-mammaliens, les pinéalocytes ont une fonction double : photoréceptrice, grâce à des organites cellulaires rappelant ceux des cellules réceptrices de la rétine, et neuro-endocrinienne, produisant la mélatonine. Encore présente, de façon rudimentaire chez les Oiseaux, la fonction sensorielle a complètement disparu chez les Mammifères.

\section{BIOSYNTHÈSE DE LA MÉLATONINE}

La mélatonine a été étudiée chez beaucoup d'espèces, depuis les Dinoflagellés (Gonyaulax) et les Algues, jusqu'aux humains. Elle présente dans tous ces cas un rythme circadien très net, dans sa production comme dans sa sécrétion, avec le niveau le plus élevé pendant la période nocturne (Hardeland et coll., 1995 ; Reiter, 1995).

La biosynthèse de la mélatonine, principale sécrétion épiphysaire, nécessite l'intervention de deux enzymes: une $\mathrm{N}$-acétyltransférase (NAT) qui transforme la sérotonine en acétylsérotonine, et l'hydroxyindole-O-méthyltransférase (HIOMT) qui conduit à la mélatonine $(\mathrm{Mt})$.

Dans toute la chaîne des synthèses qui conduit du tryptophane à la Mt à travers la sérotonine (fig. 10.2.a), la NAT joue un rôle limitant très important, en cela que l'activité de cette enzyme est bloquée lorsque l'animal ou l'homme se trouve dans un environnement éclairé. C'est pourquoi, chez toutes les espèces connues, la synthèse finale de la Mt n'intervient que de nuit (fig. 10.2.b), en un ou plusieurs épisodes, ce qui donne à cette hormone la valeur d'un signal de début et / ou de fin de nuit, élément fondamental de la biologie des rythmes circadiens et circannuels (voir l'introduction concernant les rythmes biologiques).

La mélatonine circulante est presque exclusivement d'origine pinéale, elle n'est pratiquement pas stockée dans la glande. Indépendamment de son pic nocturne, la sécrétion de mélatonine présente une pulsatilité surimposée au rythme nycthéméral, qui apparaît indépendante de la pulsatilité sécrétoire de la LH (de Leiva et coll., 1990).

La demi-vie de la mélatonine plasmatique est courte, de 20 à 50 min.

Le principal métabolite excrété est la 6-sulphatoxy-mélatonine urinaire ; son taux, qui réflète assez bien le taux de mélatonine plasmatique ou épiphysaire (Matthews et coll., 1991), permet d'apprécier de façon non-invasive la fonction de la glande pinéale, ce qui est particulièrement intéressant, par exemple chez les enfants. 
<smiles>NCCc1c[nH]c2ccc(O)cc12</smiles>

5-hydroxytryptamine (5-HT)<smiles>CC(=O)NCCc1c[nH]c2ccc(O)cc12</smiles>

N-acétyl 5-hydroxytryptamine (NAc 5-HT)<smiles>COc1ccc2[nH]cc(CCCNC(C)=O)c2c1</smiles>

$\mathrm{N}$-acétyl 5-méthoxytryptamine (mélatonine)

\section{a - Biosynthèse}

SAdH : S-adénosyl-homocystéine ; SAdM : S-adénosyl-méthionine.

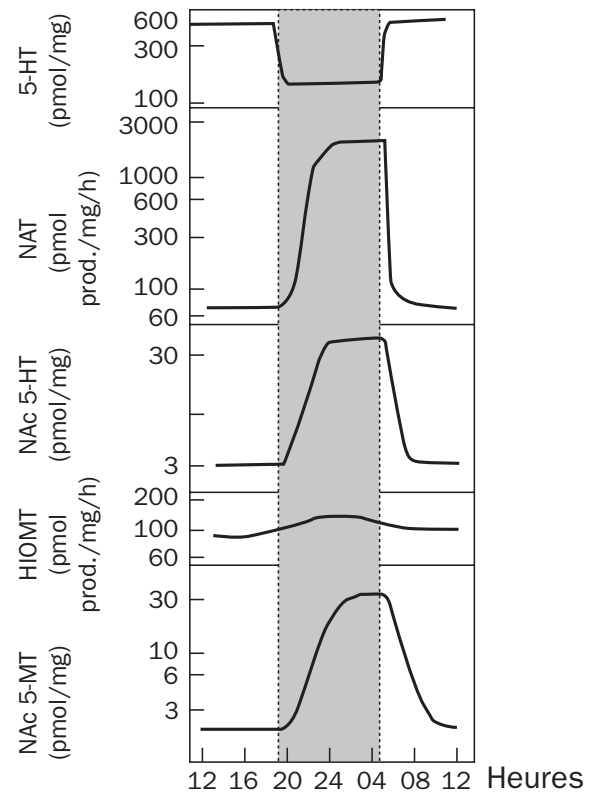

b - Variation circadienne des substrats et enzymes de la chaîne de biosynthèse chez le rat

Figure 10.2 - La mélatonine 


\section{RôLE DE L'ÉPIPHYSE}

\subsection{L'ÉPIPHYSE, UNE HORLOGE INTERNE}

La découverte récente de la Mt, et surtout de certains de ses sites de liaison tissulaire (certains noyaux cérébraux, dont les noyaux suprachiasmatiques (NSC) et la pars tuberalis de l'hypophyse), a entièrement réorienté la physiologie de la glande pinéale. Au stade actuel de nos connaissances, c'est, chez les Vertébrés supérieurs, dans le domaine de la chronobiologie neuro-endocrinienne, que l'épiphyse trouve sa place première. Encore faut-il clairement distinguer les Oiseaux des Mammifères. On a vu plus haut que l'épiphyse des Oiseaux se distingue déjà par le maintien d'une fonction phototransductrice à côté de sa fonction neuro-endocrinienne. De plus, les travaux de Binkley et coll. (1978) ont montré qu'à la différence des Mammifères, la pinéale des oiseaux a les propriétés d'un véritable pacemaker circadien. Cultivée in vitro et à l'obscurité (pour ne pas bloquer la NAT par la lumière), la pinéale de poulet relâche la Mt selon un rythme circadien de période proche de $24 \mathrm{~h}$. Cette glande est ici à la fois une véritable horloge circadienne et, par ses photorécepteurs, une horloge directement synchronisée par la photopériode nycthémérale (fig. 10.3 et 10.4).

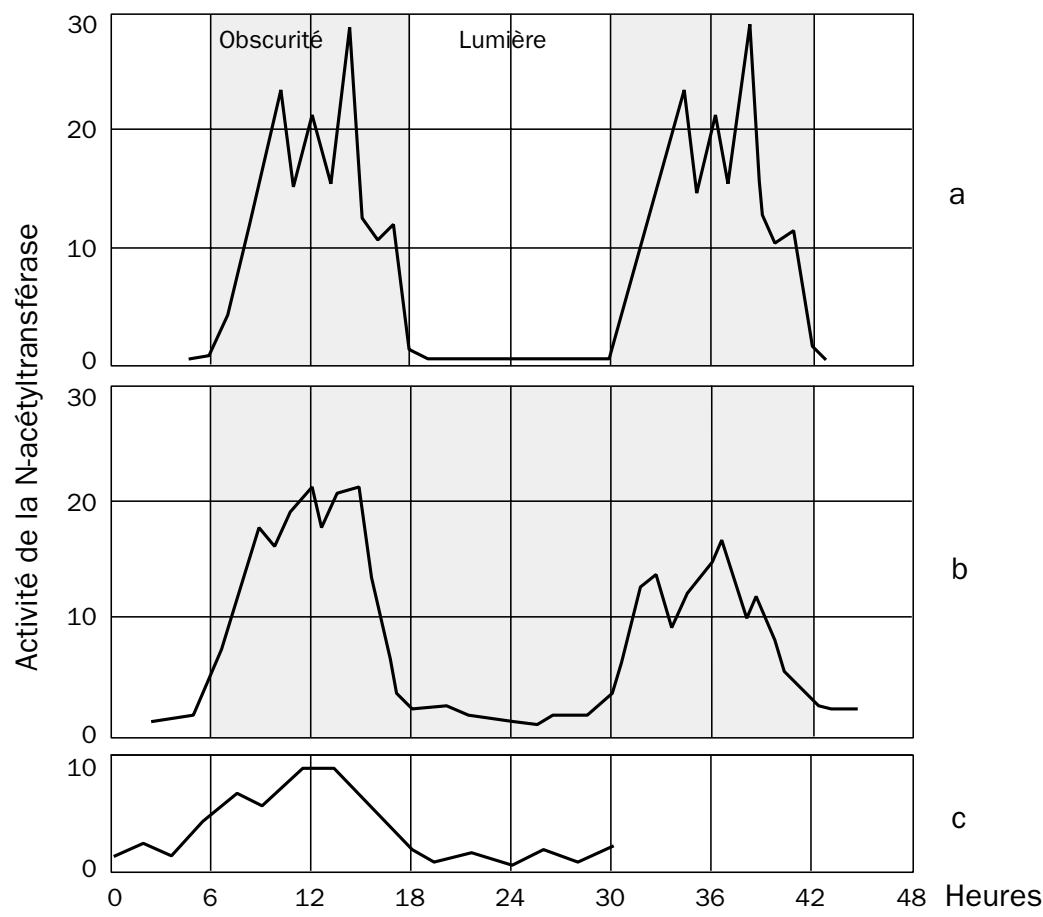

Figure 10.3 - Origine endogène de l'activité de la N-acétyltransférase (d'après Binkley et coll., 1978)

Le rythme de l'activité $N$-acétyltransférase a été étudié chez le poulet soumis à une alternance de périodes de $12 \mathrm{~h}$ de lumière et $12 \mathrm{~h}$ d'obscurité (a). Ce rythme persiste chez le poulet soumis à l'obscurité continue (b), mais il disparaît chez le poulet soumis à une lumière continue (c). 


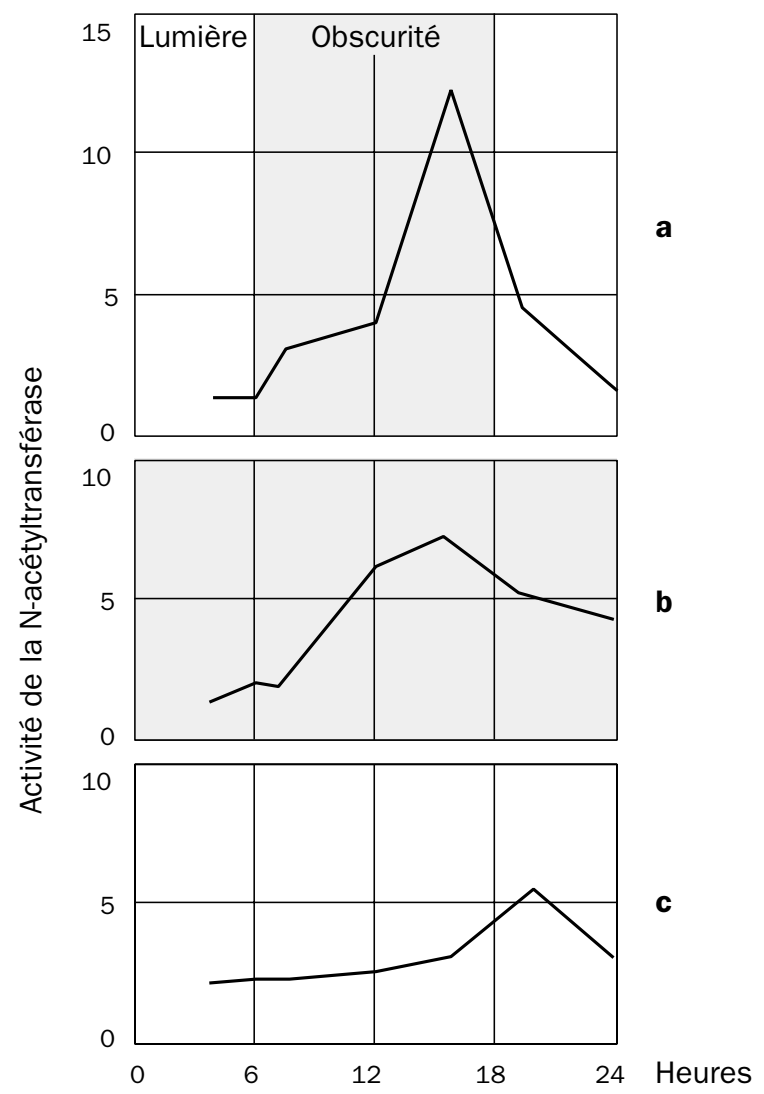

Figure 10.4 - Activité de la $\mathbf{N}$-acétyltransférase dans la glande pinéale en culture (d'après Binkley et coll., 1978)

Réponse de la glande pinéale de poulet, en culture, prélevée chez le poulet tué à la fin d'une période d'éclairement d'un cycle nycthéméral lumière-obscurité et soumis, soit à l'obscurité continue (b), soit à la lumière continue (c). Elle démontre une perception directe de la lumière par la glande pinéale.

Il en va autrement chez les Mammifères, où la glande pinéale n'est pas un organe de photoréception. La sécrétion quotidienne (nocturne) de Mt intervient ici sous le contrôle des pacemakers cérébraux mentionnés plus haut (NSC), eux-mêmes entraînés par le contrôle synchronisant de l'alternance jour-nuit, transmis depuis la rétine par une voie optique accessoire (faisceau rétino-hypothalamique) qui relaie dans le NSC, puis dans le noyau paraventriculaire ${ }^{1}$, le cordon latéral de la moelle, le ganglion sympathique cervical supérieur, et l'innervation adrénergique que celui-ci envoie à la pinéale (fig. 10.5).

1 Des lésions bilatérales de ce noyau abolissent les variations diurnes de la sécrétion de mélatonine, et celles des taux de $\mathrm{N}$-acétyltransférase chez le rat et le hamster. Elles bloquent également la régression testiculaire induite par le raccourcissement du jour chez le hamster. 


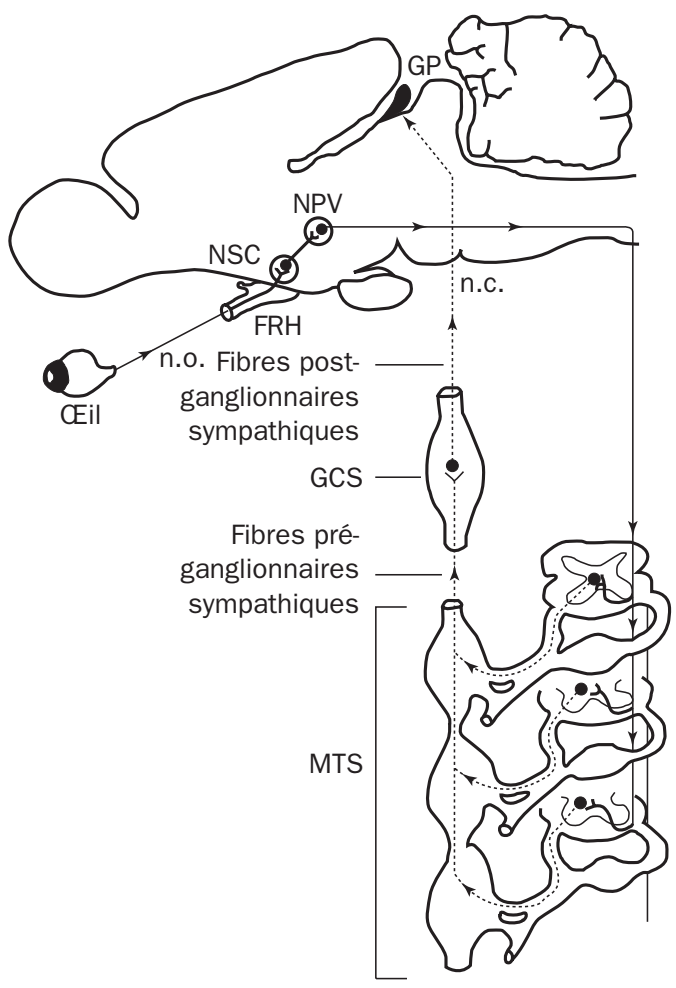

Figure 10.5 - Voies nerveuses liées au photopériodisme

FRH : faisceau rétino-hypothalamique; GSC : ganglion sympathique cervical supérieur ; MTS : moelle thoracique supérieure; n.c. : nerf carotidien; NSC : noyau suprachiasmatique ; n.o. : nerf optique; NPV : noyau paraventriculaire ; GP : glande pinéale.

Représentation schématique de la chaîne morphologique et fonctionnelle impliquée dans le transfert de l'information photopériodique.

La glande pinéale, par la Mt, est donc essentiellement un organe de transmission, par voie hormonale, de signaux de lecture de la durée de la nuit (et donc du jour). Si on connaît encore mal l'importance précise de la sécrétion circadienne de Mt dans la physiologie complexe des rythmes circadiens neuro-endocriniens, neurovégétatifs et comportementaux, on sait, en revanche, que ces signaux sont indispensables à la "lecture" de la longueur des jours, indispensables à la rythmicité circannuelle (saisonnière) de la reproduction des animaux sauvages (voir plus haut). Ainsi, la pinéalectomie chez le hamster (animal à "jours longs") empêche-t-elle la régression testiculaire induite par le raccourcissement saisonnier des jours, alors que chez le vison (animal à "jours courts"), la privation de Mt empêche, au contraire, la reprise sexuelle induite par la diminution annuelle des jours. Des traitements appropriés à la Mt réparent ce déficit (Boissin-Agasse et coll., 1988 ; Pevet, 1988).

Il existe en général une relation entre la latitude et l'importance de la glande pinéale : tandis que les glandes pinéales sont très développées chez les manchots, elles sont quasiment absentes chez les crocodiliens. 
Des expériences ont été faites sur des hommes sains, vivant en Antarctique, chez lesquels des injections de mélatonine ont créé une photopériode artificielle, modifiant le décalage physiologique entre hiver et été.

Il est vraisemblable que les propriétés de la mélatonine pourront être utilisées en pathologie pour traiter des insomnies, la maladie des fuseaux horaires et certains problèmes induits par la chimiothérapie (chronothérapie).

La démonstration récente (Weaver et coll., 1993) de récepteurs à la mélatonine dans le noyau suprachiasmatique humain suggère bien une action directe de la mélatonine sur celui-ci, et à travers lui sur les rythmes circadiens.

\subsection{MÉCANISMES MOLÉCULAIRES DU FONCTIONNEMENT DE L'HORLOGE BIOLOGIQUE}

Le premier gène affectant le rythme circadien a été identifié au début des années 1970 chez la drosophile (Konopka et Benzer, 1971). Le clonage de ce gène, le gène per (period), a permis de montrer que le taux de l'ARN per oscillait cycliquement avec une période de $24 \mathrm{~h}$. Ce fut ensuite l'isolement d'un deuxième mutant tim (timeless) qui retarde l'auto-inhibition de per et permet d'entretenir le mouvement de l'horloge biologique. Il a été cloné et séquencé et les protéines respectives constituent des partenaires coopérant au fonctionnement de l'horloge biologique. Ce mécanisme a été retrouvé chez un autre organisme, Neurospora crassa, dont un gène frq (frequency) altérant les rythmes circadiens a été retrouvé (Hunter-Ensor et coll., 1996).

Dans le cas de la glande épiphysaire, le mécanisme génique reste à identifier. Les pinéalocytes reçoivent des terminaisons nerveuses sympathiques qui libèrent de la noradrénaline pendant la nuit. En agissant sur les récepteurs $\beta$-adrénergiques, la noradrénaline provoque l'élévation de l'AMPc. Cette action est potentialisée par des récepteurs $\alpha$-adrénergiques. Au niveau moléculaire, Stehle et coll. (1993) ont identifié un répresseur (ICER ou inducible cAMP early repressor) qui présente, comme la mélatonine, un rythme circadien avec une traduction d'ARNm maximale la nuit, qui réprime la transcription induite par l'AMPc. L'action des analogues de l'AMPc, qui est plus efficace durant la période nocturne du cycle circadien, paraît en partie due à l'augmentation de l'influx de $\mathrm{Ca}^{2+}$ durant cette période.

Des travaux récents (D'Souza et Dryer, 1996) ont permis d'identifier un autre mécanisme spécifique, lié à un canal cationique 40-pS, dit Ilot (pour "long open time"). Il a été découvert dans les cellules en culture de glande pinéale de poulet. Il est perméable au $\mathrm{Ca}^{2+}$ et actif la nuit mais pas le jour. L'activité nocturne du canal Ilot n'est pas supprimée par des pulses lumineux brefs. Le courant Ilot n'est pas sensible au voltage ni activé par l'étirement, il présente des ouvertures de longue durée, et ses caractéristiques persistent en configuration d'enregistrement inside-out en l'absence de $\mathrm{Ca}^{2+}$ et de nucléotides cycliques. L'identification et le clonage du gène correspondant permettraient d'approfondir le fonctionnement de l'horloge épiphysaire. 


\subsection{LA MÉLATONINE ET LE VIEILLISSEMENT}

Le chef d'orchestre du vieillissement, au niveau des glandes endocrines, parait être l'épiphyse.

\subsubsection{Sécrétion et rythme sécrétoire de la mélatonine}

La sécrétion de mélatonine par la glande pinéale apparaît pratiquement vers 3 mois dans l'espèce humaine. Lorsqu'elle commence, elle devient circadienne et atteint son niveau nocturne le plus élevé vers l'âge de 1 à 3 ans (fig. 10.6). Durant toute l'enfance, le taux nocturne de la mélatonine s'abaisse progressivement jusqu'à $80 \%$ de cette valeur maximale pour atteindre (fig. 10.7) les niveaux de l'adulte (Waldhauser et coll., 1993). Le taux nocturne de la mélatonine chez l'adulte est de trois à dix fois plus élevé que le taux diurne (Klein, 1979).

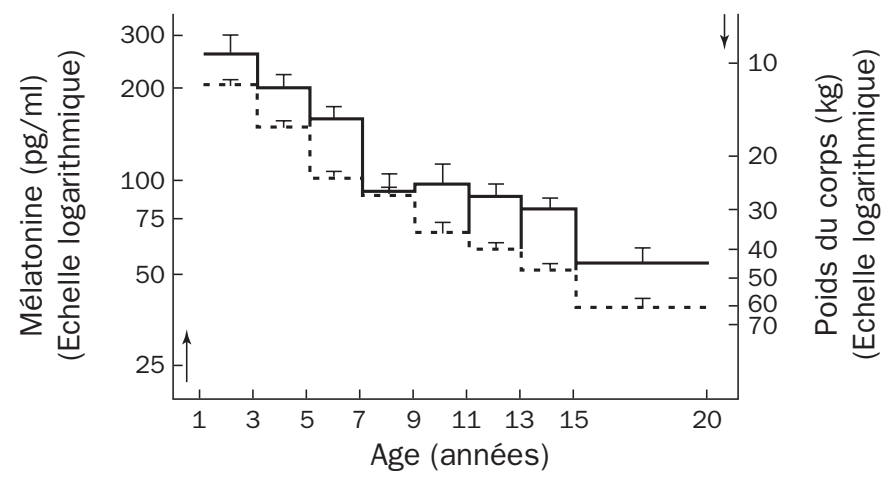

Figure 10.6 - Taux nocturnes de mélatonine sérique (moyenne \pm SEM) et poids du corps de 208 enfants et adolescents (1 à 20 ans), regroupés en fonction de leur âge (d'après Waldhauser et coll., 1993)

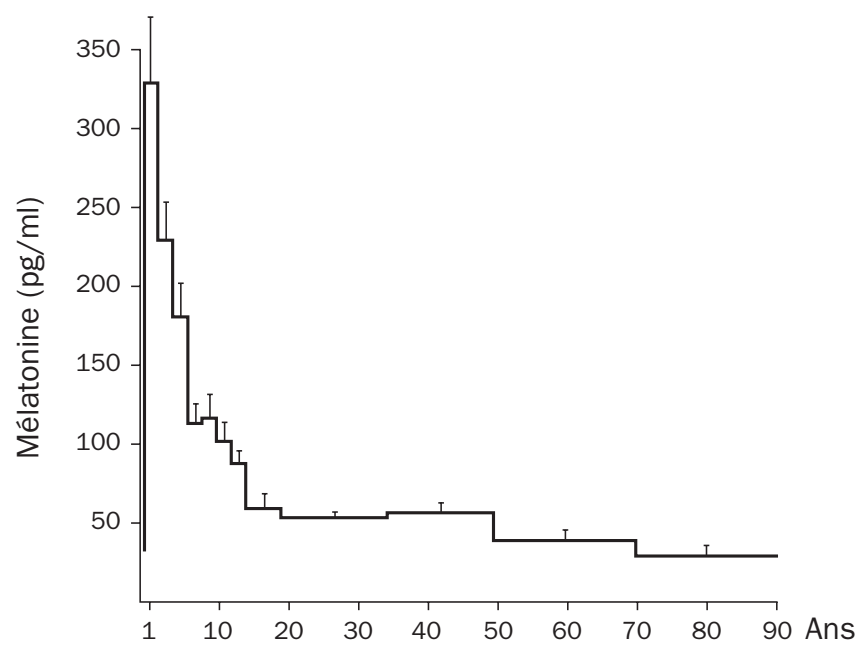

Figure 10.7 - Moyennes ( \pm SEM) des concentrations nocturnes de mélatonine sérique de 367 sujets normaux âgés de $\mathbf{3}$ jours à 90 ans (d'après Waldhauser et coll., 1993) 
Le taux de mélatonine continue de diminuer progressivement avec l'âge, aussi bien chez les animaux que chez l'homme (Reiter, 1995, fig. 10.8).

21-25 ans

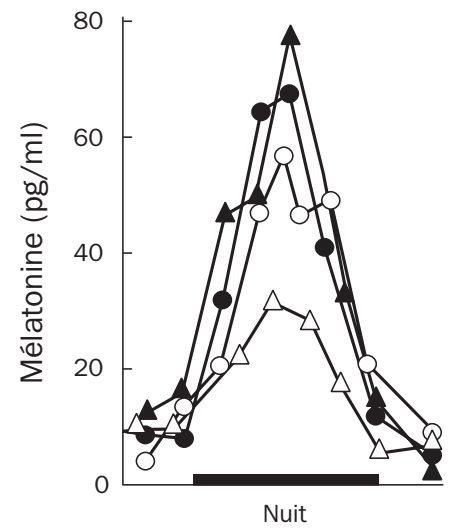

$51-55$ ans

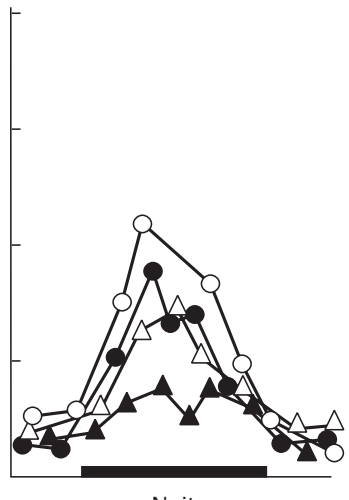

Nuit
$82-86$ ans

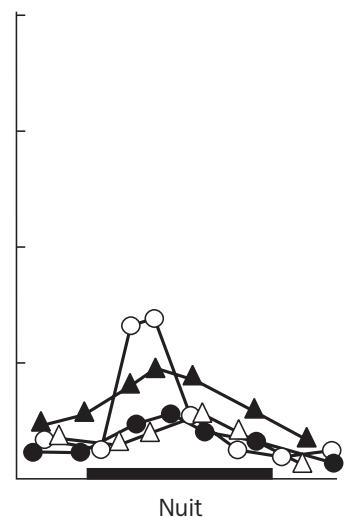

Figure 10.8 - Représentation des taux de mélatonine plasmatique

durant le jour et la nuit chez trois groupes d'âges différents (d'après Reiter, 1995) Les ronds et les triangles représentent quatre individus différents dans chacun des trois groupes.

Pour Asplund et coll. (1995), le taux plasmatique de mélatonine mesuré chez un groupe de 69 volontaires ( 42 hommes et 27 femmes), âgés respectivement de $75,6 \pm 8,8$ ans (SD) et 73,5 $\pm 9,5$ ans, est au plus bas en novembre, il s'élève en février et est le plus élevé en avril, chez les hommes comme chez les femmes. Touitou et coll. (1984) avaient obtenu des résultats similaires, sauf pour le pic sécrétoire qu'ils observaient en juin. Le taux de mélatonine est beaucoup plus bas chez les hommes ou femmes souffrant de la maladie d'Alzheimer (fig. 10.9).

Le rythme circadien de la mélatonine a été étudié chez seize femmes cliniquement en bonne santé, âgées de 66 à 90 ans (Ferrari et coll., 1995). Les auteurs ont observé une diminution sélective de la sécrétion nocturne de la mélatonine. Touitou et coll. (1984) avaient observé des résultats semblables, toutefois la diminution est plus marquée chez les femmes que chez les hommes, sauf pendant la période de juin, et elle est la plus basse pour les patients atteints de la maladie d'Alzheimer.

La périodicité circadienne de la sécrétion de mélatonine (de même que celle de la TSH) a été étudiée chez 22 sujets âgés comparativement à 13 adultes servant de contrôles. Cette périodicité, appréciée par la méthode du Cosinor, est nettement détériorée, et cette détérioration est corrélée avec la disparition des fonctions cognitives, et quantifiée par l'évaluation MMS (Mini Mental State). Ces altérations peuvent être considérées comme des marqueurs du processus de vieillissement (Murialdo et coll., 1993), sans qu'il soit possible de dire si elles sont une cause ou une conséquence de ce processus (Touitou et Haus, 1994). 


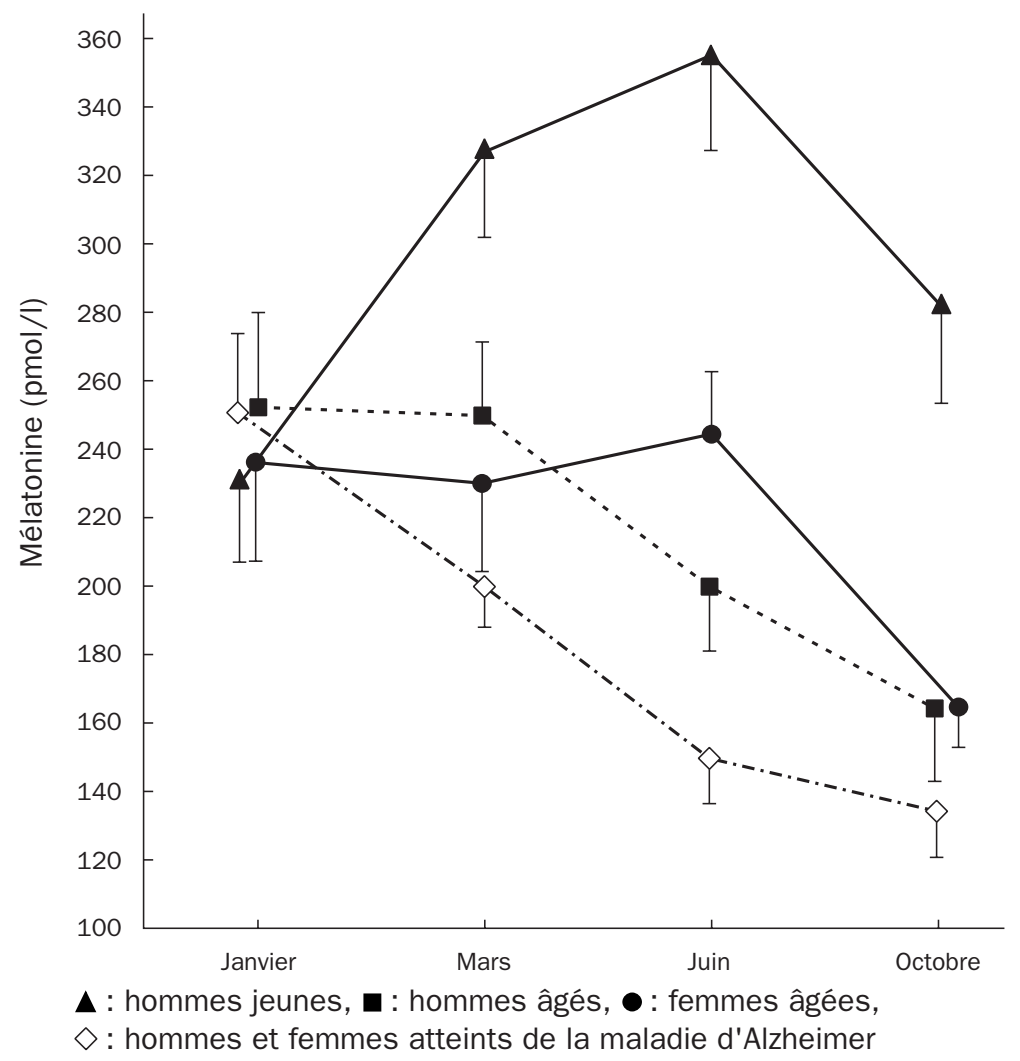

Figure 10.9 - Variations saisonnières de la mélatonine plasmatique (d'après Touitou et coll., 1984)

On peut supposer que la modification du rythme de production de la mélatonine au cours du vieillissement entraîne un affaiblissement et une désynchronisation des autres rythmes circadiens, et que cette perturbation rend les animaux plus sujets aux maladies liées au vieillissement (Reiter, 1995).

Parmi les procédés qui permettent de prolonger la vie chez l'animal, la restriction alimentaire est un des plus efficaces chez le rat. Etudiée sur 344 rats, elle permet une prolongation de vie de près de $30 \%$ (Masoro, 1988). Or cette restriction préserve le rythme de la mélatonine (Stokkan et coll., 1991).

\subsubsection{Actions de la mélatonine}

Un argument plus direct en faveur du rôle de la mélatonine au cours du vieillissement est que la mélatonine est un piégeur puissant des radicaux libres (Reiter, 1994 (1) ; Pierrefiche et Laborit, 1995). En particulier, elle neutralise (Tan et coll., 1993) ce qui est généralement considéré comme le radical libre le plus toxique et le plus agressif produit dans l'organisme : le radical hydroxyle $\left(\mathrm{OH}^{\bullet}\right)$ (fig. 10.10). Elle est cinq fois plus efficace que le glutathion et protège ainsi les principales cibles des radicaux libres que sont les macromolécules et spécialement l'ADN. 
On a pu retrouver des récepteurs intranucléaires de la mélatonine (Acuna-Castroviejo et coll., 1993, 1994) et il est probable que la liaison de la mélatonine, particulièrement abondante dans le noyau (Menendez-Pelaez et coll., 1993), s'effectue à proximité de l'ADN.

$$
\begin{gathered}
\mathrm{O}_{2}+\mathrm{e}^{-} \longrightarrow \mathrm{O}_{2}^{\bullet-} \\
\mathrm{O}_{2}^{\bullet-}+\mathrm{e}^{-}+2 \mathrm{H}^{+} \longrightarrow \mathrm{H}_{2} \mathrm{O}_{2} \\
\mathrm{H}_{2} \mathrm{O}_{2}+\mathrm{e}^{-}+\mathrm{H}^{+} \longrightarrow \mathrm{H}_{2} \mathrm{O}+\mathrm{OH}^{\bullet}
\end{gathered}
$$

Figure $\mathbf{1 0 . 1 0}$ - Formation des radicaux libres $\mathbf{O H}^{\bullet}$ (d'après Reiter, 1995)

Si la dégénérescence anatomique et fonctionnelle que les organes subissent au cours du vieillissement est une conséquence des lésions produites par l'accumulation des radicaux libres, la mélatonine joue alors un rôle significatif dans le processus du vieillissement. Cette action de protection contre l'accumulation des radicaux libres s'explique par plusieurs mécanismes :

- La réduction de la mélatonine au cours du vieillissement entraîne une réduction de l'activité de la guanylate cyclase, donc une diminution du GMPc et une augmentation de l'AMPc (Vacas et coll., 1981 ; Vesely, 1981). En d'autres termes, la mélatonine diminue le rapport GMPc/AMPc.

- La mélatonine stimule l'activité de l'enzyme anti-oxydante qu'est le glutathion peroxidase, réduisant également par ce biais les lésions dues aux radicaux libres. Ces actions protègent tout spécialement le système nerveux central, dont on connaît la vulnérabilité à l'agression par les radicaux libres, l'incapacité à se régénérer et le rôle joué par sa dégradation dans le vieillissement.

- Mais la mélatonine agit également au niveau du compartiment membranaire puisqu'elle réduit in vivo la peroxydation des lipides (Pierrefiche et coll., 1993) qui serait, comme les lésions de l'ADN, un facteur important du vieillissement ( $\mathrm{Yu}$, 1993). L'activité anti-oxydante de la mélatonine au niveau des membranes est confirmée par son action stimulante de la pompe calcique dans les membranes cardiaques de rat traité par l'alloxane, composé générateur de radicaux libres (Chen et coll., 1994).

\subsubsection{L'expérimentation animale}

De nombreuses autres expériences faites chez l'animal corroborent ces données :

- L'addition de mélatonine à l'eau de boisson accroît la durée de vie de la souris qui s'allonge de $752 \pm 80$ à $931 \pm 80$ jours (Maestroni et coll., 1989). En reprenant l'administration nocturne de mélatonine ou en pratiquant la greffe de glande pinéale, Pierpaoli et Regelson (1994) confirment qu'elles prolongent la vie (fig. 10.11) et démontrent qu'elles préservent la fonction de l'immunité cellulaire.

- Chez le rat, l'induction de cataracte (qui serait due à l'attaque des macromolécules du cristallin par les radicaux libres) par une réduction de son taux de glutathion, est prévenue par l'injection quotidienne de mélatonine (Reiter et coll., 1995). 


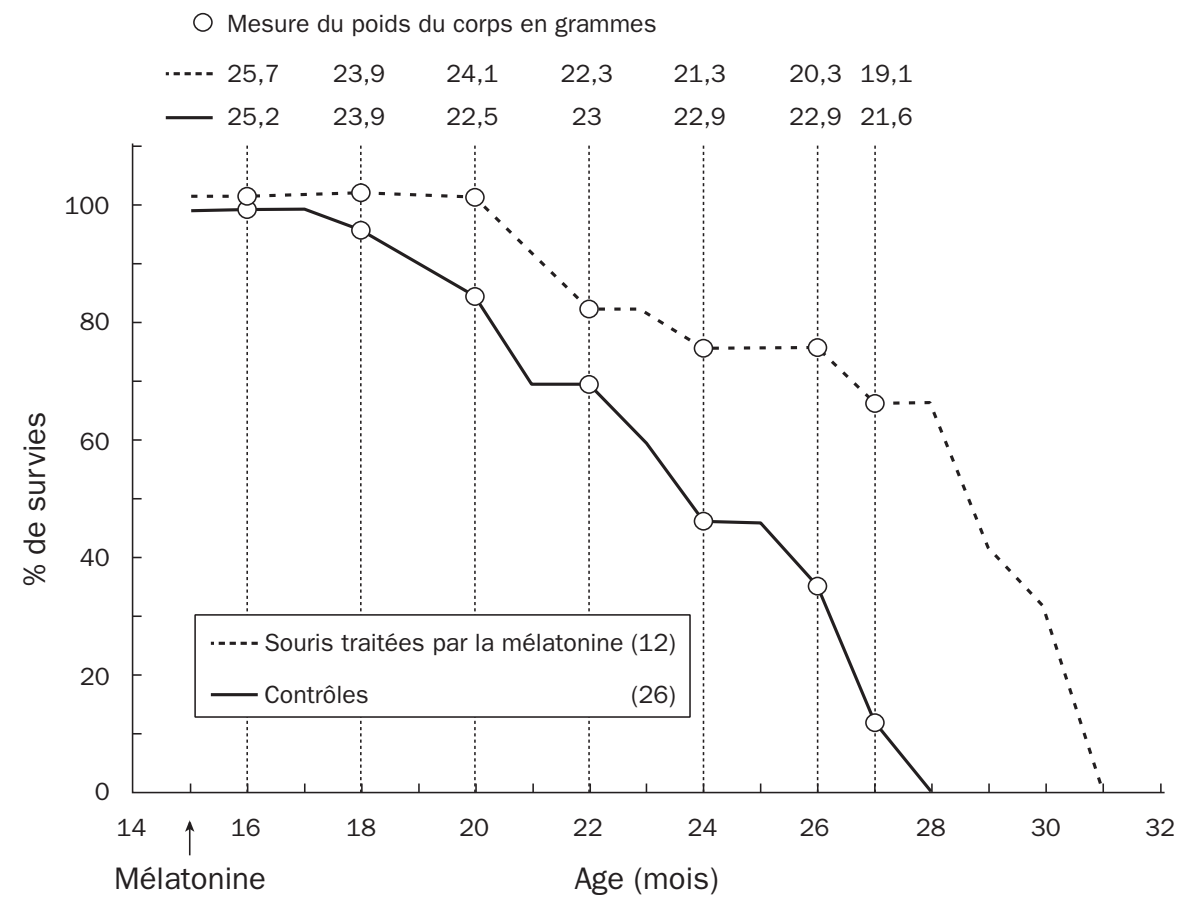

Figure 10.11 - Survie de la souris après addition nocturne d'eau de boisson ou d'eau additionnée de mélatonine (d'après Pierpaoli et Regelson, 1994)

- L'administration nocturne de mélatonine dans l'eau de boisson $(0,4 \mathrm{mg} / \mathrm{ml})$ à des rats entre l'âge de 14 et l'âge de 24 mois retarde l'augmentation du taux de la LH sérique et la diminution de la réponse de la $\mathrm{LH}$ à la GnRH chez les rats de 16, 18 et 20 mois (Trentini et coll., 1992). Le traitement par la mélatonine empêche la perte de la réponse de LH à la naloxone (un antagoniste des opiacés, voir chap. 4, $\S$ 8.4) qui apparaît chez les contrôles entre 16 et 20 mois. On peut donc supposer que la diminution nocturne de la sécrétion de mélatonine au cours du vieillissement implique la participation des substances opiö̈des du système nerveux central.

- La mélatonine joue également un rôle de modulateur de la réponse immune. Le rythme circadien de la prolifération lymphocytaire, dont le pic a lieu à 22 h, est, chez le rat, supprimé par la pinéalectomie. L'administration de mélatonine stimule la prolifération lymphocytaire (Ding et coll., 1995).

\subsection{AUTRES ACTIONS DE LA MÉLATONINE}

\subsubsection{Mélatonine et effets pigmentaires}

Il est connu depuis le début du siècle que la glande pinéale, réduite en poudre et injectée, éclaircit la peau des Batraciens. En effet, chez les Vertébrés inférieurs et, en particulier chez les Batraciens, la mélatonine, au niveau des mélanocytes, inhibe la synthèse de la mélanine (pigment noir) et la translocation dans le mélanocyte des 
granules qui contiennent le pigment, les mélanosomes. Si, chez les Amphibiens, la mélatonine exerce un puissant effet sur la rétraction des mélanophores, chez l'homme, outre son rôle dans le contrôle de l'activité rythmique, elle exerce de multiples actions.

\subsubsection{Mélatonine et système nerveux central}

On comprend que la mélatonine exerce de nombreuses actions sur le système nerveux central. Elle a une influence stabilisante sur l'activité électrique du cerveau (Brailowsky, 1976), accroît la survenue des ondes alpha, manifeste une action sédative, diminue les symptômes du décalage horaire provoqué par le franchissement des fuseaux (jet-lag). Ses effets sur le sommeil sont multiples : raccourcissement de l'endormissement, prolongation des stades de sommeil profond, amélioration de l'efficacité du sommeil. Dans l'espèce humaine, la pratique régulière de la méditation augmente les taux de mélatonine ; cette augmentation a été observée chez huit femmes qui méditaient, comparativement à huit femmes qui ne méditaient pas. La sécrétion de mélatonine serait donc non seulement photosensible, mais aussi psychosensible (Massion et coll., 1995). La différence observée n'est peut-être due qu'à l'occlusion des yeux pendant la durée de la méditation.

\subsubsection{Mélatonine et stress}

Le stress physique (exercice sur une bicyclette) entre $22 \mathrm{~h} 40$ et $23 \mathrm{~h}$ provoque une réduction de l'ascension habituelle du taux de la mélatonine plasmatique. Cette réduction est précédée de l'élévation du cortisol, qui pourrait être corrélée à cette modification de la sécrétion de mélatonine (Monteleone et coll., 1992).

\subsubsection{Mélatonine et troubles psychiques}

Des arguments théoriques permettent de penser à un rôle de l'épiphyse dans deux syndromes psychiatriques (Waldhauser et coll., 1993), le syndrome dépressif majeur $(\mathrm{SDM})$ et le "désordre affectif saisonnier" (DAS). C'est la raison pour laquelle la mélatonine a été essayée comme traitement de ces deux syndromes et, bien qu'on n'ait pu observer d'anomalie du taux de la mélatonine dans ces deux pathologies, le traitement paraît efficace pour le DAS, et peut être intéressant pour le SDM. En revanche, on sait qu'il y a une baisse des taux de mélatonine dans la schizophrénie.

\subsubsection{Mélatonine et maladies cardio-vasculaires}

La mélatonine inhiberait l'agrégation plaquettaire et la libération de thromboxane (Leach et Thorburn, 1980). Ces données et d'autres (en particulier son pouvoir antioxydant) suggèrent que la mélatonine exerce un effet favorable sur la maladie coronarienne.

\subsubsection{Mélatonine : une hormone oncostatique}

La mélatonine apparaît comme un puissant inhibiteur de la croissance cancéreuse. Cela a été observé sur des souches cellulaires de cancer du sein humain (MCF-7), à 
des concentrations physiologiques de l'ordre de $10^{-9} \mathrm{M}$. Cette action est surtout efficace en administration nocturne (Blask et coll., 1991). Le traitement par la mélatonine chez des patients cancéreux stimule également les cellules NK (natural killers), et inhibe l'immunosuppression induite par le stress (Maestroni et coll., 1989 ; Pierpaoli et Maestroni, 1987). Ce dernier effet est probablement médié par le système opioïde endogène car la naltrexone, un antagoniste opioïde, supprime chez la souris les effets immunostimulants de la mélatonine. Enfin, on a découvert dans les lymphocytes des sites de liaison avec la mélatonine qui peuvent expliquer l'action de cette hormone sur les cellules immunocompétentes (Martin-Cacao et coll., 1993). Une revue générale sur ce chapitre pourra être trouvée dans Grad et Rozencwaig (1993).

\subsubsection{Mélatonine : un contraceptif oral}

On a observé que la sécrétion de LH chutait chez les femmes à qui l'on avait donné de la mélatonine en même temps qu'un progestatif synthétique, à des fins de contraception (Voordouw et coll., 1992). L'association avec la norethistérone avait même un effet synergique (Cohen et coll., 1993).

L'avantage de la mélatonine par rapport aux œstrogènes est l'absence d'effet nuisible sur les vaisseaux, et une action protectrice à l'égard du risque de cancer du sein. L'inhibition de l'axe hypothalamo-hypophyso-ovarien procède sans doute de plusieurs mécanismes : altération du rythme pulsatile de la sécrétion de GnRH hypothalamique, action sur la synthèse et/ou la libération de LH hypophysaire, et/ou un effet direct sur l'ovaire (Webb et Puig-Domingo, 1995).

\subsubsection{Mélatonine et mort subite du nourrisson}

Le syndrome de la mort subite du nourisson pourrait être dû à une maturation imparfaite du système photo-neuro-endocrine, causée par l'absence ou la mutation du gène de l'enzyme qui contrôle la biosynthèse de la mélatonine, la $\mathrm{N}$-acétyltransférase (Weissbluth et Weissbluth, 1994). Cette maturation incomplète s'accompagne de troubles du sommeil nocturne et d'épisodes d'apnée, et pourrait causer la mort du nourrisson par des effets neurotoxiques et cardiomyotoxiques dus à des taux anormalement élevés de catécholamines et d'ions calcium intracellulaires.

\subsubsection{Effets des champs magnétiques sur la mélatonine}

Le rythme sécrétoire de la mélatonine pourrait être influencé non seulement par les radiations lumineuses, mais aussi par les longueurs d'onde dans l'ultraviolet, ainsi que par les champs électriques et magnétiques de basse fréquence (Olcese, 1990).

L'atténuation du rythme circadien de la mélatonine par un champ magnétique a été démontrée chez le rat adulte par Wilson et coll., en 1989. Il est dès lors permis de se demander si les expositions à des champs magnétiques (usine, proximité de lignes à haute tension) ne risquent pas de provoquer une perturbation du rythme de production de la mélatonine, avec toutes ses conséquences. Toutefois, d'autres expériences chez 
le rat de 22 mois, soumis pendant 25 jours à un champ magnétique statique émis par des micro-aimants implantés dans le cerveau occipital, provoquent au contraire une augmentation de la réponse immunitaire humorale et suppriment l'immunodéficience provoquée par une pinéalectomie (Jankovic et coll., 1994).

\section{LES RÉCEPTEURS DE LA MÉLATONINE}

Pendant longtemps, la nature des récepteurs qui expriment la multiplicité des effets de la mélatonine a été mal connue. D'autant que la mélatonine, lipophile, peut pénétrer à l'intérieur des cellules et se lier à la fois à des cibles extracellulaires et intracellulaires.

Un récepteur à la mélatonine (R-Mt1), avec une affinité picomolaire, a finalement pu être identifié chez Xenopus laevis. Il appartient à la superfamille des récepteurs à sept domaines transmembranaires (7-TM) couplés à une protéine G, avec une séquence de 420 AA (Hagan et Oakley, 1995). Toutefois, un autre site récepteur, nommé R-Mt2, a pu être identifié. Il présente une affinité nanomolaire avec la mélatonine, mais il apparaît plus spécifique de la prazosine et du N-acétyl 5-HT. Enfin, il est apparu que la mélatonine peut interagir avec des cibles intracellulaires. Elle se comporte comme un antagoniste $\mathrm{Ca}^{2+}$-calmoduline, et jouerait son rôle protecteur contre les radicaux libres en se liant avec des protéines nucléaires ou avec l'ADN (Reiter et coll., 1994 ; Acuna-Costroviejo et coll., 1994). Une protéine nucléaire appelée RZRg, qui se lie avec une affinité nanomolaire pour la mélatonine (Carlberg et coll., 1994), pourrait être la cible nucléaire de la mélatonine (fig. 10.12).

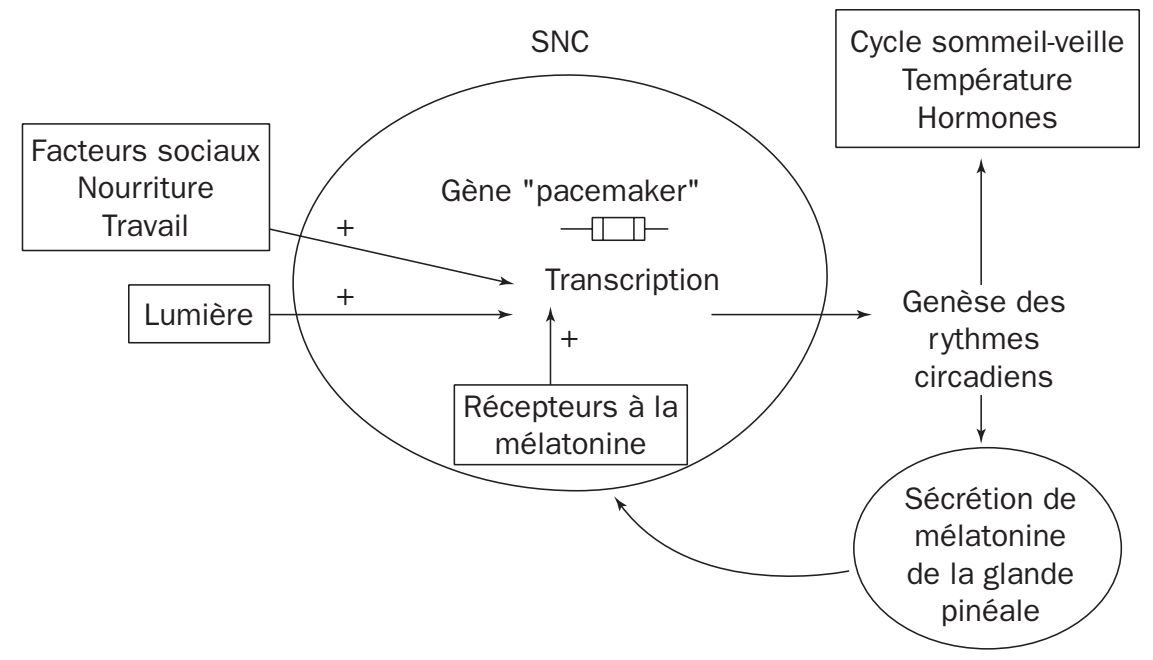

Figure 10.12 - Interaction de la mélatonine et des rythmes circadiens au niveau moléculaire (d'après Hagan et Oakley, 1995)

La structure et la fonction des récepteurs de la mélatonine ont été détaillées par Jockers et coll. (1998) et Vanecek (1998). 



\section{RÉFÉRENCES BIBLIOGRAPHIQUES DE LA DEUXIÈME PARTIE}

\section{LE COMPLEXE HYPOTHALAMO-HYPOPHYSAIRE}

ALEXINSKY T. \& CHAPOUTHIER G., A new behavioral model for studying delayed response in rats, Behav. Biol., 24, 442-456, 1978.

ALLIOT J., NAUTON P. \& BRUHAT M.A., Administration of LHRH analog can improve working memory in aged female rats, Psychoneuroendocrino., 18, 543-550, 1993.

ASSENMACHER I., Recherches sur le contrôle hypothalamique de la fonction gonadotrope pré-hypophysaire chez le Canard, Arch. anat. micr. Morphol. exp., 47, 447-572, 1958.

ASSENMACHER I. \& BOISSIN J., Rythmes circannuels et circadiens du fonctionnement corticosurrénalien et thyroïdien en relation avec le réflexe photosexuel, in "Neuroendocrinologie", n927, Colloques Nat., CNRS, 1969.

ASSENMACHER I. \& coll., Physiology of neural pathways affecting CRH secretion, Annals N. Y. Acad. Sci., 512, 149-161, 1987.

BABA Y., MATSUO H. \& SCHALLY A.V., II. Structure of the porcine LH and FSH releasing hormone, Biochem. Biophys. Res. Comm., 44, 459-463, 1971.

BARNEA A. \& coll., Uptake of androgens by the brain of the neonatal female rat, Brain Res., 46, 391-402, 1972.

BARRY J. \& coll., Caractérisation et topographie des neurones hypothalamiques immunoréactifs avec des anticorps anti-LRF de synthèse, CR Acad. Sci., 276, 3191-3193, 1973.

BAXTER R.C. \& coll., Pulsatility of immunoreactive somatomedin-C in chronically canulated rats, Endocrinology, 113, 729-734, 1983.

BELLISARIO R. \& coll., Human chorionic gonadotropin linear amino acid sequence of the $\alpha$-subunit, J. Biol. Chem., 248, 6796-6809, 1973.

BENOIT E. \& coll., Histoires d'aquaporines : des canaux qui font couler beaucoup d'eau, Médecine/Sciences, 12, 787-794, 1996.

BENOIT J., Hypothalamo-hypophyseal control of the sexual activity in birds, Gen. Comp. Endocrinol., suppl. 1, 254-274, 1962.

BERSON S.A. \& YALOW R.S., Some current controversies in diabetes research, Diabetes, 14, 549-572, 1965.

BERTAGNA X. \& GIRARD F., Les hormones hypophysaires cortico-lipotropes et les endorphines, Enc. Méd. Chir., 10017 N10, 1-8, 1979. 
BICKNELL R.J. \& LENG G., Endogenous opiates regulate oxytocin but not vasopressin secretion from the neurohypophysis, Nature (London), 298, 161-162, 1982.

BINART N., Le récepteur de la prolactine, une molécule-clé de la reproduction?, Médecine/Sciences, 13, 734-736, 1997.

BLALOCK J.E., The immune system as a sensory organ, J. Immunol., 132, 1067-1070, 1984.

BLOOM F., Les neuropeptides, Pour la Science, 50, 50-63, 1981.

BRAZEAU P. \& coll., Hypothalamic polypeptide that inhibits the secretion of immunoreactive pituitary growth hormone, Science, 179, 77-79, 1973.

BREMMER W.J., VITIELLO M.V. \& PRINZ P.N., Loss of circadian rhythmicity in blood testosterone levels with aging in normal men, J. Clin. Endocr. Metab., 56, 1278-1281, 1983.

BROWNSTEIN M.J., Biosynthesis of vasopressin and oxytocin, Annu. Rev. Physiol., 45, 129-135, 1983.

BROWNSTEIN M.J. \& coll., Synthesis, transport and release of posterior pituitary hormones, Science, 207, 373, 1980.

BURGUS R. \& coll., Structure moléculaire du facteur hypothalamique hypophysiotrope TRF d'origine ovine : mise en évidence par spectrométrie de masse de la séquence PCA-Hist-Pro-NH 2 , CR Acad. Sci., 269, 1870-1873, 1969.

BUVAT J. \& BUVAT-HERBAUT M., L'actualité en gynécologie et en obstétrique, Sandoz, Rueil-Malmaison, 1982.

CARLSEN R.B. \& coll., Human chorionic gonadotropin linear amino acid sequence of the $\alpha$-subunit, J. Biol. Chem., 248, 6810-6827, 1973.

CARTER-SU C., SCHWARTZ J. \& SMIT L.S., Molecular mechanism of growth hormone action, Annu. Rev. Physiol., 58, 187-207, 1996.

COIRO V., VOLPI R., MARCHESI C., FERRI A. (de), DAVOLI C., CAFFARA P., ROSSI G., CAFFARI G., DAVOLIO M. \& CHIODERA P., Abnormal serotonergic control of prolactin and cortisol secretion in patients with seasonal affective disorder, Psychoneuroendocrino., 18, 551-556, 1993.

COLBY H.D., CAFFREY J.L. \& KITAY J.I., Interaction of growth hormone and ACTH in the regulation of adrenocortical secretion in rat, Endocrinology, 93, 188-192, 1973.

COMBARNOUS V., Structure et relations structure-activité des hormones folliculostimulantes-recombinantes humaines, Médecine/Sciences, 15, 167-174, 1999.

CONN P.M \& coll., The molecular mechanism of action of gonadotropin releasing hormone (GnRH) in the pituitary, Annu. Rev. Physiol., 48, 495-513, 1986.

CORBIER P., KERDELHUE B., PICON P. \& ROFFI J., Changes in testicular weight and serum gonadotropins and testosterone levels before, during and after birth in the perinatal rat, Endocrinology, 103, 1985-1991, 1978.

CORBIER P., PICON R. \& ROFFI J., Elévation de la testostéronémie chez le rat nouveau-né, CR Acad. Sci., 285, 1247-1249, 1977.

CORBIER P., RHODA J., KERDELHUE B. \& ROFFI J., Recherches sur la crise testiculaire du rat nouveau-né, Pathol. Biol., 29, 365-366, 1981. 
DESIR D. \& coll., Nycthemeral profiles of plasma prolactin after jet lag in normal man, Prog. Reprod. Biol., 6, 61-65, 1980.

DESIR D., VANCAUTER E., L'HERMITTE M., REFETOFF S., JADOT C., CAUFRIEZ A., COPINSHI G. \& ROBYN C., Effects of jet lag on hormonal patterns. III. Demonstration of an intrinsic circadian rhythmicity in plasma prolactin, J. Clin. Endocr. Metab., 55, 849-857, 1982.

DOCHERTY K. \& STEINER D.F., Post-translational proteolysis in polypeptide hormone biosynthesis, Annu. Rev. Physiol., 44, 625-638, 1982.

DOUGLAS W.W., Aspect of the calcium hypothesis of stimulus-secretion coupling : electrical activity in adenohypophyseal cells, and membrane retrieval, after exocytosis, Methods in Cell Biology, 23, 483-501, 1981.

DREIFUSS J.J., Mécanismes de sécrétion des hormones neuro-hypophysaires. Aspects cellulaires et subcellulaires, J. Physiol. (Paris), 67, 5A-54A, 1973.

DUBOIS M.P., Immunoreactive somatostatin is present in discrete cells of the endocrine pancreas, Proc. Natl. Acad. Sci. (USA), 72, 1340-1343, 1975.

DUFY B. \& coll., Electrophysiological study of prolactin-secreting pituitary cells in culture, Prog. Reprod. Biol., 6, 31-43, 1980.

DUFY-B ARBE L., Les hormones de l'hypothalamus, la Recherche, 160, 1352-1360, 1984.

DUNCAN J.A. \& coll., Regulation of pituitary gonadotropin-releasing hormone $(\mathrm{GnRH})$ receptors by pulsatile GnRH in female rats : effects of estradiol and prolactin, Endocrinology, 118, 320-327, 1986.

EPELBAUM J., PELLEGRINI E., KORDON C. \& BLUET-PAJOT M.T., Nouvelles données dans la régulation centrale de la pulsatilité de la sécrétion d'hormone de croissance: l'hormone elle-même donne le signal, Médecine/Sciences, 13, 387-389, 1997.

ESCH F. \& coll., Isolation and characterization of the bovine hypothalamic corticotropin-releasing factor, Biochem. Bioph. Res. Co., 122, 899-905, 1984.

EWING L.L. \& ZIRKIN B., Leydig cell structure and steroidogenic function, Rec. Progr. Horm. Res., 39, 599-636, 1983.

FOREST M.G. \& coll., Hypophyso-gonadal function in humans during the first year of life. I. Evidence for testicular activity in early infancy, J. Clin. Invest., 53, 819-828, 1974.

FOSSATI P. \& ASFOUR M., L’hormone somatotrope, Enc. Méd. Chir., 10017 K ${ }^{10}$, 1979.

GAVER O., Contrôle neuro-endocrinien du volume plasmatique, J. Physiol. (Paris), 76, 373-379, 1980.

GERSHENGORN M.C., Inositol triphosphate mediates thyrotropin-releasing hormone mobilization of nonmitochondrial calcium in rat mammotropic pituitary cells, J. Biol. Chem., 259, 10675-10681, 1984.

GERSHENGORN M.C., Thyrotropin-releasing hormone action : mechanism of calcium-mediated stimulation of prolactin secretion, Rec. Progr. Horm. Res., 41, 607-653, 1985.

GORSKI R.A., Localization and sexual differentiation of the nervous structures which regulate ovulation, J. Reprod. Fertil., suppl. 1, 67-88, 1960. 
GORSKI R.A. \& coll., Evidence for a morphological sex difference within the medial preoptic area of the rat brain, Brain Res., 148, 333-346, 1978.

GREEN J.D. \& HARRIS G.W., The neurovascular link between the neurohypophysis and adenohypophysis, J. Endocrinol., 5, 136-146, 1947.

GUILLEMIN R. \& coll., Thyroid stimulating hormone releasing factor (TRF).4. Regulation of secretion, Methods Invest. Diagn. Endocrinol., 217, 493-498, 1973.

GUILLEMIN R., Peptides in the brain : the neuroendocrinology of the neuron, Science, 4366, 390-402, 1978.

GUILLEMIN R. \& coll., Somatocrinin, the growth hormone releasing factor, Rec. Progr. Horm. Res., 40, 233-299, 1984.

HALL P.F., Trophic stimulation of steroidogenesis : in search of the elusive trigger, Rec. Progr. Horm. Res., 41, 1-31, 1985.

HARRIS G.W., Neural control of the pituitary gland, Arnold, London, 1955.

HARRIS G.W., Hormonal differentiation of the developing central nervous system with respect to patterns of endocrin function, Phil. Trans. Roy. Soc. (London), B, 259, 165-177, 1970.

HODGES J.K., Regulation of œstrogen-induced LH release in male and female marmoset monkeys Callithrix jucchus, J. Reprod. Fertil., 60, 389-398, 1980.

HÖKFELT T. \& coll., Neurons with multiple messengers with special reference to neuroendocrine systems, Rec. Progr. Horm. Res., 42, 70, 1986.

ISAKSSON O.G.P., EDEN S. \& JANSSON J.O., Mode of action of pituitary growth hormone on target cells, Annu. Rev. Physiol., 47, 483-499, 1985.

JARD S., Les isorécepteurs de la vasopressine dans le foie et dans le rein : relation entre fixation d'hormone et réponse biologique, J. Physiol. (Paris), 77, 621-628, 1981.

JORDAN D. \& coll., Participation of serotonin in thyrotropin release. II. Evidence for the action of serotonin on the phasic release of thyrotropin, Endocrinology, 105, 975-979, 1979.

KALIN N., A pragmatist's vision for psychoneuroendocrinology, Psychoneuroendocrino., 18, 89-90, 1993.

KELLY D.D., Sexual differentiation of the nervous system, in "Principles of Neural Science", Kandel E.R. \& Schwartz J.H. eds, 771-783, Elsevier, Amsterdam, 1985.

KELLY P.A. \& coll., The interaction of prolactin with its receptors in target tissues and its mechanism of action, Rec. Progr. Horm. Res., 40, 379-439, 1984.

KNOBIL E., The neuroendocrine control of the menstrual cycle, Rec. Progr. Horm. Res., 36, 53-88, 1980.

LEBRUN J.J. \& KELLY P.A., Les mécanismes de la transduction du signal par le récepteur de la prolactine, Médecine/Sciences, 10, 1018-1020, 1994.

LE CAM A. \& LEGRAVEREND C., Mode d'action de l'hormone de croissance, Médecine/Sciences, 9, 1352-1361, 1993.

LEFKOWITZ R.J., Turned on to ill effect, Nature, 365, 603-604, 1993.

LEONG D.A., FRANLEY L.S. \& NEILL J.D., Neuroendocrine control of prolactin secretion, Annu. Rev. Physiol., 45, 109-127, 1983. 
LI C. \& coll., Human pituitary growth hormone. XIX. The primary structure of the hormone, Arch. Biochem. Biophys., 133, 70-91, 1969.

LINCOLN D.W. \& coll., Hypothalamic pulse generators, Rec. Progr. Horm. Res., 41, 369-419, 1985.

LUPIEN S. \& FORGET H., Glucocorticoïdes et cognition, Médecine/Sciences, 11, 1524-1530, 1995.

MAINS R.E., EIPPER B.A. \& LING N., Common precursor to corticotropins and endorphins, Proc. Natl. Acad. Sci., 74, 3014-3018, 1977.

MATHESON G.K., Effects of GABA agonists and antagonists on ACTH release, Brain. Res. Bull., 5, suppl. 2, 447-452, 1980.

MATSUO H. \& coll., Structure of the porcine LH and FSH-releasing hormone. I. The proposed amino acid sequence, Biochem. Biophys. Res. Comm., 43, 1334-1339, 1971.

MILLER A.E. \& REAGLE G., Temporal patterns of serum luteinizing hormone releasing hormone in ageing male rats, J. Gerontol., 37, 522-528, 1982.

MINEGISH T., NAKAMURA K., TAKAKURA Y. \& coll., Cloning and sequencing of human LH.hCG receptor cDNA, Biochem. Biophys. Res. Comm., 172, 1049-1054, 1990.

MINEGISH T., NAKAMURA K., TAKAKURA Y. \& coll., Cloning and sequencing of human FSH receptor cDNA, Biochem. Biophys. Res. Comm., 175, 1125-1130, 1991.

MISRAHI M. \& coll., Les récepteurs des hormones glycoprotéiques hypophysaires, Ann. Endocrinol. (Paris), 56, 487-493, 1995.

MONNIER M. \& DESBALS B., Dosage radioimmunologique de l'ACTH plasmatique chez le lapin : relations stress-ACTH-corticostéroïdes et diarrhées, Reprod. Nutr. Dev., 25, 1017-1028, 1985.

MONOD G., L'hormone de la monogamie, J. Invest. Med., 290, 11, 1993.

MORLEY J.E., Neuro-endocrine effects of endogenous opioid peptides in human subjects : a review, Psychoneuroendocrino., 8, 361-379, 1983.

MURRI L., BARRECA T., CERONE G., MASSETANI R., GALAMINI A. \& BALDASSARE M., The 24h pattern of human prolactin and growth hormone in healthy elderly subjects, Chronobiologia, 7, 87-92, 1981.

NAKANISHI S. \& coll., Nucleotide sequence of cloned cDNA for bovine corticotropin- $\beta$ lipotropin precursor, Nature, 278, 423-427, 1979.

NIS HIMORI K., Y OUNG L.J., GUO Q., W A N G Z., INSEL T.R. \& MATSUK M.M., Oxytocin is required for nursing but is not essential for parturition or reproductive behavior, Proc. Natl. Acad. Sci. (USA), 93, 11699$11704,1996$.

PARMA J., DUPREZ L., SANDE J. (Van) \& coll., Somatic mutations in the thyrotropin receptor gene cause hyperfunctioning thyroid adenomas, Nature, 365, 649-651, 1993.

PERLEMUTER L. \& HAZARD J., Diabète insipide de l'adulte, Presse médicale, 79, 2445-2450, 1971.

PFEIFFER C.A., Sexual differences of the hypophyses and their determination by the gonads, Am. J. Anat., 58, 195-225, 1936. 
PHILIPS S.M. \& SHERWIN B.B., Effects of estrogen on memory function in surgically menopausal women, Psychoneuroendocrino., 17, 485-495, 1992.

POPA G.T. \& FIELDING N., A portal circulation from the pituitary to the hypothalamic region, J. Anat. (London), 65, 88-91, 1931.

PORTER J.C. \& coll., Hypothalamic peptide and catecholamine secretion : roles of portal and retrograde flow in the pituitary stalk in the release of hypothalamic dopamine and pituitary prolactine and LH, Clin. Obstet. Gynecol., 5, 271-282, 1978.

POULAIN D.A. \& WAKERLEY J.B., Electrophysiology of hypothalamic magnocellular neurones secreting ocytocin and vasopressin, Neuroscience, 7, 773-808, 1982.

RIVIER C.L. \& PLOTSKY P.M., Mediation by corticotropin releasing factor (CRF) of adenohypophysial hormone secretion, Annu. Rev. Physiol., 48, 475-494, 1986.

ROSS R.J.M. \& coll., Treatment of growth-hormone deficiency with growthhormone-releasing hormone, Lancet, $1: 8523,5-8,1987$.

SASSIN J., FRANTZ A.G., WEITZMAN A.G. \& KAPEN S., Human prolactin : 24h pattern with increase release during sleep, Science, 177, 1205-1207, 1972.

SCAPAGNINI U., Relation of brain 5-hydroxytryptamine content to the diurnal variation in plasma corticosterone in the rat, Neuroendocrinology, 7, 90-96, 1971.

SCHALLY A.V. \& coll., Isolation and structure of somatostatin from porcine hypothalami, Biochemistry, 15, 509-514, 1976.

SCHARRER E., Die Lichtempfindlichkeit Blinder Eritzen. I. Untersuchungen über das Zwischenturn der Fische, Z. vergl. Physiol., 7, 1-38, 1928.

SCHIMMER B.P., Cyclic nucleotides in hormonal regulation of adrenocortical function, Adv. Cyclic Nucleotides Res., 13, 181-214, 1980.

SCHMALE H. \& RICHTER D., Single base deletion in the vasopressin gene is the cause of diabetes insipidus in Brattleboro rats, Nature, 308, 705-709, 1984.

SEEBURG P.H. \& ADELMAN J.P., Characterization of cDNA for precursor of human luteinizing hormone releasing hormone, Nature, 311, 666-668, 1984.

SIMON D., Les somatomédines : leur structure, leur rôle, leur régulation, Enc. Méd. Chir., 10017 KID, 1982.

SIMPKINS J.W., KALRA P.S. \& KALRA S.P., Alterations in daily rhythms of testosterone and progesterone in old male rats, Exp. Aging Res., 7, 25-32, 1981.

SIMPSON E.R. \& WATERMAN M.R., Regulation of the synthesis of steroidogenic enzymes in adrenocortical cells by ACTH, Annu. Rev. Physiol., 50, 427-440, 1988.

SPIESS J., RIVIER J. \& VALE W., Primary structure of corticotropin-releasing factor from ovine hypothalamus, Proc. Natl. Acad. Sci. (USA), 78, 6517-6521, 1981.

SPRENGEL R., BRAUN T., NIKOLICS K. \& coll., The testicular receptor for follicle stimulating hormone : structure and functional/expression of cloned cDNA, Mol. Endocrinol., 4, 525-530, 1990. 
TANNENBAUM G.S. \& MARTIN J.B., Evidence for an endogenous ultradian rhythm governing growth hormone secretion in the rat, Endocrinology, 98, 562-570, 1976.

THORNER M.O. \& coll., Physiological and clinical studies of GRF and GH, Rec. Progr. Horm. Res., 42, 589-640, 1986.

TOUITOU Y., FEVRE M., LAGOGUEY M., CARAYON A., BOGDAN A., REIBERG A., BECK H., CESSELIN F. \& TOUITOU C., Age and mental health-related circadian rhythm of plasma levels of melatonin, prolactin, luteinizing hormone and follicle-stimulating hormone in man, J. Endocrinol., 91, 467-475, 1981.

TOUITOU Y., LAGOGUEY M., BOGDAN A., REINBERG A. \& BECK H., Seasonal rhythms of plasma gonadotrophins : their persistence in elderly men and women, J. Endocrinol., 96, 15-21, 1983b.

TOUITOU Y. \& HAUS E., Aging of the human endocrine and neuroendocrine time structure, Ann. N.Y. Acad. Sci., 719, 378-397, 1994.

VALCKI J.C. \& coll., Critères d'interprétation du test utilisant l'hormone de libération de la lutéostimuline (LH-RH), Ann. Endocrinol. (Paris), 35, 423-443, 1974.

VALE W. \& coll., Chemical and biological characterization of corticotropin releasing factor, Rec. Progr. Horm. Res., 39, 245-270, 1983.

VINCENT J.D., Régulation hypothalamique de la balance hydrique, La Nouvelle Pr. Med., 2, 2805-2810, 1973.

YALOW R.S. \& BERSON S.A., Immunoassay of endogenous plasma insulin in man, J. Clin. Invest., 39, 1157-1175, 1960.

\section{LA GLANDE THYROÏDE}

ADAMS D.D. \& PURVE H.D., Abnormal responses in the assay of thyrotropin, Proc. Univ. Otago Med. School, 34, 11, 1956.

BACHELOT I., L'exploration fonctionnelle des hyperthyroïdies, Rev. méd. d'act. fr., 1, 717-723, 1972.

BAULIEU E. \& coll., Glandes endocrines, Flammarion, Paris, 1990.

CLAMAN H.N. \& coll., Immunocompetence of transferred thymus-marrow cell combinations, J. Immunol., 97, 828-832, 1966.

DONIACH D., Humoral and genetic aspects of thyroid autoimmunity, Clin. Endocrinol. Metabol., 1975, 4, 267-285, 1975.

DONIACH D. \& ROITT I.M., Autoimmunity in Hashimoto's disease and its implications, J. Clin. Endocr. Metab., 17, 1293-1304, 1957.

GROSS J. \& PITT-RIVERS R., 3,5,3'-triiodothyronine. I. Isolation from thyroid gland and synthesis, Biochem. J., 53, 645-650, 1953.

Handbook of Physiology, sect. 7, III. Thyroid, 1974.

KOHRLE J., The sodium-iodide-symporter (NIS) : function, regulation and clinical importance, Z. Arztl. Fortbild. Qualitatssich, 93, suppl. 1, 17-22, 1999.

LEGRAND J., Hormones thyroïdiennes et maturation du système nerveux, J. Physiol. (Paris), 78, 603-652, 1983. 
MARCHAL S. \& coll., Mécanismes moléculaires impliqués dans l'activité myogénique de la triiodothyronine (T3), Médecine/Sciences, 12, 1065-1076, 1996.

MOREAU J.F. \& CARLIER-CONRADS L., Imagerie diagnostique des glandes thyroïde et parathyroïde, Vigot, Paris, 1984.

MOREL Y. \& MORNEX R., L'hormone thyréotrope, Enc. Méd. Chir., 10017 J10, $1-7,1980$.

MORNEX R. \& BERTHEZENE F., Le contrôle de la sécrétion de TSH. II. Exploration de l'axe thyréotrope en clinique, in "Le Cerveau et les Hormones", Klotz H.P. éd., 109-131, l'Expansion Scientifique Française (Paris), 1974.

NAOUN A., HARTEMANN P. \& ROBERT J., L'exploration de la thyroïde, Maloine, Paris, 1980.

ORGIAZZI J., Mécanisme d'action de la TSH, Lyon Méd., 235, 217-227, 1976.

PITT-RIVERS R. \& TATA J.R., The thyroid hormones, Pergamon Press, London, 1959.

PURVES H.D. \& ADAMS D.D., I. Thyroid stimulating hormone, Brit. Med. Bull., $16,128-132,1960$.

ROCHE J. \& coll., Sur la déshalogénation enzymatique des iodotyrosines par le corps thyroïde et sur son rôle physiologique, Biochim. Biophys. Acta, 9, 161-169, 1952.

ROCHE J., LISSITZKY S. \& MICHEL R., Sur la triiodothyronine, produit intermédiaire de la transformation de diiodothyronine en thyroxine, CR Acad. Sci. (Paris), 234, 997-999, 1952.

ROCHE J. \& MICHEL R., On the peripheral metabolism of the thyroid hormones, Ann. N.Y. Acad. Sci., 86, 454-468, 1960.

SAMUEL H.H. \& coll., Organization of the thyroid hormone receptor in chromatin, Rec. Progr. Horm. Res., 38, 557-599, 1982.

SIMON C., Dynamique de la sécrétion thyroïdienne, J. Physiol. (Paris), 76, 347-356, 1980.

TATA J., Growth and development action of thyroid hormones at the cellular level, in "Handbook of Physiology", sect. 7, III. Thyroid, 469-478, 1974.

TEPPERMAN J., Physiologie endocrine et métabolisme, Masson, Paris, 1969.

WERNER S.C. \& INGBAR S.H. (eds), The thyroid, Harper and Row, 1971.

WRUTNIAK C. \& CABELLO G., La voie d'action mitochondriale directe de la triiodothyronine : mythe ou réalité ?, Médecine/Sciences, 12, 475-9484, 1996.

ZARA M., La thyroïde, l'Expansion Scientifique Française, 1969.

\section{LES GLANDES SURRÉNALES}

\section{Ouvrages généraux}

Handbook of Physiology, sect. 7, VI. Adrenal gland, Amer. Phys. Soc. (Washington), 1975.

CAREY R.M. \& SEN S., Recent progress in the control of aldosterone secretion, Rec. Progr. Horm. Res., 42, 251-296, 1986. 
LIPSETT M.B. \& coll., The defective glucocorticoid receptor in man and nonhuman primates, Rec. Progr. Horm. Res., 41, 199-248, 1985.

PERRAUDIN V. \& coll., Vasopressin stimulates cortisol secretion from human adrenocortical tissue through activation of V1 receptors, J. Clin. Invest., 76, 1522-1528, 1993.

SIITERI P.K., MURAI J. \& HAMMOND G.L., The serum transport of steroid hormones, Rec. Progr. Horm. Res., 38, 457-510, 1982.

SYMINGTON T., Fonctional pathology of the human adrenal gland, Livingstone ltd. (Edinburgh and London), 1969.

\section{Le cortex surrénal}

AGUILERA G., HARWOOD J.P. \& CATT K.J., Somatostatin modulates effects of angiotensine II in adrenal glomerulosa zone, Nature, 292, 262-263, 1981.

BALLARD P.L., Delivery and transport of glucocorticoids to target cells, Monogr. Endocrinol., 12, 25-48, 1979.

BAULIEU E.E., Dehydroepiandrosterone (DHA) : a fountain of youth (editorial), J. Clin. Endocr. Metab., 81, 3147-3151, 1996.

BAULIEU E.E., Un nouveau produit de sécrétion cortico-surrénalienne : le sulfate de déhydro-épiandrostérone, Rev. Fr. Etude Clin. Biol., 10, 264-270, 1965.

CAREY R.M. \& SEN S., Recent progress in the control of aldosterone secretion, Rec. Progr. Horm. Res., 42, 251-296, 1986.

CHESTER JONES I. \& HENDERSON I.W. (eds), General, comparative and clinical endocrinology of the adrenal cortex, vol. I et II, Ac. Press, 1976.

CRABBE J., L'aldostérone comme facteur de régulation des volumes extracellulaires : mécanisme d'action, J. Physiol. (Paris), 82, 75-82, 1987.

DA COSTA A.C., Le cortex surrénal, Masson, Paris, 1952.

DALLMAN M.F \& coll., Regulation of ACTH secretion : variations on a theme of B, Rec. Progr. Horm. Res., 43, 113-174, 1987.

FANESTIL D.D., Mechanism of action of aldosterone, Ann. Rev. Med., 20, 223-232, 1969.

GALLO-PAYET N., Nouveaux concepts sur la régulation de la sécrétion d'aldostérone ; interactions endocrines, paracrines, autocrines et neurocrines, Médecine/Sciences, 9, 943-951, 1993.

GAUER O., Contrôle neuro-endocrinien du volume plasmatique, J. Physiol. (Paris), 76, 373-379, 1980.

HECHTER O. \& coll., Transformation of cholesterol and acetate to adrenal cortical hormones, Arch. Biochem. Biophys., 46, 201-214, 1953.

KENDALL E.L. \& coll., The chemical nature and physiological action of the hormone of the suprarenal cortex, J. Biol. Chem., 105, 45-46, 1934.

LIER J.F., La physiologie du système rénine-angiotensine, J. Physiol. (Paris), 75, 179-193, 1979.

Mc KERNS K.W. (ed.), Functions of the adrenal cortex, vol. I et II, North Holland Pub. Co., Amsterdam, 1968. 
MENARD J. \& coll., Système rénine-angiotensine et son inhibition, in "La fonction rénale, acquisitions et perspectives", Bonvalet J.P. éd., 189-205, Flammarion, Paris, 1980.

MILLER W.L. \& STRAUSS J.F., Molecular pathology and mechanism of action of the steroidogenic acute regulatory protein, StAR, J. Steroid Biochem. Mol. Biol., 69, 131-141, 1999.

SHARP G.W.G. \& LEAF A., Mechanism of action of aldosterone, Physiol. Rev., 46, 593-633, 1966.

STOCCO D.M., An update on the mechanism of action of the Steroidogenic Acute Regulatory (StAR) protein, Exp. Clin. Endocr. Diab., 107, 229-235, 1999.

VINSON G.P. \& JONES I.C., The in vitro production of ostrogens from progesterone by mouse adrenal glands, J. Endocrinol., 29, 185-191, 1964.

WATERMAN M.R., Steroidogenesis, StAR and PBR : is there light at the end of the tunnel ?, Proc. Soc. Exp. Biol. Med., 217, 121-122, 1998.

ZILZ A., LI H., CASTELLO R., PAPADOPOULOS V. \& WIDMAIER E.P., Developmental expression of the peripheral-type benzodiazepine receptor and the advent of steroidogenesis in rat adrenal glands, Endocrinology, 140, 859-864, 1999.

\section{La médullo-surrénale}

AUNIS D. \& HENRY J.P., La décharge d'adrénaline et les granules chromaffines, Pour la Science, 83, 55-65, 1984.

AXELROD J., The formation, metabolism, uptake and release of noradrenaline and adrenaline, in "Symposium on the clinical chemistry of monoamines", Varley H. \& Gowenlock A.H. eds, Ellester Publ. Co., Amsterdam, 1963.

EMORINE L. \& STROSBERG D., Structure et fonction du récepteur $\beta 3$-adrénergique, Médecine/Sciences, 9, 1228-1235, 1993.

EULER U.S. (Von), FRANKSSON C. \& HELLSTROM J., Adrenaline and noradrenaline output in urine after unilateral and bilateral adrenalectomy in man, Acta Physiol. Scand., 31, 1-5, 1954.

HEDBERG A., Adrenergic receptors, methods of determination and mechanisms of regulation, Acta Med. Scand., suppl. 672, 7-15, 1983.

HOEBEKE J., La seconde boucle extracellulaire des récepteurs couplés aux protéines $\mathrm{G}$ : une cible préférentielle pour des auto-anticorps fonctionnels, Médecine/Sciences, 11, 1661-1667, 1995.

LANDS A.M., Differentiation of receptor systems activated by sympathicomimetic amines, Nature, 214, 577-597, 1987.

LEFKOWITZ R.J. \& CARON M.G., Molecular and regulation properties of adrenergic receptors, Rec. Progr. Horm. Res., 43, 469-497, 1987.

MORRIS D., Le singe nu, Grasset, Paris, 1967.

SUTHERLAND E.W. \& RALL T.W., The relation of adenosine-3',5'-phosphate and phosphorylase to actions of catecholamines and other hormones, Pharmacol. Rev., 12, 265-299, 1960. 


\section{Le stress}

ADER R., Psychoneuro-immunology, Ac. Press, 1981.

ANOKHIN P., Biologie et neurophysiologie du réflexe conditionné, Moscou, 1975.

ARMARIO A., MARTI O., GAVALDA A., GIRALT M. \& JOLIN T., Effects of chronic immobilization stress on GH and TSH secretion in the rat : response to hypothalamic regulatory factors, Psychoneuroendocrino., 18, 405-413, 1993.

ARRIGA A.P. \& coll., Les petites protéines de stress : des nouveaux modulateurs de la mort cellulaire, Médecine/Sciences, 13, 740-741, 1997.

BAULIEU E.E. \& KELLY P.A., Hormones, Hermann, Paris, 1990.

BAULIEU E.E., Connection between immunosuppressants and steroids via HSP 90, Ann. N.Y. Acad. Sci., 761, 50-55, 1995.

BAYLISS E.M. \& coll., An examination of the control mechanism postulated to control growth hormone secretion in man, in "Growth hormone", Excerpta Med. Found., Reulle \& Müller, 1968.

BENSABAT S., Stress, Hachette, Paris, 1980.

BONFILS S., Impertinente psychosomatique, John Libbey Eurotext ed., Montrouge, 1993.

BORYSENKO M.H. \& BORYSENKO J., Stress, behavior and immunity : animal models and mediating mechanisms, Gen. Hosp. Psychiat., 4, 59-67, 1982.

DANTZER R., L'illusion psychosomatique, O. Jacob, Paris, 1989.

DEANFIELD J.E., SHEA M., KENSETT M., HORLOCK P., WILSON R.A., LANDSHEERE C.M. (de) \& SELWYN A.P., Silent myocardial ischemia due to mental stress, Lancet, $2: 8410,1001-1005,1984$.

DIMSDALE J.E. \& MOSS J., Plasma catecholamine in stress and exercise, JAMA, 243, 340-344, 1980.

FANSELOW M.S., Odors released by stressed rats produce opioid analgesia in unstressed rats, Behav. Neurosci., 99, 589-592, 1985.

FARABOLLINI F., ALBONETTI M.E., ALOISI A.M., FACHINETTI F., GRASSO G., LODI L., LUPO C. \& MUSCETTOLA M., Immune and neuroendocrine response to restraint in male and female rats, Psychoneuroendocrino., 18, 175-182, 1993.

FAVRE R. \& coll., Incidence de diverses situations stressantes sur la tumorigénicité étudiée sur deux modèles expérimentaux murins, Psychologie médicale, 15, 1589-1591, 1983.

FOLLICK M.J., GORKIN L., CAPONE R.J., SMITH T.N., AHERN D.K., STABLEIN D., NIAURA R. \& VISCO J., Psychological distress as a predictor of ventricular arrythmias in a post-myocardial infarction population, Am. Heart J., 116, 32-35, 1988.

FRICCHIONE G.L. \& VLAY S.C., Psychiatry aspect of patients with malignant ventricular arrythmias, Am. J. Psychiat., 143, 1518-1526, 1986.

FRIEDMAN S.B., MASON J.W. \& HAMBURG D.A., Urinary 17-hydroxycorticosteroid levels in parents with neoplastic disease : a study of chronic psychological stress, Psychosom. Med., 25, 364-376, 1963. 
FUJIEDA K. \& HIROSHIGE T., Changes in rat hypothalamic content of corticotrophin-releasing factor (CRF) activity, plasma ACTH and corticosterone under stress and the effect of cycloheximide, Acta Endocrinologica, 89, 10-19, 1978.

GACHELIN G., Emotions et immunité, la Recherche, 17, 662-666, 1986.

GROSSMAN C.J., Interactions between the gonadal steroids and the immune system, Science, 227, 257-261, 1985.

HILL C.W., GREER W.E. \& FELSENFELD O., Psychological stress, early response to foreign protein, and blood cortisol in vervets, Psychosom. Med., 29, 279, 1967.

HIRATA-HIBI M., Plasma cell reaction and thymic germinal centers after a chronic form of electric stress, J. Reticulo-endoth. Soc., 4, 370, 1967.

HUHMAN K.L., HEBERT M.A., MEYERHOFF J.L. \& BUNNELL B.N., Plasma cyclic AMP increases in Hamsters following exposure to a graded footshock stressor, Psychoneuroendocrino., 16, 559-563, 1991.

JACQUIER-SARLIN M.R. \& POLLA G.S., Protéines de stress : soi, non-soi et réponse immune, Médecine/Sciences, 10, 31-41, 1994.

JOHNSTON C.A. \& NEGRO-VILAR A., Maturation of the prolactin and proopiomelanocortin-derived peptide responses to ether stress and morphine : neurochemical analysis, Endocrinology, 118, 797-804, 1986.

KANT G.J. \& coll., Graded footshock stress elevates pituitary cyclic AMP and plasma $\beta$-endorphin, $\beta$-LPH, corticosterone and prolactin, Life Sci., 33, 2657-2663, 1983.

KUNTZ E., VALETTE N. \& LABORIT H., Rôle de 1'apprentissage dans le mécanisme d'inhibition comportemental et de l'hypertension artérielle consécutive à l'application de stimulus aversifs sans possibilité de fuite ou de lutte, Agressologie, 6, 381-385, 1974.

KVETNANSKY R. \& MIKULAJ L., Adrenal and urinary catecholamines in rats during adaptation to repeated immobilization stress, Endocrinology, 87, 738-743, 1970.

LABORIT H., Eloge de la fuite, R. Laffont, Paris, 1976.

LABORIT H., L'inhibition de l'action, 2e édit., Masson, Paris, 1986.

LAZARUS R.S. \& LAUNIER R., Stress-related transactions between person and environment, in "Perspectives in interactional Psychology", Pervin L.A. \& Lewis M. eds, Plenum, New York, 1978.

LEDUC J., Cathecholamine production and release in exposure and acclimatation to cold, Acta Physiol. Scand., 53, suppl. 183, 1, 1961.

LESHNER A.L., The role of hormones in control of submissiveness, in "A multidisciplinary approach to agression research", Brain P.E. \& Benton D. eds, Elsevier, Amsterdam, 1981.

LOO P. \& LOO H., Le stress permanent, Masson, Paris, 1986.

LUPULESCU A.P., Hormones, vitamins, and growth factors in cancer treatment and prevention. A critical appraisal, Cancer, 78, 2264-2280, 1996.

MALLION J.M., Stress et tension artérielle, Specia, 1982. 
MARTI O., GAVALDA A., JOLIN T. \& ARMARIO A., Effect of regulatory exposure to chronic immobilization stress on the circadian pattern of pituitary adrenal hormones, growth hormone and thyroid stimulating hormone in the adult male rat, Psychoneuroendocrino., 18, 67-77, 1993.

MENORET A. \& LE PENDU J., Protéines de choc thermique et antigènes tumoraux, Médecine/Sciences, 10, 665-671, 1994.

MEREDITH I.T., BROUGHTON A., JENNINGS G.L. \& ESLER M.D., Evidence of a selective increase of cardiac sympathetic activity in patients with sustained ventricular arrythmias, New Engl. J. Med., 325, 618-624, 1991.

MINUCHIN S., Familles en thérapie, Delarge, Paris, 1979.

MONJAN A.A. \& COLLECTOR M.I., Stress-induced modulation of the immune response, Science, 196, 307-308, 1977.

MONNIER M. \& DESBALS B., Dosage radio-immunologique de l'ACTH chez le lapin : relations stress-ACTH-corticostéroïdes et diarrhées, Reprod. Nutr. Dev., 25, 1017-1028, 1985.

MORRIS D., Le singe nu, Livre de poche, Hachette, Paris, 1970.

MULLER E.E. \& PECILE A., Studies on the neural control of growth hormone secretion, in "Growth hormone", Excerpta Med. Found., 253-266, Reulle \& Müller, 1968.

NATELSON B.H., Neurocardiology. An interdisciplinary area for the 80s, Arch. Neurol., 42, 178-184, 1985.

OLDS J. \& MILNER P., Positive reinforcement produced by electrical stimulation of septal area and other regions of the brain, J. Comp. Physiol. Psychol., 47, 419-427, 1954.

ORR T.E., MEYERHOFF J.L., MOUGEY E.H. \& BUNNELL B.N., Hyperresponsiveness of the rat neuroendocrine system due to repeated exposure to stress, Psychoneuroendocrino., 15, 317-328, 1990.

PETROVSKII I.N., Problems of nervous control in immunity reactions. II. The influence of experimental neuroses on immunity reactions, $\mathrm{Zh}$. Mikrobiol. Epidemiol. Immunobiol., 32, 63, 1961.

REICH P. \& coll., Acute psychological disturbance preceding lifethreatening ventricular arrythmias, JAMA, 246, 233-235, 1981.

ROSE R.M., POE R.O. \& MASON J.W., Psychological state and body size as determinants of 17-OH CS excretion, Arch. Intern. Med. (Chicago), 121, 406-413, 1968.

ROSSIER J. \& coll., Footshock induced stress increases $\beta$-endorphin levels in blood, but not in brain, Nature, 270, 618-620, 1977.

SCHACHTER S. \& SINGER J., Cognitive, social and physiological determinants of emotional state, Psychol. Rev., 69, 379-399, 1962.

SCHLACH D.S. \& REICHLIN S., Stress and growth hormone release, in "Growth hormone", Excerpta Med. Found., 211-225, Reulle \& Müller, 1968.

SELYE H., A syndrome produced by diverse nocuous agents, Nature, 32, 138, 1936.

SELYE H., Perspectives in stress research, Perspect. Biol. Med., 2, 403-416, 1959.

SELYE H., Le stress de la vie, Gallimard, Paris, 1975. 
SHAVIT Y. \& coll., Stress opioid peptides, the immune system, and cancer, J. Immunol., 135, 834s-837s, 1985.

SHKLAR G. \& SCHWARTZ J., Oral cancer inhibition by micronutrients. The experimental basis for clinical trials, Eur. J. Cancer B. Oral Oncol., 29B, 9-16, 1993.

SKLAR L.S. \& ANISMAN H., Stress and cancer, Psychol. Bull., 89, 369-406, 1981.

SOLOMON G.F., Stress and antibody response in rats, Int. Arch. Allergy Appl. Immunol., 35, 97-104, 1969.

STEIN L., Chemistry of reward and punishment, in "Psychopharmacology, a review of Progress" (1957-1967), Efron D.H. ed., 105-123, US Government Printing Office, Washington, 1968.

STEIN M., KELLER S.E. \& SCHLEIFER S.J., Stress and immuno-modulation, the role of depression and neuroendocrine function, J. Immunol., 135, $827 \mathrm{~s}-833 \mathrm{~s}, 1985$.

TERMAN G.W, SHAVIT Y., LEWIS J.W., CANNON J.T. \& LIEBESKIND J.C., Intrinsic mechanisms of pain inhibition : activation by stress, Science, 14, 1270-1277, 1984.

VESSEY S.H., Effects of grouping on levels of circulating antibodies in mice, Proc. Soc. Biol., 115, 252-255, 1964.

VINCENT C., A la recherche des molécules chaperons, Le Monde, 6 juin 1997.

ZARROW M.X. \& coll., Plasma and adrenal corticosterone levels following exposure of the two-day-old rat to various stressors, Proc. Soc. Exp. Biol. Med., 125, 113-116, 1967.

ZIMMERMANN E. \& CRITCHLOW V., Effects of diurnal variation in plasma corticosterone levels on adrenocortical response to stress, Proc. Soc. Exp. Biol. Med., 125, 658-663, 1967.

\section{Le vieillissement}

BAULIEU E.E., Studies on dehydroepiandrosterone (DHA) and its sulfate during aging, CR Acad. Sci. III, 318, 7-11, 1995.

BRAMBILLA F., Psychopathological aspects of neuroendocrine diseases : possible parallels with the psychoendocrine aspects of normal aging, Psychoneuroendocrino., 17, 283-291, 1992.

CUGINI P., SCA VO D., HALBERG F., S CHR A MM A., PUSH A.J.\& FRANKE H., Methodogically critical interaction of circadian rhythms : sex and aging characterize serum aldosterone of the female andropause, J. Gerontol., 37, 403-411, 1982.

FERRARI E., MAGRI F., DORI D., MIGLIORATI G., NESCIS T., MOLLA G., FIORA VANTI M. \& SOLERTE S.B., Neuroendocrine correlates of the aging brain in humans, Neuroendocrinology, 61, 464-470, 1995.

HAUS E., NICOLAU G., LAKATUA D.J., SACKETT-LUNDEEN L. \& PETRESCU E., Circadian rhythm parameters of endocrine functions in elderly subjects during the seventh to the ninth decade of life, Chronobiologia, 16, 331352,1989 . 
MIGEON C.J., KELLER A.R., LAWRENCE B. \& SHEPARD T.H., Dehydroepiandrosterone and androsterone levels in human plasma. Effect of age and sex, day-to-day and diurnal variations, J. Clin. Endocr. Metab., 17, 1051-1062, 1957.

MORALES A.J. \& coll., Effects of replacement dose of dehydroepiandrosterone in men and women of advancing age, J. Clin. Endocr. Metab., 78, 1360-1367, 1994.

ORENTREICH N. \& coll., Age changes and sex differences in serum dehydroepiandrosterone sulfate concentrations throughout adulthood, J. Clin. Endocr. Metab., 59, 551-555, 1984.

PARKER L., GRAL T., PERRIGO V. \& SKOWSKY R., Decreased adrenal androgen sensitivity to ACTH during aging, Metabolism, 30, 601-604, 1981.

SAPOLSKY R.M., KREY L.C. \& Mc EWEN B.S., Corticosterone receptors decline in a site-specific manner in the aged rat brain, Brain Res., 289, 235-240, 1983.

TOUITOU Y., SULON J., BOGDAN A., TOUITOU C., REINBERG A., BECK H., SODOYEZ J.C. \& CAUWENBERGE H. (Van), Adrenal circadian system in young and elderly human subjects : a comparative study, J. Endocrinol., 93, 201-210,1982.

TOUITOU Y., SULON J., BOGDAN A., REINBERG A., SODOYEZ J.C. \& DEMEY-PONSART E., Adrenocortical hormones ageing and mental condition: seasonal and circadian rhythms of plasma 18-hydroxy-11deoxycorticosterone, total and free cortisol and urinary corticosteroids, J. Endocrinol., 96, 53-64, 1983a.

TOUITOU Y. \& HAUS E., Aging of the human endocrine and neuroendocrine time structure, Ann. N.Y. Acad. Sci., 719, 378-397, 1994.

\section{LE PANCRÉAS ENDOCRINE}

ASSAN R. \& coll., Diabète insulinodépendant : maladie par auto-immunisation, in "Progrès récents en immunopathologie", 40-53, Masson, 1985.

BANTING F.G. \& BEST C.H., The internal secretion of the pancreas, J. Lab. Clin. Med., 7, 251-266, 1921-22.

BARNETT A.H., EFF C. \& coll., Diabetes in identical twins, Diabetologia, 20, 87-93, 1981.

BAYLISS W.M. \& STARLING E.H., The mechanism of pancreatic secretion, J. Physiol. (London), 28, 325-353, 1902.

BELL G.I. \& coll., Sequence of the human insulin gene, Nature, 284, 26-32, 1980.

BERSON S.A. \& YALOW R.S., Recent studies on insulin-binding antibodies, Ann. N.Y. Acad. Sci., 82, 338-344, 1959.

BERSON S.A. \& YALOW R.S., Some current controversies in diabetes research, Diabetes, 14, 549-572, 1965.

BJORNTORP P., Metabolic implications of body fat distribution, Diabetes Care, 14, 1132-1143, 1991.

CARPENTIER J.L. \& coll., Down regulation and recycling of insulin receptors, J. Biol. Chem., 259, 14190-14196, 1984. 
CARPENTIER J.L., Internalisation et recyclage du récepteur de l'insuline, Médecine/Sciences, 4, 83-89, 1988.

CHENG K. \& LARNER J., Intracellular mediators of insulin action, Annu. Rev. Physiol., 47, 405-424, 1985.

CLAUSER E., Le récepteur de l'insuline, second messager de l'hormone, Médecine/Sciences, 4, 72-82, 1988.

CONRAD B., WEISSMAHR R.N., BONI J., ARCARI R., SCHUPBACK J. \& $\mathrm{MACH}$ B., A human endogenous retroviral superantigen as candidate autoimmune gene in type I diabetes, Cell, 90, 303-313, 1997.

CZECH M.P., New perspectives on the mechanism of insulin action, Rec. Progr. Horm. Res., 40, 347-377, 1984.

DANI C. \& GRIMALDI P., Modulation de l'expression des gènes par l'insuline, Médecine/Sciences, 4, 90-95, 1988.

Diabetes mellitus, Technical Reports Series, n²727, OMS, 1985.

Diabetes Prevention Program (DPP), d'après une intervention de GORDEN P., NATHAN D., MONTEZ M., VINICOR F., 56 Congrès American Diabetes Association, San Francisco, juin 1996, Parution dans le Quotidien du Médecin, n5899, 3 septembre 1996.

DURLACH V. \& coll., Serum lipoprotein (a) concentrations in a population of 819 NIDD patients, Diabetes Metab., 22, 319-323, 1996.

EMILSSON V. \& coll., Expression of the functional leptin receptor mRNA in pancreatic islets and direct inhibitory action of leptin on insulin secretion, Diabetes, 46, 313-316, 1997.

EXTON J.H., Mechanisms of hormonal regulation of hepatic glucose metabolism, Diabetes Metab. Rev., 3, 163-183, 1987.

FAN J.V. \& coll., Receptor-mediated endocytosis of insulin : role of microvilli, coated pits, and coated vesicles, Proc. Natl. Acad. Sci. (USA), 79, 7788-7791, 1982.

FEHLMANN M. \& coll., Internalized insulin receptors are recycled to the cell surface in rat hepatocytes, Proc. Natl. Acad. Sci. (USA), 79, 5921-5925, 1982.

FELIG P. \& coll., Insulin, glucagon and somatostatin in normal physiology and diabetes mellitus, Diabetes, 25, 1091-1099, 1976.

FREYCHET P., Mécanisme d'action de l'insuline, Médecine/Sciences, 4, 70-71, 1988.

FROGUEL P., VAXILLAIRE M., SUN F. \& coll., Close linkage of glucokinase locus on $7 \mathrm{p}$ is closely linked to early onset non insulin dependent diabete mellitus, Nature, 356, 162-164, 1992.

FRONZO R.A. (de), The triumvirate : $\beta$ cell, muscle, liver. A collusion responsible for NIDDM, Diabetes, 37, 667-687, 1988.

GAMMELTOFT S. \& coll., Insulin receptors in rat brain : insulin stimulates phosphorylation of its receptors b-subunit, Febs Lett., 172, 87-90, 1984.

GIRARD J., Is leptin the link between obesity and insulin resistance ?, Diabetes Metab., 23, suppl. 3, 16-24, 1997.

GOLDFINE I.D., ROTH J. \& BIRNBAUMER L., Glucagon receptors in $\beta$-cells, J. Biol. Chem., 247, 1211-1218, 1972. 
GRANNER D.K. \& coll., Insulin regulates expression of the phosphoenolpyruvate carboxykinase gene, Rec. Progr. Horm. Res., 42, 111-136, 1988.

GRIMALDI A. \& coll., Les neuropathies diabétiques dans les diabètes, Comprendre pour traiter, Editions Médicales Internationales, 334-335, 1993.

GRIMALDI A., SACHON L. \& BOSQUE F., Les diabètes, Comprendre pour traiter, Editions Médicales Internationales, 1993.

Handbook of Physiology, sect. 7, I. Endocrine pancreas, 1972.

HEDO J.A. \& SIMPSON I.A., Internalization of insulin receptors in the isolated rat adipose cell, J. Biol. Chem., 259, 11083-11089, 1984.

HENQUIN J.C., Les mécanismes cellulaires du contrôle de la sécrétion d'insuline, Arch. intern. Physiol. Bioch., 98, A 61-A 80, 1990.

HENQUIN J.C. \& GILON P., Le contrôle de la sécrétion d'insuline par le glucose : signaux déclenchants et amplificateurs, Médecine/Sciences, 11, 1235-1242, 1995.

KADOWAKI T. \& coll., Two mutant alleles of the insulin receptor gene in a patient with extreme insulin resistance, Science, 240, 787-90, 1988.

KAHN C.R. \& coll., Insulin receptors, receptors antibodies and the mechanism of insulin action, Rec. Progr. Horm. Res., 37, 477-538, 1981.

KANNEL W.B., Mc GEE D.L. \& GORDON T., A general cardiovascular risk profile : the Framingham Study, Am. J. Cardiol., 38, 46-51, 1976.

KASUGA M., KARSSON F.A. \& KAHN C.R., Insulin stimulates the phosphorylation of the 95000 Daltons subunit of its own receptor, Science, 215, 185-187, 1982.

KLEIN R., KLEIN B.E.K., MOSS S.E. \& coll., The Wisconsin epidemiological study of diabete retinopathy II, Prevalence and risk of diabetic retinopathy when age at diaposis is 30 or more years, Arch. Ophtalmol., 1021, 527-532, 1984.

KOBAYASHI M. \& coll., Insulin resistance by improcessed insulin proreceptors point mutation at the cleavage site, Biochem. Bioph. Res. Co., 153, 657-663, 1988.

KONO T., Action of insulin on glucose transport and cAMP phosphodiesterase in fat cells : involvement of two distinct molecular mechanisms, Rec. Progr. Horm. Res., 39, 519-557, 1983.

LE MARCHAND-BRUSTEL Y. \& coll., Insulin receptor tyrosine kinase is defective in skeletal muscle of insulin-resistant obese mice, Nature, 315, 676$679,1988$.

LEUTENEGGER M. \& BERTIN E., Diabetes mellitus and atherosclerosis. Physiopathology of diabetic macroangiopathy, Rev. Med. Int., 16, 31-42, 1995.

LILJENQUIST J.E. \& coll., Insulin and glucagon actions and consequences of derangements in secretion, Handbook of Physiology, sect. 7, I, 981-994, 1972.

LOUBATIERES A., The mechanism of action of the hypoglycemic sulfonamides : a concept based on investigations in animals and in human beings, Ann. N.Y. Acad. Sci., 71, 192-206, 1957.

LOUBATIERES A., The hypoglycemic sulfonamides : history and development of the problem from 1942 to 1955, Ann. N.Y. Acad. Sci., 71, 4-11, 1957.

LUISOT P., Biochimie, Simap, Paris, 1983.

MALAISSE W.J., Sécrétion d'insuline, Enc. Méd. Chir., 10362 E ${ }^{10}, 1985$. 
MANTZOROS C.S. \& FLIER J.S., Insulin resistance : the clinical spectrum, Adv. in Endocrinology and Metabolism, 6, 193-232, 1995.

MAUGENDRE D., BARDET S., ROHMER V. \& coll., Dépistage des sujets à risque de diabète, Revue de Médecine Interne, 14, 25-31, 1993.

Mc GARRY J.D., New perspectives in the regulation of ketogenesis, Diabetes, 28, 517-523, 1979.

MOGENSEN C.E., Microalbuminuria predicts clinical proteinuria and early mortality in maturity-onset diabetes, New Engl. J. Med., 310, 356-360, 1984.

NOTKINS A., Les causes du diabète, Pour la Science, 27, 14-28, 1980.

OBBERGHEN E. (Van) \& GAMMELTOFT S., Insulin receptors : structure and function, in "Development of hormone receptors", Csaba G. ed., 31-45, Birkhäuser Verlag, Basel/Boston, 1987.

ORCI L., VASSALI J.D. \& PERRELET A., La production de l'insuline, Pour la Science, 133, 36-47, 1988.

PAPOZ I. \& ESCHWEGE E., Epidémiologie du DNID in "Traité de Diabétologie", Tchobrowtsky \& coll., Pradel, Paris, 1990.

PARVING H.H., Hypertension and diabetes in "The diabetes Annual", Marschall S.M., Home P.D., Alberti K.G.M.M. \& Krall L.P. eds, 7, Elsevier, Amsterdam, 1993.

PATZELT C. \& coll., Identification and processing of proglucagon in pancreatic islets, Nature, 282, 260-266, 1979.

PELLEYMOUNTER M.A. \& coll., Effects of the obese gene product on body weight regulation in ob/ob mice, Science, 269, 540-543, 1996.

PIRART J., Diabète et complications dégénératives. Présentation d'une étude prospective portant sur 4400 cas observés entre 1947 et 1973, Diabète et métabolisme, 3, 97-103, 173-182 et 245-256, 1977.

REAVEN G.M., Role of insulin resistance in human disease, Diabetes, 37, 1595-1607, 1988.

ROQUES M. \& PINGET M., Les voies de transmission du signal insuline, Médecine/Sciences, 12, 1247-1252, 1996.

ROSSELIN E.G., Les dosages de l'insuline, de l'hormone de croissance et de glucagon plasmatiques au cours de la charge en glucose par voie orale en physiologie humaine, dans le diabète, l'obésité, les hypoglycémies et les syndromes hypophysaires, La Revue du Praticien, 18, 4001-4023, 1968.

SANGER F., Chemistry of insulin, Science, 129, 1340-1344, 1959.

SANGER F., THOMPSON E.O.P. \& KITAI R., The amide groups of insulin, Biochem. J., 59, 509-518, 1955.

SCOTT E.W., Milk and type I diabetes, Diabetes Care, vol. 19, n²4, 379-383, avril 1996.

SHAW W.N. \& CHANCE R.F., Effect of porcine preinsulin in vitro on adipose tissue and diaphragm of the normal rat, Diabetes, 17, 737-745, 1968.

SOMAN V. \& FELIG P., Glucagon and insulin binding to liver membranes in a partially nephrectomized uremic rat model, J. Clin. Invest., 60, 224-232, 1977.

SUTTER B.C., Régulation hormonale de la sécrétion de l'insuline, J. Physiol. (Paris), 78, 119-130, 1982. 
TEMPLE R.C., CLARK P.M.S., NAGI D.K. \& coll., Radio immunoassay may over estimate, Insulin in NIDDM, Clin. Endocrinol., 32, 689-693, 1990.

The Diabetes Control and Complications Research Group (DCCT), Effects of intensive diabete management on macrovascular events and risk factors in the diabetes control and complication trial, Am. J. Cardiol., 75, 894-903, 1995.

THIVOLET C., Formes nosologiques du diabète, Endocrinologie-Diabète-Nutrition pour le Praticien, SIMEP, 314-322, 1994.

THIVOLET C., in "Précis d'Endocrinologie", Tourniaire J. éd., 313-322, Flammarion, Paris, 1996.

UNGER R.H. \& coll., The role of aminogenic glucagon secretion in blood glucose homeostasis, J. Clin. Invest., 48, 810-822, 1969.

UNGER R.H. \& LEFEBVRE R.J., in “Glucagon”, Pergamon Press, 1972.

UNGER R.H., DOBBS R.E. \& ORCI L., Insulin glucagon and somatostatin secretion on the regulation of metabolism, Annu. Rev. Physiol., 40, 307-343, 1978.

UUSITOPA M. \& coll., Prevalence of coronopathy heart disease left ventricular failure and HTA in middle aged nexly diagnosed type 2 diabete, Diabetologia, 28, 220-227, 1985.

WILKIN T.J. \& coll., Grave's disease of the $\beta$-cell : glucose dysregulation due to islet-cell stimulating antibodies, Lancet, 2 : 8621, 1155-1158, 1988.

WILLIAMS R.H. \& PORTE D., in "Textbook of Endocrinology", Saunders W.B. ed., 520, 1974.

WOLFFENBUTTEL B. \& coll., Long-term assessment of glucose control by haemoglobin. AGE measurement, Lancet, 347 : 9000, 513-515, 1996.

WOLLHEIM C.B. \& SCHARP G.W.G., Regulation of insulin release by calcium, Physiol. Rev., 61, 914-963, 1981.

XIONG W. \& GRAY J.D., The role of receptor abnormalities in the pathogenesis and chronic complications of type 2 diabetes mellitus, Clin. Invest. Med., 22, 85-105, 1999.

YALOW R.S. \& BERSON S.A., Immunoassay of endogenous plasma insulin in man, J. Clin. Invest., 39, 1157-1175, 1960.

YAMAGATA K. \& coll., Mutations in the hepatocyte nuclear factor-1alpha gene in maturity-onset diabetes of the young, Nature, 384, 407-408, 1996.

YOSHIMASA Y. \& coll., Insulin-resistant diabetes due to point-mutation that prevents insulin proreceptor processing, Science, 240, 784-787, 1988.

\section{LES PARATHYROÏDES ET L'ÉQUILIBRE PHOSPHOCALCIQUE}

AKIZAWA T. \& FUKAGAWA M., Modulation of parathyroïd cell function by calcium ion in health and uremia, Am. J. Med. Sci., 317, 358-362, 1999.

ALBRIGHT F. \& ELLSWORTH R., Studies on the physiology of the parathyroid gland. I. Calcium and phosphorus studies on a case of idiopathic hypoparathyroidism, J. Clin. Invest., 7, 183-201, 1929.

BROWN E.M. \& POLLACK M., The extracellular calcium-sensing receptor : its role in health and disease, Ann. Rev. Med., 49, 15-29, 1998. 
CARE A.D. \& coll., Evaluation by radioimmunoassay of factors controlling the secretion of parathyroid hormone, Nature, 209, 52-55, 1966.

COHN D.V. \& ECTING J., Biosynthesis, processing and secretion of Pth and secretory protein, Rec. Progr. Horm. Res., 39, 181-209, 1983.

COLLIP J.B., The extraction of a parathyroid hormone which will prevent or control parathyroid tetany and which regulates the level of blood calcium, J. Biol. Chem., 63, 395-438, 1925.

COLLIP J.B., The parathyroid glands, Harvey lect., 21, 113, 1925-1926.

COPP D.H., Parathyroids, calcitonin and control of plasma calcium, Rec. Progr. Horm. Res., 20, 59-77, 1964.

COPP D.H., Endocrine control of calcium homeostasis, J. Endocrinol., 43, 137-161, 1969.

COPP D.H. \& coll., Evidence for calcitonin, a new hormone from the parathyroid that lowers blood calcium, Endocrinology, 70, 638-649, 1962.

Handbook of Physiology, sect. 7, VII. Parathyroid gland, 1976.

HAUSSLER M.R. \& coll., Molecular biology of the vitamine D hormone, Rec. Progr. Horm. Res., 44, 263-305, 1988.

HUGHES M.R. \& coll., Point mutations in the human vitamine D receptor gene associated with hypocalcemic rickets, Science, 242, 1702-1705, 1988.

KRONENBERG H.M. \& coll., Structure and expression of the human parathyroid hormone gene, Rec. Progr. Horm. Res., 42, 641-664, 1986.

LEE H.S., Mc CUAIG K.A. \& WHITE J.H., Structure et expression tissulaire spécifique du gène codant pour le récepteur de l'hormone parathyroïdienne, Médecine/Sciences, 12, 183-188, 1996.

MILHAUD G., Données récentes sur la thyrocalcitonine, Ann. Endocrinol. (Paris), 29, 563-575, 1968.

MILHAUD G. \& JOB J.C., Thyrocalcitonin : effect on idiopathic hypercalcemia, Science, 154, 794-796, 1966.

PEARCE S.H. \& THAKKER R.V., The calcium-sensing receptor : insight into extracellular calcium homeostasis in health and disease, J. Endocrinol., 154, 371-378, 1997.

POTTS J.T. Jr \& coll., The amino acid sequence of porcine thyrocalcitonin, Proc. Natl. Acad. Sci. (USA), 59, 1321-1328, 1968.

ROSENFELD M.G. \& coll., Altered expression of the calcitonin gene associated with RNA polymorphism, Nature, 290, 63-65, 1981.

ROSENFELD M.G. \& coll., Calcitonin, prolactin and growth hormone gene expression as model systems for the characterization of neuroendocrine regulation, Rec. Progr. Horm. Res., 39, 305-351, 1983.

ROSENFELD M.G., AMARA S.G. \& EVANS R.M., Alternative RNA processing events as a critical developmental regulatory strategy in neuroendocrine gene expression, Biochem. Soc. Symp., 49, 27-44, 1985.

TALMAGE R.V. \& BELANGER L.F. (eds), Parathyroid hormone and thyrocalcitonin (calcitonin), Excerpta Med. Found., Amsterdam, 1968.

THOMSON D.L. \& COLLIP J.B., The parathyroid glands, Physiol. Rev., 12, 309-383, 1932. 


\section{LES STRUCTURES ENDOCRINES DIFFUSES}

\section{Le thymus}

BACH J.F., Immunologie, Flammarion, Paris, 1976-1979.

BACH J.F. \& CARNAUD C., Thymic factors, Prog. Allergic, 21, 342-408, 1976.

BACH J.F. \& coll., Evidence for a serum-factor secreted by the human thymus, Lancet, 2 : 7786, 1056-1058, 1972.

COMSA J., Hormones interactions of the thymus, in "Thymic Hormones", Luckey T.D. ed., Univ. Park Press, Baltimore, 1973.

COMSA J. \& coll., Hormonal influences on the secretion of the thymus, Thymus, 1, 81-93, 1979.

COMSA J. \& coll., Hormonal coordination of the immune response, Rev. Physiol. Biochem. Pharmacol., 92, 115-191, 1982.

DESCHAUX P., Le thymus, organe endocrinien, J. Physiol., 76, 357-371, 1980.

GOLDSTEIN A.L. \& coll., Preparation, assay and partial purification of a thymic lymphocytopoietic factor (thymosin), Proc. Natl. Acad. Sci. (USA), 56, 1010-1017, 1966.

GOLDSTEIN G., The isolation of thymopoietin (thymosin), Ann. N.Y. Acad. Sci., 28, 177-185, 1975.

MILLER J.F. \& MITCHELL G.F., Thymus and antigen reactive cells, Transplant. Rev., 1, 3-42, 1969.

\section{Les hormones gastro-intestinales}

BLOOM S.R., Hormones of the gastrointestinal tract, Brit. Med. Bull., 30, 62-67, 1974.

CHISHOLM D.I. \& coll., The gastrointestinal stimulus to insulin release. I. Secretin, J. Clin. Invest., 48, 1453-1460, 1969.

GOLDE D. \& GASSON J., Les cellules du sang et leurs hormones, Pour la Science, 131, 64-73, 1988.

GREGORY R.A. \& TRACY H.J., The constitution and properties of two gastrins extracted from hog antral mucosa, Gut, 5, 103-117, 1964.

GROSSMAN M.I., Gastrointestinal hormones, Physiol. Rev., 30, 33, 1950.

HAMMOND C. \& coll., Cholecystokinin induces a decrease in $\mathrm{Ca}^{++}$current in snail neurons that appears to be mediated by protein kinase C, Nature, 325, 809-811, 1987.

JORPES E., The isolation and chemistry of secretin and cholecystokinin, Gastroenterology, 55, 157-164, 1968.

JORPES E. \& MUTT V., Gastrointestinal hormones, in "The hormones", Pincus G., Thimann K.V. \& Astwood E.B. eds, vol. 4, 365, Academic Press, New York, 1964.

LE DOUARIN N.M. \& TEILLET M.A., The migration of neural crest to the wall of the digestive tract in avian embryo, J. Embryol. Exp. Morpho., 30, 31-48, 1966. 
PRESHAW R.M. \& coll., Pancreatic secretion induced by stimulation of the pyloric gland area of the stomach, Science, 148, 1347-1348, 1965.

SCHAYER R.W. \& IVY A.C., Evidence that histamine is a gastric secretory hormone in the rat, Am. J. Physiol., 189, 369-372, 1957.

\section{L'érythropoïétine}

ERSLEV A.J., The erythropoietic effect of hematocrit variations in normovolemic rabbits, Blood, 27, 629-636, 1966.

JACOBSON L.O. \& coll., Studies of erythropoietin : the hormone regulating red cell production, Ann. N.Y. Acad. Sci., 77, 551-573, 1959.

KAMEL M., L'érythropoiétine est devenue médicament, Quotidien Méd., 4129, 5-6, 1988.

LACOMBE C.\& MAYEUX P., L’érythropoïétine, Médecine/Sciences, 11, 947-955, 1995.

REISSMANN K.R. \& SAMORAPOOMPICHIT S., Effect of erythropoietin on regeneration of hematopoietic stem cells after 5-fluorouracil administration, J. Lab. Clin. Med., 73, 544-550, 1969.

SKEGGS L.T. \& coll., The amino acid sequence in hypertensin II, J. Exp. Med., 104, 193-197, 1956.

VARET B., L'érythropoïétine, quel avenir, Médecine/Sciences, 11, 943-945, 1995.

\section{L'ANF}

ATLAS A.A., Atrial natriuretic factor : a new hormone of cardiac origin, Rec. Progr. Horm. Res., 42, 207-239, 1986.

MENARD J. \& CORVOL P., Le facteur natriurétique auriculaire, Concours médical, 108, 3531-3533, 1986.

NEEDLEMAN P. \& GREENWALD J.J.E., Atriopeptin : a cardiac hormone intimately involved in fluid, electrolyte and blood pressure homeostasis, New Engl. J. Med., 314, 828-834, 1986.

STANDAERT D.G. \& coll., Inhibition of the firing of vasopressin neurones by atriopeptin, Nature, 329, 151-153, 1987.

VANTYGHEM M.C. \& LEFEBVRE J., Facteurs natriurétiques, Pathol. Biol., 35, 405-415, 1987.

\section{L'endothélium vasculaire}

FREMINET A. \& VERDETTI J., Hormones et fonctionnement de l'appareil cardiovasculaire in "Hormone et Grandes Fonctions", Dupouy J.P. coordinateur, 303-379, Ellipse, Paris, 1993.

\section{L'ÉPIPHYSE}

ACUNA-CASTROVIEJO D., PABLOS M.I., MENENDEZ-PELAEZ A. \& REITER R.J., Melatonin receptors in purified cell nuclei of liver, Res. Commun. Chem. Pathol. Pharmacol., 82, 253-256, 1993. 
ACUNA-CASTROVIEJO D., REITER R.J., MENENDEZ-PELAEZ A., PABLOS M.I. \& BURGOS A., Characterization of high-affinity melatonin binding sites in purified cell nuclei of rat liver, J. Pineal Res., 16, 100-113, 1994.

ARIONS KAPPERS J., The mammalian pineal gland, a survey, Acta Neurochir., 34, 109-149, 1976.

ASPLUND R., ABERG H. \& WETTERBERG L., Seasonal changes in the levels of antidiuretic hormone and melatonin in the elderly, J. Pineal Res., 18, 154158, 1995.

AXELROD J., The pineal gland : a neurochemical transducer. Chemical signals from nerves regulate synthesis of melatonin and convey information about internal clocks, Science, 184, 1341-1348, 1974.

BINKLEY S., Pineal gland biorhythms : N-acetyltransferase in chickens and rats, Fed. Proc., 35, 2347-2352, 1976.

BINKLEY S., The pineal : endocrine and nonendocrine function, Prentice Hall, 1988.

BINKLEY S. \& coll., The pineal gland : a biological clock in vitro, Science, 202, 1198-1201, 1978.

BLAS K D.E., PELLETIER D.B., HILL S.M., LEMUS-WIL S ON A., GROSSO D.S., WILSON S.T. \& WISE M.E., Pineal melatonin inhibition of tumor promotion in the $\mathrm{N}$-nitroso-N-methylurea model of mammary carcinogenesis : potential involvement of antiestrogenic mechanisms in vivo, J. Cancer Res. Clin. Oncol., 117, 526-532, 1991.

BOISSIN-AGASSE L. \& coll., Long-term effects of pinealectomy on testicular function, luteinizing hormone-releasing hormone hypothalamic system, and plasma prolactin levels in the mink, a short day breeder, J. Pineal Res., 5, 385-396, 1988.

BRAILOWSKY S., Effects of melatonin on the photosensitive epilepsy of the baboon, Papio papio, Electroen. Clin. Neuro., 41, 314-319, 1976.

C A R L B E R G C., H O O F T V a n H U I S D U I J E N R., S T A P L E J ., LAMARTER J.F. (de) \& BECKER-ANDRE M., RZRs, a new family of retinoid-related orphan receptors that function as both monomers and homodimers, Mol. Endocrinol., 8, 757-770, 1994.

CHEN L.D. \& coll., Melatonin prevents the suppression of cardiac $\mathrm{Ca}^{[2+]}$ stimulated ATPase activity induced by alloxan, Am. J. Physiol., 267, E57-62, 1994.

COHEN M., HEUSDEN A.M. (Van), VERDONK H.E.R. \& WIJNHAMER P., Melatonin/norethisterone contraception, in "Melatonin and the Pineal Gland, from basic sciences to clinical application", Touitou Y., Arendt J. \& Pévet P. eds, 339-345, Excerpta Medica, Amsterdam, 1993.

COHEN R.A. \& coll., Some clinical, biochemical and physiological actions of the pineal gland, Ann. Intern. Med., 61, 1144-1161, 1964.

COLLIN J.P. \& coll., Le troisième œil, la Recherche, 203, 1154-1165, 1988.

COLLIN J.P. \& coll., Pinéale et rétine, Médecine/Sciences, 4, 16-26, 1988.

DING C.H., WEI W. \& XU S.Y., Effects of pineal body and melatonin on lymphocyte proliferation and dinoprostone production in rat spleen, Chung Kuo Yao Li Hsueh Pao, 16, 54-57, 1995. 
D'SOUZA T. \& DRYER S.E., A cationic channel regulated by a vertebrate intrinsic circadian oscillator, Nature, 382, 165-167, 1996.

FERRARI E., MAGRI F., DORI D., MIGLIORATI G., NESCIS T., MOLLA G., FIORAVANTI M. \& SOLERTE S.B., Neuroendocrine correlates of the aging brain in humans, Neuroendocrinology, 61, 464-470, 1995.

FOSTER D.L. \& coll., Determinants of puberty in a seasonal breeder, Rec. Progr. Horm. Res., 42, 331-384, 1986.

GRAD B.R. \& ROZENCWAIG R., The role of melatonin and serotonin in aging : update, Psychoneuroendocrino., 18, 283-295, 1993.

HAGAN R.M. \& OAKLEY N.R., Melatonin comes of age ?, Trends Pharmacol. Sci., 16, 81-83, 1995.

HARDELAND R., BALZER I., POEGELLER B., FUHRBERG B., URIA H., BEHRMAN G., WOLF R., MEYER T.J. \& REITER R.J., On the primary functions of melatonin in evolution : mediation of photoperiodic signals in a unicell, photooxydation, and scavenging of free radicals, J. Pineal Res., 18, 104-111, 1995.

HUNTER-ENSOR M., OUSLEY A. \& SEHGAL A., Regulation of the Drosophila protein Timeless suggests a mechanism for resetting the circadian clock by light, Cell, 84, 677-685, 1996.

JANKOVIC B.D., NIKOLIC P., CUPIC V. \& HLADNI K., Potentiation of immune responsiveness in aging by static magnetic fields applied to the brain, Ann. N.Y. Acad. Sci., 719, 410-418, 1994.

JOCKERS R. \& coll., Structure et fonction des récepteurs de la mélatonine, CR Séances Soc. Biol. Fil., 192, 659-667, 1998.

KARSCH F.J. \& coll., Neuroendocrine basis of seasonal reproduction, Rec. Progr. Horm. Res., 40, 185-225, 1984.

KLEIN D.C., Circadian rhythms in the pineal gland, in "Endocrine rhythms", Krieger D.T. ed., 203-223, Raven Press, New York, 1979.

KLEIN D.C., SUGDEN D. \& WELLER J.L., Postsynaptic alpha-adrenergic receptors potentiate the beta-adrenergic stimulation of pineal serotonin N-acetyltransferase, Proc. Natl. Acad. Sci. (USA), 80, 599-603, 1983.

KONOPKA R. \& BENZER S., Clock mutants of Drosophila melanogaster, Proc. Natl. Acad. Sci. (USA), 68, 21-26, 1971.

LEACH C.M. \& THORBURN G.D., A comparison of the inhibitory effects of melatonin and indomethacin on platelet aggregation and thromboxane release, Prostaglandins, 20, 51-56, 1980.

LEGAIT H. \& LEGAIT E., Contribution à l'étude de la glande pinéale humaine. Etude faite à l'aide de 747 glandes, Bull. Ass. Anat., 61, 107-121, 1977.

LEIVA A. (de), TORTOSA F., PEINADO M.A., SERRANO J., RODRIGUEZESPINOSA J. \& PUIG-DOMINGO M., Episodic nycthemeral secretion of melatonin in adult humans : lack of relation with LH pulsatile pattern, Acta Endocrinologica (Copenhagen), 122, 76-82, 1990.

MAESTRONI G.J.M., CONTI A. \& PIERPAOLI W., Melatonin, stress and the immune system, Pineal Res. Rev., 7, 203-226, 1989. 
MARTIN-CACAO A., LOPEZ-GONZALEZ M.A., REITER R.J., CALVO J.R. \& GUERRERO J.M., Binding of 2-[1251] melatonin by rat thymus membranes during post natal development, Immunol. Lett., 36, 59-63, 1993.

MASORO E.J., Food restriction in rodents : an evaluation of its role in aging, J. Gerontol., 43, B59-B64, 1988.

MASSION A.O., TEAS J., HEBERT J.R., WERTHEIMER M.D. \& KABATZINN J., Meditation, melatonin and breast/prostate cancer : hypothesis and preliminary data, Med. Hypotheses, 44, 39-46, 1995.

MATTHEWS C.D., GUERIN M.V. \& WANG X., Human plasma melatonin and urinary 6-sulphatoxymelatonin : studies in natural annual photoperiod and in extended darkness, Clin. Endocrinol., 45, 21-27, 1991.

MENENDEZ-PELAEZ A., POEGGELER B., REITER R.J., BARLOWWALDEN L.R., PABLOS M.I. \& TAN D.X., Nuclear localization of melatonin in different mammalian tissues: immunocytochemical and radioimmunoassay evidence, J. Cell Biochem., 53, 372-382, 1993.

MONTOLEONE P., FUSCHINO A., NOLFE G. \& MAJ M., Temporal relationship between melatonin and cortisol responses to nighttime physical stress in humans, Psychoneuroendocrino., 17, 81-86, 1992.

MURIALDO G., COSTELli P., FONZI S., PARODI C., TORRE F., CENACCHI T. \& POLLERI A., Circadian secretion of melatonin and thyrotropin in hospitalized aged patients, Aging (Milano), 5, 39-46, 1993.

OLCESE J., The neurobiology of magnetic fields detection in rodents, Prog. Neurobiol., 35, 325-330, 1990.

PEVET P., The role of the pineal gland in the photoperiodic control of reproduction in different hamster species, Reprod. Nutr. Dev., 28, 443-458, 1988.

PIERPAOLI W. \& MAESTRONI J.M., Melatonin : a principal neuroimmunoregulatory and anti-stress hormone : its anti-aging effects, Immunol. Lett., 16, 355-362, 1987.

PIERPAOLI W. \& REGELSON W., Pineal control of aging : effects of melatonin and pineal grafting on aging mice, Proc. Natl. Acad. Sci. (USA), 91, 787-791, 1994.

PIERREFICHE G. \& LABORIT H., Oxygen free radicals, melatonin and aging, Exp. Gerontol., 30, 213-227, 1995.

PIERREFICHE G., TOPPAL G., COURBAIN G., HENRIET I. \& LABORIT H., Antioxidant capacity of melatonin in mice, Res. Commun. Chem. Pathol. Pharmacol., 80, 211-223, 1993.

REITER R.J., Circannual reproductive rhythms in mammals related to photoperiod and pineal function : a review, Chronobiologia, 1, 365-395, 1974.

REITER R.J., Pineal and associated neuroendocrine rhythms, Psychoneuroendocrino., 5, 219-255, 1977.

REITER R.J. (ed.), J. Pineal Res., New York, 1984 \& années suivantes.

REITER R.J., Melatonin as a free radical scavenger : implication for aging and agerelated diseases, Ann. N.Y. Acad. Sci., 719, 1-12, 1994.

REITER R.J., Pineal function during aging : attenuation of the melatonin rhythm and its neurobiological consequences, Acta Neurobiol. Exp. Warsz., 54 suppl., 3139, 1994. 
REITER R.J., The pineal gland and melatonin in relation to aging : a summary of the theories and of the data, Exp. Gerontol., 30, 199-212, 1995.

REITER R.J., TAN D.X., POEGGELER B., MENENDEZ-PELAEZ A., CHEN L.D. \& SARRELA S., Melatonin as a free radical scavenger: implication for aging and age-related diseases, Ann. N.Y. Acad. Sci., 719, 1$12,1994$.

REITER R.J., MELCHIORI D., SEWERYNEK E., POEGELLER B., BARLOWWALDEN L., CHUANG J., ORTIZ G.G. \& ACUNA-CASTROVIEJO D., A review of the evidence supporting melatonin's role as an antioxidant, J. Pineal Res., 18, 1-11, 1995.

SHEPHERD G.M., Neurobiology, Oxford Univ. Press, 1983.

STEHLE J.H., FOULKES N.S., MOLINA C.A., SIMMONNEAUX V., PEVET P. \& SASSONE-CORSI P., Adrenergic signals direct rhythmic expression of transcriptional repressor CREM in the pineal gland, Nature, 365, 314-320, 1993.

STOKKAN K.A., REITER R.J., NONAKA K.O., LERCHI A., YU B.P. \& VAUGHAN M.K., Food restriction retards aging of the pineal gland, Brain Res., 545, 66-72, 1991.

T A N D.X., CHEN D.X., POEGGELER B., M A N CHESTER L.C.\& REITER R.J., Melatonin : a potent, endogenous hydroxyl radical scavenger, Endocr. J., 1, 57-60, 1993.

TOUITOU Y. \& HAUS E., Aging of the human endocrine and neuroendocrine time structure, Ann. N.Y. Acad. Sci., 719, 378-397, 1994.

TOUITOU Y., FEVRE M., BOGDAN A., REINBERG A., PRINS J. (de), BECK H. \& TOUITOU C., Pattern of plasma melatonin with ageing and mental condition : stability of nycthemeral rhythms and differences in seasonal variations, Acta Endocrinol., 106, 145-151, 1984.

TRENTINI G.P., GENAZZANI A.R., CRISCUOLO M., PETRAGLIA F., GAETANI C. (de), FICARRA G., BIDZINSKA B., MIGALDI M. \& GENAZZANI A.D., Melatonin treatment delays reproductive aging of female rat via the opianergic system, Neuroendocrinology, 56, 364-370, 1992.

TUREK F.W. \& coll., Role of circadian system in reproductive phenomena, Rec. Progr. Horm. Res., 40, 143-177, 1984.

VACAS M.I., KELLER-SARMENTO M.I. \& CARDINALI D.P., Melatonin increases cGMP and decreases cAMP levels in rat medial basal hypothalamus in vitro, Brain Res., 225, 207-211, 1981.

VANECEK J., Cellular mechanisms of melatonin action, Physiol. Rev., 78, 687-721, 1998.

VESELY D.L., Melatonin enhances guanylate cyclase activity in a variety of tissues, Mol. Cell Biochem., 35, 55-58, 1981.

VOORDOUW B.C.G., EUSER R., VERDONK R.E.R., ALBERDA B.T.H., DE JONG F.H., DROGENDIJK A.C., FAUSER B.C.J.M. \& COHEN M., Melatonin and melatonin-progestin combinations alter pituitary-ovarian function in women and can inhibit ovulation, J. Clin. Endocr. Metab., 74, 108$117,1992$. 
WALDHAUSER F., ERHART B. \& FORSTER E., Clinical aspects of the melatonin action : impact of development, aging, and puberty, involvement of melatonin in psychiatric disease and importance of immunoendocrine interactions, Experientia, 49, 671-681, 1993.

WEAVER D.R., STEHLE J.H., STOPA E.G. \& REPPERT S.M., Melatonin receptors in human hypothalamus and pituitary : implications for circadian and reproductive responses to melatonin, J. Clin. Endocr. Metab., 76, 295-301, 1993.

WEBB S.M. \& PUIG-DOMINGO M., Role of melatonin in health and disease, Clin. Endocrinol., 42, 221-234, 1995.

WEISSBLUTH L. \& WEISSBLUTH M., Sudden infant death syndrome : a genetically determined impaired maturation of the photoneuroendocrine system. A unifying hypothesis, J. Theor. Biol., 167, 13-25, 1994.

WILSON B.W., STEVENS R.G. \& ANDERSON L.G., Neuroendocrine mediated effects of electromagnetic field exposure : possible role of the pineal gland, Life Sci., 45, 1319-1332, 1989.

YU B.P., Oxidative damage by free radicals and lipid peroxidation in aging, in "Free Radicals in Aging", Yu B.P. ed., 57-88, CRC Press, 1993. 



\section{TROISIÈME PARTIE}

\section{ENDOCRINOLOGIE DE LA REPRODUCTION}

Chapitre 11 Généralités sur les appareils de reproduction

Chapitre 12 Physiologie de l'appareil de reproduction femelle

Chapitre 13 Physiologie de l'appareil de reproduction mâle

Chapitre 14 Fécondation - Gestation - Lactation

Chapitre 15 La commande de la reproduction 

CHAPITRE 11

\section{GÉNÉRALITÉS SUR LES APPAREILS \\ DE REPRODUCTION}

\section{ORGANOGENÈSE}

\subsection{ETAT SEXUEL INDIFFÉRENCIÉ}

Entre la $4 \mathrm{e}$ et la $10^{\mathrm{e}}$ semaine du développement embryonnaire, l'appareil reproducteur est identique dans les deux sexes, c'est l'état sexuel indifférencié.

Dans la région lombaire de l'embryon, à la face antéro-interne du corps de Wolff ou mésonéphros (voir fig. 11.1 et 11.2), s'individualise une saillie longitudinale : la crête génitale.

A ce niveau, le cœlome recouvrant prolifère et produit des cordons épithéliaux, les cordons sexuels dont les cellules, les gonocytes primordiaux, s'enfoncent dans le mésenchyme sous-jacent pour se regrouper à l'intérieur des canaux de Wolff et de Müller et constituer la gonade primordiale qui persistera jusqu'à la fin de la $6^{\mathrm{e}}$ semaine. La gonade est reliée au canal de Wolff par un réseau anastomotique : le rete ou tubes mésonéphrotiques qui se jettent dans le canal de Wolff, conduit excréteur qui part du diaphragme en haut, descend verticalement en direction du pelvis au niveau duquel il s'abouche dans le sinus urogénital ou cloaque urogénital, individualisé dès lors que naît l'éperon périnéal séparant le compartiment urogénital antérieur de la partie digestive postérieure. Les canaux de Müller, également symétriques et bilatéraux, dérivent aussi d'une invagination du cœlome dans le mésenchyme immédiatement externe aux canaux de Wolff. Ils prennent naissance au niveau d'un pavillon supérieur, sous-diaphragmatique, longent le mésonéphros en dehors duquel ils descendent, se rejoignent sur la ligne médiane et s'abouchent en canon de fusil à l'intérieur des canaux de Wolff dans le sinus urogénital.

\subsection{LA DIFFÉRENCIATION MÂLE (fig. 11.1.a et 11.2.b)}

Elle est conditionnée par l'existence du gène TDF (testis determining factor) que portent les chromosomes $\mathrm{Y}$, par la présence de l'antigène $\mathrm{H}-\mathrm{Y}$ qui a le pouvoir de 
réprimer la féminité, par la sécrétion de testostérone des cellules de Leydig et enfin par la production de l'hormone antimüllérienne des cellules de Sertoli.

La gonade primitive engendre le testicule, dans lequel se différencient les tubes séminifères, sites de la spermatogenèse alors que, dans le tissu interstitiel, s'individualisent les cellules androgéno-sécrétantes de Leydig. Ce faisant, le canal de Wolff et le mésonéphros suivent la descente testiculaire dans les bourses et, alors que la portion juxtagonadique génère l'épididyme et le canal déférent, la portion terminale du canal de Wolff engendre l'urètre, la prostate et les vésicules séminales. On doit remarquer que le conduit excréteur mésonéphrotique terminal, à partir de la prostate, est commun aux voies urinaires et génitales.

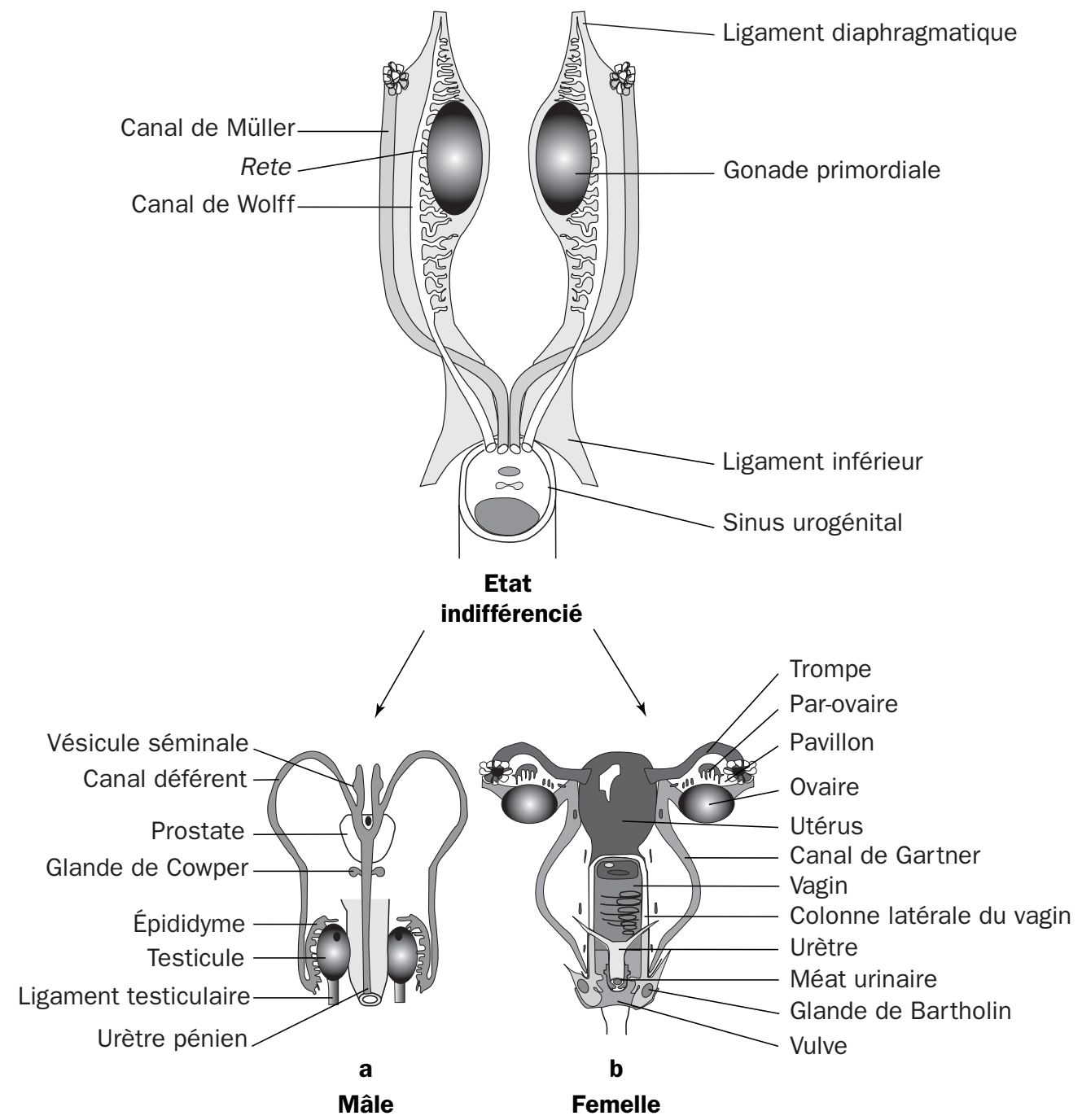

Figure 11.1 - Embryogenèse de la gonade humaine (vues anatomiques) 
Pendant la mise en œuvre de cette différenciation, les canaux de Müller s'atrophient et disparaissent en laissant un reliquat vestigial : l'utricule prostatique. Ainsi mise en place, cette anatomie du mâle va entrer dans une période de quiescence relative qui va durer jusqu'à la puberté.

\subsection{LA DIFFÉRENCIATION FEMELLE (fig. 11.1.b et 11.2.a)}

La différenciation femelle est réalisée quand il y a absence d'antigène $\mathrm{H}-\mathrm{Y}$, de testostérone et d'hormone antimüllérienne.

Dans l'ovaire, les gonocytes primordiaux s'entourent de cellules folliculaires et engendrent les follicules primordiaux. Le corps de Wolff involue et ne persiste que sous forme de reliquats vestigiaux au niveau du canal de Gärtner qui longe le bord externe de l'utérus et la colonne latérale du vagin où parfois il est possible d'observer des kystes vestigiaux.

Les canaux de Müller s'accolent au niveau de leur tiers moyen, réalisant ainsi de haut en bas les trompes ou salpinx, le corps et le col utérins, ainsi que les $4 / 5$ supérieurs du vagin.

\subsection{LES ORGANES GÉNITAUX EXTERNES}

Au niveau des organes génitaux externes, prennent place les mêmes séquences évolutives de la différenciation sexuelle.

Lors de la $5^{\mathrm{e}}$ semaine, l'embryon indifférencié présente sur la face ventrale inférieure de l'abdomen une éminence génitale qui comprend, en avant, un tubercule génital, futur gland ou clitoris et, latéralement, le gonflement labioscrotal qui entoure le sinus urogénital, invagination ectodermique qui deviendra l'urètre terminal. Dans la partie postérieure du sinus urogénital apparaît le septum urogénital ou périnée primitif séparant le compartiment anal, digestif, postérieur, du compartiment génital antérieur que représentera la verge ou le vagin.

Vers la 7 e semaine, s'amorce la différenciation mâle ou femelle. Chez le mâle, le tubercule génital prend des allures de verge ou phallus, l'invagination urétrale se ferme sur le raphé périnéal médian, les plis labioscrotaux latéraux forment les bourses et s'intègrent dans les sillons génito-cruraux. En cas de différenciation femelle, le gland s'atrophie, engendre le clitoris et son capuchon, alors que les éminences latérales forment les grandes lèvres pendant que l'urètre terminal se constitue et que, à la partie externe de l'invagination urétrale, apparaissent les petites lèvres ou nymphes ainsi que l'hymen. Le méat urinaire s'abouche en avant au niveau de la commissure antérieure, alors que la fourchette ou commissure postérieure sépare la vulve de l'anus par le périnée fibreux. 


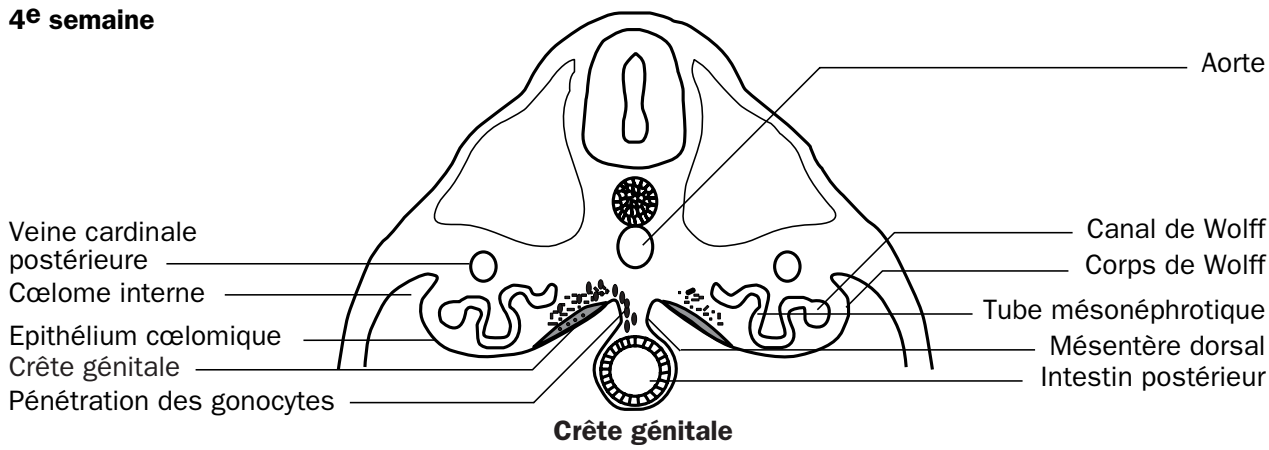

Stade indifférencié $\left(\rightarrow 10^{\mathrm{e}}\right.$ semaine $)$

\section{$15^{e}$ semaine}
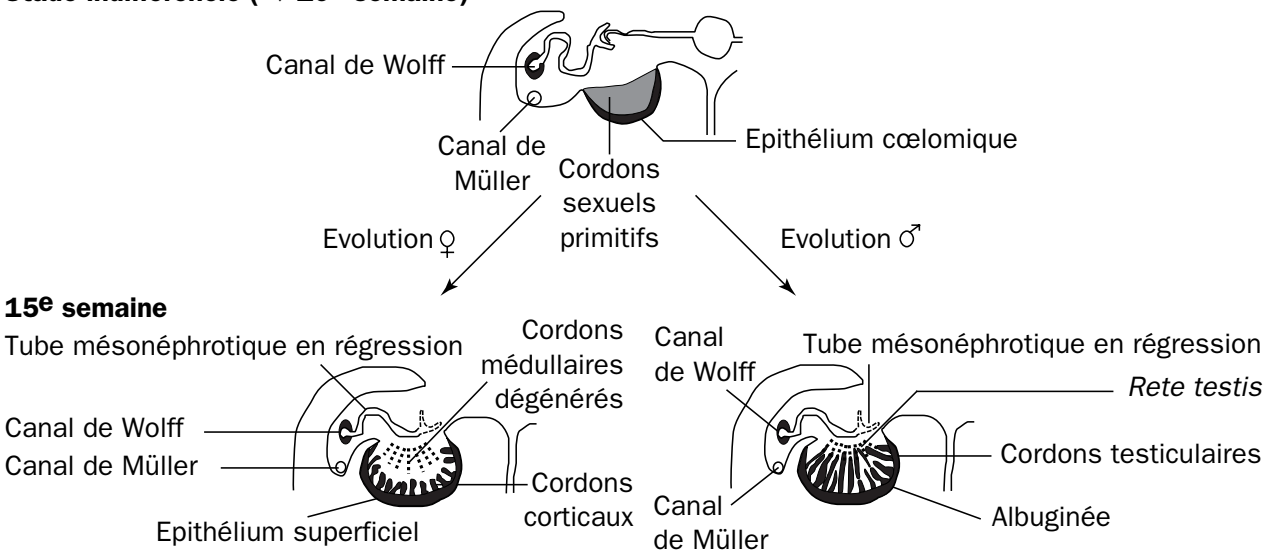

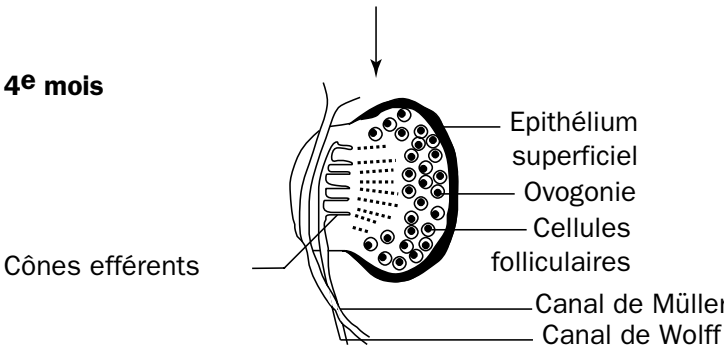

a

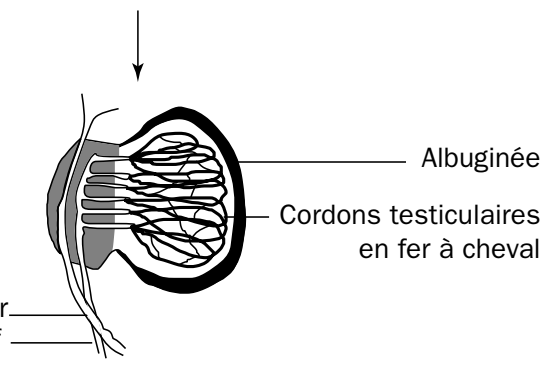

b

Figure 11.2 - Embryogenèse de la gonade humaine (coupes histologiques)

\subsection{LES ANOMALIES DE LA DIFFÉRENCIATION SEXUELLE}

Elles ne sont pas rares, surtout les anomalies de la descente testiculaire avec de fréquentes cryptorchidies, de même les troubles de la fermeture urétrale avec les hypospades (péniens ou scrotaux).

Chez la femme, en clinique humaine, on rencontre des imperforations hyménales, des aplasies vaginales, des duplications génitales plus ou moins importantes ou des cloisons vaginales par trouble de la résorption du canal terminal de Müller. 


\section{BASES ANATOMIQUES DES APPAREILS DE REPRODUCTION}

Directement dérivées de l'organogenèse, elles permettent très schématiquement de distinguer :

\subsection{LES CARACTÈRES SEXUELS PRIMAIRES}

Constitués dès la naissance, ils sont représentés par (voir fig. 11.1 et 11.2)

- les gonades : ovaires ou testicules,

- la filière génitale : oviducte ou trompe, utérus, corps et col, vagin et vulve chez la femelle, cônes efférents, épididyme et canal déférent chez le mâle,

- les glandes annexes : principalement les glandes de Bartholin chez la femme, les vésicules séminales, la prostate et les glandes de Cowper chez l'homme.

\subsection{LES CARACTÈRES SEXUELS SECONDAIRES}

Ils sont le propre de la maturité sexuelle ; hormonodépendants, ils conditionnent le comportement psychosexuel, des modifications somatiques comme la pilosité chez l'homme, la crinière du lion, le bois des cervidés, la crête chez le coq...

Chez les Vertébrés, les gonades sont des glandes mixtes, à la fois endocrines du fait des hormones sécrétées et exocrines en élaborant les gamètes.

Chez les Invertébrés, la gonade ne fabrique que les gonocytes ; l'hormone de la glande androgène chez les Crustacés, présente chez le mâle seulement, détermine à la fois les caractères sexuels primaires et secondaires. 



\section{CHAPITRE 12}

\section{PHYSIOLOGIE DE L'APPAREIL DE REPRODUCTION FEMELLE}

\section{GAMÉTOGENÈSE ET FOLLICULOGENÈSE}

La gamétogenèse correspond à la formation et à la maturation des gamètes ; c'est la spermatogenèse chez l'homme (voir chap. $13, \S 2$ ) et l'ovogenèse chez la femme.

La gamétogenèse a pour fonction principale de préparer les gamètes à une éventuelle fécondation, c'est-à-dire d'obtenir des cellules haploïdes à $n$ chromosomes qui donneront par leur union un zygote ou œuf à $2 \mathrm{n}$ chromosomes.

Chez la femme, la gamétogenèse est indissociable de la folliculogenèse : longue période de maturation allant du follicule primordial depuis le moment où il sort de la réserve ovarienne et évolue, en passant par diverses étapes qui aboutissent au follicule mûr pré-ovulatoire.

\subsection{ASPECTS MORPHOLOGIQUES DE LA FOLLICULOGENÈSE}

Morphologiquement, cette maturation s'accompagne de modifications ovocytaires et folliculaires séparées en cinq stades (fig. 12.1).

- Le follicule primordial mesure 15 à $25 \mu \mathrm{m}$; il est formé par l'association d'une cellule germinale, l'ovogonie ou ovocyte primordial (de premier ordre), qu'entoure une seule couche de cellules folliculaires dites de la granulosa et une fine membrane lamellaire, la membrane de Slavjansky.

- Le follicule primaire a une taille plus importante $(50 \mu \mathrm{m}) \mathrm{du}$ fait de la forte augmentation volumétrique du noyau de l'ovocyte situé au centre du follicule. Une seule couche de cellules folliculaires entoure le gamète.

- Le follicule secondaire, dit encore follicule plein, poursuit sa croissance, mesure de 50 à $500 \mu \mathrm{m}$, avec un gros ovocyte central qu'entourent quatre à cinq couches de cellules de la granulosa. La multiplication de ces dernières est très active, au point que, à ce stade, on peut bien distinguer une couche péri-ovocytaire, la corona radiata, séparée du gamète par la membrane pellucide, dite encore membrane vitelline. 


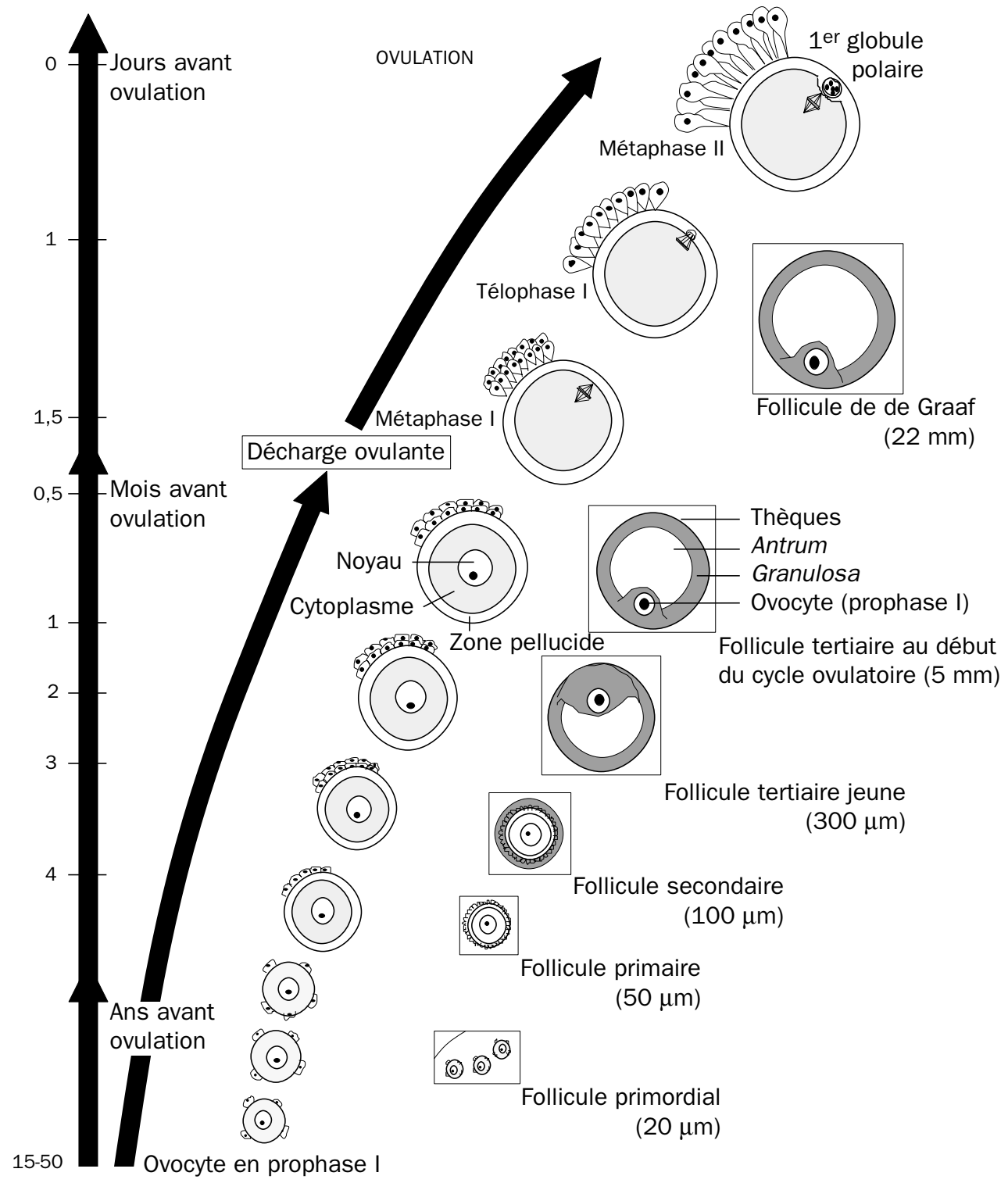

Figure 12.1 - L'ovogenèse chez les Mammifères (d'après Testart, 1982)

- Le follicule antral (cavitaire ou tertiaire) de $500 \mu \mathrm{m}$ à 10-15 mm de diamètre, avec un ovocyte de l'ordre de $100 \mu \mathrm{m}$ disposé de façon excentrique et six à dix couches de cellules de la granulosa creusées de l'antrum du fait de la production de liquor folliculi. A l'extérieur de la membrane de Slavjansky se sont différenciées deux thèques :

- la thèque externe, principalement conjonctive et fibreuse,

- la thèque interne, véritable glande endocrine avec ses cordons cellulaires richement vascularisés. 
- Le follicule pré-ovulatoire, ou follicule de de Graaf, terme de cette évolution, est encore beaucoup plus gros, puisque sa taille peut dépasser 15-30 $\mathrm{mm}$ de diamètre. C'est le follicule mûr avec ses structures histologiquement bien différenciées.

\subsection{ASPECTS DYNAMIQUES DE LA FOLLICULOGENÈSE}

D'un point de vue dynamique, dans l'espèce humaine, la production ovocytaire s'étale sur une période relativement brève entre 12 ans, âge habituel de la puberté, et 50 ans, âge de la ménopause. Cependant l'évolution de la lignée germinale commence très tôt, dès la période fotale. En effet, entre le $2^{\mathrm{e}}$ et le $7^{\mathrm{e}}$ mois de la vie intra-utérine, la corticalité de l'ovaire fœetal est le siège d'une active multiplication des ovogonies (6 à 7 millions à 5 mois de gestation) qui atteignent près du terme le nombre de plusieurs millions ; un capital unique et définitif qui constitue le pool de réserve primordial. Toutes ces ovogonies à $2 \mathrm{n}$ chromosomes, dès leur différenciation, ont amorcé une méiose qui s'est bloquée en prophase au stade diplotène.

A la naissance, les ovaires ne possèdent plus que 2 millions d'ovocytes primaires, prouvant ainsi qu'un assez grand nombre d'entre eux a déjà involué. Lors de l'enfance, 90\% des follicules primordiaux, ainsi que leurs ovocytes, vont évoluer au maximum jusqu'au stade antral et ensuite dégénérer. A la puberté, il ne reste plus dans l'ovaire que 100 à 400000 follicules primordiaux dont le plus grand nombre va encore s'atrésier à divers stades de l'évolution, pour ne laisser, à 45 ans, qu'un stock de réserve de l'ordre de 1500 éléments.

Pendant le cycle, en début de phase folliculaire, dix à quarante follicules sortent de la réserve, seule une cohorte de cinq à dix follicules tertiaires sont recrutés, un seul, dit follicule dominant ${ }^{1}$, va ovuler, terminer la division réductionnelle de la méiose, émettre le premier globule polaire et engendrer l'ovocyte de deuxième ordre, haploïde, en attente d'une éventuelle fécondation. Ainsi, seulement 500 ovocytes ont le privilège de terminer leur ultime évolution pendant les 40 ans que dure la vie de reproduction. Seuls ces 500 ovocytes auront la possibilité de décondenser le noyau spermatique lors de la fécondation. Si l'on considère l'importance du stock initial et le résultat final, la disparition de la plupart des cellules germinales (99\% des follicules qui entrent en croissance dégénèrent au cours de leur développement) apparaît comme un gaspillage phénoménal. On sait qu'il faut 25 jours pour passer du follicule secondaire au follicule antral, que 60 jours sont nécessaires à celui-ci pour mûrir et devenir "pré-ovulatoire". Ainsi, le follicule qui ovule à un cycle donné a commencé son ultime évolution au moins trois cycles auparavant (fig. 12.2). Ceci laisse escompter que les résultats d'une thérapeutique sur le follicule seront complets seulement 3 mois après son administration.

1 La "dominance" pourrait résulter, selon Dizerega et coll. (1980), de la sécrétion par le follicule dominant d'une protéine appelée FRP (follicular regulary protein), qui jusqu'à présent n'a pas encore été identifiée. 


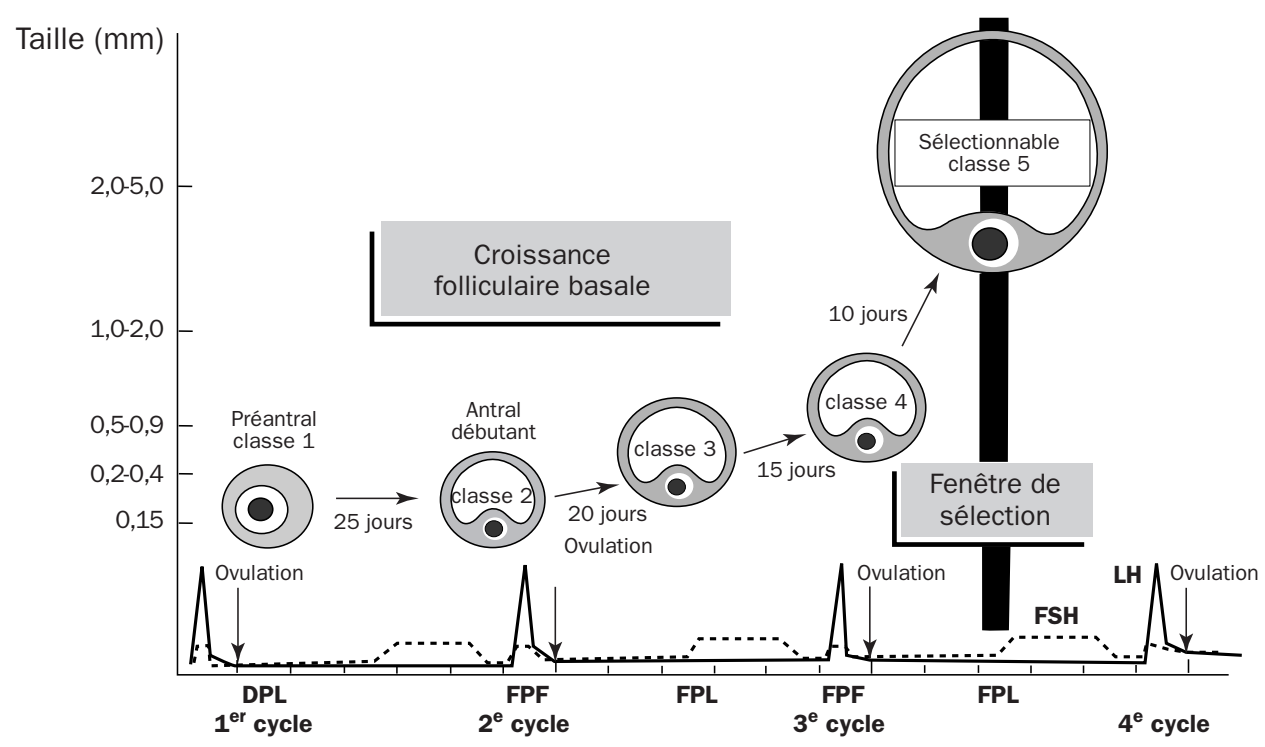

Figure 12.2 - Chronologie du développement folliculaire de la cohorte d'où sera issu le follicule ovulatoire (d'après Gougeon, 1996)

DPL : début de phase lutéale ; FPF : fin de phase folliculaire ; FPL : fin de phase lutéale ; FSH : follicle stimulating hormone ; $\mathrm{LH}$ : luteinizing hormone.

On peut définir deux grandes phases dans la croissance du follicule ovarien :

- une phase de croissance "basale" des cellules de la granulosa, qui va du stade follicule primordial au stade follicule de $5 \mathrm{~mm}$ chez la femme. Cette phase est indépendante de l'action des gonadotrophines, elle est essentiellement sous la dépendance de facteurs de croissance à action paracrine. D'après des expériences "in vitro", ces facteurs appartiennent à la famille de l'EGF (epidermal growth factor), des IGF (insulin-like growth factor), du TGF $\beta$ (transforming growth factor) et du FGF (fibroblast growth factor).

L'absence d'hormonosensibilité de la phase initiale de la folliculogenèse implique qu'elle est difficile sinon impossible à manipuler en clinique humaine par opposition à l'évolution terminale de la cohorte folliculaire recrutée en début de cycle, directement liée aux taux de FSH en phase menstruelle et en tout début de première phase.

- une phase de croissance "dépendante des gonadotrophines", qui va de la fin de la croissance "basale" jusqu'à l'ovulation. La folliculogenèse ovarienne est donc caractérisée par des processus d'intense prolifération puis de différenciation (stéroïdogenèse) des cellules de la granulosa dans les follicules en croissance, mais aussi d'apoptose dans les follicules atrétiques. Des expériences de transgenèse chez la souris ont permis de confirmer le fonctionnement des gènes impliqués dans la régulation endocrine et paracrine de ces phénomènes (Monget et coll., 1999). 
La sélection folliculaire correspondant à l'émergence du follicule ovulatoire est en relation avec le rétro-contrôle négatif de l'inhibine et l'œstradiol qui détermine, d'une part, l'involution des follicules hormonosensibles et, d'autre part, l'évolution terminale du follicule dominant qui deviendra ovulatoire. Dès le stade pré-ovulatoire, le follicule dominant (parfois plusieurs dans les grossesses multiples) est détectable par exploration cœlioscopique ou par échographie pelvienne. Il mesure de 15 à $20 \mathrm{~mm}$, bombe en général au niveau de la corticalité ovarienne et s'apprête à subir les profondes modifications contemporaines de la ponte ovulaire.

La maturation de l'ovocyte est souvent associée à la méiose. Cependant elle recouvre également des phénomènes cytoplasmiques moins bien connus mais d'une grande importance. Cette maturation, très complexe, va permettre à l'ovule d'acquérir sa capacité d'assumer la fécondation et de préparer le développement embryonnaire. Trois aspects (noyau, cytoplasme et environnement somatique) vont évoluer pour déterminer cette capacité :

1. au niveau du noyau, la reprise de la méiose correspondrait à un passage entre le stade $\mathrm{G} 2$ et le stade $\mathrm{M}$ du cycle cellulaire. Cette reprise repose sur l'activation du MPF (M-phase promoting factor), hétérodimère composé de la protéine $\mathrm{P} 34 \mathrm{Cdc} 2$ et d'une cycline B. L'ovocyte restera alors en métaphase II jusqu'à l'entrée du spermatozoïde. Le blocage à ce stade est dû à un facteur cytostatique dont la nature n'est pas encore établie.

2. au niveau du cytoplasme, c'est la concentration des granules corticaux aux abords de la membrane plasmique. Il s'agit de petites vésicules sphériques de 200 à $600 \mathrm{~nm}$ de diamètre ; la libération de leur contenu enzymatique dans l'espace vitellin lors de la fécondation provoquera des modifications de la structure de la zone pellucide, empêchant la pénétration de spermatozoïdes surnuméraires.

3. au niveau de l'environnement, un des phénomènes importants est l'expansion du cumulus proliger. Cette expansion s'installe du fait de l'effet positif de la FSH du liquor folliculi dont l'action serait modulée par la LH. Il en résulte une production par les cellules du cumulus d'une matrice viscoélastique riche en acide hyaluronique. Ceci entraine, d'une part, la séparation du complexe cumulo-ovocytaire du reste des cellules de la granulosa et, d'autre part, l'augmentation du contenu hydrique de l'antrum.

Le liquor folliculi et les cellules de la granulosa se chargent en activateurs du plasminogène, ce qui entraîne une ascension des taux de plasmine. L'albuginée (enveloppe ovarienne) sécrète des enzymes protéolytiques, en particulier des collagénases. Les cellules de la granulosa produisent des substances inductrices de l'angiogenèse, vectrices de macrophages, mastocytes, polynucléaires et des prostaglandines qui vont intervenir dans le processus de rupture folliculaire. 
L'appareil neuromusculaire périfolliculaire, également sollicité, participe à l'ovulation par le biais probable de catécholamines que régulent les gonadotrophines, et par celui de facteurs locaux que libèrent les cellules de la granulosa.

La déhiscence folliculaire résulte de l'harmonieuse coordination de tous ces phénomènes. Elle implique également la participation de prostaglandines et de récepteurs adrénergiques capables de modifier la microcirculation de l'apex folliculaire et d'entraîner, à ce niveau, la dégénérescence des cellules épithéliales déterminant la libération d'hydrolases lysosomiales qui achèvent la destruction de la paroi folliculaire.

\section{L'ATRÉSIE FOLLICULAIRE}

L'atrésie des $99 \%$ de follicules qui entrent en croissance dans l'ovaire est moins bien connue dans les follicules pré-antraux que dans les follicules à antrum.

Elle est caractérisée par l'arrêt de la prolifération et la mort par apoptose ${ }^{2}$. L'induction de l'apoptose est suivie par la libération d'éléments mitochondriaux, l'activation de protéases et d'endonucléases, conçue comme une étape finale de la dégradation de l'ADN. L'ensemble de ces phénomènes constitue une mort cellulaire programmée. Il y a en fait deux formes d'atrésie folliculaire, l'une a l'ovocyte pour cible et touche les follicules pré-antraux, particulièrement à la fin de la vie fotale et pendant la période prépubertaire, l'autre a pour cibles les cellules de la granulosa et touche uniquement les follicules à antrum.

Le déterminisme de l'atrésie folliculaire, qui aboutit à la sélection d'un lot limité de follicules ovulatoires (et en général un seul hors de chaque cycle ovarien), est complexe. Il semble que n'importe quel follicule qui entre en développement terminal hors d'une vague folliculaire ait les potentialités de se développer jusqu'au stade préovulatoire. Chaque follicule est caractérisé par un équilibre local entre des facteurs paracrines stimulants (œstradiol, IGF, activine...) et inhibiteurs (androgènes, IGFBP ou IGF binding proteins, follistatine...). Seul le follicule le mieux adapté continuerait son développement (évolution opportuniste plutôt que prédéterministe). Les autres, sous l'effet d'une augmentation de la synthèse de facteurs inhibiteurs et la perte de synthèse de facteurs stimulants, rentreraient en atrésie : activation de Fas et du récepteur du TNF $\alpha$ (tumor necrosing factor), déséquilibre en faveur des facteurs proapoptotiques (Bcl-2), activation de p53 et des caspases (Monniaux et coll., 1999).

2 Une apoptose limitée $(<2 \%$ des cellules de la granulosa) se manifeste toutefois dans la quasi-totalité des follicules en croissance, et même dans certains follicules pré-ovulatoires. 


\section{L'OVULATION}

L'ovulation proprement dite correspond à la rupture folliculaire. C'est un phénomène bref en réponse au signal gonadotrope ovulatoire, qui conduit à la libération de l'ovocyte mûr dans les voies génitales ${ }^{3}$. Elle est cliniquement précédée par une tension du bas-ventre parallèle à la mise en pression du liquor folliculi.

L'éclatement folliculaire, quant à lui, n'est pas perçu ; en revanche, l'épanchement intrapéritonéal conséquent détermine habituellement une réaction pelvienne douloureuse due à l'irritation du péritoine adjacent. D'ordinaire, l'épanchement est modéré, de 50 à $100 \mathrm{ml}$, déterminant un syndrome du 14e jour que connaissent bien les femmes fonctionnelles. Parfois, en particulier dans les syndromes d'hyperstimulation ovarienne, apparaissent de véritables hémorragies avec douleur "exquise", anémie et signes péritonéaux si préoccupants qu'il convient d'intervenir pour assurer une hémostase correcte du follicule rompu.

Au moment de son expulsion, l'ovocyte, jusqu'alors bloqué en prophase de première division méiotique par l'effet de l'OMI (ovocyte maturation inhibitor), se trouve libéré de cet effet (fig. 12.3), et termine rapidement sa multiplication qui aboutit à deux cellules filles très inégales en valeur et en volume : l'ovocyte secondaire, ou de deuxième ordre, de $100 \mu$ environ, conservant la presque totalité du cytoplasme de la cellule mère et le premier globule polaire nettement plus petit, repoussé à la périphérie ovocytaire sous la membrane pellucide dans l'espace périvitallin. La deuxième division méiotique commence aussitôt et restera à son tour bloquée en métaphase jusqu'à une éventuelle fécondation. L'AMPc semble également jouer un rôle important dans le blocage et la reprise de la méiose dans de nombreuses espèces.

Ainsi, entouré de la membrane pellucide et des cellules du cumulus oophorus ou corona radiata, le gamète femelle constitue une masse visqueuse de plusieurs millimètres cubes que recueille le pavillon tubaire dont les franges embrassent littéralement l'ovaire : c'est le "baiser de la trompe", un phénomène actif que facilite la turgescence des franges du pavillon.

Le transit tubaire, en revanche, est un phénomène passif que favorise le courant des sécrétions tubaires allant du pavillon vers l'utérus. Les contractions tubaires et l'activité ciliaire de la muqueuse endoluminale jouent également un rôle. Le trajet dure habituellement 4 jours et, en l'absence de fécondation, l'ovule dégénère et s'évacue dans la cavité utérine. Dans le cas contraire, lorsque, dans le tiers externe de la trompe, la fécondation se produit, on assiste à la fin de la deuxième mitose réductionnelle, à

3 Deux phénomènes sont importants pour la datation de l'ovulation : la température de base (effet de la progestérone) et la glaire cervicale (effet des œstrogènes). Par ailleurs, on trouve actuellement dans le commerce des tests à lecture colorimétrique qui permettent de détecter (à domicile), à l'aide d'anticorps monoclonaux, la décharge ovulante de LH (donc 24 à 46 h avant l'ovulation). 
l'émission du deuxième globule polaire, à la transformation de l'œuf fécondé en morula puis en blastocyste qui va se fixer dans la cavité utérine vers le $20^{\mathrm{e}}$ jour du cycle.

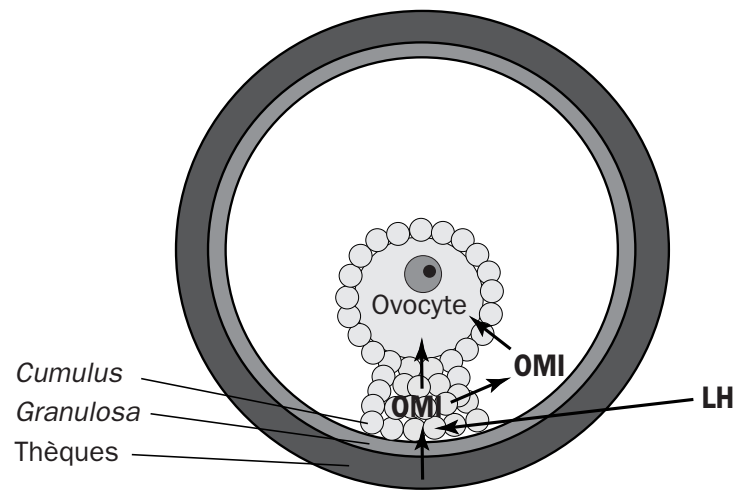

Figure 12.3 - Schéma hypothétique du blocage méiotique intrafolliculaire (d'après Mermillod et Marchal, 1999)

Un signal inhibiteur serait originaire de la thèque interne et transmis à la granulosa. Celle-ci activerait ce signal et le transmettrait à l'ovocyte via les jonctions perméables ou le fluide folliculaire (OMI). Lors de la décharge gonadotrope ovulante (LH), ce signal inhibiteur ne serait plus transmis par la granulosa.

Pathologiquement, du fait d'une sténose tubaire ou d'une endométriose, l'œuf peut se fixer dans la trompe et réaliser le tableau d'une grossesse extra-utérine (GEU). L'évolution de cette grossesse ectopique s'accompagne de mise en tension de la trompe, de douleurs et d'hémorragie intrapéritonéale par rupture de la paroi tubaire, ce qui nécessite une intervention médico-chirurgicale d'urgence.

Dès l'ovulation, le follicule rompu, vidé de son contenu, se transforme en un corps jaune à fonction endocrine : la membrane de Slavjansky se dissocie, ceci permet aux vaisseaux d'envahir la granulosa dont les cellules se lutéinisent, c'est-à-dire se vacuolisent et se chargent de lipides tout en assurant la sécrétion des œstrogestatifs ovariens de la deuxième phase ou cycle. La thèque externe s'épaissit pendant que les cellules de la thèque interne s'hypertrophient et migrent de façon centripète en passant par les intervalles que laisse la membrane de Slavjansky.

La survie du corps jaune hors fécondation correspond à une activité fonctionnelle d'environ 10 à 12 jours. Il involue ensuite en corpus albicans ou corps blanc, s'atrésie et laisse sa cicatrice sous forme d'une rétraction fibreuse plus ou moins étoilée au niveau de la corticalité ovarienne. Lorsqu'il y a fécondation, le corps jaune devient gestatif (ou gravidique), persistant jusqu'aux environs du $3^{\mathrm{e}}$ mois de grossesse, date approximative du relais placentaire.

L'ovulation est dite spontanée lorsqu'elle est cyclique ; c'est le cas chez la femme où elle survient tous les 28 jours, la rate ou la souris (tous les 4 ou 5 jours), le cobaye (tous les 15 jours) ou la vache (tous les 21 jours), la plupart des animaux sauvages (une fois par an) ou la chienne (deux fois par an). 
L'ovulation est dite provoquée, par exemple chez la lapine, le furet ou la chatte. Dans ce cas, ce sont des réflexes tacto-hypothalamo-hypophysaires contemporains du coït qui déclenchent la ponte.

D'autres espèces peuvent avoir une ovulation postcoïtale différée, telle la chauvesouris qui ovule 3 mois après la copulation.

\section{LES CYBERNINES OVARIENNES}

Les cybernines ovariennes sont des substances polypeptidiques produites par l'ovaire ; elles interviennent à toutes les étapes de la folliculogenèse et de l'ovulation.

\subsection{L'INHIBITEUR DE LA MATURATION OVOCYTAIRE (OMI)}

L'inhibiteur de la maturation ovocytaire serait un polypeptide dont la taille est encore imprécise, sécrété par les cellules folliculaires de la granulosa. Plusieurs candidats à activité OMI ont été proposés : le TGF $\beta$, l'AMH (antimullerian hormone), l'activine, l'inhibine (voir plus loin), ou encore une protéine de $60 \mathrm{kDa}$. L'OMI, qui pourrait être d'origine thécale, est libéré dans le liquor folliculi et inhibe la première méiose de maturation ovocytaire bloquée en prophase (voir fig. 12.2). Plus le follicule est petit, plus la concentration de l'OMI est importante. C'est la dissociation des cellules du cumulus proliger et la désolidarisation de l'ovocyte lors de la ponte qui déterminent la reprise et l'accomplissement de la première méiose de maturation.

\subsection{L'INHIBITEUR DE LA FIXATION DE FSH (FSH-BI)}

C'est une cybernine de 700 daltons qui empêche la fixation de FSH sur ses récepteurs. De ce fait, la FSH-BI va, d'une part, isoler le follicule dominant dès le $5^{\mathrm{e}}$ jour du cycle et, d'autre part, bloquer l'évolution éventuelle d'autres follicules hormonodépendants. Par ailleurs, comme la maturation des cellules de la granulosa est liée à la FSH et que l'aromatisation du noyau $\mathrm{A}$ des androgènes de la thèque aboutit au $17 \beta$-œstradiol, on peut dire que la FSH-BI entraîne une accumulation d'androgènes et une carence œstrogénique. De même, comme c'est la FSH qui induit la synthèse des récepteurs pour la LH et la sécrétion progestative, on peut dire que la FSH-BI voue le follicule à l'involution et à l'atrésie.

\subsection{L'INHIBITEUR DE LA LUTÉINISATION (LI)}

La transformation du follicule rompu en corps jaune se fait en quelques heures mais, si l'on isole des cellules folliculaires en culture avant l'ovulation, elles se lutéinisent spontanément. D'où l'idée vérifiée que l'ovocyte puisse être à l'origine d'une substance 
inhibant la lutéinisation spontanée. Il s'agit, en fait, de deux polypeptides de 3500 et 10000 daltons diminuant la synthèse d'AMPc et la sécrétion progestative.

\subsection{LES CYBERNINES INTERVENANT DANS LA RÉGULATION HYPOTHALAMO-HYPOPHYSO-GONADIQUE}

Entre l'ovaire et le système nerveux central s'établit un rétro-contrôle permanent auquel participent plusieurs cybernines ovariennes.

\subsubsection{L'inhibine}

L'inhibine a été isolée et caractérisée en 1985. C'est une hormone glycoprotéique produite par les cellules de la granulosa, la thèque interne, les cellules lutéales et le placenta. Son rôle physiologique essentiel est d'inhiber la sécrétion de la FSH hypophysaire.

Elle existe sous deux formes, $\mathrm{A}$ et $\mathrm{B}$, qui possèdent la même sous-unité $\alpha$ mais avec une sous-unité associée $\beta \mathrm{A}$ ou $\beta \mathrm{B}$ (de structure voisine de la TGF $\beta$ ).

En phase folliculaire, sous l'effet de la FSH, la concentration de l'inhibine B dans le plasma crôt avec la taille du follicule (et son taux dans le liquor folliculi va en augmentant) puis, après un bref pic post-ovulatoire, décroît en phase lutéale. Ce profil est l'inverse de celui de l'inhibine A qui s'élève progressivement en phase folliculaire tardive, suit le pic de LH, puis remonte à nouveau en phase lutéale. La régulation de la FSH au cours du cycle menstruel est cependant davantage liée à l'œstradiol qui s'élève bien avant la diminution de l'inhibine.

A contrario, lors de la lutéolyse, la diminution de l'activité sécrétoire du corps jaune entraîne une augmentation relative de la FSH périmenstruelle, ce qui va susciter le recrutement folliculaire du cycle suivant.

L'action de l'inhibine serait spécifique et s'exercerait sur un site hypophysaire différent de celui de la GnRH, car l'œstradiol, qui a des effets similaires, agit non seulement sur l'hypophyse mais aussi sur la LH hypothalamique, action non-observée pour l'inhibine.

\subsubsection{L'activine et la follistatine}

Au cours des étapes de la purification de l'inhibine, on a découvert deux autres protéines synthétisées par l'ovaire : l'activine, dimère des sous-unités $\beta$ de l'inhibine, activatrice de la sécrétion de FSH et la follistatine, polypeptide glycosylé, qui est fortement liée à l'activine.

L'activine a surtout des activités autocrines et paracrines au niveau de l'ovaire. La régulation de la FSH par l'activine s'exerce directement au niveau des cellules gonadotropes hypophysaires, l'activine comme la follistatine étant également sécrétées par l'hypophyse. 


\subsubsection{Les gonadocrines}

De même, les gonadocrines, polypeptides de 3500 daltons isolés dans le liquor folliculi, seraient capables de se fixer sur les récepteurs GnRH pour les stimuler, tant au niveau central qu'au niveau ovarien.

\section{BIOCHIMIE DES HORMONES SEXUELLES CHEZ LA FEMELLE}

L'ovaire peut être divisé en deux compartiments capables de produire des hormones sexuelles :

- le compartiment interstitiel, fait des cellules du stroma ovarien et du hile, qui produisent, sous l'effet de la LH, des androgènes (androstène-dione et DHEA) ${ }^{4}$;

- le compartiment folliculaire, où l'unité fonctionnelle thèque interne-granulosa produit dans le liquor folliculi et dans le sang, de façon cyclique, le $17 \beta$-œstradiol et la progestérone 5 .

Les cellules endocrines de l'ovaire contiennent, à leur surface, des récepteurs aux LDL. Ces récepteurs permettent de lier les $\operatorname{LDL}^{6}$ et de les internaliser, ce qui va permettre un apport de cholestérol dont les LDL sont riches. C'est à partir de ce cholestérol et sous l'influence de la LH que la synthèse des hormones stéroïdes est possible (fig. 12.4).

Figure 12.4 - Schéma général des voies de synthèse des stéroïdes ovariens

A : $\Delta 4$-androstène-dione

DHEA : déhydro-épiandrostérone

E1 : œstrone

E2 : œstradiol

$P$ : progestérone

Pgn : prégnénolone

$T$ : testostérone.

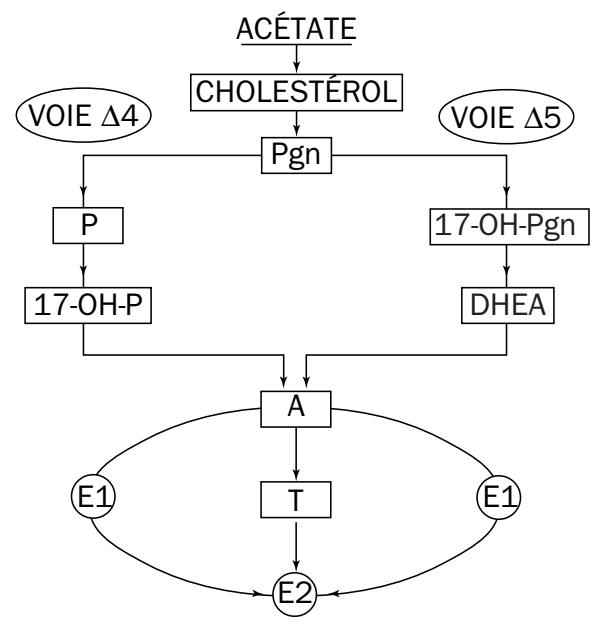

4 Chez la femelle hypophysectomisée, qui ne sécrète donc pas de FSH, l'injection de LH stimule essentiellement, dans l'ovaire, l'élaboration de ces androgènes.

5 L'ovaire élabore également de la relaxine, substance polypeptidique intervenant peut-être au moment de l'accouchement.

6 LDL : low density lipoproteins ou lipoprotéines de basse densité (20 à 25\% seulement de protéines); elles représentent les principaux transporteurs du cholestérol dans le sang. 


\subsection{LES HORMONES GESTROGÈNES}

\subsubsection{Origine et nature des hormones aestrogènes (fig. 12.5)}

Ce sont :

- L'œstrone ou folliculine. Elle est d'origine essentiellement placentaire. Ce n'est pas la véritable hormone ovarienne, bien que l'ovaire en sécrète une faible quantité $(\approx 30 \mathrm{ng} / \mathrm{ml}$ de liquor folliculi) .

- L'ostradiol ou dihydrofolliculine (E2), qui est le principal œstrogène ovarien. Il possède un $\mathrm{OH}$ en $17 \beta$.

- L'ostriol (non-détecté dans le sang), détecté dans le liquor folliculi uniquement pendant la phase lutéinique du cycle ( $24 \mu \mathrm{g}$ pour $10 \mathrm{~g}$ de liquor folliculi).

Les œstrogènes ne sont pas libres dans le sang mais liés à des protéines plasmatiques ( $\beta$-lipoprotéines). Cette liaison est faible et transitoire.

Si la source principale de ces hormones est le follicule cavitaire, elles sont également sécrétées par les cellules interstitielles de l'ovaire, le corps jaune, le placenta, le testicule et le cortex surrénal pathologique. Elles provoquent le rut chez la femelle impubère et chez la femelle castrée.

La thèque interne élabore à partir du cholestérol des stéroïdes androgènes (en C19), androstène-dione et testostérone, qui vont constituer des précurseurs de la biosynthèse des œstrogènes. Cette thèque interne possède des récepteurs à la $\mathrm{LH}$ et la castration ou la ménopause, en provoquant l'augmentation de la LH, entraîneront une stimulation de cette sécrétion d'androgènes ovariens.

Les cellules de la granulosa sont dépourvues de 17-hydroxylase et de desmolase, mais elles possèdent l'équipement enzymatique nécessaire à l'aromatisation des androgènes de la thèque interne, qu'elles convertissent en œstrogènes sous l'action de la FSH. Elles possèdent également des récepteurs à l'œstradiol, d'où une action "mitogénique" entrânant une multiplication cellulaire 7.

Au cours de la phase folliculaire, les cellules de la thèque interne, stimulées par la LH, produisent une quantité accrue d'androgènes que les cellules de la granulosa, stimulées par la FSH, transforment en œstrogènes. La thèque interne est toutefois capable de sécréter directement des œstrogènes. La granulosa a une capacité de synthèse à peu près constante d'œstradiol, alors qu'avec la croissance du follicule la thèque acquiert une autonomie de production des œstrogènes avec potentialisation de ses sécrétions : c'est une coopération cellulaire.

7 Cet effet est indépendant de l'action de la FSH mais, en multipliant les cellules folliculaires, il potentialise l'action de la FSH sur ses récepteurs. Les actions de l'œstradiol et de la FSH sont donc synergiques. 


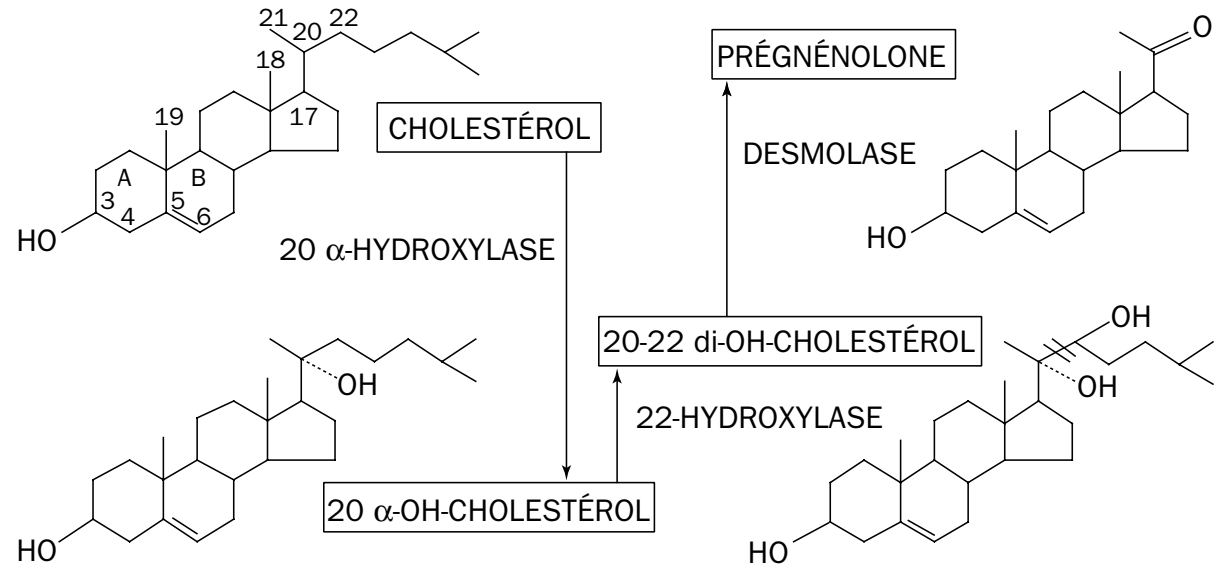

Première étape : synthèse de la prégnénolone à partir du cholestérol

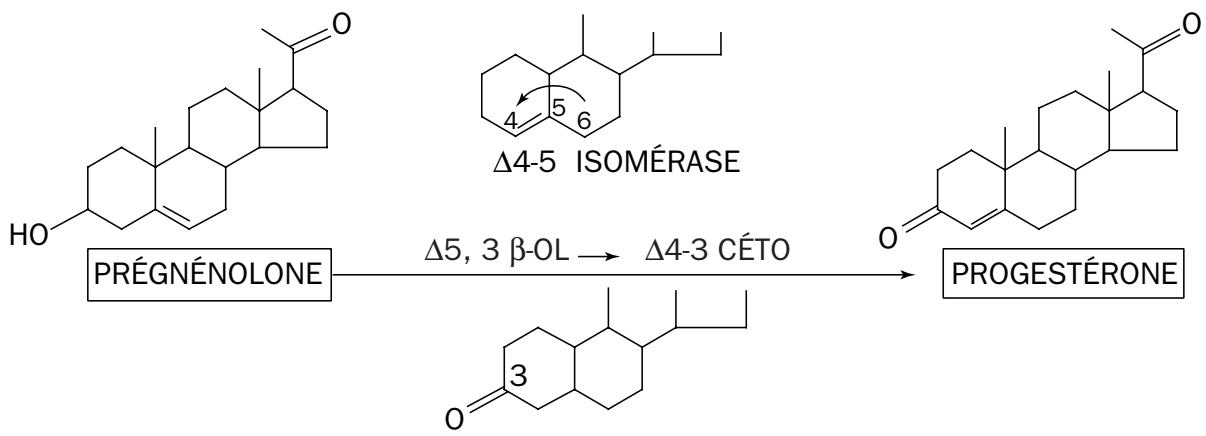

$3 \beta$-OL-DÉSHYDROGÉNASE

Deuxième étape : voie $\Delta 4$, de la prégnénolone à la progestérone<smiles>CC12CCC(=O)C=C1CCC1C2CCC2(C)C(O)CCC12</smiles>

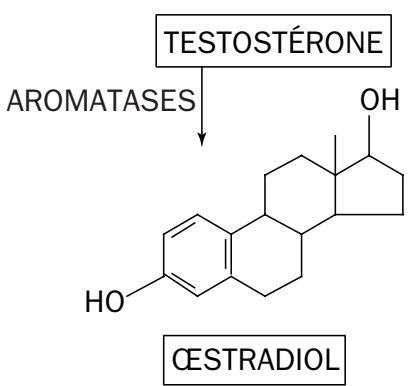

\section{7 -DÉSHYDROGÉNASE}

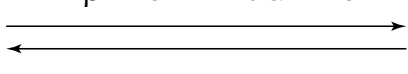

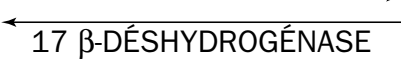<smiles>CC12CCC3C(CCC4=CC(=O)CCC43C)C1CCC2=O</smiles>

$\triangle 4$-ANDROSTÈNE-DIONE<smiles>CC12CCC3c4ccc(O)cc4CCC3C1CCC2=O</smiles>

CESTRONE

Dernière étape : synthèse des œstrogènes à partir des androgènes

Figure 12.5 - Biosynthèse des hormones sexuelles femelles 


\subsubsection{Catabolisme des hormones aestrogènes}

Au niveau du foie, $20 \%$ des œstrogènes seront excrétés dans l'urine sous forme conjuguée (sulfo- ou glucurono-conjuguée). On y trouve surtout de l'œstriol (trihydrofolliculine) et de l'œstrone dans un rapport voisin de 1 (l'œstriol est un catabolite de l'œstrone).

\subsubsection{Action physiologique des aestrogènes}

Les œstrogènes ont une action sur le tractus génital et des effets métaboliques.

Dans le cadre de l'action sur la sphère génitale, on distingue :

- la restauration de l'endomètre utérin (voir § 6.2);

- l'augmentation de la contractibilité myométriale et l'accroissement de la sensibilité à l'ocytocine ;

- l'action sur la filance de la glaire cervicale (voir § 6.2);

- l'effet majorant sur le péristaltisme tubaire, ce qui peut, en cas d'excès, entraîner dans l'utérus des blastocystes immatures incapables de nidation ;

- l'effet prolifératif sur la muqueuse vaginale ;

- l'action sur la croissance des canaux galactophores ;

- l'action sur la croissance folliculaire, en sachant toutefois qu'à forte dose, prolongée, les œstrogènes entraînent une atrophie ovarienne par action directe et rétroaction hypophysaire.

Dans le cadre des actions métaboliques, les œstrogènes

- favorisent les rétentions hydrosodées ;

- stimulent l'activité des ostéoblastes, d'où leur utilité dans le traitement préventif et curatif de l'ostéoporose ;

- déterminent une augmentation du bon cholestérol (le HDL ou high density lipoproteins), ce qui justifie leur utilité dans le traitement préventif des artériopathies de surcharge.

Enfin, les œstrogènes sont hypothermisants : la température corporelle basale reste inférieure à $37^{\circ} \mathrm{C}$ pendant la phase folliculaire.

L'œstradiol stimule la synthèse et la libération de prolactine, ce qui explique l'aggravation des adénomes hypophysaires à prolactine lors des contraceptions orales.

\section{Estrogènes et physiologie artérielle}

L'effet cardio-protecteur des œstrogènes a été très étudié mais les mécanismes par lesquels les œstrogènes protègent de l'athérosclérose n'est pas encore très clair. Les œstrogènes augmentent la biodisponibilité de $\mathrm{NO}$ au niveau des artères chez la lapine castrée, le rat, le cochon d'Inde, le cochon. Cette action ne résulte pas d'une augmentation de la production de NO, mais plutôt d'une moindre dégradation de NO, secondaire à une diminution de la génération d'anions superoxydes par l'endothélium. 
Les hormones œstrogènes agissent sans doute également sur les cellules monocytaires, lymphocytes et monocytes/macrophages, retrouvées dans la paroi artérielle saine ou pathologique.

\subsubsection{Dosages biologiques et chimiques des aestrogènes}

Le dosage biologique repose sur certaines des actions caractéristiques des œstrogènes :

- déclenchement de l'œstrus et réactions vaginales qui l'accompagnent ; il est testé sur les Rongeurs (test d'Allen et Doisy) et l'on a défini une unité "souris" et une unité "rat" telles que, par exemple, $1 \mathrm{mg}$ d'œstradiol est égal à 10000 unités "souris";

- test de la pigmentation des plumes du chapon; la pigmentation noire chez la race Leghorn dorée est liée au génotype neutre, donc mâle ; l'injection d'œstrogène chez le chapon déplumé redonnera la plume qui repousse brun clair ;

- augmentation du poids utérin.

Ces dosages, de même que les dosages chimiques, n'ont plus qu'une valeur historique et ont été remplacés par le dosage radioimmunologique de l'œstradiol.

- Au cours du cycle œstrien :

- en phase folliculaire : 66 à $120 \mathrm{pmol} / 1=18$ à $40 \mathrm{ng} / 1$;

- en phase pré-ovulatoire : 173 à $890 \mathrm{pmol} / 1=45$ à $250 \mathrm{ng} / 1$;

- en phase post-ovulatoire : 96 à 545 pmol/1 = 25 à $150 \mathrm{ng} / 1$.

- Au cours de la grossesse :

- à la $12^{\mathrm{e}}$ semaine : $10600 \mathrm{pmol} / 1$;

- à la 24e semaine : $93000 \mathrm{pmol} / 1$;

- à la $37 \mathrm{e}$ semaine : $129000 \mathrm{pmol} / 1$.

- Au cours de la ménopause : 50 à $80 \mathrm{pmol} / 1$.

\subsubsection{Mode d'action des oestrogènes}

Le récepteur aux œstrogènes (R-E $\alpha)$ a été mis en évidence dans tous les tissus cibles concernés par la reproduction. En l'absence d'hormone, ce récepteur, membre de la superfamille des récepteurs nucléaires (voir chap. 2, § 4), est intégré au sein d'un complexe constitué de protéines de choc thermique et d'immunophilines. La liaison de l'hormone provoque la dissociation du complexe, l'homodimérisation des récepteurs qui deviennent alors capables de se lier aux séquences d'ADN spécifiques. Une deuxième forme du récepteur (R-E $\beta$ ) vient d'être identifiée, $R-E \alpha$ et $R-E \beta$ lient l'œstradiol avec une affinité comparable $\left(\mathrm{K}_{\mathrm{D}}=0,2-0,5 \cdot 10^{-9} \mathrm{M}\right)$. 


\subsection{LA PROGESTÉRONE}

\subsubsection{Origine et nature de la progestérone}

C'est le précurseur de toutes les hormones stéroïdes. La synthèse s'arrête à ce stade dans les cellules du corps jaune ovarien dont elle constitue l'hormone essentielle. L'ovaire est relayé par le placenta au $2^{\mathrm{e}}$ mois de la grossesse, ce qui entraîne l'involution du corps jaune gravidique.

Il est possible d'obtenir de la progestérone :

- à partir du corps jaune de baleine, ou

- à partir du stigmastérol extrait des graines de soja ;

- par biosynthèse (voir chap. 1, § 7.3).

L'ovaire sécrète encore deux autres substances progestagènes chez la femme : les $20 \alpha$ - et $20 \beta$-hydroxyprogestérones.

\subsubsection{Catabolisme de la progestérone}

Elle est très rapidement détruite, essentiellement par le foie. Les métabolites qui ont un $\mathrm{OH}$ en $3 \alpha$ sont la prégnénolone (5\%) et le prégnandiol (95\%), qui passent dans l'urine sous forme glucurono-conjuguée.

\subsubsection{Actions physiologiques de la progestérone}

- Sur l'utérus : elle forme la dentelle endométriale, après sensibilisation de l'utérus par les œstrogènes. Les glandes deviennent flexueuses, riches en glycogène. L'activité contractile du myomètre diminue.

La progestérone rend ainsi la muqueuse utérine apte à la nidation et au maintien de la gestation.

Au niveau du col utérin, la glaire cervicale se transforme dès l'ovulation en un bouchon opaque de coagulum glaireux qui empêche la pénétration utérine d'éventuels spermatozoïdes. La progestérone agit en inhibant la sécrétion des glandes de l'endocol.

- Sur les trompes utérines : le déficit de progestérone accélère le transit tubaire, alors qu'un excès en progestérone le retarde; dans les deux cas, on aboutit à une infertilité par anomalie de la nidation.

- Sur l'ovaire : sécrétée sous l'influence de la LH, la progestérone induit spécifiquement l'ovulation.

Administrée dès le début du cycle, elle entraîne une inhibition, par feed-back, de la sécrétion des gonadostimulines et la mise au repos de l'ovaire (principe des contraceptifs).

- Sur le vagin : on observe sous l'effet de la progestérone la prolifération des cellules épithéliales non-kératinisées et l'apparition de leucocytes (chez les Rongeurs). 
- Sur les glandes mammaires : la progestérone provoque la croissance des acini.

- Sur la température de base : un décalage thermique, par remontée de la température et maintien en plateau au-dessus de $37^{\circ} \mathrm{C}$, résulte de l'action thermogénique de la progestérone. Il est le témoin de l'ovulation. L'élévation de la température est de l'ordre de 5/10 de degré.

\subsubsection{Dosage de la progestérone}

- Au cours du cycle œstrien

- en phase folliculaire : 630 à 5100 pmol $=0,2$ à $1,6 \mu \mathrm{g} / 1$;

- en phase post-ovulatoire : 31000 à 54000 pmol/1 = 10 à $17 \mu \mathrm{g} / 1$

- Au cours de la grossesse

- 17 à 18 semaines : $95000 \mathrm{pmol} / 1$;

- 28 à 30 semaines : $207000 \mathrm{pmol} / 1$;

- 38 à 40 semaines : $382000 \mathrm{pmol} / 1$.

\subsection{LES HORMONES ANDROGÈNES CHEZ LA FEMME}

Le taux de production de la testostérone chez la femme est de l'ordre de $0,4 \mathrm{mg} / 24 \mathrm{~h}$. La moitié de ce taux correspond à la conversion périphérique de la $\Delta 4$-androstènedione au niveau du foie et du sang, $10 \%$ proviennent de la surrénale et $40 \%$ de l'ovaire. La $\Delta 4$-androstène-dione est à $80 \%$ d'origine glandulaire, mixte ovarienne et surrénalienne.

La déhydro-épiandrostérone provient essentiellement de la surrénale.

\subsection{TRANSPORT PLASMATIQUE DES HORMONES OVARIENNES}

Ces hormones sont de petites molécules et leur transport plasmatique nécessite un couplage avec une protéine de transport qui est plus ou moins spécifique :

- Deux protéines spécifiques de haute affinité $\left(\mathrm{K}_{\mathrm{D}}<0,1 \mu \mathrm{M}\right)$ et de faible capacité de transport :

- CBG (corticosteroid binding globulin ou transcortin) liant les stéroïdes en C21 avec une structure $\Delta 4-3$, céto (cortisol, corticostérone, progestérone, 17-hydroxyprogestérone). C'est une $\alpha$-glycoprotéine de PM 25000 . Son $K_{D}$ est de l'ordre de $10^{-8} \mathrm{M}^{8}$.

- SBG (sex hormone binding globulin) liant l'œstradiol, la testostérone (dite aussi SHBG ou SBGF ou TeBG). C'est une $\beta$-glycoprotéine de PM 50000 à 100000 . Elle est sécrétée par le foie.

8 L'élévation du taux de la transcortine au cours de la gestation, sous l'effet des œstrogènes, augmente la quantité de progestérone liée. En effet la progestérone, pendant la grossesse, circule essentiellement liée à la transcortine. 
Les œstrogènes et les hormones thyroïdiennes stimulent la production hépatique de SBG et les androgènes semblent l'inhiber.

L'affinité de liaison des œstrogènes pour la SBG est deux fois moindre que celle de la testostérone ou de la dihydrotestostérone. La $\Delta 4$-androstène-dione et la déhydro-épiandrostérone ne sont pas, ou peu, liées par la SBG.

- Une protéine non-spécifique, l'albumine, qui lie de façon non-spécifique tous les stéroïdes, avec une faible affinité et une très grande capacité. Une concentration 1000 à 100000 fois plus élevée $(40 \mathrm{~g} / 1)$ mais une constante de dissociation entre $1 \mu \mathrm{M}$ (œstrogènes) et $1 \mathrm{mM}$ (cortisol).

- Des protéines propres à certaines espèces, et dans certaines situations physiologiques, par exemple la PBP (progesterone binding plasma protein) présente chez le cobaye gestant. Il est à noter que seule la fraction libre de l'hormone est active au niveau des cellules cibles.

\section{LE CYCLE MENSTRUEL OU CYCLE CESTRIEN}

Il représente l'ensemble des modifications cycliques qui se manifestent chez la femme tous les 28 jours, de la puberté à la ménopause (voir fig. 12.6).

En général, il s'installe progressivement en 6 à 12 mois, vers la $12^{\mathrm{e}}$ année, se régularise ensuite pour rester stable jusque vers 40-50 ans, âge habituel du début de la ménopause, s'arrête de façon plus ou moins capricieuse vers 50 ans, âge moyen de l'arrêt des règles.

Chez la femme jusqu'à la ménopause, il se manifeste par des modifications répétitives avant et après l'ovulation : du $1^{\mathrm{er}}$ au $14^{\mathrm{e}}$ jour c'est la phase folliculaire ${ }^{9}$, pendant laquelle le follicule arrive à maturité ; du $14^{\mathrm{e}}$ au $28^{\mathrm{e}}$ jour, caractérisé par l'activité endocrine du corps jaune, c'est la phase lutéale.

L'anœstrus caractérise l'état du tractus génital féminin, avant la maturité sexuelle, après castration, après la ménopause, entre deux cycles espacés ou, à un degré moindre, lorsqu'il existe une carence ovarienne plus ou moins profonde.

\subsection{LE CYCLE OVARIEN}

Il comporte des variations histocytologiques et hormonales caractéristiques (voir fig. 12.8).

Lors de la phase folliculaire, l'évolution terminale de la folliculogenèse aboutit au follicule mûr de de Graaf. L'hormonosécrétion est principalement œstrogénique avec

9 Arbitrairement, le $1^{\text {er }}$ jour des règles est considéré comme le $1^{\text {er }}$ jour du cycle. 
des taux d'œstradiol de l'ordre de $100 \mathrm{pg} / \mathrm{ml}$ et un pic avoisinant $300 \mathrm{pg} / \mathrm{ml}$ vers le $10^{\mathrm{e}}$ jour, juste avant l'ovulation qui a lieu en principe vers le $14^{\mathrm{e}}$ jour, terme de cette première phase du cycle.

Lors de la phase lutéale, le follicule a laissé sa place au corps jaune qui va durer, hors grossesse, de 10 à 12 jours. Les œstrogènes continuent d'être sécrétés au taux approximatif de 150 à $200 \mathrm{pg} / \mathrm{ml}$; la progestérone augmente rapidement dès l'ovulation avec un maximum de $10 \mathrm{ng} / \mathrm{ml}$ vers le $21^{\mathrm{e}}$ jour. Ces taux sont variables selon la qualité du corps jaune considéré.

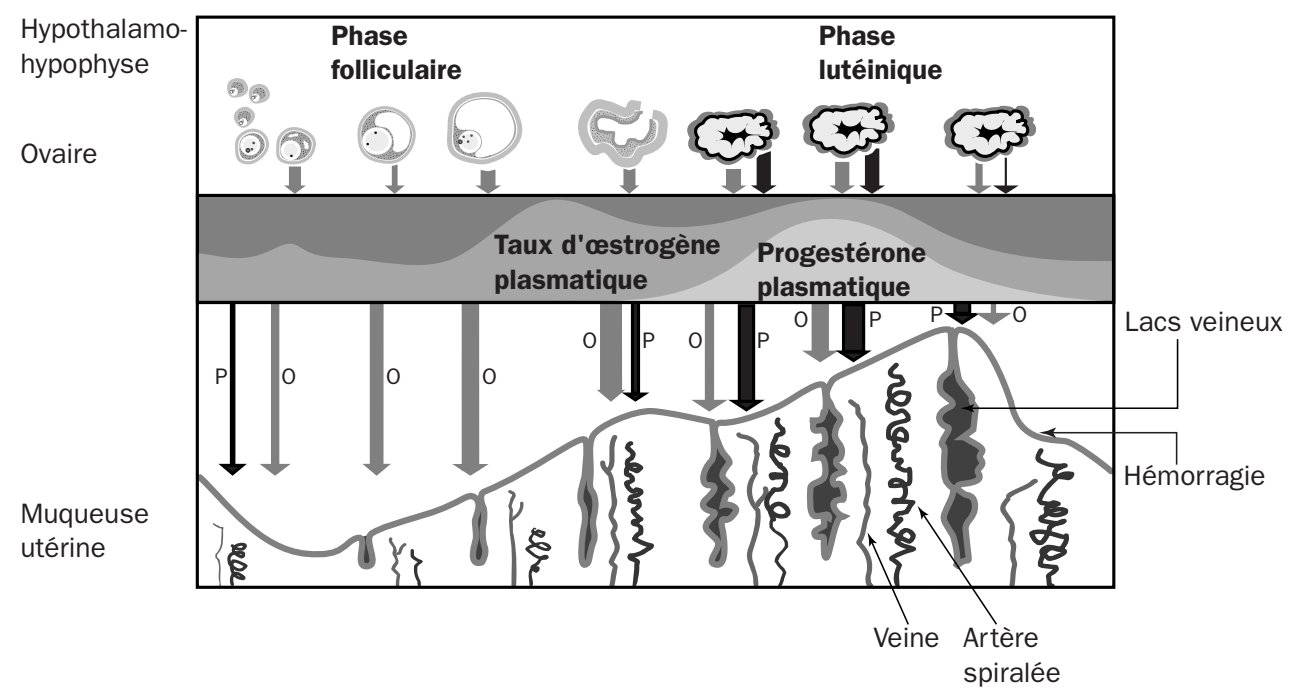

a - Les différentes phases du cycle

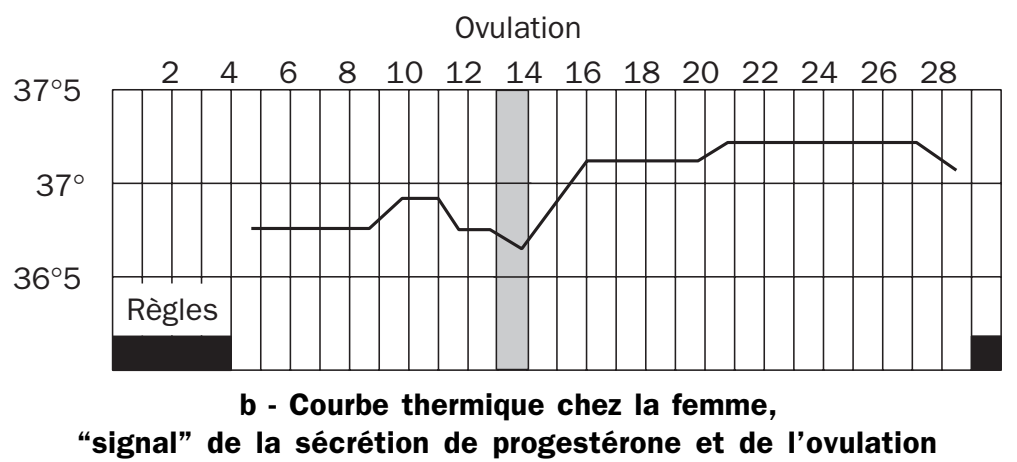

Figure 12.6 - Le cycle menstruel

\subsection{LE CYCLE UTÉRIN}

Sous l'influence des hormones ovariennes, la muqueuse utérine, pratiquement abrasée par les règles, va restaurer son épaisseur sous l'influence des œstrogènes en première phase, lutéiniser l'endomètre en deuxième phase, réalisant la "dentelle utérine" très propice à une éventuelle implantation de blastocyste. 
Au niveau du col, l'hormonosensibilité se manifeste par une augmentation progressive de la filance de la glaire cervicale qui va cristalliser en "feuilles de fougère" vers le 14 e jour, période la plus favorable à la pénétration spermatique. Cette même glaire, l'ovulation accomplie, va se coaguler en un bouchon intra-cervical, le bouchon muqueux, protégeant la cavité utérine contre d'éventuelles agressions microbiennes, ou autres, issues du vagin.

\subsection{LE CYCLE VAGINAL}

De la même façon, il existe un cycle vaginal. L'hormonodépendance de la muqueuse se manifeste par son degré et son type de desquamation. Les frottis vaginaux (F.V.), principalement utilisés pour le dépistage du cancer du col de l'utérus, révèlent également la qualité de l'imprégnation hormonale.

En post-règles, anœstrus, prépuberté ou post-ménopause, les F.V. montrent surtout des cellules basales ou parabasales à cytoplasme basophile et gros noyau. Lors de la phase folliculaire, l'augmentation du nombre des cellules éosinophiles à petit noyau est le garant d'une bonne restauration de la muqueuse vaginale et endométriale. En phase lutéale, des F.V. "sales" avec de nombreux polynucléaires, des cellules plicaturées dites "naviculaires" reflètent une imprégnation hormonale, de type progestatif, satisfaisante.

\subsection{LES MODIFICATIONS CYCLIQUES EXTRAGÉNITALES}

D'autres modifications cycliques, extragénitales, sont bien connues : le gonflement mammaire douloureux avant les règles (mastodynies prémenstruelles), les rétentions d'eau et de sels minéraux, les modifications thermiques dues à l'effet hyperthermisant des progestatifs du corps jaune ${ }^{10}$, les troubles de l'humeur... Toutes ces manifestations, de même que l'ostéoporose de l'anœstrus, sont le témoin de l'effet systémique des sécrétions ovariennes sur de nombreux récepteurs centraux et périphériques.

\subsection{LA MENSTRUATION ET SON DÉTERMINISME (fig. 12.7)}

La menstruation, en raison de son importance, mérite une place particulière. Elle correspond à la desquamation de la partie superficielle de l'endomètre; elle s'accompagne d'ordinaire d'une perte sanguine de 60 à $100 \mathrm{ml}$ répartie sur 5 jours.

Son déterminisme est de nature hormonale, c'est l'imprégnation œstroprogestative séquentielle qui engendre l'œdème endométrial, l'ischémie relative des couches superficielles de l'endomètre et la nécrose menstruelle. La privation hormonale brutale

10 Un décalage thermique de 4 à $5 / 10^{\mathrm{e}}$ de degré est contemporain de l'ovulation (fig. 12.6.b). La persistance du décalage témoigne de la bonne activité fonctionnelle du corps jaune. 
contemporaine de la lutéolyse joue également un rôle en engendrant les spasmes des vaisseaux spiralés et les plages d'ischémie avec nécrose de l'endomètre fonctionnel. De ce fait, on conçoit en clinique humaine le traitement des dysménorrhées par insuffisance lutéale et l'effet heureux des progestatifs sur la douleur.

Chez la plupart des Mammifères, les modifications cycliques du tractus génital sont tout à fait comparables au cycle menstruel de la femme. Cependant, l'ovulation ou œstrus s'accompagne de "chaleurs" et la phase folliculaire prend le nom de proœstrus, alors que la phase lutéale se décompose en di-œstrus I correspondant au corps jaune fonctionnel et di-œstrus II caractéristique de la régression du corps jaune.

a

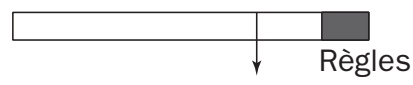

Ovariectomie

b

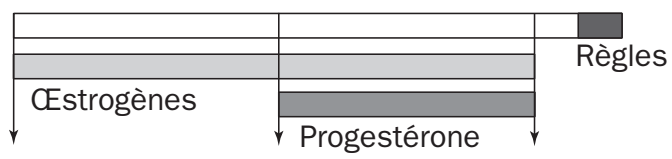

Ovariectomie

C

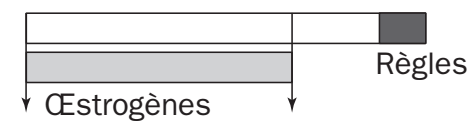

Ovariectomie

Arrêt des

œstrogènes

d

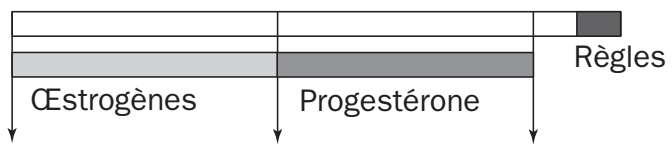

Ovariectomie

Arrêt des

Arrêt de la

œstrogènes

progestérone

Femme normale

e

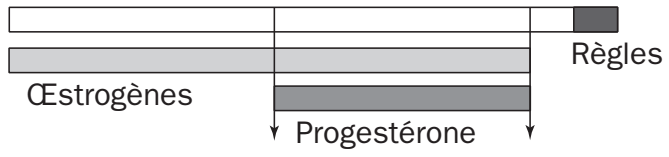

Ovulation

Figure 12.7 - Déterminisme de la menstruation

On peut faire apparaître la menstruation chez l'animal (guenon) après ovariectomie (a) ou imprégnation hormonale; l'association œstrogènes + progestérone $(b, d)$ entraîne, dès son arrêt, une menstruation plus précoce qu'avec les œstrogènes seuls (c). 


\subsection{LE CONTRÔLE NEURO-ENDOCRINIEN DU CYCLE ESTRIEN}

\subsubsection{Caractères généraux}

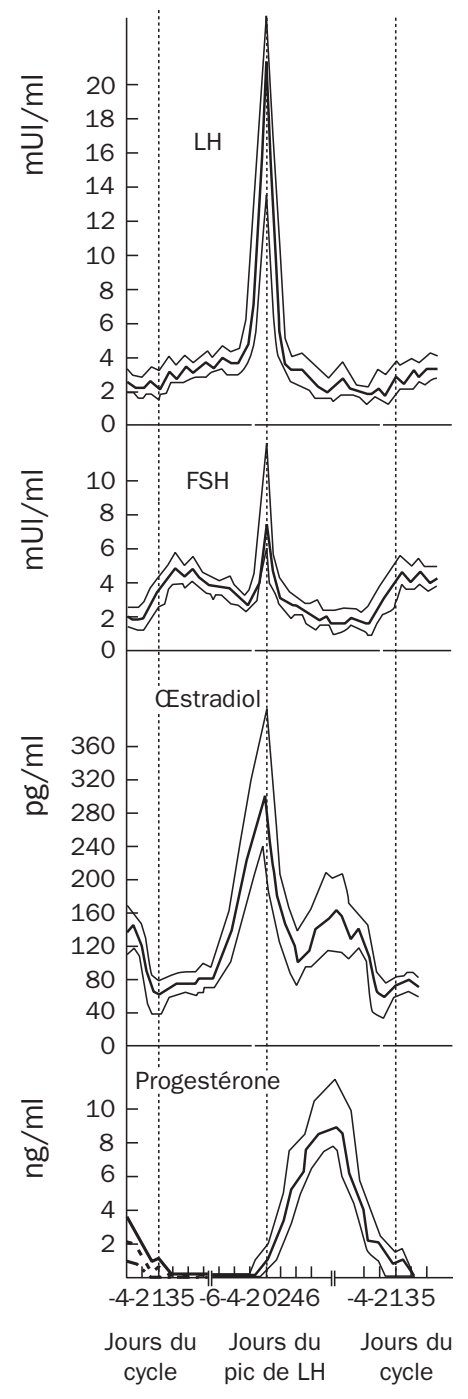

Figure 12.8 - Les hormones du cycle menstruel chez la femme (d'après Rotten et coll., 1985)
L'activité ovarienne est soumise à un contrôle hormonal multifactoriel dans lequel s'intègrent les activités de l'hypothalamus, de l'hypophyse et de l'ovaire lui-même (fig. 12.8).

L'hypothalamus produit une gonadolibérine, la GnRH ou LH-RH, qui va agir sur la synthèse et la libération des gonadotrophines hypophysaires.

L'hypophyse sécrète trois hormones gonadotropes : FSH, LH et LTH ou Prl. La sécrétion de FSH présente, par rapport à une sécrétion de base d'environ $3 \mathrm{mUI} / \mathrm{ml}$ de plasma, une élévation dans la première partie de la phase folliculaire, un pic à $8 \mathrm{mUI} / \mathrm{ml}$, synchrone de celui de LH vers le 13 e jour du cycle et un taux relativement bas en phase lutéale avec toutefois une légère remontée en fin de cycle.

LH a une sécrétion de base de l'ordre de $3 \mathrm{mUI} / \mathrm{ml}$, présente vers le $13^{\mathrm{e}}$ jour une ascension importante de ses taux : la décharge ovulante qui précède l'ovulation de 37 à $40 \mathrm{~h}$.

LTH (prolactine) favorise chez les rongeurs la sécrétion et le maintien du corps jaune. On détecte en effet, chez le rat, un pic de LTH synchrone de celui de LH. Chez les primates, en revanche, l'activité gonadotrope de la prolactine est discutée, bien que le corps jaune humain possède des récepteurs à LTH et que ceux-ci soient stimulés par LH. On s'accorde actuellement pour attribuer à la prolactine un rôle de potentialisation de l'effet LH sur la sécrétion progestative en normo-prolactinémie.

A ce titre, la LTH ferait partie du complexe lutéotrophique. En revanche, en cas d'hyperprolactinémie, la LTH entraînerait une inhibition ovarienne, témoin le syndrome d'aménorrhée-galactorrhée dans lequel des taux excessifs de prolactine engendrent un blocage ovarien complet.

Au niveau de l'ovaire, les gonadotrophines agissent sur la thèque et la granulosa, ainsi que sur le corps jaune et le stroma. 
FSH a des récepteurs sur les cellules de la granulosa où elle induit ses propres récepteurs, la synthèse de l'inhibine, les enzymes de l'aromatisation des androgènes et, en fin de phase folliculaire, les récepteurs à LH.

LH a des récepteurs sur la thèque interne pendant toute la durée du cycle, elle y induit la synthèse des androgènes et des œstrogènes. Sur la granulosa, elle possède également ses propres récepteurs et y détermine la diminution de ceux de FSH. En phase lutéale, les récepteurs de LH sont présents et l'activité fonctionnelle du corps jaune est en relation directe avec cette gonadotrophine. Enfin, la LH induit la synthèse des androgènes par le stroma ovarien.

Au total, ceci permet de construire les séquences fonctionnelles synergiques suivantes (fig. 12.9).

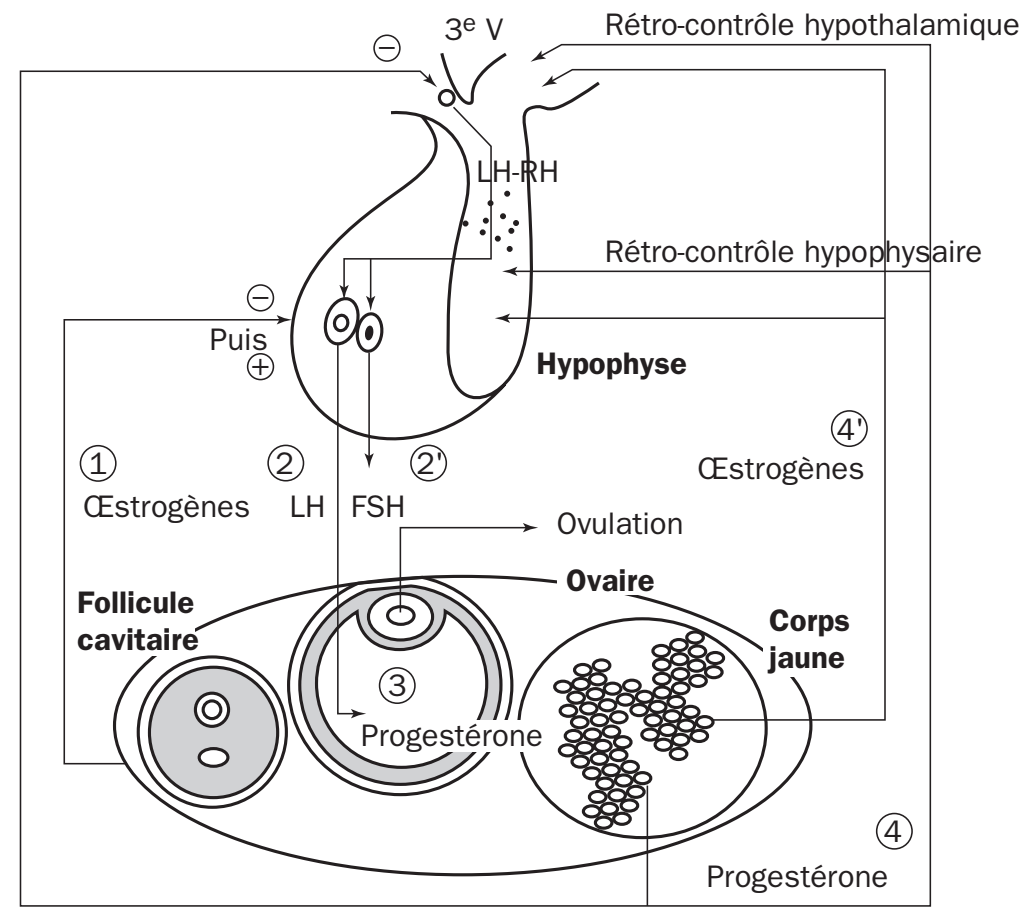

Figure 12.9 - Le rétro-contrôle hormonal dans le cycle œstrien

La sécrétion d'œstrogènes par l'ovaire (1) exerce un effet inhibiteur sur la sécrétion de FSH (rétro-contrôle ou feed-back négatif) puis, à partir d'un certain taux, provoque la décharge de $\mathrm{LH}$ (2) et FSH (2') (rétro-contrôle positif). La décharge de LH provoque la sécrétion de progestérone par les cellules de la granulosa (3), qui vont se transformer en cellules lutéiniques, et l'ovulation. La sécrétion de progestérone par les cellules lutéiniques (4) exerce un effet inhibiteur sur les neurones hypothalamiques à LH-RH (rétro-contrôle négatif) et, avec les œstrogènes qui continuent d'être sécrétés par le corps jaune (4'), un autre rétro-contrôle, au niveau hypophysaire, sur LH et FSH respectivement. 


\subsubsection{Contrôle de la phase folliculaire}

La LH induit la synthèse des androgènes au niveau de la thèque interne. La FSH, via ses effets stimulant la production d'aromatases (enzymes provoquant l'aromatisation du cycle A) par la granulosa, entraîne leur transformation en ostrogènes. Comme la FSH détermine ses propres récepteurs, cette aromatisation est auto-entretenue, de même que les effets des œstrogènes stimulant la prolifération folliculaire.

Le follicule de de Graaf dominant, riche en récepteurs R-FSH, sécrète des taux d'œstradiol importants qui entraînent un rapport E2 / androgènes plus élevé que celui des autres follicules recrutés ; de ce fait, ces derniers sont voués à l'atrésie.

Des rétro-contrôles limitent ces actions : d'une part, les œstrogènes vont faire diminuer la sécrétion de FSH et, d'autre part, exercer un effet positif sur l'excrétion de LH hypophysaire (voir fig. 12.9). Ainsi, les œstrogènes pré-ovulatoires vont conditionner la décharge ovulante de LH, pendant que l'œstradiol et l'inhibine vont assurer le rétro-contrôle négatif de FSH.

\subsubsection{Contrôle de la phase lutéale}

La LH détermine et entretient la sécrétion majoritairement progestative du corps jaune. La progestérone a le pouvoir de bloquer la croissance d'autres follicules et, en outre, inhibe sa propre sécrétion. Ainsi, par ce rétro-contrôle hypophysaire négatif, le corps jaune s'autorégule. Enfin, la progestérone, en stimulant la production de FSH hypophysaire, amorce le cycle suivant.

\section{PARTiCularités de L'OVUlation ET DE LA PHASE LUTÉINIQUE CHEZ DIFFÉRENTS MAMMIFÈRES}

Chez les Mammifères, le nombre des ovules émis paraît de plus en plus limité à mesure que les chances de survie du jeune deviennent plus grandes :

- un œuf par ovulation dans l'espèce humaine (soit 400 à 500 ovules pondus sur 500000 environ présents dans l'ovaire de la jeune fille) ;

- généralement un seul œuf par ovulation chez la vache ;

- une douzaine d'œufs chez la truie ;

- 500 œufs par an chez la grenouille (la ponte est saisonnière) ;

- et, au cours de sa vie entière :

- 5 à 10 millions d'œufs chez l'anguille ;

- 10 millions d'œufs chez une reine de termites ;

- 60 millions d'œufs chez une femelle d'ascaris.

Chez de nombreuses espèces, l'ovule s'entoure au cours de son cheminement d'enveloppes protectrices ou membranes (membranes secondaire et tertiaire). La membrane primaire est la membrane vitelline, sécrétée par la couche de cellules folliculaires. 
Chez les Batraciens, se différencient autour de la membrane vitelline le chorion et la gangue muqueuse. Chez les Sauropsidés (Reptiles et Oiseaux), se constitue une coque, molle chez les Reptiles, mieux calcifiée chez les Oiseaux.

Le cycle œstrien présente des variations remarquables selon les Mammifères.

Deux types s'opposent presque, que nous proposons de qualifier de "cigale" et de "fourmi".

- Le type "cigale" est représenté par la femme qui, de toute façon, qu'il y ait rapport sexuel ou pas :

- présente une ovulation ;

- accomplit une phase lutéinique complète avec, à chaque fois, le développement d'une "dentelle" utérine complète qui permettrait une nidation. Remarquons, en outre, que la femme est le seul Mammifère qui accepte le mâle à n'importe quel moment de son cycle œstrien.

- Le type "fourmi" est représenté par la lapine, mais aussi la chatte et le furet. Deux cas de figure sont possibles, qui constituent chaque fois une économie de sécrétions hormonales et de modifications sexuelles superflues :

- pas de coït, pas d'ovulation : l'ovulation est dite "provoquée", c'est un mécanisme nerveux qui déclenche la décharge de LH-RH et donc le pic de LH ;

- après ovulation provoquée, deux éventualités sont possibles :

- le rapport n'est pas fécondant, le corps jaune est dit pseudo-gestatif et ne dure, chez la lapine, que 16-17 jours ;

- le rapport est fécondant, le corps jaune est gestatif et dure chez la lapine 3032 jours.

- La rate constitue un cas intermédiaire. C'est un animal à ovulation périodique, comme la femme. Mais la durée de la phase lutéinique varie selon qu'il y a ou non présence de mâle(s). Trois cas de figure sont alors possibles :

- pas de mâle(s) : ovulation périodique tous les 4 ou 5 jours (selon l'animal). La phase lutéinique, qui dure moins de 3 jours, ne développe pas une "dentelle" propre à la nidation.

- coït non-fécondant : le corps jaune pseudo-gestatif dure 13-15 jours.

- coït fécondant : le corps jaune gestatif dure 22 jours.

\section{RÉGULATION DE LA FONCTION GONADOTROPE FEMELLE}

\subsection{INFLUENCE DES HORMONES OVARIENNES (voir fig. 12.9)}

L'ovariectomie ou la ménopause provoquent une augmentation de la FSH et de la LH. L'œstradiol exerce en effet un contrôle inhibiteur tonique (rétro-contrôle négatif) sur la sécrétion des cellules gonadotropes hypophysaires. La sécrétion de FSH est plus affectée que celle de LH (voir (4') dans la fig. 12.9). 
L'augmentation de la durée d'imprégnation et des concentrations sériques d'œstradiol provoque au contraire une élévation du taux de FSH et de LH (rétro-contrôle positif), qui s'accroît à mesure que le taux d'œstradiol plasmatique augmente et que l'on s'approche de l'ovulation. Cette sensibilisation hypophysaire ne se concrétise qu'après un délai d'au moins $60 \mathrm{~h}$, même avec des concentrations d'œstradiol de l'ordre de $300 \mathrm{pg} / \mathrm{ml}$. Le délai serait de 5 à 6 jours avec une concentration de $90 \mathrm{pg} / \mathrm{ml}$.

Il est possible que cette réponse paradoxale s'explique par la présence de deux types de neurones hypothalamiques.

La progestérone inhibe essentiellement la LH (voir (4) dans la fig. 12.9). C'est sur ce dernier phénomène qu'est fondée la pilule anti-ovulatoire, qui comporte toujours un dérivé synthétique de la progestérone. Elle contient également une faible dose d'œstrogènes, qui assure une meilleure trophicité du tractus génital et évite souvent des troubles secondaires (métrorragies).

\subsection{RAPPORTS HYPOTHALAMO-HYPOPHYSAIRES}

La section de la tige pituitaire provoque l'arrêt du cycle œstrien et la disparition de la sécrétion de FSH et de LH.

Nous avons vu (voir le complexe hypothalamo-hypophysaire) que les relations hypothalamo-hypophysaires sont réalisées par des facteurs sécrétés par les neurones hypothalamiques :

- pour FSH et LH : un facteur unique, la LH-RH ${ }^{11}$ (ou GnRH, ou gonadolibérine), décapeptide dont l'action déclenchera la décharge de FSH ou de LH au niveau de l'hypophyse, selon le taux d'hormones sexuelles présentes dans le sang, l'excès d'œstrogènes favorisant la décharge de LH. Chez le singe, ce facteur a été retrouvé dans trois régions de l'hypothalamus : le noyau supra-optique, le noyau arqué ${ }^{12}$ et le corps mamillaire.

- pour la prolactine : un facteur inhibiteur (PIF) qui présente un précurseur commun avec la GnRH. Mais il faut tenir compte surtout de l'action inhibitrice des neurones dopaminergiques issus de la région médioventrale du tuber. Enfin la TRH a un effet stimulant sur la sécrétion de prolactine.

11 Le taux de LH-RH dans le sang du système porte varie de 200 à 800 pg / ml. Dans le sang périphérique, le taux serait voisin de $1-2 \mathrm{pg} / \mathrm{ml}$ en début de cycle et pourrait aller jusqu'à $2,5 \mathrm{pg} / \mathrm{ml}$ en milieu de cycle.

12 Il est possible d'induire la libération de LH-RH par stimulation électrique de l'hypothalamus médiobasal avec des fréquences de 10 à $100 \mathrm{~Hz}$ (Dyer et coll., 1980). 


\subsection{PUlSATILITÉ deS SÉCRÉTIONS DE LA LH-RH ET DES HORMONES GONADOTROPES}

La LH-RH est sécrétée par le noyau arqué de façon pulsatile (Ferin et coll., 1984 ; Rotten, 1985), à raison d'une pulsation toutes les 60 à 90 min ; cette pulsatilité est nécessaire au bon fonctionnement des sécrétions gonadotropes de LH et FSH, qui sont également sécrétées de façon pulsatile, en plus de leur variation cyclique dans le cycle œstrien (fig. 12.10 et 12.11).

On a pu démontrer que chaque oscillation sécrétoire ("pulse") de LH est immédiatement précédée d'une oscillation synchrone de $\mathrm{LH}$ RH (fig. 12.12 et 12.13). La neutralisation de la LH-RH par un anticorps anti-LH-RH supprime la sécrétion pulsatile de $\mathrm{LH}$.

Chez les Primates, le rôle de la LH est essentiellement "permissif" sur les sécrétions de LH et de FSH, mais l'essentiel de la régulation des hormones gonadotropes est assuré par rétrocontrôle des œstrogènes (effet biphasique, d'inhibition au début du cycle, puis rétro-contrôle positif de stimulation dans la période "critique" pré-ovulatoire). La prolactine intervient avec l'œstradiol dans la modulation de l'action de GnRH sur ses récepteurs.

L'utilisation de ces données en thérapeutique a permis le traitement de certaines stérilités par dérèglement hormonal, à l'aide d'une pompe pulsatile à LH-RH.
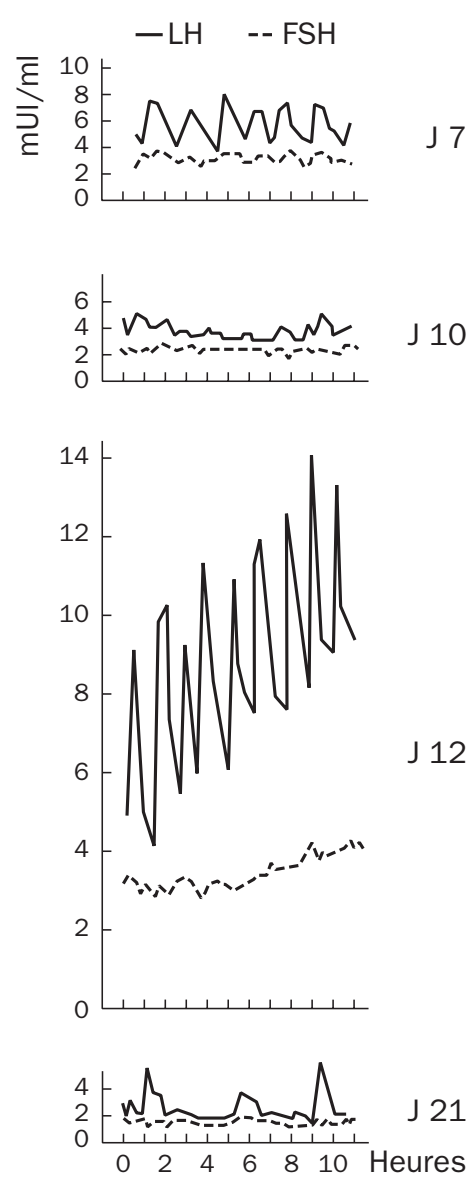

Figure 12.10 - Evolution de la pulsatilité des gonadotrophines au cours du cycle menstruel chez la femme

(d'après Rotten et coll., 1985)

\subsection{LEPTINE ET RÉGULATION DE L'AXE REPRODUCTEUR}

La leptine est une hormone sécrétée par les cellules adipeuses. Sa sécrétion est pulsatile, modulant un rythme circadien avec un pic le matin et un nadir (minimum) l'après-midi (Matkovic et coll., 1997). C'est, chez les Mammifères, une protéine de $16 \mathrm{kDa}$, apparentée à la famille des cytokines (voir chap. 2, § 2.1.4). Elle agit, par l'intermédiaire de récepteurs disséminés dans l'organisme, sur l'équilibre énergétique et la thermorégulation (en augmentant les dépenses énergétiques et la thermogenèse). 


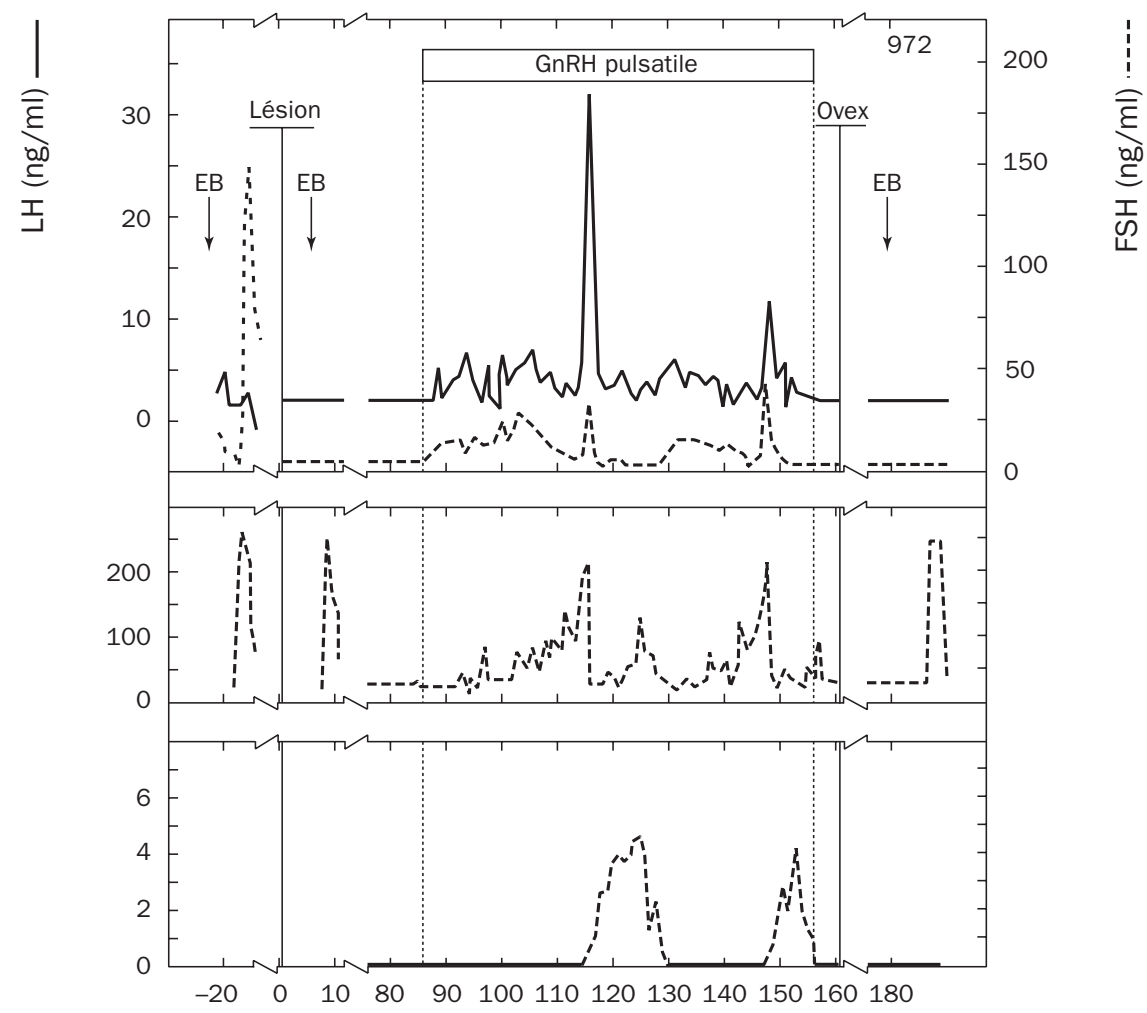

a - Action de la perfusion pulsatile de la GnRH

EB : benzoate d'œstradiol ; Ovex : ovariectomie. après déconnection hypothalamo-hypophysaire

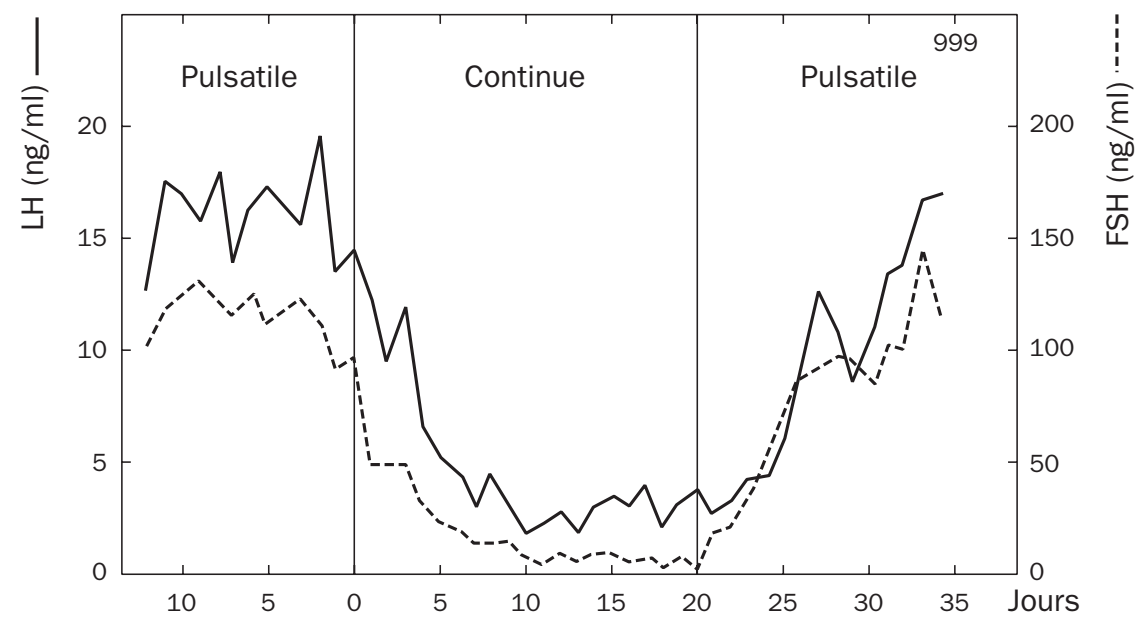

b - Action de la perfusion continue de la GnRH après lésion du noyau arqué

Figure 12.11 - Contrôle neuro-endocrine du cycle menstruel chez le singe rhésus (d'après Knobil, 1980) 


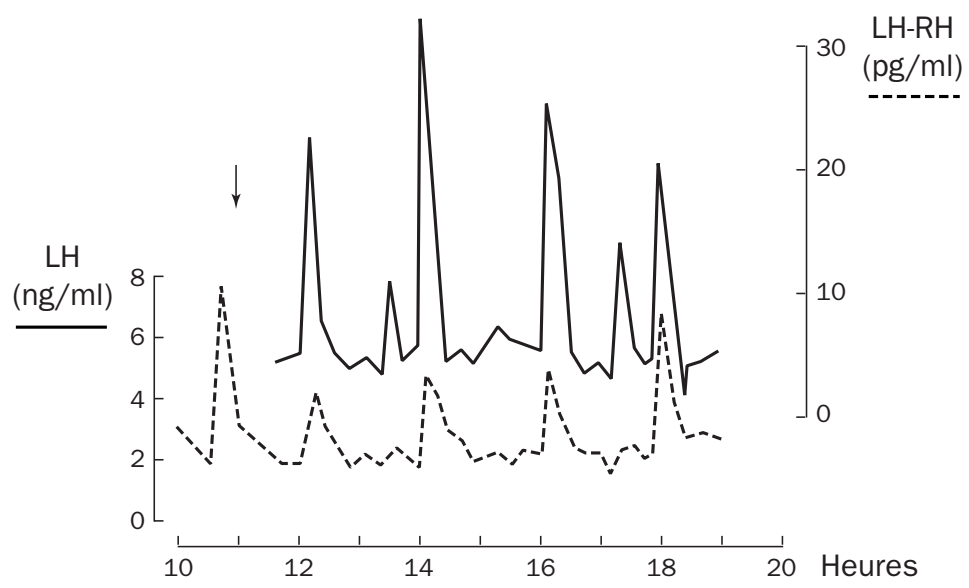

Figure 12.12 - Mesures simultanées de la LH dans la veine jugulaire et de la LH-RH dans le sang hypophysaire portal d'une brebis ovariectomisée (d'après Clarke et Cummins, 1982)

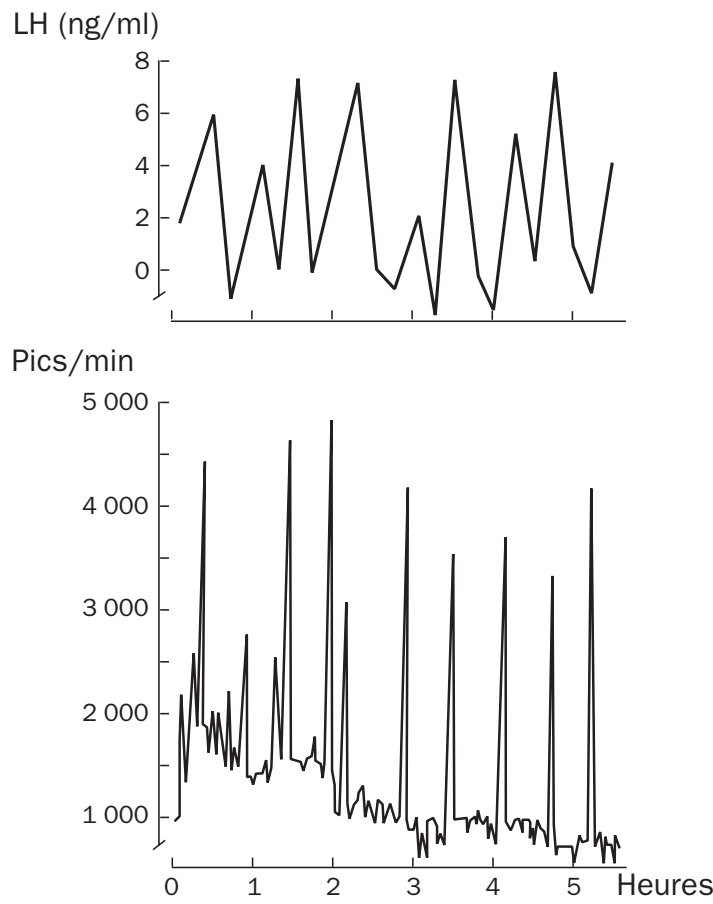

Figure 12.13 - Enregistrement comparé (sous anesthésie) de l'activité électrique (pics / min) dans le noyau arqué et des taux de LH dans le sang périphérique de rates ovariectomisées (d'après Kawakami et coll., 1982) 
C'est également un facteur satiétogène, par inhibition de l'expression hypothalamique du neuropeptide Y (NPY) qui est un stimulateur de l'appétit. L'activation de la protéine STAT3 (signal transducers and activators of transcription 3) semble être la première étape qui suit la liaison de la leptine à son récepteur hypothalamique.

L'ensemble de ces actions conduit à une perte de poids corporel. Le rôle de la leptine fut découvert grâce à l'étude des souris $o b / o b$, homozygotes pour une mutation du gène de la leptine, qui étaient obèses par incapacité de sécréter de la leptine (Zhang et coll., 1994). Mais la leptine joue un rôle fondamental dans la maturation et le fonctionnement de l'axe reproducteur.

Outre l'obésité, l'hyperglycémie et les troubles de la thermorégulation, les souris $o b / o b$ présentent un hypogonadisme et sont stériles. Chez l'homme, les concentrations de leptine sérique sont corrélées, dans les deux sexes et à tout âge, à l'indice de masse corporelle (body mass index ou BMI), et présentent un dimorphisme sexuel au cours du développement. A partir de l'âge de 12 ans environ, les filles ont des concentrations de leptine plus élevées que les garçons chez l'adulte et au même âge elles sont trois fois plus élevées chez la femme que chez l'homme.

La concentration de leptine varie durant les cycles menstruels : elle est maximale en phase lutéale et minimale en phase folliculaire. Elle augmente également pendant la grossesse et chute après l'accouchement. Une concentration minimale serait nécessaire au maintien des menstruations, la concentration plasmatique de leptine pourrait être le facteur le mieux corrélé à l'aménorrhée chez la femme anorexique.

Plusieurs études suggèrent que la leptine stimule, par l'intermédiaire de son récepteur, la fonction de reproduction en activant la sécrétion de LH-RH (activation rapide de STAT3 et de canaux potassiques dépendant de l'ATP) dont elle réglerait la sécrétion pulsatile. Elle exerce également, mais in vitro, un effet direct sur l'ovaire, par inhibition de la stéroïdogenèse dans les cellules de la granulosa. Ces deux effets contradictoires pourraient s'expliquer par l'existence des deux formes du récepteur, une forme longue présente dans l'hypothalamus mais absente dans l'ovaire où une forme courte a été détectée. Enfin, la leptine semble constituer un facteur permissif du début de la puberté chez les Mammifères ; chez l'homme sa concentration augmente juste avant le début de la montée de la concentration de testostérone (Frühbeck et coll., 1998 ; Van Gaal et coll., 1999).

En conclusion, il semble bien que la sécrétion de la leptine, corrélée à la masse graisseuse corporelle, lui confère un rôle d' "adipostat", capable de renseigner l'hypothalamus de la femelle sur l'état des réserves énergétiques à long terme, et sur leur compatibilité avec la menée à terme d'une gestation et d'une lactation ultérieures (Bruneau et coll., 1999). 


\subsection{RELATION ENTRE LA LH-RH ET SES RÉCEPTEURS HYPOPHYSAIRES}

L'interaction de la LH-RH avec ses récepteurs hypophysaires (haute affinité et nombre limité de ces récepteurs) est nécessaire à l'action de la LH-RH, elle déclenche :

- dans un premier temps, une agrégation des récepteurs occupés ;

- un phénomène calcium-dépendant (l'intervention de l'AMPc n'est pas nettement établie) ;

- puis une internalisation dans la cellule du complexe LH-RH-récepteur.

Le nombre des récepteurs de la LH-RH est maximum chez les Rongeurs le jour du pic d'œstradiol (pro-œstrus), moment où l'hypophyse est la plus sensible à la LH-RH. Il est le plus bas le jour de l'ovulation (œstrus).

Quel que soit le moment du cycle, l'injection préalable de faibles doses de LH-RH augmente la réponse de LH et de FSH à une action ultérieure de la LH-RH. C'est le phénomène d'autosensibilisation, qui traduit une augmentation du nombre des récepteurs sous l'effet de la LH-RH. Ce phénomène s'observe également chez la femme. Au contraire, la présence continue de fortes doses de LH-RH conduit à un effet de désensibilisation ${ }^{13}$, par occupation excessive des récepteurs, qui s'internalisent et rendent la cellule gonadotrope insensible à une nouvelle action immédiate de la LH-RH.

Cela explique l'efficacité de la sécrétion pulsatile de l'hormone hypothalamique et, pour que la cellule fonctionne à un maximum de rendement, il faut que la fréquence des pulses soit synchrone à la vitesse de reconstitution des récepteurs de surface.

\subsection{SÉCRÉTION DE LH-RH ET OPIACÉS}

Les peptides opiacés exercent chez le rat un effet inhibiteur sur la sécrétion pulsatile de LH-RH par les neurones de l'hypothalamus médiobasal (fig. 12.14). C'est vrai pour la morphine, la $\beta$-endorphine, la met-enképhaline et la leu-enképhaline. La naloxone lève cette inhibition (Drouva et coll., 1981).

L'enképhaline et la dynorphine sont présentes dans les noyaux magno-cellulaires (supra-optiques et paraventriculaires), mais le peptide le plus abondant est la $\beta$-endorphine dont les neurones ont leur corps cellulaire dans le noyau arqué et déversent leur produit de sécrétion en de nombreuses régions du cerveau, y compris les noyaux magno-cellulaires et les vaisseaux portes hypophysaires (Finley et coll., 1981).

13 C'est cet effet qui a été observé avec l'utilisation d'agonistes de la LH-RH, tel la busériline. Mis au point avec l'objectif d'améliorer l'induction de l'ovulation, ces agonistes, appliqués en continu pendant tout le cycle, occupent les sites récepteurs à la LH-RH et bloquent l'ovulation. Administrés à partir du milieu du cycle, ils entraînent une lutéolyse. Ils peuvent être utilisés par voie sous-cutanée ou par vaporisation nasale ! 
Le rôle principal des peptides opiacés serait de moduler le feed-back négatif des stéroïdes ovariens sur la sécrétion de LH.

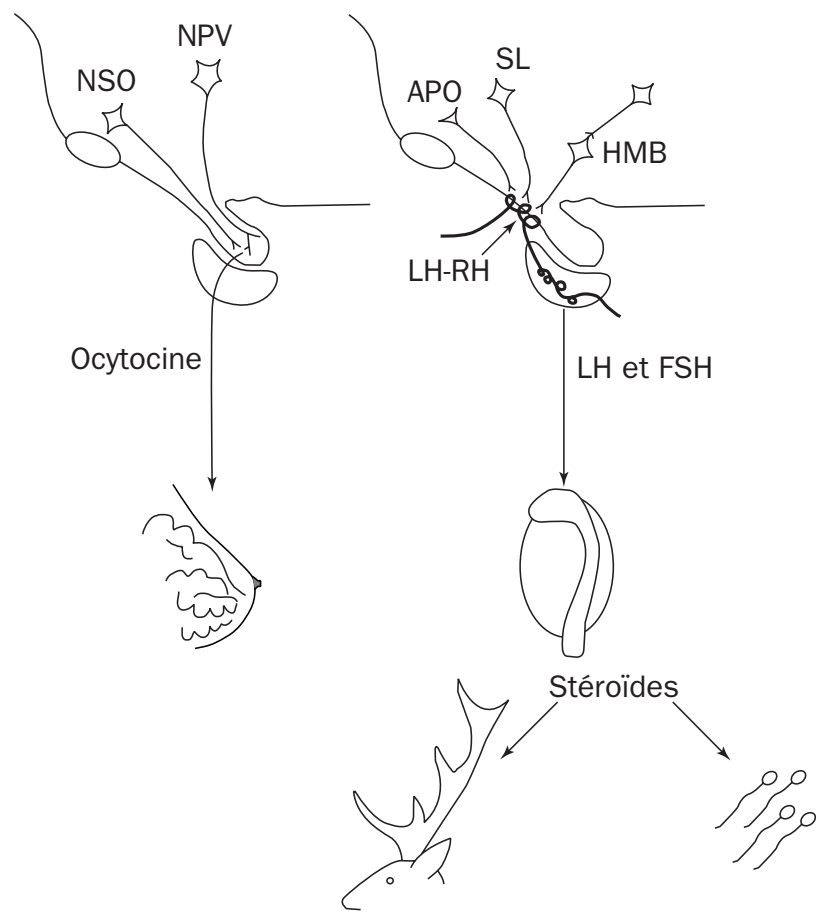

Figure 12.14 - Schéma comparatif des neurones sécréteurs

d'ocytocine et de LH-RH chez les primates (d'après Lincoln et coll., 1985)

$A P O$ : aire pré-optique ; HMB : hypothalamus médiobasal ; NPV : noyau paraventriculaire ; NSO : noyau supra-optique ; SL : septum latéral.

\subsection{LA SEXUALISATION DE L'HYPOTHALAMUS}

L'hypothalamus détermine la caractéristique fondamentale des sécrétions hormonales de l'axe gonadotrope : sécrétion cyclique chez la femelle, sécrétion continue (tonique) chez le mâle (voir chap. 1).

\subsection{LE CERVEAU ET LES HORMONES SEXUELLES}

Des récepteurs d'hormones stéroïdes sont présents dans le tissu cérébral normal, et à des taux beaucoup plus élevés dans les méningiomes (porteurs de récepteurs à hormones sexuelles féminines) et les gliomes (porteurs de récepteurs à androgènes). Plus précisément, on a trouvé (Baulieu et coll., 1987 ; Baulieu, 1991a) de la prégnénolone et de la déhydro-éthylandrostérone dans les oligodendrocytes de la substance blanche et, moins intensément, dans le bulbe olfactif et le cortex entorhinal (neurostéroïdes). Il est possible que ces substances jouent un rôle dans la reconnaissance sexuelle ou dans l'agressivité. 


\subsection{INFLUENCE DE L'ENVIRONNEMENT}

Le fonctionnement génital femelle reste étroitement lié aux conditions extérieures :

- La lumière : elle joue un rôle prépondérant chez les Vertébrés. On connaît le rapport entre la durée de l'éclairement (ou alternance lumière-obscurité) et la ponte chez les Oiseaux. La variation saisonnière de la photopériode conditionne l'activité sexuelle de certaines espèces de Mammifères.

- La température : une ambiance thermique anormale modifie la fertilité chez de nombreuses espèces.

- L'environnement : la captivité, le confinement sont des facteurs importants de stérilité.

- Les facteurs sociologiques et psychologiques : ils sont à l'origine du comportement sexuel de la plupart des espèces.

\section{EXPLORATION DE L'AXE HYPOTHALAMO-HYPOPHYSO-GONADIQUE}

Les renseignements fournis par l'étude des récepteurs périphériques ont l'énorme avantage de montrer une "imprégnation hormonale" globale, qui permet d'ordinaire d'avoir une idée assez exacte de l'état fonctionnel de l'axe hypothalamo-hypophysoovarien. Cependant, les "instantanés biologiques" que représentent les divers dosages peuvent avoir l'intérêt, soit de confirmer une carence légère ou récente, soit de préciser le site en cause.

\subsection{EVALUATION DE LA FONCTION GSTROGÉNIQUE}

En pratique courante, l'évaluation de la fonction œstrogénique comporte le dosage du $17 \beta$-œstradiol, des œstrogènes totaux, ainsi que l'étude de divers métabolites plasmatiques ou urinaires.

\subsection{LA FONCTION PROGESTATIVE}

La fonction progestative, autrefois estimée par le prégnandiol urinaire, est actuellement réalisée à l'aide d'un stéroïdogramme plasmatique qui mesure directement la progestérone, l'hydroxyprogestérone et divers produits dérivés.

\subsection{LA FONCTION ANDROGÉNIQUE}

L'évaluation de la fonction androgénique chez la femme a des indications précises et présente un certain intérêt dans le diagnostic étiologique des hyperandrogénies et des hirsutismes. 
En effet, si la $\Delta 4$-androstène-dione est principalement sécrétée par l'ovaire, le sulfate de déhydro-épiandrostérone (DHEA-S) est à 90\% d'origine corticosurrénalienne.

\subsection{LE DOSAGE DES GONADOTROPHINES}

Ce dosage par méthode radioimmunologique présente de même un certain intérêt.

Pendant l'enfance, le taux des gonadotrophines est faible ; il s'élève avant la puberté pour atteindre progressivement les taux de la femme fonctionnelle (voir cycle ovarien). A la ménopause, les taux augmentent de façon importante pour rester en plateau aux alentours de $100 \mathrm{mUI} / \mathrm{ml}$. En cas de castration, d'effondrement fonctionnel de l'ovaire, les taux de FSH-LH sont également élevés et participent ainsi au bilan étiologique des aménorrhées primaires ou secondaires.

Des tests dynamiques peuvent parfois être pratiqués :

- Le test au citrate de clomifène (Clomid®) (fig. 12.15)

Le citrate de clomifène est un inducteur de l'ovulation. Il agit par inhibition compétitive du rétro-contrôle des œstrogènes au niveau de l'hypothalamus.
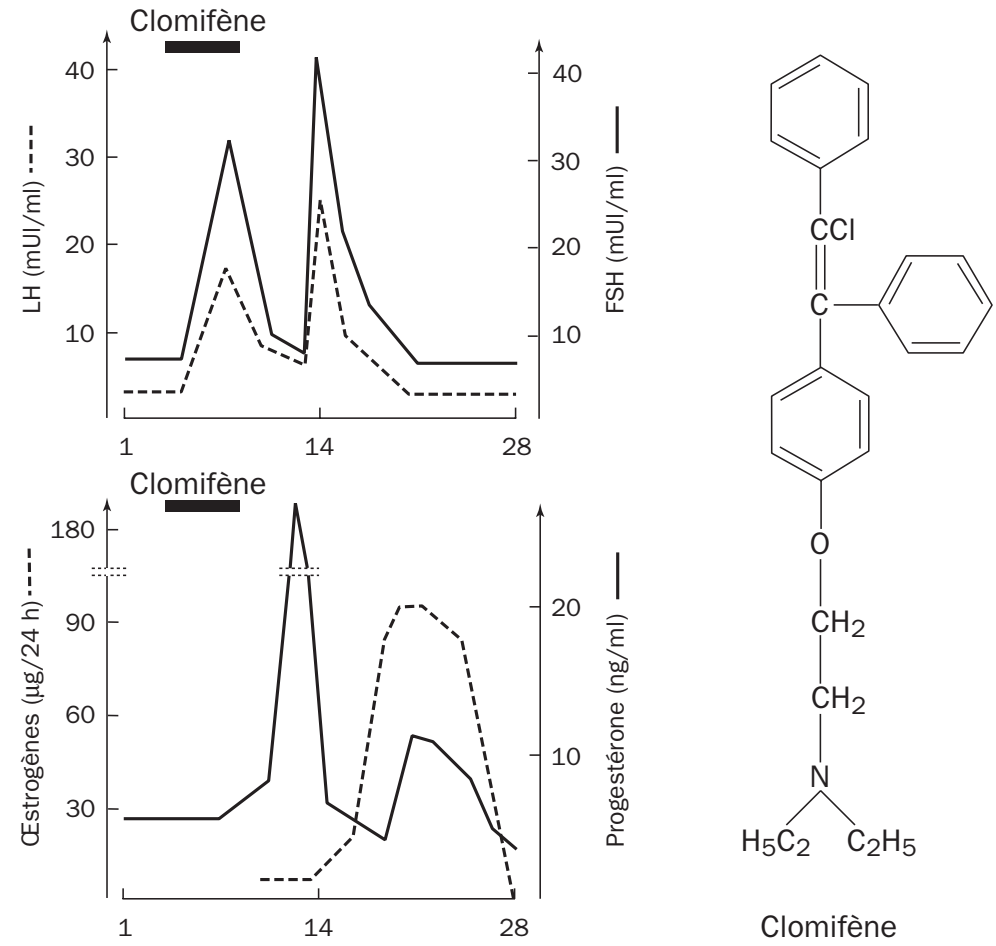

Figure 12.15 - Action du clomifène sur la sécrétion des hormones sexuelles chez la femme (d'après Tourniaire et Fèvre, 1979)

Lorsque le taux des gonadotrophines est bas, qu'il importe d'explorer l'étage en cause dans le déterminisme de l'aménorrhée, on pratique le test du clomifène qui 
vérifie l'intégrité de l'étage suprahypophysaire de l'axe hypothalamo-hypophysoovarien.

On administre le clomifène à raison de $100 \mathrm{mg} /$ jour pendant 5 jours consécutifs, en contrôlant les taux plasmatiques de FSH-LH pendant le cycle qui suit. Une réponse hormonale se traduit par une élévation des gonadotrophines dans la semaine qui suit l'arrêt du traitement. C'est le pic clomifénique équivalent de la décharge ovulante, témoin de l'intégrité fonctionnelle hypothalamique.

- Le test au LH-RH (Stimu-LH®)

Ce test peut également être utilisé : l'injection intraveineuse de 25 à $100 \mathrm{mg}$ de LH-RH agit directement sur l'hypophyse et engendre une libération précoce de FSH et de LH dans les $2 \mathrm{~h}$. Une réponse positive reflète le bon état fonctionnel de l'hypophyse.

Le déterminisme de l'atrésie folliculaire, qui aboutit à la sélection d'un lot limité de follicules ovulatoires (et en général un seul hors de chaque cycle ovarien), est complexe. Il semble que n'importe quel follicule qui entre en développement terminal hors d'une vague folliculaire ait les potentialités de se développer jusqu'au stade préovulatoire. Chaque follicule est caractérisé par un équilibre local entre des facteurs paracrines stimulants (œstradiol, IGF, activine...) et inhibiteurs (androgènes, IGFBP ou IGF binding proteins, follistatine...). Seul le follicule le mieux adapté continuerait son développement (évolution opportuniste plutôt que prédéterministe). Les autres, sous l'effet d'une augmentation de la synthèse de facteurs inhibiteurs et la perte de synthèse de facteurs stimulants, rentreraient en atrésie : activation de Fas et du récepteur du TNF $\alpha$ (tumor necrosing factor), déséquilibre en faveur des facteurs proapoptotiques (Bcl-2), activation de p53 et des caspases (Monniaux et coll., 1999). 



\section{PHYSIOLOGIE DE L'APPAREIL DE REPRODUCTION MÂLE}

L'appareil génital mâle possède une fonction exocrine, la spermatogenèse et une fonction endocrine, l'androgéno-sécrétion.

\section{STRUCTURE DE LA GONADE MÂLE}

Les deux fonctions sont le propre du testicule, organe ovoïde pair situé dans les bourse, chez l'homme, et qui présente (fig. 13.1): une capsule conjonctive, l'albuginée, comportant, au niveau de son pôle supérieur, une portion fibreuse épaissie, le corps de Highmore, les lobules testiculaires dans lesquels se tassent les tubes séminifères abouchés dans des collecteurs, les tubes droits, eux-mêmes communiquant avec le réseau canalaire du corps de Highmore, le rete testis.

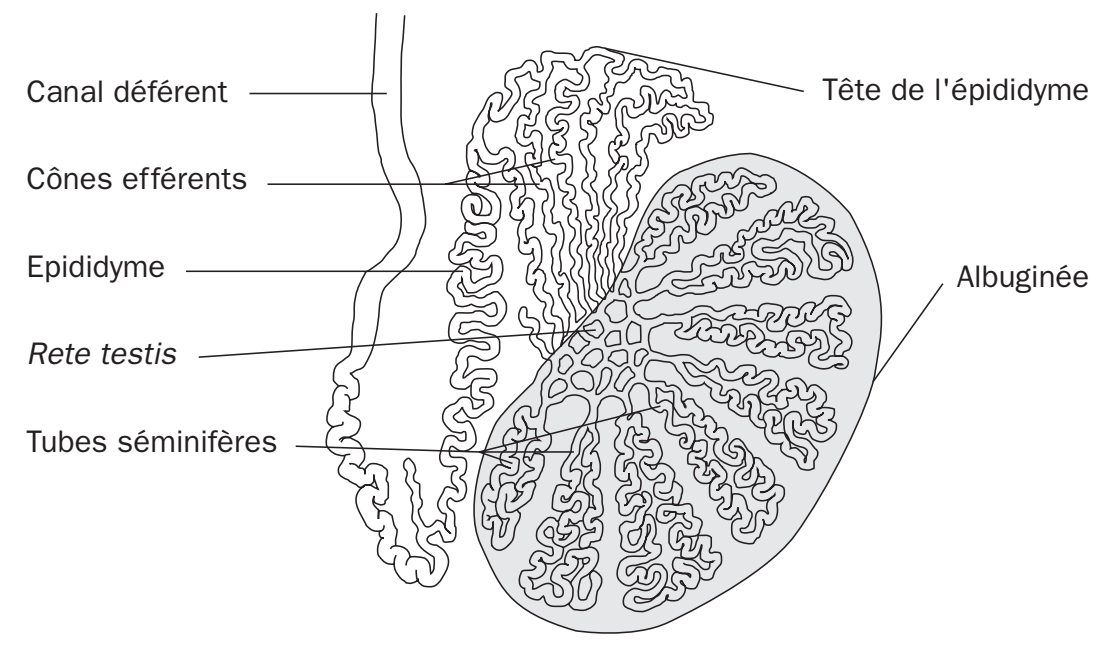

Figure 13.1 - Coupe longitudinale de la gonade mâle 
Les tubes séminifères, au nombre d'un million environ, mesurent de $30 \mathrm{~cm}$ à $1,50 \mathrm{~m}$ de long pour un calibre de 150 à $300 \mu \mathrm{m}$. Chacun d'eux est délimité par une paroi propre, la gaine péritubulaire qui englobe les éléments de la lignée germinale et les cellules de Sertoli.

Dans le compartiment intertubulaire, se trouvent des petits amas de cellules dites interstitielles de Leydig qui ne représentent que 3\% du volume testiculaire global, mais sont douées de l'activité androgéno-sécrétoire du testicule.

\section{LA LIGNÉE GERMINALE}

Elle correspond à l'ensemble des éléments dérivés des spermatogonies et qui aboutissent au gamète mûr, le spermatozoïde.

Chez l'adulte, les spermatogonies souches sont disposées à la périphérie des tubes séminifères, entre les cellules de Sertoli. Selon l'aspect de leur noyau, on distingue des spermatogonies A dites "poussiéreuses" à chromatine fine, le noyau peut être clair (spermatogonie Ap, $\mathrm{p}=$ pâle) ou sombre (spermatogonie Ad, $\mathrm{d}=$ dark) et des spermatogonies B, "croutilleuses", dont la chromatine nucléaire se présente en amas (fig. 13.2).

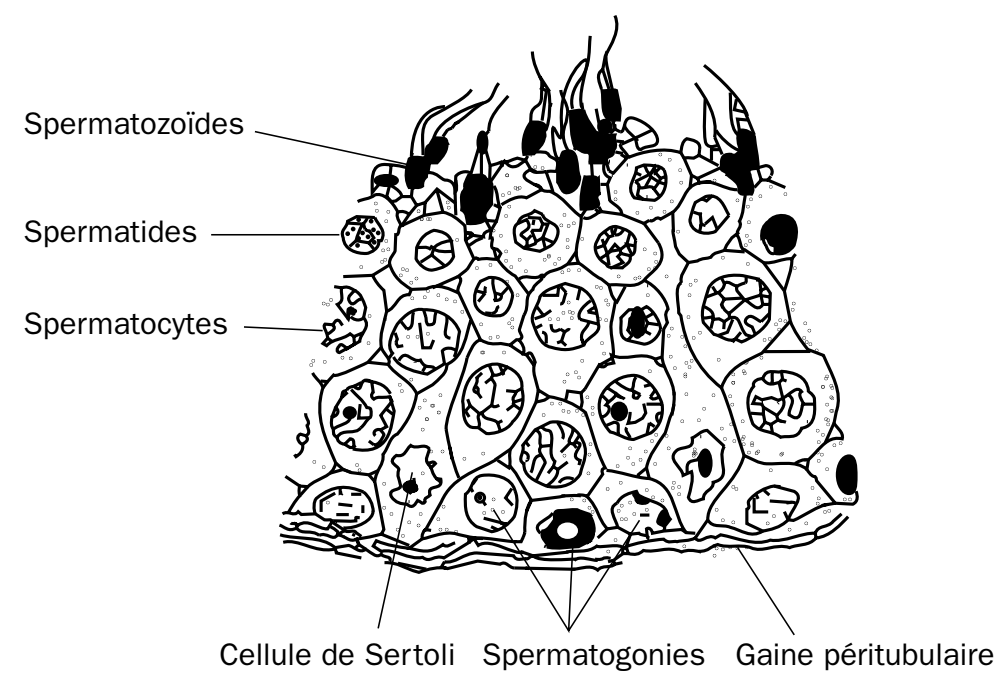

Figure 13.2 - Coupe schématique de l'épithélium séminifère

Les cellules souches subissent trois à cinq mitoses goniales, donnant naissance à des spermatocytes de premier ordre, grosses cellules germinales à $2 \mathrm{n}$ chromosomes qui, par division méiotique réductionnelle, vont engendrer des spermatocytes II haploïdes à $\mathrm{n}$ chromosomes (et $\mathrm{ADN}=\mathrm{Q}$ ) dont la taille est réduite de moitié. Ces spermatocytes de deuxième ordre, en subissant une mitose équationnelle, vont générer des spermatides haploïdes à $\mathrm{n}$ chromosomes (et $\mathrm{ADN}=\mathrm{Q} / 2$ ). 
Le spermatide ne se divise plus mais se transforme profondément en un spermatozoïde mature, à l'issue d'un processus qui constitue la spermiogenèse et qui comporte principalement : la constitution de la coiffe acrosomiale par confluence de l'appareil de Golgi ; la formation du flagelle par déplacement ordonné des centrioles au pôle postérieur du noyau ; le regroupement des mitochondries, soit en largeur au niveau du col, soit en hélice au niveau du flagelle ; l'écoulement cytoplasmique sur le pourtour du noyau.

Lors de la spermiation, les cellules d'une même génération restent liées entre elles par des ponts cytoplasmiques, réalisant de ce fait une structure pseudosyncytiale. Ainsi, au fur et à mesure de l'avancement de la spermatogenèse, les cellules générées près de la membrane péritubulaire vont progressivement migrer vers la lumière du tube séminifère où se retrouvent les spermatozoïdes, terme de cette différenciation.

Disposées en bouquets, plantées dans les cellules de Sertoli, les cellules mûres sont relarguées dans la lumière tubulaire, les tubes droits et le rete testis avant de pénétrer dans l'épididyme où le fluide testiculaire, riche en testostérone, les emporte.

Cette progression est un phénomène passif, la mobilité spermatique n'est acquise qu'après passage et séjour dans le corps et surtout la queue épididymaire. L'imprégnation par la FMP (forward mobility protein) joue en cela un rôle déterminant, de même que le fructose des vésicules séminales dont la production représente 50 à $80 \%$ de l'éjaculat. Les sécrétions prostatiques, riches en acide citrique, en choline, catécholamines et prostaglandines, jouent également un rôle important.

Le transit spermatique extratesticulaire, contemporain de l'orgasme, se produit lors de l'éjaculation qui comporte, d'une part, des contractions à point de départ pénien poussant le sperme (issu également des vésicules séminales) hors des voies génitales et, d'autre part, la fermeture du sphincter prostatique qui empêche toute éjaculation rétrograde intravésicale. Ainsi, chez l'adulte, à une production testiculaire continue, correspond une émission spermatique intermittente.

D'un point de vue cinétique, la spermatogenèse commence à la puberté, persiste jusqu'à un âge avancé. Cependant, la qualité spermatique décline après 50 ans en raison d'un pourcentage croissant d'aberrations chromosomiques, en particulier sur le chromosome 21 responsable du mongolisme.

Il faut 74 jours pour qu'une spermatogonie aboutisse au spermatozoïde mature. Le transit spermatique intratesticulaire, épididymaire et déférentiel dure de 1 à 2 semaines pendant lesquelles s'opère la capacitation ${ }^{1}$. De ce fait, on pense donc qu'il faut environ 3 mois pour apprécier les effets d'une thérapeutique sur la spermatogenèse.

La qualité du sperme s'apprécie grâce au spermogramme, le recueil se faisant par masturbation ou rapport interrompu, après 4 à 5 jours d'abstinence. L'examen se

1 C'est la majoration du pouvoir fécondant résultant d'échanges entre le spermatozoïde et les sécrétions épididymo-déférentielles. 
pratique in vivo, entre lame et lamelle, dans l'heure qui suit l'émission hors des voies génitales et après transport, le cas échéant, dans des conditions de températures acceptables (le spermatozoïde est très sensible au froid). La première partie de l'éjaculat correspond à la vidange de la filière terminale, à savoir le déférent et les vésicules séminales.

Normalement, l'éjaculat total est d'environ $4 \mathrm{ml}( \pm 2 \mathrm{ml})$, mais il peut être nettement inférieur, de l'ordre de $0,5 \mathrm{ml}$ (aspermie), ou supérieur à $6 \mathrm{ml}$, comme c'est le cas dans les infections ou les abstinences prolongées. De couleur blanchâtre et d'odeur sui generis due à l'oxydation de la spermine, l'éjaculat se liquéfie en $30 \mathrm{~min}$, son pH est légèrement alcalin. La concentration spermatique oscille entre 40 et 200 millions par $\mathrm{ml}$, dont $80 \%$ de formes vivantes. La mobilité sur place et les trajets directs représentent de bons facteurs de la fécondance du sperme.

Le spermogramme permet d'apprécier la morphologie du spermatozoïde : tête, col et flagelle. D'ordinaire, il existe moins de 30\% de formes anormales, celles-ci étant représentées par des malformations de la tête (tête effilée, acrosome malformé, micro- ou macrocéphalie), de la pièce intermédiaire ou du flagelle (absent ou bifide).

Des tests fonctionnels, comme le test postcoïtal de Hühner, constituent un moyen indirect d'apprécier la qualité de la survie spermatique dans son milieu naturel : la glaire cervicale péri-ovulatoire. Les tests peuvent se pratiquer après optimisation de la glaire par la prise d'éthinyl-œstradiol, à raison de $100 \mu \mathrm{g} /$ jour du $1^{\mathrm{er}}$ au $12^{\mathrm{e}}$ jour du cycle, l'examen ayant lieu à l'issue du traitement.

Divers facteurs peuvent influencer la qualité spermatique : l'exposition aux radiations, les traitements cytotoxiques, les androgènes, qui entraînent une oligospermie par effet indirect hypothalamique, les œstrogènes qui diminuent non seulement la libido mais également la spermatogenèse ; le surmenage, le tabac et l'alcool ont également un rôle délétère sur la qualité du sperme.

\section{LES HORMONES DU TESTICULE}

Deux types de cellules testiculaires peuvent produire des hormones : les cellules de Leydig du tissu interstitiel et les cellules de Sertoli du tube séminifère.

Les cellules de Leydig sécrètent principalement des androgènes en C19 (dont la testostérone et son dérivé, la déhydrotestostérone) (fig. 13.3), la déhydro-épiandrostérone (DHEA) et l'androstène-dione, forme $3 \beta \Delta 5$ déshydrogénée ; l'œstradiol est également sécrété, mais en très faible proportion.

Les cellules de Sertoli, outre leur rôle nutritionnel pour l'épithélium séminal, leur rôle de cohésion entre les éléments de la lignée germinale, leur rôle dans la spermiation, synthétisent toute une série de protéines extrudées dans le fluide testiculaire, telles l'ABP ou androgen binding protein, l'inhibine, les gonadocrines, un inhibiteur de la 
protéine kinase... Enfin, elles sont le siège de l'aromatisation des androgènes en $17 \beta$-œstradiol.

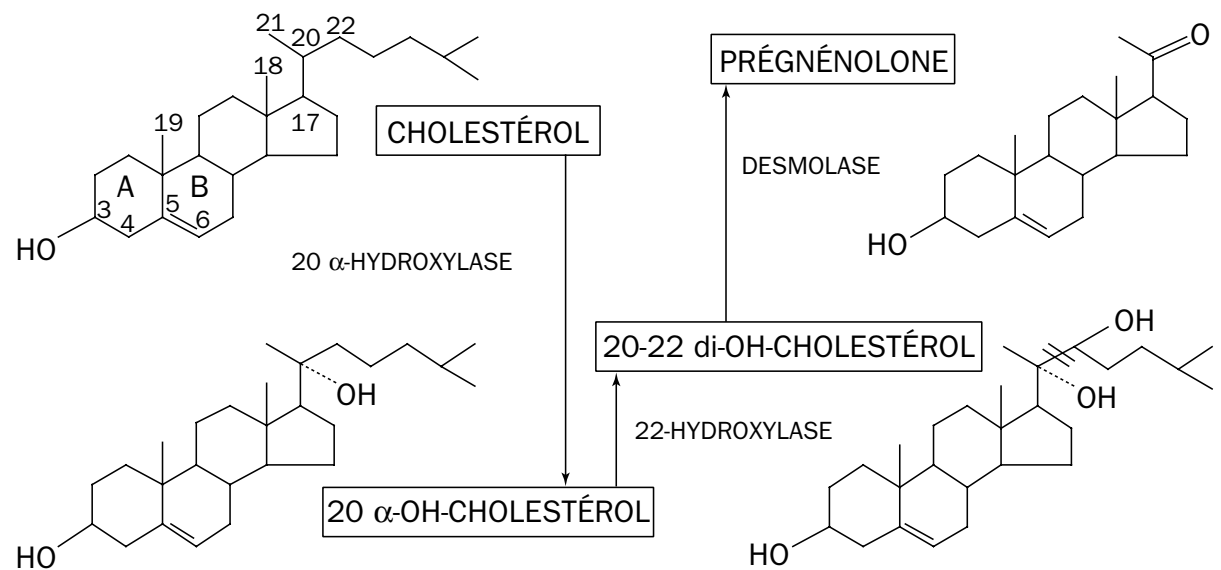

Synthèse de la prégnénolone à partir du cholestérol

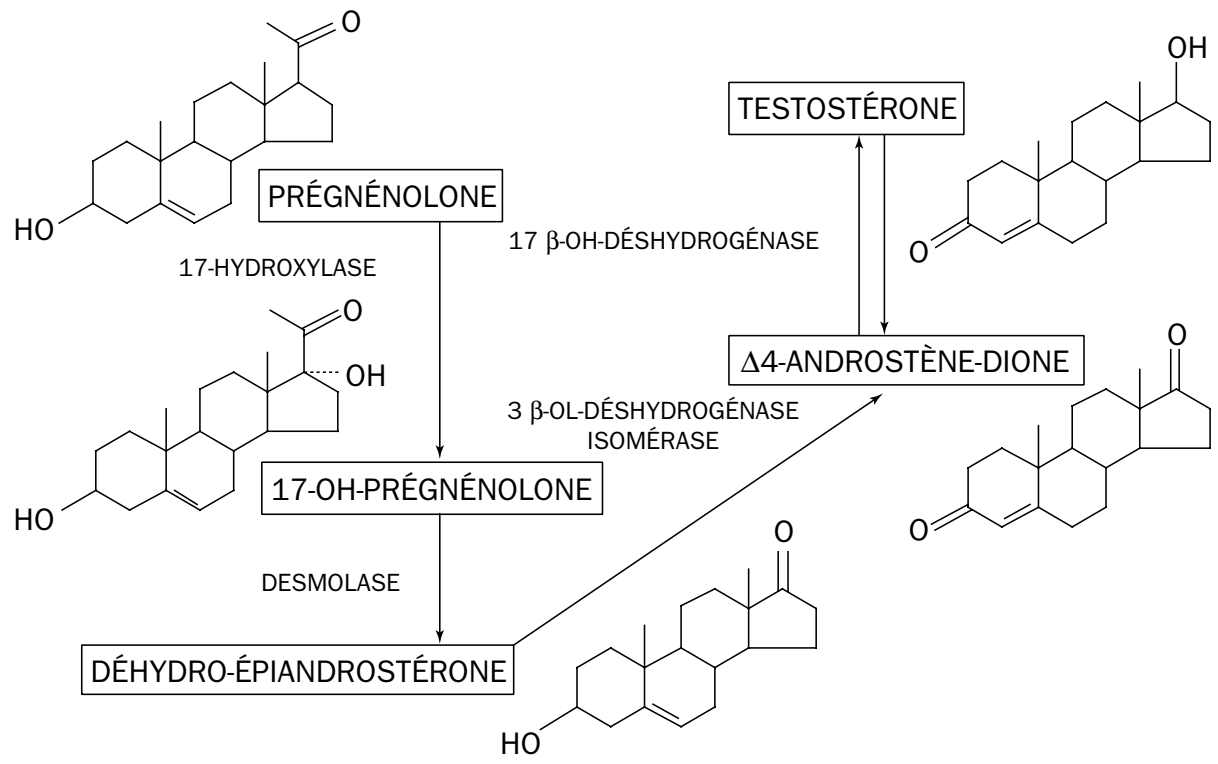

Voie $\Delta 5$ : de la prégnénolone aux androgènes

Figure 13.3 - Biosynthèse des hormones androgènes

Les deux fonctions exocrine et endocrine du testicule sont relativement indépendantes, comme le montre l'étude des cryptorchidies. L'atrophie des tubes séminifères due à la cryptorchidie entraîne une infertilité par arrêt de la spermatogenèse, mais n'altère en rien l'androgéno-sécrétion qui reste normale.

Le catabolisme des androgènes testiculaires produit de l'androstérone et de l'étiocholanolone, des 17-cétostéroïdes que l'on retrouve sous cette forme éliminés 
dans les urines à raison de 7 à $10 \mathrm{mg} / 24 \mathrm{~h}$. Chez la femme, on retrouve également des 17-cétostéroïdes dont la production est principalement surrénalienne.

Le dosage plasmatique ou urinaire, autrefois réalisé par le test du chapon (l'augmentation de la surface de la crête était proportionnelle à la quantité d'androgènes), est actuellement le propre des dosages par chromatographie ou méthodes radioimmunologiques (normalement, 7,9 $\pm 1,8 \mathrm{ng} / \mathrm{ml}$ d'hormones androgènes chez l'homme adulte).

\section{ETUDE EXPÉRIMENTALE DE LAFONCTIONANDROGÈNE}

\subsection{CASTRATION}

Les résultats sont différents selon que l'intervention est pratiquée avant ou après la puberté.

- La castration prépubérale entraîne un déficit global qui fait de l'individu un eunuque. Les organes annexes du tractus génital ne se développent pas ; les caractères sexuels secondaires n'apparaissent pas ; libido et puissance sexuelle sont absentes ou atténuées.

- La castration après la puberté provoque :

- l'involution des structures annexes ;

- mais les caractères sexuels secondaires, une fois fixés, persistent ; il n'y a ni impuissance ni perte de libido, dans la mesure où le psychisme n'est pas perturbé.

\subsection{EFFETS DE L'ADMINISTRATION DES HORMONES ANDROGÈNES}

Leurs effets sont doubles : - action androgène, - action métabolique.

En effet, les hormones androgènes, en dehors de leur action virilisante, dont les manifestations dépendront de l'âge où elles seront administrées, agissent sur le métabolisme protidique, et sur la croissance. Les androgènes stimulent l'anabolisme protidique, surtout au niveau du muscle et des os, d'où un poids plus élevé chez le mâle que chez la femelle. Ils déclenchent la poussée de croissance pubérale, stimulant l'activité du cartilage de conjugaison, mais aussi sa maturation (soudure des épiphyses fertiles).

On a mis au point des dérivés de synthèse plus anabolisants qu'androgènes, mais dont l'effet virilisant (mue de la voix et pousse des poils chez la femme) n'est pas toujours éliminé. C'est ce type de molécules qui a été utilisé dans le dopage des athlètes.

La nandrolone, par exemple, est un dérivé de la testostérone non détecté chez l'homme. En revanche, elle est présente dans l'urine de brebis gravide avec une 
structure spatiale modifiée (épiandrolone). Il s'agit d'un anabolisant très puissant. Le produit synthétique est sur le marché du médicament depuis 1959. Il est utilisé pour traiter les états de dénutrition, les grands brûlés et en traitement adjuvant de certaines formes d'ostéoporose et du SIDA. Rapidement détournée de ses indications thérapeutiques, elle est devenue la substance la plus utilisée comme dopant. Bien qu'elle induise des altérations cardio-vasculaires et des modifications de la formule sanguine, elle est utilisée car elle augmente à la fois la masse musculaire, la confiance en soi et l'agressivité, ceci sans action virilisante chez la femme.

\section{RÉGULATION DE L'ACTIVITÉ HORMONALE DU TESTICULE}

L'hypophysectomie entraîne l'involution des cellules de Leydig et l'arrêt de la spermatogenèse (celle-ci étant normalement stimulée par la sécrétion hormonale du testicule).

S'il est admis que la FSH stimule la gamétogenèse, et que la LH (ou ICSH, interstitial cells stimulating hormone) stimule les cellules de Leydig, on voit que ces hormones hypophysaires sont étroitement associées dans le fonctionnement normal du testicule.

On retrouve pour les hormones androgènes une régulation par feed-back, parfois paradoxale, car la castration semble stimuler davantage la sécrétion de FSH que celle de LH. Les hormones androgènes inhibent la sécrétion de LH-RH par rétro-contrôle de l'hypothalamus, ainsi que la réponse de la LH à la LH-RH. L'inhibition de la sécrétion de FSH est assurée par une cybernine d'origine testiculaire (inhibine), sécrétée par les cellules de Sertoli, dont l'existence a été postulée dès 1932 et que l'on retrouve également dans les cellules de la granulosa. En plus de son effet central, l'inhibine agit directement au niveau du testicule en diminuant la multiplication des spermatogonies.

\section{MODE D'ACTION DE LA TESTOSTÉRONE (fig. 13.4)}

La testostérone est transportée dans le sang liée à trois protéines : l'albumine $\left(\mathrm{K}_{\mathrm{D}}=0,2 \mathrm{mM}\right.$ ), la CBG (corticosteroid binding globulin) dont le $\mathrm{K}_{\mathrm{D}}$ est $0,2 \mu \mathrm{M}$ et surtout la SBG (sex hormone binding globulin) dont le $\mathrm{K}_{\mathrm{D}}$ est de l'ordre de la $\mathrm{nM}$. La concentration plasmatique normale de la testostérone est d'environ $5 \mathrm{ng} / \mathrm{ml} \mathrm{chez}$ l'homme adulte.

La testostérone constitue un cas particulier dans son mode d'action, au sein des stéroïdes, car elle se comporte dans la plupart des tissus cibles comme une préhormone, qu'une $5 \alpha$-réductase cytoplasmique, présente dans les cellules cibles, transforme de façon irréversible en dihydrotestostérone (DHT). C'est la DHT qui est 
alors l'hormone active. C'est ce qui se passe au niveau de la peau, du tractus génital. En revanche, le muscle strié, en particulier celui des cordes vocales, a pour effecteur hormonal la testostérone elle-même. Toutefois, chez le fœus, la $5 \alpha$-réductase n'apparaît que tardivement et la différenciation mâle (maintien des canaux de Wolff) est le résultat de la testostérone elle-même.

La $5 \alpha$-DHT liée à son récepteur (voir chap. 2, § 4) va agir dans le noyau sur le matériel génétique, selon des modalités qui restent à préciser.

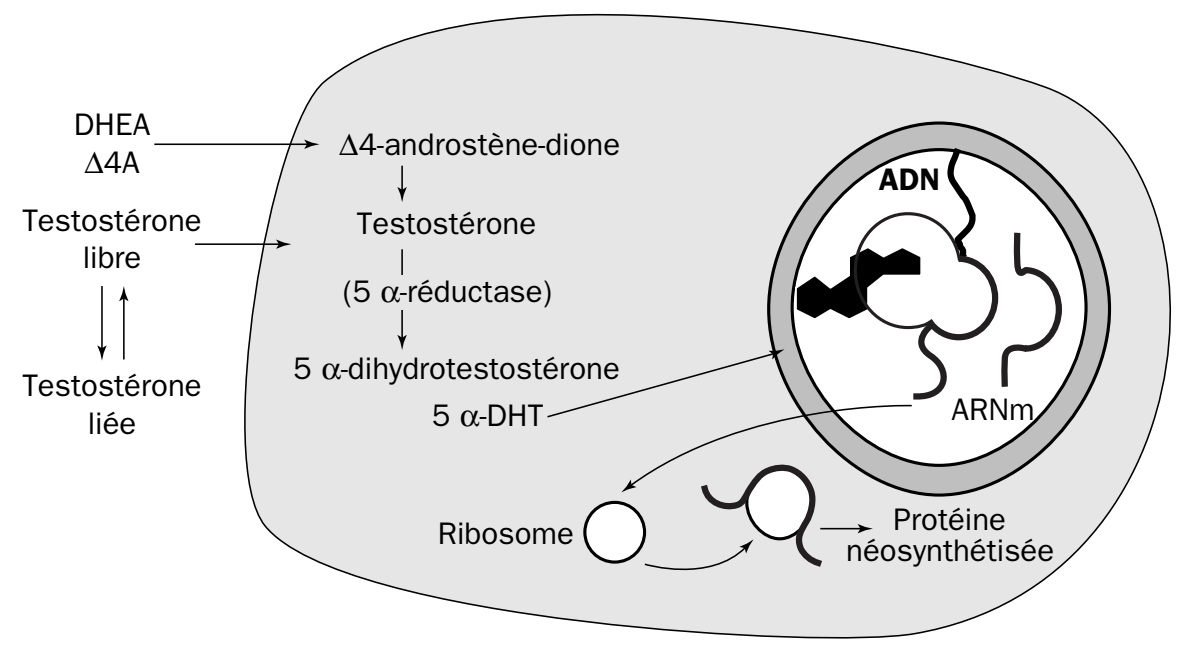

Figure 13.4 - Mode d'action de la testostérone

\section{LA CONTRACEPTION HORMONALE CHEZ L'HOMME}

La spermatogenèse requiert des taux plasmatiques normaux de FSH et de LH. L'inhibition de ces hormones, soit directement, soit indirectement, via un blocage de la LH-RH, entraînera une réduction de la production du sperme. Mais elle provoquera en même temps une diminution de la sécrétion de testostérone, et par conséquent la possibilité de diminution de la libido et de la puissance sexuelle.

\subsection{L'UTILISATION DE L'HORMONE SEXUELLE OU DE SES DÉRIVÉS}

Aussi les recherches se sont-elles plutôt orientées vers l'utilisation de la testostérone, ou d'un dérivé de synthèse de la testostérone, afin de diminuer par feed-back les hormones hypophysaires sans pour autant atteindre la libido. A une dose convenable, la testostérone, chez l'homme comme chez l'animal, supprime effectivement la spermatogenèse et compense la carence en testostérone androgène provoquée par le rétro-contrôle négatif. 
On a essayé :

- des esters de testostérone en injections intramusculaires tous les 15 jours, par exemple la testostérone undecanoate ;

- la testostérone en implantation sous la peau, dans une capsule siliconée ;

- l'association de testostérone et de progestatifs ;

- l'association méthyl-testostérone/éthinyl-œstradiol, mais avec le risque de gynécomastie (développement de la glande mammaire) et de maladie thrombotique ;

- un androgène faible, le danazol, à raison de $500 \mathrm{mg} /$ jour per os, associé à $250 \mathrm{mg}$ d'œnanthate de testostérone.

Le retour à une taille normale des testicules suit l'arrêt thérapeutique mais, tandis que les spermogrammes demandent 4 à 10 semaines pour être sévèrement déprimés, le retour à la normale est beaucoup plus long et peut, dans quelques cas, dépasser 5 mois.

\subsection{LES AGONISTES DE LA LH-RH}

Nous avons vu que les agonistes entrent en compétition avec la LH-RH gène, et finalement inhibent la sécrétion de FSH et de LH par occupation des sites hypophysaires. Deux produits sont actuellement expérimentés chez l'homme, mais il reste à démontrer leur absence de toxicité. D'autre part, leur emploi crée un déficit en testostérone, avec les conséquences possibles sur la libido et la puissance sexuelle. Un délai d'au moins 1 à 2 mois est nécessaire à la suppression de la spermatogenèse, ainsi qu'à sa réapparition, une fois l'essai terminé.

D'une façon générale, toutes ces méthodes hormonales contraceptives sont peu faciles à utiliser compte tenu :

- de la longueur du délai d'apparition de l'infécondité ;

- des fluctuations des résultats obtenus ;

- de la nécessité de plusieurs contrôles du spermogramme ;

- de la longueur de la phase de retour.

\subsection{L'UTILISATION ÉVENTUELLE DE L'INHIBINE}

Cette substance est capable de supprimer la sécrétion de FSH hypophysaire sans atteindre celle de la LH. L'inhibition sélective de FSH devrait conduire à une stérilité masculine, sans atteindre la sécrétion d'androgènes. Une expérimentation animale reste à faire, avec cette substance convenablement purifiée, avant d'envisager l'application humaine.

\subsection{L'ACÉTATE DE CYPROTÉRONE}

L'acétate de cyprotérone, progestatif de synthèse, dérivé de la $17 \alpha$-hydroxyprogestérone, possède un effet spécifique anti-androgénique par inhibition compétitive de la 
liaison de la $5 \alpha$-dihydrotestostérone à son récepteur cytosolique dans les cellules cibles. Il empêche chez l'homme l'action des androgènes sécrétés par les testicules et les corticosurrénales sur les organes cibles androgéno-dépendants tels que la prostate.

L'effet anti-androgénique a pour résultat possible de supprimer la spermatogenèse. Mais la diminution parallèle de la testostérone a les inconvénients que nous avons vus, et cette substance ne peut être retenue comme moyen contraceptif. 


\section{CHAPITRE 14}

\section{FÉCONDATION - GESTATION - LACTATION}

\section{LA FÉCONDATION}

La fécondation représente les phénomènes corrélés, contemporains ou conséquents à la rencontre du spermatozoïde et de l'ovocyte. Elle aboutit à la fusion des gamètes qui réalisent un œuf ou zygote diploïde, début de l'embryogenèse.

Lorsqu'elle a lieu dans le milieu extérieur, elle est dite externe ; c'est le cas, par exemple, chez certains animaux aquatiques. Par opposition, elle est dite interne lorsqu'elle se déroule dans la filière génitale, comme c'est le cas pour l'animal terrestre, les Mammifères dont l'homme.

\subsection{LES SPERMATOZOÏDES}

Dans l'espèce humaine, ils sont déposés lors du coït dans le cul de sac postérieur du vagin ou lac spermatique, dans lequel baigne le col. L'éjaculat représente environ de 5 à 600 millions d'éléments qui, du fait de l'acidité vaginale, vont fuir la filière génitale basse et ascensionner jusqu'à l'ovocyte.

Le canal cervical représente un parcours ascendant de 25 à $30 \mathrm{~mm}$ de muqueuse plissée, "l'arbre de vie", qui mène le spermatozoïde jusqu'à l'orifice intérieur du col plus ou moins confondu avec l'isthme utérin. Quelques centaines de glandes enchassées dans la muqueuse tapissent le canal et sécrètent la glaire cervicale, un hydrogel riche en glycoprotéines, maillé tel un filet plus ou moins perméable.

En phase pré-ovulatoire, par contre, l'abondance de la sécrétion et la filance passent par un maximum qui favorise les mouvements du flagelle et permet la progression spermatique. La glaire, ainsi, joue non seulement le rôle de filtre, mais elle offre également un milieu propice à la survie et à l'ascension du gamète mâle si bien que, dans la $1 / 2 \mathrm{~h}$ qui suit le rapport, la plupart des spermatozoïdes se retrouvent dans la glaire. Seuls les éléments mobiles ont le pouvoir de pénétrer les mailles des sécrétions cervicales. Les spermatozoïdes morts ou immobiles, les cellules germinales immatures, le liquide séminal, les bactéries restent invariablement dans la cavité vaginale. 
L'ascension de la cavité utérine, environ 50 à $60 \mathrm{~mm}$, s'effectue approximativement en 1 ou $2 \mathrm{~h}$. Seulement quelques centaines de spermatozoïdes vont atteindre l'ampoule tubaire après avoir subi une série de modifications qui permettront la traversée de la membrane pellucide ; c'est la capacitation, qui résulte de deux phénomènes : d'une part la séparation spermatozoïdes-plasma séminal, d'autre part des échanges spermatozoïdes-utérus.

La séparation spermatozoïdes-plasma séminal a lieu principalement au niveau du col. Le pH de l'éjaculat s'abaisse considérablement du fait de l'acidité vaginale qui favorise la fuite des gamètes vers le $\mathrm{pH}$ plus alcalin de la glaire cervicale. Ceci explique, en clinique humaine, le peu d'efficacité des douches vaginales contraceptives postcoïtales, surtout si elles sont tardives; les gamètes les plus vigoureux passent rapidement le canal cervical, les autres sont retenus dans les cryptes de l'endocol et c'est leur libération progressive pendant les $24 \mathrm{~h}$ suivantes qui va ordonner l'ascension spermique.

Le déplacement spermatique s'effectue grâce aux mouvements du flagelle, mais aussi du fait des contractions musculaires de l'utérus et de la trompe, ainsi que de l'activité ciliaire des muqueuses.

Lors du cheminement utérin, le spermatozoïde entre en contact avec des sécrétions endométriales endo-utérines dont la quantité varie selon les phases du cycle. Leur maximum est contemporain de la dentelle utérine endométriale (vers le $21^{\mathrm{e}}$ jour). Ces sécrétions entretiennent la mobilité et la survie spermatiques pendant toute la durée du trajet utérin qui peut aller jusqu'à 4 jours. La capacitation est donc une étape indispensable du fait de la pauvreté du cytoplasme du gamète mâle.

\subsection{L'OVOCYTE}

Le ou les ovocytes de deuxième ordre (voir ovulation, chap. 12, § 3) atteignent l'ampoule dans les $2 \mathrm{~h}$ qui suivent la ponte. L'antipéristaltisme tubaire permet l'ascension spermatique de l'isthme jusqu'au tiers externe de la trompe, siège habituel de la rencontre des gamètes. Ceux-ci cohabitent pendant 2 ou 3 jours et c'est l'arrêt des mouvements antipéristaltiques de la trompe qui va permettre la descente de l'œuf dans la cavité utérine vers le $20^{\mathrm{e}}$ jour du cycle, c'est-à-dire avant la période des règles manquantes.

Les ovules non-fécondés survivent environ 24 h et sont éliminés dans l'utérus et/ou phagocytés par les macrophages. Les stéroïdes ovariens contrôlent les mouvements de la trompe ; les œstrogènes ont le pouvoir d'augmenter le péristaltisme alors que la progestérone les diminue, si bien que certaines pilules progestatives ralentissant le transit tubaire du blastocyste ont été incriminées dans le déterminisme de la grossesse extra-utérine en cas d'échec de la méthode. 


\subsection{LA TRAVERSÉE DES ENVELOPPES OVOCYTAIRES}

C'est le propre de quelques dizaines de spermatozoïdes qui, propulsés par leur flagelle, atteignent l'ovule, s'insinuent dans les espaces intercellulaires de la corona radiata, et se fixent sur la membrane pellucide par les récepteurs spécifiques de l'espèce.

C'est la réaction acrosomiale caractérisée par l'ouverture de l'acrosome spermatique, la libération d'enzymes (hydrolases, hyaluronidases et CPE ou corona penetrating enzyme) qui permet, alors, la perforation de la membrane pellucide et l'accès à l'espace périvitallin.

Un seul spermatozoïde va fusionner, il y a monospermie. Le spermatozoïde élu se dispose à plat sur la surface de l'ovocyte; il est recouvert par les microvillosités ovocytaires et pénètre avec son flagelle dans le cytoplasme du gamète femelle.

Très rapidement, en 15 min environ, l'œuf se rétracte et la deuxième méiose, bloquée jusqu'alors en métaphase, termine son ultime évolution, aboutit à l'expulsion du deuxième globule polaire qui va, dans l'espace périvitallin, rejoindre le premier globule polaire, alors que les pronuclei mâle et femelle, au centre de l'œuf, restaurent la diploïdie nucléaire et déterminent le sexe du futur embryon (fig. 14.1).

Telle se présente, dans des conditions favorables, la fécondation in vivo. En pratique, elle n'aboutit, en moyenne, qu'une fois tous les seize cycles. En effet, on pense que 15 à $20 \%$ des zygotes sont perdus lors de la 1 ère semaine, à divers stades de la préimplantation et qu'en outre, un grand nombre d'implantations très précoces sont abortives, passent inaperçues, et se manifestent, tout au plus, par un retard de règles ou des ménorragies. Au total, principalement depuis les travaux de Hertig, on pense que seuls $30 \%$ des ovocytes fertilisés dans des conditions idéales seront des enfants vivants. Parmi ceux-ci environ $1 \%$ seront porteurs de malformations graves. Le grand nombre de facteurs intervenants conditionne le grand nombre des anomalies possibles.

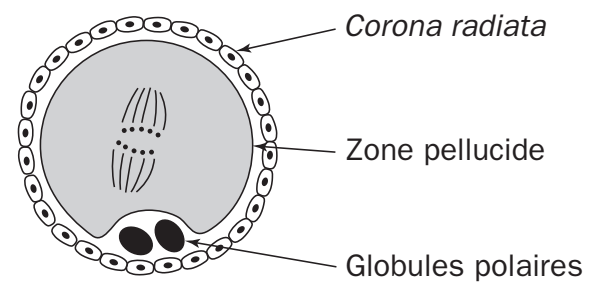

Figure 14.1 - CEuf, $1^{\text {er }}$ jour (dans le tiers externe de la trompe)

\section{LA MIGRATION TUBAIRE}

L'œuf de Mammifères, ayant peu de réserves, est destiné, s'il veut assurer son évolution, à s'implanter rapidement dans la muqueuse utérine, c'est la nidation. 
L'œuf fécondé lors de son transit tubaire commence une série de mitoses qui engendrent des cellules de plus en plus petites, les blastomères.

Cette segmentation a une chronologie précise; deux blastomères sont présents à la fin $\mathrm{du} 1^{\text {er }}$ jour suivant la fécondation; entre la $36^{\mathrm{e}}$ et la $40^{\mathrm{e}} \mathrm{h}$, c'est le stade à quatre blastomères, entre la $40^{\mathrm{e}}$ et la $50^{\mathrm{e}} \mathrm{h}$ le stade à huit blastomères, qui précède la morula retrouvée habituellement après la $72^{\mathrm{e}} \mathrm{h}$.

A raison d'une division par $24 \mathrm{~h}$, l'œuf multiplie ses cellules dont certaines, à la périphérie, sont plus petites (les micromères) que les blastomères centraux (les macromères). La membrane pellucide englobe la totalité de cette morula.

Vers le $5^{\mathrm{e}}$ jour de l'évolution de l'œuf, apparaissent des lacunes intercellulaires qui vont secondairement réaliser une cavité unique : la cavité blastocystique distinguant une couche cellulaire périphérique que sont les cellules trophoblastiques et le bouton embryonnaire (futur embryon). La migration tubaire dure 3 jours, le blastocyste, du fait des mouvements ciliaires de la muqueuse tubaire, du péristaltisme de la musculeuse et du courant endoluminal, va tomber dans la cavité utérine où il sera libre pendant $48 \mathrm{~h}$ avant de prendre contact avec la muqueuse endométriale vers le 6 e jour de sa vie (fig. 14.2).

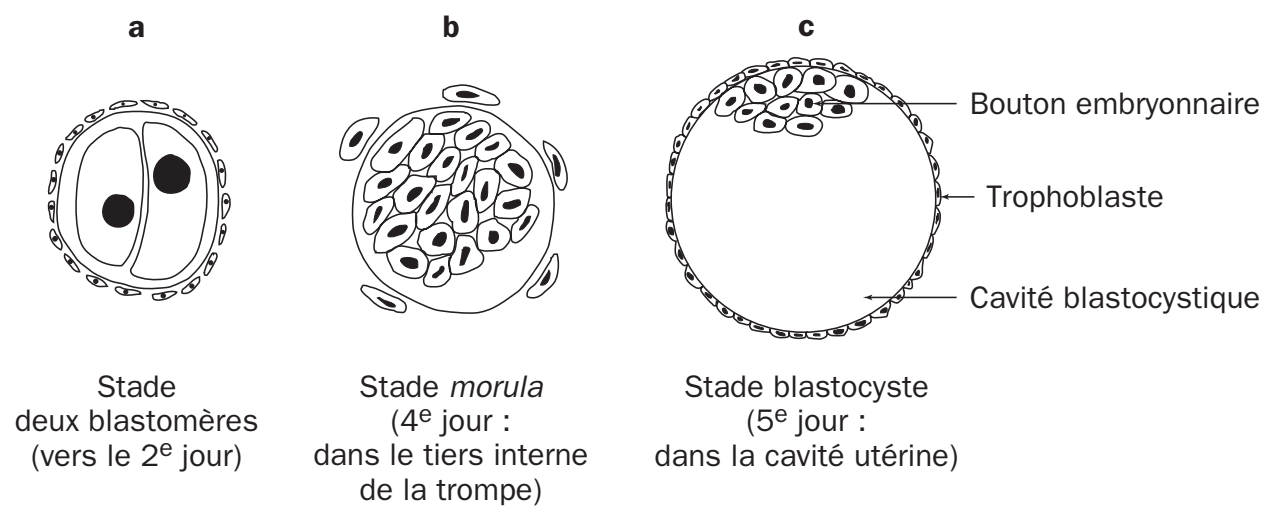

Figure 14.2 - L'œuf libre

\section{LA NIDATION}

Le début de la nidation a lieu vers le 20-21e jour du cycle, avant la période des règles manquantes, alors que l'endomètre est en pleine phase sécrétoire, au maximum de sa vascularisation, de son épaisseur et de son activité glandulaire.

Vers le 7-8e jour, les cellules trophoblastiques périphériques constituent le syncytiotrophoblaste distinct des cellules plus internes du cytotrophoblaste (voir fig. 14.3).

Vers le $10^{\mathrm{e}}-12^{\mathrm{e}}$ jour, le syncytium périphérique est lacunaire, l'œuf est enfoncé dans le chorion endométrial, au contact des vaisseaux spiralés porteurs d'éléments nutritifs. 


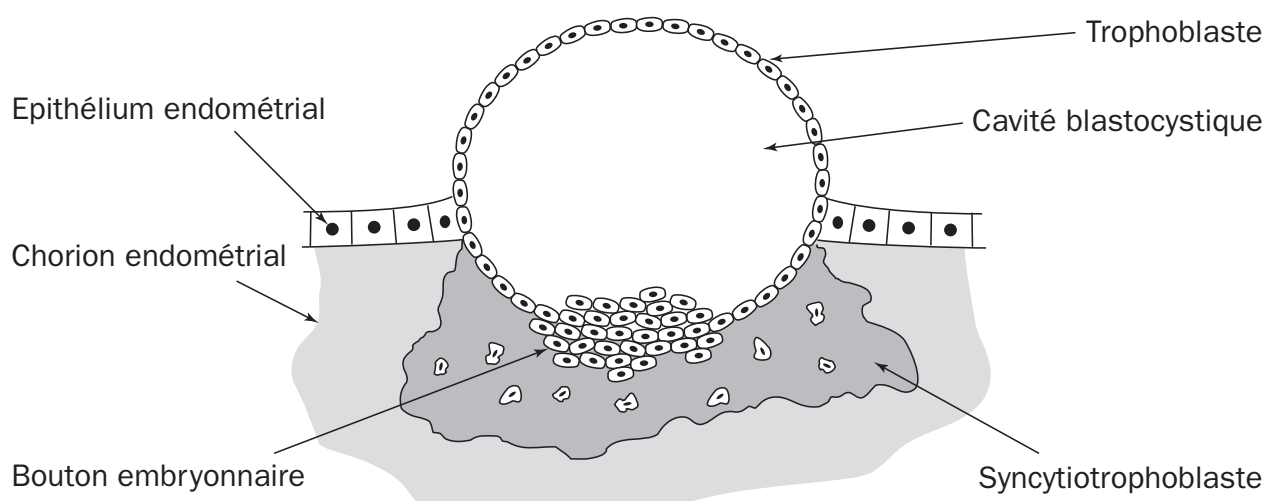

Figure 14.3 - L'œuf, $6^{\mathrm{e}}$ jour, fixé à l'endomètre (schématique)

Dès cette période de la grossesse, le blastocyste joue un double rôle :

- sécrétion de stéroïdes, en particulier d'œstradiol, qui faciliterait l'implantation en contribuant à induire la réaction déciduale ; le rôle de cette sécrétion, démontrée chez le porc, est à étayer par des preuves expérimentales ;

- rôle dans le maintien du corps jaune, à la fois par effet lutéotrope et en prévenant la lutéolyse. La sécrétion d'hormone chorionique gonadotrope (HCG) est très précoce, probablement avant même l'implantation. D'autre part, le blastocyste intervient en limitant la sécrétion par l'utérus d'une prostaglandine lutéolytique F2 $\alpha$, par un mécanisme encore mal connu.

La nidation du blastocyste pose par ailleurs un problème extrêmement subtil pour les immunologistes, celui de la tolérance d'une greffe d'un tissu à 50\% étranger (antigènes d'histocompatibilité du père). L'absence de rejet s'explique probablement par l'intrication de plusieurs phénomènes, dont une sécrétion de facteurs divers : anticorps bloquants, et une $\alpha 2$ macroglobuline trouvée dans le sérum, qui inhibe l'action cytotoxique ainsi que l'action du complément.

Plusieurs anomalies de la nidation sont connues : la segmentation anormale peut déterminer les jumeaux monozygotes (issus d'un même œuf), donc toujours du même sexe, ce qui les oppose aux faux jumeaux, dizygotes, issus de la fécondation simultanée de deux ovules, qui peuvent être de sexes différents. Des implantations ectopiques cervicales ou tubaires sont possibles. Un endomètre inadapté du fait d'imprégnation hormonale insuffisante ou discordante, une endométrite (infection de la muqueuse utérine) peuvent aussi perturber les mécanismes délicats de la nidation.

\section{LA GESTATION}

L'utérus augmente progressivement en volume. Long de 5,5 cm chez la jeune femme non-enceinte, il s'élève au-dessus de la symphyse pubienne. 
L'élévation est de :

- $9 \mathrm{~cm}$ à 3 mois ; la longueur totale du fœetus est alors de $11,5 \mathrm{~cm}$;

$\begin{array}{lll}-19 \mathrm{~cm} \text { à } 5 \text { mois ; } & " & 26 \mathrm{~cm} \text {; } \\ \text { - } 34 \mathrm{~cm} \text { à } 9 \text { mois ; } & " & 50 \mathrm{~cm} .\end{array}$

La zone d'implantation, région vasculaire à la fois fœtale (villosités choriales) et maternelle (endomètre utérin), constitue le placenta. Le fotus y est relié par le cordon ombilical, dans lequel chemine une veine et deux artères.

Le tableau 14.1 précise la durée de la gestation et le nombre des nouveaux-nés en fonction de l'espèce.

Tableau 14.1 - Durée de la gestation et nombre des nouveaux-nés en fonction de l'espèce

\begin{tabular}{|l|c|c|}
\hline Espèce & Durée de la gestation (en jours) & Nombre de nouveaux-nés \\
\hline Chat & $56-65$ & $1-8$ \\
\hline Chien & $58-63$ & $2-4$ \\
\hline Cobaye & $65-68$ & $1-6$ \\
\hline Hamster & 16 & 5 \\
\hline Lapin & $30-32$ & $1-9$ \\
\hline Rat & $21-23$ & $1-9$ \\
\hline Souris & $19-20$ & $4-8$ \\
\hline Eléphant & $607-641(20$ mois) & 1 \\
\hline Cheval & 330 & 1 \\
\hline Lion & $105-113$ & $2-6$ \\
\hline Cochon & $112-115$ & $4-12$ \\
\hline Rhinocéros & 18 mois & 1 \\
\hline Macaque & 24 semaines & 1 \\
\hline Chimpanzé & $230 \pm 13$ jours & $1-2$ \\
\hline Homme & $280 \pm 7$ jours & 1 \\
\hline
\end{tabular}

\subsection{LE PLACENTA}

L'histologie du placenta varie selon l'importance de la pénétration des villosités du chorion à l'intérieur de la muqueuse endométriale. Ainsi, il est possible de distinguer (fig. 14.4) :

- le placenta épithélio-chorial où le chorion est appliqué contre l'épithélium endométrial (cheval, porc...). Il y a donc simple juxtaposition des structures maternelles et des structures d'origine ovulaire ; 
- le placenta conjonctivo-chorial où le trophoblaste, après érosion de l'épithélium utérin, est au contact du conjonctif de la muqueuse utérine (Ruminants) ;

- le placenta endothélio-chorial où le contact s'établit entre le trophoblaste et l'endothélium vasculaire maternel (Carnivores) ;

- le placenta hémo-chorial, pour lequel l'érosion va jusqu'à détruire l'endothélium des vaisseaux utérins, de sorte que le trophoblaste est en contact direct avec le sang maternel (lapin, rat, cobaye, homme).

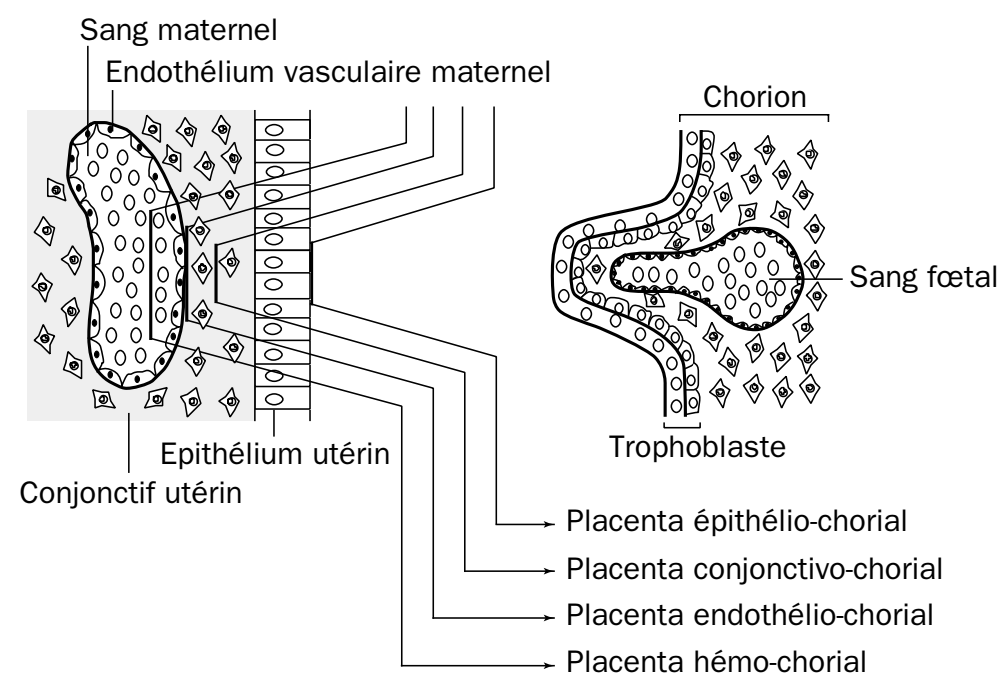

Figure 14.4 - Les différents types d'organisation histologique du placenta (selon la structure maternelle mise en contact avec le chorion) (d'après Dollander et Fenard, 1979)

Il est un peu simpliste de considérer que la nature de la perméabilité aux anticorps dépend de l'épaisseur de la "barrière placentaire". Il est vrai que l'on observe :

- une transmission des anticorps avant la naissance dans les espèces à placenta hémo-chorial. Le sang du fœtus et le sang de la mère ne sont séparés que par deux couches cellulaires : la paroi endothéliale des capillaires de la villosité choriale et l'enveloppe syncytiale amincie de la villosité ;

- l'absence de passage des anticorps chez les autres espèces.

En fait, la perméabilité en général de la "barrière placentaire" dépend plus de la présence ou de l'absence dans la membrane cellulaire de récepteurs spécifiques, d'enzymes et d'autres protéines de transport que du nombre de couches cellulaires.

Les données suivantes concernent essentiellement le placenta hémo-chorial.

Le placenta n'est en fait ni un simple filtre, ni une barrière. Le sang fotal et le sang maternel ne sont pas identiques : une série de substances ou de grosses molécules ne traverse pas le placenta. Les anticorps franchissent la barrière placentaire par pinocytose, sauf les IgM en raison de leur PM élevé. De nombreux microbes sont arrêtés 
par le placenta. En revanche, le tréponème (syphilis) le traverse, surtout en fin de gestation, ainsi que des parasites (paludisme et toxoplasmose) et la plupart des virus, dont le virus HIV qui traverse dans $20 \%$ des cas environ. Le passage du pneumocoque, du streptocoque, d'Escherichia coli, est certain surtout en fin de grossesse. Les globules rouges du fotus peuvent également passer dans la circulation maternelle, vers la fin de la gestation, et provoquer l'élaboration d'anticorps (processus à la base des conflits Rhésus). Mais cette isoimmunisation se produit surtout au moment de la délivrance, le décollement placentaire peut ouvrir des vaisseaux placentaires contenant du sang fœtal dans les sinus veineux maternels.

Certaines hormones peuvent traverser le placenta :

- les hormones polypeptidiques ne traversent pas de façon significative le placenta (transfert mère-fœetus). Même les gonadotrophines ou la HPL (hormone placentaire lactotrope, voir § 4.2.1) ne se retrouvent qu'à un taux très faible chez le fotus. L'insuline, T3 et T4, la parathormone, l'ACTH, la TSH, la prolactine, ne passent pas la barrière placentaire. Toutefois, l'insuline passerait dans le sens fœtus-mère. L'adrénaline traverse le placenta dans les deux sens.

- les stéroïdes (œstrogènes, progestérone, testostérone) passent le placenta avec facilité, dans les deux sens. Le transfert des corticostéroïdes est mal connu et diffère selon les espèces.

En plus de son implication dans le transit sélectif d'hormones de la mère vers le foetus, le placenta est aussi un organe endocrine (voir § 4.2.1). Lien vital entre la mère et le foetus, il constitue l'organe de la respiration, de la nutrition et de l'excrétion du fœtus.

- Du côté maternel : il comporte des lacunes sanguines dans lesquelles les artères spiralées placentaires chassent le sang oxygéné maternel, et au niveau desquelles des veines reprennent le sang circulant $\left(150 \mathrm{~cm}^{3}\right.$ de sang qui est renouvelé trois à quatre fois par minute). Au cours du $4^{\mathrm{e}}$ et $5^{\mathrm{e}}$ mois, l'endomètre placentaire (caduque basilaire) émet des cloisons qui séparent le placenta maternel en compartiments appelés cotylédons.

- Du côté fœetal : des villosités choriales d'origine trophoblastique représentent une surface d'échange de 4 à $15 \mathrm{~m}^{2}$ suivant les auteurs, soit à peu près la surface de l'intestin grêle de l'adulte. Limitées au début de la vie de l'embryon par une double couche : syncytiale externe (syncytiotrophoblaste) et cellulaire (cellules de Langerhans ou cytotrophoblaste) interne, elles ne possèdent plus vers le $4^{\mathrm{e}}$ mois de la gestation, chez la femme, que l'enveloppe syncytiale. Les ramifications terminales des artères ombilicales s'y épanouissent en capillaires qui sont drainés par des veinules vers la veine ombilicale. La longueur totale du réseau capillaire des villosités du placenta à terme a été évaluée à $50 \mathrm{~km}$.

Le placenta ainsi constitué préside aux échanges gazeux mère-fœtus, portant sur l'oxygène et le gaz carbonique. 
Il assure la nutrition du fœtus, lui transmettant les acides aminés, les glucides, les acides gras, les électrolytes et les vitamines nécessaires à son développement. L'eau passe par osmose. Elle sert au fotus et au renouvellement du liquide amniotique. Les sels minéraux suivent l'eau. Le placenta permet enfin l'élimination des déchets de l'embryon, qui seront excrétés par les reins de la mère.

Dès le milieu de la gestation, le foetus avale, en outre, le liquide amniotique qui repasse dans le sang maternel par l'intermédiaire du placenta. En l'absence de ce mécanisme (atrésie de l'œsophage du fœtus ou trouble de la déglutition chez un anencéphale), le liquide amniotique s'accumule (hydramnios).

\subsection{ENDOCRINOLOGIE DE LA GESTATION}

\subsubsection{Les hormones de la gestation (chez la femme)}

L'état gestatif est caractérisé par des modifications importantes :

- au niveau de l'ovaire, le cycle œstrien est interrompu, et le corps jaune, au lieu d'involuer en corpus albicans, se développe en un corps jaune de gestation (ou corps jaune gravidique) qui persiste durant la durée de celle-ci ;

- la muqueuse utérine est hypertrophiée, favorisant la nidation, puis la nutrition de l'embryon ;

- une nouvelle glande apparaît : le placenta. Le placenta est un organe endocrine sécréteur d'hormones protéiques : la gonadotrophine chorionique (HCG), l'hormone placentaire lactotrope (HPL) et des stéroïdes (œstrogènes, progestérone). Du point de vue des stéroïdes, c'est un organe endocrine incomplet qui ne peut effectuer la synthèse du cholestérol de novo à partir d'acétate, et ne peut transformer la prégnénolone ou la progestérone en androgènes par manque de $17 \alpha$ hydroxylase et de 17-20 desmolase. Il ne peut donc produire des œstrogènes qu'à partir des androgènes fotaux ou maternels. Cela conduit à considérer en fait l'unité fœto-placentaire comme un ensemble fonctionnel (Diczfalusy, 1969) qui s'intègre dans le tryptique dont le placenta est le centre, entouré de ses deux volets, le fœtus et la mère (fig. 14.5).

Le taux de la plupart des hormones maternelles s'élève au cours de la gestation, mais on observe plus particulièrement les variations (fig. 14.6) :

- de la progestérone. Elle est d'origine principalement placentaire, à partir de la $6^{\mathrm{e}}$ semaine de gestation, mais le corps jaune gravidique continue d'en sécréter jusqu'à terme. Son taux plasmatique s'élève régulièrement jusqu'à la $36^{\mathrm{e}}$ semaine environ, puis se maintient en plateau jusqu'à terme. Elle passe ainsi de 10 à 200$250 \mathrm{mg} /$ jour.

- des œstrogènes, d'origine essentiellement placentaire. Leur taux dans le sang maternel s'élève progressivement au cours de la grossesse, pour atteindre pour l'œstrone et l'œstradiol libres cent fois celui du cycle menstruel (300 mg/jour en fin de grossesse). 


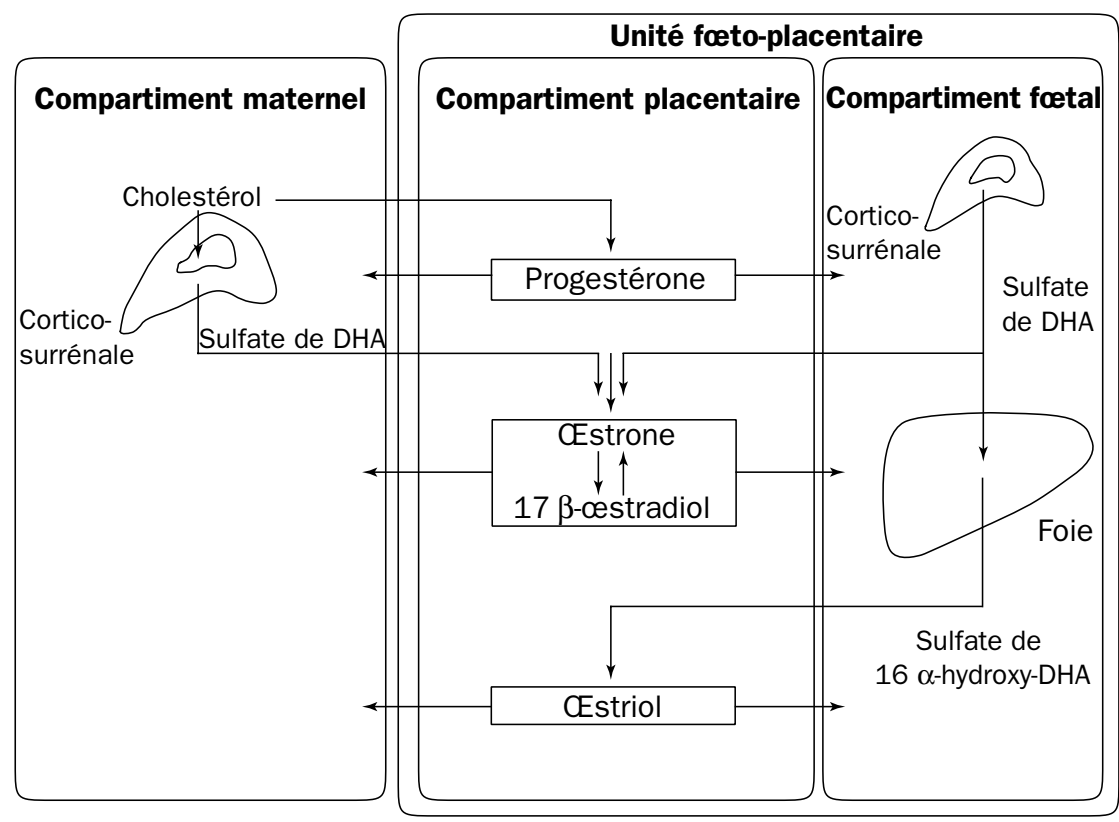

Figure 14.5 - La production des hormones stéroïdes par le placenta (d'après Poirier et coll., 1981)

L'origine ovarienne des œstrogènes et de la progestérone est négligeable.

Pour ces deux types d'hormones, le taux s'élève rapidement dès que le corps jaune devient gravidique. Le taux reste étale vers le $9^{\mathrm{e}}$ mois et diminue brutalement avant la parturition ; la diminution du taux de la progestérone débute avant celle des œstrogènes.

Chez le rat (voir fig. 14.7), le placenta ne synthétise que de faibles quantités de stéroïdes avec une concentration maximale de progestérone le $15^{\mathrm{e}}$ jour de la gestation.

- la gonadotrophine chorionique ou HCG est une hormone spécifique de la gestation. C'est une hormone placentaire, une glycoprotéine de 237 AA (PM 38 kDa) dont les effets, variables suivant les espèces, sont comparables à ceux de la LH. Comme FSH et $\mathrm{LH}$, elle est formée de deux sous-unités $\alpha$ (92 AA) et $\beta$ (145 AA) liées de façon non-covalente ; la spécificité de l'hormone est portée par la sous-unité $\beta$. La correspondance entre les séquences de $\beta$-HCG et $\beta$-LH est de $67 \%$.

HCG apparaît très rapidement dans le sang et dans l'urine dès le moment où l'œuf fécondé s'attache à la muqueuse utérine (voir fig. 14.8.a). Sa mise en évidence est à la base du diagnostic précoce de la grossesse ${ }^{1}$.

1 Le pourcentage de $\beta$-HCG libre serait un bon marqueur de la qualité du trophoblaste : inférieur à $1 \%$ au cours de la grossesse normale, compris entre 1 et $5 \%$ en cas de môle hydatiforme, et supérieur à $5 \%$ en cas de choriocarcinome placentaire. 


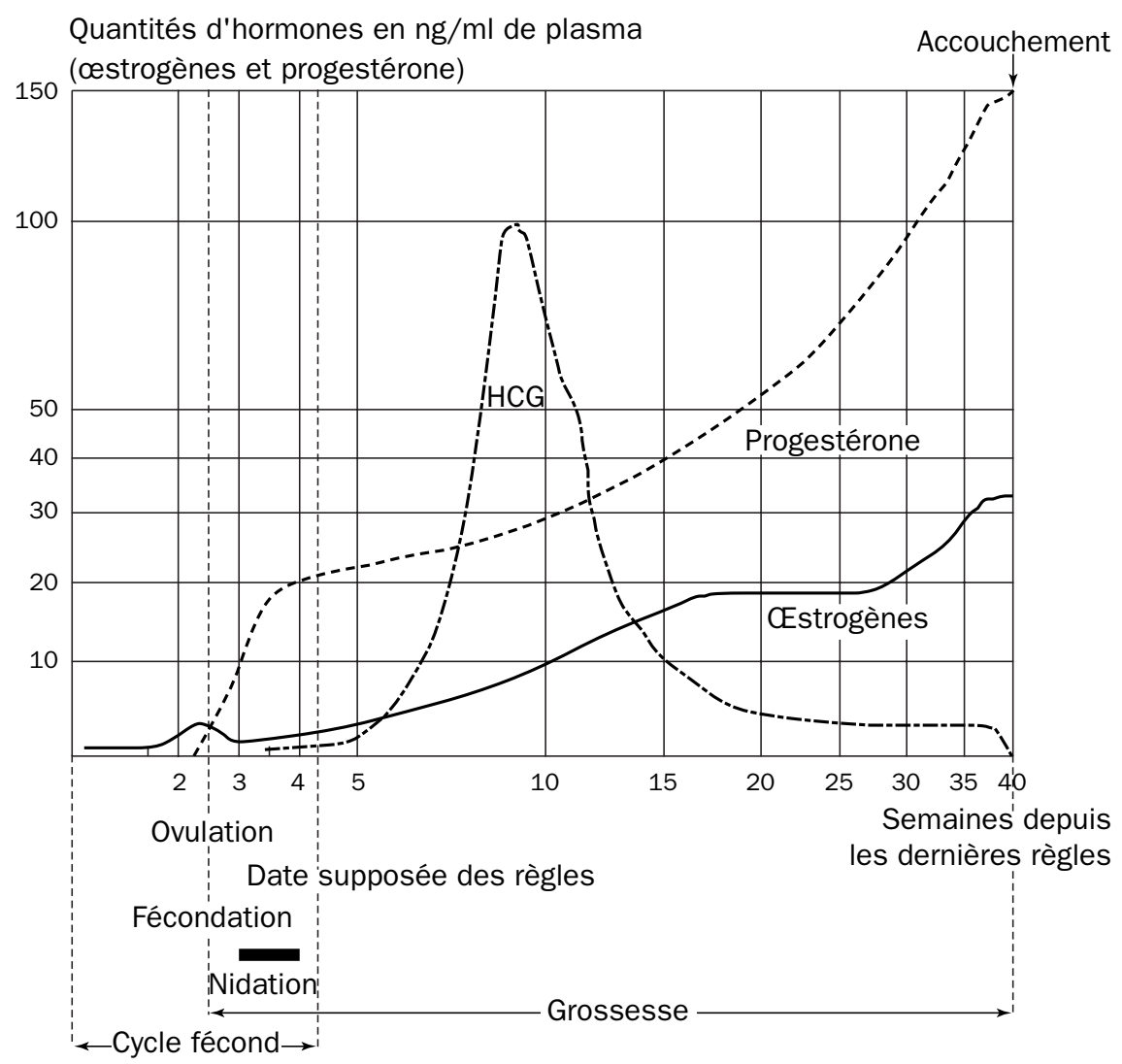

Figure 14.6 - Courbes d'évolution des hormones au cours de la grossesse chez la femme

Son taux augmente très rapidement jusqu'au $3^{\mathrm{e}}$ mois (environ $11000 \mathrm{ng} / \mathrm{ml}$ ), décroît au $4^{\mathrm{e}}$ mois, puis prend la forme d'un plateau avec une légère remontée (environ $3000 \mathrm{ng} / \mathrm{ml}$ ) vers le $8^{\mathrm{e}}$ mois. Ce taux décroît ensuite pour s'annuler au moment de la parturition (expulsion du placenta) ${ }^{2}$.

Chez le mâle, l'hormone placentaire stimule les cellules de Leydig (action de type LH) et favorise la migration du testicule cryptorchide en position scrotale.

Chez le rat, elle apparaît le $8^{\mathrm{e}}$ jour et sa concentration est maximale le $13^{\mathrm{e}}$ jour de la gestation.

- l'hormone placentaire lactotrope, HPL ou CGP ou HCS (human chorionic somato-mammotrophin) est une protéine (PM 22000) de 191 AA qui présente des analogies de structure avec la $\mathrm{GH}$ et la prolactine, évoquant un précurseur commun. Elle est sécrétée par le syncytiotrophoblaste sans participation fotale.

2 Le dosage de $\beta$-HCG libre et d'HCG effectué 14 à 16 jours après une fécondation in vitro permettrait de prédire l'évolution normale ou la survenue d'une fausse couche chez les patientes. 


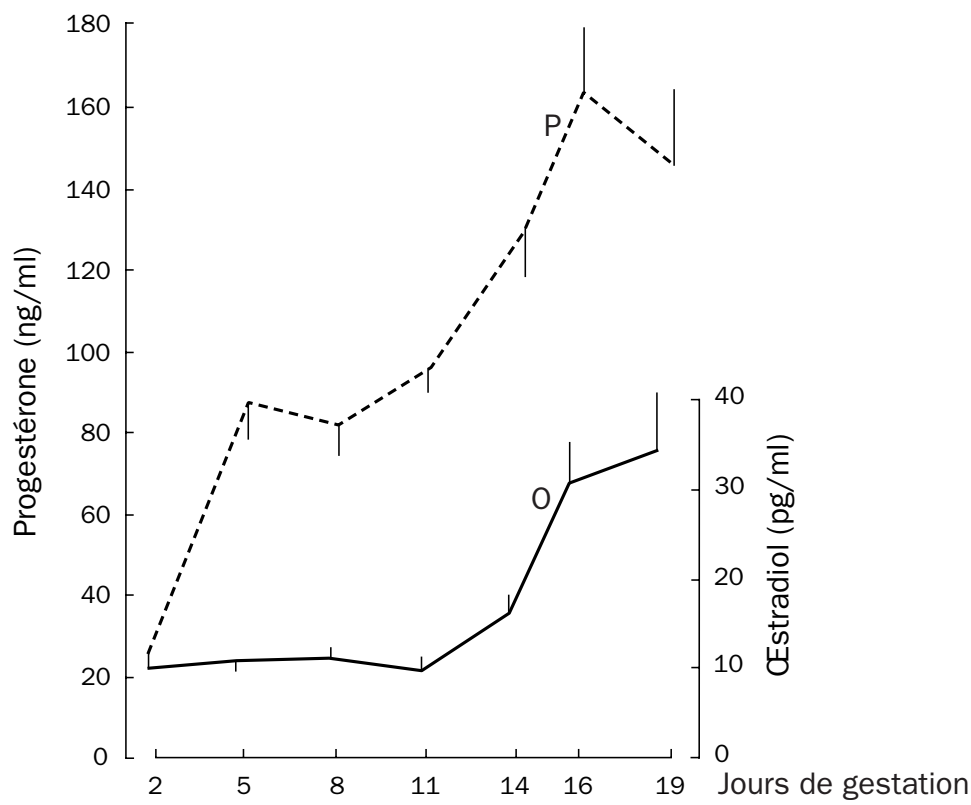

a - Evolution des œstrogènes $(\mathbf{0})$ et de la progestérone $(\mathbf{P})$ (d'après Matt et coll., 1986)

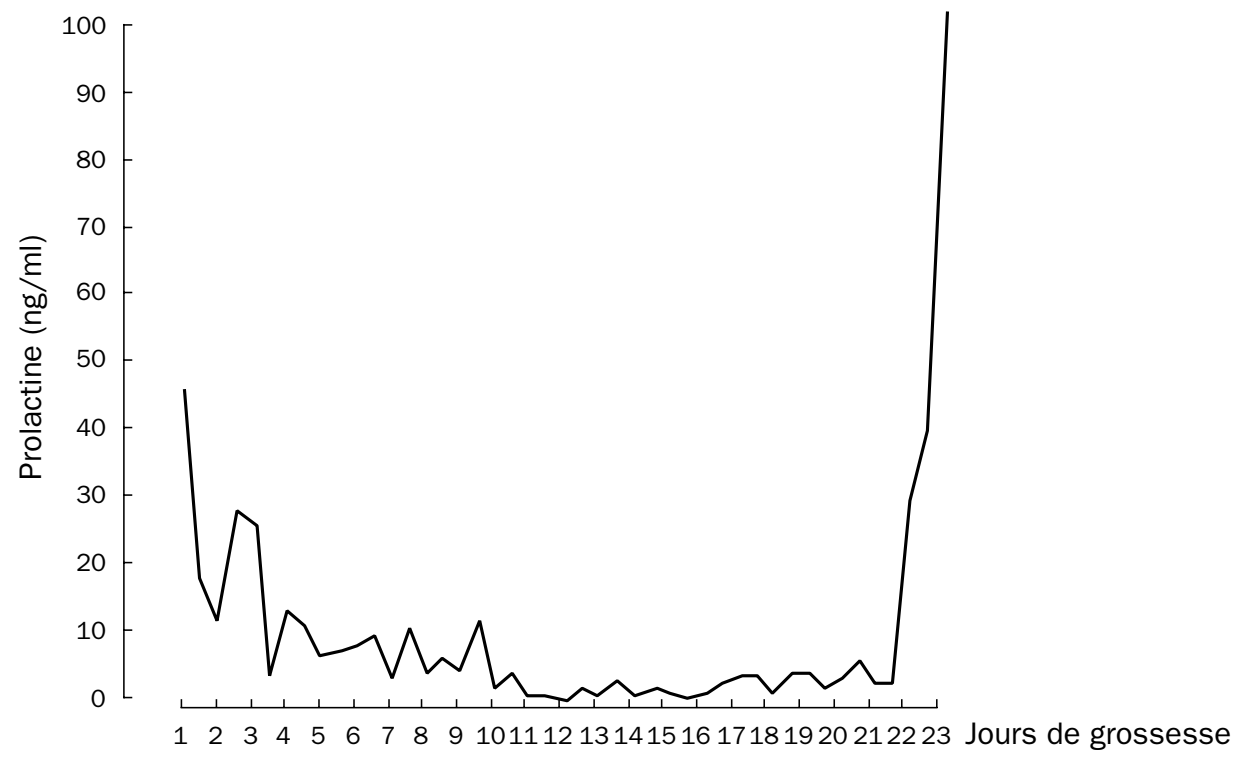

b - Evolution de la prolactine (d'après Morishige et Rothchild, 1974)

Figure 14.7 - Courbes d'évolution des hormones au cours de la gestation chez la rate

Sa sécrétion est décelable dans le plasma de la femme enceinte dès la $3^{\mathrm{e}}$ semaine. Elle suit une courbe ascendante régulière, atteignant un maximum en fin de grossesse ; son taux est alors d'environ 3 à $5 \mu \mathrm{g} / \mathrm{ml}$ de sérum et la quantité produite par jour est de l'ordre du gramme en fin de grossesse (voir fig. 14.8.b). C'est une hormone hyperglycémiante. 

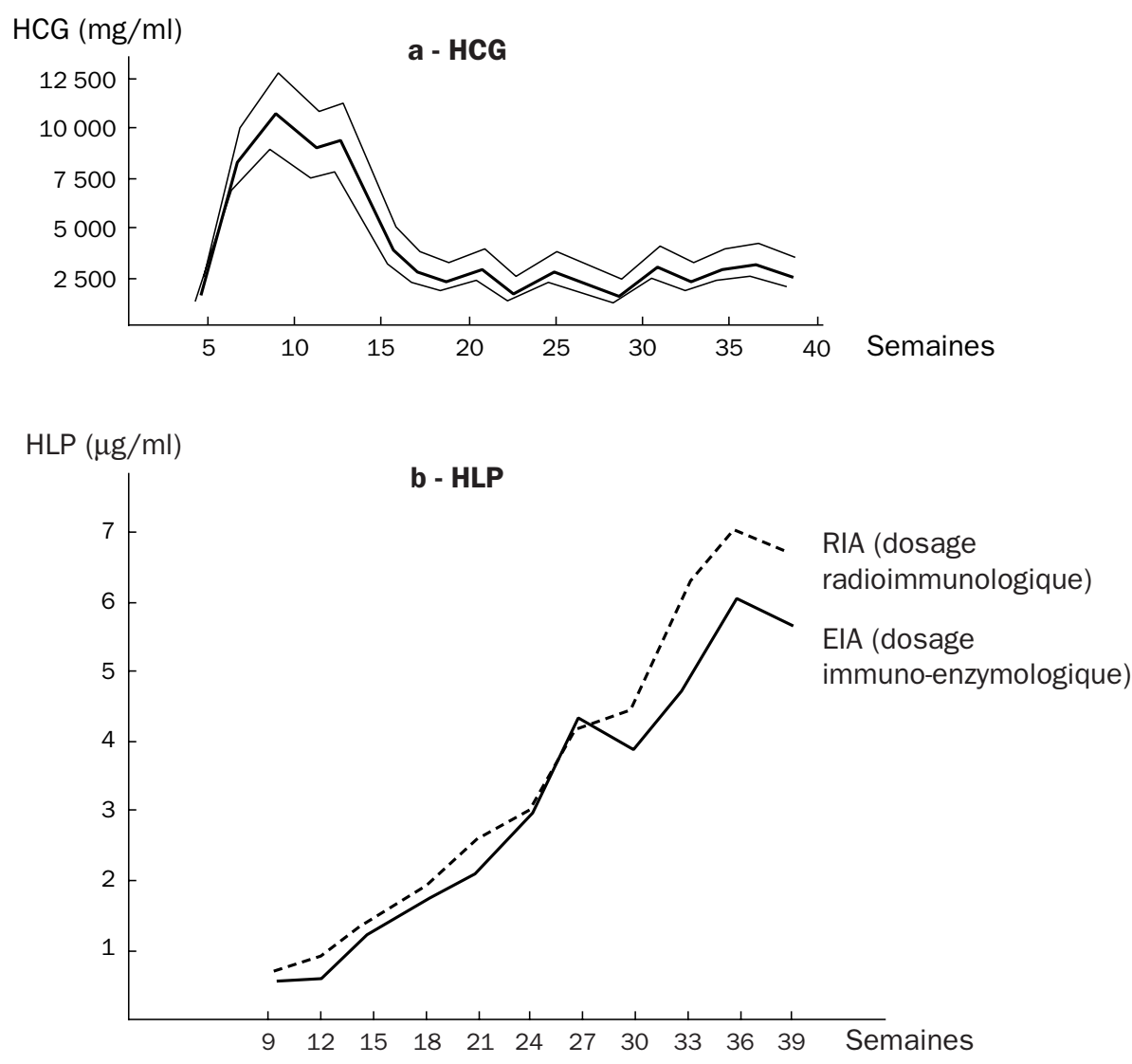

Figure 14.8 - Courbes d'évolution de I'HCG et de I'hormone lactogène

(d'après Gaspard, 1979)

Comme l'hormone de croissance avec laquelle elle présente une parenté structurale et fonctionnelle, elle facilite :

- l'anabolisme protidique,

- la sécrétion d'insuline,

- la lipolyse,

et agit aussi comme antagoniste de l'insuline.

Si les cellules des îlots de Langerhans ne peuvent s'hyperplasier ou si l'insuline sécrétée est inefficace, on se trouve dans une situation d'hyperglycémie liée à la sécrétion d'HPL : c'est le diabète gestationnel.

La fonction lactogénique de l'hormone lactogène placentaire est discutable ; elle a plutôt un rôle de préparation à la lactogenèse. Son rôle métabolique est complexe (elle agit sur les AGL, l'équilibre azoté, la sécrétion d'aldostérone).

Chez le rat, l'hormone lactogène placentaire est présente sous deux formes pendant la gestation : une forme est produite préférentiellement au début et au milieu de la gestation, alors que l'autre forme est produite durant les derniers jours. Les 
deux formes ne dérivent pas d'un précurseur commun et leurs rôles sont différents : la première est un facteur lutéotrope, tandis que la seconde est un facteur mammotrope. La forme lutéotrope est peut-être un facteur inhibiteur de la sécrétion de prolactine hypophysaire qui s'interrompt au milieu de la gestation (et s'élève considérablement dès la mise bas).

- de la prolactine serait également sécrétée par le placenta (Rosenberg et coll., 1980) (voir fig. 14.7.b).

\subsubsection{Rôle du placenta}

- L'hypophysectomie pratiquée au début de la gestation provoque l'avortement. Si elle est réalisée plus tardivement, l'avortement ne se produit pas. Le placenta, par l'intermédiaire de sa gonadotrophine, supplée aux hormones hypophysaires et, par sa sécrétion propre, à la progestérone et aux œstrogènes du corps jaune gravidique.

- La castration de la femelle (ovariectomie),

- provoque toujours l'avortement chez la lapine, la souris, la rate ;

- provoque l'avortement chez le cobaye, la jument, la chatte, lorsque la castration est pratiquée au début de la grossesse ; elle ne provoque plus l'avortement si l'opération est faite en fin de gestation : le placenta prend le relai des sécrétions ovariennes ;

- ne provoque jamais l'avortement chez les Primates, même au début de la gestation.

Le placenta supplée donc très tôt la fonction endocrienne ovarienne. Il supplée également très tôt la fonction gonadotrope hypophysaire. L'activité gonadotrope hypophysaire ne reprend que dans les jours qui suivent la parturition.

\subsubsection{Action des hormones au cours de la gestation}

- En synergie avec les œstrogènes, la progestérone :

- assure la trophicité de l'endomètre utérin ;

- diminue la motricité spontanée du myomètre ;

- prépare la glande mammaire à l'élaboration du lait lors de la parturition ;

- associée aux œstrogènes, elle inhibe par effet feed-back la libération des gonadotrophines hypophysaires et bloque ainsi l'ovulation (pilule contraceptive).

- Les œstrogènes seuls ont un effet abortif variable suivant les espèces animales. L'effet est net chez la lapine, il est pratiquement nul chez la femme. Ils peuvent augmenter l'activité contractile du myomètre.

Les œstrogènes exercent un effet antidopamine qui favorise la sécrétion de prolactine. Cet effet se manifeste au niveau des mécanismes de couplage entre les récepteurs dopaminergiques et l'adénylate cyclase dans les membranes de cellules hypophysaires. L'adénylate cyclase est activée par les récepteurs D1 et inhibée par les récepteurs D2 à la dopamine. En présence d'œstradiol, l'inhibition est 
supprimée tandis que la stimulation est augmentée. Au contact de l'hormone sexuelle, les cellules sécrétrices de prolactine deviennent donc moins sensibles à la présence du neuromédiateur inhibiteur.

- Les gonadotrophines chorioniques prolongent la vie du corps jaune et permettent sa transformation en corps jaune gravidique. Elles déterminent une production suffisante de progestérone et d'œstrogènes pour assurer le développement de l'utérus et du placenta lui-même, jusqu'à ce que celui-ci devienne capable de conduire la gestation à son terme.

Chez la lapine pourtant, le maintien du corps jaune n'est pas dû aux hormones du placenta, mais à une simple action de contact sur la muqueuse utérine qui agit par voie réflexe sur les sécrétions ovariennes.

- La relaxine (PM 6000), sécrétée par le corps jaune dans l'ovaire de Mammifères, joue un rôle au cours de la parturition. Elle produit un relâchement de la symphise pubienne chez le cobaye, mais on connaît mal son action chez la femme. La structure de ce peptide se rapproche de celle de l'insuline et des facteurs de croissance : deux chaînes A et B, reliées par un peptide commun (peptide C) dans la pro-relaxine. Cette substance a aussi été trouvée dans l'ovaire des Sélaciens et pourrait, de façon générale, être associée au phénomène de viviparité ou d'ovoviviparité. On l'a même retrouvée dans des extraits d'ovaires d'Ascidies (Georges, 1990, a et b, 1999).

- La prolactine est sécrétée, à des taux élevés, au cours de la gestation. Mais la lactation ne peut apparaître au cours de la gestation car il y a blocage des récepteurs à la prolactine sous l'effet de la progestérone.

\subsubsection{Dosage de la gonadotrophine chorionique}

Il peut être biologique ou immunologique. Il permet de faire le diagnostic précoce d'une grossesse, et de préciser si l'évolution de la grossesse est normale ou anormale (môle hydatiforme qui est une dégénérescence kystique des villosités choriales, susceptible de se transformer en un chorio-épithélium).

- Le dosage biologique, qui a plus qu'une valeur historique, peut être pratiqué selon des tests variés (tab. 14.2).

- Le dosage immunologique est devenu un dosage de routine. L'HCG est un excellent antigène naturel. Il est facile d'obtenir des anticorps anti-hormone. Mais ce mélange HCG-sérum anti-hormone donne in vitro une précipitation qui n'est pas directement visible.

Une méthode simple utilise des particules homogènes de polystyrène enrobées d'HCG ; mises en contact avec de l'anti-HCG et de l'urine, elles donnent lieu à une agglomération des particules si l'urine ne contient pas d'HCG, à une suspension homogène si la femme est enceinte. Une autre méthode repose sur le principe de l'inhibition (par l'HCG de la femme enceinte) de l'hémagglutination que réaliserait un mélange d'hématies et d'HCG avec des anticorps anti-hormone. Le résultat est 
positif, suivant la sensibilité du test utilisé, dès le 1er jour après le début présumé des règles manquantes.

Tableau 14.2 - Dosage de l'HCG par les méthodes biologiques

\begin{tabular}{|l|c|c|c|}
\hline Animal & Sexe & \multicolumn{1}{|c|}{ Critères } & Délai \\
\hline Souris impubère & $\mathrm{F}$ & $\begin{array}{c}\text { Points hémorragiques } \\
\text { au niveau de l'ovaire }\end{array}$ & $96 \mathrm{~h}$ \\
\hline Lapine & $\mathrm{F}$ & $\begin{array}{c}\text { Points hémorragiques } \\
\text { au niveau de l'ovaire }\end{array}$ & $48 \mathrm{~h}$ \\
\hline Crapaud africain & $\mathrm{F}$ & Ponte ovulaire & $8-12 \mathrm{~h}$ \\
\hline Rate impubère & $\mathrm{F}$ & $\begin{array}{c}\text { 1. Hyperémie de l'ovaire } \\
\text { 2. Poids de l'utérus }\end{array}$ & $\begin{array}{c}6 \mathrm{~h} \\
\text { Plusieurs jours }\end{array}$ \\
\hline Crapaud européen & $\mathrm{M}$ & $\begin{array}{c}\text { Emission de sperme } \\
\text { 2-4 h }\end{array}$ \\
\hline Souris impubère & $\mathrm{M}$ & $\begin{array}{c}\text { Développement des } \\
\text { vésicules séminales }\end{array}$ & 10 jours \\
\hline
\end{tabular}

\section{LA PARTURITION OU MISE BAS}

C'est, chez les Mammifères, l'évacuation du fœtus à terme, et du placenta. Elle est caractérisée par trois phases :

- contractions utérines s'accompagnant d'une dilatation cervicale ;

- expulsion du fœetus ;

- élimination du placenta.

\subsection{DÉTERMINISME DE LA PARTURITION}

Son mécanisme exact est encore inconnu dans l'espèce humaine. Chez les Mammifères, en général, le système nerveux n'est pas indispensable à la parturition. Il ne s'agit pas de réflexes à point de départ utérin : des chiennes à moelle épinière sectionnée peuvent accoucher.

Le déterminisme serait hormonal, mais le mécanisme est encore imprécis :

- l'hypophyse ne paraît pas indispensable : les lapines ou chattes hypophysectomisées expulsent leur fœtus ;

- l'ovaire ne paraît pas indispensable : la parturition peut se produire chez la rate ovariectomisée.

\subsubsection{Rôle des stéroüdes ovariens}

- La progestérone a une action inhibitrice sur la contraction utérine. Son rôle varie selon les espèces animales. 
- Chez la chèvre, la vache, la chienne, la lapine, son origine est ovarienne et son taux décroît brutalement avant la parturition. Son rôle serait indirect, par inhibition de la synthèse des prostaglandines.

- Chez la brebis, la rate, son origine est mixte, ovarienne et placentaire et la diminution de la progestérone est modérée. On peut prouver expérimentalement que cette diminution n'est pas la condition nécessaire de la parturition.

- Chez la jument et les Primates, la progestérone plasmatique ne s'abaisse pas de façon significative avant le travail. Des mécanismes complexes ont été invoqués qui impliquent toutefois la progestérone : diminution locale, variation de la proportion progestérone libre/progestérone conjuguée, modification des récepteurs utérins.

- Les œstrogènes jouent un rôle facilitant les contractions du myomètre.

- Chez la chèvre, le taux des œstrogènes augmente progressivement pendant la gestation, puis plus rapidement 4 à 5 jours avant la mise bas (leur origine pourrait être fotale).

- Chez la brebis, le taux d'œstradiol est bas en cours de gestation, il augmente brutalement dans les $24 \mathrm{~h}$ précédant la parturition; l'élévation du rapport œstradiol / progestérone entraînerait la libération de prostaglandine F2 $\alpha$.

- Chez le cobaye, la vache, la brebis, l'administration d'œstrogènes peut provoquer la mise bas.

- Chez la femme, si le taux d'œstrogènes augmente progressivement au cours de la grossesse, il ne subit pas d'augmentation nette avant le travail. Si les œstrogènes favorisent le développement du myomètre et l'accroissement de la sensibilité à l'ocytocine, ils ne suffisent pas pour déclencher le travail. Ils ne semblent pas non plus favoriser la libération de prostaglandines F.

\subsubsection{Rôle de l'ocytocine}

L'action contractile de l'ocytocine sur les muscles lisses, d'où son emploi pour déclencher les contractions ou accélérer une expulsion, permettait de penser qu'elle jouait un rôle déclenchant dans l'initiation de la parturition. Il n'en est rien et son rôle précis en fin de gestation reste inconnu.

- Chez l'animal pourtant, l'ocytocine est sécrétée en quantité massive lors de l'expulsion. La diminution de la concentration plasmatique de la progestérone stimule la sécrétion d'ocytocine. D'autre part, la dilatation du col stimule également, par voie réflexe, les noyaux hypothalamiques sécréteurs de l'ocytocine.

- Chez la femme, l'ocytocine est libérée par "pulses" successifs au cours du travail avec un maximum pendant l'expulsion. Elle permettrait l'accroissement du travail en cours, peut-être aussi en facilitant la synthèse de prostaglandines. 


\subsubsection{Rôle des prostaglandines}

- Expérimentalement, les prostaglandines PgE2 et PgF2 $\alpha$ peuvent déclencher l'avortement ou l'accouchement. Leur administration déclenche des contractions utérines et l'expulsion du fœetus, à tous les stades de la grossesse.

- Les prostaglandines PgE2 et PgF2 $\alpha$ sont effectivement présentes au cours de la gestation dans le liquide amniotique, le sang et les urines maternelles et leur taux augmente pendant les dernières semaines. Il subit une élévation plus importante en cours de parturition ou d'avortement. Lorsque le travail est en cours, les perturbations mécaniques et l'hypoxie favorisent la libération de l'acide arachidonique dans les membranes cellulaires altérées, d'où une synthèse accrue de prostaglandines. Le travail est ainsi auto-entretenu.

\subsubsection{Rôle des corticostérö̈des}

Si leur rôle est démontré chez la brebis, il n'est que suspecté dans l'espèce humaine.

- Chez la brebis, l'élévation du cortisol d'origine fœetale, en fin de gestation, favorise la transformation de la progestérone en œstrogènes, d'où la diminution de la progestérone et l'élévation des œstrogènes.

L'hypophysectomie ou la surrénalectomie fotales entraînent une parturition prématurée, tandis que la perfusion du cortisol ou de l'ACTH entraîne une prolongation de la grossesse. En revanche, les surrénales maternelles ne jouent aucun rôle.

- Chez la femme, certains arguments plaident en faveur du rôle des corticostéroïdes dans le déclenchement du travail. Les femmes enceintes recevant un traitement par des glucocorticoïdes accouchent malgré un taux d'œstrogènes abaissé. L'hyperplasie corticosurrénale du fœtus est fréquemment associée à un accouchement prématuré. Mais le mécanisme d'action des glucocorticoïdes pendant le travail reste inconnu.

\subsubsection{Rôle du PAF (platelet activating factor)}

Il a été avancé un rôle du PAF dans le déterminisme de la parturition.

\subsection{LE POST-PARTUM}

Il correspond à la restauration de la muqueuse de l'utérus et du vagin.

Le volume de l'utérus décroît progressivement, la plaie placentaire se cicatrise. Les tests de grossesse deviennent négatifs en 4 à 8 jours (sinon, risque de chorioépithéliome).

L'aménorrhée (arrêt des règles) cesse au bout de 5 à 6 semaines chez la femme qui n'allaite pas, c'est le "retour de couches". Elle est prolongée chez la femme qui allaite. 


\section{LA LACTATION}

Elle nécessite :

- une préparation hormonale réalisée pendant la gestation ;

- et l'intervention du nouveau-né.

L'hypophyse joue un rôle fondamental :

- pratiquée avant l'accouchement, l'hypophysectomie empêche la montée laiteuse ou lactogenèse ;

- pratiquée au cours de la sécrétion lactée (galactopoïèse), l'hypophysectomie l'arrête.

\subsection{DÉVELOPPEMENT DES GLANDES MAMMAIRES}

Les glandes mammaires existent dans les deux sexes, mais elles ne sont pas fonctionnelles chez le mâle. Dans le sein de la femme pubère, elles prennent l'aspect de glandes en grappes tubulo-acineuses.

Leur développement chez la femelle se fait en quatre phases successives :

- Une différenciation embryonnaire anhormonale avec formation de bourgeons tubulaires. A la naissance, la glande mammaire est rudimentaire dans les deux sexes, elles n'est constituée que de dix à quinze canaux galactophores enfouis dans le mésenchyme. Le déclenchement de la sécrétion de prolactine en fin de gestation provoque chez $30 \%$ des nouveaux-nés, quel que soit le sexe, une discrète tuméfaction mammaire, souvent unilatérale (!), et même un écoulement ("lait de sorcière").

- Une croissance prépubérale limitée, qui porte à la fois sur les structures tubulaires qui se ramifient et sur le tissu conjonctivo-adipeux qui s'accroît.

- Un développement pubertaire important. Sous l'influence conjuguée des œstrogènes et de la progestérone, la glande mammaire se développe. La croissance des canaux est due aux œstrogènes. Les ramifications de canaux progressent dans un tissu adipeux de plus en plus abondant. A leur extrémité, sous l'influence de l'action conjuguée des œstrogènes et de la progestérone, se forment des culs de sac sécrétoires, les acini.

La glande mammaire conserve cette structure tout au long de l'activité sexuelle, avec toutefois des modifications liées aux variations cycliques du taux des hormones sexuelles hypophysaires et ovariennes. On observe en effet un accroissement des canaux mammaires au cours de la seconde phase du cycle ovarien, comme si la glande mammaire se préparait à chaque cycle à une éventuelle gestation. En fin de cycle, ces phénomènes régressent.

Le schéma de développement ainsi décrit varie en fait suivant les espèces. D'autre part, les hormones ovariennes semblent avoir davantage un rôle de régulation sur 
la mitogenèse et la différenciation cellulaire qu'une action directe sur la mammogenèse, qui serait liée à l'action d'un complexe hormonal. Dans ce complexe interviennent les hormones hypophysaires (GH et Prl), l'insuline, les glucocorticoïdes.

- Pendant la gestation, la glande mammaire atteint son plein développement. Les extrémités de chacun des canaux s'élargissent en alvéoles creuses, dont les cellules vont élaborer le lait. Ici encore, la mammogenèse dépend de l'action d'un complexe hormonal :

- des stéroïdes sexuels, œstrogènes et progestérone ; les œstrogènes provoquent une activité mitotique intense qui conduit à une expansion des canaux galactophores, mais la synergie œstrogène et progestérone est nécessaire à l'obtention de la réponse lobulo-acineuse typique de la glande mammaire de gestation ;

- des hormones lactogènes : HPL et GH, mais surtout la prolactine qui peut, en l'absence de tout stéroïde ovarien, induire à elle seule une mammogenèse (alors que l'inverse n'est pas vrai). D'autres substances responsables de la multiplication cellulaire (insuline, glucocorticoïdes, EGF) interviennent sur le tissu mammaire sensibilisé par les hormones sexuelles.

\subsection{DÉTERMINISME DE LA LACTATION}

- La sécrétion lactée est préparée par les bouleversements hormonaux qui précèdent et accompagnent la parturition (voir fig. 14.9-1 et 2). La concentration élevée de la progestérone bloque l'induction de la lactation tout en favorisant le développement de la glande mammaire (voir fig. 14.9-3). La diminution brutale de la progestérone lors de la délivrance lève cette inhibition (voir fig. 14.9-4), tandis que le pic sécrétoire de glucocorticoïdes, qui déclenche la parturition, favorise la synthèse abondante de lait en amplifiant l'action de la prolactine.

- A ces phénomènes hormonaux s'ajoutent des phénomènes nerveux : stimulation de l'arc réflexe neuro-endocrinien par les premières mises au sein (fig. 14.9-5), amorce de l'action de vidange mammaire. L'ablation des mamelons chez des rates suspend la sécrétion lactée. L'élaboration du lait est donc entretenue par la succion du mamelon. Ces mêmes influx nerveux inhiberaient la sécrétion des neurones dopaminergiques et des neurones sécréteurs du PIF dans l'hypothalamus, stimulant la sécrétion de prolactine.

- L'expulsion du lait est assurée directement par la succion. Celle-ci, par réflexe tacto-hypothalamo-hypophysaire, provoque la sécrétion d'ocytocine qui contracte les cellules myo-épithéliales de la glande mammaire (voir fig. 14.9-6 et 6'). Au cours de la tétée, l'ocytocine est libérée de manière pulsatile (chez le rat, toutes les 5-15 min), provoquant à chaque libération une éjection de lait. 


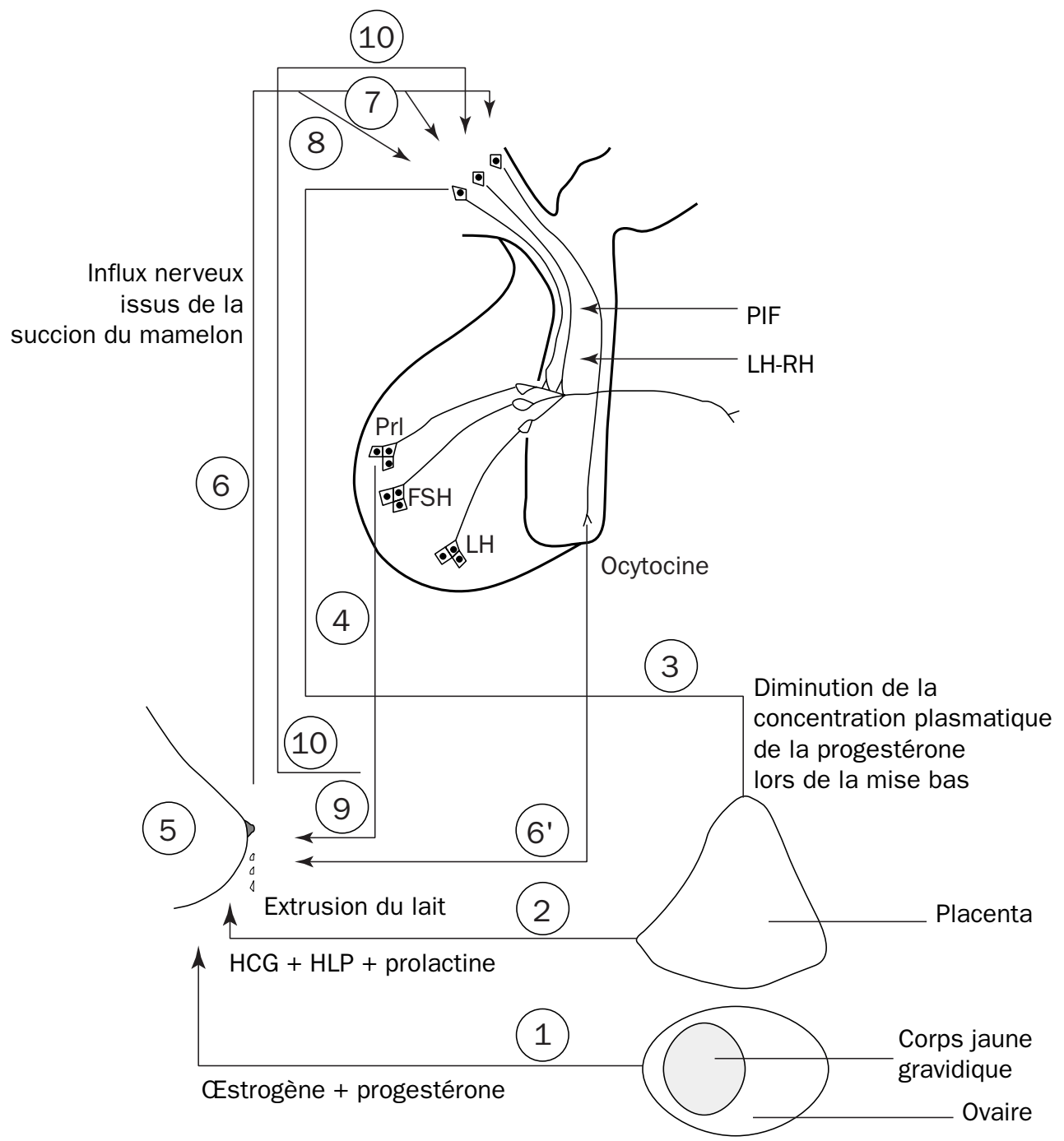

Figure 14.9 - Représentation schématique des mécanismes impliqués dans le contrôle de la lactation

1. Imprégnation gravidique de la glande mammaire par les hormones du corps jaune.

2. Imprégnation de la glande mammaire par la gonadotrophine chorionique (HCG), I'HPL et la prolactine en fin de gestation.

3. Expulsion du placenta ; la diminution de la concentration plasmatique de la progestérone

4. stimule la sécrétion de prolactine (élaboration du lait).

5. La succion du mamelon provoque, par voie nerveuse,

6. la stimulation des neurones longs à ocytocine (réflexe tacto-hypothalamo-hypophysaire) $\longrightarrow$ extrusion du lait (6').

7. L'inhibition des neurones longs à $\mathrm{LH}-\mathrm{RH} \longrightarrow$ maintien de l'aménorrhée.

8. L'inhibition des neurones sécréteurs de PIF

9. entretient la sécrétion de prolactine.

10. L'hyperprolactinémie maintient également l'aménorrhée par inhibition de la sécrétion pulsatile de LH. 
- Pendant l'allaitement, les neurones à ocytocine présentent des décharges en rafales (bursts) d'une centaine de pics par seconde, séparées par des intervalles de quelques minutes de silence (voir chap. 1, fig. 1.33.a). C'est à la fin de chaque burst que survient la décharge d'une "pulse" d'ocytocine (entraînant à la périphérie l'éjection du lait), ce qui pose un important problème de synchronisation de l'exocytose de milliers de neurones à ocytocine.

\subsection{DÉTERMINISME DE L'AMÉNORRHÉE POST-PARTUM}

- L'aménorrhée post-partum (arrêt des ovulations après l'accouchement) peut s'expliquer par un effet inhibiteur direct de l'hyperprolactinémie sur les fonctions ovariennes. Mais l'hyperprolactinémie agit surtout au niveau de l'hypothalamus, où elle supprime la libération pulsatile de LH et inhibe l'effet de rétro-contrôle positif des œstrogènes (fig. 14.9-10).

- L'inhibition de l'ovulation au cours de la lactation est également nerveuse ; les influx nerveux du mamelon stimulent les $\beta$-endorphines hypothalamiques, d'où une inhibition de la LH-RH et donc de la LH, et une stimulation des cellules à prolactine (voir fig. 14.9-7 à 9). Plus précisément, il y a diminution ou abolition de la pulsatilité de la LH-RH. Ainsi, la tétée à heures irrégulières pourrait favoriser l'effet contraceptif (anti-ovulatoire) de l'allaitement.

A l'échelle mondiale, la lactation est un agent contraceptif plus efficace que tous les moyens contraceptifs ${ }^{3}$.

\subsection{CONTRÔLE DE LA LACTATION}

- La durée de la lactation est plus ou moins longue selon les espèces et paraît être en rapport avec le degré de maturité du nouveau-né à la naissance.

- Le temps consacré à l'allaitement varie avec l'évolution de la lactation, il diminue en général vers la fin de la lactation.

- La quantité de lait éjecté est proportionnelle au nombre de mamelons sollicités et au rythme des sollicitations.

- Le bon entretien de la lactation dépend à la fois :

- de l'action mécanique : vidange régulière de la glande ;

- d'un complexe endocrinien : prolactine et cortisol. Les stéroïdes sexuels, à cet égard, ne paraissent pas nécessaires.

Complexe endocrinien et action mécanique sont étroitement liés, puisque c'est la succion du mamelon qui déclenche les réponses hormonales nécessaires à la sécrétion

3 Toutefois, à son début, l'aménorrhée du post-partum ne dépend pas que de la prolactine. L'hypophyse est probablement encore sous l'effet de la freination prolongée par les stéroïdes de la grossesse. Cet état dure 4 semaines, même en l'absence de lactation. 
et à l'extrusion du lait. Le retour des cycles n'entraîne pas de diminution de la lactorrhée, une fois la lactation établie.

\subsection{LE LAIT}

Le liquide des premiers jours de la lactation (période de la montée laiteuse ou lactogenèse) constitue le colostrum. Il est moins sucré et plus riche en protéines (en particulier en anticorps) que le lait (tab. 14.3). Il est laxatif et débarrasse le nouveau-né de son méconium (premières selles), éliminant les résidus de l'assimilation du liquide amniotique.

Tableau 14.3 - Composition chimique du lait de femme au début de la lactation (les valeurs sont données en $\mathrm{g} / \mathrm{l}$ )

\begin{tabular}{|l|c|c|c|}
\hline & Protéines & Lipides & Glucides \\
\hline Colostrum du 1er jour & 97,5 & 25,9 & 27,6 \\
\hline Colostrum du 2e jour & 74,5 & 21,7 & 35 \\
\hline Lait à 1 mois & 13 & 32,6 & 70 \\
\hline
\end{tabular}

Rappelons que la sécrétion de prolactine dépend d'un contrôle neuro-endocrine où la dopamine joue un rôle inhibiteur, tandis que son facteur stimulant spécifique est la TRH.

Il y a autant de laits que de Mammifères. L'homme utilise, en dehors de celui de la femme, les laits de vache, de chèvre et de brebis.

Chez les animaux, la quantité de lait sécrétée par jour varie suivant les espèces (tab. 14.4) et, au sein d'une espèce, suivant les races. Pour une même race de vaches, plus la quantité de lait est élevée, plus la richesse de ce lait est faible, notamment en lipides.

Tableau 14.4 - Comparaison de la quantité journalière de lait et de la durée de lactation chez la femme et la vache

\begin{tabular}{|l|c|c|}
\hline & Quantité de lait par jour & Durée de la lactation \\
\hline Femme $(60 \mathrm{~kg})$ & $\begin{array}{c}500 \mathrm{~g} \mathrm{la} 2^{\mathrm{e}} \text { semaine } \\
900 \mathrm{~g} \mathrm{la} 9^{\mathrm{e}} \text { semaine }\end{array}$ & un an ou plus \\
\hline Vache $(600 \mathrm{~kg})$ & 301 & 300 jours \\
\hline
\end{tabular}

Composition chimique du lait (les valeurs sont données en $\mathrm{g}$ ou $\mathrm{mg} / \mathrm{l}$ )

Compte tenu des données comparées du lait de femme et du lait de vache (tab. 14.5), il faut sucrer le lait de vache. Ce lait est souvent trop gras pour le nourrisson, on peut l'écrémer. Il faut le couper avec de l'eau. 


\section{Tableau 14.5 - Comparaison de la composition chimique des laits de femme et de vache}

\begin{tabular}{|l|c|c|}
\hline & Femme & Vache \\
\hline Glucides : lactose & $70 \mathrm{~g}$ & $47 \mathrm{~g}$ \\
\hline Lipides & $36 \mathrm{~g}$ & $36 \mathrm{~g}$ \\
\hline Protides & $13 \mathrm{~g}$ & $34 \mathrm{~g}$ \\
\hline Calcium & $340 \mathrm{mg}$ & $1200 \mathrm{mg}$ \\
\hline Magnésium & $30 \mathrm{mg}$ & $120 \mathrm{mg}$ \\
\hline Sodium & $140 \mathrm{mg}$ & $500 \mathrm{mg}$ \\
\hline Potassium & $580 \mathrm{mg}$ & $1500 \mathrm{mg}$ \\
\hline Fer & $0,7 \mathrm{mg}$ & $0,5 \mathrm{mg}$ \\
\hline Zinc & $2,8 \mathrm{mg}$ & $3,5 \mathrm{mg}$ \\
\hline Phosphore & $140 \mathrm{mg}$ & $950 \mathrm{mg}$ \\
\hline Chlore & $420 \mathrm{mg}$ & $950 \mathrm{mg}$ \\
\hline
\end{tabular}

- Les glucides sont constitués par un sucre spécial, le lactose. On en retrouve dans l'urine de la femme enceinte (à ne pas prendre pour de la glycosurie).

- Les lipides sont caractérisés par une teneur élevée en acides gras à chaîne courte. Ils sont faciles à hydrolyser et très digestes.

- Les protides sont constitués essentiellement :

- de caséine (30 g/l) qui précipite sous l'action de la présure ou d'acides dilués. Elle forme le "caillé" des fromages ;

- de lactalbumine et de lactoglobuline.

- Matières minérales : $\mathrm{K}, \mathrm{Na}, \mathrm{Ca}, \mathrm{Mg} \ldots$ Le rapport $\frac{\mathrm{Ca}}{\mathrm{P}}$ est voisin de 1,39.

- Vitamines : A, B, C (20 mg/l), D.

La lactation constitue pour le nourrisson un véritable "cordon lacté" permettant également le transfert d'hormones, mais aussi de virus ${ }^{4}$. En revanche, la protection du nouveau-né humain par les anticorps maternels (qui l'immunisent pendant près de 6 mois contre la plupart des maladies infectieuses) est assuré plutôt par les anticorps (IgG), qui ont traversé le placenta dans la période embryonnaire prénatale, que par les anticorps (surtout IgA) sécrétés au cours de la phase colostrale. Néanmoins, le lait de femme constitue, pour le nouveau-né, le meilleur aliment qui puisse lui être donné. De nombreuses statistiques démontrent que la mortalité et la morbidité (en particulier les diarrhées) sont moins élevées chez les enfants nourris au sein.

4 L’allaitement sera donc déconseillé aux femmes séropositives. 
Si les courbes de poids d'enfants nourris au lait de vache sont plus ascendantes que celles des bébés nourris au sein, cela est dû à une rétention d'eau et de sel, et non à une vraie croissance.

Les laits "maternisés" sont des laits dont chaque constituant a été amené aussi près que possible du niveau du constituant homologue du lait humain. Mais ils sont dépourvus d'anticorps, des bactéries apportées par le colostrum qui implantent une flore utile toute la vie, et d'un composé sucré : le facteur bifidus, absent dans le lait de vache, et qui assure le développement d'une flore intestinale favorable.

Enfin et surtout, la qualité du lait maternel évolue de jour en jour, suivant des interactions mère-enfant spécifiques à chaque cas, indépendamment du lien affectif établi par la tétée, dont les implications sur le développement du futur adulte ne sont encore que soupçonnées.

\subsection{LE RÉCEPTEUR DE LA PROLACTINE : UNE MOLÉCULE CLÉ DE LA REPRODUCTION}

La prolactine exerce ses effets via des récepteurs transmembranaires. Le mode d'expression du gène unique du récepteur prolactine (R-Prl) est complexe : il existe au moins sept transcrits à partir desquels quatre récepteurs sont synthétisés. La structure de ce gène a été récemment établie, et il a pu être inactivé afin de constituer des souris hétérozygotes $\mathrm{R}-\mathrm{Prl}^{+/}$puis homozygotes $\left(\mathrm{R}-\mathrm{Prl} \mathrm{P}^{-/}\right)$.

Binart (1997) a pu ainsi établir que les deux allèles du gène du récepteur de la prolactine sont nécessaires pour une lactation correcte, et étendre ses résultats aux aspects de la reproduction qui sont résumés dans le tableau 14.6.

\section{Tableau 14.6 - Effet de différents génotypes $\mathrm{R}-\mathrm{Prl}^{+/-}$et $\mathrm{R}-\mathrm{Prl}^{-/}$ sur la lactation et la reproduction}

\begin{tabular}{|c|c|c|}
\hline & $\mathrm{Prl}^{+/-}$ & Prl $^{-/-}$ \\
\hline $\begin{array}{l}\text { Développement } \\
\text { de la glande mammaire }\end{array}$ & Lactation partielle & $\begin{array}{l}\text { Pas de lactation } \\
\text { - pas d'alvéole } \\
\text { - pas de gestation }\end{array}$ \\
\hline Reproduction : • femelle & normale & $\begin{array}{l}\text { Stérilité } \\
\text { - pas de pseudo-gestation } \\
\text { - ovulation et maturation } \\
\text { des ovocytes réduites } \\
\text { - pas d'implantation } \\
\text { Fertilité retardée }\end{array}$ \\
\hline
\end{tabular}

L'obtention de souris sans récepteur de la prolactine est un modèle d'étude du rôle de cette hormone, dont l'action chez le Mammifère est beaucoup moins limitée qu'il n'est apparu dans les premiers travaux. 



\section{CHAPITRE 15}

\section{LA COMMANDE DE LA REPRODUCTION}

\section{LA CONTRACEPTION}

Historiquement, deux intérêts sont en présence, qui se confondent et parfois s'affrontent : l'intérêt (au sens large moral, matériel...) de l'individu ou du groupe familial d'une part, l'intérêt de la collectivité d'autre part. Tandis que, dans une Europe où la moyenne d'âge s'élève, les gouvernements poussent à la natalité, les parents préfèrant attendre des enfants désirés (planning familial), le tiers-monde, quant à lui, refuse la contraception alors que les gouvernements voudraient limiter le nombre d'enfants.

La contraception doit être conçue pour le couple, non comme une méthode de prévention des naissances, mais comme une possibilité de planification des naissances, après une information suffisante et dans la plénitude des libertés de tous.

En fait, les méthodes contraceptives existent depuis longtemps : dès l'Antiquité, les Arabes mettaient des pierres dans l'utérus des chamelles pour les empêcher d'être fécondées pendant les longues traversées du désert ; l'abbé Spallanzani, en 1777, mettait des caleçons aux grenouilles mâles pour démontrer le rôle du mâle dans la genèse de l'embryon (il est en quelque sorte l'inventeur du préservatif). Pour chacune de ces méthodes, il faut envisager plusieurs critères de "qualité".

Une enquête de l'INED (Institut national d'études démographiques) sur les méthodes contraceptives utilisées en France montre qu'en 1979, environ 60\% des couples observent une contraception et que la majorité des femmes s'estime bien informée.

Dans le détail, les couples utilisent :

- pilule

$$
\begin{array}{r}
28 \% \\
8 \% \\
18 \% \\
5 \%
\end{array}
$$

- abstinence périodique

- autres méthodes

- pas de méthode

- retrait

- préservatif

Il est probable que l'extension de l'épidémie du SIDA a, depuis, largement majoré la contraception par préservatif. 


\subsection{LES MOYENS CONTRACEPTIFS CHEZ LA FEMME}

\subsubsection{Moyens mécaniques}

- L'abstention : 0\% d'échec.

- L'abstention périodique

L'abstention périodique par la méthode des températures (méthode dite d'OginoKnaus, améliorée) : on observe un décalage thermique de 3/10 e de degré au minimum entre la moyenne des températures de la semaine avant l'ovulation et celle des 3 jours du plateau post-ovulatoire.

Elle n'autorise les relations sexuelles que pendant une période de 10 jours au maximum, du $18 \mathrm{e}$ au $28^{\mathrm{e}}$ jour du cycle par exemple.

- Avantage

C'est une méthode naturelle.

- Echecs

$18 \%$ en raison :

- d'une courbe de température parfois difficile à interpréter ;

- de cycles raccourcis ou allongés en fonction d'une émotion, de fatigue et du fait que le spermatozoïde peut parfois subsister de 5 à 10 jours dans les voies génitales ;

- d'une hyperthermie infectieuse ;

- d'une ovulation provoquée par le coït.

- L'inconvénient

Il est d'ordre psychologique.

Remarque : un chercheur suisse a mis au point un thermomètre à mémoire, pourvu d'un microprocesseur qui permet en cas de cycles réguliers de tabler sur une période de non-fertilité allant jusqu'à 14 jours.

\section{- Le diaphragme}

Il est posé chez la femme, dans le vagin, de façon à couvrir le col de l'utérus. Il doit être remplacé au bout d'un an, après un amaigrissement ou une grossesse. Pour plus d'efficacité, il doit être complété par l'application d'un produit spermicide (gelée, pommade, mousse). L'indication (compatibilité mécanique et psychologique) du modèle est établie par le médecin. La femme doit mettre ellemême en place l'obturateur de façon convenable $\mathbf{2} \mathbf{h}$ avant les rapports sexuels, et le retirer $\mathbf{8}$ à $\mathbf{1 0} \mathbf{h}$ après.

- Avantages

Il constitue une alternative possible à la pilule pour les femmes présentant des contre-indications à celle-ci. Par exemple :

- mastopathies,

- risques thrombo-emboliques,

- tabagisme. 
- Echecs

Selon les auteurs, il est de 7 à $12 \%$ AF (années femme) ${ }^{1}$ et peut être abaissé à $4 \%$ avec l'addition de la gelée spermicide. Les échecs sont dus à un manque de tonicité de la musculature vaginale, ou à une mauvaise mise en place.

- Inconvénients

- psychologique,

- risque de mauvaise mise en place de l'obturateur, soit par la faute de la femme, soit du fait d'une modification anatomique (hypotonie des muscles releveurs ou périnée),

- il est inapplicable à un certain nombre de femmes pour des raisons anatomiques (grande multiparité).

- Variantes

Crèmes, gelées, mousses, capsules ou tampons spermicides peuvent également être utilisés, soit en "dépannage", soit en méthodes "relais", soit lorsque les rapports sont très espacés.

\section{- Le dispositif intra-utérin (DIU) ou stérilet}

Il a été introduit en France en par le Dr P. Simon (1965; Ancla et coll., 1967). C'est un filament en polyéthylène opaque aux RX (présence de sulfate de baryum), à mémoire élastique brève. Les stérilets au cuivre présentent une efficacité plus élevée (antinidatoire et spermicide) : 1\% (c'est-à-dire une grossesse pour 1200 cycles) au lieu de 12\%. On peut aussi adjoindre au stérilet des substances contraceptives (stérilets à la progestérone). Le stérilet empêche la fixation de l'œuf fécondé. Il est posé par un médecin en première partie de cycle, de préférence en fin de règles.

- Avantages

- C'est une méthode très commode pour le couple.

- C'est une méthode de choix dans les contre-indications de la pilule.

- C'est une méthode de relai de la pilule chez la femme de 35-40 ans.

- Il n'y a pas de risques d'oubli, de manipulations, de médicaments à absorber.

- Il respecte le fonctionnement hormonal de la femme.

- Inconvénients

- Quelques risques de rejet (donc d'échec éventuel).

- Il est déconseillé chez la nullipare du fait d'un risque infectieux non-négligeable et donc de stérilité par infection tubaire.

- Risque augmenté de grossesse extra-utérine.

1 AF : les échecs contraceptifs sont comptés en nombre de grossesses pour 100 ans-femme, c'est-à-dire 1200 cycles. C'est l'indice de Pearl (IP). Sans contraception, à raison de trois à quatre rapports par semaine, avec un pouvoir fécondant normal : l'IP = cinquante grossesses pour 1200 cycles, soit une grossesse tous les 2 ans. C'est le dénominateur référent de toutes les méthodes contraceptives. 
- Effets indésirables : douleurs, leucorrhée ou métrorragies persistantes qui peuvent engendrer une anémie ferriprive.

- Echecs

Ils sont estimés entre deux et cinq grossesses pour 1200 cycles avec les stérilets au cuivre actuellement sur le marché.

- Mécanismes induits par le stérilet

- Il provoque un état inflammatoire de la muqueuse utérine qui devient impropre à la nidation.

- Il favorise la lutéolyse dont le point de départ serait des prostaglandines utérines, d'où l'effet anticontraceptif des anti-inflammatoires tels que corticoïdes ou aspirine.

- Le cuivre est spermicide.

- Le stérilet à la progestérone réduit, voire supprime, les douleurs menstruelles et diminue le flux menstruel d'environ $40 \%$, contrairement aux autres stérilets.

\section{- L'anneau vaginal}

L'anneau vaginal, aux œstroprogestatifs, n'a pour l'instant qu'un intérêt spéculatif.

\subsubsection{Moyens biochimiques}

\section{- La pilule}

Elle est utilisée depuis 40 ans. Mise au point par Pincus en 1956, son principe repose sur le rétro-contrôle négatif de la progestérone sur la décharge ovulante de LH (Pincus, 1966).

Les progestatifs utilisés au début étaient tous des dérivés de la norethindrone (ou norethistérone). Puis apparurent les progestatifs de deuxième génération, comme le norgestrel (ou son dérivé le levonogestrel), beaucoup plus puissants que les premiers. Mais ils restaient fortement androgéniques et diminuaient le taux de HDL-cholestérol. D'où la mise au point de progestatifs dits de troisième génération, dont le chef de file est le désogestrel, qui ne diminuent pas le HDLcholestérol, au contraire (fig. 15.1).

Le dérivé de la progestérone est habituellement associé à un œstrogène qui, d'une part, assure un meilleur état trophique du tractus génital, permettant une gestation normale dès l'arrêt de la pilule et, d'autre part, exerce aussi une action antiovulatoire $^{2}$.

Parallèlement à l'évolution de la nature du progestagène, les progrès de la contraception orale sont liés à la diminution des doses d'œstrogènes.

2 Malgré les faibles taux hormonaux utilisés en particulier dans les "minipilules", les femmes sous contraception orale ont pratiquement toujours des règles pauvres ou symboliques. 
On trouve ainsi la pilule à des dosages qui permettent de distinguer :

- la pilule normodosée ${ }^{3}: 50 \mu \mathrm{g}$ d'œstrogènes et de $0,5 \mathrm{à} 2 \mathrm{mg}$ de progestagène ;

- la minipilule : $35 \mu \mathrm{g}$ d'œstrogènes et deux fois moins de dérivés de progestagène ;

- la micropilule où le progestatif est utilisé seul, en prise continue. Pour mémoire, la pilule de Pincus contenait $150 \mu \mathrm{g}$ d'œstrogènes et $20 \mathrm{mg}$ de progestagène 4 .

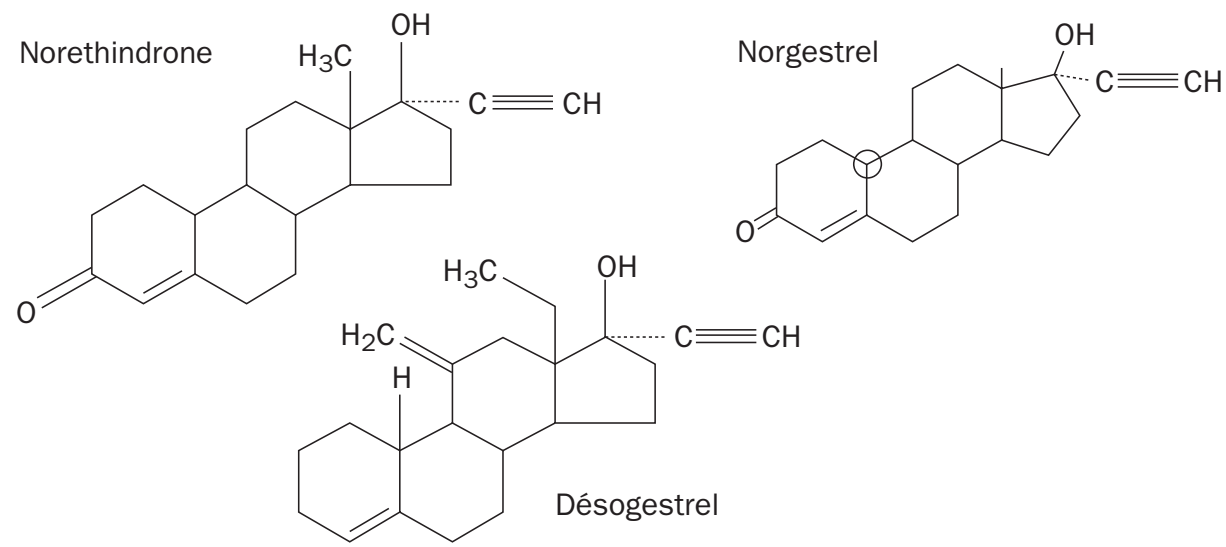

Figure 15.1 - Progestatifs utilisés en contraception

Bien que de plus en plus faiblement dosées, pilule normodosée et minipilule agissent toujours par inhibition de l'appareil hypothalamo-hypophysaire. L'action de la micropilule favorisant principalement la formation d'un bouchon muqueux épais au niveau de la glaire cervicale, elle s'oppose de ce fait pendant toute sa prise à l'ascension cervicale des spermatozoïdes.

La pilule peut être prise de façons diverses :

- soit monophasique ;

- soit biphasique non-séquentielle : les dosages respectifs d'œstrogènes et de progestagène changent entre les deux types de pilules ;

- soit biphasique séquentielle : l'œstrogène seul au début du cycle, auquel fait suite l'association d'œstrogène et de progestagène 5 ;

3 La pilule normodosée tolère un oubli de $24 \mathrm{~h}$, alors que pour les pilules minidosées il est de 4 à $6 \mathrm{~h}$.

4 La micropilule est recommandée aux femmes après 40 ans ou s'il y a contre-indication des œstrogènes. Les échecs sont de l'ordre de 2 à $8 \%$ AF (années femme). Elle entraîne soit une absence prolongée des règles, soit des saignements dans 20 à $30 \%$ des cas.

5 La pilule séquentielle facilite la remise en état d'une muqueuse utérine et sera conseillée après une IVG ou certains accouchements. La pilule prise correctement n'entraîne pratiquement pas d'échec. Si l'on fait abstraction de la tolérance qui n'est pas toujours bonne, la pilule est une excellente méthode contraceptive. 
- soit triphasique (fig. 15.2), pour laquelle se succèdent trois types de pilules qui comportent toujours $35 \mu \mathrm{g}$ d'éthinyl-œstradiol associé à $0,5 \mathrm{mg}$, puis à $0,75 \mathrm{mg}$, puis à $1 \mathrm{mg}$ de progestagène (norethistérone base) ${ }^{6}$.

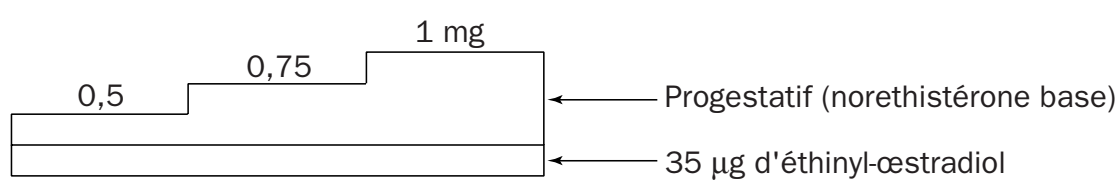

Figure 15.2 - Exemple de pilule triphasique

Les inconvénients de la pilule sont variés :

- risque métabolique : elle entraîne une altération de la tolérance au glucose avec hyperinsulinisme, accroît la rétention hydrosodée (prise de poids), diminue le taux du HDL-cholestérol (le bon cholestérol).

- risque thrombo-embolique ${ }^{7}$, que l'on a d'abord attribué aux œstrogènes, d'où la mise au point de pilule minidosée, mais que l'on peut imputer aux progestatifs de synthèse ;

- risque cancérigène, qui est réel chez le rongeur, mais très discutable et très discuté chez la femme. Il est par contre admis, et souvent ignoré, que la pilule protège la femme contre les cancers de l'ovaire et de l'endomètre. Cependant, elle est déconseillée en cas de mastopathie ou d'adénome mammaire.

Aussi, avant toute contraception par pilule, il est nécessaire de faire un bilan préalable :

- biologique (bilan lipidique, glycémie, plaquettes, fibrinogène, antithrombine III) ;

- gynécologique (sein, frottis vaginaux);

- clinique (varices, antécédents de phlébite...).

Nous avons vu que les progestatifs de synthèse type norgestrel diminuent les taux d'HDL, ayant un effet protecteur sur la maladie athéromateuse. Aussi utilise-t-on de préférence le désogestrel ${ }^{8}$, qui élève le taux des HDL-cholestérols et celui de la SBG (ce qui inactive une grande partie des androgènes circulants). Il n'a pas les effets androgéniques de certains dérivés de progestagène, n'entraîne pas de prise de poids anormale, et assure une meilleure protection vasculaire lorsque le tabagisme ${ }^{9}$ est associé à la pilule.

6 Des études faites sur 619 femmes pendant plus d'un an (plus de 10000 cycles) ont donné un indice de Pearl de 0,22.

7 Le risque thrombo-embolique est en relation avec des modifications de facteurs de la coagulation, une majoration du "mauvais" cholestérol-LDL (de basse densité) et une stase veineuse en particulier au niveau des réseaux jambiers.

8 Il fait partie de ce que l'on appelle les progestatifs de troisième génération.

9 Le tabagisme est en principe une contre-indication à la pilule. 
Les femmes présentant des manifestations d'hyperandrogénie (séborrhée cutanée ou du cuir chevelu, acné et/ou hyperpilosité) pourront prendre une pilule à base d'œstrogène $(50 \mu \mathrm{g})$ et d'un anti-androgène antiprogestatif, l'acétate de cyprotérone ( $2 \mathrm{mg}$ ). Les effets sur la peau, la pilosité... sont en général nets.

\section{- La pilule du lendemain}

En faisant desquamer l'endomètre lors d'une éventuelle implantation de zygote, elle détermine une "fausse couche" très précoce et, pour être efficace, doit être mise en œuvre au plus tard $48 \mathrm{~h}$ après le rapport non-protégé.

- On a d'abord prescrit des œstrogènes à fortes doses :

- éthinyl-œstradiol $100^{10}$, un comprimé 5 jours de suite

- ou distilbène $25 \mathrm{mg}$, un comprimé 5 jours de suite.

- Actuellement, aves deux pilules normodosées, à renouveler $12 \mathrm{~h}$ après, on obtient les mêmes résultats et une meilleure tolérance.

- La pilule “abortive” ou RU 486 (mifépristone ou mifégyne)

Mise au point par Baulieu et son équipe (Herrmann et coll., 1982), c'est un 19-norstéroïde (fig. 15.3), antagoniste de la progestérone au niveau de ses récepteurs (Baulieu, 1991b). C'est un contraceptif (elle provoque une interruption de la phase lutéinique pendant le cycle menstruel) et, de ce fait, un abortif précoce (elle est efficace à condition d'être absorbée avant le $1^{\text {er }}$ jour de retard des règles). Son efficacité, de l'ordre de $80 \%$, devient proche de $100 \%$ si elle est associée à des dérivés de prostaglandines. Mais cette association favorise chez les lapines des malformations du fœtus.

Le RU 486, qui a une action à la fois antiprogestérone et antiglucocorticoïdes, fait partie des molécules anti-hormones. Son mécanisme (voir fig. 15.4) est encore mal élucidé.

\section{- Les contraceptifs injectables à longue durée d'action}

C'est une méthode contraceptive commode pour les pays en voie de développement. Il s'agit de progestatifs de synthèse : médroxyprogestérone ou norethistérone, que l'on utilise habituellement à raison d'une injection intramusculaire (350 mg) tous les 3 mois. Ils bloquent l'ovulation et modifient la glaire cervicale.

\section{- Le vaccin contraceptif}

Ce vaccin est fabriqué à partir d'un fragment peptidique synthétique de la chaine $\beta$ de HCG. Il provoque la formation d'anticorps et sensibilise les lymphocytes contre HCG, empêchant l'implantation du blastocyste. Il a été efficace et sans danger chez le babouin et est actuellement en essai chez la femme, en Inde et en Australie, sous forme de deux injections à 6 semaines d'intervalle. Un tel vaccin doit répondre à trois impératifs : réversibilité de son action, absence d'effets

10 Ce qui équivaut à une prise quotidienne de dix pilules normodosées. 
croisés avec d'autres hormones ou d'autres fonctions physiologiques, absence d'effets secondaires et en particulier auto-immuns.

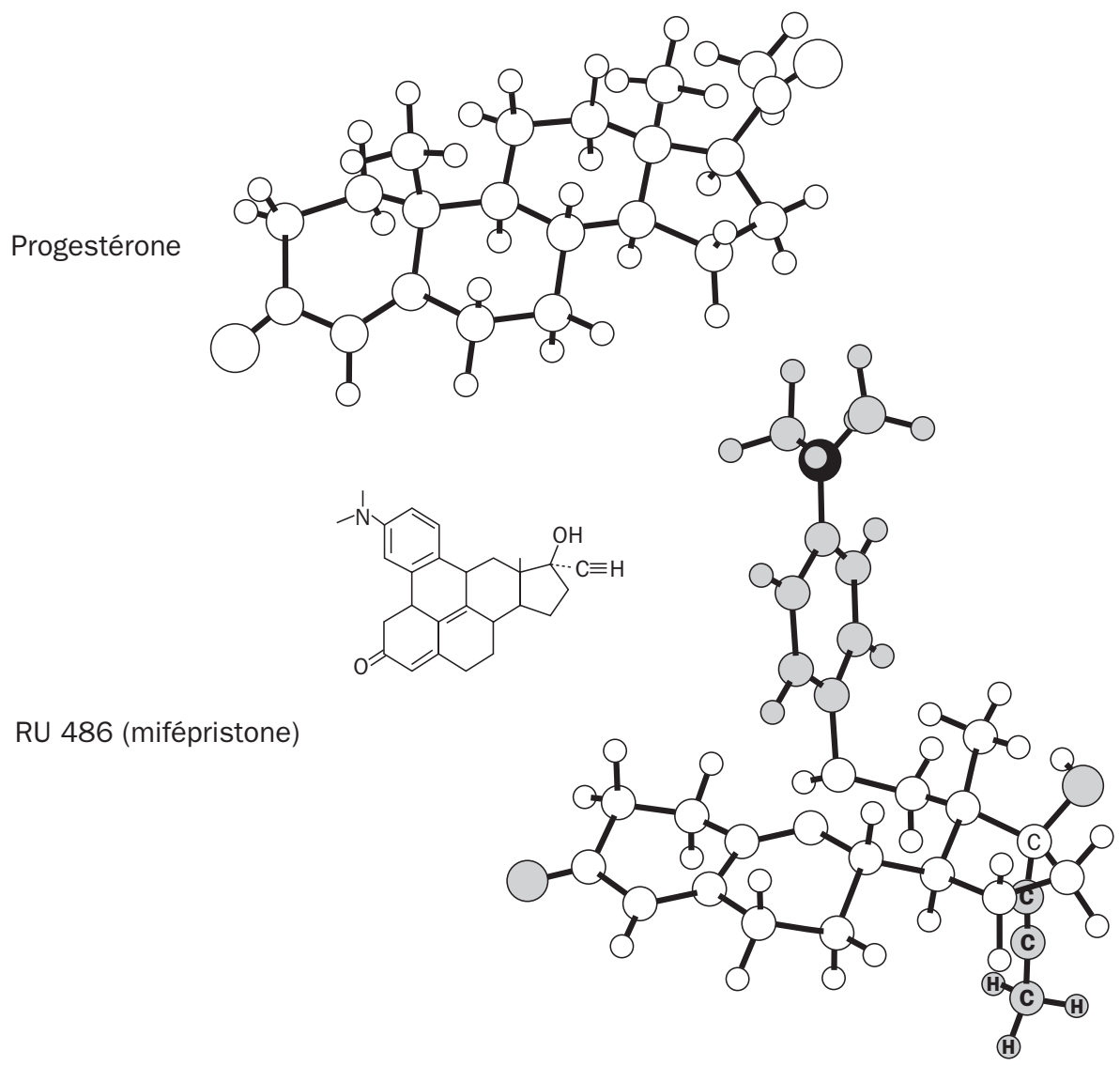

Figure 15.3 - Structure comparée de la mifépristone (RU 486) et de la progestérone

(d'après Baulieu et Kelly, 1990)

\section{- Le vaccin anti-ovocyte}

En fonction du même principe d'utilisation d'anticorps, mais au stade expérimental seulement, on a essayé d'induire une immunité contre des glycoprotéines de la zone pellucide (la molécule D632 chez l'homme). Un vaccin a été employé chez le ouistiti (infertilité pendant 47 semaines) et chez le porc (effet contraceptif persistant dans $86 \%$ des cas).

\section{- Les agonistes de la LH-RH}

En supprimant l'action pulsatile de la LH-RH sur l'hypophyse, les agonistes de la LH-RH provoquent un effondrement des gonadotrophines, en particulier de la LH. Ils ont donc une action contraceptive anti-ovulatoire, qui est exploitée cliniquement dans les situations où un contraceptif stérö̈dien n'est pas recommandé. 


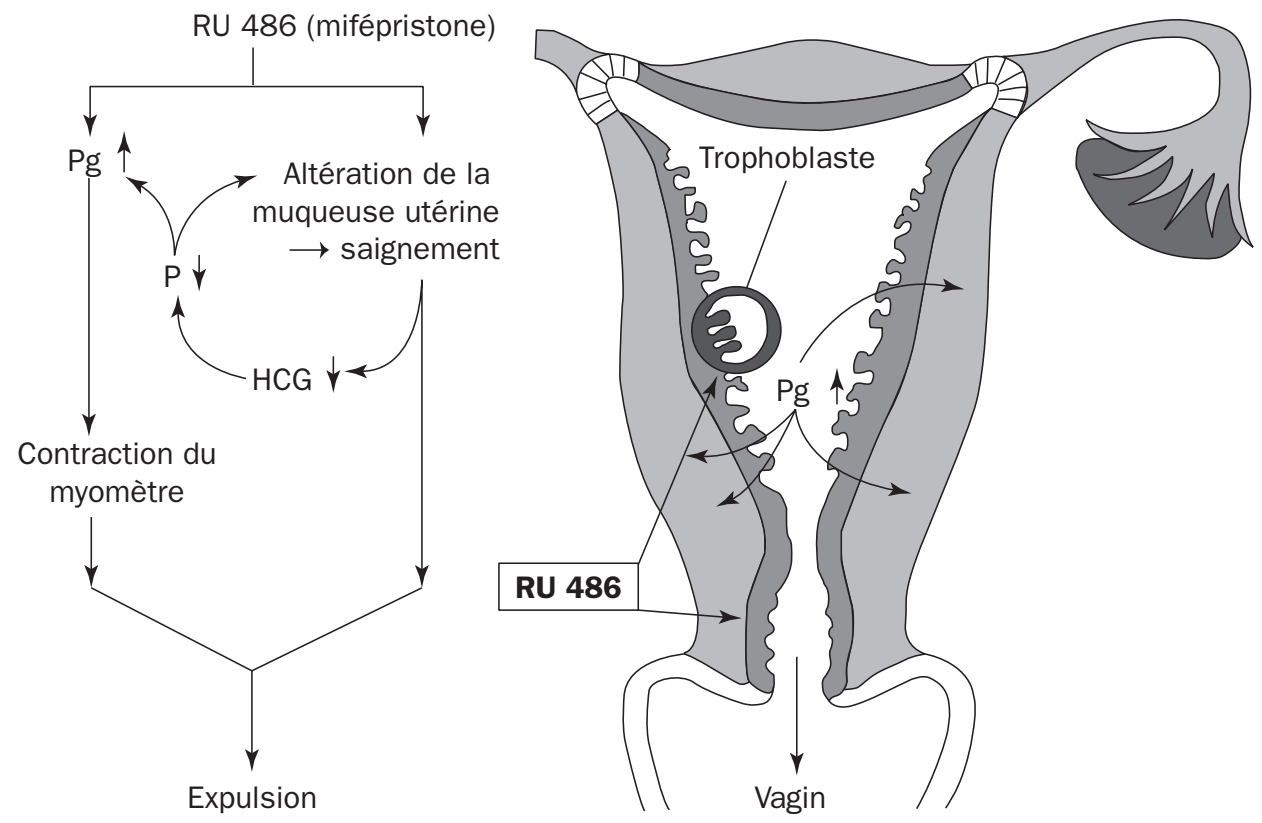

Figure 15.4 - Mécanisme d'action de la mifépristone (RU 486)

(d'après Baulieu et Kelly, 1990)

La mifépristone agit au niveau de la muqueuse utérine en occupant les sites récepteurs à la progestérone dont elle est un analogue structural. La libération de prostaglandine (Pg) provoque la contraction du myomètre et l'ouverture du col utérin. La lutéolyse survient secondairement.

C'est le cas des pubertés précoces et de la fécondation "in vitro", qui est nettement améliorée par la suppression des pics de LH. C'est le cas de la contraception de la femme qui allaite, lorsque l'allaitement ne constitue pas la seule alimentation donnée au bébé, ou lorsque le temps de tétée est inférieur à $50 \mathrm{~min} /$ jour (l'allaitement complet est généralement associé à la suppression de l'ovulation). L'agoniste (par exemple la busériline) est alors employé pour une période relativement courte (elle n'excède pas 2 ans), et permet à la mère de recouvrer ses forces physiques et émotionnelles entre deux grossesses.

\subsection{LES MOYENS CONTRACEPTIFS CHEZ L'HOMME}

\subsubsection{Moyens mécaniques}

- L'abstention : 0\% d'échec.

- L'éjaculation retardée et externe ("coïtus interruptus") : simplicité de la méthode, mais échecs élevés. Indice de Pearl : 18.

- Le condom (préservatif ou "capote anglaise" en France, "french leathers" en Angleterre) est en vente libre depuis son invention au XVIII' siècle. Il n'enfreignait pas la loi de 1920, car il était considéré comme préservant des maladies sexuellement transmissibles (MST). 
- Avantages

- Il permet un rapport à n'importe quel moment du cycle féminin ;

- il est indiqué après une grossesse ;

- c'est un excellent moyen de prévention des maladies sexuelles transmissibles, en particulier le SIDA.

- Echecs

Indice de Pearl : de 10 à 15.

- La vasectomie (équivalent de la ligature des trompes chez la femme)

La vasectomie (ligature des canaux déférents) est une méthode contraceptive encouragée dans certains pays du tiers-monde. Elle est également pratiquée en France, mais pour des raisons d'ordre médical ${ }^{11}$.

L'inconvénient de cette méthode est son caractère traumatisant, physiquement (c'est une intervention chirurgicale, à vrai dire bénigne et sous anesthésie locale) et moralement (l'homme rendu infécond peut être affecté psychiquement).

La conservation de la semence par le CECOS fait perdre à la ligature des déférents son caractère d'irréversibilité. D'autre part, la microchirurgie permet, théoriquement, la reperméabilisation. Elle s'effectue sous anesthésie locale : il faut 10 min pour ligaturer les déférents, mais $3 \mathrm{~h}$ pour les réparer et avec 50\% d'échecs.

\subsubsection{Moyens biochimiques}

Le principe de la contraception hormonale masculine est semblable à celui découvert par Pincus chez la femme. Elle repose sur une inhibition de la spermatogenèse par un feed-back hypothalamo-hypophysaire. Elle a été décrite au chapitre $13, \S 7$.

A une dose convenable, la testostérone, chez l'homme comme chez l'animal, supprime effectivement la spermatogenèse et compense la carence en testostérone endogène provoquée par le rétro-contrôle négatif. On a essayé :

- des esters de testostérone en injections intramusculaires tous les 15 jours, par exemple la testostérone undecanoate ;

- la testostérone en implantation sous la peau, dans une capsule siliconée ;

- l'association méthyl-testostérone/éthinyl-œstradiol, mais avec le risque de gynécomastie et de maladie thrombotique ;

- un androgène faible, le danazol, à raison de $500 \mathrm{mg} /$ jour per os, associé à $250 \mathrm{mg}$ d'œnanthate de testostérone.

Le retour à une taille normale des testicules suit l'arrêt thérapeutique, mais tandis que les spermogrammes demandent 4 à 10 semaines pour être sévèrement déprimés, le retour à la normale est beaucoup plus long et peut dépasser 5 mois dans quelques cas.

11 Légalement, cette opération, lorsqu'elle est à visée contraceptive, n'est pas autorisée par la loi. Elle relève du Code pénal (coups et blessures volontaires). 


\section{- Les agonistes de la LH-RH}

Nous avons vu que les agonistes entrent en compétition avec la LH-RH endogène, et finalement inhibent la sécrétion de FSH et de LH par occupation des sites hypophysaires. Deux produits sont actuellement expérimentés chez l'homme, mais il reste à démontrer leur absence de toxicité. D'autre part, leur emploi crée un déficit en testostérone, avec les conséquences possibles sur la libido et la puissance sexuelle. Un délai d'au moins 1 à 2 mois est nécessaire à la suppression de la spermatogenèse ainsi qu'à sa réapparition, une fois l'essai terminé.

D'une façon générale, toutes ces méthodes hormonales contraceptives sont peu faciles à utiliser compte tenu :

- de la longueur du délai d'apparition de l'infécondité ;

- des fluctuations des résultats obtenus ;

- de la nécessité de plusieurs contrôles du spermogramme ;

- de la longueur de la phase de retour.

\section{- L'utilisation éventuelle de l'inhibine}

Cette substance est capable de supprimer la sécrétion de FSH hypophysaire, sans atteindre celle de la LH. L'inhibition sélective de FSH devrait conduire à une stérilité masculine, sans atteindre la sécrétion d'androgènes. Une expérimentation animale reste à faire, avec cette substance convenablement purifiée, avant d'envisager l'application humaine.

\section{- L'acétate de cyprotérone}

Un impact testiculaire s'ajoute à l'inhibition hypophysaire, et l'effet antiandrogénique a pour résultat possible de supprimer la spermatogenèse. Mais la diminution parallèle de la testostérone a les inconvénients que nous avons vus et cette substance ne peut être retenue comme moyen contraceptif.

\section{LES PROCRÉATIONS MÉDICALEMENT ASSISTÉES (PMA)}

\subsection{GÉNÉRALITÉS}

Les procréations médicalement assistées ou PMA ont, depuis une dizaine d'années, complètement transformé le pronostic des stérilités. Elles s'appuient schématiquement sur deux techniques : les inductions ovulatoires qui restaurent en principe une ovulation normale et les fécondations externes dites encore in vitro (FIV) qui, après recueil d'ovocytes, prennent en charge la fécondation en milieu artificiel et se terminent par un transfert d'embryon.

\subsection{LES INDUCTIONS OVULATOIRES}

En fonction de la cause considérée (hypothalamo-hypophysaire ou ovarienne), les procédés utilisés peuvent varier. 
Le citrate de clomifène (Clomid®, voir fig. 12.14), isolé ou en association avec l'éthinyl-œstradiol 12 à raison de $100 \mathrm{mg} /$ jour les 5 premiers jours du cycle, peut engendrer, dans la semaine qui suit l'arrêt du traitement, une décharge ovulante souvent utilisée en priorité dans le traitement des anovulations hypothalamiques, en raison de sa simplicité.

On peut également solliciter l'étage hypophysaire grâce aux pompes à GnRH qui vivent des échecs du clomifène. L'administration intraveineuse pulsatile de 5 à $20 \mu \mathrm{g}$ de gonadolibérine, par micropompe, permet d'obtenir une grossesse dans environ $30 \%$ des cas. Toutefois, ces grossesses induites sont fragiles, témoin le nombre important de fausses couches qu'elles ont à supporter (25\%).

La sollicitation ovarienne, par voie intramusculaire, à l'aide des gonadotrophines post-ménopausiques (HMG ou human menopausal gonadotrophin) comportant à parts égales FSH (75 UI par ampoule) et LH (75 UI par ampoule), peut être indiquée dans certaines anovulations par insuffisance gonadique. En général, la posologie de une à quatre ampoules par jour à partir des $1^{\text {ers }}$ jours du cycle augmentera progressivement en fonction de la surveillance précise du volume ovarien, de la qualité de la glaire, des œstrogènes et des données échographiques. A un follicule mûr correspond un œstradiol plasmatique de $400 \mathrm{pcg} / \mathrm{ml}$; à l'échographie, ce follicule mesurera de 15 à $20 \mathrm{~mm}$; la glaire présentera un brusque changement de filance (c'est le shift de la glaire) contemporain de la maturité folliculaire.

On provoque le déclenchement ovulatoire par l'injection, $48 \mathrm{~h}$ après la dernière intramusculaire de HMG, de 5000 UI de gonadotrophines chorioniques (HCG à effet LH), éventuellement répétée 2 jours plus tard.

Il importe de pratiquer l'apport en HCG lorsque tous les critères de maturité complète sont présents ; tout déclenchement ovulatoire trop précoce entraînerait la ponte d'un ovule immature, inapte à la fécondation, tout retard engendrerait un ovocyte en involution, également inapte.

De même, il faut insister sur la nécessité d'une surveillance de traitement étroite, car les accidents de surdosage avec kystes fonctionnels, grossesses multiples... sont fréquents. Dans ces conditions, le maniement précis des inducteurs ovulatoires permet d'obtenir environ $80 \%$ d'ovulations.

\subsection{LA FÉCONDATION IN VITRO (FIV)}

Depuis la première naissance d'un "bébé éprouvette", en 1978, la fécondation in vitro, avec transfert d'embryon, a largement fait ses preuves dans le traitement des stérilités

12 Le clomifène étant anti-œstrogène et asséchant la glaire cervicale, il convient de l'utiliser, soit isolé lorsque le taux de $17 \beta$-œstradiol circulant est supérieur à $50 \mathrm{pcg} / \mathrm{ml}$, soit en association avec un œstrogène majorant la glaire. 
tubaires (et les autres), au point que son utilisation s'est largement diffusée, d'une part, et banalisée, d'autre part.

Cependant, malgré une codification assez précise et relativement simple, cette technique doit rester le privilège d'équipes bien rodées, étant donné la lourdeur de leur mise en œuvre et l'importance de leur coût.

Avec de multiples variantes, toutes ces techniques consistent à prélever un ovule, à le féconder en laboratoire, puis à replacer le zygote 3 jours plus tard, au stade 8 blastomères, dans l'utérus maternel.

Bien que, dans la majorité des cas, les patientes candidates soient normo-ovulantes, la mise en ouvre préalable d'une superovulation induite est quasi systématique.

De même, il est d'usage de bloquer la fonction gonadotrope hypophysaire à l'aide d'analogues de la GnRH, afin d'éviter d'éventuelles interférences endogènes de la sécrétion de $\mathrm{LH}$, perturbatrices de la maturation folliculaire. Ce procédé a, en outre, l'avantage de permettre un recrutement folliculaire plus important.

$36 \mathrm{~h}$ après l'injection de $5000 \mathrm{UI}$ de HCG (voir induction ovulatoire), la ponction du follicule mature pratiquée par voie abdominale transvésicale, soit par voie vaginale, sous repérage échographique, soit par cœlioscopie transpariétale, permet de recueillir une cohorte de cinq à dix ovules fécondables.

L'insémination ovocytaire peut alors être entreprise à l'aide d'un sperme isolé ou plasma séminal par centrifugation douce, et sélectionné par migration ascendante.

Après 24 h d'insémination, le dénudage de l'œuf à la pipette fine permet de vérifier les témoins d'une fécondation normale (deux pronuclei, deux globules polaires), qui autorisent le transfert du zygote dans un milieu de culture neuf et permettent le transfert in utero du ou des embryons (en général trois ou quatre) frais par voie transcervicale sur un endomètre antérieurement préparé.

Les embryons surnuméraires peuvent être congelés, conservés et éventuellement transférés au cours de cycles ultérieurs.

Le résultat global de la FIV, représenté par le nombre de naissances "normales", est de $11 \%$ par cycle de stimulation, de 16\% par transfert. C'est dire que les grossesses obtenues sont fragiles, que le nombre de fausses couches est fréquent (environ 20\%), de même que les grossesses extra-utérines (environ 6,5\%).

Enfin, si ces techniques ont permis de faire des progrès dans la compréhension des mécanismes de la reproduction, elles ont aussi généré des problèmes éthiques importants, concernant :

- une éventuelle sélection du sexe ;

- la gestion des embryons surnuméraires ;

- la possibilité de mères rémunérées porteuses d'embryon ;

- les risques de grossesses multiples ;

- le danger de manipulations génétiques ; 
- la vogue d'une méthode coûteuse pour la collectivité (100000 F en moyenne $\left.{ }^{13}\right)$, avec les risques qu'elle comporte ${ }^{14}$ chez des couples simplement peu fertiles et pour lesquels d'autres méthodes seraient possibles ;

- l'aspect un peu irritant de la fabrication à grands frais d'enfants de la biotechnique dans le Nord du monde, alors que 40000 enfants meurent chaque jour de malnutrition dans le Sud.

L'acuité de ces questions est encore plus grande. En effet, des chercheurs viennent de mettre au point des souris transgéniques capables de produire des ovocytes humains. La large production potentielle d'embryons qui en découle augmente les possibilités (et les risques) de sélection.

On peut craindre une évolution vers la manipulation de la vie humaine, susceptible de conduire à des déviations. C'est encore plus vrai pour le clonage humain. Le seul frein à une telle application réside dans le poids de considérations éthiques ou philosophiques. Ainsi, par l'application des techniques de biologie moléculaire, l'homme peut-il devenir l'acteur de sa propre évolution. L'outil biologique, comme la langue d'Esope, n'est-il pas finalement la meilleure ou la pire des choses, suivant l'usage qu'en feront les hommes?

13 Elle plafonne actuellement autour de 20000 tentatives par an en France.

14 Pour l'enfant, ce sont les fausses couches, les naissances prématurées (le triple de la normale), les "naissances à problèmes" dont les malformations congénitales (le double de la normale), le taux de mortalité périnatale (quatre fois celui des grossesses normales).

Pour la mère, les fausses couches (deux à trois fois la normale), les grossesses extrautérines (deux à trois fois la normale), la probabilité de grossesses multiples (20 à 27 fois le risque normal). Sans compter les risques associés à la stimulation ovarienne (kystes ovariens, hypertrophie des ovaires...). 


\section{RÉFÉRENCES BIBLIOGRAPHIQUES DE LA TROISIÈME PARTIE}

ANCLA M., BRUX J. (de) \& SIMON P., Aneurismal microthrombosis associated with intrauterine devices in the human endometrium. An electronmicroscopical study, Lab. Invest., 17, 61-67, 1967.

AUSTIN C.R. \& SHORT R.V. (eds), Reproduction in mammals, Cambridge Univ. Press, 1972.

BAULIEU E.E. \& KELLY P.A., Hormones, Hermann, Paris, 1990.

BAULIEU E.E., Neurosteroids : a new function in the brain, Biol. Cell., 71, 3-10, 1991a.

BAULIEU E.E., The steroid hormone antagonist RU 486. Mechanism at the cellular level and clinical applications, Endocrin. Metab. Clin. (North America), 20, 873-891, 1991b.

BAULIEU E.E., ROBEL P., VATIER O. \& coll., Neurosteroids : pregnenolone and dehydroepiandrosterone in the brain, in "Receptor-receptor interactions", 89-104, Fuxe K., Agnati L.F. eds, MacMillan Press Ltd, 1987.

BINART N., Le récepteur de la prolactine, une molécule-clé de la reproduction ?, Médecine/Sciences, 13, 734-736, 1997.

BOISSIN J. \& coll., Cycle annuel de la fonction gonadotrope et de la prolactinémie ; régulation de l'activité testiculaire saisonnière, Ann. Endocrinol. (Paris), 44, 319-321, 1983.

BOISSIN-AGASSE L. \& BOISSIN J., Incidence of a circadian cycle of photosensitivity in the regulation of the annual testis cycle in the mink : a shortday mammal, Gen. Comp. Endocr., 60, 109-115, 1985.

BRUNEAU G., VAISSE C., CARATY A. \& MONGET P., La leptine : une clé pour la reproduction, Médecine/Sciences, 15, 191-196, 1999.

BUVAT J., Prolactine, in "Physiologie de la reproduction humaine", 63-74, Tournaire M. éd., Masson, 1985.

CANIVENC R. \& coll., Réalisation expérimentale précoce de l'ovo-implantation chez le blaireau européen (Meles meles L.) pendant la période de latence blastocytaire, CR Acad. Sci., 273, 1855-1857, 1971.

CANIVENC R. \& MAYER G., La nidation de l'œuf et ses modalités, in "Traité de Zoologie”, Grassé P.P. éd., t. XVI, fasc. VII, 165-213, Masson, 1982.

CEDARD L., Hormonologie de la grossesse, in "Physiologie de la grossesse", Tournaire M. éd., 165-176, Masson, 1982.

CHANNING C.P. \& coll., The role of non-steroidal regulators in control of oocyte and follicular maturation, Rec. Progr. Horm. Res., 38, 331-408, 1982. 
CHAOUAT G. \& coll., Immunologie de la relation materno-fœtale, Médecine/Sciences, n ${ }^{\circ}$ spécial août, 20-26, 1989.

CLARKE I.J. \& CUMMINS J.T., The temporal relationship between gonadotropin releasing hormone $(\mathrm{GnRH})$ and luteinizing hormone $(\mathrm{LH})$ secretion in ovariectomized ewes, Endocrinology, 111, 1737-1739, 1982.

CUTLER G.B. \& coll., Pubertal growth : physiology and physio-pathology, Rec. Progr. Horm. Res., 42, 443-470, 1986.

DECLERCK M., Glande mammaire, in "Physiologie de la reproduction humaine", Tournaire M. ed., 187-196, Masson, 1985.

DELLENBACH P., Physiologie de la nidation, in "Physiologie de la grossesse", Tournaire M. éd., 37-46, Masson, 1982.

DEWAILLY D. \& coll., Physiologie de la prolactine, Enc. Méd. Chir., 10017 M ${ }^{10}$, 1-14, 1984.

DEWART P.J. \& coll., Etude d'un agoniste de la LH-RH, la busériline, comme contraceptif dans le post-partum, Contraception-fertilité-sexualité, 17, 203-207, 1989.

DICFALUSY E., Steroid metabolism in the fœto-placental unit, in "The fœtoplacental unit", Pecile A. \& Finzi C. eds, 1969.

DIZEREGA G.S. \& HODGEN G.D., The primate ovarian cycle suppression of human menopausal gonadotropin-induced follicular growth in the presence of the dominant follicle, J. Clin. Endocr. Metab., 50, 819-825, 1980.

DOLLANDER A. \& FENARD R., Eléments d'embryologie, Flammarion, Paris, 1979.

DROUVA S.V. \& coll., Opiate receptors modulate LH-RH and SRIF release from mediobasal hypothalamic neurons, Neuroendocrinology, 32, 163-167, 1981.

DUMEZ Y., Echanges placentaires, in "Physiologie de la grossesse", Tournaire M. ed., 135-142, Masson, 1982.

DUNCAN J.A. \& coll., Regulation of pituitary gonadotropin-releasing hormone $(\mathrm{GnRH})$ receptors by pulsatile GnRH in female rats : effects of œstradiol and prolactin, Endocrinology, 118, 320-327, 1986.

DYER R.G. \& coll., Discharge of gonadotropin-releasing hormone from the mediobasal part of the hypothalamus : effect of stimulation frequency and gonadal steroids, Exp. Brain. Res., 39, 453-460, 1980.

FEINSTEIN-SOLDAT M.C. \& SCHOLLER R., II. Propriétés chimiques, biologiques, immunologiques de la choriogonadotropine humaine (hCG), Actualités Gyn., 186-195, 1978.

FERIN M. \& coll., The hypothalamic control of the menstrual cycle and the role of endogenous opioid peptides, Rec. Progr. Horm. Res., 40, 441-485, 1984.

FINLEY J.C.W. \& coll., Immunocytochemical localization of $\beta$-endorphincontaining neurons in the rat brain, Neuroendocrinology, 33, 28-42, 1981.

FOOTE N.D. \& THIBAULT C., Recherches expérimentales sur la maturation in vitro des ovocytes de truie et de veau, Ann. Biol. Anim. Biochem. Bioph., 9, 329-349, 1969.

FOREST M.G. \& PUGEAT M., Binding proteins of steroid hormones, Colloque INSERM, John Libbey Eurotext ed., Londres/Paris, 1986. 
FRÜHBECK G., JEBB S.A. \& PRENTICE A.M., Leptin : physiology and pathophysiology, Clin. Physiol., 18, 399-419, 1998.

GAAL L.F. (Van) \& coll., Clinical endocrinology of human leptin, Int. J. Obesity, 23, suppl. 1, 29-36, 1999.

GASPARD U., Etude de la sécrétion de l'hormone lactogène placentaire, de la choriogonadotrophine et de ses sous-unités, Thèse, Liège, 1979.

GEORGES D. \& coll., Relaxin-like peptide in Ascidians. I. Identification of the peptide and its mRNA in ovary of Herdmania momus, Gen. Comp. Endocr., 3, 423-428, 1990a.

GEORGES D. \& coll., Relaxin-like peptide in Ascidians. II. Bioassay and immunolocalization with anti-porcine relaxin in three species, Gen. Comp. Endocr., 3, 429-438, 1990b.

GEORGES D. \& SCHWABE C., Porcine relaxin a 500 million-year-old hormone ! The tunicate Ciona intestinalis has porcine relaxin, Faseb J., 13, 1269-1275, 1999.

GOUGEON A., Regulation of ovarian follicular development in primates : facts and hypotheses, Endocr. Rev., 17, 121-155, 1996.

GRADY R.R. \& coll., Characterization of the FSH-suppressing activity in follicular fluid, Rec. Progr. Horm. Res., 38, 409-456, 1982.

HERRMANN W., WYSS R., RIONDEL A., PHILIBERT D., TEUTSCH G., SAKIZ E. \& BAULIEU E.E., Effet d'un stéroïde anti-progestérone chez la femme : interruption du cycle menstruel et de la grossesse au début, CR Acad. Sci., 294, 933-938, 1982.

KAWAKAMI M. \& coll., Electrophysiological correlates of pulsatile gonadotropin release in rats, Neuroendocrinology, 35, 63-67, 1982.

KNOBIL E. \& coll., Control of the Rhesus monkey menstrual cycle : permissive role of hypothalamic gonadotropin-releasing hormone, Science, 207, 1371-1373, 1980.

KNOBIL E., The neuroendocrine control of the menstrual cycle, Rec. Progr. Horm. Res., 36, 53-88, 1980.

LAFFARGUE F. \& MARES P., Ovaire, in "Physiologie de la reproduction humaine", Tournaire M. éd., 75-92, Masson, 1985.

LEONG D.A. \& coll., Neuroendocrine control of prolactin secretion, Annu. Rev. Physiol., 45, 109-127, 1983.

LE GOASCOGNE C. \& coll., Neurosteroids : cytochrome P-450 scc $_{\text {in }}$ rat brain, Science, 237, 1212-1214, 1987.

LINCOLN D. \& coll., Hypothalamic pulse generators, Rec. Progr. Horm. Res., 41, 369-419, 1985.

MARSHALL J.C. \& KELCH R.P., Low dose pulsatile gonadotropin-releasing hormone in anorexic nervosa : a model of human pubertal development, J. Clin. Endocr. Metab., 49, 712-718, 1979.

MASLAR I.A. \& RIDDICK D.H., Prolactin production by human endometrium during the normal menstrual cycle, Am. J. Obstet. Gynecol., 135, 751-754, 1979. 
MATKOVIC V. \& coll., Gain in body fat is inversely related to the nocturnase in serum leptin levels in young females, J. Clin. Endocr. Metab., 82, 1368-1372, 1997.

MATT D.W. \& coll., Chronological changes in fertility, fecondity and steroid hormone secretion during consecutive pregnancies in aging rats, Biol. Reprod., 34, 478-487, 1986.

Mc LACHLAN R.I. \& coll., Circulating immuno-reactive inhibin levels during the normal human menstrual cycle, J. Clin. Endocr. Metab., 69, 954-961, 1987.

Mc NATTY K.P. \& coll., The production of progesterone, androgens and œstrogens by granulosa cells, thecal tissue, and stromal tissue from human ovaries in vitro, J. Clin. Endocr. Metab., 49, 687-699, 1979.

MERMILLOD P. \& MARCHAL R., La maturation de l'ovocyte de mammifères, Médecine/Sciences, 15, 148-156, 1999.

MILLER R.K. \& coll., The transport of molecules across placental membranes, in "The cell surface", Poste G. \& Nicolson G.L. eds, North Holland Pub. Co., 1976.

MONGET P. \& coll., La physiologie ovarienne : ce que nous disent les souris..., Médecine/Sciences, 15, 141-147, 1999.

MONNIAUX D., MANDON-PEPIN B. \& MONGET P., L'atrésie folliculaire, un gaspillage programmé, Médecine/Sciences, 15, 157-166, 1999.

MORISHIGE W.K. \& ROTHCHILD I., Temporal aspect of the regulation of corpus luteum function by $\mathrm{LH}$, prolactin and placental luteotrophin during the first half of pregnancy in the rat, Endocrinology, 95, 260-274, 1974.

OJEDA J.R. \& coll., Mechanism of female puberty, Rec. Progr. Horm. Res., 42, 388-442, 1986.

PINCUS G., Control of conception by hormonal steroids, Science, 153, 493-500, 1966.

POHL C.R. \& KNOBIL E., The role of the central nervous system in the control of ovarian function in higher primates, Annu. Rev. Physiol., 44, 583-593, 1982.

POIRIER J. \& coll., Embryologie humaine, Maloine, Paris, 1981.

POULAIN D.A. \& WAKERLEY J.B., Electrophysiology of hypothalamic magnocellular neurones secreting oxytocin and vasopressin, Neuroscience, 7, 773-808, 1982.

PUGEAT M., TeBG, protéine de liaison plasmatique des hormones sexuelles, Rev. Fr. Endocrinol. Clin., 25, 506-512, 1984.

RIBADEAU-DUMAS B., Le lait maternel, la Recherche, 14, 8-18, 1983.

ROSENBERG S.M. \& coll., Decidual production of prolactin in late gestation : further evidence for a decidual source of amniotic fluid prolactin, Am. J. Obstet. Gynecol., 138, 681-685, 1980.

ROTTEN D. \& ENJALBERT A., Physiologie neuroendocrinienne; hypothalamus et hypophyse gonadotropes chez la femme, in "Physiologie de la reproduction humaine", Tournaire M. éd., 45-62, Masson, 1985.

ROTTEN D., Lactation, in "Physiologie de la grossesse", Tournaire M. éd., 273-283, Masson, 1982. 
ROTTEN D., LEBEEUF D. \& PHILIPPE H.J., Cycle menstruel, in "Physiologie de la reproduction humaine", Tournaire M. éd., 197-209, Masson, 1985.

RYAN R.J. \& coll., Structure-function relationships of gonadotropins, Rec. Progr. Horm. Res., 43, 383-429, 1987.

SAIRAM M.R., Les hormones gonadotropes de l'hypophyse humaine (FSH, LH et prolactine). Structure et mécanismes d'action, Médecine de la reproduction, Mauvais-Jarvis P., Flammarion, 1986.

SCHOLLER R., Anti-hormones naturelles, Actualités Gyn., 146-153, 1989.

SERADOUR B. \& coll., Méthodes d'investigation de la fonction ovarienne, Enc. Méd. Chir., 10027 B ${ }^{10}, 1978$.

SHERWOOD O.D., Relaxin, in "The Physiology of Reproduction", Knobil E. \& Neill J. eds, 585-673, Raven Press, 1988.

SHORT R., L'allaitement, Pour la Science, 80, 12-20, 1984.

SIMON P., Vers la suppression de l'avortement thérapeutique et de la ligature des trompes : le stérilet, Bull. Féd. Soc. Gynécol. Obst., 17, 219-225, 1965.

TESTARD J., La fécondation externe de l'œuf humain, la Recherche, 130, 144-156, 1982.

TESTART J., La fécondation, in "Physiologie de la grossesse", Tournaire M. éd., 27-36, Masson, 1982.

THALABARD J.C. \& coll., Rythmes et reproduction, Pour la Science, 77, 92-102, 1984.

THIBAULT C., Are follicular maturation and oocyte maturation independant processes, J. Reprod. Fertil., 51, 1-15, 1977.

THIBAULT C. \& DAUZIER L., Analyse des conditions de la fécondation in vitro de l'œuf de lapine, Ann. Biol. Anim. Biochem. Bioph., 1, 277-294, 1961.

THIBAULT C., La fécondation chez les Mammifères, in "Traité de Zoologie", Grassé P.P. éd., 16, 911-963, Masson, Paris, 1969.

TOURNAIRE M., Déclenchement spontané du travail, in "Physiologie de la grossesse", Tournaire M. éd., 235-243, Masson, 1982.

TOURNIAIRE J. \& FEVRE M., Les gonadotropines hypophysaires, Enc. Méd. Chir., $100170 \mathrm{M}^{10}, 1-6,1979$.

TUREK F.W. \& coll., Role of the circadian system in reproductive phenomena, Rec. Progr. Horm. Res., 40, 143-177, 1984.

VALCKE J.C. \& coll., Critères d'interprétation du test utilisant l'hormone de libération de la lutéostimuline (LH-RH), Ann. Endocrinol. (Paris), 35, 423-443, 1974.

VOISIN G.A., Immune agents of the facilitation reaction (enhancing antibodies and suppressor cells) in pregnancy. Their possible roles in the protection of the placental allograft, in "Placenta. A neglected experimental animal", Beaconsfield P. \& Villée C. eds, 283-294, Pergamon Press, 1979.

WRIGHT P.A., Induction of ovulation in vitro in Rana pipiens with steroids, Gen. Comp. Endocr., 1, 20-23, 1961.

ZHANG F. \& coll., Positional cloning of the obese gene and its human homologue, Nature (London), 372, 425-432, 1994. 



\section{QuATRIÈme PARTIE}

\section{IMMUNITÉ ET ÉVOLUTION}

Chapitre 16 : Hormones et immunité

Chapitre 17 : Hormones et évolution 



\section{CHAPITRE 16}

\section{HORMONES ET IMMUNITÉ}

\section{INTRODUCTION}

Les corrélations entre systèmes endocrinien et immunitaire (constituant le cadre d'une endocrino-immunologie) ont été mises en évidence par de nombreux chercheurs.

\subsection{INTERRELATIONS THYMUS - GLANDES ENDOCRINES}

Schwartz, puis Deschaux ont mis en évidence les interrelations thymus-glandes endocrines en étudiant les effets de diverses ablations de glandes endocrines, l'action de leurs hormones sur "l'hormone thymique" (Schwartz, 1973 ; Comsa, 1979) ou ceux de la thymectomie ou des extraits thymiques sur ces glandes endocrines (Deschaux, 1980). Si la surrénalectomie provoque une hypertrophie thymique, l'hypophysectomie entraîne une involution du thymus (Schwartz, 1973). Les effets de la thymectomie ne sont évidents chez le rat que jusqu'à l'âge de 60 jours. Elle provoque un déséquilibre hormonal important, au niveau de l'axe hypophysosurrénalien (diminution de la teneur plasmatique en ACTH et de la corticostérone après une stimulation initiale) et hypophyso-gonadique (diminution de la concentration plasmatique de LH et de testostérone). La thymectomie néo-natale entraîne, en outre, une élévation du taux plasmatique de la GH (mais son efficacité est diminuée). La dysgénésie ovarienne, provoquée chez la souris ou le rat par une thymectomie néo-natale, est corrigée par des injections de thymosine.

\subsection{RôLE IMMUNITAIRE DU THYMUS}

Miller a montré, en 1961, que la thymectomie néo-natale s'accompagne d'une déficience immunologique à médiation cellulaire chez la souris ; puis des chercheurs ont mis en évidence les facteurs hormonaux d'origine thymique qui permettent la différenciation des lymphocytes pré-T en lymphocytes $\mathrm{T}$ et l'immunomodulation de leur activité :

- l' $\alpha$ 1-thymosine (ou plutôt la pro-thymosine $\alpha$ ) (A.L. Goldstein et coll., 1966) ;

- les thymopoiétines I et II (G. Goldstein, 1975);

- et la thymuline ou facteur thymique sérique (Bach et coll., 1972). 
Seuls, les deux derniers facteurs seraient spécifiques du thymus. Mais d'autres facteurs thymiques, qui n'ont pas encore été identifiés, interviennent certainement dans l'immunomodulation et l'acquisition de l'immunocompétence.

\subsection{AUTO-IMMUNITÉ ET PATHOLOGIE ENDOCRINIENNE}

Dans le domaine de la pathologie, l'étiologie auto-immune de nombreuses maladies est une réalité qui s'est imposée ces dernières années, en même temps que s'affirmaient les méthodes de détection et que s'approfondissaient les mécanismes pathogéniques de ces maladies. C'est en 1956 que Doniach et Roitt mettent en évidence des anticorps antithyroglobuline dans la thyroïdite de Hashimoto, que l'on considéra dès lors comme une maladie auto-immune ${ }^{1}$. La découverte du LATS (long acting thyroid stimulator) par Adams et Purves, la même année, (voir chap. 5.9) n'a pas suffi à l'époque à convaincre que la maladie de Basedow relevait du même mécanisme, d'autant que cet anticorps avait une action stimulante (et non pas neutralisante) sur la cellule thyroïdienne. On sait actuellement mieux comprendre ce paradoxe. Et de très nombreuses autres maladies endocriniennes s'avèrent relever d'un processus auto-immun : le diabète de type I (voir chap. 7, § 8.4.1), la maladie d'Addison (son autre étiologie, tuberculeuse, ayant presque disparu)...

\subsection{INTERRELATIONS HORMONES - CELLULES IMMUNITAIRES}

Les travaux plus récents mettent en évidence deux ordres de faits :

- les lymphocytes B ou T, les macrophages et éventuellement d'autres cellules intervenant dans la réponse immunitaire (mastocytes...) possèdent des récepteurs spécifiques à de nombreuses hormones. Celles-ci exercent sur les cellules immunitaires des effets modulateurs de leurs activités.

- les cellules immunitaires (lymphocytes, macrophages...) sécrètent des facteurs qui, pour certains, agissent sur des cellules endocrines, tandis que d'autres semblent voisins sinon identiques en structure à des hormones.

\section{RÉCEPTEURS SPÉCIFIQUES AUX HORMONES ET ACTION DES HORMONES SUR LES LYMPHOCYTES}

Les lymphocytes $\mathrm{T}$ et $\mathrm{B}$ possèdent des récepteurs aux hormones suivantes ${ }^{2}$ :

- prolactine (Russel et coll., 1984);

1 Ce qui n'était qu'un argument présomptif, et non une preuve, car les auto-anticorps peuvent être secondaires à l'altération cellulaire et non la cause de cette altération.

2 Mais, pour les œstrogènes, les récepteurs seraient présents sur les cellules épithéliales du thymus et non sur les thymocytes. 
- GH (Pandian et Talwar, 1971);

- prolactine (Russel et coll., 1985) ;

- opiacés : $\alpha$ - et $\beta$-endorphines (Gilman et coll., 1984);

- adrénaline et NA (Miles et coll., 1984);

- ACTH (Johnson et Torres, 1985) ;

et les lymphocytes $\mathrm{T}$ des récepteurs à :

- l'ADH (Johnson et Torres, 1985);

- l'acétylcholine (Shapiro, 1980);

- l'insuline (Murphy et coll., 1984);

- la substance P (Payan et Gœtzl, 1985);

- le VIP (O'Dorisio et coll., 1985) ;

- la met-enképhaline (Wybran et Schandené, 1986)...

\subsection{L'HORMONE DE CROISSANCE}

- Elle ne représente qu'un facteur de croissance adjuvant pour les lymphocytes.

- Elle est active en synergie avec T4 (Pierpaoli et coll., 1969). La thyroxine aurait un effet permissif sur la sécrétion et l'action de l'hormone thymique (Comsa et coll., 1974).

- L'addition de GH à des lymphocytes $\mathrm{T}$ de souris, in vitro, n'entraîne pas de prolifération significative (Snow et coll., 1981). Au contraire, si les lymphocytes ont été stimulés par la ConA (concanavaline A) ou la PHA (phytohémagglutinine), l'addition de GH inhibe la réponse blastogénique (Grossman et Rodelle, 1983).

- Toutefois, la réponse des lymphocytes aux lectines (incorporation de thymidine ${ }^{3} \mathrm{H}$ ) est GH-dépendante (Schimpff et Bozzola, 1984).

\section{2. $L^{\prime} A C T H$}

- Pour certains auteurs, elle joue un rôle modulateur de la croissance et de la différenciation des lymphocytes B (qui sont stimulés). Cette action in vitro nécessite la présence de BCGF (B cell growth factor) ou de l'IL2 (interleukine 2) (Alvarez-Mon, 1985) ;

- pour d'autres, c'est un inhibiteur puissant de la production in vitro d'IFN $\alpha$ (interféron $\alpha$ ) par des splénocytes de souris stimulées par des mitogènes (Johnson et coll., 1984), et elle supprime la réponse anticorps des splénocytes de souris aux GRM (globules rouges de mouton). 


\subsection{LES ENDORPHINES}

- L' $\alpha$-endorphine (comme les enképhalines) est un inhibiteur puissant de la réponse Ac aux GRM. $\beta$ - et $\gamma$-endorphines sont beaucoup moins actifs (Johnson et coll., 1982). L'effet inhibiteur de l' $\alpha$-endorphine est bloqué par la naloxone.

- La $\beta$-endorphine augmente la prolifération des lymphocytes T stimulée par ConA ou PHA, alors que l' $\alpha$-endorphine (comme les enképhalines) n'a aucun effet sur cette prolifération. Cet effet de la $\beta$-endorphine n'est pas supprimée par la naloxone. Aucun de ces opiacés endogènes n'a d'action sur la prolifération des lymphocytes B stimulés par un mélange dextran-LPS (Gilman et coll., 1982).

La $\beta$-endorphine augmente l'activité cytolytique et la production d'IFN (interféron) des cellules NK (natural killers).

\subsection{LA TSH}

- Elle augmente la réponse in vitro aux GRM (globules rouges de mouton) qui sont Ag thymodépendants ;

- elle augmente aussi la réponse in vitro à Brucella abortus-TNP (Ag thymoindépendant) (Kruger et Blalock, 1986).

\subsection{LA SOMATOSTATINE}

Elle a été testée in vitro sur des lymphocytes de rate, des plaques de Peyer et des ganglions mésentériques de souris stimulés par la ConA :

- elle diminue de 30 à $50 \%$ la synthèse d'ADN ;

- elle inhibe de 20 à $50 \%$ la sécrétion des IgA ;

- elle inhibe de 10 à $30 \%$ la sécrétion des IgM.

\section{6. $L^{\prime} \alpha-M S H$}

Elle inhibe l'effet de l'IL1 (interleukine 1) sur ses cellules cibles (elle serait un antagoniste endogène) concernant la prolifération des thymocytes de souris "in vitro" et la production des PgE par les fibroblastes, mais pas sur l'inhibition de la prolifération induite par l'IL2 des LT (lymphocytes T) cytotoxiques (Cannon et coll., 1986).

\subsection{LA PROLACTINE}

Elle intervient comme modulateur de la réponse des LT à la stimulation antigénique, réponse qui est inhibée par la bromocryptine. Le mode d'action de la cyclosporine A, qui est un immunosuppresseur puissant, peut s'expliquer par un effet compétitif avec la prolactine sur un même récepteur au niveau des lymphocytes T (Hiestand et coll., 1986). 
Ce tour d'horizon des effets des hormones hypothalamo-hypophysaires sur le système immunitaire permet de concevoir la réalité de l'impact du stress sur ce système, et aussi sa complexité. Si l'effet global sur les hormones paraît être une stimulation de la réponse immunitaire, il peut être compensé par l'effet inhibiteur des glucocorticoïdes (sur lesquels existe une littérature très abondante). Quant à l'adrénaline, certaines données seraient en faveur d'une inhibition des T suppresseurs (via des récepteurs $\alpha 2$ ) et d'une stimulation de l'activité cytotoxique (via des récepteurs $\beta$ ).

\section{FACTEURS SÉCRÉTÉS PAR LES CELLULES IMMUNITAIRES}

Les études ont été réalisées principalement par le groupe de Blalock au Texas. Le traitement des splénocytes de souris (probablement les macrophages) par des inducteurs de la sécrétion d'IFN $\alpha$ (interféron $\alpha$ ) entraîne la sécrétion d'ACTH-like et d'endorphin-like (Blalock et Smith, 1980-1981).

Ces facteurs sont semblables aux hormones hypophysaires du point de vue antigénique et activité biologique. Les cellules immunitaires seraient capables de sécréter non seulement des dérivés de la POMC, mais aussi de la TSH (Smith et coll., 1983), du VIP, de la somatostatine (Lygren et coll., 1984), et peut-être aussi de la gonadotrophine chorionique, de la GH, de la FSH et de la LH. Les cytokines des monocytes (par exemple l'interleukine 1 $\beta$ ) possèdent une puissante action stimulatrice sur l'axe hypothalamo-hypophyso-surrénalien (CRF 41-ACTH-corticoïde).

Si ces données sont confirmées, elles autorisent à concevoir un impact des cellules immunitaires sur le système des cellules endocrines. Ce rôle doit être toutefois limité, car il faut rappeler qu'une souris "nude" ${ }^{3}$ ne présente pas de désordres endocriniens considérables.

\section{STRESS ET IMMUNITÉ}

Les nombreux travaux qui mettent en évidence un lien entre le stress et le système immunitaire ont permis de développer une nouvelle discipline : la psycho-neuroimmunologie (Weinberg, 1994). On en trouvera des mises au point dans Baltrusch et coll. (1991), Cacciopo (1993), Stone et Boubjerb (1994).

3 Mutation qui entraîne une agénésie congénitale du thymus associée à l'absence de pelage. 


\subsection{BASES PHYSIOLOGIQUES ET MOLÉCULAIRES}

Le système nerveux central peut interagir avec le système immunitaire :

- via l'axe hypothalamo-hypophyso-surrénalien, mettant en jeu le CRF, l'ACTH et les glucocorticoïdes ;

- via l'innervation périphérique des organes lymphoïdes ;

- mais aussi par libération de neurotransmetteurs dans le sang.

Parmi ceux-ci, la substance $\mathrm{P}$, le vasoactive intestinal peptide (VIP) et les peptides opioïdes peuvent agir directement sur les lymphocytes (Payan et Goetzl, 1985 ; Morley et coll., 1987 ; Ruff et coll., 1988) ; en outre, des récepteurs pour de nombreux neurotransmetteurs ont été mis en évidence dans les lymphocytes humains circulants (Harper et coll., 1984 ; Bondy et coll., 1985 ; Rabey et coll., 1986 ; Eva et coll., 1989). C'est ainsi que le CRF est l'un des principaux agents des modifications immunitaires dans le stress puisqu'il peut stimuler l'ACTH et les endorphines non seulement au niveau de l'adénohypophyse, mais aussi à partir des lymphocytes (Smith et coll., 1986) et libérer ainsi la sécrétion de cortisol (Smith et coll., 1982).

- Une étude exhaustive sur l'altération de la fonction immunologique sous l'effet du stress a été réalisée par Rabin et coll. (1990). Ces auteurs ont recherché, sur deux lignées différentes de rats, l'effet de deux agents stressants, le choc électrique et le 2-déoxy-D-glucose (qui est un agent stressant métabolique). Les modifications portant sur les lymphocytes ont été observées dans le sang, la rate (pour les cellules NK) et les ganglions lymphatiques. Ils ont enfin déterminé le mécanisme de ces modifications, et en particulier les implications des stéroïdes surrénaliens et des opioïdes endogènes.

Les résultats observés ont été identiques quelle que soit la lignée utilisée. Les auteurs ont pu définir trois mécanismes différents : un mécanisme surrénaliendépendant à l'égard de la fonction mitogénique des lymphocytes sanguins périphériques, qui est déprimée (le retour à la normale nécessite 4 à 5 jours); un mécanisme surrénalien-indépendant dans le cas des lymphocytes spléniques, à récupération plus rapide ; une modification de la fonction des cellules NK (natural killers) de la rate par un mécanisme opioïde (antagonisé par la naltrexone).

- L'étude exhaustive rapportée par Cacciopo (1993) est le résultat d'une recherche commune à plusieurs équipes. La réponse de l'immunité cellulaire à un stress psychologique aigu se traduit par une baisse sensible de la fonction mitogénique des lymphocytes (fig. 16.1.a), par une élévation des $\mathrm{CD}^{+4}$ (et une baisse du rapport $\left.\mathrm{CD}^{+} / \mathrm{CD}^{+}\right)$, et une élévation importante du nombre et de la toxicité des cellules NK (fig. 16.1.b).

4 CD4 et CD8 sont des molécules glycoprotéiques; CD4 est liée aux molécules de classe II du complexe majeur d'histocompatibilité $(\mathrm{CMH})$, dans le cadre de la reconnaissance de la cellule présentatrice d'antigène; CD8 se lie aux molécules HLA (human leucocyte antigen) de classe I. 


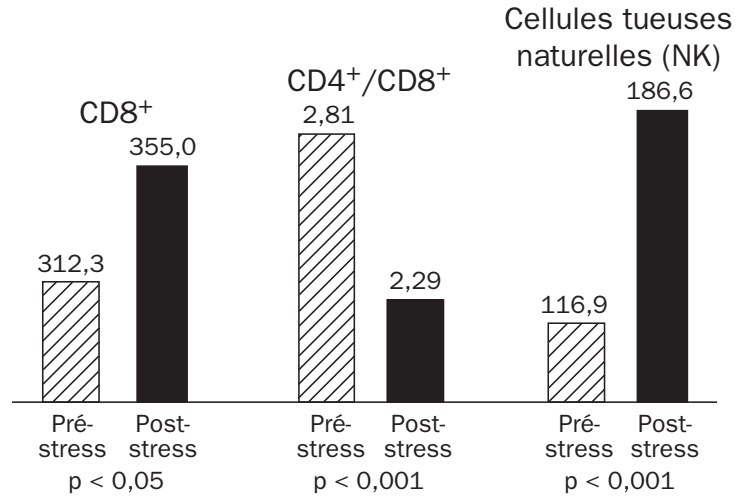

a - Réponse mitogénique à la ConA (concanavaline A) et à la PHA (phytohémagglutinine) - la réponse est exprimée en log des valeurs du comptage par minute

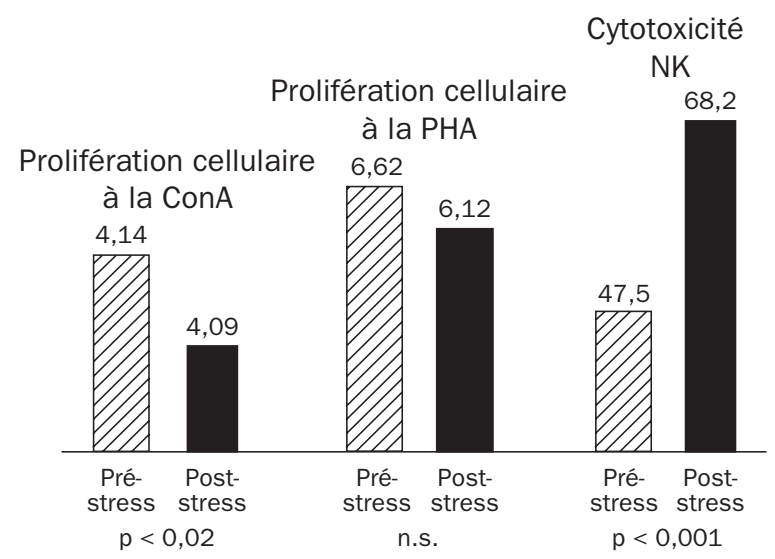

b - Réponse des différents types cellulaires - les chiffres représentent le nombre des cellules par $\mathrm{mm}^{3}$

Figure 16.1 - Réponse immunitaire cellulaire à un stress psychologique aigu

- L'étude biochimique des drogues utilisées pour traiter les symptômes pathologiques du stress peut constituer un outil d'étude des mécanismes impliqués dans les réactions du stress.

En particulier, les benzodiazépines (BDZ) semblent les plus utilisées pour traiter les manifestations d'anxiété, qui apparaissent liées au stress chronique chez l'homme. Ces benzodiazépines neutralisent en effet les modifications comportementales (Haefely et coll., 1981), neurochimiques (Rossetti et coll., 1990) et hormonales (Bizzi et coll., 1984) induites par le stress.

\subsubsection{Etude des récepteurs aux benzodiazépines (BDZ)}

Ferrarese et coll. (1993) se sont attachés à l'étude des récepteurs aux BDZ et à l'inhibiteur de liaison au diazépam (une benzodiazépine) relativement au stress. 
L'effet anxiolytique de BDZ est médié par un récepteur du système nerveux central (CBR ou central binding receptor) couplé à un récepteur GABA-A ${ }^{5}$; il agit par facilitation de la transmission gabaergique. Ces récepteurs sont nombreux dans le cerveau mammalien, particulièrement dans le cortex, le cervelet et les aires limbiques.

Les agonistes de ces récepteurs, tels que les BDZ, inhibent la libération de CRF en facilitant le tonus inhibiteur gabaergique, et agissent ainsi en immunosuppresseurs.

Mais les BDZ sont également actifs à un niveau périphérique sur une autre catégorie de récepteurs (PBR ou peripheral binding receptors) qui ont été trouvés dans tous les tissus de mammifères, parmi lesquels les cellules mononucléaires, la glande surrénale, les testicules et les ovaires. Ces récepteurs ne sont pas couplés à des récepteurs GABA-A, ils sont formés de deux sub-unités de respectivement 30 et $18 \mathrm{kDa}$.

Les auteurs ont étudié les récepteurs PBR dans les lymphocytes circulants de patients anxieux (suivant le DSM III-R, voir chap. 4 , § 10.5) et les effets de traitements aigus ou prolongés avec du diazépam. Le nombre des récepteurs, qui est diminué chez les patients anxieux, est restauré par le diazépam. Ces modifications paraissent spécifiques à l'anxiété.

Le rôle immunomodulateur joué par les récepteurs PBR semble doublé, in vitro, d'une action de contrôle sur la prolifération et la différenciation des cellules normales et cancéreuses. Le mécanisme biochimique qui lierait ces deux actions (immunomodulation et inhibition de la prolifération) est encore controversé, il passerait par une action sur la membrane externe de la mitochondrie et résulterait d'une inhibition à ce niveau de la stéroïdogenèse.

Les auteurs ont ensuite étudié les récepteurs CBR et PBR à la suite d'un stress (suite à un choc électrique sur la patte, ou une exposition au froid...). Les modifications observées ne sont pas univoques, elles dépendent de la nature de l'agent stressant ; les deux types de récepteurs peuvent même présenter des réponses de sens opposé.

\subsubsection{L’inhibiteur de liaison au diazépam et le stress}

La question qui s'est alors posée est : les ligands endogènes de ces récepteurs sont-ils impliqués dans la réponse au stress ? Parmi ceux-ci, l'attention s'est portée sur l'inhibiteur de liaison au diazépam (DBI), qui peut se lier aussi bien avec le CBR qu'avec le PBR.

On le trouve dans de nombreux organes (cerveau, foie, rein, surrénale...) de différentes espèces. Ce polypeptide est un précurseur de nombreux peptides qui se lient soit au PBR, soit au CBR, et qui sont des neuropeptides biologiquement actifs.

Il a été étudié chez des rats stressés et des patients anxieux.

5 GABA est un neurotransmetteur exerçant une action inhibitrice via l'activation de son récepteur (A) qui est un canal $\mathrm{Cl}^{-}$, et une relation stimulatrice via son récepteur (B). 
- Chez le rat stressé (stress aigu provoqué par le bruit) : élévation du DBI au niveau de l'hippocampe et de la glande surrénale, de façon très précoce, parallèlement au niveau de la corticostérone plasmatique. On peut supposer que le DBI est le médiateur de l'action stéroïdogène de l'ACTH au niveau de la glande surrénale.

- Chez les patients anxieux : diminution (-40\%) du taux de DBI dans les lymphocytes (due à un "turn-over" augmenté en faveur de petits peptides plus actifs ?) ; ce taux s'élève après un traitement prolongé par le diazépam.

En définitive, de nombreux arguments permettent de supposer que le DBI est un médiateur des effets centraux et périphériques du stress, en se liant aux deux types de récepteurs aux benzodiazépines.

\subsection{ETUDES EXPÉRIMENTALES ET CLINIQUES}

Divers travaux permettent de conforter l'hypothèse que certains événements de la vie exercent une influence sur l'évolution d'un cancer. C'est le cas des travaux qui, dans le cadre de l'immunomodulation, démontrent l'influence du psychisme en général, et du stress en particulier, sur notre système immunitaire (Villemain, 1989 ; Ferrarese et coll., 1993).

\subsubsection{L'expérimentation animale}

Chez les animaux de laboratoire, il apparaît que, si le stress aigu et le stress chronique peuvent se manifester de façon opposée quant à plusieurs paramètres du stress, leur effet sur le système immunitaire est habituellement le même, c'est-à-dire une inhibition de ce système (Borg et Moller, 1978 ; Armario et coll., 1984 ; Goodkin et coll., 1986 ; Lahiri et Banerjee, 1986 ; Steplewski et Vogel, 1986 ; Dorian et Garfinkel, 1987).

Mais c'est une vision trop simpliste des choses, il faut préciser, lorsqu'on rapporte ces expériences, quelles modalités de la réponse immunitaire sont impliquées.

\section{Le stress aigu}

Le stress aigu diminue l'immunité (Rasmussen, 1969 ; Solomon, 1969 ; Keller et coll., 1981 et 1983).

Chez des souris soumises à des chocs électriques ou à des sons intenses, on observe un rejet diminué des greffes hétérologues (tissus d'animaux différents), une plus grande sensibilité aux virus pathogènes et, en cas d'infection, une diminution de la synthèse d'interféron. Les chocs électriques provoquent également une diminution de l'activité lymphocytaire en réponse aux mitogènes (Laudenslager, 1983), ainsi que de la production d'anticorps spécifiques (Laudenslager, 1988).

Le retentissement des agressions contre l'organisme dépend de la capacité de contrôle de l'agression. Il devrait en être de même pour les effets du stress sur l'immunité et c'est effectivement ce que l'on observe. 
En 1988, Mormède et coll. ont montré sur des rats soumis à des chocs électriques que la possibilité de contrôle de la situation (ici un évitement) entraîne, par rapport à des rats qui n'ont pas cette possibilité, une prolifération lymphocytaire plus élevée mais une production d'anticorps plus basse (fig. 16.2).

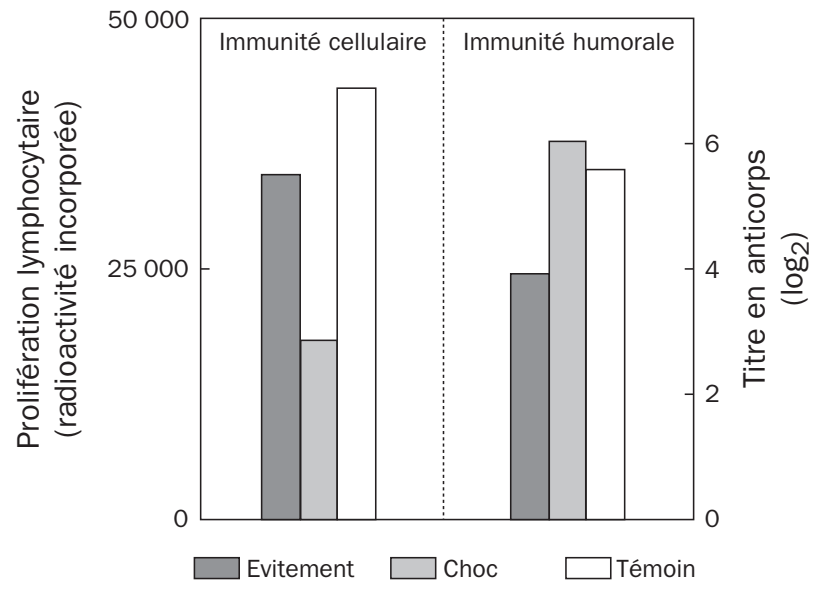

Figure 16.2 - Influence de la possibilité de contrôler le choc électrique

sur l'immunité cellulaire et humorale du rat (d'après Mormède et coll., 1988)

Des rats ayant appris à éviter des chocs électriques (évitement) sont comparés à des rats soumis aux mêmes chocs, mais sans possibilité d'évitement (choc), et à des animaux témoins sans choc (témoin), après dix séances de conditionnement. L'immunité cellulaire est mesurée par la prolifération lymphocytaire en réponse à un mitogène, tandis que l'immunité humorale est estimée par le titre en anticorps contre des globules rouges de mouton injectés au $5^{e}$ jour de l'expérience.

La plupart des expériences utilisent ainsi des agents stressants physiques qui ont l'avantage de la commodité. Les résultats sont parfois contradictoires. Mais leur caractère artificiel doit faire préférer des agressions survenant dans un contexte social. Ainsi, chez les rongeurs, diverses expériences démontrent que les animaux dominés présentent une diminution des réponses d'immunité cellulaire et humorale (Raab et coll., 1986).

En revanche, chez le Singe, la rupture de l'attachement entre le jeune et ses compagnons de captivité, si elle provoque une immunodépression de certains aspects de la réponse immunitaire (nombre des lymphocytes et des éosinophiles circulants, taux sériques d'immunoglobulines $\mathrm{G}$ ), favorise au contraire d'autres fonctions immunitaires : activité hémolytique du complément, action oxydative des macrophages (Reite et coll., 1981 ; Coe et coll., 1987).

\section{Le stress chronique}

Si le stress aigu est dépresseur de l'immunité cellulaire, les situations de stress chronique ou de stress répété peuvent au contraire, dans certaines conditions, entraîner une stimulation de l'immunité : augmentation de la prolifération lymphocytaire, de l'activité NK et de la réponse anticorps (Dunn, 1989). C'est dire qu'il faut être 
prudent dans les interprétations des relations entre stress et pathologie, d'autant que les résultats expérimentaux dépendent du type de facteur de stress utilisé, de même que de l'espèce animale étudiée.

Kort (1994) fait une étude détaillée des effets du stress chronique sur le système immunitaire et la carcinogenèse expérimentale chez le rat. Comme le fait remarquer cet auteur, il est difficile de réaliser un stress chronique. En effet, un agent stressant prolongé entraîne habituellement une adaptation et, s'il est peu intense, une habituation (voir Borg et Moller [1978] dans le cas d'un bruit). Aussi Kort et son groupe (Kort et Weijma, 1982 ; Kort et coll., 1986a et b) ont-ils préféré utiliser un stress physiologique inévitable, un stress par modification du rythme lumièreobscurité. Dans ces conditions, ils observent toujours une inhibition du système immunitaire.

\subsubsection{Stress et immunité chez l'homme}

On trouve généralement une diminution des défenses immunitaires chez des individus stressés.

On peut en fournir plusieurs exemples : la dépression, le deuil, le stress induit par un examen, la perte du travail. Un certain nombre de ces observations sont rapportées par Mazet (1986) ou Galinowski (1993).

\section{La dépression}

Les observations faites au cours de la dépression mettent en évidence des modifications significatives de la défense immunitaire. On en trouvera une étude détaillée dans la thèse de Maffre (1995). Dès 1973, de nombreux auteurs (Shopsin et coll., 1973 ; Johnston et Whaley, 1975 ; Deberdt et coll., 1976 ; Cappel et coll., 1978) rapportaient que la fonction lymphocytaire était altérée durant la phase aiguë de la maladie dépressive.

En comparant des sujets hospitalisés pour un épisode dépressif majeur, avec une population contrôle, le groupe de Stein (Schleifer et coll., 1984 et 1985) met en évidence une immunodépression qui porte à la fois sur l'immunité cellulaire et l'immunité humorale, tandis que les taux de cortisolémie sont augmentés. Des expériences ultérieures ont permis de conclure que l'hospitalisation par elle-même ne peut être à l'origine de cette inhibition immunitaire.

A la même époque, Kronfol et coll. (1983) font état d'une corrélation significative entre l'intensité de la dépression, mesurée par l'échelle de Hamilton (1967), et l'inhibition de la réponse lymphocytaire à un agent mutagène, le pokeweed ou PWM (fig. 16.3). Un an plus tard, en 1984, Kronfol et coll., partant de la constatation que la dépression primitive est souvent associée à une hyperactivité de l'axe hypothalamohypophyso-surrénalien, et donc à une hypercortisolémie (Sachar, 1975 ; Schlesser et coll., 1980), observent une diminution significative du nombre des lymphocytes chez 177 patients déprimés non-traités. 


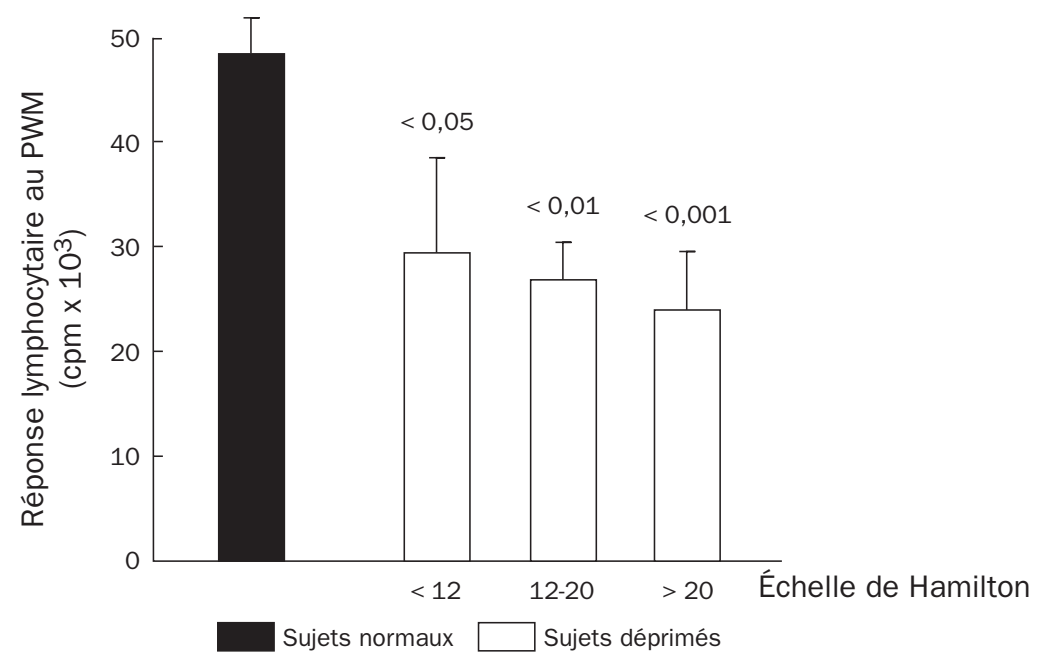

Figure 16.3 - Corrélation entre l'intensité de la dépression et l'inhibition de la réponse lymphocytaire (d'après Kronfol, 1983)

Shekelle et coll. (1981), dans une étude prospective portant sur 2020 hommes suivis pendant 17 puis 20 ans (Persky et coll., 1987), mettent en évidence une augmentation significative $(\times 2)$ de l'incidence des maladies néoplasiques chez des sujets présentant un score élevé de dépression, révélé au début de l'étude par le test MMPI ${ }^{6}$.

Cette conclusion n'était pas partagée par Kronfol qui exprimait, en 1983, que la relation entre les anomalies biologiques observées chez les déprimés et la plus grande vulnérabilité des déprimés aux infections et au cancer restait à établir. Et, effectivement, Zonderman et coll. (1989), dans une étude extensive sur 3980 sujets de plus de 55 ans, commencée en 1986 et comportant une mesure psychométrique des symptômes dépressifs à l'aide des échelles CES-D (Center for epidemiologic studies depression) et GWB-D (general well-being Schedule), dont 3814 (96\%) ont été revus à un deuxième check-up, concluent à l'absence de corrélation significative entre les symptômes dépressifs et le risque de morbidité ou de mortalité cancéreuse.

\section{Le deuil}

Des recherches ont été faites sur les effets de la perte d'un conjoint ou d'un enfant sur le système immunitaire. On doit à Bartrop et coll. (1977) la première étude objectivant un déficit immunitaire fonctionnel chez des sujets ayant perdu leur conjoint. On peut observer dans un délai de 2 à 6 semaines une diminution significative de la réponse proliférative lymphocytaire à deux agents mutagènes (stimulation par la PHA ou phytohémagglutinine et la ConA ou concanavaline A), c'est-à-dire de l'immunité cellulaire retardée. En revanche, il n'a pas été retrouvé de différence en ce qui concerne le nombre de lymphocytes $\mathrm{B}$ ou $\mathrm{T}$, la concentration d'immunoglobines, la

6 “Minnesota Multiphasic Personality Inventory" test. C'est un questionnaire destiné à quantifier des données attachées à une personnalité et à en faire une analyse statistique. 
présence d'anticorps, ni le taux des différentes hormones : cortisol, prolactine, hormone de croissance ou hormones thyroïdiennes.

Schleifer et coll. (1983) étudient quinze sujets dont la femme souffre d'un cancer à la période terminale. La comparaison entre leur système immunitaire avant le décès de leur épouse et dans les 2 mois qui ont suivi montre une diminution significative de trois tests immunitaires fonctionnels (les trois agents mutagènes sont la PHA, la ConA et le pokeweed). Mais ils ne relèvent aucune différence quant au nombre relatif ou absolu des lymphocytes B ou T.

Comme le fait remarquer Bonfils (1993), "si le décès d'un proche est assimilé, dans une certaine mesure, à une perte, il serait alors logique qu'un rôle déclenchant identique puisse être objectivé dans certaines situations vécues comme des pertes symboliques, telles que divorces, ruptures, licenciements, pertes monétaires". Toute proportion gardée, c'est bien ce que l'on a pu observer dans le stress conjugual (divorce), familial (décès du conjoint) ou professionnel où l'on observe une diminution des réponses d'immunité cellulaire et une augmentation de l'immunité humorale à l'égard de virus déjà présents dans l'organisme, comme le virus de l'herpès (Glaser et coll., 1987 ; Kiecolt-Glaser et coll., 1988).

Spratt et Denney (1991) trouvent, chez des parents d'enfant brutalement décédé, une perturbation durable des lymphocytes T-suppresseurs (qui sont diminués), des Thelpers (qui sont augmentés), mais pas de modification du taux de la cortisolémie.

Toutefois, Martin-Du Pan fait remarquer (1991) que les modifications immunitaires observées après un deuil sont beaucoup plus faibles que dans le SIDA, ou même chez les séropositifs.

\section{Les examens}

Quarante étudiants en médecine ont été testés 6 semaines avant les examens de fin d'année et juste le 1er jour des examens (voir fig. 16.4) : on a pu observer une forte réduction de la production d'interféron leucocytaire et une diminution du nombre et de l'activité des cellules NK (Glaser et coll., 1986).

\section{Tableau 16.1 - Influence des examens sur la production d'interféron leucocytaire et l'activité des cellules NK}

(d'après Glaser et coll., 1986)

\begin{tabular}{|l|c|c|c|}
\hline \multirow{2}{*}{} & $\begin{array}{c}\text { Interféron leucocytaire } \\
\text { (unités / } \mathrm{ml} \text { ) }\end{array}$ & \multicolumn{2}{|c|}{ Cellules tueuses naturelles (NK) } \\
\cline { 3 - 4 } & 2000 & $\begin{array}{c}\text { Pourcentage } \\
\text { circulant }\end{array}$ & $\begin{array}{c}\text { Activité } \\
\text { cytolytique }\end{array}$ \\
\hline Ligne de base & 80 & 16,3 & $45 \%$ \\
Examens & 9,1 & $30 \%$ \\
\hline
\end{tabular}

Les quarante étudiants en médecine ont été testés 6 semaines avant les examens de fin d'année (ligne de base) et le $1^{\text {er }}$ jour des examens. 
Dans une autre étude, Jemmott et coll. (1983) ont mesuré la sécrétion d'immunoglobulines dans la sécrétion salivaire de 64 étudiants en chirurgie dentaire, et trouvé que la sécrétion en IgA varie notablement :

- selon que l'examen représente une étape capitale du curriculum (haut stress) ou au contraire un contrôle de routine (bas stress) ;

- et selon la personnalité des étudiants, la sécrétion étant plus élevée chez ceux qui recherchent une relation interpersonnelle chaleureuse, et plus basse chez ceux qui réfrènent leur volonté de pouvoir (fig. 16.4).

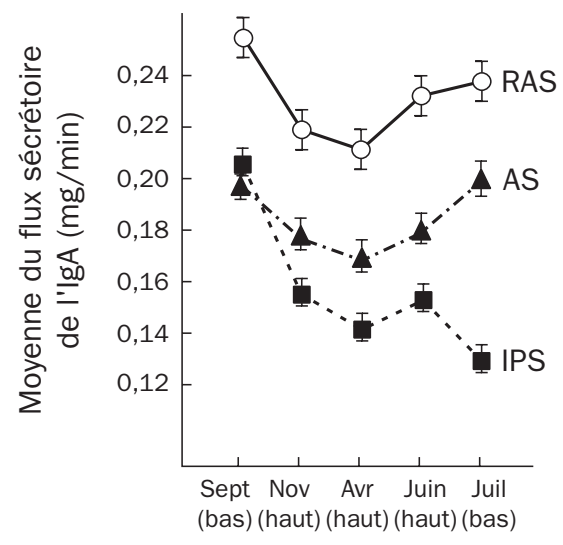

Figure 16.4 - Flux sécrétoire des IgA salivaires d'étudiants, selon le niveau haut ou bas du stress de l'examen et la personnalité de l'étudiant

(d'après Jemmot et coll., 1986)

As correspond à l'ensemble des étudiants, RAS à ceux qui recherchent une relation interpersonnelle chaleureuse et IPS à ceux qui réfrènent leur motivation de pouvoir.

\section{Autres causes de stress}

- Les troubles paniques (d'après la définition du DSM III), qui peuvent être d'ailleurs déclenchés par un facteur de stress, s'accompagnent d'une baisse significtive des IgA sériques (Ramesh et coll., 1991). Mais la validité de ce test ayant été critiquée (Stone et coll., 1977), la critique s'applique donc également à l'expérience précédente.

- L'effet de la perte de travail est un exemple de stress chronique. Il a été étudié chez des femmes qui avaient perdu leur emploi 9 mois avant le début de cette étude (Brenner, 1979). L'effet n'en était que psychologique car ces femmes avaient reçu une allocation correspondant à $90 \%$ de leur salaire. Le résultat observé était une diminution de la réponse à la PHA (phytohémagglutinine) et au PPD (dérivé protéique purifié de la tuberculine).

- Un autre exemple de stress chronique concerne les habitants de Three Mile Island, lieu d'un accident d'une centrale atomique en 1979. Ces habitants vivaient dans la peur des séquelles concernant leur santé et la crainte de la réouverture de la centrale. Ils ont présenté une réduction des lymphocytes $\mathrm{B}$, des cellules T suppressives et cytotoxiques, et des cellules NK (McKinnon et coll., 1989). 


\section{AUTO-ANTICORPS ET ENDOCRINOPATHIES AUTO-IMMUNES}

Dans le cadre de ces endocrinopathies, la relation entre système immunitaire et cellules endocriniennes n'a rien de spécifique, et il faut rechercher dans une prédisposition du "terrain", c'est-à-dire au niveau de gènes du système HLA ou dans la spécificité de l'agent causal ${ }^{7}$ (virus), la raison de l'atteinte du système endocrinien, lorsque celle-ci est isolée. Dans d'autres cas, l'endocrinopathie ne représente qu'un symptôme auto-immun parmi d'autres, elle n'est alors qu'une des expressions d'un dérèglement de la coopération/régulation des cellules immunitaires.

\subsection{LES AUTO-ANTICORPS - LE RÉSEAU IDIOTYPIQUE}

Il s'agit d'anticorps dirigés contre des constituants cellulaires d'un individu. Ces constituants antigéniques sont en général des composants biochimiques de la cellule : thyroglobuline, myéline ou des éléments membranaires, cytoplasmiques, microsomiaux ou nucléaires qu'on ne retrouve pas normalement dans la circulation. Ce peuvent être aussi des cellules entières, telles les spermatozoïdes, cellules qui n'existaient pas à la naissance et qui sont normalement élaborées puis éliminées à l'intérieur d'une cavité épithéliale fermée, et normalement sans contact avec le système immunitaire.

On pensait que l'apparition de ces auto-anticorps constituait un dérèglement pathologique de la régulation immunitaire. On sait qu'en fait l'organisme peut sécréter normalement, mais en très faible quantité, ces auto-anticorps.

Un exemple en est donné par le réseau idiotypique (fig. 16.5). Au départ hypothèse élaborée par Oudin (1968) puis Jerne (1984), elle a, depuis, reçu de nombreuses confirmations qui ont valu à Jerne le prix Nobel 1984. Soit un anticorps (Ab1) avec son idiotype, constitué par les parties variables des chaînes lourdes et légères (Fab) et qui porte des déterminants appelés idiotopes. Ces idiotopes peuvent être à l'intérieur ou à l'extérieur du site de liaison. Ceux qui sont à l'intérieur constituent le paratope, qui est stériquement complémentaire du site antigénique ou épitope. Selon Jerne, l'anticorps est susceptible d'induire des anticorps anti-idiotypes (Ab2), qui sont euxmêmes contrôlés par des anti-anti-idiotypes (Ab3).

L'anticorps anti-idiotype est en quelque sorte un auto-anticorps et c'est la raison pour laquelle son existence, compte tenu aussi de la sensibilité insuffisante des méthodes de dosage des anticorps à l'époque où Jerne a exprimé son hypothèse, était controversée. Dans la mesure où l'anti-idiotype est dirigé contre des idiotypes situés à l'intérieur du paratope, il est clair qu'il peut jouer le rôle de l'antigène d'origine, dont

7 Elle repose sur la similitude entre les molécules membranaires de la cellule endocrine et celles de l'enveloppe du virus. 
il sera une "image interne". Si cet antigène d'origine est une hormone, l'anti-idiotype est capable d'interagir avec le récepteur à l'hormone, pour lequel il se comportera comme un anticorps antirécepteur :

- soit bloquant (par exemple le diabète insulinorésistant). Il fonctionne comme antagoniste du site récepteur ;

- soit stimulant (par exemple la maladie de Basedow). Il se comporte alors comme un agoniste sur le site récepteur.
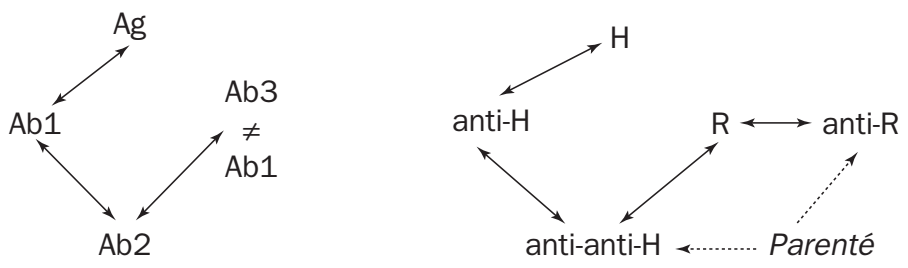

Figure 16.5 - Le réseau idiotypique de Jerne

\subsection{LA MALADIE AUTO-IMMUNE}

La maladie auto-immune correspond soit à des auto-anticorps sécrétés en quantité anormale (maladie auto-immune humorale), soit à une présence active de lymphocytes cytotoxiques dirigés contre les cellules de l'organisme (maladie auto-immune cellulaire). Ces deux types de dysfonctionnement auto-immun peuvent, bien sûr, être associés.

Les endocrinopathies auto-immunes, isolées ou associées, comprennent l'hypoparathyroïdie, l'hypothyroïdie primitive, la maladie de Graves-Basedow, la thyroïdite de Hashimoto, l'insuffisance surrénale chronique, l'hypogonadisme primitif, le diabète de type I, et même certains déficits hypophysaires isolés.

Maladie d'Addison auto-immune et maladie de Graves-Basedow représentent deux exemples différents d'endocrinopathie auto-immune.

- Dans les pays développés, la maladie d'Addison est liée deux fois plus souvent à une pathologie immune qu'à la tuberculose. On retrouve souvent (mais pas toujours) des anticorps anticortex surrénal. Une autre endocrinopathie lui est associée dans environ $1 / 3$ des cas, la surrénale ne représentant pas alors nécessairement la première atteinte endocrinienne. La maladie auto-immune entraîne dans ce premier exemple une insuffisance sécrétoire, c'est la conséquence la plus habituelle de l'atteinte auto-immune. On retrouve ce phénomène dans la thyroïdite autoimmune d'Hashimoto ${ }^{8}$, qui se traduit par un goître hypofonctionnel et pour

8 Le goître d'Hashimoto est l'une des trois formes distinctes de ce que l'on appelle la thyroïdite auto-immune, les deux autres formes étant le myxœdème spontané de l'adulte et la thyroïdite atrophique asymptomatique. 
laquelle on retrouve presque toujours une cytotoxicité à $\mathrm{T}$ cytotoxiques et parfois une ADCC (antibody dependant cytotoxicity).

Il est probable que la rupture de l'autotolérance résulte d'une prédisposition génétique HLA-dépendante (souvent DR3 et DR4, parfois B8). Elle est accompagnée dans le cas de la thyroïdite auto-immune, qui a été étudiée, d'un dérèglement du rapport entre les cellules $\mathrm{T}$ helper et $\mathrm{T}$ suppressives, et d'un défaut de fonctionnement de la cellule thyroïdienne.

- La maladie de Graves-Basedow est bien due à des anticorps, mais des anticorps immunostimulants. Les immunoglobulines sont des antirécepteurs à la TSH et agiraient soit comme agonistes de ces récepteurs, soit par une action sur la configuration du récepteur, ou d'une structure membranaire qui lui est associée. 



\section{CHAPITRE 17}

\section{HORMONES ET ÉVOLUTION}

L'évolution des Vertébrés s'est exprimée à travers des changements profonds d'adaptation à l'environnement : passage de l'eau de mer à l'eau douce, et de la vie aquatique à la vie terrestre ou aérienne (Wingfield et coll., 1997). Parallèlement à ces changements sont apparues des modifications profondes au niveau des organes et de leurs fonctions : croissance, reproduction, qui ont nécessairement retenti sur la nature et le rôle des messagers que sont les hormones de l'organisme. Certaines hormones ont assumé des rôles nouveaux ou ont restreint leur spécificité d'action, d'autres hormones sont apparues pour assumer des fonctions nouvelles.

On peut considérer du point de vue de l'adaptation phylogénétique trois grands secteurs que contrôle le fonctionnement hormonal : les échanges ioniques avec le monde extérieur (adaptation au monde extérieur), l'appareil et les fonctions de reproduction (survie de l'espèce) et le métabolisme général de l'organisme (survie de l'individu). Comme nous l'avons exprimé au cours de cet ouvrage, alors que les hormones protéiques ont beaucoup varié au cours de l'Evolution, témoignant de l'évolution des gènes correspondants, les hormones stéroïdes ont peu évolué, sans doute parce que la plus grande complexité de leur biosynthèse rendait les variations éventuelles (mutations) non-viables.

\section{LE CONTRÔLE DE LA CONCENTRATION EN IONS DU MILIEU INTÉRIEUR}

C'est un des problèmes majeurs au cours de la phylogenèse des sécrétions hormonales, en particulier pour les ions $\mathrm{Na}^{+}$et $\mathrm{Ca}^{2+}$.

\subsection{LE CONTRÔLE DU Na+}

Pour le $\mathrm{Na}^{+}$, l'une des hormones essentielles est de nature stérö̈de. C'est le cortisol chez les Poissons, sauf pour les Dipneustes qui synthétisent en plus l'aldostérone. Ce cortisol a une action différente suivant la nature de l'environnement aquatique. Chez 
les poissons osseux d'eau de mer, il stimule l'excrétion active de $\mathrm{Na}^{+}$, alors que chez

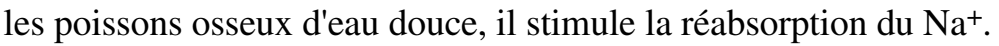

Le cortisol est également sécrété en réponse au stress, ce qui lui confère une double capacité énergétique et de régulation de la pression osmotique. Les Amphibiens, les Reptiles et les Oiseaux synthétisent corticostérone et aldostérone. Le point d'impact de celle-ci, qui contrôle plus spécifiquement la réabsorption $\mathrm{du} \mathrm{Na}^{+}$, est la peau chez les Amphibiens adultes, la vessie chez les Reptiles, l'intestin chez les Oiseaux et le rein chez les Mammifères. Tandis que la corticostérone (ou le cortisol, pour certains Mammifères) est concernée par le métabolisme énergétique et la réaction au stress.

\subsection{LE CONTRôlE DU Ca ${ }^{2+}$}

Pour le contrôle du $\mathrm{Ca}^{2+}$, trois hormones sont impliquées, mais avec des effets différents selon l'espèce et les problèmes qu'elle doit résoudre. Ces trois hormones sont : la calcitonine, la parathormone et le 1,25-(OH) $)_{2}-\mathrm{D} 3$. La calcitonine est sécrétée par le corps ultimo-branchial chez les Poissons, dont l'ébauche migre à l'intérieur de celle du corps thyroïde au cours de l'embryogenèse chez les Mammifères. Chez tous les Vertébrés, elle abaisse la teneur du calcium plasmatique. La parathormone, au contraire, est hypercalcémiante chez les Oiseaux ou les Mammifères, elle est sécrétée au niveau des glandes parathyroïdes. Mais les poissons osseux possèdent une hormone analogue à la parathormone, qui est sécrétée par des glandes situées en arrière des reins, les corpuscules de Stannius ${ }^{1}$. Cette parathormone de poisson agit comme la calcitonine pour abaisser la concentration du calcium plasmatique. Dans cette classe, la défense contre un environnement trop riche en ions, que ce soit le $\mathrm{Na}^{+}$ou le $\mathrm{Ca}^{2+}$, induit donc une action régulatrice qui sera inversée (pour le minéralocorticoïde, comme pour la parathormone) dans les classes plus évoluées. Cet effet inversé pour la parathormone est lié à un changement de cible pour l'hormone, qui favorise l'excrétion des ions $\mathrm{Ca}^{2+}$ au niveau des branchies (ce qui fait diminuer la calcémie) chez les Poissons, alors qu'elle provoque la déminéralisation de l'os chez les Vertébrés aériens.

\section{LE CONTRÔLE DE LA VOLÉMIE}

Un problème tout aussi majeur, et qui, chez les Mammifères, est même prioritaire sur le précédent, est le contrôle de la volémie. Il est assumé chez les Mammifères par une des hormones de la neurohypophyse, l'hormone antidiurétique (ou vasopressine) qui constitue, avec l'ocytocine, un de ces "couples" hormonaux, à gène ancestral unique (Hoyle, 1998), comme le sont par exemple la FSH et la LH (et la TSH), ou la GH et

1 La parenté immunologique de cette hormone avec les parathormones de Mammifères permet de supposer que ces hormones proviennent de gènes très voisins. 
la prolactine (et l'HCG placentaire). Le gène initial a subi à un stade plus ou moins précoce une duplication (ou triplication) et les gènes ainsi réalisés ont pu subir au cours de l'évolution, soit des mutations multiples, soit une évolution plus complexe (Wallis, 1993) avec, par exemple, un ou plusieurs dédoublements successifs.

En ce qui concerne le "couple" vasopressine-ocytocine, il n'était représenté que par une seule hormone, la vasopressine, chez les Agnathes, et devait contrôler la circulation sanguine. Un deuxième nonapeptide apparaît chez les Poissons cartilagineux par duplication du gène ancestral, et la vasotocine devient active sur un deuxième récepteur, présent sur les muscles lisses de l'oviducte. A partir des Dipneustes et jusqu'aux Reptiles, la neurohypophyse sécrète, en plus de la vasotocine, soit de l'ocytocine, soit de la mésotocine. Chez les Oiseaux, ce sont la vasotocine et l'ocytocine. Et ce n'est que chez les Mammifères que l'on voit apparaitre la vasopressine (arginine ou lysine vasopressine) comme élément du couple hormonal : hormone de régulation $(\mathrm{ADH})$ et hormone de reproduction (ocytocine).

\section{L'ÉVOLUTION DES HORMONES À PARTIR D'UN GÈNE ANCESTRAL COMMUN}

Cette évolution d'hormones qui assument les deux fonctions essentielles, survie de l'espèce (reproduction) et survie de l'individu (métabolisme), apparaît donc aussi pour les couples GH-prolactine et TSH-hormones gonadotropes. Un autre exemple est constitué par le couple ADH-ocytocine.

\subsection{GH - PROLACTINE (RUSSEL ET NICOLL, 1990)}

Ce couple existe déjà chez les poissons osseux et la structure de la séquence en acides aminés n'a cessé de muter au cours de l'évolution, ce qui pose un problème quant à la structure des récepteurs correspondants et aux modalités de l'interaction hormonerécepteur (Onta, 1993). Ce n'est sans doute pas un hasard si ces deux hormones subissent, dans leur modalité d'action au niveau cellulaire, un processus identique d'internalisation dont le mécanisme et le rôle sont encore mal connus.

L'hormone de croissance a gardé sa spécificité d'action tout au long de l'évolution, mais par des mécanismes qui ont pu varier. Au contraire, les effets de la prolactine sont très divers, et peuvent être classés en trois types principaux :

- des effets liés au développement (croissance larvaire chez les têtards d'Amphibiens, croissance chez les Oiseaux);

- des effets liés à l'osmorégulation, par diminution de la perméabilité des téguments ; elle limite l'entrée d'eau et la perte de $\mathrm{Na}^{+}$au niveau des branchies chez les poissons osseux en eau douce, et a donc favorisé la conquête des eaux douces chez les poissons ; 
- des effets liés à la reproduction au niveau comportemental ou métabolique, depuis le contrôle de la formation du nid chez les Poissons cyclidés, ou de la couvaison au moment de la nidation chez les Oiseaux, jusqu'à la stimulation de la lactation et de la fonction lutéotrope chez les Mammifères.

La duplication du gène commun à la $\mathrm{GH}$ et à la prolactine s'est nécessairement produite très tôt dès le début de l'évolution des Vertébrés (ou même avant). En revanche, la duplication qui a conduit au gène de l'HCG a dû se produire durant l'évolution des Primates, après leur séparation des autres Mammifères placentaires.

\subsection{TSH - HORMONES GONADOTROPES (FSH ET LH)}

Il s'agit d'hormones glycoprotéiques constituées de deux sous-unités $\alpha$ et $\beta$. Pour une espèce de Mammifère donnée, la sous-unité $\alpha$ est identique pour les trois hormones. La spécificité de structure et donc d'action est, par conséquent, assumée par la sousunité $\beta$, la sous-unité $\alpha$ pouvant intervenir dans le déclenchement de la stimulation de l'activité métabolique après la liaison de l'hormone à son récepteur. L'hypothèse la plus probable est que les deux sous-unités dériveraient par dédoublement d'un gène ancestral unique. Par la suite, la sous-unité $\beta$ aurait évolué de façon complexe. Au début, chez les Agnathes, elle n'a conféré qu'une potentialité gonadotrope unique. Chez des poissons primitifs, elle aurait acquis une potentialité supplémentaire thyréotrope. Puis le gène codant pour la sous-unité $\beta$ se serait dédoublé, codant pour deux sous-unités distinctes, l'une à fonction gonadotrope et l'autre à fonction thyréotrope, ce qui a permis, comme pour le couple GH-prolactine, un contrôle distinct du développement et de la reproduction. Chez les ancêtres des Amphibiens, le gène codant pour la sous-unité $\beta$ à fonction thyréotrope se serait à nouveau dédoublé, codant pour deux sous-unités $\beta$ dont l'une aurait conservé la fonction thyréotrope, tandis que l'autre aurait acquis une fonction gonadotrope $\mathrm{FSH}$, prenant en charge une partie des fonctions assumées par la potentialité gonadotrope "primitive" (stimulation de la croissance des follicules ovariens), tandis que cette dernière n'assumerait plus que les stades finaux, caractérisant la fonction LH (maturation ovocytaire et ponte). Une telle différenciation a permis de rendre la ponte ovulaire indépendante et donne à l'animal davantage de possibilités d'adaptation aux variations des conditions d'environnement. Par ailleurs, des mutations ponctuelles ont affecté aussi bien la sous-unité $\alpha$ que ces trois sous-unités $\beta$, déterminant une spécificité zoologique propre à chaque espèce.

\subsection{LES HORMONES NEUROHYPOPHYSAIRES}

Les neuropeptides hypothalamo-hypophysaires (ADH et ocytocine) ont également évolué à partir d'un gène unique, produisant la vasotocine, qui s'est ultérieurement dupliqué en deux gènes, à travers des mutations sur les acides aminés 3 et 8 (voir tab. 4.2). 


\section{UBIQUITÉ ÉVOLUTIVE DES HORMONES}

En fait, les messagers qui constituent les hormones chez les Vertébrés ont fait leur apparition bien avant les 600 millions d'années qui précèdent notre ère et qui correspondraient au moment de l'apparition des Vertébrés.

\subsection{LES MICRO-ORGANISMES : BACTÉRIES ET LEVURES}

\subsubsection{Les Bactéries}

Les bactéries sont apparues il y a presque 3 milliards d'années, et elles fabriquaient déjà (ou tout au moins elles fabriquent actuellement) des molécules ressemblant à des hormones de Vertébrés qui devancent donc la différenciation des systèmes endocrines. La fonction de ces molécules n'est pas connue. D'autre part, on retrouve chez ces bactéries d'autres molécules qui ressemblent aux récepteurs correspondants de Vertébrés, ou au moins à la partie du récepteur qui contient le site de liaison.

C'est ainsi que l'on trouve des molécules ressemblant à :

- la TSH chez Clostridium perfringens ;

- la neurotensine chez Escherichia coli ;

- l'insuline chez Escherichia coli, Bordetella pertussis ;

- la somatostatine chez Escherichia coli, Bacillus subtilis ;

- la calcitonine chez Escherichia coli.

\subsubsection{Les Levures}

Chez les levures, on trouve des molécules semblables à :

- la calcitonine chez Candida albicans ;

- aux hormones stéroïdes (œstrogènes chez Saccharomyces cervisiae, corticostérone chez Candida albicans ); ces levures possèdent également les récepteurs correspondants ;

- enfin, un facteur peptidique membranaire d'une levure (Saccharomyces cerevisiae) provoque par reconnaissance d'un récepteur spécifique l'accouplementfusion de deux cellules haploïdes ; or, ce peptide (facteur $\alpha$ ) a une séquence d'acides aminés très voisine de celle de la LH-RH. Il en reconnaît le récepteur et est capable de stimuler la fonction reproductrice des Mammifères !

\subsection{LES PROTOZOAIRES}

Chez les Protozoaires, par exemple chez Tetrahymena (Le Roith et coll., 1986), on a pu mettre en évidence des substances immunologiquement semblables à :

- des endorphines,

- de l'insuline,

- de la somatostatine, 
- de la vasotocine,

- de l'ACTH,

- de la calcitonine,

qui peuvent soit agir à distance sur d'autres individus, soit se lier sur la même cellule à des autorécepteurs. De même, on peut observer sur Tetrahymena les systèmes de second messager de type AMPc, GMPc, IP3 et calmoduline (Kovacs et Csaba, 1990).

\subsection{LES INVERTÉBRÉS}

Des peptides, tels que l'ACTH, la prolactine, les endorphines, présents à la fois dans le système nerveux et dans le système endocrinien des Vertébrés, ne sont détectables chez les Invertébrés qu'au niveau de leurs neurones.

D'après cet exemple, et d'autres du même type, il semblerait que les substances hormonales, au cours de la phylogenèse, soient d'abord neuro-endocrines, les substances sécrétées agissant soit au voisinage immédiat de l'extrémité neuronale (neuromédiateur synaptique), soit à distance par diffusion à partir de cette extrémité (pseudo-hormone). Le gène ancestral s'exprime dans les neurones avant que ses descendants ne s'expriment dans d'autres types cellulaires. Comme le rappellent Vincent et Simonnet (1986), l'existence de glandes endocrines nettement indépendantes du système nerveux est un avatar relativement récent de l'évolution, propre aux Vertébrés et aux Invertébrés supérieurs.

\subsection{LES PLANTES}

Chez les plantes, on a pu retrouver des molécules qui sont immunoréactives (qui se comportent comme des anticorps) :

- à l'insuline (épinard),

- à la somatostatine C14 et C28 (épinard),

- à la LH-RH (avoine),

- à la TRH (alfa).

\section{UBIQUITÉ FONCTIONNELLE DES HORMONES}

Ces exemples que nous avons cités confirment l'importance du rôle joué par le système endocrinien au cours de l'évolution des espèces. L'évolution a pu se faire par différenciation de molécules voisines qui assument des tâches différentes, préalablement assumées par une seule hormone, d'où une autonomie, une indépendance croissantes des diverses fonctions assumées. Elle a pu se faire également par une diversification de la localisation des récepteurs, si bien qu'un même peptide peut agir 
au cours de l'évolution selon diverses modalités. Un cas particulier de cette diversification, qui constitue un exemple étonnant de convergence adaptative, est que ce sont souvent les mêmes substances qui interviennent dans les mécanismes d'une réponse métabolique et dans ceux de la réponse comportementale qui lui est habituellement associée.

La même substance agit alors dans le sang sous forme d'une hormone classique et dans le cerveau comme neurohormone :

- c'est le cas de la LH-RH qui, par injection dans le sang, provoque l'ovulation et, injectée dans le cerveau, déclenche la séquence du comportement reproducteur ;

- c'est le cas de l'angiotensine II qui provoque par voie sanguine la contraction des vaisseaux et la libération d'aldostérone, et agit dans le cerveau à la fois pour déclencher le comportement dipsique (recherche de boisson), réguler la pression artérielle et favoriser la libération de l'ADH ;

- même double destinée pour l'insuline, l'ocytocine, la CCK, le VIP, témoignant de la formation, au sein du cerveau, des mêmes substances que celles utilisées au niveau des organes périphériques, pour assurer harmonieusement un même destin fonctionnel ;

- c'est aussi le cas pour des hormones sexuelles, la prégnénolone et la déhydroépiandrostérone, qui paraissent sécrétées par les oligodendrocytes chez les rats et les singes, pour lesquels elles seraient impliquées dans l'agressivité et la reconnaissance sexuelle (Le Goascogne et coll., 1987).

\section{LA NOTION DE CELLULE CIBLE}

La notion de cellule cible est un concept pragmatique qui ne doit pas impliquer une finalité ou une "télé-finalité". Il est évident que l'hormone n'a pas "choisi" ses cellules cibles. C'est l'apparition d'un récepteur stériquement complémentaire de la molécule hormonale qui est la condition nécessaire (mais non-suffisante - il faut aussi que la reconnaissance entraîne l'activation d'un métabolisme cellulaire spécifique) pour que la cellule devienne une cellule cible.

Comme nous l'avons vu, le couplage molécule hormonale-récepteur existe déjà chez les Levures. Ce couplage ne préjuge pas de l'antériorité de l'un ou l'autre élément de ce couple, et seuls ont dû se maintenir des couplages (peut-être fortuitement apparus) qui constituent des adaptations évolutives. On pourrait en dire autant pour un certain nombre de coaptations, dont celle des organes sexuels chez les Vertébrés et les Invertébrés ! 



\section{RÉFÉRENCES BIBLIOGRAPHIQUES DE LA QUATRIÈME PARTIE}

\section{HORMONES ET IMMUNITÉ}

ADAMS D.D. \& PURVES H.D., Abnormal responses in the assay of thyrotropin, Proc. Univ. Otago Med. School, 34, 11, 1956.

ARMARIO A., CASTELLANOS J.M. \& BALASH J., Effect of acute and chronic psychogenic stress on corticoadrenal and pituitary-thyroid hormones in male rats, Horm. Res., 20, 241-245, 1984.

Auto-immunité et affections endocriniennes, 24e Journées internationales d'Endocrinologie clinique, Paris, mai 1981.

BACH J.F. \& coll., Evidence for a serum-factor secreted by the human thymus, Lancet, 2 : 7786, 1056-1058, 1972.

BALTRUSH H.J.F., STANGEL W. \& TITZE I., Stress, cancer and immunity, Acta Neurol. Napoli, 13, 315-327, 1991.

BARTROP R.W., LUCKHURST E., LAZARUS L. \& coll., Depressed lymphocyte functions after bereavement, Lancet, 1 : 8016, 834-836, 1977.

BIZZI A., RICCI M.R., VENERONI E., AMATO M. \& GARATTINI S., Benzodiazepine receptors antagonists reverse the effect of diazepam on plasma corticosterone in stressed rats, J. Pharm. Pharmacol., 36, 134-135, 1984.

BLALOCK J.E., Relationship between neuroendocrines hormones and lymphokines, Lymphokines, 2, 1-13, 1984.

BONDY B., ACKENHEIL M., ELBERS R. \& FROHLER M., Binding of 3-Hspiperone to human lymphocytes : a biological marker in schizophrenia ?, Psychiat. Res., 15, 41-48, 1985.

BONFILS S., Impertinente psychosomatique, John Libbey Eurotext ed., Montrouge, 1993.

BORG E. \& MOLLER A.R., Noise and blood pressure : effect of lifelong exposure in the rat, Acta Physiol. Scand., 103, 340-342, 1978.

BRENNER M.H., Mortality and the national economy, Lancet, 2 : 8142, 568-573, 1979.

CACCIOPO J.T., Social neuroscience : autonomic, neuroendocrine and immune response to stress, Psychophysiology, 31, 113-128, 1993.

CAPPEL R., GREGOIRE F., THIRY L. \& SPRECHER S., Antibody and cell mediated immunity to herpes simplex virus in psychotic depression, J. Clin. Psychiat., 39, 266-268, 1978. 
COE C.L. \& coll., Immunological consequences of psychological disturbance and maternal loss in infancy, in "Advances in Infancy Research", Rove-Collier \& Lipsitt eds, Ablex Pub. Corp., Norwood, 1987.

COMSA J., Hormones interactions of the thymus, in "Thymic hormones", Luckey T.D. ed., Univ. Park Press, Baltimore, 1973.

COMSA J. \& coll., Hormonal influences on the secretion of the thymus, Thymus, 1 , 81-93, 1979.

COMSA J. \& coll., Hormonal coordination of the immune response, Rev. Physiol. Biochem. Pharmacol., 92, 115-191, 1982.

DEBERDT R., HOOREN J. (Van), BIESBROUCK M. \& coll., Antinuclear factorpositive mental depression : a single disease entity, Biol. Psychiat., 11, 69-74, 1976.

DESCHAUX P., Le thymus, organe endocrinien, J. Physiol., 76, 357-371, 1980.

DONIACH D. \& ROITT I.M., Autoimmunity in Hashimoto's disease and its implications, J. Clin. Endocr. Metab., 17, 1293-1304, 1957.

DORIAN B. \& GARFINKEL P.E., Stress, immunity and illness : a review, Psychol. Med., 17, 393-407, 1987.

DUNN A.J., A review of animal studies of nervous system-immune system interactions, Psychoneuroendocrino., 4, 251-274, 1989.

EVA C., FERRERO P., ROCCA P., FUNARO A., BERGAMSCO B., RAVIZZA L. \& GENAZZANI E., 3H-N-methylscopolamine binding to muscarinic receptors in human peripheral blood lymphocytes : characterization, localization on T-lymphocytes subsets and age-dependant changes, Neuropharmacology, 28, 719-726, 1989.

FERRARESE C., APPOLONIO I., BIANCHI G., FRIGO M., MARZORATI C., PECOR N., PEREGO M., PIERPAOLI C. \& FRATTOLA L., Benzodiazepine receptors and diazepam binding inhibitor : a possible link between stress, anxiety and the immune system, Psychoneuroendocrino., 18, 322,1993 .

GALINOWSKI A., Stress et panique, aspects immunologiques, L'Encéphale, 19, 147-151, 1993.

GLASER R., RICE J., SHERIDAN J., FERTEL R., STOUT J., SPEICHER C., PINSKY D., KOTUR M., POST A. \& BECK M. \& coll., Stress-related immune suppression : health implication, Brain Behav. Immun., 1, 7-20, 1987.

GLASER R., RICE J., SPEICHER C.E., STOUT J.C. \& KIECOLT-GLASER J.K., Stress depresses interferon production by leukocytes concomitant with a decrease in natural killer cell activity, Behav. Neurosci., 100, 675-678, 1986.

GOLDSTEIN A.L. \& coll., Preparation, assay and partial purification of a thymic lymphocytopoietic factor (thymosin), Proc. Natl. Acad. Sci. (USA), 56, 1010-1017, 1966.

GOLDSTEIN G., The isolation of thymopoietin (thymosin), Ann. N.Y. Acad. Sci., 28, 177-185, 1975.

GOODKIN K., ANTONI M.H. \& BLANEY P., Stress and hopelessness in the promotion of cervical intraepithelial neoplasia to invasive squamous cell carcinoma of the cervix, J. Psychosom. Res., 30, 67-76, 1986. 
HAEFELY W. \& coll., General pharmacology and neuropharmacology of benzodiazepine derivatives, in "Handbook of experimental Pharmacology / Psychotropic agents", Hoffmeister \& Stille eds, part. II, vol. 55, 73-262, Springer-Verlag, Berlin, 1981.

HALPER J.P., MANN J.J., WEKSLER M.E. \& coll., $\beta$ adrenergic receptors and cyclic AMP levels in intact human lymphocytes : effect of age and gender, Life Sci., 35, 855-863, 1984.

HAMILTON M., Development of a rating scale for primary depressive illness, Brit. J. Soc. Clin. Psychol., 6, 278-296, 1967.

IRVINE W.J., Autoimmunity in endocrine disease, Rec. Progr. Horm. Res., 36, 509-556, 1980.

JEMMOT J.B., BORYSENKO J.Z., BORYSENKO M., Mc CLELLAND D.C., CHAPMAN R. \& MEYER D., Academic stress, power motivation and decrease in secretion rate of salivary secretory Immunoglobulin A, Lancet, $1: 8339,1400-1402,1983$.

JERNE N.K., Idiotypic networks and other preconceived ideas, Immunol. Rev., 79, 5-24, 1984.

JOHNSTONE E.C. \& WHALEY K., Antinuclear antibodies in psychiatric illness : their relationship to diagnosis and drug treatment, Brit. Med. J., 2, 724-725, 1975.

KELLER S.E., STEIN M., CAMERINO M.S., SCHLEIFER S.J.\& SHERIDAN J., Suppression of immunity by stress effect of a graded series of stressors, Science, 213, 1397-1399, 1981.

KELLER S.E., WEISS J.M., SCHLEIFER S.J., MILLER N.E. \& STEIN M., Stress-induced immunosuppression of immunity in adrenalectomized rats, Science, 221, 1301-1304, 1983.

KIECOLT-GLASER J.K., KENNEDY S. \& MALKOFF S. \& coll., Marital discord and immunity in males, Psychosom. Med., 50, 213-229, 1988.

KORT W.J., The effect of chronic stress on the immune response, Adv. Neuroimmunol., 4, 1-11, 1994.

KORT W.J. \& WEIJMA J.M., Effect of chronic light-dark shift stress on the immune response of the rat, Physiol. Behav., 29, 1083-1087, 1982.

KORT W.J., ZONDERVAN P.E., HULSMAN L.O., WEIJMA J.M. \& WESTBROEK D.L., Light-dark shift stress, with special reference to spontaneous tumor incidence in female BN rats, J. Natl. Cancer I., 76, 439-446, 1986a.

KORT W.J., WEIJMA J.M., ZONDERVAN P.E. \& WESTBROEK D.L., The effect of chronic stress on tumor growth : an experimental study in the rat, J. Exp. Clin. Canc. Res., 5, 233-238, 1986 b.

KRONFOL Z., SILVA J. Jr, GREDEN J., DEMBINSKI S., GARDNER R. \& CARROL B., Impaired lymphocyte function in depressive illness, Life Sci., 33, 241-247, 1983.

KRONFOL Z., TURNER R., NASRALLAH H. \& WINOKUR G., Leukocyte regulation in depression and schizophrenia, Psychiat. Res., 1026-1027, 1984. 
LAHIRI T. \& BANERJEE M., Differential responses of carcinogen-induced fibrosarcoma of mice to altered regimes of cold exposure, Neoplasma, 33, 307-312, 1986.

LAUDENSLAGER M.L., Coping and immunosuppression : inescapable but not escapable shock suppresses lymphocyte proliferation, Science, 221, 568-570, 1983.

LAUDENSLAGER M.L., Suppression of specific antibody production by inescapable shock : stability under varying conditions, Brain Behav. Immun., 2, 92-101, 1988.

MARTIN-DU PAN R., Conquêtes et limites de la neuropsychosomatique, Rev. Méd. Suisse Romande, 2e partie : III, 891-899 et 3e partie : III, 1061-1070, 1991.

MAZET P., Une perspective nouvelle en psychosomatique : les relations entre psychisme et défenses immunitaires, Psychosomatique, 6, 19-25, 1986.

Mc KINNON W., WEISSE C.S., REYNOLDS C.P., BOWLES C.A. \& BAUM A., Chronic stress, leukocyte subpopulations, and humoral responses to latent viruses, Health Psychology, 8, 389-402, 1989.

MEREDITH I.T., BROUGHTON A., JENNINGS G.L. \& ESLER M.D., Evidence of a selective increase of cardiac sympathetic activity in patients with sustained ventricular arrythmias, New Engl. J. Med., 325, 618-624, 1991.

MILLER J.F.A.P. \& MITCHELL G.F., Thymus and antigen-reactive cells, Transplant. Rev., 1, 3-42, 1969.

MORLEY S.E. \& coll., Neuropeptides : conductors of the immune orchestra, Life Sci., 41, 527-544, 1987.

MORMÈDE P., DANTZER R., MICHAUD B., KELLEY K.W. \& LE MOAL M., Influence of stressor predicability and behavior control on lymphocyte reactivity, antibody responses and neuroendocrine activation in rats, Physiol. Behav., 43, 577-583, 1988.

MURPHY R.F. \& coll., Internalization and acidification of insulin by activated human lymphocytes, J. Cell Physiol., 121, 351-356, 1984.

OUDIN J., Heterogeneity of the immunoglobulins as revealed by their 3 kinds of antigenic specificity : isotypic, allotypic and idiotypic, Bull. Soc. Chim. Biol. (Paris), 50, 965-990, 1968.

PAYAN D.G. \& GOETZL E.J., Modulation of lymphocyte function by sensory neuropeptides, J. Immunol., 135, 783s-786s, 1985.

PERSKY V.W., KEMPTHORNE-RAWSON J. \& SHEKELLE R.B., Personnality and risk of cancer : 20-year follow up of the Western lectric study, Psychol. Med., 49, 435-449, 1987.

PLAUT M., Lymphocyte hormone receptors, Ann. Rev. Immunol., 5, 621-669, 1987.

RAAB A., DANTZER R., MICHAUD B., MORMÈDE P., TAGHZOUTI K., SIMON H. \& LE MOAL M., Behavioural, physiological and immunological consequences of social status and agression in chronically coexisting residentintruder dyads of male rats, Physiol. Behav., 36, 223-228, 1986. 
RABEY J.M., SHENKMAN L. \& GILAD G.M., Cholinergic muscarinic binding by human lymphocytes : changes with aging, antagonist treatment, and senile dementia of Alzheimer type, Ann. Neurol., 20, 628-631, 1986.

RABIN B.S., CUNNICK J.E. \& LYSLE D.T., Stress-induced alteration of immune function, Progress in Neuro-Endocrino-Immunology, 3, 116-124, 1990.

RAMESH C., YERAGANI V.K., BALON R. \& POHL R., A comparative study of immune status in panic disorders patients and controls, Acta Psychiat. Scand., 84, 396-397, 1991.

RASMUSSEN A.F., Emotions and immunity, Ann. N.Y. Acad. Sci., 164, 458-462, 1969.

REICH P., DA SILVA R.A., LOWN B. \& MURAWSKI B.J., Acute psychological disturbance preceding lifethreatening ventricular arrythmias, JAMA, 246, 233-235, 1981.

REITE M., HARBECK R. \& HOFMAN A., Altered cellular immune response following peer separation, Life Sci., 29, 1133-1136, 1981.

ROSSETTI Z.L. \& coll., Stress increases adrenaline release in the rat frontal cortex : prevention by diazepam, Eur. J. Pharmacol., 176, 229-231, 1990.

RUFF M.R. \& coll., Neuropeptides are shared components of nervous and immune system, in "Neuropeptides and stress", Tachy \& Morley eds, 235-246, Heyle Symposia, Springer-Verlag, Berlin, 1988.

SACHAR N., Neuroendocrine abnormality in depressive illness, in "Topics in Psychoendocrinology”, Sachar E. ed., Grune \& Stratton, New York, 1975.

SCHLEIFER S.J., KELLER S.E., CAMERINO M., THORNTON J.C. \& STEIN M., Suppression of lymphocyte stimulation following bereavement, JAMA, 250, 374-377, 1983.

SCHLEIFER S.J., KELLER S.E., MEYERSON A.T., R AS KIAN M.J., DAVIS K.L. \& STEIN M., Lymphocyte function in major depressive disorder, Arch. Gen. Psychiat., 41, 484-486, 1984.

SCHLEIFER S.J., KELLER S.E., SIRIS S.G., DAVIS K.L. \& STEIN M., Depression and immunity, lymphocyte function in ambulatory depressed patients, hospitalized schizophrenic patients, and patients hospitalized for herniorrhaphy, Arch. Gen. Psychiat., 42, 129-133, 1985.

SCHLESSER M.A., WINOKUR G. \& SHERMAN B.M., Hypothalamic-pituitaryadrenal axis activity in depressive illness, Arch. Gen. Psychiat., 37, 737-743, 1980.

SCHWARTZ J.A., COMSA J. \& ZIEGLER P., Influence of thymus hormone on immune response of hypophysectomized and thymectomized rat, Verth. Dtsch. Ges. Inn. Med., 79, 579-582, 1973.

SHEKELLE R.B., RAYNOR W.J., OSTFELD A.M. \& coll., Psychological depression and 17 year risk of death from cancer, Psychosom. Med., 43, 117125, 1981.

SHOPSIN B., SATHANANTHAN G.L., CHAN T.L. \& coll., Antinuclear factor in psychiatric patients, Biol. Psychiat., 7, 81-86, 1973.

SMITH E.M., MEYER W.J. \& BLALOCK J.E., Virus-induced increases in corticosterone in hypophysectomized mice : a possible lymphoid adrenal axis, Science, 218, 1311-1313, 1982. 
SMITH E.M., MORRIL A.C., MEYER W.J. \& BLALOCK J.E., Corticotropin releasing factor induction of leukocyte-derived immunoreactive ACTH and endorphins, Nature, 322, 881-882, 1986.

SOLOMON G.F., Stress and antibody response in rats, Int. Arch. Allergy Imm., 35, 97-104, 1969.

SPRATT M.L. \& DENNEY D.R., Immune variables, depression and plasma cortisol over time in suddenly bereaved parents, J. Neuropsych. Clin. Neurosci., 3, 299-306, 1991.

STEPLEWSKI Z. \& VOGEL W.H., Total leukocytes, T cell subpopulation and natural killer (NK) cell activity in rat exposed to restraint stress, Life Sci., 38, 2419-2427, 1986.

STONE A.A. \& BOUBJERB D.H., Stress and humoral immunity : a review of the human studies, Adv. Neuroimmunol., 4, 49-56, 1994.

STONE A.A., COX D.S., VALDIMARSDOTTIR H. \& NEALE J.M., Secretory $\operatorname{IgA}$ as a mesure of immunocompetence, Journal of Human Stress, 13, 136-140, 1987.

VILLEMAIN F., Stress et immunologie, PUF, Paris, 1989.

WEINBERG I.R., Psychoneuro-immunology : a new concept in holistic health care, Med. Law, 13, 205-211, 1994.

ZONDERMAN A.B. \& coll., Depression as a risk for cancer morbidity and mortality in a nationally representative sample, JAMA, 262, 1191-1195, 1989.

\section{HORMONES ET ÉVOLUTION}

BARRINGTON E.J.W., Evolutionary aspects of hormonal structure and function in "Comparative endocrinology", Gaillard P.J. \& Boer H.H. eds, 381-396, Elsevier, Amsterdam, 1978.

BARRINGTON E.J.W., The phylogeny of the endocrin system, in "Development of hormone receptors", Csaba G. ed., 137-148, 1989.

BÜCHMANN D., Common origin and phylogenetic diversification of animal hormonal systems, in "Development of hormone receptors", Csaba G. ed., 155-166, 1989.

CSABA G., A new approach to the molecular evolution of hormone : the receptorial aspect, in "Development of hormone receptors", Csaba G. ed., 149-154, 1989.

FONTAINE Y.A., Les hormones et l'évolution, la Recherche, 153, 310-320, 1984.

GEORGES D. \& coll., Relaxin-like peptide in Ascidians. I. Identification of the peptide and its mRNA in ovary of Herdmania momus, Gen. Comp. Endocr., 79, 423-428, 1990.

LE GOASCOGNE C. \& coll., Neurosteroids : Cytochrome P-450 $0_{\text {scc }}$ in rat brain, Science, 237, 1212-1214, 1987.

LE ROITH D. \& coll., Evolutionary aspects of the endocrine and nervous systems, Rec. Progr. Horm. Res., 42, 549-587, 1986.

NIALL H.D., The evolution of peptide hormones, Annu. Rev. Physiol., 44, 615-624, 1982. 
OHTA T., Pattern of nucleotide substitutions in growth-hormone-prolactin gene family : a paradigme for evolution by gene duplication, Genetics, 134, 1271-1276, 1993.

ROTH J. \& coll., Evolutionary origins of neuropeptides, hormones and receptors. Possible applications to immunology, J. Immunol., 135, 8165-8195, 1985.

RUSSEL S.M. \& NICOLL C.S., Evolution of growth hormone and prolactin receptors and effectors, Prog. Clin. Biol. Res., 342, 168-173, 1990.

VINCENT J.D. \& SIMONNET G., Les neurohormones, J. Physiol., 81, 51-87, 1986.

WALLIS M., Remarkably high rate of molecular evolution of ruminant placental lactogens, J. Mol. Evol., 37, 86-88, 1993.

WINGFIELD J.C., JACOBS J. \& HILLGARTH N., Ecological constraints and the evolution of hormone-behavior interrelationships, Ann. N.Y. Acad. Sci., 807, 22-41, 1997. 

AnNEXES 



\section{ANNEXE 1}

\section{TABLEAU DE CORRESPONDANCE ENTRE LE SYSTÈME INTERNATIONAL D'UNITÉS (SI) ET LES UNITÉS TRADITIONNELLES POUR LES PRINCIPALES HORMONES}

\begin{tabular}{|c|c|c|c|c|}
\hline Constituants & $\begin{array}{c}\text { Unité } \\
\text { traditionnelle }\end{array}$ & $\begin{array}{l}\text { Facteur de } \\
\text { conversion } \\
\text { tradit. } \rightarrow \text { SI }\end{array}$ & Unité SI & $\begin{array}{l}\text { Facteur de } \\
\text { conversion } \\
\text { SI } \rightarrow \text { tradit. }\end{array}$ \\
\hline Adrénaline & $\mu \mathrm{g} / 1$ & 5,458 & $\mathrm{nmol} / \mathrm{l}$ & 0,1832 \\
\hline Aldostérone & $\mu \mathrm{g} / 1$ & 2,774 & $\mathrm{nmol} / \mathrm{l}$ & 0,360 \\
\hline $\begin{array}{l}\text { 17-cétostéroïdes, } \\
\text { déhydro-épiandrostérone }\end{array}$ & $\mathrm{mg} / \mathrm{l}$ & 3,467 & $\mu \mathrm{mol} / 1$ & 0,2884 \\
\hline Cortisol & $\mathrm{mg} / \mathrm{l}$ & 2,76 & $\mu \mathrm{mol} / 1$ & 0,3625 \\
\hline ACTH & $\mathrm{ng} / \mathrm{l}$ & 0,220 & $\mathrm{pmol} / \mathrm{l}$ & 4,541 \\
\hline 11-désoxycorticostéroïdes & $\mu \mathrm{g} / \mathrm{l}$ & 0,3026 & $\mu \mathrm{mol} / 1$ & 330,4 \\
\hline 17-hydroxycorticostéroïdes & $\mathrm{mg} / \mathrm{l}$ & 2,759 & $\mu \mathrm{mol} / 1$ & 0,362 \\
\hline Insuline & $\mu \mathrm{g} / 1$ & 172,2 & $\mathrm{pmol} / \mathrm{l}$ & 0,0058 \\
\hline $\begin{array}{l}\text { Iode protéique (PBI) } \\
\text { Iode hormonal (BEI) }\end{array}$ & $\mu \mathrm{g} / 1$ & 7,88 & $\mathrm{nmol} / \mathrm{l}$ & 0,1269 \\
\hline Noradrénaline & $\mu \mathrm{g} / \mathrm{l}$ & 5,911 & $\mathrm{nmol} / \mathrm{l}$ & 0,1692 \\
\hline Estradiol & $\mu \mathrm{g} / 1$ & 3,671 & $\mathrm{nmol} / \mathrm{l}$ & 0,272 \\
\hline Estriol & $\mu \mathrm{g} / \mathrm{l}$ & 3,468 & $\mathrm{nmol} / \mathrm{l}$ & 0,288 \\
\hline Estrone & $\mu \mathrm{g} / \mathrm{l}$ & 3,70 & $\mathrm{nmol} / \mathrm{l}$ & 0,270 \\
\hline Prégnandiol & $\mathrm{mg} / \mathrm{l}$ & 3,120 & $\mu \mathrm{mol} / 1$ & 0,3205 \\
\hline Prégnanetriol & $\mathrm{mg} / \mathrm{l}$ & 2,972 & $\mu \mathrm{mol} / 1$ & 0,336 \\
\hline Progestérone & $\mu \mathrm{g} / \mathrm{l}$ & 3,180 & $\mathrm{nmol} / \mathrm{l}$ & 0,3145 \\
\hline Testostérone & $\mu \mathrm{g} / \mathrm{l}$ & 3,467 & $\mathrm{nmol} / \mathrm{l}$ & 2,228 \\
\hline Thyroxine (T4) & $\mu \mathrm{g} / 1$ & 1,287 & $\mathrm{nmol} / \mathrm{l}$ & 0,7769 \\
\hline Triiodothyronine (T3) & $\mu \mathrm{g} / \mathrm{l}$ & 0,1536 & $\mathrm{nmol} / \mathrm{l}$ & 6,51 \\
\hline
\end{tabular}




\section{ANNEXE 2}

\section{EXAMENS BIOLOGIQUES CHEZ L'HOMME* (ADULTE)}

\begin{tabular}{|c|c|c|c|}
\hline I. SANG & Valeurs moyennes & Unités SI & Unités traditionnelles \\
\hline Urée & $0,35 \mathrm{~g}=4 \mathrm{mmol} / \mathrm{l}$ & $<8,3 \mathrm{mmol} / \mathrm{l}$ & $<0,50 \mathrm{~g} / 1$ \\
\hline Créatinine & $10 \mathrm{mg}=88 \mu \mathrm{mol} / 1$ & $\begin{array}{l}\sigma^{7}<97 \mu \mathrm{mol} / 1 \\
\text { † }<79 \mu \mathrm{mol} / 1\end{array}$ & $\begin{array}{l}<11 \mathrm{mg} / \mathrm{l} \\
<9 \mathrm{mg} / \mathrm{l}\end{array}$ \\
\hline Glucose à jeun & $1 \mathrm{~g} / \mathrm{l}=5,56 \mathrm{mmol} / \mathrm{l}$ & 4,21 à $6,10 \mathrm{mmol} / \mathrm{l}$ & 0,76 à $1,10 \mathrm{~g} / 1$ \\
\hline Acide urique & $50 \mathrm{mg} / \mathrm{l}=297 \mu \mathrm{mol} / \mathrm{l}$ & $\begin{array}{l}\sigma^{7}<420 \mu \mathrm{mol} / 1 \\
\text { † }<340 \mu \mathrm{mol} / 1\end{array}$ & $\begin{array}{l}<70 \mathrm{mg} / \mathrm{l} \\
<57 \mathrm{mg} / \mathrm{l}\end{array}$ \\
\hline Cholestérol & $1,70=4,40 \mathrm{mmol} / \mathrm{l}$ & $<5,2 \mathrm{mmol} / \mathrm{l}$ & $<2,00 \mathrm{~g} / \mathrm{l}$ \\
\hline Cholestérol-HDL & & $\begin{array}{l}\text { ல > 1,41 mmol/1 } \\
\text { む > 1,67 mmol/1 }\end{array}$ & $\begin{array}{l}>0,55 \mathrm{~g} / 1 \\
>0,65 \mathrm{~g} / 1\end{array}$ \\
\hline Cholestérol-LDL & & $<3,35 \mathrm{mmol} / \mathrm{l}$ & $<1,30 \mathrm{~g} / 1$ \\
\hline Cholestérol LDL/HDL & \multicolumn{3}{|c|}{$\begin{array}{l}\text { Le risque d'athérosclérose est : } \\
\text { - multiplié par } 2 \text { si }>9,5 \text { chez l'homme, et }>7 \text { chez la femme } \\
\text { - multiplié par } 3 \text { si }>23,5 \text { chez l'homme, et }>11 \text { chez la femme }\end{array}$} \\
\hline Triglycérides & $1,25 \mathrm{~g} / \mathrm{l}=1,42 \mathrm{mmol} / \mathrm{l}$ & $<2,3 \mathrm{mmol} / \mathrm{l}$ & $<2 \mathrm{~g} / \mathrm{l}$ \\
\hline Lipoprotéines & $\begin{array}{l}\alpha: 15 \text { à } 40 \% \\
\beta: 40 \text { à } 45 \% \\
\delta:<20 \%\end{array}$ & & \\
\hline Apolipoprotéine A1 & & & 1,04 à $2,25 \mathrm{~g} / 1$ \\
\hline Apolipoprotéine B & & & 0,60 à $1,33 \mathrm{~g} / 1$ \\
\hline Apo B/Apo A1 & \multicolumn{3}{|c|}{$=$ index d'athérosclérose (normal : 0,5 à 0,9 ) } \\
\hline
\end{tabular}

\begin{tabular}{|c|c|c|c|}
\hline IONOGRAMME & Valeurs moyennes & Unités SI & Unités traditionnelles \\
\hline Natrémie & & 135 à $145 \mathrm{mmol} / \mathrm{l}$ & 135 à $145 \mathrm{mEq} / \mathrm{l}$ \\
\hline Kaliémie & & 3,5 à $5,0 \mathrm{mmol} / \mathrm{l}$ & 3,5 à $5,0 \mathrm{mEq} / 1$ \\
\hline Chlorémie & & 95 à $105 \mathrm{mmol} / \mathrm{l}$ & 95 à $105 \mathrm{mEq} / 1$ \\
\hline $\mathrm{RA}\left(\mathrm{CO}_{3} \mathrm{H}^{-}\right)$ & & 23 à $33 \mathrm{mmol} / \mathrm{l}$ & 23 à $33 \mathrm{mmol} / \mathrm{l}$ \\
\hline Protides totaux & & 66 à $87 \mathrm{mmol} / \mathrm{l}$ & 66 à $87 \mathrm{~g} / 1$ \\
\hline Calcium & $100 \mathrm{~m} / \mathrm{l}=2,50 \mathrm{mmol} / \mathrm{l}$ & 2,15 à $2,55 \mathrm{mmol} / \mathrm{l}$ & 81 à $104 \mathrm{mg} / \mathrm{l}$ \\
\hline Magnésium & $22,8 \mathrm{mg} / \mathrm{l}=0,93 \mathrm{mmol} / \mathrm{l}$ & 0,70 à $100 \mathrm{mmol} / \mathrm{l}$ & 17 à $25 \mathrm{mg} / \mathrm{l}$ \\
\hline Magnésium érythrocytaire & $58 \mathrm{mg} / \mathrm{l}=2,38 \mathrm{mmol} / \mathrm{l}$ & & 40 à 60 mg/l \\
\hline Phosphore & $40 \mathrm{mg} / \mathrm{l}=1,28 \mathrm{mmol} / \mathrm{l}$ & & \\
\hline Fer & 50 à $150 \mu \mathrm{g} / 1$ & $\begin{array}{c}\sigma^{7} 10,6 \text { à } 23,8 \mu \mathrm{mol} / 1 \\
\text { t } 6,6 \text { à } 26 \mu \mathrm{mol} / 1\end{array}$ & $\begin{array}{l}37 \text { à } 145 \mu \mathrm{g} / \mathrm{dl} \\
59 \text { à } 158 \mu \mathrm{g} / \mathrm{dl}\end{array}$ \\
\hline Phosphatases alcalines & & $\begin{array}{l}\text { ○゙ }<270 \mathrm{U} / 1 \\
\text { む }<240 \mathrm{U} / 1\end{array}$ & $\begin{array}{c}<4,50 \mu \mathrm{kat} / 1 \\
<4,0 \mu \mathrm{kat} / 1\end{array}$ \\
\hline
\end{tabular}


II. URINES (par 24 h) Valeurs moyennes Unités SI Unités traditionnelles

\begin{tabular}{|l|c|c|c|}
\hline Acide urique & & 2,2 à $5,5 \mathrm{mmol} / \mathrm{l}$ & 370 à $920 \mathrm{mg} / \mathrm{l}$ \\
\hline Calcium & & 8,92 à $13,0 \mathrm{mmol} / \mathrm{l}$ & 357 à $520 \mathrm{mg} / \mathrm{l}$ \\
\hline Créatinine & & 8 à $27 \mathrm{mmol} / \mathrm{l}$ & 900 à $3000 \mathrm{mg} / \mathrm{l}$ \\
\hline Magnésium & 1 à $6 \mathrm{mmol} / \mathrm{l}$ & 24 à $145 \mathrm{mg} / \mathrm{l}$ \\
\hline Phosphore & & 12,8 à $43,52 \mathrm{mmol} / \mathrm{l}$ & 400 à $1360 \mathrm{mg} / \mathrm{l}$ \\
\hline Potassium & 20 à $80 \mathrm{mmol} / \mathrm{l}$ & 20 à $80 \mathrm{mEq} / \mathrm{l}$ \\
\hline Sodium & 54 à $190 \mathrm{mmol} / \mathrm{l}$ & 54 à $190 \mathrm{mEq} / 1$ \\
\hline Urée & & 150 à $500 \mathrm{mmol} / \mathrm{l}$ & 900 à $3000 \mathrm{mg} / \mathrm{l}$ \\
\hline
\end{tabular}

* Clinilab, 38400 Saint-Martin d'Hères, France. 

GLOSSAIRE 



\section{GLOSSAIRE}

5-HT

A

AA

AAc

ABP

AC

Ac

ACE

$\mathrm{ACh}$

ACTH

ADCC

ADH

ADN

ADNc

ADP

ADP-RT

ADPc

ADPR

ADPRc

AG

Ag

AGL

$\mathrm{AMH}$

AMP

AMPA

AMPc

ANCP

ANF

Ang

AP1

ARN sérotonine $=5$ hydroxytryptamine

adrénaline

acide aminé

acide arachidonique

protéine de liaison à l'androgène androgen binding protein

adénylate cyclase

anticorps

enzyme de conversion de l'angiotensine

acétylcholine

hormone corticotrope $=$ corticotrophine

adrenocorticotropin hormone

cytotoxicité dépendante de l'anticorps

antibody dependant cytotoxicity

hormone antidiurétique $=$ vasopressine

antidiuretic hormone

acide désoxyribonucléique

ADN complémentaire

adénosine diphosphate

ADP-ribosyltransférase

adénosine diphosphate cyclique

adénosine-ribose diphosphate

adénosine-ribose diphosphate cyclique

acides gras

antigène

acides gras libres

hormone antimullérienne

antimullerian hormone

adénosine monophosphate

acide $\alpha$-amino-3-hydroxy-5-méthyl-4-isoazolepronique

$\alpha$-amino-3-hydroxy-5-methyl-4-isoazolepronic acid

adénosine monophosphate cyclique

protéine porteuse de l'adénine nucléotide

adenine nucleotide carrier protein

facteur natriurétique atrial

atrial natriuremic factor

angiotensine (I, II)

système activateur protéique

proteic system activator

acide ribonucléique 


\begin{tabular}{|c|c|}
\hline $\mathrm{ARNm}$ & ARN messager \\
\hline $\mathrm{ARNt}$ & ARN de transfert \\
\hline AT & acétyltransférase \\
\hline ATP & adénosine-ribose triphosphate \\
\hline ATPase & enzyme de transfert de la liaison riche en énergie de l'ATP \\
\hline $\mathrm{ATPc}$ & adénosine-ribose triphosphate cyclique \\
\hline AVC & accidents vasculaires cérébraux \\
\hline BCGF & $\begin{array}{l}\text { facteur de croissance des lymphocytes B } \\
\text { B cell growth factor }\end{array}$ \\
\hline BDZ & benzodiazépines \\
\hline BH4 & tétrahydrobioptéridine \\
\hline BK & bradykinine \\
\hline BMI & $\begin{array}{l}\text { index de la masse du corps } \\
\text { body mass index }\end{array}$ \\
\hline $\mathrm{bNOS}=\mathrm{nNOS}$ & NO synthase constitutive du système nerveux $(b=$ brain $)$ \\
\hline $\mathrm{BP}$ & $\begin{array}{l}\text { protéine de liaison } \\
\text { binding protein }\end{array}$ \\
\hline BTG1 & $\begin{array}{l}\text { gène } 1 \text { de translocation du lymphocyte } B \\
\text { B-cell translocation gene } 1\end{array}$ \\
\hline Ca-Calm & calcium-calmoduline \\
\hline Calm & calmoduline \\
\hline CBG & $\begin{array}{l}\text { transcortine } \\
\text { corticosteroid binding globulin }\end{array}$ \\
\hline CBR & central binding receptor \\
\hline CCK & cholécystokinine \\
\hline CCK-PZ & cholécystokinine-pancréozymine \\
\hline $\mathrm{Cdc} 25$ & domaine d'échange du nucléotide guanine de Ras \\
\hline $\mathrm{cdk}$ & $\begin{array}{l}\text { kinase dépendante des cyclines } \\
\text { cyclin dependent kinase }\end{array}$ \\
\hline $\mathrm{CGP}=\mathrm{HCS}=\mathrm{HPL}$ & hormone placentaire lactotrope \\
\hline CGRP & calcitonin gene related peptide \\
\hline CICR & $\mathrm{Ca}^{2+}$ induced $\mathrm{Ca}^{2+}$ release \\
\hline CLIP & corticotrophin like intermediate peptide \\
\hline $\mathrm{CMH}$ & complexe majeur d'histocompatibilité \\
\hline cNOS & NO synthase constitutive : NOSI (NOS1) et NOSIII (NOS3) \\
\hline COMT & catéchol-O-méthyl-transférase \\
\hline ConA & concanavaline A \\
\hline CREB & cAMP response element binding protein \\
\hline CRF & $\begin{array}{l}\text { facteur de libération de l'hormone corticotrope } \\
\text { corticotropin releasing factor }\end{array}$ \\
\hline $\mathrm{CRH}$ & $\begin{array}{l}\text { corticolibérine } \\
\text { corticotropin releasing hormone }\end{array}$ \\
\hline $\mathrm{CS}$ & corticostatine \\
\hline $\mathrm{Ct}$ & calcitonine \\
\hline $\mathrm{Da}$ & dopamine \\
\hline $\mathrm{DAB}$ & 3-3'diamino benzidine \\
\hline DAG & diacylglycérol $=s n-1,2$ diacylglycérol \\
\hline
\end{tabular}




\begin{tabular}{|c|c|}
\hline DAS & désordre affectif saisonnier \\
\hline DBI & inhibiteur de liaison au diazépam \\
\hline DHEA ou DHA & déhydro-épiandrostérone \\
\hline DHEA-S & sulfate de DHEA \\
\hline DHT & dihydrotestostérone \\
\hline DID & diabète insulinodépendant \\
\hline DIT & diiodotyrosine \\
\hline DIU & dispositif intra-utérin \\
\hline DNID & diabète non-insulinodépendant \\
\hline DOC & désoxycorticostérone \\
\hline DOPA & dihydroxyphénylalanine \\
\hline DXM & dexaméthasone \\
\hline E1 & œstrone \\
\hline E2 & œstradiol \\
\hline EB & benzoate d'œstradiol \\
\hline $\mathrm{Ec}$ & ecdysone \\
\hline ECEt & enzyme de conversion de l'endothéline \\
\hline EDHF & facteur hyperpolarisant dérivé de l'endothélium \\
\hline EDRF & $\begin{array}{l}\text { facteur de relaxation de l'endothélium } \\
\text { endothelium derived relaxing factor }\end{array}$ \\
\hline EDTA & acide éthylène diamino-tétracétique \\
\hline EGF & $\begin{array}{l}\text { facteur de croissance épitdermique } \\
\text { epidermal growth factor }\end{array}$ \\
\hline eNOS & NO synthase constitutive de l'endothélium \\
\hline EPO & érythropoïétine \\
\hline ERK & isoformes des MAP kinases \\
\hline ES (cellules) & cellules souches embyonnaires murines \\
\hline Et & endothéline \\
\hline FAD & flavine adénine dinucléotide \\
\hline FGF & $\begin{array}{l}\text { facteur de croissance du fibroblaste } \\
\text { fibroblast growth factor }\end{array}$ \\
\hline FITC & fluorescéine \\
\hline FIV & fécondations in vitro \\
\hline FMN & flavine mononucléotide \\
\hline FMP & forward mobility protein \\
\hline FRH & faisceau rétino-hypothalamique \\
\hline FRP & $\begin{array}{l}\text { protéine de régulation folliculaire } \\
\text { follicular regulary protein }\end{array}$ \\
\hline FSH & $\begin{array}{l}\text { hormone folliculo-stimulante } \\
\text { follicle stimulating hormone }\end{array}$ \\
\hline FSH-BI & $\begin{array}{l}\text { inhibiteur de la fixation de FSH } \\
\text { FSH binding inhibitor }\end{array}$ \\
\hline FTS & facteur thymique sérique \\
\hline G & protéine $\mathrm{G}$ \\
\hline GABA & $\begin{array}{l}\text { acide } \gamma \text {-amino-butyrique } \\
\text { gamma-amino-butyric acid }\end{array}$ \\
\hline $\mathrm{AD}$ & acide glutamique décarboxylase \\
\hline
\end{tabular}




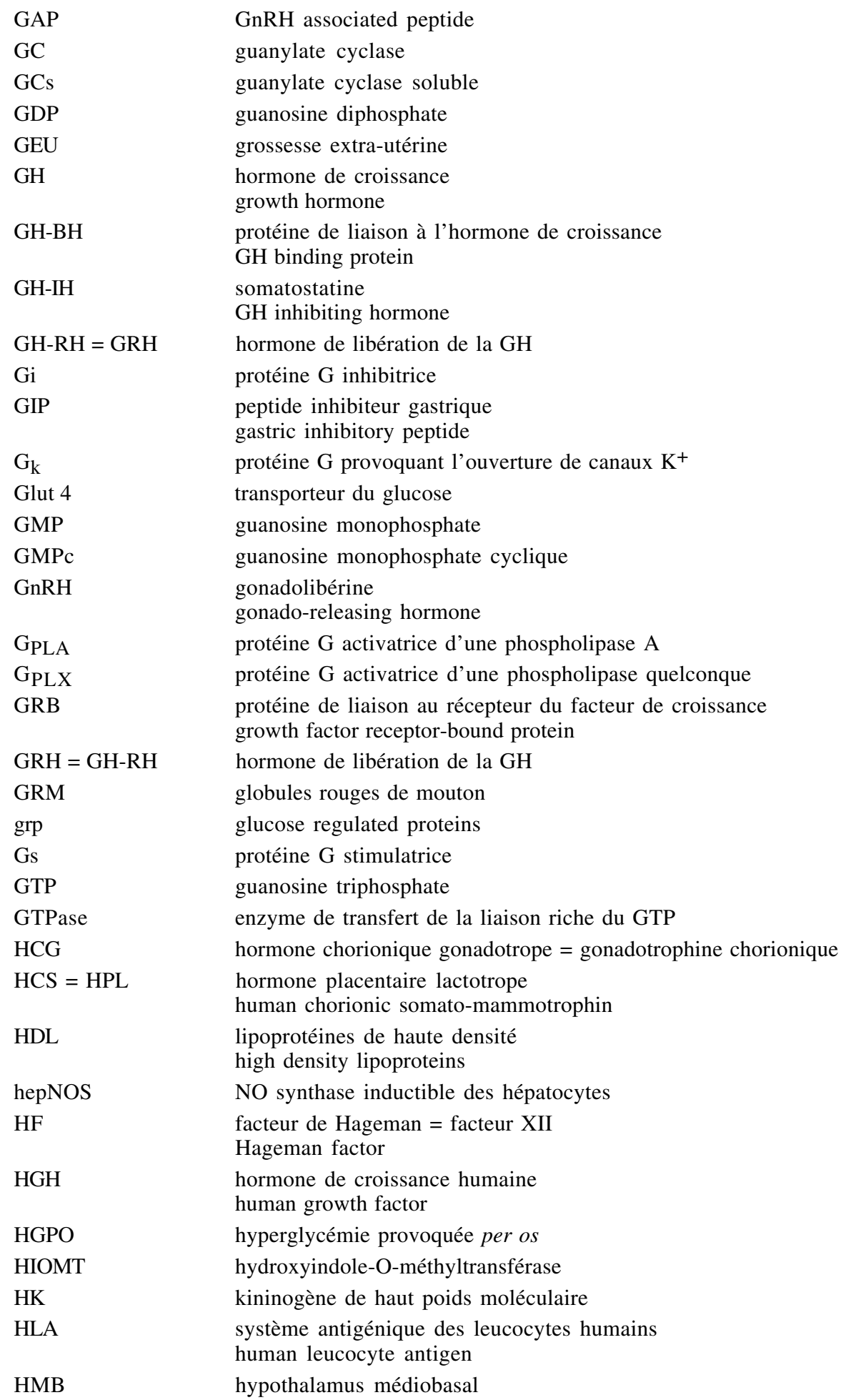




\section{HMG}

HNF

$\operatorname{HPETE}_{(\mathrm{s})}$

HPL $=$ HCS

hsc

hsp

HTA

IACE

ICA

ICER

$\mathrm{ICSH}=\mathrm{LH}$

IEC

IF

IFN

Ig

IGF

IGF1

IGF2

IGFBP

IH

IL

IMAO

iNOS

Ins

InsP

IP3

IP4

IRF

IRM

IRS

JAK

$\mathrm{K}_{\mathrm{A}}$

$\mathrm{k}_{\mathrm{a}}$

$\mathrm{K}_{\mathrm{D}}$

$\mathrm{k}_{\mathrm{d}}$

KII-ACE

KII-NEP gonadotrophines post-ménopausiques

human menopausal gonadotrophin

facteurs hépatiques nucléaires

hydroperoxy-licosotétraénoïque

hormone placentaire lactotrope

protéine apparentée à la protéine de choc thermique

heat shock cognate protein

protéine de choc thermique

heat shock protein

hypertension artérielle

inhibiteur de l'enzyme de conversion de l'angiotensine

anticorps anti-îlots

islet cell antibody

récepteur inductible de la transcription AMPc dépendante

inducible cAMP early repressor

hormone de stimulation des cellules interstitielles

interstitial cells stimulating hormone

inhibiteur de l'enzyme de conversion

facteur hypothalamique inhibiteur d'une hormone hypophysaire inhibiting factor

interféron $(\alpha, \gamma)$

immunoglobuline (A, E, G, M)

facteur de croissance insulinique

insulin like growth factor

somatomédine A

somatomédine $\mathrm{C}$

protéine de liaison à l'IGF

IGF binding protein

hormone hypothalamique inhibitrice d'une hormone hypophysaire inhibiting hormone

interleukine $(1,2,4,10)$

inhibiteurs de la mono-amine-oxydase

NO synthase inductible $=$ NOSII $($ NOS2 $)$

insuline

inositol phosphate

Ins $(1,4,5) \mathrm{P} 3=$ inositol $(1,4,5)$ triphosphate

Ins $(1,3,4,5) \mathrm{P} 4=$ inositol $(1,3,4,5)$ tétraphosphate

iron responsive factor

imagerie en résonnance magnétique nucléaire

insulin receptor substrat

Janus activated kinase

constante d'association intrinsèque à l'équilibre

constante de vitesse d'association

constante de dissociation intrinsèque à l'équilibre

constante de vitesse de dissociation

kininase II-angiotensine I converting enzyme

kininase II-neutralendopeptidase enképhalinase 
$\mathrm{KP}$

L-NAA

L-NAME

L-NMA

L-NMMA

LATS

LB

LDL

LH

\section{LH-RF}

LH-RH

LI

LK

LP

LPH

LPS

LT

$\mathrm{Lt}$

LTD

LTH

LTP

Lys-BK

macNOS

MAO

MAP

MAPK

MB

MEK

Met-Lys-BK

MFB

MIT

MODY

MPF

MSH

MSH-IH = MIF kallicréine plasmatique

plasmatic kallicrenin

$\mathrm{NG}^{\mathrm{G}}$-amino-L-arginine

$\mathrm{N}^{\mathrm{G}}$-nitro-L-arginine méthyl ester

$\mathrm{N}^{\mathrm{G}}$-nitro-L-arginine

$\mathrm{NG}$-monométhyl-L-arginine

long acting thyroid stimulator

lymphocyte B

lipoprotéines de basse densité

low density lipoproteins

hormone lutéinique

luteinizing hormone

facteur de décharge de la $\mathrm{LH}$

releasing factor de la $\mathrm{LH}$

lulibérine

LH releasing hormone

inhibiteur de la lutéinisation

kininogène de bas poids moléculaire

lipoprotéine

hormone lipotropique

lipotropic hormone

lipopolysaccharide

lymphocyte $\mathrm{T}(4,8)$

leucotriène (A4, B4, D4, E4)

dépression à long terme

hormone lutéotropique

lutéotropic hormone

potentialisation à long terme

lysyl-bradykinine $=$ kallidine

NO synthase inductible des macrophages

mono-amine-oxydase

mitogen activated protein

MAP kinase

mitogen activated protein kinase

métabolisme basal

MAP kinase-kinase

méthyl-lysyl-bradykinine

faisceau médian du télencéphale

median forebrain bundle

monoiodotyrosine

maturity onset diabetes in the young

facteur de promotion de la phase $\mathrm{M}$

M-phase promoting factor

hormone mélanotrope

melanocyte stimulating hormone

hormone hypothalamique inhibitrice de la libération de MSH

MSH inhibiting hormone 
MSH-RH

MST

Mt

NA

$\mathrm{NAD}^{+}$

$\mathrm{NADH}$

$\mathrm{NADP}^{+}$

$\mathrm{NADPH}$

NANC

NAT

NGF

NIS

NK

NMDA

nNOS $=$ bNOS

NO

NOS

NPH

NPV

NPY

NSC

NSO

OMI

Ot

$\mathrm{P}$

P-chol

PA

PAF

PAI

PBI

PBP

PC

PCPA

PDGF

PDH

peptide Lt

$\mathrm{Pg}$

PgI2

Pgn hormone hypothalamique de décharge de la MSH

MSH releasing hormone

maladies sexuellement transmissibles

mélatonine

noradrénaline

nicotinamide adénine dinucléotide

nicotinamide adénine dinucléotide réduite

nicotinamide adénine dinucléotide phosphate

nicotinamide adénine dinucléotide phosphate réduite

non adrénergique et non cholinergique

$\mathrm{N}$-acétyltransférase

necrosing growth factor

symport sodium-iode

cellules lymphocytaires "tueuses" naturelles

natural killers

$\mathrm{N}$-méthyl-D-aspartate

NO synthase constitutive du système nerveux

monoxyde d'azote

NO synthase, inductible (iNOS) ou constitutive (cNOS) (de

l'endothélium $=$ eNOS $;$ neuronale $=$ nNOS $)$

neutral protamine hagedorn

noyau paraventriculaire

neuropeptide $\mathrm{Y}$

noyau suprachiasmatique

noyau supra-optique

inhibiteur de la maturation ovocytaire

ovocyte maturation inhibitor

ocytocine

progestérone

phosphocholine

pression artérielle

facteur activateur des plaquettes

platelet activating factor

plasminogène activateur inhibiteur

iodure lié à la protéine

protein bound iodine

protéine plasmatique de liaison avec la progestérone

progesteron binding plasma protein

phosphatidylcholine

p-chlorophénylalanine

facteur de croissance plaquettaire

platelet derived growth factor

pyruvate déshydrogénase

peptidoleucotriène

prostaglandine (D2, E1, E2, F2 $\alpha, \mathrm{G} 2, \mathrm{H} 2$ )

prostaglandine $\mathrm{I} 2=$ prostacycline

prégnénolone 
$\mathrm{PH}$

PHA

PIF

PIP2

PK

PL

PM

PMA

POMC

$\mathrm{PP}$

PPA

PPD

PPSE

PPSI

Pré-PK

Prl

Pro

$\mathrm{Pt}$

PtB

PTBR

Ptd Ins

PTH

PTU

PVS

PWM

PYY

$\mathrm{R}$

R-AR

R-CPG

R-E

$\mathrm{R}-\mathrm{Ec}$

R-Ec-E-USP

R-Et

$\mathrm{R}-\mathrm{Mt}$

R-PPA

R-Prl

R-T

$\mathrm{R}-\mathrm{VD}$

R-XR

Ras, Raf

$\mathrm{Rb}$ plectrin homology

phytohémagglutinine

facteur inhibiteur de la prolactine prolactin inhibiting factor

Ptd Ins(4,5)P = phosphatidylinositol (4,5) biphosphate

protéine kinase $(\mathrm{A}, \mathrm{C}, \mathrm{G})$

phospholipase (A, A2, C)

poids moléculaire

procréations médicalement assistées

pro-opiomélanocortine

polypeptide pancréatique

peroxisome proliferator activated

dérivé protéique purifié de la tuberculine

potentiel postsynaptique excitateur

potentiel postsynaptique inhibiteur

pré-kallicréine plasmatique

prolactine

proline

phosphotyrosine

liaison à la phosphotyrosine

phosphotyrosin binding

récepteur à la benzodiazépine de type périphérique

peripheral type benzodiazepin receptor

phosphatidylinositol

parathormone

propylthiouracile

système périventriculaire

periventricular system

pokeweed mutagen

peptide YY

récepteur

récepteur de l'acide rétinoïque tout-trans $(t-\mathrm{AR})$

récepteur couplé aux protéines $\mathrm{G}$

récepteur aux œstrogènes $(\alpha, \beta)$

récepteur de l'ecdysone

hétérodimère constitué par le récepteur de l'ecdysone et la protéine ultraspiracle, liés à l'ecdysone

récepteur à l'endothéline (A, B)

récepteur à la mélatonine

récepteur activé par les proliférateurs de peroxysome et les acides gras

récepteur à la prolactine

récepteur de l'hormone thyroïdienne T3

récepteur de la vitamine D3

récepteur de l'acide rétinoïque 9 cis $(9 c-\mathrm{AR})$

proto-oncogènes

rétinoblastome 


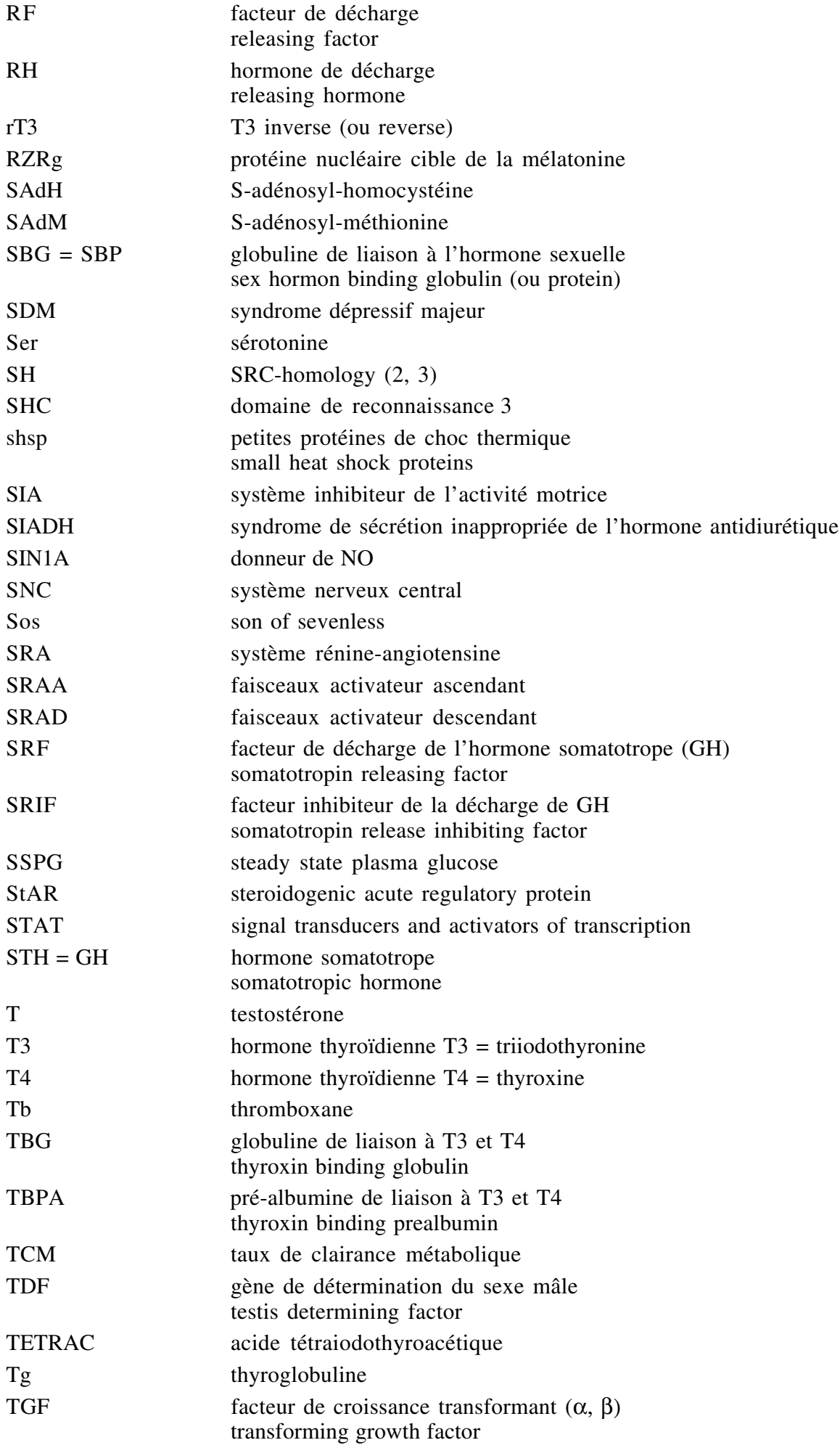

RF

RH

rT3

RZRg

SAdH

SAdM

$\mathrm{SBG}=\mathrm{SBP}$

SDM

Ser

$\mathrm{SH}$

SHC

shsp

SIA

SIADH

SIN1A

SNC

Sos

SRA

SRAA

SRAD

SRF

SRIF

SSPG

StAR

STAT

$\mathrm{STH}=\mathrm{GH}$

$\mathrm{T}$

T3

$\mathrm{T} 4$

$\mathrm{Tb}$

TBG

TBPA

TCM

TDF

TETRAC

$\mathrm{Tg}$

TGF

facteur de décharge

releasing factor

hormone de décharge

releasing hormone

T3 inverse (ou reverse)

protéine nucléaire cible de la mélatonine

S-adénosyl-homocystéine

S-adénosyl-méthionine

globuline de liaison à l'hormone sexuelle

sex hormon binding globulin (ou protein)

syndrome dépressif majeur

sérotonine

SRC-homology $(2,3)$

domaine de reconnaissance 3

petites protéines de choc thermique small heat shock proteins

système inhibiteur de l'activité motrice

syndrome de sécrétion inappropriée de l'hormone antidiurétique

donneur de NO

système nerveux central

son of sevenless

système rénine-angiotensine

faisceaux activateur ascendant

faisceaux activateur descendant

facteur de décharge de l'hormone somatotrope (GH)

somatotropin releasing factor

facteur inhibiteur de la décharge de $\mathrm{GH}$

somatotropin release inhibiting factor

steady state plasma glucose

steroidogenic acute regulatory protein

signal transducers and activators of transcription

hormone somatotrope

somatotropic hormone

testostérone

hormone thyroïdienne T3 = triiodothyronine

hormone thyroïdienne $\mathrm{T} 4=$ thyroxine

thromboxane

globuline de liaison à T3 et T4

thyroxin binding globulin

pré-albumine de liaison à $\mathrm{T} 3$ et $\mathrm{T} 4$

thyroxin binding prealbumin

taux de clairance métabolique

gène de détermination du sexe mâle

testis determining factor

acide tétraiodothyroacétique

thyroglobuline

facteur de croissance transformant $(\alpha, \beta)$

transforming growth factor 
TNF

facteur de nécrose tumorale tumor necrosing factor

TP taux de production

TRH hormone de libération de la TSH

TRIAC thyrotropin releasing hormone

TSH acide triiodothyroacétique

USP thyréostimuline

VDAC protéine ultraspiracle lipoprotéines de très faible densité voltage dependant anion carrier

VIP

VLDL peptide intestinal vaso-actif vasoactive intestinal peptide

VMA very low density lipoproteins

VOC acide vanilmandélique voltage operated channel

$\mathrm{VP}$ vaisseaux portes 
INDEX 



\section{INDEX}

\begin{tabular}{|c|c|c|c|c|}
\hline $1 \alpha$-hydroxylase & 338 & - acéto-acétique & \multirow{2}{*}{\multicolumn{2}{|c|}{$64,104,235,470$}} \\
\hline $1 \alpha$-hydroxylase rénale & 340 & - arachidonique & & \\
\hline $1,25-(\mathrm{OH})_{2}-\mathrm{D} 3$ & 338,520 & - $\gamma$-amino-butyrique & \multicolumn{2}{|c|}{ voir GABA } \\
\hline $11 \beta$-hydroxy-D4-androstène- & $-3,17$ dione & - glutamique décarboxylase & & 302 \\
\hline 11-DOC & 227 & - rétinoïque & & 67 \\
\hline${ }^{123} \mathrm{I}$ & 212 & - tétraiodothyroacétique & \multicolumn{2}{|c|}{ voir TETRAC } \\
\hline $17 \beta$-œstradiol & 415,417 & - triiodothyroacétique & \multicolumn{2}{|c|}{ voir TRIAC } \\
\hline 17-cétostéroïde & 232,447 & - vanilmandélique & \multicolumn{2}{|c|}{ voir VMA } \\
\hline 17-hydroxylase & 418 & acide aminé & \multicolumn{2}{|c|}{290,291} \\
\hline 17-hydroxystéroïde & 224,232 & acide gras & \multicolumn{2}{|c|}{$264,290,291$} \\
\hline 19-norstéroïde & 485 & acide gras libre & \multicolumn{2}{|c|}{ voir AGL } \\
\hline 2-déoxy-D-glucose & 506 & acidocétose & \multicolumn{2}{|r|}{309} \\
\hline $20 \alpha$-hydroxyprogestérone & 422 & acidose lactique & \multicolumn{2}{|r|}{310} \\
\hline $20 \beta$-hydroxyprogestérone & 422 & acidose sanguine & \multicolumn{2}{|r|}{279} \\
\hline 25-hydroxylase microsomiale & 342 & acini & \multicolumn{2}{|r|}{471} \\
\hline 25-OH-D3-BP & 342 & aconitase mitochondriale & \multicolumn{2}{|r|}{114} \\
\hline $3 \beta$-déshydrogénase & 227 & acromégalie & \multicolumn{2}{|r|}{188} \\
\hline 3,3',5'triiodo-L-thyronine & 206 & acrophase & \\
\hline 3,3',5'triiodothyronine & 211 & $\mathrm{ACTH}$ & \multicolumn{2}{|c|}{$6,241,255,256$} \\
\hline 3,5,3'triiodothyronine & 20 & \multicolumn{3}{|c|}{$273,348,460,503,506,524$} \\
\hline $5 \alpha-\mathrm{DHT}$ & 450 & \multicolumn{3}{|l|}{ ACTH-like } \\
\hline $5 \alpha$-réductase & $44 c$ & \multicolumn{3}{|l|}{ action virilis } \\
\hline 5'-déiodinase & $20^{7}$ & \multicolumn{3}{|r|}{264} \\
\hline 5-hydroxytryptamine & 104 & \multicolumn{3}{|r|}{416} \\
\hline 6-sulphatoxy-mélatonine & 356 & \multicolumn{3}{|l|}{ activité rénine } \\
\hline${ }^{99} \mathrm{TC}$ & 212 & \multicolumn{3}{|l|}{ activité thyréotrope } \\
\hline & & \multicolumn{3}{|c|}{ ADA (American Diabetes Association) 297} \\
\hline A & & ADCC (antibody dependant $\mathrm{c}$ & cytotoxicity) & 517 \\
\hline$\alpha$-amino-3-hydroxy-5-methyl & & & & 138 \\
\hline 4-isoazolepronic acid & 111 & adénome & & 186 \\
\hline$\alpha$-endorphine & 504 & - mammaire & & 484 \\
\hline$\alpha$-méthyl DOPA & 171 & - somatotrope & & 188 \\
\hline$\alpha-\mathrm{MSH}$ & $157,160,50$ & - toxique & & 213 \\
\hline$\alpha$-thymosine & 347 & ADH (hormone antidiurétique & 178, & 242 \\
\hline$\alpha 2$ macroglobuline & 457 & 255,35 & $53,520,522$ & 2,525 \\
\hline A (adrénaline) & $244,294,460,505$ & adhésivité des leucocytes & & 106 \\
\hline $\mathrm{ABP}$ & 446 & adipocyte & & 248 \\
\hline Acanthosis nigricans & 298 & adipostat & & 436 \\
\hline acarbose (Glucor®) & 327 & ADPR cyclique & & 58 \\
\hline accouchement & 470 & adrénaline & & voir A \\
\hline ACE (enzyme de conversion & & adrénalinémie & & 252 \\
\hline de l'angiotensine) & 91 & adrenocorticotropin hormone & & 158 \\
\hline acétate de cyprotérone & 451,489 & $\mathrm{AF}$ (année femme) & & 481 \\
\hline acétylcholine & 10 & AGL (acide gras libre) & 279 & 9,285 \\
\hline acide & $14 \varepsilon$ & agoniste de la LH-RH & & 6,489 \\
\hline
\end{tabular}


agrégation plaquettaire

albuginée

albumine

aldostérone

aldostéronurie

alloxane

Alzheimer

aménorrhée

aménorrhée-galactorrhée

AMPc (AMP cyclique)

amyline

anabolisme protidique

analgésie

androgen binding protein

androgène

- fœtal ou maternel

androstène-dione

androstérone

ANF (facteur natriurétique atrial)

$241,252,352$

103, 106, 411

314

angiographie fluorescéinique

angiotensine

- I

- II

- III

$237,239,353,525$

angiotensinogène

angor

anion superoxyde

anneau vaginal

anœstrus

antibody dependant cytotoxicity

anticorps

anticorps anti-LH-RH

anticorps bloquant

antidiuretic hormone

antigène

$-\mathrm{H}-\mathrm{Y}$

- HLA DP

- HLA DQ

- HLA DR

antipéristaltisme

antivieillissement

antrum

apo-B

apoptose

aquaporine

arginine-vasopressine

ARN polymérase II

aromatase

aromatisation

arythmie

asthénie

446

$67,423,448$

461

$232,417,446$

232,447

240 ,

239

239

322

235

482

426

voir ADCC

459

433

457

178

401

320

$62,410,412$

180

178

76

430

$418,430,447$

270

224
103, 106 athérogenèse

athérome

athérosclérose

atrésie

- folliculaire

atriopeptide

auto-anticorps

auto-immunité

autocrine

autocrinie

autoradiographie

AVC (accident vasculaire cérébral)

avortement

B

$\beta$-endorphine $\quad 158,161,183,260,437,474$

$\beta$-galactosidase

33

$\beta$-hydroxybutyrique $\quad 279$

$\beta$-lipoprotéine $\quad 418$

$\beta$-LPH 160

$\beta$-MSH

B cell growth factor

158,160

baclofène

voir BCGF

bactérie $\quad 523$

balanite 310

baro-récepteur

bathmotrope

$181,240,252$

Bayliss et Starling

BCGF (B cell growth factor)

Bcl-2

bifidus

biguanide

binding protein

biosynthèse

blastocyste

blastomère

BMI (body mass index)

bombésine

bouton embryonnaire

BP (binding protein)

bradycardie

bradykinine

bromocryptine

Brown-Séquard

busériline
C

c-Fos

76

76

76

207

520

49 
caduque basilaire

calcémie

calcification

calcitonin gene related peptide voir CGRP

calcitonine

199, 216, 339, 520, 523, 524

calcitriol

calcium

calmoduline

canal

- de Gärtner

- de Müller

- de Santorini

- de Wirsung

- de Wolff

- déférent

- galactophore

- potassique sensible à l'AT

capacitation

captation de type I

captation de type II

caractère sexuel primaire

cardiomyopathie

caséine

caspase

castration

cataracte

catéchol-O-méthyl-transférase

catécholamine

CBG (transcortine)

CBR (central binding receptor)

CCK (cholécystokinine)

CD44

$\mathrm{cdk}$

cdk-cycline

cellule

$-\mathrm{A} 1$

$-\mathrm{A} 2$

$-\mathrm{B}$

$-\mathrm{C}$

- chromaffine

- cible

$-\mathrm{D}$

- de Langerhans

- de Leydig

- de Sertoli

- $\eta$ (éta)

$-\mathrm{F}$

- interrénale

- interstitielle de Leydig

- juxtaglomérulaire

- myo-épithéliale

- myocardique

- NK
338

62, 342

62

403

401

277

277

401

405,488

420,471

04, 290, 436

445,454

246

246

405

323

476

412, 441

418, 448, 449

317

voir COMT

$244,353,412$

$31,231,423,449$

508

291, 349

49

81

81

277

277

277

199

223

525

277

460

402, 446, 449

402, 444, 446, 449

147

277

222

444

240

183

107

voir NK
- "parafolliculaire"

339

- PP

277

- principale

329

- $\mathrm{T}$ cytotoxique

271

- thécale

152

- trophoblastique

456

Center for epidemiologic

studies depression

512

central binding receptor

voir CBR

céramide

61

céruloplasmine

97

cétogenèse

285, 288

cétonémie

279

$\begin{array}{ll}\text { cétonurie } & 279 \\ \text { CGRP (calcitonin gene related peptide) } & 339\end{array}$

chlorpromazine $\quad 164$

cholécalciférol

340

cholécystokinine

voir CCK

cholérèse

349

cholestérol

227,229

cholinergique 267

chondrogenèse 145

chromaffine

243

chromosome 2

152,153

chromosome 20

165

chronopharmacologie 21

chronotrope

248

chymodénine

351

citrate de clomifène

440, 490

clairance métabolique

29

clamp euglycémique

hyperinsulinique

295, 305

CLIP (corticotrophin like

intermediate peptide)

157

clitoris

403

Clomid

440,490

clonage

492

CMH (complexe majeur

d'histocompatibilité)

300

coiffe acrosomiale

445

coït

453

col

col utérin

426, 454, 469

colostrum

487

475

coma hyperosmolaire $\quad 310$

communication synaptique 109

complexe hypothalamo-hypophysaire $\quad 162$

complexe majeur d'histocompatibilité

voir $\mathrm{CMH}$

COMT (catéchol-O-méthyl-transférase) 246

ConA (concanavaline A) 503, 507, 512

condom

487

cône

405 
conjonctivo-chorial

contraceptif

contraception

coping

corona penetrating enzyme

corona radiata

corps cétonique

corps de Highmore

corps de Wolff

corps jaune

- gestatif

- gravidique

- pseudo-gestatif

corps ultimo-branchial

corpus albicans

corpuscule de Stannius

cortex

corticolibérine

corticostatine

corticosteroid binding globulin

corticostéroïde

corticostérone

$227,292,520,523$

corticotropin releasing hormone

cortisol

227, 265, 273, 292, 344, 470, 474, 519

cortisolémie

237

cortol

cortolone

cotylédon

courant calcique de type $\mathrm{L}$

CPE (corona penetrating enzyme)

crâniopharyngiome

CREB (cAMP response element binding protein)

crétin des Alpes

CRF (corticotropin releasing factor)

CRH (corticolibérine)

croissance

cryptorchidie

cumulus proliger

cyanure

cybernine

- ovarienne

cycle

- cellulaire

- menstruel

- œstrien

- ovarien

- utérin

- vaginal

cycline

450, 479

261

voir $\mathrm{CPE}$

407, 455

290, 291

443

222, 401

$152,414,422$,

461, 467

431

198, 339, 520

414,461

339,520

223

voir $\mathrm{CRH}$

242

voir $\mathrm{CBG}$

209

197

237,

506, 508

168,255

206

404, 447

411,415

333

169

415
$459-\mathrm{A}$ et B

$422-D$ et $\mathrm{E}$

cyclosporine

- A

cytokine

cytomégalovirus

cytotrophoblaste

D

d,l-fenfluramine

195

D3-BP

342

342

D3-binding protein

D4-androstène-3,17 dione

D5 prégnénolone

DAG (diacylglycérol)

danazol

DAS (désordre affectif saisonnier)

DBI (diazepam binding inhibitor)

décharge ovulante

déférent

déhiscence folliculaire

déhydro-épiandrostérone

déhydrotestostérone

dentelle endométriale

dentelle utérine

dépigmentation

dépôt amyloïde

dépression

- à long terme

désamination oxydative

désensibilisation

desmolase

désogestrel

désordre affectif saisonnier

deuil

deuxième globule polaire

développement

dexaméthasone

227, 274, 440

DHEA (déhydro-épiandrostérone)

$274,417,423,446,525$

DHT (dihydrotestostérone)

450

di-œstrus I et II

427

diabète

235

- "cortisonique"

292

- de Jung

81 - de type I

426 - de type II

426 - essentiel

292

voir DID

voir DNID

299

298, 465

303

178, 191

voir DID 
- insulinonécessitant

- maigre

- MODY

- non-insulinodépendant

- primitif

- secondaire

- sucré

diacylglycérol

diaphragme

diazepam binding inhibitor

diazépam

DID

diencéphale

différenciation mâle

dihydrofolliculine

dihydrotestostérone

dihydroxyphénylalanine

diiodotyrosine

diplotène

dispositif intra-utérin

distilbène 25

distrophine

DIT (diiodotyrosine)

DIU (dispositif intra-utérin)

DNID

domaine

$-\mathrm{PH}$

$-\mathrm{SH} 2$

$-\mathrm{SH} 3$

DOPA (dihydroxyphénylalanine)

dopamine

dosage

- immunologique

- radioimmunologique

down-regulation

DQ2

DQ3

DR3

DR4

dromotrope

DSM III

DSM III-R

DXM (dexaméthasone)

dynorphine

dysgénésie ovarienne

dysménorrhée

E

E2 (œstradiol)

ecdysone

échelle

- de Hamilton

- CES-D

.

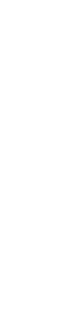

308

299

voir MODY

voir DNID

297, 299

297

296

voir DAG

480

voir DBI

507, 508

$117,297,299,502,516$

355

401

418

voir DHT

voir DOPA

voir DIT

409

voir DIU

485

117

204

481

297, 303

74,78

74

74

244

166, 266, 475

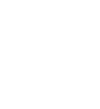

$411,417,421,430$

125

159,237

183,437

501

427

467

421

38,149

300

300

300, 517

300,517

248

514

194

- GWB-D

512

échotomographie thyroïdienne

213

éclairement

439

EDRF (endothelium derived relaxing factor)

EDTA

104

effet allostérique

335,345

EGF (epidermal growth factor)

éjaculat

éjaculation

éjection du lait

Elipten ${ }^{\circledR}$

ELISA

éminence médiane

endocol

endocrinie

endocrino-immunologie

endomètre

- placentaire

- utérin

endométrite

endorphin-like

endorphine

endothéline

endothélio-chorial

endothélium

enképhaline

entéroglucagon

environnement

enzyme de conversion

épididyme

épiphyse

épithalamus

epithelial growth factor

épithélio-chorial

EPO (érythropoïétine)

épreuve au thiocyanate

épreuve de l'eau

Epstein Barr

épuisement

ergocalciférol

ERK1

ERK2

érythropoḯtine

ésérine

éthinyl-œstradiol 100

étiocholanolone

eunuque

eustress

examen

exocytose

511

512
111

$80,410,472$

453

445

183

237

33

138

454

72

501

420, 426, 457

460

466

457

505

$259,267,523$

122, 241, 319

459

103, 353

$183,260,437,504$

291, 351

439

239

405

355

355

voir EGF

458

351

215

235

301

260

340

76

76

voir EPO

251

485

232, 447

448

253

513

177, 284

469 
$\mathbf{F}$

facteur

- VIII de Willebrandt

- XII (de Hageman)

- activateur des plaquettes

- anti-angiogénique

- de croissance

- natriurétique atrial

- paracrine

- satiétogène

- thymique sérique

faire face

faisceaux activateurs de la substance réticulée

fécondation

- in vitro

feed-back

FGF (fibroblast growth factor)

fibrillation ventriculaire

fibrinolyse

fibroblast growth factor

fidélité conjugale

FIV (fécondation in vitro)

flagelle

fluorure

FMP (forward mobility protein)

fœtus

follicle stimulating hormone

follicular regulary protein

follicule

- antral

- de de Graaf

- mûr de de Graaf

- ovarien

- primaire

- primordial

- secondaire

folliculogenèse

follistatine

fond d'œil

forward mobility protein

froid

frottis vaginal

FRP (follicular regulary protein)

fructose

FSH (follicle stimulating hormone) 150,151 , $410,411,415,418,428$, $432,437,449,505,520,522$

FSH-BI (FSH binding inhibitor)

FTS (facteur thymique sérique)

et SRAD
415

103,319
voir HF
voir PAF
106
50,72
voir ANF
412,440
436
voir FTS
261

(1)

453

voir FIV

173

$80,241,410$

270

103

voir FGF

194

489,490

445

333

445

461

voir FSH

voir FRP

408

409

426

95

407

403, 407

407

407, 426

416

314

voir FMP

218

426, 484

409

445

(1)

(1)

glycéraldéhyde-3-phosphate

déshydrogénase

347,501

$\gamma$-LPH

GABA

galactopoïèse

gamétogenèse

gastric inhibitory peptide

gastrine

gastrone

gène

- d'HNF I $\alpha$

- frq

- per

gestation

GH (growth hormone)

glaire cervicale

glande

- androgène

- de Bartholin

- de Cowper

- mammaire

- pinéale

- surrénale

- thyroïde

gliome

glucagon

- plasmatique

glucokinase

glucose

glucose regulated protein

glut 1

glut 2

glut 4

glutathion

glycogène glycémie

G-6-P

285

158,160

$148,301,508$

471

407, 449

GAP (GnRH associated peptide)

166

voir GIP

291,348

350

304

361

361

general well-being Schedule

512

217,457

GEU (grossesse extra-utérine) 414, 491

$142,255,292$,

$348,472,503,505,520$

GH-BH (GH binding protein)

146

GH-IH (somatostatine) $145,155,165,239$,

291, 296, 313, 348, 505, 523

GIP (gastric inhibitory peptide)

350

$413,420,426,453$

405

405

405

423,466

355

221

197

globule rouge de mouton

438

voir GRM

286, 291, 348

295

glucocorticoïde $235,257,348,472,505,506$

285,304

291

voir grp

285

285

285,307

114

365

312

$252,278,289,295$

114

glycogène synthase 287

glycogénogenèse 286

glycogénolyse

206, 251, 285, 286, 294 
glycolyse

glycosurie

GMPc (GMP cyclique)

GnRH (gonadolibérine)

goître

gonadocrine

gonadotrophine

- chorionique

GP (glande pinéale)

granulosa

GRB (growth factor receptor-bound protein) 76

GRH (GH-RH)

$145,155,165,255,258$

GRM (globule rouge de mouton)

grossesse extra-utérine

growth hormone

grp (glucose regulated protein)

guanosine monophosphate cyclique

guanylate cyclase

gynécomastie

voir GEU

voir GH

271

104

104

451

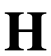

HAD

$\mathrm{Hb} \mathrm{a}_{1} \mathrm{C}$ (hémoglobine $\mathrm{a}_{1} \mathrm{C}$ )

178

324

HCG 151, 457, 462, 467, 473, 485, 491, 505

- placentaire

HCS

HDL (high density lipoprotein)

HDL-cholestérol

heat shock cognate protein

heat shock protein

Helicobacter pylori

hémo-chorial

hémochromatose

hexokinase

HF (facteur de Hageman = facteur XII)

HGH (human growth factor)

HPL

voir HPL

420,484

482

voir hes

voir hsp

115

459

298

285

83

40

HGPO (hyperglycémie provoquée per os) 297

high density lipoprotein

voir HDL

HIOMT (hydroxyindole-O-méthyltransférase)

356

hippocampe

$194,257,274$

hirsutisme

226,440

235

tamine

300,517

HMG (human menopausal gonadotrophin) 490

HNF $\alpha$

304

hormone

- androgène

- antidiurétique

- antimüllérienne

- chorionique gonadotrope

- corticosurrénalienne
- de croissance

- gastro-intestinale

- glucocorticoïde

- lipotropique

- lutéinique

- lutéotropique

- mélanotrope

- neurohypophysaire

- placentaire lactotrope

- thyréotrope

- thyroïdienne

463, 472

hsc (heat shock cognate protein)

hsp (heat shock protein)

270

HTA (hypertension artérielle) 243, 323

human chorionic somato-mammotrophin 463

human leucocyte antigen

voir HLA

human menopausal gonadotrophin voir HMG

hyaluronidase

455

hybridation in situ

42

hydramnios

461

hydrolase

455

- lysosomiale

412

hydroxyapatite

333

hydroxyindole-O-méthyltransférase

hydroxyle

356

hymen

364

hyperandrogénie

hypercalcémie

hyperglycémie

- provoquée

hyperkaliémie

hypernatrémie

hyperparathyroïdie

hyperphosphaturie

hyperphosphorémie

hyperpigmentation

hyperplasie surrénale congénitale

hyperprolactinémie

hypertension

- artérielle

hypertriglycéridémie

403

440,485

332

251, 278

294

224

225

332

332

331

160

225

474

251,254

voir HTA

320

331

331

353

310

516

225

225

224

516

337 
hypophosphaturie

hypophyse

hypophysectomie

hypospade

hypothalamus

hypothyroïdie primitive

I

iatrogène

171

ICER (inducible cAMP early repressor) 361

ICSH (interstitial cells stimulating hormone)

voir $\mathrm{LH}$

idiotype

IF (inhibiting factor)

IFN (interféron)

- IFN $\alpha$

- IFN $\gamma$

Ig (immunoglobuline)

$-\operatorname{Ig} \mathrm{A}$

$-\operatorname{IgE}$

$-\mathrm{IgG}$

$-\operatorname{IgM}$

IGF (insulin-like growth factor)

- IGF1

- IGF2

IH (inhibiting hormone)

IL (interleukine)

- IL1

- IL2

ilot

îlot de Langerhans

IMAO

immuno-enzymatique

immuno-histochimique

immunocytochimie

immunoglobuline

immunomodulation

impuissance

$\mathrm{INa}$

indice de Pearl

inducible cAMP early repressor

induction ovulatoire

infarctus

inflammation

infundibulum

inhibine

\section{6, 449, 451, 489}

$411,416,429$

inhibiteur

- de la maturation ovocytaire

- de la mono-amino-oxydase

- des $\alpha$-glucosidases

inhibiting factor

inhibiting hormone

164

115

476

459

145,410

$146,189,275$

146

164

114,235

102

503

voir Ig

508

448

212

481

voir ICER

489

322

103

138
331 inhibition de l'action

263

inositol phosphate 60

inotrope 248

404 insuffisance parathyrö̈dienne 330

253, 428 insuffisance surrénale chronique 516

516 insulin-like growth factor voir IGF

insulin receptor substrat voir IRS

insuline $280,348,460,465,472,523,525$

- mode d'action

286

insulinémie

295,307

insulinopénie

307

insulinorésistance

insulinosécrétion (facteurs)

$296,305,320$

insulinothérapie

intégrine

interféron

interleukine

internalisation

476, 514 interstitial cells

stimulating hormone

intertrigo

iodacétate

iode

289

324

48

voir IFN

voir IL

38

iodémie 210

iodure

IP3

202

61

IRM (imagerie en résonnance

magnétique nucléaire)

188

iron regulatory factor $\quad 114$

IRS (insulin receptor substrat) 287

ischémie/reperfusion 107

ischémie cardiaque 270

isoimmunisation 460

isoprénaline 248

isoproniazide 246

isoprotérénol 248

isothiourée 103

IVG 483

J

JAK (Janus activated kinase) $\quad 75$

jet-lag

367

jumeaux

457

\section{$\mathbf{K}$}

$\mathrm{K}^{+}$

240

kallicréine 83

kallidine $\quad 86$

katacacine 339

voir IMAO kininase KI et KII 86

326 kinine 86

voir IF kininogène 84 
$\mathbf{L}$

L-arginine

lactalbumine

lactate

lactation

lactogenèse

lactoglobuline

lactorrhée

lactose

lait

LATS (long acting thyroid stimulator)

LDL (low density lipoprotein)

lectine

leptine

leucocyte

levure

LH (hormone lutéinique)

$368,411,415,418,422,430,432$, $437,449,474,482,490,505,520,522$

LH-RH (lulibérine)

$167,432,436,437$, $449,474,523,524,525$

LI (inhibiteur de la lutéinisation)

415

libido

446, 448, 450

lipase

lipolyse

lipopolysaccharide

lipotropic hormone

liquide amniotique

liquor folliculi

lobe intermédiaire

lomidine

long acting thyroid stimulator

"long open time"

low density lipoprotein

LPH (hormone lipotropique)

LPS (lipopolysaccharide)

LTD (dépression à long terme)

LTH (hormone lutéotropique)

206, 248, 259, 465

101,102

160

461

408

160

302

voir LATS 361

voir LDL

160

101,102

110

147,428

LTP (potentialisation à long terme)

lulibérine

lumière

luteinizing hormone

lutéolyse

lymphocyte B

lymphopénie

lysine-vasopressine

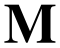

M-phase promoting factor

macro-angiopathie

macrogénitosomie

macromère

macrophage

235

178

voir MPF

355

456

$114,411,454$ macula densa

240

mal perforant plantaire

317

maladie

- auto-immune

299

- d'Addison

- d'Alzheimer

- de Huntington

- de Creutzfeldt-Jacob

- de Cushing

- de Graves-Basedow

- de Recklinghausen

mammogenèse

MAO (mono-amino-oxydase)

MAP kinase

MAP kinase-kinase

MAPK (MAP kinase)

marcotte pancréatique

mastocyte

mastodynie prémenstruelle

mastopathie

matrice organique

maturation

- ovocytaire

MB (métabolisme basal)

méconium

median forebrain bundle

médroxyprogestérone

médulla

médullo-surrénale

méiose

MEK (MAP kinase-kinase)

mélanine

melanocyte stimulating hormone

mélanodermie

mélanosome

mélatonine

membrane

- de Slavjansky

- pellucide

- vitelline

mémoire

méningiome

ménopause

menstruation

mésotocine

messager chimique

met-enképhaline

métabolisme basal

318 métanéphrine

métaphase II

méthode d'Ogino-Knaus

métopirone

$160,224,502$

$94,112,363$

111

270

225

200, 218

299, 502, 516

332

472

246

voir MAPK

voir MEK

57, 76, 77, 287

279

411

426

480, 484

333

411

522

205

475

voir MFB

485

223

243

$409,411,455$

76

160

voir $\mathrm{MSH}$

160, 224

160

voir Mt

407

407,454

430

193

438

$154,418,426,431$

426

521

47

158, 348

voir $\mathrm{MB}$

246

411

480

159, 227, 237 
métrorragie

MFB (median forebrain bundle)

micro-angiopathie

micro-organisme

micromère

micropilule

MIF (MSH-IH)

mifégyne

mifépristone

minéralocorticoïde

minipilule

"Minnesota Multiphasic

Personality Inventory" test

mise bas

MIT (monoiodotyrosine)

mitogen activated protein kinase

MMS (Mini Mental State)

mode d'action des œstrogènes

MODY (maturity onset diabetes

in the young)

mongolisme

monoiodotyrosine

monospermie

monoxyde d'azote

morula

motilité utérine

MPF (M-phase promoting factor)

MSEL-neurophysine

MSH (hormone mélanotrope)

MSH-IH (MSH inhibiting hormone) voir MIF

MSH-RH (MSH releasing hormone)

Mt (mélatonine)

muscle lisse

mydriase

myocardite

myomètre

myopathie de Duchesne

myxœdème

\section{$\mathbf{N}$}

$\mathrm{N}$-acétyltransférase

$\mathrm{N}$-méthyl-D-aspartate

$\mathrm{N}$-méthyl-transférase

NA (noradrénaline)

$\mathrm{Na}^{+}$

nadir

$\mathrm{NADPH}$

naloxone

naltrexone

nandrolone

NAT (N-acétyltransférase)

natrémie

natural killer

311

523

456

483

voir MAPK

voir MIT

voir NO

414, 456

177

160

273, 355

95

244, 250

466, 469, 487

117

200, 516

voir NAT

voir NMDA

244, 266

240, 519

$171,184,268,437,504$

268, 368, 506

242, 252
432 néoglucogenèse

266 néoténique

256, 279, 285, 286

169

485

485

257

482

512

468

204

363

421

304

298

455

183

411

169

107

244

273

237

448

356

368 néphropathie

202

315

nerf grand splanchnique

251

nétaglinide

325

neurodénégérative

112

neurone

- NANC

113

- nitrinergique 112

neuropathie

316

- végétative

neuropeptide $\mathrm{Y}$

316

voir NPY

177

523

111

422,456

96,103

96, 103

voir SINIA

nitroprussiate de sodium

$368,506,510,513$

(natural killer)

$\begin{array}{lr}\text { NMDA (N-méthyl-D-aspartate) } & 110 \\ \text { NO (monoxyde d'azote) } 88,96,299, & 302,352\end{array}$

NO synthase

voir NOS

nodule chaud

213

noradrénaline

voir NA

norethistérone

485

norgestrel

482

normétanéphrine 246

northern blot

42

NOS (NO synthase)

98

- cNOS (NO synthase constitutive) 98

- iNOS (NO synthase inductible) $\quad 98$ noyau

- catéchol

245

- dorso-médian

138

- infundibulaire (ou arqué) 138, 161, 165,

$167,176,432,433,437$

- magno-cellulaire

437

- paraventriculaire (NPV)

138,360

- supra-optique (NSO)

138

- suprachiasmatique (NSC)

358

- ventro-médian

138

NPY

nude

436, 351

505

\section{O}

obésité

304

ocytocine

œnanthate de testostérone

voir $\mathrm{Ot}$

488

œstradiol

voir E2

œstriol

418

œstrogène

$66,155,418,426,425,454,460$,

$461,466,467,469,471,472,523$ 


œstrone
OH॰
oligodendrocyte
oligospermie
OMI (ovocyte maturation inhibitor)
oncogenèse
oncostatique
opiacé
$\quad$ - endogène
opsiurie
oreillons
organes génitaux externes
orgasme
os
osmo-récepteur
osmo-récepteur hypothalamique
osmorégulation
osséine
ossification
ostéoblaste
ostéoclaste
ostéogenèse
ostéolyse
ostéomalacie
ostéoporse

438, 525

446

413,415

226, 235

302

403

445

337

240

180

521

332

333

337,420

337

337,345

337,345

331,341

426

ostéoporose

$183,469,520,522,525$

ovaire

ovariectomie

ovocyte maturation inhibitor

ovocyte

- primaire

- secondaire

ovogonie

ovulation

- périodique

- provoquée

- spontanée

\section{$\mathbf{P}$}

$\mathrm{P}$ (progestérone) 66, 227, 417, 422, 425, 430, $454,460,461,467,468,471,472,482,485$

PA (pression artérielle)

P-chlorophénylalanine

p53

pacemaker

- circadien

$217,413,430,466$

409,422

431,466

voir OMI

409

413

409

431

415,431

414

voir PCPA

76,272

paracrinie

72

parahormone

50

parathormone

voir PTH

parathyroïdectomie totale

330

parathyroïde

329

paratope

515

pars nervosa

138

particule de reconnaissance (SRP) 334

parturition 468, 470, 472

PBI (protein bound iodine) 210, 229

PBP (progesteron binding plasma protein)

$$
31,426
$$

PCPA (P-chlorophénylalanine)

PDGF (platelet derived growth factor)

241,319

PDH (pyruvate déshydrogénase) 306

pentoses-phosphates 286

peptide C 281, 303

peptide YY 351

peripheral binding receptor 229, 508

peripheral type benzodiazepine receptor

péristaltisme tubaire

voir PTBR

periventricular system

420

peroxisome proliferator activated voir PPA

peroxynitrite $\mathrm{ONOO}^{-}$

Pg (prostaglandine)

96

$-\mathrm{PgF} 2 \alpha$

$-\mathrm{PgE} 2$

$411,412,457$,

$469,470,485$

- PgI2 (prostacycline)

457,470

470

Pgn (prégnénolone)

319

PHA (phytohémagglutinine) 503, 507,

phallus

512,514

phase folliculaire

403

phase

426

$-\mathrm{G} 1, \mathrm{G} 1 \mathrm{H}$

81

$-\mathrm{G} 2$

81

- lutéale

416,426

- lutéinique

$-\mathrm{S}$

phénothiazine 171

phentolamine

248

phénylalanine 244

358 phéochrome 243

PAF (platelet activating factor)

118,470

phéochromocytome

243

460 phosphate tricalcique 333

paludisme

277

pancréas

$$
\text { phosphatémie }
$$

345

277

278

pancréatectomie

phospho-mono-estérase

333

phospholipase

voir PL

phosphore

344

48 
phosphotyrosin binding

phosphotyrosine

photorécepteur

phytohémagglutinine

picrotoxine

pied diabétique

PIF (prolactin inhibiting factor)

pilule

- anti-ovulatoire

- du lendemain

pinéalectomie

pinéalocyte

PK (protéine kinase)

$-\mathrm{A}$

$-\mathrm{C}$

$90,91,236,249$

$52,58,90,91,121$

- G (dépendante du GMPc) 104, 109, 113

PL (phospholipase)

$-\mathrm{A}$

$-\mathrm{C}$

placebo

placenta

plasmine

platelet activating factor

platelet derived growth factor

plectrin homology

PMA (procréations

médicalement assistées)

poche de Rathke

pokeweed

polydipsie

polynévrite

polynucléaire

polyurie

POMC (pro-opiomélanocortine)

pontage coronarien

ponte

post-partum

potassium

potentialisation à long terme

potentiel post-synaptique

potomanie

PPA (peroxisome proliferator activated) 308

PPD (dérivé protéique purifié de la tuberculine)

PPS (potentiel post-synaptique)

- PPSE (excitateur)

- PPSI (inhibiteur)

pré-hormone

pré-pro-glucagon

pré-pro-insuline

prégnandiol

prégnénolone

premier globule polaire
$90,92,121$

$88,90,121$

193

458

411

voir PAF

voir PDGF

78

489

137

511,513

178, 279

316

411

178,279

156,505

322

522

470,474

240

voir LTP

voir PPS

182

514

109

109

109

28, 449

286

281

422

voir Pgn

413 préservatif

pression artérielle

487

prion

voir PA

39,270

Prl (prolactine) 147, 258, 420, 428, 433, 464, $466,467,471,472,474,504,521$

pro-glucagon

286

pro-hormone

28,49

pro-insuline

281

pro-kallicréine

83

pro-œstrus

427

pro-opiomélanocortine voir POMC

pro-thymosine $\alpha \quad 501$

processing (apprêtage) 84

procréation médicalement assistée $\quad 489$

progesterone binding plasma protein $\quad 426$

progesterone binding protein 31

progestérone

voir P

prolactin inhibiting factor

voir PIF

prolactine

prolifération

voir $\operatorname{Prl}$

- gliale

508

272

propanolol

propylthiouracile

240, 248

prostacycline

prostaglandine

prostate

protéine kinase

protéine de "choc thermique"

protéine de transport

protéine $\mathrm{G}$

$-\mathrm{Gi}$

- Gs

protéine STAT

voir PTU

voir PgI2

voir $\mathrm{Pg}$

405, 452

voir PK

270

29

60

60

60

78

protéolyse

235

pseudo-puberté 226

psycho-neuro-endocrinologie 192

psycho-neuroimmunologie $\quad 505$

Pt (phosphotyrosine) 75

PtB (phosphotyrosin binding) $\quad 74$

PTBR (peripheral type

benzodiazepine receptor)

229,508

PTH (parahormone)

$216,334,460,520$

PTHrP (PTH related peptide) 338

PTU (propylthiouracile) 219

puberté 436

puissance sexuelle 450

PVS (periventricular system) $\quad 266$

PWM (pokeweed) 511

pyruvate déshydrogénase voir PDH

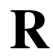

$\mathrm{R}$ (récepteur) 34

- adrénergique $\alpha 1, \alpha 2, \beta 1, \beta 2$ et $\beta 3 \quad 248$ 
- AMPA

- aux BDZ

- aux œstrogènes (R-E $\alpha, R-E \beta)$

- BK1 (R-BK1)

- BK2 (R-BK2)

- canal ionique

- couplé aux protéines G (R-CPG)

- de l'acide rétinoïque 9 cis (R-XR) 67, 209

- de l'acide rétinoïque tout-trans (R-AR) 67

- de la FSH

153

- de la LH

152

- de la mélatonine (R-Mt1, R-Mt2)

369

- de la prolactine (R-Prl)

- de la TSH

- des cytokines

- du calcium (R-Ca)

- enzyme

- GABA-A

- K2 (R-K2)

- membranaire

- métabotropique

- NMDA

- nucléaire

$-\mathrm{V} 1$

$-\mathrm{V} 1 \mathrm{a}$

- V2

rachitisme

radical libre

radioimmunologique

Raf

Ras

Ras-GDP

Ras-GTP

réaction

- acrosomiale

- d'alarme 253

réflexe (tacto-hypothalamo-hypophysaire) 183 régulation

- autocrine

- paracrine

rejet de greffe

relaxine

releasing factor

releasing hormone

rénine

répaglinide (Novonorm $\left.{ }^{\circledR}\right)$

reproduction

réseau idiotypique

résistance

rete testis

rétinopathie

rétro-contrôle

$\mathrm{RF}$ (releasing factor)

507

421

88

88

51

56

335

51

508

88

51

109

110

66

180, 186

243

186

331,341

$313,320,364$

32

76

76

76

241

241

107

467

voir RF

voir $\mathrm{RH}$

238

325

522

515

255

443

313

173
111 RH (releasing hormone)

164

53

- circadien

- nycthéméral de l'ACTH

RZRg (protéine nucléaire cible de la mélatonine)

460

114

206

485

418

150,358

158

369

$\mathbf{S}$

156 S-nitro-hémoglobine

97

S-nitroso-thiol

96,103

$\mathrm{SBG}=\mathrm{SBP}$ (sex hormone

binding globulin)

$31,423,449,484$

schizophrénie

367

scintigraphie par fluorescence

213

scintigraphie thyroïdienne

213

sclérose en plaques

299

SDM (syndrome dépressif majeur) $\quad 367$

second messager

sécrétine

sécrétion pulsatile

57

- de l'ACTH

288, 291, 349

- de la LH-RH

144,356

159

433

sécrétion prostatique

445

Ser (sérotonine)

171,348

sérotoninergique

267

sex hormone binding globulin

voir SBG

sexe de l'hypothalamus

176

sexocorticoïde

236

sexualisation

438

voir SBG

shsp (small heat shock protein)

271

SIA (système inhibiteur

de l'activité motrice)

267

SIADH (syndrome de sécrétion inappropriée

de l'hormone antidiurétique)

179

SIDA

$479,488,513$

signal mitogénique

signe de Chvostek

332

signe de Trousseau

332

SIN1A

103

small heat shock protein $\quad$ voir shsp

sodium-perméase

232

somatocrinine

145,165

somatomédine

145

$-\mathrm{A}$

146

$-\mathrm{C}$

somatostatine

146, 188, 189

voir GH-IH

somatotropic hormone 
somatotropin release inhibiting factor

somatotropin releasing factor

souris homozygote

souris $o b / o b$

spasmophilie

spermatide

spermatocyte

(de premier et de deuxième ordre)

spermatogonie

spermatozoïde

spermiation

spermine

spermogramme

sprue

SRA (système rénine-angiotensine)

SRAA (faisceau activateur ascendant)

SRAD (faisceau activateur descendant)

SRC-homology 2 domain

SRC-homology 3 domain

SRF (somatotropin releasing factor)

SRIF (somatotropin release inhibiting factor)

SSPG (teady state plasma glucose) 296

StAR (steroidogenic acute regulatory protein)

STAT3

steady state plasma glucose

stérilet

stérilité

stéroïde

stéroïdogenèse

steroidogenic acute regulatory protein

stéroïdogramme

STH (hormone somatotrope)

Stimu-LH

streptozotocine

stress

- aigu

- chronique

stroma

- ovarien

sulfamide hypoglycémiant

sulfate de DHEA

superovulation induite

superoxyde dismutase

Sutherland

$250,252,367,505$

Synacthène®

syncytiotrophoblaste

syndrome

- de Conn
- de Cushing

- de Klinefelter

159, 194, 225

- de Schwartz-Bartter

298

191

- de Sheehan

189

- de Turner

298

- de Wolfram

298

- dépressif majeur

voir SDM

- général d'adaptation

253

$-\mathrm{X}$

321,323

système

- de la punition

266

- de la récompense

266

- HLA

300,515

- inhibiteur de l'activité motrice

- rénine-angiotensine

voir SIA

voir SRA
229

436

voir SSPG

481

433,439

457,460

436

voir StAR

439

voir $\mathrm{GH}$

441

302

509

510

428

417

326

voir DHEA-S

491

T

$\mathrm{T}$ (testostérone)

T-helper

449, 460, 488

T-suppresseur

513

513

T3 (triiodothyronine) 155, 197, 204, 460

T3 inverse

206

T4 (tyroxine) $\quad 155,197,203,344,460,503$

tabagisme

484

tachycardie

248,270

tachystérol

340

taux de production

29

TBG (thyroxin binding globulin)

TBPA (thyroxin binding prealbumin)

TDF (testis determining factor)

TeBG

401

technetium

voir SBG

température

212

439

- de base

413,423

test

- à l'arginine

295

- au glucagon

295

- au tolbutamide

295

- de Hamolsky

214

- de Querido

212, 213

- de Thorn

224

- de Werner

213

- MMPI

512

- postcoïtal

446

testis determining factor

voir TDF

voir $\mathrm{T}$ tétanie 330, 331

TETRAC (acide tétraiodothyroacétique)

$159,224,237$

tétracosactide

206, 211

$456,460,463$

tétrahydrostéroïde

237

232

tétraiodothyronine

204

224

Tg (thyroglobuline)

197, 204 
TGF (transforming growth factor)

thèque

- externe

- interne

thermorégulation

thionitrite

thiouracile

thrombine

thromboxane

thromboxane A2

thrombus

thymectomie

thymopoiétine I et II

thymuline

thymus

thyréostimuline

thyroglobuline

thyroïdectomie

thyroïdite de Hashimoto

thyrolibérine

thyrotoxicose

thyrotropin releasing hormone

thyroxin binding globulin

thyroxine

thyroxinémie

tige infundibulaire

tim (timeless)

TNF (tumor necrosing factor)

$-\alpha$

tonus vasculaire

toxoplasmose

traducteur d'information

transcortine

transducteur d'information

transduction

transforming growth factor

transgénique

travail

tréponème

TRH (hyrotropin releasing hormone)

$168,255,475,524$

TRIAC (acide triiodothyroacétique) 206, 211

triiodothyroninémie

trisomie

troglitazone

trompe

trompes utérines

TSH (thyréostimuline)

$259,460,504,505,520,522,523$

tubes droits

tubes séminifères

tumor necrosing factor

241,410

408

206

217

104

368

319

319

501

347,501

347,501

347

voir TSH

voir $\mathrm{Tg}$

201

299, 502, 516

168

213

voir TRH

voir TBG

voir T4

200

138

361

114,241

412, 441

85

460

35

voir TGF

43

470

460

155 ,

402,443

voir TNF
114, tyrosine kinase

307

U

ultradien

23

149

up-regulation

utérus

422,454

utricule prostatique

403

34

V

vaccin

- anti-ovocyte

486

- contraceptif

vagin

485

422

488

vasectomie

vaso-constriction

104,251

vaso-relaxation

vasoactive intestinal peptide

104

voir VIP

vasopressine

vasotocine

very low density lipoprotein

voir ADH

521,524

vésicules séminales

voir VLDL

405,445

Viagra ${ }^{\circledR}$

113

vieillissement

$150,153,272,362$

villosité choriale

459

VIP (vasoactive intestinal peptide) 84, 288,

350,505

virus

476,515

virus coxsackie

B4 301

virus HIV

460

vitamine

$-\mathrm{C}$

257, 272

$-\mathrm{D}$

331

340

340

34 VLDL (very low density lipoprotein) 320

VLDV-neurophysine

177

VMA (acide vanilmandélique)

246

voie

- des polyols

312

- du sorbitol

312

volémie

von Mering et Minkovski

$241,242,520$

278

403

vulve

310

vulvo-vaginite

223

223

411

223

407, 453 



\section{TABLE DES MATIÈRES}

Avant-propos ............................................................................................................................5

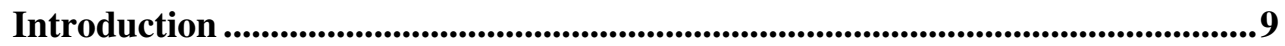

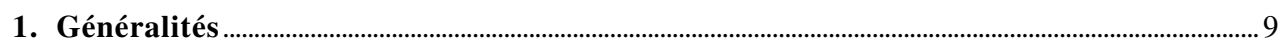

1.1. Endocrinologie et physiologie des régulations..........................................................................

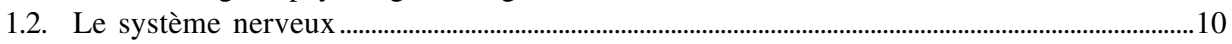

1.3. Le système hormonal

(glandes endocrines et cellules endocrines ou neuro-endocrines) ........................................10

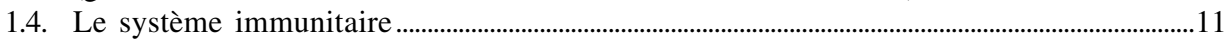

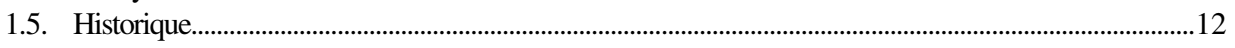

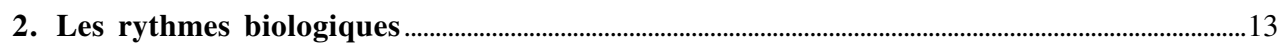

2.1. Les rythmes biologiques indépendants de l'environnement ........................................................14

2.2. Les rythmes biologiques inféodés à l'environnement..................................................................14

2.1.1. Les rythmes circadiens .........................................................................................................

2.1.2. Les rythmes circannuels.................................................................................................... 19

2.3. Variabilité physiologique des hormones ........................................................................................21

Références bibliographiques .................................................................................................................21

\section{Première partie - Méthodes et communications cellulaires}

Chapitre 1 - Méthodes utilisées en endocrinologie........................................................27

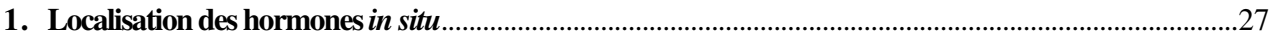

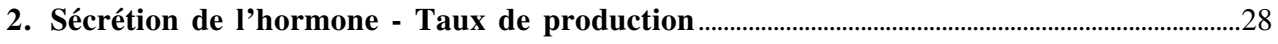

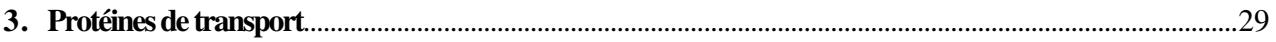

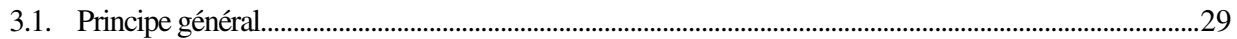

3.2. Les protéines de transport ………………………………………………………………………...

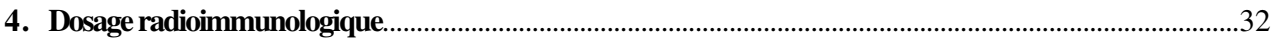

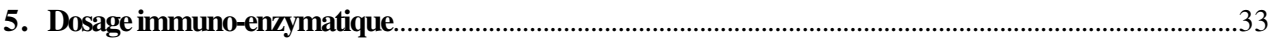

Application au dosage de la progestérone (méthode compétitive) ..........................................33

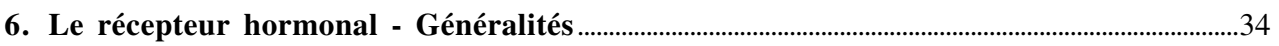

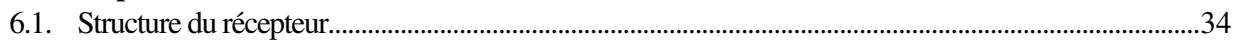

6.2. Propriétés du récepteur............................................................................................................................

6.3. Régulation du nombre des récepteurs ............................................................................................

6.4. Internalisation des complexes récepteurs-hormones polypeptidiques........................................38

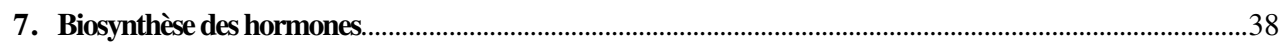

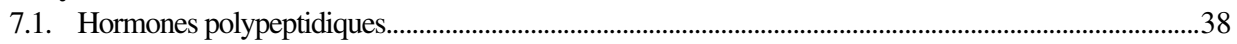

7.2. Etude dynamique de la biosynthèse des hormones polypeptidiques ..........................................41

7.2.1. L'autoradiographie en microscopie électronique .................................................................41

7.2.2. L'immunocytochimie en microscopie électronique...........................................................42

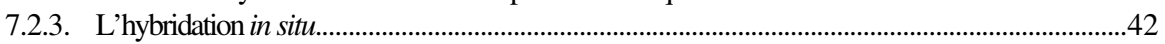

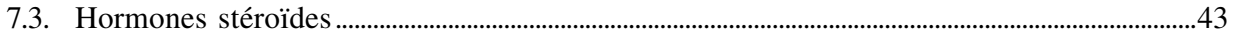

8. Les souris transgéniques :

un outil pour une approche moléculaire de l'endocrinologie. 
Chapitre 2 - Les messagers chimiques............................................................................47

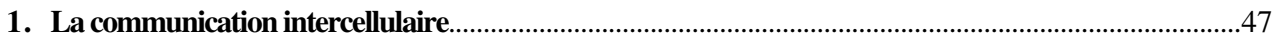

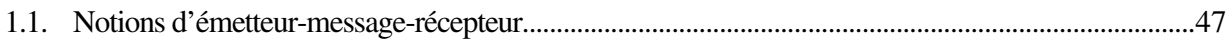

1.2. Les différents modes de communication entre les cellules..........................................................48

1.3. Les différents types de messagers chimiques impliqués dans la communication

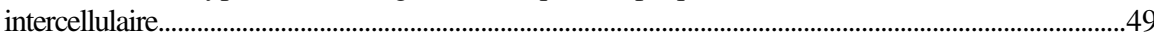

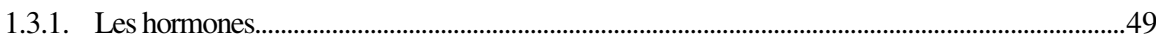

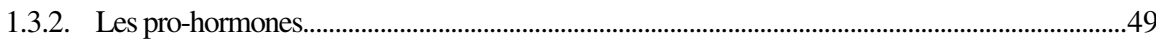

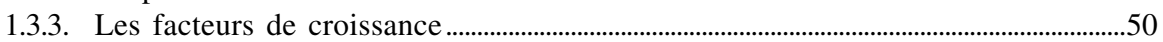

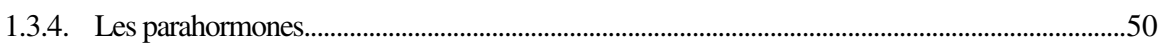

2. Traduction membranaire des messagers chimiques ……........................................................5

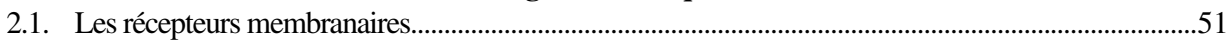

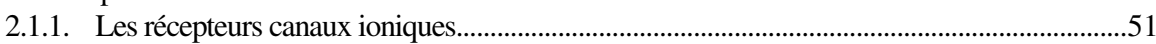

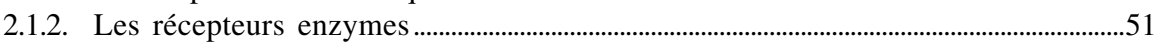

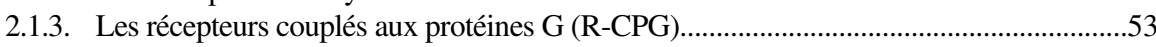

2.1.4. Les récepteurs de la superfamille des cytokines.............................................................55

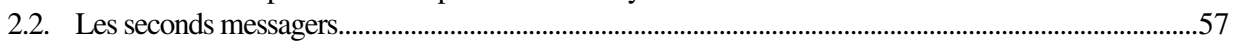

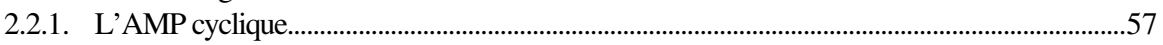

2.2.2. Le GMP cyclique ..............................................................................................................5

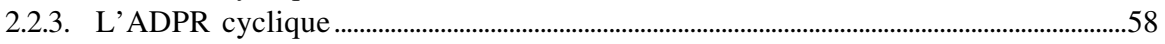

2.2.4. Les inositols phosphates et le diacylglycérol ......................................................................60

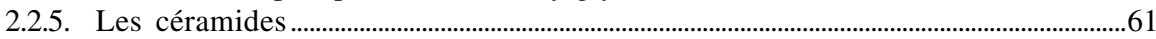

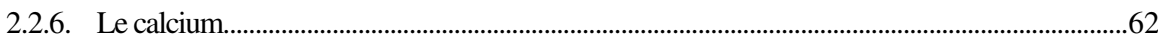

2.2.7. L'acide arachidonique et ses dérivés.........................................................................................63

3. Traduction des messagers capables de diffuser au travers des membranes......................64

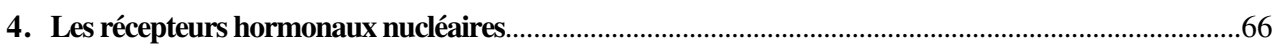

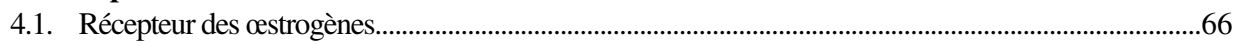

4.2. Récepteur de la progestérone..................................................................................................................66

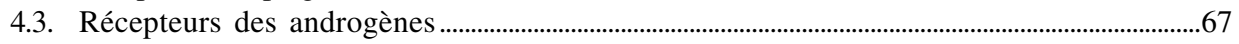

4.4. Récepteurs de l'acide rétinoïque...........................................................................................................67

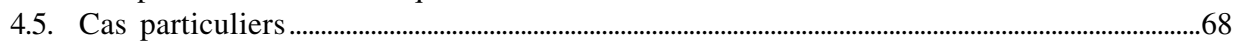

5. Interactions entre les différents systèmes activés par les messagers chimiques................68

6. Pathologies de la communication intercellulaire et thérapie ...................................................... 70

Chapitre 3 - Messagers chimiques particuliers :

signaux mitogéniques, kinines, NO, PAF, endothéline, ecdysone ........................71

1. Mécanismes de réception et de transmission des signaux mitogéniques................................71

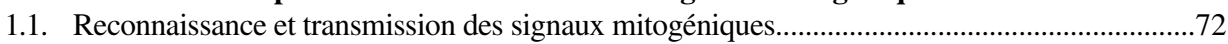

1.1.1. Fixation du facteur de croissance et activation du récepteur........................................72

1.1.2. Fonctions des récepteurs de facteurs de croissance..........................................................

1.1.3. Rôle des domaines SH2, SH3, PtB et PH

dans les réseaux de signalisation cellulaire ....................................................................... 74

1.1.4. Cas des récepteurs à plusieurs sous-unités.............................................................................74

1.2. Propagation des signaux de la membrane plasmique au noyau cellulaire :

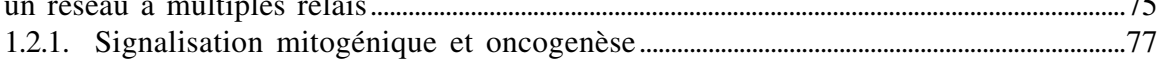

1.2.2. La voie des MAP kinases :

une voie de signalisation mitogénique universelle ?.....................................................77

1.2.3. Spécificité et plasticité des réseaux de signalisation cellulaire.................................78

1.3. Régulation du cycle cellulaire ........................................................................................................ 81

1.3.1. Régulation des cdk-cyclines par phosphorylation-déphosphorylation .........................81

1.3.2. Protéines inhibitrices des cdk-cyclines............................................................................ 82 
2. Les kinines

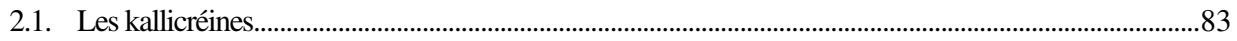

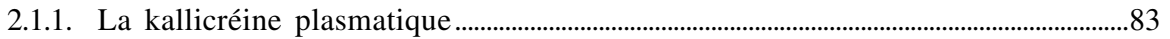

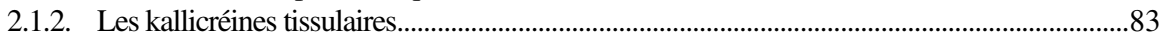

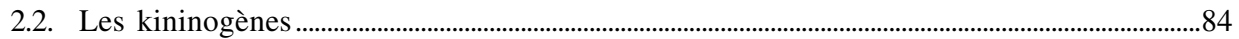

2.2.1. Structure chimique et métabolisme............................................................................................8

2.2.2. Rôles physiologiques ………………………………………………………………….... 85

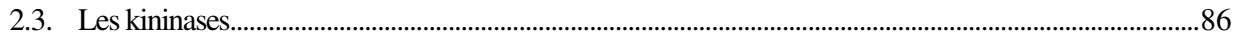

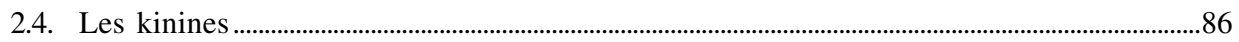

2.4.1. Structure chimique et métabolisme.......................................................................................

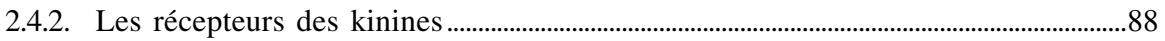

2.4.3. Rôles physiologiques .......................................................................................................91

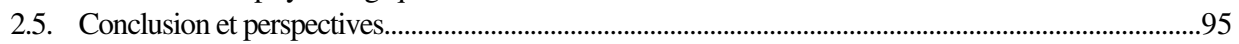

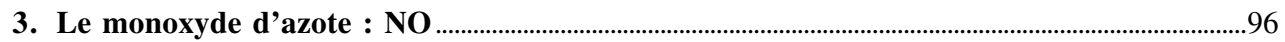

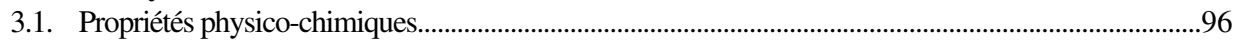

3.2. Biosynthèse et donneurs de NO ...........................................................................................................98

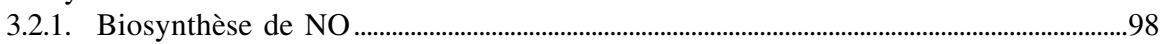

3.2.2. Les donneurs de NO, le métabolisme de NO, cible potentielle
d'actions thérapeutiques

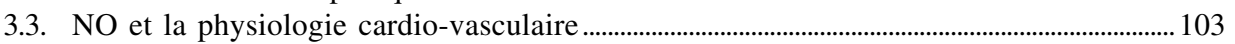

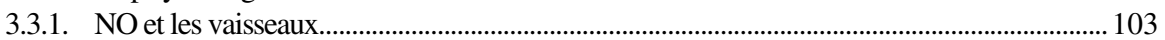

3.3.2. NO et le muscle cardiaque .............................................................................................. 107

3.4. NO et le système nerveux................................................................................................................... 109

3.4.1. NO et le système nerveux central ........................................................................................ 109

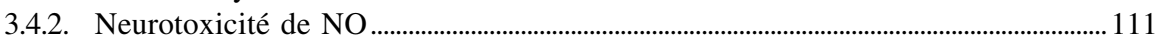

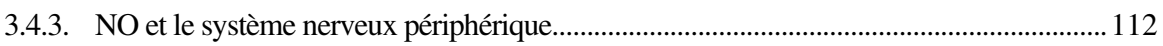

3.5. NO - Autres effets cytotoxiques .................................................................................................... 113

3.5.1. NO et les macrophages..................................................................................................... 114

3.5.2. Autres types cellulaires et cytotoxicité de NO ............................................................... 115

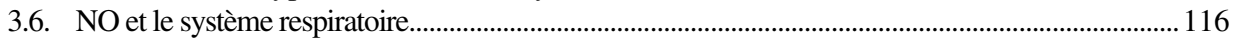

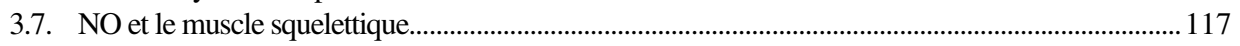

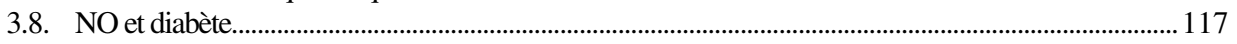

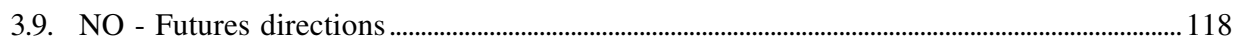

4. Le facteur activateur des plaquettes (PAF) ............................................................................. 118

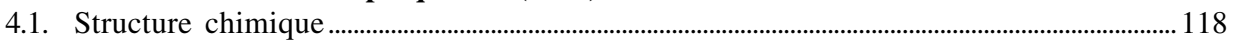

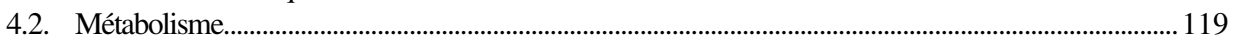

4.2.1. La synthèse vicariante ....................................................................................................... 120

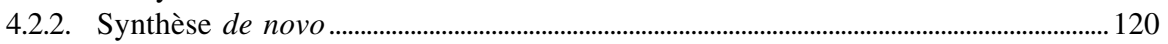

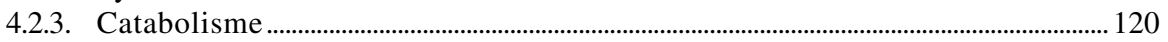

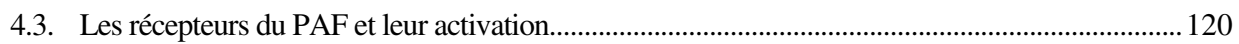

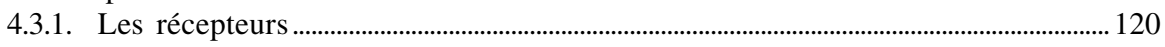

4.3.2. Activation des récepteurs du PAF................................................................................ 121

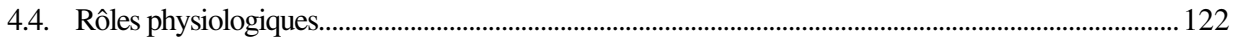

4.5. Conclusions et perspectives........................................................................................................... 122

5. L'endothéline

Effets cardio-vasculaires de l'endothéline .................................................................................... 124

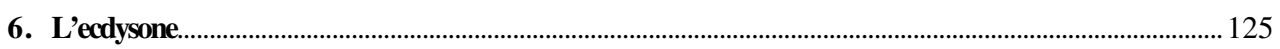

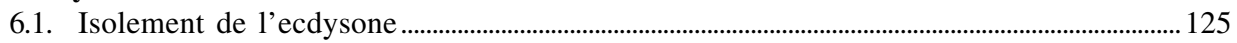

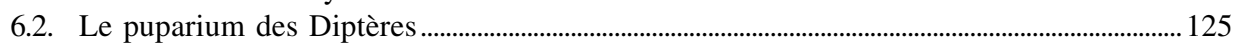

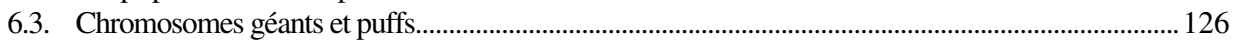

6.4. Mise en évidence du rôle de l'ecdysone .......................................................................................... 126

Références bibliographiques de la première partie...............................................129 


\section{Deuxième partie - Endocrinologie générale}

Chapitre 4 - Le complexe hypothalamo-hypophysaire 137

1. Embryologie de l'hypophyse. 137

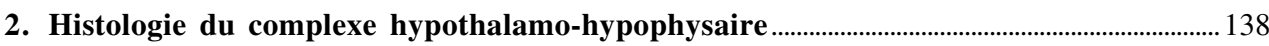

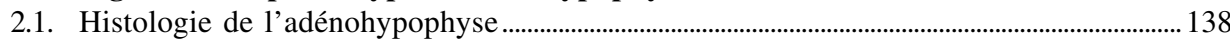

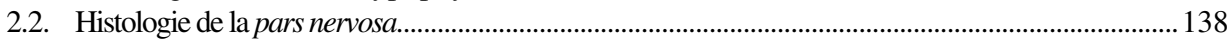

2.3. Histologie de l'hypothalamus......................................................................................................... 138

3. Données anatomo-cliniques et expérimentales ......................................................................... 141

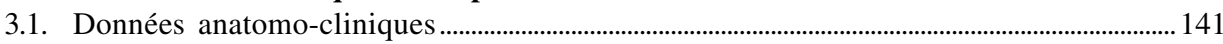

3.2. Données expérimentales : l'hypophysectomie............................................................................... 141

4. Les hormones de la pars distalis et de la pars intermedia ……………….................................... 142

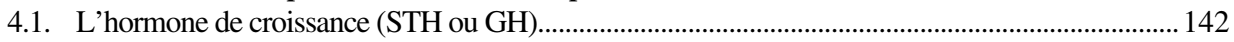

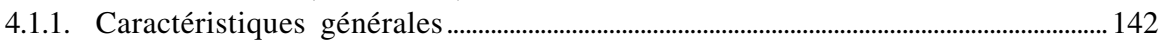

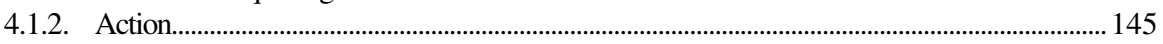

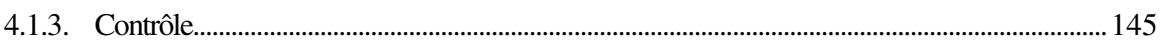

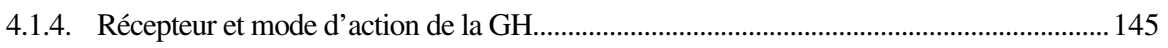

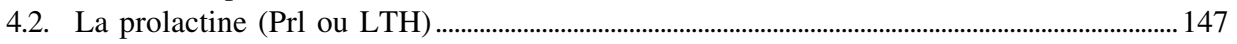

4.2.1. Caractéristiques générales ................................................................................................ 147

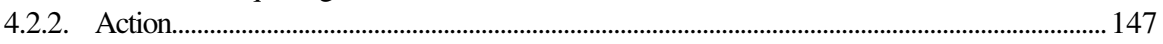

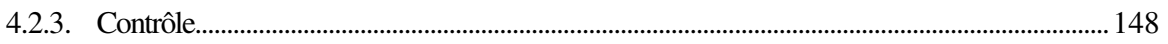

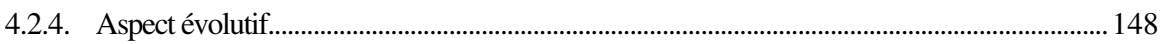

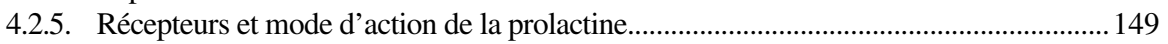

4.2.6. L'hormone de croissance et la prolactine au cours du vieillissement..................... 150

4.3. Les hormones gonadotropes ou gonadotrophines hypophysaires ........................................... 150

4.3.1. La FSH (follicle stimulating hormone) …………………………………………….... 151

4.3.2. La LH (luteinizing hormone)............................................................................................ 151

4.3.3. Récepteurs et mode d'action des hormones gonadotropes ............................................ 152

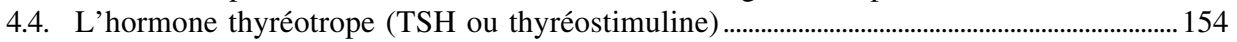

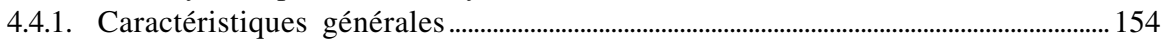

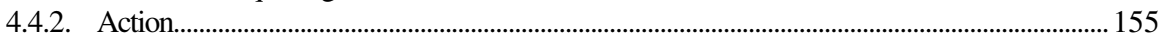

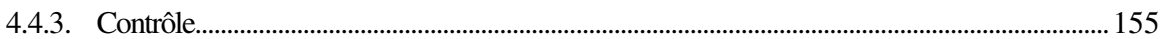

4.4.4. Récepteur et mode d'action de la TSH............................................................................ 156

4.5. Les hormones dérivées de la pro-opiomélanocortine (POMC)................................................. 156

4.5.1. L'ACTH (adrenocorticotropin hormone) ou hormone corticotrope............................158

4.5.2. La LPH (lipotropic hormone) ............................................................................................ 160

4.5.3. La MSH (melanocyte stimulating hormone) ou hormone mélanotrope................. 160

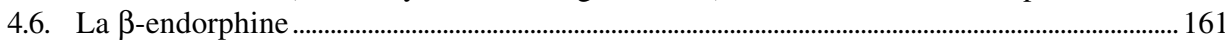

4.7. Dosage des hormones de la pars distalis .................................................................................... 161

5. Notion de complexe hypothalamo-hypophysaire ................................................................................. 162

6. Les hormones hypothalamiques hypophysiotropes ……………………………………………..... 164

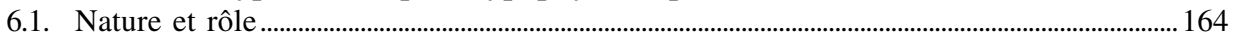

6.1.1. Cas des cellules somatotropes (cellules productrices de l'hormone

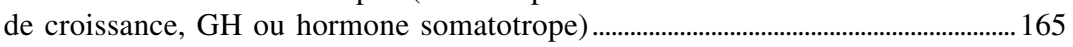

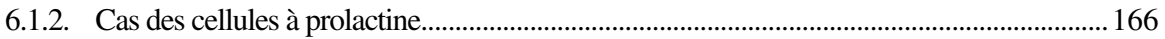

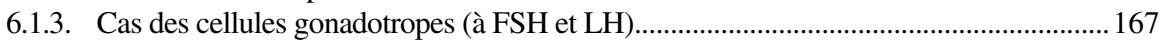

6.1.4. Cas des cellules thyréotropes (à TSH) ......................................................................... 168

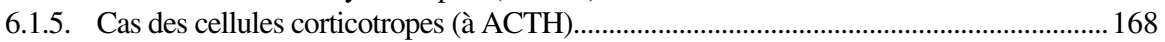

6.1.6. Cas des cellules mélanotropes (à MSH) ........................................................................ 169

6.2. Contrôle mono-aminergique ou peptidergique

des neurones hypothalamiques hypophysiotropes......................................................................... 169

6.2.1. Axe somatocrinine/somatostatine et GH................................................................... 170

6.2.2. Axe PIF et prolactine ........................................................................................................... 171 


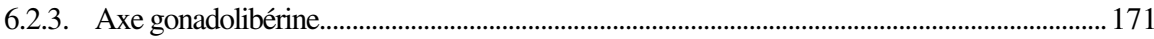

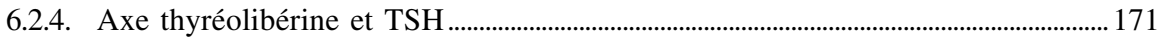

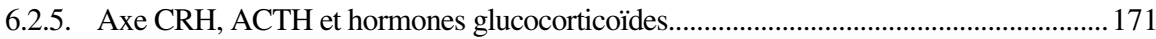

6.3. La notion de feed-back (rétro-contrôle) …………………………………………………………....... 173

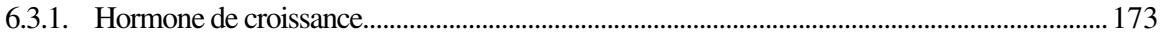

6.3.2. Axe hypothalamo-hypophyso-thyroïdien........................................................................... 173

6.3.3. Axe hypothalamo-hypophyso-surrénal ............................................................................ 174

6.3.4. Axe hypothalamo-hypophyso-gonadique ……………………………………………...... 174

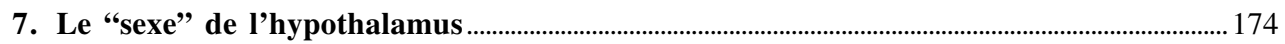

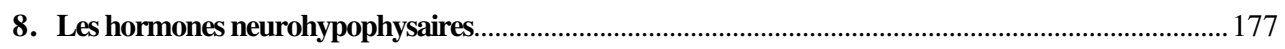

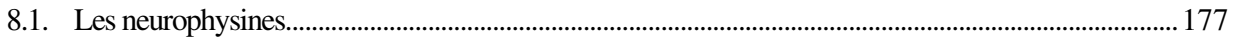

8.2. L'hormone antidiurétique ou vasopressine (HAD ou ADH : antidiuretic hormone) ...... 178

8.2.1. Structure et localisation ..................................................................................................... 178

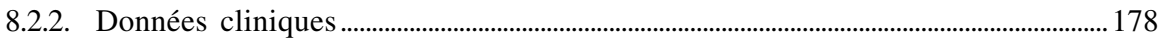

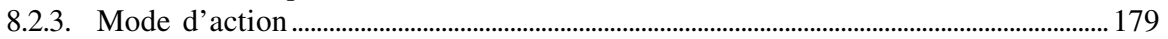

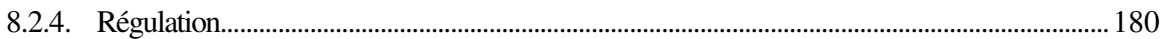

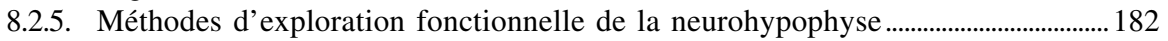

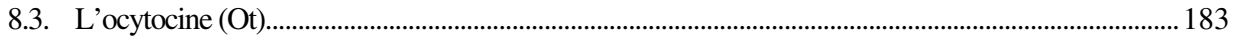

8.3.1. Structure et localisation ...................................................................................................... 183

8.3.2. Actions physiologiques ………………………………………………………………..... 183

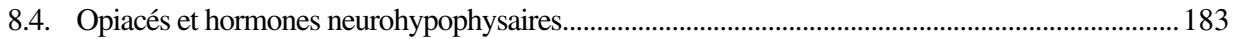

8.5. Récepteurs des hormones neurohypophysaires ............................................................................ 184

9. Les pathologies du complexe hypothalamo-hypophysaire .......................................................... 186

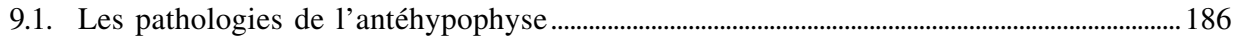

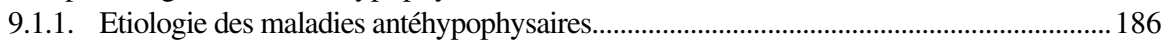

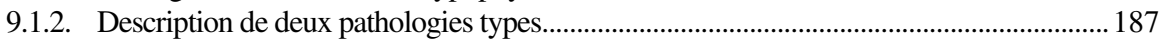

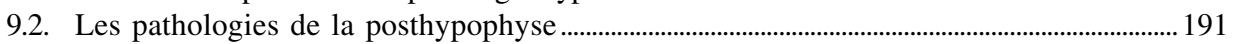

9.2.1. Le diabète insipide ....................................................................................................................... 191

9.2.2. Le syndrome d'hypersécrétion de Schwartz-Bartter ...................................................... 191

10. Psycho-neuro-endocrinologie

10.1. Hormones neurohypophysaires et mémoire …………………………………………………....... 193

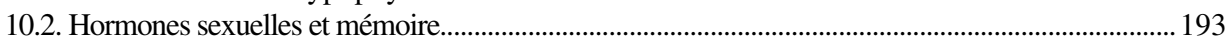

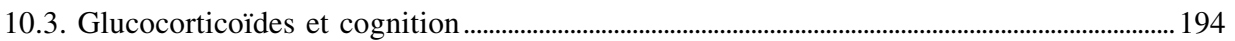

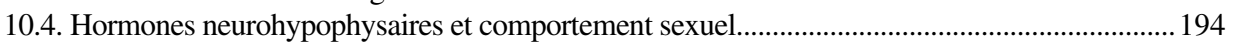

10.5. Neuromédiateurs et troubles psychiatriques............................................................................... 194

Chapitre 5 - La glande thyroïde ............................................................197

1. Caractéristiques générales ................................................................................................................... 197

2. Données anatomo-cliniques et expérimentales ...............................................................................2 200

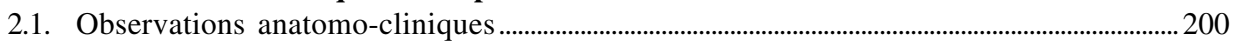

2.1.1. Un hyperfonctionnement : la maladie de Basedow …………………...........................200

2.1.2. Un hypofonctionnement : le myxœedème............................................................................200

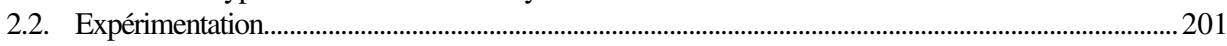

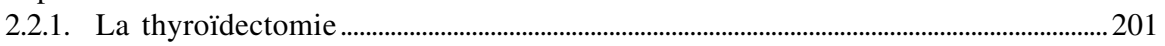

2.2.2. L'administration d'hormones thyrö̈diennes ..................................................................... 201

3. Biochimie et biosynthèse des hormones thyroïdiennes (T3 et T4) .......................................... 202

3.1. Captation et concentration des iodures par les cellules thyroïdiennes (trapping)..........202

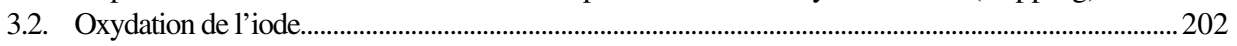

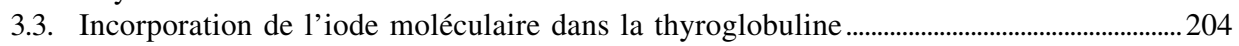

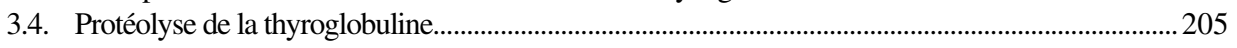

4. Rôle physiologique des hormones thyrö̈diennes ...................................................................205

4.1. Principaux effets des hormones thyrö̈diennes chez les Mammifères ...................................... 205

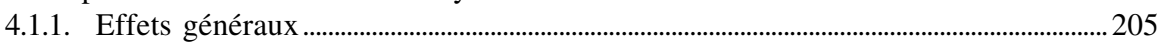




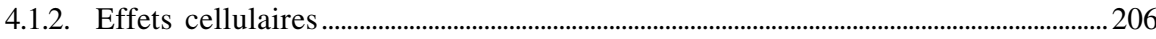

4.2. Mode d'action des hormones thyroïdiennes .....................................................................................207

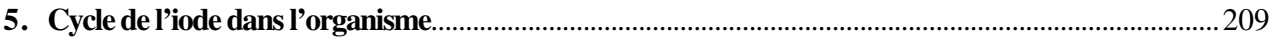

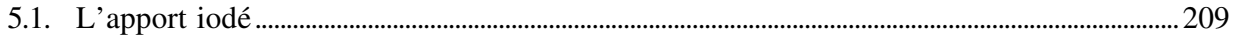

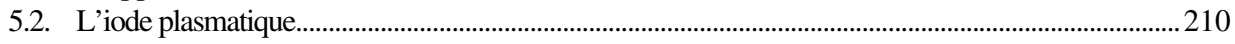

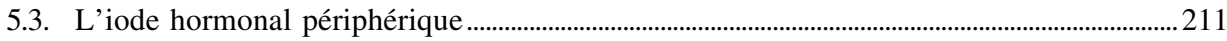

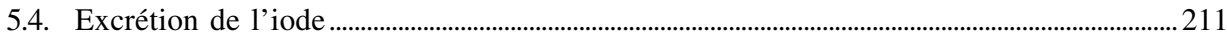

6. Epreuves fonctionnelles de l'activité thyroïdienne ........................................................................212

6.1. Fixation de l'iode radioactif .........................................................................................................2 212

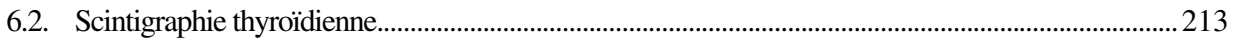

6.3. Etude des composés iodés circulants et des protéines porteuses............................................214

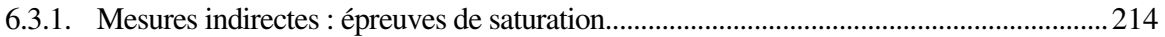

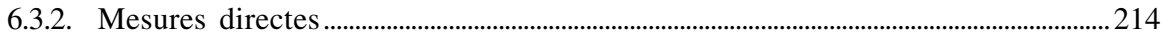

6.4. Etude de l'utilisation hormonale périphérique ..........................................................................215

6.5. Mesure de l'activité thyréotrope hypothalamo-hypophysaire ………………………………....215

6.5.1. L'épreuve à la TRH........................................................................................................... 215

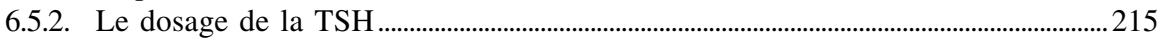

7. Thyrö̈de et métabolisme calcique …………………………………………………………………....216

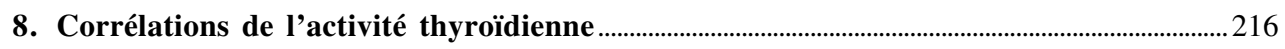

8.1. Avec l'hypothalamo-hypophyse ................................................................................................... 216

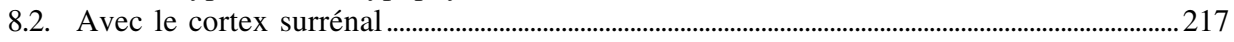

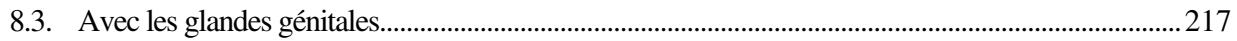

8.4. Autres interactions des hormones thyroïdiennes ......................................................................... 218

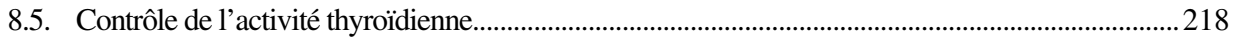

9. La maladie de Graves-Basedow : une maladie auto-immune .....................................................218

Chapitre 6 - Les glandes surrénales....................................................................221

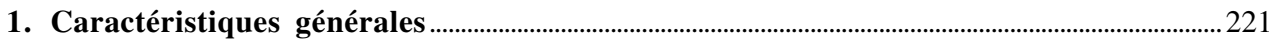

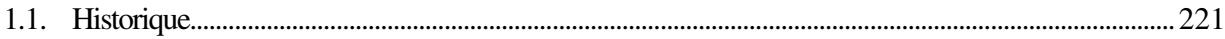

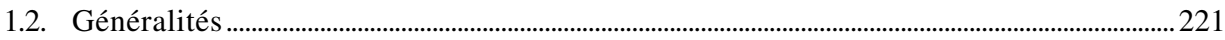

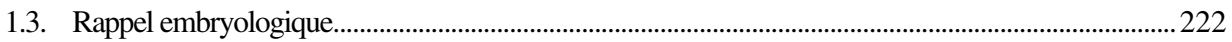

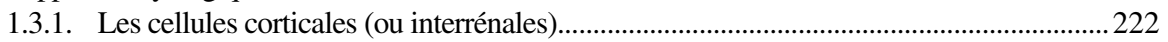

1.3.2. Les cellules médullaires (ou chromaffines) ..................................................................22 223

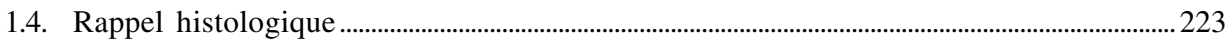

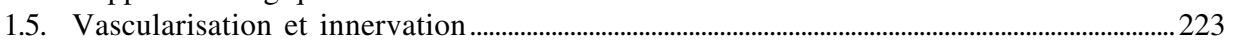

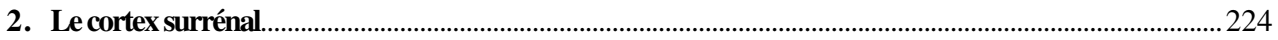

2.1. Données anatomo-cliniques et expérimentales ........................................................................224

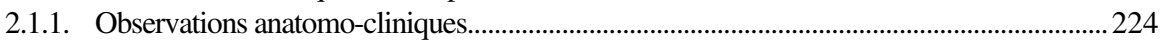

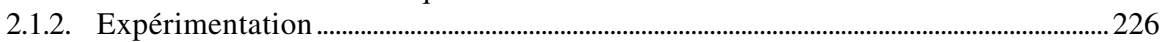

2.2. Biochimie des hormones corticosurrénaliennes ............................................................................22 227

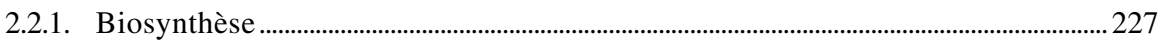

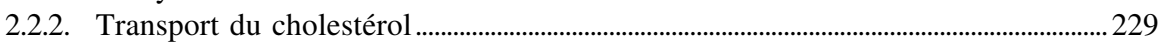

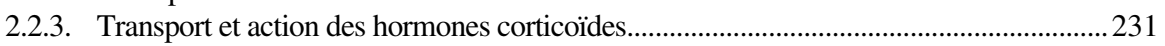

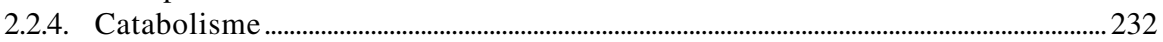

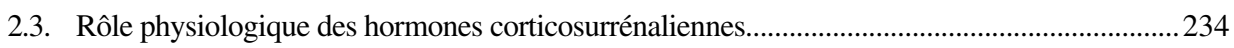

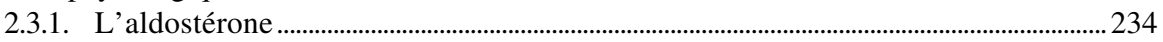

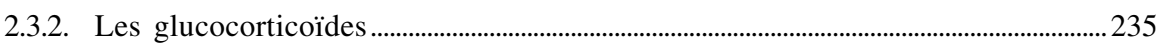

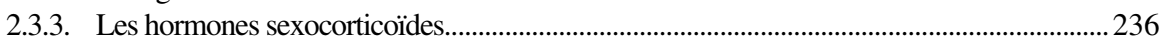

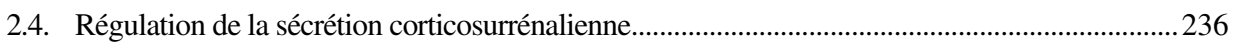

2.4.1. Contrôle de la sécrétion des glucocorticoïdes et des sexocorticoïdes....................236

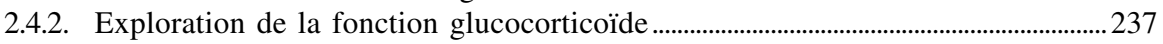

2.4.3. Contrôle de la sécrétion d'aldostérone...............................................................................237

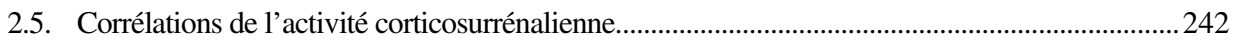




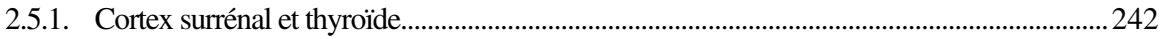

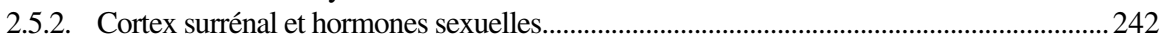

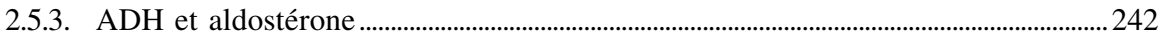

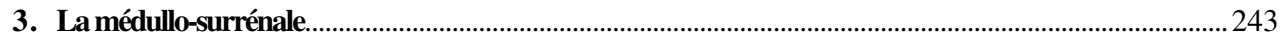

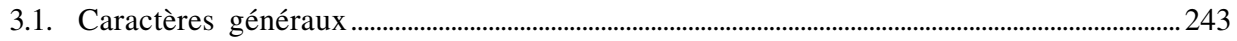

3.2. Données anatomo-cliniques et expérimentales ...........................................................................243

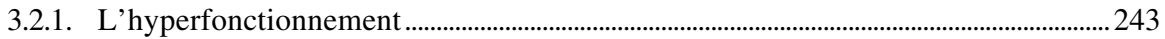

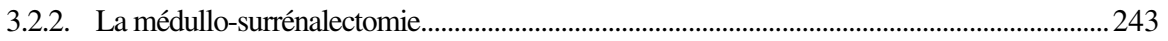

3.2.3. Les injections d'hormones ou d'analogues hormonaux ...................................................24

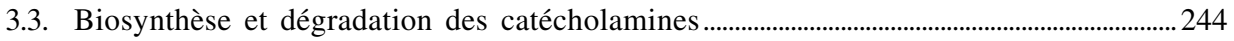

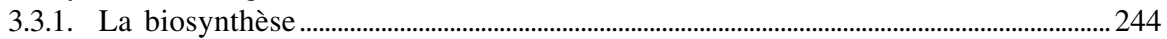

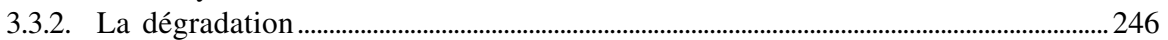

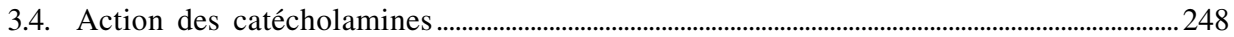

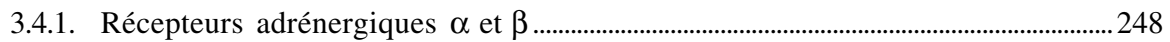

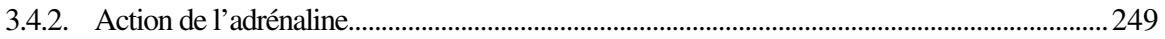

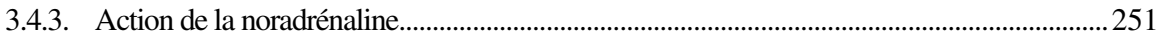

3.5. Régulation de l'activité de la médullo-surrénale .......................................................................251

3.5.1. Les centres nerveux adrénalino-sécréteurs et leurs voies efférentes .......................251

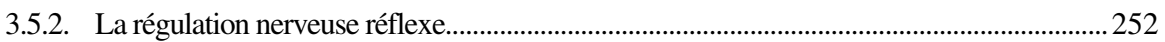

3.5.3. La régulation humorale.......................................................................................................... 252

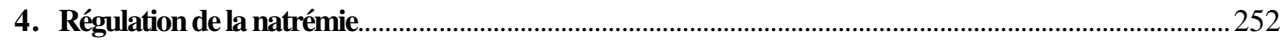

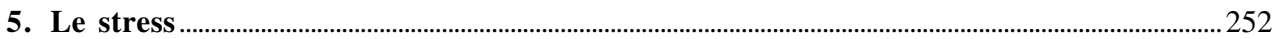

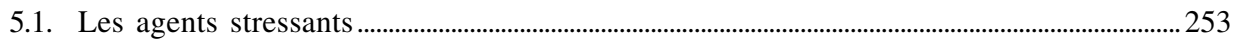

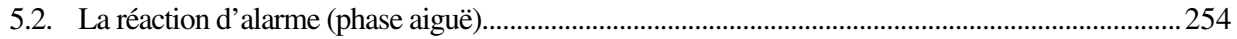

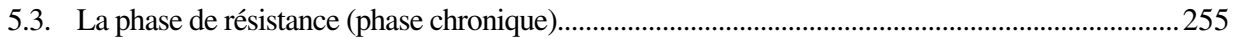

5.3.1. La décharge d'ACTH et de glucocorticoïdes.....................................................................256

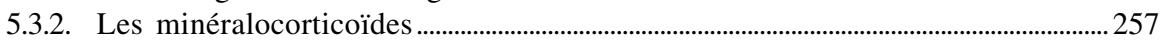

5.3.3. L'hormone de croissance ........................................................................................................ 258

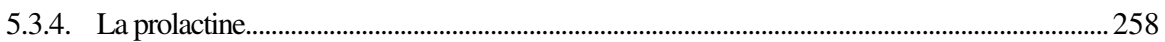

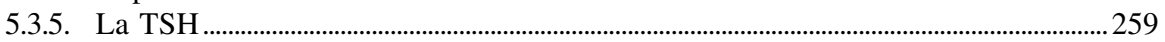

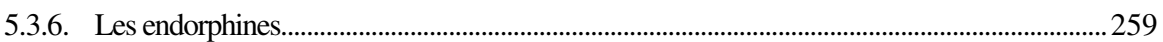

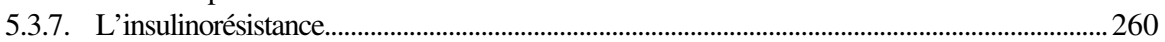

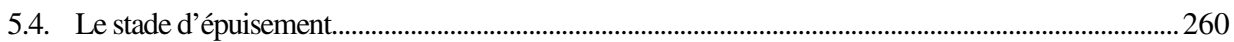

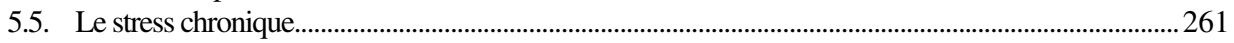

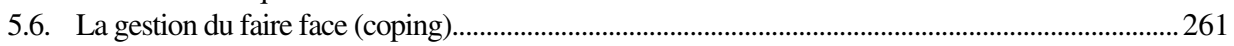

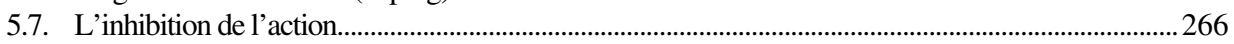

5.7.1. Le système de la récompense ......................................................................................... 266

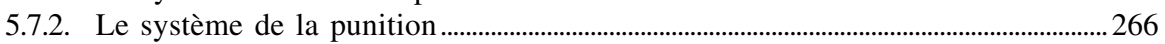

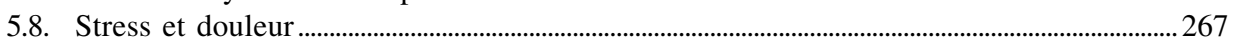

5.8.1. Quel rôle peut jouer cette analgésie dans le stress ?.....................................................267

5.8.2. Mais quelle est l'origine de cette analgésie ? ................................................................2. 268

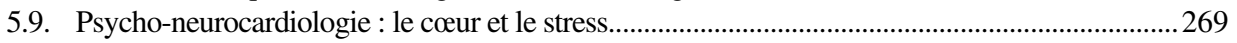

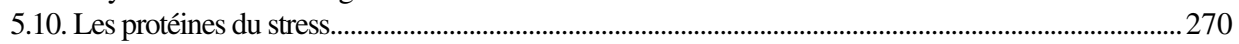

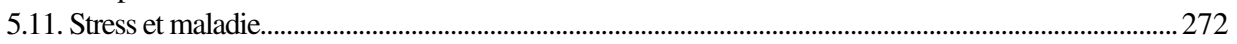

6. L'axe hypothalamo-hypophyso-surrénalien au cours du vieillissement ..............................2 272

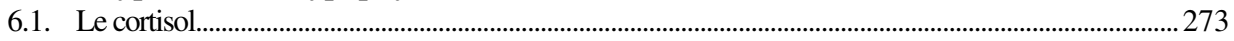

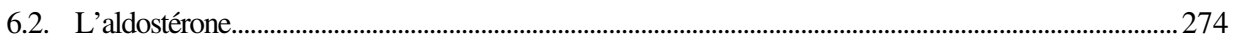

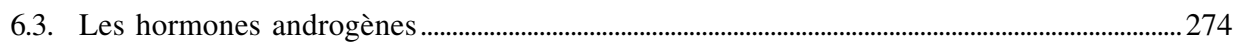

Chapitre 7 - Le pancréas endocrine .....................................................................2277

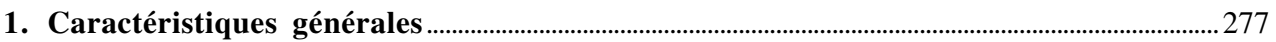

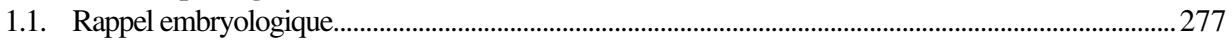

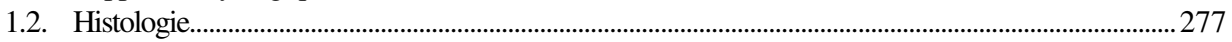

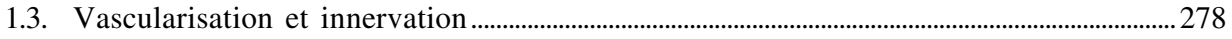


2. Etude expérimentale

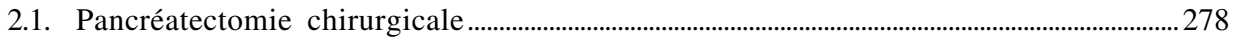

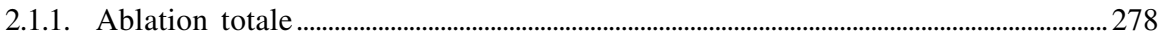

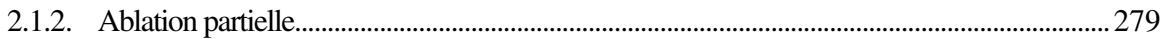

2.1.3. Ligature des canaux de Wirsung et Santorini.................................................................29

2.1.4. Greffe d'un fragment de pancréas...................................................................................... 280

2.2. Pancréatectomie chimique ............................................................................................................... 280

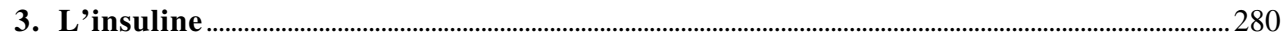

4. Actions physiologiques et mode d'action de l'insuline .................................................................282

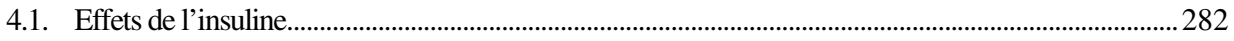

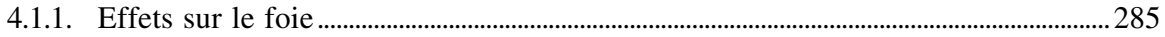

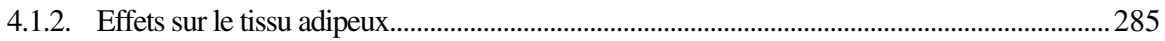

4.1.3. Effets sur le muscle strié (squelettique et cardiaque) ………………………………....225

4.1.4. Effets périphériques (adipocytes et muscles) …………………………………………....28

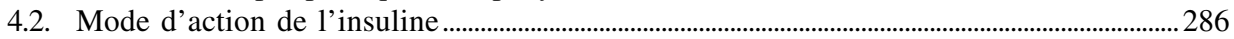

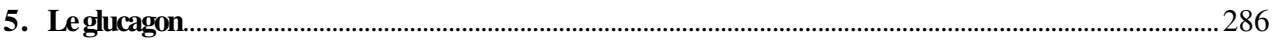

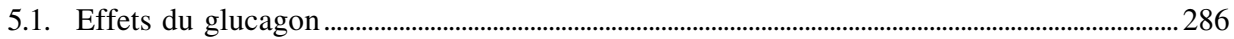

5.2. Mode d'action du glucagon............................................................................................................ 288

6. Régulation de la sécrétion des hormones pancréatiques ……………………………………......28

6.1. Facteurs déclenchant l'insulinosécrétion ...................................................................................28

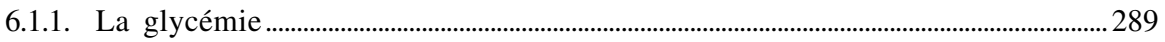

6.1.2. Les acides aminés, acides gras et corps cétoniques .......................................................290

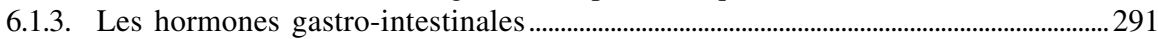

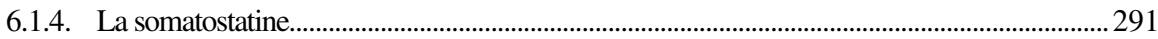

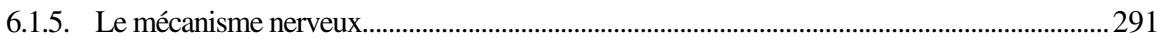

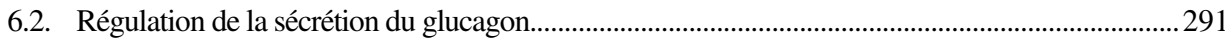

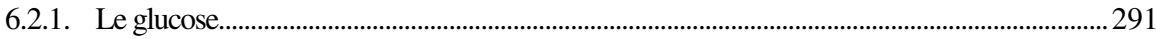

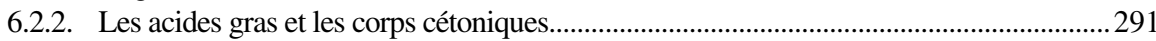

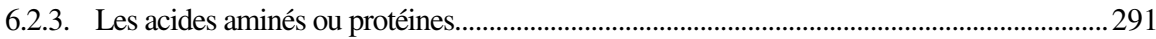

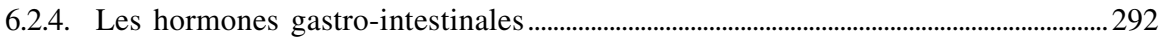

6.2.5. Les mécanismes nerveux............................................................................................................ 292

6.3. Corrélations avec les autres glandes endocrines ......................................................................292

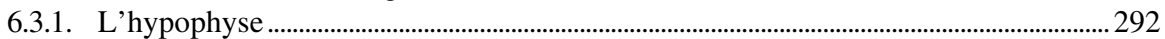

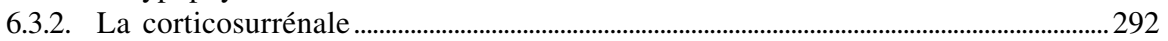

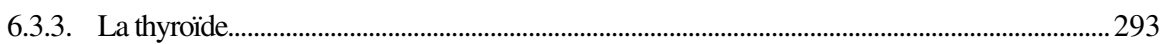

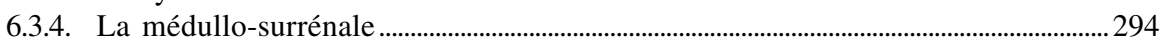

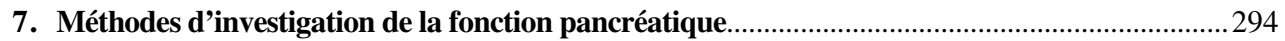

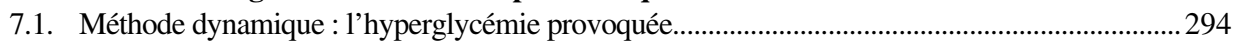

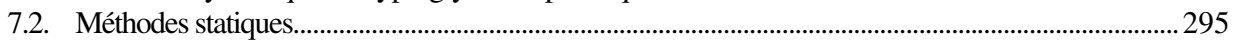

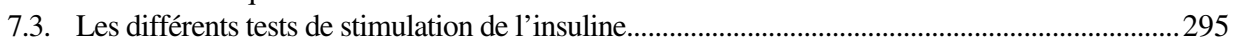

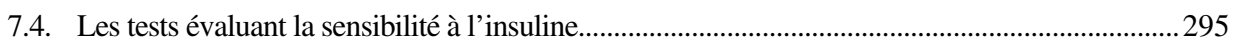

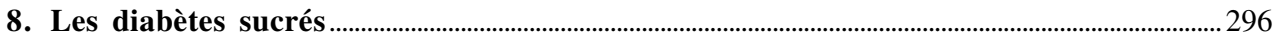

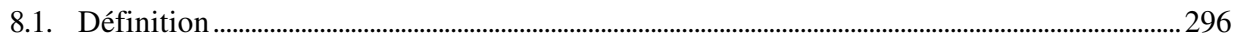

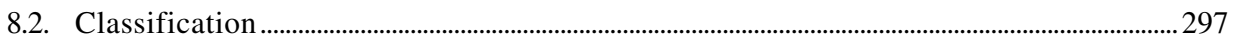

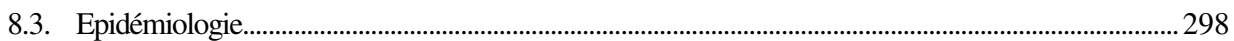

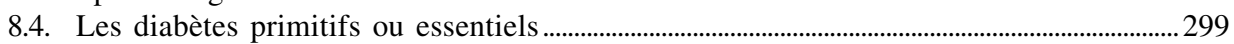

8.4.1. Le diabète insulinodépendant (DID) ou de type I (diabète maigre) ....................... 299

8.4.2. Le diabète non-insulinodépendant (DNID) ou de type II (diabète gras) ................ 303

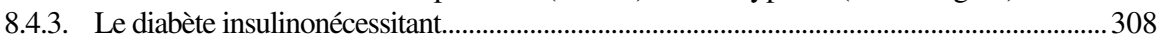

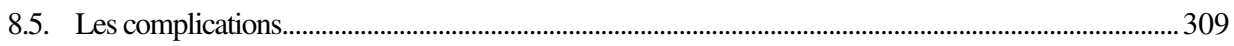

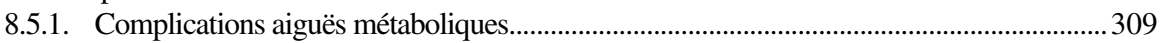

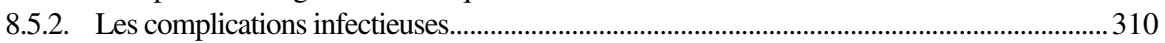

8.5.3. Les complications chroniques ………………………………………………………..... 311 


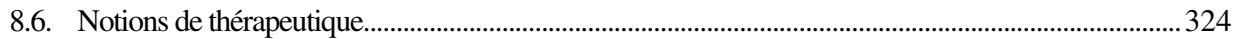

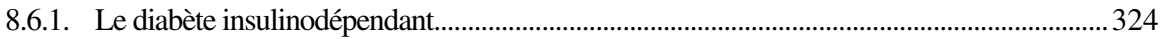

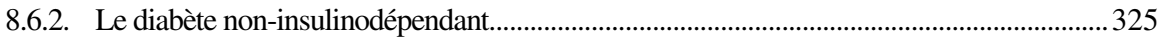

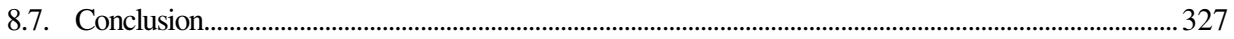

Chapitre 8 - Les parathyroïdes et l'équilibre phosphocalcique............................329

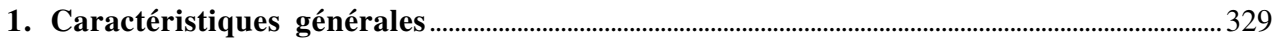

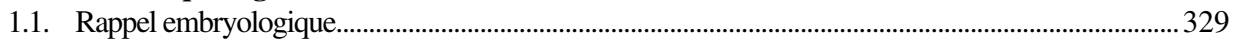

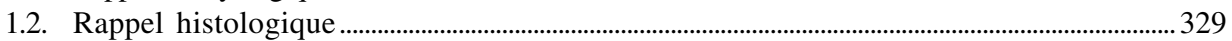

1.3. Vascularisation et innervation ................................................................................................ 330

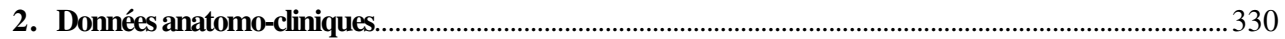

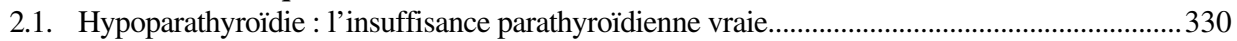

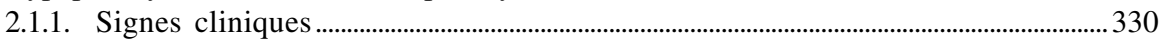

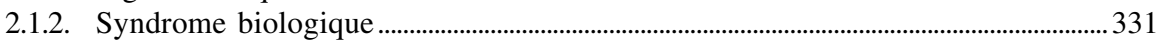

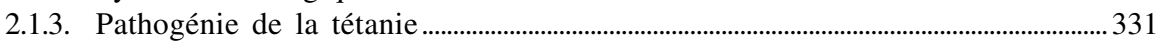

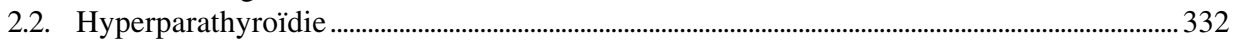

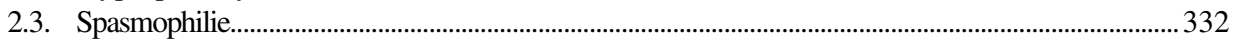

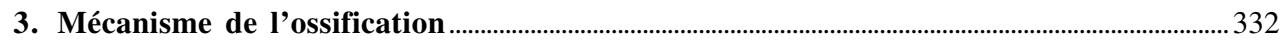

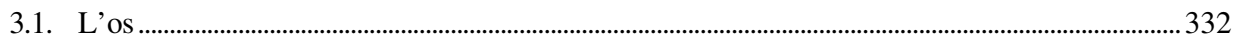

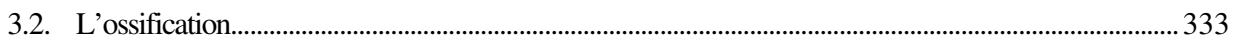

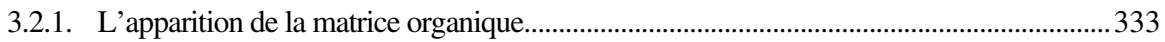

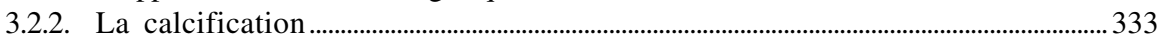

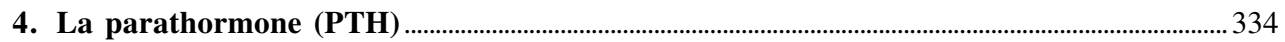

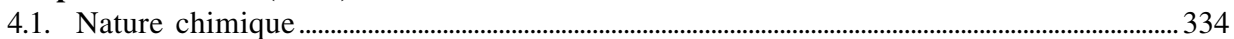

4.2. Déterminisme de la sécrétion ........................................................................................................ 334

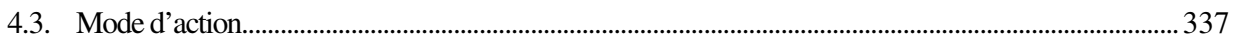

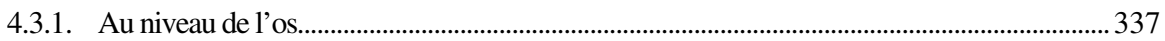

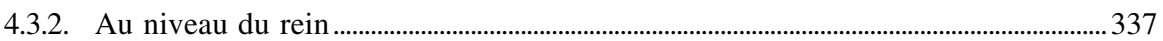

4.3.3. Activation de la $1 \alpha$-hydroxylase ................................................................................ 338

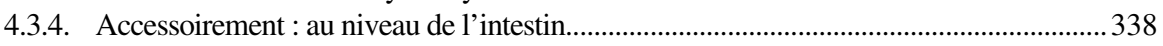

4.4. Le récepteur de l'hormone parathyrö̈dienne .................................................................................... 338

5. Calcitonine et vitamine D .................................................................................................................................. 339

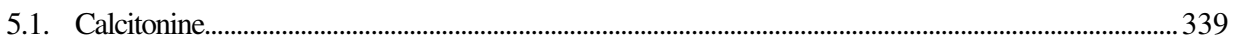

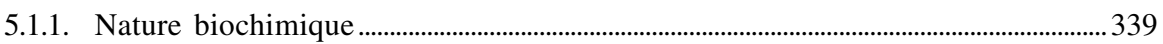

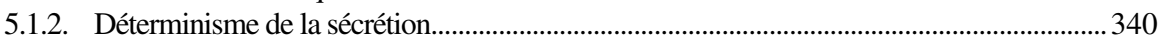

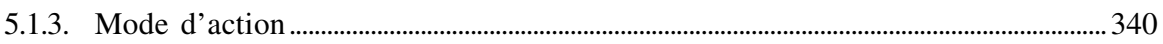

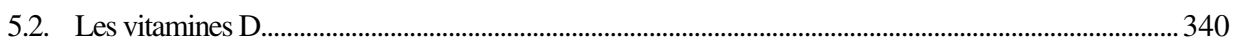

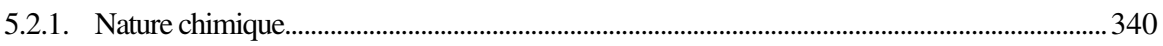

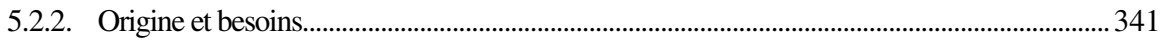

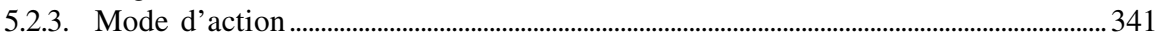

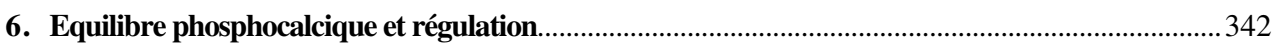

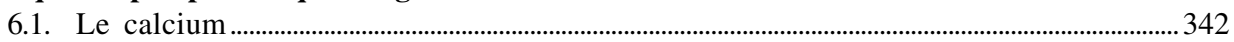

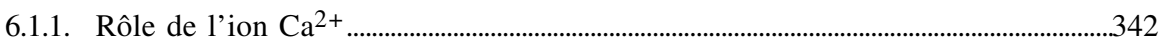

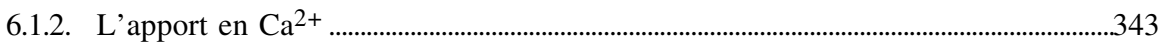

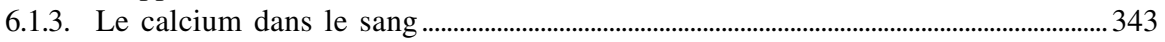

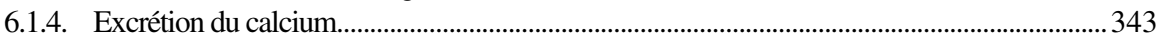

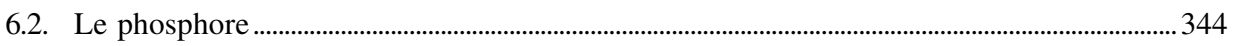

6.3. Régulation de l'équilibre phosphocalcique (homéostasie phosphocalcique) ......................344

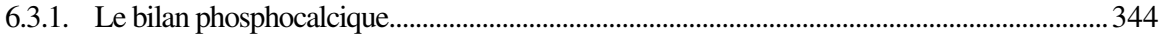

6.3.2. Le taux plasmatique de calcium et de phosphate ........................................................... 344 
Chapitre 9 - Les structures endocrines diffuses......................................................347

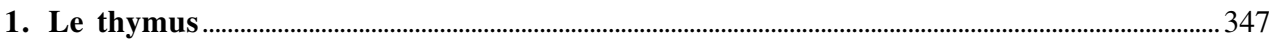

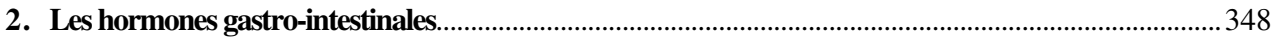

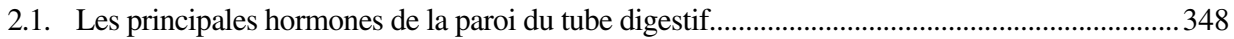

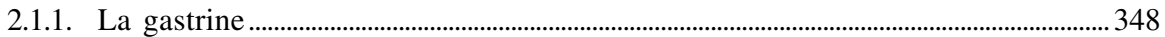

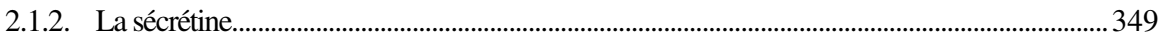

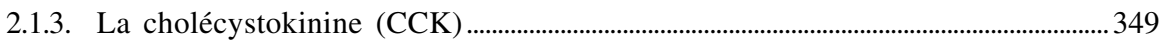

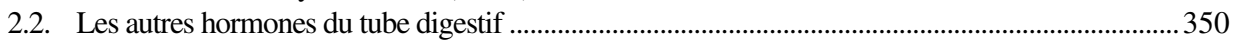

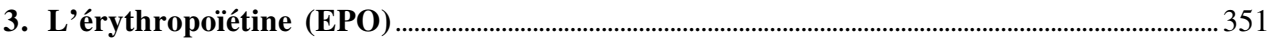

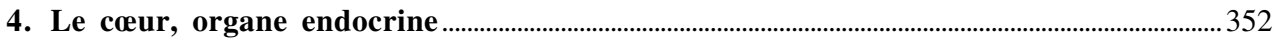

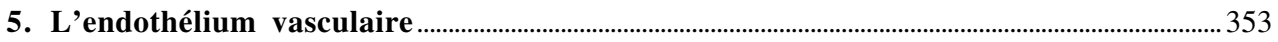

Chapitre 10 - L'épiphyse........................................................................355

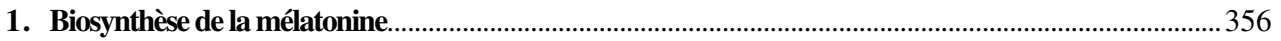

2. Rôle de l'épiphyse

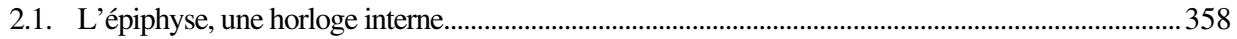

2.2. Mécanismes moléculaires du fonctionnement de l'horloge biologique...................................... 361

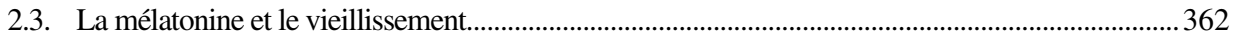

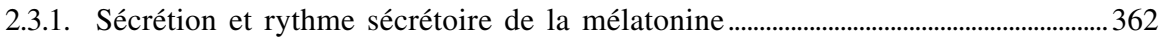

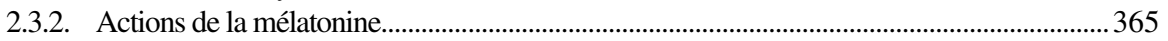

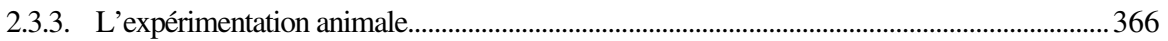

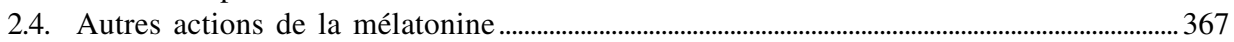

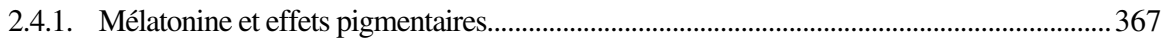

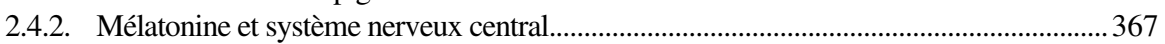

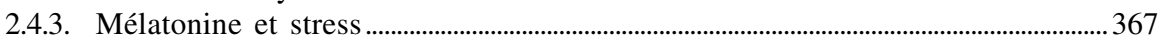

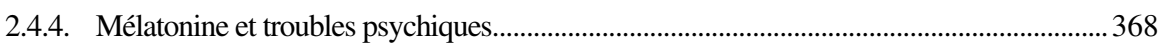

2.4.5. Mélatonine et maladies cardio-vasculaires ........................................................................... 368

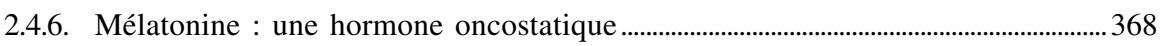

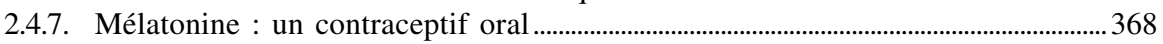

2.4.8. Mélatonine et mort subite du nourrisson ........................................................................ 369

2.4.9. Effets des champs magnétiques sur la mélatonine............................................................ 369

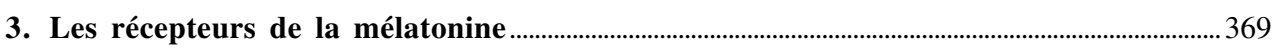

Références bibliographiques de la deuxième partie................................................373

\section{Troisième partie - Endocrinologie de la reproduction}

Chapitre 11 - Généralités sur les appareils de reproduction ..................................401

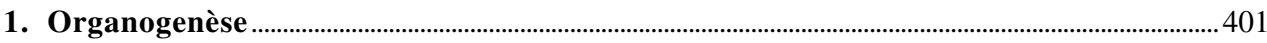

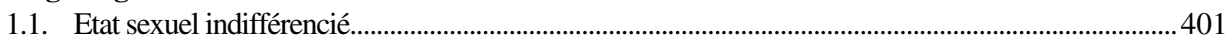

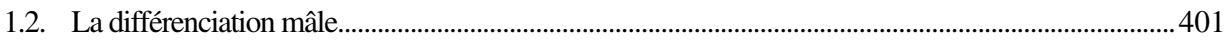

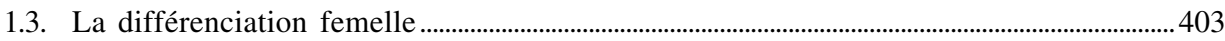

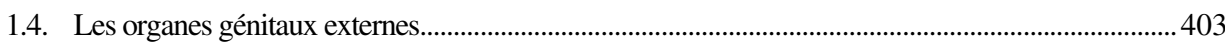

1.5. Les anomalies de la différenciation sexuelle.............................................................................. 404

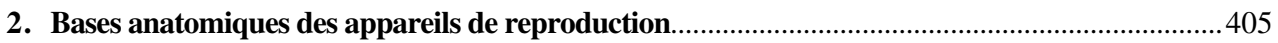

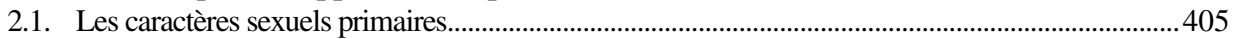

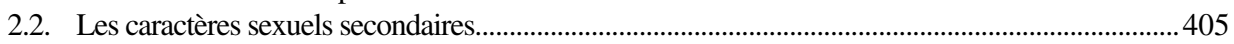

Chapitre 12 - Physiologie de l'appareil de reproduction femelle.......................407

1. Gamétogenèse

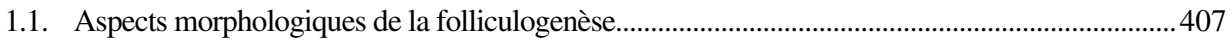

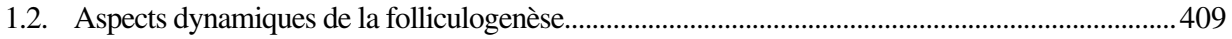




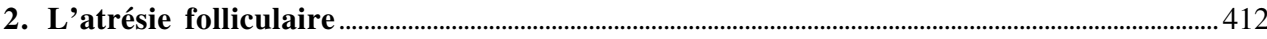

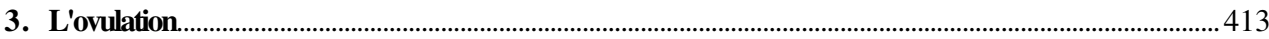

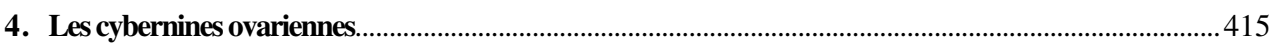

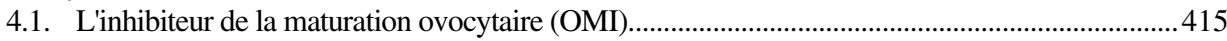

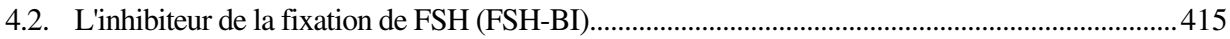

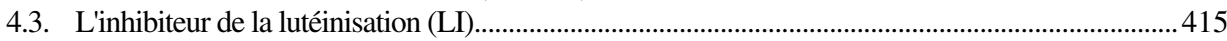

4.4. Les cybernines intervenant dans la régulation hypothalamo-hypophyso-gonadique.......416

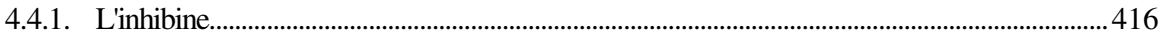

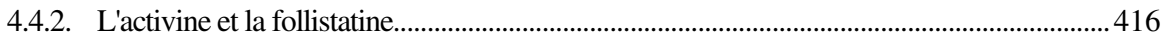

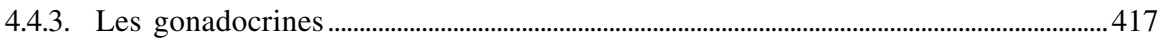

5. Biochimie des hormones sexuelles chez la femelle ..............................................................417

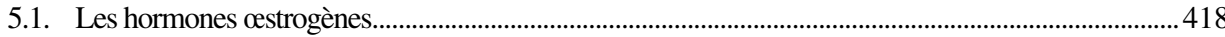

5.1.1. Origine et nature des hormones œstrogènes.........................................................................418

5.1.2. Catabolisme des hormones œstrogènes.................................................................................420

5.1.3. Action physiologique des œstrogènes ………………………………………………....... 420

5.1.4. Dosages biologiques et chimiques des œstrogènes ........................................................... 421

5.1.5. Mode d'action des œstrogènes ............................................................................................. 421

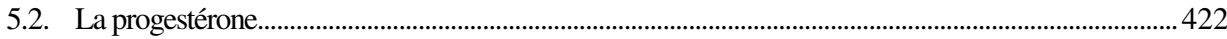

5.2.1. Origine et nature de la progestérone …………………………………………………..... 422

5.2.2. Catabolisme de la progestérone .......................................................................................... 422

5.2.3. Actions physiologiques de la progestérone ..........................................................................422

5.2.4. Dosage de la progestérone .............................................................................................. 423

5.3. Les hormones androgènes chez la femme ...................................................................................... 423

5.4. Transport plasmatique des hormones ovariennes........................................................................... 423

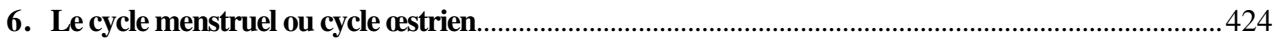

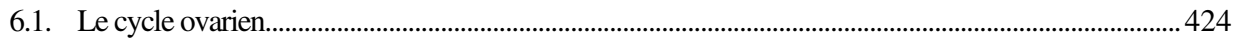

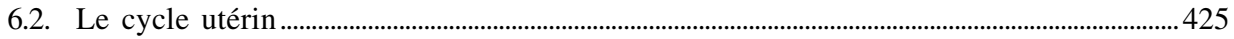

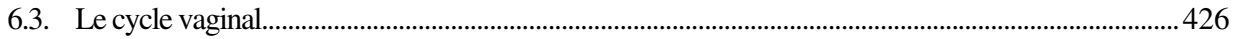

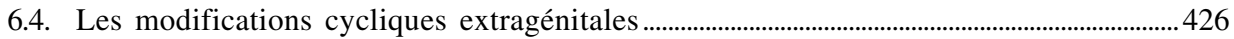

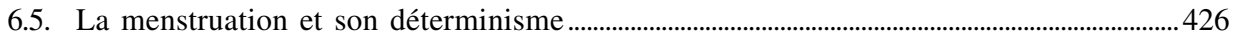

6.6. Le contrôle neuro-endocrinien du cycle æstrien ......................................................................... 428

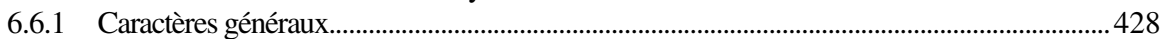

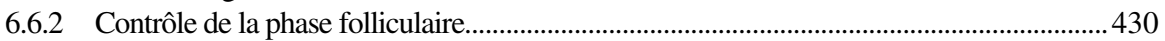

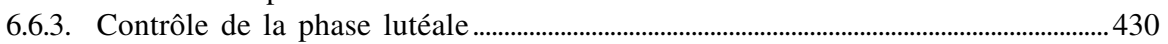

7. Particularités de l'ovulation et de la phase lutéinique chez différents Mammifères.. 430

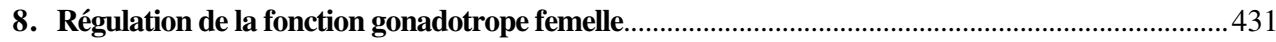

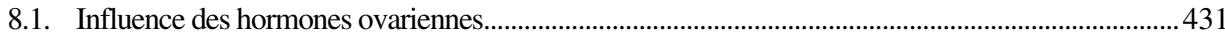

8.2. Rapports hypothalamo-hypophysaires ……………………………………………………….... 432

8.3. Pulsatilité des sécrétions de la LH-RH et des hormones gonadotropes.................................433

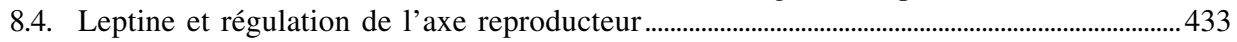

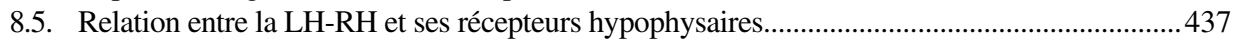

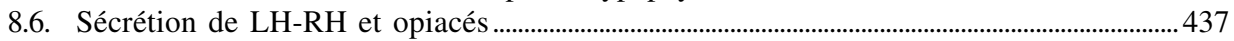

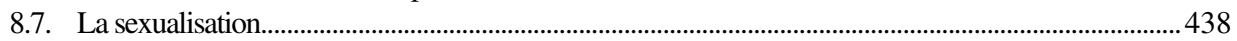

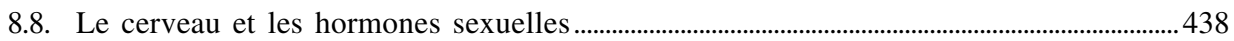

8.9. Influence de l'environnement ..................................................................................................... 439

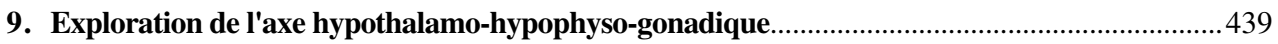

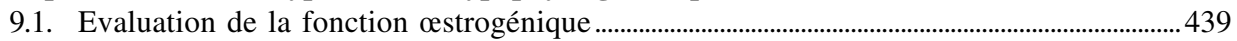

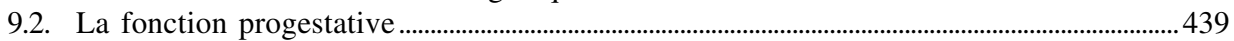

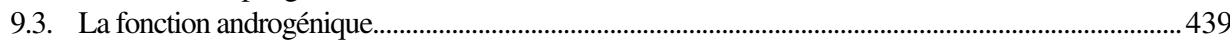

9.4. Le dosage des gonadotrophines............................................................................................... 440 
Chapitre 13 - Physiologie de l'appareil de reproduction mâle 443

1. Structure de la gonade mâle. .443

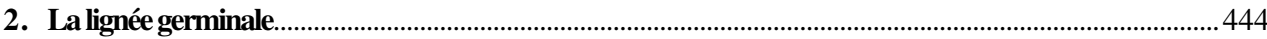

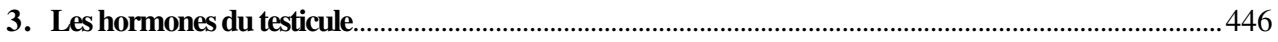

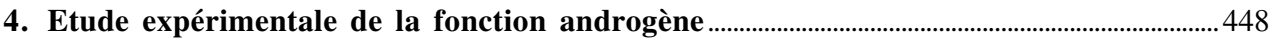

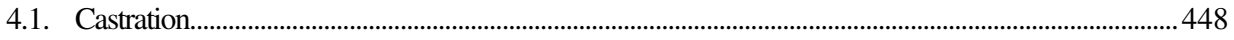

4.2. Effets de l'administration des hormones androgènes........................................................................ 448

5. Régulation de l'activité hormonale du testicule ............................................................................. 449

6. Mode d'action de la testostérone ……………………………………………………………………..... 449

7. La contraception hormonale chez l'homme .................................................................................... 450

7.1. L'utilisation de l'hormone sexuelle ou de ses dérivés .................................................................450

7.2. Les agonistes de la LH-RH .............................................................................................................. 451

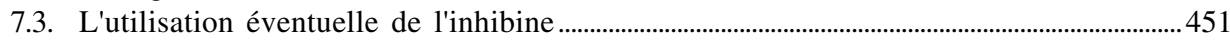

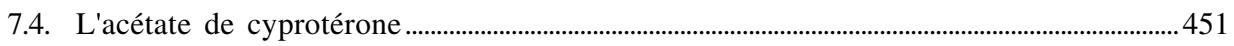

Chapitre 14 - Fécondation - Gestation - Lactation...................................................453

1. La fécondation

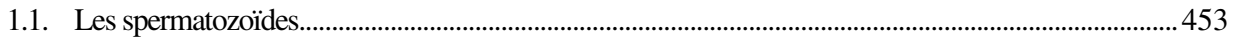

1.2. L'ovocyte

1.3. La traversée des enveloppes ovocytaires .................................................................................. 455

2. La migration tubaire

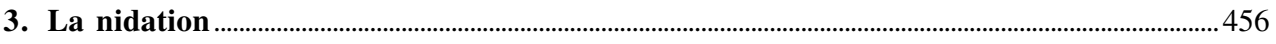

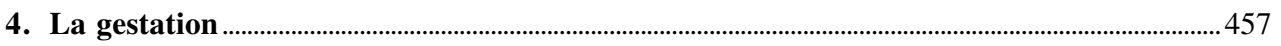

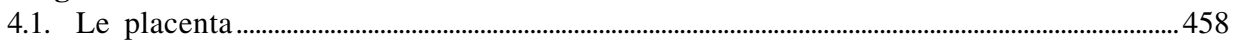

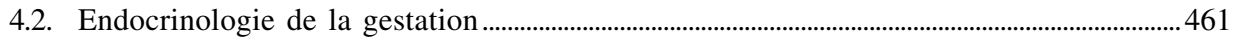

4.2.1. Les hormones de la gestation (chez la femme) ............................................................. 461

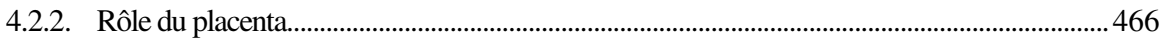

4.2.3. Action des hormones au cours de la gestation .................................................................. 466

4.2.4. Dosage de la gonadotrophine chorionique........................................................................... 467

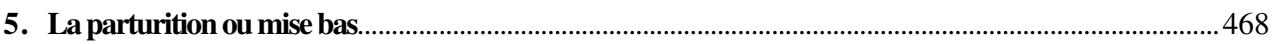

5.1. Déterminisme de la parturition............................................................................................... 468

5.1.1. Rôle des stéroïdes ovariens ............................................................................................468

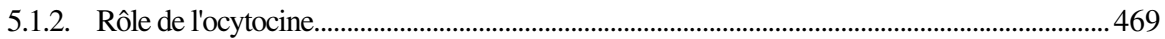

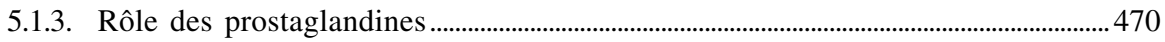

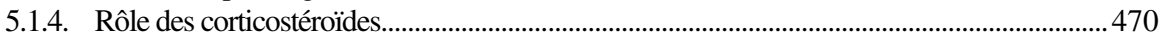

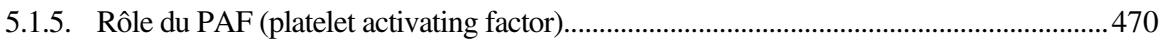

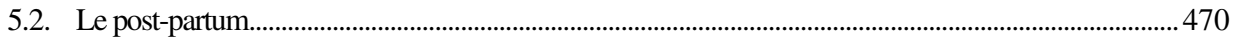

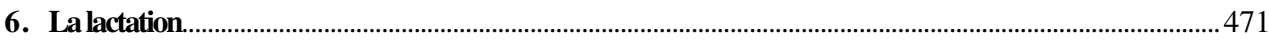

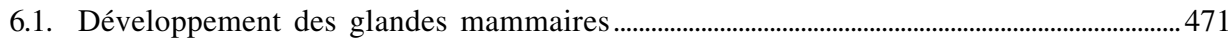

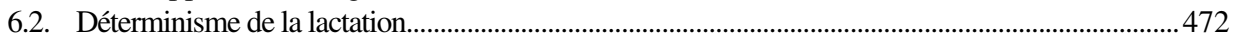

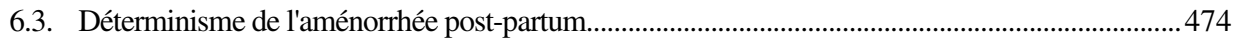

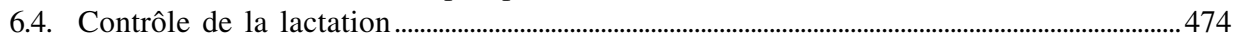

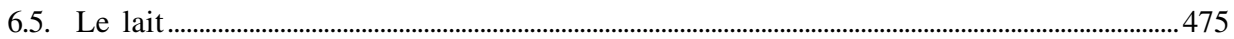

6.6 Le récepteur de la prolactine : une molécule clé de la reproduction....................................475

Chapitre 15 - La commande de la reproduction.......................................................479

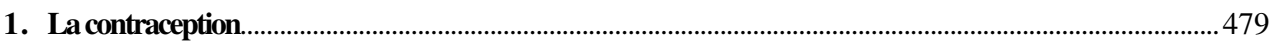

1.1. Les moyens contraceptifs chez la femme................................................................................. 480

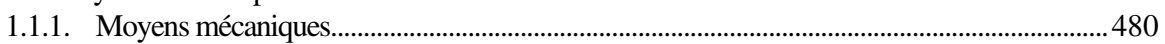

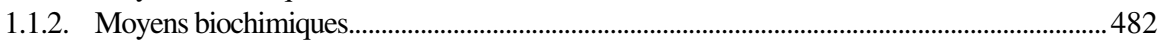




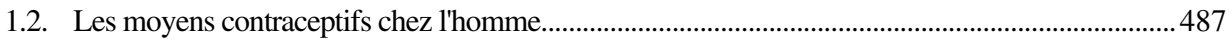

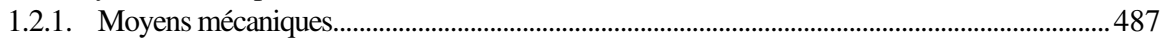

1.2.2. Moyens biochimiques.......................................................................................................... 488

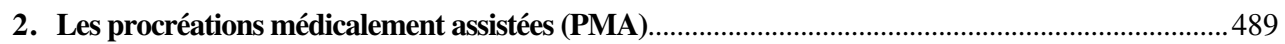

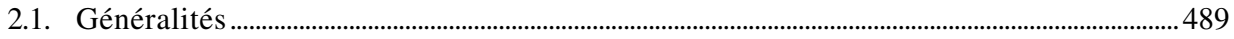

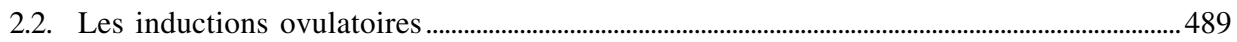

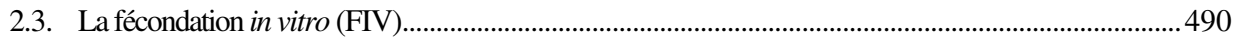

Références bibliographiques de la troisième partie...............................................493

\section{Quatrième partie - Immunité et évolution}

Chapitre 16 - Hormones et immunité ..........................................................................501

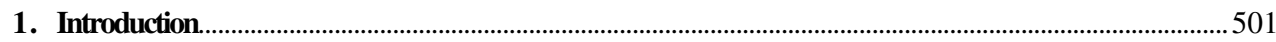

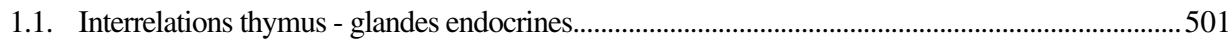

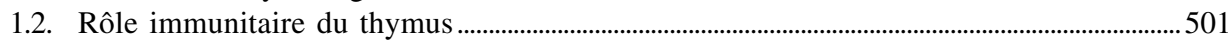

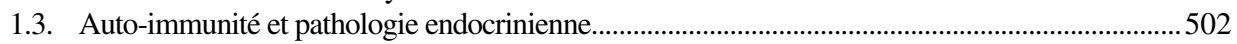

1.4. Interrelations hormones - cellules immunitaires .......................................................................... 502

2. Récepteurs spécifiques aux hormones et action des hormones sur les lymphocytes.. 502

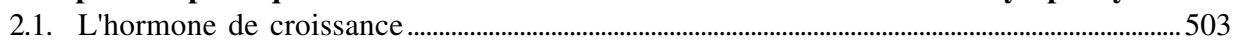

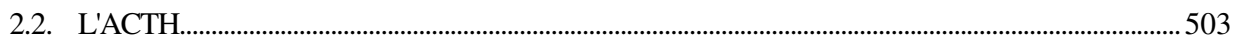

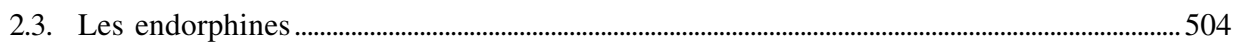

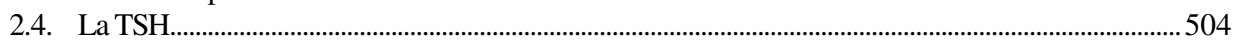

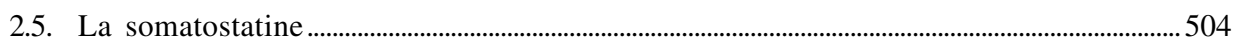

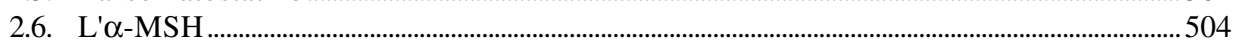

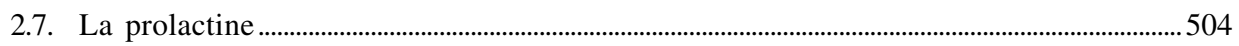

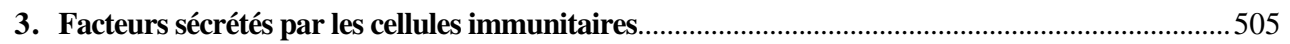

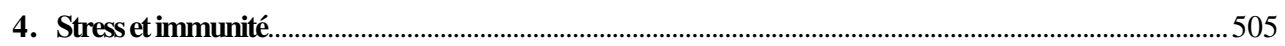

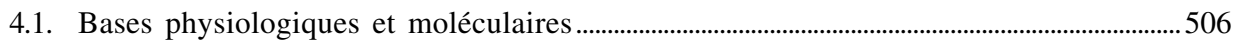

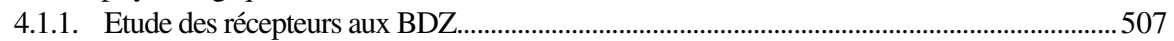

4.1.2. L'inhibiteur de liaison au diazépam et le stress.............................................................508

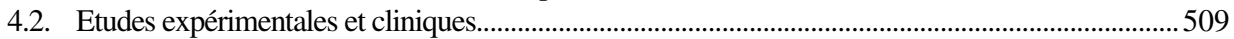

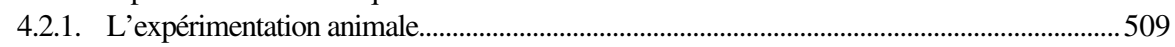

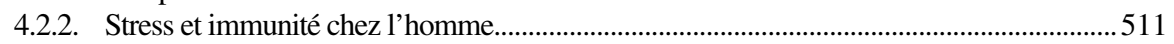

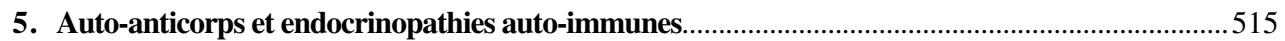

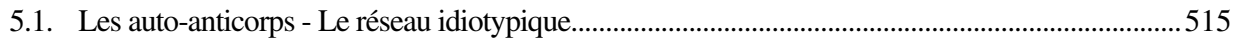

5.2. La maladie auto-immune ......................................................................................................... 516

Chapitre 17 - Hormones et évolution..........................................................519

1. Le contrôle de la concentration en ions du milieu intérieur .....................................................519

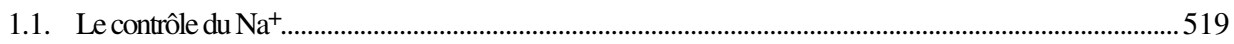

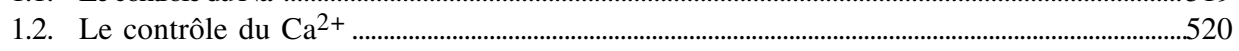

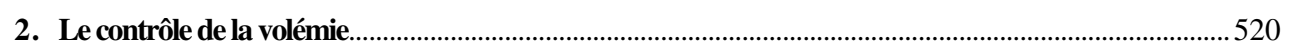

3. L'évolution des hormones à partir d'un gène ancestral commun .......................................521

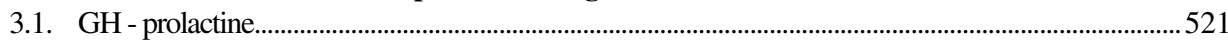

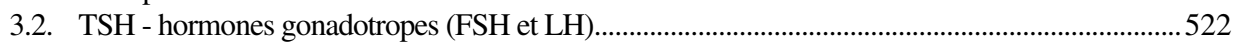

3.3. Les hormones neurohypophysaires................................................................................................. 522

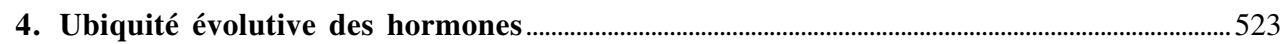

4.1. Les micro-organismes : Bactéries et Levures .............................................................................5 523

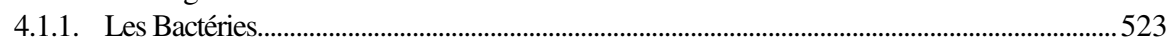

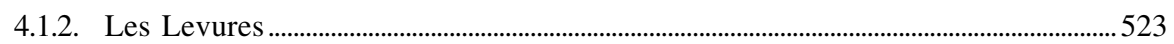




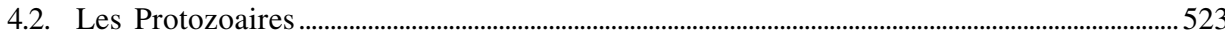

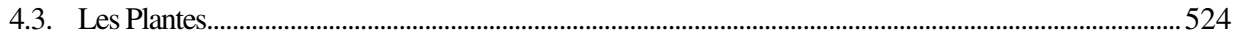

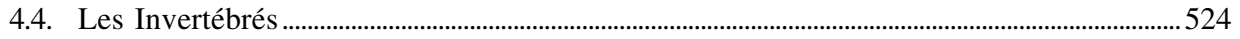

5. Ubiquité fonctionnelle des hormones .................................................................................................524

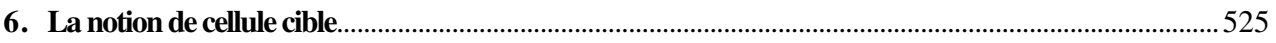

Références bibliographiques de la quatrième partie......................................529

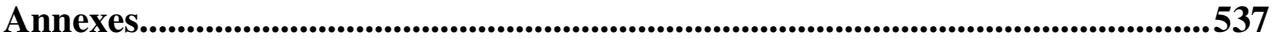

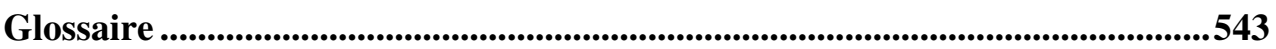

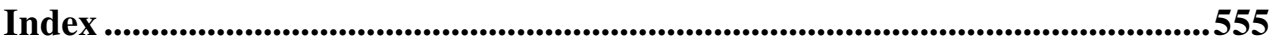

Table des matières..........................................................................................................571 


\section{ENDOCRINOLOGIE ET COMMUNICATIONS CELLULAIRES}

Cet ouvrage d'endocrinologie générale, sexuelle et moléculaire présente aussi bien les données fondamentales qu'il est indispensable de posséder que les apports plus récents de l'endocrinologie moderne : rythme biologique, physiologie des récepteurs, modes d'action des hormones.

L'ouvrage est destiné tant aux étudiants de médecine qu'à ceux de biologie. II permet aux enseignants et professionnels de la santé d'actualiser leurs connaissances.

\section{LES AUTEURS}

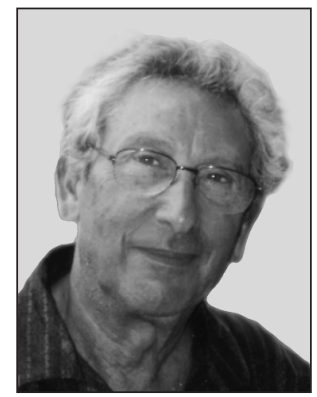

Après une double formation de médecin et de scientifique, Simon Idelman (à gauche) obtint une thèse sur la cytophysiologie de la surrénale au laboratoire d'évolution des êtres organisés de P.P. Grassé. Ses recherches concernent la glande surrénale puis l'action des hormones sur le système immuni-

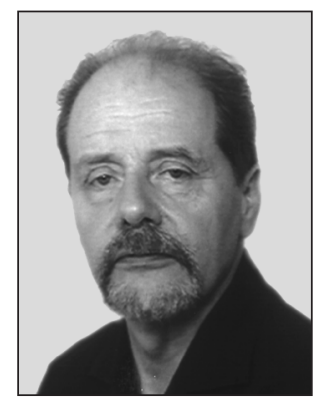
taire (thymus, ganglions lymphatiques). Simon Idelman est professeur honoraire de physiologie à l'Université Joseph Fourier.

Professeur à l'Université Joseph Fourier, Jean Verdetti (à droite) anime le groupe d'électrophysiologie moléculaire (GEM) où il étudie les mécanismes de I'homéostasie calcique intracellulaire. II enseigne dans les différents cycles de l'enseignement supérieur et participe au jury de l'agrégation des sciences de la vie et de la terre.

Ont également contribué à la réalisation de l'ouvrage Ivan Bachelot et Serge Halimi, professeurs à I'Université de Grenoble (CHU), Claude Cochet, directeur de recherches à I'INSERM, et des médecins spécialistes: Robert Elkaïm, Philippe Léger et Danielle Pallo. 